UNIVERSIDADE DE SÃO PAULO

INSTITUTO DE GEOCIÊNCIAS

\title{
ESTUDO HIDROGEOQUÍMICO, SEDIMENTOLÓGICO E DOS FORAMINÍFEROS DE ÁREAS SUBMETIDAS A ESGOTOS DOMÉSTICOS E PETROQUÍMICOS DO CANAL DE SÃO SEBASTIÃO, SP
}

\author{
Andreia C. Teodoro \\ Orientadora: Prof ${ }^{a} \operatorname{Dr}^{a}$ Wânia Duleba
}

TESE DE DOUTORAMENTO

Programa de Pós-Graduação em Geoquímica e Geotectônica

SÃO PAULO

2011 
Dedico este trabalho à Leonor Cyrino, minha eterna estrela guia 


\section{AGRADECIMENTOS}

À Wânia Duleba, por todo o seu profissionalismo e dedicação. Agradeço, especialmente, por você sempre ter respeitado a minha necessidade de ser livre.

Ao meu grande amigo Silas Gubitoso, uma das poucas pessoas que sempre foi presente em meu lado pessoal e profissional.

À Rafaela Lançone, pela ajuda e apoio durante a fase final desta tese.

À Mirian Liza, pela grande ajuda nas análises estatísticas e por ter me apresentado a Regiane Saturnino, ecóloga que me ensinou como comparar as estruturas composicionais das associações de foraminíferos.

Aos amigos Guilherme, Evelyn e Felipe do Laboratório Estudos Paleobiológicos.

Ao Isaac J. Sayeg, do LabMev do IGc-USP, pelas sugestões e explicações durante as sessões de MEV.

Ao Prof Dr Thomas Rich Fairchild pela correção do abstract.

À Elaine Aparecida da Silva Sinfrônio do LaBsed do IGc-USP

À CETESB e seus funcionários: Cláudia Lamparelli, José Bevilacqua, Débora Ogler de Moura, pela cessão dos dados físico-químicos da água, pela atenção e pelas campanhas realizadas no Canal de São Sebastião.

À Ana Paula e Magali da secretaria de pós-graduação.

Aos funcionários da gráfica, pela paciência durante a entrega e encadernação desta tese

Aos funcionários das bibliotecas do IGc e IO-USP.

À Luciana Fillipos e Juliana Braga e Silva, presentes em todos os momentos no Laboratório de Micropaleontologia Setembrino Petri.

À Sandra Andrade, do Laboratório de Química do IGc-USP, pelas análises de C, N e S.

Ao Prof Dr Silvio Miranda Prada, pelas análises de fósforo na Unifieo e pela ajuda no tratamento dos dados.

Ao meu irmão, José Carlos, por todo o apoio dado durante estes anos todos.

À FAPESP, pelo auxilio financeiro e pelas sugestões dadas a este estudo pelo seu relator 


\section{SUMÁRIO}

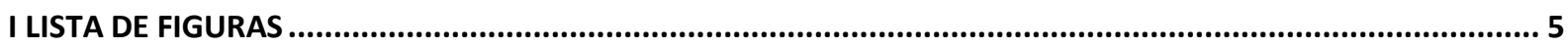

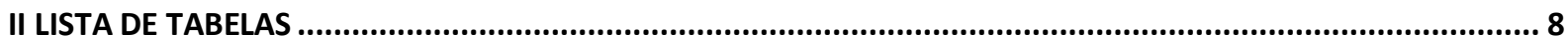

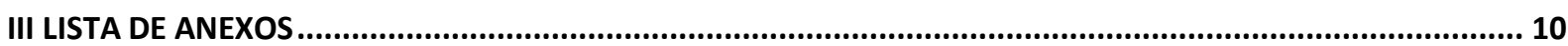

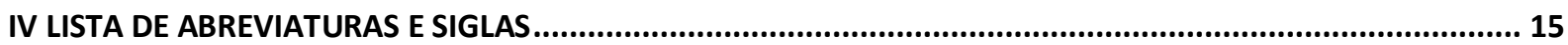

V LISTA DE SÍMBOLOS .............................................................................................................................. 16

VI RESUMO

VII ABSTRACT

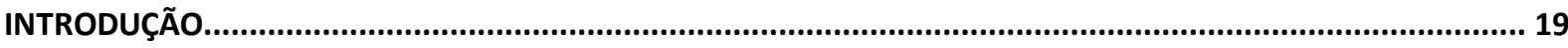

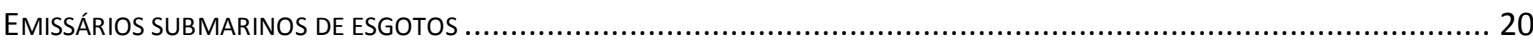

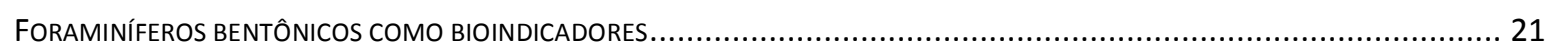

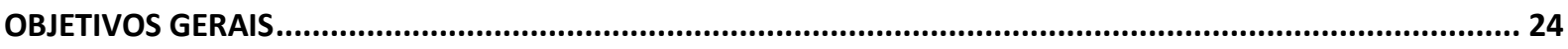

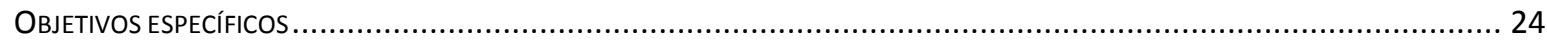

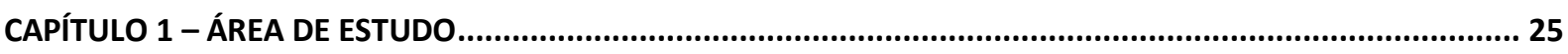

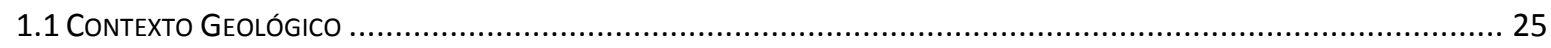

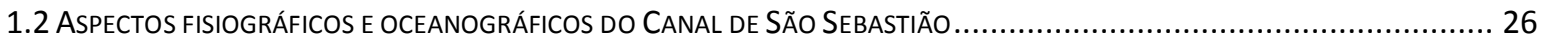

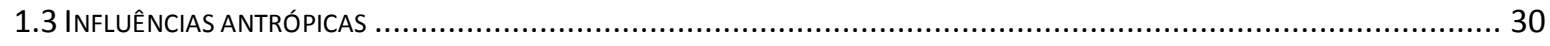

1.3.1 Emissário submarino de esgotos domésticos do Araçá ..................................................... 31

1.3.2 Emissário submarino de esgotos domésticos do Saco da Capela ..................................................32

1.3.3 Emissário de efluente petroquímico do Terminal Marítimo Almirante Barroso (TEBAR) ................. 33

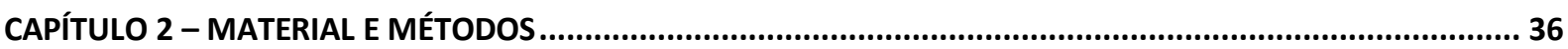

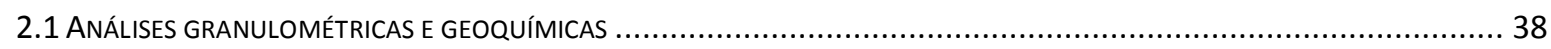

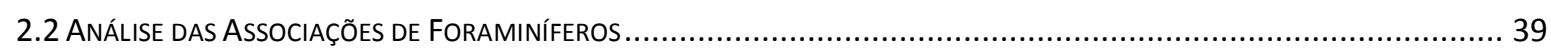

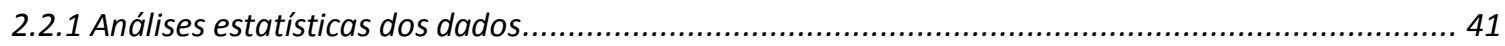

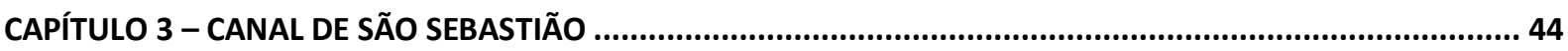

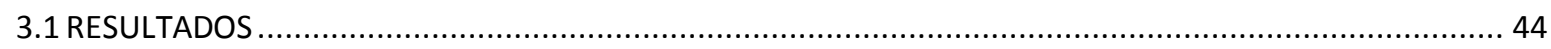

3.1.1 Posicionamento geográfico e dados físico-químicos da coluna d'água ......................................44

3.1.2 Distribuição granulométrica, geoquímica e razões elementares............................................ 46

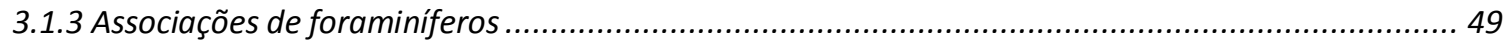

3.1.3.1 Biocenoses - composição, padrão de distribuição e análise morfométrica ..............................................49

3.1.3.2. Tanatocenoses - composição e padrão de distribuição....................................................................... 51

3.1.3.2.1 Aspectos morfométricos e tafonômicos (coloração e grau de preservação) observados nas carapaças 
3.1.3.3 Estudo comparativo da estrutura das comunidades que compuseram as biocenoses e tanatocenoses ....54

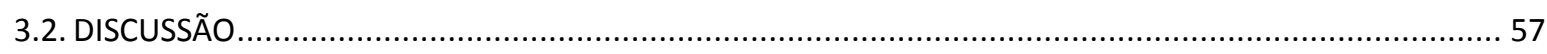

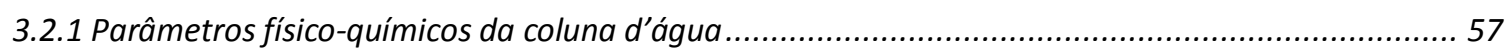

3.2.2 Parâmetros granulométricos e geoquímicos........................................................................... 58

3.2.3 Associações de foraminíferos - biocenoses e tanatocenoses ................................................63 63

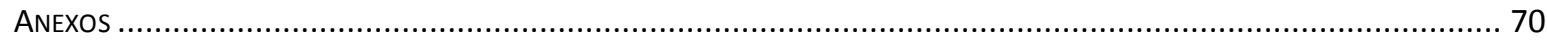

CAPÍTULO 4 - EMISSÁRIO SUBMARINO DE ESGOTO DOMÉSTICO DO ARAÇÁ..............................................85

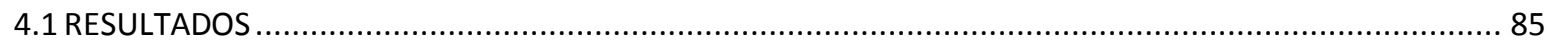

4.1.1 Posicionamento geográfico e dados físico-químicos da coluna d'água ......................................85

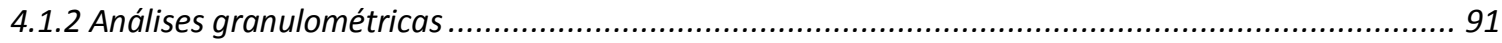

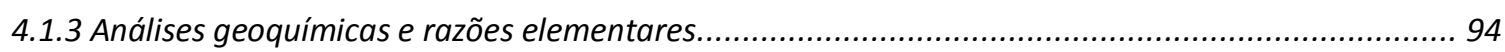

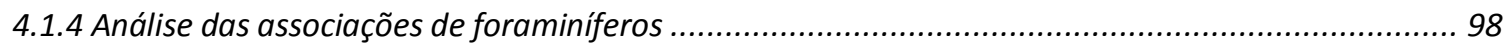

4.1.4.1 Biocenoses - composição, distribuição e análise morfométrica ..........................................................98

4.1.4.2 Tanatocenoses - composição, distribuição, aspectos morfométricos e tafonômicos (coloração e grau de

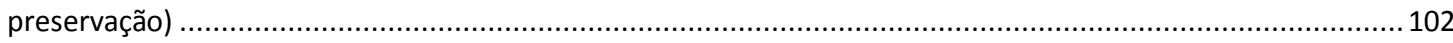

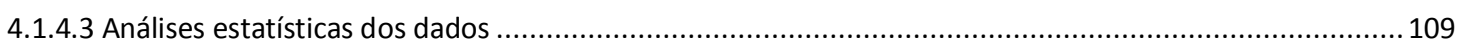

4.1.4.3.1 Coeficientes de correlação de Pearson $(r)$............................................................................. 109

4.1.4.3.2 Estudo comparativo da estrutura das comunidades de foraminíferos ........................................... 110

4.1.4.3.2.1 Biocenoses - estudo comparativo entre os períodos de coleta .......................................... 110

4.1.4.3.2.2 Tanatocenoses - estudo comparativo entre os períodos de coleta......................................... 112

4.1.4.3.2.3 Biocenoses versus Tanatocenoses - estudo comparativo entre os períodos de coleta ............114

4.1.4.3.3 Análise de Correspondência Canônica ....................................................................................... 118

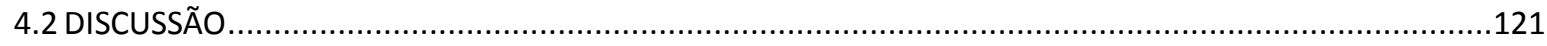

4.2.1 Parâmetros físico-químicos da coluna d'água ............................................................121

4.2.2 Parâmetros granulométricos e geoquímicos ..................................................................123

4.2.3 Associações de foraminíferos - biocenoses e tanatocenoses ....................................................128

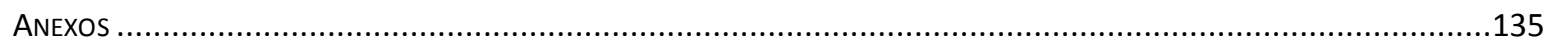

CAPÍTULO 5 - EMISSÁRIO SUBMARINO DE ESGOTO DOMÉSTICO DO SACO DA CAPELA ..............................166

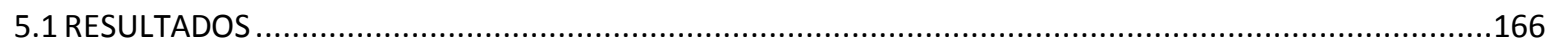

5.1.1 Posicionamento geográfico e dados físico-químicos da coluna d'água .........................................166

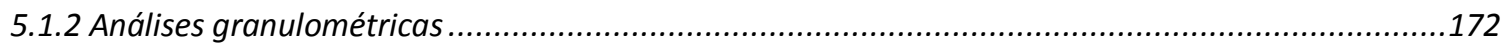

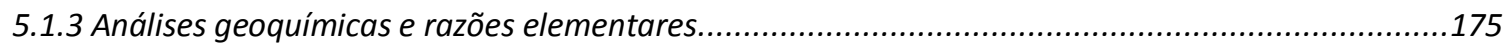

5.1.4 Análise das associações de foraminíferos ..................................................................179

5.1.4.1 Biocenoses - composição, distribuição e análise morfométrica .........................................................179

5.1.4.2 Tanatocenoses - composição, distribuição, aspectos morfométricos e tafonômicos (coloração e grau de

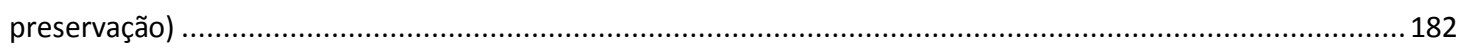

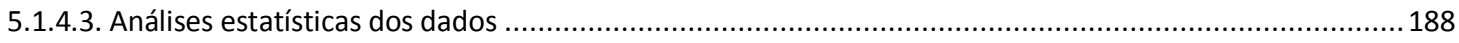

5.1.4.3.1 Coeficientes de correlação de Pearson $(r)$................................................................................ 188 
5.1.4.3.2 Estudo comparativo da estrutura das associações de foraminíferos ............................................. 189

5.1.4.3.2.1 Biocenoses - estudo comparativo entre os períodos de coleta ............................................ 189

5.1.4.3.2.2 Tanatocenoses - estudo comparativo entre os períodos de coleta...................................... 191

5.1.4.3.2.3 Biocenoses versus Tanatocenoses - estudo comparativo entre os períodos de coleta ............ 193

5.1.4.3.3 Análise de Correspondência Canônica ..................................................................................... 197

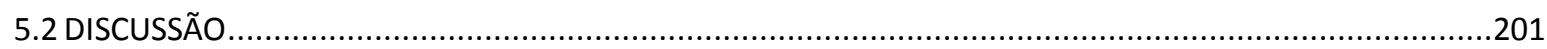

5.2.1 Parâmetros físico-químicos da coluna d'água .......................................................................201

5.2.2 Parâmetros granulométricos e geoquímicos......................................................................202

5.2.3 Associações de foraminíferos - biocenoses e tanatocenoses ................................................205

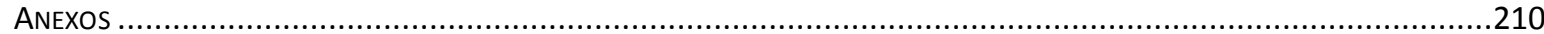

CAPÍTULO 6 - EMISSÁRIO SUBMARINO PARA EFLUENTES PETROQUÍMICOS TERMINAL MARÍTIMO

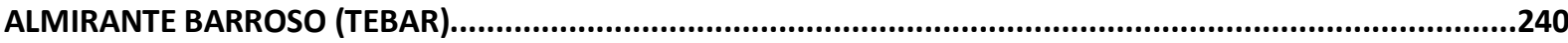

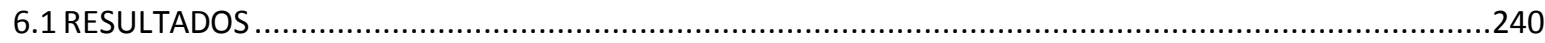

6.1.1 Posicionamento geográfico e dados físico-químicos da coluna d'água .....................................240

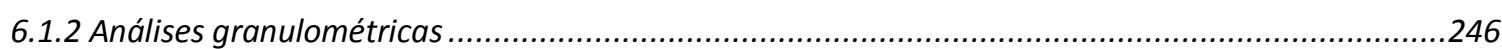

6.1.3 Análises geoquímicas e razões elementares...................................................................249

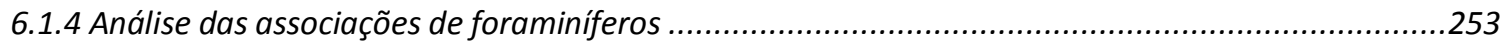

6.1.4.1 Biocenoses - composição, distribuição e análise morfométrica ........................................................253

6.1.4.2 Tanatocenoses - composição, distribuição, aspectos morfométricos e tafonômicos (coloração e grau de

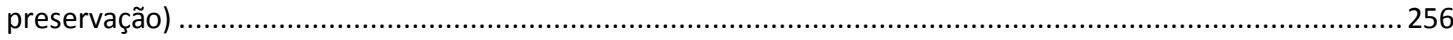

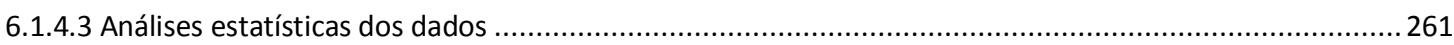

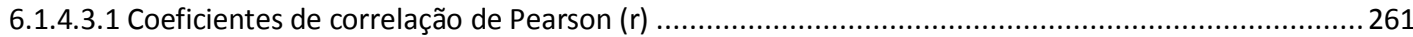

6.1.4.3.2 Estudo comparativo da estrutura das associações de foraminíferos ...........................................262

6.1.4.3.2.1 Biocenoses - estudo comparativo entre os períodos de coleta .........................................262

6.1.4.3.2.2 Tanatocenoses - estudo comparativo entre os períodos de coleta........................................265

6.1.4.3.2.3 Biocenoses versus Tanatocenoses - estudo comparativo entre os períodos de coleta ............267

6.1.4.3.3 Análise de Correspondência Canônica ........................................................................................ 271

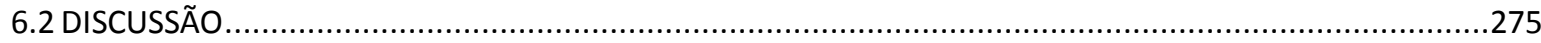

6.2.1 Parâmetros físico-químicos da coluna d'água ...............................................................275

6.2.2 Parâmetros granulométricos e geoquímicos .........................................................................277

6.2.3 Associações de foraminíferos - biocenoses e tanatocenoses ...................................................280

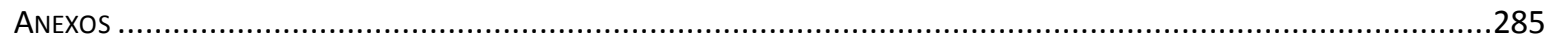

CAPÍTULO 7 - ESTUDO COMPARATIVO ENTRE AS ÁREAS DE ESTUDO E INTEGRAÇÃO DE DADOS..................316

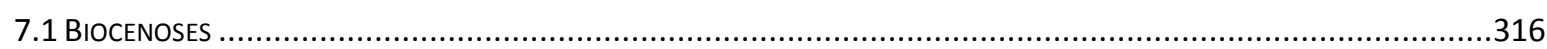

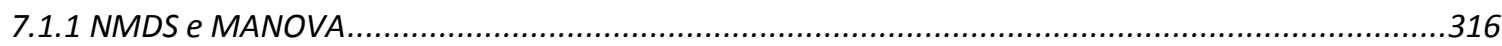

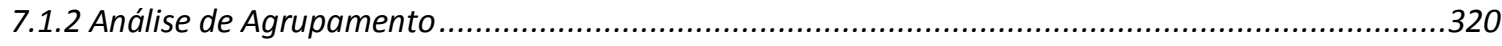

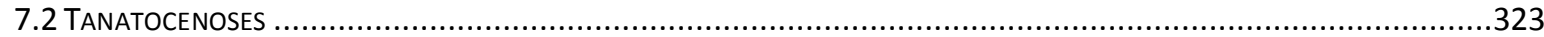

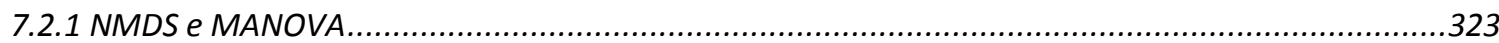




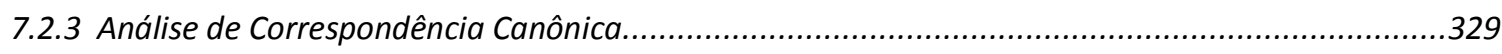

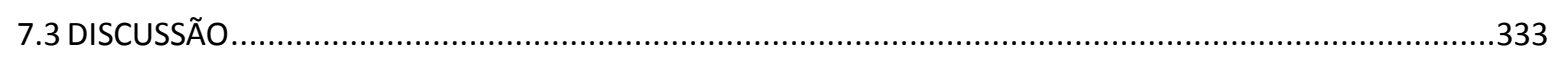

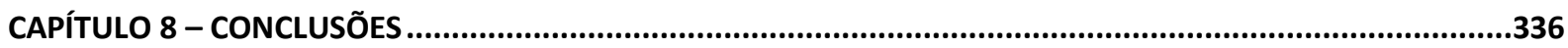

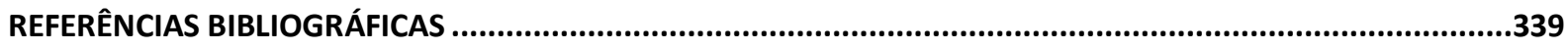

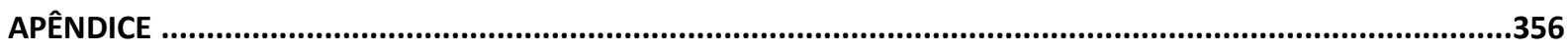

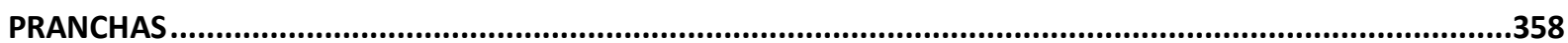




\section{LISTA DE FIGURAS}

FIGURA 01 - ESQUEMATIZAÇÃO DO SISTEMA DE DISPOSIÇÃO OCEÂNICA DE ESGOTOS.

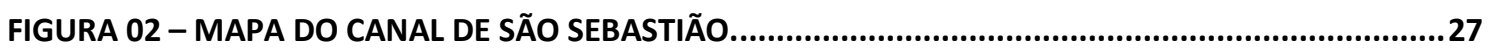

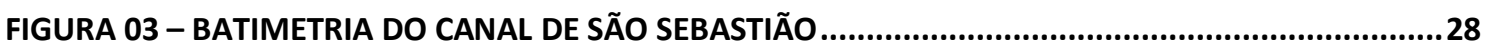

FIGURA 04 - MAPA DA LOCALIZAÇÃO DO EMISSÁRIO SUBMARINO DE ESGOTOS DOMÉSTICOS DO ARAÇÁ E RESPECTIVA MALHA DE AMOSTRAGEM.

FIGURA 05 - MAPA DA LOCALIZAÇÃO DO EMISSÁRIO SUBMARINO DE ESGOTOS DOMÉSTICOS DO SACO DA CAPELA E RESPECTIVA MALHA DE AMOSTRAGEM.

FIGURA 06 - MAPA DA LOCALIZAÇÃO DO EMISSÁRIO DE EFLUENTES PETROQUÍMICOS DO TEBAR E RESPECTIVA MALHA DE AMOSTRAGEM.

FIGURA 07 - POSICIONAMENTO DAS AMOSTRAS COLETADAS AO LONGO DO CANAL DE SÃO SEBASTIÃO.

FIGURA 08 - MAPA DA DISTRIBUIÇÃO GRANULOMÉTRICA OBTIDA AO LONGO DO CANAL DE SÃO SEBASTIÃO.

FIGURA 09 - GRÁFICO DE ORDENAÇÃO DAS COMUNIDADES DE FORAMINÍFEROS QUE COMPUSERAM AS BIOCENOSES E TANATOCENOSES OBTIDAS AO LONGO DO CANAL DE SÃO SEBASTIÃO.....................55 FIGURA 10 - DENDROGRAMA DO AGRUPAMENTO DAS ESTAÇÕES, MODO Q, COM DIFERENCIAÇÃO ENTRE BIOCENOSES E TANATOCENOSES.

FIGURA 11 - GRÁFICOS DE ORDENAÇÃO, OBTIDOS PELAS TÉCNICAS DE NMDS E TESTE T, PARA O ESTUDO COMPARATIVO DAS BIOCENOSES ENTRE OS PERÍODOS DE COLETA.

FIGURA 12 - GRÁFICOS DE ORDENAÇÃO, OBTIDOS PELAS TÉCNICAS DE NMDS E TESTE T, PARA 0 ESTUDO COMPARATIVO DAS TANATOCENOSES ENTRE OS PERÍODOS DE COLETA.

FIGURA 13 - GRÁFICOS DE ORDENAÇÃO PARA O ESTUDO COMPARATIVO DAS TANATOCENOSES OBTIDAS EM ABRIL E SETEMBRO DE 2006.

FIGURA 14 - GRÁFICO DE ORDENAÇÃO DAS BIOCENOSES E TANATOCENOSES OBTIDAS PRÓXIMO AO EMISSÁRIO DO ARAÇÁ, NOS PERÍODOS DE JULHO DE 2005, ABRIL E SETEMBRO DE 2006. 115 FIGURA 15 - DENDROGRAMA, EM MODO Q, OBTIDO PARA O PERÍODO DE JULHO DE 2005. 116 FIGURA 16 - DENDROGRAMA, EM MODO Q, OBTIDO PARA O PERÍODO DE ABRIL DE 2006. 117 FIGURA 17 - DENDROGRAMA, EM MODO Q, OBTIDO PARA O PERÍODO DE SETEMBRO DE 2006. 
FIGURA 18 - DIAGRAMA DE ORDENAÇÃO DA RELAÇÃO EXISTENTE ENTRE AS ESPÉCIES DE FORAMINÍFEROS COMPÕEM AS BIOCENOSES E OS PARÂMETROS ABIÓTICOS.

FIGURA 19 - DIAGRAMA DE ORDENAÇÃO DAS RELAÇÕES EXISTENTES ENTRE AS ESTAÇÕES E OS PARÂMETROS ABIÓTICOS.

FIGURA 20 - GRÁFICOS DE ORDENAÇÃO OBTIDOS NO ESTUDO COMPARATIVO ENTRE AS

BIOCENOSES.

FIGURA 21 - DIAGRAMAS DE ORDENAÇÃO OBTIDOS NO ESTUDO COMPARATIVO ENTRE AS TANATOCENOSES

FIGURA 22 - DIAGRAMAS DE ORDENAÇÃO OBTIDOS NOS ESTUDOS COMPARATIVOS ENTRE BIOCENOSES E TANATOCENOSES.

FIGURA 23 - DENDROGRAMA, MODO Q, OBTIDO PARA O PERÍODO DE SETEMBRO DE 2005. 195

FIGURA 24 - DENDROGRAMA, MODO Q, OBTIDO PARA O PERÍODO DE JUNHO DE 2006. 196

FIGURA 25 - DENDROGRAMA, MODO Q, OBTIDO PARA O PERÍODO DE OUTUBRO DE 2006.

FIGURA 26 - DIAGRAMA DE ORDENAÇÃO DA RELAÇÃO EXISTENTE ENTRE AS ESPÉCIES DE FORAMINÍFEROS QUE COMPÕEM AS BIOCENOSES E OS PARÂMETROS ABIÓTICOS.

FIGURA 27 - DIAGRAMA DE ORDENAÇÃO DAS RELAÇÕES EXISTENTES ENTRE AS ESTAÇÕES E OS PARÂMETROS ABIÓTICOS.

FIGURA 28 - GRÁFICOS DE ORDENAÇÃO (NMDS E TESTE T) OBTIDOS NO ESTUDO COMPARATIVO ENTRE AS BIOCENOSES.

FIGURA 29 - GRÁFICOS DE ORDENAÇÃO (NMDS E TESTE T) OBTIDOS NO ESTUDO COMPARATIVO ENTRE AS TANATOCENOSES.

FIGURA 30 - GRÁFICOS DE ORDENAÇÃO (NMDS E TESTE T) DOS ESTUDOS COMPARATIVOS ENTRE AS TANATOCENOSES E AS BIOCENOSES. 268

FIGURA 31 - DENDROGRAMA, MODO Q, OBTIDO PARA O PERÍODO DE AGOSTO DE 2005. 269

FIGURA 32 - DENDROGRAMA, MODO Q, OBTIDO PARA O PERÍODO DE MARÇO DE 2006. 270

FIGURA 33 - DENDROGRAMA, MODO Q, OBTIDO PARA O PERÍODO DE AGOSTO DE 2006 271 FIGURA 34 - DIAGRAMA DE ORDENAÇÃO DA RELAÇÃO EXISTENTE ENTRE AS ESPÉCIES DE FORAMINÍFEROS QUE COMPÕEM AS BIOCENOSES E OS PARÂMETROS ABIÓTICOS.

FIGURA 35 - DIAGRAMA DE ORDENAÇÃO DAS RELAÇÕES EXISTENTES ENTRE AS ESTAÇÕES E OS PARÂMETROS ABIÓTICOS. 
FIGURA 36 - DIAGRAMA DE ORDENAÇÃO OBTIDO PARA O ESTUDO COMPOSIÇÃO DAS ESPÉCIES IDENTIFICADAS AO LONGO DO CANAL DE SÃO SEBASTIÃO, NO ARAÇÁ, NO SACO DA CAPELA E NO TEBAR.

FIGURA 37 - DIAGRAMA DE ORDENAÇÃO OBTIDO PARA O ESTUDO COMPOSIÇÃO DAS ESPÉCIES IDENTIFICADAS AO LONGO DO CANAL DE SÃO SEBASTIÃO, NO ARAÇÁ, NO SACO DA CAPELA E NO TEBAR.

FIGURA 38 - DIAGRAMA DE ORDENAÇÃO OBTIDO PARA O ESTUDO COMPOSIÇÃO DAS ESPÉCIES IDENTIFICADAS AO LONGO DO CANAL DE SÃO SEBASTIÃO, NO ARAÇÁ, NO SACO DA CAPELA E NO TEBAR.

FIGURA 39 - DENDROGRAMA OBTIDO PARA AS ESTAÇõES AMOSTRADAS NO ANO DE 2005.

FIGURA 40 - DENDROGRAMA OBTIDO PARA AS ESTAÇõES AMOSTRADAS NO PRIMEIRO SEMESTRE DE 2006.

FIGURA 42 - DIAGRAMA DE ORDENAÇÃO OBTIDO PARA O ESTUDO COMPOSIÇÃO DAS ESPÉCIES IDENTIFICADAS AO LONGO DO CANAL DE SÃO SEBASTIÃO, NO ARAÇÁ, NO SACO DA CAPELA E NO TEBAR

FIGURA 43 - DIAGRAMA DE ORDENAÇÃO OBTIDO PARA O ESTUDO COMPOSIÇÃO DAS ESPÉCIES IDENTIFICADAS AO LONGO DO CANAL DE SÃO SEBASTIÃO, NO ARAÇÁ, NO SACO DA CAPELA E NO TEBAR.

FIGURA 44 - DIAGRAMA DE ORDENAÇÃO OBTIDO PARA O ESTUDO COMPOSIÇÃO DAS ESPÉCIES IDENTIFICADAS AO LONGO DO CANAL DE SÃO SEBASTIÃO, NO ARAÇÁ, NO SACO DA CAPELA E NO TEBAR.

FIGURA 45 - DENDROGRAMA OBTIDO PARA AS ESTAÇÕES AMOSTRADAS EM 2005.

FIGURA 46 - DENDROGRAMA OBTIDO PARA AS ESTAÇÕES AMOSTRADAS NO PRIMEIRO SEMESTRE DE 2006.

FIGURA 47 - DENDROGRAMA OBTIDOS PARA AS ESTAÇÕES AMOSTRADAS NO SEGUNDO SEMESTRE DE 2006.

FIGURA 48 - DIAGRAMA DE ORDENAÇÃO DA RELAÇÃO EXISTENTE ENTRE AS ESPÉCIES DE FORAMINÍFEROS QUE COMPÕEM AS BIOCENOSES E OS PARÂMETROS ABIÓTICOS.

FIGURA 49 - DIAGRAMA DE ORDENAÇÃO OBTIDO PARA O RELACIONAMENTO EXISTENTE ENTRE AS ESTAÇÕES E PARÂMETROS AMBIENTAIS 


\section{LISTA DE TABELAS}

TABELA 01 - POSICIONAMENTO GEOGRÁFICO E DADOS FÍSICO-QUÍMICOS DA COLUNA D’ÁGUA.........45 TABELA 02 - DISTRIBUIÇÃO GRANULOMÉTRICA OBTIDA EM AMOSTRAS COLETADAS AO LONGO DO CANAL DE SÃO SEBASTIÃO.

TABELA 03 - PROFUNDIDADES, PARÂMETROS GEOQUÍMICOS E RAZÕES ELEMENTARES OBTIDAS AO LONGO DO CANAL DE SÃO SEBASTIÃO.

TABELA 04 - POSICIONAMENTOS GEOGRÁFICOS E DADOS FíSICO-QUÍMICOS DA COLUNA D’ÁGUA OBTIDOS PRÓXIMO AO EMISSÁRIO DO ARAÇÁ

TABELA 05 - RESULTADOS GRANULOMÉTRICOS OBTIDOS EM REGIÃO CIRCUNJACENTE AOS DIFUSORES DO EMISSÁRIO SUBMARINO DO ARAÇÁ.

TABELA 06 - RESULTADOS GEOQUÍMICOS E RAZÕES ELEMENTARES OBTIDOS EM REGIÃO CIRCUNJACENTE AO EMISSÁRIO SUBMARINO DE ESGOTOS DOMÉSTICOS DO ARAÇÁ.

TABELA 07 - SÍNTESE DOS RESULTADOS OBTIDOS PELA ANÁLISE DE CORRESPONDÊNCIA CANÔNICA.

TABELA 08 - POSICIONAMENTOS GEOGRÁFICOS E DADOS FÍSICO-QUÍMICOS DA COLUNA D’ÁGUA OBTIDOS PRÓXIMO AO EMISSÁRIO DO SACO DA CAPELA.

TABELA 09 - RESULTADOS GRANULOMÉTRICOS OBTIDOS EM REGIÃO CIRCUNJACENTE AOS

DIFUSORES DO EMISSÁRIO SUBMARINO DO SACO DA CAPELA.

TABELA 10 - RESULTADOS GEOQUÍMICOS E RAZÕES ELEMENTARES OBTIDOS PRÓXIMO AOS DIFUSORES DO EMISSÁRIO SACO DA CAPELA.

TABELA 11 - SÍNTESE DOS RESULTADOS OBTIDOS PELA ANÁLISE DE CORRESPONDÊNCIA CANÔNICA.

TABELA 12 - POSICIONAMENTOS GEOGRÁFICOS E DADOS FíSICO-QUÍMICOS DA COLUNA D’ÁGUA OBTIDOS PRÓXIMO AO EMISSÁRIO DO TEBAR.

TABELA 13 - RESULTADOS GRANULOMÉTRICOS OBTIDOS EM REGIÃO CIRCUNJACENTE AOS DIFUSORES DO EMISSÁRIO SUBMARINO DO TEBAR.

TABELA 14 - RESULTADOS GEOQUÍMICOS E RAZÕES ELEMENTARES OBTIDOS EM REGIÃO CIRCUNJACENTE AO EMISSÁRIO SUBMARINO DO TEBAR.

TABELA 15 - SÍNTESE DOS RESULTADOS OBTIDOS PELA ANÁLISE DE CORRESPONDÊNCIA CANÔNICA. 
TABELA 16 - SÍNTESE DOS RESULTADOS OBTIDOS PELA ANÁLISE DE CORRESPONDÊNCIA CANÔNICA.

.330 


\section{LISTA DE ANEXOS}

ANEXO 01 - TEORES DE CARBONATO DE CÁLCIO E CARBONO ORGÂNICO TOTAL OBTIDAS AO LONGO DO CANAL DE SÃO SEBASTIÃO.

ANEXO 02 - TEODRES DE NITROGÊNIO E FÓSFORO TOTAL OBTIDAS AO LONGO DO CANAL DE SÃO SEBASTIÃO.

ANEXO 03 - TEORES DE FÓSFORO ORGÂNICO E INORGÂNICO OBTIDAS AO LONGO DO CANAL DE SÃO

SEBASTIÃO.

ANEXO 04 - TEORES DE ENXOFRE OBTIDAS AO LONGO DO CANAL DE SÃO SEBASTIÃO. .73

ANEXO 05 - ORIGEM DA MATÉRIA ORGÂNICA (RAZÕES C/N) E POTENCIAL DE OXI-REDUÇÃO DOS SEDIMENTOS AMOSTRADOS AO LONGO DO CANAL DE SÃO SEBASTIÃO.

ANEXO 07 - DISTRIBUIÇÃO DE ESPÉCIES BIOINDICADORAS DE AMBIENTE ÓXICO E RICO EM MATÉRIA ORGÂNICA IDENTIFICADAS AO LONGO DO CANAL DE SÃO SEBASTIÃO.

ANEXO 08 - MATRIZ DE CORRELAÇÃO DE PEARSON OBTIDA PARA OS DADOS BIÓTICOS E ABIÓTICOS OBTIDOS NO CANAL DE SÃO SEBASTIÃO

ANEXO 09 - RESULTADO DAS ANÁLISES MORFOMÉTRICAS REALIZADAS NAS CARAPAÇAS DOS FORAMINÍFEROS (BIOCENOSES E TANATOCENOSES) OBTIDAS AO LONGO DO CANAL DE SÃO SEBASTIÃO.

ANEXO 10 - ESTADO DE PRESERVAÇÃO E COLORAÇÃO DAS CARAPAÇAS DOS FORAMINÍFEROS QUE COMPUSERAM AS TANATOCENOSES. VALORES EM PORCENTAGEM.

ANEXO 11 - MODELO PROPOSTO PARA A CIRCULAÇÃO NO INTERIOR DO CANAL DE SÃO SEBASTIÃO. 84 ANEXO 12 - DISTRIBUIÇÃO GRANULOMÉTRICA OBTIDA PRÓXIMO AO EMISSÁRIO SUBMARINO DE ESGOTOS DOMÉSTICOS DO ARAÇÁ.

ANEXO 13 - CONCENTRAÇõES DE CARBONATO DE CÁLCIO OBTIDAS PRÓXIMO AO EMISSÁRIO DO ARAÇÁ.

ANEXO 14 - CONCENTRAÇÕES DE CARBONO ORGÂNICO TOTAL OBTIDAS PRÓXIMO AO EMISSÁRIO DO ARAÇÁ.

ANEXO 15 - CONCENTRAÇÕES DE NITROGÊNIO OBTIDAS PRÓXIMO AO EMISSÁRIO DO ARAÇÁ........138 ANEXO 16 - CONCENTRAÇÕES DE FÓSFORO TOTAL OBTIDAS PRÓXIMO AO EMISSÁRIO DO ARAÇÁ. 139 ANEXO 17 - CONCENTRAÇÕES DE FÓSFORO ORGÂNICO OBTIDAS PRÓXIMO AO EMISSÁRIO DO ARAÇÁ. 
ANEXO 18 - CONCENTRAÇÕES DE FÓSFORO INORGÂNICO OBTIDAS PRÓXIMO AO EMISSÁRIO DO ARAÇÁ.

ANEXO 19 - CONCENTRAÇÕES DE ENXOFRE OBTIDAS PRÓXIMO AO EMISSÁRIO DO ARAÇÁ...............142

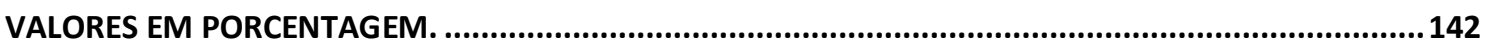

ANEXO 20 - ORIGEM DA MATÉRIA ORGÂNICA ANALISADA POR MEIO DE RAZÕES ELEMENTARES C/N.

ANEXO 21 - POTENCIAL DE OXI-REDUÇÃO DOS SEDIMENTOS DE FUNDO ANALISADO POR MEIO DE RAZÕES ELEMENTARES C/S.

ANEXO 22 - ABUNDÂNCIAS RELATIVAS DAS ESPÉCIES DE FORAMINÍFEROS IDENTIFICADAS PRÓXIMO AO EMISSÁRIO DO ARAÇÁ

ANEXO 23 - (BIOCENOSES) DISTRIBUIÇÃO DE ESPÉCIES BIOINDICADORAS DE AMBIENTE ÓXICO E ENRIQUECIDO POR MATÉRIA ORGÂNICA IDENTIFICADAS PRÓXIMO AO EMISSÁRIO DO ARAÇÁ.......149 ANEXO 24 - (BIOCENOSES) RESULTADO DAS ANÁLISES MORFOMÉTRICAS REALIZADAS NAS CARAPAÇAS DOS FORAMINÍFEROS OBTIDAS PRÓXIMO AO EMISSÁRIO DO ARAÇÁ.

ANEXO 25 - ABUNDÂNCIAS RELATIVAS DAS ESPÉCIES DE FORAMINÍFEROS IDENTIFICADAS PRÓXIMO AO EMISSÁRIO DO ARAÇÁ. 151 ANEXO 26 - (TANATOCENOSES) DISTRIBUIÇÃO DE ESPÉCIES BIOINDICADORAS DE AMBIENTE ÓXICO E ENRIQUECIDO POR MATÉRIA ORGÂNICA IDENTIFICADAS PRÓXIMO AO EMISSÁRIO DO ARAÇÁ. ....159 ANEXO 28 - GRAU DE PRESERVAÇÃO DAS CARAPAÇAS QUE COMPUSERAM AS TANATOCENOSES...161 ANEXO 29 - ESTADO DE PRESERVAÇÃO E COLORAÇÃO DAS CARAPAÇAS DOS FORAMINÍFEROS QUE COMPUSERAM AS TANATOCENOSES.

ANEXO 30 - MATRIZ DE CORRELAÇÃO DE PEARSON OBTIDA PARA OS DADOS BIÓTICOS E ABIÓTICOS OBTIDOS NO ARAÇÁ, EM JUNHO DE 2005. 163 ANEXO 31 - MATRIZ DE CORRELAÇÃO DE PEARSON OBTIDA PARA OS DADOS BIÓTICOS E ABIÓTICOS OBTIDOS NO ARAÇÁ, EM ABRIL DE 2006

ANEXO 32 - MATRIZ DE CORRELAÇÃO DE PEARSON OBTIDA PARA OS DADOS BIÓTICOS E ABIÓTICOS OBTIDOS NO ARAÇÁ, EM SETEMBRO DE 2006. 165 ANEXO 33 - DISTRIBUIÇÃO GRANULOMÉTRICA OBTIDA PRÓXIMO AO EMISSÁRIO SUBMARINO DE ESGOTOS DOMÉSTICOS SACO DA CAPELA.

ANEXO 34 - CONCENTRAÇÕES DE CARBONATO DE CÁLCIO OBTIDAS PRÓXIMO AO EMISSÁRIO SACO DA CAPELA.

ANEXO 35 - CONCENTRAÇÕES DE CARBONO ORGÂNICO TOTAL OBTIDAS PRÓXIMO AO EMISSÁRIO SACO DA CAPELA. 
ANEXO 36 - CONCENTRAÇõES DE NITROGÊNIO OBTIDAS PRÓXIMO AO EMISSÁRIO SACO DA CAPELA.

ANEXO 37 - CONCENTRAÇÕES DE FÓSFORO TOTAL OBTIDAS PRÓXIMO AO EMISSÁRIO SACO DA CAPELA.

ANEXO 38 - CONCENTRAÇÕES DE FÓSFORO ORGÂNICO OBTIDAS PRÓXIMO AO EMISSÁRIO SACO DA CAPELA.

ANEXO 39 - CONCENTRAÇÕES DE FÓSFORO INORGÂNICO OBTIDAS PRÓXIMO AO EMISSÁRIO SACO DA CAPELA.

ANEXO 40 - CONCENTRAÇÕES DE ENXOFRE OBTIDAS PRÓXIMO AO EMISSÁRIO SACO DA CAPELA. .217 ANEXO 41- ORIGEM DA MATÉRIA ORGÂNICA ANALISADA POR MEIO DE RAZÕES ELEMENTARES C/N.

ANEXO 42 - POTENCIAL DE OXI-REDUÇÃO DOS SEDIMENTOS DE FUNDO ANALISADO POR MEIO DE RAZÕES ELEMENTARES C/S.

ANEXO 43 - ABUNDÂNCIAS RELATIVAS DAS ESPÉCIES DE FORAMINÍFEROS IDENTIFICADAS PRÓXIMO AO EMISSÁRIO SACO DA CAPELA.

ANEXO 44 - (BIOCENOSES) DISTRIBUIÇÃO DE ESPÉCIES BIOINDICADORAS DE AMBIENTE ÓXICO E ENRIQUECIDO POR MATÉRIA ORGÂNICA IDENTIFICADAS PRÓXIMO AO EMISSÁRIO SACO DA CAPELA.

ANEXO 45 - (BIOCENOSES) RESULTADO DAS ANÁLISES MORFOMÉTRICAS REALIZADAS NAS CARAPAÇAS DOS FORAMINÍFEROS OBTIDAS PRÓXIMO AO EMISSÁRIO SACO DA CAPELA.

ANEXO 46 - ABUNDÂNCIAS RELATIVAS DAS ESPÉCIES DE FORAMINÍFEROS IDENTIFICADAS PRÓXIMO AO EMISSÁRIO SACO DA CAPELA.

ANEXO 47 - (TANATOCENOSES) DISTRIBUIÇÃO DE ESPÉCIES BIOINDICADORAS DE AMBIENTE ÓXICO E ENRIQUECIDO POR MATÉRIA ORGÂNICA IDENTIFICADAS PRÓXIMO AO EMISSÁRIO SACO DA CAPELA.

ANEXO 48 - (TANATOCENOSES) RESULTADO DAS ANÁLISES MORFOMÉTRICAS REALIZADAS NAS CARAPAÇAS DOS FORAMINÍFEROS OBTIDAS PRÓXIMO AO EMISSÁRIO SACO DA CAPELA.

ANEXO 49 - GRAU DE PRESERVAÇÃO DAS CARAPAÇAS QUE COMPUSERAM AS TANATOCENOSES. DADOS OBTIDOS PRÓXIMO AO EMISSÁRIO SACO DA CAPELA.

ANEXO 50 - ESTADO DE PRESERVAÇÃO E COLORAÇÃO DAS CARAPAÇAS DOS FORAMINÍFEROS QUE COMPUSERAM AS TANATOCENOSES. DADOS OBTIDOS PRÓXIMO AO EMISSÁRIO SACO DA CAPELA. 
ANEXO 51 - MATRIZ DE CORRELAÇÃO DE PEARSON OBTIDA PARA OS DADOS BIÓTICOS E ABIÓTICOS OBTIDOS NO SACO DA CAPELA, EM SETEMBRO DE 2005.

ANEXO 52 - MATRIZ DE CORRELAÇÃO DE PEARSON OBTIDA PARA OS DADOS BIÓTICOS E ABIÓTICOS OBTIDOS NO SACO DA CAPELA, EM JUNHO DE 2006.

ANEXO 53 - MATRIZ DE CORRELAÇÃO DE PEARSON OBTIDA PARA OS DADOS BIÓTICOS E ABIÓTICOS OBTIDOS NO SACO DA CAPELA, EM OUTUBRO DE 2006.

ANEXO 54 - DISTRIBUIÇÃO GRANULOMÉTRICA OBTIDA PRÓXIMO AO EMISSÁRIO SUBMARINO DE ESGOTOS DOMÉSTICOS DO TEBAR.

ANEXO 55 - CONCENTRAÇÕES DE CARBONATO DE CÁLCIO OBTIDAS PRÓXIMO AO EMISSÁRIO DO TEBAR

ANEXO 56 - CONCENTRAÇÕES CARBONO ORGÂNICO TOTAL OBTIDAS PRÓXIMO AO EMISSÁRIO DO TEBAR.

ANEXO 58 - CONCENTRAÇÕES FÓSFORO TOTAL OBTIDAS PRÓXIMO AO EMISSÁRIO DO TEBAR........289 ANEXO 59 - CONCENTRAÇõES FÓSFORO ORGÂNICO OBTIDAS PRÓXIMO AO EMISSÁRIO DO TEBAR.

ANEXO 60 - CONCENTRAÇÕES FÓSFORO INORGÂNICO OBTIDAS PRÓXIMO AO EMISSÁRIO DO TEBAR.

ANEXO 61 - CONCENTRAÇÕES ENXOFRE OBTIDAS PRÓXIMO AO EMISSÁRIO DO TEBAR. 292

ANEXO 62 - ORIGEM DA MATÉRIA ORGÂNICA ANALISADA PELAS RAZÕES ELEMENTARES C/N. 293

ANEXO 63 - POTENCIAL DE OXI-REDUÇÃO DOS SEDIMENTOS DE FUNDO ANALISADO POR MEIO DE RAZÕES ELEMENTARES C/S.

ANEXO 64 - ABUNDÂNCIAS RELATIVAS DAS ESPÉCIES DE FORAMINÍFEROS IDENTIFICADAS PRÓXIMO AO EMISSÁRIO TEBAR.

ANEXO 65 - (BIOCENOSES) DISTRIBUIÇÃO DE ESPÉCIES BIOINDICADORAS DE AMBIENTE ÓXICO E ENRIQUECIDO POR MATÉRIA ORGÂNICA IDENTIFICADAS PRÓXIMO AO EMISSÁRIO DO TEBAR........301 ANEXO 66 - (BIOCENOSES) RESULTADO DAS ANÁLISES MORFOMÉTRICAS REALIZADAS NAS CARAPAÇAS DOS FORAMINÍFEROS OBTIDAS PRÓXIMO AO EMISSÁRIO SACO DA CAPELA. 302 ANEXO 67- ABUNDÂNCIAS RELATIVAS DAS ESPÉCIES DE FORAMINÍFEROS IDENTIFICADAS PRÓXIMO AO EMISSÁRIO DO TEBAR.

ANEXO 68 - (TANATOCENOSES) DISTRIBUIÇÃO DE ESPÉCIES BIOINDICADORAS DE AMBIENTE ÓXICO E ENRIQUECIDO POR MATÉRIA ORGÂNICA IDENTIFICADAS PRÓXIMO AO EMISSÁRIO DO TEBAR........309 ANEXO 69 - (TANATOCENOSES) RESULTADO DAS ANÁLISES MORFOMÉTRICAS REALIZADAS NAS CARAPAÇAS DOS FORAMINÍFEROS OBTIDAS PRÓXIMO AO EMISSÁRIO SACO DO TEBAR. 
ANEXO 70 - GRAU DE PRESERVAÇÃO DAS CARAPAÇAS QUE COMPUSERAM AS TANATOCENOSES...311

ANEXO 71 - COLORAÇÃO DAS CARAPAÇAS DOS FORAMINÍFEROS QUE COMPUSERAM AS

TANATOCENOSES...

ANEXO 72 - MATRIZ DE CORRELAÇÃO DE PEARSON OBTIDA PARA OS DADOS BIÓTICOS E ABIÓTICOS

OBTIDOS PRÓXIMO AO EMISSÁRIO DO TEBAR, EM AGOSTO DE 2005.

ANEXO 73 - MATRIZ DE CORRELAÇÃO DE PEARSON OBTIDA PARA OS DADOS BIÓTICOS E ABIÓTICOS

OBTIDOS PRÓXIMO AO EMISSÁRIO DO TEBAR, EM MARÇO DE 2006.

314

ANEXO 74 - MATRIZ DE CORRELAÇÃO DE PEARSON OBTIDA PARA OS DADOS BIÓTICOS E ABIÓTICOS

OBTIDOS PRÓXIMO AO EMISSÁRIO DO TEBAR, EM AGOSTO DE 2006.

.315 


\section{LISTA DE ABREVIATURAS E SIGLAS}

CETESB - Companhia Ambiental do Estado de São Paulo

SABESP - Companhia de Saneamento Básico do Estado de São Paulo

CONAMA - Conselho Nacional do Meio Ambiente

TEBAR - Terminal Petrolífero Almirante Barroso

ETE - Estação de tratamento de efluentes

SAO - Sistema separador de água e óleo

Cot - Carbono Orgânico

P total - Fósforo total

P org - Fósforo orgânico

$\mathrm{P}$ inorg - Fósforo inorgânico

MEV - Microscópio Eletrônico de Varredura

EDS - Espectrômetro de Energia Dispersiva

MANOVA - Multivariate Analysis of Variance

NMDS - Non-metric multi dimensional scaling 
V LISTA DE SÍMBOLOS

$\bar{x}-$ média

$\delta$ - desvio padrão

$\mu \mathrm{m}$ - micrômetro

$p$ - nível de significância

$\mathrm{r}$ - coeficiente de correlação 


\section{RESUMO}

O presente estudo teve por objetivo analisar a influência da disposição oceânica de esgotos domésticos e petroquímicos na coluna d'água, nos sedimentos e nas associações de foraminíferos bentônicos. Para atingir tal objetivo foram coletadas amostras próximo aos emissários do Araçá, do Saco da Capela e do Terminal Petrolífero Almirante Barroso (TEBAR), em 2005 e 2006. Coletou-se também 10 amostras ao longo do Canal de São Sebastião, SP, em 2008. Em cada ponto amostral foram obtidos dados físicoquímicos da coluna d'água, sedimentológicos (granulometria, Cot, N, P e S) e das associações de foraminíferos. As biocenoses e tanatocenoses foram estudadas separadamente. Os resultados das análises hidrogeoquímicas não demonstraram alterações de origem antrópica. Os valores de todos os parâmetros analisados estiveram dentro dos limites estabelecidos pelo CONAMA. Os resultados das análises granulométricas e geoquímicas indicaram dois setores distintos no Canal de São Sebastião, um na região norte, com sedimentos arenosos e teores baixos de Cot, N, P e $\mathrm{S}$ e outro na região central, com predominância de sedimentos finos e teores elevados Cot, N, P e S. Na região central verificou-se abundância significativa de espécies euribiontes. Segundo os resultados granulométricos e geoquímicos obtidos para a região do Saco da Capela, o estresse ambiental decorrente do esgoto disposto ocorre de forma pontual, i.e. na saída do emissário submarino. As associações de foraminíferos são compostas predominantemente por espécies típicas de ambientes bem oxigenados. $\mathrm{O}$ emissário do Araçá está posicionado em região com circulação de fundo oscilando entre moderada e fraca. Os resultados geoquímicos indicaram enriquecimento orgânico, decorrente do efluente disposto, na região nordeste. Nesta região foram obtidas as maiores abundâncias de espécies euribiontes, com declínio de espécies estenobióticas. Pelas tanatocenoses de Setembro de 2006, constatou-se grau elevado de estresse na saída do emissário (estação Ar1), onde ocorreu dominância de foraminíferos aglutinantes, sendo observados sinais de dissolução em espécimes hialinos. A região circundante ao emissário do TEBAR é a que apresenta maior nível de degradação ambiental. Nesta região os sedimentos são predominantemente lamosos, com elevados teores de Cot, N, P e S. As condições redutoras dos sedimentos de fundo são observadas pelos valores negativos de Eh, pelo valor levemente ácido de $\mathrm{pH}$ e pelos valores baixos das razões $\mathrm{C} / \mathrm{S}$. As associações de foraminíferos são compostas dominantemente por espécies bioindicadoras de ambientes hipóxicos. Os estudos comparativos (NMDS, MANOVA e teste $t$ ) evidenciaram diferenças significativas nas estruturas composicionais quando as biocenoses e tanatocenoses são comparadas entre si, bem como quando as biocenoses são comparadas com as tanatocenoses. Pelos resultados obtidos verificou-se que as interpretações seriam diferentes das obtidas, caso os estudos de avaliação ambiental fossem realizados com a associação total de foraminíferos (vivos + mortos).

Palavras-chave: emissário submarino, esgotos domésticos, esgotos petroquímicos, geoquímica, foraminíferos bentônicos, Canal de São Sebastião 


\section{ABSTRACT}

The influence of oceanic disposal of domestic and petrochemical effluents on physicochemical parameters of the water column, geochemistry of sediments and foraminiferal assemblages was assessed in this study. Water and sediment samples were collected near Araçá, Saco da Capela and Almirante Barroso Terminal Petroliferous (TEBAR) outfalls, in the São Sebastião Channel, São Paulo, Brazil, in 2005 and 2006. Ten other samples distributed along the channel were collected in 2008. For each water sample physicochemistry analyses were carried out. In the sediments, grain size, geochemistry (TOC, N, P and S) and foraminiferal composition were analyzed. Live and dead benthic foraminiferal composition and distribution were studied separately. The water column analyses did not demonstrate human-induced changes. The values of almost all parameters were within the National Environmental Council (CONAMA) limits. Grain size analysis and geochemistry results indicated two different morphosedimentary sectors in the São Sebastião Channel, one in the north with sandy sediments and low TOC, N, P and S, and the other in the central region with predominantly fine sediments, significant nutrient, TOC and $\mathrm{S}$ values. The Saco da Capela submarine outfall is positioned in high hydrodynamic environment. Geochemical results indicated that the environmental stress occurs only at the outfall end (station Ar1). The foraminiferal assemblage is composed of species typical of welloxygenated bottom waters and low organic content. The Araçá submarine outfall is located in an area with moderate to weak bottom circulation. Organic enrichment due the domestic effluent disposal was observed in the southeast and northeast area, mainly by $\mathrm{P}$ and $\mathrm{S}$ and, to a lesser extent, by TOC values. In these regions opportunistic foraminiferal species dominate and stenobiotic species are absent or present in diminished values. The highest level of environmental degradation was registered in September, 2006, when dominance of agglutinated shells and signals of dissolution in hyaline shells were observed in the thanatocenosis. The area around TEBAR diffusers presents high levels of environmental stress. In this area, characterized by muddy sediments, the highest TOC, N, P and S contents were registered in all the periods were found. Reducing conditions in the region are demonstrated by values of $\mathrm{Eh}$, acid $\mathrm{pH}$ and low $\mathrm{C} / \mathrm{S}$ ratios. In the foraminiferal assemblage, environmental degradation was inferred by the dominance hypoxic species. Comparative studies (NMDS, MANOVA and test) indicated significant differences in foraminiferal composition among biocenosis, among thanatocenosis and between biocenosis and thanatocenosis. These results demonstrate that biocenosis and thanatocenosis must be studied separately.

Keywords: submarine outfall, domestic sewage, petrochemical sewage, geochemistry, benthonic foraminiferal, São Sebastião Channel. 


\section{INTRODUÇÃO}

Nas últimas décadas, os ambientes costeiros brasileiros têm sofrido processos constantes de degradação ambiental causados pela crescente pressão antrópica sobre os recursos naturais (IBAMA, 2002).

Em decorrência do adensamento urbano exponencial e, muitas vezes, sem planejamento, os esgotos domésticos passaram a ser um dos principais fatores de impactos ambientais em regiões costeiras. O aporte do esgoto para os oceanos pode ocorrer de forma difusa, i.e. pelos rios, ou de forma pontual, o qual ocorre através de disposição oceânica pelos emissários submarinos (Lamparelli, 2006).

Os emissários submarinos podem representar sistema seguro para remoção de agentes contaminantes da região costeira, desde que sejam bem projetados (Gonçalves e Souza, 1997) e os esgotos recebam tratamento adequado antes de serem liberados para o corpo receptor (Werme e Hunt, 2004).

Se no passado, o oceano era considerado como corpo receptor ideal para a disposição de esgotos domésticos e/ou industriais, devido à sua capacidade de autodepuração, nos últimos anos este conceito vem sendo questionado (EPA, 2003). Muitos estudos têm constatado que o impacto ambiental causado pelos efluentes dispostos por emissários submarinos pode ter efeito deletério sobre a fauna e a flora (Rachid, 1996, 2002; Brasil-Lima, 1998; Heitor, 2002; CETESB, 2005; Abessa et al., 2005; Filippos, 2010). Os níveis de impacto são dependentes da composição, do volume e do tipo de tratamento recebido pelo esgoto.

Dentre os diversos problemas gerados ao meio ambiente, o enriquecimento orgânico e o potencial de toxicidade dos efluentes são considerados como os mais críticos. O enriquecimento orgânico localizado tende a alterar os níveis de oxigenação, gerando condições hipóxicas e, eventualmente, anóxicas no compartimento bentônico (Fenchel e Finalay, 1995). Já em relação aos componentes tóxicos, os mesmo podem se bioacumular e /ou biomagnificar na cadeia trófica (Pearson, 1986).

$\mathrm{Na}$ tentativa de elucidar e caracterizar as alterações ambientais decorrentes de estressores antrópicos, e.g. disposição oceânica de esgotos domésticos e industriais, muitos pesquisadores têm utilizado a geoquímica em conjunto com organismos pertencentes à meiofauna (bioindicadores) (Armynot Du Châtelet et al., 2004; Burone et al., 2006; Debenay e Fernandes, 2009). 
De acordo com as propriedades geoquímicas dos sedimentos, podem-se ser inferidas fontes de origem da matéria orgânica e o grau de estresse ambiental. Por sua vez, a utilização de bioindicadores parte da premissa de que determinados organismos auxiliam a elucidar eventos naturais e/ou antrópicos que ocorrem nos ecossistemas, sejam estes temporais e/ou espaciais (Boltovskoy, 1959).

\section{Emissários submarinos de esgotos}

É uma estrutura hidráulica linear constituída por três componentes principais: i) a estação de lançamento, a qual pode conter uma estação de pré-tratamento de efluentes domésticos e industriais, ii) a tubulação, que transporta o efluente, por gravidade ou bombeamento, para o local da disposição e iii) o sistema difusor, o qual pode conter bocais ou orifícios, que auxiliam no lançamento e dispersão do efluente no corpo receptor (CETESB, 2007) (Figura 01).

Atualmente a disposição oceânica de esgotos domésticos é uma prática usual e ocorre em diversos países. Os esgotos antes de serem liberados para o corpo receptor recebem desde um simples pré-tratamento até níveis mais elevados, i.e. tratamento primário, secundário e terciário.

No Brasil,o sistema de disposição oceânica através de emissários submarinos de esgotos domésticos começou a ocorrer em 1970, com a instalação do emissário na praia de Ipanema (RJ). Atualmente, existem 20 emissários submarinos em operação na costa brasileira. Dentre os quais, 8 estão localizados no estado de São Paulo, nas cidades de Praia Grande, Santos/São Vicente, Guarujá, São Sebastião e Ilhabela. Em São Sebastião há também um emissário submarino para efluentes petroquímicos. 


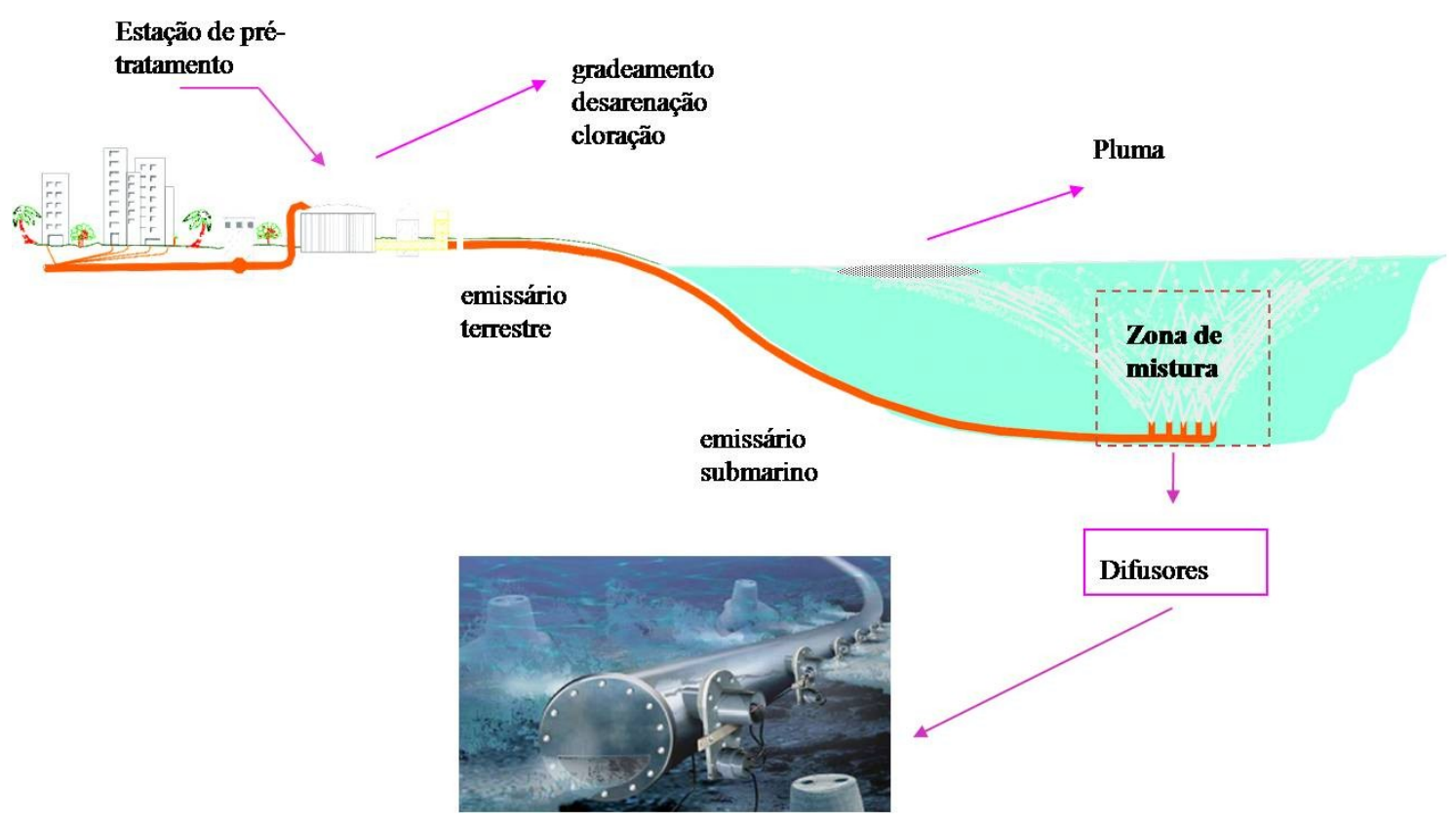

Figura 01 - Esquematização do sistema de disposição oceânica de esgotos.

\section{Foraminíferos bentônicos como bioindicadores}

Os foraminíferos, embora não estejam incluídos em protocolos oficiais de agências governamentais para caracterizações ambientais (Debenay e Fernandez, 2009), são considerados excelentes bioindicadores, pois possuem ciclo de vida curto e elevada sensibilidade a alterações físico-químicas, o que faz com que respondam rapidamente a alterações ambientais. Além disso, são abundantes, diversificados taxonomicamente, possuem ampla distribuição espacial e temporal (i.e. estratigráfica) e sua amostragem causa impacto mínimo ao meio ambiente (Boltovskoy, 1958; Alve, 1991; Yanko et al.,1994; Alve, 1995).

Além do já exposto, os foraminíferos são bons traçadores geoquímicos, pois a composição das carapaças calcárias reflete a geoquímica da água do mar e as condições ambientais presentes durante a precipitação da calcita.

Desta forma, torna-se possível a partir da composição de suas associações, análises geoquímicas das carapaças, análises tafonômicas e morfométricas das carapaças é possível inferir o padrão de circulação estuarina e oceânica, identificar massas de água, bem como compreender a dinâmica sedimentar local (Bonetti, 2000; Duleba e Debenay, 2003; Bonfante et al.,2005). 
Foraminíferos têm sido amplamente utilizados como indicadores de impactos ambientais de origem antrópica. Zalesny (1959) e Resig (1960) foram os primeiros pesquisadores a realizarem trabalhos utilizando foraminíferos como bioindicadores. A partir de então, muitos outros estudos foram realizados para avaliar e monitorar impactos ambientais decorrentes do aporte, em ambiente marinho, de esgotos domésticos e industriais, metais pesados e hidrocarbonetos (Alve, 1995; Cearreta et al., 2002; Saraswat et al., 2004; Ferraro et al.,2006; Le Cadre e Debenay, 2006; Burone et al., 2006, Romano et. al. 2009, Cherchi et al. 2009; Coccioni et al., 2009; Sabean et al., 2009; Debenay e Fernandez, 2009; Aloulou et al., 2011; Buzas-Stephens et al., 2011, Frontalini e Coccioni, 2011)

Apesar de significativo o número de estudos com foraminíferos em ambientes impactados, os quais são em grande maioria regiões costeiras marinhas e estuarinas, a caracterização da qualidade ambiental precisa ser feita de modo interdisciplinar, ou seja, em conjunto com análises granulométricas, geoquímicas e físico-químicas. Tal integração deve-se ao fato de que: i) regiões costeiras são ambientes em que alterações físico-químicas (e.g. temperatura, salinidade) ocorrem naturalmente, ii) o mesmo tipo de poluente pode afetar os ambientes de forma diferenciada e iii) diferentes tipos de poluentes podem ser lançados em ambiente marinho ao mesmo tempo e os foraminíferos podem responder de formas distintas a esta mistura (Alve, 1995).

Estudos de caracterização ambiental e/ou biomonitoramento disponíveis na literatura, verifica-se opiniões divergentes em relação à utilização da fauna total (vivos + mortos). De acordo com alguns autores a fauna total é a mais indicada para estudos ambientais, uma vez que representa o acúmulo espécimes de vários períodos sazonais, o que representaria com mais fidedignidade as condições ambientais da região (Scott e Medioli, 1980; Debenay et al., 2001; Albani et al., 2007; Debenay e Fernandez, 2009).

A fauna viva de foraminíferos, em contrapartida, representaria somente as condições ambientais à que o meio estava sujeito no período da coleta (Buzas et al., 2002). Para outros autores, entretanto, o acúmulo de vários períodos poderia mascarar os resultados, uma vez, que as carapaças de foraminíferos estão sujeitas a uma série de processos post mortem, como transporte (i.e. seleção hidráulica das carapaças por tamanho e introdução de espécies alóctones) e diagênese (i.e. seleção das carapaças por dissolução e abrasão mecânica) (Murray, 1982, 1986; Alve e Murray, 1994; van der Zwaan et al., 1999). Para estes autores, os foraminíferos bentônicos vivos representam com mais acuidade as condições ambientais a que a região a ser estudada está sujeita. 
Segundo Murray (2003), a origem das associações de foraminíferos mortos apresenta-se complexa; sem a informação proveniente das associações de foraminíferos vivos, na mesma região, os resultados podem ser de difícil interpretação.

Outro fator que gera controvérsias é a utilização do corante Rosa de Bengala $\left(\mathrm{C}_{20} \mathrm{H}_{2} \mathrm{Cl}_{4} \mathrm{I}_{4} \mathrm{Na}_{2} \mathrm{O}_{5}\right)$ para distinguir foraminíferos vivos dos mortos, no momento em que as amostras são coletadas. Embora seja uma prática reconhecida (q.v. Bernhard, 1992; Alve e Bernhard, 1995), alguns autores tem mencionado que foraminíferos de ambientes profundos e com baixos níveis de oxigenação podem permanecer corados por longo período após a sua morte, o que não seria condizente com a realidade (Corliss e Emerson, 1990; Jorissen et al., 1995). Matéria orgânica incorporada nas carapaças vazias também pode ser corada, o que induz interpretações errôneas.

Mesmo diante do disposto, a utilização de Rosa de Bengala é considerada a melhor forma de identificar os foraminíferos vivos no momento da coleta, e segundo Lutze e Altenbach (1991), se cuidadosamente empregada, a metodologia possui $96 \%$ de acurácia. 


\section{OBJETIVOS GERAIS}

* Estudar a hidroquímica, a sedimentologia (granulometria e geoquímica) e a meiofauna (foraminíferos) de três áreas submetidas à disposição oceânica de esgotos domésticos (Araçá e Saco da Capela) e petroquímicos (TEBAR), com o intuito de avaliar os efeitos dos efluentes sobre a biota bentônica.

\section{Objetivos específicos}

* Analisar o padrão de distribuição espacial da granulometria e da geoquímica dos sedimentos amostrados ao longo do Canal de São Sebastião, bem como dos sedimentos coletados ao redor dos difusores dos emissários submarinos;

* Estudar a composição e o padrão de distribuição (temporal e sazonal) das associações de foraminíferos bentônicos vivos (biocenoses) e mortos (tanatocenoses);

* Analisar, por meio de análises estatísticas, se há similaridade entre a composição faunística das biocenoses e das tanatocenoses de uma mesma região, e entre as áreas de estudo;

* Comparar os resultados abióticos e bióticos das áreas de estudo entre si, bem como com outras regiões litorâneas, com o intuito de avaliar a influência da disposição oceânica sobre o compartimento bentônico. 


\section{CAPÍTULO 1 - ÁREA DE ESTUDO}

\subsection{Contexto Geológico}

A região de São Sebastião, localizada no litoral norte do Estado de São Paulo, encontra-se inserida no domínio tectônico Maciço de Joinville, situado a sudeste do falhamento de Cubatão (Almeida et al., 1981). A região é recortada pela falha transcorrente de Bertioga-Caraguatatuba, com direção SW-NE, a qual delimita o encontro do Bloco de São Sebastião com o Bloco de Ubatuba (Melo e Pires Neto, 1977). A tectônica para a formação destes blocos é responsável pela formação da Serra do Mar, bem como do relevo da costa norte paulista (Melo e Pires Neto, 1977).

O Bloco de São Sebastião é formado por migmatitos homogêneos estromáticos do Complexo Costeiro, em que se encontram núcleos metabasíticos envolvidos por migmatitos agmatíticos, intercalações de anfibolito e um pequeno corpo de rochas granitóides (Garda, 1995). Junto à Falha Bertioga-Caraguatatuba, as rochas encontramse cataclasadas em intensidade variável, com ocorrência de faixas de protomilonitos, milonitos e ultramilonitos (Garda, 1995). O Bloco de São Sebastião também se apresenta cortado por muitos diques de rochas básicas e ultrabásicas (Garda, 1995).

A Ilha de São Sebastião tem sua estrutura associada ao intenso vulcanismo alcalino, ocorrido do Cretáceo Superior ao Paleoceno (Furtado et al., 2008). As rochas, oriundas deste intenso vulcanismo alcalino, foram datadas em aproximadamente 80 milhões de anos AP (Amaral et al.,1966).

Segundo Furtado et al. (2008), São Sebastião tem sua origem e evolução associadas à formação de margens continentais do tipo Atlântico e ao acondicionamento por dois conjuntos de eventos de escalas temporais distintas.

O primeiro relaciona-se às reativações tectônicas, que ocorreram durante o final do Mesozóico e início do Cenozóico, responsáveis pelo soerguimento da Serra do Mar e pela subsidência da Bacia de Santos. O segundo evento relaciona-se com a sedimentação decorrente das sucessivas transgressões e regressões marinhas quaternárias que modelaram a área.

O Canal de São Sebastião (CSS) encontra-se posicionado em uma zona de fraqueza, abatida e propícia a erosão, entre a Ilha de São Sebastião e a Serra de Juqueriquerê (Furtado et al., 2008). Orienta-se de acordo com as estruturas gerais da 
área (NE-SW), configurando-se, inicialmente, como um vale produzido pelo abatimento de blocos decorrente dos sistemas de falhamentos da Serra do Mar (Furtado et al., 2008).

\subsection{Aspectos fisiográficos e oceanográficos do Canal de São Sebastião}

O Canal de São Sebastião (latitudes $23^{\circ} 43^{\prime}$ S e $23^{\circ} 54^{\prime} \mathrm{S}$ e longitudes $45^{\circ} 28^{\prime}$ e $45^{\circ} 20^{\prime}$ W) está localizado na Plataforma Continental Norte de São Paulo, entre o município de São Sebastião e a Ilha de São Sebastião (Figura 02).

Segundo Furtado et al. (2008), o Canal de São Sebastião é um canal costeiro não influenciado significativamente pelas correntes de maré e nem por aporte de água doce, o que o torna, sob o ponto de vista físico, diferente da maioria dos canais costeiros. Ainda de acordo com os autores, o Canal de São Sebastião é somente uma via de comunicação física para as duas partes da plataforma continental, adjacentes às suas extremidades.

A extensão do Canal de São Sebastião é de aproximadamente $24 \mathrm{~km}$, com largura variando entre $5,8 \mathrm{~km}$ e $6,4 \mathrm{~km}$ nas entradas norte e sul, respectivamente. A região central é a mais estreita, apresenta extensão aproximadamente $2 \mathrm{~km}$, próximo à Ponta do Araçá.

A topografia de fundo do canal reflete a origem tectônica, caracterizada pela presença de um eixo principal, com orientação SW-NE, deslocado para o lado da Ilha de São Sebastião, sendo, entretanto, observado na porção sul do canal um eixo secundário em ângulo oblíquo com o principal, alinhado com as estruturas secundárias.

Segundo Furtado et al. (2008), embora não existam informações para o detalhamento do processo de modelagem sedimentar no canal, é possível, com os dados existentes, inferir que o ingresso de águas marinhas ocorreu pela entrada sul, com conseqüente transporte de sedimentos de sudoeste para nordeste. Tal inferência tem como embasamento as feições topográficas sedimentares que ocorrem na região, como por exemplo a feição tabular existente na entrada sul do canal (Pires-Vanin et al., 2008). 


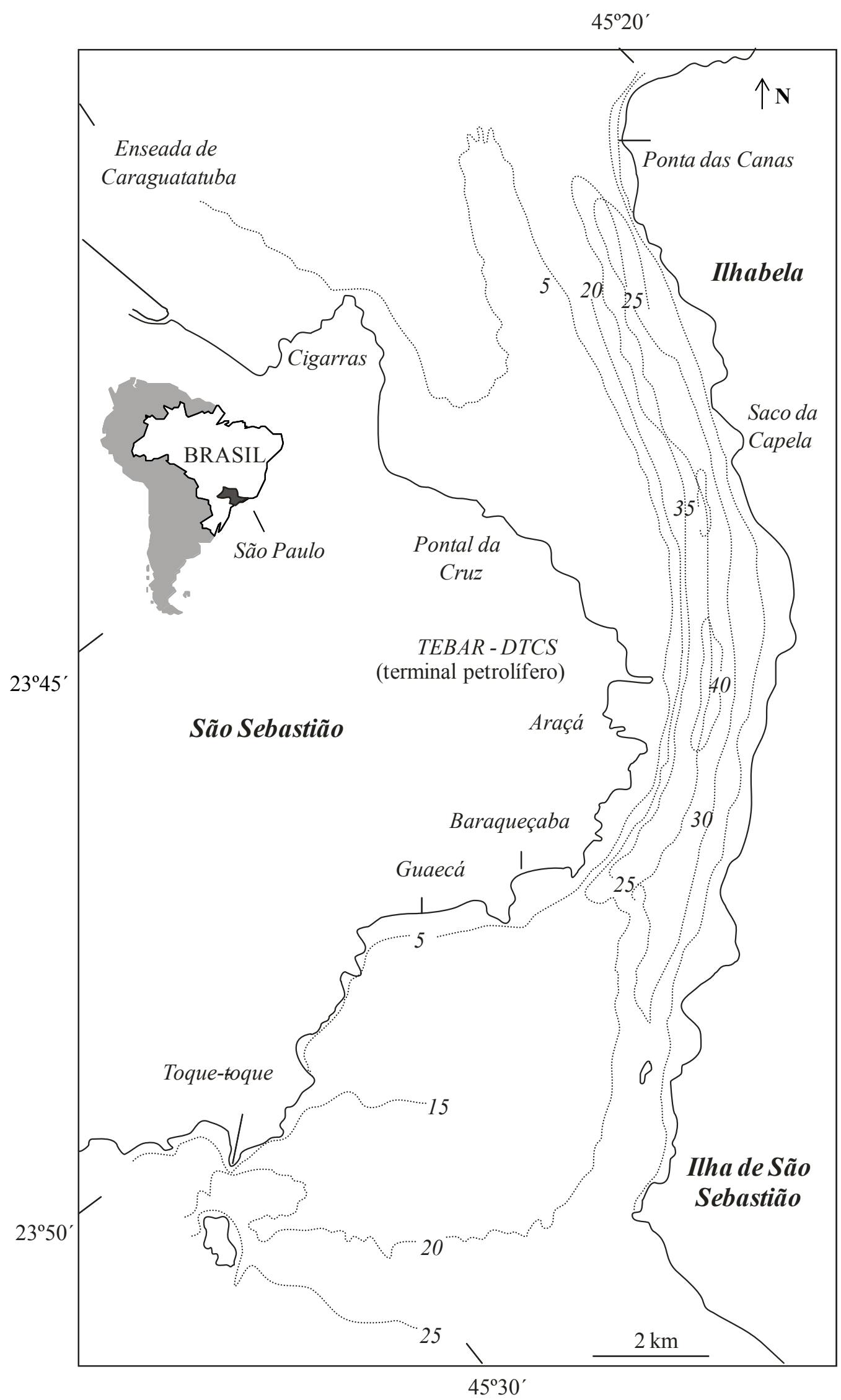

Figura 02 - Mapa do Canal de São Sebastião. 
Na região central, próximo ao Porto de São Sebastião, o canal possui cerca de 45 $\mathrm{m}$ de profundidade, ao norte, mais precisamente próximo à Ponta das Canas possui 25 $\mathrm{m}$ e ao sul, próximo a Ponta da Sela, o canal possui aproximadamente $23 \mathrm{~m}$ de profundidade (Figura 03). As menores profundidades, aproximadamente $6 \mathrm{~m}$, ocorrem no lado continental. Taludes topográficos abruptos, transversais ao canal, marcam a transição entre as regiões mais rasas e as regiões mais profundas, também denominadas canal de navegação (Furtado et al., 2008).

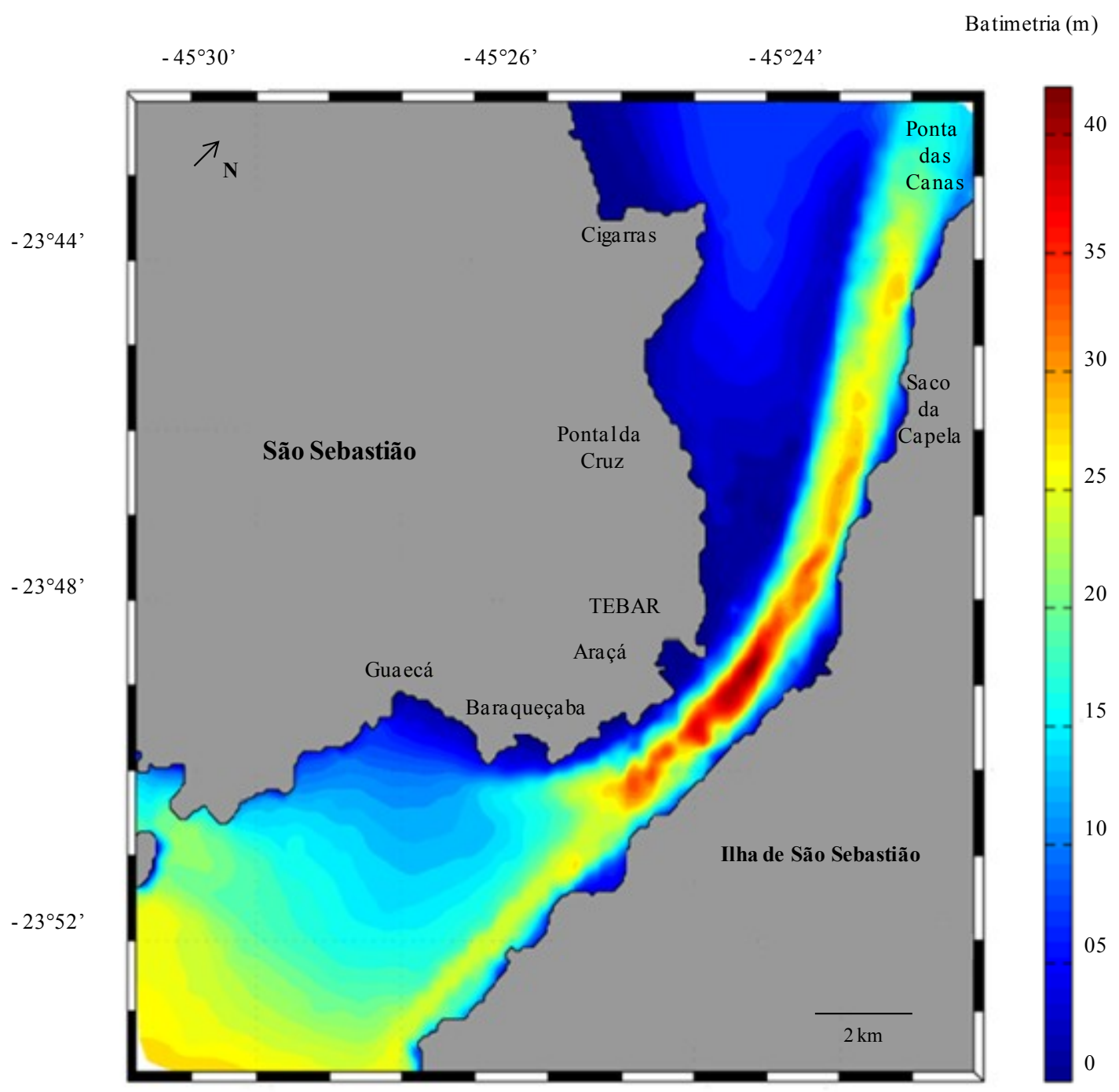

Figura 03 - Batimetria do Canal de São Sebastião

(modificado de Soutelino et al., 2006; extraído de Paixão, 2008).

Um aspecto importante neste canal é a circulação, que está intimamente relacionada com a circulação geral das massas de água sobre a plataforma continental, a 
qual é sazonal (Castro Filho, 1985), bem como à marcante influência dos ventos sobre a circulação superficial no canal (Castro Filho, 1990). As correntes de maré são desprezíveis em termos energéticos (Kvinge, 1967; Castro, 1990; Miranda e Castro, 1995; Fontes, 1995; Silva, 1995). Ventos provenientes de NE impulsionam correntes longitudinais ao canal com sentido SW, ao passo que ventos oriundos de SW, geralmente associados à passagem dos sistemas metereológicos frontais, forçam correntes longitudinais com sentido NE (Furtado et al., 2008).

As correntes de superfície são consideradas intensas, com velocidade média de 0,7 a $1,0 \mathrm{~m} \mathrm{~s}^{-1}$, em sentido preferencial de SW a NE (FUNDESPA, 1999). Contudo, este sentido pode ser rapidamente invertido, caso haja alternância na direção dos ventos (Miranda e Castro-Filho, 1995).

No verão a circulação ocorre em duas camadas: a superficial em direção sudoeste e a profunda para noroeste, sendo esta associada à intrusão da massa Água Central do Atlântico Sul (ACAS) ${ }^{1}$, a qual adentra o canal pela extremidade sul, lado insular. No outono, inverno e primavera a circulação é barotrópica, com sentido unidirecional para noroeste (Silva et al., 2001). Neste período é possível ocorrer a intrusão da massa Água Tropical ${ }^{2}$. A Água Costeira ${ }^{3}$ é a massa de água predominante o ano inteiro, nas águas de superfície.

De modo geral, as águas do Canal de São Sebastião oscilam entre oligotróficas e mesotróficas (Gianesella et al., 1999; Catena, 2004, Fundespa, 2009). No entanto, durante as intrusões da ACAS constata-se considerável aumento de nutrientes no Canal de São Sebastião (Cattena 2004).

As marés na região de São Sebastião são do tipo micromarés e com desigualdades diurnas (Ministério da Marinha, 1993 apud Lopes, 1997). A amplitude média das marés no local é de 1,2 m com nível médio de 0,66 m. As marés são fortemente influenciadas pelas perturbações atmosféricas, principalmente por passagens de frentes frias (Ministério da Marinha, 1993 apud Lopes, 1997).

Em relação à composição textural dos sedimentos, a distribuição granulométrica no canal é heterogênea, e está associada à geometria, topografia e a dinâmica de circulação (Furtado et al., 2008).

\footnotetext{
1 Água Central do Atlântico Sul (ACAS) - massa de água que possui como características físicoquímicas: temperatura entre 9 e $18^{\circ} \mathrm{C}$, salinidade entre 34,5 e 36 (Miranda, 1982).

2 Água Tropical (AT) - massa de água que possui como características físico-quimicas temperaturas superiores a $20^{\circ} \mathrm{C}$ e salinidade superior a 36,4 (Miranda, 1982).

3 Água Costeira (AC) - massa de água que possui como características físico-quimicas temperaturas superiores a $20^{\circ} \mathrm{C}$ e salinidade inferior a 35 (Miranda, 1982).
} 
Na entrada sul, lado continental, há a presença de uma feição tabular, com presença de areia fina, bem selecionada, a qual devido à constante incidência de ondas não permite a deposição de finos (Pires-Vanin et al., 2008). Do centro até a região nordeste do canal, há um pontal arenoso submerso, com presença de uma depressão entre ele e o continente. Na depressão formada, em função de fluxo de baixa energia no sentido sudoeste, ocorre a deposição de finos (Pires-Vanin et al., 2008).

Devido a configuração fisiográfica do canal, verifica-se ambiente com características deposicionais no lado continental, ao passo que a região insular possui características erosivas (Furtado, 1978; Furtado et al., 2008). Devido ao forte hidrodinamismo que há na região insular, os sedimentos são contituídos predominante por sedimentos arenosos, principalmente nas frações areia média e grossa (Furtado, 1978; Furtado et al., 2008).

\subsection{Influências antrópicas}

A região costeira de São Sebastião está sujeita a diversos tipos de intervenções antrópicas. Dentre as atividades antrópicas existentes na região menciona-se o turismo, as atividades náuticas, o porto de São Sebastião, que recebe embarcações de pequeno e médio calado e o Terminal Petrolífero Almirante Barroso (TEBAR), o qual transporta e armazena produtos derivados de petróleo.

Além do já mencionado, no interior do canal há a disposição oceânica que ocorre por meio de quatro emissários submarinos, sendo três para esgotos domésticos, localizados na Baía do Araçá (região sul, lado continental), na Praia de Cigarras (região norte, lado continental), no Saco da Capela (região norte, lado insular) e um para efluente petroquímico, localizado no TEBAR (região central, lado continental).

Dos emissário submarinos acima mencionados, 3 fazem parte do presente estudo e suas características técnicas serão abaixo detalhadas. 


\subsubsection{Emissário submarino de esgotos domésticos do Araçá}

A Baía do Araçá localiza-se na plataforma continental interna, região central do CSS, entre as latitudes $23^{\circ} 48^{\prime}$ e $23^{\circ} 49^{\prime} \mathrm{S}$ e longitudes $45^{\circ} 23^{\prime} \mathrm{e} 45^{\circ} 24^{\prime} \mathrm{W}$ (Figura 04). Trata-se de uma baía artificial formada durante a construção do Porto de São Sebastião, em 1936 (CAP, 2009). A profundidade máxima no interior da baía é de $10 \mathrm{~m}$, com marés que oscilam entre $+2,06$ m (máxima), - 0,04 m (mínima) e nível intermediário de $+1,15 \mathrm{~m}$ (Marcellino, 2000).

Em relação à granulometria dos sedimentos, próximo a Ponta do Araçá, ocorre distribuição de forma heterogênea, em manchas, sendo, entretanto, predominantes sedimentos arenosos, na fração areia média a grossa (Conti, 1998). No interior da baía observa-se composição textural variando entre silte e areia muito fina (Conti, 1998; Barcellos, 2000).

O emissário do Araçá (Figura 04), gerenciado pela companhia de Saneamento Básico do Estado de São Paulo (SABESP), está em operação desde 1990. A atende a uma população média de 21.200 habitantes e apresenta vazão média de $0,14 \mathrm{~m}^{3} \mathrm{~s}^{-1}$ (CETESB, 2007). O trecho terrestre do emissário é composto por tubos de ferro fundido, com diâmetro de $400 \mathrm{~mm}$ e extensão de $3800 \mathrm{~m}$. A parte submarina, a qual se inicia na praia, é composta por tubulação de polietileno de alta densidade (PEAD). Tem extensão de $1090 \mathrm{~m}$ e possui um trecho difusor com 17 orifícios, os quais estão distribuídos nos últimos $10 \mathrm{~m}$ do emissário submarino (CETESB, 2007) (Figura 03). O trecho difusor está localizado próximo à Ponta do Araçá, a $7 \mathrm{~m}$ de profundidade (CETESB, 2007).

O efluente, derivado de esgotos domésticos e águas pluviais, na estação de précondicionamento (EPC), recebe somente tratamento preliminar (pré-tratamento), o qual consiste na passagem por peneiras estáticas, por caixas de areia e posterior desinfecção por cloração. Após o tratamento preliminar o efluente é disposto no ambiente marinho (CETESB, 2007). 


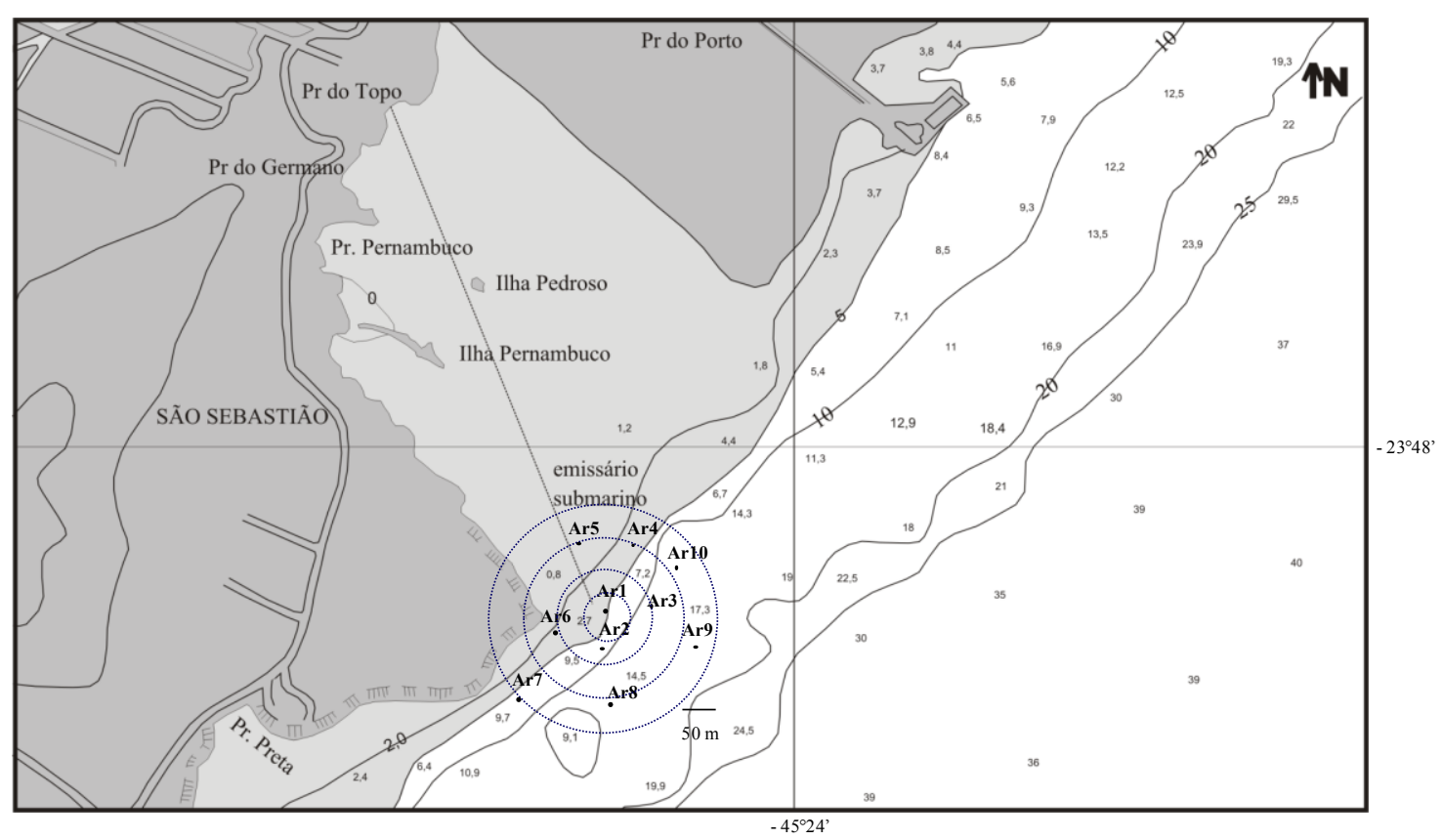

Figura 04 - Mapa da localização do emissário submarino de esgotos domésticos do

Araçá e respectiva malha de amostragem.

(modificado de CETESB, 2007)

Fonte: Carta náutica 1643 - Canal de São Sebastião (parte norte)..

\subsubsection{Emissário submarino de esgotos domésticos do Saco da Capela}

O emissário Saco da Capela localiza-se em Ilhabela, lado insular do Canal de São Sebastião (latitude $23^{\circ} 46,5 \mathrm{~S}$ e longitude $45^{\circ} 21,6 \mathrm{~W}$ ) (Figura 05).

O emissário submarino, gerenciado pela SABESP, está em operação desde 1997. Atende uma população de aproximadamente 4900 habitantes, sendo sua vazão máxima de $0,03 \mathrm{~m}^{3} \mathrm{~s}^{-1}$ (CETESB, 2007).

A parte submarina é composta por tubulação de polietileno de alta densidade (PEAD), possui diâmetro de $250 \mathrm{~mm}$ e extensão de $220 \mathrm{~m}$ (Marcellino, 2000). O trecho difusor está posicionado a uma profundidade de $24 \mathrm{~m}$, possui 24 orifícios, os quais estão espaçados entre si a cada $0,20 \mathrm{~cm}$. Nesta região há predominância de sedimentos arenosos, principalmente nas frações areia grossa e média.

O efluente, derivado de esgotos domésticos e águas pluviais, recebe tratamento similar ao verificado para o emissário do Araçá, antes de ser disposto no ambiente marinho (CETESB, 2007). 


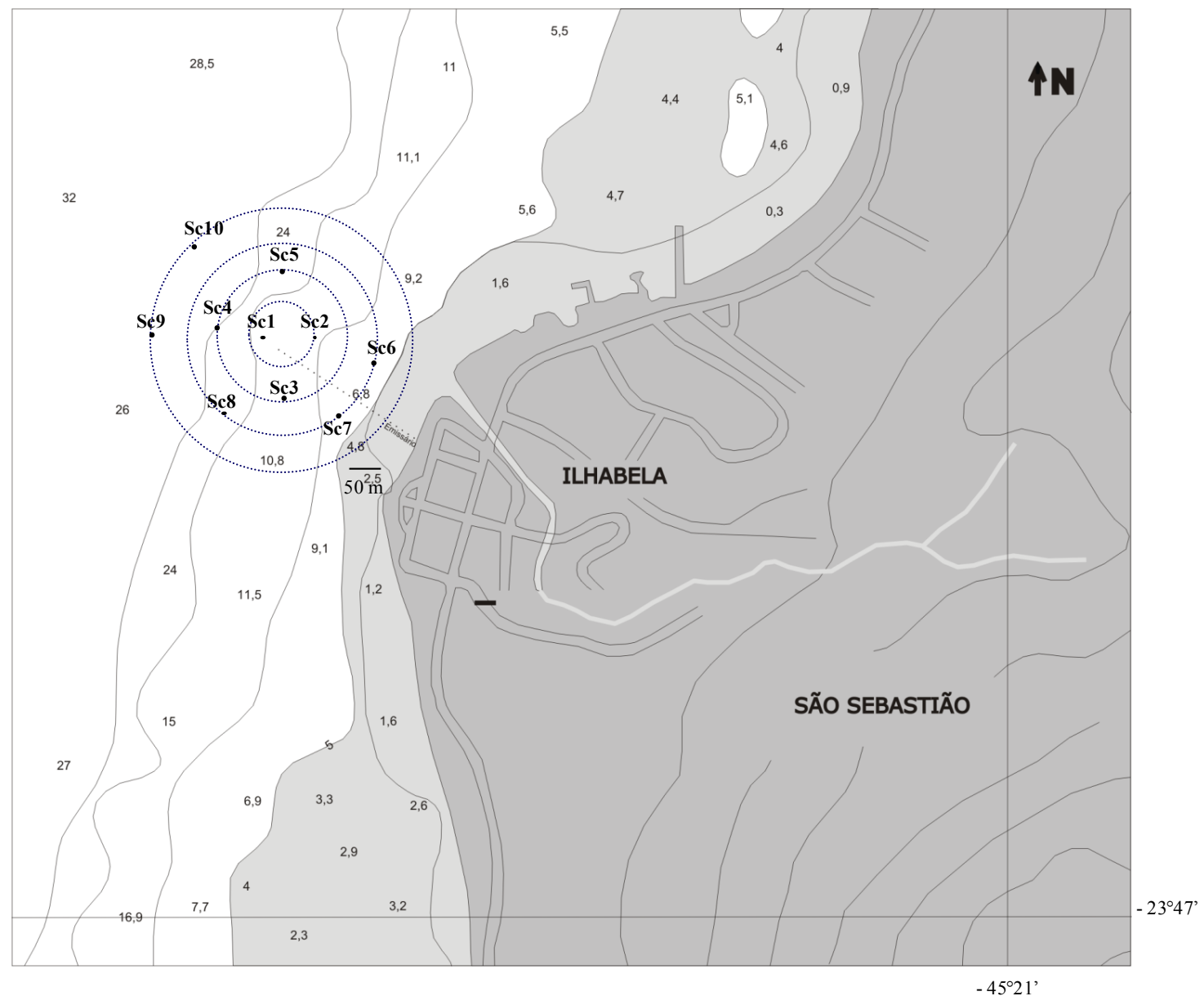

Figura 05 - Mapa da localização do emissário submarino de esgotos domésticos do Saco da Capela e respectiva malha de amostragem.

(modificado de CETESB, 2007)

Fonte: Carta náutica 1643 - Canal de São Sebastião (parte norte).

1.3.3 Emissário de efluente petroquímico do Terminal Marítimo Almirante Barroso (TEBAR)

O Terminal Almirante Barroso (TEBAR) está localizado na região central do Canal de São Sebastião (latitude $23^{\circ} 48,33 \mathrm{~S}$ e longitude $45^{\circ} 23,2 \mathrm{~W}$ ) (Figura 06). Também é conhecido como Terminal Aquaviário de São Sebastião (TASSE) e é considerado um dos maiores terminais petrolíferos do país. Foi inaugurado em Abril de 1969, pela companhia Petróleo do Brasil (PETROBRAS). A partir de 1992, com a criação dos Dutos e Terminais do Centro-Sul (DTCS), o TEBAR passou a ser 
considerado unidade operacional do DTCS e há três anos integra a Gerência de Terminais Aquaviários da Transpetro (Gubitoso, 2010).

O TEBAR recebe, armazena e transfere petróleo para posterior tratamento nas refinarias de Paulínia, Cubatão, Capuava e São José dos Campos, SP. O terminal é constituído de um oleoduto que interliga um conjunto de 40 tanques de armazenamento, na parte terrestre, a duas plataformas, localizadas no meio do Canal de São Sebastião.

Em 1998, uma Estação de Tratamento de Efluente (ETE) e um emissário submarino entratam em funcionamento no TEBAR, com o intuito de dispor no interior do canal o efluente gerado.

O emissário foi construído em polietileno de alta densidade (PEAD) e é dividido em linhas sul (1600 m de comprimento) e norte (1400 $\mathrm{m}$ de comprimento), as quais estão posicionadas em paralelo ao terminal aquaviário (Figura 06). No final de cada emissário (linha) há uma seção difusora com 3 tubos verticais (risers), com aproximadamente $1,5 \mathrm{~m}$ de comprimento e diâmetro de $150 \mathrm{~mm}$, cada um, voltados para a superfície (CETESB, 2007).

Os efluentes lançados pelo emissário são provenientes dos Sistemas de Separação de Águas Oleosas (SAO) e da Estação de Tratamento de Efluentes (ETE) (Fortis, 2005). Segundo CETESB (2007) e Arnalot (2002), são dispostos dois tipos básicos de efluentes no TEBAR:

- Tipo 1 - efluente composto por águas de produção ${ }^{4}$, as quais são transportadas junto com o petróleo cru, águas do fundo dos tanques e dos navios atracados no terminal aquaviário;

- Tipo 2 - águas pluviais e industriais misturadas com óleo.

O tratamento dos efluentes ocorre de forma diferenciada. Os efluentes do Tipo 1 recebem tratamento físico-químico, com etapas de flotação, de adição de peróxido de hidrogênio, de adição de ácido sulfúrico e de soda cáustica. Os efluentes do Tipo 2, por sua vez, são tratados por diferença de densidade em locais denominados Sistemas de Separação de Águas Oleosas (SAO) (CETESB, 2007). Após o tratamento o efluente é

\footnotetext{
${ }^{4}$ Água de produção: consiste em uma mistura da água de formação ou conata, i.e. água do reservatório proveniente da degradação da matéria orgânica que deu origem ao petróleo, com a água do mar injetada no interior dos poços para aumentar a pressão interna e facilitar a extração do petróleo (Sommerville et al., 1987). Possui composição complexa, sendo encontrados hidrocarbonetos, metais pesados, ácidos orgânicos, fenóis, aditivos químicos, tais como anticorrosivos (Utvik, 1999; OGP, 2002).
} 
transferido para o poço de bombeamento e o descarte é feito por meio do emissário submarino. A vazão máxima do emissário é de $0,208 \mathrm{~m}^{3} \mathrm{~s}^{-1}$ (CETESB, 2007).

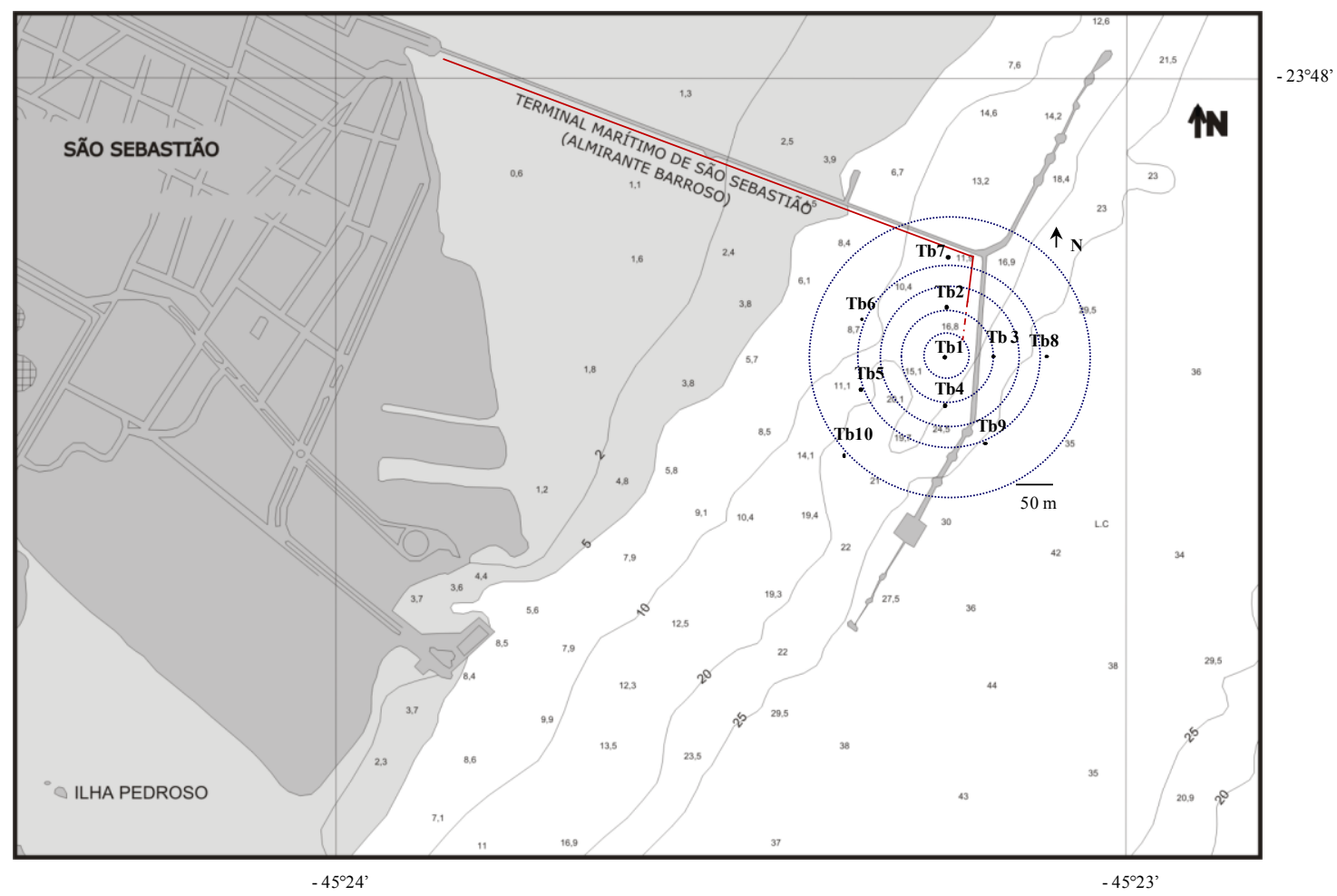

Figura 06 - Mapa da localização do emissário de efluentes petroquímicos do TEBAR e respectiva malha de amostragem.

(modificado de CETESB, 2007)

Fonte: Carta Náutica 1643 - Canal de São Sebastião (parte norte). 


\section{CAPÍTULO 2 - MATERIAL E MÉTODOS}

Foram coletadas 10 amostras, em três períodos distintos, próximo aos difusores dos emissários do Araçá, do Saco da Capela e do TEBAR. As coletas foram realizadas nos anos de 2005 e 2006, onde buscou-se estudar a sazonalidade da influência da disposição oceânica sobre o compartimento bentônico. Ao longo do Canal de São Sebastião, por sua vez, a amostragem foi realizada em 2008. No total, foram coletadas 30 amostras, por emissário, e 10 amostras ao longo do Canal de São Sebastião. O cronograma das amostragens encontra-se abaixo mencionado:

- Araçá: Julho de 2005; Abril de 2006 e Setembro de 2006;

- Saco da Capela: Setembro de 2005; Junho de 2006 e Outubro de 2006;

- TEBAR: Agosto de 2005; Março de 2006 e Agosto de 2006;

- Canal de São Sebastião: Março de 2008.

No tocante aos emissários submarinos (Figuras 04 a 06), a malha amostral foi feita em círculos concêntricos, espaçados entre si a cada 50 e $100 \mathrm{~m}$. O primeiro ponto (estação) posicionado na saída de cada emissário. Este tipo de delineamento visa acompanhar o distanciamento dos efluentes, no ambiente marinho, do seu ponto de origem, i.e. área de maior influência, até regiões mais afastadas. Já no Canal de São Sebastião, a malha de amostragem foi elaborada para abranger áreas sem influência dos emissários submarinos, bem como mapear áreas próximas aos mesmos, porém distantes das zonas de mistura dos efluentes (Figura 07).

O posicionamento das estações foi obtido por meio de GPS (Global Positioning System).

As campanhas de coleta foram realizadas em conjunto com a Companhia Ambiental do Estado de São Paulo (CETESB).

Em cada estação, realizou-se, por meio de sonda CDT Seacat, medidas nas águas de superfície, meio e fundo as profundidades, as temperaturas, as salinidades e oxigênio dissolvido. Os parâmetros turbidez e pH foram obtidos por meio de método Nefolométrico e através de potenciômetro Beckman Zeromatic II, respectivamente. 


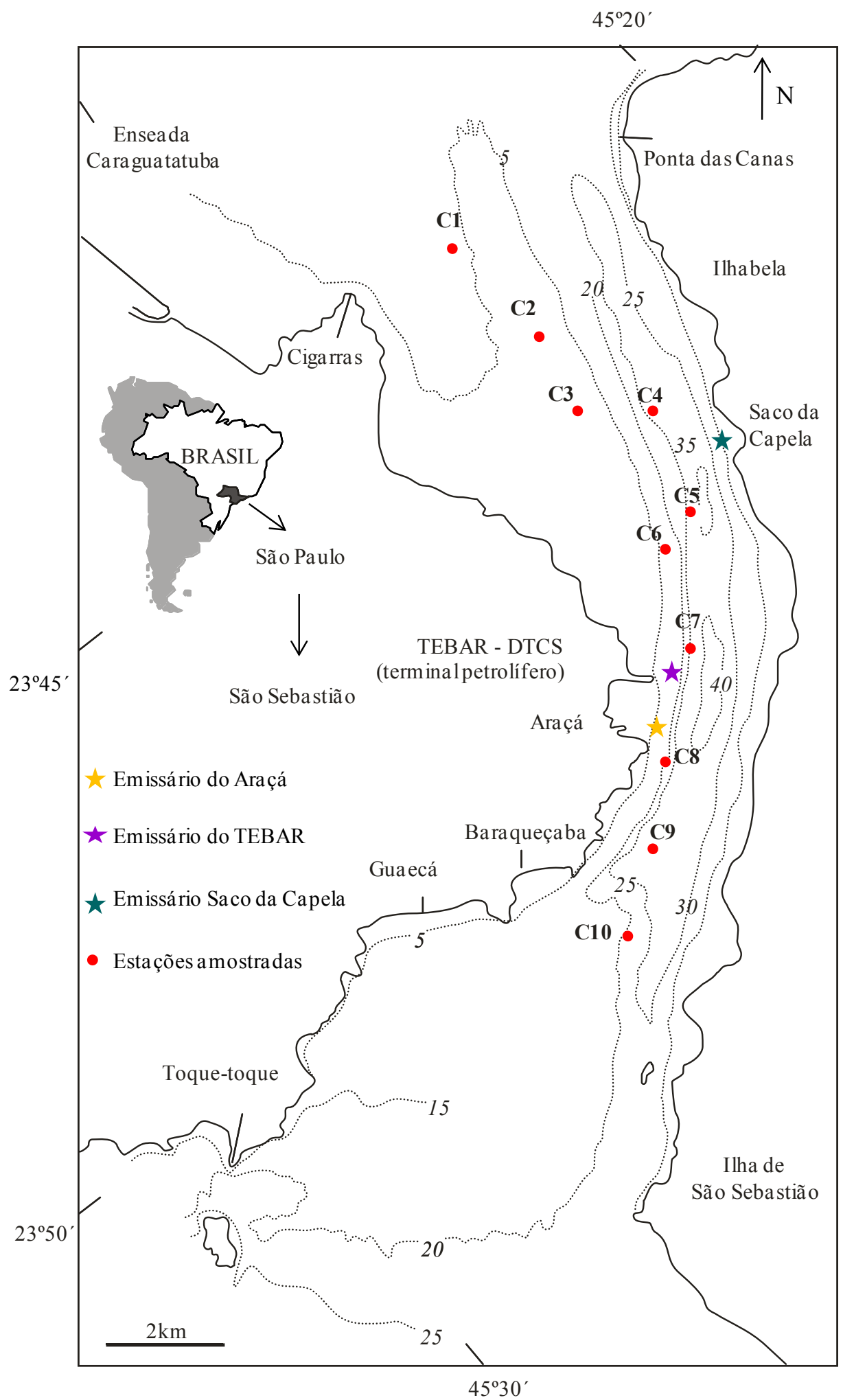

Figura 07 - Posicionamento das amostras coletadas ao longo do Canal de São Sebastião. 
As análises para quantificar os teores de nitrogênio amoniacal, nitrogênio Kjeldahl, fósforo total e ortofosfato da coluna d'água foram realizadas nos laboratórios do Departamento de Tecnologia de Águas Superficiais e Efluentes Líquidos da CETESB, o qual cedeu os resultados para o presente estudo. A metodologia empregada seguiu os procedimentos descritos na Norma Técnica CETESB ou Norma Técnica Brasileira (NBR-ABTN), pertinente, com revisão de procedimento operacional baseado em método similar descrito no Standard Methods for the Examination of Water and Wastewater $19^{\text {th }}$ ed. (APHA, 1995).

Os dados de nitrogênio amoniacal foram determinados por meio de fotocolorimetria automática, com mistura de fenol alcalino. Para determinação do nitrogênio Kjeldahl, cada amostra foi previamente submetida à digestão com mistura oxidante de ácido sulfúrico/sulfato de potássio em processo térmico. O fósforo total foi obtido por meio de digestão prévia, de cada amostra, em mistura com oxidante de ácido sulfúrico/sulfato de potássio/óxido de mercúrio em processo térmico. $\mathrm{O}$ ortofosfato foi determinado por meio de fotocolorimetria automática com molibdato e ácido ascórbico.

Nos mesmos locais, onde foram feitas as coletas de água, foram obtidas amostras de sedimento de superfície, por meio de pegador do tipo Petersen, com área de amostragem de $20 \mathrm{~cm}^{2}$. As amostras foram divididas em três subamostras para as análises: i) granulométricas, ii) geoquímicas e iii) determinação das associações de foraminíferos bentônicos. As amostras para as análises geoquímicas foram congeladas, com o intuito de evitar degradação bacteriana.

\subsection{Análises granulométricas e geoquímicas}

A análise granulométrica foi realizada por meio de metodologia padrão de pipetagem (fração $<0,062 \mathrm{~mm}$ ) e peneiramento (fração entre 0,062 e $2 \mathrm{~mm}$ ), descrita em Suguio (1973). A composição textural e o grau de seleção foram classificados de acordo com o proposto em Shepard (1954) e Folk e Ward (1957), respectivamente.

Foram realizadas análises dos teores de carbonato de cálcio $\left(\mathrm{CaCO}_{3}\right)$, de carbono orgânico total (Cot), de nitrogênio total $(\mathrm{N})$, de fósforo total, orgânico e inorgânico (Ptotal, Porg e Pinorg) e de enxofre total (S). Os teores de $\mathrm{CaCO}_{3}$ foram obtidos pela diferença de massa após dissolução ácida em $\mathrm{HCl}$ a 10\% (Gross, 1971). As concentrações de carbono orgânico total e nitrogênio foram obtidas por meio do analisador $\mathrm{CHN}-1000$ e as concentrações de enxofre pelo analisador SC-432, ambos da 
LECO $^{\circledR}$. As análises de fósforo total e fósforo inorgânico foram feitas pelo método espectrofotométrico de ácido ascórbico (Legg e Black, 1955), com adaptação para sistema de análise de injeção de fluxo (Zagatto et al., 1981). Os teores de fósforo orgânico foram obtidos pela diferença de concentração entre fósforo total e fósforo inorgânico.

Com base nos resultados obtidos para as análises de carbono orgânico total, nitrogênio e enxofre, foram calculadas razões elementares para identificar a origem da matéria orgânica (razões $\mathrm{C} / \mathrm{N}$ ) e o potencial de oxi-redução dos sedimentos (razões $\mathrm{C} / \mathrm{S})$.

As análises granulométricas foram realizadas no Laboratório de Sedimentologia do IGc-USP (Labsed-IGc-USP), as análises de fracionamento de fósforo foram feitas no Laboratório de Química do Centro Universitário FIEO (UNIFIEO). As demais análises geoquímicas foram realizadas no Laboratório de Química do IGc-USP.

As imagens de alguns exemplares de foraminíferos foram realizadas por meio de Microscopia Eletrônica de Varredura (MEV), no LabMEV-IGc-USP.

\subsection{Análise das Associações de Foraminíferos}

Para o estudo dos foraminíferos bentônicos, somente a camada superior $(5 \mathrm{~cm})$ de sedimento, sem sinais de mistura com camadas de subsuperfície, foi amostrada em cada estação.

Imediatamente após a amostragem, os sedimentos foram preservados em álcool 70 GL e corados com Rosa de Bengala, para distinguir espécimes vivos dos mortos, no momento da coleta (Walton, 1952).

No presente estudo, as associações de foraminíferos vivos (biocenoses) e mortos (tanatocenoses) foram estudadas com diferentes objetivos. A partir do estudo das biocenoses, as quais estão sob influência direta dos parâmetros ambientais locais (Murray, 1991; Armynot du Châtelet et al., 2004), buscou-se identificar a composição e distribuição da meiofauna, caracterizar a qualidade ambiental do compartimento bentônico localizado circunjacente aos emissários submarinos e ao longo do Canal de São Sebastião. Pela composição, padrão de distribuição, aspectos tafonômicos e morfométricos das tanatocenoses inferiu-se a circulação hídrica e a dinâmica sedimentar das áreas de estudo. 
Em laboratório, devido à baixa densidade de foraminíferos bentônicos vivos, alíquotas de $10 \mathrm{~cm}^{3}$ de sedimento foram triadas, em sua totalidade, até a obtenção de no mínimo 100 foraminíferos, número considerado viável para análises estatísticas (Murray, 1991). Já para a análise das associações de foraminíferos mortos, foi analisada uma alíquota fixa de $10 \mathrm{~cm}^{3}$ de sedimento, sendo triados, aproximadamente, 300 espécimes.

Os foraminíferos foram separados do sedimento por flutuação-decantação em tricloroetileno $\left(\mathrm{CCl}_{4}\right)$. Os resíduos da análise densimétrica foram posteriormente analisados sob lupa estereoscópica para evitar perda de espécimes mais pesados, que, porventura, não foram decantados.

A classificação taxonômica baseou-se no Atlas de Foraminíferos do Atlântico Sul (Boltovskoy et al., 1980), e nos exemplares da coleção micropaleontológica de referência do Laboratório de Micropaleontologia, Instituto de Geociências da Universidade de São Paulo (IGc-USP).

Para a análise morfométrica, realizada em todas as carapaças de foraminíferos triadas (biocenoses e tanatocenoses), utilizou-se o programa de análise de imagens AnalySis 5 (Soft Imaging System Corp.). De acordo com os resultados obtidos, as carapaças foram divididas em quatro classes de tamanho: pequenas $(<125 \mu \mathrm{m})$, médias $(125$ a $250 \mu \mathrm{m})$, grandes $(250 \mathrm{a} 500 \mu \mathrm{m})$ e pertencentes à macroforaminíferos $(<500$ $\mu \mathrm{m})$. A definição das classes de tamanho foi baseada na escala granulométrica proposta por Wentworth (1922), respectivamente, frações areia fina, média, grossa e muito grossa.

A análise tafonômica baseou-se no estudo da coloração e grau de preservação das carapaças de foraminíferos, que compuseram as tanatocenoses. Por meio da análise da coloração foram quantificadas: i) carapaças sem impregnação ou preenchimento (carapaças normais); ii) preenchidas por monossulfeto de ferro/pirita (carapaças cinzas, pretas ou douradas) e iii) impregnadas por óxido/hidróxido de ferro (carapaças acastanhadas). Em relação ao grau de preservação as carapaças foram classificadas em i) inteiras (sem sinais de abrasão mecânica ou dissolução química); ii) parcialmente fragmentadas e iii) fragmentos.

Considerando que foraminíferos bentônicos respondem sensivelmente às mudanças nas variáveis abióticas (i.e., aumento do fluxo de matéria orgânica, nível de oxigenação e hidrodinamismo, dentre outros fatores), as espécies identificadas foram divididas em dois grupos: espécies bioindicadoras de ambiente enriquecido por matéria 
orgânica (Apêndice 1.1) e espécies bioindicadoras de ambiente bem oxigenado (Apêndice 1.2). O uso de foraminíferos bentônicos como proxie qualitativo para analisar enriquecimento orgânico e nível de oxigenação foi principalmente baseado em Kaiho (1994) e Duleba et al. (2005).

Menciona-se que Ammonia tepida não foi incluída em nenhum dos dois grupos de espécies; a dominância desta espécie em quase todos os períodos e áreas de estudo, poderia mascarar os resultados, motivo pelo qual optou-se por não associá-la a um grupo em específico.

\subsubsection{Análises estatísticas dos dados}

Devido ao baixo número de indivíduos obtidos nas biocenoses, a densidade foi expressa como foraminíferos por $\mathrm{cm}^{3}$ de sedimento (Murray, 2003). Nas tanatocenoses, as densidades foram expressas como foraminíferos por $10 \mathrm{~cm}^{3}$ de sedimento. A riqueza foi definida como o número total de espécies identificadas em cada estação, a diversidade específica foi determinada pelo índice de Shannon - Wiener (Shannon, 1948):

$$
\mathrm{H}^{\prime}=-\sum p_{i} \ln p_{i}
$$

e a equitabilidade foi obtida de acordo com o índice de Pielou (Pielou, 1969):

$$
\mathrm{J}=\frac{H^{\prime}}{\ln S},
$$

onde i) $\mathrm{p}_{i}$ é a proporção de cada espécie na amostra, ii) $\mathrm{S}$ é o número de espécies identificadas em cada amostra e iii) $\ln =\log _{10}$.

Para que a estrutura composicional das associações de foraminíferos pudesse ser estudada, primeiramente, realizou-se a redução da sua dimensionalidade por meio de técnicas de ordenação indireta. Tal procedimento foi executado no programa PAST, versão 1.94b (Hammer et al., 2001). Utilizou-se como metologia o escalonamento multidimensional não métrico (Non-metric multi dimensional scaling, NMDS) e BrayCurtis como índice de similaridade.

A padronização dos dados de abundância absoluta das espécies de foraminíferos foi feita por divisão pela soma. Tal procedimento visou fornecer a mesma escala de variação para todas as espécies, retirando o peso daquelas muito abundantes. Este procedimento foi executado para duas matrizes; a primeira composta pela abundância 
absoluta de foraminíferos vivos nas quatro áreas de estudo e, a segunda pela abundância absoluta de foraminíferos vivos e mortos presentes em uma mesma área.

Para determinar se as composições das biocenoses e tanatocenoses diferiam entre as áreas de estudo, foi realizada Análise de Variância Multivariada (Multivariate Analysis of Variance, MANOVA), utilizando os escores dos dois eixos de ordenação, obtidos pelo NMDS, como variáveis dependentes. Os escores obtidos com a segunda matriz foram utilizados em um Teste t, para verificar se a abundância das espécies de foraminíferos vivos e mortos diferia em uma mesma área. A MANOVA e o teste $\mathrm{t}$ foram executados no programa Systat, versão 10.2 (Hammer et al., 2001).

Para complementar, e facilitar a visualização das informações obtidas pelo NMDS, a similaridade das composições microfaunísticas também foi estudada por meio da Análise de Agrupamento (Cluster Analysis), algorítimo de Agrupamento Pareado Igualmente Ponderado (Unweighted pair-group average, UPGMA), similaridade de Bray-Curtis, em Modo Q. A matriz utilizada foi elaborada com espécies de foraminíferos, cujas abundâncias absolutas foram iguais ou superiores a 20 espécies nas amostras que compuseram as biocenoses e tanatocenoses. Utilizou-se o mesmo método de normalização aplicado para o NMDS.

O relacionamento entre as espécies que compuseram as biocenoses e as variáveis ambientais foi estudado por meio de Análise Bivariada (coeficientes de correlação de Pearson), cujo programa computacional utilizado foi o Minitab, versão 15 (Minitab ${ }^{\circledR}$ Inc.).

A integração de dados bióticos e abióticos, obtidos nas áreas de estudo, foi feita por meio da Análise de Correspondência Canônica (ACC). O programa computacional utilizado foi o CANOCO, versão 4.5 (Ter Braak e Smilauer, 2002). A matriz utilizada, para a análise foi elaborada com base nos principais parâmetros abióticos comuns a todos os períodos de coletas e/ou áreas de estudo e nas principais espécies identificadas nas biocenoses.

Assim como para a Análise de Agrupamento, a matriz dos dados bióticos foi feita com espécies de foraminíferos que apresentaram abundância absoluta superior ou igual a 20 espécimes. Espécies raras não foram consideradas, pois as mesmas quase não interferem nos resultados (Duleba e Debenay, 2003); entretanto, podem dificultar a interpretação da análise (Gauch, 1982). 
O nível de significância estatístico considerado para a relação existente entre as variáveis bióticas e abióticas foi de $p<0,05$, obtido por meio do Teste de Permutação de Monte Carlo, com 999 permutações. 


\section{CAPÍTULO 3 - CANAL DE SÃO SEBASTĨ̃O}

\subsection{RESULTADOS}

3.1.1 Posicionamento geográfico e dados físico-químicos da coluna d'água

O posicionamento geográfico das estações amostradas e os dados físicoquímicos obtidos encontram-se sumarizados na Tabela 01 .

Os valores de temperatura e salinidade oscilaram, respectivamente, entre $20,1 \mathrm{e}$ $24,1^{\circ} \mathrm{C}$ e entre 36,0 e $37,2^{\circ} \mathrm{C}$. Excetuando-se a estação $\mathrm{C} 3$, suave estratificação termohalina foi observada nas demais estações analisadas; observou-se declínio de valores de temperatura e aumento dos valores de salinidade das águas de superfície em direção as águas do fundo. A coluna d'água, no local onde a estação C3 foi posicionada, apresentou-se homogênea para os dois parâmetros.

Horizontalmente, os valores de $\mathrm{pH}$ estiveram distribuídos de forma quase uniforme por entre as estações. Ao longo da coluna d'água (verticalmente), entretanto, observou-se suave estratificação. Os valores oscilaram entre 7,95 e $8,08(\bar{x}=8,03 \pm$ $0,04)$.

As concentrações de oxigênio dissolvido variaram de 4,81 (água de fundo da estação C8) a 7,72 $\mathrm{mg} \mathrm{L}^{-1}$ (água do meio da estação C5). Em todas as estações ocorreu decréscimo de valores no sentido das águas de fundo. Valores abaixo do limite estabelecido pela Resolução CONAMA $357 / 05^{5}\left(6 \mathrm{mg} \mathrm{L}^{-1}\right)$, para águas salinas Classe 1, foram observados nas águas de meio e fundo das estações $\mathrm{C} 1, \mathrm{C} 7$ a C10. A estação C6 apresentou valores inferiores a $6 \mathrm{mg} \mathrm{L}^{-1}$ em toda a coluna d'água.

Os valores de turbidez variaram entre 0,55 e 3,10 UNT. Os maiores valores ocorreram nas águas de superfície das estações C3 e C4 (3,10 UNT em cada estação).

As concentrações de nitrogênio amoniacal e Kjeldahl total, ortofosfato e fósforo total estiveram abaixo do limite de detecção do método analítico ${ }^{6}$.

\footnotetext{
${ }^{5}$ Resolução CONAMA 357 de 17 de Março de 2005 - dispõe sobre a classificação dos corpos de água e diretrizes ambientais para o seu enquadramento, bem como estabelece as condições e padrões de lançamento de efluentes.

${ }^{6}$ Nitrogênio amoniacal $<0,01 \mathrm{mg} \mathrm{L}^{-1}$, nitrogênio Kjeldahl total $<0,1 \mathrm{mg} \mathrm{L}^{-1}$, ortofosfato $<0,01 \mathrm{mg} \mathrm{L}^{-1} \mathrm{e}$ fósforo total $<0,01 \mathrm{mg} \mathrm{L}^{-1}$.
} 
Tabela 01 - Posicionamento geográfico e dados físico-químicos da coluna d'água.

Valores abaixo do estabelecido pela Resolução CONAMA 357/05 encontram-se em vermelho.

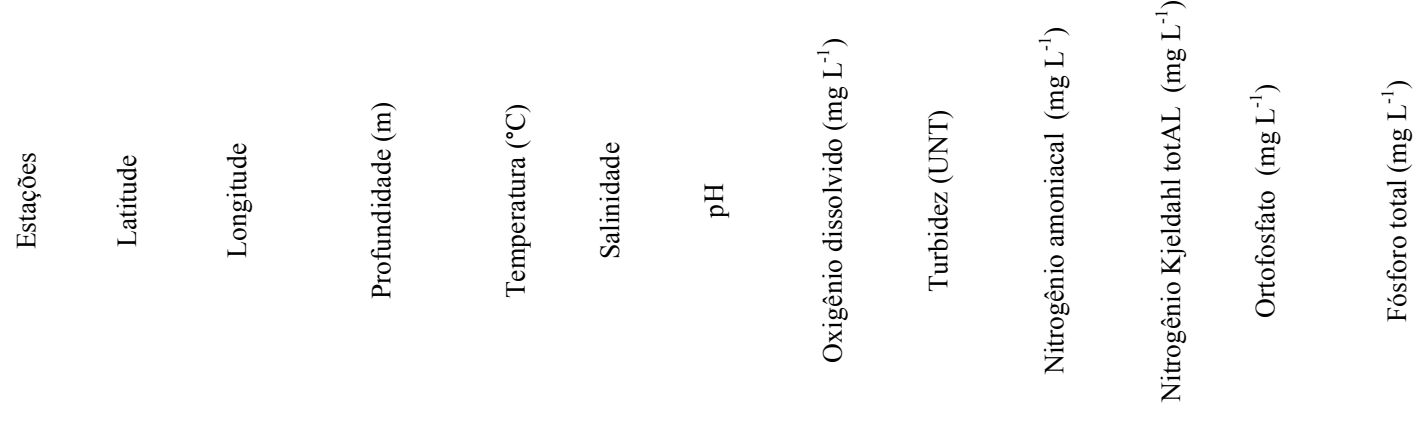

\begin{tabular}{|c|c|c|c|c|c|c|c|c|c|c|c|c|}
\hline \multicolumn{5}{|c|}{ Padrão CONAMA 357/05 (Classe 1 - salina) } & \multirow{2}{*}{$\begin{array}{l}\geq 30 \\
36,70\end{array}$} & \multirow{2}{*}{$\frac{6,5-8,5}{8,06}$} & \multirow{2}{*}{$\frac{6 \mathrm{mg} \mathrm{L}^{-1}}{6,65}$} & \multicolumn{3}{|c|}{$0,4 \mathrm{mg} \mathrm{L}^{-1}$} & \multicolumn{2}{|r|}{$0,062 \mathrm{mg} \mathrm{L}^{-1}$} \\
\hline \multirow{3}{*}{$\mathrm{C} 1$} & \multirow{3}{*}{$-23,728$} & \multirow{3}{*}{$-45,377$} & Superfície (0) & 22,50 & & & & 2,00 & $<0,01$ & $<0,1$ & $<0,01$ & $<0,01$ \\
\hline & & & Meio $(*)$ & 22,40 & 37,00 & 8,02 & 5,82 & 1,90 & $<0,01$ & $<0,1$ & $<0,01$ & $<0,01$ \\
\hline & & & Fundo $(*)$ & 21,20 & 37,10 & 7,97 & 5,20 & 1,90 & $<0,01$ & $<0,1$ & $<0,01$ & $<0,01$ \\
\hline \multirow{3}{*}{$\mathrm{C} 2$} & \multirow{3}{*}{$-23,75$} & \multirow{3}{*}{$-45,375$} & Superfície (0) & 24,10 & 36,70 & 8,08 & 6,85 & 2,50 & $<0,01$ & $<0,1$ & $<0,01$ & $<0,01$ \\
\hline & & & Meio $(*)$ & 24,00 & 36,70 & 8,07 & 6,74 & 2,90 & $<0,01$ & $<0,1$ & $<0,01$ & $<0,01$ \\
\hline & & & Fundo $(*)$ & 23,80 & 36,80 & 8,05 & 6,37 & 2,80 & $<0,01$ & $<0,1$ & $<0,01$ & $<0,01$ \\
\hline \multirow{3}{*}{$\mathrm{C} 3$} & \multirow{3}{*}{$-23,765$} & \multirow{3}{*}{$-45,378$} & Superfície (0) & 24,00 & 36,70 & 8,07 & 6,87 & 3,10 & $<0,01$ & $<0,1$ & $<0,01$ & $<0,01$ \\
\hline & & & Meio $(1,7)$ & 24,00 & 36,70 & 8,07 & 6,86 & 2,80 & $<0,01$ & $<0,1$ & $<0,01$ & $<0,01$ \\
\hline & & & Fundo $(3,4)$ & 24,00 & 36,70 & 8,06 & 6,84 & 2,30 & $<0,01$ & $<0,1$ & $<0,01$ & $<0,01$ \\
\hline \multirow{3}{*}{$\mathrm{C} 4$} & \multirow{3}{*}{$-23,774$} & \multirow{3}{*}{$-45,367$} & Superficie (0) & 23,50 & 36,80 & 8,07 & 7,07 & 3,10 & $<0,01$ & $<0,1$ & $<0,01$ & $<0,01$ \\
\hline & & & Meio $(4,6)$ & 22,40 & 37,00 & 8,08 & 7,22 & 0,84 & $<0,01$ & $<0,1$ & $<0,01$ & $<0,01$ \\
\hline & & & Fundo $(5,2)$ & 20,40 & 37,20 & 8,02 & 6,85 & 0,98 & $<0,01$ & $<0,1$ & $<0,01$ & $<0,01$ \\
\hline \multirow{3}{*}{$\mathrm{C} 5$} & \multirow{3}{*}{$-23,793$} & \multirow{3}{*}{$-45,373$} & Superfície (0) & 23,70 & 36,70 & 8,01 & 7,16 & 1,20 & $<0,01$ & $<0,1$ & $<0,01$ & $<0,01$ \\
\hline & & & Meio $(6,6)$ & 22,30 & 37,00 & 8,06 & 7,72 & 0,70 & $<0,01$ & $<0,1$ & $<0,01$ & $<0,01$ \\
\hline & & & Fundo $(12,2)$ & 21,40 & 37,10 & 8,05 & 7,49 & 1,40 & $<0,01$ & $<0,1$ & $<0,01$ & $<0,01$ \\
\hline \multirow{3}{*}{ C6 } & \multirow{3}{*}{$-23,795$} & \multirow{3}{*}{$-45,381$} & Superficie (0) & 23,60 & 36,00 & 8,06 & 5,97 & 1,00 & $<0,01$ & $<0,1$ & $<0,01$ & $<0,01$ \\
\hline & & & Meio $(4,0)$ & 22,70 & 36,10 & 8,03 & 5,67 & 1,10 & $<0,01$ & $<0,1$ & $<0,01$ & $<0,01$ \\
\hline & & & Fundo $(8,0)$ & 22,10 & 36,20 & 8,00 & 5,12 & 1,00 & $<0,01$ & $<0,1$ & $<0,01$ & $<0,01$ \\
\hline \multirow{3}{*}{$\mathrm{C} 7$} & \multirow{3}{*}{$-23,812$} & \multirow{3}{*}{$-45,386$} & Superfície (0) & 22,60 & 36,70 & 8,05 & 6,33 & 1,40 & $<0,01$ & $<0,1$ & $<0,01$ & $<0,01$ \\
\hline & & & Meio $(4,8)$ & 21,00 & 37,10 & 7,99 & 5,11 & 0,91 & $<0,01$ & $<0,1$ & $<0,01$ & $<0,01$ \\
\hline & & & Fundo $(9,6)$ & 20,60 & 37,10 & 8,02 & 5,19 & 2,40 & $<0,01$ & $<0,1$ & $<0,01$ & $<0,01$ \\
\hline & & & Superfície (0) & 23,70 & 36,20 & 8,04 & 6,42 & 1,40 & $<0,01$ & $<0,1$ & $<0,01$ & $<0,01$ \\
\hline $\mathrm{C} 8$ & $-23,826$ & $-45,405$ & Meio $(3,4)$ & 22,20 & 37,00 & 7,98 & 5,60 & 0,85 & $<0,01$ & $<0,1$ & $<0,01$ & $<0,01$ \\
\hline & & & Fundo $(6,8)$ & 21,00 & 37,10 & 7,95 & 4,81 & 1,60 & $<0,01$ & $<0,1$ & $<0,01$ & $<0,01$ \\
\hline & & & Superficie (0) & 23,56 & 36,60 & 8,05 & 6,59 & 1,00 & $<0,01$ & $<0,1$ & $<0,01$ & $<0,01$ \\
\hline C9 & $-23,836$ & $-45,415$ & Meio $(6,7)$ & 21,72 & 37,00 & 7,99 & 5,45 & 1,10 & $<0,01$ & $<0,1$ & $<0,01$ & $<0,01$ \\
\hline & & & Fundo $(13,4)$ & 20,10 & 37,10 & 7,96 & 4,82 & 0,55 & $<0,01$ & $<0,1$ & $<0,01$ & $<0,01$ \\
\hline & & & Superfície (0) & 23,50 & 36,60 & 8,03 & 6,04 & 0,83 & $<0,01$ & $<0,1$ & $<0,01$ & $<0,01$ \\
\hline $\mathrm{C} 10$ & $-23,846$ & $-45,43$ & Meio $(6,0)$ & 22,50 & 36,90 & 8,00 & 5,48 & 0,78 & $<0,01$ & $<0,1$ & $<0,01$ & $<0,01$ \\
\hline & & & Fundo $(12,0)$ & 21,30 & 37,10 & 7,96 & 4,92 & 0,83 & $<0,01$ & $<0,1$ & $<0,01$ & $<0,01$ \\
\hline
\end{tabular}


3.1.2 Distribuição granulométrica, geoquímica e razões elementares

Os resultados das análises granulométricas estão sumarizados na Tabela 2 e ilustrados na Figura 08.

Tabela 02 - Distribuição granulométrica obtida em amostras coletadas ao longo do Canal de São Sebastião.

Legenda: D. médio $=$ diâmetro médio, D. padrão $=$ desvio padrão, Mto $=$ Muito

\begin{tabular}{|c|c|c|c|c|c|c|c|c|c|c|}
\hline & \multicolumn{5}{|c|}{ Areia } & \multicolumn{2}{|c|}{ Pelíticos } \\
\hline Estação & $\begin{array}{c}\text { D. médio } \\
\varphi\end{array}$ & $\begin{array}{c}\text { D. padrão } \\
\delta \\
\end{array}$ & $\begin{array}{c}\text { Grânulos } \\
(\%) \\
\end{array}$ & \multicolumn{4}{|c|}{$(\%)$} & Mto fina & Silte & Argila \\
\hline $\mathrm{C} 1$ & 4,47 & 1,7 & 0 & 0,02 & 0,52 & 0,81 & 6,56 & 49,23 & 35,71 & 7,15 \\
\hline $\mathrm{C} 2$ & 4,10 & 1,56 & 0,06 & 0,09 & 0,45 & 0,84 & 3,75 & 72,00 & 16,77 & 6,04 \\
\hline $\mathrm{C} 3$ & 3,15 & 2,26 & 6,94 & 2,63 & 5,02 & 6,20 & 16,39 & 45,67 & 11,57 & 5,59 \\
\hline $\mathrm{C} 4$ & 0,58 & 2,57 & 37,89 & 19,32 & 15,67 & 12,22 & 2,95 & 1,48 & 6,36 & 4,12 \\
\hline $\mathrm{C} 5$ & 3,56 & 4,78 & 18,35 & 4,94 & 14,9 & 22,42 & 10,91 & 2,97 & 22,36 & 3,15 \\
\hline C6 & 4,77 & 1,94 & 0,00 & 0,05 & 0,80 & 2,61 & 6,96 & 37,68 & 42,66 & 9,25 \\
\hline $\mathrm{C} 7$ & 3,76 & 3,25 & 9,56 & 5,65 & 13,96 & 8,09 & 4,75 & 7,68 & 43,42 & 6,89 \\
\hline $\mathrm{C} 8$ & 5,79 & 2,09 & 0,00 & 0,06 & 0,10 & 1,17 & 5,79 & 18,60 & 56,54 & 17,75 \\
\hline C9 & 4,25 & 2,09 & 0,12 & 0,52 & 1,51 & 4,25 & 24,65 & 31,03 & 30,51 & 7,42 \\
\hline $\mathrm{C} 10$ & 4,85 & 2,35 & 1,39 & 0,35 & 0,84 & 2,20 & 15,22 & 28,37 & 37,97 & 13,65 \\
\hline
\end{tabular}

A região norte, onde estão posicionadas as estações $\mathrm{C} 1$ a $\mathrm{C} 4$, é marcada pela predominância de areia $(51,63$ a 77,13\%, $\bar{x}=65,45 \%)$, com elevados teores de areia fina e muita fina nas estações $\mathrm{C} 1$ a $\mathrm{C} 3$, e areia média a muito grossa nas estações $\mathrm{C} 4$ e C5. Sedimentos pelíticos foram observados em concentrações elevadas nas regiões central (estações C6 a C8) e sul (C9 e C10). A maior porcentagem de sedimentos finos ocorreu na estação C8 (74,3\%).

Grânulos, os quais são em grande maioria constituídos por conchas de moluscos, foram observados nas estações $\mathrm{C} 2$ a C5, C7, C9 e C10. A maior concentração foi identificada na estação C4 (37,89\%).

De acordo com a classificação textural proposta por Shepard (1954), os sedimentos são denominados: i) areia síltica - estações C1, C3, C5, C6, C9 e C10; ii) areia - estações C2 a C4 e iii) silte arenoso - estações C7 e C8.

Foram observados sedimentos pobremente selecionados nas estações C1, C2 e C6 (1,56 a 1,94 $\delta)$, muito pobremente selecionados nas estações C3, C4, C7 a C10 (2,09 a 4,00 $\delta)$ e extremamente mal selecionados na estação C5 (4,78 $\delta)$. 


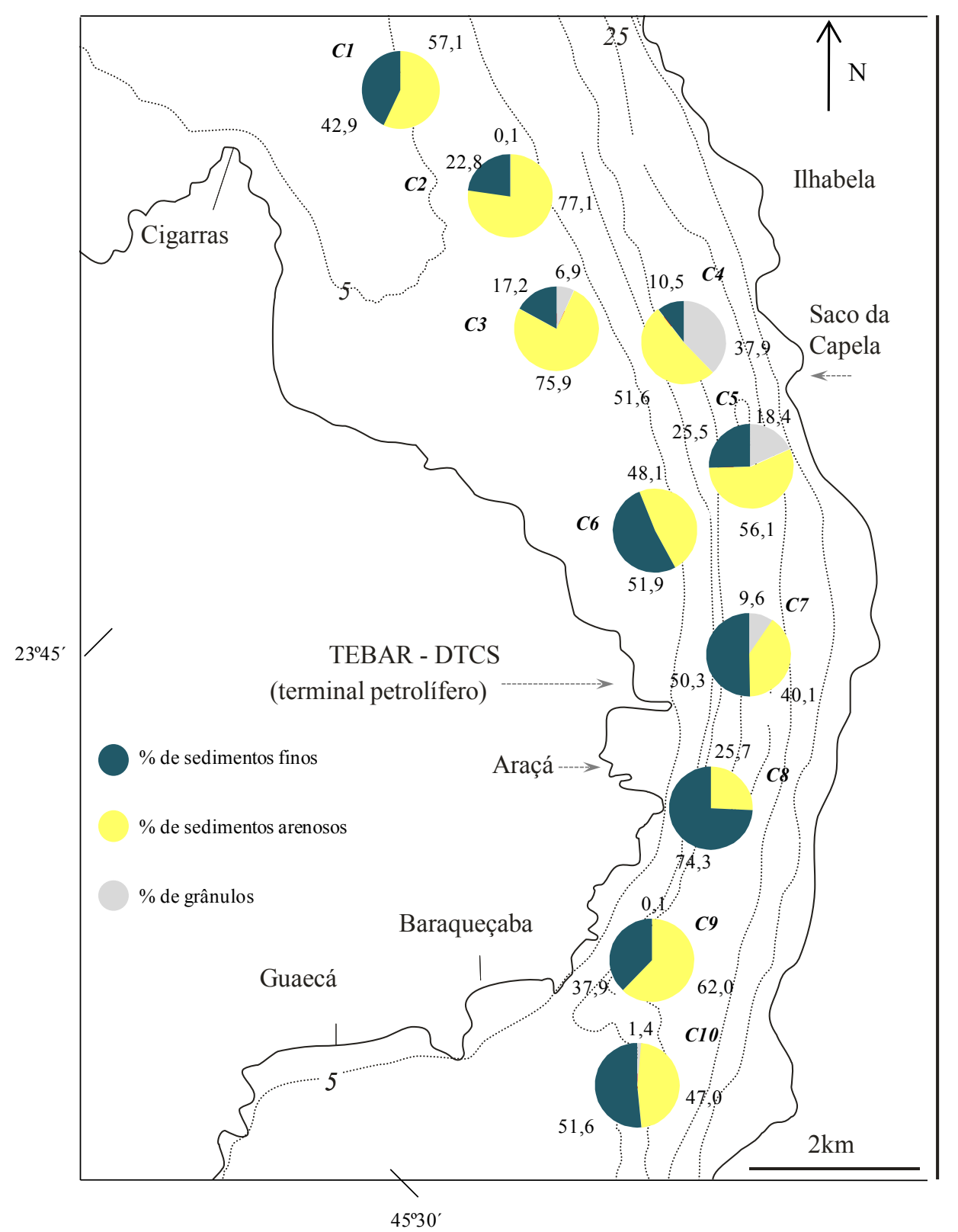

Figura 08 - Mapa da distribuição granulométrica obtida ao longo do Canal de São Sebastião.

As profundidades, os resultados geoquímicos e razões elementares estão mencionados na Tabela 3 e ilustrados nos Anexos 01 a 05. 
Tabela 03 - Profundidades, parâmetros geoquímicos e razões elementares obtidas ao longo do Canal de São Sebastião.

Obs.: * não analisado.

\begin{tabular}{lcccccccccccc}
\hline Estações & Prof. $(\mathrm{m})$ & $\mathrm{pH}$ & $\mathrm{Eh}(\mathrm{mV})$ & $\mathrm{CaCO}(\%)$ & $\mathrm{Cot}(\%)$ & $\mathrm{N}(\%)$ & Potal (\%) & Pinorg (\%) & Porg (\%) & $\mathrm{S}(\%)$ & $\mathrm{C} / \mathrm{N}$ & $\mathrm{C} / \mathrm{S}$ \\
\hline $\mathrm{C} 1$ & $*$ & 7,2 & -79 & 11,97 & 1,18 & 0,13 & 0,041 & 0,031 & 0,010 & 0,23 & 9,08 & 5,13 \\
$\mathrm{C} 2$ & $*$ & 6,9 & -59 & 8,02 & 0,58 & 0,17 & 0,024 & 0,018 & 0,005 & 0,16 & 3,41 & 3,63 \\
$\mathrm{C} 3$ & 3,9 & 6,9 & 58 & 11,81 & 0,53 & 0,09 & 0,021 & 0,018 & 0,003 & 0,08 & 5,89 & 6,63 \\
$\mathrm{C} 4$ & 9,7 & 7,7 & 233 & 11,53 & 0,39 & 0,25 & 0,017 & 0,015 & 0,002 & 0,07 & 1,56 & 5,57 \\
$\mathrm{C} 5$ & 13,7 & 7,3 & -67 & 23,37 & 1,15 & 0,21 & 0,050 & 0,038 & 0,012 & 0,23 & 5,48 & 5,00 \\
$\mathrm{C} 6$ & 8,5 & 6,9 & -77 & 14,82 & 1,80 & 0,29 & 0,051 & 0,033 & 0,018 & 0,36 & 6,21 & 5,00 \\
$\mathrm{C} 7$ & 10,1 & 7,2 & -62 & 20,60 & 1,86 & 0,20 & 0,055 & 0,032 & 0,023 & 0,35 & 9,30 & 5,31 \\
$\mathrm{C} 8$ & 7,3 & 7,1 & -79 & 17,91 & 2,67 & 0,21 & 0,053 & 0,038 & 0,015 & 0,49 & 12,71 & 5,45 \\
$\mathrm{C} 9$ & 13,9 & 7,4 & -73 & 12,51 & 1,15 & 0,21 & 0,036 & 0,023 & 0,013 & 0,25 & 5,48 & 4,60 \\
$\mathrm{C} 10$ & 12,5 & 7,3 & 103 & 13,15 & 1,21 & 0,20 & 0,046 & 0,031 & 0,015 & 0,22 & 6,05 & 5,50 \\
\hline
\end{tabular}

Devido a problemas técnicos, não foram obtidos valores batimétricos para as estações C1 e C2, para as demais estações, as profundidades oscilaram entre 3,9 e 13,9 $\mathrm{m}(\bar{x}=9,95 \pm 3,4 \mathrm{~m})$.

Os valores de $\mathrm{pH}$ e de Eh dos sedimentos variaram de 6,9 a 7,7 e de - 79 e 233 $\mathrm{mV}$, respectivamente. Eh positivo foi observado somente nas estações C3, C4 e C10 (Tabela 03).

Os teores de carbonato de cálcio foram de 8,02 a $23,37 \%(\bar{x}=14,57 \pm 4,7 \%)$, indicando sedimentação litoclástica $(<30 \%$ de carbonato de cálcio). As maiores concentrações ocorreram nas estações C5 (23,37\%) e C7 (20,60\%), e a menor na estação C2 (8,02\%).

Os teores de carbono orgânico total variaram entre 0,39 e $2,67 \%(\bar{x}=1,25 \pm$ $0,70 \%$ ). Os maiores teores ocorreram na porção central do canal, mais precisamente estações C6 (1,80\%), C7 (1,86\%) e C8 (2,67\%).

Excetuando-se as estações $\mathrm{C} 1$ a $\mathrm{C} 3$, as concentrações de nitrogênio estiveram distribuídas de forma quase homogênea ao longo do canal. Os valores obtidos oscilaram entre 0,09 e $0,29(\bar{x}=0,20 \pm 0,06 \%)$.

Em relação ao fósforo, foram obtidos os seguintes valores: fósforo total entre 0,017 e $0,055 \%$, fósforo orgânico entre 0,002 e $0,023 \%$, fósforo inorgânico de 0,015 a $0,038 \%$. As maiores concentrações de fósforo total encontram-se centralizadas na porção central do canal, estações C5 a C8. 
Os teores de enxofre variaram de 0,07 a $0,49 \%(\bar{x}=0,24 \pm 0,13 \%)$. Os maiores teores foram observados nas estações C6, C7 e C8, posicionadas na parte central do canal. As menores concentrações, por sua vez, estão localizadas nas estações C3 e C4, posicionadas na região norte.

Os valores das razões $\mathrm{C} / \mathrm{N}$ oscilaram entre 1,56 e 12,71 (Anexo 05). Verificou-se alternância entre origens marinha (razões <6) e mista (razões entre 6 e 12). Matéria orgânica de origem continental foi identificada somente na estação $\mathrm{C} 8(\mathrm{C} / \mathrm{N}=12,71)$.

Os resultados obtidos pela razão $\mathrm{C} / \mathrm{S}$ indicaram bom nível de oxigenação ao longo do canal (Anexo 05). Somente a estação $\mathrm{C} 2(\mathrm{C} / \mathrm{S}=3,63)$ apresentou sedimentos com tendências redutoras.

\subsubsection{Associações de foraminíferos}

\subsubsection{Biocenoses - composição, padrão de distribuição e análise morfométrica}

Para análise das biocenoses foram utilizados volumes de sedimento que oscilaram entre 10 e $60 \mathrm{~cm}^{3}$.

Foram identificados 17 gêneros e 71 espécies de foraminíferos (Anexo 6). A Subordem Rotaliina é predominante (53 espécies) seguida por Textulariina (17 espécies). Foi encontrado somente um exemplar da Subordem Miliolina (Quinqueloculina milletti).

As densidades de foraminíferos por $10 \mathrm{~cm}^{3}$ de sedimento oscilaram entre $16 \mathrm{e}$ 296 espécies. As maiores densidades ocorreram nas estações C3 e C6, 266 e 296 foraminíferos por $10 \mathrm{~cm}^{3}$ de sedimento.

Os valores de riqueza variaram de 12 a 33 espécies $\left(\bar{x}=26^{ \pm} 7\right.$ espécies). As estações C4 (30 espécies), C5 (33 espécies) e C8 (32 espécies) apresentaram os maiores valores. Em contrapartida, os menores valores foram encontrados nas estações C1 (12 espécies) e C2 (13 espécies).

Os valores de diversidade específica oscilaram entre 1,59 e 3,25 , e os de equitatividade entre 0,64 e 0,93 .

Excetuando-se as estações C4 e C5, Ammonia tepida é a espécie predominante na maioria das estações, cujas abundâncias relativas oscilaram de 5,5 a 56,1\% $(\bar{x}=27,7$ \pm 16,3\%). Cassidulina crassa $(18,8 \%)$ é a espécie mais abundante na estação C4; já na 
estação C5, Cassidulina crassa e Cassidulina subglobosa são as espécies dominantes (10,2\% para cada espécie).

Posteriormente, as espécies que apresentaram significativas abundâncias relativas, em ordem decrescente de importância, foram Ammonia parkinsoniana (2 a $19,6 \% ; \bar{x}=11,5 \%)$, Brizalina striatula $(0,8$ a $11,6 \% ; \bar{x}=6,5 \%)$, Buliminella elegantissima (2 a $8,5 \% ; \bar{x}=5,2 \%)$, Cassidulina crassa (0 a $18,8 \% ; \bar{x}=4,6 \%)$, Pseudononion opima (0 a 9,1\%; $\bar{x}=3,2 \%)$, Cassidulina subglobosa (0 a 10,2\%; $\bar{x}=$ $2,3 \%$ ), Bulimina marginata (0 a 5,9\%; $\bar{x}=2,5 \%)$, Pseudononion atlanticum ( 0 a 5,8\%; $\bar{x}=2,0 \%)$, Hopkinsina pacifica (0 a 5,3\%; $\bar{x}=1,8 \%)$, Fursenkoina fragilis $(0$ a $8,5 \%$; $\bar{x}=1,7 \%)$, Rosalina floridensis (0 a $6,1 \% ; \bar{x}=1,4 \%)$, Hanzawaia boueana ( 0 a 5,1\%, $\bar{x}=1,2 \% 0$, Gavelinolepsis praegeri (0 a 5,5\%, $\bar{x}=1,0 \%)$ e Bolivina pseudoplicata $(0$ a $5,1 \% ; \bar{x}=0,9 \%$ ). As espécies não mencionadas, estiveram presentes em abundâncias relativas inferiores a 5\%, motivo pelo qual são consideradas raras.

De acordo com as preferências ecológicas das espécies, constatou-se que espécies bioindicadoras de ambiente rico em matéria orgânica são dominantes em todas as estações, com porcentagens que oscilaram entre 10,8 e $62,6 \%\left({ }^{-}=41,5^{ \pm} 16,11 \%\right)$ (Anexo 07). As espécies bioindicadoras de ambiente óxico, por sua vez, não foram encontradas nas estações C1 e C2. Nas demais estações, as abundâncias variaram de 0,7 e $25,5 \%\left(\bar{x}=7,1^{ \pm} 8,5 \%\right)$ (Anexo 07).

A análise de correlação de Pearson, demonsttrou que as densidades das biocenoses são influenciadas pelo $\mathrm{pH}(\mathrm{r}=-0,67 ; p<0,05)$, pela temperatura $(\mathrm{r}=0,73 ; p$ $<0,05)$ e pela salinidade $(\mathrm{r}=-0,83 ; p<0,01)$ (Anexo 08). Ammonia tepida, Brizalina striatula, Pseudononion atlanticum correlacionaram-se negativamente aos valores de $\mathrm{pH}$, sendo observada correlação posisitiva para Cassidulina crassa, Cassidulina subglobosa, Rosalina floridensis e Hanzawaia boueana. Secundariamente, as variáveis que apresentaram correlação significativa com a distribuição das espécies identificadas foram Eh (Brizalina striatula, Cassidulina crassa, Pseudononion atlanticum e Gavelinolepsis praegeri) e salinidade (Ammonia tepida, Ammonia parkinsoniana, Brizalina striatula e Pseudononion atlanticum). 
Pseudononion opima correlacionou-se positiva e significantemente com nitrogênio e fósforo. Fursenkoina fragilis correlacionou-se positivamente com fósforo e enxofre. Bulimina marginata correlacionaou-se positivamente com nitrogênio.

Os resultados das análises morfométricas permitiram identificar a presença de quatro classes de tamanho ao longo do Canal de São Sebastião, i.e. carapaças pequenas, médias, grandes e macroforaminíferos (Anexo 09).

Carapaças médias são predominantes em 70\% das estações analisadas (C3, C5 a $\mathrm{C} 10)$, as porcentagens encontradas variaram entre 34,2 e $68,6 \%\left(\bar{x}=55^{ \pm} 11,6 \%\right)$.

As porcentagens de carapaças pequenas oscilaram de 15,2 a $65,1 \%(\bar{x}=35,2 \pm$ 16,4\%), sendo as maiores concentrações observadas estações C1, C2 e C4,localizadas na região norte do canal.

Excetuando-se a estação $\mathrm{C} 2$, carapaças grandes foram identificadas em todas as estações $(0,7$ a $20,2 \% ; \bar{x}=9,4 \pm 6,3 \%)$. As maiores porcentagens ocorreram nas estações C7 (16,2\%) e C9 (20,2\%), localizadas nas regiões central e sul do canal, respectivamente.

Macroforaminíferos ocorreram nas estações C3, C4, C8 a C10, em porcentagens que oscilaram entre 0,04 e $1 \%(\bar{x}=0,4 \pm 0,4 \%)$. Cribroelphidium exacavatum, Hanzawaia boueana, Bolivina sphatulata e Gaudryina exilis foram as espécies identificadas como macroforaminíferos.

Excetuando-se carapaças grandes, as demais classes de tamanho não apresentaram padrão de distribuição associado às variáveis ambientais (Anexo 08). Carapaças grandes apresentaram correlação significativa com carbonato de cálcio $(\mathrm{r}=$ $0,72 ; p<0,05)$.

\subsubsection{Tanatocenoses - composição e padrão de distribuição}

Ao longo do Canal de São Sebastião foram identificados 26 gêneros e 114 espécies de foraminíferos, as quais encontram-se distribuídas entre as Subordens Miliolina (18 espécies), Textulariina (19 espécies) e Rotaliina (77 espécies). Foi encontrada uma espécie de tecameba (Centropyxis aculeata), na estação C6.

As densidades de foraminíferos oscilaram entre 456 e 7008 indivíduos por 10 $\mathrm{cm}^{3}$ de sedimento. Os menores valores de densidade ocorreram nas estações C4 e C5, posicionadas no lado insular do canal. A estação C3, posicionada na entrada norte, 
apresentou a maior densidade; nesta estação foram obtidos 7008 foraminíferos por 10 $\mathrm{cm}^{3}$.

As riquezas variaram de 23 a 67 espécies $\left(\bar{x}=46^{ \pm} 13\right)$, sendo observados os menores valores nas estações C1 (23 espécies) e C2 (27 espécies), posicionadas na entrada norte do canal.

Os valores de diversidade específica e equitatividade variaram entre 2,51 e 3,63 e entre 0,76 e 0,90 , respectivamente.

Excetuando-se a estação C9, Pararotalia cananeiaensis é a espécie predominante, em abundâncias relativas que oscilaram entre 13 e $35,1 \%(\bar{x}=21,1 \pm 7,8$ \%). Bulimina marginata é a espécie mais abundante na estação C9 (16,5\%). As espécies que apresentaram as maiores abundâncias relativas, em ordem decrescente, foram Ammonia tepida $(3,5$ a $16,5 \% ; \bar{x}=10,2 \pm 4,5 \%)$, Bulimina marginata $(1,8$ a $16,5 \% ; \bar{x}=$ $5,5 \pm 4,5 \%)$, Ammonia parkinsoniana (1,4 a 8,9\%; $\bar{x}=4,2 \pm 2,4 \%$ ), Pseudononion atlanticum $\left(1,3\right.$ a $\left.7,6 \% ; \bar{x}=3,6^{ \pm} 1,9 \%\right)$, Cassidulina crassa (0 a 9,4\%; $\left.\bar{x}=3,5^{ \pm} 3 \%\right)$, Cribroelphidium poyeanum $(0,6$ a $6,6 \% ; \bar{x}=2,3 \pm 1,7 \%)$ e Hanzawaia boueana $(0,6$ a $5,4 \% ; \bar{x}=1,9 \pm 1,4 \%)$.

Assim como o observado nas biocenoses, as espécies bioindicadoras de ambiente rico em matéria orgânica são também predominantes nas tanatocenoses $(18,9$ a $40 \% ; \bar{x}=30,1 \pm 6,8 \%)($ Anexo 07).

Espécies bioindicadoras de ambiente óxico ocorreram em todas as estações em abundâncias que variaram de 2,1 a 19,3\% $(\bar{x}=10,5 \pm 6,4 \%)$ (Anexo 07). As maiores concentrações foram observadas nas estações C4 e C5, localizadas na região norte e nas estações C9 e C10, localizadas na região sul do canal.

3.1.3.2.1 Aspectos morfométricos e tafonômicos (coloração e grau de preservação) observados nas carapaças

Ao longo do Canal de São Sebastião foram observadas carapaças pequenas, médias, grandes e macroforaminíferos (Anexo 09).

Carapaças pequenas e médias foram as mais abundantes. Carapaças pequenas ocorreram em porcentagens que oscilaram entre 21,4 e $72,5 \%(\bar{x}=44,2 \pm 19 \%)$. As 
maiores porcentagens ocorreram nas estações C1, C2, C5 e C6. Carapaças médias, por sua vez, ocorreram em porcentagens que variaram de 26,2 a $60,2 \%(\bar{x}=45,3 \pm 9,8 \%)$. A maior porcentagem foi observada na estação C3 (60,2\%).

As porcentagens de carapaças grandes oscilaram entre 0,3 e $34,6 \%(\bar{x}=9,0 \pm$ 12,0\%), sendo observadas as maiores concentrações nas estações C3 (16,8\%), C9 $(34,6 \%)$ e $\mathrm{C} 10(24,1 \%)$.

Excetuando-se as estações C1, C2, C6 e C7, macroforaminíferos ocorreram nas demais estações, em porcentagens que variaram de 0,3 a $7,7 \%(\bar{x}=2,53 \pm 2,7 \%)$. Quinqueloculina spp, Hanzawaia boueana, Poroeponides lateralis, Rolshauseni rolshauseni, Fursenkoina pontoni, Pseudononion atlanticum, Cribroelphidium excavatum e Textularia aglutinans foram as espécies identificadas como macroforaminíferos.

A análise do grau de preservação das carapaças indicou alternância de predominância entre carapaças inteiras (i.e. sem sinais de abrasão mecânica e/ou dissolução química) e parcialmente fragmentadas (Anexo 10).

As porcentagens de carapaças inteiras oscilaram entre 43,7 e $63,5 \%(\bar{x}=48,9 \pm$ $7,9 \%$ ). Verificou-se ligeiro aumento na porcentagem de carapaças inteiras de sul para norte do canal, ocorrendo as maiores porcentagens nas estações C1, C2, C5, C7 e C10.

Carapaças parcialmente fragmentadas estiveram presentes em porcentagens que variaram de 35,4 a $60,6 \%(\bar{x}=48,8 \pm 7,3 \%)$. As maiores porcentagens ocorreram nas estações C3 (60,6\%), C9 (54,3\%) e C8 (54,6\%).

Fragmentos de carapaças foram observados em todas as estações em porcentagens que oscilaram de 1 a 4,6\% $(\bar{x}=2,3 \pm 1,4 \%)$. As maiores concentrações ocorreram nas estações C3, C5 e C6.

No tocante à coloração, observou-se carapaças normais, acastanhadas e preenchidas por monossulfeto de ferro/pirita.

Carapaças normais, sem sinais de impregnação, foram predominantes em todas as estações em porcentagens que oscilaram entre 60,2 e $9,9 \%(\bar{x}=82,9 \pm 12,3 \%)$. De modo geral, observou-se decréscimo de concentração de carapaças normais de norte em direção à entrada sul do canal. As maiores porcentagens foram observadas nas estações $\mathrm{C} 2$ e C3, e o contrário nas estações C9 e C10. 
As porcentagens de carapaças acastanhadas variaram de 0 (estação C2) a 12,3\%. As maiores porcentagens foram observadas nas estações C4 e C5, respectivamente, $6,1 \%$ e $12,3 \%$.

Carapaças preenchidas por monossulfeto de ferro/pirita ocorreram em todas as estações, em porcentagens que variaram entre 3,2 e $37,4 \%\left(\bar{x}=13{ }^{ \pm} 12,5 \%\right)$. O padrão de distribuição é quase o inverso ao observado para carapaças normais. As maiores concentrações ocorreram na região central do canal, mais precisamente a partir da estação $\mathrm{C} 7$, em direção à entrada sul.

Apesar de não ser ilustrado por meio de gráficos, foram observadas algumas carapaças com sinais de bioerosão nas estações C3 (3 foraminíferos), C4 (3 foraminíferos), C6 (1 foraminífero), C9 (2 foraminíferos) e C10 (2 foraminíferos).

Na estação C6 também foi observada uma carapaça com sinais de dissolução química (Fissurina laevigata).

3.1.3.3 Estudo comparativo da estrutura das comunidades que compuseram as biocenoses e tanatocenoses

A análise de ordenação, realizada por meio do NMDS, permitiu a identificação de dois grupos e um subgrupo, gerados a partir da diferenciação na estrutura composicional das biocenoses e tanatocenoses (Figura 09). O baixo estresse, obtido na técnica empregada (estresse 0,22) para a redução da dimensionalidade (i.e. normalização), indica baixa distorção dos dados.

Observou-se diferença entre a composição das biocenoses e tanatocenoses somente no Eixo 2 do NMDS $(\mathrm{t}=8,712 ; p=0,000 ; \mathrm{N}=10)$. Os resultados obtidos para o Eixo 1 foram: $\mathrm{t}=-0,620 ; p=0,543 ; \mathrm{N}=10$. Observou-se também um agrupamento das espécies identificadas nas estações C1 e C2 (Figura 09). 


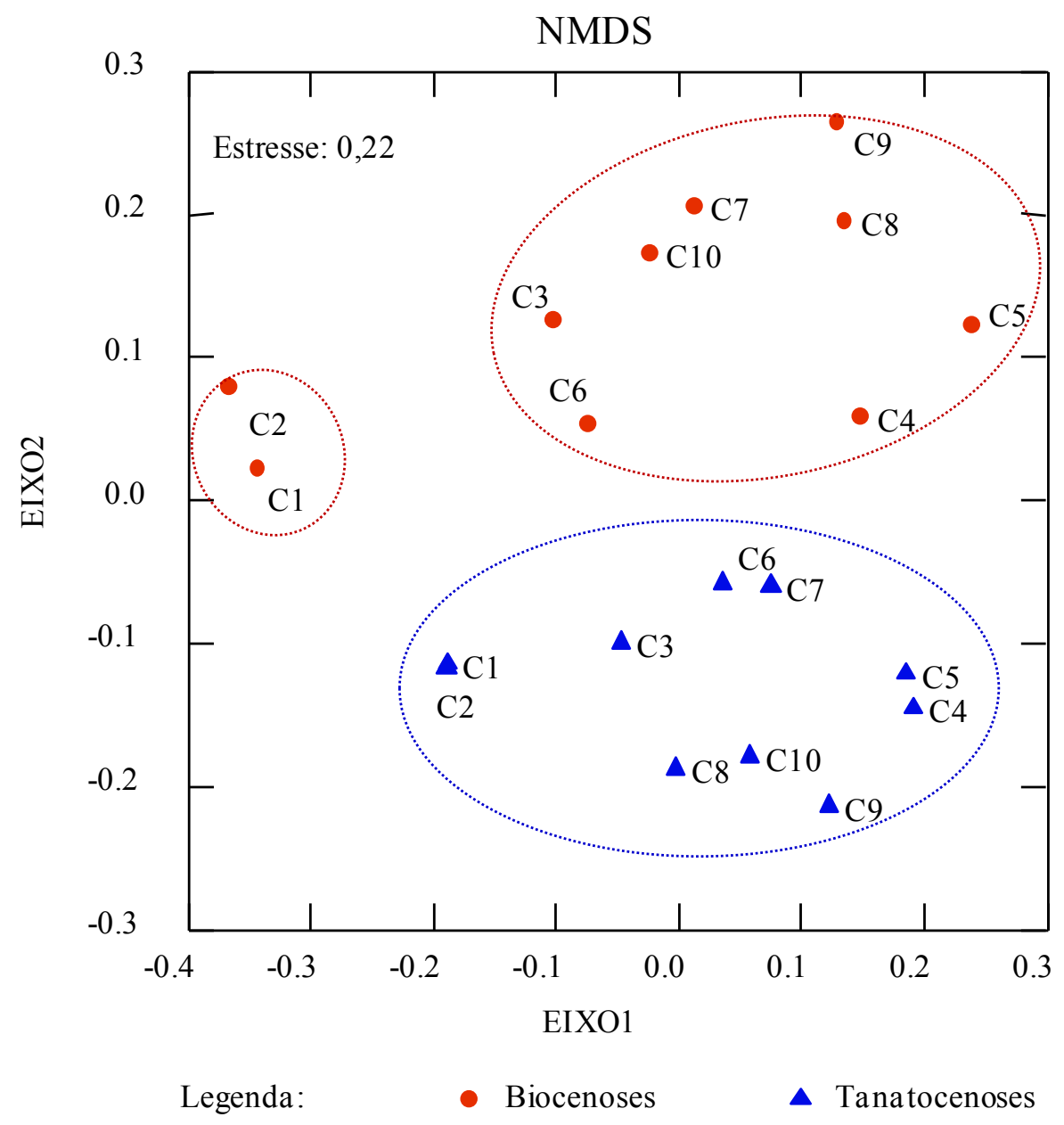

Figura 09 - Gráfico de ordenação das comunidades de foraminíferos que compuseram as biocenoses e tanatocenoses obtidas ao longo do Canal de São Sebastião.

A partir da Análise de Agrupamento, modo Q, nível de similaridade de 0,56, verificou-se a formação de dois grupos distintos, i.e. tanatocenoses e biocenoses (Figura 10), o que corrobora a diferenciação na composição de espécies obtida por meio do NMDS. 


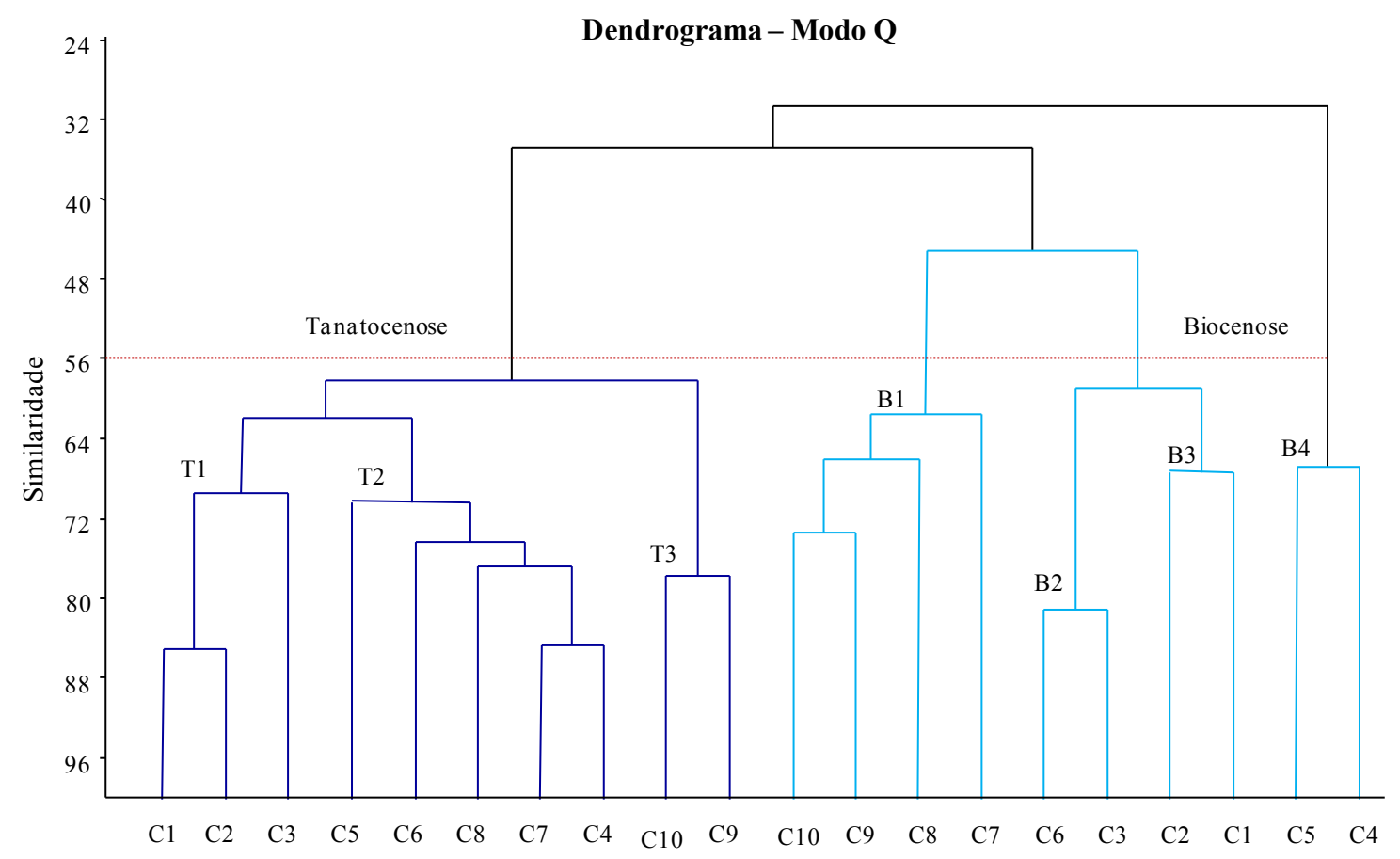

Figura 10 - Dendrograma do agrupamento das estações, Modo Q, com diferenciação entre biocenoses e tanatocenoses.

O grupo formado pelas tanatocenoses divide-se em 3 subgrupos: T1 formado pelas estações C1, C2 e C3, as quais localizam-se na região norte do canal; T2 formado pelas estações $\mathrm{C} 4, \mathrm{C} 5, \mathrm{C} 6, \mathrm{C} 7, \mathrm{C} 8$, sendo a estação $\mathrm{C} 4$ localizada na região norte, no lado insular, e as demais estações na região central do canal e T3 composto pelas estações C9 e C10, posicionadas na região sul.

O grupo formado pelas biocenoses também divide-se em subgrupos, os quais foram denominados B1, B2 , B3 e B4. O grupo B1 é composto pelas estações C7, C8, C9 e C10. O grupo B2 é formado pelas estações C3 e C6. Assim como no NMDS, as estações C1 e C2 agruparam-se formando o grupo B3. As estações C4 e C5 formam o grupo B4.

Descritivamente, verificou-se que $50 \%$ das espécies de foraminíferos que compõem as biocenoses também estão presentes nas tanatocenoses, com diferenciação nas abundâncias relativas, as quais são maiores nas biocenoses. Das espécies que não são comuns às biocenoses e tanatocenoses, 6 encontram-se descritas somente nas biocenoses em baixa abundância relativa (Ammoscalaria pseudospiralis, Ammotium diversus, Astalacus credipulus, Bolivina alata, Deuteramina discorbis e Rosalina bradyi) e as demais encontram-se presentes somente nas tanatocenoses. Excetuando-se 
Bolivina pulchella, Cribroelphidium discoidale e Discorbis williamsoni, as espécies constantes somente nas tanatocenoses possuem abundâncias relativas inferiores a 5\%.

\subsection{DISCUSSÃO}

\subsubsection{Parâmetros físico-químicos da coluna d'água}

Apesar de levemente alcalinos, os valores de pH são característicos de ambiente marinho, i.e. 7,5 a 8,4 (Soares-Gomes e Figueiredo, 2002). Já os valores de turbidez são considerados baixos, sendo típicos de ambientes oligotróficos.

Dentre as estações analisadas, 60\% (C1, C6 a C10) apresentaram níveis de oxigênio dissolvido abaixo do limite estabelecido pela Resolução CONAMA 357/2005, para águas salinas de Classe 1 (i.e. inferiores a $6 \mathrm{mg} \mathrm{L}^{-1}$ ), nas águas de meio e fundo.

Segundo Esteves (1998), há dois fatores controladores indiretos para a baixa concentração de oxigênio dissolvido na coluna d'água, sendo um deles a ocorrência de um período prolongado da estratificação térmica, o qual é mais freqüente em ambientes profundos, e o outro a concentração de matéria orgânica na fração dissolvida e/ou particulada. O primeiro fator pode ser descartado, uma vez que as coletas foram realizadas em ambiente raso (profundidades entre 3,9 e 13,9 m), cuja hidrodinâmica local não permite estratificação prolongada. O segundo fator, por sua vez, é plausível, e será melhor abordado quando o tópico geoquímica for discutido.

Os resultados de nitrogênio amoniacal e Kjeldahl total, ortofosfato e fósforo total não evidenciaram enriquecimento orgânico na coluna d'água; os valores obtidos foram muito baixos, sendo inclusive inferiores ao limite de detecção do método analítico. No interior do Canal de São Sebastião, o enriquecimento orgânico e inorgânico são pouco evidenciados, ou mesmo ausentes, devido ao forte hidrodinamismo que há na região (Cascady e FUNDESPA, 2002 in Cattena, 2004). A velocidade das correntes de superfície podem atingir velocidades de 0,7 a $1,0 \mathrm{~m} \mathrm{~s}^{-1}$ (Furtado et al., 2008). 


\subsubsection{Parâmetros granulométricos e geoquímicos}

O Canal de São Sebastião possui complexo padrão de distribuição granulométrica, o qual segundo Furtado (1978), é reflexo da topografia de fundo e da hidrodinâmica.

A partir resultados granulométricos, verificou-se distribuição heterogênea dos grãos ao longo do Canal de São Sebastião. De modo geral, verificou-se aumento gradativo de sedimentos arenosos das estações da região sul para as localizadas na região norte do canal. Na região central há maior concentração de sedimentos finos (estações C6, C7 e C8).

$\mathrm{Na}$ região central, observa-se complexa heterogeneidade no tamanho dos grãos, sendo observada em uma mesma amostra desde grânulos à argila (estações C5 e C7). Segundo Furtado (1978) e Furtado et al. (2008), a região central apresenta intricado fluxo de correntes, com alternância na velocidade, bem como de sentido devido à presença de giros anti-horários (q.v. Figura 03). Ainda segundo os autores, a quebra de energia associada à alteração de fluxo propicia a deposição e preservação de sedimentos arenosos, principalmente nas frações areia fina e muito fina, assim como de silte e argila.

No lado insular da região norte verificou-se a presença de sedimentos mais grossos, com presença significativa de grânulos (estação $\mathrm{C} 4$ ) oriundos de fluxo mais intenso, o qual, segundo Furtado et al. (2008), é aumentado devido ao estreitamento do canal. Os resultados granulométricos obtidos para as estações C1 e C2, i.e. predominância de areia muito fina e silte, indicam que a faixa central da região norte, local onde as estações foram posicionadas, é ambiente de baixa energia de fundo.

Os resultados granulométricos obtidos nas amostras posicionadas ao longo do canal são similares aos descritos na literatura e permitiram identificar áreas de maior e menor taxa deposicional. Conforme consta na literatura, a configuração topográfica do Canal de São Sebastião permite que haja maior taxa de deposição de sedimentos finos no lado continental (Furtado et al., 2008). O lado insular, por sua vez, em decorrência de aumento de fluxo de energia, possui características erosivas, com predomínio de sedimentos arenosos, principalmente nas frações areia média e grossa (Furtado, 1978; Furtado et al., 2008). A alternância no fluxo principal não altera estas características, no entanto, em momentos de diminuição de energia de fundo, há a deposição de 
sedimentos finos, os quais se misturam aos sedimentos arenosos, dando origem à distribuição em manchas (Fundespa, 2000).

Os parâmetros geoquímicos analisados possuem distribuição diretamente relacionada aos teores de sedimentos finos (q.v. Anexo 08), devido à maior capacidade de adsorção do silte e da argila (Bordovskiy, 1965).

Por meio de análises geoquímicas, foram observadas áreas com indícios de enriquecimento orgânico, cujos sinais de degradação ambiental ocorrem no compartimento sedimentar.

Os valores de Eh na maioria das estações são negativos (estações C1, C2, C5 a C9), o que torna possível inferir aumento do consumo de oxigênio na interface águasedimento para degradação de elevada quantidade de matéria orgânica. Valores de Eh entre - 50 e $-150 \mathrm{mV}$ são característicos de ambientes com indícios de hipoxia ${ }^{7}$ (Wildish et al., 2001). Os valores de Eh obtidos nas estações C3 (58 mV), C4 (233 mV) e C10 (103 mV), por sua vez, indicam boa oxigenação na interface água-sedimento, o que deve ser atribuído a maior circulação de fundo e/ou menor aporte de matéria orgânica.

Os valores de $\mathrm{pH}$, apesar de apresentarem leve sinal de acidez nos sedimentos das estações C2, C3 e C6, não são indicativos de alterações ambientais.

Os valores de carbono orgânico total, fósforo e enxofre, de acordo com as correlações observadas (q.v. Anexo 08), possuem padrão de distribuição similar, sendo passível de se inferir fonte similar de origem. As maiores concentrações de carbono orgânico total, fósforo e enxofre ocorreram na área central do canal, nesta região, há a presença de dois emissário submarinos (Araçá e TEBAR), além da presença do porto de São Sebastião. O esgoto doméstico disposto pelo emissário do Araçá recebe somente tratamento preliminar, o que permite que grande quantidade de matéria orgânica seja depositada no ambiente marinho. O efluente petroquímico liberado TEBAR, apesar de receber tratamento, também libera para o interior do canal quantidade significativa de compostos orgânicos e inorgânicos (Catena, 2004).

De modo geral, os valores de carbono orgânico total são considerados entre moderados e baixos. Somente a estação C8 (2,76\%) apresentou teor similar ao verificado em locais sob processo de eutrofização, i.e. entre 2 e 4\% (Diz et al., 2006). Esta estação encontra-se posicionada próxima a parte final do emissário submarino de

\footnotetext{
${ }^{7}$ Hipoxia - definida como valor limite, abaixo do qual a biota pode ser impactada (Mojtahid et al., 2009). Valor de oxigênio dissolvido inferior a $2 \mathrm{mg} \mathrm{L}^{-1}$ (Tyson e Pearson, 1991).
} 
esgotos domésticos do Araçá. Mendes (2007), obteve valor semelhante de carbono orgânico total (2,65\%), em amostra coletada no inverno de 2005, a aproximadamente 150 m da estação C8, o que sugere aporte crônico de matéria orgânica na região.

Os valores de nitrogênio apresentam certa homogeneidade de valores para as estações C5 a C10 $(\bar{x}=0,22 \pm 0,03 \%)$. Os menores teores foram observados nas estações posicionadas na região norte $(\mathrm{C} 1, \mathrm{C} 2$ e $\mathrm{C} 3)$, sendo duas vezes menores em relação aos teores obtidos nas demais estações.

Excetuando-se a estação C1, o mesmo padrão de distribuição e concentração foi observado para fósforo. Os valores encontrados, apesar de elevados, não são considerados críticos $(0,017$ a 0,$055 ; \bar{x}=0,039 \%)$. Segundo Baturin (2003), para a caracterização de estresse ambiental decorrente de atividades antropogênicas, os valores de fósforo devem ser superiores a $0,07 \%$. Os teores de fósforo obtidos nos anos de 2005 e 2006, cujos resultados serão discutidos posteriormente, são expressivamente superiores aos obtidos ao longo do canal em amostras realizadas em 2008. A diminuição de concentração deve-se a Resolução CONAMA 359/2005², a qual regulamenta a diminuição nos teores de fósforo nos detergentes em pó a partir de 2005.

No tocante ao enxofre, os valores encontrados em quase todas as estações são indicativos de atividades antropogênicas (0,13\%; Turekian e Wedepohl, 1961). As concentrações elevadas de enxofre podem ser oriundas dos efluentes dipostos (doméstico e petroquímico) e da circulação de navios de pequeno e médio calado que navegam no interior do canal e são atracados no porto de São Sebastião e no TEBAR. As fontes de enxofre serão melhor detalhadas quando os resultados das demais áreas de estudo forem discutidos.

$\mathrm{Na}$ tentativa de identificar as fontes de matéria orgânica para o interior do canal, foram calculadas razões $\mathrm{C} / \mathrm{N}$. A utilização de razões $\mathrm{C} / \mathrm{N}$ como proxie para identificar a proveniência da matéria orgânica parte do pressuposto que matéria orgânica de origem marinha e continental possuem distintas razões $\mathrm{C} / \mathrm{N}$, devido à diferença de composição elementar, i.e. concentrações de carbono orgânico total e nitrogênio total. Bactérias, fitoplâncton e zooplâncton possuem elevados teores de nitrogênio em sua composição, motivo pelo qual os valores das razões $\mathrm{C} / \mathrm{N}$ são baixos, ou seja, inferiores a 6; por outro lado, plantas vasculares terrestres, cuja constituição é rica em celulose e lignina, com

\footnotetext{
${ }^{8}$ Resolução CONAMA 359 de 29 de Abril de 2005 - regulamenta a diminuição nos teores de fósforo (P) em detergentes em pó, em todo o território nacional. Foi concedido período máximo de 3 anos para a regularização dos teores.
} 
baixa concentração de nitrogênio, possuem razões $\mathrm{C} / \mathrm{N}$ superiores a 12 (Bordowskiy, 1965; Stein, 1991). Valores entre 6 e 12, por sua vez, representam fonte mista, ou seja, marinha e continental. Identificou-se matéria orgânica de origem marinha $(\mathrm{C} / \mathrm{N}<6)$ nas estações $\mathrm{C} 2, \mathrm{C} 3, \mathrm{C} 4, \mathrm{C} 5, \mathrm{C} 9$ e matéria orgânica de origem mista $(\mathrm{C} / \mathrm{N}$ entre 6 e 12) nas estações C1, C6, C7 e C10, possuindo esta última estação forte componente marinho. A parte continental da matéria orgânica, obtida para a estação $\mathrm{C} 1$, pode ocorrer devido a mesma estar sob influência da disposição de esgotos domésticos do emissário de Cigarras e do material proveniente do rio Juqueriquerê. Matéria orgânica de origem continental $(\mathrm{C} / \mathrm{N}<12)$, foi somente identificada na estação $\mathrm{C} 8$, a qual pode ter como fonte o esgoto disposto pelo emissário do Araçá.

Razões C/S foram utilizadas como proxie para analisar o potencial de oxiredução dos sedimentos de fundo. A utilização de razões $\mathrm{C} / \mathrm{S}$, como proxie qualitativo para diferenciar sedimentos depositados em condições óxicas de sedimentos depositados em eventos de anoxia ou de semi-anoxia, é baseada em processos de redução de sulfato por bactérias sulfato redutoras (Stein, 1991; Borrego et al., 1998). As razões $\mathrm{C} / \mathrm{S}$ refletem a redução do sulfato durante a decomposição da matéria orgânica, tornando possível inferir as condições do potencial redox do ambiente deposicional (Borrego et al., 1998). Valores de razões $\mathrm{C} / \mathrm{S}$, em média, inferiores a 2,8 ${ }^{ \pm} 0,8$ indicam sedimentos depositados sob condições redutoras (Lyons e Berner, 1992; Borrego et al., 1998). Aller et al. (2004), estudando o complexo deltaico do Golfo de Papua (Nova Guiné), observaram razão C/S entre 4 e 6 para ambiente marinho sub-óxico e menor do que 3 para ambientes redutores. Com base no disposto, infere-se que os sedimentos da estação C3 foram depositados em ambiente com bom nível de oxigenação. Os sedimentos das demais estações foram depositados em condições sub-óxicas. Os resultados obtidos corroboram, parcialmente, o potencial de oxi-redução da interface água-sedimento obtido por meio dos valores de Eh.

De acordo com os dados apresentados, observa-se que as estações posicionadas nas regiões central e sul estão sob influência antrópica. As estações C6, C7 e C8, localizadas na região central do canal, aparentemente estão sob influência dos emissários do Araçá (esgoto domésticos), do TEBAR (petroquímico) e do porto de São Sebastião. Desta forma, tais estações recebem significativa quantidade de matéria orgânica e da água de produção disposta pelo emissário submarino do terminal petrolífero. A mesma configuração foi descrita por Zanardi et al. (1996) e Weber et al. (1998); os autores observaram que a matéria orgânica na região central do canal é 
predominantemente composta por hidrocarbonetos de esgoto urbano e petróleo, oriundos da emissão de esgotos domésticos dispostos pelo emissário submarino, bem como pelas residências locais e das atividades do terminal petrolífero.

Já as estações C9 e C10 estão posicionadas próximo à área onde navios de médio e grande calado atracam antes de entrar no canal para serem direcionados ao TEBAR. Bícego et al. (2008), ao analisarem as concentrações de hidrocarbonetos em amostras dispostas ao longo do Canal de São Sebastião, associaram os valores obtidos, em amostras posicionadas próximo as áreas onde estão localizadas as estações C9 e C10, à liberação clandestina de água de lastro, bem como lavagem de tanques de navios petroleiros.

Além da presença expressiva de atividades antrópicas na região central do canal, existem outros fatores oceanográficos que favorecem o enriquecimento orgânico na região. Devido ao forte hidrodinamismo que há na região, cujo sentido preferencial das correntes é predominantemente de SW-NE é plausível inferir que o material particulado e os compostos orgânicos e inorgânicos a ele associado seriam carreados para a região norte. Entretanto, tal transporte ocorre somente em pequena escala; devido à presença de giros anti-horários existentes na região norte há o retorno de parte do fluxo e do material em suspensão para o interior do canal, o qual é acondicionado na região central (Furtado et al., 2008).

O enriquecimento orgânico e estresse ambiental que há na região central do Canal de São Sebastião também foram observados por outros autores. Melo e Nipper (2007), ao analisarem a toxicidade dos sedimentos do Canal de São Sebastião, observaram que os maiores níveis de toxicidade para os organismos (Tiburonella viscana) ocorreram em amostras coletadas na região central, na faixa existente entre o emissário do Araçá e TEBAR. Mendes (2007), ao estudar amostras coletadas ao longo do canal, com maior enfoque na região central, inferiu que as maiores concentrações de metais e hidrocarbonetos estão associadas ao emissário do Araçá, ao porto e ao TEBAR. Catena (2004), ao analisar o potencial trófico/tóxico das águas de produção do terminal petrolífero dispostas pelo emissário submarino no interior do Canal de São Sebastião, verificou que as maiores concentrações das formas de nitrogênio e fósforo ocorreram na região central. Ainda segundo a autora, processos de eutrofização e efeitos tóxicos sobre o fitoplâncton não são visualizados devido ao forte hidrodinamismo que há no canal. Entretanto, quando in natura o efluente possui elevado poder tóxico. 


\subsubsection{Associações de foraminíferos - biocenoses e tanatocenoses}

A partir das análises estatísticas realizadas (NMDS, teste $\mathrm{t}$ e Análise de Agrupamento), constatou-se que a estrutura composicional das biocenoses difere-se significantemente das tanatocenoses, o que inviabilizou a utilização da fauna total na caracterização ambiental do Canal de São Sebastião. Menciona-se, entretanto, a importância da integração das informações obtidas pelas duas associações, uma vez que as biocenoses indicam as condições ambientais existentes no período da coleta, e as tanatocenoses, por sua vez, auxiliam no entendimento do regime hidrodinâmico e, consequentemente, do menor ou maior grau de oxigenação e fluxo de matéria orgânica a que o compartimento bentônico está sujeito.

Dentre os diversos parâmetros ambientais que podem influenciar a distribuição e composição das associações de foraminíferos bentônicos, verificou-se que os valores de densidades das biocenoses são significantemente influenciadas pela temperatura, salinidade e $\mathrm{pH}$ dos sedimentos. Aparentemente, os esses fatores ambientais estão refletindo as preferências ecológicas do gênero Ammonia sp, uma vez que o mesmo é dominante em $70 \%$ das estações.

Ammonia tepida é característica de regiões costeiras, é adaptada a uma grande variedade de parâmetros ambientais, tais como profundidade, salinidade, temperatura, granulometria, pH e nível de oxigenação (Bradshaw, 1961; Murray, 1991; Kitazato, 1994). No presente estudo, elevados valores de salinidade e $\mathrm{pH}$, usualmente obtidos em ambientes marinhos, apresentaram-se desfavoráveis à sua presença. As maiores abundâncias relativas de Ammonia tepida foram obtidas em estações com valores de pH levemente ácidos, bem como em estações onde foram obtidos os menores valores de salinidade. De acordo com Bradshaw (1961), Ammonia tepida pode sobreviver em sedimentos com pH próximo a 2,0, pelo período de 25 minutos a 1 hora e 15 minutos. Ainda segundo o autor, a reprodução da espécie ocorre em ambientes com valores de salinidade oscilando de 13 a 40.

No Canal de São Sebastião, Ammonia tepida ocorreu em maior abundância em estações posicionadas no lado continental do canal. Em amostras coletadas na faixa central, tendendo ao lado insular, verificou-se alternância na distribuição e composição das espécies. Ammonia tepida teve sua distribuição inversamente proporcional à Cassidulina crassa, Cassidulina subglobosa, Rosalina floridensis, Hanzawaia boueana e Gavelinolepsis praegeri, as quais, excetuando-se a última espécie, possuem suas 
distribuições positivamente relacionadas com o $\mathrm{pH}$. Tais espécies foram observadas em maior abundância nas estações C4 e C5, posicionadas no lado insular da Ilha de São Sebastião, local onde ocorrem as maiores profundidades, há maior hidrodinâmica, e de acordo com os valores de salinidade, possui maior influência marinha. As estações posicionadas nesta faixa do canal, bem como a estação C7, apresentaram as maiores diversidades específicas bem como equitatividade, o que permite inferir menor estresse ambiental.

Cassidulina sp é o gênero predominante nas estações C4 e C5, sendo Cassidulina crassa e Cassidulina subglobosa as espécies mais abundantes. Elevadas abundâncias de Cassidulina crassa são associadas à ambientes ricos em matéria orgânica e pobres em oxigênio dissolvido (Alavi, 1988; Bernhard e Sen Gupta, 1999; Martins et al., 2006). No presente estudo, entretanto, o relacionamento é o inverso ao esperado. As maiores abundâncias da espécie ocorreram em estações com concentrações baixas (C4) e moderada (C5) de matéria orgânica, a qual foi inferida como sendo de origem marinha.

Os resultados das correlações de Pearson não indicaram quais os parâmetros abióticos que estão influenciando as densidades, riquezas, diversidades específicas e equitatividades. Entretanto, verificou-se as maiores abundâncias de Pseudononion opima e Bulimina marginata ocorreram em estações com elevados teores de nitrogênio, sendo a primeira espécie também associada à fósforo orgânico. Ambas são espécies calcárias marinhas e infaunais (Murray, 1991). Significativas abundâncias de Bulimina marginata têm sido observadas em ambientes com elevada produtividade (Burone e Pires-Vanin, 2006; Martins et al., 2006; Nagai et al., 2009), inclusive em regiões de ressurgência (Phleger e Soutar, 1973).

Fursenkoina fragilis foi somente identificada nas estações C6, C7 e C8. Verificou-se para a espécie forte correlação positiva com carbono orgânico total $(\mathrm{r}=$ $0,83 ; p<0,01)$ e enxofre $(\mathrm{r}=0,84 ; p<0,01)$, o que sugere enriquecimento orgânico para região onde as estações foram posicionadas. Fursenkoina sp é um gênero detritívoro (Murray, 1991), pertencente à infauna profunda e indicativo de ambientes disóxicos ${ }^{9}$ (Bubenshchikova et al., 2010).

Espécies bioindicadoras de enriquecimento orgânico (Anexo 07), as quais são infaunais, e em sua grande maioria detritívoras, estiveram distribuídas por todo o canal,

\footnotetext{
${ }^{9}$ Disóxico - teores de oxigênio dissolvido entre 0,3 e $0,1 \mathrm{ml} \mathrm{L}^{-1}$ (in Bubenshchikova et al., 2010).
} 
sendo predominantes em todas as estações. Devido ao anteriormente descrito, bem como à correlação positiva de Cassidulina crassa e Cassidulina subglobosa com espécies bioindicadoras de ambiente óxico, o gênero Cassidulina sp não foi associado à este grupo.

Observou-se aumento de concentração de espécies bioindicadoras de ambiente rico em matéria orgânica de norte para o sul do canal, sendo as maiores abundâncias identificadas na região central, mais precisamente estações C7 (62,6\%) e C8 (51,6\%). O enriquecimento orgânico que há na estação C7, pode ser devido ao aporte crônico de componentes orgânicos e inorgânicos pelo emissário do TEBAR, cuja distância, aproximada, é de $800 \mathrm{~m}$, bem como também pode ocorrer devido a presença do porto de São Sebastião. A estação C8, por sua vez, está posicionada a aproximadamente $700 \mathrm{~m}$ da parte final do emissário do Araçá.

Espécies bioindicadoras de ambiente óxico (Anexo 07) estiveram presentes somente a partir da estação C3, sendo as maiores concentrações observadas nas estações C4 e C5, o que reflete a maior circulação e oxigenação pelas correntes de fundo no compartimento bentônico.

Mendes (2007), ao analisar os macrozoobentos ao longo do Canal de São Sebastião, observou diferenças significativas entre as comunidades das regiões norte e sul. Segundo o autor, na região norte há predominância de espécies predadoras móveis e suspensívoras; as regiões central e sul são caracterizadas pela dominância de espécies oportunistas detritívoras. Ainda de acordo com o mesmo autor, a região adjacente ao emissário do Araçá, do porto de São Sebastião e do TEBAR apresentou os menores índices de densidade, de riqueza e de diversidade de espécies, o que no presente estudo não ocorreu. Os valores de densidade das estações posicionadas próximo ao Araçá e TEBAR são similares aos de outras localidades do canal, como por exemplo, nos locais onde estão posicionadas as estações C5, C9 e C10.

Muniz e Pires-Vanin (1999), ao analisarem a macrofauna em estações posicionadas ao longo do Canal de São Sebastião, observaram que a estrutura trófica é composta predominantemente por poliquetas, cujos grupos tróficos possuem significativa correlação com o tamanho dos grãos e com o conteúdo de carbono orgânico. Segundo os autores no interior do canal há dominância de organismos detritívoros, seguidos de organismos carnívoros.

Inferências sobre a qualidade ambiental do compartimento bentônico também puderam ser obtidas por meio do tamanho das carapaças de foraminíferos. O tamanho 
dos foraminíferos pode ser uma resposta ao nível de oxigenação do meio, ao elevado aporte de matéria orgânica, ou mesmo devido às duas variáveis em conjunto, uma vez que a degradação de elevada concentração de matéria orgânica induz a redução dos níveis de oxigenação da interface água-sedimento. De acordo com alguns estudos, em ambientes com alta produtividade, as associações de foraminíferos tendem a ser dominadas por espécimes pequenos, como uma adaptação à diminuição dos níveis de oxigênio dissolvido e/ou mudança na estratégia de reprodução, i.e. reprodução acelerada, devido à abundância de alimento e ausência de competição (Phleger e Soutar, 1973; Bernhard e Reimers, 1991; Sen Gupta e Machain-Castillo, 1993; Diz et al., 2006). Por meio dos resultados apresentados, apesar da dominância de espécies bioindicadoras de ambiente com baixos níveis de oxigenação na interface águasedimento (Bolivina spp, Fursenkoina spp, Buliminella elegantissima, Pseudononion spp, entre outras espécies), percebe-se bom nível de oxigenação ao longo do Canal de São Sebastião. Apesar de significativa a porcentagem de carapaças pequenas $(<125$ $\mu \mathrm{m}$ ), observou-se a presença conspícua de carapaças grandes (entre 250 e $500 \mu \mathrm{m}$ ) e até mesmo de macroforaminíferos $(<500 \mu \mathrm{m})$.

Nas estações C1 e C2 foi observado o predomínio de carapaças pequenas, além de valores baixos de riqueza e de diversidade específica, o que se deve a abundância expressiva de Ammonia parkinsoniana e Ammonia tepida, bem como pela ausência de espécies bioindicadoras de ambiente óxico. Os resultados obtidos permitem inferir que o lado continental da região norte do canal, onde as estações foram posicionadas, possui energia de fundo muito baixa.

No tocante às tanatocenoses, além das diferenças mencionadas no início deste capítulo, e que foram resultantes de análises estatísticas, outras diferenças apenas descritivas puderam ser observadas. Comparativamente, verificou-se por meio dos valores de riqueza, diversidade específica e equitatividade uma distribuição mais heterogênea das espécies. Outra observação é a melhor representatividade da Subordem Miliolina, pois excetuando-se as estações $\mathrm{C} 1$ e C2, miliolídeos estiveram presentes nas demais estações.

Por meio das tanatocenoses, importantes informações acerca da hidrodinâmica no interior do canal puderam ser observadas. As correlações de Pearson indicaram que nenhum fator abiótico estudado está influenciando a distribuição dos foraminíferos no interior do canal, observação esta já esperada, uma vez que após a morte do organismo, sua carapaça torna-se parte do sedimento de fundo e, conseqüentemente, está sujeito ao 
regime hidrodinâmico do local onde foi depositada. Desta forma, a distribuição das espécies pertencentes às tanatocenoses pode ou não refletir a ecologia das espécies. No presente estudo, a hidrodinâmica é o principal fator que está influenciando a distribuição e, em determinados casos, a composição das tanatocenoses.

Pararotalia cananeiaensis, espécie predominante em todas as estações analisadas, é uma espécie epifaunal, herbívora, característica de ambiente marinho (Murray, 1991; Debenay et al., 2001). O primeiro registro desta espécie ocorreu no ano de 1995, em amostras coletadas no Complexo Estuarino-Lagunar de Cananéia (Debenay et al., 2001), entretanto, suas preferências ecológicas não são ainda totalmente reconhecidas. Debenay et al. (2001), em amostras coletadas ao longo do Canal de São Sebastião, registrou abundâncias relativas de Pararotalia cananeiaensis superiores a $49 \%$, porém, segundo os autores, não foi possível associar a distribuição da espécie a nenhuma variável ambiental estudada, i.e. profundidade, salinidade e temperatura. Pararotalia cananeiaensis tem sido utilizada como espécie bioindicadora de influência marinha em regiões costeiras (Debenay et al., 1998; Debenay et al., 2001; Burone et al., 2006), bem como para o entendimento e caracterização do regime hidrodinâmico em estuários do litoral sudeste brasileiro (Debenay et al., 1998; Duleba e Debenay, 2003). Segundo Debenay et al. (2001), devido ao seu pequeno tamanho $(<200 \mu \mathrm{m})$, as carapaças são transportadas em suspensão de ambientes marinhos, sendo depositadas em ambientes de menor energia, motivo pelo qual as abundâncias desta espécie podem providenciar informações sobre a dinâmica sedimentar. Diante disto, por meio das abundâncias absolutas das carapaças de Pararotalia cananeiaensis a hidrodinâmica do canal pôde ser mapeada.

De acordo com o modelo proposto (Anexo 11), verificou-se configuração da hidrodinâmica no interior do canal semelhante à descrita por Furtado (1978). As correntes marinhas adentram o canal pela região sul, aumentam o fluxo hidrodinâmico na região central, devido ao afunilamento existente, para em seguida diminuir o fluxo em sentido noroeste (lado continental) e aumentar no lado insular do canal. A estação C8, por sua vez, de acordo com a abundância obtida para a espécie, encontra-se posicionada em ambiente de baixa circulação de fundo, inferência esta que também corrobora os dados apresentados em Furtado (1978).

A entrada de correntes marinhas pela região sul para o interior do canal também foi confirmada pela presença de foraminíferos planctônicos. Apesar da baixa abundância, espécimes planctônicos estiveram presentes nas estações C10 a C4. 
Os resultados morfométricos refletem o grau de heterogeneidade existente no canal e que foi anteriormente evidenciado pela granulometria. Em quase todas as amostras foram observadas as quatro classes de tamanho (i.e. pequenas, médias, grandes e pertencentes à macroforaminíferos); a ausência de seleção hidráulica em relação ao tamanho das carapaças é indicativa de fluxos alternados, tanto no tocante a direção, bem como velocidade das correntes de fundo, o que segundo Furtado et al. (2008), é comumente observado no interior do canal.

No tocante ao grau de preservação, infere-se que as carapaças, quando depositadas no fundo marinho, podem ser transportadas por suspensão, que diminui e/ou inibe fragmentações (parcial ou total), ou por rolação/saltação. Quando o transporte é feito em contato direto com o sedimento de fundo (rolação/saltação) o atrito existente entre as carapaças e grãos de sedimento (abrasão mecânica) ocasiona a fragmentação parcial ou total. Desta forma, com as devidas ressalvas, o grau de preservação das carapaças pode inferir a hidrodinâmica local. A ressalva que deve ser levada em consideração é a constituição das carapaças, ou seja, carapaças mais delicadas e pouco resistentes podem não se preservar dependendo das condições hidrodinâmicas e geoquímicas locais.

O padrão de distribuição de carapaças inteiras, parcialmente fragmentadas e fragmentos corrobora os resultados obtidos pelas análises granulométricas, análises geoquímicas, análises morfométricas e pelas abundâncias absolutas de Pararotalia cananeiaensis.

A coloração das carapaças é também um importante aspecto da análise tafonômica e ferramenta para o entendimento dos processos geoquímicos existentes no compartimento sedimentar. Em geral, os foraminíferos possuem carapaças calcárias esbranquiçadas ou aglutinadas pardacentas, entretanto dependendo da presença de alguns elementos, como por exemplo, o ferro, seja em sua forma oxidada ou reduzida, pode ocorrer alteração na coloração (Loeblich e Tappan, 1964; Duleba, 1994). Carapaças esbranquiçadas foram observadas em predominância ao longo de todo o canal. Carapaças acastanhadas ocorreram em maior porcentagem nas estações C4 e C5, estações que também apresentaram as maiores abundâncias relativas de espécies bioindicadoras de ambiente óxico (biocenoses), bem como de grânulos (q.v. Figura Anexo 10). De acordo com Duleba (1994), carapaças impregnadas com óxido e/ou hidróxido de ferro são indicativas de ambientes com maior oxigenação na interface água-sedimento. 
A presença de monossulfeto de ferro e pirita $\left(\mathrm{Fe}_{2} \mathrm{~S}\right)$, por sua vez dá às carapaças coloração escura, preto iridescente ou dourada. O monossulfeto de ferro origina-se em ambiente redutor, pela ação de bactérias anaeróbicas na redução do sulfato, para a metabolização da matéria orgânica existente no sedimento (Leventhal, 1983). A pirita, por sua vez, é gerada a partir do monossulfeto de ferro, caso este permaneça em ambiente redutor com elevados teores de enxofre (Duleba, 1994). Entretanto, para que a pirita seja formada são necessárias determinadas condições ambientais, bem como anos, uma vez que a pirita é característica de sedimentos mais antigos. As condições ambientais necessárias são elevados teores de matéria orgânica, com conseqüente anoxia do compartimento sedimentar e redução do sulfato pela ação de bactérias sulfato redutoras (Martins et al. 2007; Werne et al., 2009).

As concentrações de carapaças preenchidas por monossulfeto de ferro/pirita ocorreram, em ordem decrescente, de sul para norte do canal, sendo as maiores porcentagens observadas nas estações $\mathrm{C} 7$ a C10. Pelo padrão de distribuição infere-se que no local, onde as estações mencionadas estão posicionadas, há elevada concentração de sedimentos/carapaças relíquia, bem como há aporte crônico de matéria orgânica.

Sinais de bioerosão foram observados nas estações C3 (Bolivna pulchella, Bulimina marginata e Ammonia tepida), C4 (Triloculina baldai, Rosalina floridensis e Pararotalia cananeiaensis), C6 (Pseudononion opima), C9 (Cribroelphidium excavatum e Quinqueloculina seminula) e estação C10 (Buccella peruviana e Pseudononion grateloupi). As marcas observadas nas carapaças (circunferência) podem ter sido feitas por poliquetos, anelídeos ou nemátodas, organismos que estão entre os principais predadores invertebrados dos foraminíferos (Debenay et al. 1996). 


\section{Anexos}

Anexo 01 - Teores de carbonato de cálcio e carbono orgânico total obtidas ao longo do Canal de São Sebastião.

Valores em porcentagem.
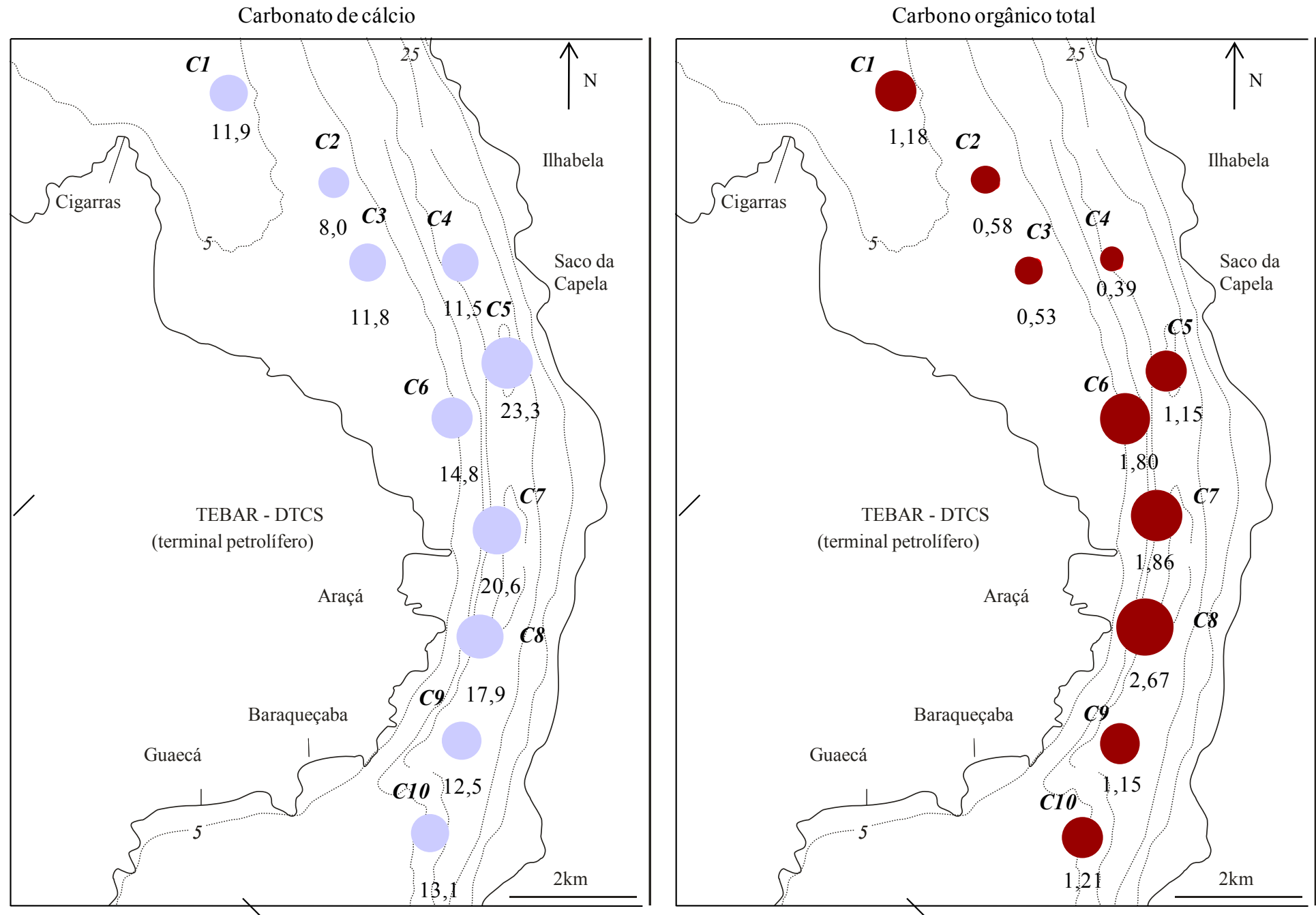
Anexo 02 - Teores de nitrogênio e fósforo total obtidas ao longo do Canal de São Sebastião.

Valores em porcentagem.
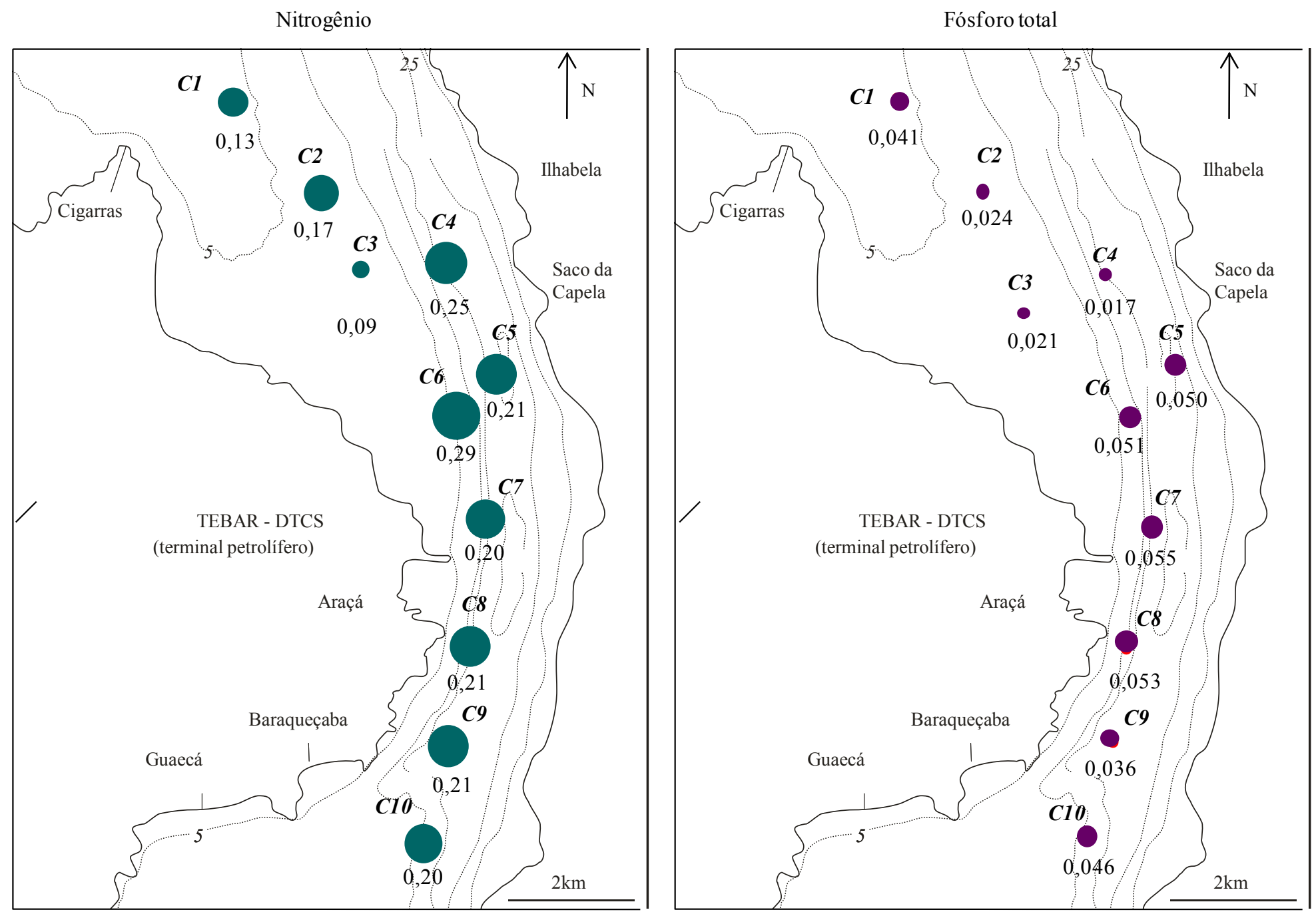
Anexo 03 - Teores de fósforo orgânico e inorgânico obtidas ao longo do Canal de São Sebastião.

Valores em porcentagem.

Fósforo orgânico

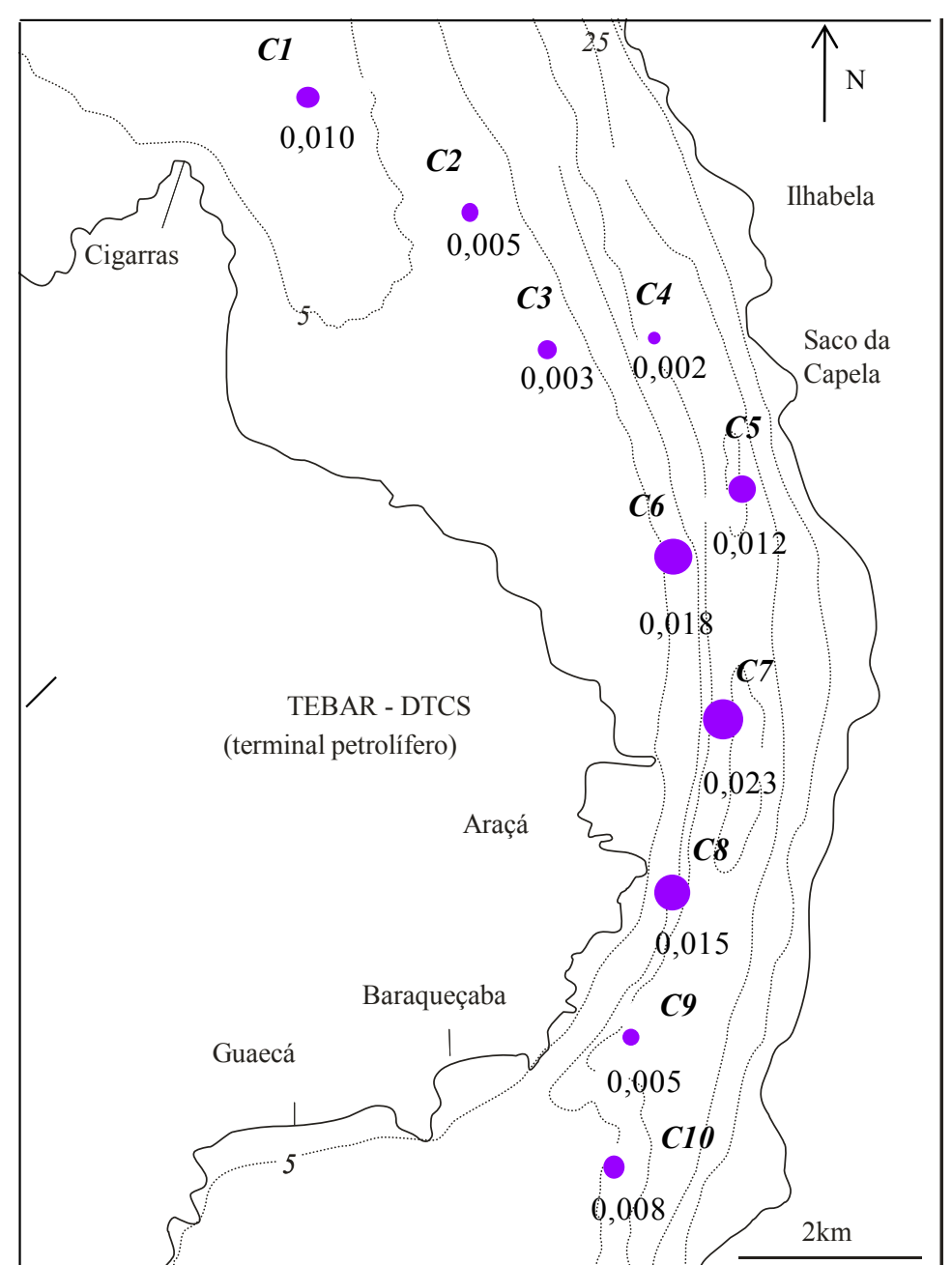

Fósforo inorgânico

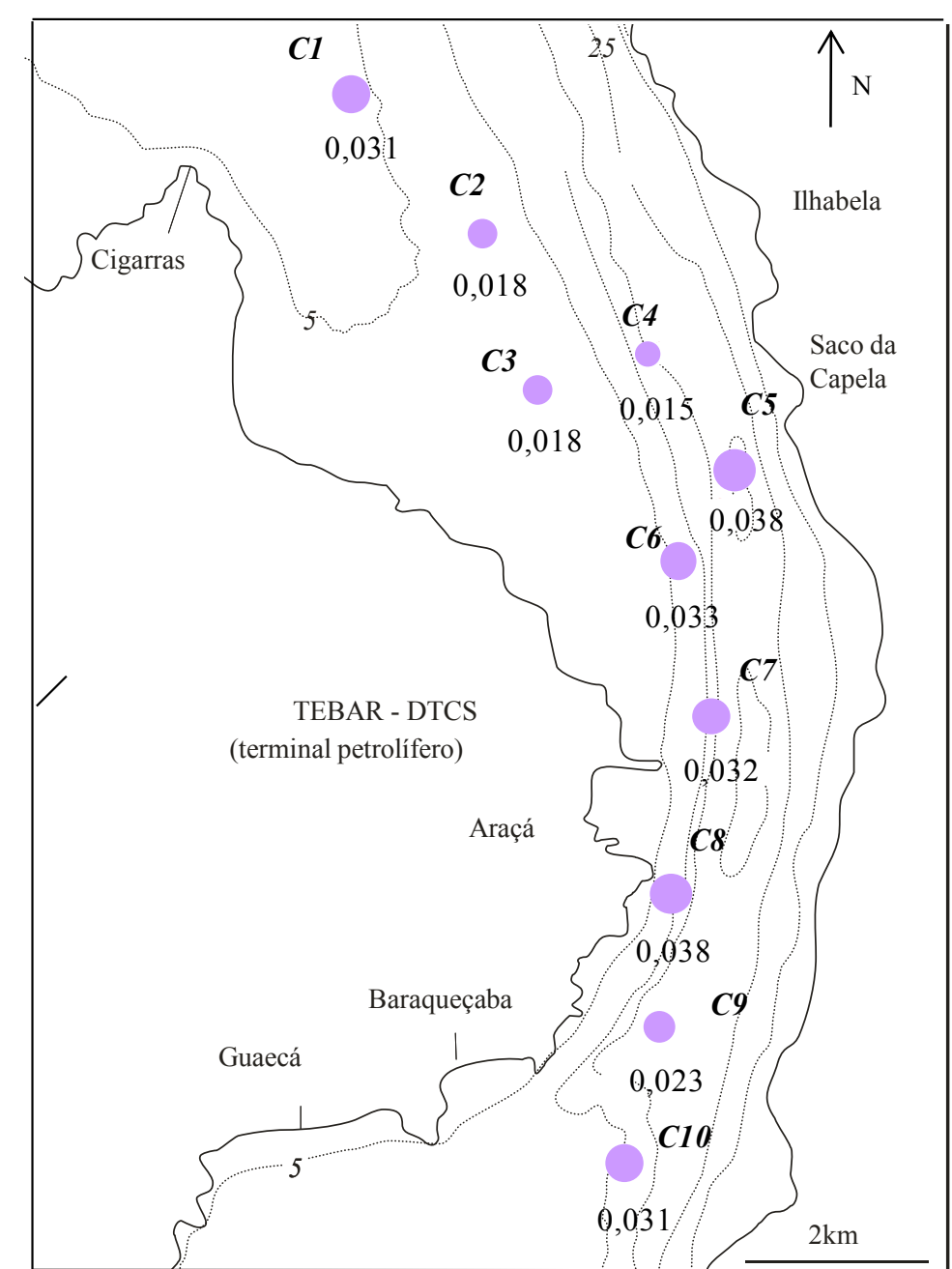


Anexo 04 - Teores de enxofre obtidas ao longo do Canal de São Sebastião.

Valores em porcentagem.

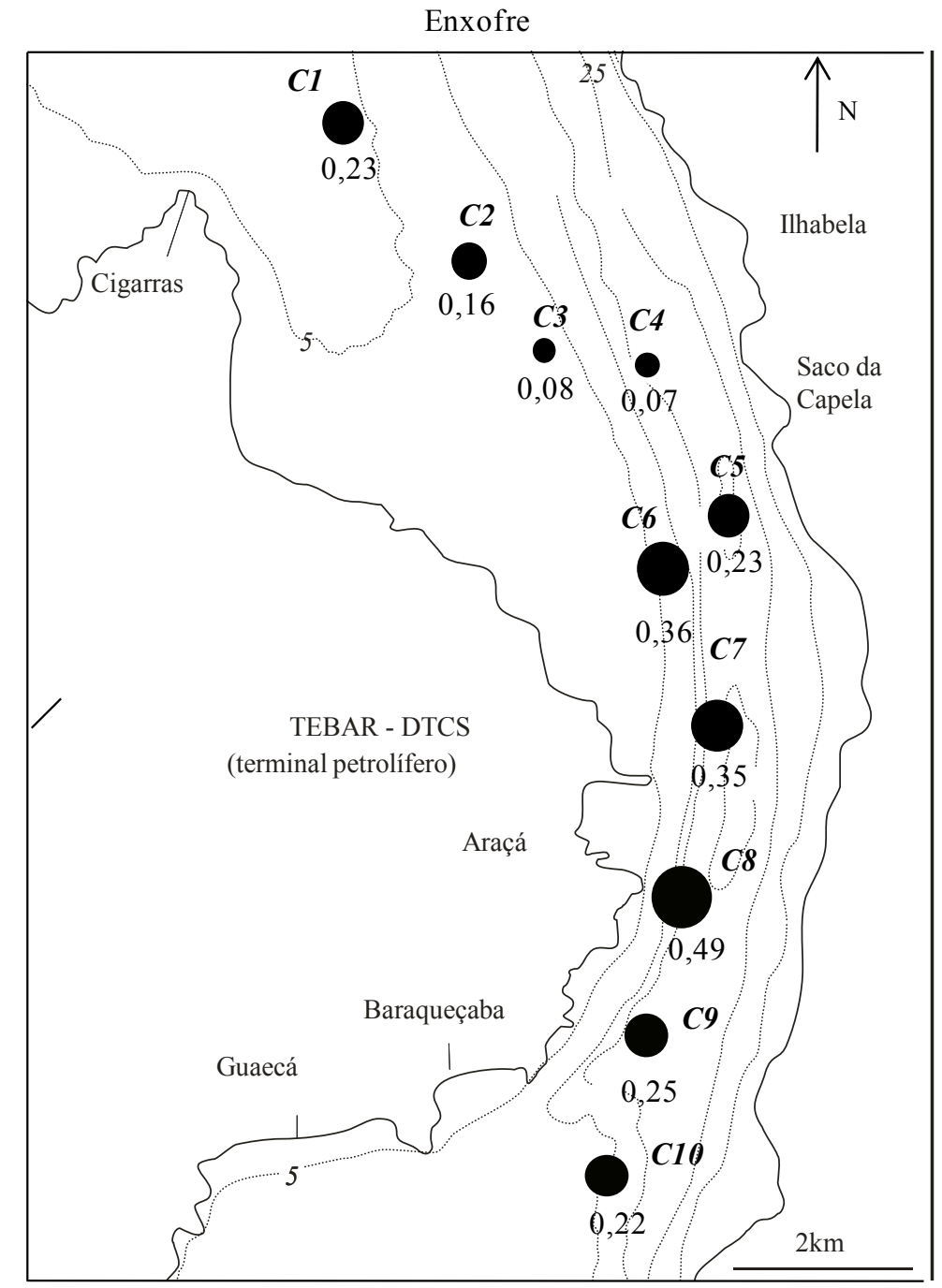


Anexo 05 - Origem da Matéria orgânica (razões C/N) e potencial de oxi-redução dos sedimentos amostrados ao longo do Canal de São Sebastião.

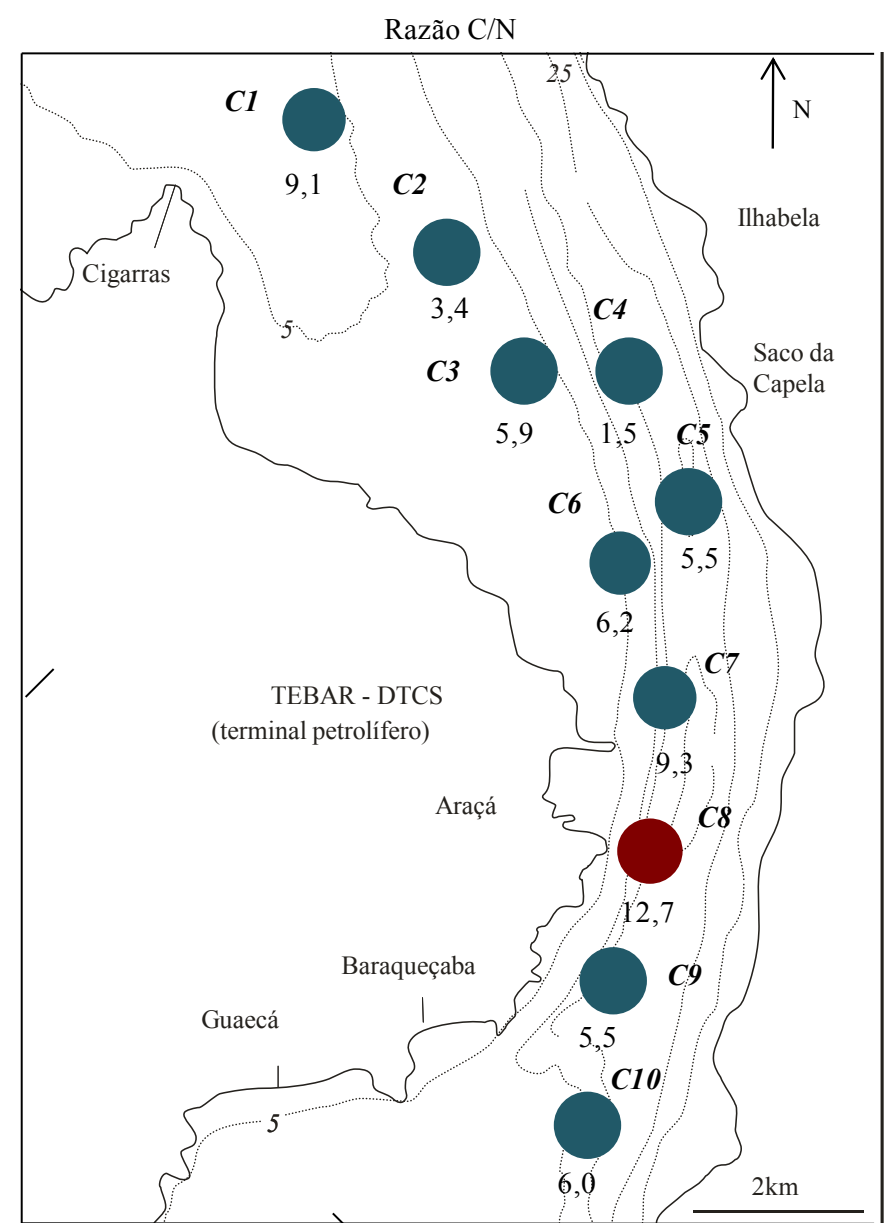

Matéria orgânica de origem marinha

Matéria orgânica de origem continental

Matéria orgânica de origem mista

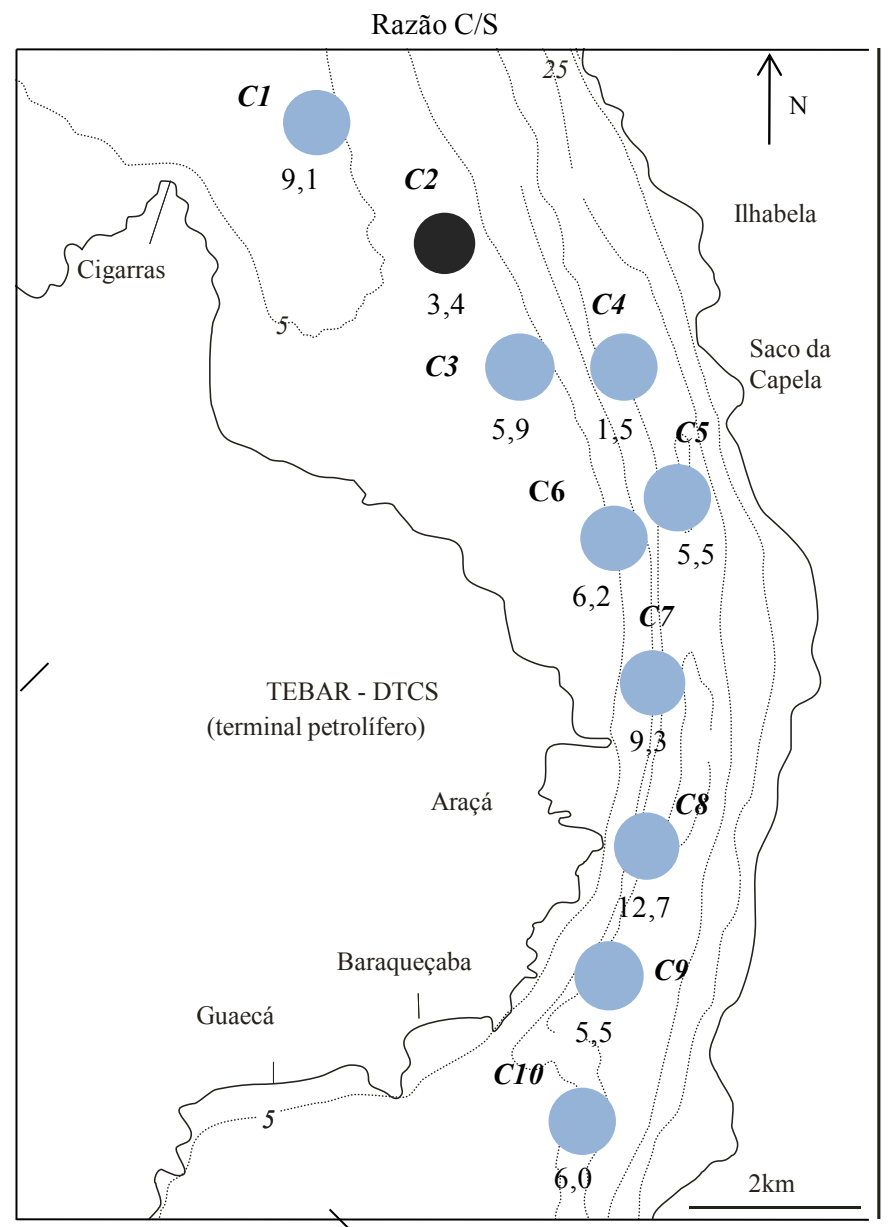

Ambiente óxico

Ambiente redutor

Ambiente com tendências redutoras 
Anexo 06 - Abundâncias relativas das espécies de foraminíferos identificadas ao longo do Canal de São Sebastião

\begin{tabular}{|c|c|c|c|c|c|c|c|c|c|c|c|c|c|c|c|c|c|c|c|c|}
\hline \multirow[b]{2}{*}{ Estações } & \multicolumn{10}{|c|}{ Biocenoses } & \multicolumn{10}{|c|}{ Tanatocenoses } \\
\hline & $\mathrm{C1}$ & $\mathrm{C2}$ & $\mathrm{C3}$ & $\mathrm{C4}$ & C5 & C6 & C7 & C8 & C9 & C10 & C1 & $\mathrm{C} 2$ & C3 & $\mathrm{C4}$ & C5 & C6 & $\mathrm{C} 7$ & C8 & C9 & $\mathbf{C 1 0}$ \\
\hline Centropyxis aculeata (tecameba) & 0,0 & 0,0 & 0,0 & 0,0 & 0,0 & 0,0 & 0,0 & 0,0 & 0,0 & 0,0 & 0,0 & 0,0 & 0,0 & 0,0 & 0,0 & 0,3 & 0,0 & 0,0 & 0,0 & 0,0 \\
\hline Adelosina mediterranensis & 0,0 & 0,0 & 0,0 & 0,0 & 0,0 & 0,0 & 0,0 & 0,0 & 0,0 & 0,0 & 0,0 & 0,0 & 0,0 & 0,4 & 0,0 & 0,0 & 0,0 & 0,0 & 0,0 & 0,0 \\
\hline Ammonia parkinsoniana & 19,6 & 17,3 & 16,2 & 4,7 & 2,0 & 15,2 & 2,0 & 13,6 & 10,5 & 14,2 & 6,4 & 6,4 & 8,9 & 2,9 & 3,3 & 5,9 & 1,4 & 3,6 & 1,5 & 1,5 \\
\hline Ammonia tepida & 56,1 & 39,4 & 42,5 & 5,5 & 7,1 & 37,5 & 16,2 & 22,0 & 23,2 & 26,4 & 12,2 & 16,5 & 15,8 & 7,2 & 5,8 & 15,3 & 9,4 & 11,6 & 3,5 & 5,0 \\
\hline Ammonia $\mathrm{sp}$ & 6,1 & 4,8 & 1,9 & 0,0 & 0,0 & 2,4 & 0,0 & 0,8 & 2,1 & 0,9 & 4,2 & 3,8 & 3,2 & 6,8 & 8,7 & 10,1 & 8,0 & 3,6 & 4,1 & 3,8 \\
\hline Ammoscalaria pseudospiralis & 0,0 & 0,0 & 0,4 & 0,0 & 0,0 & 0,0 & 0,0 & 0,0 & 0,0 & 0,9 & 0,0 & 0,0 & 0,0 & 0,0 & 0,0 & 0,0 & 0,0 & 0,0 & 0,0 & 0,0 \\
\hline Ammoscalaria $\mathrm{sp}$ & 0,7 & 1,9 & 0,0 & 0,0 & 0,0 & 0,0 & 0,0 & 0,0 & 0,0 & 0,0 & 0,0 & 0,0 & 0,0 & 0,0 & 0,0 & 0,0 & 0,0 & 0,0 & 0,0 & 0,0 \\
\hline Ammotium diversus & 0,0 & 0,0 & 0,4 & 0,0 & 0,0 & 0,0 & 0,0 & 0,0 & 0,0 & 0,0 & 0,0 & 0,0 & 0,0 & 0,0 & 0,0 & 0,0 & 0,0 & 0,0 & 0,0 & 0,0 \\
\hline Ammotium salsum & 0,0 & 0,0 & 0,4 & 0,8 & 2,0 & 0,0 & 0,0 & 0,8 & 0,0 & 0,9 & 0,0 & 0,0 & 0,0 & 0,4 & 0,7 & 0,3 & 0,3 & 0,0 & 0,0 & 0,3 \\
\hline Amphicoryna scalaris & 0,0 & 0,0 & 0,0 & 0,0 & 0,0 & 0,0 & 0,0 & 0,0 & 0,0 & 0,0 & 0,0 & 0,0 & 0,0 & 0,0 & 0,4 & 0,0 & 0,0 & 0,0 & 0,2 & 0,0 \\
\hline Angulogerina angulosa & 0,0 & 0,0 & 0,0 & 0,0 & 0,0 & 0,0 & 0,0 & 0,0 & 0,0 & 0,0 & 0,0 & 0,0 & 0,2 & 0,2 & 0,0 & 0,0 & 0,0 & 0,3 & 0,0 & 0,0 \\
\hline Angulogerina $\mathrm{sp}$ & 0,0 & 0,0 & 0,0 & 0,8 & 0,0 & 0,0 & 0,0 & 0,0 & 0,0 & 0,0 & 0,0 & 0,0 & 0,0 & 0,0 & 0,0 & 0,0 & 0,0 & 0,0 & 0,0 & 0,0 \\
\hline Astalacus crepidulus & 0,0 & 0,0 & 0,0 & 0,0 & 0,0 & 0,0 & 0,0 & 0,0 & 1,1 & 0,0 & 0,0 & 0,0 & 0,0 & 0,0 & 0,0 & 0,0 & 0,0 & 0,0 & 0,0 & 0,0 \\
\hline Asterigerinata mamilla & 0,0 & 0,0 & 0,0 & 0,0 & 0,0 & 0,0 & 0,0 & 0,0 & 0,0 & 0,0 & 0,0 & 0,0 & 0,0 & 0,2 & 0,0 & 0,0 & 0,0 & 0,0 & 0,0 & 0,0 \\
\hline Astrononion sp & 0,0 & 0,0 & 0,0 & 0,0 & 0,0 & 0,0 & 0,0 & 0,0 & 0,0 & 0,0 & 0,0 & 0,0 & 0,2 & 0,0 & 0,4 & 0,0 & 0,0 & 0,3 & 0,2 & 0,3 \\
\hline Bolivina alata & 0,0 & 0,0 & 0,0 & 0,0 & 0,0 & 0,3 & 0,0 & 0,0 & 0,0 & 0,0 & 0,0 & 0,0 & 0,0 & 0,0 & 0,0 & 0,0 & 0,0 & 0,0 & 0,0 & 0,0 \\
\hline Bolivina compacta & 0,7 & 1,9 & 4,1 & 0,0 & 0,0 & 1,7 & 4,0 & 0,8 & 2,1 & 0,0 & 0,0 & 0,3 & 0,2 & 0,0 & 0,4 & 0,3 & 0,6 & 0,3 & 0,0 & 0,0 \\
\hline Bolivina danvillensis & 0,7 & 0,0 & 0,0 & 0,0 & 0,0 & 0,0 & 1,0 & 1,7 & 0,0 & 0,0 & 1,0 & 0,8 & 0,2 & 0,2 & 0,4 & 0,0 & 0,3 & 0,3 & 0,0 & 0,3 \\
\hline Bolivina dilatata & 0,0 & 0,0 & 0,4 & 0,0 & 0,0 & 0,7 & 0,0 & 0,0 & 0,0 & 0,0 & 0,0 & 0,0 & 0,0 & 0,7 & 0,4 & 0,0 & 0,0 & 0,0 & 0,0 & 0,0 \\
\hline Bolivina doniezi & 2,7 & 1,0 & 0,8 & 0,0 & 0,0 & 1,0 & 2,0 & 0,8 & 0,0 & 3,8 & 1,3 & 1,1 & 0,5 & 0,2 & 1,1 & 1,4 & 1,1 & 0,9 & 0,0 & 1,0 \\
\hline Bolivina lowani & 0,0 & 0,0 & 0,0 & 0,8 & 0,0 & 0,0 & 5,1 & 3,3 & 0,0 & 0,9 & 0,0 & 0,0 & 0,0 & 0,4 & 0,0 & 0,0 & 0,9 & 0,3 & 0,0 & 0,0 \\
\hline Bolivina ordinaria & 0,0 & 1,0 & 1,5 & 3,9 & 3,1 & 3,0 & 4,0 & 3,4 & 1,1 & 0,9 & 0,6 & 0,8 & 0,7 & 0,4 & 1,1 & 0,3 & 0,6 & 0,6 & 0,2 & 0,3 \\
\hline Bolivina pulchella & 0,0 & 0,0 & 0,0 & 0,0 & 0,0 & 0,0 & 0,0 & 0,0 & 0,0 & 0,0 & 1,9 & 3,2 & 1,8 & 1,1 & 0,4 & 3,1 & 1,1 & 1,5 & 0,0 & 0,3 \\
\hline Bolivina sphatulata & 0,0 & 0,0 & 0,0 & 0,0 & 1,0 & 0,0 & 1,0 & 0,8 & 4,2 & 0,0 & 0,0 & 0,0 & 0,0 & 0,0 & 0,0 & 0,3 & 0,3 & 0,0 & 0,0 & 0,8 \\
\hline Bolivina translucens & 0,0 & 0,0 & 0,0 & 0,0 & 0,0 & 0,0 & 0,0 & 0,0 & 0,0 & 0,0 & 0,0 & 0,0 & 0,0 & 0,2 & 0,4 & 0,0 & 0,0 & 0,0 & 0,0 & 0,0 \\
\hline Bolivina variabilis & 0,0 & 0,0 & 0,0 & 0,0 & 0,0 & 0,0 & 0,0 & 0,0 & 0,0 & 0,0 & 0,0 & 0,0 & 0,0 & 0,0 & 0,0 & 0,0 & 0,0 & 0,6 & 0,4 & 0,5 \\
\hline Bolivina $\mathrm{sp}$ & 1,4 & 1,9 & 1,5 & 0,0 & 1,0 & 1,0 & 3,0 & 0,0 & 1,1 & 1,9 & 0,3 & 0,5 & 1,1 & 2,2 & 1,8 & 0,7 & 2,0 & 2,1 & 0,4 & 0,3 \\
\hline Bolivinellina pescicula & 0,0 & 0,0 & 0,0 & 0,8 & 0,0 & 0,0 & 2,0 & 0,0 & 1,1 & 0,0 & 0,0 & 0,0 & 0,0 & 0,2 & 0,0 & 0,0 & 0,0 & 0,0 & 0,0 & 0,0 \\
\hline Brizalina striatula & 2,0 & 7,7 & 7,9 & 0,8 & 7,1 & 5,7 & 8,1 & 3,4 & 11,6 & 10,4 & 1,9 & 1,6 & 1,6 & 1,5 & 0,7 & 1,4 & 0,6 & 3,0 & 1,7 & 2,3 \\
\hline Brizalina subaenariensis & 0,0 & 0,0 & 0,0 & 0,0 & 0,0 & 0,0 & 0,0 & 0,0 & 1,1 & 1,9 & 0,0 & 0,0 & 0,0 & 0,0 & 0,0 & 0,0 & 0,6 & 0,0 & 0,0 & 0,0 \\
\hline Brizalina variabilis & 0,0 & 0,0 & 0,0 & 0,0 & 0,0 & 0,0 & 0,0 & 0,0 & 0,0 & 0,0 & 0,0 & 0,0 & 0,0 & 0,2 & 0,0 & 0,0 & 0,0 & 0,0 & 0,0 & 0,0 \\
\hline Buccela peruviana f. campsi & 0,0 & 0,0 & 0,0 & 0,0 & 0,0 & 0,0 & 0,0 & 0,0 & 0,0 & 0,0 & 0,0 & 1,1 & 0,2 & 0,0 & 0,0 & 0,0 & 0,0 & 0,0 & 0,6 & 0,3 \\
\hline Buccella sp & 0,0 & 0,0 & 0,0 & 0,0 & 0,0 & 0,0 & 0,0 & 0,0 & 0,0 & 0,0 & 0,0 & 0,0 & 0,0 & 0,0 & 0,0 & 0,0 & 0,0 & 0,0 & 0,0 & 0,3 \\
\hline
\end{tabular}




\section{Anexo 06 - Continuação}

\begin{tabular}{|c|c|c|c|c|c|c|c|c|c|c|c|c|c|c|c|c|c|c|c|c|}
\hline \multirow[b]{2}{*}{ Estações } & \multicolumn{10}{|c|}{ Biocenoses } & \multicolumn{10}{|c|}{ Tanatocenoses } \\
\hline & C1 & $\mathrm{C} 2$ & C3 & $\mathbf{C 4}$ & C5 & C6 & $\mathbf{C 7}$ & C8 & C9 & C10 & $\mathrm{C} 1$ & $\mathrm{C} 2$ & $\mathbf{C 3}$ & $\mathrm{C} 4$ & C5 & C6 & C7 & $\mathbf{C 8}$ & C9 & $\mathrm{C} 10$ \\
\hline Bulimina marginata & 0,0 & 0,0 & 0,4 & 1,6 & 4,1 & 4,7 & 3,0 & 5,9 & 4,2 & 0,9 & 5,5 & 4,8 & 8,9 & 2,2 & 1,8 & 1,7 & 2,3 & 2,1 & 16,5 & 9,0 \\
\hline Bulimina pupoides & 0,0 & 0,0 & 0,0 & 0,0 & 0,0 & 0,0 & 0,0 & 0,0 & 0,0 & 0,0 & 1,0 & 0,8 & 0,0 & 0,0 & 0,0 & 0,0 & 0,0 & 0,0 & 0,2 & 0,0 \\
\hline Buliminella elongata & 0,0 & 0,0 & 0,4 & 0,0 & 0,0 & 0,3 & 0,0 & 0,0 & 1,1 & 0,0 & 0,0 & 0,0 & 0,0 & 0,2 & 0,4 & 0,0 & 0,0 & 0,0 & 0,0 & 1,8 \\
\hline Bulimina $\mathrm{sp}$ & 0,0 & 0,0 & 0,0 & 0,8 & 0,0 & 0,0 & 0,0 & 0,0 & 0,0 & 0,0 & 0,3 & 0,8 & 0,0 & 0,2 & 0,0 & 0,0 & 0,0 & 0,0 & 0,0 & 0,3 \\
\hline Buliminella elegantissima & 2,7 & 6,7 & 7,5 & 7,0 & 2,0 & 3,4 & 6,1 & 8,5 & 4,2 & 3,8 & 3,9 & 1,6 & 0,7 & 2,9 & 3,6 & 4,5 & 2,8 & 3,0 & 0,6 & 1,3 \\
\hline Blysmasphaera sp & 0,0 & 0,0 & 0,0 & 0,0 & 0,0 & 0,0 & 0,0 & 0,0 & 0,0 & 0,0 & 0,0 & 0,0 & 0,0 & 0,0 & 0,0 & 0,0 & 0,0 & 0,0 & 0,0 & 0,3 \\
\hline Cancris sagra & 0,0 & 0,0 & 0,0 & 0,0 & 1,0 & 0,0 & 0,0 & 0,0 & 1,1 & 0,0 & 0,0 & 0,0 & 0,0 & 0,0 & 0,0 & 0,0 & 0,0 & 0,0 & 0,0 & 0,0 \\
\hline Cassidulina laevigata & 0,0 & 0,0 & 0,0 & 2,3 & 0,0 & 0,0 & 0,0 & 0,0 & 0,0 & 0,0 & 0,0 & 0,0 & 0,0 & 0,9 & 1,8 & 0,3 & 0,3 & 0,3 & 0,0 & 0,5 \\
\hline Cassidulina minuta & 0,0 & 0,0 & 0,0 & 3,1 & 4,1 & 0,0 & 0,0 & 0,8 & 0,0 & 0,0 & 1,6 & 1,6 & 0,0 & 0,0 & 0,0 & 0,0 & 0,0 & 0,0 & 0,0 & 0,0 \\
\hline Cassidulina subglobosa & 0,0 & 0,0 & 0,0 & 7,0 & 10,2 & 0,0 & 1,0 & 0,8 & 3,2 & 0,9 & 0,0 & 0,0 & 0,9 & 1,5 & 3,3 & 2,1 & 3,1 & 1,2 & 2,2 & 2,8 \\
\hline Cassidulina sp & 0,7 & 0,0 & 0,0 & 0,0 & 0,0 & 0,3 & 0,0 & 0,8 & 0,0 & 0,0 & 0,3 & 0,8 & 0,0 & 0,2 & 0,0 & 0,7 & 0,6 & 0,3 & 0,2 & 0,0 \\
\hline Cibicides variabilis & 0,0 & 0,0 & 0,0 & 0,0 & 0,0 & 0,0 & 0,0 & 0,0 & 0,0 & 0,0 & 0,0 & 0,0 & 0,0 & 0,0 & 0,0 & 0,0 & 0,0 & 0,3 & 0,0 & 0,5 \\
\hline Cibicides sp & 0,0 & 0,0 & 0,0 & 0,0 & 0,0 & 0,0 & 1,0 & 0,0 & 0,0 & 0,0 & 0,0 & 0,0 & 0,0 & 0,7 & 0,4 & 0,0 & 0,0 & 0,0 & 0,0 & 0,3 \\
\hline Cornobella pateliformis & 0,0 & 0,0 & 0,0 & 0,0 & 0,0 & 0,0 & 0,0 & 0,0 & 0,0 & 0,0 & 0,0 & 0,0 & 0,2 & 0,0 & 0,4 & 0,7 & 0,0 & 0,0 & 0,0 & 0,0 \\
\hline Cribroelphidium advenum & 0,7 & 1,0 & 1,5 & 0,8 & 0,0 & 0,0 & 0,0 & 0,0 & 0,0 & 0,0 & 2,3 & 1,3 & 0,2 & 0,2 & 0,0 & 0,0 & 0,0 & 0,0 & 0,0 & 0,3 \\
\hline Cribroelphidium gunteri & 0,0 & 0,0 & 0,0 & 0,0 & 0,0 & 0,0 & 0,0 & 0,0 & 0,0 & 0,0 & 1,0 & 1,3 & 0,0 & 0,0 & 0,0 & 0,0 & 0,0 & 0,0 & 0,2 & 0,0 \\
\hline Cribroelphidium poyeanum & 0,7 & 0,0 & 0,8 & 0,8 & 0,0 & 0,0 & 0,0 & 0,0 & 0,0 & 0,0 & 3,5 & 2,7 & 6,6 & 1,5 & 1,4 & 0,7 & 0,6 & 1,2 & 2,8 & 1,8 \\
\hline Cribroelphidium sp & 0,0 & 0,0 & 0,0 & 0,0 & 0,0 & 0,0 & 0,0 & 0,0 & 0,0 & 0,0 & 3,2 & 2,4 & 0,7 & 1,1 & 1,1 & 0,7 & 1,7 & 1,2 & 0,6 & 0,3 \\
\hline Cribrostomoides jeffreysii & 0,0 & 0,0 & 0,0 & 1,6 & 1,0 & 0,0 & 0,0 & 0,8 & 0,0 & 0,9 & 0,0 & 0,0 & 0,0 & 0,4 & 0,0 & 0,0 & 0,0 & 0,0 & 0,2 & 0,0 \\
\hline Cribrostomoides sp & 0,7 & 0,0 & 0,0 & 0,8 & 0,0 & 0,0 & 0,0 & 0,0 & 0,0 & 0,0 & 0,0 & 0,0 & 0,0 & 0,0 & 0,0 & 0,0 & 0,0 & 0,0 & 0,0 & 0,0 \\
\hline Cycloforina $\mathrm{sp}$ & 0,0 & 0,0 & 0,0 & 0,0 & 0,0 & 0,0 & 0,0 & 0,0 & 0,0 & 0,0 & 0,0 & 0,0 & 0,0 & 0,0 & 0,0 & 0,0 & 0,0 & 0,0 & 0,2 & 0,0 \\
\hline Dentalina $\mathrm{sp}$ & 0,0 & 0,0 & 0,0 & 0,0 & 0,0 & 0,0 & 0,0 & 0,8 & 0,0 & 0,0 & 0,0 & 0,0 & 0,0 & 0,0 & 0,0 & 0,0 & 0,0 & 0,0 & 0,0 & 0,3 \\
\hline Deuteramina discorbis & 0,0 & 0,0 & 0,0 & 0,0 & 0,0 & 0,0 & 0,0 & 0,8 & 0,0 & 0,0 & 0,0 & 0,0 & 0,0 & 0,0 & 0,0 & 0,0 & 0,0 & 0,0 & 0,0 & 0,0 \\
\hline Discorbinela bertheloti & 0,0 & 0,0 & 0,8 & 0,0 & 2,0 & 0,0 & 0,0 & 0,0 & 0,0 & 0,0 & 0,0 & 0,0 & 0,0 & 0,2 & 0,0 & 0,0 & 0,0 & 0,0 & 0,9 & 0,0 \\
\hline Discorbis williamsoni & 0,0 & 0,0 & 0,0 & 0,0 & 0,0 & 0,0 & 0,0 & 0,0 & 0,0 & 0,0 & 1,3 & 1,1 & 1,8 & 0,4 & 0,7 & 0,7 & 1,1 & 1,5 & 0,9 & 1,5 \\
\hline Eggerela scabra & 0,0 & 0,0 & 0,0 & 4,7 & 1,0 & 0,0 & 0,0 & 0,0 & 0,0 & 1,9 & 0,0 & 0,0 & 0,0 & 1,5 & 0,4 & 0,7 & 1,4 & 0,0 & 0,0 & 0,3 \\
\hline Epistominella vitrea & 0,0 & 0,0 & 0,0 & 1,6 & 1,0 & 2,0 & 3,0 & 0,0 & 1,1 & 0,9 & 0,0 & 0,0 & 0,2 & 0,9 & 1,8 & 0,0 & 0,9 & 0,0 & 0,2 & 1,0 \\
\hline Eponides rapandus & 0,0 & 0,0 & 0,0 & 0,0 & 0,0 & 0,0 & 0,0 & 0,0 & 0,0 & 0,0 & 0,0 & 0,0 & 0,0 & 0,0 & 0,4 & 0,0 & 0,3 & 0,0 & 0,2 & 0,0 \\
\hline Fissurina laevigata & 0,0 & 1,0 & 0,0 & 0,0 & 0,0 & 0,0 & 0,0 & 0,0 & 0,0 & 0,0 & 1,3 & 1,1 & 0,0 & 0,0 & 0,0 & 0,0 & 0,0 & 0,9 & 0,2 & 1,5 \\
\hline
\end{tabular}




\section{Anexo 06 - Continuação}

\begin{tabular}{|c|c|c|c|c|c|c|c|c|c|c|c|c|c|c|c|c|c|c|c|c|}
\hline \multirow[b]{2}{*}{ Estações } & \multicolumn{10}{|c|}{ Biocenoses } & \multicolumn{10}{|c|}{ Tanatocenoses } \\
\hline & $\mathrm{C} 1$ & C2 & $\mathrm{C3}$ & $\mathrm{C} 4$ & C5 & C6 & C7 & C8 & C9 & C10 & C1 & $\mathrm{C} 2$ & C3 & $\mathrm{C} 4$ & C5 & C6 & C7 & C8 & C9 & C10 \\
\hline Fissurina lucida & 0,0 & 0,0 & 0,0 & 0,0 & 2,0 & 0,0 & 0,0 & 0,0 & 0,0 & 0,9 & 0,0 & 0,0 & 0,2 & 1,1 & 0,0 & 2,1 & 0,0 & 0,0 & 0,6 & 0,0 \\
\hline Fissurina sp & 0,0 & 0,0 & 0,0 & 0,0 & 0,0 & 0,0 & 0,0 & 0,0 & 0,0 & 0,0 & 0,0 & 0,3 & 0,0 & 0,0 & 0,0 & 0,0 & 0,0 & 0,0 & 0,0 & 0,0 \\
\hline Fissuripolimorphina williansoni & 0,0 & 0,0 & 0,0 & 0,0 & 0,0 & 0,3 & 0,0 & 0,0 & 0,0 & 0,0 & 0,0 & 0,0 & 0,0 & 0,0 & 0,0 & 0,0 & 0,0 & 0,3 & 0,0 & 0,0 \\
\hline Fursenkoina acuta & 0,0 & 0,0 & 0,0 & 0,0 & 0,0 & 0,0 & 0,0 & 0,0 & 0,0 & 0,0 & 0,0 & 0,0 & 0,0 & 0,0 & 0,0 & 0,0 & 0,0 & 0,3 & 0,0 & 0,0 \\
\hline Fursenkoina fragilis & 0,0 & 0,0 & 0,0 & 0,0 & 0,0 & 2,4 & 6,1 & 8,5 & 0,0 & 0,0 & 0,0 & 0,0 & 0,0 & 0,0 & 0,0 & 0,3 & 0,6 & 0,0 & 0,0 & 0,3 \\
\hline Fursenkoina pontoni & 0,0 & 0,0 & 0,0 & 0,8 & 0,0 & 1,0 & 0,0 & 0,0 & 1,1 & 0,0 & 0,0 & 0,0 & 0,2 & 0,7 & 0,0 & 1,0 & 0,6 & 0,3 & 0,6 & 0,3 \\
\hline Fursenkoina nodosa & 0,0 & 0,0 & 0,0 & 0,0 & 0,0 & 0,0 & 0,0 & 0,0 & 0,0 & 0,0 & 0,0 & 0,0 & 0,0 & 0,0 & 0,0 & 0,0 & 0,6 & 0,0 & 0,0 & 0,0 \\
\hline Gaudryina exilis & 0,0 & 0,0 & 0,4 & 0,0 & 0,0 & 1,0 & 0,0 & 0,0 & 0,0 & 0,9 & 0,0 & 0,8 & 0,2 & 0,9 & 0,7 & 0,3 & 0,3 & 0,0 & 0,0 & 0,0 \\
\hline Gavelinolepsis praegeri & 0,0 & 0,0 & 0,0 & 5,5 & 3,1 & 0,0 & 0,0 & 1,7 & 0,0 & 0,0 & 0,0 & 0,0 & 0,2 & 2,2 & 1,8 & 0,3 & 1,7 & 2,7 & 1,3 & 1,8 \\
\hline Globigerinoides ruber & 0,0 & 0,0 & 0,0 & 0,0 & 0,0 & 0,0 & 0,0 & 0,0 & 0,0 & 0,0 & 0,0 & 0,0 & 0,0 & 0,0 & 0,7 & 0,3 & 0,3 & 0,0 & 0,4 & 0,3 \\
\hline Globorotalia compressa & 0,0 & 0,0 & 0,0 & 0,0 & 0,0 & 0,0 & 0,0 & 0,0 & 0,0 & 0,0 & 0,0 & 0,0 & 0,0 & 0,7 & 0,0 & 0,3 & 0,3 & 0,3 & 0,2 & 0,5 \\
\hline Gutulina lactea & 0,0 & 0,0 & 0,0 & 0,0 & 1,0 & 0,0 & 0,0 & 0,0 & 0,0 & 0,0 & 0,0 & 0,0 & 0,0 & 0,0 & 0,0 & 0,0 & 0,0 & 0,0 & 0,0 & 0,0 \\
\hline Hanzawaia boueana & 0,0 & 0,0 & 0,0 & 3,1 & 5,1 & 0,3 & 1,0 & 0,0 & 1,1 & 0,9 & 0,6 & 0,8 & 1,6 & 2,6 & 2,2 & 1,0 & 1,1 & 0,9 & 5,4 & 3,0 \\
\hline Haynesina depressula & 0,0 & 0,0 & 0,0 & 0,0 & 0,0 & 0,0 & 0,0 & 0,0 & 0,0 & 0,0 & 0,0 & 0,0 & 0,0 & 0,0 & 0,0 & 1,0 & 0,0 & 0,9 & 0,2 & 0,3 \\
\hline Haynesina germanica & 0,0 & 0,0 & 1,1 & 0,0 & 0,0 & 1,0 & 0,0 & 0,8 & 0,0 & 0,0 & 0,0 & 0,0 & 0,9 & 0,9 & 1,8 & 0,7 & 0,6 & 0,9 & 0,9 & 1,5 \\
\hline Lagena striata & 0,0 & 0,0 & 0,0 & 0,0 & 0,0 & 0,0 & 1,0 & 0,0 & 0,0 & 1,9 & 0,0 & 0,0 & 0,0 & 0,0 & 0,0 & 0,0 & 0,0 & 0,0 & 0,6 & 0,0 \\
\hline Lenticulina gibba & 0,0 & 0,0 & 0,0 & 0,0 & 0,0 & 0,0 & 0,0 & 0,0 & 0,0 & 0,9 & 0,0 & 0,0 & 0,0 & 0,0 & 0,7 & 0,0 & 0,0 & 0,3 & 0,0 & 0,0 \\
\hline Lenticulina $\mathrm{sp}$ & 0,0 & 0,0 & 0,0 & 0,0 & 1,0 & 0,0 & 0,0 & 0,0 & 0,0 & 0,0 & 0,0 & 0,0 & 0,0 & 0,7 & 0,7 & 0,0 & 0,0 & 0,0 & 0,2 & 0,3 \\
\hline Lepdoteuramina ochracea & 0,0 & 0,0 & 0,0 & 2,3 & 0,0 & 0,0 & 0,0 & 0,8 & 0,0 & 0,0 & 0,0 & 0,0 & 0,0 & 0,0 & 0,4 & 0,0 & 0,3 & 0,0 & 0,2 & 0,0 \\
\hline Leptohalisis catela & 0,0 & 0,0 & 0,4 & 0,8 & 1,0 & 0,0 & 0,0 & 0,0 & 1,1 & 0,0 & 0,0 & 0,0 & 0,5 & 0,2 & 0,0 & 0,0 & 0,0 & 0,0 & 0,0 & 0,0 \\
\hline Lobatula lobatula & 0,0 & 0,0 & 0,0 & 3,9 & 5,1 & 0,0 & 0,0 & 0,8 & 0,0 & 0,0 & 0,0 & 0,0 & 0,0 & 1,1 & 2,9 & 0,3 & 1,7 & 0,3 & 0,2 & 1,0 \\
\hline Miliolinella subrotunda & 0,0 & 0,0 & 0,0 & 0,0 & 0,0 & 0,0 & 0,0 & 0,0 & 0,0 & 0,0 & 0,0 & 0,0 & 0,0 & 0,2 & 0,4 & 0,0 & 0,6 & 0,9 & 0,4 & 0,3 \\
\hline Miliolinella $\mathrm{sp}$ & 0,0 & 0,0 & 0,0 & 0,0 & 0,0 & 0,0 & 0,0 & 0,0 & 0,0 & 0,0 & 0,0 & 0,0 & 0,0 & 0,0 & 0,0 & 0,0 & 0,0 & 0,0 & 0,2 & 0,3 \\
\hline Neocornobina marginata & 0,0 & 0,0 & 0,4 & 1,6 & 1,0 & 0,3 & 1,0 & 0,0 & 0,0 & 0,9 & 0,0 & 0,0 & 0,0 & 0,2 & 0,0 & 0,3 & 0,3 & 0,0 & 0,0 & 0,3 \\
\hline Neocornobina terquemi & 0,0 & 0,0 & 2,3 & 0,0 & 0,0 & 0,0 & 1,0 & 0,0 & 1,1 & 0,0 & 0,0 & 0,0 & 0,2 & 0,7 & 0,4 & 0,0 & 0,6 & 0,3 & 0,0 & 0,3 \\
\hline Neoeponides bradyi & 0,0 & 0,0 & 0,0 & 0,0 & 0,0 & 0,0 & 0,0 & 0,0 & 0,0 & 0,0 & 0,0 & 0,0 & 0,5 & 0,0 & 0,4 & 0,0 & 0,0 & 0,3 & 0,0 & 0,0 \\
\hline Oolina $\mathrm{sp}$ & 0,0 & 1,0 & 0,0 & 0,0 & 0,0 & 0,0 & 0,0 & 0,0 & 0,0 & 0,0 & 0,0 & 0,0 & 0,0 & 0,0 & 0,0 & 0,0 & 0,0 & 0,0 & 0,0 & 0,0 \\
\hline Patelina corrugata & 0,0 & 0,0 & 0,0 & 0,0 & 1,0 & 0,0 & 0,0 & 0,8 & 0,0 & 0,0 & 0,0 & 0,0 & 0,0 & 0,0 & 0,4 & 0,0 & 0,0 & 0,0 & 0,0 & 0,0 \\
\hline Patelinella cf. P. lanzawai & 0,0 & 0,0 & 0,0 & 0,0 & 0,0 & 0,0 & 0,0 & 0,0 & 0,0 & 0,0 & 0,0 & 0,0 & 0,0 & 0,2 & 0,0 & 0,0 & 0,0 & 0,0 & 0,0 & 0,0 \\
\hline Pararotalia cananeiaensis & 0,0 & 3,8 & 0,0 & 0,0 & 0,0 & 0,0 & 0,0 & 0,0 & 0,0 & 0,0 & 32,5 & 35,1 & 16,9 & 18,0 & 13,4 & 18,1 & 19,4 & 27,5 & 13,0 & 17,0 \\
\hline
\end{tabular}




\begin{tabular}{|c|c|c|c|c|c|c|c|c|c|c|c|c|c|c|c|c|c|c|c|c|}
\hline \multirow{3}{*}{$\begin{array}{l}\text { Anexo } 06 \text { - Continuação } \\
\text { Estações }\end{array}$} & & & & & & & & & & & & & & & & & & & & \\
\hline & \multicolumn{10}{|c|}{ Biocenoses } & \multicolumn{10}{|c|}{ Tanatocenoses } \\
\hline & $\mathrm{C1}$ & $\mathbf{C 2}$ & $\mathbf{C 3}$ & $\mathrm{C4}$ & $\mathrm{C5}$ & C6 & C7 & C8 & C9 & $\mathrm{C10}$ & $\mathbf{C 1}$ & $\mathrm{C2}$ & C3 & $\mathrm{C4}$ & $\mathbf{C 5}$ & C6 & C7 & C8 & C9 & $\mathrm{C10}$ \\
\hline Paratrochammina clossi & 0,0 & 0,0 & 0,0 & 0,0 & 0,0 & 0,0 & 0,0 & 0,0 & 0,0 & 0,0 & 0,0 & 0,0 & 0,0 & 0,2 & 0,0 & 0,0 & 0,0 & 0,0 & 0,0 & 0,0 \\
\hline Poroeponides lateralis & 0,0 & 0,0 & 0,0 & 0,0 & 0,0 & 0,0 & 0,0 & 0,0 & 0,0 & 0,0 & 0,0 & 0,0 & 0,0 & 0,4 & 0,7 & 0,0 & 0,0 & 0,0 & 0,0 & 0,0 \\
\hline Protochista findens & 0,0 & 0,0 & 0,4 & 0,0 & 0,0 & 0,3 & 0,0 & 0,0 & 0,0 & 0,0 & 0,0 & 0,0 & 0,0 & 0,2 & 0,7 & 0,0 & 0,3 & 0,0 & 0,2 & 0,3 \\
\hline Pseudononion atlanticum & 2,0 & 5,8 & 1,5 & 0,0 & 1,0 & 2,0 & 3,0 & 0,8 & 2,1 & 1,9 & 4,2 & 1,3 & 2,1 & 2,0 & 3,6 & 3,1 & 1,7 & 5,4 & 7,6 & 5,0 \\
\hline Pseudononion grateloupi & 0,0 & 0,0 & 0,0 & 0,8 & 0,0 & 1,0 & 0,0 & 0,0 & 0,0 & 0,0 & 0,0 & 0,0 & 0,9 & 0,9 & 0,0 & 0,3 & 1,1 & 1,5 & 2,6 & 2,5 \\
\hline Pseudononion opima & 0,0 & 0,0 & 0,0 & 2,3 & 2,0 & 5,7 & 9,1 & 4,2 & 6,3 & 1,9 & 0,0 & 0,0 & 0,2 & 0,4 & 0,0 & 0,7 & 2,3 & 0,3 & 2,6 & 3,3 \\
\hline Pseudononion sp & 0,0 & 0,0 & 0,4 & 0,0 & 1,0 & 2,4 & 1,0 & 0,8 & 0,0 & 0,0 & 0,3 & 0,3 & 0,9 & 1,8 & 2,5 & 1,7 & 2,0 & 0,0 & 1,7 & 2,0 \\
\hline Pseudoclavulina curta & 0,0 & 0,0 & 0,0 & 0,0 & 0,0 & 0,0 & 0,0 & 0,0 & 0,0 & 0,0 & 0,0 & 0,0 & 0,0 & 0,0 & 0,0 & 0,0 & 0,6 & 0,0 & 0,2 & 0,0 \\
\hline Pyrgo nasuta & 0,0 & 0,0 & 0,0 & 0,0 & 0,0 & 0,0 & 0,0 & 0,0 & 0,0 & 0,0 & 0,0 & 0,0 & 0,0 & 0,0 & 0,0 & 0,0 & 0,0 & 0,0 & 0,0 & 0,3 \\
\hline Pyrgo ringens & 0,0 & 0,0 & 0,0 & 0,0 & 0,0 & 0,0 & 0,0 & 0,0 & 0,0 & 0,0 & 0,0 & 0,0 & 0,0 & 0,0 & 0,0 & 0,0 & 0,0 & 0,0 & 0,2 & 0,0 \\
\hline Pyrgo subsphaerica & 0,0 & 0,0 & 0,0 & 0,0 & 0,0 & 0,0 & 0,0 & 0,0 & 0,0 & 0,0 & 0,0 & 0,0 & 0,0 & 0,0 & 0,0 & 0,0 & 0,0 & 0,0 & 0,0 & 0,3 \\
\hline Quinqueloculina atlantica & 0,0 & 0,0 & 0,0 & 0,0 & 0,0 & 0,0 & 0,0 & 0,0 & 0,0 & 0,0 & 0,0 & 0,0 & 0,0 & 0,0 & 0,4 & 0,0 & 0,6 & 0,0 & 0,0 & 0,0 \\
\hline Quinqueloculina horrida & 0,0 & 0,0 & 0,0 & 0,0 & 0,0 & 0,0 & 0,0 & 0,0 & 0,0 & 0,0 & 0,0 & 0,0 & 0,0 & 0,0 & 0,0 & 0,0 & 0,0 & 0,0 & 1,5 & 0,8 \\
\hline Quinqueloculina lamarckiana & 0,0 & 0,0 & 0,0 & 0,0 & 0,0 & 0,0 & 0,0 & 0,0 & 0,0 & 0,0 & 0,0 & 0,0 & 0,0 & 0,0 & 0,0 & 0,0 & 0,0 & 0,0 & 1,5 & 0,5 \\
\hline Quinqueloculina seminula & 0,0 & 0,0 & 0,0 & 0,0 & 0,0 & 0,0 & 0,0 & 0,0 & 0,0 & 0,0 & 0,0 & 0,0 & 0,0 & 0,2 & 0,0 & 0,0 & 0,0 & 0,0 & 0,2 & 0,0 \\
\hline Quinqueloculia stalkeri & 0,0 & 0,0 & 0,0 & 0,0 & 0,0 & 0,0 & 0,0 & 0,0 & 0,0 & 0,0 & 0,0 & 0,0 & 0,0 & 0,0 & 0,0 & 0,0 & 0,0 & 0,0 & 0,0 & 0,3 \\
\hline Quinqueloculina sp & 0,0 & 0,0 & 0,0 & 0,0 & 0,0 & 0,0 & 0,0 & 0,0 & 0,0 & 0,0 & 0,0 & 0,0 & 0,5 & 0,7 & 0,0 & 0,0 & 0,3 & 0,0 & 1,1 & 0,0 \\
\hline Reophax scorpiurus & 0,0 & 0,0 & 0,0 & 0,0 & 0,0 & 0,3 & 0,0 & 0,0 & 0,0 & 0,0 & 0,0 & 0,0 & 0,9 & 0,7 & 0,7 & 0,0 & 0,3 & 0,3 & 0,0 & 0,3 \\
\hline Reophax sp & 0,0 & 0,0 & 0,0 & 0,0 & 0,0 & 0,0 & 0,0 & 0,0 & 0,0 & 0,0 & 0,0 & 0,0 & 0,5 & 0,7 & 0,4 & 0,3 & 0,0 & 0,3 & 0,0 & 0,0 \\
\hline Rolshauseni rolshauseni & 0,0 & 0,0 & 0,0 & 0,0 & 0,0 & 0,0 & 0,0 & 0,0 & 0,0 & 0,0 & 0,3 & 0,3 & 0,2 & 0,2 & 0,0 & 0,0 & 0,0 & 0,0 & 2,8 & 2,8 \\
\hline Rosalina floridensis & 0,0 & 0,0 & 0,0 & 2,3 & 6,1 & 0,0 & 3,0 & 0,8 & 2,1 & 0,0 & 0,0 & 0,0 & 0,2 & 1,5 & 1,8 & 1,4 & 0,0 & 1,2 & 0,6 & 0,5 \\
\hline Rosalina bradyi & 0,0 & 0,0 & 0,0 & 0,0 & 0,0 & 0,0 & 0,0 & 0,8 & 1,1 & 0,0 & 0,0 & 0,0 & 0,0 & 0,0 & 0,0 & 0,0 & 0,0 & 0,0 & 0,0 & 0,0 \\
\hline Rosalina orientalis & 0,0 & 0,0 & 0,0 & 0,0 & 0,0 & 0,0 & 0,0 & 0,0 & 0,0 & 0,0 & 0,0 & 0,0 & 0,0 & 0,0 & 0,0 & 0,0 & 0,0 & 0,0 & 0,0 & 0,3 \\
\hline Rosalina vilardeboana & 0,0 & 0,0 & 0,8 & 0,0 & 0,0 & 0,0 & 0,0 & 0,0 & 1,1 & 0,0 & 0,0 & 0,0 & 0,0 & 0,0 & 0,0 & 0,0 & 0,0 & 0,0 & 0,0 & 0,3 \\
\hline Rosalina $\mathrm{sp}$ & 0,0 & 0,0 & 0,4 & 0,0 & 0,0 & 0,0 & 1,0 & 0,0 & 1,1 & 1,9 & 0,0 & 0,0 & 0,0 & 1,1 & 0,0 & 0,0 & 0,0 & 0,0 & 0,0 & 0,0 \\
\hline Sigmoilopsis minuta & 0,0 & 0,0 & 0,0 & 0,0 & 1,0 & 0,0 & 0,0 & 0,8 & 0,0 & 0,0 & 0,0 & 0,0 & 0,0 & 0,0 & 0,0 & 0,0 & 0,0 & 0,0 & 0,0 & 0,0 \\
\hline Sigmoilopsis schlumbergeri & 0,0 & 0,0 & 0,0 & 1,6 & 0,0 & 0,0 & 0,0 & 0,0 & 0,0 & 0,0 & 0,0 & 0,0 & 0,0 & 0,0 & 1,1 & 0,0 & 0,3 & 0,0 & 0,2 & 0,0 \\
\hline Spirilina vivipara & 0,0 & 0,0 & 0,0 & 0,0 & 0,0 & 0,0 & 0,0 & 0,0 & 0,0 & 0,0 & 0,0 & 0,0 & 0,0 & 0,0 & 0,0 & 0,0 & 0,0 & 0,3 & 0,0 & 0,0 \\
\hline Spirobolivina sp & 0,0 & 0,0 & 0,4 & 0,8 & 0,0 & 0,0 & 0,0 & 0,0 & 0,0 & 0,0 & 0,0 & 0,0 & 0,0 & 0,2 & 0,0 & 0,0 & 0,0 & 0,0 & 0,2 & 0,0 \\
\hline Spiroloculina antillarium & 0,0 & 0,0 & 0,0 & 0,0 & 0,0 & 0,0 & 0,0 & 0,0 & 0,0 & 0,0 & 0,0 & 0,0 & 0,0 & 0,0 & 0,4 & 0,0 & 0,0 & 0,0 & 0,0 & 0,0 \\
\hline
\end{tabular}




\section{Anexo 06 - Continuação}

\begin{tabular}{|c|c|c|c|c|c|c|c|c|c|c|c|c|c|c|c|c|c|c|c|c|}
\hline \multirow[b]{2}{*}{ Estações } & \multicolumn{10}{|c|}{ Biocenoses } & \multicolumn{10}{|c|}{ Tanatocenoses } \\
\hline & C1 & $\mathrm{C2}$ & $\mathrm{C3}$ & $\mathrm{C4}$ & C5 & C6 & C7 & C8 & C9 & C10 & C1 & $\mathrm{C2}$ & $\mathrm{C3}$ & $\mathrm{C4}$ & C5 & C6 & C7 & C8 & C9 & C10 \\
\hline Spiroloculina $\mathrm{sp}$ & 0,0 & 0,0 & 0,0 & 0,0 & 0,0 & 0,0 & 0,0 & 0,0 & 0,0 & 0,0 & 0,0 & 0,0 & 0,0 & 0,0 & 0,0 & 0,0 & 0,3 & 0,0 & 0,0 & 0,0 \\
\hline Stainforthia concava & 0,0 & 0,0 & 0,0 & 0,0 & 0,0 & 0,0 & 1,0 & 0,0 & 0,0 & 0,9 & 0,0 & 0,0 & 0,2 & 0,2 & 0,0 & 0,0 & 0,3 & 0,0 & 0,9 & 0,5 \\
\hline Stainforthia fusiformis & 0,0 & 0,0 & 0,0 & 0,0 & 0,0 & 0,0 & 0,0 & 0,0 & 0,0 & 0,0 & 0,0 & 0,0 & 0,0 & 0,0 & 0,0 & 0,0 & 0,3 & 0,0 & 0,0 & 0,0 \\
\hline Textularia aglutinans & 0,0 & 0,0 & 0,0 & 0,0 & 0,0 & 0,0 & 0,0 & 0,0 & 0,0 & 0,0 & 0,0 & 0,0 & 0,0 & 0,2 & 0,0 & 0,3 & 0,3 & 0,0 & 0,0 & 0,0 \\
\hline Textularia candeiana & 0,0 & 0,0 & 0,0 & 0,0 & 0,0 & 0,0 & 0,0 & 0,0 & 1,1 & 0,0 & 0,0 & 0,0 & 0,0 & 0,0 & 0,0 & 0,0 & 0,0 & 0,0 & 0,2 & 0,0 \\
\hline Textularia earlandi & 0,7 & 0,0 & 0,0 & 0,0 & 0,0 & 0,0 & 0,0 & 0,0 & 0,0 & 0,0 & 0,0 & 0,0 & 0,0 & 0,0 & 0,0 & 0,0 & 0,3 & 0,0 & 0,0 & 0,0 \\
\hline Textularia foliacea & 0,0 & 0,0 & 0,0 & 0,0 & 0,0 & 0,0 & 0,0 & 0,0 & 0,0 & 0,0 & 0,0 & 0,0 & 0,0 & 0,2 & 0,0 & 0,0 & 0,0 & 0,0 & 0,0 & 0,0 \\
\hline Textularia gramen & 0,0 & 0,0 & 0,0 & 0,0 & 2,0 & 0,0 & 0,0 & 0,0 & 0,0 & 0,0 & 0,0 & 0,0 & 0,0 & 0,7 & 0,0 & 0,0 & 0,0 & 0,0 & 0,0 & 0,0 \\
\hline Textularia $\mathrm{sp}$ & 0,7 & 1,0 & 0,0 & 1,6 & 0,0 & 0,0 & 0,0 & 0,0 & 0,0 & 0,0 & 0,0 & 0,3 & 0,2 & 0,2 & 0,0 & 0,0 & 0,6 & 0,0 & 0,0 & 0,5 \\
\hline Tiphotrocha sp & 0,0 & 0,0 & 0,0 & 0,0 & 0,0 & 0,0 & 0,0 & 0,0 & 0,0 & 0,9 & 0,0 & 0,0 & 0,0 & 0,0 & 0,0 & 0,0 & 0,0 & 0,0 & 0,0 & 0,0 \\
\hline Triloculina baldai & 0,0 & 0,0 & 0,0 & 0,0 & 0,0 & 0,0 & 0,0 & 0,0 & 0,0 & 0,0 & 0,0 & 0,0 & 0,0 & 1,3 & 0,4 & 0,0 & 0,0 & 0,0 & 0,0 & 0,3 \\
\hline Triloculina cultrata & 0,0 & 0,0 & 0,0 & 0,0 & 0,0 & 0,0 & 0,0 & 0,0 & 0,0 & 0,0 & 0,0 & 0,0 & 0,0 & 0,0 & 0,4 & 0,0 & 0,0 & 0,0 & 0,0 & 0,0 \\
\hline Triloculina laevigata & 0,0 & 0,0 & 0,0 & 0,0 & 0,0 & 0,0 & 0,0 & 0,0 & 0,0 & 0,0 & 0,0 & 0,0 & 0,0 & 0,2 & 0,0 & 0,0 & 0,0 & 0,3 & 0,0 & 0,0 \\
\hline Triloculina oblonga & 0,0 & 0,0 & 0,0 & 0,0 & 0,0 & 0,0 & 0,0 & 0,0 & 0,0 & 0,0 & 0,0 & 0,0 & 0,0 & 0,2 & 0,0 & 0,0 & 0,3 & 0,3 & 0,2 & 0,0 \\
\hline Trochammina inflata & 0,0 & 0,0 & 0,0 & 0,0 & 0,0 & 0,0 & 0,0 & 0,0 & 0,0 & 0,0 & 0,0 & 0,0 & 0,0 & 0,0 & 0,4 & 0,0 & 0,0 & 0,0 & 0,0 & 0,0 \\
\hline Trochammina ochracea & 0,0 & 0,0 & 0,0 & 0,0 & 0,0 & 0,3 & 0,0 & 0,0 & 0,0 & 0,0 & 0,0 & 0,0 & 0,0 & 0,2 & 0,4 & 0,0 & 0,0 & 0,0 & 0,2 & 0,0 \\
\hline Trochammina squamata & 0,0 & 0,0 & 0,0 & 0,0 & 0,0 & 0,0 & 1,0 & 0,0 & 0,0 & 0,0 & 0,0 & 0,0 & 0,0 & 0,0 & 0,0 & 0,0 & 0,0 & 0,0 & 0,0 & 0,0 \\
\hline Trochammina $s p$ & 0,0 & 0,0 & 0,0 & 1,6 & 0,0 & 0,0 & 0,0 & 0,0 & 0,0 & 0,0 & 0,0 & 0,0 & 0,2 & 0,0 & 0,4 & 0,0 & 0,3 & 0,6 & 0,0 & 0,5 \\
\hline Uvigerina peregrina & 0,0 & 1,0 & 0,0 & 0,0 & 0,0 & 0,0 & 0,0 & 0,0 & 0,0 & 0,0 & 0,0 & 0,0 & 0,0 & 0,2 & 0,0 & 0,0 & 0,0 & 0,0 & 0,0 & 0,0 \\
\hline Uvigerina peregrina cf parvula & 0,0 & 0,0 & 0,0 & 0,0 & 0,0 & 0,0 & 0,0 & 0,0 & 0,0 & 0,0 & 0,0 & 0,0 & 0,0 & 0,2 & 0,0 & 0,0 & 0,0 & 0,0 & 0,4 & 0,0 \\
\hline Uvigerina striata & 0,0 & 0,0 & 0,0 & 0,0 & 0,0 & 0,0 & 0,0 & 0,0 & 0,0 & 0,0 & 0,0 & 0,0 & 0,0 & 0,0 & 0,0 & 0,0 & 0,0 & 0,3 & 0,0 & 0,0 \\
\hline Wienesrella auriculata & 0,0 & 0,0 & 0,0 & 0,0 & 0,0 & 0,0 & 0,0 & 0,0 & 0,0 & 0,0 & 0,0 & 0,0 & 0,2 & 0,4 & 0,0 & 0,0 & 0,0 & 0,0 & 0,0 & 0,0 \\
\hline Indeterminado & 0,7 & 1,0 & 0,4 & 1,6 & 2,0 & 0,3 & 1,0 & 0,0 & 0,0 & 0,9 & 0,6 & 1,6 & 2,3 & 2,0 & 2,2 & 1,7 & 1,1 & 1,5 & 0,2 & 1,8 \\
\hline Fragmento & 0,0 & 0,0 & 0,0 & 0,0 & 0,0 & 0,0 & 0,0 & 0,0 & 0,0 & 0,0 & 1,3 & 0,0 & 4,6 & 1,1 & 4,7 & 4,2 & 2,6 & 1,8 & 1,5 & 1,5 \\
\hline \multicolumn{21}{|c|}{ Parâmetros bióticos } \\
\hline Volume de sedimento analisado $\left(\mathrm{cm}^{3}\right)$ & 20 & 10 & 10 & 20 & 30 & 10 & 40 & 20 & 60 & 40 & 10 & 10 & 10 & 10 & 10 & 10 & 10 & 10 & 10 & 10 \\
\hline Fração analisada & \multicolumn{10}{|c|}{ Frações analisadas em sua totalidade } & $1 / 8$ & $1 / 8$ & $1 / 16$ & 1 & $1 / 2$ & $1 / 16$ & $1 / 2$ & $1 / 8$ & $1 / 8$ & $1 / 8$ \\
\hline Foraminíferos $/ \mathrm{cm}^{3}$ de sedimento & $148 / 20$ & $104 / 10$ & $266 / 10$ & $128 / 20$ & $98 / 30$ & $296 / 10$ & $99 / 40$ & $118 / 20$ & $95 / 60$ & $196 / 40$ & 311 & 376 & 438 & 456 & 276 & 288 & 351 & 335 & 462 & 400 \\
\hline Foraminíferos $/ 10 \mathrm{~cm}^{3}$ de sedimento & 74 & 104 & 266 & 64 & 33 & 296 & 25 & 59 & 16 & 49 & 2488 & 3008 & 7008 & 456 & 552 & 4608 & 702 & 2680 & 3696 & 3200 \\
\hline Riqueza & 12 & 13 & 27 & 30 & 33 & 27 & 26 & 31 & 28 & 27 & 23 & 27 & 40 & 67 & 54 & 40 & 53 & 47 & 55 & 57 \\
\hline Diversidade específica & 1,59 & 2,11 & 2,2 & 3,16 & 3,25 & 2,41 & 3,04 & 2,9 & 2,85 & 2,72 & 2,57 & 2,51 & 2,93 & 3,63 & 3,61 & 3,10 & 3,36 & 3,03 & 3,37 & 3,53 \\
\hline Equitatividade & 0,64 & 0,82 & 0,67 & 0,93 & 0,93 & 0,73 & 0,93 & 0,84 & 0,86 & 0,83 & 0,82 & 0,76 & 0,79 & 0,86 & 0,90 & 0,83 & 0,84 & 0,78 & 0,84 & 0,87 \\
\hline
\end{tabular}


Anexo 07 - Distribuição de espécies bioindicadoras de ambiente óxico e rico em matéria orgânica identificadas ao longo do Canal de São Sebastião. Valores em porcentagem.
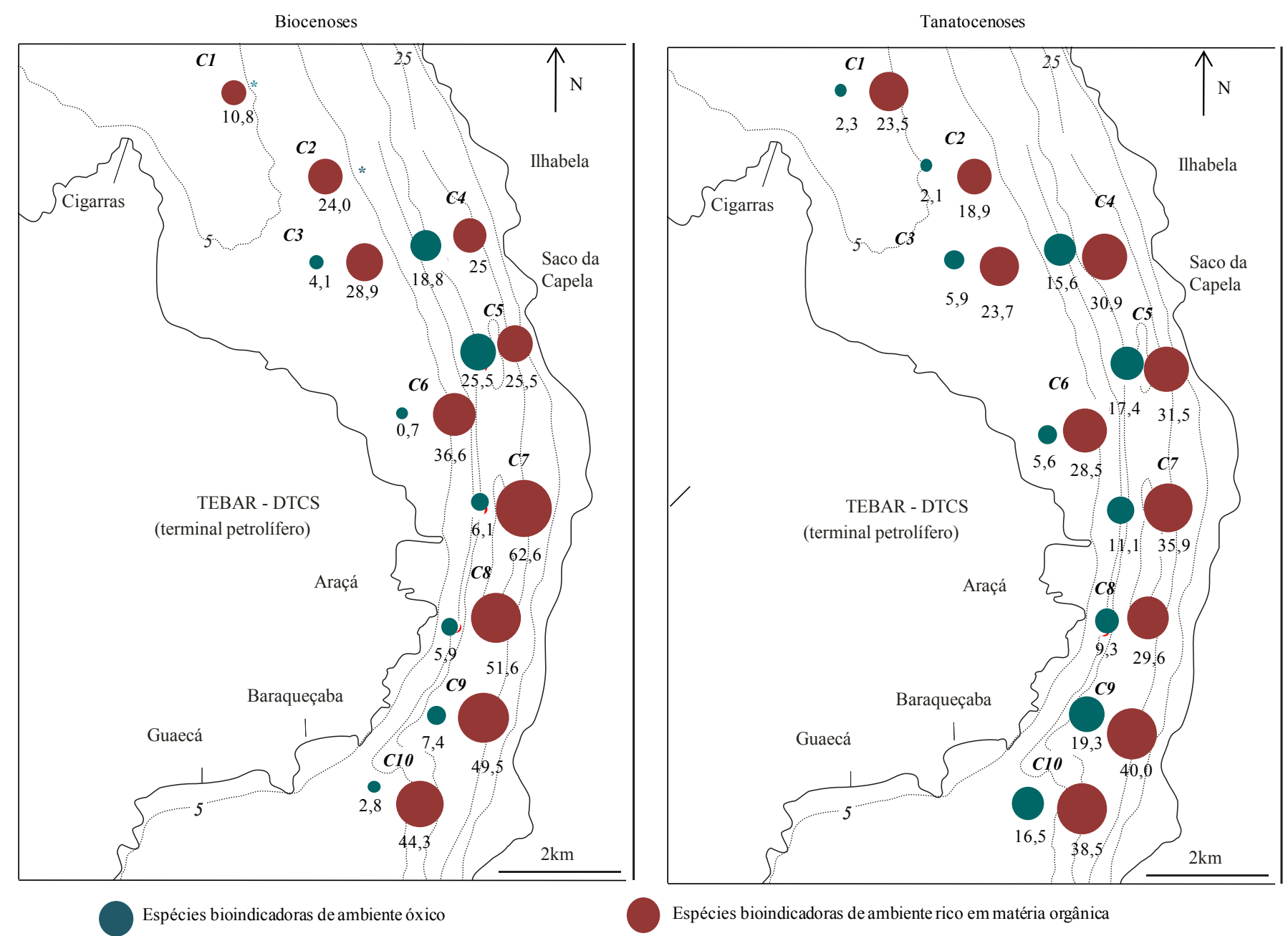

* $\quad$ Ausência de espécies bioindicadoras de ambiente óxico 
Anexo 08 - Matriz de correlação de Pearson obtida para os dados bióticos e abióticos obtidos no Canal de São Sebastião

Níveis de significância: $p<0,01$ (em vermelho) e $p<0,05$ (em negrito)

Dens. 1,00

$\begin{array}{rr}1,00 & -0,19 \\ -0,51 & 1,00\end{array}$

$-0,51 \quad 0,85 \quad 1,00$

$\mathbf{- 0 , 6 6} \quad 0,51 \quad 0,89 \quad 1,00$

$\begin{array}{llllll}\mathbf{0}, 72 & -0,46 & -0,81 & -0,93 & 1,00\end{array}$

$\begin{array}{lllllll}0,75 & -0,37 & -0,74 & -0,88 & 0,91 & 1,00\end{array}$

$\begin{array}{lllllll}0,31 & 0,12 & -0,13 & -0,33 & 0,54 & 0,36 & 1,00\end{array}$

$\begin{array}{lllllllll}\mathbf{0 , 7 4} & 0,10 & -0,19 & -0,38 & 0,50 & 0,56 & 0,20 & 1,00\end{array}$

$\begin{array}{lllllllllll}-0,58 & 0,56 & 0,78 & 0,77 & -0,87 & -0,74 & -0,49 & -0,36 & 1,00 & -1,0\end{array}$

$\begin{array}{lllllllllll}-0,17 & 0,60 & 0,60 & 0,43 & -0,23 & -0,26 & 0,10 & -0,03 & 0,24 & 1,00 & \end{array}$

$\begin{array}{rlllllllllll}0,05 & \mathbf{0}, 73 & 0,58 & 0,29 & -0,13 & -0,12 & 0,20 & 0,10 & 0,12 & 0,89 & 0,25 & 1,00\end{array}$

$\begin{array}{rrrrrrrrrrrrr}0,47 & -0,56 & -\mathbf{0 . 6 5} & -0,58 & 0,78 & 0,53 & \mathbf{0}, 71 & 0,21 & -0,82 & -0,17 & -0,85 & -0,20 & 1,00\end{array}$

$\begin{array}{llllllllllllll}0,10 & \mathbf{0}, 73 & 0,40 & 0,01 & 0,16 & 0,18 & 0,53 & 0,39 & -0,72 & \mathbf{0 , 6 4} & -0,02 & \mathbf{0 , 7 5} & -0,02 & 1,00\end{array}$

$\begin{array}{lllllllllllllll}0,16 & 0,30 & 0,23 & 0,10 & 0,12 & 0,01 & 0,09 & 0,31 & -0,12 & \mathbf{0 , 7 1} & -0,26 & \mathbf{0 , 7 0} & 0,10 & 0,48 & 1,00\end{array}$

$\begin{array}{llllllllllllllllll}-0,60 & 0,55 & 0,79 & 0,81 & -0,88 & -0,91 & -0,38 & -0,43 & \mathbf{0 , 6 8} & 0,36 & -0,88 & 0,35 & -0,67 & 0,03 & 0,03 & 1,00\end{array}$

$\begin{array}{lllllllllllllllll}-0,37 & 0,56 & \mathbf{0 , 7 2} & \mathbf{0 , 6 8} & -\mathbf{0}, 77 & -\mathbf{0 , 6 9} & -0,29 & 0,45 & 0,79 & 0,36 & 0,89 & 0,34 & \mathbf{- 0 , 6 5} & -0,01 & -0,19 & \mathbf{0}, 77 & 1,00\end{array}$

$\begin{array}{llllllllllllllllll}-0,16 & 0,47 & 0,59 & 0,55 & -\mathbf{0 . 7 2} & -0,47 & -\mathbf{0}, 71 & -0,06 & \mathbf{0 , 7 0} & 0,09 & 0,80 & 0,23 & -0,89 & -0,12 & -0,04 & \mathbf{0 , 6 5} & \mathbf{0 , 6 6} & 1,00\end{array}$

$\begin{array}{llllllllllllllllllll}-0,39 & 0,34 & 0,49 & 0,50 & -0,39 & -0,47 & -0,29 & 0,11 & 0,46 & 0,43 & 0,10 & 0,23 & -0,32 & 0,17 & 0,62 & 0,32 & 0,01 & 0,19 & 1,00\end{array}$

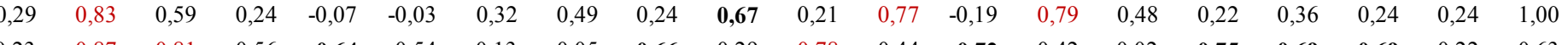

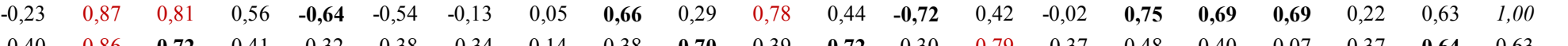

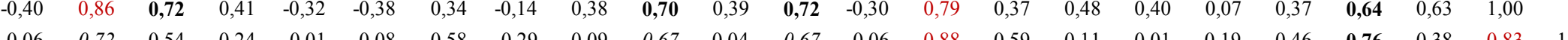

$\begin{array}{rrrrrrrrrrrrrrrrrrrrrrrrrr}-0,06 & 0,72 & 0,54 & 0,24 & 0,01 & -0,08 & 0,58 & -, 29 & 0,09 & 0,67 & -0,04 & 0,67 & 0,06 & 0,88 & 0,59 & 0,1 & 0,01 & -0,19 & 0,46 & 0,76 & 0,38 & 0,83 & 1,00 & 0 \\ 0,35 & -0,63 & -0,55 & -0,33 & 0,12 & 0,26 & -0,47 & -0,02 & -0,20 & -0,72 & -0,04 & -0,63 & -0,03 & -0,79 & -0,55 & -0,26 & -0,05 & 0,26 & -0,52 & -0,56 & -0,32 & -0,88 & -0,93 & 1,00\end{array}$

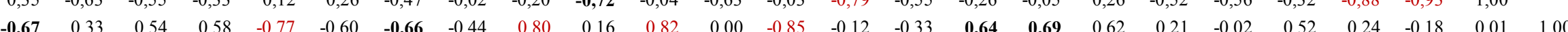

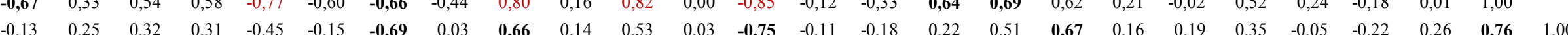

\begin{tabular}{llllllllllllllllllllllllllllll}
$-0,34$ & 0,62 & 0,59 & 0,42 & $-0,41$ & $-0,58$ & 0,02 & $-0,33$ & 0,41 & 0,54 & 0,41 & 0,62 & $-0,32$ & 0,33 & 0,51 & $\mathbf{0 , 6 3}$ & 0,44 & 0,28 & 0,46 & 0,39 & 0,53 & $\mathbf{0}, 72$ & 0,47 & $-0,55$ & 0,15 & $-0,16$ & 1,00 & & & \\
\hline
\end{tabular}

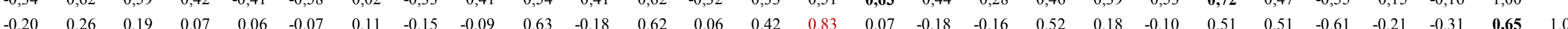

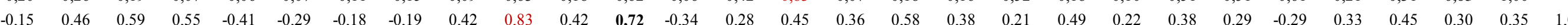

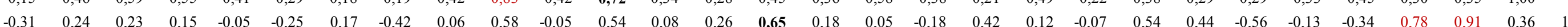

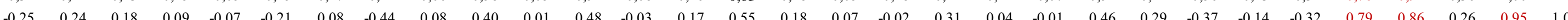

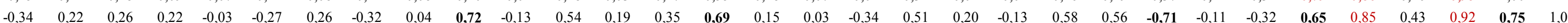

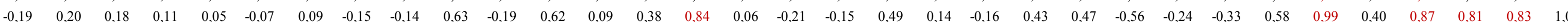

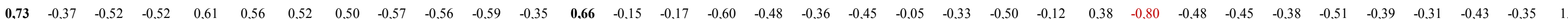

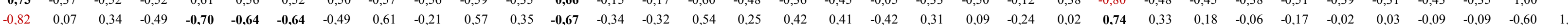

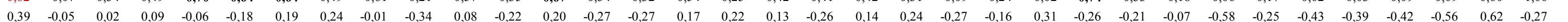

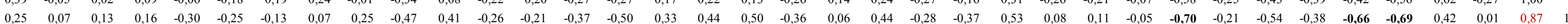

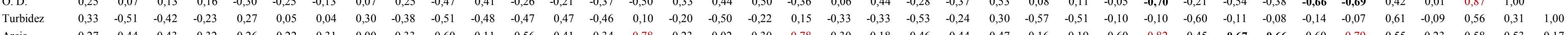

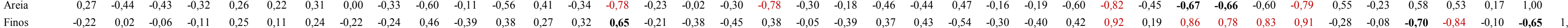

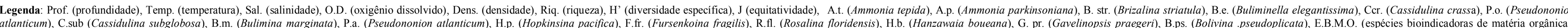

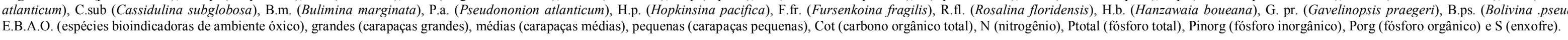


Anexo 09 - Resultado das análises morfométricas realizadas nas carapaças dos foraminíferos (biocenoses e tanatocenoses) obtidas ao longo do Canal de São Sebastião.

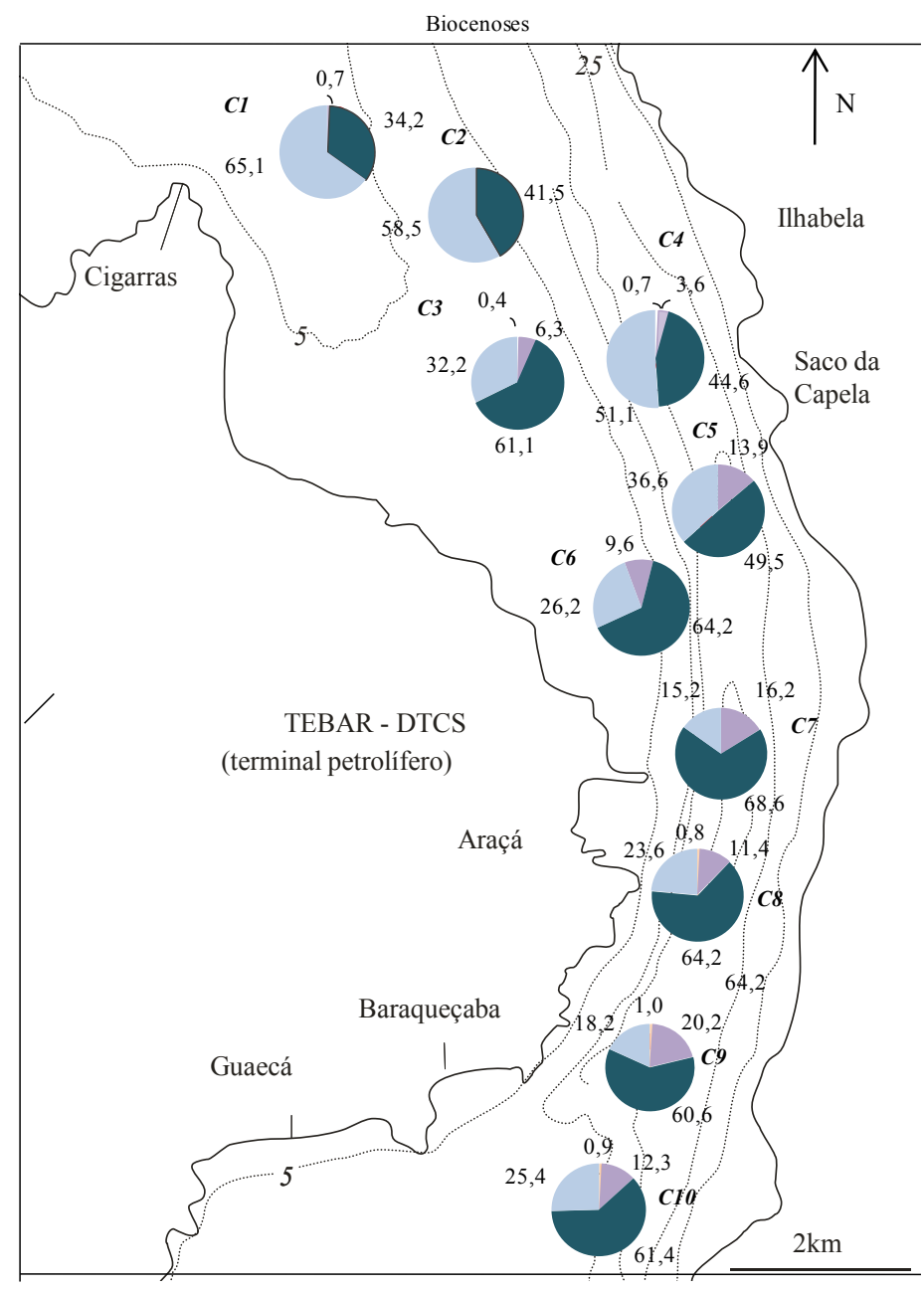

$\%$ de carapaças pequenas

$\%$ de carapaças médias

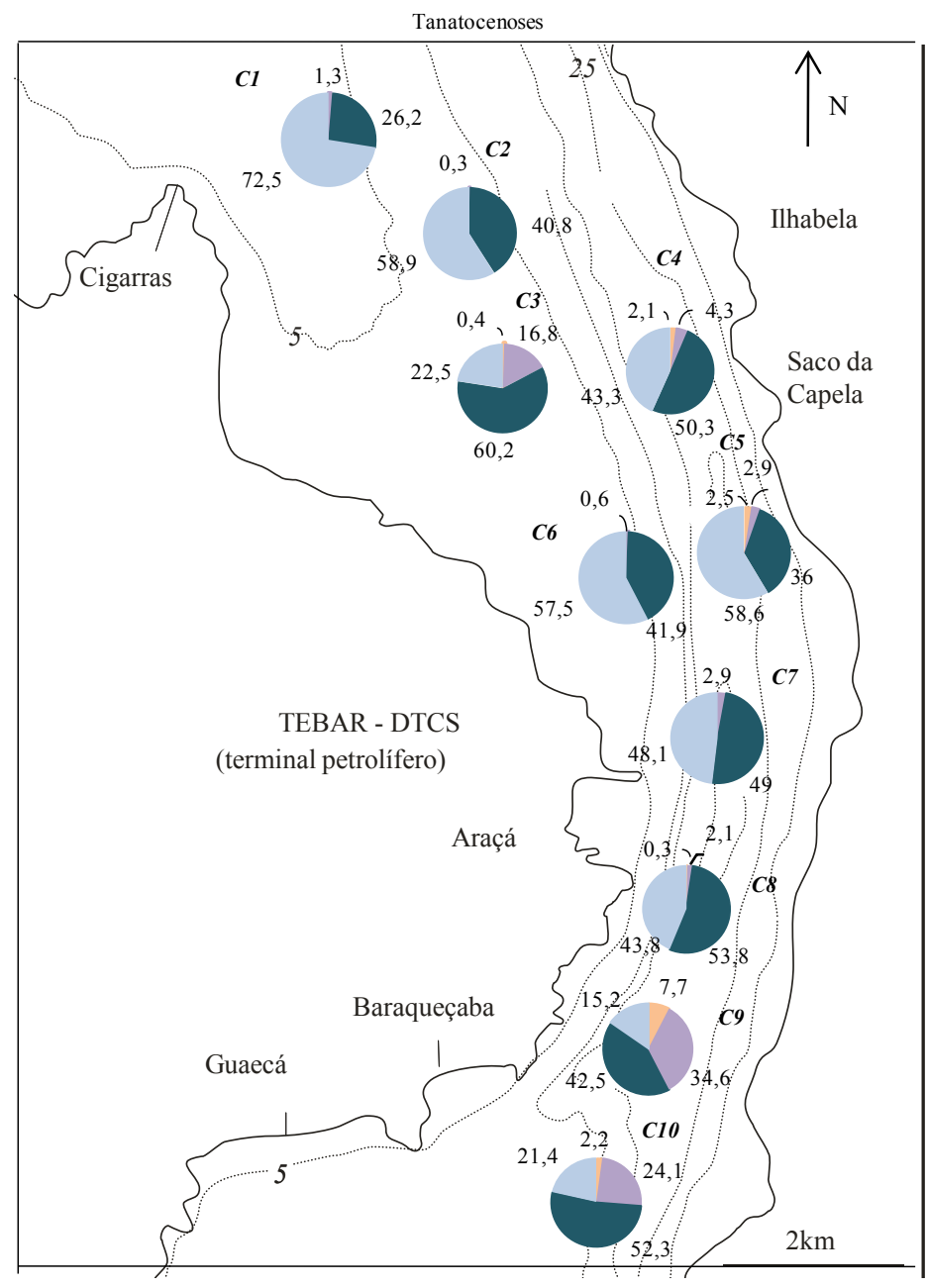

$\%$ de carapaças grandes

$\%$ de macroforaminiferos 
Anexo 10 - Estado de preservação e coloração das carapaças dos foraminíferos que compuseram as tanatocenoses. Valores em porcentagem.

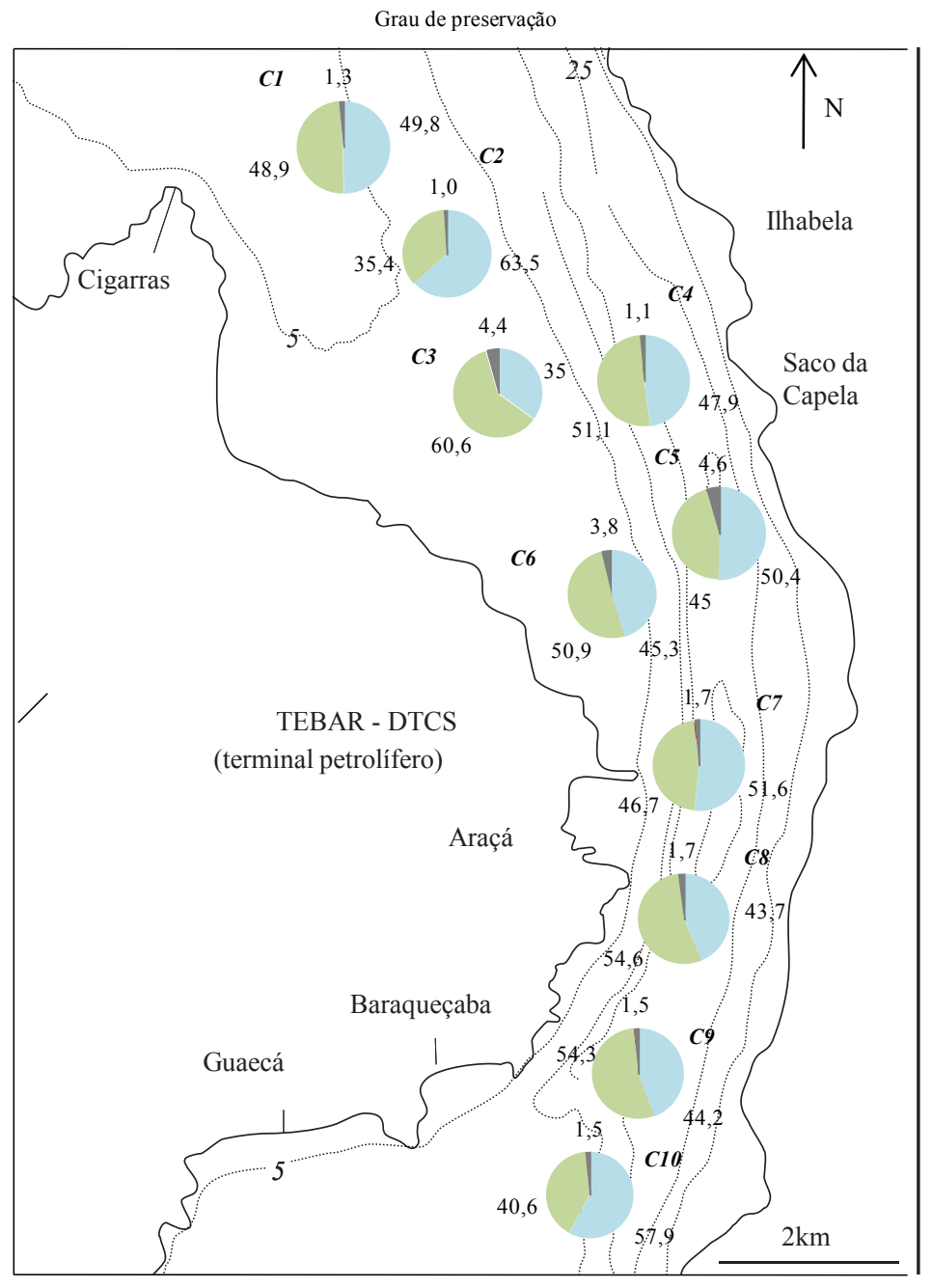

Carapaças parcialmente fragmentada

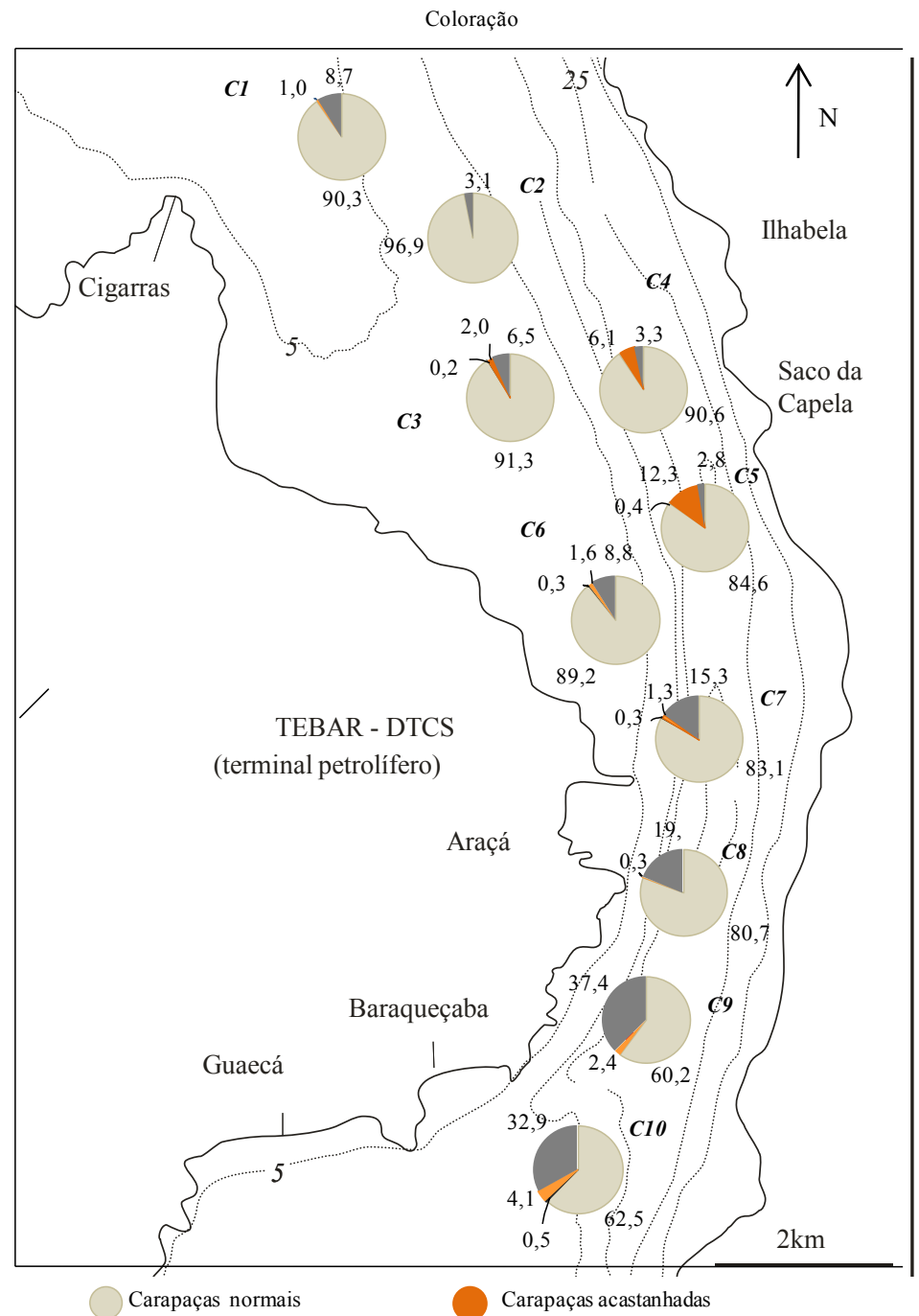

Carapaças com presença de monossulfeto de ferro/pirita 
Anexo 11 - Modelo proposto para a circulação no interior do Canal de São Sebastião.

Legenda: * dado retirados de Furtado (1978), ** dados obtidos por meio da abundância absoluta de carapaças de Pararotalia cananeiaensis (tanatocenoses).

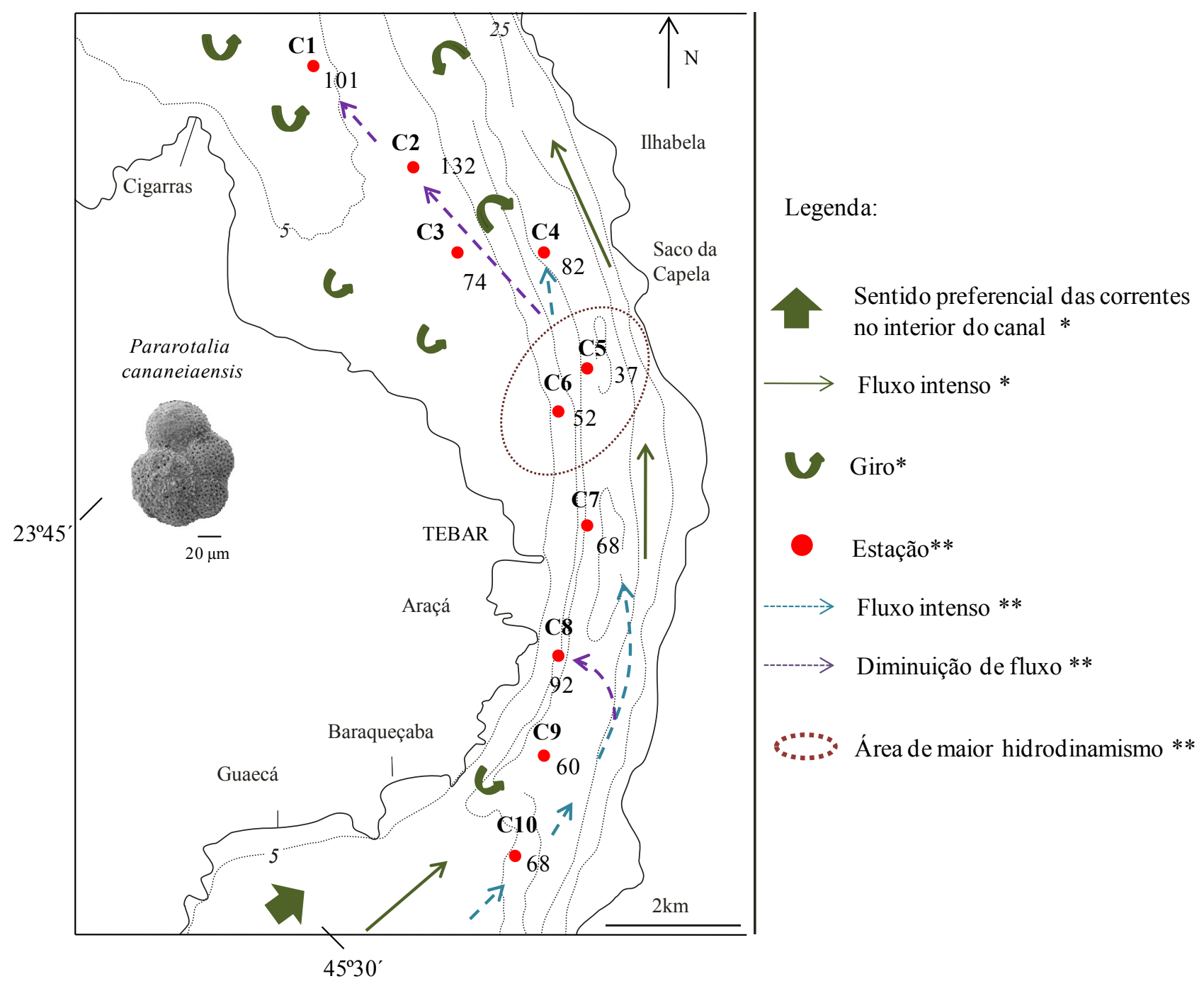




\section{CAPÍTULO 4 - EMISSÁRIO SUBMARINO DE ESGOTO DOMÉSTICO DO ARAÇÁ}

\subsection{RESULTADOS}

4.1.1 Posicionamento geográfico e dados físico-químicos da coluna d’água

O posicionamento geográfico das estações de amostragem e dados físicoquímicos da coluna d'água, obtidos nos anos de 2005 e 2006 (Abril e Setembro de 2006), encontram-se na Tabela 04.

Coletas realizadas em Julho de 2005

Os valores de temperatura e salinidade oscilaram entre 22,1 e $23,3{ }^{\circ} \mathrm{C}$ e entre 34,6 e $35,1^{\circ} \mathrm{C}$, respectivamente. Observou-se suave estratificação termohalina durante período de amostragem.

Os valores de $\mathrm{pH}$ da coluna d'água variaram de 8,17 a 8,24. A diferença entre os valores obtidos foi pouco significativa, sendo inexistente em algumas estações (e.g. Ar4 e $\operatorname{Ar} 10)$.

As concentrações de oxigênio dissolvido oscilaram entre 6,33 e 7,60 $\mathrm{mg} \mathrm{L}^{-1}$. Excetuando-se as estações Ar3, Ar4 e Ar5, observou-se decréscimo progressivo das concentrações da superfície em direção ao fundo da coluna d'água. O padrão mencionado foi mais acentuado para as estações Ar7, Ar8 e Ar9, posicionadas nas regiões sudoeste, sul e sudeste, respectivamente.

Os valores de turbidez variaram de 0,71 a 4,30 UNT. Não se observou padrão de dispersão. Entretanto, os maiores valores ocorreram na superfície e nas águas do meio.

A maioria dos valores de nitrogênio amoniacal, nitrogênio Kjeldahl, ortofosfato e fósforo total apresentaram valores abaixo do limite de detecção do método analítico ${ }^{10}$. As estações Ar 1 e Ar4 apresentaram concentrações de 0,46 e 0,12 mg L $\mathrm{m}^{-1}$ de nitrogênio Kjeldahl nas águas de superfície. Nas águas de superfície da estação Ar2 foram obtidos

\footnotetext{
${ }^{10}$ Limite de detecção: nitrogênio amoniacal $<0,01 \mathrm{mg} \mathrm{L}^{-1}$, nitrogênio Kjeldahl $<0,01 \mathrm{mg} \mathrm{L}^{-1}$, ortofosfato $<0,001 \mathrm{mg} \mathrm{L}^{-1}$, fósforo total $<0,001 \mathrm{mg} \mathrm{L}^{-1}$
} 
os seguintes valores: $0,30 \mathrm{mg} \mathrm{L}^{-1}$ para nitrogênio amoniacal, $0,21 \mathrm{mg} \mathrm{L}^{-1}$ para nitrogênio Kjeldahl, 0,20 $\mathrm{mg} \mathrm{L}^{-1}$ para ortofosfato e $0,20 \mathrm{mg} \mathrm{L}^{-1}$ para fósforo total.

A estação Ar6, por sua vez, apresentou nas águas de superfície concentrações de $0,02 \mathrm{mg} \mathrm{L}^{-1}$ de nitrogênio amoniacal, $0,18 \mathrm{mg} \mathrm{L}^{-1}$ de nitrogênio Kjeldahl e 0,03 $\mathrm{mg} \mathrm{L}^{-1}$ para ortofosfato e fósforo total.

\section{Coletas realizadas em Abril de 2006}

Os valores de temperatura e salinidade oscilaram entre 25,5 e $27^{\circ} \mathrm{C}$ e entre 33,7 e $34,6^{\circ} \mathrm{C}$, respectivamente. Em Abril de 2006, excetuando-se as estações $\operatorname{Ar} 2, \operatorname{Ar} 3$ e Ar6, observou-se suave estratificação termohalina, com diminuição dos valores de temperatura e aumento dos valores de salinidade das águas de superfície em direção às águas de fundo.

Os valores de $\mathrm{pH}$ da coluna d'água oscilaram de 7,90 a 8,26. Observou-se, com exceção da estação Ar1, suave declínio de valores das águas de superfície em direção às águas de fundo.

As concentrações de oxigênio dissolvido variaram de 5,06 a $6,95 \mathrm{mg} \mathrm{L}^{-1}$. Os resultados obtidos nas estações Ar4, Ar7, Ar8 e Ar9 apresentaram-se abaixo do limite para preservação da vida aquática, i.e. $6 \mathrm{mg} \mathrm{L}^{-1}$, estabelecido pela Resolução CONAMA 357/05, para águas salinas da Classe 1.

Os valores de turbidez variaram entre 0,40 a 12 UNT. Os maiores valores ocorreram nas águas de superfície (10 UNT) e de fundo (12 UNT) da estação Ar5. A partir do padrão de distribuição vertical dos valores, observou-se sentido preferencial de dispersão da pluma de sudoeste para norte-nordeste.

Quase todos os valores de nitrogênio amoniacal, nitrogênio Kjeldahl, fósforo total e ortofosfato obtidos em Abril de 2006 estiveram abaixo do método analítico. Concentrações acima do método analítico, porém dentro dos limites da Resolução CONAMA 357/05 ocorreram somente nas estações Ar1 e Ar3 (Tabela 04).

\section{Coletas realizadas em Setembro de 2006}

Os valores de temperatura e salinidade oscilaram entre 21,90 e $22,78^{\circ} \mathrm{C}$ e entre 33,43 e $34,28{ }^{\circ} \mathrm{C}$, respectivamente. Foi observada suave estratificação termohalina em 
quase todas as estações. Somente a estação Ar10 apresentou valores de temperatura homogêneos ao longo da coluna d'água. Os valores de $\mathrm{pH}$ variaram entre 7,98 e 8,14.

As concentrações de oxigênio dissolvido oscilaram entre 5,58 e 7,58 $\mathrm{mg} \mathrm{L}^{-1}$. Assim como o observado em Abril de 2006, as estações Ar7, Ar9 e Ar10 apresentaram concentrações abaixo do limite de preservação à vida aquática. Menciona-se que a estação Ar10 apresentou valores baixos ao longo de toda a coluna d'água.

Os valores de turbidez variaram de 2,20 e 13 UNT. Os maiores valores foram identificados nas águas de fundo da estação Ar9 (13 UNT) e águas de superfície da estação Ar10 (12 UNT). A partir dos valores obtidos, verificou-se dispersão da pluma no sentido sudeste-nordeste da malha de amostragem.

No tocante as análises de nitrogênio amoniacal, nitrogênio Kjeldahl, fósforo total e ortofosfato, todas as estações apresentaram valores abaixo do limite de detecção do método analítico. 
Tabela 04 - Posicionamentos geográficos e dados físico-químicos da coluna d'água obtidos próximo ao emissário do Araçá.

Obs.: Em vermelho, valores abaixo dos limites estabelecidos pela Resolução CONAMA $357 / 2005$.

\begin{tabular}{|c|c|c|c|c|c|c|c|c|c|c|c|c|c|}
\hline & 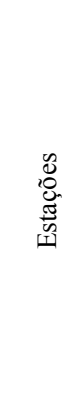 & $\begin{array}{l}\text { 营 } \\
\text { 莺 }\end{array}$ & 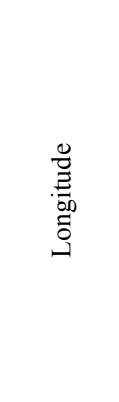 & 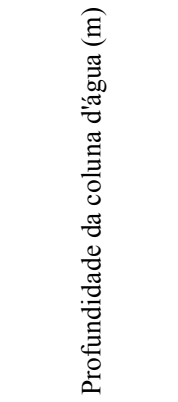 & 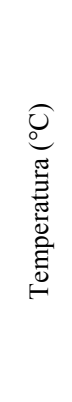 & 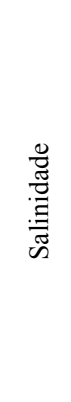 & $\stackrel{T}{2}$ & 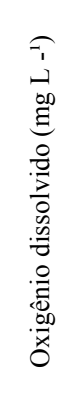 & 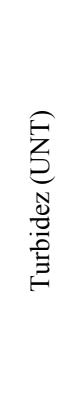 & 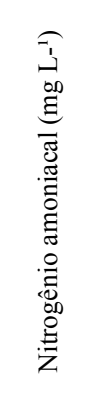 & 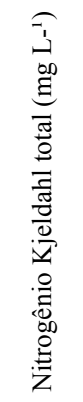 & 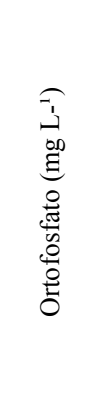 & 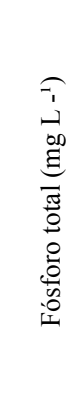 \\
\hline & \multicolumn{3}{|c|}{ Resolução CONAMA 357/05 } & & & $\geq 30$ & 6,5 a 8,5 & 6 & & 0,4 & & & 0,06 \\
\hline \multirow{30}{*}{ 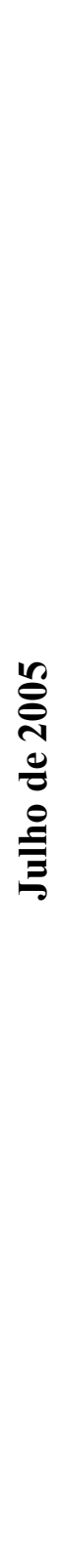 } & \multirow{3}{*}{ Ar1 } & \multirow{3}{*}{$-23,8193$} & \multirow{3}{*}{$-45,404$} & Superfície (0) & 22,3 & 34,8 & 8,17 & 7,19 & 1,50 & $<0,01$ & 0,46 & $<0,01$ & $<0,01$ \\
\hline & & & & Meio (2) & 22,3 & 34,8 & 8,18 & 7,19 & 1,70 & $<0,01$ & $<0,1$ & $<0,01$ & $<0,01$ \\
\hline & & & & Fundo (3) & 22,3 & 34,7 & 8,18 & 7,16 & 1,8 & $<0,01$ & $<0,1$ & $<0,01$ & $<0,01$ \\
\hline & \multirow{3}{*}{$\operatorname{Ar} 2$} & \multirow{3}{*}{$-23,8199$} & \multirow{3}{*}{$-45,4044$} & Superficie (0) & 23,3 & 34,6 & 8,19 & 7,17 & 2,00 & 0,3 & 0,21 & 0,20 & 0,20 \\
\hline & & & & Meio (4) & 22,3 & 34,8 & 8,20 & 7,13 & 1,90 & $<0,01$ & $<0,1$ & $<0,01$ & $<0,01$ \\
\hline & & & & Fundo (9) & 22,1 & 34,8 & 8,20 & 6,92 & 1,30 & $<0,01$ & $<0,1$ & $<0,01$ & $<0,01$ \\
\hline & \multirow{3}{*}{ Ar3 } & \multirow{3}{*}{$-23,8203$} & \multirow{3}{*}{$-45,4035$} & Superfície (0) & 22,4 & 34,7 & 8,21 & 7,09 & 2,00 & $<0,01$ & $<0,1$ & $<0,01$ & $<0,01$ \\
\hline & & & & Meio (6) & 22,3 & 34,8 & 8,21 & 7,19 & 1,20 & $<0,01$ & $<0,1$ & $<0,01$ & $<0,01$ \\
\hline & & & & Fundo (12) & 22,5 & 34,9 & 8,22 & 7,16 & 0,71 & $<0,01$ & $<0,1$ & $<0,01$ & $<0,01$ \\
\hline & \multirow{3}{*}{ Ar4 } & \multirow{3}{*}{$-23,8192$} & \multirow{3}{*}{$-45,4031$} & Superfície (0) & 22,4 & 34,7 & 8,21 & 7,00 & 2,40 & $<0,01$ & 0,12 & $<0,01$ & $<0,01$ \\
\hline & & & & Meio (6) & 22,3 & 34,8 & 8,21 & 7,15 & 1,30 & $<0,01$ & $<0,1$ & $<0,01$ & $<0,01$ \\
\hline & & & & Fundo (12) & 22,4 & 34,9 & 8,21 & 7,04 & 1,10 & $<0,01$ & $<0,1$ & $<0,01$ & $<0,01$ \\
\hline & \multirow{3}{*}{$\operatorname{Ar} 5$} & \multirow{3}{*}{$-23,8185$} & \multirow{3}{*}{$-45,4037$} & Superfície (0) & 22,6 & 34,8 & 8,23 & 7,58 & 4,30 & $<0,01$ & $<0,1$ & $<0,01$ & $<0,01$ \\
\hline & & & & Meio (2) & 22,6 & 34,8 & 8,23 & 7,60 & 4,00 & $<0,01$ & $<0,1$ & $<0,01$ & $<0,01$ \\
\hline & & & & Fundo (3) & 22,6 & 34,8 & 8,18 & 7,60 & 4,00 & $<0,01$ & $<0,1$ & $<0,01$ & $<0,01$ \\
\hline & \multirow{3}{*}{ Ar6 } & \multirow{3}{*}{$-23,8201$} & \multirow{3}{*}{$-45,4045$} & Superfície (0) & 22,6 & 34,6 & 8,21 & 7,34 & 3,70 & 0,02 & 0,18 & 0,03 & 0,03 \\
\hline & & & & Meio (4) & 22,6 & 34,8 & 8,22 & 7,15 & 3,80 & $<0,01$ & $<0,1$ & $<0,01$ & $<0,01$ \\
\hline & & & & Fundo (8) & 22,3 & 34,9 & 8,21 & 6,89 & 1,90 & $<0,01$ & $<0,1$ & $<0,01$ & $<0,01$ \\
\hline & \multirow{3}{*}{ Ar7 } & \multirow{3}{*}{$-23,8205$} & \multirow{3}{*}{$-45,4051$} & Superfície (0) & 22,7 & 34,9 & 8,21 & 7,34 & 2,20 & $<0,01$ & $<0,1$ & $<0,01$ & $<0,01$ \\
\hline & & & & Meio (4) & 22,5 & 34,8 & 8,21 & 7,01 & 1,90 & $<0,01$ & $<0,1$ & $<0,01$ & $<0,01$ \\
\hline & & & & Fundo (9) & 22,4 & 35 & 8,2 & 6,67 & 1,70 & $<0,01$ & $<0,1$ & $<0,01$ & $<0,01$ \\
\hline & \multirow{3}{*}{ Ar8 } & \multirow{3}{*}{$-23,8208$} & \multirow{3}{*}{$-45,4038$} & Superfície (0) & 22,5 & 34,9 & 8,23 & 7,25 & 1,50 & $<0,01$ & $<0,1$ & $<0,01$ & $<0,01$ \\
\hline & & & & Meio (5) & 22,5 & 34,9 & 8,22 & 7,16 & 1,4 & $<0,01$ & $<0,1$ & $<0,01$ & $<0,01$ \\
\hline & & & & Fundo (11) & 22,1 & 35,1 & 8,18 & 6,33 & 1,5 & $<0,01$ & $<0,1$ & $<0,01$ & $<0,01$ \\
\hline & & & & Superficie (0) & 22,6 & 34,8 & 8,24 & 7,35 & 1,5 & $<0,01$ & $<0,1$ & $<0,01$ & $<0,01$ \\
\hline & $\operatorname{Ar} 9$ & $-23,82$ & $-45,4025$ & Meio (8) & 22,4 & 35 & 8,21 & 7,05 & 0,95 & $<0,01$ & $<0,1$ & $<0,01$ & $<0,01$ \\
\hline & & & & Fundo (17) & 22,2 & 35,1 & 8,2 & 6,53 & 1,2 & $<0,01$ & $<0,1$ & $<0,01$ & $<0,01$ \\
\hline & & & & Superficie (0) & 22,5 & 34,8 & 8,22 & 7,28 & 1,9 & $<0,01$ & $<0,1$ & $<0,01$ & $<0,01$ \\
\hline & Ar10 & $-23,8187$ & $-45,4025$ & Meio (6) & 22,4 & 34,9 & 8,22 & 7,21 & 2,3 & $<0,01$ & $<0,1$ & $<0,01$ & $<0,01$ \\
\hline & & & & Fundo (13) & 22,3 & 35 & 8,22 & 7,02 & 1,8 & $<0,01$ & $<0,1$ & $<0,01$ & $<0,01$ \\
\hline
\end{tabular}




\begin{tabular}{|c|c|c|c|c|c|c|c|c|c|c|c|c|c|}
\hline & 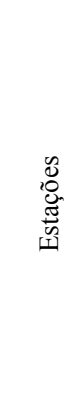 & 胥 & 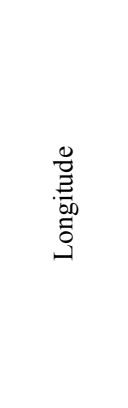 & 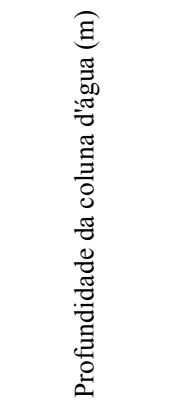 & 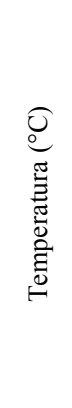 & 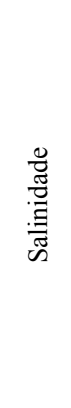 & 胥 & 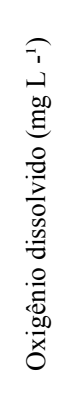 & 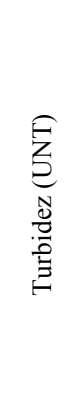 & 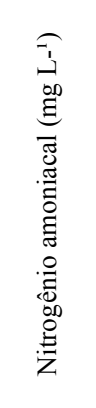 & 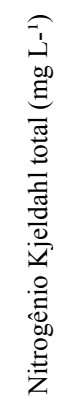 & 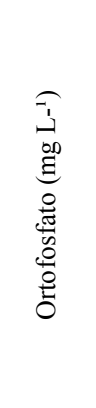 & 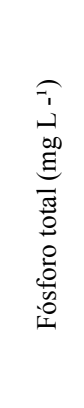 \\
\hline & \multicolumn{3}{|c|}{ Resolução CONAMA 357/05 } & & & $\geq 30$ & 6,5 a 8,5 & 6 & & 0,4 & & & 0,06 \\
\hline \multirow{30}{*}{ 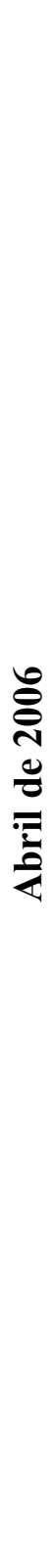 } & \multirow{3}{*}{ Ar1 } & \multirow{3}{*}{$-23,8193$} & \multirow{3}{*}{$-45,4035$} & Superfície (0) & 26,1 & 33,7 & 8,18 & 6,67 & 2,40 & 0,13 & 0,15 & 0,03 & 0,03 \\
\hline & & & & Meio (3) & 26,1 & 33,7 & 8,19 & 6,59 & 2,10 & $<0,01$ & $<0,1$ & $<0,01$ & $<0,01$ \\
\hline & & & & Fundo (6) & 26,2 & 34,1 & 8,19 & 6,58 & 0,87 & $<0,01$ & $<0,1$ & $<0,01$ & $<0,01$ \\
\hline & \multirow{3}{*}{$\operatorname{Ar} 2$} & \multirow{3}{*}{$-23,8199$} & \multirow{3}{*}{$-45,4038$} & Superfície $(0)$ & 26,1 & 34 & 8,17 & 6,58 & 0,40 & $<0,01$ & $<0,1$ & $<0,01$ & $<0,01$ \\
\hline & & & & Meio (5) & 26,1 & 34,1 & 8,17 & 6,55 & 0,76 & $<0,01$ & $<0,1$ & $<0,01$ & $<0,01$ \\
\hline & & & & Fundo (10) & 26,1 & 34,1 & 8,16 & 6,36 & 1,60 & $<0,01$ & $<0,1$ & $<0,01$ & $<0,01$ \\
\hline & \multirow{3}{*}{$\mathrm{Ar} 3$} & \multirow{3}{*}{$-23,8194$} & \multirow{3}{*}{$-45,403$} & Superfície (0) & 26,1 & 34,1 & 8,17 & 6,45 & 1,70 & 0,18 & 0,2 & 0,02 & 0,03 \\
\hline & & & & Meio (5) & 26,1 & 34,1 & 8,18 & 6,51 & 0,69 & $<0,01$ & $<0,1$ & $<0,01$ & $<0,01$ \\
\hline & & & & Fundo (10) & 26,1 & 34,1 & 8,06 & 6,39 & 3,40 & $<0,01$ & $<0,1$ & $<0,01$ & $<0,01$ \\
\hline & \multirow{3}{*}{ Ar4 } & \multirow{3}{*}{$-23,8188$} & \multirow{3}{*}{$-45,4028$} & Superfície (0) & 26,2 & 33,8 & 8,22 & 6,98 & 3,30 & $<0,01$ & $<0,1$ & $<0,01$ & $<0,01$ \\
\hline & & & & Meio (4) & 26,2 & 34,1 & 8,2 & 6,60 & 1,50 & $<0,01$ & $<0,1$ & $<0,01$ & $<0,01$ \\
\hline & & & & Fundo (8) & 25,9 & 34,3 & 8,17 & 5,97 & 0,91 & $<0,01$ & $<0,1$ & $<0,01$ & $<0,01$ \\
\hline & \multirow{3}{*}{ Ar5 } & \multirow{3}{*}{$-23,8186$} & \multirow{3}{*}{$-45,4041$} & Superfície (0) & 26,5 & 33,7 & 8,26 & 7,69 & 10,00 & $<0,01$ & $<0,1$ & $<0,01$ & $<0,01$ \\
\hline & & & & Meio (2) & 26,5 & 33,7 & 8,26 & 7,55 & 6,80 & $<0,01$ & $<0,1$ & $<0,01$ & $<0,01$ \\
\hline & & & & Fundo (3) & 26,4 & 33,8 & 8,22 & 6,95 & 120 & $<0,01$ & $<0,1$ & $<0,01$ & $<0,01$ \\
\hline & \multirow{3}{*}{ Ar6 } & \multirow{3}{*}{$-23,8199$} & \multirow{3}{*}{$-45,4043$} & Superficie (0) & 26,1 & 34 & 7,94 & 6,62 & 0,62 & $<0,01$ & $<0,1$ & $<0,01$ & $<0,01$ \\
\hline & & & & Meio (4) & 26,1 & 34,1 & 7,9 & 6,55 & 0,55 & $<0,01$ & $<0,1$ & $<0,01$ & $<0,01$ \\
\hline & & & & Fundo (7) & 26,1 & 34,1 & 7,9 & 6,52 & 0,77 & $<0,01$ & $<0,1$ & $<0,01$ & $<0,01$ \\
\hline & \multirow{3}{*}{ Ar7 } & \multirow{3}{*}{$-23,8208$} & \multirow{3}{*}{$-45,405$} & Superfície (0) & 26,5 & 33,9 & 8,22 & 7,22 & 2,90 & $<0,01$ & $<0,1$ & $<0,01$ & $<0,01$ \\
\hline & & & & Meio (5) & 26,2 & 34,1 & 8,19 & 6,53 & 0,70 & $<0,01$ & $<0,1$ & $<0,01$ & $<0,01$ \\
\hline & & & & Fundo (12) & 25,8 & 34,4 & 8,15 & 5,61 & 0,98 & $<0,01$ & $<0,1$ & $<0,01$ & $<0,01$ \\
\hline & \multirow{3}{*}{ Ar8 } & \multirow{3}{*}{$-23,8208$} & \multirow{3}{*}{$-45,4036$} & Superficie (0) & 26,4 & 33,8 & 8,2 & 6,73 & 1,5 & $<0,01$ & $<0,1$ & $<0,01$ & $<0,01$ \\
\hline & & & & Meio (6) & 26,1 & 34,1 & 8,18 & 6,42 & 0,67 & $<0,01$ & $<0,1$ & $<0,01$ & $<0,01$ \\
\hline & & & & Fundo (13) & 25,5 & 34,6 & 8,13 & 5,32 & 4,9 & $<0,01$ & $<0,1$ & $<0,01$ & $<0,01$ \\
\hline & & & & Superfície (0) & 26,6 & 33,7 & 8,15 & 7,72 & 4,10 & $<0,01$ & $<0,1$ & $<0,01$ & $<0,01$ \\
\hline & $\operatorname{Ar} 9$ & $-23,82$ & $-45,4024$ & Meio (8) & 25,9 & 34,3 & 8,08 & 5,89 & 0,93 & $<0,01$ & $<0,1$ & $<0,01$ & $<0,01$ \\
\hline & & & & Fundo (15) & 27 & 34,6 & 8,07 & 5,06 & 1,50 & $<0,01$ & $<0,1$ & $<0,01$ & $<0,01$ \\
\hline & & & & Superfície (0) & 27 & 33,8 & 8,18 & 7,84 & 3,30 & $<0,01$ & $<0,1$ & $<0,01$ & $<0,01$ \\
\hline & Ar10 & $-23,8188$ & $-45,4025$ & Meio (6) & 26,2 & 34,1 & 8,11 & 6,45 & 0,91 & $<0,01$ & $<0,1$ & $<0,01$ & $<0,01$ \\
\hline & & & & Fundo (12) & 25,7 & 34,5 & 8,08 & 5,71 & 0,85 & $<0,01$ & $<0,1$ & $<0,01$ & $<0,01$ \\
\hline
\end{tabular}




\begin{tabular}{|c|c|c|c|c|c|c|c|c|c|c|c|c|c|}
\hline & 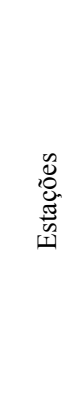 & 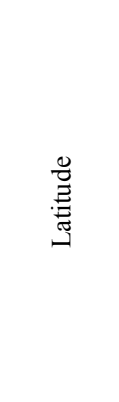 & $\begin{array}{l}0 \\
\stackrel{0}{0} \\
.00 \\
\tilde{0} \\
.\end{array}$ & 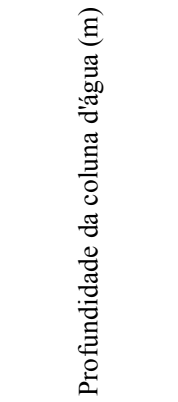 & 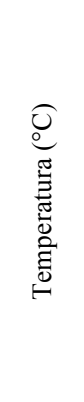 & 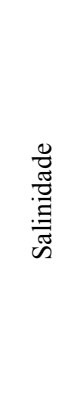 & $\stackrel{T}{2}$ & 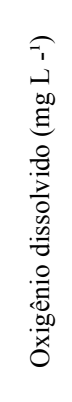 & 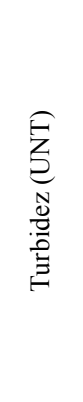 & 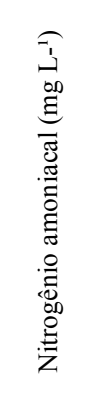 & 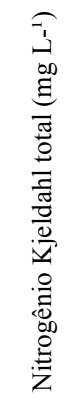 & 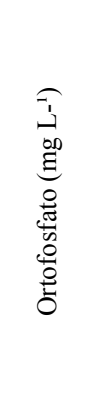 & 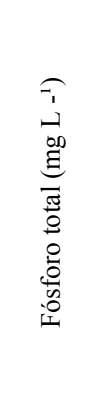 \\
\hline & \multicolumn{3}{|c|}{ Resolução CONAMA 357/05 } & & & $\geq 30$ & 6,5 a 8,5 & 6 & & 0,4 & & & 0,06 \\
\hline \multirow{30}{*}{ 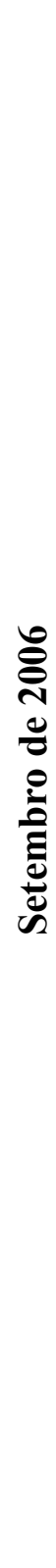 } & \multirow{3}{*}{$\operatorname{Ar} 1$} & \multirow{3}{*}{$-23,8193$} & \multirow{3}{*}{$-45,4035$} & Superfície (0) & 22,78 & 34,09 & 8,12 & 6,76 & 2,70 & $<0,01$ & $<0,1$ & $<0,01$ & $<0,01$ \\
\hline & & & & Meio (3) & 22,58 & 34,11 & 8,1 & 6,54 & 3,10 & $<0,01$ & $<0,1$ & $<0,01$ & $<0,01$ \\
\hline & & & & Fundo (7) & 22,01 & 34,28 & 8,1 & 6,41 & 3,00 & $<0,01$ & $<0,1$ & $<0,01$ & $<0,01$ \\
\hline & \multirow{3}{*}{$\operatorname{Ar} 2$} & \multirow{3}{*}{$-23,8199$} & \multirow{3}{*}{$-45,4038$} & Superfície (0) & 22,59 & 33,95 & 7,98 & 6,95 & 3,30 & $<0,01$ & $<0,1$ & $<0,01$ & $<0,01$ \\
\hline & & & & Meio (3) & 22,69 & 34 & 8,07 & 6,75 & 2,70 & $<0,01$ & $<0,1$ & $<0,01$ & $<0,01$ \\
\hline & & & & Fundo (6) & 22,15 & 34,21 & 8,08 & 6,61 & 4,20 & $<0,01$ & $<0,1$ & $<0,01$ & $<0,01$ \\
\hline & \multirow{3}{*}{ Ar3 } & \multirow{3}{*}{$-23,8194$} & \multirow{3}{*}{$-45,403$} & Superfície (0) & 22,41 & 34,2 & 8,11 & 6,56 & 2,40 & $<0,01$ & $<0,1$ & $<0,01$ & $<0,01$ \\
\hline & & & & Meio (6) & 22,08 & 34,24 & 8,10 & 6,27 & 2,20 & $<0,01$ & $<0,1$ & $<0,01$ & $<0,01$ \\
\hline & & & & Fundo (12) & 21,9 & 33,43 & 8,10 & 6,12 & 3,80 & $<0,01$ & $<0,1$ & $<0,01$ & $<0,01$ \\
\hline & \multirow{3}{*}{$\operatorname{Ar} 4$} & \multirow{3}{*}{$-23,8188$} & \multirow{3}{*}{$-45,4028$} & Superfície (0) & 22,55 & 34,15 & 8,11 & 7,18 & 3,40 & $<0,01$ & $<0,1$ & $<0,01$ & $<0,01$ \\
\hline & & & & Meio (2) & 22,32 & 34,18 & 8,11 & 6,99 & 3,40 & $<0,01$ & $<0,1$ & $<0,01$ & $<0,01$ \\
\hline & & & & Fundo (4) & 22,12 & 34,25 & 8,11 & 6,77 & 3,00 & $<0,01$ & $<0,1$ & $<0,01$ & $<0,01$ \\
\hline & \multirow{3}{*}{ Ar5 } & \multirow{3}{*}{$-23,8186$} & \multirow{3}{*}{$-45,4041$} & Superfície (0) & 22,78 & 34,14 & 8,12 & 6,57 & 3,60 & $<0,01$ & $<0,1$ & $<0,01$ & $<0,01$ \\
\hline & & & & Meio (1) & 22,49 & 34,18 & 8,11 & 6,48 & 3,00 & $<0,01$ & $<0,1$ & $<0,01$ & $<0,01$ \\
\hline & & & & Fundo (2) & 22,41 & 34,16 & 8,11 & 6,56 & 3,20 & $<0,01$ & $<0,1$ & $<0,01$ & $<0,01$ \\
\hline & \multirow{3}{*}{ Ar6 } & \multirow{3}{*}{$-23,8199$} & \multirow{3}{*}{$-45,4043$} & Superfície (0) & 22,54 & 34,13 & 8,12 & 6,34 & 3,40 & $<0,01$ & $<0,1$ & $<0,01$ & $<0,01$ \\
\hline & & & & Meio (3) & 22,25 & 34,06 & 8,11 & 6,30 & 2,70 & $<0,01$ & $<0,1$ & $<0,01$ & $<0,01$ \\
\hline & & & & Fundo (6) & 22,1 & 34,05 & 8,11 & 6,15 & 2,80 & $<0,01$ & $<0,1$ & $<0,01$ & $<0,01$ \\
\hline & \multirow{3}{*}{$\operatorname{Ar} 7$} & \multirow{3}{*}{$-23,8208$} & \multirow{3}{*}{$-45,405$} & Superfície (0) & 22,29 & 34,03 & 8,14 & 6,28 & 4,60 & $<0,01$ & $<0,1$ & $<0,01$ & $<0,01$ \\
\hline & & & & Meio (5) & 22,27 & 34,04 & 8,13 & 6,05 & 4,50 & $<0,01$ & $<0,1$ & $<0,01$ & $<0,01$ \\
\hline & & & & Fundo (10) & 22,27 & 34,05 & 8,13 & 5,97 & 5,40 & $<0,01$ & $<0,1$ & $<0,01$ & $<0,01$ \\
\hline & \multirow{3}{*}{ Ar8 } & \multirow{3}{*}{$-23,8208$} & \multirow{3}{*}{$-45,4036$} & Superfície (0) & 22,31 & 34,06 & 8,13 & 7,58 & 3,30 & $<0,01$ & $<0,1$ & $<0,01$ & $<0,01$ \\
\hline & & & & Meio (8) & 22,25 & 34,06 & 8,13 & 7,36 & 4,70 & $<0,01$ & $<0,1$ & $<0,01$ & $<0,01$ \\
\hline & & & & Fundo (16) & 22,23 & 34,05 & 8,13 & 6,85 & 5,80 & $<0,01$ & $<0,1$ & $<0,01$ & $<0,01$ \\
\hline & & & & Superfície (0) & 22,21 & 34,04 & 8,13 & 6,15 & 4,90 & $<0,01$ & $<0,1$ & $<0,01$ & $<0,01$ \\
\hline & $\operatorname{Ar} 9$ & $-23,82$ & $-45,4024$ & Meio (8) & 22,11 & 34,01 & 8,13 & 5,89 & 6,60 & $<0,01$ & $<0,1$ & $<0,01$ & $<0,01$ \\
\hline & & & & Fundo (15) & 22,12 & 34,02 & 8,13 & 5,69 & 13,00 & $<0,01$ & $<0,1$ & $<0,01$ & $<0,01$ \\
\hline & & & & Superfície (0) & 22,06 & 33,95 & 8,13 & 5,85 & 12,00 & $<0,01$ & $<0,1$ & $<0,01$ & $<0,01$ \\
\hline & Ar10 & $-23,8188$ & $-45,4025$ & Meio (6) & 22,06 & 33,97 & 8,14 & 5,66 & 10,00 & $<0,01$ & $<0,1$ & $<0,01$ & $<0,01$ \\
\hline & & & & Fundo (10) & 22,06 & 33,98 & 8,14 & 5,58 & 11,00 & $<0,01$ & $<0,1$ & $<0,01$ & $<0,01$ \\
\hline
\end{tabular}




\subsubsection{Análises granulométricas}

Os resultados das análises granulométricas das coletas dos anos de 2005 e 2006 (Abril e Setembro) encontram-se na Tabela 05 e ilustrado no Anexo 12.

\section{Coletas realizadas em Julho de 2005}

Os sedimentos coletados ao redor dos difusores do emissário submarino do Araçá ocorrem de forma heterogênea e são predominantemente arenosos, principalmente na fração areia muito fina. Os teores de areia oscilaram entre 46,40 e $82,68 \%\left(\bar{x}=70,45^{ \pm} 12,87 \%\right)$.

Observou-se porcentagem significativa de sedimentos finos na estação Ar10 $(53,24 \%)$, posicionada na região nordeste da malha de amostragem. Os teores de sedimentos finos variaram entre 11,32 e $53,24 \%\left(\bar{x}=25,06^{ \pm} 12,74 \%\right)$.

Grânulos foram identificados em quase todas as estações em porcentagens que variaram de 0,36 e 12,59\%. Menciona-se que a fração grânulo é em sua maioria composta por fragmentos de conchas de moluscos.

Com base nos intervalos propostos por Shepard (1954), os sedimentos são classificados como i) areia - estações Ar1, Ar2, Ar5, Ar6 e Ar8; ii) areia síltica estações Ar3, Ar7, e Ar9; iii) silte arenoso - estação Ar10. Quanto ao grau de seleção, analisado segundo o disposto em Folk \& Ward (1957), constatatou-se sedimentos pobremente selecionados nas estações $\operatorname{Ar} 5$ e $\operatorname{Ar} 10(1,61$ a ,96 $\delta)$ e muito pobremente selecionados nas demais estações $(2,19$ a 3,17 $\delta)$.

A estação Ar4 não foi amostrada devido à elevada quantidade de conchas.

\section{Coletas realizadas em Abril de 2006}

Os resultados granulométricos são semelhantes aos obtidos em Julho de 2005 . Verificou-se predominância de sedimentos arenosos, cujas porcentagens oscilaram entre 7,93 e $89,33 \%\left(\bar{x}=53,54{ }^{ \pm} 23,83 \%\right)$.

Entretanto, observou-se aumento significativo nos teores de finos, de 10 a 20\% em relação ao período anterior. As concentrações de sedimentos finos variaram entre 
8,40 e $92,07 \%(\bar{x}=42,25 \pm 24,96 \%)$, sendo observado na estação Ar10 a maior porcentagem.

Excetuando-se a estação Ar10, grânulos, foram observados nas demais estações em porcentagens que variaram de 0,3 e $13,77 \%$.

Segundo a classificação proposta por Shepard (1954) os sedimentos obtidos para o período são denominados i) areia - estações Ar1 e Ar6; ii) areia síltica - estações Ar2, Ar3, Ar5, Ar7 e Ar8; iii) silte arenoso - estações Ar4 e Ar9; iv) silte argiloso - estação Ar10.

No tocante ao grau de seleção, foram identificados sedimentos pobremente selecionados nas estações $\operatorname{Ar} 1, \operatorname{Ar} 4, \operatorname{Ar} 5$ e $\operatorname{Ar} 10(1,70$ a 1,94 $\delta)$ e muito pobremente selecionados nas demais estações $(2,28$ a 3,05 $\delta)$.

\section{Coletas realizadas em Setembro de 2006}

Assim como o observado nos dois períodos anteriores de coleta, verificou-se sedimentos com granulometria heterogênea, com predominância da fração areia muito fina. Os teores de areia variaram entre 27,88 e $91,12 \%(\bar{x}=54,82 \pm 18,62 \%)$.

Em relação aos demais períodos de amostragem, as concentrações de sedimentos finos são consideradas intermediárias. As porcentagens oscilaram entre 7,10 e 71,63\% ( $\bar{x}=31,32 \pm 21,43 \%$ ). As estações Ar3 e Ar10 apresentaram os maiores teores de sedimentos finos, $53,46 \%$ e $71,63 \%$, respectivamente.

As concentrações de grânulos variaram entre 0 e 42,82\%. As maiores concentrações foram obtidas nas estações Ar6, Ar7 e Ar8.

De acordo com a classificação proposta por Shepard (1954), os sedimentos obtidos ao redor dos difusores do emissário do Araçá são i) areia - estações Ar2, Ar5 a Ar7; ii) areia síltica - estações Ar1, Ar3, Ar4, Ar8 e Ar9; iii) silte arenoso - estação Ar10.

Em relação ao grau de seleção, sedimentos pobremente selecionados $(1,32$ a 1,65 $\delta$ ) ocorreram nas estações Ar2, Ar4 e Ar5. Nas demais estações, foram observados sedimentos muito pobremente selecionados (2,07 a 2,89 $\delta)$.

Apesar de ter sido constatado alteração nos teores de sedimentos arenosos e finos, o padrão de distribuição permanece o mesmo, i.e. com sentido preferencial de diminuição de fluxo hidrodinâmico de sudoeste para nordeste. 
Tabela 05 - Resultados granulométricos obtidos em região circunjacente aos difusores do emissário submarino do Araçá.

Legenda: D. médio = diâmetro médio; D. padrão = desvio padrão; Mto. = muito.

\begin{tabular}{|c|c|c|c|c|c|c|c|c|c|c|c|}
\hline \multirow{2}{*}{\multicolumn{2}{|c|}{ Estações }} & \multirow[b]{2}{*}{ D. Médio $(\Phi)$} & \multirow[b]{2}{*}{ D. Padrão $(\delta)$} & \multirow[b]{2}{*}{ Grânulos (\%) } & \multicolumn{5}{|c|}{ Areia (\%) } & \multicolumn{2}{|c|}{ Pelíticos (\%) } \\
\hline & & & & & Mto. Grossa & Grossa & Média & Fina & Mto. Fina & Silte & Argila \\
\hline \multirow{10}{*}{ 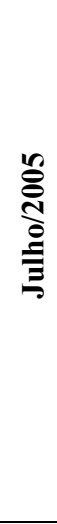 } & Ar1 & 2,44 & 2,21 & 3,85 & 6,73 & 15,21 & 18,28 & 18,74 & 23,72 & 9,38 & 4,09 \\
\hline & $\operatorname{Ar} 2$ & 2,16 & 2,82 & 8,71 & 14,61 & 18,34 & 14,36 & 12,82 & 13,13 & 11,23 & 6,82 \\
\hline & $\mathrm{Ar} 3$ & 2,98 & 3,17 & 7,55 & 9,85 & 19,71 & 8,51 & 8,32 & 14,63 & 20,98 & 10,45 \\
\hline & Ar4 & $* *$ & $* *$ & $* *$ & $* *$ & $* *$ & $* *$ & $* *$ & $* *$ & $* *$ & $* *$ \\
\hline & Ar5 & 3,99 & 1,61 & 0,00 & 0,37 & 0,48 & 1,48 & 7,21 & 67,56 & 17,10 & 5,80 \\
\hline & Ar6 & 2,19 & 2,26 & 3,14 & 11,66 & 18,16 & 16,81 & 16,82 & 22,09 & 7,11 & 4,21 \\
\hline & Ar7 & 3,53 & 2,75 & 1,60 & 11,39 & 8,00 & 5,96 & 6,18 & 37,75 & 18,68 & 10,43 \\
\hline & Ar8 & 1,81 & 2,19 & 2,56 & 11,91 & 35,48 & 15,28 & 5,06 & 12,28 & 15,25 & 2,19 \\
\hline & Ar9 & 2,27 & 3,00 & 12,59 & 18,45 & 14,42 & 9,86 & 5,68 & 10,37 & 21,95 & 6,67 \\
\hline & Ar10 & 4,12 & 1,96 & 0,36 & 0,36 & 4,52 & 10,46 & 10,10 & 20,96 & 47,77 & 5,47 \\
\hline \multirow{10}{*}{ 总 } & Ar1 & 1,90 & 1,92 & 2,27 & 7,35 & 17,04 & 43,45 & 14,71 & 6,78 & 5,18 & 3,22 \\
\hline & Ar2 & 2,89 & 2,76 & 13,77 & 8,76 & 5,06 & 6,11 & 11,98 & 15,31 & 33,34 & 5,67 \\
\hline & Ar3 & 3,36 & 2,28 & 0,37 & 1,26 & 13,92 & 16,89 & 12,94 & 18,99 & 29,36 & 6,27 \\
\hline & Ar4 & 4,78 & 1,79 & 0,03 & 0,16 & 1,35 & 4,87 & 9,24 & 19,80 & 57,88 & 6,67 \\
\hline & Ar5 & 4,53 & 1,70 & 0,06 & 0,02 & 0,07 & 0,42 & 3,19 & 53,33 & 35,55 & 7,36 \\
\hline & Ar6 & 2,07 & 2,46 & 8,33 & 9,05 & 19,65 & 17,78 & 15,81 & 16,34 & 7,96 & 5,08 \\
\hline & Ar7 & 3,08 & 3,05 & 4,04 & 7,56 & 16,94 & 23,84 & 5,97 & 9,00 & 21,92 & 10,73 \\
\hline & Ar8 & 2,60 & 2,72 & 6,69 & 14,97 & 16,24 & 9,24 & 5,72 & 14,77 & 27,37 & 5,00 \\
\hline & Ar9 & 4,48 & 2,98 & 6,52 & 5,50 & 4,95 & 4,38 & 7,19 & 9,60 & 51,46 & 10,40 \\
\hline & Ar10 & 6,51 & 1,94 & 0,00 & 0,00 & 0,24 & 0,40 & 1,16 & 6,13 & 63,25 & 28,82 \\
\hline \multirow{10}{*}{ 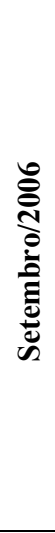 } & Ar1 & 4,26 & 2,27 & 1,64 & 1,69 & 4,03 & 5,62 & 10,85 & 39,84 & 27,53 & 8,80 \\
\hline & Ar2 & 1,94 & 1,65 & 1,79 & 1,21 & 11,12 & 57,44 & 20,84 & 0,51 & 4,12 & 2,97 \\
\hline & Ar3 & 4,98 & 2,11 & 0,16 & 0,74 & 0,92 & 2,58 & 8,35 & 33,78 & 41,37 & 12,09 \\
\hline & Ar4 & 4,25 & 1,63 & 0,00 & 0,03 & 0,24 & 1,14 & 6,26 & 60,20 & 25,89 & 6,23 \\
\hline & Ar5 & 4,09 & 1,32 & 0,52 & 0,18 & 0,49 & 1,07 & 2,30 & 73,06 & 18,35 & 4,02 \\
\hline & Ar6 & 1,44 & 2,34 & 19,22 & 12,11 & 12,11 & 23,55 & 11,19 & 13,56 & 5,03 & 3,21 \\
\hline & Ar7 & 1,74 & 2,89 & 26,88 & 9,95 & 9,69 & 13,74 & 8,67 & 13,48 & 12,55 & 5,04 \\
\hline & Ar8 & 0,72 & 2,68 & 42,82 & 12,25 & 15,89 & 6,22 & 3,57 & 4,46 & 11,70 & 3,09 \\
\hline & $\operatorname{Ar} 9$ & 4,63 & 2,09 & 0,05 & 0,08 & 1,64 & 5,11 & 10,27 & 33,32 & 40,64 & 8,89 \\
\hline & Ar10 & 5,51 & 2,07 & 0,49 & 0,53 & 0,67 & 1,26 & 4,85 & 20,56 & 57,36 & 14,27 \\
\hline
\end{tabular}

** estação não amostrada 
4.1.3 Análises geoquímicas e razões elementares

Os resultados das análises geoquímicas e razões elementares $\mathrm{C} / \mathrm{N}$ e $\mathrm{C} / \mathrm{S}$, obtidos para os anos de 2005 e 2006 (Abril e Setembro de 2006), encontram-se na Tabela 06 e ilustrados nos Anexos 13 a 21.

Coletas realizadas em Julho de 2005

Os dados de $\mathrm{pH}$ e Eh não foram obtidos neste período devido à problemas técnicos com o equipamento de amostragem.

Os teores de carbonato de cálcio variaram de 4,02 a 57,34\% $\left({ }^{x}=28,19^{ \pm}\right.$ 16,24\%). Segundo classificação proposta por Larsonneur et al. (1982), foram observados sedimentos litoclásticos ${ }^{11}$ nas estações $\operatorname{Ar} 1, \operatorname{Ar} 5, \operatorname{Ar} 6, \operatorname{Ar} 7$ e $\operatorname{Ar} 10$ e sedimentos litobioclásticos ${ }^{12}$ nas estações $\operatorname{Ar} 2$, Ar3 e Ar9. Na estação Ar8 foram identificados sedimentos biolitoclásticos ${ }^{13}$.

Os teores de carbono orgânico total oscilaram entre 0,10 e $3,37 \%\left({ }^{x}=31,32 \pm\right.$ 21,43\%). Os maiores valores ocorreram nas estações $\operatorname{Ar} 8$ (3,31\%) e Ar9 (3,37\%). Nestas estações foram observadas concentrações cerca de 3 a 30 vezes superiores às estações adjacentes.

As concentrações de nitrogênio variaram de 0,01 a $0,10 \%(\bar{x}=0,03 \pm 0,03 \%)$. A maior concentração foi observada na estação Ar8, ocorrendo o contrário nas estações Ar3, Ar6 e Ar9.

Em relação ao fracionamento do fósforo, foram obtidos os seguintes teores: fósforo total entre 0,069 e $0,19 \%$; fósforo orgânico entre 0,002 e $0,053 \%$ e fósforo inorgânico entre $0,058 \%$ e $0,159 \%$. As maiores concentrações de fósforo total ocorreram nas estações Ar8 e Ar9, localizadas nas regiões sul e sudeste da malha de amostragem, respectivamente.

Os teores de enxofre oscilaram de 0,09 e $0,46 \%\left(\bar{x}=0,18{ }^{ \pm} 0,11 \%\right)$. O maior teor foi obtido na estação Ar10, cujo valor é aproximadamente 2 a 4 vezes superior ao encontrado em estações circunvizinhas.

\footnotetext{
${ }^{11}$ Litoclástico - teores de carbonato de cálcio inferiores a $30 \%$.

${ }^{12}$ Litobioclástica - teores de carbonato de cálcio oscilando entre 30 e $50 \%$.

${ }^{13}$ Biolitoclástica - teores de carbonato de cálcio variando entre 50 e $70 \%$.
} 
Os resultados das razões $\mathrm{C} / \mathrm{N}$ variaram entre 2,40 e 337. Já os valores obtidos para as razões C/S oscilaram entre 0,8 e 19,94.

Coletas realizadas em Abril de 2006

Os valores de $\mathrm{pH}$ e Eh oscilaram de 7,34 a 8,16 $\left(\bar{x}=7,78^{ \pm} 0,29 \%\right)$ e de -100 a $211 \mathrm{mV}$, respectivamente.

Os teores de carbonato de cálcio variaram de 7,70 a $290,90 \%\left(\bar{x}=18,7^{ \pm}\right.$ 6,70\%), o que confere a região estudada características de ambiente litoclástico.

As concentrações de carbono orgânico total variaram entre 0,27 e $2,19 \%(\bar{x}=$ $1,01 \pm 0,60 \%)$. As maiores porcentagens ocorreram na estação Ar4 (1,35\%), localizada na região norte da área de estudo, e nas estações Ar9 (1,73\%) e Ar10 (2,19\%), posicionadas nas regiões sudeste e nordeste. As menores concentrações ocorreram nas estações $\operatorname{Ar} 1(0,32 \%)$ e $\operatorname{Ar} 6(0,27 \%)$, localizadas na saída do emissário submarino e região sudoeste, respectivamente.

Os teores de nitrogênio variaram de 0,01 a $0,33 \%(\bar{x}=0,19 \pm 0,10 \%)$. As maiores porcentagens foram observadas nas estações $\operatorname{Ar} 4(0,33 \%)$ e $\operatorname{Ar} 10$ (0,32\%), e a menor na estação $\operatorname{Ar} 1(0,01 \%)$.

Para os dados de fósforo, foram obtidos os seguintes valores: fósforo total 0,055 a $0,176 \%$; fósforo orgânico 0,024 a $0,131 \%$ e fósforo inorgânico 0,028 a 0,047\%. A maior concentração de fósforo total e orgânico ocorreu na estação Ar10, sendo observado na estação Ar9 o maior teor de fósforo inorgânico.

Os valores de enxofre oscilaram entre 0,003 e $0,60 \%(\bar{x}=0,23 \pm 0,20 \%)$. As menores concentrações ocorreram quase na mesma proporção nas estações Ar6 $(0,004 \%), \operatorname{Ar} 7(0,004 \%)$ e $\operatorname{Ar} 8(0,003 \%)$, posicionadas nas regiões sudoeste e sul da área de estudo. A maior concentração, por sua vez, foi observada na estação Ar10.

Os valores das razões $\mathrm{C} / \mathrm{N}$ e $\mathrm{C} / \mathrm{S}$ oscilaram, entre 4 e 32 e entre 2,9 e 266,6 respectivamente. 
Os valores de $\mathrm{pH}$ variaram entre 7,05 e 7,88 $(\bar{x}=7,44 \pm 0,26)$ e os de Eh entre 60 e-70 mV. Excetuando-se a estação Ar6, valores de Eh negativos ocorreram em todas as demais estações.

Os teores de carbonato de cálcio variaram de 4,85 a $29,92(\bar{x}=15,07 \pm 6,970 \%)$, o que indica presença de sedimentos litoclásticos. Verificou-se para este período de amostragem, bem como para Abril, diminuição significativa dos teores de carbonato de cálcio.

As concentrações de carbono orgânico total oscilaram entre 0,27 e $2,14 \%(\bar{x}=$ $0,94 \pm 0,60 \%)$. As maiores concentrações foram obtidas nas estações $\operatorname{Ar} 9$ (2,14\%) e $\operatorname{Ar} 10$ (1,57\%). As estações Ar2 (0,27\%) e Ar5 (0,29\%), por sua vez, apresentaram os menores teores.

Os teores de nitrogênio oscilaram de 0,005 a $0,19 \%(\bar{x}=0,09 \pm 0,07 \%)$. As maiores concentrações ocorreram nas estações Ar3 e Ar4, ambas com 0,19\% de nitrogênio.

Em relação ao fracionamento do fósforo, os seguintes valores foram obtidos: fósforo total 0,022 a $0,059 \%$; fósforo orgânico 0,001 a $0,023 \%$ e fósforo inorgânico 0,017 a $0,048 \%$. A maior concentração de fósforo total e orgânico ocorreu na estação Ar9, sendo observado na estação Ar8 o maior teor de fósforo inorgânico.

Os teores de enxofre oscilaram entre 0,01 e $0,48 \%(\bar{x}=0,19 \pm 0,16 \%)$. As estações $\operatorname{Ar} 1(0,48 \%), \operatorname{Ar} 9(0,38 \%)$ e $\operatorname{Ar} 10(0,33)$ apresentaram os maiores teores. Os menores valores ocorreram em estações posicionadas nas regiões sul e sudoeste da malha de amostragem.

Os resultados das razões $\mathrm{C} / \mathrm{N}$ e $\mathrm{C} / \mathrm{S}$ oscilaram entre 3,58 e 157 e entre 2,13 e 53,75 respectivamente. 
Tabela 06 - Resultados geoquímicos e razões elementares obtidos em região circunjacente ao emissário submarino de esgotos domésticos do Araçá.

\begin{tabular}{|c|c|c|c|c|c|c|c|c|c|c|c|c|c|}
\hline \multirow{10}{*}{ 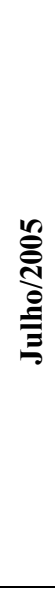 } & Estações & $\begin{array}{l}\text { Prof. } \\
\text { (m) }\end{array}$ & $\mathrm{pH}$ & Eh & $\begin{array}{c}\mathrm{CaCO}_{3} \\
(\%)\end{array}$ & $\begin{array}{l}\text { Cot } \\
(\%)\end{array}$ & $\begin{array}{l}\mathrm{N} \\
(\%)\end{array}$ & $\begin{array}{c}\text { Ptotal } \\
(\%)\end{array}$ & $\begin{array}{c}\text { Porg } \\
(\%)\end{array}$ & $\begin{array}{c}\text { Pinorg } \\
(\%)\end{array}$ & $\begin{array}{c}\text { S } \\
(\%)\end{array}$ & $\begin{array}{c}\text { Razão } \\
\text { C/N }\end{array}$ & $\begin{array}{l}\text { Razão } \\
\text { C/S }\end{array}$ \\
\hline & Ar1 & 3,5 & $*$ & $*$ & 25,92 & 0,12 & 0,05 & 0,083 & 0,002 & 0,081 & 0,11 & 2,40 & 1,11 \\
\hline & Ar2 & 9,5 & * & $*$ & 42,57 & 0,62 & 0,04 & 0,102 & 0,008 & 0,094 & 0,13 & 15,50 & 4,96 \\
\hline & Ar3 & 12,5 & $*$ & $*$ & 31,67 & 0,33 & 0,01 & 0,112 & 0,020 & 0,091 & 0,18 & 33,00 & 1,88 \\
\hline & Ar5 & 3,5 & * & $*$ & 4,02 & 0,38 & 0,02 & 0,069 & 0,011 & 0,058 & 0,19 & 19,00 & 1,99 \\
\hline & Ar6 & 8,5 & $*$ & $*$ & 24,46 & 0,14 & 0,01 & 0,106 & 0,013 & 0,093 & 0,09 & 14,00 & 1,65 \\
\hline & Ar7 & 9,5 & $*$ & $*$ & 10,02 & 0,10 & 0,03 & 0,152 & 0,024 & 0,128 & 0,12 & 3,33 & 0,84 \\
\hline & Ar8 & 11,5 & $*$ & $*$ & 57,34 & 3,31 & 0,10 & 0,180 & 0,032 & 0,150 & 0,17 & 33,10 & 19,94 \\
\hline & Ar9 & 17,5 & $*$ & $*$ & 36,23 & 3,37 & 0,01 & 0,190 & 0,033 & 0,159 & 0,20 & 337,00 & 16,68 \\
\hline & Ar10 & 13,5 & $*$ & $*$ & 21,51 & 1,49 & 0,04 & 0,140 & 0,053 & 0,082 & 0,46 & 37,25 & 3,24 \\
\hline \multirow{10}{*}{ 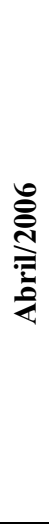 } & Ar1 & 6,5 & 7,66 & -180 & 7,70 & 0,32 & 0,01 & 0,063 & 0,025 & 0,039 & 0,10 & 32,00 & 3,11 \\
\hline & Ar2 & 10,5 & 8,00 & -101 & 21,10 & 1,07 & 0,26 & 0,063 & 0,024 & 0,039 & 0,29 & 4,12 & 3,73 \\
\hline & Ar3 & 10,5 & 8,06 & -180 & 13,60 & 0,80 & 0,10 & 0,077 & 0,039 & 0,039 & 0,25 & 8,00 & 3,24 \\
\hline & Ar4 & 8,5 & 7,34 & -180 & 19,20 & 1,35 & 0,33 & 0,079 & 0,042 & 0,037 & 0,44 & 4,09 & 3,08 \\
\hline & Ar5 & 3,5 & 8,16 & -211 & 13,70 & 0,82 & 0,16 & 0,090 & 0,059 & 0,031 & 0,28 & 5,13 & 2,95 \\
\hline & Ar6 & 7,5 & 7,43 & -100 & 12,90 & 0,27 & 0,16 & 0,055 & 0,027 & 0,028 & 0,004 & 1,69 & 67,50 \\
\hline & Ar7 & 12,5 & 7,50 & -147 & 19,80 & 0,70 & 0,20 & 0,068 & 0,030 & 0,039 & 0,004 & 3,50 & 175,00 \\
\hline & Ar8 & 13,5 & 8,00 & -154 & 26,10 & 0,80 & 0,19 & 0,093 & 0,057 & 0,036 & 0,003 & 4,21 & 266,67 \\
\hline & Ar9 & 15,5 & 7,92 & -164 & 29,90 & 1,73 & 0,17 & 0,086 & 0,038 & 0,047 & 0,38 & 10,18 & 4,56 \\
\hline & Ar10 & 12,5 & 7,76 & -180 & 23,10 & 2,19 & 0,32 & 0,176 & 0,131 & 0,045 & 0,60 & 6,84 & 3,66 \\
\hline \multirow{10}{*}{ 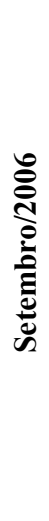 } & Ar1 & 7,0 & 7,18 & -146 & 15,07 & 1,22 & 0,15 & 0,035 & 0,001 & 0,034 & 0,48 & 8,13 & 2,54 \\
\hline & Ar2 & 7,5 & 7,88 & -7 & 4,85 & 0,27 & 0,01 & 0,035 & 0,003 & 0,032 & 0,04 & 54,00 & 7,30 \\
\hline & Ar3 & 11,0 & 7,27 & -115 & 15,08 & 1,21 & 0,19 & 0,043 & 0,017 & 0,026 & 0,25 & 6,37 & 4,94 \\
\hline & Ar4 & 4,0 & 7,45 & -170 & 11,00 & 0,83 & 0,19 & 0,030 & 0,007 & 0,023 & 0,22 & 4,37 & 3,86 \\
\hline & Ar5 & 1,8 & 7,61 & -135 & 8,53 & 0,29 & 0,07 & 0,022 & 0,005 & 0,017 & 0,14 & 4,14 & 2,13 \\
\hline & Ar6 & 7,5 & 7,69 & 60 & 12,17 & 0,43 & 0,12 & 0,032 & 0,004 & 0,028 & 0,01 & 3,58 & 53,75 \\
\hline & Ar7 & 11,0 & 7,48 & -59 & 15,55 & 0,56 & 0,03 & 0,039 & 0,007 & 0,032 & 0,10 & 18,67 & 5,66 \\
\hline & Ar8 & 17,0 & 7,62 & -113 & 29,92 & 0,94 & 0,07 & 0,050 & 0,002 & 0,048 & 0,02 & 13,43 & 52,22 \\
\hline & Ar9 & 16,0 & 7,05 & -118 & 21,47 & 2,14 & 0,05 & 0,059 & 0,023 & 0,036 & 0,38 & 42,80 & 5,68 \\
\hline & Ar10 & 11,0 & 7,21 & -77 & 17,06 & 1,57 & 0,01 & 0,049 & 0,019 & 0,030 & 0,33 & 157,00 & 4,74 \\
\hline
\end{tabular}


4.1.4 Análise das associações de foraminíferos

\subsubsection{Biocenoses - composição, distribuição e análise morfométrica}

A relação das espécies identificadas nas coletas realizadas em Julho de 2005, Abril e Setembro de 2006, bem como suas respectivas abundâncias relativas encontramse mencionadas no Anexo 22.

Coletas realizadas em Julho de 2005

Foram identificados 10 gêneros e 42 espécies de foraminíferos, as quais estão distribuídas entre as Subordens Miliolina (5 espécies), Textulariina (8 espécies) e Rotaliina (29 espécies). Algumas das espécies de foraminíferos encontram-se ilustradas na Prancha 1.

Foram analisados volumes de sedimento que oscilaram entre 10 e $40 \mathrm{~cm}^{3}$ para a obtenção de 100 espécimes vivos. O volume de $20 \mathrm{~cm}^{3}$ foi utilizado em 6 das 9 estações analisadas.

As densidades variaram entre 28 e 98 foraminíferos por $10 \mathrm{~cm}^{3}$ de sedimento $(\bar{x}$ $=63{ }^{ \pm} 22$ ). A maior densidade foi observada na estação Ar1, onde foram identificados 98 foraminíferos em $10 \mathrm{~cm}^{3}$ de sedimento. O contrário, por sua vez, foi observado nas estações Ar9 e Ar10, onde foram obtidos 38 e 28 foraminíferos por $10 \mathrm{~cm}^{3}$ de sedimento.

Os valores de riqueza oscilaram de 12 e 26 espécies $(\bar{x}=22 \pm 4)$, sendo observado na estação Ar10 o menor valor e o contrário na estação Ar7.

Os valores de diversidade específica e equitatividade variaram entre 1,70 e 2,64 ( $\left.\bar{x}=2,31^{ \pm} 0,28\right)$ e entre 0,68 e $0,85\left(\bar{x}=0,76^{ \pm} 0,06\right)$, respectivamente.

Ammonia tepida é a espécie dominante em todas as estações; as abundâncias relativas oscilaram entre 24,7 e $47,3 \%\left(\bar{x}=37,3^{ \pm} 7,8 \%\right)$.

Em ordem decrescente de importância, as espécies que apresentaram as maiores abundâncias relativas foram Pararotalia cananeiaensis $(1,8$ a $17 \% ; \bar{x}=6,9 \pm 4,3 \%)$, Brizalina striatula $\left(3,2\right.$ a $\left.7,7 \% ; \bar{x}=5,9^{ \pm} 1,4 \%\right)$, Lobatula lobatula $(0$ a $11,9 \% ; \bar{x}=4,9$ $\pm 3,7 \%)$, Bolivina ordinaria $(1,1$ a $11,3 \% ; \bar{x}=4,8 \pm 3,1 \%)$, Buliminella elegantissima $(0$ 
a $7,8 \% ; \bar{x}=3,4 \pm 2,9 \%)$, Pseudononion atlanticum (0 a $6,1 \% ; \bar{x}=3,2 \pm 2,1 \%)$, Ammonia parkinsoniana (0 a 5,4\%; $\left.\bar{x}=2,4^{ \pm} 1,7 \%\right)$, Cassidulina crassa $(0$ a $6,1 \% ; \bar{x}=$ $\left.1,8^{ \pm} 1,9 \%\right)$, Hanzawaia boueana (0 a $\left.5 \% ; \bar{x}=1,2 \pm 1,6 \%\right)$.

Espécies bioindicadoras de ambiente rico em matéria orgânica são significantemente mais abundantes do que espécies bioindicadoras de ambiente óxico (Anexo 23). A abundância relativa das espécies bioindicadoras de ambiente rico em matéria orgânica varia de 22,3 a $46,1 \%(\bar{x}=30,5 \pm 7,4 \%)$ do total das espécies de foraminíferos identificadas. Já as abundâncias relativas das espécies bioindicadoras de ambiente óxico oscilaram entre 4,5 e $29,4 \%(\bar{x}=17,2 \pm 8,7 \%)$, sendo observadas as maiores porcentagens nas estações Ar6 (26,8\%) e Ar8 (29,4\%).

Os resultados das análises morfométricas permitiram identificar carapaças de três classes de tamanho: pequenas, médias e grandes. Excetuando-se as estações Ar3 e Ar8, carapaças médias são dominantes em toda a área de estudo, em porcentagens que oscilaram entre 43 e $76 \%\left(\bar{x}=59,2^{ \pm} 11,6 \%\right)$.

Carapaças pequenas são dominantes nas estações Ar3 e Ar8, ambas com 54\%. As porcentagens oscilaram entre 21 e $54 \%(\bar{x}=37,1 \pm 11,6 \%)$. Carapaças grandes foram identificadas em todas as estações em concentrações que variaram de 2 a $7 \%(\bar{x}$ $=3,7 \pm 1,4 \%)$.

Coletas realizadas em Abril de 2006

Foram identificados 10 gêneros e 61 espécies de foraminíferos bentônicos, as quais encontram-se distribuídas entre as Subordens Textulariina (8 espécies), Miliolina (10 espécies) e Rotaliina (43 espécies). Os volumes de sedimentos analisados variaram entre 10 e $40 \mathrm{~cm}^{3}$, sendo o volume de $20 \mathrm{~cm}^{3}$ utilizado em $80 \%$ das amostras analisadas; padrão similar ao observado para as coletas realizadas em 2005 (Anexo 22).

As densidades variaram entre 29 e 236 foraminíferos por $10 \mathrm{~cm}^{3}$ de sedimento ( $\bar{x}=82 \pm 58$ ). A maior densidade foi observada na estação Ar5, onde foram obtidos 236 foraminíferos em $10 \mathrm{~cm}^{3}$ de sedimento. O contrário, por sua vez, ocorreu na estação Ar1, onde foram analisados $40 \mathrm{~cm}^{3}$ de sedimento para obtenção de 117 espécimes, i.e. 29 foraminíferos por $10 \mathrm{~cm}^{3}$ de sedimento. 
Os valores de riqueza oscilaram entre 19 e 36 espécies $(\bar{x}=26 \pm 6)$. As maiores riquezas foram identificadas nas estações Ar6 (36 espécies) e Ar8 (34 espécies), e as menores nas estações Ar3 (19 espécies) e Ar10 (21 espécies).

Os valores de diversidade específica e equitatividade variaram entre 1,87 e 2,95 ( $\bar{x}=2 \pm 0,30)$ e entre 0,61 e $0,82(\bar{x}=0,70 \pm 0,06)$, respectivamente.

A espécie dominante em todas as estações analisadas é Ammonia tepida, cujas abundâncias relativas oscilaram entre 20,6 e 49,6\% $(\bar{x}=41,4 \pm 8,2 \%)$. Subsequentemente, as espécies com as maiores abundâncias relativas são, em ordem decrescente, Brizalina striatula ( 3 a $13,2 \% ; \bar{x}=6,2 \pm 3,2 \%$ ), Buliminella elegantissima $(0,9$ a $9,2 \% ; \bar{x}=4,9 \pm 2,9 \%)$, Hopkinsina pacifica $(0,9$ a $8,7 \% ; \bar{x}=4,4 \pm 2,1 \%)$, Ammonia parkinsoniana (0 a 9,7\%; $\bar{x}=3,8 \pm 2,8 \%$ ), Rosalina floridensis $(0$ a $7,4 \% ; \bar{x}$ $=2,3 \pm 2,5 \%)$, Pseudononion atlanticum (0 a 5,1\%; $\bar{x}=3,1 \pm 1,6 \%)$, Cassidulina crassa (0 a $\left.5,1 \% ; \bar{x}=2,1^{ \pm} 1,7 \%\right)$, Gaudryina exilis (0 a 7,7\%; $\bar{x}=2,0 \pm 2,4 \%$ ) e Bolivina doniezi ( 0 a $\left.5 \% ; \bar{x}=1,6^{ \pm} 1,4 \%\right)$.

Espécies bioindicadoras de ambiente rico em matéria orgânica, assim como o verificado para Junho de 2005, são predominantes em todas as estações (Anexo 23). As porcentagens oscilaram entre 28,2 a $46 \%\left(\bar{x}=38,4{ }^{ \pm} 6 \%\right)$ do total das espécies de foraminíferos identificadas, e ocorre, em média, quase na mesma proporção em todas as estações analisadas, conforme pode ser observado na Figura 23.

Já as abundâncias espécies bioindicadoras de ambiente óxico variaram de 1,7 a $31,6 \%(\bar{x}=10,3 \pm 8,8 \%)$. Conforme observado na Figura 23, verifica-se diminuição de distribuição de sudoeste para norte-nordeste da área de estudo.

Em relação às análises morfométricas, foram identificadas três classes de tamanho (Anexo 24). Em todas as estações analisadas, carapaças médias são dominantes, com valores que oscilaram entre 53 e $69 \%(\bar{x}=61 \pm 5 \%)$.

As porcentagens de carapaças pequenas variaram de 25 a $47 \%(\bar{x}=35 \pm 6 \%)$, sendo a maior porcentagem observada na estação Ar10

Excetuando-se a estação Ar10, carapaças grandes ocorreram em todas as estações, em porcentagens que oscilaram de 3 a $11 \%(\bar{x}=4 \pm 3 \%)$. A maior concentração de carapaças grandes foi observada na estação Ar6, posicionada na região sudoeste, em relação à saída do emissário submarino. 
Foram identificados 17 gêneros e 90 espécies de foraminíferos bentônicos, as quais encontram-se distribuídas entre as Subordens Miliolina (12 espécies), Textulariina (17 espécies) e Rotaliina (62 espécies). Os volumes de sedimento utilizados variaram entre 10 e $210 \mathrm{~cm}^{3}$, sendo o vlume de $10 \mathrm{~cm}^{3}$ utilizado em 7 das 10 estações analisadas.

As densidades oscilaram de 5 a 262 foraminíferos por $10 \mathrm{~cm}^{3}$ de sedimento $(\bar{x}=$ $133 \pm$ 86). As maiores densidades foram observadas nas estações Ar4, Ar5 e Ar7, localizadas, respectivamente, nas regiões nordeste, norte e sudoeste da área de estudo. A menor densidade, por sua vez, foi obtida na estação Ar1, localizada na saída do emissário submarino. Analisou-se $210 \mathrm{~cm}^{3}$ para a obtenção de 105 espécimes (Anexo 22).

Os valores de riqueza variaram entre 14 e 46 espécies $(\bar{x}=24 \pm 10 \%)$, sendo observados os maiores valores nas estações Ar3 (46 espécies) e Ar7 (36 espécies). As estações Ar1 e Ar5, por sua vez, apresentaram os menores valores, somente 14 espécies em cada estação.

Os valores de diversidade específica e equitatividade foram de 0,98 a $2,70(\bar{x}=$ $2,4 \pm 0,5 \%)$ e de 0,37 a $0,79(\bar{x}=0,65 \pm 0,1 \%)$.

Assim como para os demais períodos de estudo, Ammonia tepida é a espécie dominante $(26,2$ a $74 \% ; \bar{x}=42,7 \pm 15,2 \%)$. Posteriormente, as espécies que apresentaram significativas abundâncias foram Ammonia parkinsoniana (5,5 a 22,7\%; $\bar{x}=11,5 \pm 4,8 \%)$, Buliminella elegantissima $(0$ a $15,1 \% ; \bar{x}=6,2 \pm 5,1 \%)$, Brizalina striatula (0 a 13,8\%; $\bar{x}=5,4 \pm 4,2 \%$ ), Rosalina floridensis (0 a 12\%; $\bar{x}=3 \pm 4,5 \%)$, Lobatula lobatula (0 a $10,4 \% ; \bar{x}=2,7 \pm 3,8 \%$ ), Pseudononion atlanticum (0 a $5,8 \% ; \bar{x}$ $\left.=0,7^{ \pm} 1,8 \%\right)$.

Espécies bioindicadoras de ambiente rico em matéria orgânica permanecem como dominantes (Anexo 23). As abundâncias relativas oscilaram entre 11,1 e 53,1\% ( $\bar{x}=27,2 \pm 10,7 \%$ ). A maior concentração ocorreu na estação Ar4, sendo contrário observado na estação Ar5.

Excetuando-se as estações Ar5 e Ar10, espécies bioindicadoras de ambiente óxico estiveram presentes em abundâncias relativas que variaram de 1,2 a $31,2(\bar{x}=$ $12,4 \pm 13,4 \%)$. As maiores abundâncias foram obtidas nas estações Ar2 (30\%), Ar6 
$(31,2 \%)$ e $\operatorname{Ar} 7$ (27,7\%), localizadas nas regiões sul e sudoeste da área de estudo (Ar6 e $\operatorname{Ar} 7)$.

Os resultados das análises morfométricas indicaram a presença de 4 classes de tamanho: pequenas, médias, grandes e um macroforaminífero na estação Ar6.

Carapaças médias são predominantes em todas as estações analisadas, em porcentagens que variaram entre 51 e $65 \%(\bar{x}=59 \pm 4 \%)$. Carapaças pequenas estiveram presentes em todas as estações em porcentagens que oscilaram entre 29 e $44 \%(\bar{x}=37 \pm 5 \%)$. As maiores concentrações foram observadas nas estações $\operatorname{Ar} 9 \mathrm{e}$ Ar10, posicionadas nas regiões sudeste e nordeste da área de estudo, respectivamente. Carapaças grandes estiveram em todas as estações em porcentagens que variaram de $1 \mathrm{a}$ $6 \%(\bar{x}=4 \pm 2 \%)$.

\subsubsection{Tanatocenoses - composição, distribuição, aspectos morfométricos $e$ tafonômicos (coloração e grau de preservação)}

A relação das espécies identificadas nas coletas realizadas em Julho de 2005, Abril e Setembro de 2006, bem como suas respectivas abundâncias relativas encontramse sumarizadas no Anexo 25.

Coletas realizadas em Julho de 2005

Foram identificados 15 gêneros e 81 espécies de foraminíferos, as quais encontram-se distribuídas entre as subordens Textulariina (11 espécies), Miliolina (20 espécies) e Rotaliina (50 espécies). Algumas das espécies identificadas encontram-se ilustradas nas Pranchas 01 a 10.

As densidades oscilaram entre 516 e 2791 foraminíferos por $10 \mathrm{~cm}^{3}$ de sedimento. A maior densidade foi obtida na estação Ar5, sendo as menores observadas nas estações Ar3 e Ar8, 568 e 516 foraminíferos por $\mathrm{cm}^{3}$ de sedimento, respectivamente (Anexo 25).

Os valores das riquezas variaram entre 30 e 45 espécies ( $\bar{x}=36^{ \pm} 5$ espécies). A estação Ar2 (45 espécies), localizada na região sul da área de estudo, apresentou a maior riqueza, o contrário, por sua vez, foi observado na estação Ar6 (30 espécies), localizada na região sudoeste. 
Os valores de diversidade específica e equitatividade variaram de 2,46 a 3,03 ( $\bar{x}$ $\left.=2,78^{ \pm} 0,21\right)$ e de 0,72 a $0,84(\bar{x}=0,77 \pm 0,04 \%)$.

Excetuando-se a estação Ar1, Pararotalia cananeiaensis é a espécie predominante em todas as demais estações; as abundâncias relativas variaram entre 12 e $27,3\left(\bar{x}=17,7^{ \pm} 5,4 \%\right)$. Bulimina marginata é a segunda espécie mais abundante, sendo predominante na estação Arl (16\%). As abundâncias relativas desta espécie oscilaram entre 6,2 e $16 \%\left(\bar{x}=9,8^{ \pm} 3 \%\right)$. As demais espécies que apresentaram significativas abundâncias relativas, em ordem decrescente, foram Ammonia tepida $(4,8$ a 15,2\%; $\bar{x}=$ $\left.8,1^{ \pm} 3,2 \%\right)$, Pseudononion atlanticum $\left(1,7\right.$ a $\left.8,5 \% ; \bar{x}=5^{ \pm} 2,2 \%\right)$, Hanzawaia boueana $(6,3$ a $3,6 \% ; \bar{x}=3,6 \pm 2 \%)$, Cribroelphidium excavatum $(0,2$ a $6,5 \% ; \bar{x}=3,2 \pm 2 \%)$, Cribroelphidium poyeanum $\left(0,3\right.$ a $\left.7,2 \% ; \bar{x}=2,9^{ \pm} 2,1 \%\right)$, Rolshauseni rolshauseni $(8,3$ a $2,4 \% ; \bar{x}=2,4^{ \pm} 2,6 \%$ ). As espécies que apresentaram abundâncias relativas inferiores a 5\%, em todas as estações, são consideradas raras e encontram-se relacionadas no Anexo 25.

Assim como o observado para as biocenoses, espécies bioindicadoras de ambiente enriquecido por matéria orgânica são predominantes (Anexo 26); as abundâncias relativas oscilaram entre 28,7 e $38,8 \%\left(\bar{x}=32,8^{ \pm} 3,1 \%\right)$.

Espécies bioindicadoras de ambiente óxico estiveram presentes em todas as estações, em abundâncias relativas que oscilaram de 7,5 a $23,4 \%(\bar{x}=14,6 \pm 6,4 \%)$ (Anexo 26).

Os resultados das análises morfométricas identificaram a presença de foraminíferos com carapaças pequenas, médias, grandes e pertencentes à macroforaminíferos (Anexo 27). Carapaças médias, excetuando-se as estações Ar8 e Ar10, são predominantes em porcentagens que oscilaram entre 34 e $71 \%(\bar{x}=52 \pm$ 12\%). Carapaças pequenas, predominantes nas estações Ar8 (41\%) e Ar10 (48\%), foram observadas em porcentagens que variaram de 6 a $48 \%(\bar{x}=25 \pm 13,2 \%)$. A menor porcentagem ocorreu na estação Ar1, posicionada na saída do emissário submarino. Carapaças grandes ocorreram em todas as estações em porcentagens que foram de 6 a $35 \%(\bar{x}=22 \pm 10,5 \%)$. As maiores porcentagens foram observadas nas estações Ar1 (34\%), Ar2 (30\%) e ar9 (35\%), a menor porcentagem, por sua vez, ocorreu na estação Ar10 (6\%). Carapaças pertencentes à macroforaminíferos foram observadas 
nas estações Ar1, Ar2, Ar3, Ar8 e Ar9, em baixas porcentagens, entre 0 e 4\% $(\bar{x}=1,2 \pm$ $1,5 \%)$.

No tocante ao grau de preservação verificou-se predominância de carapaças fragmentadas, devido à abrasão mecânica (Anexo 28); as porcentagens ocilaram entre 52,3 e $68,5(\bar{x}=58 \pm 6 \%)$. Conforme observado no Anexo 28, verificou-se diminuição de concentração de carapaças parcialmente fragmentadas de sudoeste para nortenordeste da malha de amostragem.

Carapaças inteiras ocorreram em porcentagens que variaram de 27,2 e $46,2 \%(\bar{x}$ $\left.=38,3^{ \pm} 6,69 \%\right)$. As menores porcentagens de carapaças inteiras foram observadas nas estações Ar6 e Ar7.

Fragmentos de carapaças ocorreram em todas as estações, em porcentagens que oscilaram entre 1,5 e $6,2 \%(\bar{x}=3,7 \pm 1,5 \%)$.

A análise da coloração das carapaças permitiu identificar a predominância de carapaças normais em todas as estações analisadas. As porcentagens obtidas variaram de 55,7 a $74,4 \%(\bar{x}=66 \pm 6,07 \%)$.

Carapaças preenchidas por monossulfeto de ferro e/ou pirita ocorreram em todas as estações, em porcentagens que oscilaram entre 17,4 e $35,5 \%\left(\bar{x}=26,3^{ \pm} 6,7 \%\right)$. A estação Ar1 apresentou a maior porcentagem, 35,5\%.

Carapaças de coloração acastanhada ocorreram em porcentagens que variaram de 2,4 a $11,7\left(\bar{x}=7,7^{ \pm} 2,81 \%\right)$. As maiores porcentagens ocorreram nas estações $\operatorname{Ar} 7 \mathrm{e}$ Ar8, posicionadas nas regiões sudoeste e sul da malha de amostragem.

Foram observadas carapaças com sinais de bioerosão nas estações $\operatorname{Ar} 1$ (Bulimina marginata, Fursenkoina pontoni e Quinqueloculina seminula), Ar3 (Bulimina marginata, Pseudononion atlanticum e Pseudononion grateloupi) e Ar7 (2 espécimes de Pseudononion atlanticum).

Coletas realizadas em Abril de 2006

Foram identificados 18 gêneros e 100 espécies de foraminíferos, as quais se distribuem entre as Subordens Miliolina (14 espécies), Textulariina (20 espécies) e Rotaliina (66 espécies). Algumas das espécies identificadas encontram-se ilustradas na Prancha 1. 
As densidades oscilaram entre 141e 9568 foraminíferos por $10 \mathrm{~cm}^{3} \mathrm{de}$ sedimento. A maior densidade, assim como o verificado para a coleta realizada em Junho de 2005, foi observada na estação Ar5, localizada na região norte da área de estudo. A estação Ar1 apresentou a menor densidade, nesta estação foram obtidos 148 espécimes.

Os valores de riqueza variaram de 24 a 51 espécies $(\bar{x}=42 \pm 8$ espécies). As estações Ar6 e Ar8, apresentaram os maiores valores (51 espécies). O menor valor de riqueza ocorreu na estação Ar1, onde foram identificadas 24 espécies.

Os valores de diversidade específica e equitatividade variaram entre 2,32 e 3,18 ( $\left.\bar{x}=2,85^{ \pm} 0,24\right)$ e entre 0,72 e $0,80\left(\bar{x}=0,75^{ \pm} 0,03 \%\right)$.

A espécie dominante em todas as estações analisadas é Pararotalia cananeiaensis, cujas abundâncias relativas oscilaram entre 15,1 e $26,2 \%(\bar{x}=21,6 \pm$ 3,3\%). As demais espécies que apresentaram significativas abundâncias relativas, em ordem decrescente, foram Ammonia tepida (6,6 a 16,6\%; $\bar{x}=12,4 \pm 3,2 \%)$, Bulimina marginata $(1,4$ a $10,9 \% ; \bar{x}=4,5 \pm 3,2 \%)$, Ammonia parkinsoniana $(1,1$ a $10 \% ; \bar{x}=4,6$ $\pm 2,7 \%)$, Pseudononion atlanticum $(0,7$ a $6,6 \% ; \bar{x}=3,2 \pm 1,9 \%)$, Hanzawaia boueana $(0,3$ a $6 \% ; \bar{x}=3,1 \pm 1,6 \%)$ e Gaudryina exilis $(0,3$ a $5,7 \% ; \bar{x}=1,3 \pm 1,6 \%)$.

Espécies bioindicadoras de ambiente enriquecido por matéria orgânica são dominantes em todas as estações (17 e 36,9\%; $\bar{x}=30,3^{ \pm} 5,8 \%$ ) (Anexo 26).

Espécies bioindicadoras de ambiente óxico foram observadas em abundâncias relativas que variaram de 2,0 a $18,1 \%(\bar{x}=10,2 \pm 4,4 \%)$. Observou-se diminuição de concentração de sudoeste para nordeste da área de estudo (Anexo 26).

Os resultados das análises morfométricas indicaram a existência de carapaças pequenas, médias, grandes e pertencentes à macroforaminiferos (Anexo 27).

As porcentagens de carapaças pequenas oscilaram entre 17,8 e $61,3 \%(\bar{x}=43,6$ \pm 14,9\%). As maiores concentrações foram obtidas nas estações $\operatorname{Ar} 9$ (61,3\%) e $\operatorname{Ar} 10$ $(59,5 \%)$.

Carapaças médias ocorreram em porcentagens que variaram de 35,6 a 64,9\% $\bar{x}=46,7^{ \pm} 9,4 \%$ ). De acordo com os resultados, carapaças pequenas e médias estiveram distribuídas, na área de estudo, quase na mesma proporção. 
Carapaças grandes ocorreram em todas as estações em porcentagens que oscilaram de 2,5 a $27,1(\bar{x}=9 \pm 8,1 \%)$. A estação apresentou a maior concentração (27,1\%), sendo o contrário observado nas estações Ar9 e Ar10, 2\% em cada estação.

Carapaças pertencentes à macroforaminíferos ocorreram somente nas estações Ar2, Ar3, Ar4, Ar6, Ar8 e Ar9, em porcentagens que foram de 0,27 a 4,68\% ( $\bar{x}=1,18 \pm$ $1,72 \%)$.

A análise do estado de preservação das carapaças dos foraminíferos indicou a predominância de carapaças parcialmente fragmentadas, devido à abrasão mecânica (Anexo 28). As porcentagens oscilaram entre 52,2\% e 71,3\% $(\bar{x}=61,8 \pm 6,2 \%)$, sendo as maiores concentrações observadas nas estações Ar1 e Ar6. Carapaças inteiras foram identificadas em todas as estações em porcentagens que variaram de 25,6 a $46,1 \%(\bar{x}=$ $\left.36,3^{ \pm} 6,5 \%\right)$. As porcentagens de fragmentos de carapaças ocorreram em porcentagens que oscilaram entre 0,6 e $3,8 \%\left(\bar{x}=1,9^{ \pm} 0,8 \%\right)$.

No tocante ao grau de coloração, carapaças normais são dominantes em todas as estações analisadas, em porcentagens que oscilaram entre 67,7 e $88,8 \%(\bar{x}=75,7 \pm$ 6,2\%) (Anexo 29). Carapaças preenchidas por monossulfeto de ferro e/ou pirita ocorreram em porcentagens que variaram entre 9,7 e $27,2 \%(\bar{x}=20,9 \pm 4,8 \%)$. De forma geral verificou-se aumento de concentração de sudoeste para norte-nordeste da área de estudo (Anexo 29).

Carapaças de coloração acastanhada ocorreram em porcentagens que variaram de 1,1 a $10,6 \%\left(\bar{x}=3,4^{ \pm} 3 \%\right)$ (Anexo 29). As estações Ar6 e Ar7, localizadas na região sudoeste da área de estudo, apresentaram as maiores porcentagens, respectivamente, $10,6 \%$ e $7,1 \%$.

Foram observadas carapaças com sinais de bioerosão nas estações Ar2 (Pseudononion atlanticum), Ar4 (Pseudononion atlanticum), Ar5 (Quinqueloculina patagonica, Ammonia tepida e Pseudononion atlanticum), Ar8 (Bulimina marginata) e Ar9 (Bulimina marginata).

Coletas realizadas em Setembro de 2006

Foram identificados 21 gêneros e 125 espécies de foraminíferos, as quais encontram-se distribuídas por entre as Subordens Miliolina (16 espécies), Textulariina 
(21 espécies) e Rotaliina ( 88 espécies). A Subordem Rotaliina é dominante, em todos os períodos analisados, em porcentagens que variaram entre 61 e $70,4 \%$.

As densidades obtidas para a coleta realizada em Setembro de 2006 foram de 259 a 19584 por $10 \mathrm{~cm}^{3}$ de sedimento. A estação Ar10, localizada na região nordeste da área de estudo, apresentou a maior densidade, sendo o contrário observado na estação Ar2, posicionada na região sul.

Os valores de riqueza variaram entre 28 e 65 espécies $(\bar{x}=49 \pm 10$ espécies), sendo observado na estação Arl o menor número de espécies.

Os valores de diversidade específica e equitatividade oscilaram entre 2,50 e 3,23 $(\bar{x}=2,96 \pm 0,22)$ e entre 0,73 e $0,82\left(\bar{x}=0,75^{ \pm} 0,03\right)$.

Pararotalia cananeiaensis, assim como o observado para os demais períodos de estudo, é a espécie dominante em quase todas as estações, em porcentagens que variaram de 3,6 a $29,1 \%\left(\bar{x}=0,76^{ \pm} 0,03\right)$. Gaudryina exilis é a espécie predominante na estação $\operatorname{Ar} 1$ (24,3\%), as abundâncias relativas desta espécie variaram de 0,2 a 24,3\% $(\bar{x}=3,7 \pm 7 \%)$.

As demais espécies que apresentaram significativas abundâncias relativas foram Ammonia tepida $(5,7$ a $16,1 \% ; \bar{x}=10,3 \pm 3,2 \%)$, Bulimina marginata $(2,3$ a $12,5 \% ; \bar{x}=$ $5,8 \pm 3 \%)$, Ammonia parkinsoniana (2,3 a $8,3 \% ; \bar{x}=4,5 \pm 1,7 \%)$, Pseudononion atlanticum $(0,4$ a $7,5 \% ; \bar{x}=3,8 \pm 2,2 \%)$, Hanzawaia boueana $(0$ a $5,5 \% ; \bar{x}=2,4 \pm$ $1,5 \%)$, Cassidulina crassa $\left(0\right.$ a 5,$\left.1 ; \bar{x}=2,4^{ \pm} 1,3 \%\right)$, Textularia earlandi $(0$ a 6,$4 ; \bar{x}=$ $\left.0,80^{ \pm} 1,9 \%\right)$, Reophax dentaliformis (0 a 5,7\%; $\left.\bar{x}=0,70 \pm 1,7 \%\right)$.

Assim como o verificado para as coletas realizadas em Julho e Abril, espécies bioindicadoras de ambiente enriquecido por matéria orgânica são predominantes; as abundâncias relativas oscilaram de 27,5 a 66,1\% ( $\left.\bar{x}=36,6^{ \pm} 11,06 \%\right)$ (Anexo 26).

Espécies bioindicadoras de ambiente óxico apresentaram significativa diminuição de abundâncias relativas entre um período e outro. As abundâncias relativas para Setembro de 2006 variaram entre 0,4 e 17,3\% $(\bar{x}=9,4 \pm 6,11 \%)$. O padrão de distribuição é semelhante ao verificado para as coletas realizadas em Abril, i.e. diminuição de concentração de sudoeste para nordeste (Anexo 26).

Assim como para os demais períodos, verificou-se a presença de carapaças pequenas, médias, grandes e pertencentes à macroforaminíferos (Anexo 28). Carapaças pequenas ocorreram em porcentagens que variaram entre 26,8 e $43 \%(\bar{x}=35 \pm 5,8 \%)$. 
As maiores porcentagens ocorreram nas estações $\operatorname{Ar} 9$ (43\%) e $\operatorname{Ar} 10$ (40,1\%), sendo o contrário observado nas estações $\operatorname{Ar} 1$ (27,3\%) e $\operatorname{Ar} 3$ (26,8\%).

As porcentagens de carapaças médias oscilaram de 43,8 a $61 \%(\bar{x}=54,5 \pm$ 4,8\%). Carapaças grandes ocorreram em todas as estações em porcentagens que foram de 3,5 a $17,7 \%\left(\bar{x}=9,9^{ \pm} 5,7 \%\right)$. As maiores concentrações ocorreram nas estações $\operatorname{Ar} 7$ $(17,7 \%)$ e $\operatorname{Ar} 8(16,8 \%)$, sendo observado na estação $\operatorname{Ar} 5$ (3,5\%) a menor porcentagem. Macroforaminíferos estiveram presentes em quase todas as estações; as porcentagens obtidas variaram de 0 a $1,5 \%(\bar{x}=0,50 \pm 0,50 \%)$.

No tocante ao grau de preservação, verificou-se alternância de predominância entre carapaças inteiras e parcialmente fragmentadas (Anexo 29). Em média as diferenças obtidas foram de 3,4\%, sendo que carapaças parcialmente fragmentadas foram predominantes nas estações Ar1, Ar2 e Ar6. Observou-se na estação Ar1 elevada porcentagem de carapaças com sinais de dissolução química, conforme pode ser verificado na Prancha 2.

As porcentagens de carapaças inteiras variaram entre 36,9 e $60,7 \%(\bar{x}=50,4 \pm$ 7,3\%). A maior porcentagem foi obtida na estação Ar5, sendo o contrário observado na estação Ar2.

As porcentagens de carapaças parcialmente fragmentadas foram de 36,3 a $61 \%$ (

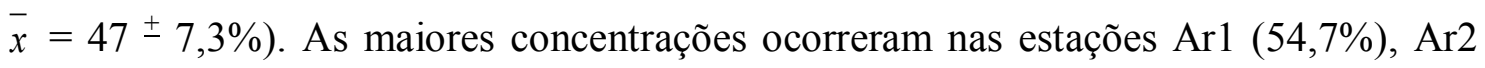
(61\%) e Ar6 (53,7), localizadas, respectivamente, na saída do emissário submarino, região sul e sudoeste da área de estudo.

Fragmentos de carapaças ocorreram em todas as estações, em porcentagens que variaram entre 0,6 e $5,2 \%\left(\bar{x}=2,6^{ \pm} 1,5 \%\right)$.

Excetuando-se a estação Ar1, carapaças normais foram dominantes, em porcentagens que variaram de 50,2 a $87,1 \%(\bar{x}=79,7 \pm 10,6 \%)$. Na estação Ar1 as carapaças apresentaram coloração diferenciada (pardacentas), devido à elevada porcentagem de textulariineos $(49,13 \%)$.

Carapaças com sinais de preenchimento por monossulfeto de ferro e/ou pirita foram observadas em todas as estações, em porcentagens que oscilaram entre 0,3 e $25,4 \%\left(\bar{x}=14^{ \pm} 6,3 \%\right)$. Observou-se aumento de concentração de sudoeste para sudeste da área de estudo. As maiores porcentagens ocorreram nas estações Ar3 (25\%) e Ar5 (18\%). 
A porcentagem de carapaças de coloração acastanhada é considerada baixa, os valores obtidos variaram entre $03 \mathrm{e} 2,5 \%(\bar{x}=1,3 \pm 1,0 \%)$, com ausência de representantes na estação Ar10.

Foram observadas carapaças com sinais de bioerosão nas estações Ar3 (Bulimina marginata e Cribroelphidium excavatum), Ar6 (Bulimina marginata e Triloculina oblonga) e Ar2 (2 exemplares de Bulimina marginata).

\subsubsection{Análises estatísticas dos dados}

\subsection{Coeficientes de correlação de Pearson (r)}

Em Julho de 2005, observou-se que os menores valores de densidades e de riqueza foram identificadas em estações com elevadas concentrações de sedimentos finos enriquecidos por fósforo orgânico e enxofre. As equitatividades, por sua vez, são negativamente influenciadas pelos teores de enxofre (Anexo 30).

As abundâncias de Pararotalia cananeiaensis são significantemente e positivamente relacionadas aos teores de enxofre $(\mathrm{r}=0,81 ; p<0,001)$.

Ammonia parkinsoniana tem sua distribuição positivamente associada aos sedimentos finos $(\mathrm{r}=0,68 ; p<0,05)$, com elevados teores de enxofre $(\mathrm{r}=0,77 ; p<$ $0,05)$.

Hanzawaia boueana tem seu padrão de distribuição associado positivamente aos teores de nitrogênio $(\mathrm{r}=0,77 ; p<0,05)$ e carbonato de cálcio $(\mathrm{r}=0,81 ; p<0,001)$, i.e. suas maiores abundâncias ocorrerm am estações sob maior influência marinha.

Para as coletas realizadas em Abril de 2006, verificou-se que as riquezas possuem relação significantemente inversa em relação a carbono orgânico total $(r$ = $0,51 ; p<0,05)$, enxofre $(\mathrm{r}=-0,69 ; p<0,05)$ e fósforo inorgânico $(\mathrm{r}=-0,58 ; p<0,05)$. As diversidades específicas $(\mathrm{r}=-0,79 ; p<0,001)$ e as equitatividades $(\mathrm{r}=-0,78 ; p<$ 0,001) são negativamente influenciadas pelos valores Eh.

Conforme observado no Anexo 31, algumas das espécies de foraminíferos tem suas distribuições associadas aos valores de carbonato de cálcio, de profundidade, de salinidade, de temperatura e de oxigênio dissolvido (Anexo 31).

Em relação às coletas realizadas em Setembro de 2006 (Anexo 32), verificou-se que as principais variáveis ambientais que influenciam negativamente as densidades $(\mathrm{r}=$ 
- 0,70; $\mathrm{p}<0,05)$ e as riquezas $(\mathrm{r}=-0,70 ; p<0,05)$ foram os teores de fósforo inorgânico e os valores de salinidade, respectivamente.

\subsection{Estudo comparativo da estrutura das comunidades de foraminiferos}

\subsection{Biocenoses - estudo comparativo entre os periodos de coleta}

$\mathrm{O}$ resultados das análises de NMDS e teste $\mathrm{t}$, indicaram diferenças entre na estrutura das espécies que compuseram as biocenoses, nos períodos de Julho de 2005 e Abril de 2006 (Figura 11). A composição das biocenoses diferiu significantemente somente no Eixo 1 (t: 7,435; $p<0,0001)$. O resultado obtido para o Eixo 2 foi $-\mathrm{t}$ : 0,$835 ; p=0,415$.

Entre Julho de 2005 e Setembro de 2006, verificou-se que a composição das associações de foraminíferos também diferiu somente no Eixo 1 (Figura 11 A), sendo observado moderado nível de significância $-\mathrm{t}$ : $-2,403 ; p=0,028$. Os resultados obtidos para o Eixo 2 foram - t: 1,594; $p=0,219$.

Não há diferenciação na estrutura composicional das espécies de foraminíferos das coletas realizadas em Abril (Figura 11B) e Setembro de 2006 (Figura 11 C). Os resultados obtidos para os eixos do gráfico de ordenação foram: Eixo 1 t: 0,$171 ; p=$ 0,866 e Eixo 2 t: - 1,174; $p=0,256$.

Os valores de estresse obtidos nos estudos comparativos são considerados baixo, entre 0,20 e 0,28, motivo pelo qual infere-se ausência de distorção dos dados na técnica empregada. 

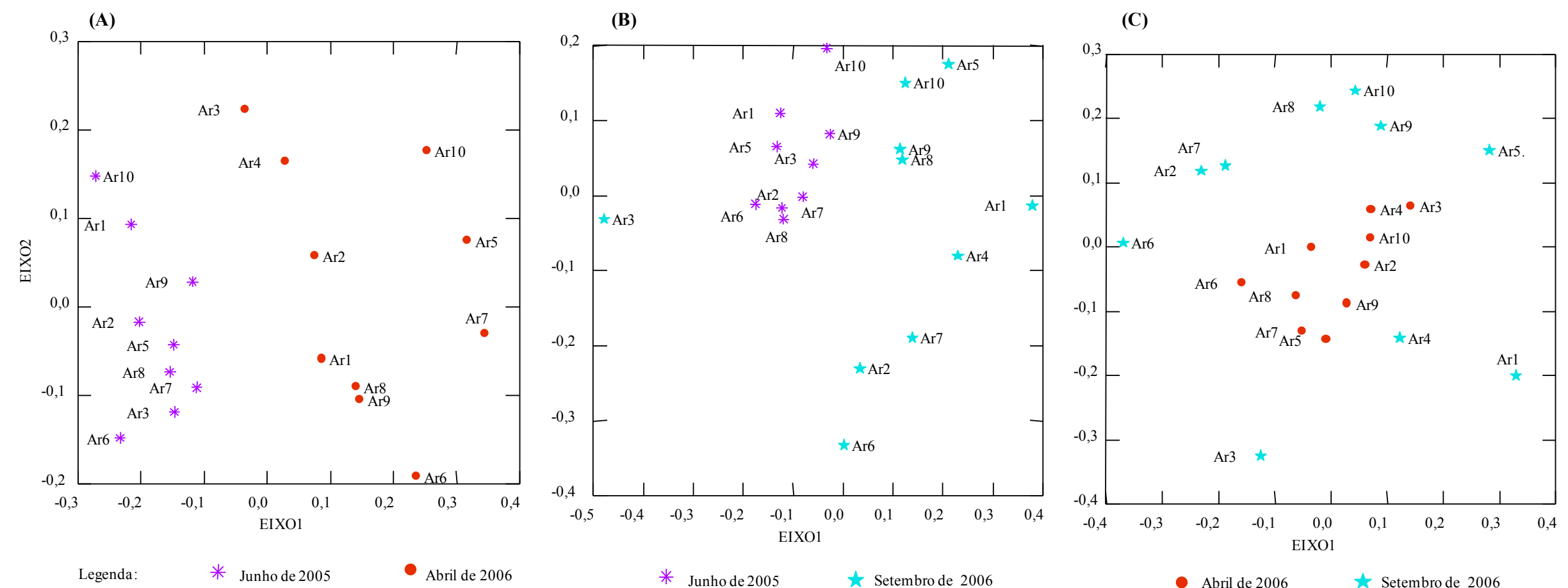

Figura 11 - Gráficos de ordenação, obtidos pelas técnicas de NMDS e teste t, para o estudo comparativo das biocenoses entre os períodos de coleta. 


\subsection{Tanatocenoses - estudo comparativo entre os periodos de coleta}

Assim como o verificado para as biocenoses, o estudo comparativo da estrutura das tanatocenoses indicaram diferenças na composição entre os períodos de coleta (Figuras 12 e 13).

Entre Julho de 2005 e Abril de 2006, verificou-se diferenciação em ambos os eixos, sendo, entretanto, significativo somente para o Eixo 1 (t: 7,536; $p<0,0001$ ). Apesar do Eixo 2 apresentar diferenciação, o nível de significância obtido é considerado baixo (t: $-0,359 ; p=0,098)$ (Figura $12 \mathrm{~A})$.

De acordo com a Figura 12, verifica-se maior homogeneidade composicional para a coleta realizada em Julho de 2005. Observou-se também que as estações Ar1 e Ar6, coletadas em Abril, e estação Ar5, coletada em Julho de 2005, indicam maior diferenciação na composição das espécies em relação às demais estações (Figura 12 A).

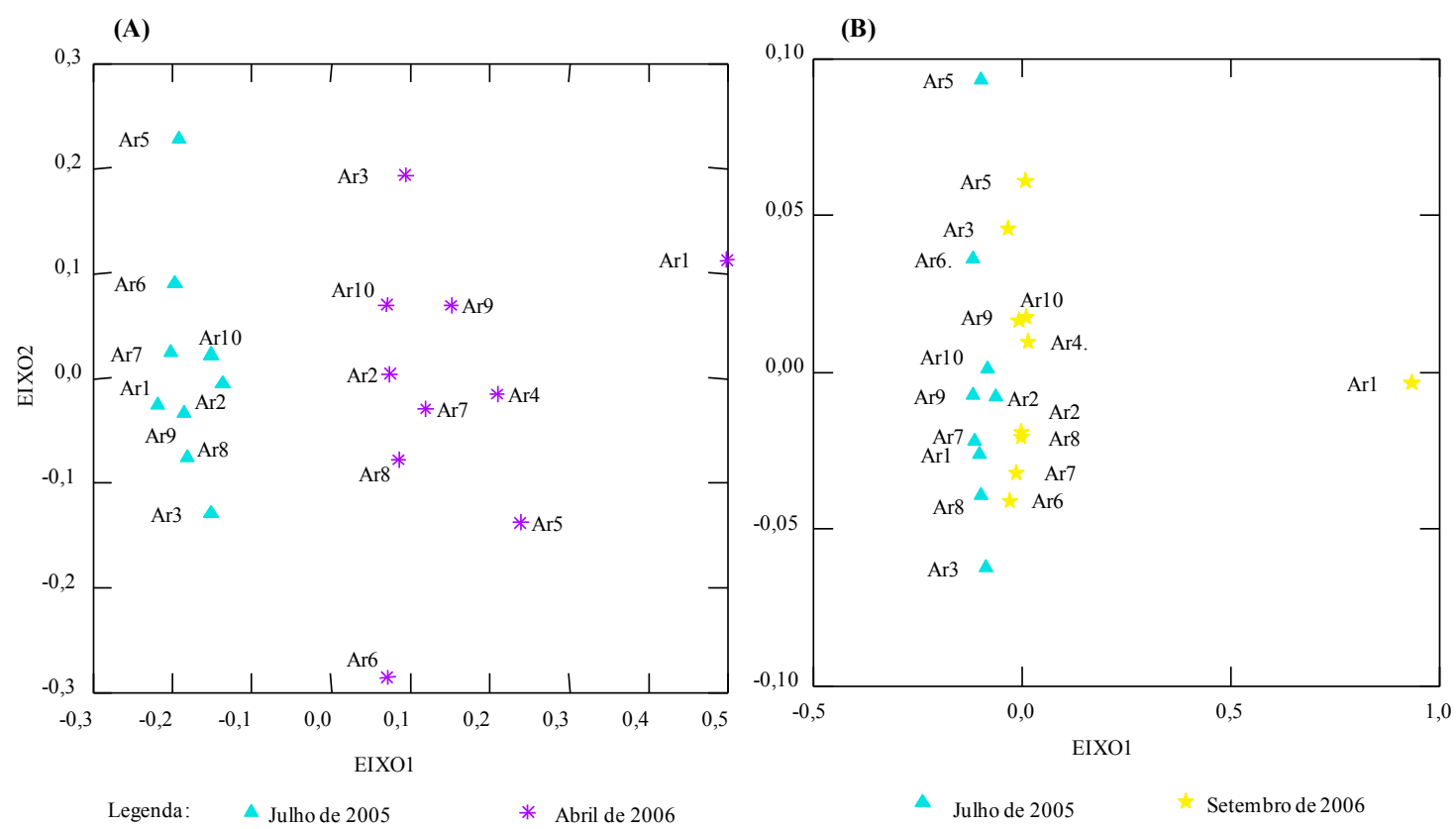

Figura 12 - Gráficos de ordenação, obtidos pelas técnicas de NMDS e teste t, para o estudo comparativo das tanatocenoses entre os períodos de coleta. 
Entre Julho de 2005 e Setembro de 2006, verificou-se maior homogeneidade composicional das espécies. Apesar de ser identificada diferenciação na estrutura composicional, os níveis de significância dos Eixos 1 e 2 são considerados baixos. Os valores obtidos para o Eixo 1 foram $\mathrm{t}=-1,966 ; p=0,080$, e para o Eixo 2: $\mathrm{t}=-0,412 ; p$ $=0,686$.

Assim como o observado em Julho de 2005, as estações Ar5 e Ar1 apresentaram diferenciação de estrutura composicional em relação às demais estações analisadas (Figura $12 \mathrm{~B}$ ).

Não se observou diferenciação composicional entre os períodos de Abril e Setembro de 2006 (Figura 13 A). Devido à proximidade com que as estações foram plotadas, para melhor visualização dos resultados, optou-se por ilustrar o gráfico de ordenação por período e não simultaneamente como até então havia sido demonstrado.

Os valores obtidos para o Eixo 1 foram t: - 1,755; $p=0,096$ e para o Eixo 2 foram t: $-0,663 ; p=0,516$. O posicionamento da estação Ar1, para ambos os períodos, indica estrutura composicional diferente das demais estações (Figura 13 A e B).

Os valores de estresse otidos nos estudos comparativos, entre 0,21 e 0,31, indicam ausência de distorção dos dados na técnica utilizada.

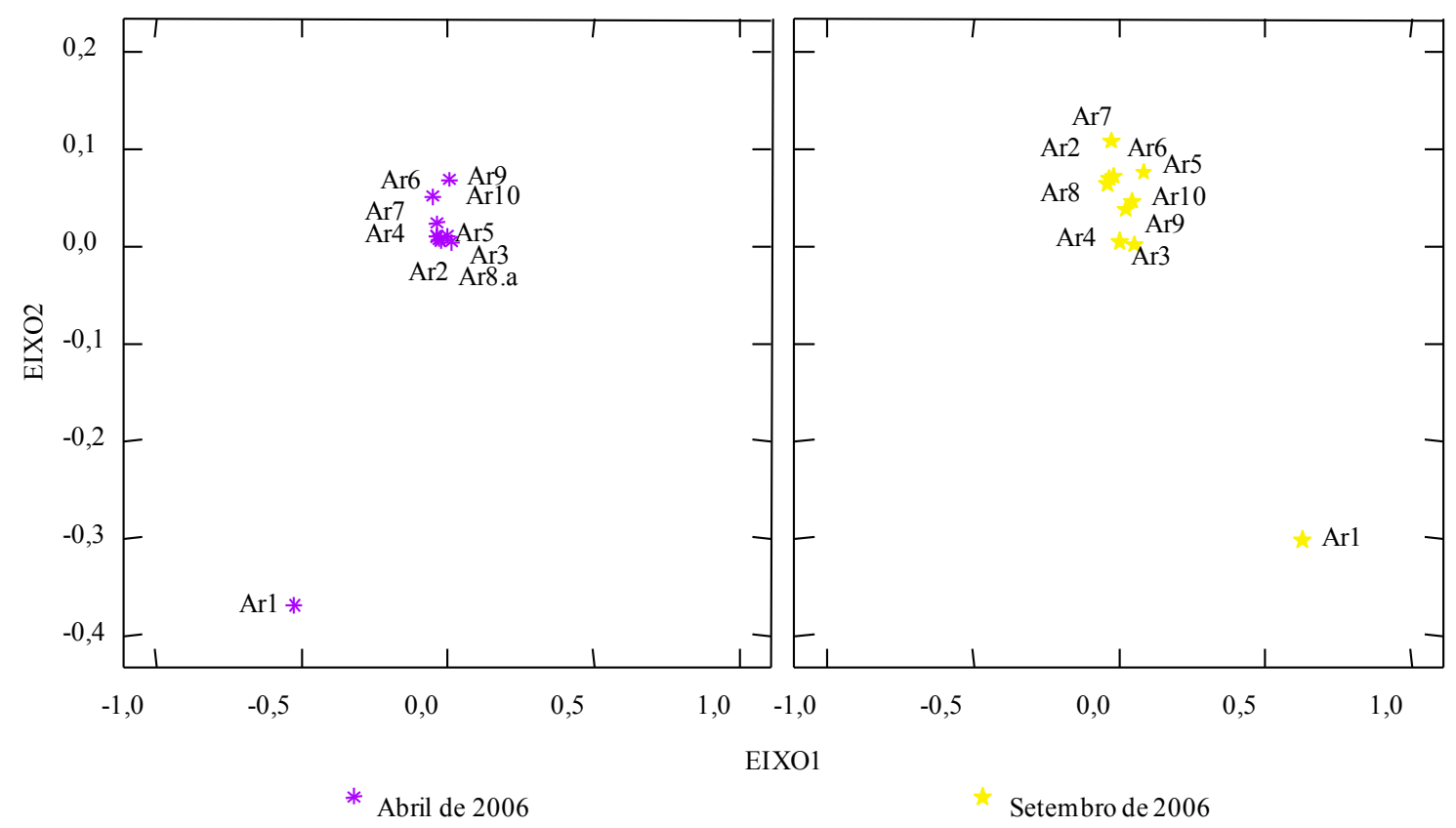

Figura 13 - Gráficos de ordenação para o estudo comparativo das tanatocenoses obtidas em Abril e Setembro de 2006. 
4.1.4.3.2.3 Biocenoses versus Tanatocenoses - estudo comparativo entre os períodos de coleta

As análises de NMDS e teste $t$ permitiram visualizar diferenciações significativas entre a composição faunística das biocenoses e tanatocenoses (Figura 14).

O gráfico de ordenação ilustra os resultados verificados para Julho de 2005 (Figura 14 A). Para o Eixo 1 obteve-se t: 16,247; $p<0,0001$, para o Eixo 2 obteve-se t: 0,$046 ; p=0,964$.

Em Abril de 2006, as estruturas diferiram significativamente no Eixo 1 (t: 8,620; $p<0,0001)$ e moderadamente no Eixo 2 ( $\mathrm{t}:$ - 0,360; $\mathrm{p}=0,097)$ ((Figura $14 \mathrm{~B})$.

Em Setembro de 2006, diferença significativa na estrutura entre as biocenoses e tanatocenoses foi obtida somente para o Eixo 1 (t: 5,061; $p<0,0001$ ). Os valores obtidos para o Eixo 2 foram t: 1,293; $p=0,212$ (Figura 14 C).

Os valores de estresse obtidos nos estudos comparativos são considerados baixos, entre 0,18 e 0,23 , o que permite inferir ausência de distorção dos dados na técnica utilizada. 

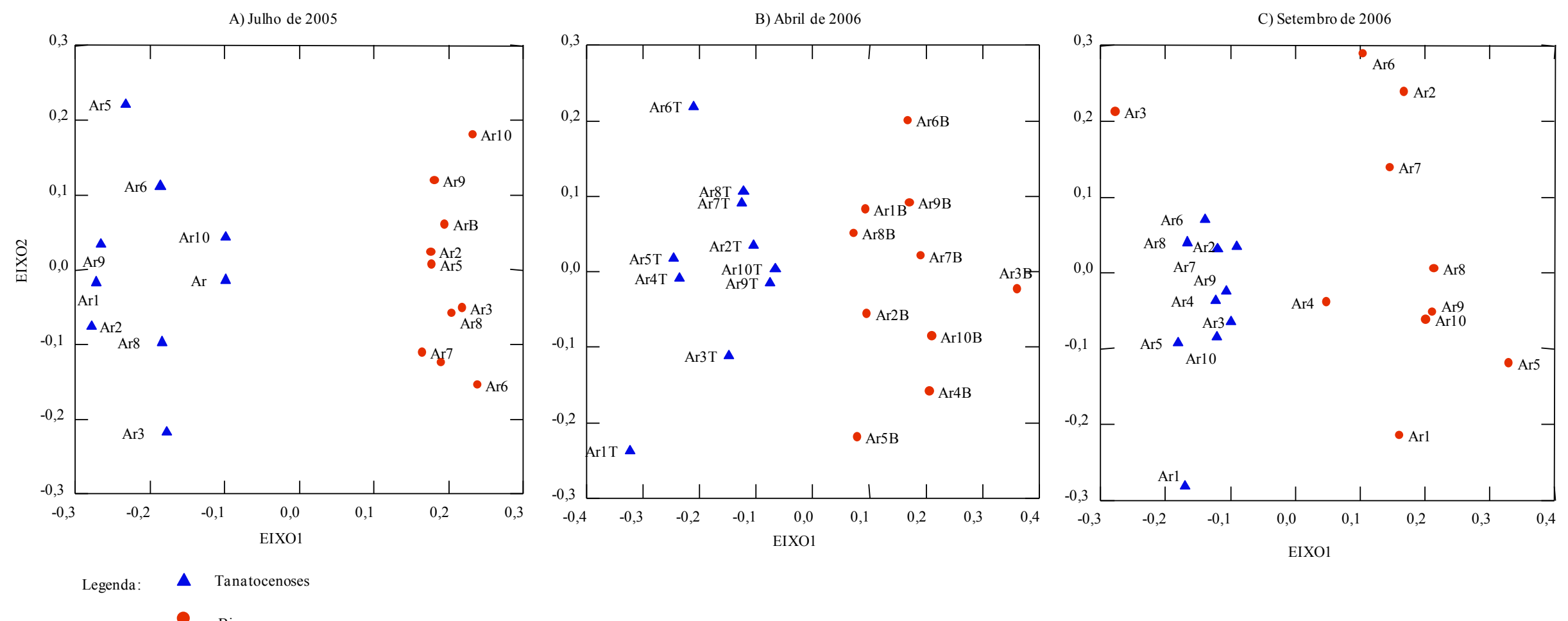

Figura 14 - Gráfico de ordenação das biocenoses e tanatocenoses obtidas próximo ao emissário do Araçá, nos períodos de Julho de 2005, Abril e Setembro de 2006 . 
As Análises de Agrupamento, em modo Q, corroboram as dissimilaridades existentes entre as biocenoses e tanatocenoses observadas pelas análises de NMDS e teste t.

Conforme observado na Figura 15, as tanatocenoses e biocenoses, pertencentes às coletas realizadas em Julho de 2005, formaram dois grupos distintos. O nível de similaridade obtido foi de 0,64 .

O grupo das tanatocenoses, subdivide-se em T1, o qual compreende as estações Ar1, Ar5, Ar7, Ar6 e Ar2; o subgrupo T2 é composto pelas estações Ar9, Ar8 e Ar3. A estação Ar10 encontra-se separa das demais estações.

O grupo das biocenoses abrange 3 subgrupos, sendo o B1 formado pelas estações Ar7 e Ar3; o B2 composto pelas estações Ar8, Ar6 e Ar2, o subgrupo B3, por sua vez, compreende as estações Ar9, Ar10 e Ar5. A estação Ar1 encontra-se posicionada em separado.

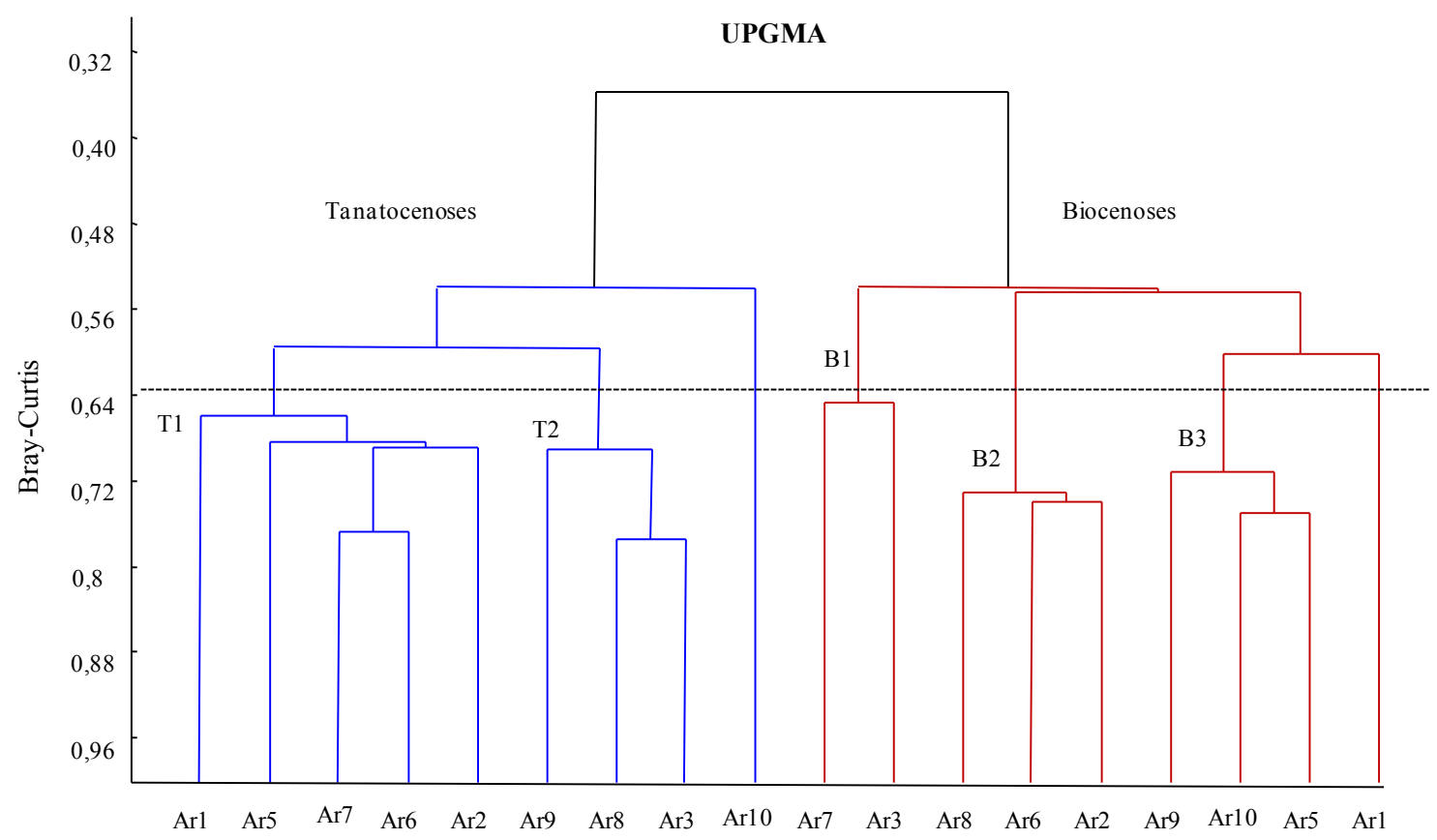

Figura 15 - Dendrograma, em modo Q, obtido para o período de Julho de 2005.

Assim como o verificado para Julho, em Abril de 2006, as estações pertencentes às tanatocenoses e biocenoses agruparam-se separadamente (Figura 16). O nível de similaridade foi de 0,53 , com coeficiente cofonético igual a 0,84 . 
O grupo formado pelas tanatocenoses subdivide-se em T1.1, o qual compreende as estações Ar5, Ar8, Ar9, Ar7 e Ar7. O subgrupo T1.2, por sua vez, é composto pelas estações Ar6, Ar4, Ar3 e Ar2.

O grupo formado pelas biocenoses subdivide-se em B1, cujas estações que o formam são Ar7 e Ar5; o subgrupo B2 engloba as estações Ar4, Ar10 e Ar4; o subgrupo B3, por sua vez, compreende as estações Ar9 e Ar2. As estações Ar1 (tanatocenoses), Ar6 e Ar1, ambas pertencentes à biocenose, não foram agregadas em nenhum dos subgrupos. Tal fato, aparentemente, relaciona-se às diferenças composicionais das estações em relação às demais amostras.

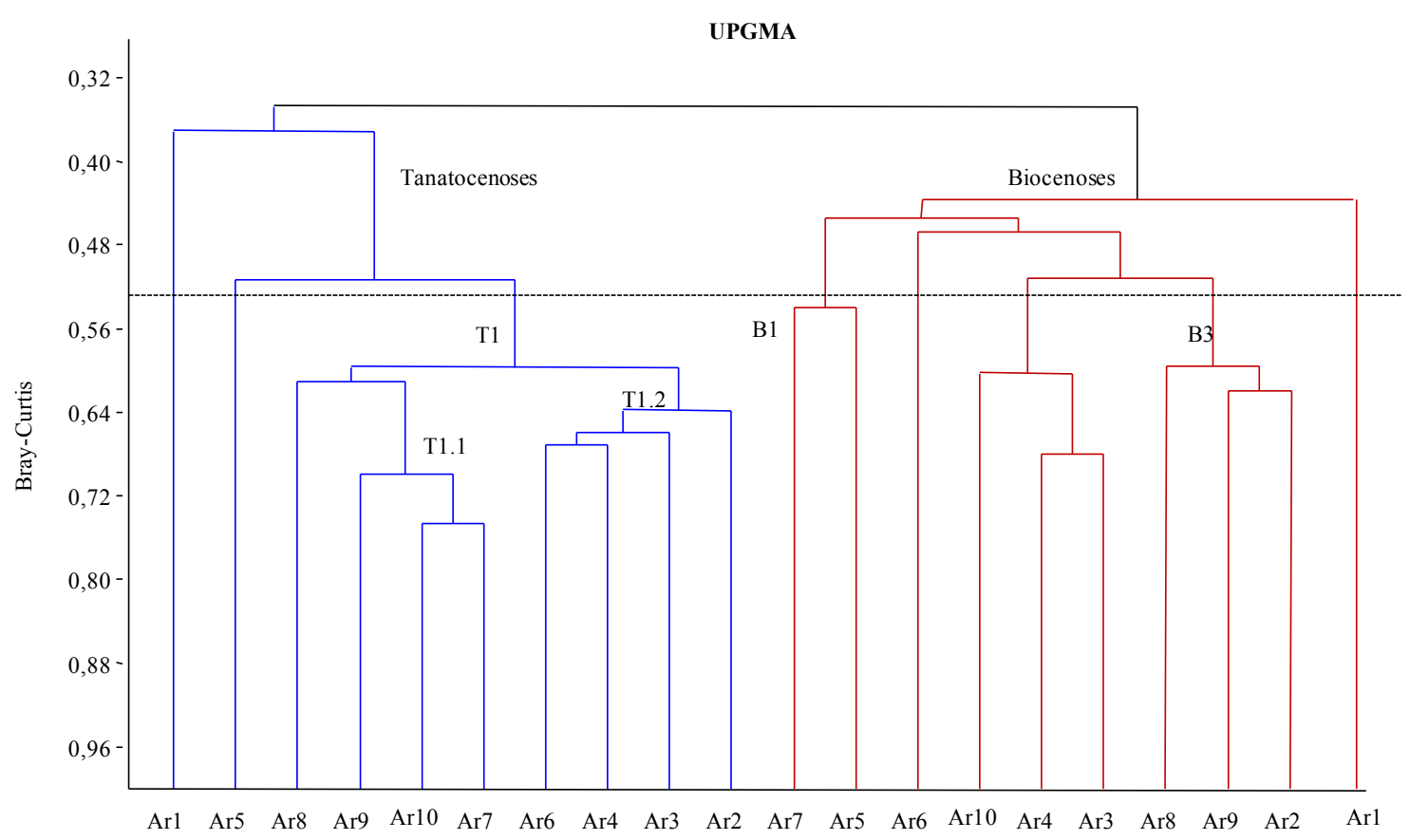

Figura 16 - Dendrograma, em modo Q, obtido para o período de Abril de 2006

Em Setembro de 2006, com nível de similaridade de 0,45, observou-se resultados semelhantes ao obtidos para Julho e Abril de 2006, onde dois grupos distintos foram formados (Figura 17).

O grupo das tanatocenoses é formado por dois subgrupos: T1.1 e T1.2. O subgrupo T1.1 é composto pelas estações Ar5, Ar8, Ar7, Ar6 e Ar3; o subgrupo T1.2, por sua vez, é formado pelas estações Ar10, Ar9, Ar4 e Ar2.

O grupo das biocenoses subdivide-se em B1 e B2. O subgrupo B1 engloba as estações Ar6, Ar7, Ar8 e Ar2, enquanto o subgrupo B2 é formado pelas estações Ar5, Ar4, Ar10, Ar9 e Ar3. 
Assim como o verificado para Julho e Abril, a estação Ar1 permanece isolada. Mesma situação ocorreu para a estação Ar1 das tanatocenoses, porém somente para os períodos de Abril e Setembro de 2006.

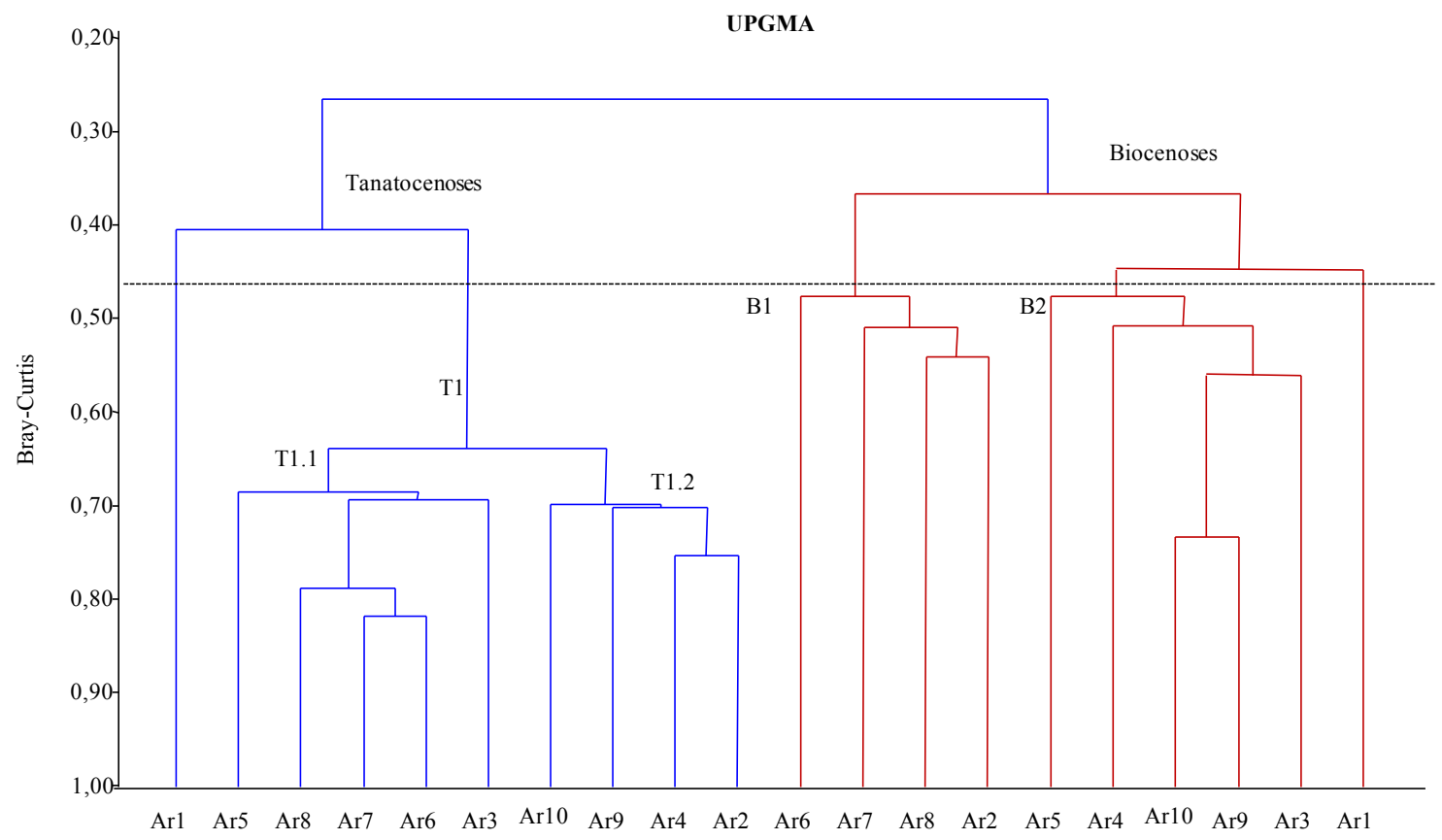

Figura 17 - Dendrograma, em modo Q, obtido para o período de Setembro de 2006.

\subsection{Análise de Correspondência Canônica}

A Análise de Correspondência Canônica indicou que as espécies de foraminíferos são significantemente influenciadas pelos parâmetros ambientais: nitrogênio $(\mathrm{N})$, fósforo total (Ptotal), carbonato de cálcio $\left(\mathrm{CaCO}_{3}\right)$, oxigênio dissolvido (OD) e enxofre (S) (Figura 18). 


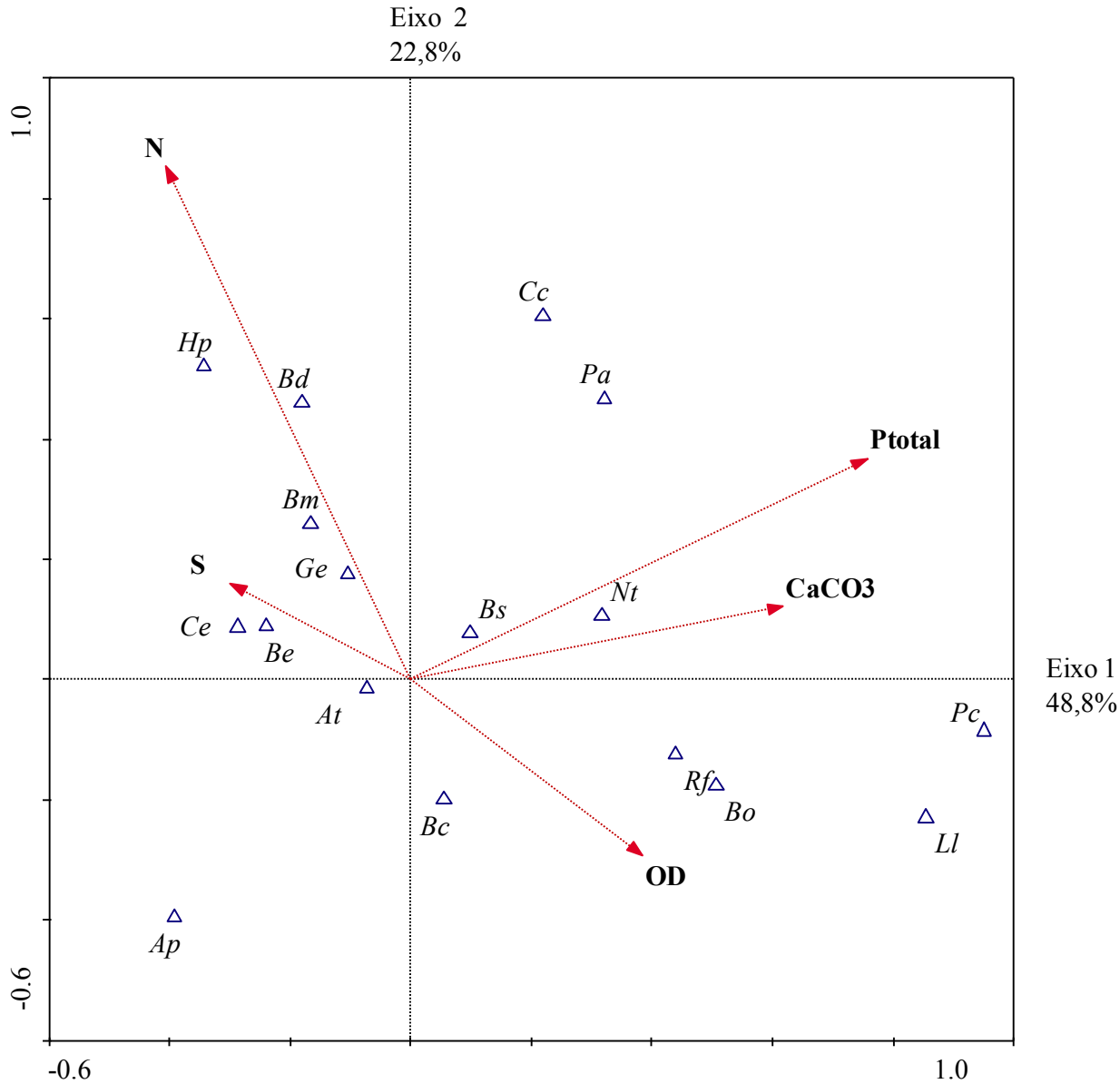

Figura 18 - Diagrama de ordenação da relação existente entre as espécies de foraminíferos compõem as biocenoses e os parâmetros abióticos.

Legenda: Ap (Ammonia parkinsoniana), At (Ammonia tepida), Bc (Bolivina compacta), Bd (Bolivina doniezi), Bo (Bolivina ordinaria), Bs (Brizalina striatula), Bm (Bulimina marginata), Be (Buliminella elegantissima), Cc (Cassidulina crassa), Ce (Cribroelphidium excavatum), Ge (Gaudryina exilis), Hp (Hopkinsina pacifica), Ll (Lobatula lobatula), Nt (Neocornobina terquemi), Pc (Pararotalia cananeiaensis), Pa (Pseudononion atlanticum), Rf (Rosalina floridensis).

Fósforo total, carbonato de cálcio, oxigênio dissolvido e enxofre estão associados ao Eixo 1 e nitrogênio associa-se ao Eixo 2. A variância da relação existente entre a composição e distribuição das associações de foraminíferos e os parâmetros abióticos é 71,6\% explicada pelos Eixos 1 e 2. O Eixo 1 explica 48,8\% e o Eixo 2 explica 22,8\% das variâncias existentes (Tabela 07). 
Tabela 07 - Síntese dos resultados obtidos pela Análise de Correspondência Canônica.

\begin{tabular}{lccccc}
\hline \multicolumn{1}{c}{ Eixos } & 1 & 2 & 3 & 4 & Inércia total \\
\hline Autovalores & 0,107 & 0,05 & 0,038 & 0,017 & 0,493 \\
Correlações: espécies - ambiente & 0,887 & 0,847 & 0,742 & 0,758 & \\
Variância em porcentagem acumulada: & & & & & \\
dos dados das espécies & 21,8 & 31,9 & 39,5 & 43,1 & \\
dos dados das espécies e ambiente & 48,8 & 71,6 & 88,7 & 96,6 & \\
\hline
\end{tabular}

Ao Eixo 1, lado positivo, estão associadas as espécies Pararotalia cananeiaensis, Lobatula lobatula, Bolivina ordinaria, Rosalina floridensis, Neocornobina terquemi e Brizalina striatula. , ao lado negativo estão associadas as espécies Ammonia tepida, Buliminella elegantissima e Cribroelphidium excavatum. No eixo 2, lado positivo, encontram-se associadas Gaudryina exilis, Bulimina marginata, Bolivina doniezi, Hopkinsina pacifica, Cassidulina crassa e Pseudononion atlanticum, no lado negativo, por sua vez, somente foi observada a espécieolivina compacta. Ammonia parkinsoniana encontra-se posicionada na extremidade negativa do diagrama de ordenação, o que impossibilita inferir as variáveis que influenciam a sua distribuição.

O diagrama de ordenação da relação existente entre as estações e as variáveis ambientais (Figura 19) indicou características ambientais diferenciadas para cada período de amostragem, na região do Araçá.

Segundo o posicionamento das estações no Eixo 1, verificou-se gradual enriquecimento orgânico de Junho de 2005 a Setembro de 2006. No lado positivo do Eixo 1, onde estão posicionadas as estações amostradas em Junho de 2005, os parâmetros abióticos indicam ambiente com características mais marinhas e oxidantes. Excetuando-se Bolivina ordinaria, as espécies associadas são epifaunais e bioindicadoras de ambiente óxico. As estações amostradas em Setembro de 2006 foram associadas ao lado negativo do Eixo 1, onde verifica-se declínio dos níveis de oxigênio dissolvido. Espécies infaunais, bioindicadoras de enriquecimento orgânico estiveram associadas ao mesmo lado do Eixo 1. Em relação à Abril de 2006, o nitrogênio foi o principal parâmetro abiótico que influenciou a composição das associações de foraminíferos. 


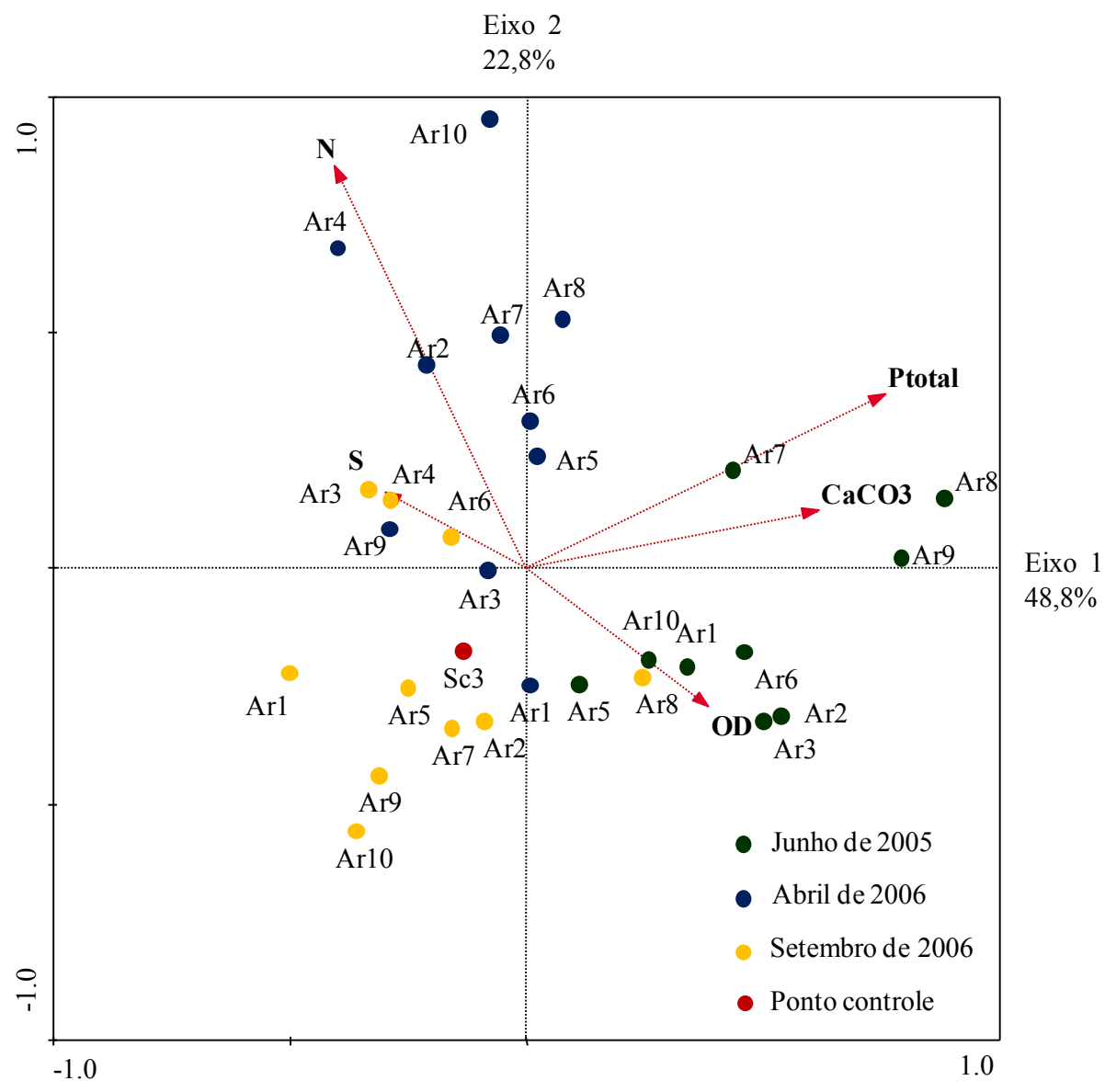

Figura 19 - Diagrama de ordenação das relações existentes entre as estações e os parâmetros abióticos.

\subsection{DISCUSSÃO}

\subsubsection{Parâmetros físico-químicos da coluna d'água}

Durante todos os períodos analisados não se observou estratificação na coluna d'água, o que se deve a pouca profundidade da área de estudo. A massa de água atuante foi a Água Costeira, a qual é predominante durante quase o ano inteiro.

Níveis de oxigênio dissolvido, abaixo do limite de proteção à vida aquática ${ }^{14}$, foram observados somente nas coletas realizadas em Abril e Setembro de 2006. Os valores obtidos podem estar associados ao esgoto disposto pelo emissário submarino,

\footnotetext{
${ }^{14}$ Resolução CONAMA 357/2005, para águas salinas Classe 1: valores de oxigênio dissolvido devem ser superiores a $6 \mathrm{mg} \mathrm{L}^{-1}$
} 
uma vez que o mesmo antes de ser liberado, recebe somente pré-condicionamento. Devido ao fato de o esgoto ser predominantemente doméstico, há a liberação de quantidade significativa de matéria orgânica dissolvida e particulada para o ecossistema aquático. A decomposição da matéria orgânica lábil por microorganismos tende a acelerar o consumo de oxigênio do meio, e por consequência, acarretar a diminuição de oxigenação das águas de fundo (Connel e Miller, 1984; Esteves, 1998).

Em Abril e Setembro de 2006, os maiores valores de turbidez foram identificados nas mesmas estações onde foram obtidos os menores valores de oxigênio dissolvido. $\mathrm{Na}$ amostragem realizada em Setembro, observou-se valores baixos de oxigênio dissolvido ao longo da coluna d'água de onde a estação Ar10 foi posicionada, nesta estação foram obtidos os maiores valores de turbidez. O valor obtido na estação Ar5 (12 UNT, Abril de 2006), pode tanto estar associado ao efluente disposto pelo emissário, bem como pode ser devido ao processo de eutrofização que ocorreu na região, o que será posteriormente discutido.

De acordo com os valores de turbidez, os quais tenderam a aumentar de Junho de 2005 para Setembro de 2006, verificou-se singular sentido preferencial de dispersão da pluma gerada pelo efluente de sudoeste para nordeste da área de estudo. Este mesmo sentido foi sugerido pela CETESB (2007), após utilização do programa de modelagem computacional Cormix (Cornel Mixing Zone).

Em relação aos nutrientes analisados na coluna d'água, na maioria das análises os valores obtidos estiveram abaixo do limite de detecção do método analítico ou abaixo dos limites estabelecidos pela Resolução CONAMA 357/2005. Somente na amostragem realizada em Junho, estação $\operatorname{Ar} 2$, obteve-se valor de fósforo total $\left(0,2 \mathrm{mg} \mathrm{L}^{-1}\right)$ indicativo de alteração ambiental decorrente do efluente disposto.

Em anos posteriores ao do presente estudo, mais precisamente em 2007 e 2008, FUNDESPA (2009), obteve valores de fosfato acima do liomite padrão estabelecido pelo CONAMA, na região próxima ao emissário do Araçá.

Os baixos valores obtidos para os nutrientes indicam que o efluente esta sendo dispersado rapidamente. Na região região central do canal as correntes de superfície podem atingir 1,0 $\mathrm{m} \mathrm{s}^{-1}$ (Furtado et al., 2008). 


\subsubsection{Parâmetros granulométricos e geoquímicos}

A distribuição dos sedimentos na área de estudo ocorre de forma heterogênea, sendo encontrada em uma mesma amostra desde grânulos a argila. A alternância da velocidade das correntes, bem como a quebra de energia é inferida pelo baixo grau de seleção dos grãos, o qual oscila entre pobremente e muito pobremente selecionado, bem como pela presença de minerais micáceos.

Durante um período e outro de amostragem, verificou-se aumento nos teores de sedimentos finos, os quais são mais significativos nas coletas realizadas em Abril de 2006. Infere-se que este aumento ocorreu devido à maior taxa pluvial em dias, semanas anteriores. $\mathrm{O}$ aporte de sedimentos para o interior do canal ocorre devido ao carreamento de material do continente pelas chuvas, ou é proveniente do retrabalhamento de sedimentos relictos pelas correntes de fundo (Furtado et al., 2008), sendo no primeiro caso, marcado pelo aumento de sedimentos finos e no segundo caso por sedimentos de maior granulação.

Os resultados granulométricos, obtidos nos três períodos de estudo, indicam que as regiões sudoeste e central da malha de amostragem estão sob influência direta das correntes de fundo, bem como do fluxo gerado pelo efluente disposto, no caso da região central. Estas regiões apresentaram as maiores concentrações de sedimentos arenosos, bem como melhor grau de seleção dos grãos, o qual está acondicionado ao maior retrabalhamento dos sedimentos de fundo pelas correntes. Em contrapartida, nas regiões norte e nordeste da área de estudo há predominância de sedimentos finos, indicativo de diminuição de hidrodinâmica para estas regiões.

Pelo padrão de distribuição da granulometria, infere-se como sentido deposicional de sudoeste para norte-nordeste da área de estudo. O sentido deposicional inferido está de acordo com o sentido preferencial das correntes no interior do canal, a qual, durante quase todo o ano, ocorre de forma unidirecional em sentido nordeste (Silva et al., 2001). Os dados obtidos no presente estudo corroboram os resultados apresentados em Gubitoso et al., (2008).

Os parâmetros geoquímicos analisados possuem distribuição diretamente relacionada à composição textural dos sedimentos. Tal fato ocorre devido à maior capacidade de adsorção dos grãos; as concentrações aumentam com a diminuição do tamanho dos grãos (Bordovskiy, 1965). Diante disto, elevadas concentrações de carbono orgânico total, nitrogênio, fósforo e enxofre não foram identificadas na estação 
Ar1, localizada na saída do emissário submarino, onde há predomínio de sedimentos arenosos, mas sim em estações com elevados teores de silte e argila.

O enriquecimento orgânico que há na região é evidenciado pelos teores de nutrientes, carbono orgânico total, enxofre, bem como pelo potencial de oxi-redução dos sedimentos.

Os resultados encontrados no ponto controle (estação C3), para todos os parâmetros analisados, são inferiores aos obtidos no emissário do Araçá.

Os valores de Eh são quase todos negativos, indicando degradação por anaerobiose da matéria orgânica. Segundo intervalos de enriquecimento orgânico proposto por Sutherland et al. (2007), valores entre - 50 e $-150 \mathrm{mV}$, encontrados na maioria das estações amostradas em Setembro de 2006 (Tabela 06), são obtidos em locais com sinais de hipoxia ${ }^{15}$ no compartimento sedimentar. Valores inferiores a -150 $\mathrm{mV}$, obtidos em quase todas as estações em Abril de 2006, por sua vez, são comumente encontrados em ambientes em sinais de anoxia (Wildish et al., 2001). De acordo com Mitsch e Gosselink (1986 in Esteves, 1998), em ambientes com os valores de Eh semelhantes aos obtidos no presente estudo, há a redução de nitrogênio para amônia $(220 \mathrm{mV})$ e de enxofre para sulfeto $(-75 \mathrm{a}-150 \mathrm{mV})$. Somente a estação Ar6, coletada em Setembro de 2006, apresentou Eh positivo, indicativo de ambiente óxico.

Os teores de carbono orgânico total, dos períodos de amostragem, são considerados moderados. Teores similares aos encontrados em regiões sob processos de eutrofização (Cot entre 2 e 4\%; Diz et al., 2006), foram somente observados nas estações Ar8 e Ar9 (Junho de 2005), Ar10 (Abril de 2006) e Ar9 (Setembro de 2006).

Comparativamente, os valores de carbono orgânico total obtidos próximo aos difusores do Araçá, são similares aos encontrados em ambientes sob estresse ambiental. Aston e Hewit (1977) obtiveram concentrações de carbono orgânico total de 0,07 a 1,97\% em Walton Backwater (Essex, Inglaterra). A região analisada pelos autores é área sob impacto ambiental devido à presença de portos, atividades agrícolas e pela disposição oceânica de esgotos. Carreira e Wagener (1998), em região próxima ao emissário submarino de Ipanema (Rio de Janeiro, RJ), encontraram concentrações que variaram de $0,79 \%$ a 3,18\%. O emissário de Ipanema dispõe, diariamente, em média 8 $\mathrm{m}^{3} \mathrm{~s}^{-1}$ de esgoto doméstico com tratamento preliminar (Carreira e Wagener, 1998).

\footnotetext{
${ }^{15}$ Hipoxia - definida como valor limite, abaixo do qual a biota pode ser impactada (Mojtahid et al., 2009). Valor de oxigênio dissolvido inferior a $2 \mathrm{mg} \mathrm{L}^{-1}$ (Tyson e Pearson, 1991).
} 
Abessa et al., (2005), obtiveram valores que oscilaram entre 0,09 e 2,91\% de carbono orgânico total próximo aos difusores do emissário de Santos (Santos, SP). Diariamente, 0,6 a $1,6 \mathrm{~m}^{3} \mathrm{~s}^{-1}$ de esgoto doméstico são dispostos pelo emissário no interior da Baía de Santos. Cesar et al. (2007) encontraram teores de carbono orgânico total entre 0,85 e 3,75\% no sistema estuarino de Santos e São Vicente, área densamente urbanizada, que compreende o maior complexo industrial brasileiro, bem como há o Porto de Santos, considerado o maior porto da América Latina.

O padrão de distribuição dos valores de carbono orgânico total obtidos em Abril e Setembro diferem do observado em Junho de 2005. Em Junho verificou-se gradual aumento de valores de noroeste para sul-sudeste. Já em Abril e Setembro contatou-se aumento de valores de carbono orgânico total de sudoeste para nordeste. Esta diferenciação no padrão de distribuição pode indicar alternância no sentido das correntes de fundo.

Nitrogênio e fósforo são nutrientes que contribuem para o aumento da produção primária. Quando em excesso podem iniciar processos de eutrofização e, por conseguinte, alterações ambientais, tais como turbidez, gerada pelo aumento de biomassa microalgal, e depleção nos níveis de oxigenação (Esteves, 1998). O aporte destes dois nutrientes no ambiente marinho pode ocorrer de forma natural e/ou antrópica. Dentre as fontes antrópicas, a principal é o esgoto doméstico, que possui volume expressivo de compostos nitrogenados (Aston e Hewit, 1977; Faganelli et al. 1988) e fosfatados em sua composição (Lassen et al., 1984; Faganelli et al., 1988; Ozório e Oliveira, 2001).

Os valores de nitrogênio obtidos em Abril de 2006 são aproximadamente duas ou três vezes mais elevados, em relação aos valores obtidos em Junho de 2005 e Setembro de 2006. Não há como confirmar se esse aumento dos teores é de origem antrópica ou natural, uma vez que os teores dos outros elementos não sofreram tal acréscimo. Infere-se que os valores elevados obtidos podem ser de origem natural. Dentre as fontes naturais menciona-se a pluviosidade e os materiais alóctones, que por ventura, são carreados pelas chuvas (Esteves, 1998). De acordo com os resultados granulométricos de Abril de 2006, verificou-se porcentagens elevaas de sedimentos finos, que podem ter sido carreados do continente devido à chuvas em ocorreram em dias anteriores à coleta. 
Conforme Bader (1955) há maior taxa de preservação de nitrogênio em sedimentos com elevados teores de sedimentos finos, relação esta observada pelo coeficiente de correlação de Pearson (Anexo 31).

Os teores de fósforo de $90 \%$ das estações amostradas em Julho de 2005, e 60\% das estações de Abril de 2006 são indicativos de atividades antropogênicas. De acordo com Baturin (2003), valores acima de $700 \mu \mathrm{g} \mathrm{g}^{-1}$ são indicativos de estresse ambiental decorrente de atividades antrópicas. $\mathrm{O}$ fósforo pode ocorrer no meio ambiente de forma natural ou antrópica, dentre as formas antrópicas a introdução pode ocorrer pelos fertilizantes, pelos detergentes polifosfatados e ortofosfatados e pelos fosfatos inorgânicos condensados de esgotamentos sanitários não tratados (Aston e Hewit, 1977; Ozório e Oliveira, 2001; Marins et al., 2007).

Comparativamente observou-se significativo declínio dos valores de fósforo entre as coletas realizadas, de 70 a $50 \%$ entre os períodos estudados. Tal diminuição aparentemente está associada à Resolução CONAMA 359, que entrou em vigor em Abril de 2005 e regulamenta a diminuição dos teores de fósforo nos detergentes em pó. Os resultados obtidos ressaltou a importância do fósforo como traçador de efluentes domésticos e industriais que são dispostos no canal.

Os valores de fósforo obtidos no Canal de São Sebastião estão entre os valores obtidos por Carreira e Wagener (1998; 369,81 $\mu \mathrm{g} \mathrm{g}^{-1}$ a 2284,57 $\left.\mu \mathrm{g} \mathrm{g}^{-1}\right)$, CETESB (2007; $373,13 \mu \mathrm{g} \mathrm{g}^{-1}$ a $\left.1787,53 \mu \mathrm{g} \mathrm{g}^{-1}\right)$ e por Aston e Hewit $\left(1977 ; 10 \mu \mathrm{g} \mathrm{g}^{-1}\right.$ a $\left.2040 \mu \mathrm{g} \mathrm{g}^{-1}\right)$.

No tocante ao enxofre, os valores encontrados em $60 \%$ das estações são superiores a 0,13\% (q.v. Tabela 06), o que de acordo com Turekian e Wedepohl (1961) é indicativo de atividades antrópicas. Na natureza, o enxofre ocorre como resultado de emissões vulcânicas, de aerossóis de sais marinhos, do metabolismo do fitoplâncton marinho, das queimadas florestais e da decomposição da matéria orgânica (Sígolo e Pinheiro, 2010). Como origem antrópica menciona-se o esgoto doméstico. O enxofre está presente tanto na matéria orgânica ppresente nos esgotos, como também nos resíduos de detergentes, os quais contêm em sua formulação sulfatos e sulfetos inorgânicos, surfactantes, alquil-sulfonado-lineares (Jordão e Pessoa, 1995; Cabrera, 2005). Os teores de enxofre obtidos sugerem degradação anaeróbica da matéria orgânica por bactérias sulfato-redutoras. Em todas as estações foram identificadas esférulas de matéria orgânica em processo de remineralização para monossulfeto de ferro, cujo processo ocorre somente em ambiente anóxico e com aporte crônico de matéria orgânica. 
Na tentativa de identificar a proveniência da matéria orgânica foram calculadas razões $\mathrm{C} / \mathrm{N}$. A origem da matéria orgânica na área de estudo é de complexo entendimento, uma vez que se trata de região costeira; entretanto, pelos resultados obtidos inferências puderam ser feitas. No decorrer dos períodos analisados observou-se alteração no padrão de distribuição da origem da matéria orgânica; contudo foi possível inferir matéria orgânica de origem continental, cuja principal fonte é o esgoto disposto pelo emissário. Matéria orgânica de origem continental foi mais proeminente em Julho e Setembro. Excetuando-se a estação Ar5 (Julho de 2005), verificou-se que matéria orgânica de origem continental passa a ocorrer em estações posicionadas após o término do trecho difusor e em sentido preferencial de deposição, o qual já foi inferido por meio da granulometria. Em Abril de 2006 verificou-se predominância de matéria orgânica de origem marinha, o que leva a concluir que no período da amostragem houve maior fluxo de águas marinhas que carrearam nutrientes para o interior do canal.

Além da problemática da proximidade da área de estudo com a linha de costa, outro fator que deve ser levado em consideração é a composição textural dos sedimentos, uma vez que em locais com elevadas porcentagens de sedimentos arenosos, tais como estações Ar7 e Ar8, a taxa de preservação do carbono orgânico total é superior a taxa de preservação do nitrogênio (Bader, 1955), e consequentemente os resultados podem ser mascarados.

A baixa qualidade do compartimento sedimentar também pode ser verificada pelo potencial de oxi-redução dos sedimentos. Para os três períodos de estudo, os resultados das razões $\mathrm{C} / \mathrm{S}$ caracterizaram a área de estudo como ambiente redutor e/ou com tendências redutoras. Em geral, verificou-se que as estações com os melhores níveis de oxigenação, na interface água sedimento, são as que se encontram posicionadas na região sudoeste da malha de amostragem, a qual está sob maior influência marinha e possui maior retrabalhamento pelas correntes de fundo.

Os resultados das razões $\mathrm{C} / \mathrm{S}$ corroboram, em partes, o baixo potencial de oxiredução dos sedimentos inferido pelos valores de Eh, os quais evidenciam aumento de consumo de oxigênio na interface-água sedimento para degradação de elevada quantidade de matéria orgânica. 
4.2.3 Associações de foraminíferos - biocenoses e tanatocenoses

A composição das biocenoses e tanatocenoses diferem significativamente entre si. As dissimilaridades obtidas na estrutura composicional das associações de foraminíferos refletem a dinâmica dos parâmetros ambientais a que o compartimento bentônico está submetido. Alterações na salinidade, temperatura, oxigênio dissolvido, maior ou menor aporte de matéria orgânica tendem a alterar a composição das espécies, sendo observado, em alguns casos, o desaparecimento de espécies estenobióticas para aumento de dominância de espécies euribiontes (Alve, 1995). No tocante as tanatocenoses, as carapaças estão sujeitas à transporte e a diagênese.

Na região do Araçá, o principal fator que modelou a composição e a distribuição das biocenoses foi o estabelecimento de ambiente redutor, devido ao aporte crônico de matéria orgânica, conforme foi evidenciado pelas análises uni e multivariadas (e.g. correlação de Pearson e Análise de Correspondência Canônica). As coletas realizadas em três períodos diferentes, com espaçamento de meses, permitiram acompanhar a progressiva alteração ambiental que ocorreu na região.

As densidades obtidas nas biocenoses são consideradas baixas quando comparadas com outras regiões costeiras, bem como com o ponto controle (estação C3). Na estação C3, localizada na região norte do lado continental do Canal de São Sebastião foram obtidos 266 foraminíferos por $10 \mathrm{~cm}^{3}$ de sedimento. Filippos (2010), ao analisar a influência da disposição de efluentes domésticos através de emissário submarino em Cigarras (São Sebastião, SP), obteve densidades que variaram de 65 a 215 e de 85 a 250 foraminíferos por $\mathrm{cm}^{3}$ de sedimento, nos anos de 2006 e 2007, respectivamente. Já na Baía de Santos, área considerada impactada pela disposição oceânica que ocorre no interior da baía e pela presença do Porto de Santos, CETESB (2007), verificou densidades que oscilaram de 6 a 68 foraminíferos por $10 \mathrm{~cm}^{3}$.

A densidade é considerada um importante descritor ecológico para análises ambientais, desde que outros parâmetros sejam analisados, como por exemplo, as diversidades específicas e equitatividades, as quais são consideradas entre moderadas e baixas nas análises realizadas próximo ao emissário do Araçá.

Excetuando-se os valores obtidos nas estações Ar1 e Ar5 (Abril de 2006), nos primeiros períodos de estudo, os volumes de sedimento e as densidades apresentaramse, em média, quase similares. Já no terceiro período, desconsiderando-se as estações Ar1 e Ar2, as densidades aumentaram significantemente; utilizou-se o volume de 10 
$\mathrm{cm}^{3}$ de sedimento em $60 \%$ das estações analisadas. Entretanto, para este período, foram identificadas as menores diversidades específicas e equitatividades devido à elevada abundância de espécies consideradas tolerantes, e.g. Ammonia tepida e Buliminella elegantissima.

A estação Ar1, localizada na saída do emissário submarino, apresentou gradativa diminuição de densidade entre os períodos estudados. Em áreas de lançamento de esgotos há a predisposição de haver diminuição de densidade e até mesmo a geração de uma zona azóica na área imediatamente adjacente ao lançamento (Alve, 1995; Mojtahid et al., 2008). Zonas azóicas não foram observadas, entretanto, a densidade obtida foi muito baixa. Na amostragem realizada em Setembro de 2006, foram necessários 210 $\mathrm{cm}^{3}$ de sedimento para a obtenção de 105 foraminíferos. Nas análises de comparação composicional (NMDS, teste t e Agrupamento), a estação Ar1 permaneceu separada das demais em todos os períodos, indicando diferenciação em sua composição em relação às demais estações.

Assim como foi observado nas biocenoses, também foi detectada diferença significativa entre a estrutura composicional das biocenoses e das tanatocenoses. A diferença mais significativa foi o amento de espécimes pertencentes à Subordem Textulariina, sendo Gauudryina exilis a espécie dominante em Setembro de 2006. A preponderância de aglutinantes, em locais onde até então espécimes hialinas eram dominantes, está associada a processos post mortem de dissolução química, que pode ocorrer nas associações de foraminíferos (Alve, 1995). Processos de dissolução em carapaças calcárias de foraminíferos ocorrem em ambientes com $\mathrm{pH}$ ácido, a partir de 6,8 (Boltovskoy e Wright, 1976). No período da coleta, os valores de $\mathrm{pH}$ eram alcalinos, entretanto, infere-se que em períodos anteriores as condições ambientais foram favoráveis à processos de dissolução, conforme pode ser observado nas fotomigrografias realizadas nas carapaças de alguns exemplares de foraminíferos das tanatocenoses (Prancha 2).

A maior densidade encontrada na estação Ar5, em Abril e Setembro, deve-se às abundâncias de Ammonia spp. A elevada abundância de Ammonia tepida aparentemente relaciona-se ao processo de eutrofização que ocorreu nesta estação, e que é inferido pelas concentrações de clorofila $a$ e feofitina. Segundo dados apresentados em CETESB (2008), os valores de clorofila $a$ e feofitina obtidos em Abril de $2006\left(18,86 \mu \mathrm{g} \mathrm{L}^{-1} \mathrm{e}\right.$ $\left.5,15 \mu \mathrm{g} \mathrm{L}^{-1}\right)$ e Setembro de $2006\left(17,71 \mu \mathrm{g} \mathrm{L}^{-1}\right.$ e $\left.7,08 \mu \mathrm{g} \mathrm{L}^{-1}\right)$ são indicativos de 
alteração no estado trófico da região. A clorofila $a^{16}$, por ser a mais comum das clorofilas, é considerada como principal variável indicadora do estado trófico em ambientes aquáticos (Wetzel e Likens, 1991). A feofitina, por sua vez, é o produto da degradação da clorofila $a$, motivo pelo qual se infere que elevadas concentrações de feoftina são indicativas de processo de eutrofização (Wetzel e Likens, 1991).

A disposição oceânica de esgotos domésticos pode ter efeito negativo, positivo ou nulo sobre as associações de foraminíferos (Alve, 1995). Um efeito positivo indireto é o aumento da biomassa microalgal (e.g. produtores primários), devido ao aporte contínuo de nutrientes (Ward et al., 2003). O aumento da biomassa microalgal, apesar de não ter sido quantificado, foi evidenciado pela elevada concentração de frústulas de diatomáceas observadas nos sedimentos da estação Ar5. O aumento de produtores primários é considerado suprimento alimentar para espécies de foraminíferos herbívoros (Ward et al., 2003; Armynot du Chatêlet et al., 2004), como por exemplo, para o gênero Ammonia sp. Em estudo realizado na Baía de Ubatuba (SP), Burone et al. (2007) correlacionaram o aumento na abundância de Ammonia tepida à elevadas concentrações de clorofila $a$.

Ammonia tepida, predominante em todas as estações e períodos analisados, é uma espécie euribionte, característica de ambientes costeiros rasos, adaptada a grandes variações ambientais (Bradshaw, 1961; Murray, 1991; Kitazato, 1994). Devido ao fato de possuir metabolismo anaeróbico facultativo, Ammonia tepida sobrevive em ambiente disóxicos por 1 ou dois meses (Kitazato, 1994), bem como em ambientes anóxicos por 24 horas (Bradshaw, 1961; Moodley and Hess, 1992). Tem sido reportada por muitos autores como dominante em regiões sob estresse ambiental (Alve, 1995; Armynot du Châtelet, Debenay, Soulard, 2004; Burone et al., 2006; Ferraro et al., 2006; Lê Cadre e Debenay, 2006), sendo inclusive considerada espécie com potencial para biomonitoramentos, principalmente quando se refere a impactos ambientais ocasionados por atividades antrópicas (Debenay e Fernandez, 2009).

Ferraro et al. (2006) obteve abundâncias relativas de Ammonia tepida que oscilaram entre $1,8 \%$ e $100 \%(\bar{x}=40,6 \%)$ no Porto de Nápoles (Itália). Burone et al. (2006) obtiveram abundância relativas que foram de 15,4 a $98 \%(\bar{x}=65,1 \%)$, em estudo realizado na zona costeira de Montevideu (Uruguai). Debenay e Fernandez

\footnotetext{
${ }^{16}$ por ser a mais comum das clorofilas representa aproximadamente 1 a $2 \%$ do peso seco de material orgânico em todas as algas planctônicas, fato que a faz indicadora de biomassa algal (Wetzel e Likens, 1991),
} 
(2009), em Sainte Marie Bay (Nova Caledônia), obtiveram abundâncias relativas semelhantes desta espécie (entre 20 e 50\%), e as relacionaram, em parte, ao aumento de aporte de matéria orgânica lábil por meio de disposição oceânica de esgotos. A predominância Ammonia tepida em áreas sob estresse ambiental deve-se à sua maior capacidade de adaptação e taxa de reprodução, independentemente da fonte causadora das alterações físico-químicas (Alve, 1995; Thomas et al., 2000 [Ammonia beccarii]).

O estresse ambiental que ocorre no Araçá devido à disposição oceânica de esgotos não é caracterizado somente pela dominância de somente uma espécie, mas também pela elevada abundância de espécies infaunais e detritívoras, comumente identificadas em locais com sinais de depleção de oxigênio dissolvido na interface águasedimento e com elevados teores de matéria orgânica, tais como Bolivina spp, Brizalina striatula, Buliminella elegantissima, Cassidulina crassa e Hopkinsina pacifica (Apêndice 1.1). Resultado similar foi obtido por Amaral et al. (2003) ao pesquisarem a macrofauna existente na Baía do Araçá. Os autores verificaram que as espécies mais abundantes são oportunistas e bioindicadoras de enriquecimento orgânico (e.g. Heteromastus filiformis e Capitella capitata [poliquetas] e Kalliapseudes schubartii [crustáceo]).

Pararotalia cananeiaensis foi à segunda espécie mais abundante em Junho de 2005, com decréscimo de abundância até quase desaparecer em Setembro (1 espécime na estação Ar3). Pararotalia cananeiaensis ainda não possui suas preferências ecológicas bem conhecidas, entretanto, no presente estudo, sua presença foi significantemente correlacionada aos teores de enxofre $(\mathrm{r}=0,81 ; p<0,01)$, e em menor escala, aos teores de fósforo orgânico $(\mathrm{r}=0,61 ; p=0,08)$.

Espécies epifaunais, suspensívoras, bioindicadoras de ambiente com baixas concentrações de matéria orgânica e bons níveis de oxigenação, como por exemplo, Lobatula lobatula, Hanzawaia boueana e Rosalina floridensis (Apêndice 1.2), diminuíram progressivamente de abundância, no decorrer dos períodos analisados, com ausência de indivíduos nas estações Ar5 e Ar10, em Setembro de 2006. A distribuição destas espécies é inversamente proporcional ao padrão obtido para os teores de matéria orgânica. As maiores abundâncias ocorreram nas estações sudoeste e sul, as quais estão sob maior influência de águas marinhas e posicionadas em sentido inverso ao da pluma disposta pelo emissário submarino.

Outro fator que corrobora a baixa qualidade ambiental da região circundante aos difusores do emissário submarino é a presença conspícua e em elevada porcentagem de 
foraminíferos com carapaças pequenas. Conforme discutido anteriormente (Capítulo 03), a presença de foraminíferos com carapaças pequenas tanto pode ser indicativo de mudança na estratégia reprodutiva devido à abundância de alimento (Murray, 1991), bem como representar uma adaptação dos organismos em áreas com tendências de hipoxia (Sen Gupta e Machain-Castillo, 1993).

No presente estudo, verificou-se que os tamanhos das carapaças estão associados aos teores de matéria orgânica, cujo aporte crônico está influenciando nos níveis de oxigenação. Verificou-se que o estresse ambiental, que ocorre na região, subsidia condições favoráveis à manutenção metabólica de organismos com carapaças pequenas e médias. Carapaças grandes estão comumente relacionadas a ambientes de maior oxigenação, entretanto, no Araçá, verificou-se que suas maiores abundâncias estão associadas à presença de Brizalina striatula, cuja carapaça de formato alongado atinge o tamanho estipulado para carapaças grandes $(250$ a $500 \mu \mathrm{m})$. Brizalina striatula é espécie infaunal, detritívora (Murray, 1991) e está associada à ambientes impactados, com baixos níveis de oxigenação na interface água-sedimento (Bernhard e Gupta, 1999; Martins et al., 2006; Burone et al., 2006; Frontalini e Coccioni, 2008).

$\mathrm{Na}$ região do Araçá, não houve definição de quais fatores ambientais estão modelando o padrão de distribuição de Brizalina striatula (q.v. correlações de Pearson e Análise de Correspondência Canônica). Diante do exposto, prefere-se desconsiderar as informações que, por ventura, seriam obtidas pela distribuição de foraminíferos com carapaças grandes.

Nas tanatocenoses, diferentemente do observado nas biocenoses, foram verificadas elevadas densidades, riquezas e maior heterogeneidade na composição e distribuição das espécies.Os resultados não são indicativos de ausência de estresse ambiental, mas sim representam períodos diferenciados de acúmulo de carapaças. Contudo, importantes informações foram obtidas pelas análises das tanatocenoses, as quais completam e corroboram as inferências realizadas pelas biocenoses.

Excetuando-se a estação Ar1, amostrada em Setembro de 2006, Pararotalia cananeiaensis é a espécie mais abundante nos três períodos amostrados. Sua presença confirma a entrada de águas marinhas pela região sul e, pelo seu padrão de distribuição, infere-se diminuição de fluxo de correntes de sudoeste para nordeste da área de estudo, informações similares às obtidas pela geoquímica e granulometria (Anexos 12 ao 19). 
Apesar da predominância de espécies mais tolerantes a estresse ambiental, verificou-se melhor distribuição de espécies estenobióticas, sendo o padrão de distribuição similar ao observado para as biocenoses.

O tamanho das carapaças de foraminíferos Julho de 2005 é diferente em relação à proporção de carapaças grandes. Em Julho, carapaças grandes estiveram presentes em porcentagens significativas, sendo até mesmo predominantes na estação Ar9. A elevada abundância obtida indica que no período de Julho de 2005 havia uma circulação mais forte atuando na área de estudo, a qual propiciou um maior retrabalhamento dos sedimentos de fundo, com consequente elevação nos níveis de oxigenação e menor taxa de deposição de matéria orgânica.

A hidrodinâmica mais forte é diretamente responsável pelo melhor grau de seleção dos grãos e pela abundância de fragmentos de carapaças, que ocorreram no período. Indiretamente, devido à maior oxigenação, é responsável pela presença de carapaças acastanhadas, comumente encontradas em ambientes óxicos, assim como também pela composição e distribuição das associações de foraminíferos. Em Julho de 2005, foram obtidas as maiores abundâncias de espécies epifaunais nas biocenoses.

Os resultados acima apresentados contradizem as inferências feitas pelas razões $\mathrm{C} / \mathrm{S}$, as quais em Julho caracterizaram a área de estudo como ambiente redutor. Uma explicação plausível é que em sedimentos com baixas concentrações de carbono orgânico total e enxofre, bem como de qualquer outro elemento, o cálculo de razões elementares deve ser utilizado com critério, uma vez que os resultados podem ser mascarados (Bader, 1955). Conforme Anexos 14 e 19, as estações com características redutoras apresentaram os menores valores de carbono orgânico total e enxofre.

Com a diminuição do fluxo hidrodinâmico e alteração no sentido das correntes, a região onde está posicionado o trecho difusor do emissário submarino, tornou-se ambiente redutor. Como resposta a esta alteração ambiental, observou-se gradativa substituição de espécies estenobióticas por espécies mais tolerantes, bem como diminuição de carapaças preenchidas por limonita e manutenção da porcentagem de carapaças preenchidas por monossulfeto de ferro/pirita.

Carapaças com sinais de bioerosão estiveram presentes nos três períodos analisados, o que é indicativo da presença de predadores, tais como poliquetas, os quais ao abundantes na região (Amaral et al., 2003).

As informações obtidas pelas associações de foraminíferos corroboraram os resultados obtidos pelas análises granuloétricas e geoquímicas, bem como forneceram 
informações suplementares para o entendimento da hidrodinâmica na região circunjacente aos difusores do emissário do Araçá. 


\section{Anexos}

Anexo 12 - Distribuição granulométrica obtida próximo ao emissário submarino de esgotos domésticos do Araçá.

Valores em porcentagem.

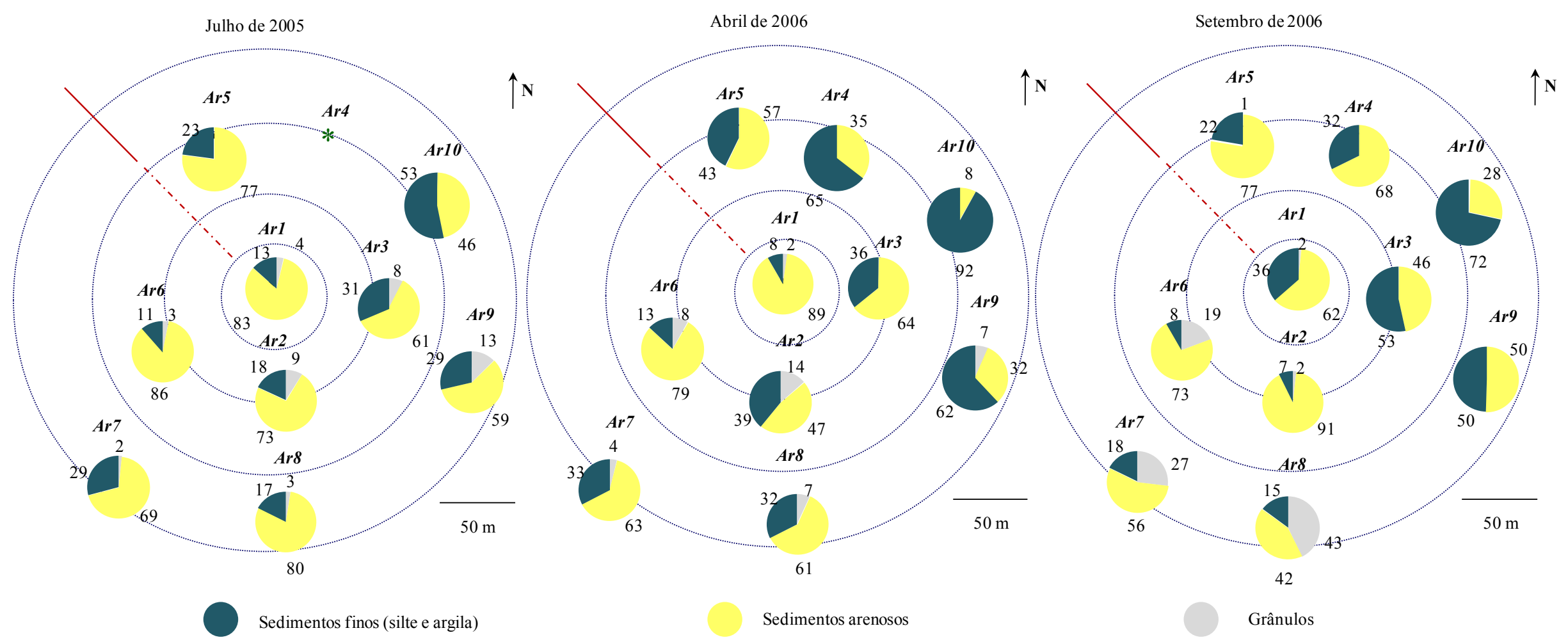

* Estação não amostrada 
Anexo 13 - Concentrações de carbonato de cálcio obtidas próximo ao emissário do Araçá.

Valores em porcentagem.
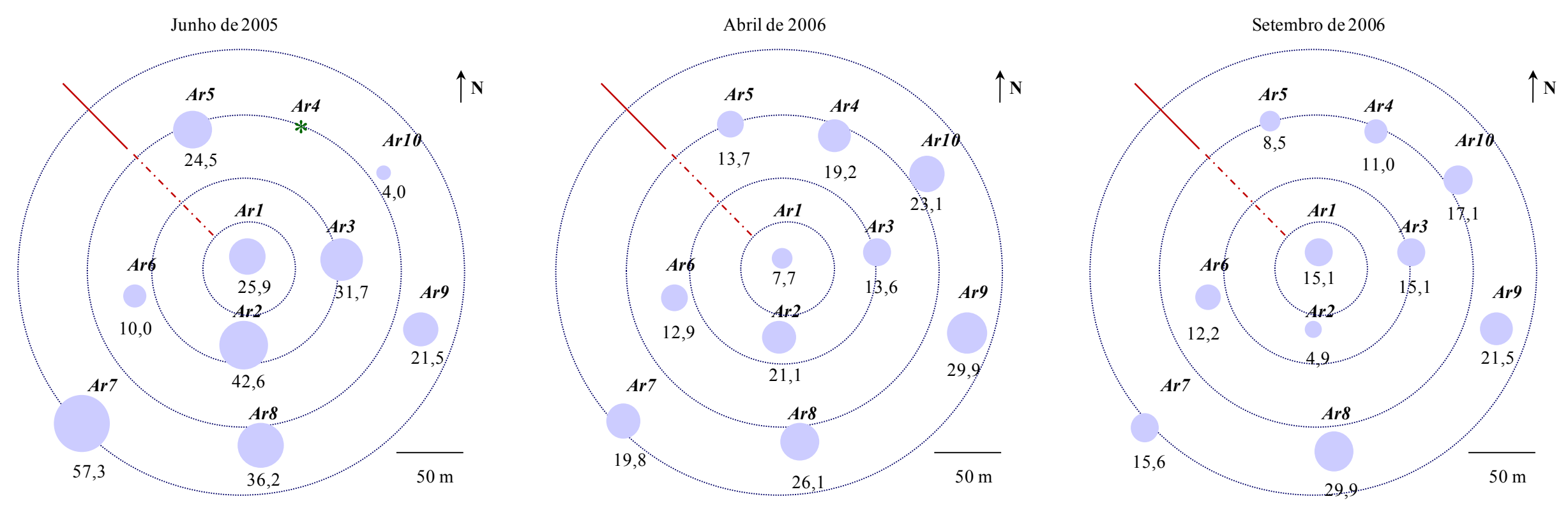

* Estação não amostrada 
Anexo 14 - Concentrações de carbono orgânico total obtidas próximo ao emissário do Araçá. Valores em porcentagem.
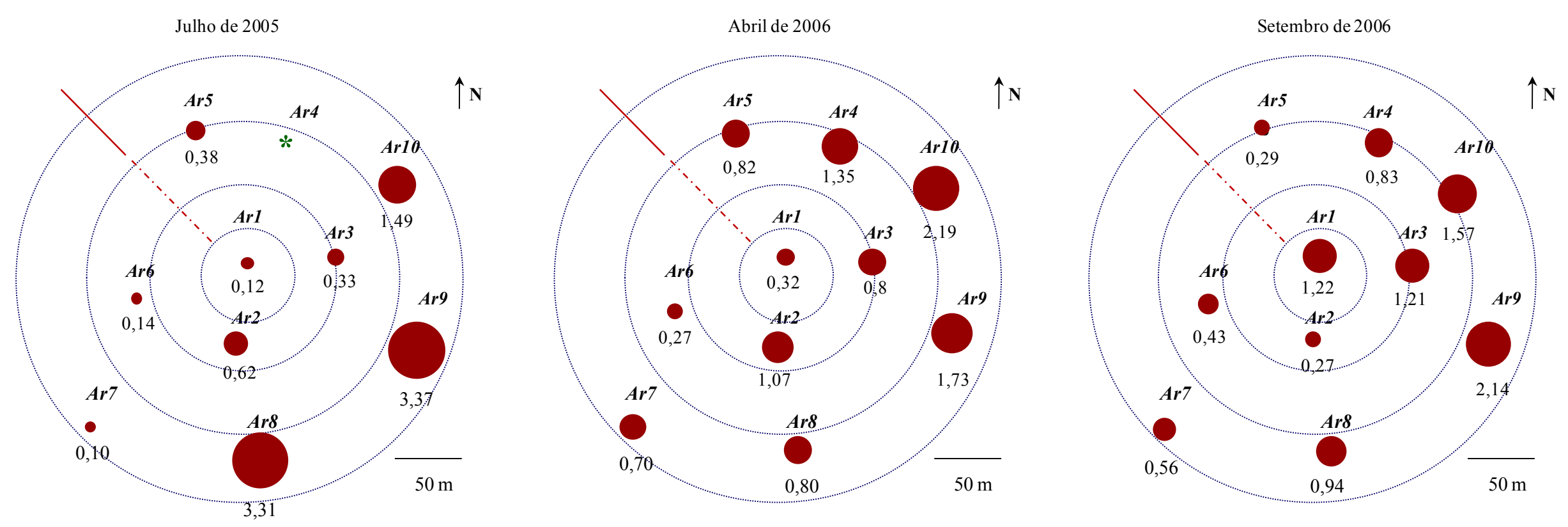

* Estação não amostrada 
Anexo 15 - Concentrações de nitrogênio obtidas próximo ao emissário do Araçá.

Valores em porcentagem.
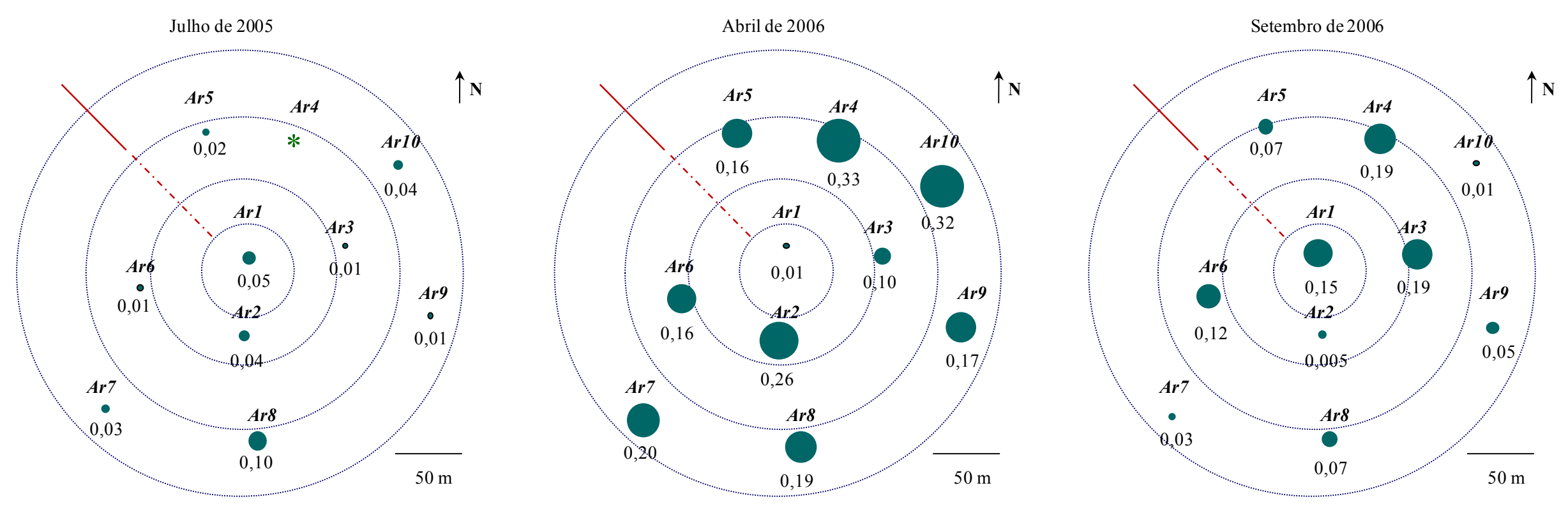

* Estação não amostrada 
Anexo 16 - Concentrações de fósforo total obtidas próximo ao emissário do Araçá.

Valores em porcentagem.
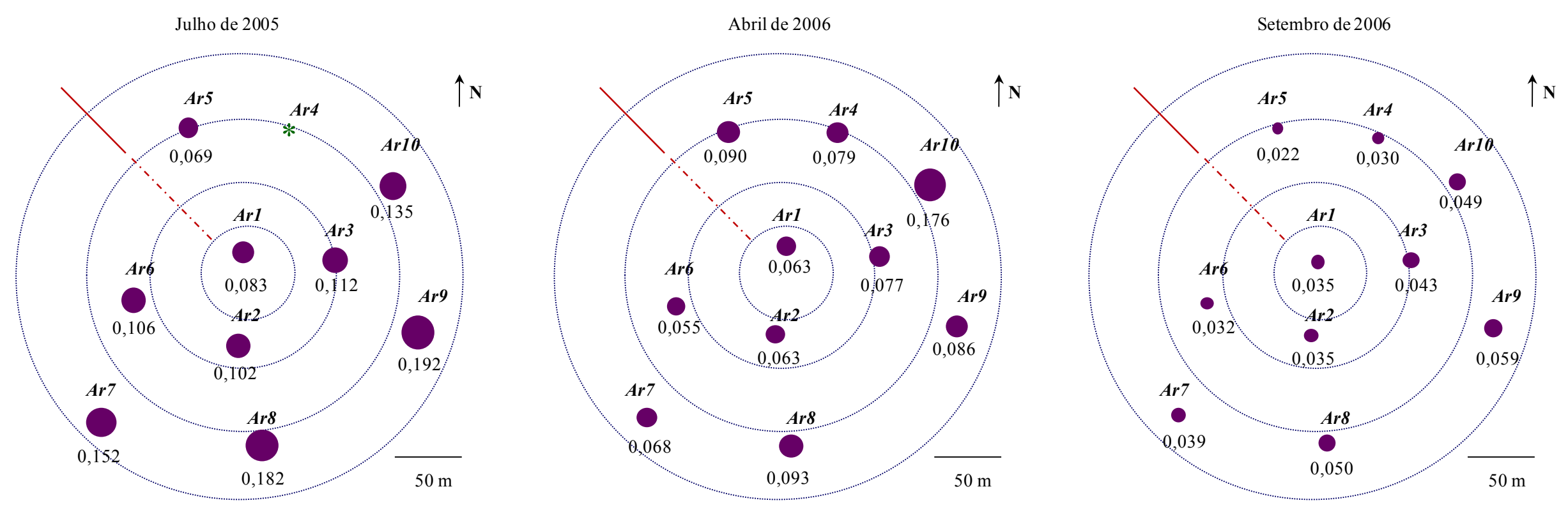

* Estação não amostrada 
Anexo 17 - Concentrações de fósforo orgânico obtidas próximo ao emissário do Araçá.

Valores em porcentagem.
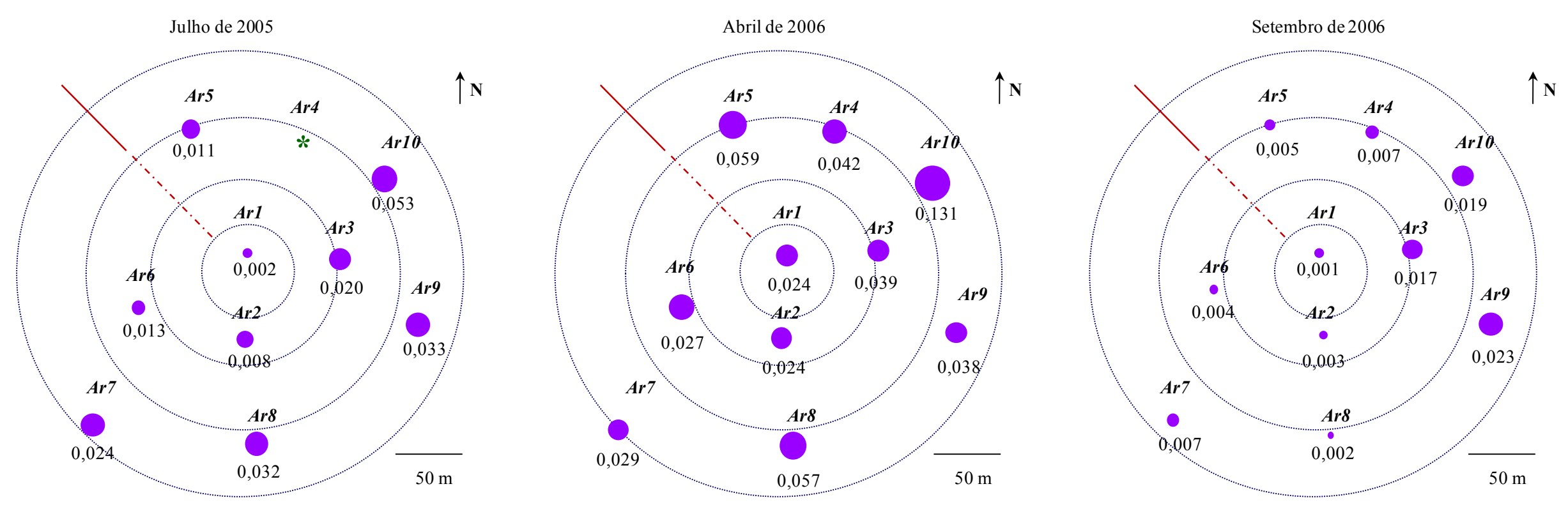

* Estação não amostrada 
Anexo 18 - Concentrações de fósforo inorgânico obtidas próximo ao emissário do Araçá.

Valores em porcentagem.
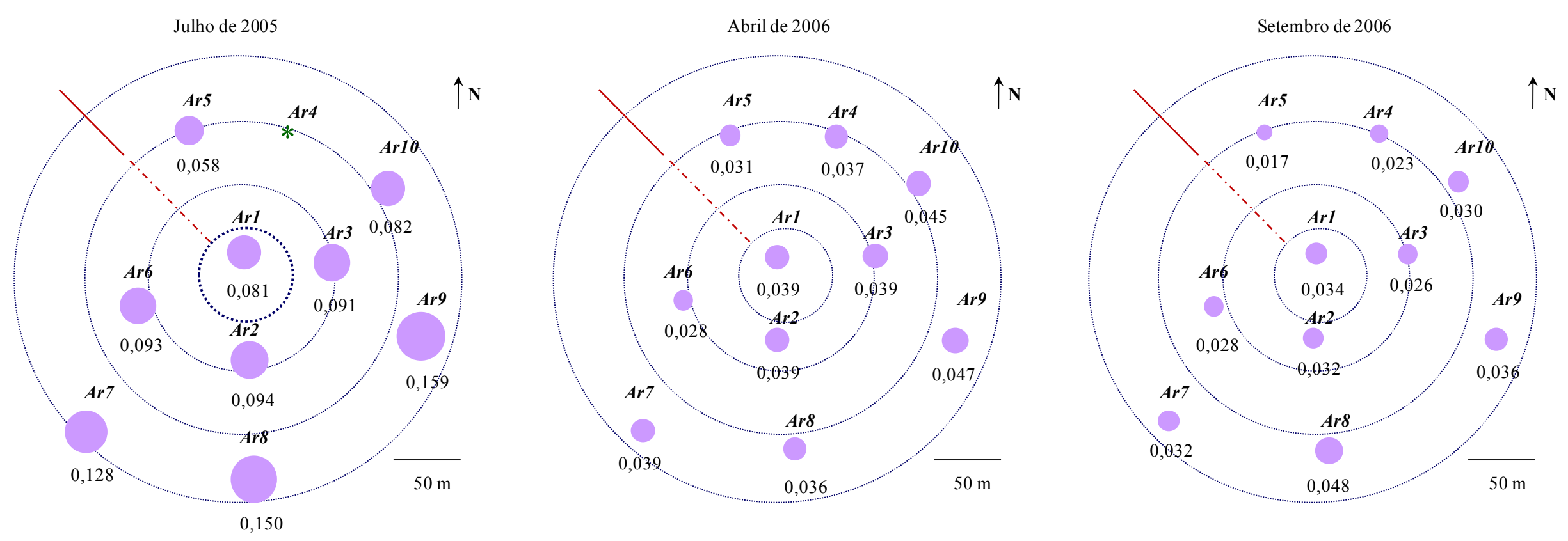

* Estação não amostrada 
Anexo 19 - Concentrações de enxofre obtidas próximo ao emissário do Araçá.

Valores em porcentagem.
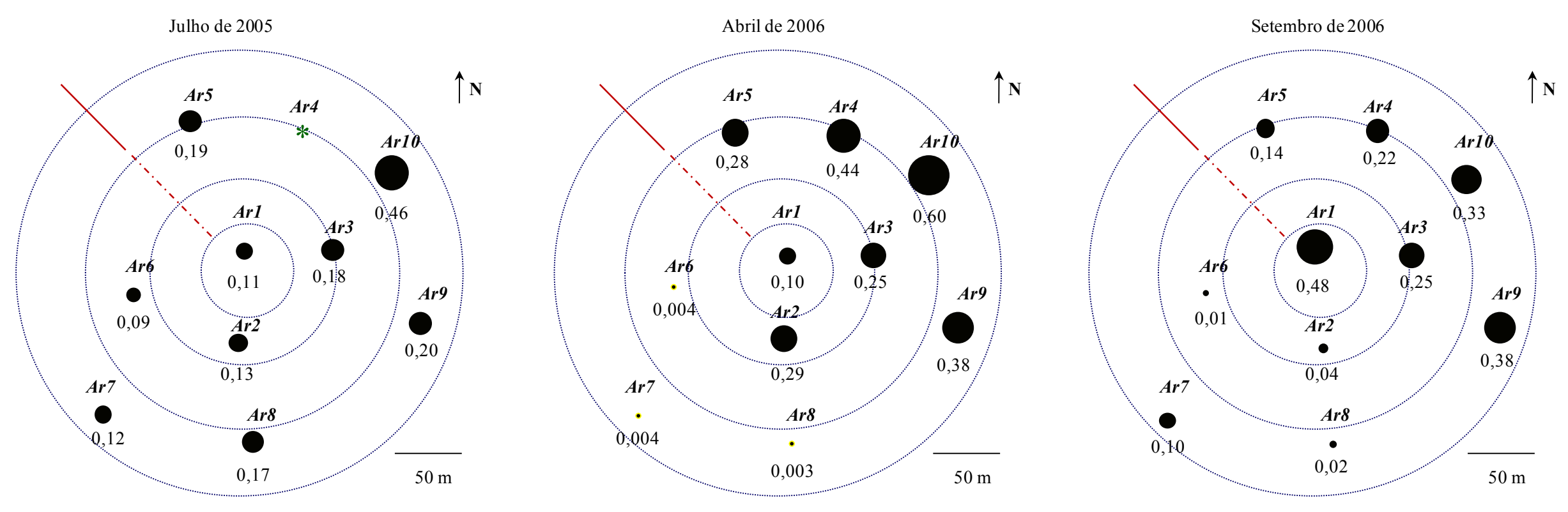

* Estação não amostrada 
Anexo 20 - Origem da matéria orgânica analisada por meio de razões elementares $\mathrm{C} / \mathrm{N}$.

Dados obtidos próximo ao emissário do Araçá.

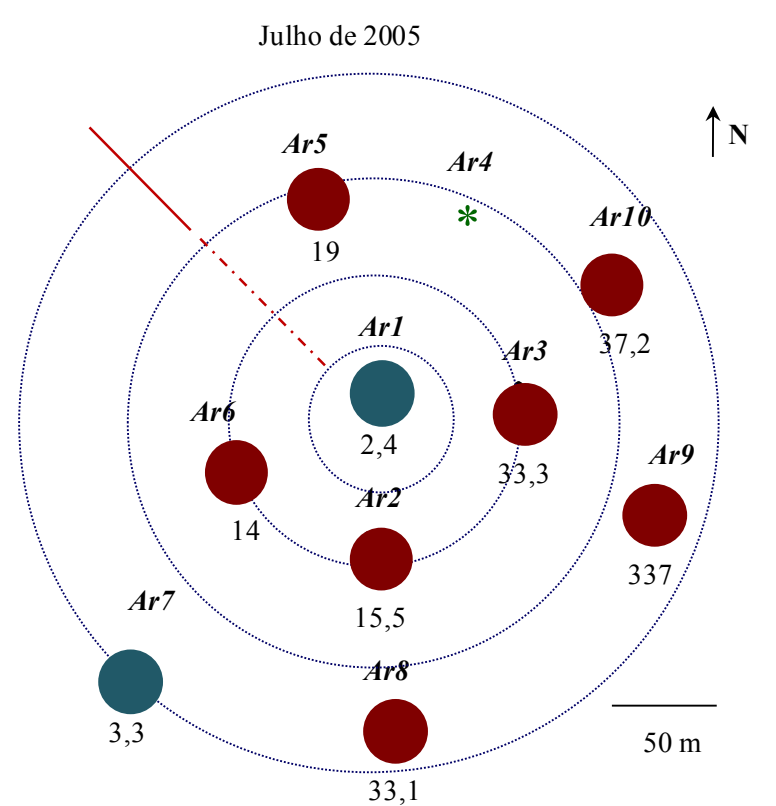

Matéria orgânica de origem marinha

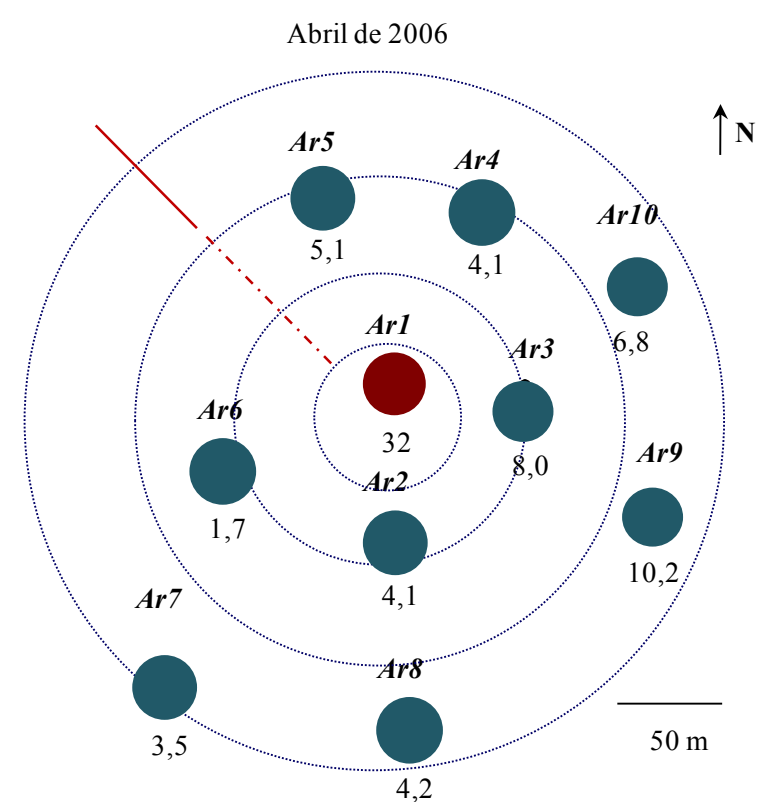

Matéria orgânica de origem continental

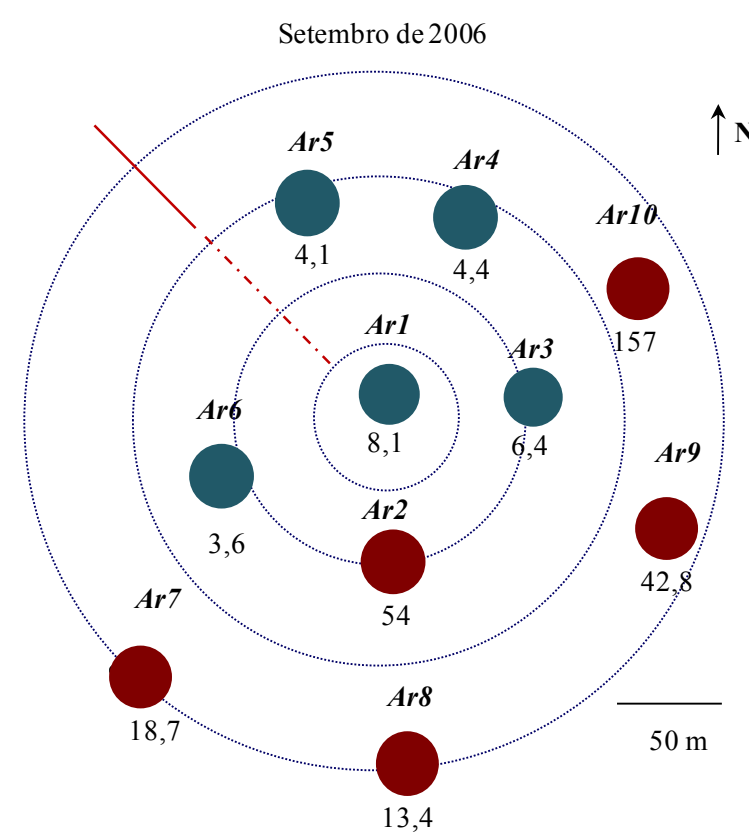

Matéria orgânica de origem mista

* Estação não amostrada 
Anexo 21 - Potencial de oxi-redução dos sedimentos de fundo analisado por meio de razões elementares C/S.

Dados obtidos próximo ao emissário do Araçá.

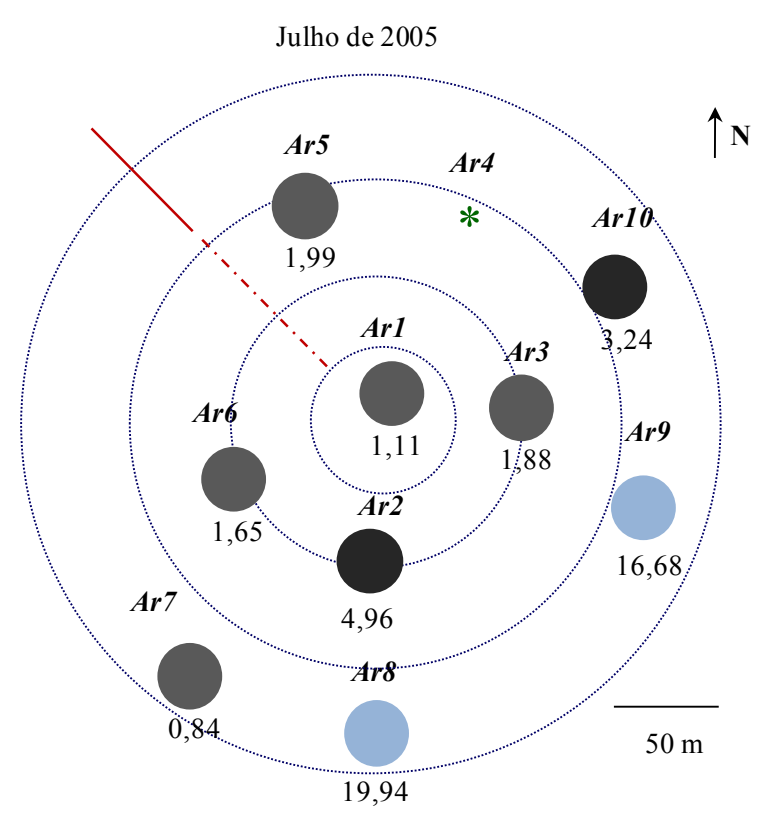

Ambiente óxico

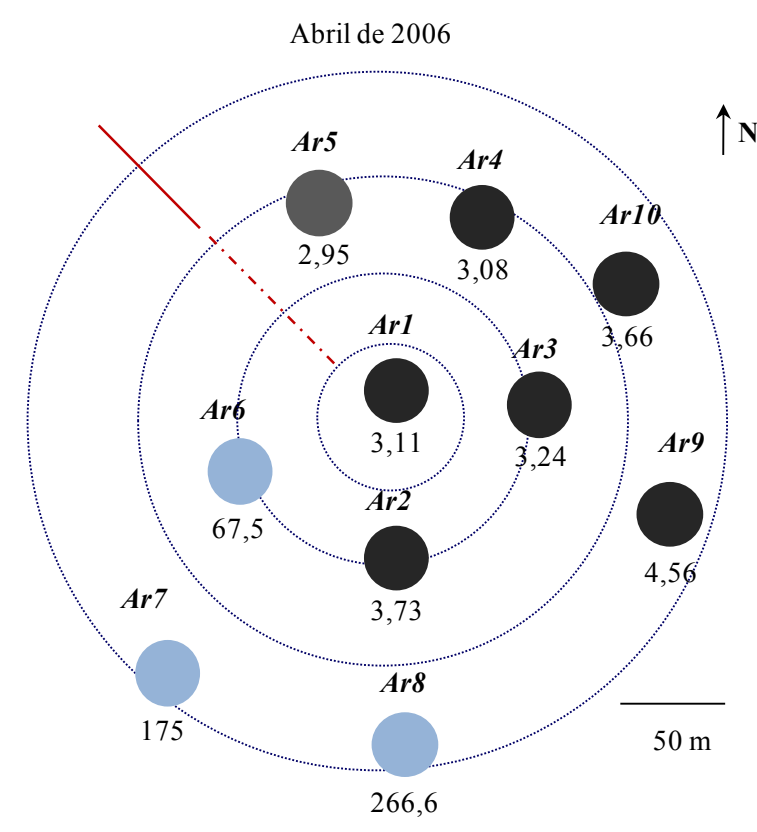

Ambiente redutor

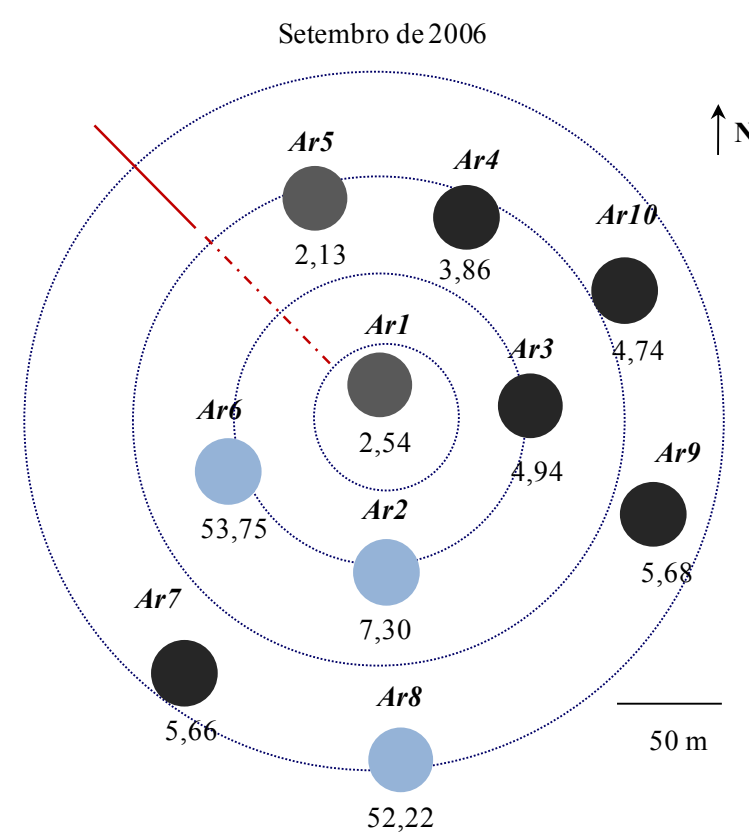

Ambiente com tendências redutoras

* Estação não amostrada 
Anexo 22 - Abundâncias relativas das espécies de foraminíferos identificadas próximo ao emissário do Araçá.

Dados pertencentes às biocenoses.

\begin{tabular}{|c|c|c|c|c|c|c|c|c|c|c|c|c|c|c|c|c|c|c|c|c|c|c|c|c|c|c|c|c|c|}
\hline \multirow[b]{2}{*}{ Estações } & \multicolumn{9}{|c|}{ Coleta realizada em Julho de 2005} & \multicolumn{10}{|c|}{ Coleta realizada em Abril de 2006} & \multicolumn{10}{|c|}{ Coleta realizada em Setembro de 2006} \\
\hline & Ar1 & Ar2 & Ar3 & Ar5 & Ar6 & Ar7 & Ar8 & $\operatorname{Ar} 9$ & Ar10 & $\operatorname{Ar} 1$ & Ar2 & Ar3 & Ar4 & Ar5 & Ar6 & Ar7 & Ar8 & Ar9 & Ar10 & Ar1 & $\mathrm{Ar} 2$ & Ar3 & $\mathrm{Ar} 4$ & Ar5 & Ar6 & Ar7 & Ar8 & Ar9 & Ar10 \\
\hline Adelosina $\mathrm{sp}$ & 0,0 & 0,0 & 0,0 & 0,0 & 0,0 & 0,0 & 0,0 & 0,0 & 0,0 & 0,0 & 0,0 & 1,0 & 0,0 & 0,0 & 0,0 & 0,0 & 0,0 & 0,0 & 0,0 & 0,0 & 0,0 & 0,6 & 0,0 & 0,0 & 0,0 & 0,0 & 0,0 & 0,0 & 0,0 \\
\hline Amobaculites exiguus & 0,0 & 0,0 & 0,0 & 0,8 & 2,4 & 0,0 & 0,7 & 0,0 & 0,0 & 0,0 & 0,0 & 0,0 & 0,0 & 0,0 & 0,0 & 0,0 & 0,0 & 0,0 & 0,0 & 0,0 & 0,0 & 0,6 & 0,0 & 0,0 & 0,0 & 0,0 & 0,0 & 0,0 & 0,0 \\
\hline Ammonia parkinsoniana & 0,0 & 2,9 & 3,2 & 3,1 & 1,6 & 0,6 & 1,4 & 3,5 & 5,4 & 6,0 & 4,4 & 2,9 & 5,0 & 4,2 & 0,7 & 2,7 & 2,5 & 9,7 & 0,0 & 12,8 & 10,0 & 7,4 & 8,0 & 10,7 & 5,5 & 10,5 & 13,5 & 13,8 & 22,7 \\
\hline Ammonia tepida & 44,9 & 34,8 & 24,7 & 45,8 & 32,3 & 41,1 & 31,5 & 33,0 & 47,3 & 45,3 & 42,2 & 49,0 & 44,6 & 49,6 & 20,6 & 43,8 & 41,4 & 37,8 & 40,0 & 51,2 & 33,0 & 50,9 & 29,5 & 74,0 & 28,4 & 26,2 & 33,3 & 53,1 & 47,3 \\
\hline Ammonia $\mathrm{sp}$ & 0,0 & 2,9 & 1,1 & 1,5 & 2,4 & 2,4 & 2,1 & 1,7 & 2,7 & 3,4 & 0,0 & 1,0 & 0,0 & 2,1 & 4,4 & 0,0 & 1,5 & 1,0 & 1,0 & 2,3 & 2,0 & 0,6 & 2,2 & 2,3 & 0,9 & 0,5 & 2,1 & 0,0 & 2,0 \\
\hline Ammotium salsum & 0,0 & 0,0 & 2,2 & 1,5 & 3,1 & 0,0 & 0,0 & 0,9 & 0,0 & 0,9 & 1,5 & 1,0 & 0,0 & 0,0 & 0,0 & 0,9 & 1,5 & 0,5 & 0,0 & 2,3 & 0,0 & 0,0 & 0,0 & 0,4 & 0,9 & 1,4 & 1,0 & 0,8 & 0,0 \\
\hline Angulogerina angulosa & 1,0 & 0,0 & 0,0 & 0,0 & 0,0 & 0,0 & 0,0 & 0,0 & 0,0 & 0,0 & 0,0 & 0,0 & 0,8 & 0,0 & 0,0 & 0,0 & 0,0 & 0,0 & 0,0 & 0,0 & 0,0 & 0,0 & 0,0 & 0,0 & 0,0 & 0,5 & 0,0 & 0,0 & 0,7 \\
\hline Astrononion $\mathrm{sp}$ & 0,0 & 0,0 & 0,0 & 0,0 & 0,0 & 0,0 & 0,0 & 0,0 & 0,0 & 0,0 & 0,0 & 0,0 & 0,0 & 0,0 & 0,7 & 0,0 & 0,0 & 0,0 & 0,0 & 0,0 & 0,0 & 0,6 & 0,0 & 0,0 & 0,0 & 0,0 & 0,0 & 0,0 & 0,0 \\
\hline Bolivina compacta & 2,0 & 0,0 & 4,3 & 3,1 & 0,0 & 2,4 & 0,0 & 2,6 & 3,6 & 0,0 & 0,7 & 1,0 & 0,8 & 0,4 & 2,2 & 0,0 & 1,0 & 1,0 & 2,0 & 1,2 & 0,0 & 0,6 & 0,9 & 0,0 & 0,9 & 1,9 & 2,1 & 3,1 & 2,7 \\
\hline Bolivina danvilensis & 0,0 & 0,0 & 0,0 & 0,0 & 0,0 & 0,0 & 0,0 & 0,0 & 0,0 & 0,0 & 0,0 & 0,0 & 0,0 & 0,0 & 0,0 & 0,0 & 0,0 & 0,0 & 0,0 & 0,0 & 1,0 & 0,0 & 0,0 & 0,0 & 0,0 & 0,5 & 2,1 & 0,8 & 0,7 \\
\hline Bolivina doniezi & 0,0 & 0,7 & 1,1 & 0,8 & 0,0 & 2,4 & 0,0 & 0,0 & 0,0 & 0,9 & 2,2 & 2,0 & 0,8 & 0,0 & 1,5 & 0,0 & 2,0 & 2,0 & 5,0 & 0,0 & 1,0 & 2,5 & 2,2 & 0,4 & 0,0 & 0,5 & 2,1 & 0,8 & 0,7 \\
\hline Bolivina ordinaria & 6,1 & 5,8 & 1,1 & 4,6 & 3,1 & 2,4 & 2,1 & 11,3 & 6,3 & 2,6 & 1,5 & 1,0 & 0,8 & 0,0 & 0,0 & 3,6 & 1,5 & 3,1 & 1,0 & 1,2 & 0,0 & 0,6 & 1,3 & 0,4 & 0,9 & 1,9 & 2,1 & 2,3 & 2,7 \\
\hline Bolivina pseudoplicata & 0,0 & 0,0 & 0,0 & 0,0 & 0,0 & 0,0 & 0,0 & 0,0 & 0,0 & 1,7 & 0,0 & 0,0 & 0,8 & 0,0 & 2,9 & 1,8 & 0,0 & 2,0 & 0,0 & 0,0 & 0,0 & 0,0 & 0,9 & 0,0 & 1,8 & 1,4 & 0,0 & 0,8 & 0,0 \\
\hline Bolivina pulchella & 0,0 & 1,4 & 0,0 & 0,0 & 0,0 & 0,0 & 0,0 & 0,0 & 0,0 & 0,0 & 0,0 & 0,0 & 0,0 & 0,0 & 0,0 & 0,0 & 0,0 & 0,0 & 0,0 & 0,0 & 0,0 & 0,6 & 0,0 & 0,0 & 0,0 & 0,0 & 0,0 & 0,0 & 0,0 \\
\hline Bolivina translucens & 0,0 & 0,0 & 0,0 & 0,0 & 0,0 & 0,0 & 0,0 & 0,0 & 0,0 & 0,0 & 0,0 & 0,0 & 0,0 & 0,0 & 0,0 & 1,8 & 0,0 & 0,0 & 0,0 & 0,0 & 0,0 & 1,2 & 0,4 & 0,0 & 0,0 & 0,0 & 0,0 & 0,0 & 0,0 \\
\hline Bolivina $\mathrm{sp}$ & 0,0 & 0,0 & 0,0 & 0,8 & 0,0 & 0,0 & 0,7 & 2,6 & 0,0 & 0,9 & 0,0 & 0,0 & 3,3 & 3,4 & 0,0 & 2,7 & 0,0 & 1,0 & 3,0 & 1,2 & 0,0 & 0,0 & 0,9 & 0,0 & 1,8 & 1,9 & 1,0 & 2,3 & 2,7 \\
\hline Brizalina sphatulata & 1,0 & 0,7 & 4,3 & 0,8 & 1,6 & 1,8 & 0,0 & 0,0 & 0,0 & 1,7 & 1,5 & 0,0 & 0,8 & 0,0 & 0,0 & 0,0 & 0,0 & 0,0 & 0,0 & 0,0 & 0,0 & 0,0 & 0,0 & 0,0 & 0,0 & 0,0 & 0,0 & 0,8 & 0,0 \\
\hline Brizalina striatula & 5,1 & 6,5 & 3,2 & 5,3 & 4,7 & 6,0 & 7,7 & 7,0 & 7,1 & 4,3 & 4,4 & 8,8 & 8,3 & 3,4 & 13,2 & 6,3 & 6,6 & 3,6 & 3,0 & 0,0 & 8,0 & 0,6 & 7,6 & 5,0 & 13,8 & 7,1 & 6,3 & 5,4 & 0,7 \\
\hline Brizalina subaenarensis & 0,0 & 0,0 & 0,0 & 0,0 & 0,0 & 0,0 & 0,0 & 0,0 & 0,0 & 0,0 & 0,0 & 0,0 & 0,0 & 0,0 & 0,0 & 0,0 & 0,0 & 0,0 & 0,0 & 0,0 & 0,0 & 0,0 & 0,4 & 0,0 & 0,0 & 0,0 & 0,0 & 0,0 & 0,0 \\
\hline Bulimina elongata & 0,0 & 0,0 & 0,0 & 0,0 & 0,0 & 0,0 & 0,0 & 0,0 & 0,0 & 0,9 & 0,0 & 0,0 & 0,0 & 0,4 & 0,0 & 0,0 & 1,0 & 1,0 & 0,0 & 1,2 & 0,0 & 0,0 & 0,9 & 0,0 & 0,9 & 0,5 & 0,0 & 0,8 & 0,0 \\
\hline Bulimina marginata & 2,0 & 1,4 & 0,0 & 0,0 & 0,8 & 0,0 & 2,1 & 1,7 & 0,0 & 0,9 & 4,4 & 3,9 & 1,7 & 0,8 & 0,7 & 0,9 & 1,0 & 1,0 & 5,0 & 0,0 & 2,0 & 2,5 & 4,9 & 0,4 & 0,0 & 0,5 & 2,1 & 2,3 & 3,3 \\
\hline Bulimina pupoides & 0,0 & 0,0 & 0,0 & 0,8 & 0,0 & 0,0 & 0,0 & 0,0 & 0,0 & 0,0 & 0,0 & 0,0 & 0,0 & 0,0 & 0,0 & 0,0 & 0,0 & 0,0 & 0,0 & 0,0 & 0,0 & 0,6 & 0,0 & 0,0 & 0,0 & 0,0 & 0,0 & 0,0 & 0,0 \\
\hline Bulimina $\mathrm{sp}$ & 0,0 & 0,0 & 0,0 & 0,0 & 0,0 & 0,0 & 0,0 & 0,0 & 0,0 & 0,0 & 0,0 & 1,0 & 1,7 & 0,4 & 0,0 & 0,0 & 0,0 & 0,0 & 0,0 & 0,0 & 0,0 & 0,6 & 0,0 & 0,0 & 0,0 & 0,0 & 0,0 & 0,0 & 0,0 \\
\hline Buliminella elegantissima & 1,0 & 0,7 & 3,2 & 3,1 & 0,0 & 7,7 & 2,1 & 7,8 & 4,5 & 0,9 & 8,9 & 5,9 & 6,6 & 5,5 & 1,5 & 3,6 & 2,0 & 9,2 & 6,0 & 15,1 & 0,0 & 1,8 & 14,7 & 1,9 & 3,7 & 6,2 & 5,2 & 6,9 & 6,7 \\
\hline Cancris sagra & 0,0 & 0,0 & 0,0 & 0,0 & 0,0 & 0,0 & 0,0 & 0,0 & 0,0 & 0,0 & 0,0 & 0,0 & 0,0 & 0,0 & 0,0 & 0,0 & 0,0 & 0,0 & 0,0 & 0,0 & 0,0 & 0,0 & 0,0 & 0,0 & 0,0 & 0,5 & 0,0 & 0,0 & 0,0 \\
\hline Cassidulina crassa & 6,1 & 0,0 & 2,2 & 2,3 & 0,8 & 0,6 & 2,1 & 1,7 & 0,0 & 0,0 & 3,0 & 1,0 & 2,5 & 0,0 & 0,7 & 2,7 & 5,1 & 3,6 & 3,0 & 0,0 & 1,0 & 0,0 & 0,4 & 0,0 & 0,9 & 0,0 & 0,0 & 0,0 & 0,0 \\
\hline Cassidulina laevigata & 0,0 & 0,0 & 0,0 & 0,0 & 0,0 & 0,0 & 0,0 & 0,0 & 0,0 & 0,0 & 0,0 & 0,0 & 0,0 & 0,0 & 0,0 & 0,0 & 0,5 & 0,0 & 0,0 & 0,0 & 0,0 & 0,6 & 0,0 & 0,0 & 0,0 & 0,0 & 0,0 & 0,0 & 0,0 \\
\hline Cassidulina subglobosa & 0,0 & 0,0 & 0,0 & 0,0 & 0,0 & 0,0 & 0,0 & 0,0 & 0,0 & 0,0 & 0,0 & 0,0 & 0,0 & 0,4 & 0,0 & 0,9 & 0,5 & 0,5 & 4,0 & 0,0 & 0,0 & 0,6 & 0,0 & 0,0 & 0,0 & 0,0 & 0,0 & 0,0 & 0,0 \\
\hline Cibicides refulgens & 0,0 & 0,0 & 0,0 & 0,0 & 0,0 & 0,0 & 0,0 & 0,0 & 0,0 & 0,0 & 0,0 & 0,0 & 0,0 & 0,0 & 0,7 & 0,0 & 0,0 & 0,5 & 0,0 & 0,0 & 0,0 & 0,6 & 0,0 & 0,0 & 0,0 & 0,0 & 0,0 & 0,0 & 0,0 \\
\hline Cibicides variabilis & 0,0 & 0,0 & 0,0 & 0,0 & 0,0 & 0,0 & 0,0 & 0,0 & 0,0 & 0,0 & 2,2 & 0,0 & 0,0 & 0,0 & 1,5 & 0,0 & 1,0 & 0,0 & 0,0 & 0,0 & 2,0 & 0,0 & 0,0 & 0,0 & 1,8 & 0,0 & 0,0 & 0,0 & 0,0 \\
\hline Cibicides sp & 0,0 & 1,4 & 1,1 & 0,0 & 0,8 & 0,0 & 0,0 & 0,0 & 0,0 & 0,0 & 0,0 & 3,9 & 0,0 & 0,4 & 0,7 & 0,9 & 2,0 & 0,0 & 0,0 & 0,0 & 0,0 & 0,0 & 0,0 & 0,0 & 0,0 & 1,4 & 0,0 & 0,0 & 0,0 \\
\hline
\end{tabular}


Anexo 22 - Continuação

\begin{tabular}{|c|c|c|c|c|c|c|c|c|c|c|c|c|c|c|c|c|c|c|c|c|c|c|c|c|c|c|c|c|c|}
\hline \multirow[b]{2}{*}{ Estações } & \multicolumn{9}{|c|}{ Coleta realizada em Julho de 2005} & \multicolumn{10}{|c|}{ Coleta realizada em Abril de 2006} & \multicolumn{10}{|c|}{ Coleta realizada em Setembro de 2006} \\
\hline & Ar1 & $\operatorname{Ar} 2$ & Ar3 & Ar5 & Ar6 & Ar7 & Ar8 & Ar9 & Ar10 & Ar1 & Ar2 & Ar3 & Ar4 & $\operatorname{Ar} 5$ & Ar6 & $\operatorname{Ar} 7$ & Ar8 & $\operatorname{Ar} 9$ & $\operatorname{Ar} 10$ & Ar1 & Ar2 & $\mathrm{Ar} 3$ & Ar4 & Ar5 & Ar6 & $\operatorname{Ar} 7$ & Ar8 & Ar9 & $\operatorname{Ar} 10$ \\
\hline Cornorbella pateliformis & 0,0 & 0,0 & 0,0 & 0,0 & 0,0 & 0,0 & 0,0 & 0,0 & 0,0 & 0,0 & 0,0 & 0,0 & 0,0 & 0,0 & 0,0 & 0,0 & 0,0 & 0,0 & 0,0 & 0,0 & 2,0 & 0,0 & 0,9 & 0,0 & 0,0 & 1,0 & 1,0 & 0,0 & 0,0 \\
\hline Cornuspira involvens & 1,0 & 0,0 & 0,0 & 0,8 & 2,4 & 1,2 & 0,7 & 0,0 & 0 , & 9 & 0,0 & 0,0 & 0 & 0,0 &, 7 & 0,0 &, 5 & 0,0 & 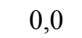 &, 0 & 1,0 & , 0 & 0,0 & , 0 & 0,0 & 0,0 & 0,0 & 0,0 & 0,0 \\
\hline Discorbis bertheloti & 0,0 & 0,0 & 0,0 & 0,0 & 0,0 & 0,0 & 0,0 & 0,0 & 0,0 &, 0 & 0,0 & 1,0 & 0,0 & 0,0 & 0,7 & 0,0 & 0,0 & 0,0 & 0,0 & 0,0 & 0,0 & 0,6 & 0,0 & 0,0 & 0,0 & 1,0 & 0,0 & 0,0 & 0,0 \\
\hline Cribroelphidium advenum & 0,0 & 0,0 & 0,0 & 0,0 & 0,0 & 0,0 & 0,0 & 0,0 & 0,0 & 0,0 & 0,0 & 0,0 & 0,0 & 0,0 & 0,0 & 0,0 & 0,0 & 0,0 & 0,0 & 0,0 & 1,0 & 0,0 & 0,0 & 0,0 & 0,0 & 0,5 & 0,0 & 0,0 & 0,0 \\
\hline Cribroelphidium discoidale & 0,0 & 0,0 & 0,0 & 0,0 & 0,0 & 0,0 & 0,0 & 0,0 & 0,0 & 0,0 & 0,0 & 0,0 & 0,0 & 0,4 & 0,7 & 0,0 & 0,0 & 0,0 & 0,0 & 0,0 & 1,0 & 0,0 & 0,0 &, 0 & 0,0 & 0,5 & 0,0 & 0,0 & 0,0 \\
\hline Cribroelphidium galvestonense & 0,0 & 0,0 & 0,0 & 0,0 & 0,0 & 0,0 & 0,0 & 0,0 & 0,0 & 0,0 & 0,0 & 0,0 & 0,0 & 0,4 & 0,0 & 0,0 & 0,0 & 0,0 & 0,0 & 0,0 & 0,0 & 0,6 & 0,0 & 0,0 & 0,0 & 0,0 & 0,0 & 0,0 & 0,0 \\
\hline Cribroelphidium excavatum & 0,0 & 0,0 & 1,1 & 0,0 & 0,0 & 0,0 & 0,7 & 0,0 & 0,0 & 0,9 & 0,0 & 1,0 & 1,7 & 2,1 & 1,5 & 0,9 & 0,5 & 0,0 & 1,0 & 0,0 & 1,0 & 1,2 & 3,6 & 1,9 & 0,0 & 1,0 & 3,1 & 1,5 & 0,7 \\
\hline Cribroelphidium poy & 1,0 & 0,0 & 4,3 & 0,0 & 1,6 & 2,4 & 1,4 & 0,9 & 0 , & 0,0 & 0,0 & 0,0 & 0,0 & 0,0 & 0,0 & 0,0 & 0,0 & 0,0 & 0,0 & 0,0 & 0,0 & 0,0 & 0,0 &, 0 & 0,0 & 0,0 & 1,0 & 0,0 & 0,7 \\
\hline Cribroelphidium sp & 0,0 & 0,0 & 0,0 & 0,0 & 0,0 & 0,0 & 0,0 & 0,0 & 0,0 & 0,0 & 0,0 & 0,0 & 0,0 & 0,0 & 0,0 & 0,0 & 0,0 & 0,0 & 0,0 & 1,2 & 0,0 & 0,6 & 0,0 & 0,0 & 0,9 & 0,0 & 0,0 & 0,0 & 0,0 \\
\hline Discorbis peruvians & 0,0 & 0,0 & 0,0 & 0,0 & 0,0 & 0,0 & 0,0 & 0,0 & 0 , & 0,0 & 0,0 & 0,0 & 0,0 & 0,0 & 0,0 & 0,0 & 0,0 & 0,0 & 0,0 & 0,0 & 0,0 & 0,0 & 0,4 &, 0 & 0,0 & 0,0 & 0,0 & 0,0 & 0,0 \\
\hline Discorbis williamsoni & 2,0 & 1,4 & 0,0 & 3,1 & 3,9 & 0,0 & 1,4 & 0,0 & 0 , & 0,0 & 0,0 & 0,0 & 0,0 & 0,0 & 0,7 & 0,0 & 0,0 & 0,0 & 0,0 & 0,0 & 0,0 & 0,6 & 0,0 & , 0 & 0,9 & 0,0 & 1,0 & 0,0 & 0,0 \\
\hline Epistominela vitrea & 0,0 & 0,0 & 0,0 & 0,0 & 0,0 & 0,6 & 0,0 & 0,0 & 0,0 & 0,0 & 0,0 & 0,0 & 0,0 & 0,0 & 0,0 & 0,0 & 0,0 & 1,0 & 0,0 & 0,0 & 0,0 & 0,6 & 0,0 & 0,0 & 0,0 & 0,0 & 0,0 & 0,0 & 0,0 \\
\hline Eponides rephandus & 0,0 & 0,0 & 0,0 & 0,0 & 0,0 & 0,0 & 0,0 & 0,0 & 0 , & 0,0 & 0,0 & 1,0 & 0,0 & 0,0 & 0,0 & 0,0 & 0,0 & 0,0 & 0 , &, 0 & 0,0 & 0,6 & 0,0 &, 0 & 0,0 & 0,0 & 0,0 & 0,0 & 0,0 \\
\hline Fissur & 0,0 & 0,0 & 0,0 & 0,0 & 0,0 & 0,0 & 0,0 & 0,0 & 0 , & 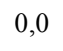 & 0,0 & 0,0 & 0,0 & 0 & 0,7 & 0 & 0,0 & 0,0 & 1, & 0 & 0,0 & 0,6 & 0,0 & , 0 & 0,0 & 0,0 & 0,0 & 0,0 & 0,0 \\
\hline Fissur & 0,0 & 0,0 & 0,0 & 0,0 & 0,0 & 0,0 & 0,0 & 0,0 & 0 & 0,0 & 0,0 & 0,0 & 0,0 & 0,0 & 0,0 & 0,0 & 0,0 & 0,0 & 0,0 & 0,0 & 0,0 & 0,6 & 1,3 & 0,4 & 0,0 & 1,0 & 0,0 & 0,0 & 0,0 \\
\hline Fursenkoina fragilis & 0,0 & 0,0 & 0,0 & 0,0 & 0,0 & 0,0 & 0,0 & 0,0 & 0 , & 0,0 & 0,0 & 0,0 & 0,0 & 0,0 & 0,0 & 0,0 & 0,0 & 0,0 & 1 , & 0 & 0,0 & 6 & 0,0 & 0 & 0,0 & 0,0 & 1,0 & 0,0 & 0,7 \\
\hline Furse & 0,0 & 0,0 & 0,0 & 0,0 & 0,0 & 0,0 & 0,0 & 0,0 & 0 & , & 0,7 & 0,0 & 0,0 & 1 & 0,7 & 4,5 & 0,0 & 1,0 & , &, 0 & 0,0 & 0,0 & 1,3 &, 0 & 0,0 & 0,5 & 0,0 & 0,0 & 0,0 \\
\hline Furse & 0,0 & 0,0 & 0,0 & 0,0 & 0,0 & 0,0 & 0,0 & 0,0 & 0 , & 0,0 & 0,0 & 0,0 & 0,0 & 0,0 & 0,0 & 0,0 & 0,0 & 0,0 & 0,0 & 1,2 & 0,0 & 0,0 & 0,0 & 0,0 & 0,0 & 0,0 & 0,0 & 0,0 & 0,0 \\
\hline Fursenkoina tegula & 0,0 & 0,0 & 0,0 & 0,0 & 0,0 & 0,0 & 0,0 & 0,0 & 0 , & 0,0 & 0,0 & 0,0 & 0,0 & 0,0 & 0,0 & 0,0 & 0,0 & 0,0 & 0 , & 0 & 0,0 & 0,0 & 0,0 & ,4 & 0,0 & 0,0 & 0,0 & 0,0 & 0,0 \\
\hline Gaudryina exilis & 3,1 & 0,7 & 1,1 & 0,0 & 0,0 & 0,0 & 0,0 & 0,0 & 0,9 & 7,7 & 3,0 & 0,0 & 0,0 & 4,2 & 0,7 & 1,8 & 1,5 & 0,5 & 1,0 & 0,0 & 2,0 & 0,6 & 3,1 & 0,4 & 0,0 & 0,0 & 0,0 & 0,8 & 0,7 \\
\hline Gavelinopsis praegeri & 0,0 & 0,0 & 0,0 & 0,0 & 0,0 & 0,0 & 0,0 & 0,0 & 0,0 & 1,7 & 0,0 & 0,0 & 0,0 & 0,8 & 2,9 & 0,9 & 1,5 & 0,0 & 0,0 & 0,0 & 2,0 & 0,0 & 0,0 & 0,0 & 0,9 & 3,8 & 0,0 & 0,0 & 0,0 \\
\hline Hanzawaia boueana & 0,0 & 2,2 & 0,0 & 0,0 & 1,6 & 0,0 & 4,9 & 0,9 & 0,9 & 0,0 & 0,0 & 0,0 & 0,0 & 0,0 & 2,9 & 0,0 & 1,0 & 0,0 & 0,0 & 0,0 & 0,0 & 0,0 & 0,0 & 0,0 & 3,7 & 0,5 & 0,0 & 0,0 & 0,0 \\
\hline Haynesina germanica & 0,0 & 0,0 & 0,0 & 0,0 & 0,0 & 0,6 & 0,0 & 0,0 & 0,0 & 0,0 & 0,0 & 0,0 & 0,8 & 0,8 & 0,0 & 0,0 & 1,5 & 0,0 & 0,0 & 0,0 & 0,0 & 0,0 & 0,0 & 0,0 & 0,0 & 0,0 & 0,0 & 0,0 & 1,3 \\
\hline Hopkinsina pacifica & 0,0 & 0,7 & 0,0 & 1,5 & 0,8 & 0,0 & 0,0 & 1,7 & 0,0 & 0,9 & 5,2 & 4,9 & 4,1 & 2,1 & 4,4 & 3,6 & 4,0 & 8,7 & 6,0 & 0,0 & 0,0 & 1,8 & 3,1 & 1,1 & 0,0 & 1,4 & 0,0 & 0,0 & 2,7 \\
\hline Lagena striata & 0,0 & 0,0 & 0,0 & 0,0 & 0,0 & 0,0 & 0,0 & 0,0 & 0,0 & 0,0 & 0,7 & 0,0 & 0,0 & 0,0 & 0,0 & 0,0 & 0,0 & 0,0 & 0,0 & 0,0 & 0,0 & 0,6 & 0,0 & 0,0 & 0,0 & 0,0 & 0,0 & 0,0 & 0,0 \\
\hline Lenticulina sp & 0,0 & 0,0 & 0,0 & 0,0 & 0,0 & 0,0 & 0,0 & 0,0 & 0,9 & 0,0 & 0,7 & 0,0 & 0,0 & 0,0 & 0,0 & 0,0 & 0,0 & 0,5 & 0,0 & 0,0 & 0,0 & 0,6 & 0,0 & 0,0 & 0,0 & 0,0 & 0,0 & 0,0 & 0,0 \\
\hline Lepidoteuramina ochracea & 0,0 & 0,0 & 0,0 & 0,0 & 0,0 & 0,0 & 0,0 & 0,0 & 0,0 & 0,9 & 0,0 & 0,0 & 0,0 & 0,0 & 0,7 & 0,0 & 0,5 & 0,5 & 0,0 & 1,2 & 0,0 & 0,0 & 0,0 & 0,0 & 0,0 & 0,5 & 4,2 & 0,0 & 0,0 \\
\hline Leptohalysis catella & 0,0 & 0,0 & 0,0 & 0,0 & 0,0 & 0,0 & 0,0 & 0,0 & 0,0 & 0,9 & 0,7 & 0,0 & 0,0 & 1,7 & 0,7 & 0,0 & 0,5 & 0,0 & 0,0 & 1,2 & 0,0 & 0,0 & 0,4 & 0,0 & 0,0 & 0,0 & 0,0 & 0,0 & 0,0 \\
\hline Lobatula lobatula & 2,0 & 7,2 & 6,5 & 0,0 & 7,1 & 5,4 & 11,9 & 2,6 & 1,8 & 1,7 & 2,2 & 1,0 & 0,0 & 0,0 & 1,5 & 0,9 & 1,0 & 0,0 & 1,0 & 0,0 & 5,0 & 0,0 & 0,0 & 0,0 & 2,8 & 7,6 & 10,4 & 0,8 & 0,0 \\
\hline Melonis sp & 0,0 & 0,0 & 0,0 & 0,0 & 0,0 & 0,0 & 0,0 & 0,0 & 0,0 & 0,0 & 0,0 & 0,0 & 0,0 & 0,0 & 0,0 & 0,9 & 0,0 & 0,0 & 0,0 & 0,0 & 0,0 & 0,6 & 0,0 & 0,0 & 0,0 & 0,0 & 0,0 & 0,0 & 0,0 \\
\hline
\end{tabular}


Anexo 22 - Continuação

\begin{tabular}{|c|c|c|c|c|c|c|c|c|c|c|c|c|c|c|c|c|c|c|c|c|c|c|c|c|c|c|c|c|c|}
\hline \multirow[b]{2}{*}{ Estações } & \multicolumn{9}{|c|}{ Coleta realizada em Julho de 2005} & \multicolumn{10}{|c|}{ Coleta realizada em Abril de 2006} & \multicolumn{10}{|c|}{ Coleta realizada em Setembro de 2006} \\
\hline & Ar1 & Ar2 & Ar3 & Ar5 & Ar6 & Ar7 & Ar8 & $\operatorname{Ar} 9$ & Ar10 & Ar1 & Ar2 & Ar3 & Ar4 & Ar5 & Ar6 & Ar7 & Ar8 & $\operatorname{Ar} 9$ & Ar10 & Ar1 & Ar2 & Ar3 & Ar4 & Ar5 & Ar6 & Ar7 & Ar8 & Ar9 & Ar10 \\
\hline Miliolinella subrotunda & 0,0 & 0,0 & 1,1 & 0,0 & 0,0 & 0,0 & 0,7 & 0,0 & 0,0 & 2,6 & 0,7 & 0,0 & 0,0 & 0,0 & 0,0 & 0,0 & 0,0 & 0,0 & 0,0 & 0,0 & 0,0 & 0,0 & 0,0 & 0,0 & 4,6 & 1,0 & 0,0 & 0,0 & 0,0 \\
\hline Miliolinella $s p$ & 1,0 & 0,7 & 1,1 & 0,0 & 0,0 & 0,0 & 0,0 & 0,0 & 0,0 & 0,0 & 0,0 & 0,0 & 0,0 & 0,0 & 0,0 & 0,0 & 0,0 & 0,0 & 0,0 & 0,0 & 0,0 & 0,6 & 0,0 & 0,0 & 0,0 & 0,0 & 0,0 & 0,0 & 0,0 \\
\hline Neocornobina terquemi & 2,0 & 1,4 & 0,0 & 0,8 & 3,1 & 1,2 & 3,5 & 0,0 & 0,0 & 0,0 & 0,7 & 1,0 & 0,8 & 0,4 & 1,5 & 0,9 & 1,5 & 1,0 & 2,0 & 0,0 & 3,0 & 0,0 & 0,4 & 0,0 & 2,8 & 1,9 & 1,0 & 0,0 & 0,0 \\
\hline Neocornobina sp & 0,0 & 0,0 & 4,3 & 0,0 & 0,0 & 0,0 & 0,0 & 0,0 & 0,0 & 0,0 & 0,0 & 0,0 & 0,0 & 0,0 & 0,0 & 0,0 & 0,0 & 0,0 & 0,0 & 0,0 & 0,0 & 0,6 & 0,0 & 0,0 & 0,0 & 0,0 & 0,0 & 0,0 & 0,0 \\
\hline Oolina $\mathrm{sp}$ & 0,0 & 0,0 & 0,0 & 0,0 & 0,0 & 0,0 & 0,0 & 0,0 & 0,0 & 0,0 & 0,0 & 0,0 & 0,0 & 0,0 & 0,0 & 0,0 & 0,0 & 0,0 & 0,0 & 0,0 & 1,0 & 0,0 & 0,0 & 0,0 & 0,0 & 0,0 & 0,0 & 0,0 & 0,0 \\
\hline Pararotalia cananeiaensis & 6,1 & 8,7 & 4,3 & 5,3 & 4,7 & 1,8 & 6,3 & 7,8 & 17,0 & 0,9 & 0,0 & 2,9 & 2,5 & 3,0 & 0,7 & 0,0 & 1,0 & 0,0 & 3,0 & 0,0 & 0,0 & 0,6 & 0,0 & 0,0 & 0,0 & 0,0 & 0,0 & 0,0 & 0,0 \\
\hline Paratrochamina sp & 0,0 & 0,7 & 0,0 & 0,0 & 0,0 & 0,0 & 0,0 & 0,0 & 0,0 & 0,0 & 0,0 & 0,0 & 0,0 & 0,0 & 0,0 & 0,0 & 0,0 & 0,0 & 0,0 & 0,0 & 0,0 & 0,6 & 0,0 & 0,0 & 0,0 & 0,0 & 0,0 & 0,0 & 0,0 \\
\hline Patelina corrugata & 0,0 & 0,0 & 0,0 & 0,0 & 0,0 & 0,0 & 0,0 & 0,0 & 0,0 & 0,0 & 0,0 & 0,0 & 0,0 & 0,0 & 3,7 & 0,0 & 0,0 & 0,0 & 0,0 & 0,0 & 0,0 & 0,6 & 0,0 & 0,0 & 0,0 & 0,0 & 0,0 & 0,0 & 0,0 \\
\hline Poroeponides lateralis & 0,0 & 0,0 & 0,0 & 0,0 & 0,0 & 0,0 & 0,0 & 0,0 & 0,0 & 0,0 & 0,0 & 0,0 & 0,0 & 0,0 & 0,0 & 0,0 & 0,0 & 0,0 & 0,0 & 0,0 & 1,0 & 0,0 & 0,0 & 0,0 & 0,0 & 0,0 & 0,0 & 0,0 & 0,0 \\
\hline Protochista findens & 0,0 & 0,0 & 0,0 & 0,0 & 0,0 & 1,2 & 0,0 & 0,0 & 0,0 & 0,9 & 2,2 & 0,0 & 0,0 & 0,0 & 0,0 & 0,0 & 0,0 & 0,5 & 0,0 & 1,2 & 0,0 & 0,0 & 0,0 & 0,0 & 0,0 & 0,0 & 0,0 & 0,0 & 0,0 \\
\hline Pseudononion atlanticum & 0,0 & 3,6 & 2,2 & 3,8 & 3,1 & 5,4 & 4,2 & 6,1 & 0,0 & 1,7 & 1,5 & 0,0 & 4,1 & 3,0 & 5,1 & 3,6 & 4,5 & 3,1 & 4,0 & 1,2 & 0,0 & 0,0 & 5,8 & 0,4 & 0,0 & 0,0 & 0,0 & 0,0 & 0,0 \\
\hline Pseudononion grateloupi & 0,0 & 0,0 & 0,0 & 0,0 & 0,0 & 0,0 & 0,0 & 0,0 & 0,0 & 0,0 & 0,0 & 0,0 & 1,7 & 0,4 & 1,5 & 1,8 & 1,0 & 0,0 & 0,0 & 0,0 & 0,0 & 0,0 & 0,0 & 0,0 & 0,0 & 0,5 & 0,0 & 0,0 & 0,0 \\
\hline Pseudononion opima & 0,0 & 1,4 & 2,2 & 0,8 & 0,0 & 0,6 & 0,0 & 1,7 & 0,0 & 0,9 & 0,7 & 0,0 & 0,0 & 0,4 & 0,0 & 0,0 & 1,0 & 0,5 & 0,0 & 0,0 & 0,0 & 0,6 & 1,3 & 0,0 & 0,0 & 0,5 & 0,0 & 0,0 & 0,0 \\
\hline Pseudononion pauperatus & 0,0 & 0,0 & 0,0 & 0,0 & 0,0 & 0,0 & 0,0 & 0,0 & 0,0 & 0,0 & 0,0 & 0,0 & 0,0 & 0,0 & 0,7 & 0,0 & 0,0 & 0,0 & 0,0 & 0,0 & 0,0 & 0,0 & 0,0 & 0,0 & 0,0 & 1,0 & 0,0 & 0,0 & 0,0 \\
\hline Pseudononion sp & 0,0 & 0,0 & 0,0 & 0,0 & 0,0 & 0,0 & 0,0 & 0,0 & 0,0 & 0,0 & 0,0 & 0,0 & 0,0 & 0,0 & 0,0 & 0,0 & 0,0 & 0,0 & 0,0 & 0,0 & 0,0 & 0,0 & 0,0 & 0,0 & 0,0 & 0,0 & 0,0 & 0,8 & 0,0 \\
\hline Quinqueloculina brodermani & 0,0 & 0,0 & 0,0 & 0,0 & 0,0 & 0,0 & 0,0 & 0,0 & 0,0 & 0,0 & 0,0 & 0,0 & 0,0 & 0,0 & 0,0 & 0,9 & 0,0 & 0,0 & 0,0 & 0,0 & 0,0 & 0,6 & 0,0 & 0,0 & 0,0 & 0,0 & 0,0 & 0,0 & 0,0 \\
\hline Quinqueloculina laevigata & 0,0 & 0,0 & 0,0 & 0,0 & 0,0 & 0,0 & 0,0 & 0,0 & 0,0 & 0,0 & 0,0 & 0,0 & 0,0 & 0,0 & 0,7 & 0,0 & 0,5 & 0,0 & 0,0 & 0,0 & 0,0 & 0,6 & 0,0 & 0,0 & 0,0 & 0,0 & 0,0 & 0,0 & 0,0 \\
\hline Quinqueloculina lamarckiana & 0,0 & 0,0 & 0,0 & 0,8 & 0,0 & 0,6 & 0,0 & 0,0 & 0,0 & 0,0 & 0,0 & 0,0 & 0,8 & 0,0 & 0,0 & 0,0 & 0,0 & 0,0 & 0,0 & 0,0 & 0,0 & 0,6 & 0,0 & 0,0 & 0,0 & 0,0 & 0,0 & 0,0 & 0,0 \\
\hline Quinqueloculina milletti & 1,0 & 1,4 & 0,0 & 0,8 & 2,4 & 0,6 & 1,4 & 0,0 & 0,0 & 1,7 & 0,7 & 1,0 & 0,0 & 0,0 & 2,9 & 0,0 & 0,5 & 0,0 & 1,0 & 0,0 & 0,0 & 0,6 & 0,0 & 0,0 & 0,0 & 0,0 & 0,0 & 0,0 & 0,0 \\
\hline Quinqueloculina patagonica & 1,0 & 0,7 & 0,0 & 0,0 & 0,8 & 1,2 & 0,0 & 0,0 & 0,0 & 0,0 & 0,0 & 0,0 & 0,0 & 0,0 & 0,0 & 0,0 & 0,0 & 0,0 & 0 & 0,0 & 0,0 & 0,6 & 0,0 & 0,0 & 0,0 & 0,0 & 0,0 & 0,0 & 0,0 \\
\hline Quinqueloculina seminula & 0,0 & 0,0 & 0,0 & 0,0 & 0,0 & 0,0 & 0,0 & 0,0 & 0,0 & 0,0 & 0,0 & 0,0 & 0,0 & 0,0 & 0,0 & 0,0 & 0,0 & 0,0 & 0,0 & 0,0 & 0,0 & 0,0 & 0,0 & 0,0 & 1,8 & 0,0 & 0,0 & 0,0 & 0,0 \\
\hline Quinqueloculina stalkeri & 0,0 & 0,0 & 0,0 & 0,0 & 0,0 & 0,0 & 0,0 & 0,0 & 0,0 & 0,0 & 0,0 & 0,0 & 0,0 & 0,0 & 0,7 & 0,0 & 0,0 & 0,5 & 0,0 & 0,0 & 0,0 & 0,6 & 0,0 & 0,0 & 0,0 & 0,0 & 0,0 & 0,0 & 0,0 \\
\hline Quinqueloculina sp & 2,0 & 0,0 & 0,0 & 0,8 & 0,0 & 0,0 & 0,7 & 0,0 & 0,0 & 0,0 & 0,0 & 0,0 & 0,0 & 0,0 & 0,0 & 0,0 & 0,0 & 0,0 & 0,0 & 0,0 & 0,0 & 0,6 & 0,0 & 0,0 & 0,0 & 0,0 & 0,0 & 0,0 & 0,0 \\
\hline Reophax scorpiurus & 0,0 & 0,0 & 0,0 & 0,0 & 0,0 & 0,0 & 0,0 & 0,0 & 0,0 & 0,0 & 0,0 & 0,0 & 0,0 & 0,0 & 0,0 & 0,0 & 0,0 & 0,0 & 0,0 & 1,2 & 0,0 & 0,0 & 0,4 & 0,0 & 0,0 & 0,0 & 0,0 & 0,0 & 0,0 \\
\hline Rolshausheni rolshauseni & 2,0 & 0,0 & 0,0 & 0,0 & 0,0 & 0,0 & 0,0 & 0,0 & 0,0 & 0,0 & 0,0 & 0,0 & 0,0 & 0,0 & 0,0 & 0,0 & 0,0 & 0,0 & 0,0 & 0,0 & 0,0 & 0,0 & 0,0 & 0,0 & 0,0 & 0,0 & 0,0 & 0,8 & 0,0 \\
\hline Rosalina floridensis & 2,0 & 4,3 & 8,6 & 3,1 & 4,7 & 7,1 & 4,2 & 3,5 & 0,0 & 6,0 & 1,5 & 1,0 & 0,8 & 0,0 & 7,4 & 1,8 & 2,5 & 0,0 & 2,0 & 0,0 & 12,0 & 0,0 & 0,4 & 0,0 & 6,4 & 9,0 & 2,1 & 0,0 & 0,0 \\
\hline Rosalina vilardeboana & 0,0 & 0,0 & 0,0 & 0,0 & 0,0 & 0,0 & 0,0 & 0,0 & 0,0 & 0,0 & 0,0 & 0,0 & 0,0 & 0,0 & 0,0 & 0,0 & 0,0 & 0,0 & 0,0 & 0,0 & 0,0 & 0,0 & 0,0 & 0,0 & 1,8 & 0,0 & 0,0 & 0,0 & 0,0 \\
\hline Siphotrochammina lobata & 0,0 & 0,0 & 2,2 & 0,0 & 2,4 & 1,2 & 0,0 & 0,0 & 0,0 & 0,0 & 0,0 & 0,0 & 0,0 & 0,0 & 0,0 & 0,0 & 0,0 & 0,0 & 0,0 & 0,0 & 0,0 & 0,6 & 0,0 & 0,0 & 0,0 & 0,0 & 0,0 & 0,0 & 0,0 \\
\hline Spirilina vivipara & 0,0 & 0,0 & 0,0 & 0,0 & 0,0 & 0,0 & 0,0 & 0,0 & 0,0 & 0,0 & 0,0 & 0,0 & 0,0 & 0,0 & 0,0 & 0,0 & 0,0 & 0,0 & 0,0 & 0,0 & 0,0 & 0,0 & 0,0 & 0,0 & 1,8 & 0,5 & 0,0 & 0,0 & 0,0 \\
\hline Spirobolivina $\mathrm{sp}$ & 0,0 & 0,0 & 0,0 & 0,0 & 0,0 & 0,0 & 0,0 & 0,0 & 0,0 & 0,0 & 0,0 & 0,0 & 1,7 & 0,0 & 0,0 & 0,0 & 1,0 & 1,0 & 0,0 & 1,2 & 0,0 & 0,0 & 0,0 & 0,0 & 0,0 & 0,0 & 0,0 & 0,0 & 0,0 \\
\hline Spiroplectamina biformis & 0,0 & 0,0 & 0,0 & 0,0 & 0,0 & 0,0 & 0,0 & 0,0 & 0,0 & 0,0 & 0,0 & 0,0 & 0,0 & 0,0 & 0,0 & 0,0 & 0,0 & 0,0 & 0,0 & 1,2 & 0,0 & 0,0 & 0,0 & 0,0 & 0,0 & 0,0 & 0,0 & 0,0 & 0,0 \\
\hline
\end{tabular}


Anexo 22 - Continuação

\begin{tabular}{|c|c|c|c|c|c|c|c|c|c|c|c|c|c|c|c|c|c|c|c|c|c|c|c|c|c|c|c|c|c|}
\hline \multirow{3}{*}{ Estações } & \multirow{2}{*}{\multicolumn{9}{|c|}{ Coleta realizada em Junho de 2005}} & \multirow{2}{*}{\multicolumn{10}{|c|}{ Coleta realizada em Abril de 2006}} & \multirow{2}{*}{\multicolumn{10}{|c|}{ Coleta realizada em Setembro de 2006}} \\
\hline & & & & & & & & & & & & & & & & & & & & & & & & & & & & & \\
\hline & Ar1 & Ar2 & Ar3 & $\operatorname{Ar} 5$ & Ar6 & Ar7 & Ar8 & $\operatorname{Ar} 9$ & Ar10 & Ar1 & Ar2 & Ar3 & Ar4 & $\operatorname{Ar} 5$ & Ar6 & $\operatorname{Ar} 7$ & Ar8 & Ar9 & Ar10 & Ar1 & Ar2 & Ar3 & $\mathrm{Ar} 4$ & Ar5 & Ar6 & Ar7 & Ar8 & Ar9 & $\operatorname{Ar} 10$ \\
\hline Stainphortia concava & 0,0 & 0,0 & 1,1 & 1,5 & 0,0 & 0,0 & 0,7 & 0,0 & 0,0 & 0,0 & 0,0 & 0,0 & 0,0 & 0,0 & 0,0 & 0,0 & 0,0 & 0,0 & 0,0 & 0,0 & 0,0 & 0,6 & 0,0 & 0,0 & 0,0 & 0,0 & 0,0 & 0,0 & 0,0 \\
\hline Stanphortia fusiformis & 0,0 & 0,0 & 0,0 & 0,0 & 0,0 & 0,0 & 0,0 & 0,0 & 0,0 & 0 & 0,0 & 0,0 & 0,0 & 0,4 & 0,0 & 0,0 & 0,0 & 0,0 & 0,0 & 0,0 & 0,0 & 0,6 & 0,0 & 0,0 & 0,0 & 0,0 & 0,0 & 0,0 & 0,0 \\
\hline Textularia aglutinans & 0,0 & 0,0 & 0,0 & 0,0 & 0,0 & 0,0 & 0,0 & 0,0 & 0,0 & 0,0 & 0,0 & 0,0 & 0,0 & 0,0 & 0,0 & 0,0 & 0,5 & 0,0 & 0,0 & 0,0 & 0,0 & 0,6 & 0,0 & 0,0 & 0,0 & 0,0 & 0,0 & 0,0 & 0,0 \\
\hline Textularia earlandi & 0,0 & 0,0 & 0,0 & 0,0 & 0,0 & 0,0 & 0,0 & 0,0 & 0,0 & 0,0 & 0,7 & 0,0 & 0,8 & 3,0 & 0,0 & 0,0 & 0,0 & 0,0 & 1,0 & 0,0 & 0,0 & 0,6 & 0,0 & 0,0 & 0,0 & 0,0 & 0,0 & 0,0 & 0,0 \\
\hline Textularia gramen & 0,0 & 0,0 & 0,0 & 0,0 & 0,8 & 0,0 & 0,0 & 0,0 & 0,0 & 0,0 & 0,0 & 0,0 & 0,0 & 0,0 & 0,0 & 0,0 & 0,0 & 0,0 & 0,0 & 0,0 & 0,0 & 0,6 & 0,0 & 0,0 & 0,0 & 0,0 & 0,0 & 0,0 & 0,0 \\
\hline Textularia $\mathrm{sp}$ & 0,0 & 0,7 & 0,0 & 0,0 & 0,0 & 0,0 & 0,0 & 0,0 & 0,0 & 0,0 & 0,0 & 0,0 & 0,0 & 0,0 & 0,0 & 0,0 & 0,0 & 0,0 & 0,0 & 0,0 & 1,0 & 0,0 & 0,0 & 0,0 & 0,0 & 0,0 & 0,0 & 0,0 & 0,0 \\
\hline Triloculina cultrata & 0,0 & 0,0 & 0,0 & 0,0 & 0,0 & 0,0 & 0,0 & 0,0 & 0,0 & 0,0 & 0,0 & 0,0 & 0,8 & 0,0 & 0,0 & 0,0 & 0,0 & 0,0 & 0,0 & 0,0 & 0,0 & 0,0 & 0,0 & 0,0 & 2,8 & 0,0 & 0,0 & 0,0 & 0,0 \\
\hline Triloculina laevigata & 0,0 & 0,0 & 0,0 & 0,0 & 0,0 & 0,0 & 0,0 & 0,0 & 0,0 & 0,0 & 0,0 & 0,0 & 0,0 & 0,0 & 0,0 & 1,8 & 1,0 & 0,0 & 0,0 & 0,0 & 0,0 & 0,6 & 0,0 & 0,0 & 0,0 & 0,0 & 0,0 & 0,0 & 0,0 \\
\hline Triloculina oblonga & 0,0 & 0,0 & 0,0 & 0,0 & 0,0 & 0,0 & 0,0 & 0,0 & 0,0 & 0,0 & 0,0 & 0,0 & 0,0 & 0,0 & 1,5 & 0,9 & 0,0 & 0,0 & 0,0 & 0,0 & 2,0 & 0,0 & 0,0 & 0,0 & 0,9 & 0,0 & 0,0 & 0,0 & 0,0 \\
\hline Trochammina inflata & 0,0 & 1,4 & 0,0 & 0,0 & 0,0 & 1,2 & 0,7 & 0,0 & 0,0 & 0,0 & 0,0 & 0,0 & 0,0 & 0,0 & 0,0 & 0,0 & 0,0 & 0,0 & 0,0 & 0,0 & 2,0 & 0,6 & 0,4 & 0,0 & 0,0 & 1,0 & 0,0 & 0,0 & 0,0 \\
\hline Trochammina ochraced & 0,0 & 0,0 & 3,2 & 0,0 & 0,0 & 0,6 & 2,8 & 0,9 & 0,0 & 0,0 & 0,0 & 0,0 & 0,0 & 0,0 & 0,0 & 0,0 & 0,5 & 0,5 & 0,0 & 0,0 & 0,0 & 0,6 & 0,0 & 0,0 & 0,0 & 0,0 & 0,0 & 0,0 & 0,0 \\
\hline Trochammina salsa & 0,0 & 0,0 & 0,0 & 0,0 & 0,0 & 0,0 & 0,0 & 0,0 & 0,0 & 0,0 & 0,0 & 0,0 & 0,0 & 0,0 & 0,0 & 0,0 & 0,0 & 0,0 & 0,0 & 0,0 & 0,0 & 0,0 & 0,0 & 0,0 & 0,9 & 0,5 & 0,0 & 0,0 & 0,0 \\
\hline Trochammina squam & 0,0 & 0,0 & 0,0 & 0,0 & 0,0 & 0,0 & 0,0 & 0,0 & 0,0 & 0,0 & 0,0 & 0,0 & 0,0 & 0,0 & 0,0 & 0,0 & 0,0 & 0,0 & 0,0 & 0,0 & 0,0 & 0,0 & 0,0 & 0,0 & 0,9 & 0,0 & 0,0 & 0,0 & 0,0 \\
\hline Trochammina sp & 1,0 & 1,4 & 5,4 & 0,0 & 3,1 & 0,0 & 0,0 & 0,0 & 0,0 & 0,0 & 0,0 & 0,0 & 0,0 & 0,0 & 0,7 & 0,9 & 0,5 & 0,0 & 0,0 & 0,0 & 0,0 & 0,6 & 0,0 & 0,0 & 0,0 & 0,0 & 0,0 & 0,0 & 0,0 \\
\hline Uvigerina bifurcata & 0,0 & 0,0 & 0,0 & 0,0 & 0,0 & 0,0 & 0,0 & 0,0 & 0,0 & 0,0 & 0,0 & 0,0 & 0,0 & 0,0 & 0,0 & 0,0 & 0,0 & 0,0 & 0,0 & 0,0 & 0,0 & 0,0 & 0,0 & 0,0 & 0,0 & 0,5 & 0,0 & 0,0 & 0,7 \\
\hline Indeterminado & 1,0 & 0,0 & 0,0 & 0,0 & 0,0 & 0,0 & 0,0 & 0,0 & 0,0 & 0,0 & 0,7 & 2,0 & 0,8 & 3,4 & 0,0 & 0,9 & 0,0 & 3,1 & 3,0 & 1,2 & 3,0 & 0,0 & 1,3 & 0,0 & 3,7 & 1,4 & 2,1 & 1,5 & 0,0 \\
\hline \multicolumn{30}{|c|}{ Descritores ecológicos } \\
\hline Densidade & 98 & 138 & 93 & 131 & 127 & 168 & 143 & 115 & 112 & 117 & 135 & 102 & 121 & 236 & 136 & 112 & 198 & 196 & 100 & 105 & 100 & 163 & 224 & 262 & 109 & 210 & 96 & 130 & 150 \\
\hline Volume de sedimento analisado & 10 & 20 & 20 & 20 & 20 & 20 & 20 & 30 & 40 & 40 & 20 & 20 & 20 & 10 & 20 & 20 & 20 & 20 & 20 & 210 & 30 & 10 & 10 & 10 & 10 & 10 & 20 & 10 & 10 \\
\hline Foraminíferos $/ 10 \mathrm{~cm}^{3}$ de sedimento & 98 & 69 & 47 & 66 & 64 & 84 & 72 & 38 & 28 & 29 & 68 & 51 & 61 & 236 & 68 & 56 & 99 & 98 & 50 & 5 & 33 & 163 & 224 & 262 & 109 & 210 & 48 & 130 & 150 \\
\hline Riqueza & 20 & 22 & 22 & 23 & 23 & 26 & 23 & 18 & 11 & 26 & 26 & 19 & 23 & 25 & 37 & 26 & 36 & 25 & 21 & 18 & 21 & 45 & 27 & 14 & 25 & 36 & 19 & 17 & 17 \\
\hline Diversidade esp & 2,09 & 2,33 & 2,64 & 2,15 & 2,51 & 2,33 & 2,46 & 2,29 & 0,70 & 2,21 & 2,35 & 1,87 & 2,10 & 1,96 & 2,97 & 2,31 & 2,51 & 2,24 & 2,27 & 1,81 & 2,32 & 2,23 & 2,45 & 0,98 & 2,56 & 2,70 & 2,28 & 1,66 & 1,66 \\
\hline Equitatividade & 0,69 & 0,75 & 0,85 & 0,69 & 0,80 & 0,71 & 0,78 & 0,79 & 0,69 & 0,68 & 0,72 & 0,63 & 0,67 & 0,61 & 0,82 & 0,71 & 0,70 & 0,70 & 0,74 & 0,62 & 0,76 & 0,58 & 0,74 & 0,37 & 0,79 & 0,75 & 0,77 & 0,59 & 0,58 \\
\hline
\end{tabular}


Anexo 23 - (Biocenoses) Distribuição de espécies bioindicadoras de ambiente óxico e enriquecido por matéria orgânica identificadas próximo ao emissário do Araçá.

Valores em porcentagem.

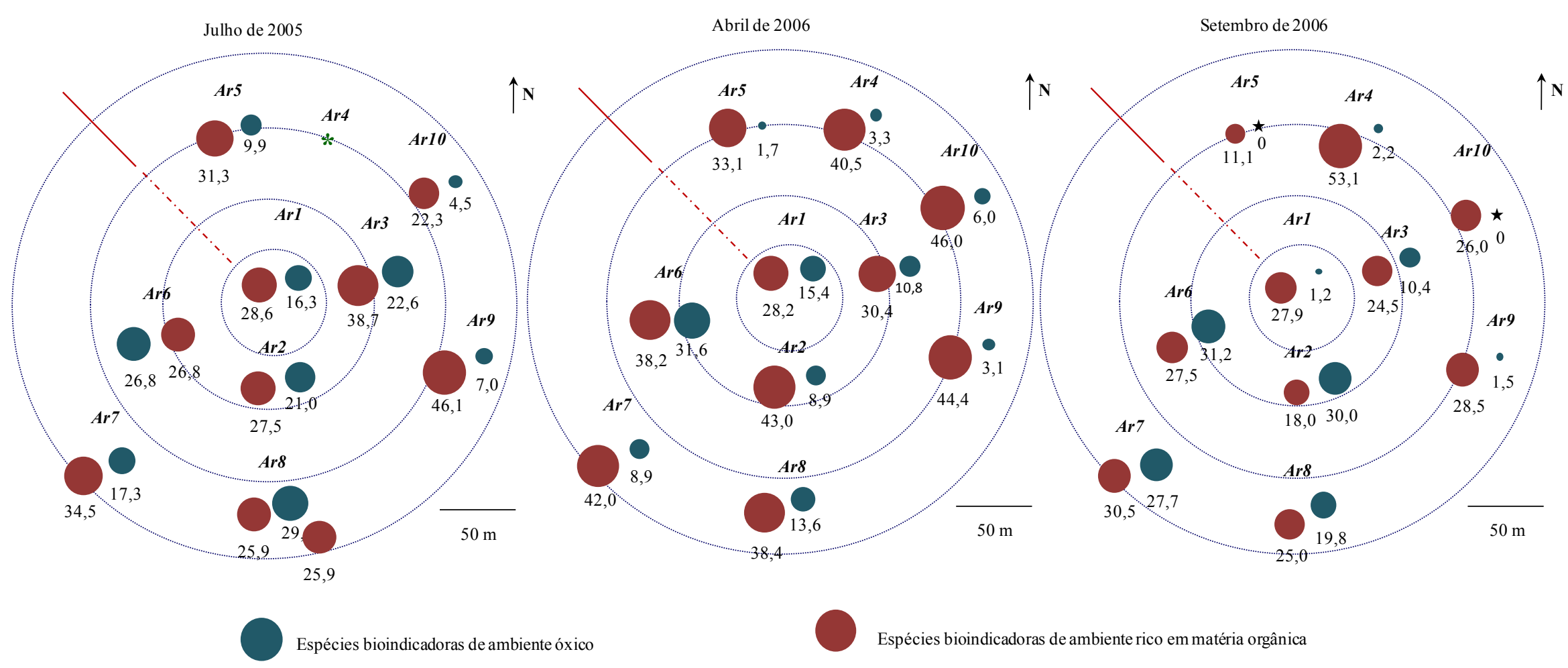

$\star$ Ausência de espécies bioindicadoras de ambiente óxico

* Estação não amostrada 
Anexo 24 - (Biocenoses) Resultado das análises morfométricas realizadas nas carapaças dos foraminíferos obtidas próximo ao emissário do Araçá. Valores em porcentagem.

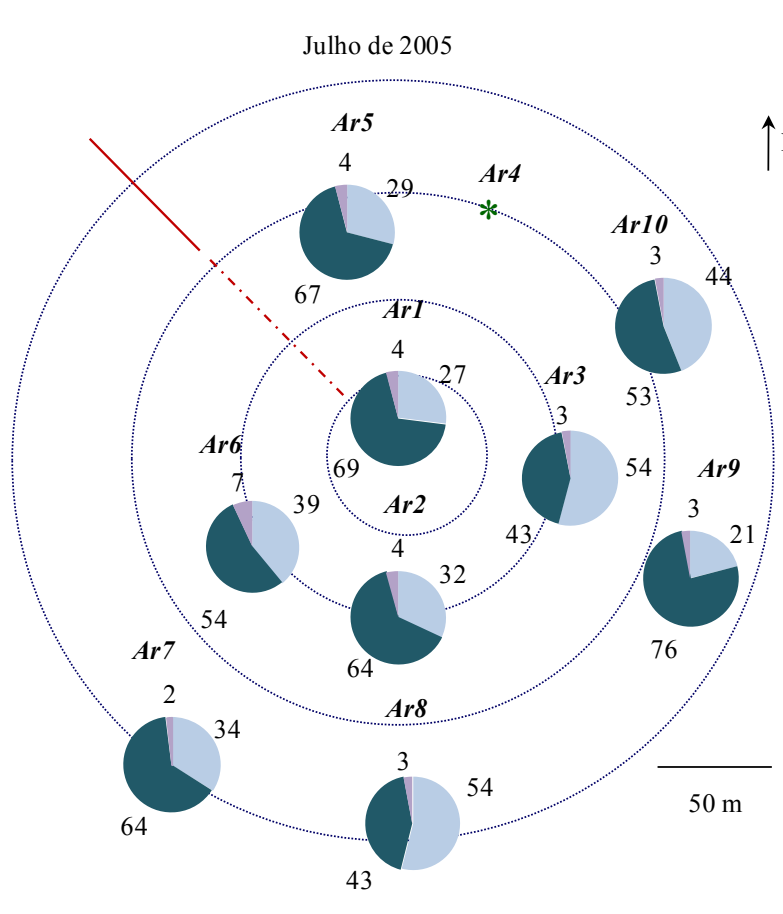

Carapaças pequenas

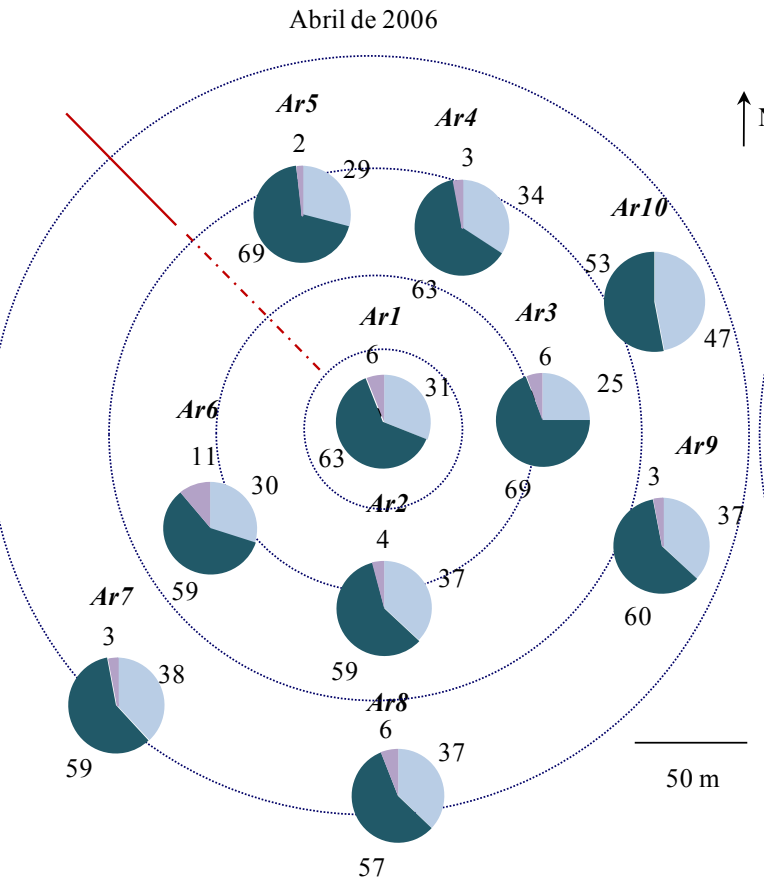

Carapaças médias
Setembro de 2006

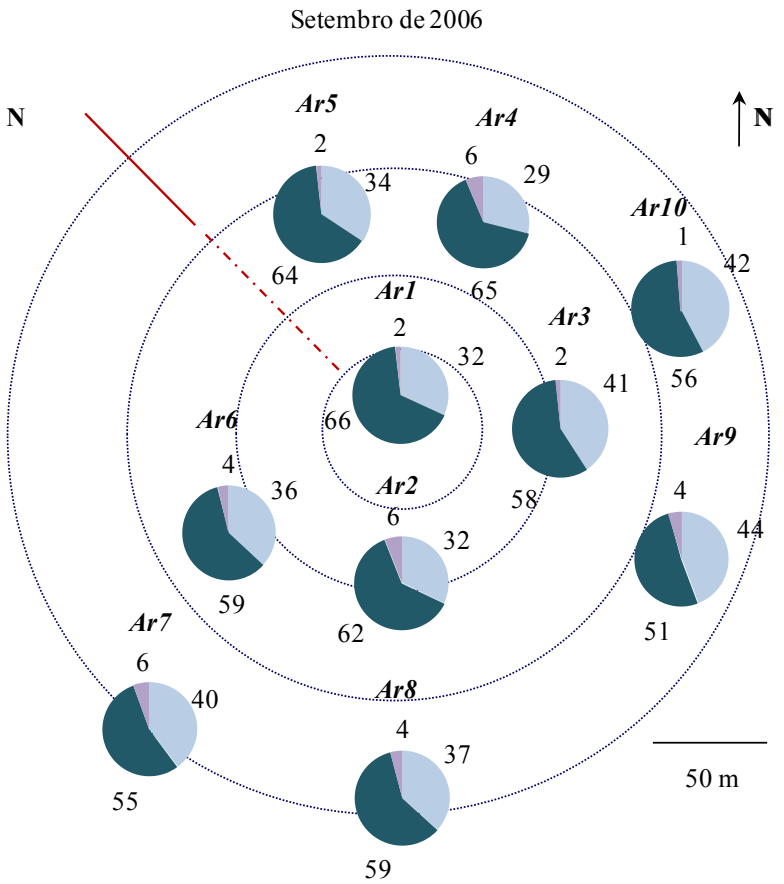

Carapaças grandes

\footnotetext{
* Estação não amostrada
} 
Anexo 25 - Abundâncias relativas das espécies de foraminíferos identificadas próximo ao emissário do Araçá.

Dados pertencentes às tanatocenoses.

\begin{tabular}{|c|c|c|c|c|c|c|c|c|c|c|c|c|c|c|c|c|c|c|c|c|c|c|c|c|c|c|c|c|c|}
\hline \multirow[b]{2}{*}{ Estação } & \multicolumn{9}{|c|}{ Junho de 2005} & \multicolumn{10}{|c|}{ Abril de 2006} & \multicolumn{10}{|c|}{ Setembro de 2006} \\
\hline & Ar2 & Ar2 & $\mathrm{Ar} 3$ & Ar5 & Ar6 & Ar7 & Ar8 & Ar9 & Ar10 & Ar1 & $\mathrm{Ar} 2$ & Ar3 & Ar4 & Ar5 & Ar6 & $\mathrm{Ar} 7$ & Ar8 & Ar9 & Ar10 & Ar1 & Ar2 & $\mathrm{Ar} 3$ & $\mathrm{Ar} 4$ & $\operatorname{Ar} 5$ & Ar6 & Ar7 & Ar8 & $\operatorname{Ar} 9$ & $\operatorname{Ar} 10$ \\
\hline Adelosina constricta & 0,0 & 0,0 & 0,0 & 0,6 & 0,4 & 0,0 & 0,0 & 0,0 & 0,0 & 0,0 & 0,0 & 0,0 & 0,0 & 0,0 & 0,0 & 0,0 & 0,0 & 0,0 & 0,0 & 0,0 & 0,0 & 0,0 & 0,0 & 0,0 & 0,0 & 0,0 & 0,0 & 0,0 & 0,0 \\
\hline Adelosina mediterranensis & 0,0 & 0,0 & 0,0 & 0,0 & 0,0 & 0,0 & 0,0 & 0,0 & 0,0 & 0,0 & 0,0 & 0,0 & 0,0 & 0,0 & 0,0 & 0,0 & 0,0 & 0,0 & 0,0 & 0,0 & 0,0 & 0,0 & 0,0 & 0,0 & 0,2 & 0,4 & 0,0 & 0,0 & 0,0 \\
\hline Adelosina sp & 0,0 & 0,0 & 0,0 & 0,0 & 0,0 & 0,0 & 0,0 & 0,0 & 0,0 & 0,0 & 0,0 & 0,0 & 0,0 & 0,0 & 0,0 & 0,0 & 0,0 & 0,0 & 0,0 & 0,0 & 0,4 & 0,0 & 0,0 & 0,0 & 0,0 & 0,0 & 0,0 & 0,0 & 0,0 \\
\hline Ammobaculites dilatatus & 0,0 & 0,0 & 0,0 & 0,3 & 0,0 & 0,0 & 0,0 & 0,0 & 0,0 & 0,0 & 0,0 & 0,0 & 0,0 & 0,0 & 0,0 & 0,0 & 0,0 & 0,0 & 0,0 & 0,0 & 0,0 & 0,0 & 0,0 & 0,0 & 0,0 & 0,0 & 0,0 & 0,0 & 0,0 \\
\hline Ammobaculites exiguus & 0,0 & 0,0 & 0,0 & 0,0 & 0,0 & 0,0 & 0,0 & 0,0 & 0,0 & 0,0 & 0,0 & 0,0 & 0,0 & 0,0 & 0,0 & 0,0 & 0,0 & 0,0 & 0,0 & 1,1 & 0,0 & 0,0 & 0,0 & 0,0 & 0,0 & 0,0 & 0,0 & 0,0 & 0,0 \\
\hline Ammonia parkinsoniana & 3,6 & 0,6 & 0,4 & 1,7 & 0,7 & 1,0 & 1,2 & 0,3 & 0,5 & 7,1 & 2,6 & 1,9 & 7,9 & 10,0 & 4,2 & 3,4 & 1,1 & 3,6 & 4,9 & 5,7 & 3,5 & 4,1 & 4,5 & 8,3 & 5,5 & 2,6 & 2,3 & 3,7 & 5,2 \\
\hline Ammonia tepida & 8,8 & 5,1 & 8,1 & 15,2 & 4,8 & 9,4 & 5,8 & 6,5 & 9,1 & 15,6 & 12,9 & 8,8 & 11,5 & 14,4 & 11,7 & 16,5 & 6,6 & 9,8 & 16,6 & 5,7 & 9,3 & 12,6 & 11,6 & 16,1 & 8,0 & 7,4 & 8,4 & 14,5 & 9,5 \\
\hline Ammoscalaria tenuimargo & 0,0 & 0,0 & 0,0 & 0,0 & 0,0 & 0,0 & 0,0 & 0,0 & 0,0 & 0,0 & 0,0 & 0,0 & 0,0 & 0,0 & 0,0 & 0,0 & 0,0 & 0,0 & 0,0 & 0,0 & 0,0 & 0,0 & 0,0 & 0,2 & 0,0 & 0,0 & 0,0 & 0,0 & 0,0 \\
\hline Ammotium salsum & 0,0 & 0,0 & 0,0 & 0,0 & 0,0 & 0,0 & 0,0 & 0,0 & 0,0 & 0,0 & 0,6 & 2,1 & 0,6 & 0,3 & 0,4 & 0,3 & 0,0 & 0,0 & 0,3 & 0,0 & 0,0 & 0,5 & 0,0 & 0,0 & 0,0 & 0,4 & 0,0 & 0,9 & 0,0 \\
\hline Angulogerina angulosa & 0,3 & 0,6 & 0,4 & 0,0 & 0,7 & 0,3 & 0,4 & 0,0 & 0,0 & 0,0 & 0,0 & 0,0 & 0,3 & 0,0 & 0,0 & 0,0 & 0,0 & 0,7 & 0,0 & 0,0 & 0,4 & 0,0 & 0,0 & 0,0 & 0,2 & 0,4 & 0,3 & 0,7 & 0,0 \\
\hline Angulogerina jamaicensis & 0,0 & 0,0 & 0,0 & 0,0 & 0,0 & 0,0 & 0,0 & 0,0 & 0,0 & 0,0 & 0,0 & 0,0 & 0,0 & 0,0 & 0,0 & 0,0 & 0,0 & 0,0 & 0,0 & 0,0 & 0,0 & 0,0 & 0,0 & 0,2 & 0,0 & 0,0 & 0,0 & 0,0 & 0,0 \\
\hline Astrononion sp & 0,0 & 0,0 & 0,0 & 0,0 & 0,0 & 0,0 & 0,0 & 0,0 & 0,0 & 0,0 & 0,0 & 0,0 & 0,0 & 0,0 & 0,0 & 0,0 & 0,0 & 0,0 & 0,0 & 0,0 & 0,4 & 0,5 & 0,7 & 0,0 & 0,0 & 0,0 & 0,0 & 0,0 & 0,0 \\
\hline Bolivina compacta & 0,3 & 0,6 & 0,4 & 0,9 & 0,0 & 0,0 & 0,0 & 0,3 & 1,1 & 0,0 & 0,3 & 0,3 & 0,0 & 0,3 & 0,0 & 0,6 & 0,3 & 0,7 & 0,5 & 0,0 & 0,0 & 0,5 & 0,3 & 0,2 & 0,2 & 0,0 & 0,6 & 0,0 & 0,3 \\
\hline Bolivina danvilensis & 0,0 & 0,0 & 0,0 & 0,0 & 0,0 & 0,0 & 0,0 & 0,0 & 0,0 & 0,0 & 0,0 & 0,0 & 0,0 & 0,0 & 0,8 & 0,3 & 0,3 & 0,0 & 0,0 & 0,0 & 0,4 & 0,0 & 0,7 & 0,2 & 0,5 & 0,7 & 0,6 & 0,5 & 0,0 \\
\hline Bolivina diformis & 0,0 & 0,0 & 0,0 & 0,0 & 0,0 & 0,0 & 0,0 & 0,0 & 0,0 & 0,0 & 0,0 & 0,0 & 0,0 & 0,0 & 0,0 & 0,0 & 0,0 & 0,0 & 0,0 & 0,0 & 0,0 & 0,0 & 0,0 & 0,2 & 0,0 & 0,0 & 0,0 & 0,0 & 0,0 \\
\hline Bolivina doniezi & 0,0 & 1,7 & 0,4 & 1,1 & 0,7 & 0,3 & 0,4 & 0,3 & 1,8 & 0,0 & 0,0 & 0,0 & 0,6 & 0,3 & 0,0 & 0,3 & 0,5 & 0,7 & 0,5 & 0,0 & 0,4 & 0,0 & 1,7 & 0,6 & 1,4 & 0,4 & 0,3 & 0,2 & 1,0 \\
\hline Bolivina gracilis & 0,0 & 0,0 & 0,0 & 0,0 & 0,0 & 0,0 & 0,0 & 0,0 & 0,0 & 0,0 & 0,0 & 0,3 & 0,0 & 0,0 & 0,0 & 0,0 & 0,3 & 0,0 & 0,0 & 0,0 & 0,0 & 0,0 & 0,3 & 0,0 & 0,0 & 0,0 & 0,0 & 0,0 & 0,0 \\
\hline Bolivina ordinaria & 1,0 & 0,3 & 0,4 & 0,3 & 0,4 & 1,0 & 1,2 & 0,3 & 0,9 & 1,4 & 0,9 & 1,1 & 0,6 & 0,7 & 0,8 & 0,9 & 1,9 & 0,3 & 0,8 & 0,4 & 0,4 & 0,3 & 0,7 & 1,3 & 0,5 & 0,0 & 0,6 & 0,0 & 0,7 \\
\hline Bolivina pseudoplicata & 0,0 & 0,3 & 0,0 & 0,0 & 0,0 & 0,0 & 0,0 & 0,0 & 0,0 & 0,0 & 0,3 & 0,0 & 0,0 & 0,0 & 0,8 & 0,0 & 0,0 & 0,0 & 0,0 & 0,0 & 0,4 & 0,0 & 1,0 & 0,0 & 0,7 & 0,0 & 0,3 & 0,7 & 0,0 \\
\hline Bolivina pulchella & 2,0 & 0,8 & 0,7 & 4,6 & 4,1 & 2,1 & 0,0 & 0,9 & 1,4 & 0,7 & 1,4 & 1,1 & 1,2 & 4,0 & 1,5 & 0,9 & 0,3 & 0,3 & 1,1 & 2,5 & 1,2 & 0,8 & 1,4 & 4,0 & 2,0 & 2,6 & 0,3 & 0,9 & 1,3 \\
\hline Bolivina selmaensis & 0,0 & 0,0 & 0,0 & 0,0 & 0,0 & 0,0 & 0,0 & 0,0 & 0,0 & 0,0 & 0,0 & 0,0 & 0,0 & 0,0 & 0,0 & 0,0 & 0,0 & 0,0 & 0,0 & 0,0 & 0,0 & 0,0 & 0,0 & 0,0 & 0,0 & 0,0 & 0,3 & 0,0 & 0,0 \\
\hline Bolivina subexcavata & 0,0 & 0,0 & 0,0 & 0,0 & 0,0 & 0,0 & 0,0 & 0,0 & 0,0 & 0,0 & 0,0 & 0,0 & 0,0 & 0,3 & 0,0 & 0,0 & 0,0 & 0,0 & 0,0 & 0,0 & 0,0 & 0,0 & 0,0 & 0,0 & 0,0 & 0,0 & 0,0 & 0,0 & 0,0 \\
\hline Bolivina translucens & 0,7 & 0,0 & 0,0 & 0,0 & 0,7 & 0,3 & 0,0 & 0,0 & 0,0 & 0,7 & 0,6 & 0,3 & 0,6 & 0,0 & 0,0 & 0,3 & 0,3 & 0,0 & 0,5 & 0,0 & 0,0 & 0,0 & 0,0 & 0,2 & 0,0 & 0,0 & 0,0 & 0,2 & 0,3 \\
\hline Bolivina sp. & 0,7 & 0,0 & 0,7 & 0,9 & 0,4 & 1,4 & 0,0 & 1,2 & 1,8 & 0,7 & 1,1 & 0,5 & 0,6 & 2,0 & 1,5 & 1,8 & 0,3 & 2,0 & 0,5 & 0,7 & 0,0 & 0,5 & 2,7 & 1,3 & 1,1 & 1,1 & 0,9 & 0,7 & 2,3 \\
\hline Bolivinella pescicula & 0,0 & 0,0 & 0,0 & 0,0 & 0,0 & 0,0 & 0,0 & 0,0 & 0,0 & 0,0 & 0,0 & 0,0 & 0,0 & 0,0 & 0,0 & 0,0 & 0,0 & 0,0 & 0,0 & 0,0 & 0,0 & 0,0 & 0,0 & 0,0 & 0,5 & 0,0 & 0,0 & 0,0 & 0,0 \\
\hline Brizalina sphatula & 0,0 & 0,0 & 0,0 & 0,0 & 0,0 & 0,0 & 0,0 & 0,0 & 0,0 & 0,0 & 0,0 & 0,0 & 0,0 & 0,3 & 0,0 & 0,0 & 0,0 & 0,0 & 0,0 & 0,0 & 0,0 & 0,0 & 0,3 & 0,0 & 0,5 & 0,0 & 0,3 & 0,7 & 0,0 \\
\hline Brizalina striatula & 2,3 & 2,0 & 1,8 & 2,0 & 1,8 & 1,4 & 0,4 & 0,9 & 1,4 & 0,7 & 2,0 & 1,9 & 1,2 & 3,7 & 1,5 & 0,9 & 1,1 & 1,6 & 1,4 & 0,0 & 2,7 & 2,6 & 2,4 & 3,8 & 1,6 & 1,8 & 2,0 & 0,2 & 2,3 \\
\hline
\end{tabular}




\begin{tabular}{|c|c|c|c|c|c|c|c|c|c|c|c|c|c|c|c|c|c|c|c|c|c|c|c|c|c|c|c|c|c|}
\hline \multirow[b]{2}{*}{ Estação } & \multicolumn{9}{|c|}{ Coleta realizada em Julho de 2005} & \multicolumn{10}{|c|}{ Coleta realizada em Abril de 2006} & \multicolumn{10}{|c|}{ Coleta realizada em Setembro de 2006} \\
\hline & $\mathrm{Ar} 2$ & Ar2 & Ar3 & Ar5 & Ar6 & $\operatorname{Ar} 7$ & Ar8 & $\operatorname{Ar} 9$ & Ar10 & Ar1 & Ar2 & Ar3 & Ar4 & $\operatorname{Ar} 5$ & Ar6 & $\operatorname{Ar} 7$ & Ar8 & $\operatorname{Ar} 9$ & Ar10 & Ar1 & $\operatorname{Ar} 2$ & Ar3 & Ar4 & Ar5 & Ar6 & Ar7 & Ar8 & $\operatorname{Ar} 9$ & $\operatorname{Ar} 10$ \\
\hline Bolivina sp. & 0,7 & 0,0 & 0,7 & 0,9 & 0,4 & 1,4 & 0,0 & 1,2 & 1,8 & 0,7 & 1,1 & 0,5 & 0,6 & 2,0 & 1,5 & 1,8 & 0,3 & 2,0 & 0,5 & 0,7 & 0,0 & 0,5 & 2,7 & 1,3 & 1,1 & 1,1 & 0,9 & 0,7 & 2,3 \\
\hline Bolivinella pescicula & 0,0 & 0,0 & 0,0 & 0,0 & 0,0 & 0,0 & 0,0 & 0,0 & 0,0 & 0,0 & 0,0 & 0,0 & 0,0 & 0,0 & 0,0 & 0,0 & 0,0 & 0,0 & 0,0 & 0,0 & 0,0 & 0,0 & 0,0 & 0,0 & 0,5 & 0,0 & 0,0 & 0,0 & 0,0 \\
\hline Brizalina sphatula & 0,0 & 0,0 & 0,0 & 0,0 & 0,0 & 0,0 & 0,0 & 0,0 & 0,0 & 0,0 & 0,0 & 0,0 & 0,0 & 0,3 & 0,0 & 0,0 & 0,0 & 0,0 & 0,0 & 0,0 & 0,0 & 0,0 & 0,3 & 0,0 & 0,5 & 0,0 & 0,3 & 0,7 & 0,0 \\
\hline Brizalina striatula & 2,3 & 2,0 & 1,8 & 2,0 & 1,8 & 1,4 & 0,4 & 0,9 & 1,4 & 0,7 & 2,0 & 1,9 & 1,2 & 3,7 & 1,5 & 0,9 & 1,1 & 1,6 & 1,4 & 0,0 & 2,7 & 2,6 & 2,4 & 3,8 & 1,6 & 1,8 & 2,0 & 0,2 & 2,3 \\
\hline Buccella peruviana f. campsi & 0,7 & 0,0 & 0,0 & 0,3 & 0,7 & 0,7 & 0,8 & 0,0 & 0,2 & 0,0 & 0,0 & 0,0 & 0,0 & 0,0 & 0,0 & 0,0 & 0,0 & 0,0 & 0,0 & 0,0 & 0,0 & 0,3 & 0,0 & 0,0 & 0,5 & 0,4 & 0,0 & 0,2 & 1,0 \\
\hline Buccella peruviana f. typica & 0,0 & 0,0 & 0,0 & 0,0 & 0,0 & 0,0 & 0,0 & 0,0 & 0,0 & 0,0 & 0,0 & 0,0 & 0,0 & 0,0 & 0,4 & 0,0 & 0,0 & 0,0 & 0,0 & 0,0 & 0,0 & 0,0 & 0,0 & 0,0 & 0,0 & 0,0 & 0,0 & 0,0 & 0,0 \\
\hline Bulimina elongata & 1,3 & 0,8 & 0,7 & 0,0 & 0,0 & 0,0 & 1,6 & 1,2 & 0,5 & 0,0 & 0,3 & 0,3 & 0,0 & 0,0 & 0,4 & 0,0 & 0,3 & 0,0 & 0,0 & 0,0 & 0,4 & 0,3 & 0,0 & 0,6 & 0,2 & 0,0 & 0,0 & 0,0 & 0,0 \\
\hline Bulimina gibba & 0,0 & 0,0 & 0,0 & 0,0 & 0,0 & 0,0 & 0,0 & 0,0 & 0,0 & 0,7 & 0,0 & 0,0 & 0,0 & 0,0 & 0,0 & 0,0 & 0,0 & 0,0 & 0,0 & 0,0 & 0,0 & 0,0 & 0,0 & 0,0 & 0,0 & 0,0 & 0,0 & 0,0 & 0,0 \\
\hline Bulimina marginata & 16,0 & 9,1 & 7,7 & 9,2 & 12,9 & 9,1 & 7,4 & 11,0 & 6,2 & 2,8 & 4,3 & 10,2 & 3,3 & 2,7 & 10,9 & 1,8 & 5,6 & 2,0 & 1,4 & 12,5 & 4,2 & 9,0 & 3,8 & 4,0 & 5,0 & 8,1 & 5,8 & 3,2 & 2,3 \\
\hline Bulimina pupoides & 0,3 & 0,8 & 0,0 & 0,3 & 0,4 & 0,0 & 0,0 & 0,0 & 0,0 & 0,0 & 0,0 & 0,0 & 0,0 & 0,0 & 0,0 & 0,0 & 0,0 & 0,0 & 0,3 & 0,7 & 0,0 & 0,0 & 0,0 & 0,0 & 0,0 & 0,0 & 0,0 & 0,0 & 0,3 \\
\hline Bulimina $s p$ & 0,0 & 0,0 & 0,0 & 0,0 & 0,0 & 0,0 & 0,0 & 0,0 & 0,2 & 0,0 & 0,0 & 0,0 & 0,0 & 0,0 & 0,0 & 0,0 & 0,0 & 0,0 & 0,0 & 0,0 & 0,0 & 0,0 & 0,0 & 0,0 & 0,2 & 0,0 & 0,0 & 0,0 & 0,0 \\
\hline Cassidulina crassa forma media & 1,6 & 3,1 & 3,2 & 1,1 & 2,2 & 2,8 & 4,3 & 3,3 & 4,3 & 0,0 & 0,0 & 0,5 & 0,9 & 0,7 & 0,0 & 1,2 & 0,8 & 3,3 & 3,0 & 0,0 & 3,5 & 2,1 & 2,4 & 1,7 & 1,4 & 3,0 & 2,6 & 5,1 & 2,3 \\
\hline Cassidulina laevigata & 0,0 & 0,0 & 0,0 & 0,0 & 0,0 & 0,0 & 0,0 & 0,0 & 0,0 & 0,0 & 0,6 & 0,0 & 0,0 & 0,0 & 0,8 & 0,9 & 0,3 & 0,7 & 0,0 & 0,0 & 0,0 & 0,0 & 0,0 & 0,0 & 0,2 & 0,0 & 0,3 & 0,0 & 0,3 \\
\hline Cassidulina minuta & 0,0 & 0,0 & 0,0 & 0,0 & 0,0 & 0,0 & 0,0 & 0,0 & 0,0 & 0,7 & 0,9 & 0,8 & 1,5 & 0,3 & 0,8 & 0,6 & 1,1 & 1,3 & 1,1 & 0,0 & 0,4 & 0,0 & 0,3 & 0,4 & 0,7 & 0,0 & 0,3 & 0,5 & 0,0 \\
\hline Cassidulina rossensis & 0,0 & 0,0 & 0,0 & 0,0 & 0,0 & 0,0 & 0,0 & 0,0 & 0,0 & 0,0 & 0,0 & 0,0 & 0,0 & 0,0 & 0,0 & 0,0 & 0,0 & 0,0 & 0,0 & 0,0 & 0,0 & 0,8 & 0,0 & 0,0 & 0,0 & 0,0 & 0,0 & 0,0 & 0,0 \\
\hline Cassidulina subglobosa & 0,0 & 0,0 & 0,0 & 0,0 & 0,0 & 0,0 & 0,0 & 0,0 & 0,0 & 0,0 & 0,0 & 1,6 & 1,2 & 1,3 & 0,8 & 2,8 & 2,7 & 3,9 & 1,9 & 0,0 & 0,4 & 0,5 & 1,0 & 0,4 & 0,9 & 1,1 & 1,2 & 1,2 & 1,3 \\
\hline Cassidulinoides parkerianus & 0,0 & 0,0 & 0,0 & 0,0 & 0,0 & 0,0 & 0,0 & 0,0 & 0,0 & 0,0 & 0,0 & 0,0 & 0,0 & 0,0 & 0,0 & 0,0 & 0,0 & 0,0 & 0,0 & 0,0 & 0,0 & 0,0 & 0,0 & 0,0 & 0,0 & 0,0 & 0,0 & 0,0 & 0,3 \\
\hline Cibicides aknerianus & 0,3 & 0,0 & 0,0 & 0,0 & 0,0 & 0,0 & 0,0 & 0,0 & 0,0 & 0,0 & 0,0 & 0,0 & 0,0 & 0,0 & 0,0 & 0,0 & 0,0 & 0,0 & 0,0 & 0,0 & 0,0 & 0,0 & 0,0 & 0,0 & 0,0 & 0,0 & 0,0 & 0,0 & 0,0 \\
\hline Cibicides mckannai & 0,0 & 0,0 & 0,0 & 0,0 & 0,0 & 0,0 & 0,0 & 0,0 & 0,0 & 0,0 & 0,0 & 0,0 & 0,0 & 0,0 & 0,0 & 0,0 & 0,0 & 0,0 & 0,0 & 0,0 & 0,0 & 0,3 & 0,0 & 0,0 & 0,0 & 0,0 & 0,0 & 0,0 & 0,0 \\
\hline Cibicides refulgens & 0,0 & 0,0 & 0,0 & 0,0 & 0,0 & 0,0 & 0,0 & 0,0 & 0,0 & 0,0 & 0,0 & 0,0 & 0,0 & 0,0 & 0,0 & 0,0 & 0,0 & 0,0 & 0,0 & 0,0 & 0,0 & 0,0 & 0,0 & 0,0 & 0,2 & 0,4 & 0,0 & 0,0 & 0,0 \\
\hline Cibicides variabilis & 0,3 & 0,8 & 0,7 & 0,0 & 0,0 & 0,0 & 0,4 & 0,0 & 0,2 & 0,0 & 0,0 & 0,0 & 0,0 & 0,0 & 0,8 & 0,0 & 0,0 & 0,7 & 0,0 & 0,0 & 0,4 & 0,0 & 0,0 & 0,0 & 0,2 & 0,4 & 0,3 & 0,0 & 0,0 \\
\hline Cibicides sp. & 0,3 & 0,6 & 0,0 & 0,3 & 0,0 & 0,0 & 1,9 & 0,0 & 0,9 & 0,7 & 1,1 & 0,5 & 0,3 & 0,0 & 0,4 & 0,0 & 0,0 & 0,0 & 0,3 & 0,0 & 0,0 & 0,0 & 0,0 & 0,2 & 0,0 & 0,0 & 0,6 & 0,2 & 0,0 \\
\hline Clavulina tricarinata & 0,0 & 0,0 & 0,0 & 0,0 & 0,0 & 0,0 & 0,4 & 0,0 & 0,0 & 0,0 & 0,0 & 0,0 & 0,0 & 0,0 & 0,0 & 0,0 & 0,0 & 0,0 & 0,0 & 0,0 & 0,0 & 0,0 & 0,0 & 0,0 & 0,0 & 0,0 & 0,0 & 0,0 & 0,0 \\
\hline Clavulina sp & 0,0 & 0,0 & 0,0 & 0,0 & 0,0 & 0,0 & 0,0 & 0,0 & 0,0 & 0,0 & 0,0 & 0,0 & 0,0 & 0,0 & 0,4 & 0,0 & 0,0 & 0,0 & 0,0 & 0,0 & 0,0 & 0,0 & 0,0 & 0,0 & 0,0 & 0,0 & 0,0 & 0,0 & 0,0 \\
\hline
\end{tabular}




\begin{tabular}{|c|c|c|c|c|c|c|c|c|c|c|c|c|c|c|c|c|c|c|c|c|c|c|c|c|c|c|c|c|c|}
\hline \multirow[b]{2}{*}{ Estação } & \multicolumn{9}{|c|}{ Junho de 2005} & \multicolumn{10}{|c|}{ Abril de 2006} & \multicolumn{10}{|c|}{ Setembro de 2006} \\
\hline & $\operatorname{Ar} 2$ & Ar2 & Ar3 & Ar5 & Ar6 & $\operatorname{Ar} 7$ & Ar8 & Ar9 & Ar10 & Ar1 & Ar2 & Ar3 & $\mathrm{Ar} 4$ & Ar5 & Ar6 & Ar7 & Ar8 & Ar9 & Ar10 & Ar1 & Ar2 & $\mathrm{Ar} 3$ & Ar4 & Ar5 & Ar6 & Ar7 & Ar8 & Ar9 & $\operatorname{Ar} 10$ \\
\hline Buccella peruviana f. campsi & 0,7 & 0,0 & 0,0 & 0,3 & 0,7 & 0,7 & 0,8 & 0,0 & 0,2 & 0,0 & 0,0 & 0,0 & 0,0 & 0,0 & 0,0 & 0,0 & 0,0 & 0,0 & 0,0 & 0,0 & 0,0 & 0,3 & 0,0 & 0,0 & 0,5 & 0,4 & 0,0 & 0,2 & 1,0 \\
\hline Buccella peruviana f. frigida & 0,0 & 0,0 & 0,0 & 0,0 & 0,0 & 0,0 & 0,0 & 0,0 & 0,0 & 0,0 & 0,0 & 0,0 & 0,0 & 0,0 & 0,4 & 0,0 & 0,5 & 0,0 & 0,0 & 0,0 & 0,0 & 0,0 & 0,0 & 0,0 & 0,0 & 0,0 & 0,0 & 0,0 & 0,0 \\
\hline Buccella peruviana f. typica & 0,0 & 0,0 & 0,0 & 0,0 & 0,0 & 0,0 & 0,0 & 0,0 & 0,0 & 0,0 & 0,0 & 0,0 & 0,0 & 0,0 & 0,4 & 0,0 & 0,0 & 0,0 & 0,0 & 0,0 & 0,0 & 0,0 & 0,0 & 0,0 & 0,0 & 0,0 & 0,0 & 0,0 & 0,0 \\
\hline Bulimina elongata & 1,3 & 0,8 & 0,7 & 0,0 & 0,0 & 0,0 & 1,6 & 1,2 & 0,5 & 0,0 & 0,3 & 0,3 & 0,0 & 0,0 & 0,4 & 0,0 & 0,3 & 0,0 & 0,0 & 0,0 & 0,4 & 0,3 & 0,0 & 0,6 & 0,2 & 0,0 & 0,0 & 0,0 & 0,0 \\
\hline Bulimina gibba & 0,0 & 0,0 & 0,0 & 0,0 & 0,0 & 0,0 & 0,0 & 0,0 & 0,0 & 0,7 & 0,0 & 0,0 & 0,0 & 0,0 & 0,0 & 0,0 & 0,0 & 0,0 & 0,0 & 0,0 & 0,0 & 0,0 & 0,0 & 0,0 & 0,0 & 0,0 & 0,0 & 0,0 & 0,0 \\
\hline Bulimina marginata & 16,0 & 9,1 & 7,7 & 9,2 & 12,9 & 9,1 & 7,4 & 11,0 & 6,2 & 2,8 & 4,3 & 10,2 & 3,3 & 2,7 & 10,9 & 1,8 & 5,6 & 2,0 & 1,4 & 12,5 & 4,2 & 9,0 & 3,8 & 4,0 & 5,0 & 8,1 & 5,8 & 3,2 & 2,3 \\
\hline Bulimina pupoides & 0,3 & 0,8 & 0,0 & 0,3 & 0,4 & 0,0 & 0,0 & 0,0 & 0,0 & 0,0 & 0,0 & 0,0 & 0,0 & 0,0 & 0,0 & 0,0 & 0,0 & 0,0 & 0,3 & 0,7 & 0,0 & 0,0 & 0,0 & 0,0 & 0,0 & 0,0 & 0,0 & 0,0 & 0,3 \\
\hline Bulimina sp & 0,0 & 0,0 & 0,0 & 0,0 & 0,0 & 0,0 & 0,0 & 0,0 & 0,2 & 0,0 & 0,0 & 0,0 & 0,0 & 0,0 & 0,0 & 0,0 & 0,0 & 0,0 & 0,0 & 0,0 & 0,0 & 0,0 & 0,0 & 0,0 & 0,2 & 0,0 & 0,0 & 0,0 & 0,0 \\
\hline Buliminella elegantissima & 0,3 & 2,8 & 1,4 & 2,6 & 0,7 & 1,4 & 2,7 & 1,5 & 3,0 & 0,7 & 3,1 & 2,1 & 3,9 & 3,3 & 0,8 & 2,4 & 1,9 & 3,3 & 3,8 & 1,4 & 2,3 & 2,1 & 3,8 & 2,8 & 2,0 & 3,0 & 2,0 & 3,2 & 1,6 \\
\hline Cassidulina crassa forma media & 1,6 & 3,1 & 3,2 & 1,1 & 2,2 & 2,8 & 4,3 & 3,3 & 4,3 & 0,0 & 0,0 & 0,5 & 0,9 & 0,7 & 0,0 & 1,2 & 0,8 & 3,3 & 3,0 & 0,0 & 3,5 & 2,1 & 2,4 & 1,7 & 1,4 & 3,0 & 2,6 & 5,1 & 2,3 \\
\hline Cassidulina laevigata & 0,0 & 0,0 & 0,0 & 0,0 & 0,0 & 0,0 & 0,0 & 0,0 & 0,0 & 0,0 & 0,6 & 0,0 & 0,0 & 0,0 & 0,8 & 0,9 & 0,3 & 0,7 & 0,0 & 0,0 & 0,0 & 0,0 & 0,0 & 0,0 & 0,2 & 0,0 & 0,3 & 0,0 & 0,3 \\
\hline Cassidulina minuta & 0,0 & 0,0 & 0,0 & 0,0 & 0,0 & 0,0 & 0,0 & 0,0 & 0,0 & 0,7 & 0,9 & 0,8 & 1,5 & 0,3 & 0,8 & 0,6 & 1,1 & 1,3 & 1,1 & 0,0 & 0,4 & 0,0 & 0,3 & 0,4 & 0,7 & 0,0 & 0,3 & 0,5 & 0,0 \\
\hline Cassidulina rossensis & 0,0 & 0,0 & 0,0 & 0,0 & 0,0 & 0,0 & 0,0 & 0,0 & 0,0 & 0,0 & 0,0 & 0,0 & 0,0 & 0,0 & 0,0 & 0,0 & 0,0 & 0,0 & 0,0 & 0,0 & 0,0 & 0,8 & 0,0 & 0,0 & 0,0 & 0,0 & 0,0 & 0,0 & 0,0 \\
\hline Cassidulina subglobosa & 0,0 & 0,0 & 0,0 & 0,0 & 0,0 & 0,0 & 0,0 & 0,0 & 0,0 & 0,0 & 0,0 & 1,6 & 1,2 & 1,3 & 0,8 & 2,8 & 2,7 & 3,9 & 1,9 & 0,0 & 0,4 & 0,5 & 1,0 & 0,4 & 0,9 & 1,1 & 1,2 & 1,2 & 1,3 \\
\hline Cassidulinoides parkerianus & 0,0 & 0,0 & 0,0 & 0,0 & 0,0 & 0,0 & 0,0 & 0,0 & 0,0 & 0,0 & 0,0 & 0,0 & 0,0 & 0,0 & 0,0 & 0,0 & 0,0 & 0,0 & 0,0 & 0,0 & 0,0 & 0,0 & 0,0 & 0,0 & 0,0 & 0,0 & 0,0 & 0,0 & 0,3 \\
\hline Cibicides aknerianus & 0,3 & 0,0 & 0,0 & 0,0 & 0,0 & 0,0 & 0,0 & 0,0 & 0,0 & 0,0 & 0,0 & 0,0 & 0,0 & 0,0 & 0,0 & 0,0 & 0,0 & 0,0 & 0,0 & 0,0 & 0,0 & 0,0 & 0,0 & 0,0 & 0,0 & 0,0 & 0,0 & 0,0 & 0,0 \\
\hline Cibicides mckannai & 0,0 & 0,0 & 0,0 & 0,0 & 0,0 & 0,0 & 0,0 & 0,0 & 0,0 & 0,0 & 0,0 & 0,0 & 0,0 & 0,0 & 0,0 & 0,0 & 0,0 & 0,0 & 0,0 & 0,0 & 0,0 & 0,3 & 0,0 & 0,0 & 0,0 & 0,0 & 0,0 & 0,0 & 0,0 \\
\hline Cibicides refulgens & 0,0 & 0,0 & 0,0 & 0,0 & 0,0 & 0,0 & 0,0 & 0,0 & 0,0 & 0,0 & 0,0 & 0,0 & 0,0 & 0,0 & 0,0 & 0,0 & 0,0 & 0,0 & 0,0 & 0,0 & 0,0 & 0,0 & 0,0 & 0,0 & 0,2 & 0,4 & 0,0 & 0,0 & 0,0 \\
\hline Cibicides variabilis & 0,3 & 0,8 & 0,7 & 0,0 & 0,0 & 0,0 & 0,4 & 0,0 & 0,2 & 0,0 & 0,0 & 0,0 & 0,0 & 0,0 & 0,8 & 0,0 & 0,0 & 0,7 & 0,0 & 0,0 & 0,4 & 0,0 & 0,0 & 0,0 & 0,2 & 0,4 & 0,3 & 0,0 & 0,0 \\
\hline Cibicides sp. & 0,3 & 0,6 & 0,0 & 0,3 & 0,0 & 0,0 & 1,9 & 0,0 & 0,9 & 0,7 & 1,1 & 0,5 & 0,3 & 0,0 & 0,4 & 0,0 & 0,0 & 0,0 & 0,3 & 0,0 & 0,0 & 0,0 & 0,0 & 0,2 & 0,0 & 0,0 & 0,6 & 0,2 & 0,0 \\
\hline Clavulina tricarinata & 0,0 & 0,0 & 0,0 & 0,0 & 0,0 & 0,0 & 0,4 & 0,0 & 0,0 & 0,0 & 0,0 & 0,0 & 0,0 & 0,0 & 0,0 & 0,0 & 0,0 & 0,0 & 0,0 & 0,0 & 0,0 & 0,0 & 0,0 & 0,0 & 0,0 & 0,0 & 0,0 & 0,0 & 0,0 \\
\hline Clavulina sp & 0,0 & 0,0 & 0,0 & 0,0 & 0,0 & 0,0 & 0,0 & 0,0 & 0,0 & 0,0 & 0,0 & 0,0 & 0,0 & 0,0 & 0,4 & 0,0 & 0,0 & 0,0 & 0,0 & 0,0 & 0,0 & 0,0 & 0,0 & 0,0 & 0,0 & 0,0 & 0,0 & 0,0 & 0,0 \\
\hline Cornobella patelliformis & 0,0 & 0,0 & 0,4 & 0,0 & 0,0 & 0,0 & 0,0 & 0,0 & 0,0 & 0,0 & 0,0 & 0,0 & 0,3 & 0,3 & 0,4 & 0,3 & 0,0 & 0,0 & 0,0 & 0,0 & 0,0 & 0,0 & 0,0 & 0,0 & 0,2 & 0,0 & 0,3 & 0,0 & 0,0 \\
\hline Cornuspira involvens & 0,0 & 0,0 & 0,0 & 0,0 & 0,0 & 0,0 & 0,0 & 0,0 & 0,0 & 0,0 & 0,0 & 0,0 & 0,0 & 0,0 & 0,4 & 0,0 & 0,3 & 0,0 & 0,0 & 0,0 & 0,4 & 0,0 & 0,0 & 0,0 & 0,0 & 0,0 & 0,0 & 0,0 & 0,0 \\
\hline Cribroelphidium advenum & 0,0 & 0,0 & 0,0 & 0,3 & 0,0 & 0,0 & 0,4 & 0,0 & 0,0 & 0,0 & 0,0 & 0,0 & 0,0 & 0,0 & 0,4 & 0,0 & 0,0 & 0,0 & 0,0 & 0,0 & 0,0 & 0,3 & 0,0 & 0,2 & 0,0 & 0,0 & 0,0 & 0,2 & 0,0 \\
\hline Cribroelphidium alvarezianum & 0,0 & 0,0 & 0,0 & 0,0 & 0,0 & 0,0 & 0,0 & 0,0 & 0,0 & 0,0 & 0,0 & 0,0 & 0,0 & 0,0 & 0,4 & 0,0 & 0,0 & 0,0 & 0,0 & 0,0 & 0,0 & 0,0 & 0,0 & 0,2 & 0,0 & 0,0 & 0,0 & 0,0 & 0,0 \\
\hline Cribroelphidium discoidale & 2,9 & 1,7 & 1,1 & 3,2 & 2,6 & 1,4 & 0,8 & 0,0 & 0,2 & 2,8 & 1,7 & 4,5 & 1,8 & 2,3 & 3,4 & 0,6 & 0,0 & 0,7 & 0,0 & 2,1 & 2,3 & 1,5 & 0,3 & 1,7 & 1,4 & 1,8 & 3,5 & 1,2 & 3,9 \\
\hline Cribroelphidium excavatum & 4,9 & 6,5 & 3,5 & 0,9 & 2,6 & 2,8 & 2,7 & 4,7 & 0,2 & 0,7 & 0,0 & 3,5 & 0,9 & 4,0 & 1,1 & 3,1 & 2,9 & 2,6 & 5,2 & 0,0 & 1,5 & 1,5 & 2,4 & 2,1 & 1,8 & 3,3 & 1,2 & 3,2 & 3,3 \\
\hline Cribroelphidium gerthi & 0,0 & 0,0 & 0,0 & 0,0 & 0,0 & 0,0 & 0,0 & 0,0 & 0,0 & 0,0 & 0,0 & 0,0 & 0,0 & 0,0 & 0,0 & 0,0 & 0,0 & 0,0 & 0,0 & 0,4 & 0,0 & 0,0 & 0,0 & 0,0 & 0,0 & 0,0 & 0,0 & 0,0 & 0,0 \\
\hline Cribroelphidium gunteri & 0,0 & 0,0 & 0,0 & 0,0 & 0,0 & 0,0 & 0,0 & 0,0 & 0,0 & 0,0 & 0,0 & 0,0 & 0,0 & 0,0 & 0,0 & 0,0 & 0,0 & 0,0 & 0,0 & 0,0 & 0,0 & 0,0 & 0,0 & 0,0 & 0,2 & 0,0 & 0,0 & 0,0 & 0,0 \\
\hline
\end{tabular}


Anexo 25 - Continuação

Junho de 2005

Abril de 2006

Setembro de 2006

\begin{tabular}{|c|c|c|c|c|c|c|c|c|c|c|c|c|c|c|c|c|c|c|c|c|c|c|c|c|c|c|c|c|c|}
\hline Estação & $\mathrm{Ar} 2$ & $\mathrm{Ar} 2$ & Ar3 & $\operatorname{Ar} 5$ & Ar6 & Ar7 & Ar8 & Ar9 & $\operatorname{Ar} 10$ & Ar1 & Ar2 & Ar3 & Ar4 & $\operatorname{Ar} 5$ & Ar6 & Ar7 & Ar8 & Ar9 & Ar10 & Ar1 & Ar2 & Ar3 & Ar4 & $\operatorname{Ar} 5$ & Ar6 & Ar7 & Ar8 & Ar9 & $\operatorname{Ar} 10$ \\
\hline Cribroelphidium margaritaceum & 0,0 & 0,0 & 0,0 & 0,0 & 0,0 & 0,0 & 0,0 & 0,0 & 0,0 & 0,0 & 0,0 & 0,0 & 0,0 & 0,0 & 0,0 & 0,0 & 0,0 & 0,0 & 0,0 & 0,0 & 0,0 & 0,0 & 0,0 & 0,0 & 0,0 & 0,0 & 0,0 & 0,0 & 0,3 \\
\hline Cribroelphidium poyeanum & 7,2 & 4,2 & 3,5 & 2,6 & 4,1 & 1,4 & 1,9 & 0,3 & 1,1 & 0,0 & 0,9 & 0,5 & 0,9 & 1,0 & 3,8 & 2,4 & 3,4 & 0,0 & 0,8 & 0,4 & 1,5 & 2,1 & 0,7 & 2,3 & 1,4 & 1,1 & 0,3 & 0,9 & 0,3 \\
\hline Cribroelphidium $s p$ & 2,9 & 2,8 & 1,4 & 2,0 & 2,2 & 0,7 & 5,0 & 2,7 & 3,7 & 0,7 & 0,9 & 0,3 & 0,9 & 1,0 & 0,8 & 1,5 & 2,1 & 0,3 & 1,6 & 0,0 & 1,5 & 0,5 & 0,0 & 1,3 & 0,5 & 1,5 & 1,7 & 1,6 & 0,7 \\
\hline Cribrostomoides sp & 0,0 & 0,0 & 0,0 & 0,0 & 0,0 & 0,0 & 0,0 & 0,0 & 0,0 & 0,0 & 0,0 & 0,0 & 0,0 & 0,0 & 0,0 & 0,0 & 0,0 & 0,0 & 0,0 & 3,6 & 0,0 & 0,0 & 0,0 & 0,0 & 0,2 & 0,4 & 0,0 & 0,0 & 0,0 \\
\hline Discorbis peruvians & 0,0 & 0,6 & 0,4 & 0,0 & 0,0 & 0,0 & 0,0 & 0,0 & 0,0 & 0,0 & 0,0 & 0,0 & 0,0 & 0,0 & 0,0 & 0,0 & 0,0 & 0,0 & 0,0 & 0,0 & 0,4 & 0,0 & 0,0 & 0,0 & 0,9 & 0,0 & 0,0 & 0,2 & 0,3 \\
\hline Discorbis williamsoni & 0,3 & 0,8 & 1,4 & 1,1 & 1,1 & 0,7 & 1,2 & 0,3 & 2,5 & 0,0 & 0,6 & 0,0 & 0,0 & 0,0 & 0,0 & 0,3 & 0,3 & 0,0 & 0,3 & 0,0 & 0,8 & 0,3 & 0,7 & 0,6 & 0,5 & 0,4 & 0,3 & 1,2 & 1,3 \\
\hline Discorbis $s p$ & 0,3 & 0,0 & 0,0 & 0,0 & 0,0 & 0,7 & 0,0 & 0,0 & 0,7 & 0,0 & 0,0 & 0,0 & 0,0 & 0,0 & 0,0 & 0,0 & 0,0 & 0,0 & 0,0 & 0,0 & 0,0 & 0,0 & 0,0 & 0,0 & 0,0 & 0,0 & 0,0 & 0,0 & 0,0 \\
\hline Egerella scabra & 0,0 & 0,0 & 0,0 & 0,0 & 0,0 & 0,0 & 0,0 & 0,0 & 0,0 & 0,0 & 0,0 & 0,0 & 0,0 & 0,3 & 0,4 & 0,0 & 0,5 & 0,0 & 0,0 & 1,8 & 0,4 & 0,0 & 0,3 & 0,4 & 0,2 & 0,0 & 0,0 & 0,5 & 0,0 \\
\hline Eponides repandus & 0,3 & 0,0 & 0,4 & 0,0 & 0,4 & 0,3 & 0,0 & 0,6 & 0,2 & 0,0 & 0,0 & 0,0 & 0,0 & 0,0 & 0,0 & 0,0 & 0,0 & 0,0 & 0,0 & 0,0 & 0,0 & 0,0 & 0,0 & 0,0 & 0,5 & 0,4 & 0,3 & 0,0 & 0,0 \\
\hline Fissurina elliptica & 0,0 & 0,0 & 0,0 & 0,0 & 0,0 & 0,0 & 0,0 & 0,0 & 0,0 & 0,0 & 0,0 & 0,0 & 0,0 & 0,0 & 0,0 & 0,0 & 0,0 & 0,0 & 0,0 & 0,0 & 0,4 & 0,0 & 0,0 & 0,0 & 0,0 & 0,0 & 0,0 & 0,0 & 0,0 \\
\hline Fissurina laevigata & 0,0 & 0,8 & 0,7 & 1,1 & 0,0 & 0,0 & 0,0 & 1,5 & 0,9 & 0,0 & 0,6 & 1,1 & 1,5 & 1,0 & 0,4 & 0,3 & 1,6 & 0,7 & 1,4 & 0,7 & 0,8 & 0,8 & 1,7 & 1,3 & 0,5 & 0,7 & 1,2 & 0,7 & 2,0 \\
\hline Fissurina lucida & 0,0 & 0,0 & 0,0 & 0,0 & 0,0 & 0,0 & 0,0 & 0,0 & 0,0 & 0,0 & 0,0 & 0,0 & 0,0 & 0,3 & 0,0 & 0,0 & 0,0 & 0,3 & 0,0 & 0,0 & 0,0 & 0,0 & 0,0 & 0,4 & 0,0 & 0,4 & 0,3 & 0,0 & 0,0 \\
\hline Fursenkoina fragilis & 0,0 & 0,0 & 0,0 & 0,0 & 0,0 & 0,0 & 0,0 & 0,0 & 0,0 & 0,0 & 0,0 & 0,3 & 0,0 & 0,0 & 0,0 & 0,0 & 0,0 & 0,0 & 0,0 & 0,0 & 0,0 & 0,3 & 0,0 & 0,0 & 0,0 & 0,0 & 0,0 & 0,0 & 0,0 \\
\hline Fursenkoina pontoni & 0,7 & 0,6 & 0,4 & 0,0 & 0,0 & 0,0 & 0,8 & 0,0 & 0,0 & 0,7 & 0,3 & 0,0 & 0,6 & 0,3 & 0,8 & 0,3 & 0,8 & 0,0 & 0,3 & 0,0 & 0,8 & 0,3 & 1,4 & 0,2 & 0,5 & 0,4 & 0,0 & 0,2 & 0,3 \\
\hline Fursenkoina riggi & 0,0 & 0,0 & 0,0 & 0,0 & 0,0 & 0,0 & 0,0 & 0,3 & 0,0 & 0,0 & 0,0 & 0,0 & 1,2 & 0,0 & 0,0 & 0,0 & 0,0 & 0,3 & 0,0 & 0,0 & 0,0 & 0,3 & 0,0 & 0,0 & 0,0 & 0,0 & 0,0 & 0,2 & 0,7 \\
\hline Fursenkoina tegulata & 0,0 & 0,0 & 0,0 & 0,0 & 0,0 & 0,0 & 0,0 & 0,0 & 0,0 & 0,0 & 0,0 & 0,3 & 0,0 & 0,0 & 0,0 & 0,0 & 0,0 & 0,0 & 0,0 & 0,0 & 0,0 & 0,0 & 0,0 & 0,0 & 0,0 & 0,0 & 0,0 & 0,0 & 0,0 \\
\hline Gavelinolepsis praegeri & 0,0 & 0,0 & 0,0 & 0,0 & 0,0 & 0,0 & 0,0 & 0,0 & 0,0 & 0,0 & 2,0 & 0,5 & 0,6 & 0,0 & 1,5 & 1,5 & 1,3 & 2,0 & 0,8 & 0,0 & 0,8 & 1,0 & 1,4 & 0,4 & 1,6 & 3,0 & 2,9 & 1,6 & 2,3 \\
\hline Glabratella chasteri & 0,0 & 0,0 & 0,0 & 0,0 & 0,0 & 0,0 & 0,0 & 0,0 & 0,0 & 0,0 & 0,0 & 0,0 & 0,0 & 0,0 & 0,0 & 0,0 & 0,0 & 0,0 & 0,0 & 0,0 & 0,0 & 0,0 & 1,0 & 0,0 & 0,0 & 0,0 & 0,0 & 0,0 & 0,0 \\
\hline Globigerina calida & 0,0 & 0,0 & 0,0 & 0,0 & 0,0 & 0,0 & 0,0 & 0,0 & 0,0 & 0,0 & 0,0 & 0,0 & 0,3 & 0,0 & 0,0 & 0,0 & 0,0 & 1,0 & 0,3 & 0,0 & 0,0 & 0,0 & 0,0 & 0,0 & 0,0 & 0,0 & 0,0 & 0,0 & 0,0 \\
\hline Globigerinoides ruber & 0,0 & 0,0 & 0,0 & 0,0 & 0,0 & 0,0 & 0,0 & 0,0 & 0,0 & 0,7 & 0,6 & 0,0 & 0,6 & 0,7 & 0,0 & 1,5 & 0,3 & 0,3 & 0,0 & 0,0 & 0,4 & 0,0 & 0,3 & 0,2 & 0,0 & 0,4 & 0,3 & 0,2 & 0,3 \\
\hline Globorotalia compressa & 0,0 & 0,0 & 0,0 & 0,0 & 0,0 & 0,0 & 0,0 & 0,0 & 0,0 & 0,0 & 0,0 & 0,0 & 0,0 & 0,0 & 0,0 & 0,0 & 0,0 & 0,0 & 0,0 & 0,0 & 0,0 & 0,5 & 0,0 & 0,2 & 0,2 & 0,4 & 0,3 & 0,0 & 0,7 \\
\hline Gutulina $\mathrm{sp}$ & 0,0 & 0,0 & 0,0 & 0,0 & 0,0 & 0,0 & 0,0 & 0,0 & 0,0 & 0,0 & 0,0 & 0,0 & 0,0 & 0,0 & 0,0 & 0,0 & 0,0 & 0,0 & 0,0 & 0,0 & 0,0 & 0,3 & 0,0 & 0,0 & 0,0 & 0,0 & 0,0 & 0,0 & 0,0 \\
\hline Hanzawaia boueana & 1,6 & 3,4 & 6,3 & 2,9 & 5,5 & 3,1 & 3,1 & 6,2 & 0,5 & 3,5 & 2,9 & 4,8 & 6,0 & 0,3 & 4,2 & 1,5 & 2,9 & 3,0 & 1,6 & 0,0 & 1,5 & 3,1 & 1,0 & 2,1 & 3,6 & 5,5 & 3,7 & 1,8 & 1,3 \\
\hline Haynesina depressula & 0,0 & 0,0 & 0,0 & 0,0 & 0,0 & 0,0 & 0,0 & 0,0 & 0,0 & 0,0 & 0,0 & 0,0 & 0,3 & 0,0 & 0,0 & 0,0 & 0,0 & 0,0 & 0,0 & 0,0 & 0,0 & 0,0 & 0,0 & 0,0 & 0,2 & 0,7 & 0,0 & 0,7 & 0,3 \\
\hline Haynesina germanica & 0,0 & 0,3 & 0,0 & 0,9 & 0,4 & 0,3 & 0,0 & 0,0 & 0,2 & 0,0 & 2,3 & 0,5 & 0,0 & 0,0 & 0,0 & 0,6 & 1,6 & 0,7 & 0,3 & 0,0 & 0,4 & 1,0 & 1,7 & 1,7 & 1,1 & 0,4 & 0,9 & 1,2 & 1,0 \\
\hline Hopkinsina pacifica & 0,0 & 0,3 & 0,7 & 0,3 & 0,0 & 0,0 & 0,4 & 0,6 & 0,7 & 0,0 & 0,0 & 0,3 & 0,0 & 0,0 & 0,0 & 0,3 & 1,6 & 1,3 & 0,3 & 0,4 & 0,8 & 1,5 & 0,3 & 0,2 & 0,2 & 0,0 & 0,0 & 0,9 & 0,7 \\
\hline Lagena hispidula & 0,0 & 0,0 & 0,0 & 0,0 & 0,0 & 0,0 & 0,0 & 0,0 & 0,0 & 0,0 & 0,0 & 0,0 & 0,0 & 0,3 & 0,0 & 0,0 & 0,0 & 0,0 & 0,0 & 0,0 & 0,0 & 0,0 & 0,0 & 0,0 & 0,0 & 0,0 & 0,0 & 0,0 & 0,0 \\
\hline Lagena laevis f. tenuis & 0,3 & 0,0 & 0,0 & 0,0 & 0,0 & 0,0 & 0,0 & 0,0 & 0,2 & 0,0 & 0,0 & 0,0 & 0,0 & 0,3 & 0,0 & 0,0 & 0,0 & 0,0 & 0,0 & 0,0 & 0,0 & 0,0 & 0,0 & 0,0 & 0,0 & 0,0 & 0,3 & 0,0 & 0,0 \\
\hline
\end{tabular}


Anexo 25 - Continuação

\begin{tabular}{|c|c|c|c|c|c|c|c|c|c|c|c|c|c|c|c|c|c|c|c|c|c|c|c|c|c|c|c|c|c|}
\hline \multirow[b]{2}{*}{ Estação } & \multicolumn{9}{|c|}{ Junho de 2005} & \multicolumn{10}{|c|}{ Abril de 2006} & \multicolumn{10}{|c|}{ Setembro de 2006} \\
\hline & $\mathrm{Ar} 2$ & Ar2 & $\mathrm{Ar} 3$ & $\operatorname{Ar} 5$ & Ar6 & $\mathrm{Ar} 7$ & Ar8 & $\operatorname{Ar} 9$ & $\operatorname{Ar} 10$ & Ar1 & $\mathrm{Ar} 2$ & $\mathrm{Ar} 3$ & Ar4 & $\operatorname{Ar} 5$ & Ar6 & $\mathrm{Ar} 7$ & Ar8 & $\operatorname{Ar} 9$ & $\operatorname{Ar} 1$ & Ar1 & $\mathrm{Ar} 2$ & Ar3 & $\mathrm{Ar} 4$ & Ar5 & Ar6 & $\operatorname{Ar} 7$ & Ar8 & $\mathrm{Ar} 9$ & Ar10 \\
\hline Lagena laevis f. typica & 0,0 & 0,0 & 0,0 & 0,0 & 0,0 & 0,0 & 0,0 & 0,0 & 0,0 & 0,0 & 0,0 & 0,0 & 0,0 & 0,0 & 0,0 & 0,0 & 0,0 & 0,3 & 0,0 & 0,0 & 0,0 & 0,0 & 0,0 & 0,0 & 0,0 & 0,0 & 0,0 & 0,0 & 0,0 \\
\hline Lagena striata & 0,0 & 0,0 & 0,0 & 0,0 & 0,0 & 0,0 & 0,0 & 0,0 & 0,0 & 0,0 & 0,0 & 0,3 & 0,0 & 0,0 & 0,0 & 0,0 & 0,0 & 0,0 & 0,0 & 0,0 & 0,4 & 0,3 & 0,0 & 0,0 & 0,0 & 0,0 & 0,0 & 0,2 & 0,0 \\
\hline Lenticulina gibba & 0,0 & 0,0 & 0,0 & 0,0 & 0,0 & 0,0 & 0,0 & 0,0 & 0,0 & 0,0 & 0,0 & 0,0 & 0,0 & 0,0 & 0,0 & 0,0 & 0,0 & 0,0 & 0,0 & 0,0 & 0,0 & 0,0 & 0,0 & 0,0 & 0,0 & 0,0 & 0,3 & 0,0 & 0,0 \\
\hline Lenticulina $s p$ & 0,0 & 0,0 & 0,0 & 0,0 & 0,0 & 0,0 & 0,0 & 0,0 & 0,0 & 0,0 & 0,0 & 0,3 & 0,0 & 0,0 & 0,0 & 0,0 & 0,5 & 0,3 & 0,0 & 0,0 & 0,0 & 0,0 & 0,0 & 0,0 & 0,0 & 0,0 & 0,0 & 0,0 & 0,0 \\
\hline Lepdoteuramina ochracea & 0,0 & 0,0 & 0,0 & 0,0 & 0,0 & 0,0 & 0,0 & 0,0 & 0,0 & 0,0 & 0,0 & 0,0 & 0,0 & 0,0 & 0,0 & 0,3 & 0,0 & 0,7 & 0,3 & 0,4 & 0,8 & 0,0 & 0,0 & 0,4 & 0,0 & 0,4 & 0,0 & 0,0 & 0,0 \\
\hline Lepthohalysis catela & 0,0 & 0,0 & 0,0 & 0,0 & 0,0 & 0,0 & 0,0 & 0,0 & 0,0 & 0,0 & 0,6 & 0,5 & 0,0 & 0,0 & 0,0 & 0,0 & 0,3 & 0,0 & 0,0 & 0,7 & 0,0 & 0,0 & 0,0 & 0,0 & 0,0 & 0,0 & 0,0 & 0,0 & 0,0 \\
\hline Lobatula lobatula & 0,3 & 0,3 & 2,5 & 0,0 & 1,1 & 0,7 & 1,6 & 0,3 & 0,0 & 0,0 & 0,9 & 0,3 & 0,0 & 0,0 & 0,8 & 0,3 & 1,1 & 0,3 & 0,3 & 0,0 & 0,4 & 0,0 & 0,7 & 0,0 & 1,1 & 0,7 & 0,0 & 0,9 & 0,0 \\
\hline Massilina secans & 0,0 & 0,0 & 0,0 & 0,0 & 0,0 & 0,0 & 0,0 & 0,0 & 0,0 & 0,0 & 0,0 & 0,0 & 0,0 & 0,0 & 0,0 & 0,3 & 0,0 & 0,0 & 0,0 & 0,0 & 0,0 & 0,0 & 0,0 & 0,0 & 0,0 & 0,0 & 0,0 & 0,0 & 0,0 \\
\hline Miliolinella subrotunda & 0,0 & 0,3 & 0,0 & 0,0 & 0,0 & 0,0 & 0,4 & 0,0 & 0,0 & 0,0 & 0,3 & 0,0 & 0,0 & 0,0 & 0,8 & 0,3 & 1,3 & 0,7 & 0,0 & 0,0 & 0,8 & 0,0 & 0,3 & 0,0 & 0,5 & 0,4 & 0,3 & 0,0 & 0,3 \\
\hline Miliolinella $s p$ & 0,0 & 0,0 & 0,0 & 0,0 & 0,0 & 0,0 & 0,0 & 0,0 & 0,0 & 0,0 & 0,0 & 0,0 & 0,0 & 0,0 & 0,0 & 0,0 & 0,3 & 0,0 & 0,0 & 0,0 & 0,0 & 0,0 & 0,0 & 0,0 & 0,0 & 0,0 & 0,0 & 0,0 & 0,0 \\
\hline Morulaeplecta bulbosa & 0,0 & 0,0 & 0,0 & 0,0 & 0,0 & 0,0 & 0,0 & 0,0 & 0,0 & 0,0 & 0,0 & 0,0 & 0,0 & 0,0 & 0,0 & 0,0 & 0,0 & 0,0 & 0 , & 0,4 & 0,0 & 0,0 & 0,0 & 0,6 & 0,0 & 0,0 & 0,0 & 0,0 & 0,0 \\
\hline Neocornobina marginata & 0,0 & 0,0 & 0,4 & 0,0 & 0,0 & 0,0 & 0,0 & 0,0 & 0,0 & 0,0 & 0,0 & 0,0 & 0,0 & 0,0 & 0,0 & 0,0 & 0,0 & 0,0 & 0,0 & 0,0 & 0,0 & 0,0 & 0,0 & 0,0 & 0,0 & 0,0 & 0,0 & 0,2 & 0,0 \\
\hline Neocornobina terquemi & 0,0 & 0,0 & 0,0 & 0,0 & 0,4 & 0,0 & 0,0 & 0,0 & 0,0 & 0,7 & 0,0 & 0,0 & 0,0 & 0,0 & 0,4 & 0,0 & 0,0 & 0,0 & 0,0 & 0,0 & 0,0 & 0,0 & 0,0 & 0,0 & 0,0 & 0,0 & 0,0 & 0,2 & 0,0 \\
\hline Neocornobina sp & 0,0 & 0,0 & 0,0 & 0,0 & 0,0 & 0,0 & 0,0 & 0,0 & 0,0 & 0,7 & 0,9 & 0,0 & 0,0 & 0,0 & 0,4 & 0,0 & 0,0 & 0,0 & 0,0 & 0,0 & 0,0 & 0,0 & 0,0 & 0,0 & 0,0 & 0,0 & 0,0 & 0,0 & 0,0 \\
\hline Neoeponides bradyi & 0,0 & 0,0 & 0,0 & 0,0 & 0,0 & 0,0 & 0,0 & 0,0 & 0,0 & 0,0 & 0,0 & 0,0 & 0,0 & 0,0 & 0,0 & 0,0 & 0,0 & 0,0 & 0,0 & 0,0 & 0,4 & 0,0 & 0,0 & 0,2 & 0,7 & 0,4 & 0,6 & 0,0 & 0,0 \\
\hline Nonionella pauperatus & 0,0 & 0,0 & 0,0 & 0,0 & 0,0 & 0,0 & 0,0 & 0,0 & 0,0 & 0,0 & 0,0 & 0,0 & 0,0 & 0,0 & 0,4 & 0,0 & 0,0 & 0,0 & 0,0 & 0,0 & 0,4 & 0,0 & 0,0 & 0,0 & 0,0 & 0,0 & 0,0 & 0,0 & 0,0 \\
\hline Nonionella turgida & 0,0 & 0,0 & 0,0 & 0,0 & 0,0 & 0,0 & 0,0 & 0,0 & 0,0 & 0,0 & 0,0 & 0,0 & 0,0 & 0,0 & 0,0 & 0,0 & 0,0 & 0,0 & 0,0 & 0,0 & 0,0 & 0,0 & 0,3 & 0,0 & 0,0 & 0,0 & 0,0 & 0,0 & 0,0 \\
\hline Oolina caudigera & 0,0 & 0,0 & 0,0 & 0,0 & 0,0 & 0,0 & 0,0 & 0,0 & 0,0 & 0,0 & 0,0 & 0,0 & 0,0 & 0,0 & 0,0 & 0,0 & 0,0 & 0,0 & 0,0 & 0,0 & 0,0 & 0,0 & 0,3 & 0,0 & 0,0 & 0,0 & 0,0 & 0,0 & 0,0 \\
\hline Oolina costata & 0,0 & 0,0 & 0,0 & 0,0 & 0,0 & 0,0 & 0,0 & 0,0 & 0,0 & 0,0 & 0,0 & 0,0 & 0,0 & 0,0 & 0,0 & 0,0 & 0,0 & 0,0 & 0,0 & 0,0 & 0,0 & 0,0 & 0,0 & 0,0 & 0,0 & 0,0 & 0,0 & 0,2 & 0,0 \\
\hline Oolina $s p$ & 0,0 & 0,0 & 0,0 & 0,0 & 0,0 & 0,0 & 0,0 & 0,0 & 0,0 & 0,0 & 0,0 & 0,0 & 0,0 & 0,0 & 0,0 & 0,0 & 0,0 & 0,0 & 0,0 & 0,0 & 0,0 & 0,0 & 0,0 & 0,0 & 0,0 & 0,4 & 0,0 & 0,0 & 0,0 \\
\hline Pararotalia cananeiaensis & 12,4 & 18,1 & 15,5 & 16,9 & 21,4 & 27,3 & 12,0 & 12,5 & 23,3 & 26,2 & 23,4 & 25,4 & 23,9 & 20,1 & 15,1 & 19,9 & 20,2 & 23, & 18 & 3,6 & 26,6 & 28,1 & 16,4 & 18,9 & 28,2 & 18,1 & 18,4 & 20,8 & 29,1 \\
\hline Paratrochammina sp & 0,0 & 0,0 & 0,0 & 0,3 & 0,0 & 0,0 & 0,0 & 0,0 & 0,0 & 0,0 & 0,0 & 0,0 & 0,0 & 0,0 & 0,0 & 0,0 & 0,0 & 0,0 & 0,0 & 0,0 & 0,0 & 0,0 & 0,0 & 0,0 & 0,0 & 0,0 & 0,0 & 0,0 & 0,0 \\
\hline Patelina corrugata & 0,0 & 0,3 & 0,0 & 0,0 & 0,0 & 0,0 & 0,0 & 0,3 & 0,0 & 0,0 & 0,0 & 0,0 & 0,0 & 0,0 & 0,0 & 0,0 & 0,0 & 0,0 & 0,0 & 0,0 & 0,0 & 0,0 & 0,0 & 0,0 & 0,0 & 0,0 & 0,0 & 0,0 & 0,0 \\
\hline Patelina $s p$ & 0,0 & 0,0 & 0,0 & 0,0 & 0,0 & 0,0 & 0,0 & 0,6 & 0,0 & 0,0 & 0,0 & 0,0 & 0,0 & 0,0 & 0,0 & 0,0 & 0,0 & 0,0 & 0,0 & 0,0 & 0,0 & 0,0 & 0,0 & 0,0 & 0,0 & 0,0 & 0,0 & 0,0 & 0,0 \\
\hline Polysaccamina hyperhalina & 0,0 & 0,0 & 0,0 & 0,3 & 0,0 & 0,0 & 0,0 & 0,0 & 0,0 & 0,0 & 0,0 & 0,0 & 0,0 & 0,0 & 0,0 & 0,0 & 0,0 & 0,0 & 0,0 & 0,0 & 0,0 & 0,0 & 0,0 & 0,0 & 0,0 & 0,0 & 0,0 & 0,0 & 0,0 \\
\hline Poroeponides lateralis & 0,3 & 0,0 & 0,0 & 0,0 & 0,0 & 0,0 & 0,4 & 0,3 & 0,0 & 0,0 & 0,3 & 0,0 & 0,0 & 0,0 & 0,4 & 0,3 & 0,3 & 0,0 & 0,0 & 0,0 & 0,0 & 0,0 & 0,0 & 0,0 & 0,0 & 0,0 & 0,0 & 0,0 & 0,0 \\
\hline Porosononion $s p$ & 0,0 & 0,0 & 0,0 & 0,0 & 0,0 & 0,0 & 0,0 & 0,0 & 0,0 & 0,0 & 0,0 & 0,0 & 0,0 & 0,0 & 0,0 & 0,0 & 0,0 & 0,0 & 0,0 & 0,0 & 0,0 & 0,0 & 0,0 & 0,0 & 0,0 & 0,0 & 0,0 & 0,0 & 0,3 \\
\hline Protoschista findens & 0,0 & 0,0 & 0,0 & 0,0 & 0,4 & 0,3 & 0,4 & 0,0 & 0,2 & 0,0 & 0,6 & 0,0 & 0,6 & 2,0 & 0,0 & 0,6 & 0,5 & 0,0 & 0,5 & 1,8 & 0,0 & 0,0 & 0,3 & 0,4 & 0,0 & 0,0 & 0,3 & 0,0 & 0,0 \\
\hline
\end{tabular}




\begin{tabular}{|c|c|c|c|c|c|c|c|c|c|c|c|c|c|c|c|c|c|c|c|c|c|c|c|c|c|c|c|c|c|}
\hline \multirow{3}{*}{$\begin{array}{l}\text { Anexo } 25 \text { - Continuação } \\
\text { Estação }\end{array}$} & \multirow{2}{*}{\multicolumn{9}{|c|}{ Junho de 2005}} & \multirow{2}{*}{\multicolumn{10}{|c|}{ Abril de 2006}} & \multirow{2}{*}{\multicolumn{10}{|c|}{ Setembro de 2006}} \\
\hline & & & & & & & & & & & & & & & & & & & & & & & & & & & & & \\
\hline & Ar2 & $\mathrm{Ar} 2$ & $\operatorname{Ar} 3$ & Ar5 & Ar6 & $\operatorname{Ar} 7$ & Ar8 & $\operatorname{Ar} 9$ & $\operatorname{Ar} 10$ & Ar1 & $\operatorname{Ar} 2$ & Ar3 & $\mathrm{Ar} 4$ & Ar5 & Ar6 & Ar7 & Ar8 & $\operatorname{Ar} 9$ & Ar10 & Ar1 & Ar2 & $\mathrm{Ar} 3$ & Ar4 & $\operatorname{Ar} 5$ & Ar6 & $\operatorname{Ar} 7$ & Ar8 & Ar9 & $\operatorname{Ar} 10$ \\
\hline Pseudoclavulina $\mathrm{sp}$ & 0,0 & 0,0 & 0,0 & 0,0 & 0,0 & 0,0 & 0,0 & 0,0 & 0,0 & 0,0 & 0,0 & 0,0 & 0,0 & 0,0 & 0,0 & 0,0 & 0,0 & 0,0 & 0,0 & 0,0 & 0,0 & 0,0 & 0,3 & 0,0 & 0,0 & 0,0 & 0,0 & 0,0 & 0,0 \\
\hline Pseudononion atlanticum & 4,6 & 8,5 & 6,3 & 1,7 & 3,7 & 4,9 & 6,2 & 6,8 & 2,5 & 2,1 & 6,6 & 5,1 & 1,2 & 0,7 & 3,8 & 1,8 & 5,8 & 2,0 & 2,7 & 0,4 & 4,2 & 5,4 & 3,1 & 2,1 & 3,4 & 7,0 & 7,5 & 3,5 & 1,6 \\
\hline Pseudononion grateloupi & 0,0 & 0,6 & 0,0 & 0,0 & 0,0 & 0,0 & 0,0 & 0,0 & 0,0 & 0,0 & 0,3 & 1,3 & 1,5 & 0,7 & 1,9 & 1,2 & 1,1 & 0,7 & 0,3 & 0,0 & 0,4 & 2,8 & 1,4 & 1,3 & 0,2 & 0,4 & 0,6 & 0,2 & 0,3 \\
\hline Pseudononion labradorica & 0,0 & 0,0 & 0,0 & 0,0 & 0,0 & 0,0 & 0,0 & 0,0 & 0,0 & 0,0 & 0,0 & 0,0 & 0,0 & 0,0 & 0,0 & 0,0 & 0,0 & 0,0 & 0,0 & 0,0 & 0,0 & 0,0 & 0,0 & 0,2 & 0,0 & 0,0 & 0,0 & 0,0 & 0,0 \\
\hline Pseudononion opima & 0,3 & 0,8 & 0,0 & 0,6 & 0,4 & 0,0 & 0,0 & 0,3 & 0,7 & 0,0 & 0,3 & 0,5 & 0,3 & 0,3 & 0,4 & 0,3 & 1,3 & 0,0 & 0,5 & 0,0 & 0,4 & 1,0 & 1,4 & 0,0 & 0,0 & 0,4 & 0,3 & 0,7 & 0,0 \\
\hline Pseudononion sp & 1,6 & 1,4 & 3,2 & 2,3 & 3,7 & 4,2 & 1,6 & 0,9 & 2,3 & 1,4 & 1,1 & 2,4 & 1,2 & 1,0 & 0,8 & 2,8 & 1,9 & 1,6 & 1,4 & 0,0 & 0,4 & 0,3 & 0,3 & 0,2 & 0,7 & 0,7 & 0,6 & 1,2 & 0,7 \\
\hline Pyrgo ringens & 0,7 & 0,8 & 0,0 & 0,0 & 0,4 & 0,0 & 0,8 & 0,0 & 0,0 & 0,0 & 0,0 & 0,0 & 0,0 & 0,0 & 0,0 & 0,3 & 0,0 & 0,0 & 0,0 & 0,0 & 0,0 & 0,0 & 0,3 & 0,0 & 0,2 & 0,0 & 0,6 & 0,0 & 0,0 \\
\hline Pyrgo sp & 0,0 & 0,0 & 0,0 & 0,0 & 0,0 & 0,0 & 0,0 & 0,0 & 0,0 & 0,0 & 0,0 & 0,0 & 0,0 & 0,0 & 0,4 & 0,0 & 0,3 & 0,0 & 0,0 & 0,0 & 0,0 & 0,0 & 0,0 & 0,0 & 0,0 & 0,0 & 0,0 & 0,0 & 0,0 \\
\hline Quinqueloculina atlantica & 0,0 & 0,3 & 0,0 & 0,3 & 0,0 & 0,0 & 0,0 & 0,3 & 0,0 & 0,0 & 0,0 & 0,3 & 0,0 & 0,0 & 0,0 & 0,0 & 0,0 & 0,0 & 0,0 & 0,0 & 0,0 & 0,0 & 0,0 & 0,0 & 0,0 & 0,0 & 0,0 & 0,0 & 0,0 \\
\hline Quinqueloculina bosciana & 0,0 & 0,0 & 0,0 & 0,0 & 0,0 & 0,0 & 0,0 & 0,0 & 0,0 & 0,0 & 0,0 & 0,0 & 0,0 & 0,0 & 0,0 & 0,0 & 0,0 & 0,0 & 0,0 & 0,0 & 0,0 & 0,0 & 0,0 & 0,0 & 0,0 & 0,4 & 0,0 & 0,0 & 0,0 \\
\hline Quinqueloculina bradyana & 0,0 & 0,0 & 0,0 & 0,0 & 0,0 & 0,0 & 0,0 & 0,0 & 0,0 & 0,0 & 0,0 & 0,0 & 0,0 & 0,0 & 0,0 & 0,0 & 0,0 & 0,0 & 0,0 & 0,0 & 0,0 & 0,0 & 0,0 & 0,0 & 0,2 & 0,0 & 0,0 & 0,0 & 0,0 \\
\hline Quinqueloculina brodermani & 0,0 & 0,3 & 0,0 & 0,0 & 0,0 & 0,3 & 0,0 & 0,0 & 0,0 & 0,0 & 0,0 & 0,0 & 0,0 & 0,0 & 0,0 & 0,0 & 0,0 & 0,0 & 0,0 & 0,0 & 0,0 & 0,0 & 0,0 & 0,0 & 0,0 & 0,0 & 0,0 & 0,0 & 0,0 \\
\hline Quinqueloculina gregaria & 0,3 & 0,3 & 0,0 & 0,3 & 0,0 & 0,0 & 0,0 & 0,0 & 0,0 & 0,0 & 0,0 & 0,0 & 0,0 & 0,0 & 0,0 & 0,0 & 0,0 & 0,0 & 0,0 & 0,0 & 0,0 & 0,0 & 0,0 & 0,0 & 0,0 & 0,0 & 0,0 & 0,0 & 0,0 \\
\hline Quinqueloculina horrida & 0,0 & 0,0 & 0,0 & 0,0 & 0,0 & 0,0 & 0,0 & 0,0 & 0,0 & 0,0 & 0,0 & 0,0 & 0,0 & 0,0 & 0,0 & 0,0 & 0,0 & 0,0 & 0,0 & 0,0 & 0,4 & 0,0 & 0,0 & 0,0 & 0,0 & 0,0 & 0,3 & 0,0 & 0,0 \\
\hline Quinqueloculina intricata & 0,0 & 0,0 & 0,0 & 0,0 & 0,0 & 0,0 & 0,0 & 0,0 & 0,0 & 0,0 & 0,0 & 0,0 & 0,0 & 0,0 & 0,0 & 0,0 & 0,0 & 0,0 & 0,0 & 0,0 & 0,0 & 0,0 & 0,0 & 0,0 & 0,0 & 0,0 & 0,0 & 0,0 & 0,0 \\
\hline Quinqueloculina milletti & 0,0 & 0,0 & 0,4 & 0,0 & 0,0 & 0,3 & 0,8 & 0,0 & 0,0 & 1,4 & 0,3 & 0,5 & 0,6 & 0,3 & 1,1 & 0,9 & 1,1 & 0,3 & 0,5 & 0,0 & 0,8 & 0,0 & 0,0 & 0,0 & 1,1 & 0,7 & 0,6 & 0,0 & 0,0 \\
\hline Quinqueloculina patagonica & 0,3 & 0,0 & 0,4 & 0,0 & 0,0 & 0,3 & 0,8 & 0,3 & 0,0 & 0,0 & 0,0 & 0,0 & 0,0 & 0,0 & 0,8 & 0,0 & 0,5 & 0,0 & 0,0 & 0,0 & 0,4 & 0,0 & 0,0 & 0,0 & 0,2 & 0,4 & 0,9 & 0,0 & 0,0 \\
\hline Quinqueloculina polygona & 0,7 & 0,3 & 0,0 & 0,0 & 0,0 & 0,0 & 0,4 & 0,3 & 0,2 & 0,0 & 0,0 & 0,0 & 0,0 & 0,0 & 0,0 & 0,0 & 0,0 & 0,0 & 0,0 & 0,0 & 0,0 & 0,0 & 0,0 & 0,0 & 0,2 & 0,0 & 0,6 & 0,0 & 0,0 \\
\hline Quinqueloculina seminula & 0,0 & 1,1 & 0,7 & 0,3 & 0,0 & 0,7 & 1,2 & 0,9 & 0,0 & 0,0 & 0,0 & 0,3 & 0,0 & 0,0 & 0,0 & 0,0 & 0,3 & 0,0 & 0,0 & 0,0 & 0,0 & 0,0 & 0,3 & 0,0 & 0,2 & 0,0 & 0,0 & 0,0 & 0,0 \\
\hline Quinqueloculina sp. & 0,7 & 1,1 & 0,7 & 0,6 & 0,0 & 0,3 & 0,4 & 0,9 & 0,0 & 0,0 & 0,0 & 0,0 & 0,0 & 0,0 & 0,8 & 0,3 & 0,5 & 0,7 & 0,0 & 0,0 & 1,2 & 0,0 & 0,3 & 0,0 & 0,7 & 0,4 & 0,0 & 0,0 & 0,3 \\
\hline Reophax curtus & 0,0 & 0,0 & 0,0 & 0,0 & 0,0 & 0,0 & 0,0 & 0,0 & 0,0 & 0,0 & 0,0 & 0,3 & 0,6 & 0,3 & 0,4 & 0,9 & 0,0 & 0,0 & 0,3 & 0,0 & 0,8 & 0,8 & 0,7 & 0,0 & 0,0 & 0,0 & 0,6 & 0,0 & 0,0 \\
\hline Reophax dentaliformis & 0,0 & 0,0 & 0,0 & 0,0 & 0,0 & 0,0 & 0,0 & 0,0 & 0,0 & 0,0 & 0,0 & 0,0 & 0,0 & 0,0 & 0,0 & 0,0 & 0,0 & 0,0 & 0,0 & 5,7 & 0,0 & 0,0 & 0,0 & 0,0 & 0,0 & 0,0 & 0,0 & 0,9 & 0,7 \\
\hline Reophax gracilis & 0,0 & 0,0 & 0,0 & 0,0 & 0,0 & 0,0 & 0,0 & 0,0 & 0,0 & 0,0 & 0,0 & 0,0 & 0,0 & 0,0 & 0,0 & 0,0 & 0,0 & 0,0 & 0,0 & 0,7 & 0,0 & 0,0 & 0,0 & 0,0 & 0,0 & 0,0 & 0,0 & 0,0 & 0,0 \\
\hline Reophax scorpiurus & 0,0 & 0,0 & 0,0 & 0,0 & 0,0 & 0,0 & 0,0 & 0,0 & 0,0 & 0,0 & 0,9 & 0,0 & 0,0 & 0,0 & 0,0 & 0,0 & 0,0 & 0,0 & 0,0 & 0,4 & 0,4 & 0,0 & 0,0 & 0,2 & 0,2 & 0,0 & 0,3 & 0,2 & 0,3 \\
\hline Reophax sp & 0,0 & 0,0 & 0,0 & 0,0 & 0,0 & 0,0 & 0,0 & 0,0 & 0,0 & 0,0 & 0,0 & 0,0 & 0,0 & 0,3 & 0,0 & 0,0 & 0,0 & 0,0 & 0,0 & 0,4 & 0,0 & 0,0 & 0,3 & 1,3 & 0,0 & 0,4 & 0,0 & 0,2 & 0,0 \\
\hline Robertinoides bradyi & 0,0 & 0,0 & 0,0 & 0,0 & 0,0 & 0,0 & 0,0 & 0,0 & 0,0 & 0,0 & 0,0 & 0,0 & 0,0 & 0,0 & 0,0 & 0,0 & 0,0 & 0,0 & 0,0 & 0,0 & 0,0 & 0,0 & 0,0 & 0,2 & 0,0 & 0,0 & 0,0 & 0,0 & 0,0 \\
\hline Rolshausheni rolshauseni & 1,3 & 0,6 & 4,6 & 1,1 & 1,1 & 0,3 & 3,5 & 8,3 & 0,7 & 0,7 & 0,6 & 0,8 & 0,6 & 0,0 & 1,1 & 0,6 & 1,9 & 0,3 & 0,0 & 0,0 & 2,3 & 0,3 & 0,0 & 0,0 & 0,2 & 0,7 & 2,0 & 0,2 & 0,0 \\
\hline Rosalina floridensis & 0,7 & 1,1 & 2,5 & 0,6 & 1,1 & 1,0 & 2,7 & 2,7 & 1,1 & 0,7 & 0,9 & 1,1 & 1,5 & 0,7 & 1,5 & 1,8 & 1,9 & 0,7 & 1,9 & 0,0 & 1,5 & 1,0 & 0,7 & 0,2 & 2,3 & 0,7 & 2,3 & 0,5 & 0,0 \\
\hline Rosalina vilardeboana & 0,0 & 0,0 & 0,0 & 0,0 & 0,0 & 0,0 & 0,0 & 0,0 & 0,0 & 0,0 & 0,0 & 0,0 & 0,3 & 0,0 & 0,0 & 0,0 & 0,0 & 0,0 & 0,0 & 0,0 & 0,0 & 0,0 & 0,0 & 0,0 & 0,2 & 0,0 & 0,0 & 0,0 & 0,0 \\
\hline
\end{tabular}


Anexo 25 - Continuação

\begin{tabular}{|c|c|c|c|c|c|c|c|c|c|c|c|c|c|c|c|c|c|c|c|c|c|c|c|c|c|c|c|c|c|}
\hline \multirow[b]{2}{*}{ Estação } & \multicolumn{9}{|c|}{ Junho de 2005} & \multicolumn{10}{|c|}{ Abril de 2006} & \multicolumn{10}{|c|}{ Setembro de 2006} \\
\hline & $\mathrm{Ar} 2$ & Ar2 & $\mathrm{Ar} 3$ & Ar5 & Ar6 & Ar7 & Ar8 & Ar9 & Ar10 & Ar1 & $\operatorname{Ar} 2$ & Ar3 & Ar4 & Ar5 & Ar6 & Ar7 & Ar8 & $\operatorname{Ar} 9$ & Ar10 & Ar1 & Ar2 & $\mathrm{Ar} 3$ & $\mathrm{Ar} 4$ & $\operatorname{Ar} 5$ & Ar6 & Ar7 & Ar8 & Ar9 & $\operatorname{Ar} 10$ \\
\hline Rosalina $s p$ & 0,0 & 0,0 & 0,0 & 0,0 & 0,0 & 0,0 & 1,6 & 0,6 & 0,2 & 0,0 & 0,0 & 0,0 & 0,0 & 0,0 & 0,0 & 0,0 & 0,0 & 0,0 & 0,0 & 0,0 & 0,4 & 0,0 & 0,0 & 0,0 & 0,2 & 0,0 & 0,0 & 0,0 & 0,0 \\
\hline Sigmoilopsis schlumbergeri & 0,0 & 0,0 & 0,0 & 0,0 & 0,0 & 0,0 & 0,0 & 0,0 & 0,0 & 0,0 & 0,0 & 0,0 & 0,0 & 0,0 & 0,0 & 0,0 & 0,3 & 0,0 & 0,0 & 0,0 & 0,0 & 0,0 & 0,0 & 0,0 & 0,0 & 0,0 & 0,0 & 0,0 & 0,0 \\
\hline Sigmomorphina pauperata & 0,0 & 0,0 & 0,0 & 0,0 & 0,0 & 0,0 & 0,0 & 0,0 & 0,0 & 0,0 & 0,0 & 0,0 & 0,0 & 0,0 & 0,8 & 0,0 & 0,0 & 0,0 & 0,0 & 0,0 & 0,0 & 0,0 & 0,0 & 0,0 & 0,0 & 0,0 & 0,0 & 0,0 & 0,0 \\
\hline Siphogenerina repandus & 0,0 & 0,0 & 0,0 & 0,3 & 0,0 & 0,0 & 0,0 & 0,0 & 0,0 & 0,0 & 0,0 & 0,0 & 0,0 & 0,0 & 0,0 & 0,0 & 0,0 & 0,0 & 0,0 & 0,0 & 0,0 & 0,3 & 0,0 & 0,0 & 0,0 & 0,0 & 0,0 & 0,0 & 0,0 \\
\hline Siphotextularia sp & 0,0 & 0,0 & 0,0 & 0,0 & 0,0 & 0,0 & 0,0 & 0,0 & 0,0 & 0,0 & 0,0 & 0,0 & 0,0 & 0,0 & 0,0 & 0,0 & 0,0 & 0,0 & 0,0 & 0,0 & 0,0 & 0,0 & 0,0 & 0,0 & 0,2 & 0,0 & 0,0 & 0,0 & 0,0 \\
\hline Siphotrochammina lobata & 0,0 & 0,0 & 0,0 & 0,0 & 0,0 & 0,0 & 0,0 & 0,0 & 0,0 & 0,7 & 0,0 & 0,0 & 0,3 & 0,0 & 0,0 & 0,0 & 0,0 & 0,0 & 0,0 & 0,0 & 0,0 & 0,0 & 0,0 & 0,0 & 0,0 & 0,0 & 0,0 & 0,0 & 0,0 \\
\hline Spirilina vivipara & 0,3 & 0,0 & 0,0 & 0,0 & 0,0 & 0,0 & 0,0 & 0,0 & 0,0 & 0,0 & 0,0 & 0,0 & 0,0 & 0,0 & 0,0 & 0,0 & 0,0 & 0,0 & 0,0 & 0,0 & 0,0 & 0,0 & 0,0 & 0,0 & 0,2 & 0,0 & 0,0 & 0,0 & 0,0 \\
\hline Spirobolivina sp & 0,0 & 0,0 & 0,0 & 0,0 & 0,0 & 0,0 & 0,0 & 0,0 & 0,0 & 0,7 & 0,0 & 0,5 & 0,3 & 0,0 & 0,0 & 0,0 & 0,0 & 0,0 & 0,3 & 0,0 & 0,0 & 0,0 & 0,0 & 0,0 & 0,0 & 0,4 & 0,0 & 0,0 & 0,0 \\
\hline Spiroculina ornata & 0,0 & 0,0 & 0,4 & 0,0 & 0,0 & 0,0 & 0,0 & 0,0 & 0,0 & 0,0 & 0,0 & 0,0 & 0,0 & 0,0 & 0,0 & 0,0 & 0,0 & 0,0 & 0,0 & 0,0 & 0,0 & 0,0 & 0,0 & 0,0 & 0,0 & 0,0 & 0,0 & 0,0 & 0,0 \\
\hline Spiroculina planulata & 0,0 & 0,0 & 0,0 & 0,0 & 0,0 & 0,0 & 0,0 & 0,0 & 0,0 & 0,0 & 0,0 & 0,0 & 0,0 & 0,0 & 0,0 & 0,0 & 0,0 & 0,0 & 0,0 & 0,0 & 0,0 & 0,0 & 0,0 & 0,0 & 0,0 & 0,4 & 0,3 & 0,0 & 0,0 \\
\hline Spriroplectamina biformis & 0,0 & 0,0 & 0,0 & 0,3 & 0,0 & 0,0 & 0,0 & 0,0 & 0,0 & 0,0 & 0,0 & 0,0 & 0,3 & 0,0 & 0,0 & 0,0 & 0,0 & 0,3 & 0,0 & 0,0 & 0,4 & 0,0 & 0,3 & 0,0 & 0,0 & 0,0 & 0,0 & 0,0 & 0,3 \\
\hline Stainphortia concava & 0,0 & 0,3 & 0,4 & 0,3 & 0,0 & 0,0 & 0,0 & 0,0 & 0,0 & 0,0 & 0,0 & 0,0 & 0,3 & 0,3 & 0,0 & 0,0 & 0,0 & 0,0 & 0,5 & 0,0 & 0,0 & 0,3 & 0,3 & 0,2 & 0,0 & 0,0 & 0,6 & 0,2 & 0,0 \\
\hline Stainforthia fusiformis & 0,0 & 0,0 & 0,0 & 0,0 & 0,0 & 0,0 & 0,0 & 0,0 & 0,0 & 0,0 & 0,0 & 0,0 & 0,0 & 0,0 & 0,0 & 0,0 & 0,0 & 0,0 & 0,0 & 0,0 & 0,0 & 0,0 & 0,0 & 0,2 & 0,0 & 0,0 & 0,0 & 0,0 & 0,0 \\
\hline Stainforthia sp & 0,0 & 0,0 & 0,0 & 0,0 & 0,0 & 0,0 & 0,0 & 0,0 & 0,0 & 0,0 & 0,0 & 0,0 & 0,0 & 0,0 & 0,0 & 0,0 & 0,0 & 0,0 & 0,8 & 0,0 & 0,0 & 0,0 & 0,0 & 0,0 & 0,0 & 0,0 & 0,0 & 0,0 & 0,0 \\
\hline Textularia aglutinans & 0,0 & 0,0 & 0,0 & 0,0 & 0,0 & 0,0 & 0,4 & 0,0 & 0,0 & 0,0 & 0,0 & 0,0 & 0,3 & 0,3 & 0,4 & 0,0 & 0,0 & 0,0 & 0,0 & 0,0 & 0,0 & 0,0 & 0,0 & 0,0 & 0,2 & 0,0 & 0,0 & 0,0 & 0,0 \\
\hline Textularia candeiana & 0,0 & 0,0 & 0,0 & 0,0 & 0,0 & 0,0 & 0,0 & 0,0 & 0,0 & 0,0 & 0,0 & 0,0 & 0,0 & 0,0 & 0,0 & 0,0 & 0,0 & 0,0 & 0,3 & 0,0 & 0,0 & 0,0 & 0,0 & 0,0 & 0,2 & 0,0 & 0,3 & 0,5 & 0,0 \\
\hline Textularia earlandi & 0,3 & 0,6 & 0,0 & 0,3 & 0,0 & 0,0 & 0,0 & 0,0 & 0,0 & 0,0 & 0,0 & 0,3 & 0,0 & 0,0 & 0,4 & 0,3 & 0,0 & 0,0 & 0,8 & 6,4 & 0,4 & 0,0 & 0,0 & 0,2 & 0,0 & 0,4 & 0,0 & 0,2 & 0,7 \\
\hline Textularia foliacea & 0,0 & 0,0 & 0,0 & 0,0 & 0,0 & 0,0 & 0,0 & 0,0 & 0,0 & 0,0 & 0,0 & 0,0 & 0,0 & 0,0 & 0,0 & 0,0 & 0,0 & 0,0 & 0,0 & 0,4 & 0,0 & 0,0 & 0,0 & 0,0 & 0,0 & 0,0 & 0,0 & 0,0 & 0,0 \\
\hline Textularia gramen & 0,0 & 0,0 & 0,4 & 0,0 & 0,0 & 0,0 & 0,0 & 0,0 & 0,0 & 0,0 & 0,0 & 0,0 & 0,3 & 0,3 & 0,0 & 0,0 & 0,3 & 0,0 & 0,0 & 0,0 & 0,0 & 0,0 & 0,0 & 0,0 & 0,2 & 0,0 & 0,0 & 0,0 & 0,0 \\
\hline Textularia $s p$ & 0,7 & 1,4 & 0,4 & 2,3 & 0,4 & 0,7 & 0,4 & 0,0 & 0,7 & 0,0 & 0,0 & 0,3 & 0,6 & 0,7 & 1,1 & 0,3 & 0,0 & 0,0 & 0,3 & 1,8 & 0,0 & 0,0 & 0,0 & 0,4 & 0,0 & 1,1 & 0,6 & 0,2 & 1,0 \\
\hline Triloculina baldai & 0,0 & 0,0 & 0,0 & 0,0 & 0,0 & 0,0 & 0,0 & 0,0 & 0,0 & 0,0 & 0,0 & 0,0 & 0,0 & 0,0 & 0,0 & 0,3 & 0,0 & 0,0 & 0,0 & 0,0 & 0,0 & 0,0 & 0,0 & 0,0 & 0,0 & 0,0 & 0,0 & 0,0 & 0,0 \\
\hline Triloculina cultrata & 0,0 & 0,0 & 0,0 & 0,0 & 0,0 & 0,0 & 0,0 & 0,0 & 0,0 & 0,0 & 0,0 & 0,0 & 0,0 & 0,0 & 0,0 & 0,0 & 0,0 & 0,0 & 0,0 & 0,0 & 0,0 & 0,0 & 0,0 & 0,0 & 0,0 & 0,0 & 0,0 & 0,0 & 0,0 \\
\hline Triloculina laevigata & 0,0 & 0,6 & 0,0 & 0,0 & 0,0 & 0,0 & 0,0 & 0,0 & 0,0 & 0,0 & 0,3 & 0,0 & 0,0 & 0,0 & 0,0 & 0,6 & 0,3 & 0,0 & 0,0 & 0,0 & 0,0 & 0,0 & 0,0 & 0,0 & 0,2 & 0,0 & 0,3 & 0,0 & 0,0 \\
\hline Triloculina oblonga & 2,0 & 0,6 & 0,4 & 0,3 & 0,0 & 0,3 & 0,4 & 0,6 & 0,2 & 0,0 & 0,0 & 0,0 & 0,0 & 0,0 & 0,8 & 0,3 & 0,0 & 0,0 & 0,0 & 0,0 & 0,8 & 0,0 & 0,0 & 0,0 & 0,7 & 0,4 & 0,3 & 0,0 & 0,0 \\
\hline Triloculina trigonula & 0,0 & 0,0 & 0,4 & 0,0 & 0,0 & 0,0 & 0,0 & 0,0 & 0,0 & 0,0 & 0,0 & 0,0 & 0,0 & 0,0 & 0,8 & 0,0 & 0,0 & 0,0 & 0,0 & 0,0 & 0,0 & 0,0 & 0,0 & 0,0 & 0,0 & 0,0 & 0,0 & 0,0 & 0,0 \\
\hline Triloculina $s p$ & 0,0 & 0,3 & 0,0 & 0,0 & 0,0 & 0,3 & 0,0 & 0,0 & 0,0 & 0,0 & 0,0 & 0,0 & 0,0 & 0,0 & 0,0 & 0,0 & 0,0 & 0,0 & 0,0 & 0,0 & 0,0 & 0,0 & 0,0 & 0,0 & 0,0 & 0,0 & 0,0 & 0,0 & 0,0 \\
\hline Trochammina inflata & 0,0 & 0,0 & 0,0 & 0,0 & 0,0 & 0,0 & 0,0 & 0,0 & 0,0 & 0,0 & 0,0 & 0,3 & 0,0 & 0,0 & 0,0 & 0,0 & 0,3 & 0,0 & 0,0 & 0,4 & 0,0 & 0,0 & 0,0 & 0,0 & 0,0 & 0,0 & 0,0 & 0,0 & 0,0 \\
\hline Trochammina macrescens & 0,0 & 0,0 & 0,0 & 0,0 & 0,4 & 0,0 & 0,0 & 0,0 & 0,0 & 0,0 & 0,0 & 0,0 & 0,0 & 0,0 & 0,0 & 0,0 & 0,0 & 0,0 & 0,0 & 0,0 & 0,0 & 0,0 & 0,0 & 0,0 & 0,0 & 0,0 & 0,0 & 0,0 & 0,0 \\
\hline Trochammina ochracea & 0,0 & 0,0 & 0,0 & 0,3 & 0,0 & 0,7 & 0,4 & 0,0 & 0,0 & 0,0 & 0,0 & 0,0 & 0,0 & 0,0 & 0,0 & 0,0 & 0,0 & 0,0 & 0,0 & 0,0 & 0,0 & 0,0 & 0,0 & 0,0 & 0,0 & 0,0 & 0,0 & 0,0 & 0,0 \\
\hline Trochammina salsa & 0,0 & 0,0 & 0,0 & 0,0 & 0,0 & 0,0 & 0,0 & 0,0 & 0,0 & 0,7 & 0,0 & 0,0 & 0,0 & 0,0 & 0,0 & 0,0 & 0,0 & 0,0 & 0,0 & 0,0 & 0,0 & 0,0 & 0,0 & 0,0 & 0,0 & 0,0 & 0,0 & 0,0 & 0,0 \\
\hline
\end{tabular}


Anexo 25 - Continuação

\begin{tabular}{|c|c|c|c|c|c|c|c|c|c|c|c|c|c|c|c|c|c|c|c|c|c|c|c|c|c|c|c|c|c|}
\hline \multirow[b]{2}{*}{ Estação } & \multicolumn{9}{|c|}{ Junho de 2005} & \multicolumn{10}{|c|}{ Abril de 2006} & \multicolumn{10}{|c|}{ Setembro de 2006} \\
\hline & Ar2 & Ar2 & Ar3 & Ar5 & Ar6 & Ar7 & Ar8 & $\operatorname{Ar} 9$ & $\operatorname{Ar} 10$ & Ar1 & Ar2 & Ar3 & $\mathrm{Ar} 4$ & Ar5 & Ar6 & $\operatorname{Ar} 7$ & Ar8 & Ar9 & $\operatorname{Ar} 10$ & Ar1 & $\mathrm{Ar} 2$ & $\mathrm{Ar} 3$ & $\mathrm{Ar} 4$ & Ar5 & Ar6 & Ar7 & Ar8 & Ar9 & Ar10 \\
\hline Trochammina squamata & 0,0 & 0,0 & 0,0 & 0,0 & 0,0 & 0,0 & 0,0 & 0,0 & 0,0 & 0,0 & 0,0 & 0,0 & 0,0 & 0,0 & 0,4 & 0,0 & 0,0 & 0,0 & 0,0 & 0,4 & 0,4 & 0,0 & 0,0 & 0,0 & 0,0 & 0,0 & 0,0 & 0,0 & 0,0 \\
\hline Trochammina $s p$ & 0,0 & 0,0 & 0,0 & 0,0 & 0,0 & 0,0 & 0,0 & 0,0 & 0,0 & 0,0 & 0,3 & 0,0 & 0,6 & 0,0 & 0,0 & 0,6 & 0,5 & 0,0 & 0,0 & 0,4 & 0,0 & 0,0 & 0,0 & 0,0 & 0,0 & 0,0 & 0,0 & 0,2 & 0,0 \\
\hline Uvigerina peregrina & 0,0 & 0,0 & 0,0 & 0,3 & 0,4 & 0,0 & 0,0 & 0,3 & 0,0 & 0,0 & 0,3 & 0,0 & 0,0 & 0,0 & 0,4 & 0,0 & 0,0 & 0,0 & 0,0 & 0,0 & 0,0 & 0,0 & 0,0 & 0,2 & 0,0 & 0,0 & 0,0 & 0,0 & 0,0 \\
\hline Uvigerina striata & 0,0 & 0,0 & 0,0 & 0,0 & 0,0 & 0,0 & 0,0 & 0,0 & 0,0 & 0,0 & 0,0 & 0,3 & 0,0 & 0,0 & 0,0 & 0,0 & 0,0 & 0,0 & 0,0 & 0,0 & 0,0 & 0,3 & 0,3 & 0,2 & 0,0 & 0,0 & 0,3 & 0,2 & 0,3 \\
\hline Warrenita palustris & 0,0 & 0,0 & 0,0 & 0,3 & 0,0 & 0,0 & 0,0 & 0,0 & 0,0 & 0,0 & 0,0 & 0,0 & 0,0 & 0,0 & 0,0 & 0,0 & 0,0 & 0,0 & 0,0 & 0,0 & 0,0 & 0,0 & 0,0 & 0,0 & 0,0 & 0,0 & 0,0 & 0,0 & 0,0 \\
\hline Wiesnerella auriculata & 0,0 & 0,0 & 0,0 & 0,0 & 0,0 & 0,0 & 0,0 & 0,0 & 0,0 & 0,7 & 0,3 & 0,3 & 0,3 & 0,3 & 0,8 & 0,0 & 0,0 & 0,0 & 0,0 & 0,0 & 0,0 & 0,0 & 0,0 & 0,0 & 0,0 & 0,0 & 0,0 & 0,0 & 0,0 \\
\hline Indeterminado & 0,0 & 0,0 & 0,0 & 0,0 & 0,0 & 0,0 & 0,0 & 0,0 & 0,0 & 3,5 & 2,3 & 0,5 & 0,9 & 0,7 & 0,8 & 1,2 & 0,3 & 0,3 & 0,8 & 2,5 & 1,2 & 0,5 & 1,0 & 1,9 & 1,4 & 2,2 & 0,9 & 1,4 & 2,0 \\
\hline Fragmento & 1,6 & 1,7 & 2,5 & 6,0 & 5,2 & 4,5 & 4,3 & 4,5 & 3,9 & 4,3 & 2,3 & 2,1 & 2,1 & 1,7 & 0,8 & 0,6 & 2,1 & 1,3 & 1,6 & 4,6 & 1,9 & 0,8 & 4,1 & 2,5 & 1,8 & 2,6 & 5,5 & 0,7 & 1,3 \\
\hline
\end{tabular}

\begin{tabular}{lllllllllll}
\hline Densidade & 614 & 706 & 568 & 2791 & 1084 & 1144 & 516 & 676 & 882
\end{tabular}

$\begin{array}{llllllllll}\text { Fração analisada } & 1 / 2 & 1 / 2 & 1 / 2 & 1 / 8 & 1 / 4 & 1 / 4 & 1 / 2 & 1 / 2 & 1 / 2\end{array}$

$\begin{array}{lllllllllll}141 & 700 & 2992 & 2648 & 9568 & 530 & 1308 & 3016 & 2440 & 736\end{array}$

$\begin{array}{llllllllll}1120 & 259 & 6208 & 9344 & 15072 & 3520 & 8672 & 5552 & 6928 & 19584\end{array}$

Riqueza

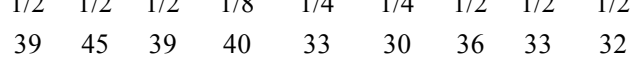

$\begin{array}{llllllllll}1 & 1 / 2 & 1 / 8 & 1 / 8 & 1 / 32 & 1 / 2 & 1 / 4 & 1 / 8 & 1 / 8 & 1 / 2\end{array}$

$\begin{array}{lllllllllll}1 / 4 & 1 / 2 & 1 / 16 & 1 / 32 & 1 / 32 & 1 / 8 & 1 / 32 & 1 / 16 & 1 / 16 & 1 / 64\end{array}$

Diversidade específica

$\begin{array}{lllllllll}2,9 & 3 & 3 & 2,77 & 2,69 & 2,46 & 3 & 2,7 & 2,5\end{array}$

$\begin{array}{llllllllll}24 & 40 & 44 & 44 & 41 & 51 & 49 & 51 & 39 & 40\end{array}$

$\begin{array}{llllllllll}28 & 55 & 41 & 48 & 51 & 65 & 49 & 60 & 53 & 43\end{array}$

Equitatividade

$\begin{array}{lllllllllllllllllll}0,8 & 0,8 & 0,8 & 0,74 & 0,76 & 0,72 & 0,8 & 0,8 & 0,7 & 0,7 & 0,7 & 0,73 & 0,75 & 0,74 & 0,8 & 0,75 & 0,8 & 0,76 & 0,8\end{array}$

$\begin{array}{llllllllll}2,5 & 3,1 & 2,76 & 3,19 & 2,91 & 3,08 & 3,12 & 3,23 & 2,99 & 2,81\end{array}$

\begin{tabular}{llllllllll}
0,74 & 0,8 & 0,74 & 0,82 & 0,73 & 0,73 & 0,79 & 0,78 & 0,75 & 0,74 \\
\hline
\end{tabular} 
Anexo 26 - (Tanatocenoses) Distribuição de espécies bioindicadoras de ambiente óxico e enriquecido por matéria orgânica identificadas próximo ao emissário do Araçá.

Valores em porcentagem.

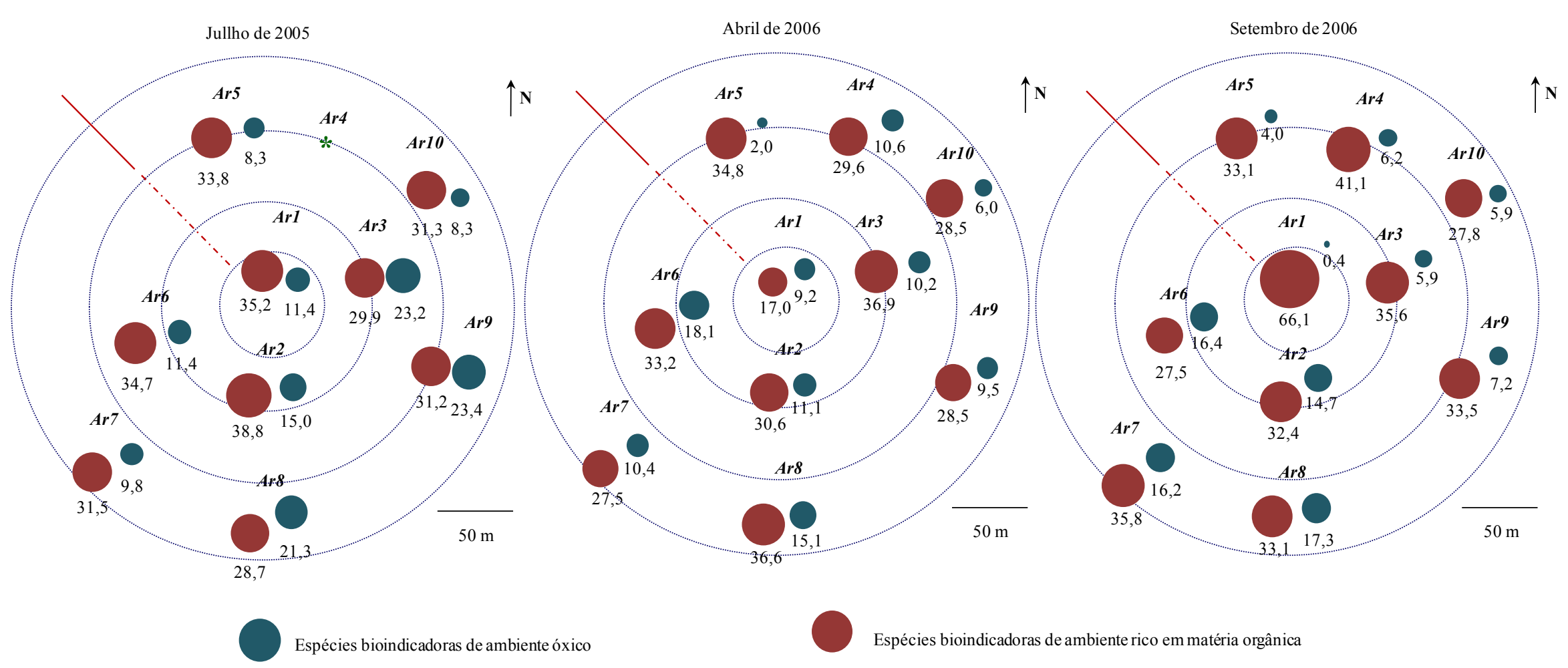

* Estação não amostrada 
Anexo 27 - (Tanatocenoses) Resultado das análises morfométricas realizadas nas carapaças dos foraminíferos obtidas próximo ao emissário do Araçá.

Valores em porcentagem.

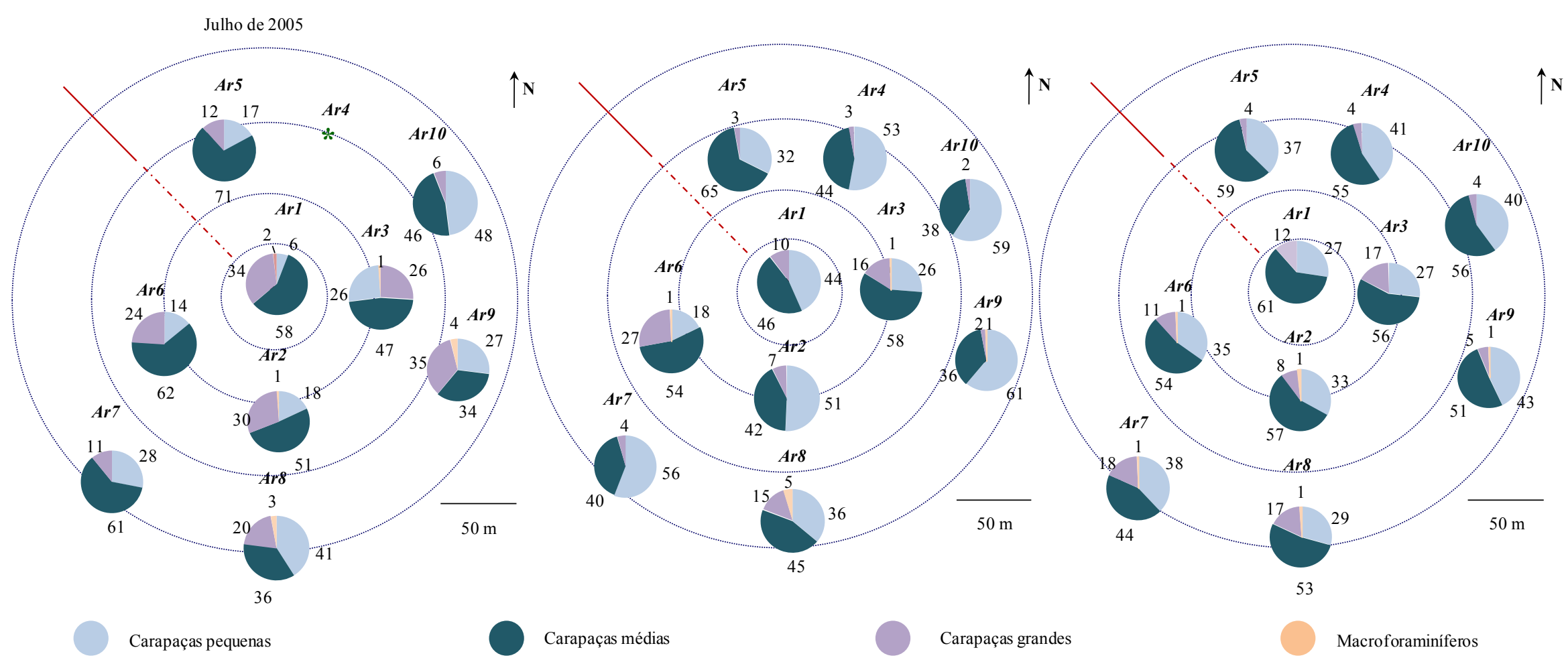

* Estação não amostrada 
Anexo 28 - Grau de preservação das carapaças que compuseram as tanatocenoses.

Valores em porcentagens.

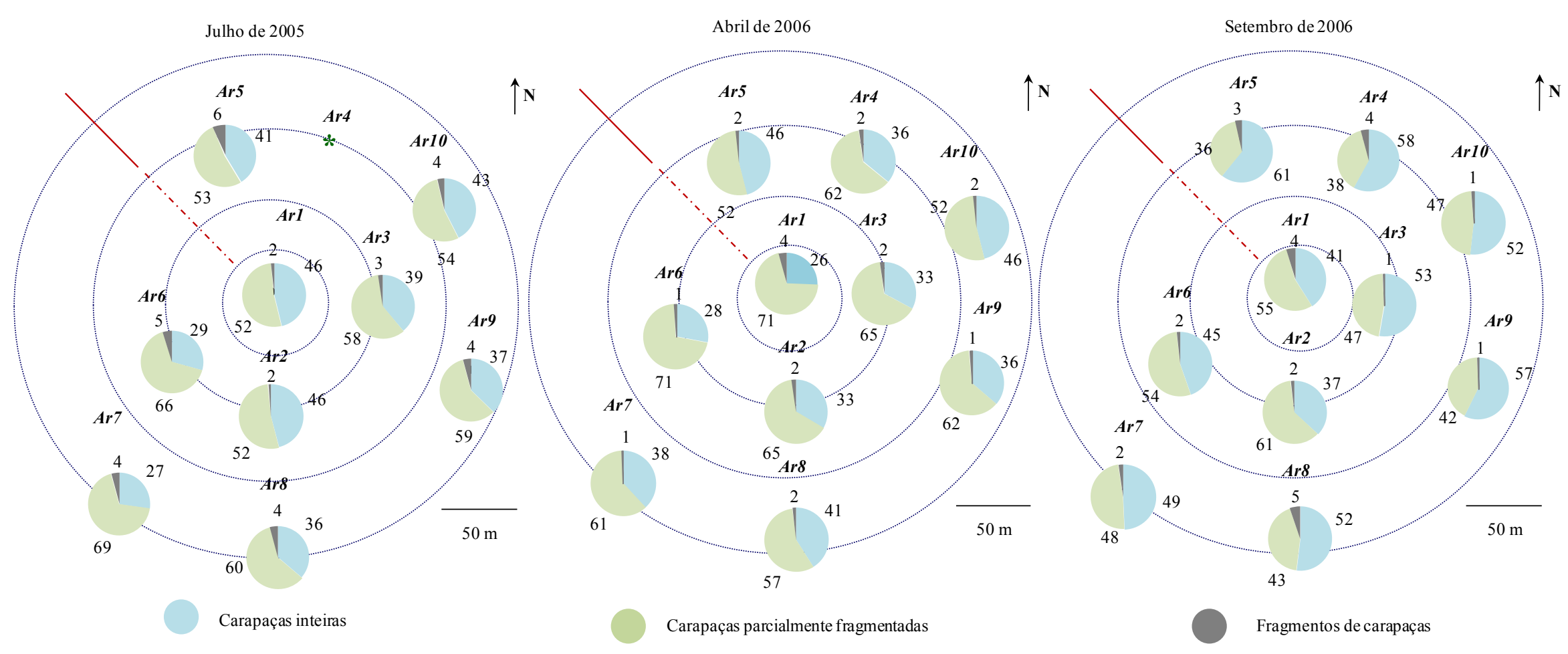

* Estação não amostrada 
Anexo 29 - Estado de preservação e coloração das carapaças dos foraminíferos que compuseram as tanatocenoses.

Valores em porcentagens.

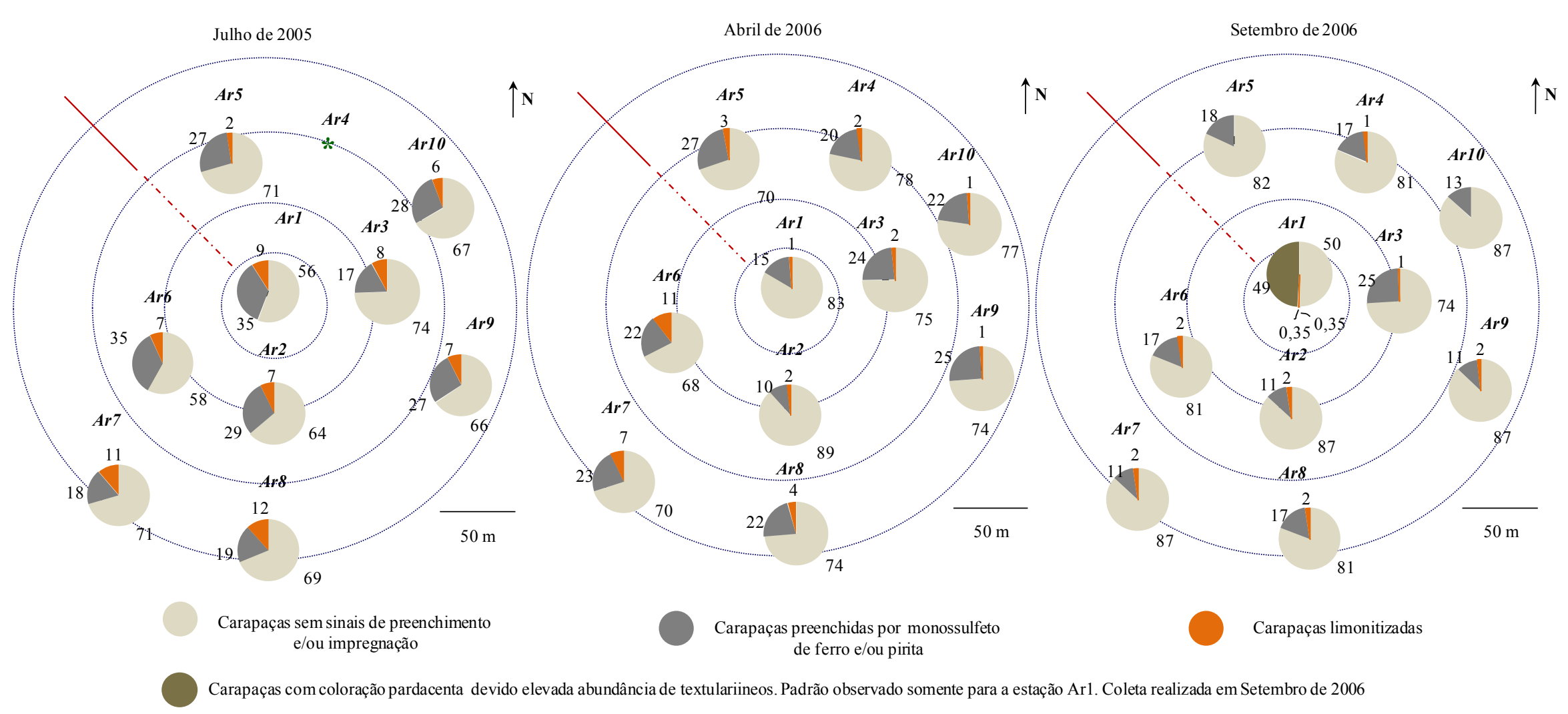

* Estação não amostrada 
Anexo 30 - Matriz de correlação de Pearson obtida para os dados bióticos e abióticos obtidos no Araçá, em Junho de 2005.

Níveis de significância: $p<0,01$ (em vermelho) e $p<0,05$ (em negrito)

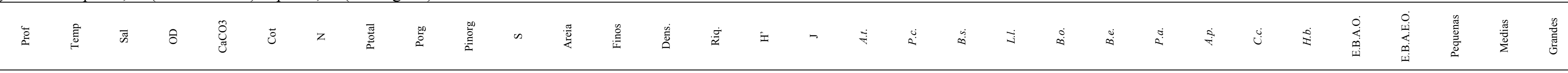

\begin{tabular}{|c|c|c|c|c|c|c|c|c|c|c|c|c|c|c|c|c|c|c|c|c|c|c|c|c|c|c|c|c|c|c|c|c|}
\hline Prof & 1 & & & & & & & & & & & & & & & & & & & & & & & & & & & & & & & \\
\hline Temp & $-0,40$ & 1 & & & & & & & & & & & & & & & & & & & & & & & & & & & & & & \\
\hline Sal & 0,81 & $-0,33$ & 1 & & & & & & & & & & & & & & & & & & & & & & & & & & & & & \\
\hline OD & $-0,63$ & 0,75 & $-0,77$ & 1 & & & & & & & & & & & & & & & & & & & & & & & & & & & & \\
\hline $\mathrm{CaCO}_{3}$ & 0,46 & $-0,81$ & 0,35 & $-0,66$ & 1 & & & & & & & & & & & & & & & & & & & & & & & & & & & \\
\hline Cot & 0,68 & $-0,57$ & 0,77 & $-0,68$ & 0,64 & 1 & & & & & & & & & & & & & & & & & & & & & & & & & & \\
\hline $\mathrm{N}$ & $-0,09$ & $-0,55$ & 0,19 & $-0,44$ & 0,58 & 0,42 & 1 & & & & & & & & & & & & & & & & & & & & & & & & & \\
\hline Ptotal & 0,82 & $-0,53$ & 0,94 & $-0,89$ & 0,49 & 0,82 & 0,29 & 1 & & & & & & & & & & & & & & & & & & & & & & & & \\
\hline Porg & 0,74 & $-0,17$ & 0,79 & $-0,41$ & 0,13 & 0,60 & 0,16 & 0,71 & 1 & & & & & & & & & & & & & & & & & & & & & & & \\
\hline Pinorg & 0,68 & $-0,58$ & 0,81 & $-0,94$ & 0,57 & 0,76 & 0,29 & 0,93 & 0,39 & 1 & & & & & & & & & & & & & & & & & & & & & & \\
\hline s & 0,42 & 0,05 & 0,34 & 0,10 & $-0,11$ & 0,31 & 0,05 & 0,23 & 0,83 & $-0,14$ & 1 & & & & & & & & & & & & & & & & & & & & & \\
\hline Areia & $-0,70$ & $-0,08$ & $-0,44$ & 0,04 & 0,08 & $-0,28$ & 0,26 & $-0,40$ & $-0,78$ & $-0,11$ & $-0,82$ & 1 & & & & & & & & & & & & & & & & & & & & \\
\hline Finos & 0,52 & 0,21 & 0,40 & 0,07 & $-0,24$ & 0,17 & $-0,16$ & 0,30 & 0,82 & $-0,05$ & 0,90 & $-0,95$ & 1 & & & & & & & & & & & & & & & & & & & \\
\hline Dens. & $-0,74$ & $-0,03$ & $-0,51$ & 0,03 & $-0,07$ & $-0,42$ & 0,36 & $-0,35$ & $-0,73$ & $-0,08$ & $-0,74$ & 0,80 & $-0,72$ & 1 & & & & & & & & & & & & & & & & & & \\
\hline Riq. & $-0,48$ & 0,15 & $-0,21$ & $-0,04$ & $-0,03$ & $-0,34$ & 0,07 & $-0,23$ & $-0,68$ & 0,07 & $-0,87$ & 0,77 & $-0,75$ & $\mathbf{0 , 7 0}$ & 1 & & & & & & & & & & & & & & & & & \\
\hline H & 0,00 & $-0,02$ & 0,03 & $-0,23$ & 0,35 & $-0,07$ & $-0,09$ & 0,01 & $-0,49$ & 0,28 & $-0,78$ & 0,53 & $-0,66$ & 0,27 & 0,76 & 1 & & & & & & & & & & & & & & & & \\
\hline J & 0,44 & $-0,16$ & 0,27 & $-0,33$ & 0,54 & 0,21 & $-0,20$ & 0,24 & $-0,10$ & 0,38 & $-0,39$ & 0,11 & $-0,31$ & $-0,23$ & 0,27 & 0,83 & 1 & & & & & & & & & & & & & & & \\
\hline A.t. & $-0,37$ & 0,14 & $-0,01$ & 0,06 & $-0,54$ & $-0,19$ & 0,17 & $-0,05$ & 0,06 & $-0,10$ & 0,10 & 0,08 & 0,13 & 0,34 & 0,17 & $-0,46$ & $-0,81$ & 1 & & & & & & & & & & & & & & \\
\hline P.c. & 0,35 & $-0,42$ & 0,19 & $-0,05$ & 0,21 & 0,38 & 0,25 & 0,18 & 0,61 & $-0,10$ & 0,81 & $-0,55$ & 0,58 & $-0,57$ & $-0,79$ & $-0,72$ & $-0,38$ & 0,10 & 1 & & & & & & & & & & & & & \\
\hline B.s. & 0,21 & $-0,54$ & 0,54 & $-0,63$ & 0,27 & 0,50 & 0,58 & 0,58 & 0,37 & 0,55 & 0,09 & 0,01 & 0,04 & 0,10 & 0,12 & $-0,17$ & $-0,32$ & 0,63 & 0,31 & 1 & & & & & & & & & & & & \\
\hline L.l. & 0,19 & $-0,59$ & 0,40 & $-0,71$ & 0,67 & 0,29 & 0,59 & 0,43 & 0,02 & 0,55 & $-0,38$ & 0,36 & $-0,38$ & 0,26 & 0,49 & 0,57 & 0,44 & $-0,06$ & $-0,14$ & 0,53 & 1 & & & & & & & & & & & \\
\hline B.o. & 0,33 & $-0,36$ & 0,14 & $-0,14$ & 0,04 & 0,44 & $-0,22$ & 0,27 & 0,17 & 0,26 & 0,23 & $-0,31$ & 0,14 & $-0,30$ & $-0,47$ & $-0,44$ & $-0,25$ & 0,11 & 0,43 & 0,24 & $-0,41$ & 1 & & & & & & & & & & \\
\hline B.e. & 0,39 & 0,17 & 0,56 & $-0,34$ & $-0,34$ & 0,21 & $-0,17$ & 0,57 & 0,45 & 0,50 & 0,16 & $-0,46$ & 0,45 & $-0,12$ & $-0,02$ & $-0,20$ & $-0,24$ & 0,48 & $-0,15$ & 0,42 & $-0,09$ & 0,25 & 1 & & & & & & & & & \\
\hline P.a. & 0,21 & $-0,13$ & 0,48 & $-0,51$ & 0,03 & 0,27 & $-0,01$ & 0,48 & $-0,01$ & 0,63 & $-0,41$ & 0,17 & $-0,23$ & 0,17 & 0,57 & 0,41 & 0,15 & 0,40 & $-0,38$ & 0,64 & 0,43 & 0,16 & 0,62 & 1 & & & & & & & & \\
\hline A.p. & 0,47 & 0,00 & 0,26 & 0,18 & $-0,02$ & 0,30 & $-0,23$ & 0,11 & 0,58 & $-0,16$ & 0,77 & $-0,71$ & 0,68 & $-0,86$ & $-0,65$ & $-0,46$ & $-0,11$ & $-0,02$ & 0,76 & 0,09 & $-0,31$ & 0,41 & 0,02 & $-0,15$ & 1 & & & & & & & \\
\hline C.c. & $-0,52$ & 0,16 & $-0,38$ & 0,20 & 0,01 & $-0,01$ & 0,28 & $-0,25$ & $-0,46$ & $-0,08$ & $-0,35$ & 0,49 & $-0,47$ & 0,57 & 0,19 & 0,07 & $-0,10$ & $-0,16$ & $-0,43$ & $-0,32$ & $-0,21$ & $-0,10$ & $-0,22$ & $-0,26$ & $-0,62$ & 1 & & & & & & \\
\hline H.b. & 0,21 & $-0,73$ & 0,43 & $-0,64$ & 0,81 & 0,60 & 0,77 & 0,45 & 0,18 & 0,49 & $-0,08$ & 0,30 & $-0,30$ & 0,06 & 0,17 & 0,28 & 0,28 & $-0,09$ & 0,25 & 0,60 & 0,83 & $-0,12$ & $-0,29$ & 0,23 & $-0,01$ & $-0,09$ & 1 & & & & & \\
\hline E.B.A.O. & $-0,17$ & $-0,28$ & $-0,04$ & $-0,33$ & 0,51 & $-0,11$ & 0,36 & $-0,03$ & $-0,41$ & 0,18 & $-0,66$ & 0,66 & $-0,66$ & 0,45 & 0,69 & 0,80 & 0,60 & $-0,31$ & $-0,46$ & 0,02 & 0,82 & $-0,66$ & $-0,44$ & 0,16 & $-0,56$ & 0,07 & 0,58 & 1 & & & & \\
\hline E.B.A.E.E.O. & 0,43 & 0,22 & 0,27 & $-0,13$ & $-0,05$ & 0,23 & $-0,54$ & 0,32 & $-0,02$ & 0,44 & $-0,23$ & $-0,26$ & 0,03 & $-0,21$ & 0,09 & 0,34 & 0,43 & $-0,32$ & $-0,47$ & $-0,23$ & $-0,24$ & 0,34 & 0,52 & 0,43 & $-0,04$ & 0,10 & $-0,39$ & $-0,23$ & 1 & & & \\
\hline Pequenas & 0,22 & $-0,01$ & 0,30 & $-0,17$ & 0,38 & 0,08 & 0,38 & 0,16 & 0,35 & 0,03 & 0,21 & $-0,11$ & 0,21 & $-0,22$ & 0,02 & 0,28 & 0,40 & $-0,34$ & 0,06 & $-0,05$ & 0,54 & $-0,77$ & $-0,25$ & $-0,22$ & 0,05 & $-0,20$ & 0,46 & 0,54 & $-0,35$ & 1 & & \\
\hline Medias & $-0,17$ & 0,01 & $-0,25$ & 0,15 & $-0,37$ & $-0,04$ & $-0,35$ & $-0,10$ & $-0,29$ & 0,02 & $-0,17$ & 0,04 & $-0,14$ & 0,21 & $-0,05$ & $-0,32$ & $-0,44$ & 0,36 & $-0,06$ & 0,09 & $-0,55$ & 0,78 & 0,33 & 0,26 & $-0,04$ & 0,20 & $-0,47$ & $-0,59$ & 0,39 & $-0,99$ & 1 & \\
\hline Grandes & $-0,36$ & $-0,04$ & $-0,40$ & 0,25 & $-0,05$ & $-0,33$ & $-0,27$ & $-0,48$ & $-0,47$ & $-0,38$ & $-0,35$ & 0,57 & $-0,55$ & 0,11 & 0,18 & 0,28 & 0,25 & $-0,23$ & $-0,07$ & $-0,34$ & 0,01 & $-0,07$ & $-0,69$ & $-0,24$ & $-0,11$ & 0,00 & 0,06 & 0,35 & $-0,33$ & $-0,10$ & $-0,03$ & 1 \\
\hline
\end{tabular}

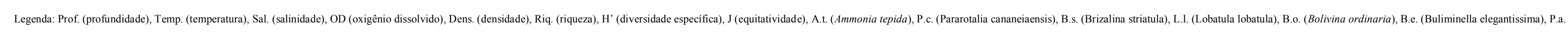

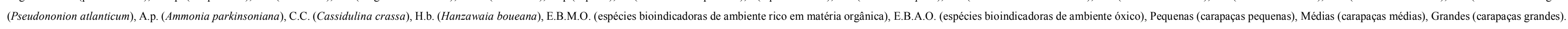


Anexo 31 - Matriz de correlação de Pearson obtida para os dados bióticos e abióticos obtidos no Araçá, em Abril de 2006. Níveis de significância: $p<0,01$ (em vermelho) e $p<0,05$ (em negrito)

\begin{tabular}{|c|c|c|c|c|c|c|c|c|c|c|c|c|c|c|c|c|c|c|c|c|c|c|c|c|c|c|c|c|c|c|c|c|c|}
\hline & 㟧 & 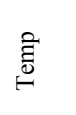 & $\overline{\tilde{n}}$ & ชิ & 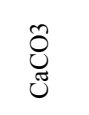 & $\overrightarrow{0}$ & z & 哭 & 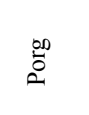 & 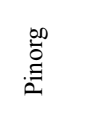 & n & 莺 & 总 & I & 雷 & $\stackrel{\dot{\mathscr{\Xi}}}{\stackrel{\Delta}{\tilde{D}}}$ & $\dot{\vec{\Xi}}$ & I & $r$ & $\dot{4}$ & 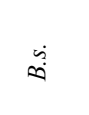 & نّ & 党 & 4 & 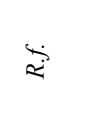 & d. & $\ddot{u}$ & نّ & $\ddot{d j}$ & $\overline{8}$ & $\stackrel{\circ}{\Sigma}$ & 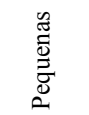 & 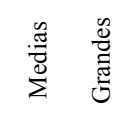 \\
\hline Prof & 1 & & & & & & & & & & & & & & & & & & & & & & & & & & & & & & & & \\
\hline Temp & $-0,91$ & 1 & & & & & & & & & & & & & & & & & & & & & & & & & & & & & & & \\
\hline Sal & $\mathbf{0 , 9 0}$ & $-0,99$ & 1 & & & & & & & & & & & & & & & & & & & & & & & & & & & & & & \\
\hline OD & $-0,92$ & 0,99 & $-0,97$ & 1 & & & & & & & & & & & & & & & & & & & & & & & & & & & & & \\
\hline $\mathrm{CaCO}_{3}$ & 0,84 & $-0,87$ & 0,81 & $-0,88$ & 1 & & & & & & & & & & & & & & & & & & & & & & & & & & & & \\
\hline Cot & 0,52 & $-0,54$ & 0,54 & $-0,54$ & 0,70 & 1 & & & & & & & & & & & & & & & & & & & & & & & & & & & \\
\hline $\mathrm{N}$ & 0,29 & $-0,37$ & 0,36 & $-0,35$ & 0,57 & 0,68 & 1 & & & & & & & & & & & & & & & & & & & & & & & & & & \\
\hline Ptotal & 0,30 & $-0,39$ & 0,41 & $-0,32$ & 0,40 & 0,79 & 0,49 & 1 & & & & & & & & & & & & & & & & & & & & & & & & & \\
\hline Porg & 0,19 & $\begin{array}{l}-0,30 \\
\end{array}$ & 0,32 & $-0,22$ & 0,31 & 0,71 & 0,49 & 0,99 & 1 & & & & & & & & & & & & & & & & & & & & & & & & \\
\hline Pinorg & 0,72 & $-0,59$ & 0,63 & $-0,64$ & 0,57 & 0,73 & 0,19 & 0,48 & 0,33 & 1 & & & & & & & & & & & & & & & & & & & & & & & \\
\hline $\mathrm{S}$ & 0,12 & $-0,12$ & 0,12 & $-0,12$ & 0,32 & 0,88 & 0,58 & 0,68 & 0,62 & 0,56 & 1 & & & & & & & & & & & & & & & & & & & & & & \\
\hline Areia & $-0,47$ & 0,50 & $\begin{array}{l}-0,46 \\
\end{array}$ & 0,49 & $\begin{array}{l}-0,70 \\
\end{array}$ & $\begin{array}{l}-0,98 \\
-10\end{array}$ & $\begin{array}{l}-0,80 \\
-\end{array}$ & $\begin{array}{l}-0, \infty \\
-0,77\end{array}$ & $\begin{array}{l}-0,70 \\
\end{array}$ & $-0,61$ & $-0,87$ & 1 & & & & & & & & & & & & & & & & & & & & & \\
\hline Finos & 0,40 & $-0,45$ & 0,44 & $-0,45$ & 0,61 & 0,97 & 0,76 & 0,81 & 0,76 & 0,60 & 0,89 & $-0,98$ & 1 & & & & & & & & & & & & & & & & & & & & \\
\hline $\mathrm{pH}$ & 0,06 & 0,09 & $-0,17$ & 0,09 & 0,18 & 0,12 & $-0,24$ & 0,17 & 0,16 & 0,14 & 0,13 & $-0,09$ & 0,07 & 1 & & & & & & & & & & & & & & & & & & & \\
\hline Eh & $-0,24$ & 0,10 & $-0,09$ & 0,07 & $-0,13$ & 0,27 & $-0,13$ & 0,42 & 0,42 & 0,21 & 0,41 & $-0,20$ & 0,36 & 0,26 & 1 & & & & & & & & & & & & & & & & & & \\
\hline Dens. & $-0,42$ & 0,30 & $-0,40$ & 0,28 & 0,03 & $-0,03$ & $-0,02$ & 0,03 & 0,10 & $-0,40$ & 0,03 & $-0,03$ & 0,06 & 0,53 & 0,37 & 1 & & & & & & & & & & & & & & & & & \\
\hline $\begin{array}{l}\text { Riq. } \\
\text { Re }\end{array}$ & $-0,04$ & $\begin{array}{l}-0,14 \\
-0,0\end{array}$ & 0,10 & $\begin{array}{l}-0,20 \\
-0,06\end{array}$ & 0,04 & $-0,51$ & $-0,15$ & $\begin{array}{l}-0,36 \\
-0,0\end{array}$ & $-0,29$ & $-0,58$ & $\begin{array}{c}-0,69 \\
-\end{array}$ & 0,46 & $-0,54$ & $\begin{array}{l}-0,16 \\
\end{array}$ & $-0,57$ & 0,11 & 1 & & & & & & & & & & & & & & & & \\
\hline $\mathrm{H}^{\prime}$ & 0,13 & $-0,23$ & 0,22 & $-0,14$ & 0,10 & $-0,27$ & 0,07 & $-0,18$ & $-0,13$ & $-0,36$ & $-0,46$ & 0,22 & $-0,33$ & $-0,42$ & $-0,79$ & $-0,23$ & 0,85 & 1 & & & & & & & & & & & & & & & \\
\hline $\mathrm{J}$ & 0,26 & $-0,28$ & 0,31 & $-0,20$ & 0,15 & $-0,02$ & 0,24 & 0,03 & 0,05 & $-0,11$ & $-0,20$ & $-0,01$ & $-0,09$ & $-0,52$ & $-0,78$ & $-0,45$ & 0,57 & 0,92 & 1 & & & & & & & & & & & & & & \\
\hline A.t. & $-0,23$ & 0,12 & $-0,21$ & 0,08 & 0,16 & 0,02 & $-0,12$ & 0,02 & 0,04 & $-0,13$ & 0,03 & $-0,03$ & 0,06 & 0,66 & 0,52 & 0,88 & 0,01 & $-0,44$ & $-0,69$ & 1 & & & & & & & & & & & & & \\
\hline B.str. & $-0,15$ & 0,02 & $-0,08$ & 0,09 & $-0,12$ & $-0,53$ & $-0,09$ & $-0,46$ & $-0,37$ & $-0,74$ & $-0,56$ & 0,44 & $-0,47$ & $-0,26$ & $-0,44$ & 0,09 & 0,75 & 0,62 & 0,40 & $-0,11$ & 1 & & & & & & & & & & & & \\
\hline B.e. & 0,20 & $-0,12$ & 0,04 & $-0,20$ & 0,54 & 0,54 & 0,27 & 0,09 & 0,02 & 0,36 & 0,53 & $-0,54$ & 0,49 & 0,49 & 0,16 & 0,52 & $-0,31$ & $-0,36$ & $-0,35$ & 0,55 & $-0,29$ & 1 & & & & & & & & & & & \\
\hline H.p. & 0,64 & $-0,63$ & 0,54 & $-0,65$ & 0,80 & 0,52 & 0,20 & 0,12 & 0,04 & 0,45 & 0, & $-0,48$ & 0, & 0, & $-0,14$ & 0 , & 0, & 0,12 & 0,12 & 2 & 0,05 & 0, & 1 & & & & & & & & & & \\
\hline A.p. & 0,15 & $-0,18$ & 0,12 & $-0,27$ & 0,37 & 0,21 & $\begin{array}{l}-0,20 \\
-2,2\end{array}$ & $\begin{array}{l}-0,19 \\
\end{array}$ & $-0,28$ & 0,34 & 0,18 & $-0,13$ & 0,11 & 0,35 & 0,25 & 0,41 & $-0,08$ & $-0,28$ & $-0,40$ & 0,59 & $-0,20$ & 0,78 & 0,69 & 1 & & & & & & & & & \\
\hline C.cr. & 0,78 & $-0,86$ & 0,80 & $-0,84$ & 0,87 & 0,35 & 0,31 & 0,17 & 0,11 & 0,36 & $\begin{array}{l}-0,05 \\
-0,25\end{array}$ & $-0,34$ & 0,25 & 0,20 & $\begin{array}{l}-0,21 \\
\end{array}$ & $\begin{array}{l}-0,04 \\
-0,0\end{array}$ & 0,36 & 0,25 & 0,15 & 0,20 & 0,12 & 0,25 & 0,65 & 0,30 & $-0,13$ & 0,49 & 1 & & & & & & \\
\hline G.e. & $-0,65$ & $\begin{array}{l}-, 0,0 \\
0,59\end{array}$ & $\begin{array}{l}-0,00 \\
-0,58\end{array}$ & $\begin{array}{c}0,0,07 \\
0,56\end{array}$ & $\begin{array}{l}-0,61 \\
-0,48\end{array}$ & $\begin{array}{l}-0,40 \\
-\end{array}$ & $\begin{array}{l}-0,31 \\
-0,49\end{array}$ & $\begin{array}{l}-0,17 \\
-0,17\end{array}$ & $\begin{array}{l}-0,11 \\
-0,12\end{array}$ & $\begin{array}{l}-0,30 \\
-0,30\end{array}$ & -0, & 0,43 & - $-0,40$ & $\begin{array}{l}0,20 \\
0,36\end{array}$ & 0,33 & $\begin{array}{l}0,54 \\
0,54\end{array}$ & $\begin{array}{l}0,50 \\
0,09\end{array}$ & $\begin{array}{c}-0,21 \\
-0,21\end{array}$ & $\begin{array}{l}-0,10 \\
-0,42\end{array}$ & $\begin{array}{l}0,20 \\
0,60\end{array}$ & $\begin{array}{l}-0, \\
-0,\end{array}$ & 0, & $\begin{array}{l}-0,37 \\
-0,37\end{array}$ & 0,24 & 0,08 & 0,06 & $\begin{array}{c}1 \\
-0,35\end{array}$ & 1 & & & & & \\
\hline B.d. & 0,68 & $-0,66$ & 0,65 & $-0,57$ & 0,67 & 0,63 & 0,33 & 0,59 & 0,53 & 0,54 & 0,39 & $-0,58$ & 0,50 & 0,27 & -0, & $-0,26$ & 0,09 & 0 , & 0,4 & $-0,18$ & $-0,11$ & 0,19 & 0,58 & 0,04 & 0,00 & 0,13 & 0,63 & $-0,43$ & 1 & & & & \\
\hline Oxi & $-0,17$ & 0,16 & $-0,14$ & 0,25 & $\begin{array}{l}-0,42 \\
-0,4\end{array}$ & $-0,65$ & $-0,37$ & $\begin{array}{l}-0,40 \\
-\end{array}$ & $-0,33$ & $-0,55$ & $-0,65$ & 0,64 & $-0,68$ & $\begin{array}{l}-0,276 \\
-0,3\end{array}$ & $\begin{array}{l}-0,6 \\
-0,6\end{array}$ & $\begin{array}{l}-0,20,35 \\
\end{array}$ & $\mathbf{0 , 7 0}$ & $\mathbf{0 , 7 9}$ & 0,70 & $\begin{array}{l}-0,16 \\
-0,55\end{array}$ & $\mathbf{0 , 6 9}$ & $-0,67$ & $\begin{array}{l}-0,25 \\
-\end{array}$ & $-0,48$ & 0,94 & 0,11 & $-0,16$ & $-0,1$ & 0,00 & 1 & & & \\
\hline мо & 0,66 & $-0,67$ & 0,65 & $-0,67$ & 0,83 & 0,71 & 0,81 & 0,40 & 0,34 & 0,45 & 0,42 & $-0,76$ & 0,66 & $-0,19$ & $-0,38$ & $-0,13$ & 0,02 & 0,31 & 0,47 & $-0,19$ & $-0,14$ & 0,41 & 0,58 & 0,09 & $-0,28$ & 0,27 & 0,56 & $-0,55$ & 0,55 & $-0,26$ & 1 & & \\
\hline Pequenas & 0,59 & $-0,66$ & 0,69 & $-0,63$ & 0,67 & 0,71 & 0,65 & 0,69 & 0,63 & 0,58 & 0,41 & $-0,71$ & 0,65 & $-0,15$ & $-0,12$ & $-0,23$ & $-0,06$ & 0,21 & 0,40 & $-0,18$ & $-0,45$ & 0,10 & 0,26 & $-0,10$ & $-0,16$ & 0,18 & 0,48 & $-0,26$ & 0,60 & $-0,29$ & 0,81 & 1 & \\
\hline Medias & $-0,60$ & 0,67 & $-0,71$ & 0,61 & $-0,5$ & $-0,41$ & $-0,49$ & $-0,45$ & $-0,42$ & $-0,35$ & $-0,08$ & 0,41 & $-0,3$ & 0,32 & 0,48 & 0,42 & $-0,34$ & $-0,63$ & $-0,75$ & 0,44 & 0,06 & 0,18 & $-0,24$ & 0,26 & $-0,29$ & $-0,28$ & $-0,53$ & 0,37 & $-0,66$ & $-0,20$ & $-0,74$ & $-0,87$ & \\
\hline $\begin{array}{l}\text { Mrenais } \\
\text { Grandes }\end{array}$ & $\begin{array}{l}-0,00 \\
-0,21\end{array}$ & $\begin{array}{l}0,1 \\
0,22\end{array}$ & $\begin{array}{l}-0, / 1 \\
-0,23\end{array}$ & $\begin{array}{l}0,01 \\
0,28\end{array}$ & $\begin{array}{l}-0,50 \\
-0,43\end{array}$ & $\begin{array}{l}-0,41 \\
-0,76\end{array}$ & $\begin{array}{l}-0,49 \\
-0,51\end{array}$ & $\begin{array}{l}-0,43 \\
-0,65\end{array}$ & $\begin{array}{l}-0,42 \\
-0,59\end{array}$ & $\begin{array}{l}-0,30 \\
-0,60\end{array}$ & $\begin{array}{l}-0,08 \\
-0,71\end{array}$ & $\begin{array}{l}\mathbf{0 , 4 1} \\
\mathbf{0 , 7 5}\end{array}$ & $\begin{array}{l}-0,022 \\
-0,79\end{array}$ & $\begin{array}{l}-0,52 \\
-0,23\end{array}$ & $\begin{array}{r}-0,48 \\
-0,56\end{array}$ & $\begin{array}{c}-0,42 \\
-0,24\end{array}$ & $\begin{array}{l}-0,54 \\
\mathbf{0 , 6 8}\end{array}$ & $\begin{array}{c}-0,03 \\
0,62\end{array}$ & $\begin{array}{l}-0, / 5 \\
0,45\end{array}$ & $\begin{array}{l}-0,44 \\
-0,36\end{array}$ & $\begin{array}{l}0,80 \\
0,80\end{array}$ & $\begin{array}{c}-, 18 \\
-0,50\end{array}$ & $\begin{array}{l}-0,24 \\
-0,14\end{array}$ & $\begin{array}{c}-0,20 \\
-0,24\end{array}$ & $\begin{array}{l}-0,29 \\
0,81\end{array}$ & $\begin{array}{l}-1,28 \\
0,10\end{array}$ & $\begin{array}{l}-0,3 \\
-0,10 \\
-\end{array}$ & $\begin{array}{r}-0,01 \\
-0,09\end{array}$ & $\begin{array}{l}-0,00 \\
-0,12\end{array}$ & $\begin{array}{l}-0,20 \\
0,91\end{array}$ & $\begin{array}{l}-0,14 \\
-0,42\end{array}$ & $\begin{array}{l}-0,81 \\
-0,58\end{array}$ & \\
\hline
\end{tabular}

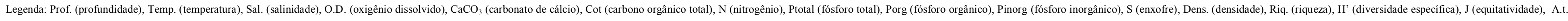

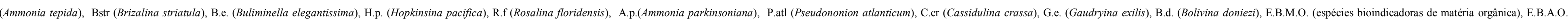
(espécies bioindicadoras de ambiente óxico), grandes (carapą̧as grandes), médias (carapaças médias), pequenas (carapaças pequenas). 
Anexo 32 - Matriz de correlação de Pearson obtida para os dados bióticos e abióticos obtidos no Araçá, em Setembro de 2006.

Níveis de significância: $p<0,01$ (em vermelho) e $p<0,05$ (em negrito)

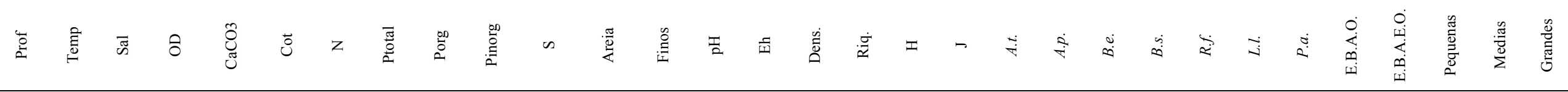

\begin{tabular}{|c|c|c|c|c|c|c|c|c|c|c|c|c|c|c|c|c|c|c|c|c|c|c|c|c|c|c|c|c|c|c|c|}
\hline Prof & 1 & & & & & & & & & & & & & & & & & & & & & & & & & & & & & & \\
\hline Temp & $-0,22$ & 1 & & & & & & & & & & & & & & & & & & & & & & & & & & & & & \\
\hline Sal & $-0,39$ & 0,50 & 1 & & & & & & & & & & & & & & & & & & & & & & & & & & & & \\
\hline OD & $-0,36$ & 0,31 & 0,40 & 1 & & & & & & & & & & & & & & & & & & & & & & & & & & & \\
\hline $\mathrm{CaCO} 3$ & 0,85 & $-0,06$ & $-0,23$ & $-0,13$ & 1 & & & & & & & & & & & & & & & & & & & & & & & & & & \\
\hline Cot & 0,61 & $-0,50$ & $-0,29$ & $-0,60$ & 0,58 & 1 & & & & & & & & & & & & & & & & & & & & & & & & & \\
\hline $\mathrm{N}$ & $-0,30$ & $-0,49$ & $-0,25$ & 0,32 & $-0,05$ & 0,03 & 1 & & & & & & & & & & & & & & & & & & & & & & & & \\
\hline Ptotal & 0,94 & $-0,34$ & $-0,37$ & $-0,52$ & 0,76 & 0,81 & $-0,30$ & 1 & & & & & & & & & & & & & & & & & & & & & & & \\
\hline Porg & 0,44 & $-0,36$ & $-0,56$ & $-0,78$ & 0,23 & 0,78 & $-0,13$ & 0,66 & 1 & & & & & & & & & & & & & & & & & & & & & & \\
\hline Pinorg & 0,83 & $-0,10$ & 0,04 & 0,05 & 0,79 & 0,34 & $-0,28$ & 0,71 & $-0,07$ & 1 & & & & & & & & & & & & & & & & & & & & & \\
\hline S & 0,04 & $-0,49$ & $-0,02$ & $-0,43$ & 0,12 & 0,76 & 0,24 & 0,30 & 0,48 & $-0,06$ & 1 & & & & & & & & & & & & & & & & & & & & \\
\hline Areia & $-0,67$ & 0,33 & 0,49 & 0,53 & $-0,76$ & $-0,72$ & 0,04 & $-0,73$ & $-0,59$ & $-0,41$ & $-0,39$ & 1 & & & & & & & & & & & & & & & & & & & \\
\hline Finos & 0,23 & $-0,53$ & $-0,45$ & $-0,64$ & 0,23 & 0,80 & 0,10 & 0,49 & 0,81 & $-0,11$ & 0,77 & $-0,72$ & 1 & & & & & & & & & & & & & & & & & & \\
\hline $\mathrm{pH}$ & $-0,34$ & 0,48 & 0,29 & 0,62 & $-0,40$ & $-0,90$ & $-0,22$ & $-0,55$ & $-0,70$ & $-0,07$ & $-0,90$ & 0,67 & $-0,85$ & 1 & & & & & & & & & & & & & & & & & \\
\hline Eh & $-0,17$ & $-0,06$ & 0,05 & 0,25 & 0,26 & 0,35 & 0,67 & $-0,09$ & 0,06 & $-0,17$ & 0,52 & $-0,23$ & 0,34 & $-0,52$ & 1 & & & & & & & & & & & & & & & & \\
\hline Dens. & $-0,37$ & 0,39 & $-0,18$ & $-0,16$ & $-0,23$ & $-0,12$ & 0,12 & $-0,32$ & 0,30 & $-0,70$ & $-0,07$ & $-0,05$ & 0,19 & $-0,09$ & 0,32 & 1 & & & & & & & & & & & & & & & \\
\hline Riq. & 0,11 & $-0,43$ & $-0,70$ & $-0,12$ & $-0,05$ & $-0,09$ & 0,44 & 0,01 & 0,17 & $-0,14$ & $-0,16$ & $-0,15$ & 0,06 & $-0,05$ & $-0,09$ & 0,26 & 1 & & & & & & & & & & & & & & \\
\hline $\mathrm{H}$ & 0,24 & $-0,28$ & $-0,11$ & 0,10 & 0,07 & $-0,23$ & 0,17 & 0,08 & $-0,22$ & 0,31 & $-0,44$ & 0,03 & $-0,37$ & 0,30 & $-0,36$ & $-0,20$ & 0,63 & 1 & & & & & & & & & & & & & \\
\hline $\mathrm{J}$ & 0,31 & $-0,21$ & 0,15 & 0,17 & 0,16 & $-0,19$ & 0,00 & 0,16 & $-0,32$ & 0,52 & $-0,43$ & 0,07 & $-0,45$ & 0,36 & $-0,42$ & $-0,44$ & 0,29 & 0,92 & 1 & & & & & & & & & & & & \\
\hline B.e. & $-0,25$ & 0,03 & 0,31 & 0,13 & $-0,04$ & 0,11 & 0,37 & $-0,14$ & 0,06 & $-0,25$ & 0,20 & $-0,08$ & 0,17 & $-0,22$ & 0,53 & 0,49 & 0,12 & 0,23 & 0,17 & 0,02 & 0,27 & 1 & & & & & & & & & \\
\hline B.str. & $-0,41$ & 0,60 & 0,39 & 0,28 & $-0,34$ & $-0,58$ & 0,01 & $-0,52$ & $-0,33$ & $-0,37$ & $-0,58$ & 0,53 & $-0,61$ & 0,52 & $-0,04$ & 0,54 & 0,07 & 0,31 & 0,26 & 0,22 & 0,03 & 0,47 & 1 & & & & & & & & \\
\hline R.f. & 0,02 & 0,31 & 0,15 & $-0,05$ & $-0,24$ & $-0,53$ & $-0,43$ & $-0,15$ & $-0,31$ & 0,09 & $-0,55$ & 0,32 & $-0,58$ & 0,50 & $-0,70$ & 0,01 & 0,34 & 0,61 & 0,55 & $-0,30$ & $-0,12$ & $-0,07$ & 0,47 & 1 & & & & & & & \\
\hline L.l. & 0,41 & 0,43 & 0,04 & 0,05 & 0,36 & $-0,29$ & $-0,38$ & 0,16 & $-0,28$ & 0,48 & $-0,52$ & $-0,11$ & $-0,49$ & 0,31 & $-0,38$ & $-0,01$ & 0,28 & 0,55 & 0,51 & $-0,28$ & $-0,02$ & $-0,03$ & 0,33 & 0,78 & 1 & & & & & & \\
\hline P.a. & $-0,45$ & $-0,01$ & 0,34 & 0,43 & $-0,23$ & $-0,09$ & 0,53 & $-0,36$ & $-0,13$ & $-0,36$ & 0,08 & 0,19 & 0,01 & 0,00 & 0,56 & 0,38 & 0,07 & 0,19 & 0,14 & 0,05 & 0,05 & 0,91 & 0,47 & $-0,20$ & $-0,25$ & 1 & & & & & \\
\hline E.B.A.O. & 0,16 & 0,12 & $-0,03$ & 0,16 & $-0,11$ & $-0,59$ & $-0,26$ & $-0,09$ & $-0,43$ & 0,28 & $-0,79$ & 0,36 & $-0,73$ & 0,71 & $-0,77$ & $-0,31$ & 0,33 & 0,72 & 0,72 & $-0,47$ & $-0,50$ & $-0,35$ & 0,35 & 0,80 & 0,64 & $-0,32$ & 1 & & & & \\
\hline E.B.A.E.O. & $-0,01$ & $-0,30$ & 0,19 & 0,08 & 0,11 & 0,23 & 0,48 & 0,06 & 0,06 & 0,02 & 0,20 & $-0,15$ & 0,14 & $-0,27$ & 0,41 & 0,15 & 0,26 & 0,53 & 0,49 & $-0,39$ & $-0,10$ & 0,89 & 0,32 & $-0,03$ & 0,01 & 0,81 & $-0,14$ & 1 & & & \\
\hline Pequenas & 0,70 & $-0,17$ & $-0,63$ & $-0,84$ & 0,50 & 0,62 & $-0,37$ & 0,75 & 0,80 & 0,25 & 0,19 & $-0,70$ & 0,54 & $-0,52$ & $-0,22$ & 0,13 & 0,20 & $-0,09$ & $-0,17$ & 0,08 & 0,35 & $-0,31$ & $-0,34$ & $-0,01$ & 0,17 & $-0,59$ & $-0,06$ & $-0,24$ & 1 & & \\
\hline Medias & $-0,74$ & 0,08 & 0,50 & 0,76 & $-0,46$ & $-0,51$ & 0,43 & $-0,75$ & $-0,72$ & $-0,32$ & 0,02 & 0,54 & $-0,31$ & 0,34 & 0,36 & $-0,12$ & $-0,26$ & $-0,19$ & $-0,13$ & 0,08 & $-0,23$ & 0,17 & 0,07 & $-0,24$ & $-0,36$ & 0,46 & $-0,19$ & 0,06 & $-0,92$ & 1 & \\
\hline Grandes & 0,03 & 0,26 & 0,41 & 0,33 & $-0,14$ & $-0,32$ & $-0,13$ & $-0,06$ & $-0,26$ & 0,16 & $-0,48$ & 0,45 & $-0,59$ & 0,46 & $-0,27$ & $-0,02$ & 0,12 & 0,64 & 0,69 & $-0,37$ & $-0,28$ & 0,42 & 0,67 & 0,60 & 0,45 & 0,43 & 0,53 & 0,49 & $-0,33$ & $-0,06$ & 1 \\
\hline
\end{tabular}




\section{CAPÍTULO 5 - EMISSÁRIO SUBMARINO DE ESGOTO DOMÉSTICO DO SACO DA CAPELA}

\subsection{RESULTADOS}

5.1.1 Posicionamento geográfico e dados físico-químicos da coluna d’água

O posicionamento geográfico e dados físico-químicos da coluna d'água das estações amostradas encontram-se na Tabela 08. Os dados apresentados referem-se aos anos de 2005 e 2006.

Coletas realizadas em Setembro de 2005

Os valores de temperatura e salinidade oscilaram de 20,50 a $20,63{ }^{\circ} \mathrm{C}$ e de 31,30 a $31,90{ }^{\circ} \mathrm{C}$, respectivamente. Não foi observada estratificação termohalina.

Os valores de $\mathrm{pH}$ foram de 7,76 a 8,12. Observou-se suave estratificação, sendo os menores valores verificados em regiões circundantes aos difusores do emissário.

Os teores de oxigênio dissolvido variaram entre 8,10 e $8,96 \mathrm{mg} \mathrm{L}^{-1}$. De forma geral, ocorreu declínio vertical de teores em quase todas as estações. Entretanto, os teores obtidos estiveram dentro dos padrões estabelecidos pela Resolução CONAMA 357/2005, para águas salinas de Classe 1.

Os valores de turbidez oscilaram de 2 a 11 UNT, sendo observado nas estações Sc5 (9,20 UNT) e Sc10 (11 UNT) as maiores concentrações. Pelo padrão de distribuição dos valores obtidos (Tabela 08) infere-se que a dispersão da pluma disposta pelo efluente ocorre de sudeste para norte-noroeste da malha de amostragem.

Excetuando-se os valores de nitrogênio Kjldahl das estações Sc1 (0,14 mg L $\left.{ }^{-1}\right), \mathrm{Sc}$ $\left(0,18 \mathrm{mg} \mathrm{L}^{-1}\right)$, Sc9 $\left(0,18 \mathrm{mg} \mathrm{L}^{-1}\right)$ e $\operatorname{Sc} 10\left(0,14 \mathrm{mg} \mathrm{L}^{-1}\right)$, os demais valores estiveram abaixo do método analítico utilizado. 
Os valores de Os valores de temperatura e salinidade variaram de 22,41 a $23,23{ }^{\circ} \mathrm{C}$ e de 34,23 a 34,91, respectivamente. Observou-se declínio dos valores de temperatura da superfície em direção às águas de fundo.

Os valores de $\mathrm{pH}$ foram de 8,16 a 8,22, com distribuição espacial e vertical quase homogênea $\left(\bar{x}=8,18^{ \pm} 0,01\right)$.

Os teores de oxigênio dissolvido oscilaram entre 6,59 e 7,33 $\mathrm{mg} \mathrm{L}^{-1}$. Verificou-se diminuição de valores das águas de superfície em direção às águas de fundo, porém todos o valores obtidos estiveram dentro do padrão estabelecido pela Resolução CONAMA 357/2005, para águas salinas de Classe 1 .

Os valores obtidos para turbidez foram de 1,90 a 6,30 UNT. Em 90\% das estações, os maiores valores ocorreram nas águas de fundo, tendo como sentido preferencial de sudeste para norte-noroeste da malha de amostragem. Esse resultado também foi bservado nas coletas realizadas em Setembro de 2005.

Os resultados dos nutrientes analisados ao longo da coluna d'água estiveram abaixo do limite de detecção do método analítico.

\section{Coletas realizadas em Outubro de 2006}

Os valores de temperatura e salinidade foram de 16,39 a $24,86{ }^{\circ} \mathrm{C}$ e de 33,82 a 33,88 , respectivamente. Observou-se estratificação de temperatura em todas as estações amostradas; em média, a diferença obtida entre as águas de superfície e de fundo foi de $5{ }^{\circ} \mathrm{C}$. Já para a salinidade, os valores apresentaram-se quase homogêneos $(\bar{x}=33,80 \pm 0,16)$.

As concentrações de oxigênio dissolvido oscilaram de 4,34 a 6,41 $\mathrm{mg} \mathrm{L}^{-1}$. Em todas as estações, nas águas de meio e fundo, verificou-se níveis de oxigênio dissolvido abaixo dos valores estabelecidos pela Resolução CONAMA/357. Valores considerados adequados à proteção da vida aquática (superior a $6 \mathrm{mg} \mathrm{L}^{-1}$ ) ocorreram somente nas águas de superfície das estações Sc1, Sc2, Sc3 e Sc6.

Os valores de turbidez obtidos, entre 1,0 e 2,40 UNT, são considerados baixos quando comparados com os períodos anteriores de amostragem. Os maiores valores foram obtidos nas águas de fundo, com padrão aleatório de distribuição. 
Assim como o observado para Junho de 2006, os resultados dos nutrientes analisados ao longo da coluna d'água estiveram abaixo do limite de detecção do método analítico. 
Tabela 08 - Posicionamentos geográficos e dados físico-químicos da coluna d'água obtidos próximo ao emissário do Saco da Capela.

Obs.: Em vermelho, valores abaixo dos limites estabelecidos pela Resolução CONAMA 357/2005.

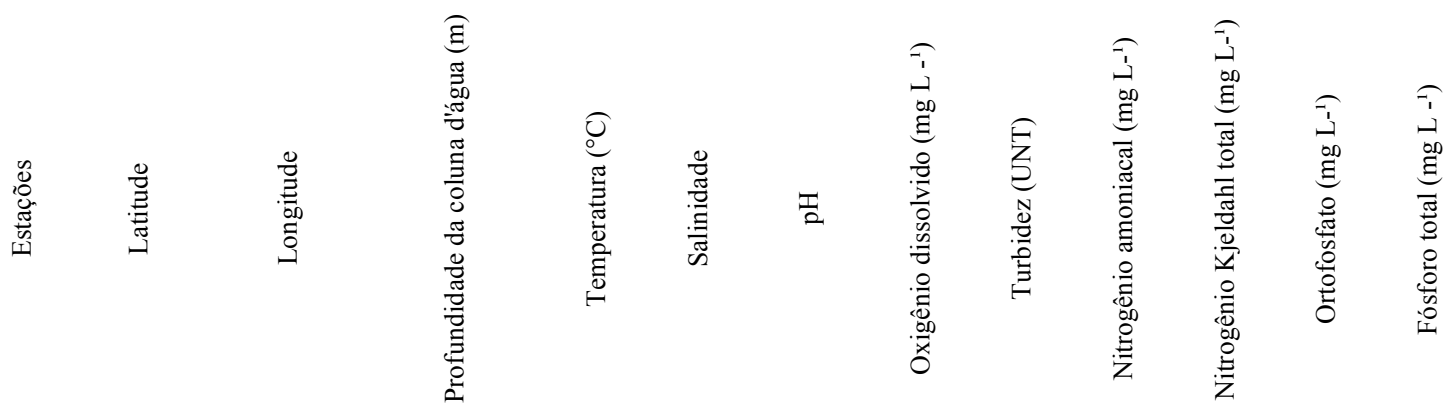

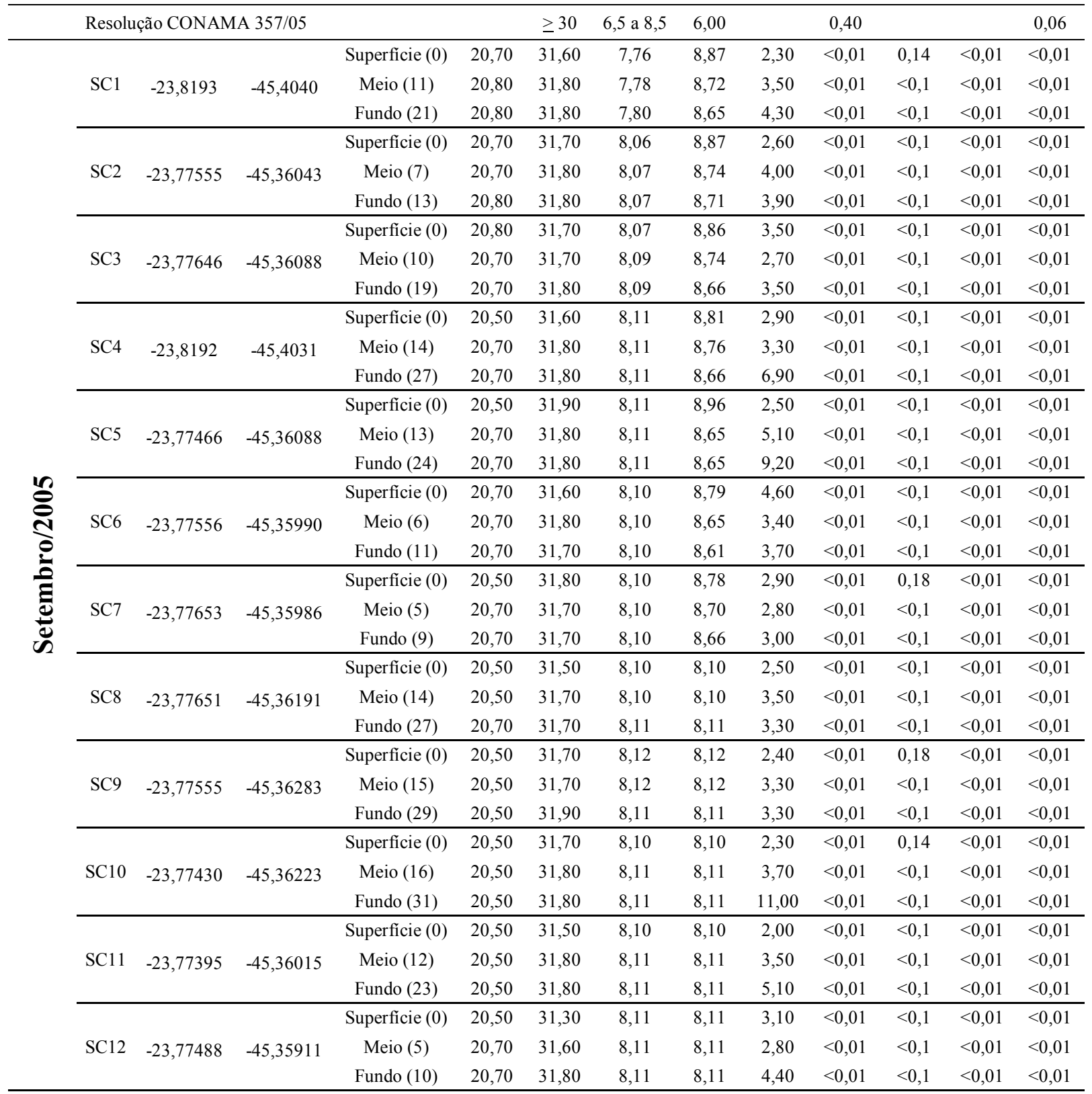


Tabela 08 - Continuação

\begin{tabular}{|c|c|c|c|c|c|c|c|c|c|c|c|c|c|}
\hline & 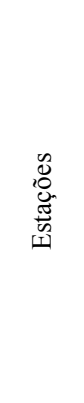 & 罤 & 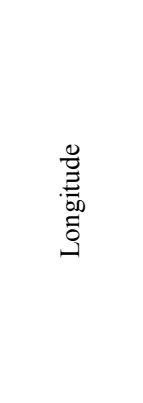 & 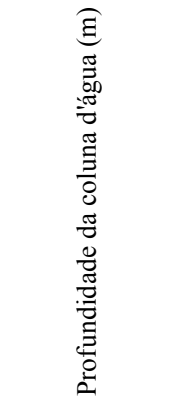 & 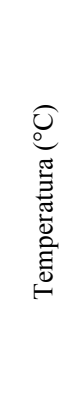 & 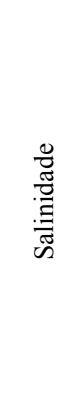 & 壳 & 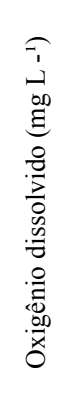 & 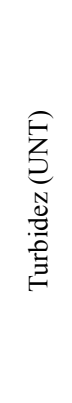 & 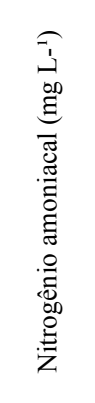 & 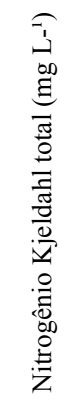 & 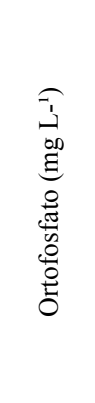 & 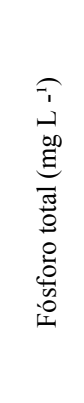 \\
\hline & \multicolumn{3}{|c|}{ Resolução CONAMA 357/05 } & & & $\geq 30$ & 6,5 a 8,5 & 6,00 & & 0,40 & & & 0,06 \\
\hline \multirow{33}{*}{ 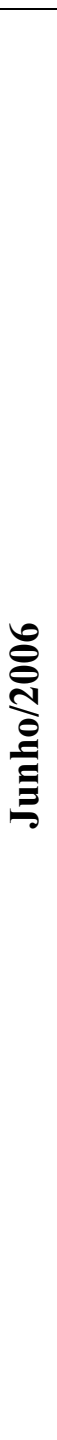 } & \multirow{3}{*}{$\mathrm{SC} 1$} & \multirow{3}{*}{$-23,77556$} & \multirow{3}{*}{$-45,36088$} & Superfície (0) & 23,23 & 34,36 & 8,19 & 7,28 & 2,5 & $<0,01$ & $<<0,1$ & $<0,01$ & $<0,01$ \\
\hline & & & & Meio (9) & 22,63 & 34,74 & 8,17 & 6,96 & 2,7 & $<0,01$ & $<0,1$ & $<0,01$ & $<0,01$ \\
\hline & & & & Fundo (17) & 22,65 & 34,86 & 8,16 & 6,67 & 3,7 & $<0,01$ & $<0,1$ & $<0,01$ & $<0,01$ \\
\hline & \multirow{3}{*}{$\mathrm{SC} 2$} & \multirow{3}{*}{$-23,77554$} & \multirow{3}{*}{$-45,36042$} & Superfície (0) & 23,17 & 34,34 & 8,17 & 7,08 & 2,9 & $<0,01$ & $<0,1$ & $<0,01$ & $<0,01$ \\
\hline & & & & Meio (6) & 23,00 & 34,60 & 8,17 & 7,02 & 2,6 & $<0,01$ & $<0,1$ & $<0,01$ & $<0,01$ \\
\hline & & & & Fundo (11) & 22,69 & 34,78 & 8,17 & 6,79 & 3,1 & $<0,01$ & $<0,1$ & $<0,01$ & $<0,01$ \\
\hline & \multirow{3}{*}{$\mathrm{SC} 3$} & \multirow{3}{*}{$-23,77646$} & \multirow{3}{*}{$-45,36089$} & Superfície (0) & 22,98 & 34,40 & 8,19 & 7,18 & 2,70 & $<0,01$ & $<0,1$ & $<0,01$ & $<0,01$ \\
\hline & & & & Meio (8) & 22,54 & 34,76 & 8,17 & 6,92 & 3,20 & $<0,01$ & $<0,1$ & $<0,01$ & $<0,01$ \\
\hline & & & & Fundo (15) & 22,58 & 34,87 & 8,17 & 6,71 & 6,30 & $<0,01$ & $<0,1$ & $<0,01$ & $<0,01$ \\
\hline & \multirow{3}{*}{$\mathrm{SC} 4$} & \multirow{3}{*}{$-23,77554$} & \multirow{3}{*}{$-45,36186$} & Superfície (0) & 22,80 & 34,45 & 8,20 & 7,30 & 2,60 & $<0,01$ & $<0,1$ & $<0,01$ & $<0,01$ \\
\hline & & & & Meio (13) & 22,52 & 34,77 & 8,18 & 6,95 & 1,90 & $<0,01$ & $<0,1$ & $<0,01$ & $<0,01$ \\
\hline & & & & Fundo (26) & 22,53 & 34,87 & 8,17 & 6,74 & 4,40 & $<0,01$ & $<0,1$ & $<0,01$ & $<0,01$ \\
\hline & \multirow{3}{*}{ SC5 } & \multirow{3}{*}{$-23,77466$} & \multirow{3}{*}{$-45,36089$} & Superfície (0) & 23,21 & 34,31 & 8,19 & 7,27 & 2,70 & $<0,01$ & $<0,1$ & $<0,01$ & $<0,01$ \\
\hline & & & & Meio (13) & 22,46 & 34,64 & 8,18 & 6,95 & 3,10 & $<0,01$ & $<0,1$ & $<0,01$ & $<0,01$ \\
\hline & & & & Fundo (25) & 22,50 & 34,83 & 8,17 & 6,73 & 5,10 & $<0,01$ & $<0,1$ & $<0,01$ & $<0,01$ \\
\hline & \multirow{3}{*}{ SC6 } & \multirow{3}{*}{$-23,77557$} & \multirow{3}{*}{$-45,3599$} & Superfície (0) & 23,14 & 34,32 & 8,22 & 7,26 & 2,70 & $<0,01$ & $<0,1$ & $<0,01$ & $<0,01$ \\
\hline & & & & Meio (4) & 23,23 & 34,49 & 8,19 & 7,12 & 2,60 & $<0,01$ & $<0,1$ & $<0,01$ & $<0,01$ \\
\hline & & & & Fundo (7) & 22,88 & 34,63 & 8,18 & 6,97 & 3,30 & $<0,01$ & $<0,1$ & $<0,01$ & $<0,01$ \\
\hline & \multirow{3}{*}{$\mathrm{SC} 7$} & \multirow{3}{*}{$-23,77652$} & \multirow{3}{*}{$-45,35985$} & Superfície (0) & 23,08 & 34,49 & 8,19 & 7,16 & 2,50 & $<0,01$ & $<0,1$ & $<0,01$ & $<0,01$ \\
\hline & & & & Meio (5) & 22,94 & 34,59 & 8,19 & 7,10 & 2,70 & $<0,01$ & $<0,1$ & $<0,01$ & $<0,01$ \\
\hline & & & & Fundo (10) & 22,58 & 34,74 & 8,18 & 6,83 & 2,60 & $<0,01$ & $<0,1$ & $<0,01$ & $<0,01$ \\
\hline & \multirow{3}{*}{ SC8 } & \multirow{3}{*}{$-23,77651$} & & Superfície (0) & 23,09 & 34,42 & 8,20 & 7,33 & 2,40 & $<0,01$ & $<0,1$ & $<0,01$ & $<0,01$ \\
\hline & & & $-45,36191$ & Meio (13) & 22,56 & 34,80 & 8,18 & 6,99 & 2,00 & $<0,01$ & $<0,1$ & $<0,01$ & $<0,01$ \\
\hline & & & & Fundo (25) & 22,57 & 34,91 & 8,17 & 6,79 & 3,40 & $<0,01$ & $<0,1$ & $<0,01$ & $<0,01$ \\
\hline & & & & Superficie (0) & 22,41 & 34,23 & 8,18 & 7,05 & 3,10 & $<0,01$ & $<0,1$ & $<0,01$ & $<0,01$ \\
\hline & SC9 & $-23,77556$ & $-45,36283$ & Meio (15) & 22,54 & 34,85 & 8,17 & 6,74 & 3,20 & $<0,01$ & $<0,1$ & $<0,01$ & $<0,01$ \\
\hline & & & & Fundo (29) & 22,54 & 34,87 & 8,17 & 6,59 & 5,40 & $<0,01$ & $<0,1$ & $<0,01$ & $<0,01$ \\
\hline & & & & Superfície (0) & 22,50 & 34,43 & 8,19 & 7,12 & 2,80 & $<0,01$ & $<0,1$ & $<0,01$ & $<0,01$ \\
\hline & $\mathrm{SC} 10$ & $-23,77429$ & $-45,36223$ & Meio (14) & 22,51 & 34,82 & 8,17 & 6,78 & 4,60 & $<0,01$ & $<0,1$ & $<0,01$ & $<0,01$ \\
\hline & & & & Fundo (28) & 22,52 & 34,85 & 8,17 & 6,71 & 5,90 & $<0,01$ & $<0,1$ & $<0,01$ & $<0,01$ \\
\hline & & & & Superfície (0) & 22,76 & 34,31 & 8,19 & 7,33 & 2,70 & $<0,01$ & $<0,1$ & $<0,01$ & $<0,01$ \\
\hline & $\mathrm{SC} 11$ & $-23,77394$ & $-45,36014$ & Meio (11) & 22,47 & 34,63 & 8,18 & 7,01 & 3,00 & $<0,01$ & $<0,1$ & $<0,01$ & $<0,01$ \\
\hline & & & & Fundo (21) & 22,48 & 34,77 & 8,18 & 6,87 & 4,50 & $<0,01$ & $<0,1$ & $<0,01$ & $<0,01$ \\
\hline
\end{tabular}


Tabela 08 - Continuação

\begin{tabular}{|c|c|c|c|c|c|c|c|c|c|c|c|c|c|}
\hline & 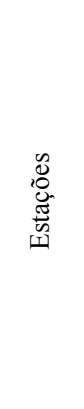 & 莺 & 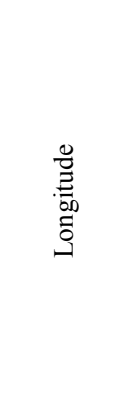 & 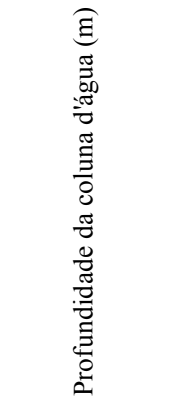 & 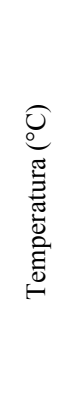 & 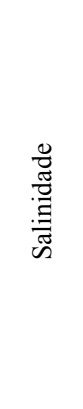 & 胥 & 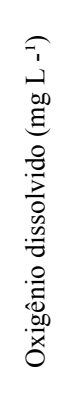 & 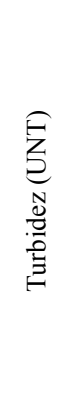 & 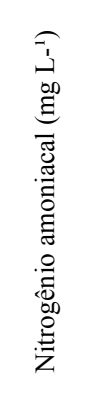 & 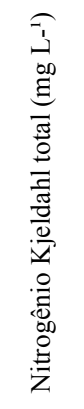 & \begin{tabular}{l}
$\widetilde{1}$ \\
\multicolumn{1}{|c}{} \\
00 \\
$\Xi$ \\
0 \\
0 \\
0 \\
0 \\
0 \\
0 \\
0 \\
0 \\
0 \\
0
\end{tabular} & 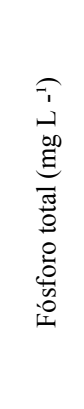 \\
\hline & \multicolumn{3}{|c|}{ Resolução CONAMA 357/05 } & & & $\geq 30$ & 6,5 a 8,5 & 6,00 & & 0,40 & & & 0,06 \\
\hline \multirow{30}{*}{ 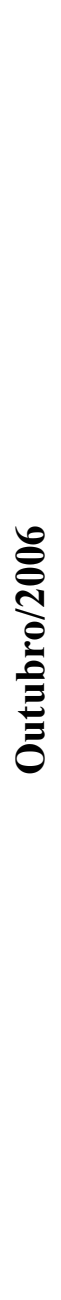 } & \multirow{3}{*}{$\mathrm{SC} 1$} & \multirow{3}{*}{$-23,77556$} & \multirow{3}{*}{$-45,36088$} & Superficie (0) & 22,6 & 33,75 & 8,32 & 6,27 & 1,20 & $<0,01$ & $<0,1$ & $<0,01$ & $<0,01$ \\
\hline & & & & Meio (12) & 20,8 & 33,88 & 8,22 & 5,08 & 1,80 & $<0,01$ & $<0,1$ & $<0,01$ & $<0,01$ \\
\hline & & & & Fundo (24) & 17,2 & 33,85 & 8,26 & 4,74 & 2,40 & $<0,01$ & $<0,1$ & $<0,01$ & $<0,01$ \\
\hline & \multirow{3}{*}{$\mathrm{SC} 2$} & \multirow{3}{*}{$-23,77554$} & \multirow{3}{*}{$-45,36042$} & Superfície (0) & 23,0 & 33,70 & 8,09 & 6,41 & 1,20 & $<0,01$ & $<0,1$ & $<0,01$ & $<0,01$ \\
\hline & & & & Meio (8) & 21,2 & 33,88 & 8,10 & 5,48 & 2,00 & $<0,01$ & $<0,1$ & $<0,01$ & $<0,01$ \\
\hline & & & & Fundo (16) & 20,5 & 33,88 & 8,15 & 5,11 & 2,00 & $<0,01$ & $<0,1$ & $<0,01$ & $<0,01$ \\
\hline & \multirow{3}{*}{$\mathrm{SC} 3$} & \multirow{3}{*}{$-23,77646$} & \multirow{3}{*}{$-45,36089$} & Superfície (0) & 23,0 & 33,75 & 8,36 & 6,15 & 1,40 & $<0,01$ & $<0,1$ & $<0,01$ & $<0,01$ \\
\hline & & & & Meio (9) & 21,1 & 33,88 & 8,28 & 5,27 & 1,70 & $<0,01$ & $<0,1$ & $<0,01$ & $<0,01$ \\
\hline & & & & Fundo (18) & 18,2 & 33,87 & 8,20 & 4,71 & 1,60 & $<0,01$ & $<0,1$ & $<0,01$ & $<0,01$ \\
\hline & \multirow{3}{*}{$\mathrm{SC} 4$} & \multirow{3}{*}{$-23,77554$} & \multirow{3}{*}{$-45,36186$} & Superficie (0) & 23,2 & 33,73 & 8,30 & 5,86 & 1,20 & $<0,01$ & $<0,1$ & $<0,01$ & $<0,01$ \\
\hline & & & & Meio (13) & 20,9 & 33,87 & 8,26 & 4,77 & 2,00 & $<0,01$ & $<0,1$ & $<0,01$ & $<0,01$ \\
\hline & & & & Fundo (26) & 16,8 & 33,85 & 8,10 & 4,58 & 2,20 & $<0,01$ & $<0,1$ & $<0,01$ & $<0,01$ \\
\hline & \multirow{3}{*}{ SC5 } & \multirow{3}{*}{$-23,77466$} & \multirow{3}{*}{$-45,36089$} & Superficie (0) & 23,3 & 33,75 & 8,31 & 5,89 & 1,30 & $<0,01$ & $<0,1$ & $<0,01$ & $<0,01$ \\
\hline & & & & Meio (13) & 20,5 & 33,86 & 8,28 & 4,74 & 1,50 & $<0,01$ & $<0,1$ & $<0,01$ & $<0,01$ \\
\hline & & & & Fundo (25) & 16,9 & 33,84 & 8,08 & 4,53 & 2,10 & $<0,01$ & $<0,1$ & $<0,01$ & $<0,01$ \\
\hline & \multirow{3}{*}{ SC6 } & \multirow{3}{*}{$-23,77557$} & \multirow{3}{*}{$-45,3599$} & Superficie (0) & 23,9 & 33,66 & 8,39 & 6,18 & 1,90 & $<0,01$ & $<0,1$ & $<0,01$ & $<0,01$ \\
\hline & & & & Meio (5) & 21,1 & 33,86 & 8,21 & 5,37 & 1,90 & $<0,01$ & $<0,1$ & $<0,01$ & $<0,01$ \\
\hline & & & & Fundo (9) & 20,8 & 33,86 & 8,25 & 4,94 & 2,00 & $<0,01$ & $<0,1$ & $<0,01$ & $<0,01$ \\
\hline & \multirow{3}{*}{$\mathrm{SC} 7$} & \multirow{3}{*}{$-23,77652$} & \multirow{3}{*}{$-45,35985$} & Superficie (0) & 24,6 & 33,52 & 8,34 & 5,81 & 1,90 & $<0,01$ & $<0,1$ & $<0,01$ & $<0,01$ \\
\hline & & & & Meio (5) & 21,2 & 33,86 & 8,30 & 5,30 & 2,30 & $<0,01$ & $<0,1$ & $<0,01$ & $<0,01$ \\
\hline & & & & Fundo (9) & 20,8 & 33,86 & 8,25 & 4,87 & 2,00 & $<0,01$ & $<0,1$ & $<0,01$ & $<0,01$ \\
\hline & \multirow{3}{*}{$\mathrm{SC} 8$} & \multirow{3}{*}{$-23,77651$} & \multirow{3}{*}{$-45,36191$} & Superficie (0) & 24,3 & 33,35 & 8,36 & 5,71 & 1,00 & $<0,01$ & $<0,1$ & $<0,01$ & $<0,01$ \\
\hline & & & & Meio (13) & 19,1 & 33,85 & 8,15 & 4,44 & 1,30 & $<0,01$ & $<0,1$ & $<0,01$ & $<0,01$ \\
\hline & & & & Fundo (25) & 16,5 & 33,84 & 8,10 & 4,35 & 1,80 & $<0,01$ & $<0,1$ & $<0,01$ & $<0,01$ \\
\hline & & & & Superficie (0) & 24,9 & 33,32 & 8,43 & 5,49 & 1,10 & $<0,01$ & $<0,1$ & $<0,01$ & $<0,01$ \\
\hline & SC9 & $-23,77556$ & $-45,36283$ & Meio (15) & 18,3 & 33,83 & 8,16 & 4,40 & 1,60 & $<0,01$ & $<0,1$ & $<0,01$ & $<0,01$ \\
\hline & & & & Fundo (29) & 16,4 & 33,85 & 8,13 & 4,34 & 2,20 & $<0,01$ & $<0,1$ & $<0,01$ & $<0,01$ \\
\hline & & & & Superficie (0) & 24,6 & 33,42 & 8,36 & 5,85 & 1,40 & $<0,01$ & $<0,1$ & $<0,01$ & $<0,01$ \\
\hline & $\mathrm{SC} 10$ & $-23,77429$ & $-45,36223$ & Meio (16) & 18,0 & 33,80 & 8,15 & 4,42 & 1,40 & $<0,01$ & $<0,1$ & $<0,01$ & $<0,01$ \\
\hline & & & & Fundo (31) & 16,4 & 33,85 & 8,18 & 4,34 & 1,90 & $<0,01$ & $<0,1$ & $<0,01$ & $<0,01$ \\
\hline
\end{tabular}




\subsubsection{Análises granulométricas}

Os resultados das análises granulométricas das coletas realizadas nos anos de $2005 \mathrm{e}$ 2006 (Junho e Outubro) encontram-se na Tabela 09 e ilustrados no Anexo 33.

Coletas realizadas em Setembro de 2005

Os sedimentos da área de estudo são arenosos, com predomínio das frações areia muito grossa e grossa. Os teores de areia variaram de 53,2 a 95,67\% ( $\left.\bar{x}=82,544^{ \pm} 12,47 \%\right)$.

Sedimentos finos ocorreram em todas as estações, em porcentagens que foram de 1,37

a $46,8 \%\left(\bar{x}=14,56^{ \pm} 13,64 \%\right)$. As maiores concentrações foram identificadas nas estações Sc9 $(46,8 \%)$ e Sc10 (25,28\%), posicionadas nas regiões oeste e noroeste da malha de amostragem (Anexo 33).

Grânulos ocorreram somente nas estações Sc2 (13,82\%), Sc6 (7,21\%) e Sc8 (7,94\%). Segundo intervalos propostos por Shepard (1954), os sedimentos analisados são classificados como i) areia - estações $\mathrm{Sc} 1$ a Sc8, Sc11 e Sc12 e ii) areia síltica - estações Sc9 e Sc10.

Já em relação ao grau de seleção, verificou-se sedimentos muito pobremente selecionados nas estações $\operatorname{Sc} 2, \operatorname{Sc} 5, \operatorname{Sc} 8$ ( $\delta$ entre 2,13 e 2,94), pobremente selecionados nas estações Sc3, Sc7 e Sc12 ( $\delta$ entre 1,31 e 1,98), moderadamente selecionados na estação Sc6 ( $\delta$ igual a 1,0$)$ e muito bem selecionados na estação $\operatorname{Sc} 9(\delta$ igual a 0,23$)$.

As estações $\mathrm{Sc} 1$ e Sc4 não foram amostradas devido à grande quantidade de conchas de moluscos, motivo pelo qual foram amostradas as estações Sc11 e Sc12.

\section{Coletas realizadas em Junho de 2006}

O predomínio de sedimentos arenosos é mantido nas coletas realizadas em Junho de 2006; os teores encontrados foram de 41,03 a $86,50 \%\left(\bar{x}=61,88^{ \pm} 14,69 \%\right)$.

As concentrações de sedimentos finos variaram de 3,10 a $45,97 \%(\bar{x}=11,92 \pm$ 12,94\%), sendo observada a maior porcentagem na estação Sc1, localizada na saída do emissário submarino (Anexo 33). 
Grânulos ocorreram em todas as estações, em expressivas concentrações, entre 9,5 e $40,03 \%\left(\bar{x}=26,20^{ \pm} 10,89 \%\right)$. As estações Sc1 e Sc8 apresentaram as menores porcentagens.

De acordo Shepard (1954), os sedimentos analisados são classificados como i) areia estações Sc2 a Sc8 e Sc11 e ii) areia síltica - estações Sc1 e Sc9.

Os sedimentos das estações Sc6, Sc7 e Sc8 foram classificados como pobremente selecionados ( $\delta$ entre 1,72 e 1,85) e muito pobremente selecionados nas estações Sc1 a Sc5, Sc9 e Sc11 ( $\delta$ entre 2,0 e 3,49$)$.

A estação Sc10 não pode ser coletada devido ao grande volume de conchas, motivo pelo qual a estação Sc11 foi amostrada.

Coletas realizadas em Outubro de 2006

Sedimentos arenosos são predominantes, em porcentagens que variaram entre 52,90 e $85 \%(\bar{x}=77,77 \pm 9,63 \%)$.

Entre os períodos analisados, verificou-se pouca variação nas porcentagens de sedimentos finos, a qual em Outubro de 2006 foi de 3,58 a $44,26(\bar{x}=13,94 \pm 12,29 \%)$. As maiores concentrações ocorreram na estação $\mathrm{Sc} 1$ e em estações circundantes, tais como $\mathrm{Sc}$, $\mathrm{Sc} 3$ e Sc4 (Anexo 33).

Segundo classificação proposta por Shepard (1954), obteve-se i) areia síltica na estação Sc1 e ii) areia nas demais estações. Já em relação ao grau de seleção, os sedimentos são classificados como pobremente selecionados nas estações Sc4, Sc6 e Sc9 ( $\delta$ entre 1,75 e $1,92)$ e muito pobremente selecionados nas demais estações ( $\delta$ entre 2,0 e 3,33 ). 
Tabela 09 - Resultados granulométricos obtidos em região circunjacente aos difusores do emissário submarino do Saco da Capela.

Legenda: D. médio = diâmetro médio; D. padrão = desvio padrão; Mto. = muito.

\begin{tabular}{|c|c|c|c|c|c|c|c|c|c|c|c|}
\hline & \\
\hline & & & & & \multicolumn{5}{|c|}{ Areia (\%) } & \multicolumn{2}{|c|}{ Pelíticos (\%) } \\
\hline \multirow{13}{*}{ 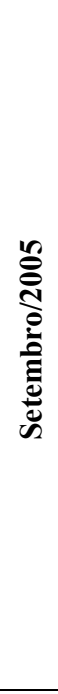 } & Estações & D. Médio (Ф) & D. Padrão $(\delta)$ & Grânulos (\%) & Mto. Grossa & Grossa & Média & Fina & Mto. Fina & Silte & Argila \\
\hline & Sc1 & $* *$ & $* *$ & $* *$ & $* *$ & $* *$ & $* *$ & $* *$ & $* *$ & $* *$ & $* *$ \\
\hline & $\mathrm{Sc} 2$ & 0,92 & 2,13 & 13,82 & 25,26 & 29,1 & 15,52 & 4,95 & 2,64 & 4,32 & 4,38 \\
\hline & $\mathrm{Sc} 3$ & 1,63 & 1,31 & 0,00 & 39,59 & 15,65 & 12,84 & 7,38 & 3,85 & 14,34 & 6,35 \\
\hline & $\mathrm{Sc} 4$ & $* *$ & $* *$ & $* *$ & $* *$ & $* *$ & $* *$ & $* *$ & $* *$ & $* *$ & $* *$ \\
\hline & Sc5 & 0,6 & 2,94 & 0,00 & 46,61 & 14,93 & 31,53 & 1,82 & 0,78 & 2,33 & 2,00 \\
\hline & Sc6 & 0,39 & 1 & 7,21 & 25,87 & 43,14 & 20,2 & 1,92 & 0,30 & 1,37 & 0,00 \\
\hline & $\mathrm{Sc} 7$ & 1,26 & 1,98 & 0,00 & 34,61 & 26,45 & 16,78 & 8,54 & 3,76 & 5,51 & 4,35 \\
\hline & Sc8 & 0,67 & 2,92 & 7,94 & 24,11 & 35,78 & 25,45 & 2,33 & 0,57 & 2,10 & 1,73 \\
\hline & Sc9 & 3,94 & 0,23 & 0,00 & 15,93 & 16,25 & 12,49 & 5,09 & 3,44 & 25,06 & 21,74 \\
\hline & Sc10 & 2,13 & 1,03 & 0,00 & 14,43 & 30,01 & 23,46 & 4,83 & 2,00 & 22,67 & 2,61 \\
\hline & Sc11 & 0,75 & 2,53 & 0,00 & 51,96 & 22,39 & 12,05 & 4,88 & 1,24 & 2,85 & 4,62 \\
\hline & $\mathrm{Sc} 12$ & 1,88 & 1,46 & 0,00 & 19,18 & 32,13 & 16,93 & 10,74 & 3,77 & 10,92 & 6,34 \\
\hline \multirow{11}{*}{ 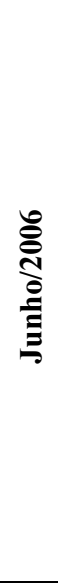 } & Sc1 & 3,29 & 3,49 & 12,99 & 7,22 & 17,17 & 10,86 & 4,90 & 0,89 & 33,88 & 12,09 \\
\hline & $\mathrm{Sc} 2$ & 0,34 & 2,09 & 40,03 & 14,13 & 18,03 & 15,64 & 5,83 & 1,02 & 2,96 & 2,35 \\
\hline & $\mathrm{Sc} 3$ & 1,20 & 2,77 & 20,78 & 12,04 & 33,43 & 16,21 & 3,27 & 1,49 & 6,17 & 6,61 \\
\hline & Sc4 & 0,39 & 2,04 & 26,26 & 27,82 & 22,61 & 14,44 & 2,66 & 0,70 & 2,90 & 2,60 \\
\hline & Sc5 & 1,23 & 2,98 & 33,15 & 9,64 & 18,11 & 13,80 & 6,20 & 3,61 & 8,65 & 6,83 \\
\hline & Sc6 & 0,43 & 1,85 & 16,05 & 33,14 & 31,06 & 12,71 & 1,92 & 0,15 & 2,86 & 2,11 \\
\hline & Sc7 & 0,15 & 1,76 & 36,84 & 12,37 & 30,10 & 13,66 & 3,34 & 0,57 & 1,59 & 1,52 \\
\hline & Sc8 & 0,80 & 1,72 & 9,05 & 12,03 & 49,47 & 22,67 & 1,95 & 0,38 & 2,10 & 2,36 \\
\hline & $\mathrm{Sc} 9$ & 1,21 & 2,98 & 35,73 & 12,41 & 11,31 & 14,39 & 7,37 & 2,21 & 11,19 & 5,39 \\
\hline & $\mathrm{Sc} 10$ & $* *$ & $* *$ & $* *$ & $* *$ & $* *$ & $* *$ & $* *$ & $* *$ & $* *$ & $* *$ \\
\hline & Sc11 & 0,28 & 2,00 & 31,12 & 18,42 & 31,50 & 9,47 & 3,39 & 1,04 & 2,86 & 2,21 \\
\hline \multirow{10}{*}{ 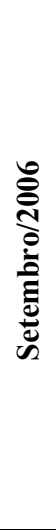 } & $\mathrm{Sc} 1$ & 3,27 & 3,33 & 2,83 & 14,13 & 23,24 & 9,16 & 4,08 & 2,29 & 33,31 & 10,96 \\
\hline & $\mathrm{Sc} 2$ & 1,62 & 2,76 & 7,81 & 26,00 & 22,92 & 16,71 & 7,94 & 2,66 & 9,55 & 6,41 \\
\hline & $\mathrm{Sc} 3$ & 1,64 & 2,94 & 6,80 & 25,26 & 26,54 & 15,51 & 6,61 & 2,49 & 7,93 & 8,87 \\
\hline & $\mathrm{Sc} 4$ & 0,23 & 1,82 & 15,98 & 46,62 & 22,74 & 7,11 & 2,09 & 1,20 & 2,20 & 2,06 \\
\hline & Sc5 & 2,12 & 2,91 & 4,30 & 16,76 & 27,30 & 19,46 & 6,79 & 3,79 & 14,78 & 6,82 \\
\hline & Sc6 & 0,70 & 1,92 & 12,59 & 28,64 & 30,78 & 16,52 & 4,49 & 2,02 & 2,50 & 2,46 \\
\hline & $\mathrm{Sc} 7$ & 0,58 & 2,00 & 8,59 & 34,62 & 35,70 & 9,80 & 3,65 & 1,87 & 2,99 & 2,78 \\
\hline & Sc8 & 1,65 & 2,50 & 2,64 & 20,03 & 28,05 & 27,18 & 8,70 & 0,64 & 6,31 & 6,44 \\
\hline & $\mathrm{Sc} 9$ & 0,26 & 1,75 & 10,95 & 38,81 & 36,47 & 7,51 & 2,02 & 0,65 & 1,38 & 2,20 \\
\hline & Sc10 & 0,97 & 2,52 & 10,40 & 34,68 & 27,52 & 12,24 & 4,08 & 1,64 & 4,05 & 5,40 \\
\hline
\end{tabular}

** estação não amostrada 
5.1.3 Análises geoquímicas e razões elementares

Os resultados das análises geoquímicas encontram-se descritos na Tabela 10 e ilustrados nos Anexos 34 a 42. Os dados referem-se às coletas realizadas nos anos de 2005 e 2006 (Junho e Outubro).

Coletas realizadas em Setembro de 2005

Os valores de $\mathrm{pH}$ e Eh variaram de 7,7 a 8,37 e de -115 a $218 \mathrm{mV}$. Foram obtidos valores negativos de Eh somente nas estações Sc3, Sc9, Sc10 e Sc11.

As concentrações de carbonato de cálcio variaram de 5,93 a $23,87 \%(\bar{x}=13,49 \pm$ 5,28\%), indicando sedimento litoclásticos para a região (Anexo 34).

Os teores de carbono orgânico total oscilaram de 0,15 a $2,27 \%(\bar{x}=1,11 \pm 0,62 \%)$, sendo observadas as maiores e menores porcentagens nas estações Sc5 e Sc6, respectivamente (Anexo 35).

Obteve-se para nitrogênio porcentagens entre 0,01 e $0,10 \%(\bar{x}=0,029 \pm 0,028 \%)$. As maiores concentrações foram identificadas nas estações Sc6, Sc7 e Sc11, as quais estão posicionadas próximas à linha de costa (Anexo 36).

Em relação ao fósforo, foram obtidos os seguintes valores: fósforo total de 0,033 a 0,093\%; fósforo orgânico de 0,0003 a 0,011\% e fósforo inorgânico de 0,031 a 0,085\% (Anexos 37, 38 e 39). As maiores concentrações de fósforo total ocorreram nas estações Sc3, Sc8 e Sc10.

Os teores de enxofre variaram de 0,003 a $0,163 \%(\bar{x}=0,06 \pm 0,05 \%)$, sendo observados os valores mais significativos nas estações Sc9 e Sc10 (Anexo 40).

Os resultados das razões $\mathrm{C} / \mathrm{N}$ foram de 3,0 a 168 e os das razões $\mathrm{C} / \mathrm{S}$ de 4,28 a 236,7 (Anexos 41 e 42).

Coletas realizadas em Junho de 2006

Os valores de pH oscilaram de 7,81 a 8,16 e os de Eh entre -100 e $183 \mathrm{mV}$. Somente as estações Sc5 (-100 mV) e Sc9 (-95 mV) apresentaram valores negativos de Eh. 
As concentrações de carbonato de cálcio foram de 5,03 a 19,37\% $(\bar{x}=11,13 \pm 4,35 \%)$ (Anexo 34).

Em Junho observou-se significativa diminuição nos teores de carbono orgânico total; não foram detectados valores para as estações Sc3 e Sc4. Para as demais estações os teores variaram 0,01 a $0,57(\bar{x}=0,21 \pm 0,25 \%)$. As maiores porcentagens foram identificadas nas estações $\operatorname{Sc} 5(0,57 \%)$ e $\operatorname{Sc} 9(0,56 \%)$ (Anexo 35$)$.

As porcentagens de nitrogênio oscilaram entre 0,02 e $0,18 \%(\bar{x}=0,12 \pm 0,05 \%)$. Os valores obtidos em Junho de 2006 são superiores aos encontrados em Setembro, aproximadamente 2 vezes em relação ao maior valor (Anexo 36).

Para fósforo, foram obtidos os seguintes valores: fósforo total de $0,020 \%$ a $0,50 \%$; fósforo orgânico de 0,002 a 0,011\% e fósforo inorgânico de 0,015 a 0,042\% (Anexos 37, 38 e 39). Excetuando-se a estação $\mathrm{Sc} 9$, as maiores porcentagens de fósforo total tenderam a se concentrar próximo à saída do emissário submarino.

Os teores de enxofre variaram entre 0,003 e $0,21 \%(\bar{x}=0,03 \pm 0,06 \%)$, sendo observada na estação Sc1 a maior porcentagem (Anexo 40).

Os valores das razões $\mathrm{C} / \mathrm{N}$ oscilaram de 0,07 a 19,50 e os das razões $\mathrm{C} / \mathrm{S}$ de 0,17 a 186,67 (Anexos 41 e 42).

\section{Coletas realizadas em Outubro 2006}

Os valores de $\mathrm{pH}$ variaram de 7,45 a 8,04 e os de Eh de -132 a $197 \mathrm{mV}$. Valores negativos de Eh foram obtidos somente nas estações Sc1, Sc3, Sc5 e Sc10.

As porcentagens de carbonato de cálcio foram de 4,32 a 15,97 ( $\bar{x}=10,19 \pm 3,73 \%$ ) (Anexo 34).

Os teores de carbono orgânico total oscilaram de 0,17 a $1,06 \%(\bar{x}=0,45 \pm 0,32 \%)$. A maior concentração foi observada na estação Sc1, localizada na saída do emissário submarino (Anexo 35).

As porcentagens de nitrogênio foram de 0,15 a $0,29 \%(\bar{x}=0,22 \pm 0,05 \%)$. Assim como em Junho, observou-se em Setembro, aumento de concentrações em todas as estações, em média duas vezes, em Setembro (Anexo 36). 
Para fósforo, foram obtidos os seguintes teores: fósforo total 0,018 a 0,056 , fósforo orgânico 0,003 a 0,032\% e fósforo inorgânico 0,001 a 0,038\% (Anexos 37, 38 e 39).

Em relação ao enxofre, foram obtidos valores entre 0,003 e $0,364 \%(\bar{x}=0,082 \pm$ 0,134\%). Os maiores teores foram observados nas estações Sc1 (0,364\%) e Sc5 (0,297\%), localizadas na saída do emissário submarino e região norte da malha de amostragem, respectivamente (Anexo 40).

Os resultados das razões $\mathrm{C} / \mathrm{N}$ variaram de 0,71 e 7,07 (Anexo 41). Já para as razões $\mathrm{C} / \mathrm{S}$ foram obtidos os valores que oscilaram entre 2,91 e 213,3 (Anexo 42). 
Tabela 10 - Resultados geoquímicos e razões elementares obtidos próximo aos difusores do emissário Saco da Capela.

Legenda: n.d. teores não detectados

\begin{tabular}{|c|c|c|c|c|c|c|c|c|c|c|c|c|c|}
\hline \multirow{13}{*}{ 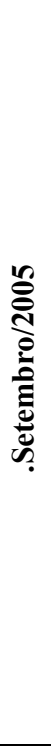 } & Estações & $\begin{array}{l}\text { Prof. } \\
\text { (m) }\end{array}$ & $\mathrm{pH}$ & $\begin{array}{l}\mathrm{Eh} \\
\mathrm{mV}\end{array}$ & $\begin{array}{c}\mathrm{CaCO}_{3} \\
(\%)\end{array}$ & $\begin{array}{l}\text { Cot } \\
(\%)\end{array}$ & $\begin{array}{l}\mathrm{N} \\
(\%)\end{array}$ & $\begin{array}{c}\text { Ptotal } \\
(\%)\end{array}$ & $\begin{array}{l}\text { Porg } \\
(\%)\end{array}$ & $\begin{array}{c}\text { Pinorg } \\
(\%)\end{array}$ & $\begin{array}{c}\text { S } \\
(\%)\end{array}$ & $\begin{array}{c}\text { Razão } \\
\text { C/N }\end{array}$ & $\begin{array}{l}\text { Razão } \\
\text { C/S }\end{array}$ \\
\hline & $\mathrm{Sc} 1$ & $* *$ & $* *$ & $* *$ & $* *$ & $* *$ & $* *$ & $* *$ & $* *$ & $* *$ & $* *$ & $* *$ & $* *$ \\
\hline & $\mathrm{Sc} 2$ & 13,5 & 7,94 & 140 & 10,80 & 0,57 & 0,01 & 0,058 & 0,011 & 0,047 & 0,043 & 57,0 & 13,3 \\
\hline & $\mathrm{Sc} 3$ & 19,5 & 7,7 & -37 & 19,31 & 1,42 & 0,02 & 0,078 & 0,011 & 0,067 & 0,107 & 71,0 & 13,3 \\
\hline & $\mathrm{Sc} 4$ & $* *$ & $* *$ & $* *$ & $* *$ & $* *$ & $* *$ & $* *$ & $* *$ & $* *$ & $* *$ & $* *$ & $* *$ \\
\hline & Sc5 & 26,5 & 8,1 & 214 & 13,09 & 2,27 & 0,02 & 0,050 & 0,0003 & 0,050 & 0,043 & 113,5 & 52,8 \\
\hline & Sc6 & 11,5 & 8,2 & 218 & 5,93 & 0,15 & 0,05 & 0,033 & 0,003 & 0,031 & 0,035 & 3,0 & 4,3 \\
\hline & $\mathrm{Sc} 7$ & 9,5 & 8,19 & 116 & 9,20 & 0,72 & 0,04 & 0,048 & 0,009 & 0,039 & 0,031 & 18,0 & 23,2 \\
\hline & Sc8 & 27,5 & 8,28 & 213 & 16,28 & 0,71 & 0,02 & 0,093 & 0,008 & 0,085 & 0,003 & 35,5 & 236,7 \\
\hline & Sc9 & 29,5 & 8,12 & -115 & 13,30 & 1,68 & 0,01 & 0,058 & 0,0004 & 0,057 & 0,163 & 168,0 & 10,3 \\
\hline & Sc10 & 31,5 & 8,37 & -98 & 23,87 & 1,37 & 0,01 & 0,075 & 0,005 & 0,069 & 0,143 & 137,0 & 9,6 \\
\hline & Sc11 & 23,5 & 8,14 & 56 & 13,93 & 0,91 & 0,1 & 0,054 & 0,001 & 0,053 & 0,035 & 9,1 & 26,0 \\
\hline & $\mathrm{Sc} 12$ & 10,5 & 8,26 & -49 & 9,22 & 1,3 & 0,01 & 0,054 & 0,004 & 0,051 & 0,038 & 130,0 & 34,2 \\
\hline \multirow{11}{*}{ 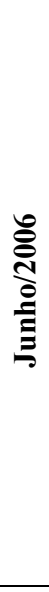 } & $\mathrm{Sc} 1$ & 20 & 7,9 & 48 & 12,08 & 0,39 & 0,02 & 0,040 & 0,006 & 0,034 & 0,211 & 19,50 & 1,85 \\
\hline & $\mathrm{Sc} 2$ & 14 & 8,05 & 170 & 13,15 & 0,13 & 0,15 & 0,033 & 0,007 & 0,026 & 0,003 & 0,87 & 43,33 \\
\hline & $\mathrm{Sc} 3$ & 22 & 8,09 & 160 & 14,23 & n.d. & 0,12 & 0,032 & 0,002 & 0,030 & 0,003 & n.d & n.d \\
\hline & Sc4 & 27 & 8,07 & 63 & 9,171 & n.d. & 0,16 & 0,026 & 0,004 & 0,021 & 0,003 & n.d & n.d \\
\hline & Sc5 & 27 & 7,81 & -100 & 13,76 & 0,57 & 0,18 & 0,043 & 0,011 & 0,033 & 0,006 & 3,17 & 95,00 \\
\hline & Sc6 & 9 & 8,11 & 177 & 5,036 & 0,03 & 0,15 & 0,020 & 0,005 & 0,015 & 0,045 & 0,20 & 0,67 \\
\hline & Sc7 & 12 & 8,12 & 154 & 11,15 & 0,01 & 0,11 & 0,027 & 0,006 & 0,022 & 0,003 & 0,09 & 3,33 \\
\hline & $\mathrm{Sc} 8$ & 27 & 8,16 & 183 & 6,14 & 0,01 & 0,14 & 0,025 & 0,007 & 0,018 & 0,003 & 0,07 & 3,33 \\
\hline & Sc9 & 30 & 7,95 & -95 & 19,37 & 0,56 & 0,13 & 0,050 & 0,008 & 0,042 & 0,003 & 4,31 & 186,67 \\
\hline & Sc10 & $* *$ & $* *$ & $* *$ & $* *$ & $* *$ & $* *$ & $* *$ & $* *$ & $* *$ & $* *$ & $* *$ & $* *$ \\
\hline & $\mathrm{Sc} 11$ & 25 & 7,96 & 131 & 7,237 & 0,01 & 0,03 & 0,025 & 0,005 & 0,021 & 0,06 & 0,33 & 0,17 \\
\hline \multirow{10}{*}{ 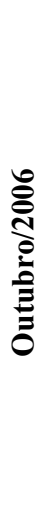 } & $\mathrm{Sc} 1$ & 25 & 7,62 & -119 & 15,46 & 1,06 & 0,15 & 0,037 & 0,007 & 0,030 & 0,364 & 7,07 & 2,91 \\
\hline & $\mathrm{Sc} 2$ & 17 & 7,87 & 97 & 9,99 & 0,29 & 0,21 & 0,028 & 0,004 & 0,024 & 0,003 & 1,38 & 96,67 \\
\hline & $\mathrm{Sc} 3$ & 19 & 7,69 & -132 & 11,84 & 0,64 & 0,28 & 0,056 & 0,032 & 0,024 & 0,003 & 2,29 & 213,33 \\
\hline & $\mathrm{Sc} 4$ & 27 & 8,04 & 118 & 6,52 & 0,17 & 0,24 & 0,020 & 0,007 & 0,014 & 0,003 & 0,71 & 56,67 \\
\hline & Sc5 & 26 & 7,45 & -50 & 15,97 & 0,89 & 0,25 & 0,046 & 0,008 & 0,038 & 0,297 & 3,56 & 3,00 \\
\hline & Sc6 & 10 & 7,97 & 120 & 4,32 & 0,19 & 0,16 & 0,018 & 0,005 & 0,013 & 0,029 & 1,19 & 6,55 \\
\hline & $\mathrm{Sc} 7$ & 10 & 7,72 & 151 & 6,67 & 0,21 & 0,23 & 0,045 & 0,029 & 0,016 & 0,042 & 0,91 & 5,00 \\
\hline & $\mathrm{Sc} 8$ & 27 & 8,04 & 197 & 9,65 & 0,18 & 0,16 & 0,027 & 0,003 & 0,024 & 0,003 & 1,13 & 60,00 \\
\hline & Sc9 & 30 & 7,85 & 177 & 10,35 & 0,29 & 0,29 & 0,024 & 0,023 & 0,0011 & 0,003 & 1,00 & 96,67 \\
\hline & $\mathrm{Sc} 10$ & 32 & 7,62 & -94 & 11,13 & 0,56 & 0,28 & 0,029 & 0,006 & 0,022 & 0,070 & 2,00 & 8,00 \\
\hline
\end{tabular}

** estação não amostrada 
5.1.4 Análise das associações de foraminíferos

5.1.4.1 Biocenoses - composição, distribuição e análise morfométrica

A relação das espécies identificadas nas coletas realizadas em Setembro de 2005, Junho e Outubro de 2006 encontra-se mencionada no Anexo 43.

Coletas realizadas em Setembro de 2005

Para a análise das biocenoses foram utilizados volumes entre 20 e $100 \mathrm{~cm}^{3}$ de sedimento.

Foram identificados 11 gêneros e 65 espécies, as quais se encontram distribuídas por entre as Subordens Textulariina (5 espécies), Miliolina (8 espécies) e Rotaliina (52 espécies).

As densidades oscilaram de 7 a 19 foraminíferos por $10 \mathrm{~cm}^{3}$ de sedimento. A maior densidade foi obtida na estação Sc12, localizada na região nordeste da malha de amostragem.

Foram identificadas entre 16 e 33 espécies $(\bar{x}=22 \pm 5)$. A maior riqueza ocorreu na estação Sc12, sendo o contrário observado na estação Sc5.

Os valores de diversidade específica e equitatividade foram de 2,27 a 2,90 e de 0,76 a 0,83 , respectivamente.

Ammonia tepida $(4,7$ a $28,7 \% ; \bar{x}=18,2 \pm 8,3 \%)$ e Gavelinopsis praegeri $(2,0$ a $32,7 \% ; \bar{x}=14,4 \pm 9,9 \%$ ) são as principais espécies. Secundariamente, as espécies que apresentaram abundâncias relativas significativas foram Brizalina striatula $(2,1$ a $20,4 \% ; \bar{x}=$ $8,9 \pm 5,8 \%)$, Hanzawaia boueana (0 a 12,1\%; $\left.\bar{x}=7,7^{ \pm} 4,2 \%\right)$, Neocornobina terquemi $(1,0$ a $\left.12,6 \% ; \bar{x}=5,6^{ \pm} 3,8 \%\right)$ e Brizalina sphatulata $\left(0\right.$ a $\left.14,4 \% ; \bar{x}=5,6^{ \pm} 4,1 \%\right)$.

Espécies epifaunais ebioindicadoras de ambiente óxico são predominantes em quase todas as estações. As abundâncias relativas variaram entre 27,8 e $76,6 \%\left(\bar{x}=48,3^{ \pm} 17,2 \%\right)$ (Anexo 44).

Espécies bioindicadoras de enriquecimento orgânico, por sua vez, ocorreram em abundâncias relativas que oscilaram de 5,1 a $41 \%(\bar{x}=23,9 \pm 11,5 \%)$ (Anexo 44). 
Os resultados obtidos pela análise morfométrica indicou a presença de quatro classes de tamanho para as carapaças dos foraminíferos, ou seja, pequenas, médias, grandes e pertencentes à macroforaminíferos (Anexo 45). Carapaças médias são predominantes em todas as estações em porcentagens que foram de 60 a $71 \%(\bar{x}=67,4 \pm 3,59 \%)$. Carapaças pequenas ocorreram em porcentagens que variaram entre 15 e $31 \%(\bar{x}=20,4 \pm 5 \%)$. As porcentagens de carapaças grandes oscilaram de 7 a $19 \%(\bar{x}=11 \pm 3,71 \%)$. Macroforaminíferos ocorreram nas estações Sc2, Sc3, Sc7, Sc8 e Sc4, em porcentagens que foram de 1 a 4\% (Anexo 45).

\section{Coletas realizadas em Junho de 2006}

Foram identificados 14 gêneros e 71 espécies de foraminíferos, as quais se encontram distribuídas entre as Subordens Miliolina (10 espécies), Textulariina (13 espécies) e Rotaliina (48 espécies).

Para a análise das biocenoses foram utilizados volumes de sedimento que oscilaram entre 20 e $70 \mathrm{~cm}^{3}$.

Os valores de densidade foram de 22 a 53 foraminíferos por $10 \mathrm{~cm}^{3}$ de sedimento; os maiores valores ocorreram nas estações $\mathrm{Sc} 3, \mathrm{Sc} 7$ e Sc11.

As riquezas oscilaram de 20 a 33 espécies $\left(\bar{x}=28^{ \pm} 4\right)$. A estação Sc5 apresentou o maior número de espécies, sendo o contrário observado na estação Sc11.

Os valores de diversidade específica foram de 2,55 a 3,02. Já para a equitatividade foram obtidos valores entre 0,78 e 0,90 .

Assim como o verificado em Setembro de 2005, as espécies mais abundantes são Ammonia tepida (1,9 a 27,2\%; $\bar{x}=10,8 \pm 7,3 \%$ ) e Gavelinopsis praegeri ( 0 a $20 \% ; \bar{x}=10,6$ $\pm 6,7 \%$ ). Posteriormente, as espécies que apresentaram significativas abundâncias relativas foram Hanzawaia boueana $(4,3$ a $18,7 \% ; \bar{x}=9,3 \pm 4,4 \%)$, Neocornobina terquemi $(1,0$ a $11,4 \% ; \bar{x}=6,0 \pm 3,7 \%)$, Rosalina floridensis $(1,1$ a $13,6 \% ; \bar{x}=5,5 \pm 4,0 \%)$, Brizalina striatula $(0,6$ a $12,0 \% ; \bar{x}=5,5 \pm 3,8 \%)$, Spirilina vivipara $(0$ a $13,7 \% ; \bar{x}=4,9 \pm 3,9 \%)$, Bolivina pseudoplicata $(0,6$ a $7,6 \% ; \bar{x}=3,7 \pm 2,4 \%)$, Bolivina ordinaria $\left(0\right.$ a $6,9 \% ; \bar{x}=3,1^{ \pm}$ 
$2,4 \%)$, Lepidoteuramina ochracea (0 a 9,0\%; $\left.\bar{x}=2,6^{ \pm} 3,2 \%\right)$ e Ammonia parkinsoniana (0 a $7,3 \% ; \bar{x}=3,1 \pm 2,2 \%)$.

Espécies bioindicadoras de ambiente óxico continuam como predominantes em Junho de 2006, as abundâncias relativas oscilaram entre 31,5 e $74,8 \%\left(\bar{x}=55,5^{ \pm} 14,5 \%\right)$ (Anexo 44). Por outro lado, verificou-se aumento na abundância de espécies bioindicadoras de ambiente rico em matéria orgânica, cujas porcentagens foram de 13,5 a $33,7 \%(\bar{x}=25,8 \pm$ $8,1 \%$ ) (Anexo 44).

Os resultados das análises morfométricas indicaram a presença de carapaças pequenas,médias, grandes e pertencentes à macroforaminíferos (Anexo 45). Carapaças médias são predominantes em porcentagens que variaram de 63 a $79 \%(\bar{x}=67,1 \pm 4,97 \%)$. Carapaças pequenas ocorreram em abundâncias que foram de 11 a $28 \%(\bar{x}=22,4 \pm 5,01 \%)$. Carapaças grandes foram observadas em todas as estações em porcentagens que oscilaram entre 6 e $15 \%$ $\left(\bar{x}=10^{ \pm} 2,53 \%\right)$. Macroforaminíferos estiveram presentes somente nas estações Sc3, Sc6, $\mathrm{Sc} 7$ e Sc8, em porcentagens que variaram de 1 a $2 \%$.

\section{Coletas realizadas em Outubro de 2006}

Para a análise das biocenoses utilizou-se volumes de sedimento que foram de 10 e 20 $\mathrm{cm}^{3}$ de sedimento.

Foram identificados 18 gêneros e 72 espécies de foraminíferos, as quais se distribuem entre as Subordens Textulariina ( 8 espécies), Miliolina (12 espécies) e Rotaliina (52 espécies).

Comparativamente, verificou-se significativo aumento nas densidades em Outubro de 2006, as quais variaram de 50 a 213 foraminíferos por $10 \mathrm{~cm}^{3}$ de sedimento $\left(\bar{x}=116^{ \pm} 52\right)$.

O número de espécies oscilou entre 29 e 45 espécies $\left(\bar{x}=36^{ \pm} 5\right)$, sendo as maiores riquezas observadas nas estações $\mathrm{Sc} 2$ (45 espécies) e Sc7 (41 espécies). As menores riquezas, por sua vez, ocorreram nas estações Sc4 e Sc8, ambas com 29 espécies.

Os valores de diversidade específica e equitatividade foram de 2,89 a $3,41(\bar{x}=3,17 \pm$ $0,19)$ e de 0,85 a $0,91\left(\bar{x}=0,88^{ \pm} 0,03\right)$. 
Ammonia tepida $\left(1,7\right.$ a $\left.20,3 \% ; \bar{x}^{\bar{x}}=10,1 \pm 5,38 \%\right)$ e Gavelinopsis praegeri $(2,0$ a $16 \%$; $(\bar{x}=7,8 \pm 4,29 \%)$ são as espécies mais abundantes. Subsequentemente, as espécies que apresentaram expressivas abundâncias foram Brizalina striatula $(0,9$ a $11,3 \% ; \bar{x}=6,0 \pm$ $3,64 \%)$, Neocornobina terquemi ( 0 a $18 \% ; \bar{x}=5,6 \pm 5,02 \%)$, Hanzawaia boueana (0 a $11,3 \% ; \bar{x}=5,0 \pm 3,82 \%)$, Rosalina floridensis $(3,0$ a $5,6 \% ; \bar{x}=4,0 \pm 1,02 \%)$, Bolivina pseudoplicata (0 a 7,8\%; $\left.\bar{x}=3,7^{ \pm} 2,35 \%\right)$, Lepidodeuteramina ochracea ( 0 a $8,5 \% ; \bar{x}=3,2$ $\pm 2,93 \%)$; Spirilina vivipara (0 a $8,4 \% ; \bar{x}=3,1 \pm 2,37 \%)$ e Ammonia parkinsoniana (0 a $6,6 \% ; \bar{x}=3,0 \pm 2,03 \%)$.

Espécies bioindicadoras de ambiente óxico e ambiente enriquecido por matéria orgânica estiveram presentes quase na mesma proporção (Anexo 44). As abundâncias relativas da primeira associação de espécies variaram de 19,7 a $63 \%\left(\bar{x}=44,3^{ \pm} 16,48 \%\right)$ e as pertencentes à segunda associação foram de 19,8 a $61,2 \%(\bar{x}=33,2 \pm 12,35 \%)$.

Os resultados das análises morfométricas indicaram a presença de foraminíferos com carapaças pequenas, médias, grandes e pertencentes à macroforaminíferos (Anexo 45). Carapaças médias permanecem como predominantes, em proporções que variaram de 51 a $71 \%(\bar{x}=58 \pm 6,59 \%)$. As porcentagens de carapaças pequenas oscilaram de 14 a $37 \%(\bar{x}=$ $30 \pm 7,02 \%$ ). Entre os períodos verificou-se ligeiro aumento de porcentagem de carapaças pequenas em Outubro. Carapaças grandes foram identificadas em todas as estações em porcentagens que variaram de 4 a $19 \%(\bar{x}=11 \pm 4,59 \%)$. Macroforaminíferos foram observados somente nas estações $\mathrm{Sc} 5$ a Sc8 e Sc10, em porcentagens que foram de 1 a 5\%.

5.1.4.2 Tanatocenoses - composição, distribuição, aspectos morfométricos e tafonômicos (coloração e grau de preservação)

A relação das espécies e gêneros identificados nas coletas realizadas em Setembro de 2005, Junho e Outubro de 2006 encontra-se mencionada no Anexo 46. 
Identificou-se 20 gêneros e 85 espécies de foraminíferos, as quais estão distribuídas entre as Subordens Textulariina (11 espécies), Miliolina (18 espécies) e Rotaliina (56 espécies). Algumas das espécies identificadas encontram-se ilustradas na Prancha 1.

Foram obtidos entre 10 e 634 espécimes por $10 \mathrm{~cm}^{3}$ de sedimento. As maiores densidades ocorreram nas estações Sc3 e Sc10, sendo o contrário observado na estação Sc6, localizada na região leste da malha de amostragem

As riquezas variaram de 6 a 54 espécies, com o maior número de espécies presente na estação Sc12.

As diversidades específicas oscilaram de 2,40 a 3,50 e as equitatividades de 0,74 a 0,92 .

Para as estações Sc6 e Sc8 não foram calculados índices de diversidade específica e equitatividade, devido à baixa densidade obtida.

Cassidulina crassa (0 a 23,4\%; $\bar{x}=9,0 \pm 7,59 \%)$ e Pararotalia cananeiaensis $(0$ a $23 \% ; \bar{x}=10,2 \pm 7,58 \%$ ) são as espécies predominantes. Subsequentemente, as espécies que apresentaram as maiores abundâncias relativas foram Ammonia tepida ( 0 a $13.7 \% ; \bar{x}=6,7^{ \pm}$ 4,01\%), a qual é predominante nas estações Sc7 e Sc12, Rosalina floridensis $(1,4$ a $10 \% ; \bar{x}=$ $4,1 \pm 2,82 \%)$, Lepidodeuteramina ochracea ( 0 a $12,9 \% ; \bar{x}=3,0 \pm 4,56 \%)$, Bulimina marginata (0 a $6,5 \% ; \bar{x}=2,4 \pm 2,24 \%)$, Lobatula lobatula (0 a $16,1 \% ; \bar{x}=2,3 \pm 4,89 \%$ ) e Discorbis williamsoni (0 a 9,7\%; $\bar{x}=1,9 \pm 2,88 \%)$.

Desconsiderando-se as estações Sc6 e Sc8, verificou-se predomínio de espécies bioindicadoras de ambiente rico em matéria orgânica (Anexo 47). As abundâncias relativas variaram de 28,1 a $46 \%(\bar{x}=34,5 \pm 6,1 \%)$. Espécies biondicadoras de ambiente óxico ocorreram em abundâncias relativas que foram de 13,8 a $35,6 \%\left(\bar{x}=24,4^{ \pm} 8,7 \%\right)$ (Anexo 47).

Os resultados das análises morfométricas indicaram que carapaças pequenas e médias estiveram presentes quase na mesma proporçãona área de estudo (Anexo 48). As porcentagens de carapaças pequenas variaram entre 32,10 e $55,24 \%(\bar{x}=44,28 \pm 8,78 \%)$. As estações Sc9 e Sc10 apresentaram as maiores abundâncias. Carapaças médias ocorreram em 
porcentagens que foram de 38,1 a $55,74 \%\left(\bar{x}=47^{ \pm} 5,72 \%\right)$. Carapaças grandes foram observadas em porcentagens que oscilaram de 1,75 a $11,44 \%(\bar{x}=6,85 \pm 3,69 \%)$. Macroforaminíferos foram identificados em quase todas as estações, em baixas concentrações, entre 0 e 6,3\%. Os resultados das estações Sc6 e Sc8 foram desconsiderados, uma vez que os resultados poderiam ser mascarados devido à baixa densidade de espécimes.

No tocante a análise tafonômica, verificou-se que em grande maioria as carapaças apresentam-se parcialmente fragmentadas, devido à abrasão mecânica (Anexo 49). As porcentagens obtidas foram de 33,3 a $85,6 \%(\bar{x}=60,9 \pm 16,6 \%)$. As porcentagens de carapaças inteiras oscilaram entre 11 e $65,1 \%\left(\bar{x}=35^{ \pm}\right.$17,6\%). A maior porcentagem foi identificada na estação Sc9. Foram observados fragmentos de carapaças em todas as estações, em concentrações que variaram de 1,6 a $7,8 \%\left(\bar{x}=4,1{ }^{ \pm} 2,1 \%\right)$.

As carapaças são predominantemente normais $(70,8$ a 95,2; $\bar{x}=86,4 \pm 8,2 \%$ ) (Anexo 50). Foram poucos os exemplares que apresentaram-se com sinais de limonitização ou preenchimento por monossulfeto de ferrro/pirita (Anexo 50). As porcentagens de carapaças com coloração acastanhadas oscilaram de 0,9 a $16,9 \%(\bar{x}=8,5 \pm 5,5 \%)$. Já carapaças preenchidas por monossulfeto de ferro/pirita estiveram presentes em concentrações que foram de 0,6 a $12,3 \%(\bar{x}=5,2 \pm 4,1 \%)$.

Carapaças com sinais de bioerosão somente ocorreram nas estações Sc2 (Quinqueloculina sp) e Sc3 (Bulimina marginata).

\section{Coletas realizadas em Junho de 2006}

Foram identificados 36 gêneros e 129 espécies, as quais se encontram distribuídas por entre as Subordens Textulariina (22 espécies), Miliolina (25 espécies) e Rotaliina (82 espécies).

Aumento significativo de densidades ocorreu entre Setembro de 2005 e Junho de 2006. Os valores obtidos foram de 160 a 6560 foraminíferos por $10 \mathrm{~cm}^{3}$ de sedimento. A estação Sc1 apresentou a maior densidade, sendo verificado o contrário na estação Sc8.

As riquezas variaram entre 40 e 77 espécies $\left(\bar{x}=57^{ \pm} 11\right)$, sendo observado na estação Sc7, localizada na região sudeste da malha de amostragem, o maior número de espécies. 
As diversidades específicas e equitatividades foram de 3,09 a 3,92 e de 0,81 a 0,92, respectivamente.

Pararotalia cananeiaensis é a espécie predominante, suas abundâncias relativas oscilaram entre 4 e $17,9 \%(\bar{x}=12,2 \pm 4,8 \%)$. Posteriormente, as espécies que apresentaram abundâncias relativas significativas foram Ammonia tepida $(2,0$ a $10,4 \% ; \bar{x}=5,0 \pm 2,8 \%)$, Cassidulina crassa $\left(1,3\right.$ a $\left.7,8 \% ; \bar{x}=4,3^{ \pm} 1,9\right)$, Gavelinopsis praegeri $\left(2,8\right.$ a $6,9 \% ; \bar{x}=3,8^{ \pm}$ $1,2 \%)$, Cribroelphidium excavatum $(0,6$ a $9,3 \% ; \bar{x}=3,2 \pm 2,5 \%)$ e Rosalina floridensis $(0,5$ a 5,$\left.0 ; \bar{x}=2,4^{ \pm} 1,2 \%\right)$.

Espécies infaunais e bioindicadoras de enriquecimento orgânico são predominantes na área de estudo (Anexo 47). As abundâncias relativas oscilaram de 27,3 a 37,6\% ( $\bar{x}=31,9 \pm$ 3,9\%). Por outro lado, espécies bioindicadoras de ambiente óxico ocorreram em abundâncias que variaram de 13,2 a $42,7 \%(\bar{x}=28,7 \pm 8,9 \%)$. As maiores concentrações foram identificadas nas estações Sc2, Sc4, Sc7, Sc8 (Anexo 47).

Foram identificados foraminíferos com carapaças pequenas, médias, grandes e pertencentes à macroforaminíferos (Anexo 48). Excetuando-se a estação Sc1, carapaças médias são predominantes, em concentrações que variaram de 37,1 a $54,1 \%\left(\bar{x}=49,6^{ \pm}\right.$ $5,34 \%$ ). Dominantes na estação Sc1, carapaças pequenas ocorreram em porcentagens que variaram de 32,5 a $60,6 \%(\bar{x}=41,7 \pm 8,10 \%)$. As porcentagens de carapaças grandes oscilaram entre 1,5 e 12,1\% $\left(\bar{x}=6,1^{ \pm} 3,46 \%\right)$. As maiores abundâncias foram observadas nas estações Sc2 (12,1\%) e Sc7 (10,8\%). Macroforaminíferos estiveram presentes em todas as estações $(0,4$ a $8,6 \%)$.

No tocante ao grau de preservação, verificou-se dominância de carapaças parcialmente fragmentadas por abrasão mecânica, as quais ocorreram em porcentagens que variaram de 49,2 a $71,2 \%\left(\bar{x}=58,3^{ \pm} 7,7 \%\right)$ (Anexo 49). As porcentagens de carapaças inteiras oscilaram entre 24,9 e $43,1 \%(\bar{x}=34,4 \pm 6,9 \%)$, sendo as maiores concentrações observadas nas estações Sc2 e Sc11 (Anexo 49). Fragmentos de carapaças estiveram presentes em todas as estações, em porcentagens entre 2,8 e $14,4 \%(\bar{x}=7,3 \pm 3,1 \%)$ (Anexo 49).

Assim como o observado em Setembro de 2005, carapaças normais são predominantes, em porcentagens que variaram de 62,4 a $93,0 \%(\bar{x}=81,8 \pm 10,8 \%)$. As 
estações Sc9 e Sc11 apresentaram as maiores concentrações, sendo observado o contrário na estação Sc1 (Anexo 50). As porcentagens de carapaças acastanhadas foram de 3 a $22 \%$ ( $\bar{x}=$ $11,1 \pm 5,5 \%)$. Carapaças preenchidas por monossulfeto de ferro/pirita ocorreram em abundância significativa na estação Sc1 (27,3\%), sendo observado para as demais estações porcentagens que oscilaram de 1,3 a 13,4\% (Anexo 50).

Carapaças com sinais de bioerosão foram observadas nas estações Sc2 (Quinqueloculina lamarckiana), Sc5 (Lenticulina sp), Sc6 (Cassidulina crassa, Ammonia tepida e Lenticulina), Sc7 (Ammonia tepida e Bolivina compacta) e Sc11 (Brizalina striatula, Rosalina floridensis e Cassidulina crassa).

Coletas realizadas em Outubro de 2006

Foram identificados 23 gêneros e 58 espécies de foraminíferos, as quais se distribuem entre as Subordens Miliolina (5 espécies), Textulariina (7 espécies) e Rotaliina (46 espécies), sendo esta dominante em todos os períodos analisados.

Foram obtidos entre 323 e 3512 foraminíferos por $10 \mathrm{~cm}^{3}$ de sedimento. As estações Sc1 e Sc2 apresentaram as maiores densidades. O contrário, por sua vez, foi observado nas estações Sc3 (416 foraminíferos), Sc4 (323 foraminíferos) e Sc (412 foraminíferos). As riquezas oscilaram de 29 a 41 espécies $(\bar{x}=33 \pm 4 \%)$. As diversidades específicas e equitatividades variaram de 2,6 a 3,11 e de 0,76 a 0,86, respectivamente.

Pararotalia cananeiaensis é a espécie mais abundante na área de estudo. As abundâncias relativas oscilaram entre 7,5 e 20,7\% $(\bar{x}=14,8 \pm 4,2 \%)$. Secundariamente, as espécies que apresentaram as maiores abundâncias relativas foram Ammonia tepida (5,6 a 14,$\left.8 ; \bar{x}=9^{ \pm} 2,9 \%\right)$, Cassidulina crassa $\left(5,4\right.$ a $\left.12,7 \% ; \bar{x}=8,7^{ \pm} 2,2 \%\right)$, Discorbis williamsoni $\left(1,8\right.$ a $\left.6,9 \% ; \bar{x}=3,9^{ \pm} 1,6 \%\right)$, Pseudononion atlanticum $\left(1,5\right.$ a 5,$\left.8 ; \bar{x}=3,4^{ \pm} 1,6 \%\right)$, Rosalina floridensis (0 a 6,$\left.1 ; \bar{x}=1,9^{ \pm} 1,7 \%\right)$ e Haynesina germanica $\left(0\right.$ a $\left.7,7 \% ; \bar{x}=2,3^{ \pm} 2,6 \%\right)$.

Espécies infaunais e bioindicadoras de ambiente enriquecido por matéria orgânica são dominantes em todas as estações analisadas (28,9 a 42,9\%; $\bar{x}=36,5 \pm 4,5 \%$ ) (Anexo 47). Comparativamente, em Outubro de 2006, verificou-se declínio na porcentagem de espécies 
bioindicadoras de ambiente óxico; as abundância relativas foram de 9,4 a 28,7\% ( $\bar{x}=19,8 \pm$ $6,2 \%)$ (Anexo 47).

Os resultados das análises morfométricas indicaram a predominância de carapaças médias na área de estudo (Anexo 48). As porcentagens oscilaram entre 47,6 a 58,7\% $(\bar{x}=$ $53,1 \pm 3,90 \%$ ). Carapaças pequenas foram observadas em concentrações que variaram de 34 a $43,6 \%\left(\bar{x}=38^{ \pm} 3,17 \%\right)$. Carapaças grandes, por sua vez, ocorreram em concentrações que foram de 5,5 a $10,9 \%\left(\bar{x}=7,8^{ \pm} 1,70 \%\right)$. Macroforaminíferos, apesar de presentes em todas as estações, foram observados em baixas porcentagens, entre 0,3 a 3,1\%.

Em todas as estações as carapaças apresentaram bom grau de preservação, em grande maioria inteiras, as porcentagem obtidas foram de 66,5 a $83 \%(\bar{x}=74,4 \pm 6,57 \%)$ (Anexo 49). Carapaças parcialmente fragmentadas, devido à abração mecânica, ocorreram em porcentagens que oscilaram de 14,4 a $29,1 \%(\bar{x}=21,1 \pm 4,94 \%)$. As estações Sc6 e Sc8 apresentaram as maiores concentrações, sendo o contrário observado nas estações Sc1 e Sc2. Fragmentos de carapaças estiveram presentes em porcentagens que variaram de 1,2 a 11,8\% ( $\bar{x}=4,5 \pm 3,16 \%)$.

Assim como o observado para os demais períodos, carapaças normais são predominantes em todas as estações (Anexo 50). As porcentagens obtidas oscilaram de 82,5 a 98\% $(\bar{x}=91,4 \pm 4,88 \%)$. Carapaças acastanhadas estiveram presentes em concentrações que foram de 1,3 a $8 \%\left(\bar{x}=4,5^{ \pm} 2,31 \%\right)$. Carapaças preenchidas por monossulfeto de ferro/pirita ocorreram em porcentagens que variaram entre 0 e $13 \%\left(\bar{x}=4,0^{ \pm} 4,27 \%\right)$. As estações $\mathrm{Sc} 1 \mathrm{e}$ $\mathrm{Sc} 2$ apresentaram as maiores concentrações.

Carapaças com sinais de bioerosão somente foram observadas nas estações $\mathrm{Sc} 4$ e Sc10. 


\subsubsection{Análises estatísticas dos dados}

\subsection{Coeficientes de correlação de Pearson (r)}

Os resultados das correlações de Pearson encontram-se nos Anexos 51, 52 e 53.

Em Setembro de 2005 (Anexo 51), observou-se que os valores de riqueza são negativamente influenciadas pelo Eh dos sedmentos $(r=-0,63 ; p<0,05)$. Já em relação à composição, verificou-se que Brizalina striatula possui sua distribuição significantemente associada aos sedimentos finos $(r=0,80 ; p<0,01)$ com elevados teores de enxofre $(r=0,71$; $p<0,05)$, bem como à salinidade $(\mathrm{r}=0,91 p<0,0,1)$. Hanzawaia boueana correlaciona-se positivamente com os valores de temperatura $(\mathrm{r}=0,65 ; p<0,05)$ e negativamente com os teores de nitrogênio $(\mathrm{r}=-0,70 ; p<0,05)$. A distribuição de Gavelinopsis praegeri está positivamente relacionada aos valores de $\mathrm{Eh}(\mathrm{r}=0,77 ; p<0,05)$. Já Neocornobina terquemi possui distribuição inversa aos teores de enxofre $(\mathrm{r}=-0,64 ; p<0,05)$.

Em Junho de 2006 (Anexo 52), observou-se que a distribuição de Ammonia tepida ocorre positivamente em relação aos teores de carbono orgânico total $(\mathrm{r}=0,64 ; p<0,05)$. Brizalina striatula está positivamente associada aos teores de carbono orgânico $(\mathrm{r}=0,67 ; p<$ 0,05), bem como possui padrão similar de distribuição ao observado pela Ammonia tepida (r $=0,90 ; p<0,01)$. A distribuição de Gavelinopsis praegeri encontra-se positivamente relacionada às profundidades $(\mathrm{r}=0,67 ; p<0,05)$ e à salinidade $(\mathrm{r}=0,65 ; p<0,05)$. Bolivina pseudoplicata, por sua vez, possui suas abundâncias relativas negativamente associadas às profundidades $(\mathrm{r}=-0,77 ; p<0,01)$.

Assim como para os demais períodos, em Outubro de 2006 (Anexo 53), não foi observada influência da matéria orgânica (carbono orgânico total, nitrogênio, fósforo e enxofre) sobre os valores de densidade, riqueza, diversidade específica e equitatividade. Os valores de riqueza, conforme correlações obtidas, são positivamente influenciadas pelos valores de temperatura $(\mathrm{r}=0,75 p<0,05)$ e de salinidade $(\mathrm{r}=0,73 p<0,05)$. Em relação às espécies, verificou-se que Gavelinopsis praegeri possui sua distribuição inversa ao observado para sedimentos finos $(\mathrm{r}=-0,68 ; p<0,05)$ e fósforo inorgânico $(\mathrm{r}=-0,68 ; p<0,05)$. As abundâncias relativas de Neocornobina terquemi são negativamente associadas aos teores de carbono orgânico total $(\mathrm{r}=-0,83 ; p<0,01)$ e em menor escala aos teores de enxofre $(\mathrm{r}=$ $0,65 ; p<0,05)$. A distribuição de Rosalina floridensis e Spirilina vivipara é positivamente 
associada aos valores de temperatura e salinidade. Bolivina pseudoplicata, por sua vez, tem sua distribuição relacionada aos valores de temperatura $(\mathrm{r}=0,65 ; p<0,05)$.

\subsection{Estudo comparativo da estrutura das associações de foraminíferos}

\subsection{Biocenoses - estudo comparativo entre os periodos de coleta}

Diferenças significativas foram observadas na composição das associações de foraminíferos entre os períodos analisados (Figura 20).

Entre Setembro e Junho (Figura 20 A), verificou-se maior diferenciação somente para o Eixo $1(\mathrm{t}=5,691 ; p<0,001)$. Os valores obtidos para o Eixo 2 foram $\mathrm{t}=1,292 ; p=0,213$. Foi observado baixo valor de estresse $(0,28)$, o que indica ausência de distorção de dados na técnica utilizada.

Entre Setembro e Outubro (Figura 20 B), a diferenciação ocorreu nos dois eixos, porém com baixo nível de significância no Eixo 2. Os valores encontrados foram Eixo $1 \mathrm{t}=$ 8,221; $p<0,001$ e Eixo $2 \mathrm{t}=-0,650 ; p=0,07$. O valor do estresse obtido foi 0,23, considerado baixo.

Em relação a comparação realizada entre Junho e Outubro (Figura $20 \mathrm{C}$ ), a diferenciação composicional ocorreu somente no Eixo $2(\mathrm{t}=-3,513 ; p=0,002)$. Os resultados obtidos para o Eixo 1 foram $\mathrm{t}=-0,869 ; p=0,397)$. O estresse obtido foi de 0,33 , apesar de superior às demais comparações, também é considerado baixo.

Descritivamente foi observado que somente $36 \%$ das espécies identificadas são comuns aos três períodos de estudo, diferindo, entretanto, em suas abundâncias relativas. Como esperado, as espécies comuns são as que possuem maior representatividade, tais como Ammonia tepida, Brizalina striatula, Gavelinopsis praegeri, Hanzawaia boueana, Neocornobina terquemi, entre outras. 
(A)

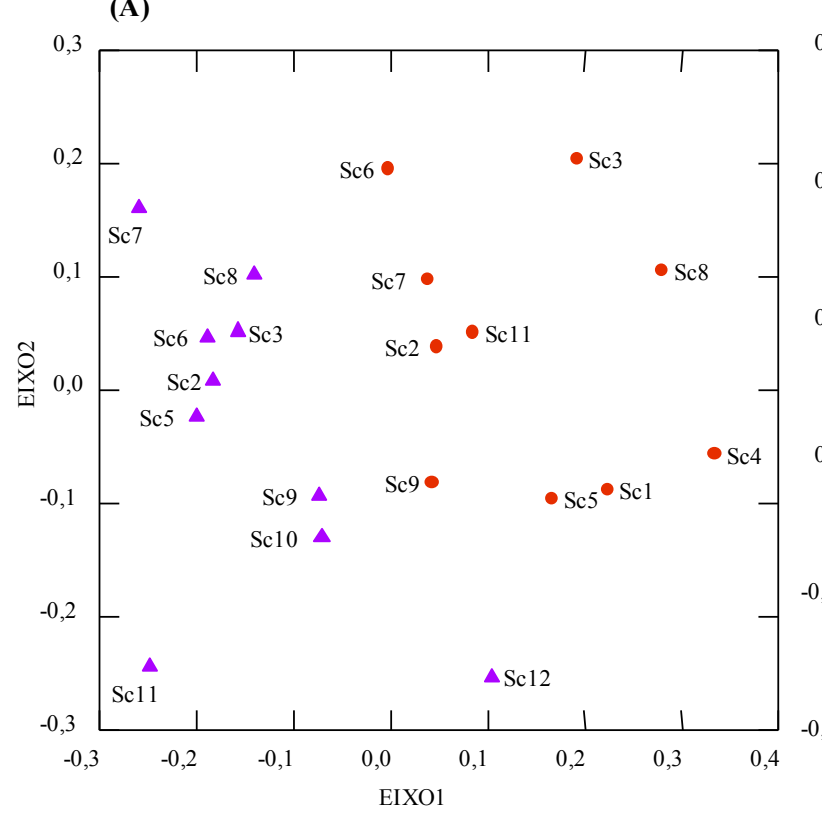

Legenda:

- Setembro de 2005

- Junho de 2006
(B)

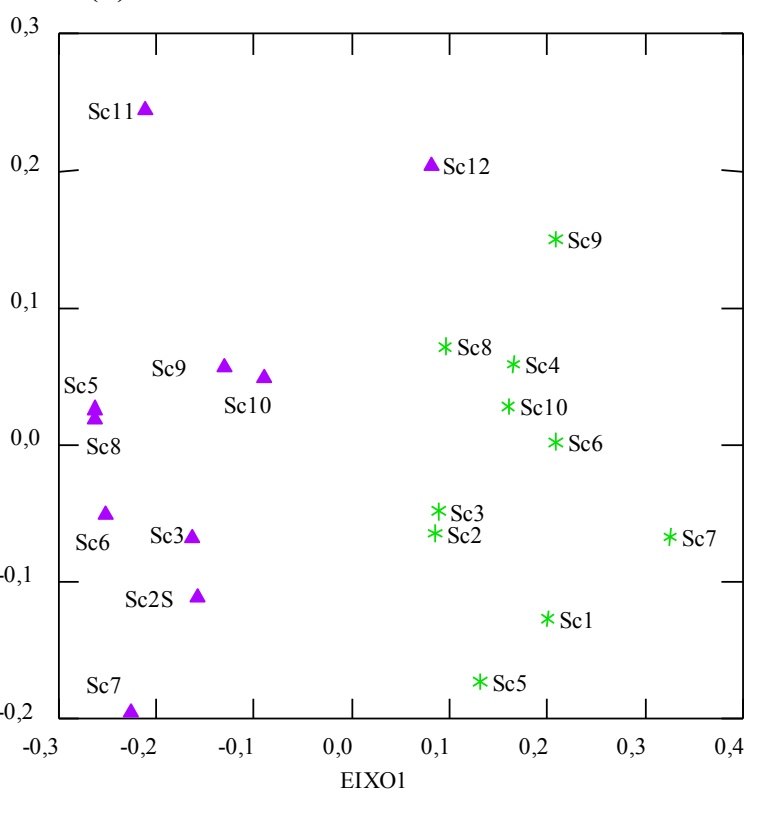

- Setembro de 2005
(C)

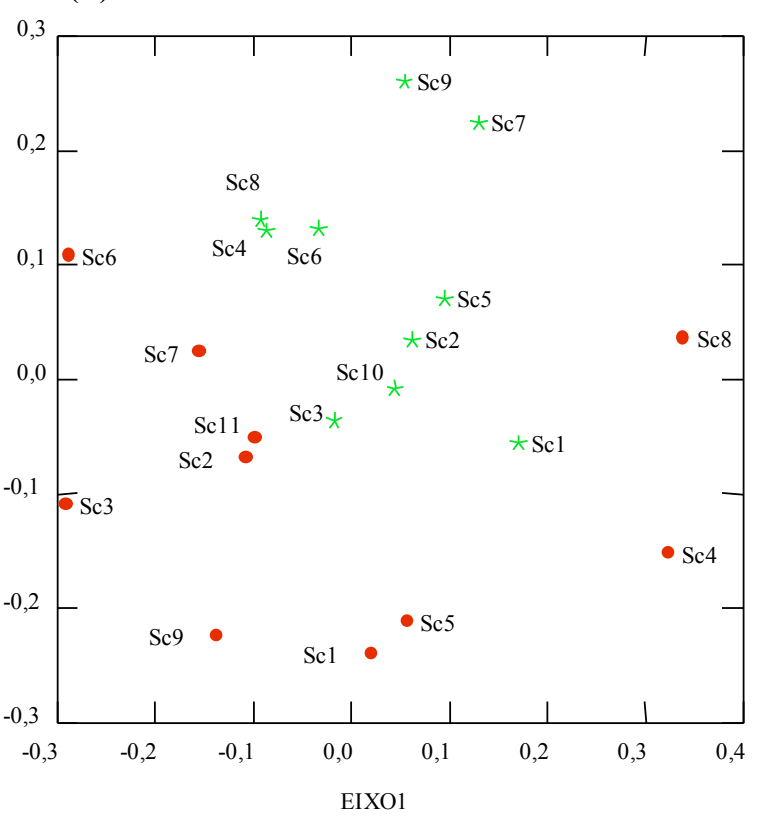

- Junho de 2006

Figura 20 - Gráficos de ordenação obtidos no estudo comparativo entre as biocenoses.

Dados referentes à Setembro de 2005, Junho e Outubro de 2006. 
5.1.4.3.2.2 Tanatocenoses - estudo comparativo entre os periodos de coleta

Entre os períodos estudados, foram verificadas significativas diferenças composicionais, conforme pode ser observado na Figura 21.

Entre Setembro de 2005 e Junho de 2006, apesar de ser observada dissimilaridade composicional, os níveis de significância são considerados baixos. Os valores observados foram Eixo $1 \mathrm{t}=1,957 ; p=0,066$ e Eixo $2 \mathrm{t}=1,570 ; p=0,134$.

Entre Setembro de 2005 e junho de 2006, verificou-se diferenciação em ambos os eixos. Os valores obtidos para o Eixo 1 foram $\mathrm{t}=4,361$; $p<0,001$ e para o Eixo 2 foram $\mathrm{t}=$ 2,$202 ; p=0,041$.

Em relação à comparação realizada entre Junho e Outubro, verificou-se diferenciação significativa somente no Eixo $1(\mathrm{t}=-43,970 ; p<0,001)$. Os valores para o Eixo 2 foram $\mathrm{t}=$ 0,$043 ; p=0.966$.

Para todos os períodos foram obtidos baixos valores de estresse (inferiores a 0,26), o que indica ausência de distorção dos dados nas técnicas utilizadas.

Descritivamente, somente $23 \%$ das espécies são comuns aos três períodos de estudo. Dentre as espécies identificadas menciona-se Pararotalia cananeiaensis, Ammonia tepida, Cassidulina crassa, Discorbis williamsoni, Pseudononion atlanticum, Buliminella elegantissima, Bulimina marginata, Bolivina pulchella e Hanzawaia boueana. 

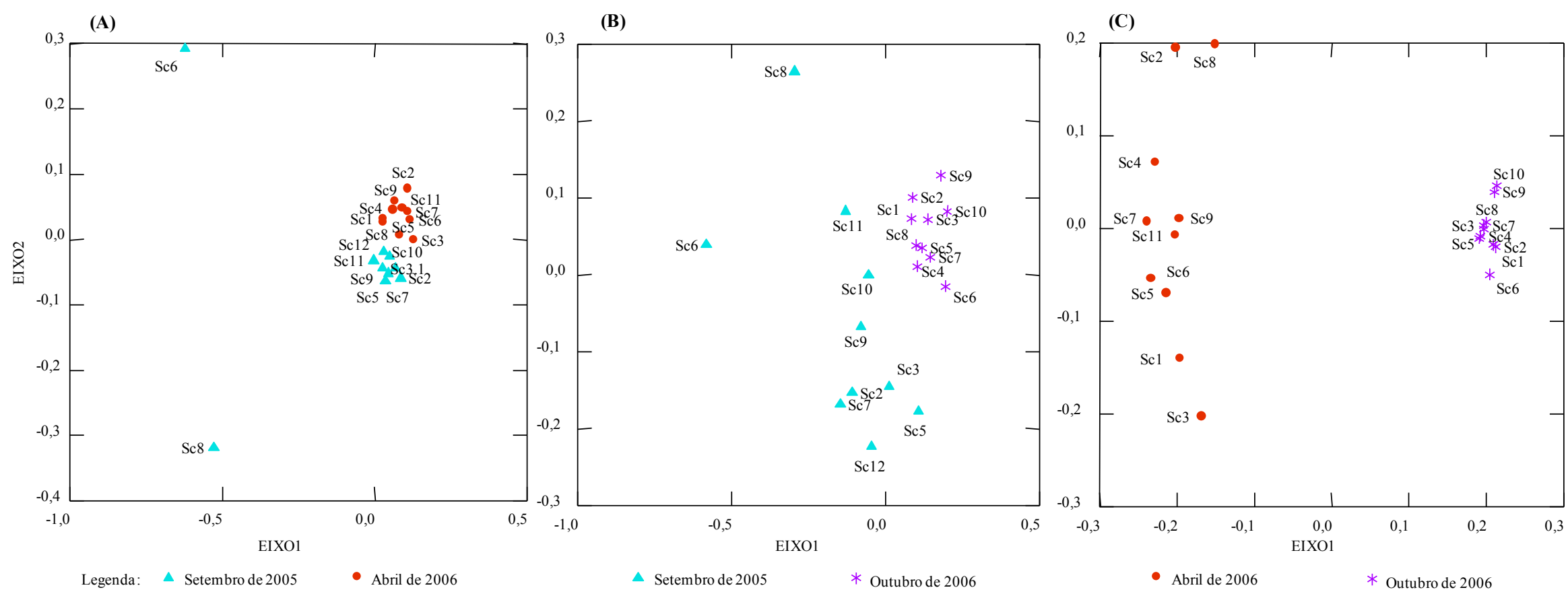

Figura 21 - Diagramas de ordenação obtidos no estudo comparativo entre as tanatocenoses.

Dados referentes às coletas realizadas em

Setembro de 2005, Junho e Outubro de 2006. 
5.1.4.3.2.3 Biocenoses versus Tanatocenoses - estudo comparativo entre os periodos de coleta

Em todos os períodos analisados, verificou-se diferenciação na estrutura composicional das associações de foraminíferos que compuseram as biocenoses e tanatocenoses. Os resultados encontram-se ilustrados na Figura 22.

Em Setembro de 2005 (Figura 22 A), a dissimilaridade foi significantemente evidenciada no Eixo 2, os valores obtidos foram $\mathrm{t}=-6,362 ; p<0,001$. Já para o Eixo 1, os resultados foram $=-1,191 ; p=0,249$.

Em Junho e Outubro de 2006 (Figura 22 B), as diferenciações foram observadas em elevado nível de significância somente no Eixo 1. Os resultados para Junho foram Eixo $1 \mathrm{t}=$ 14,221; $p<0,001$ e Eixo $2 \mathrm{t}=-0,050 ; p=0,961$.

Em Outubro (Figura $22 \mathrm{C}$ ), por sua vez, foram obtidos os seguintes valores Eixo $1 \mathrm{t}=$ - 48,377; $p<0,001$ e Eixo 2 os valores $\mathrm{t}=0,058 ; p=0,955$

Os valores de estresse são considerados baixos, i.e. inferiores a 0,22 , motivo pelo qual infere-se ausência de distorção de dados na técnica utilizada.

Conforme observado na Figura 21, verifica-se maior homogeneidade na composição das associações de foraminíferos que compuseram as biocenoses, em Setembro de 2005. Tal inferência corrobora os valores de diversidade específica e equitatividade obtidos no período (q.v. Anexo 43).

Descritivamente, verificou-se que somente $50 \%$ das espécies identificadas na área de estudo são comuns às biocenoses e tanatocenoses, havendo, entretanto, expressiva diferença nas abundâncias. As espécies comuns são consideradas as mais abundantes em ambas as associações, tais Ammonia tepida, Bolivina spp, Gavelinopsis praegeri, Pararotalia cananeiaensis, Hanzawaia boueana, Pseudononion spp, entre outras espécies. 

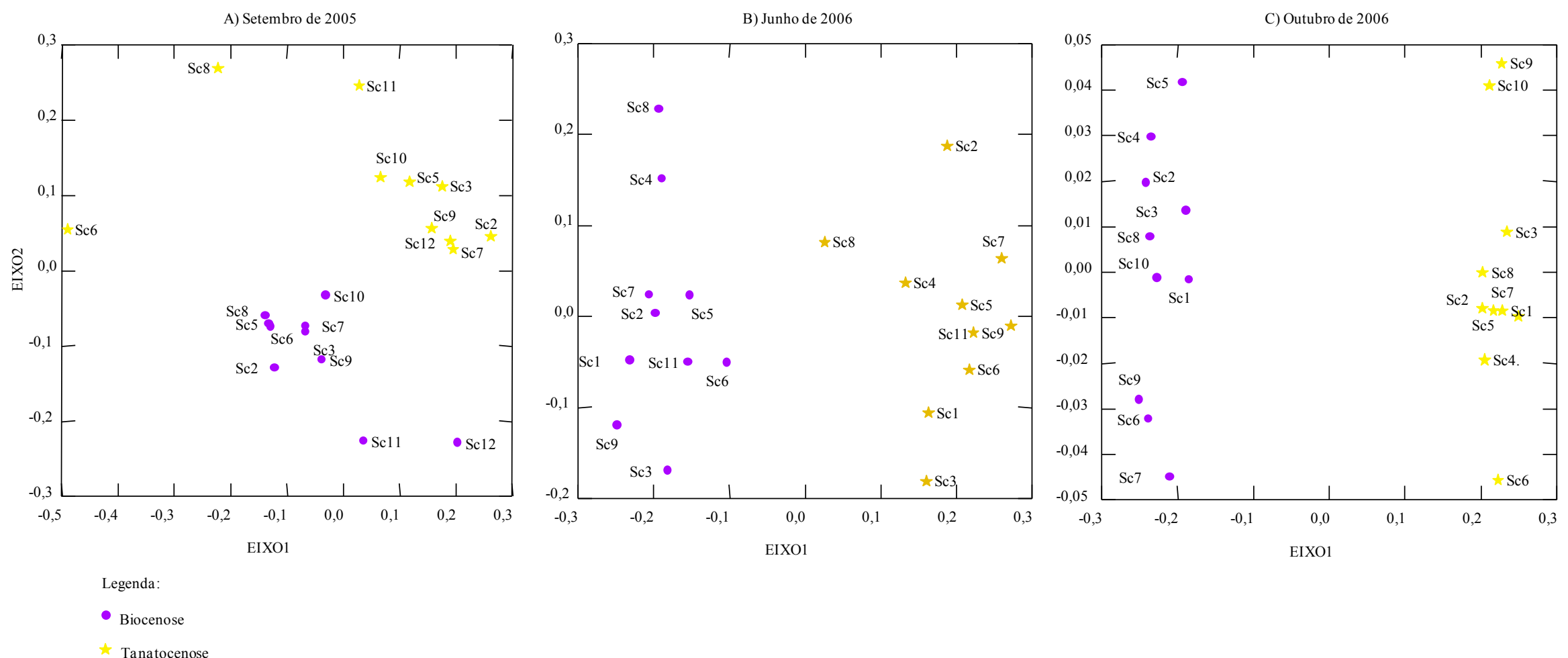

Figura 22 - Diagramas de ordenação obtidos nos estudos comparativos entre biocenoses e tanatocenoses.

Dados referentes à Setembro de 2005, Junho e Outubro de 2006. 
As Análises de Agrupamento, em modo Q, corroboram as diferenças na estrutura composicional existentes entre as biocenoses e tanatocenoses.

Em todos os períodos de estudo, verificou-se a separação das estações em dois grupos distintos, com seus respectivos subgrupos (Figuras 23, 24 e 25).

Em Setembro de 2005 (Figura 23), com nível de similariade igual a 0,45, verificou-se que as as estações que compõem as biocenoses dividem-se em dois subgrupos, sendo o B1.1, o qual engloba as estações $\mathrm{Sc} 3, \mathrm{Sc} 5, \mathrm{Sc} 7, \mathrm{Sc} 8$ e Sc6 e o subgrupo B1.2, composto pelas estações Sc9 e Sc10. As estações Sc11 e Sc12 não foram associadas aos subgrupos formados. Para as tanatocenoses, observou-se a formação de três subgrupos, o T1.1, o qual abrange as estações Sc11 e Sc5; o grupo T1.2 composto pelas estações Sc12, Sc10, Sc9 e Sc3 e o T.1.3 formado pelas estações Sc7 e Sc2. As estações Sc8 e Sc6 não foram associadas aos subgrupos; tal fato pode estar relacionado à baixa densidade de foraminíferos obtida nas duas estações.

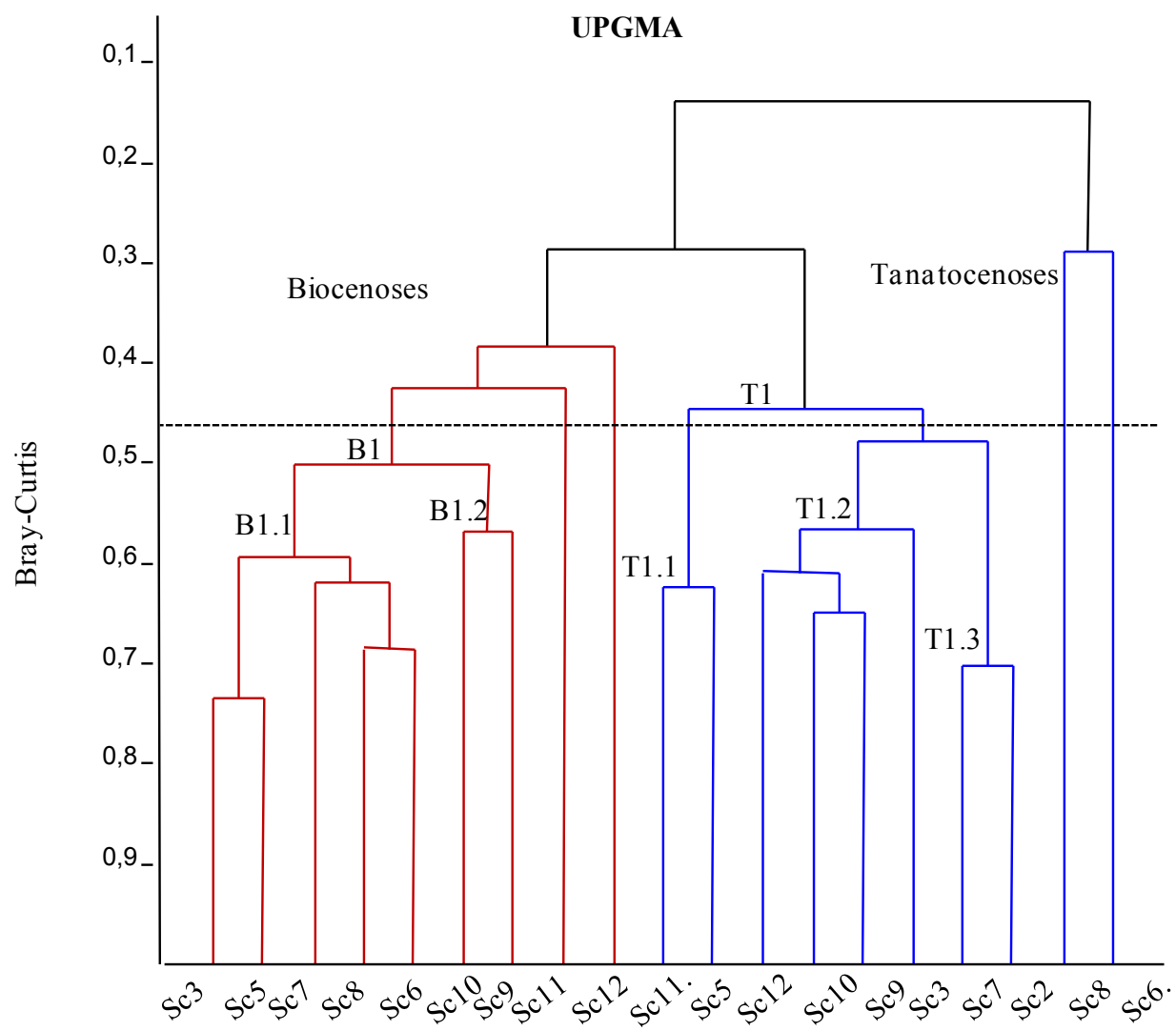

Figura 23 - Dendrograma, modo Q, obtido para o período de Setembro de 2005. 
Em Junho de 2006 (Figura 24), com nível de similaridade igual a 0,50, observou-se que as estações pertencentes às biocenoses subdividem-se em grupo B1, o qual engloba as estações Sc8 e Sc4, o grupo B2, composto pelas estações Sc3, Sc7 e sc2 e o grupo B3, que abrange as estações Sc6, Sc9, Sc1, Sc11 e Sc5. As tanatocenoses subdividiram-se em dois grupos, sendo o T1, formado somente pelas estações Sc8 e Sc2 e o grupo T2 composto pelas demais estações.

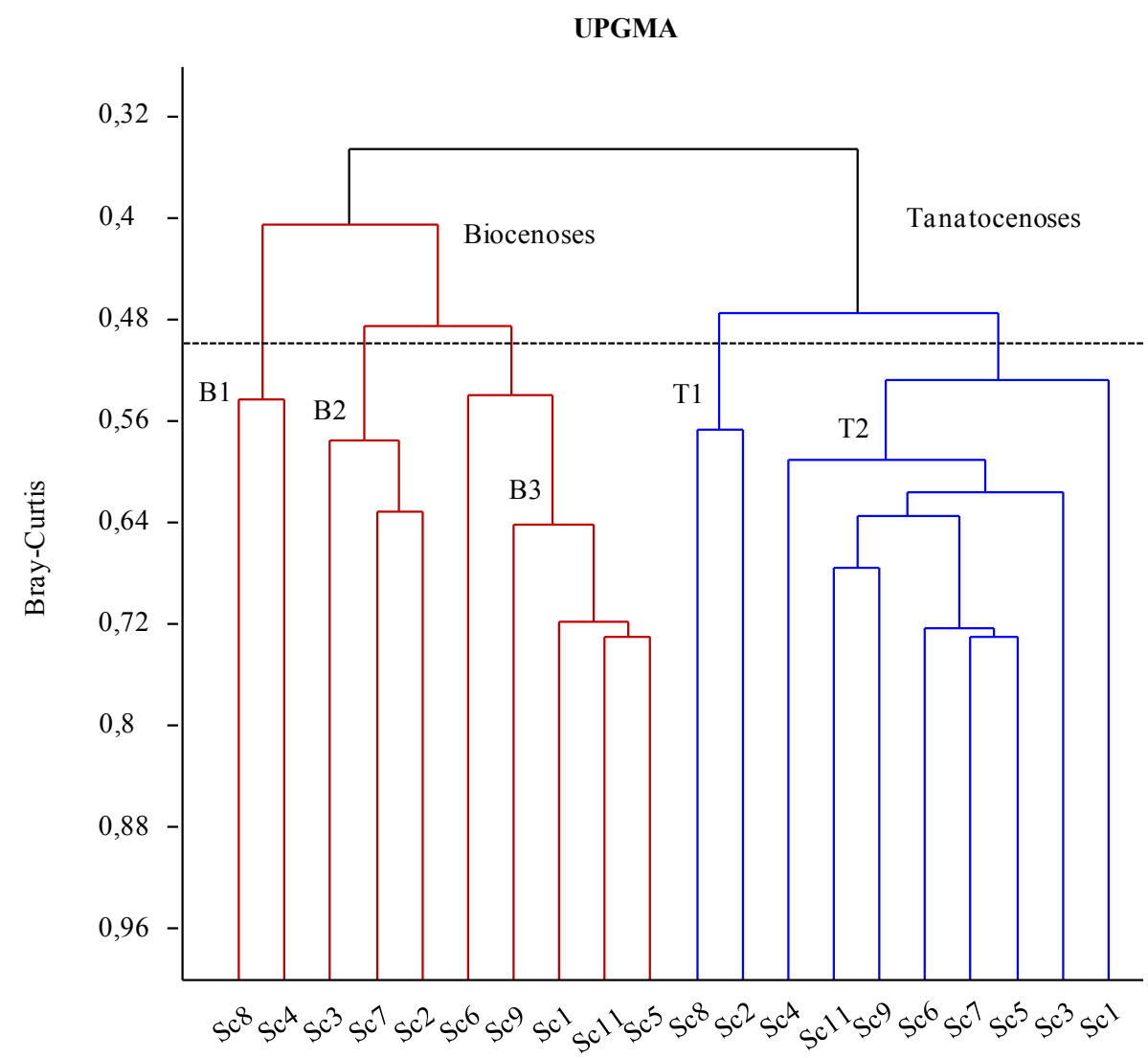

Figura 24 - Dendrograma, modo Q, obtido para o período de Junho de 2006.

Para Outubro de 2006 (Figura 25), com nível de similaridade igual a 0,50, as biocenoses dividiram-se em dois grupos, o B1, que é composto pelos subgrupos o B1.1 (estações Sc8 e Sc4) e o B1.2 (estações Sc3, Sc7 e Sc2). O grupo B2, por sua vez, abrange as estações Sc6, Sc9, Sc1, Sc11 e Sc5. As tanatocenoses formaram dois grupos, o T1, o qual abrange as estações Sc8 e Sc2 e o T2, que engloba as demais estações. 


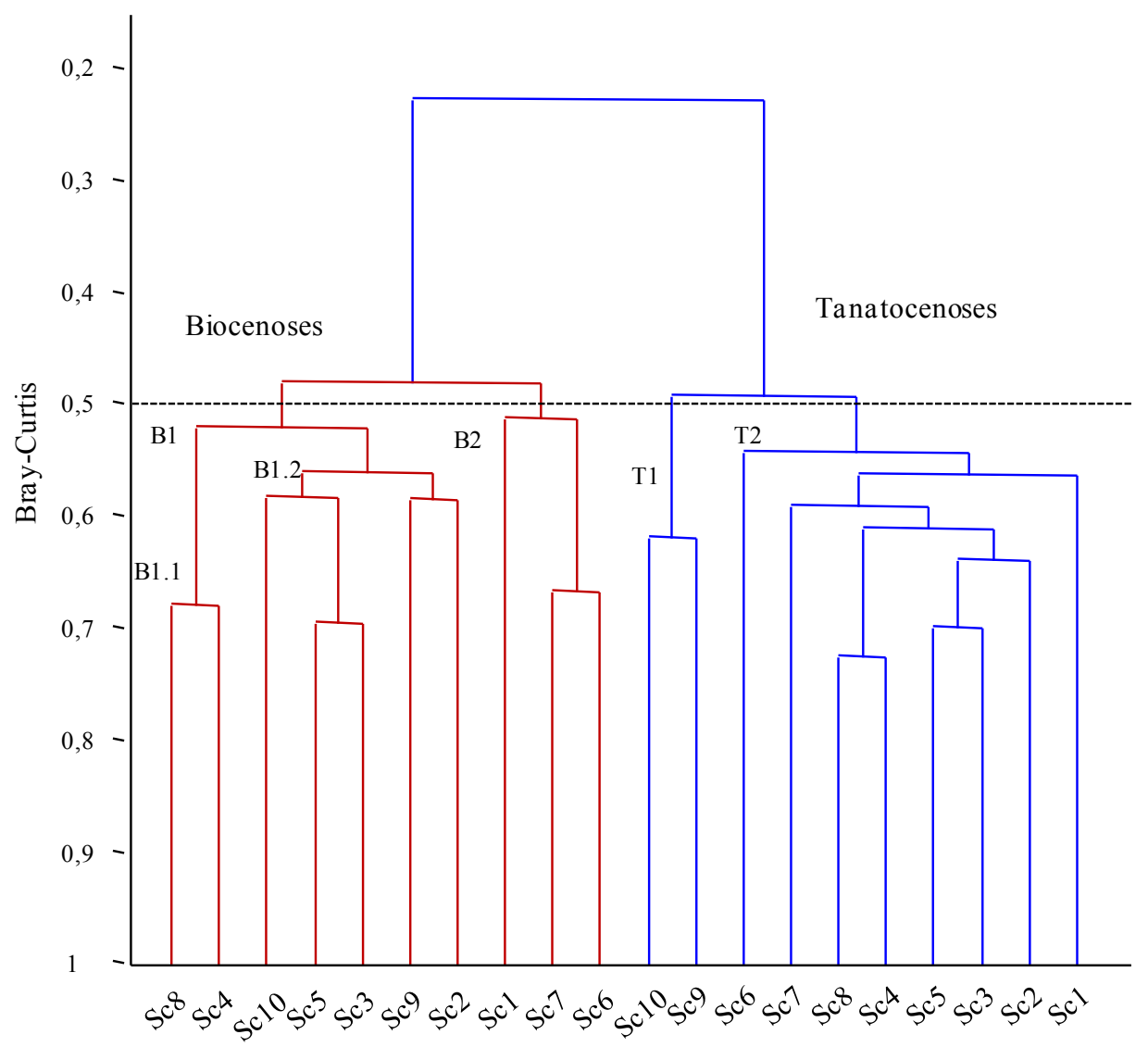

Figura 25 - Dendrograma, modo Q, obtido para o período de Outubro de 2006.

\subsection{Análise de Correspondência Canônica}

Os resultados obtidos na Análise de Correspondência Canônica permitiram inferir que o nitrogênio, o enxofre, a profundidade e a areia são os principais fatores ambientais que influenciam a distribuição das espécies de foraminíferos que compuseram as biocenoses (Figura 26).

Juntos, os Eixos 1 e 2, explicam 70,3\% da variância do relacionamento existente entre as espécies de foraminíferos e os parâmetros abióticos. O Eixo 1 explica 41,2\%, ao passo que o Eixo 2 explica 29,1\% das variâncias existentes (Tabela 11). 
Tabela 11 - Síntese dos resultados obtidos pela Análise de Correspondência Canônica.

\begin{tabular}{lccccc}
\hline \multicolumn{1}{c}{ Eixos } & 1 & 2 & 3 & 4 & Inércia total \\
\hline Autovalores & 0,073 & 0,051 & 0,033 & 0,02 & 0,63 \\
\hline Correlações: espécies - ambiente & 0,796 & 0,79 & 0,816 & 0,816 & \\
Variância em porcentagem acumulada: & & & & & \\
dos dados das espécies & 11,5 & 19,7 & 24,9 & 28 & \\
dos dados das espécies e ambiente & 41,2 & 70,3 & 88,8 & 100 & \\
\hline
\end{tabular}

Ao lado positivo do Eixo 1 associaram-se as espécies Cornuspira involvens, Cancris sagra, Brizalina sphatulata, Hanzawaia boueana, Discorbis williamsoni, Gavelinopsis praegeri, Neocornobina terquemi. Ao lado negativo do Eixo 1, relacionam-se as espécies Rosalina floridensis, Discorbis berthelotti, Cassidulina crassa, Bolivina pseudoplicata, Ammotium salsum, Bulimina marginata, Bolivina compacta, Bolivina ordinaria, Spirilina vivipara.

Ao lado positivo do Eixo 2 associaram-se as espécies Ammonia tepida, Brizalina striatula, Pseudononion atlanticum, Siphogenerina raphanus e Buliminella elegantissima. No lado negativo encontram-se as espécies Patelina corrugata, Quinqueloculina lamarckiana, Triloculina oblonga, Lepidodeuteramina ochracea, Trochammina squamata, Miliolinella subrotunda, Quinqueloculina milletti e Triloculina laevigata.

As espécies Angulogerina angulosa e Ammonia parkinsoniana estão associadas aos Eixos 1 e 2, lados positivo e negativo, respectivamente. O posicionamento da espécie Lobatula lobatula no centro do diagrama de ordenação indica que sua distribuição ocorre de forma aleatória, ou mesmo, de acordo com alguma variável não selecionada pelo programa CANOCO. 


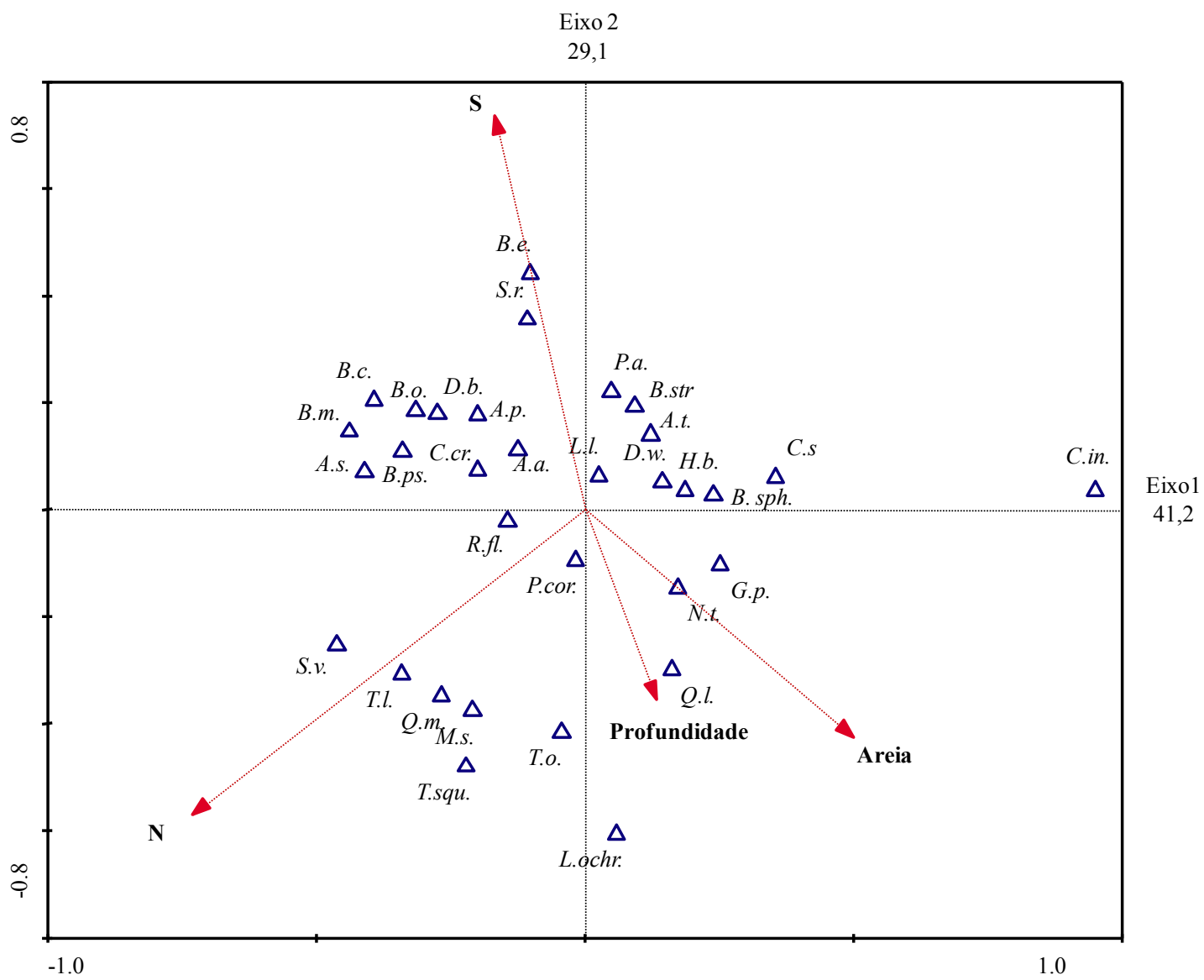

Figura 26 - Diagrama de ordenação da relação existente entre as espécies de foraminíferos que compõem as biocenoses e os parâmetros abióticos.

Legenda: A.p. (Ammonia parkinsoniana), A.t. (Ammonia tepida), A.s. (Ammotium salsum), A.a. (Angulogerina angulosa), B.c. (Bolivina compacta), B.o. (Bolivina ordinaria), B.ps. (Bolivina pseudoplicata), B.sph. (Brizalina sphatulata), B.s. (Brizalina striatula), B.m. (Bulimina marginata), B.e. (Buliminella elegantissima), C.s. (Cancris sagra), C.cr. (Cassidulina crassa), C.in. (Cornuspira involvens), D.b. (Discorbinella berthelotti), D.w. (Discorbis williamsoni), G.p. (Gavelinopsis praegeri), H.b. (Hanzawaia boueana), L. ochr. (Lepidodeuteramina ochracea), L.1. (Lobatula lobatula), M.s. (Miliolinella subrotunda), N.t. (Neocornobina terquemi), P.cor. (Patelina corrugata), P.a. (Pseudononion atlanticum), Q.1. (Quinqueloculina lamarckiana), Q.m. (Quinqueloculina milletti), R.fl.(Rosalina floridensis), S.r. (Siphogenerina raphanus), S.v. (Spirilina vivipara), T.1. (Triloculina laevigata), T.o. (Triloculina oblonga), T.squ. (Trochammina squamata).

O diagrama de ordenação, da relação existente entre as estações e os parâmetros ambientais, infere que a amostragem realizada em Setembro de 2005 foi realizada em local com características ambientais diferentes das observadas para as coletas feitas em Junho e Outubro de 2006 (Figura 27). 
Pelo posicionamento das estações, verificou-se que em Setembro as amostras foram coletadas em ambiente com predominância de sedimentos arenosos, com baixos teores de nitrogênio. As espécies que estão associadas ao mesmo lado do eixo, excetuando-ses Brizalina sphatulata, são epifaunais, comumente identificadas em ambientes bem oxigenados.

As amostragens realizadas em Junho e Outubro de 2006, segundo as variáveis ambientais e espécies associadas, indicam que grande maioria das estações foram amostradas em ambiente com expressivos teores de nitrogênio e concentrações de enxofre oscilando entre baixas e intermediárias, as profundidades estão entre intermediárias e profundas. Somente a estação Sc1 foi amostrada em local com elevados teores de enxofre.

Em relação às amostras coletadas próximo aos difusores do Saco da Capela, o ponto controle, estação $\mathrm{C} 3$, encontra-se posicionado em ambiente raso, com valores intermediários de enxofre.

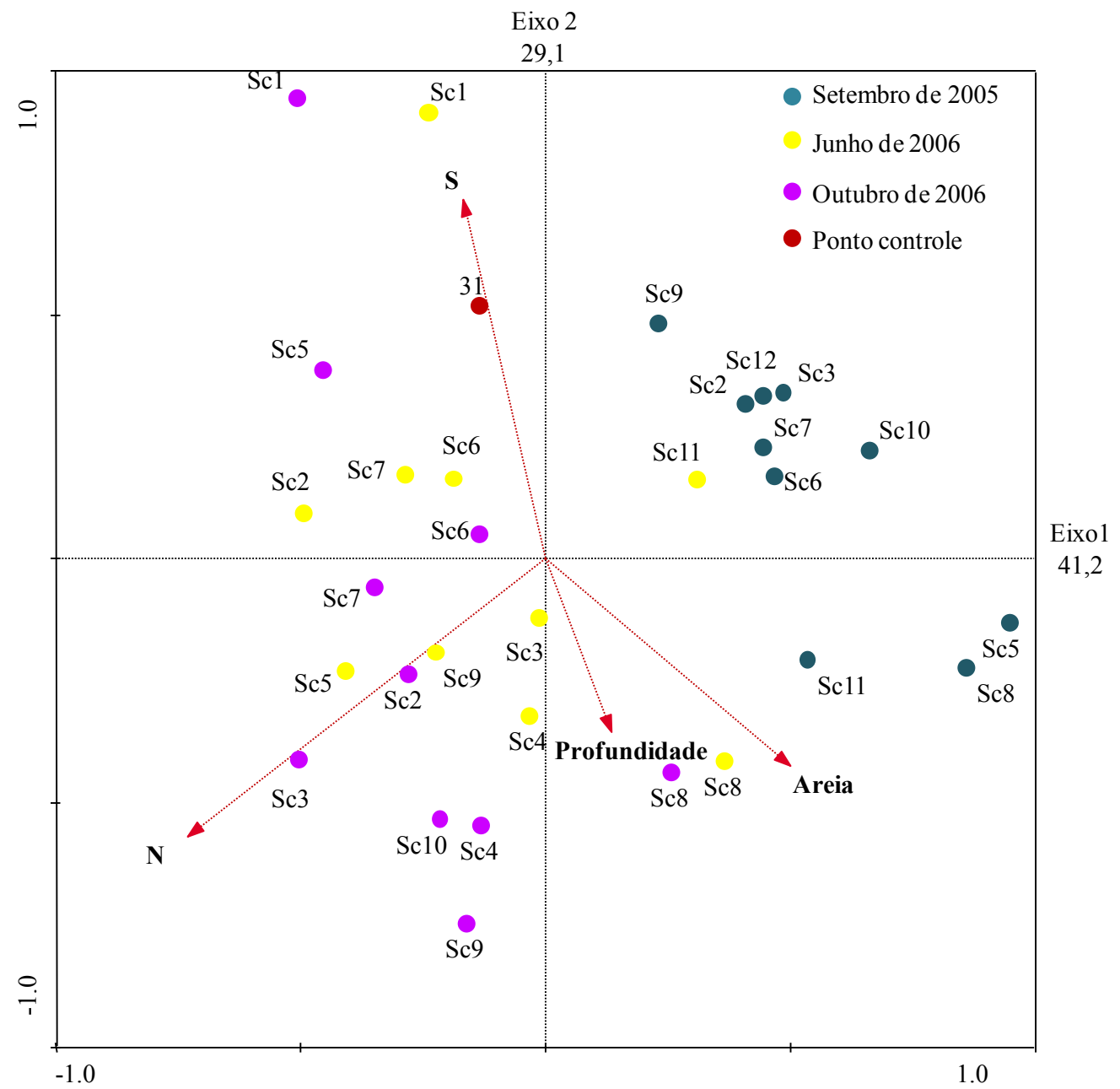

Figura 27 - Diagrama de ordenação das relações existentes entre as estações e os parâmetros abióticos. 


\subsection{DISCUSSÃO}

\subsubsection{Parâmetros físico-químicos da coluna d'água}

Para as amostragens realizadas em Setembro de 2005 e Junho de 2006 prevaleceram condições de quase homogeneidade para a temperatura e salinidade. Os valores termohalinos indicaram a presença da massa Água Costeira durante os dois períodos de coleta, o que já esperado, uma vez que é a massa de água atuante no interior do canal quase o ano inteiro. Já em Outubro de 2006, verificou-se estratificação significativa de temperatura ao longo da coluna d'água; as amostras de água de fundo apresentaram-se, de 3 a $8{ }^{\circ} \mathrm{C}$ mais frias em relação às águas de superfície. Pelos dados de temperatura, infere-se a presença da Água Costeira e da Água Central do Atlântico Sul, em Outubro. De acordo com Pires-Vanin (2008), a Água Central do Atlântico Sul ocorre no canal no final da primavera, atingindo seu auge no verão, quando pode chegar muito próxima à costa, em profundidades menores do que dez metros (Pires-Vanin, 2008).

Contudo, é raro seu afloramento em águas superficiais (Silva et al., 2001). Como na superfície há domínio da Água Costeira, forma-se uma bem definida termoclina à meia água (Aidar et al., 1993), similar a observada no presente estudo. A entrada desta massa de água, para o interior do canal, ocorre pela calha existente na entrada sul, lado insular (Silva et al., 2001). A intrusão da Água Central do Atlântico Sul pode restringir-se à entrada sul ou preencher todo o canal (FUNDESPA, 2009).

Somente em Outubro foram obtidos níveis de oxigênio dissolvido abaixo do limites de proteção à vida aquática, para águas salinas Classe 1. Infere-se que não se trata de consumo de oxigênio dissolvido para degradação de elevada quantidade de matéria orgânica, uma vez que os valores de turbidez são considerados baixos, inferiores até mesmo aos valores obtidos em períodos anteriores aos da análise. Os valores obtidos podem ser decorrentes de problemas técnicos com o equipamento, contudo, outra hipótese plausível e já apresentada por Esteves (1998), é um período prolongado de estratificação térmica.

Observou-se estratificação ao longo do dia da coleta, porém não há como precisar se em dias anteriores a mesma ocorreu. Nas camadas de superfície, 80\% das estações apresentaram-se com valores acima de $6 \mathrm{mg} \mathrm{L}^{-1}$ ou muito próximo a este valor. A depleção de 
oxigênio dissolvido foi mais significativa em estações com as mais expressivas diferenças de temperatura entre superfície e fundo, tais como estações Sc8, Sc9 e Sc10.

Os dados de turbidez são considerados baixos quando comparados aos observados na região circundante ao emissário do Araçá. O padrão de distribuição dos valores de turbidez nas águas de meio e fundo dos dois primeiros períodos de coleta, indica dispersão da pluma gerada pelo efluente de sudeste para norte-noroeste da malha de amostragem.

A partir dos resultados das análises de nutrientes, constatou-se que a coluna d'água não apresentava sinais de impacto devido ao efluente disposto pelo emissário. Contudo, deve ser ressaltado que os valores baixos podem estar associados ao potencial de diluição e/ou dispersão pelas correntes existentes no interior do canal, as quais podem atingir velocidades de $1,0 \mathrm{~m} \mathrm{~s}^{-1}$ para o norte, lado insular (Furtado et al., 208), local onde está posicionado o difusor do emissário submarino.

Apesar de no presente estudo não terem sido evidenciadas alterações ambientais de origem antrópica no compartimento aquoso, salienta-se conspícua ocorrência de contaminação por coliformes fecais, a qual é atribuída tanto a fonte difusa, bem como ao esgoto disposto pelo emissário submarino, cujo difusor encontra-se somente a $220 \mathrm{~m}$ da linha de costa (CETESB, 2008, 2009).

\subsubsection{Parâmetros granulométricos e geoquímicos}

Observou-se heterogeneidade granulométrica marcante na área circundante aos difusores do emissário submarino Saco da Capela. Apesar do constante retrabalhamento dos sedimentos de fundo, inferido pelos baixos teores de sedimentos finos, não há seletividade no tamanho dos grãos; em todas as amostras foram obtidos desde argila a grânulos. Os principais fatores por esta baixa seletividade é a alternância no sentido das correntes, bem como a ocorrência de giros em sentido horário que ocorrem na região (Furtado, 1995; Barcellos e Furtado, 1999; 2001).

O padrão de distribuição granulométrica indica que nos dois primeiros períodos de estudo o sentido preferencial de diminuição de fluxo é de sudeste para noroeste da área de estudo. No terceiro período, verificou-se que as maiores concentrações de finos ocorreram na estação Sc1, localizada na saída do emissário submarino, bem como em estações circundantes a ela. A concentração elevada de finos na estação Sclestá relacionada ao maior fluxo de 
material particulado a que a estação está submetida, bem como a profundidade em que se encontra, a qual, pelos resultados obtidos, está funcionando como uma "armadilha" para os sedimentos finos. Por outro lado, as elevadas porcentagens de grânulos observadas em Junho, período de menor índice pluviométrico, devem-se ao menor aporte de material particulado que é carreado do continente, ocasionando, desta forma, menor taxa de deposição, a qual já é baixa no lado insular do Canal de São Sebastião.

O forte regime hidrodinâmico a que a região do Saco da Capela está submetida, não permite que haja enriquecimento orgânico; os resultados geoquímicos são indicativos de ausência ou baixa alteração ambiental.

Excetuando-se carbono orgânico total e enxofre, observou-se padrão aleatório de distribuição para nitrogênio e fósforo.

Em Junho e Outubro, carbono orgânico total e enxofre foram observados em maior concentração na estação Sc1 e em estações posicionadas nas adjacências. Os teores de carbono orgânico total foram bem superiores em Setembro, em média, 2 vezes em relação à Julho e 6 vezes em relação à Outubro. Apesar das diferenças encontradas, valor indicativo de alteração trófica foi somente observado na estação Sc5 (<2\%; Diz et al., 2006). Entretanto, os teores encontrados são inferidos como sendo de origem natural, provenientes de maior contribuição continental. Em análise macroscópica verificou-se a constante presença de fragmentos de plantas vasculares (caules e folhas).

O enxofre, diferentemente dos demais elementos estudados, está fortemente associado aos teores de finos (q.v. Anexo 51, 52 e 53). Valores indicativos de contribuição antrópica ${ }^{17}$ ocorreram nas estações Sc9 e Sc10 (Setembro), estação Sc1 (Junho e Outubro) e Sc5 (Outubro). A forte correlação de enxofre com os finos indica a formação de sulfeto de ferro (FeS), em ambiente redutor. Sinais de hipoxia foram observados em algumas poucas estações pelos valores de Eh, as quais, excetuando-se a estação Sc1 (Junho), possuem as maiores concentrações de enxofre. Os valores negativos obtidos são indicativos de degradação de matéria orgânica por anaerobiose, bem como redução de enxofre para sulfeto $\left(\mathrm{S}^{2-}\right)$.

Os teores de fósforo tenderam a decrescer de 2005 para 2006, o que se deve a regulamentação da Resolução CONAMA 357/05. Independentemente da regulamentação da mencionada Resolução, os teores de fósforo obtidos desde 2005 na área de estudo são

\footnotetext{
${ }^{17} 0,13 \%$ - conforme Turekian e Wedepohl (1961)
} 
considerados baixos. Teores indicativos de influência antropogênica ${ }^{18}$ somente foram identificados nas estações Sc3, Sc8 e Sc10, nas coletas realizadas em Setembro de 2005. Para os demais períodos verificou-se que os teores de fósforo, principalmente a fração inorgânica, estão fortemente relacionados aos teores de carbonato de cálcio, ou seja, às partes duras dos organismos, tais como conchas, que são abundantes na região.

Os teores de nitrogênio aumentaram progressivamente entre os períodos analisados, sendo expressivamente maior em Outubro, período em que foi observada a presença de águas mais frias provenientes da Água Central do Atlântico Sul, a qual é rica em nutrientes.

Os valores das razões $\mathrm{C} / \mathrm{N}$, desconsiderando-se os resultados de Setembro, uma vez que os mesmos foram anteriormente discutidos, indicam a ocorrência localizada de influência continental no aporte de matéria orgânica. Origem continental e mista foi somente identificada na saída do emissário submarino, o que demonstra forte influência do esgoto liberado na matéria orgânica existente no compartimento sedimentar. Os resultados obtidos indicam maior influência de águas marinhas na área de estudo, em Junho e Outubro.

No tocante às razões $\mathrm{C} / \mathrm{S}$, desconsiderando-se as razões que foram calculadas para estações com baixos valores de carbono orgânico total e enxofre (Sc6 e Sc11 em Junho), valores característicos de ambiente redutor foram apenas observados nas estações Sc1 e Sc5.

Comparativamente, os teores de carbono orgânico total, fósforo e enxofre, excetuando-se os valores obtidos em algumas estações, são significantemente inferiores aos observados nas circunjacências do emissário do Araçá, bem como no ponto controle C3. O estresse ambiental que há na região devido à presença do emissário submarino de esgotos domésticos é localizado, restringindo-se, durante os períodos de amostragem, somente a estação Sc1, a qual se encontra posicionada na saída do emissário submarino.

A diferença nos níveis de alteração ambiental encontradas nas regiões circundantes aos emissários submarinos não se deve ao sistema de tratamento utilizado, uma vez que o tratamento utilizado é o mesmo para os dois emissários. Os fatores responsáveis pelas diferenças encontradas são as condições hidrodinâmicas, a qual é mais enérgica na região onde está posicionado o emissário do Saco da Capela, e aos volumes dos esgotos dispostos. $\mathrm{O}$ volume liberado pelo emissário do Araçá $\left(0,14 \mathrm{~m}^{3} \mathrm{~s}^{-1}\right.$;CETESB, 2007) é, aproximadamente, 4,5 vezes superior ao liberado pelo emissário do Saco da Capela $\left(0,03 \mathrm{~m}^{3} \mathrm{~s}^{-1}\right.$; CETESB, 2007).

\footnotetext{
${ }^{18} 0,07 \%$ - segundo descrito em Baturin (2003)
} 
5.2.3 Associações de foraminíferos - biocenoses e tanatocenoses

As dissimilaridades composicionais das associações de foraminíferos foram expressivas tanto quando as biocenoses foram comparadas entre si, como quando foram confrontadas com as tanatocenoses. Já em relação às tanatocenoses, diferenciações foram observadas, porém com menor nível de significância. Diferentemente das biocenoses, nas tanatocenoses as carapaças identificadas podem representar longos períodos de acúmulo, o que influencia na estrutura composicional.

Nas tanatocenoses e biocenoses, as espécies dominantes tenderam a estar representadas em todos os períodos; contudo há expressiva alteração em suas abundâncias. Descritivamente, verificou-se que é baixa a porcentagem de espécies comuns aos três períodos amostrados, sendo observada a introdução de espécies novas, porém em baixa abundância. Conforme pode ser observado pelos diagramas de ordenação gerados pelas técnicas de NMDS e teste t, verificou-se elevado grau de heterogeneidade, o qual é mais acentuado nas tanatocenoses. A heterogeneidade apresentada pelas análises estatísticas corrobora os resultados de diversidade específica e equitatividade obtidos para os períodos analisados (q.v. Anexos 43 e 46).

As associações de foraminíferos identificadas não indicam estresse ambiental na região dos difusores do emissário do Saco da Capela. Os valores de riquezas são considerados elevados e não foram observadas dominâncias de poucas espécies euribiontes, como usualmente costuma ocorrer em regiões impactadas (q.v. Alve, 1995; Burone et al., 2006; Frontalini e Coccioni, 2008; Romano et al., 2008; Armynot du Châtelet e Debenay, 2010). Os valores de densidade são considerados baixos quando comparados com os valores obtidos próximo ao emissário do Araçá. Apesar de não ter sido observado correlação entre as densidades e os parâmetros ambientais, infere-se que os menores valores obtidos podem ser resultantes da proximidade da área de estudo com a linha de costa, bem como a granulação dos sedimentos. Ainda não há consenso sobre a influência da granulometria nas densidades e diversidades dos foraminíferos. Para alguns autores, sedimentos com predominância de partículas finas propiciam ambiente favorável à ocorrência de elevadas densidades e riquezas, ocorrendo o contrário em sedimentos com granulação mais grossa (Samir and El-Din, 2001; Debenay et al., 2001; Armynot du Châtelet et al., 2008). Em contrapartida, para outros autores 
compartimentos bentônicos com elevadas concentrações de sedimentos grossos propiciam ambiente favorável ao desenvolvimento das associações de foraminíferos (Diz et al., 2008).

No presente estudo, verificou-se que a granulometria, as profundidades, os teores de nitrogênio e enxofre são os principais parâmetros ambientais que influenciam as associações de foraminíferos no Saco da Capela (q.v. Análise de Correspondência Canônica), sendo Ammonia tepida e Gavelinopsis praegeri as espécies mais abundantes. Entre os períodos verificou-se somente alternância de abundância das principais espécies e não substituição devido à competição; elas não possuem distribuição proporcionalmente inversa, conforme pode ser observado nas correlações de Pearson (Anexo 51, 52 e 53).

As preferências ecológicas de Ammonia tepida já foram mencionadas no tópico Discussão do Capítulo 04, motivo pelo qual não serão novamente discutidas. Menciona-se, contudo, que na região do Saco da Capela sua abundância foi maior em estações com expressivos teores de enxofre (q.v. gráfico de ordenação da Análise de Correspondência Canônica) e carbono orgânico total (Junho de 2006; $\mathrm{r}=0,64 ; p<0,05$ ).

Por sua vez, Gavelinopsis praegeri é espécie epifaunal, suspensívora passiva (Murray, 1991), habitualmente identificada em ambientes bem oxigenados e com baixos teores de matéria orgânica (Altenbach et al., 2003; Duleba et al., 2005; Martins et al., 2006). A distribuição de Gavelinopsis praegeri foi influenciada principalmente pelo Eh em Setembro, pelos valores de profundidade e salinidade em Junho. Em Outubro, verificou-se que suas abundâncias possuem distribuição inversa aos teores de sedimentos finos, com elevados teores de fósforo inorgânico e enxofre (q.v. correlações de Pearson, Anexo 51, 52 e 53).

Diferentemente do observado próximo ao emissário de esgotos domésticos do Araçá, no Saco da Capela verificou-se a predominância de espécies epifaunais, bioindicadoras de ambiente óxico. Dentre os diversos fatores ambientais, o fluxo de matéria orgânica (qualidade e quantidade) e oxigenação são os mais importantes fatores que regulam a composição e distribuição das associações de foraminíferos (van der Zwaan et al., 1999). Em regiões com baixos teores de matéria orgânica, como a área do presente estudo, há limitação de alimento, porém não há problemas com os níveis de oxigenação na interface água-sedimento, motivo pelo qual se sobressaem espécies epifaunais (Jorissen et al., 1995; Jorissen, 1999). As espécies mais abundantes que fizeram parte do grupo de espécies epifaunais, bioindicadoras de ambiente óxico são Gavelinopsis praegeri, Hanzawaia boueana, Neocornobina terquemi e Rosalina floridensis. 
Espécies infaunais, as quais são características de ambientes com sinais de hipoxia, ocorreram em expressivas abundâncias em estações com elevadas concentrações de sedimentos finos, enxofre e carbono orgânico total, tais como estações Sc9 e Sc10 (Setembro), Sc1, Sc5 e Sc9 (Junho), Sc1, Sc3 e Sc5 em Outubro. O resultado obtido indica que existem áreas pontuais de enriquecimento orgânico na região do Saco da Capela. Brizalina striatula, Brizalina sphatulata, Bolivina ordinaria e Bolivina pseudoplicata são as principais espécies infaunais, bioindicadoras de ambiente enriquecido por matéria orgânica e pobre em oxigênio.

Os resultados das análises morfométricas realizadas nas carapaças dos foraminíferos corroboram as características ambientais inferidas pelas análises granulométricas, geoquímicas e pela composição das associações de foraminíferos. No Saco da Capela, nos três períodos de estudo verificou-se a predominância de foraminíferos com carapaças médias em conjunto com foraminíferos com carapaças grandes. Carapaças pequenas estiveram presentes em todas as estações, com padrão aleatório de distribuição, não sendo correlacionada aos parâmetros ambientais em Setembro e Junho. Em Outubro, entretanto, verificou-se que as carapaças pequenas são influenciadas pelas abundâncias de Gavelinopsis praegeri, a qual é característica de ambientes óxicos. O tamanho dos foraminíferos é influenciado pelos níveis de oxigenação do compartimento bentônico, sendo observado em ambientes hipóxicos predominância de organismos pequenos e o contrário em ambientes óxicos (Bradshaw, 1961; Phleger e Soutar, 1973; Sen Gupta e Machain-Castillo, 1993). Diante do disposto, e devido à presença conspícua de macroforaminíferos, infere-se que o compartimento bentônico do Saco da Capela é ambiente óxico, com favorável suprimento de alimento.

As riquezas, as diversidades específicas e as equitatividades obtidas nas tanatocenoses são superiores às obtidas nas biocenoses, o que já era esperado, uma vez que diversos períodos de acúmulo encontram-se representados nas tanatocenoses.

Em relação às densidades, observou-se diferenciação de valores entre Setembro e os demais períodos. Os menores valores de densidade ocorreram em Setembro, sendo observados valores ínfimos nas estações Sc6 (10 espécimes) e Sc8 (31 espécimes). A estação $\mathrm{Sc} 1$ foi a que apresentou as maiores densidades, resultado similar ao observado para os finos, o que corrobora que esta estação está posicionada em local com propensão à deposição e preservação, seja de material particulado ou de carapaças. Entre Junho e Outubro, em média, as densidades foram similares. 
Pararotalia cananeiaensis é a espécie dominante, com significativo aumento de abundância entre os períodos analisados. Reconhecida como indicadora de aporte de águas marinhas, foi observada em maior abundância em Outubro, período em que foi observada a mistura das massas Água Costeira com a Água Central do Atlântico Sul. Apesar da presença pouco expressiva, foraminíferos planctônicos corroboram a entrada de águas da plataforma externa pelo lado insular do canal. Nas biocenoses a presença de Pararotalia cananeiaensis foi pouco expressiva, com ausência em Junho e somente um espécime em Outubro.

Além do aporte de águas marinhas, a área de estudo também recebe aporte de águas fluviais. Foram identificados espécimes de Miliammina fusca e Miliammina earlandi em Junho e Outubro. Ambas as espécies são infaunais, detritívoras, encontradas em locais com predominâncias de sedimentos lamosos (Murray, 1991) e com intenso aporte de água fluvial (Duleba et al., 2005). Infere-se que as espécies são alóctones na região, uma vez que não foram encontrados espécimes nas biocenoses. Entretanto, os espécimes foram transportados de locais não muito distantes, uma vez que as carapaças apresentaram bom grau de preservação. O lado insular do Canal de São Sebastião possui um expressivo número de rios e córregos que fluem para o ambiente marinho. O mais próximo da área de estudo é o Córrego da Cachoeira, e mais ao sul, em frente ao terminal petrolífero do TEBAR há o Rio Perequê. As maiores abundâncias de Miliammina fusca e Miliammina earlandi ocorreram em Outubro, considerado como um período de maior pluviosidade (primavera e verão), e, consequentemente, maior aporte de água pluvial para o interior do canal.

Nas tanatocenoses, verificou-se predominância de espécies infaunais, nos três períodos estudados e em quase todas as estações. Bolivinídeos e buliminídeos são os principais representantes do grupo formado pelas espécies infaunais. Por outro lado, espécies epifaunais, apesar de presentes em todas as estações, tenderam a diminuir de porcentagem entre os períodos analisados; as abundâncias obtidas nas tanatocenoses representam, aproximadamente, metade das abundâncias observadas nas biocenoses. Com base no exposto, as características ambientais passam a ser opostas às inferidas pelas análises granulométricas, geoquímicas e pelas associações de foraminíferos pertencentes às biocenoses. Os resultados obtidos ressaltam a importância de estudos em separado das tanatocenoses e biocenoses.

Os resultados das análises morfométricas são semelhantes aos observados nas biocenoses; verificou-se predominância de carapaças médias, com significativa presença de carapaças grandes. A distribuição dos tamanhos das carapaças ocorre de forma aleatória, 
coexistindo em uma mesma amostra desde carapaças pequenas a carapaças pertencentes à macroforaminíferos. Os resultados são similares aos observados para a granulometria; verificou-se que apesar de haver constante retrabalhamento dos sedimentos de fundo, as correntes não são unidirecionais, o que propicia a distribuição das carapaças de forma não seletiva. O retrabalhamento dos sedimentos de fundo também é evidenciado pelo elevado grau de carapaças parcialmente fragmentadas, decorrente de abrasão mecânica durante o transporte realizado por saltação e/ou rolação, bem como pelas porcentagens de fragmentos.

No tocante à coloração, as carapaças em sua grande maioria apresentaram-se normais, sendo observados poucos exemplares preenchidos por monossulfeto de ferro, os quais se apresentaram em porcentagens mais expressivas na região central da malha de amostragem, próximo aos difusores do emissário submarino. Em contrapartida, carapaças preenchidas por óxido/hidróxido de ferro estiveram presentes em todas as estações, em significativas abundâncias, o que confere à região do Saco da Capela características de ambiente óxico.

Carapaças com sinais de bioerosão foram identificadas, porém em uma porcentagem bem inferior à observada para a região do Araçá. Tal diferença pode ser relacionada a menor abundância de espécies predadoras, bem como ao maior hidrodinamismo que há no Saco da Capela. 


\section{Anexos}

Anexo 33 - Distribuição granulométrica obtida próximo ao emissário submarino de esgotos domésticos Saco da Capela.

Valores em porcentagem.

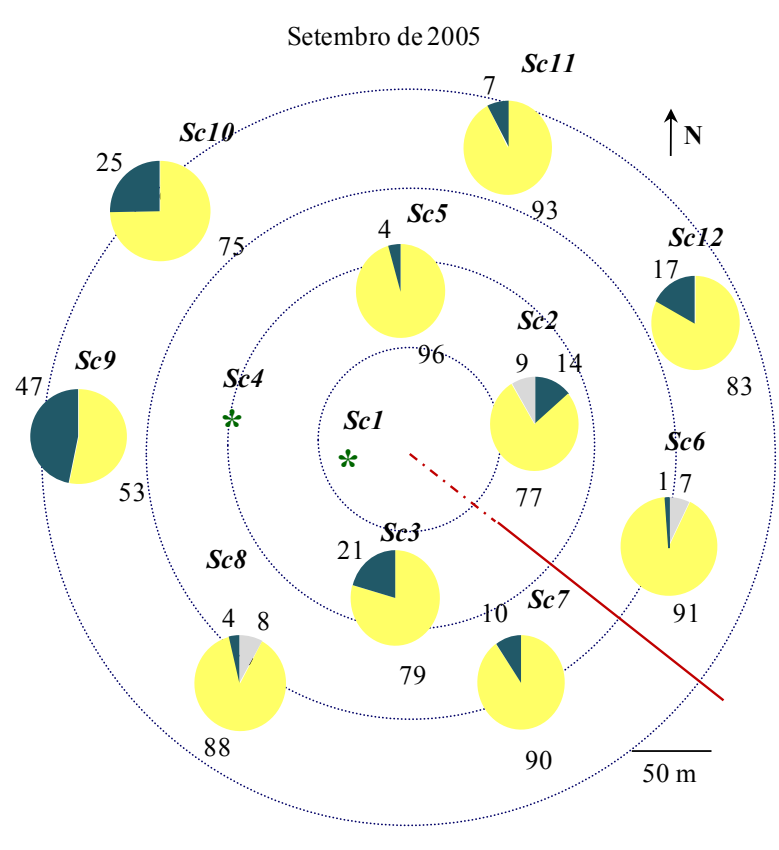

Sedimentos finos (silte e argila)

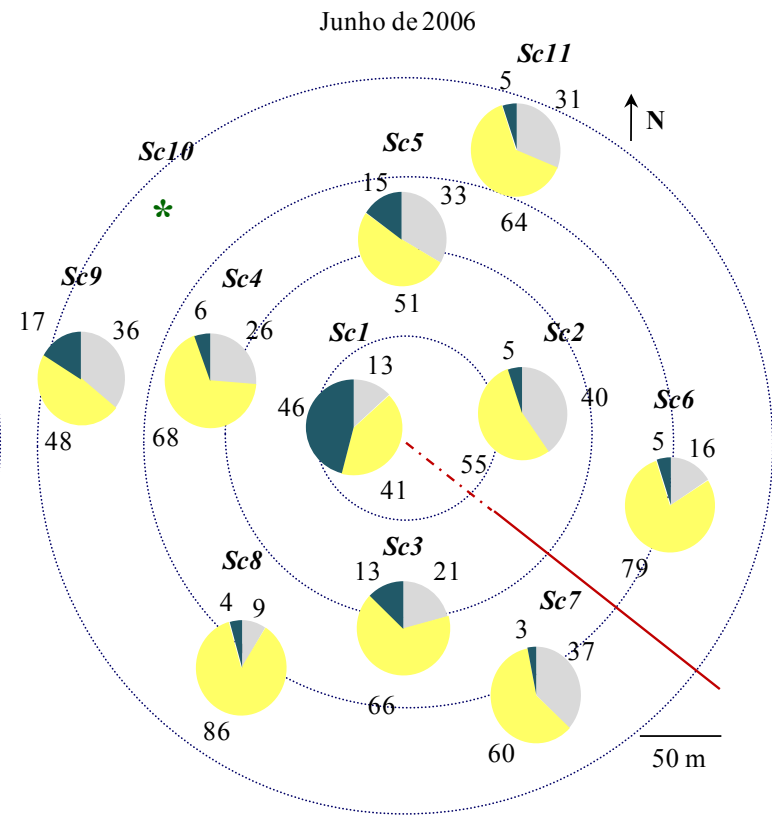

Sedimentos arenosos

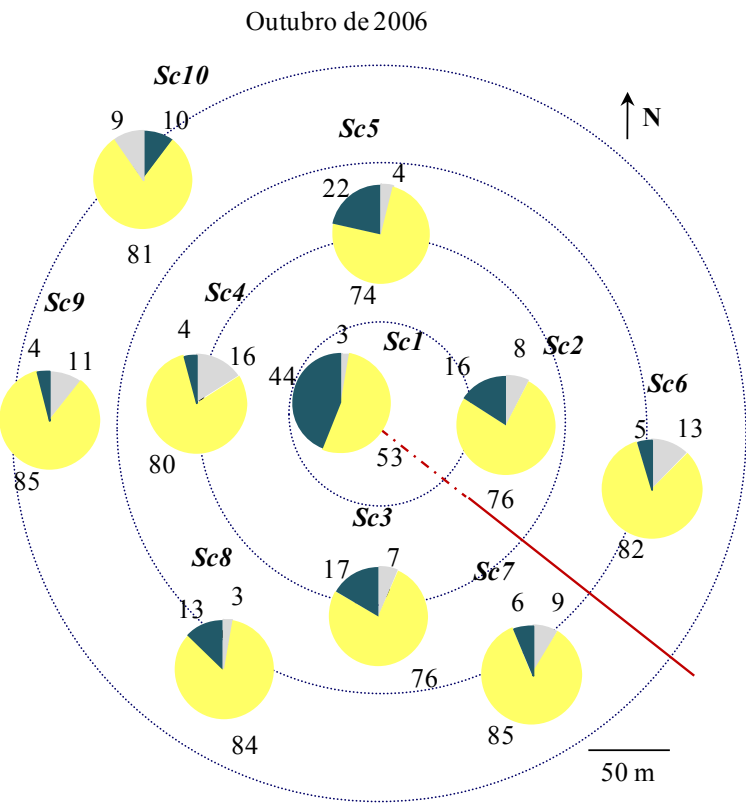

Grânulos

\footnotetext{
* Estação não amostrada
} 
Anexo 34 - Concentrações de carbonato de cálcio obtidas próximo ao emissário Saco da Capela.

Valores em porcentagem.
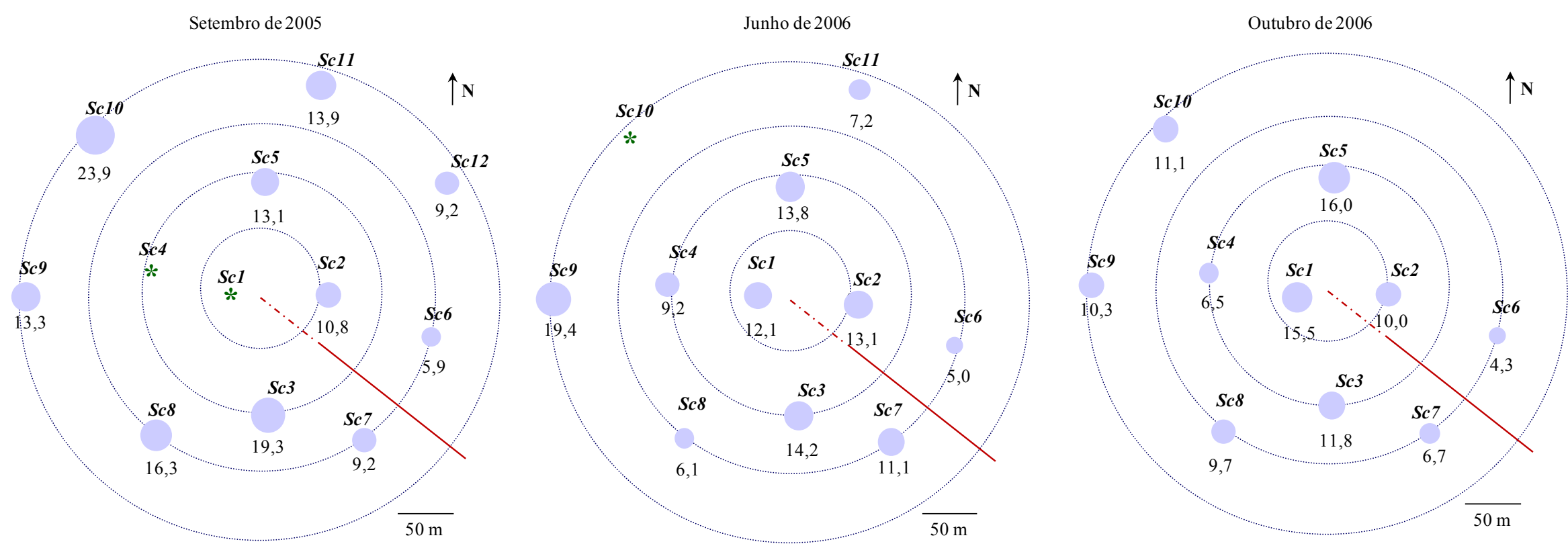

* Estação não amostrada 
Anexo 35 - Concentrações de carbono orgânico total obtidas próximo ao emissário Saco da Capela. Valores em porcentagem.
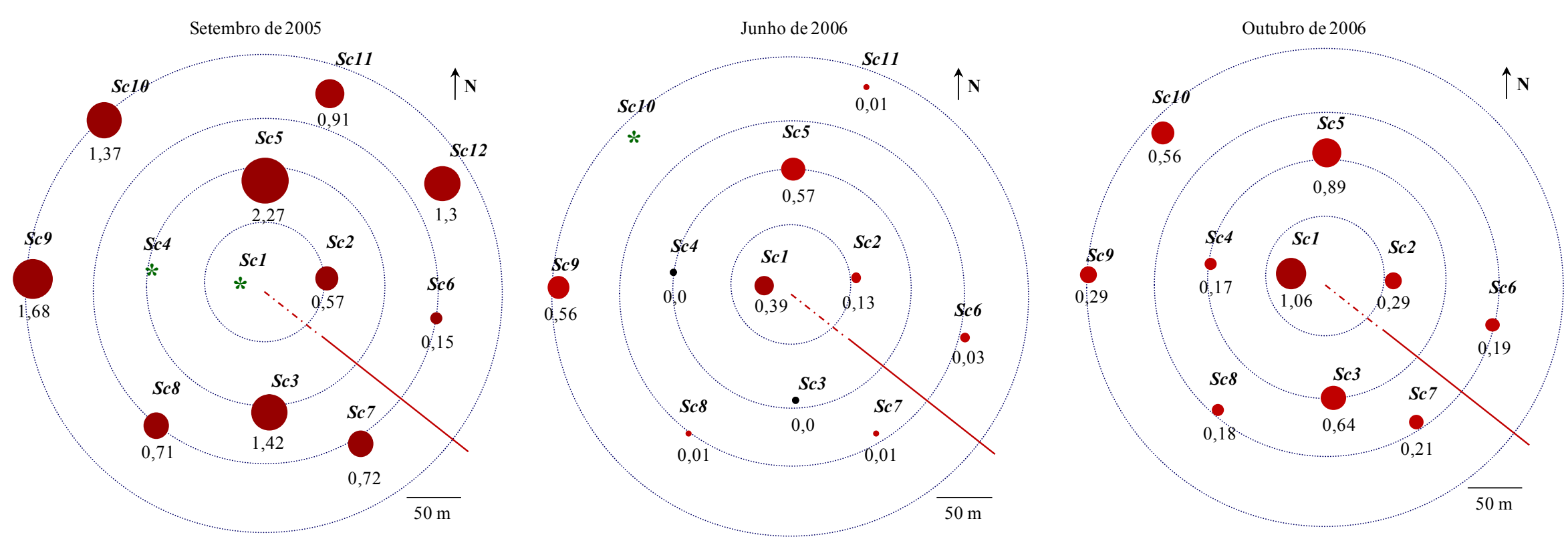

\footnotetext{
* Estação não amostrada
} 
Anexo 36 - Concentrações de nitrogênio obtidas próximo ao emissário Saco da Capela.

Valores em porcentagem.
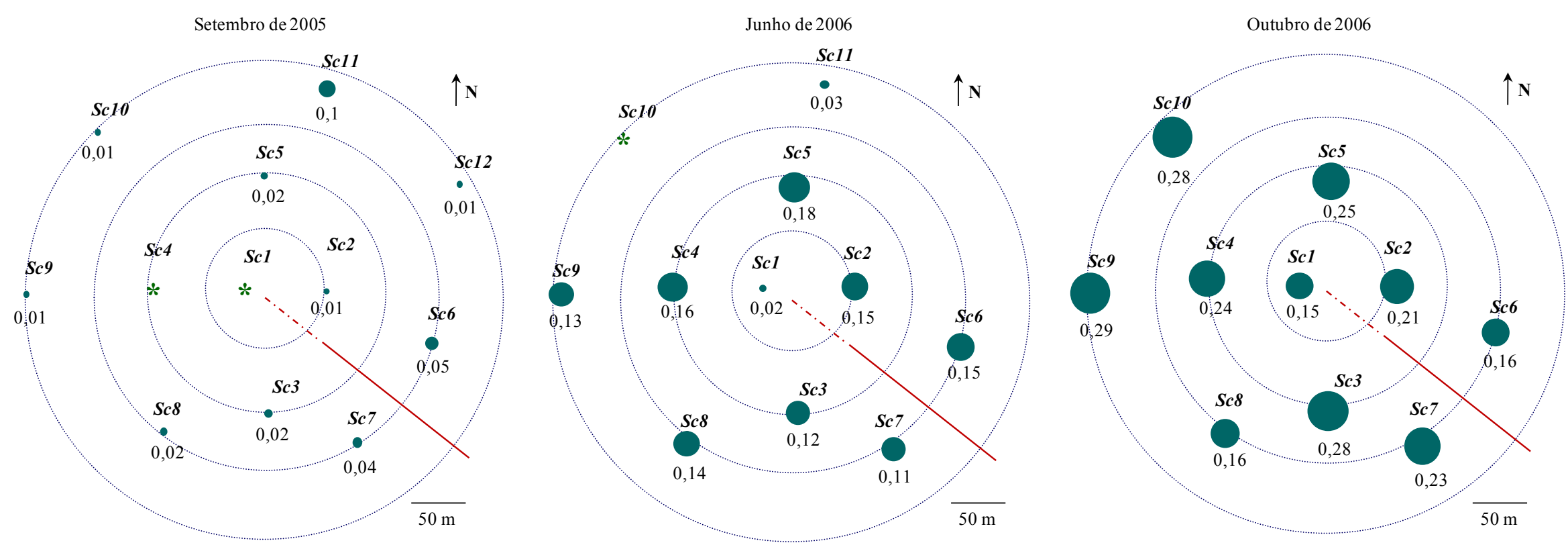

\footnotetext{
* Estação não amostrada
} 
Anexo 37 - Concentrações de fósforo total obtidas próximo ao emissário Saco da Capela.

Valores em porcentagem.
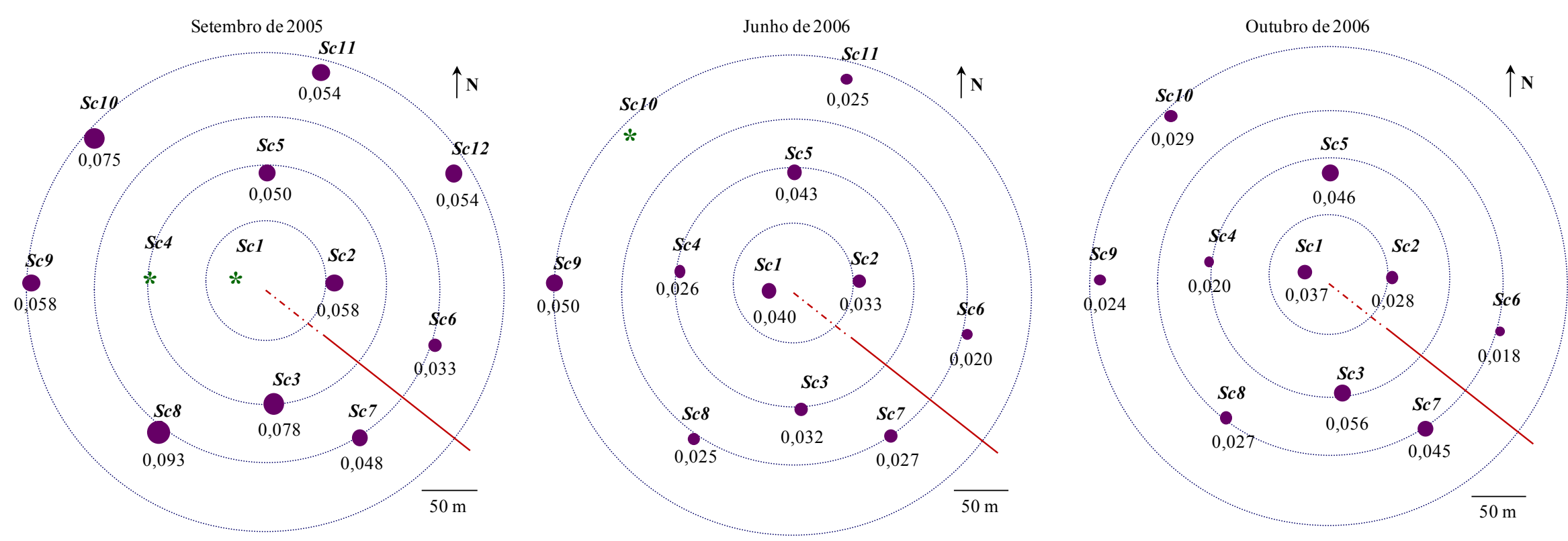

* Estação não amostrada 
Anexo 38 - Concentrações de fósforo orgânico obtidas próximo ao emissário Saco da Capela.

Valores em porcentagem.
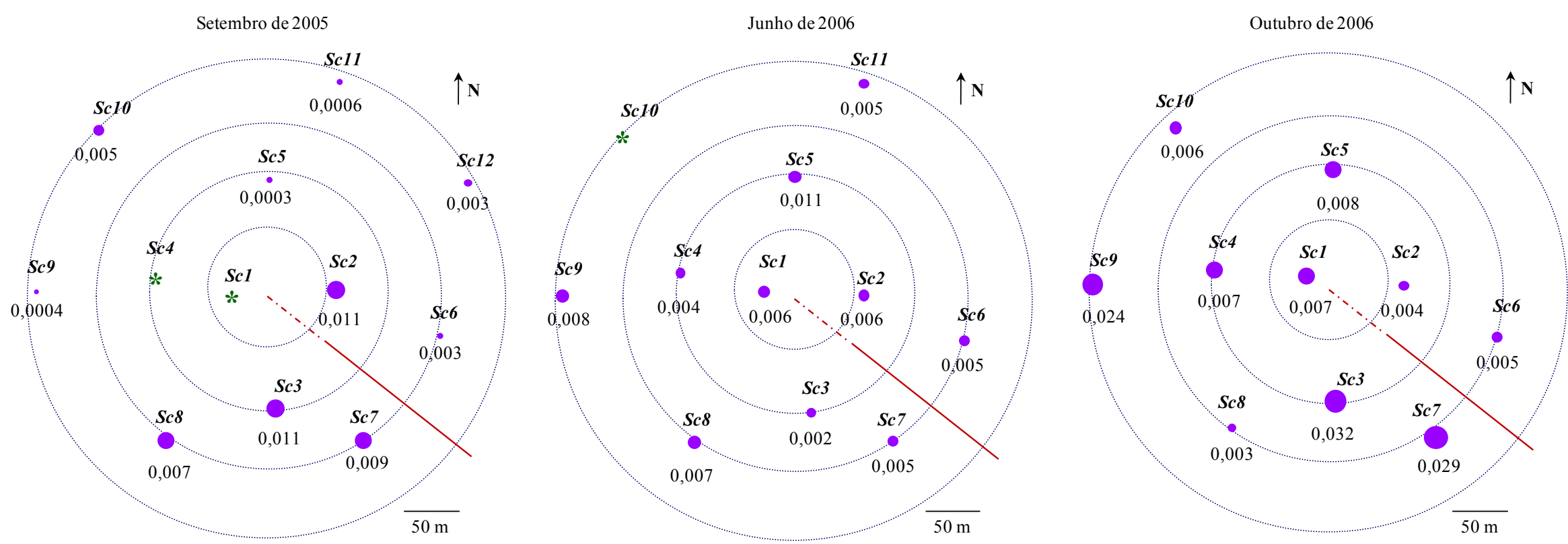

* Estação não amostrada 
Anexo 39 - Concentrações de fósforo inorgânico obtidas próximo ao emissário Saco da Capela. Valores em porcentagem.
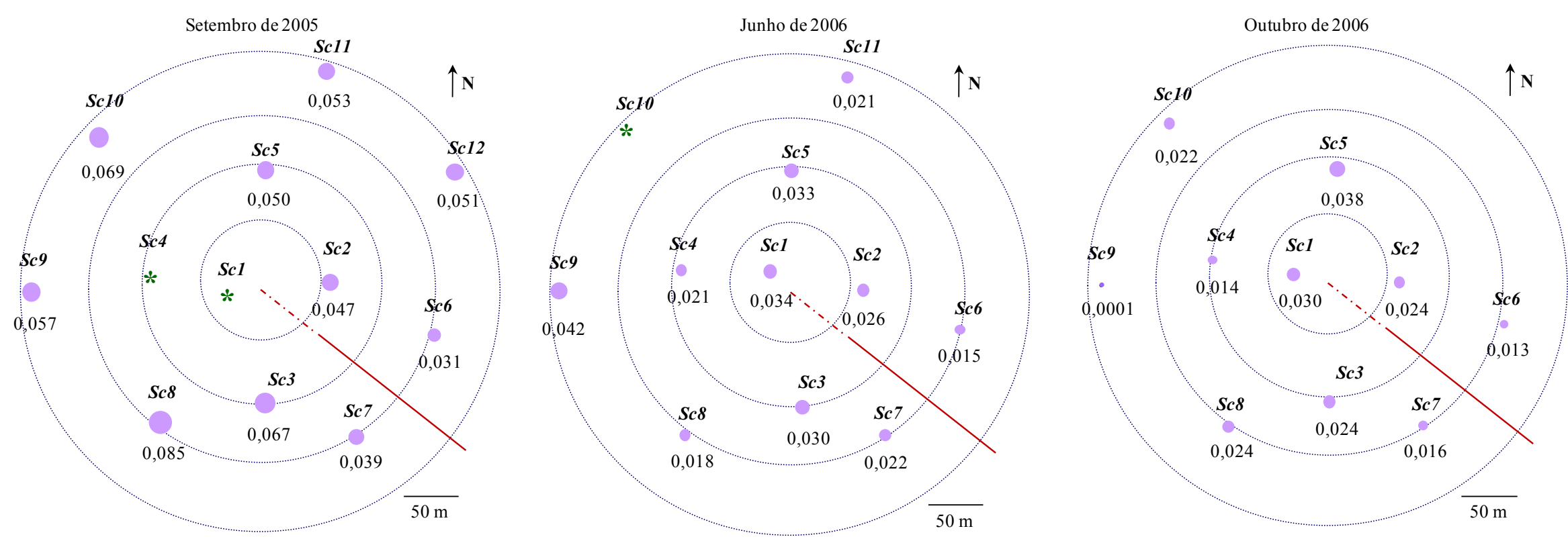

* Estação não amostrada 
Anexo 40 - Concentrações de enxofre obtidas próximo ao emissário Saco da Capela.

Valores em porcentagem.
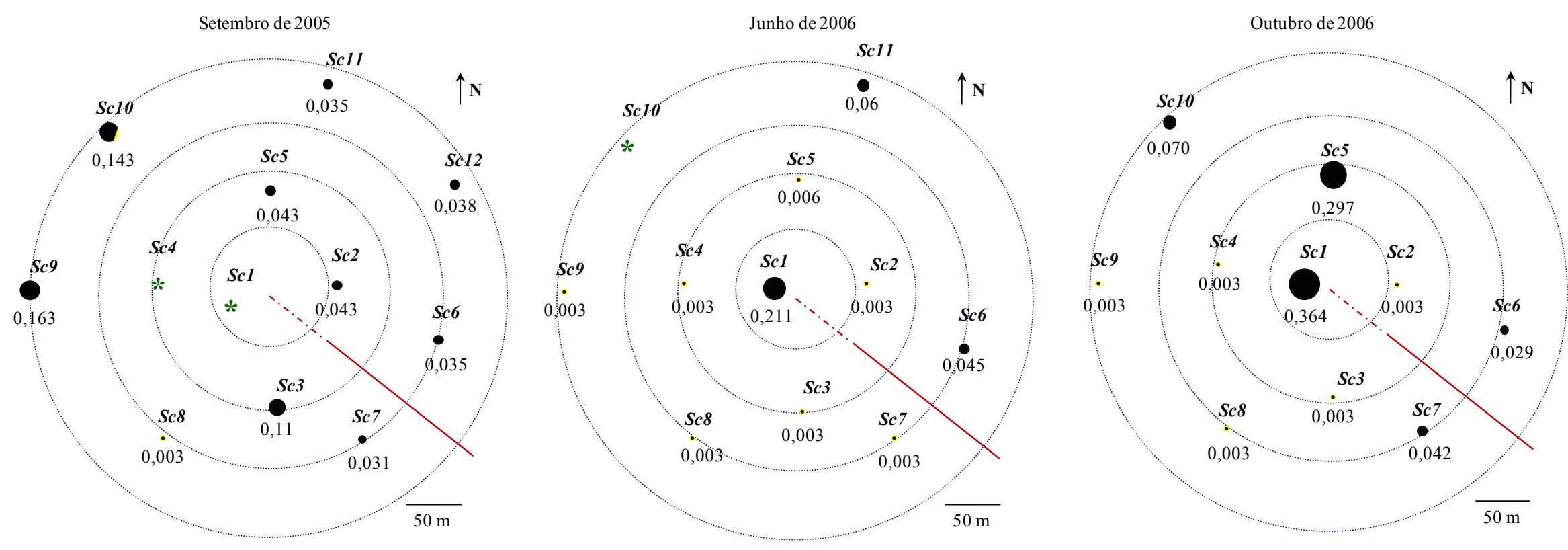

* Estação não amostrada 
Anexo 41- Origem da matéria orgânica analisada por meio de razões elementares $\mathrm{C} / \mathrm{N}$.

Dados obtidos próximo ao emissário Saco da Capela.

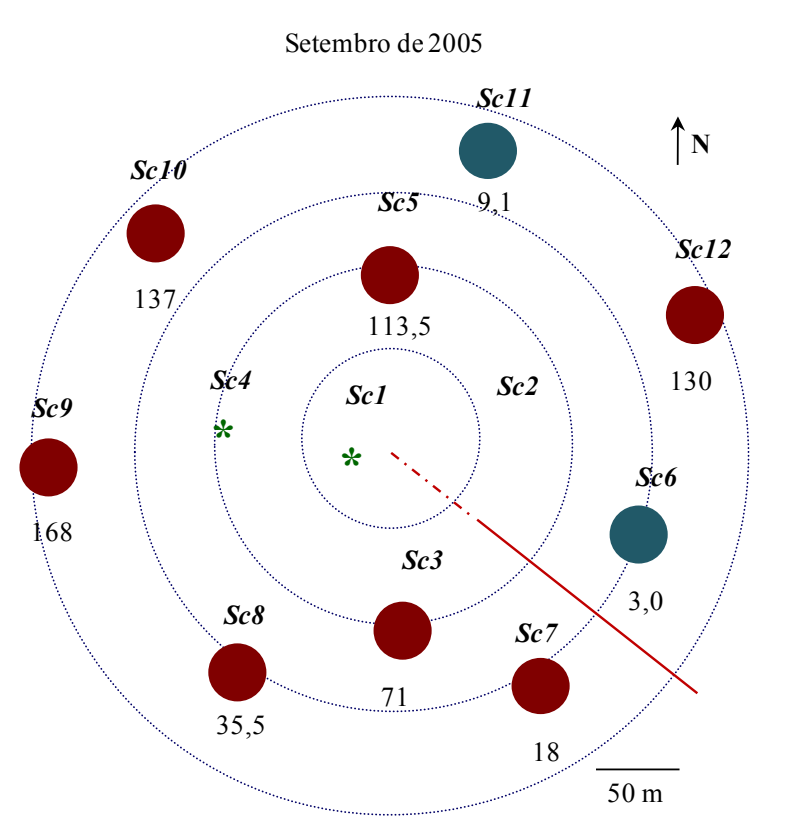

Matéria orgânica de origem marinha

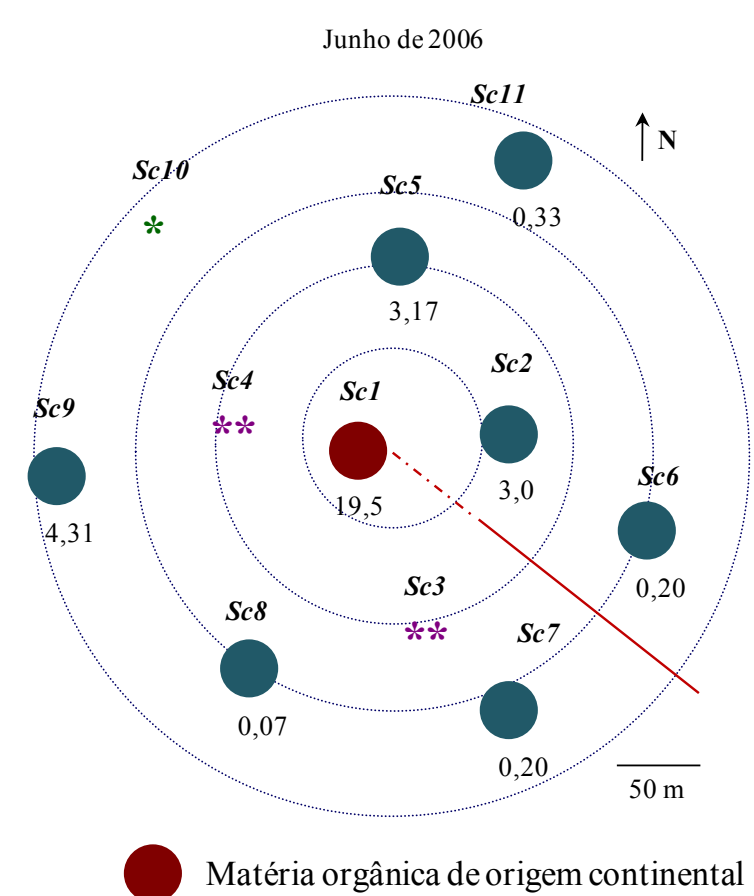

Matéria orgânica de origem continental

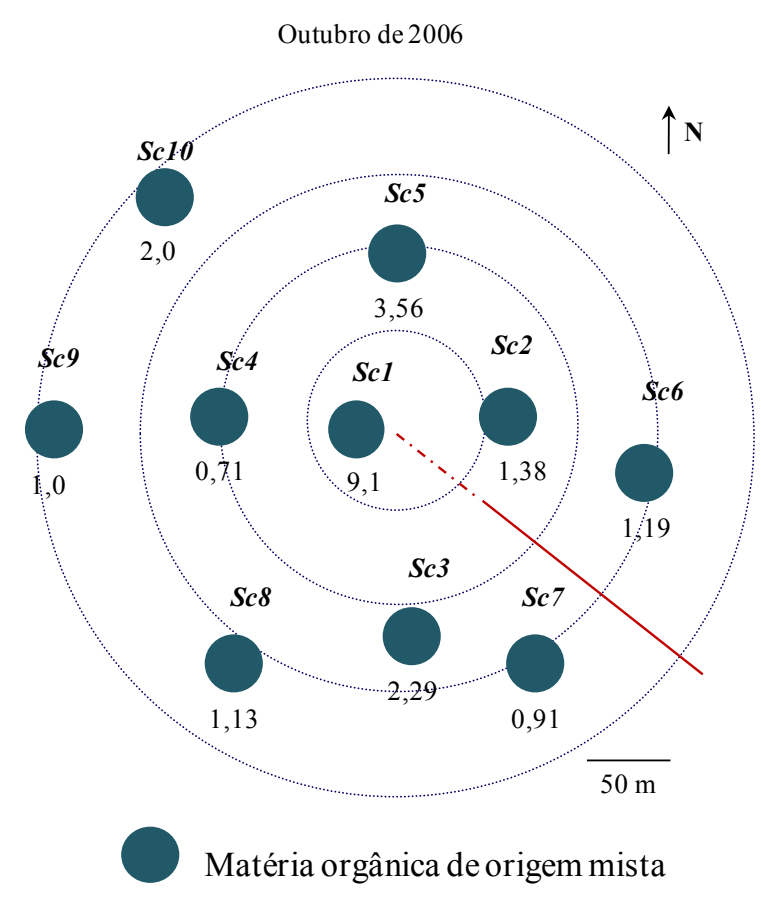

** Razão não calculada (teores de carbono orgânico total não detectados)

\footnotetext{
* Estação não amostrada
} 
Anexo 42 - Potencial de oxi-redução dos sedimentos de fundo analisado por meio de razões elementares C/S.

Dados obtidos próximo ao emissário Saco da Capela.
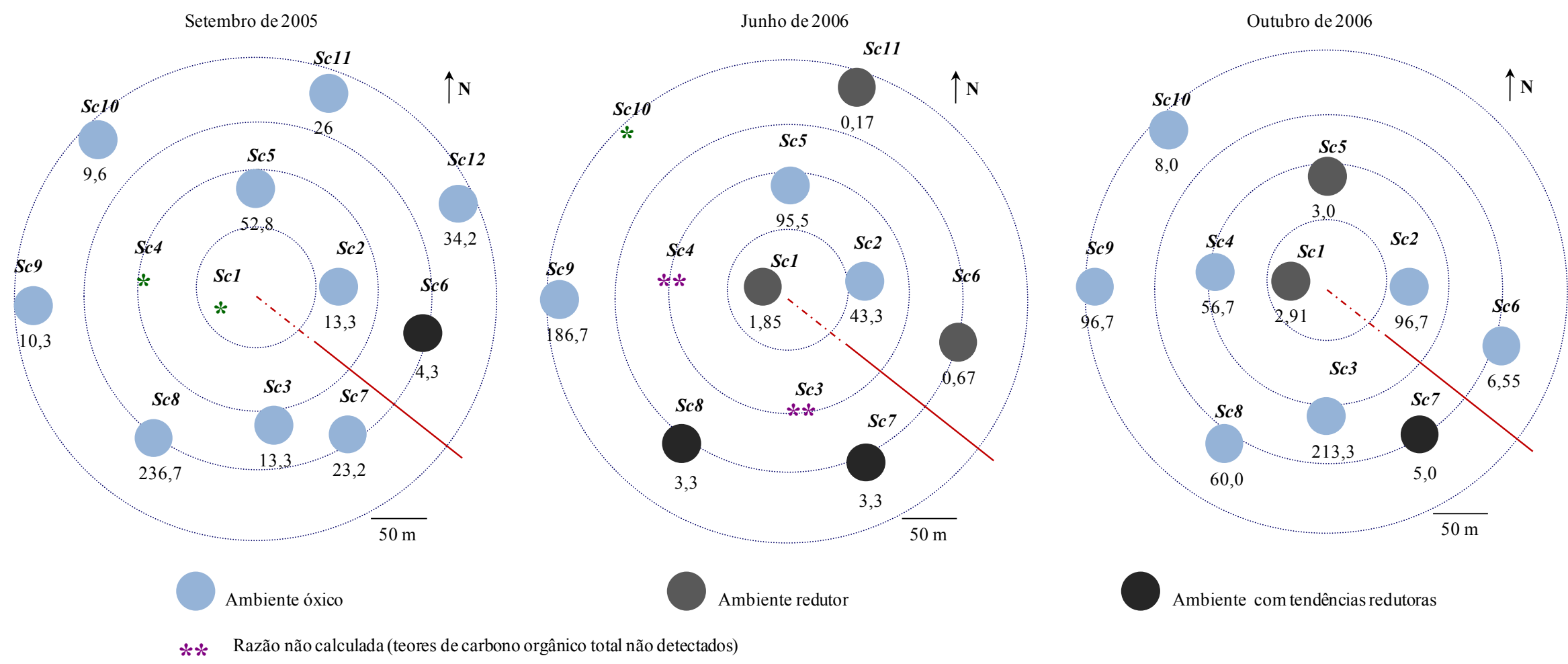

* Estação não amostrada 
Anexo 43 - Abundâncias relativas das espécies de foraminíferos identificadas próximo ao emissário Saco da Capela.

Dados pertencentes às biocenoses.

\begin{tabular}{|c|c|c|c|c|c|c|c|c|c|c|c|c|c|c|c|c|c|c|c|c|c|c|c|c|c|c|c|c|c|c|}
\hline \multirow[b]{2}{*}{ Estações } & \multicolumn{10}{|c|}{ Setembro de 2005} & \multicolumn{10}{|c|}{ Junho de 2006} & \multicolumn{10}{|c|}{ Outubro de 2006} \\
\hline & Sc2 & Sc3 & Sc5 & Sc6 & Sc7 & $\mathrm{Sc} 8$ & Sc9 & Sc10 & Sc11 & Sc12 & Sc1 & Sc2 & Sc3 & Sc4 & Sc5 & Sc6 & Sc7 & Sc8 & Sc9 & Sc11 & Sc1 & $\mathrm{Sc} 2$ & $\mathrm{Sc} 3$ & Sc4 & Sc5 & Sc6 & Sc7 & Sc8 & Sc9 & Sc10 \\
\hline Albygnya planidorso & 0,0 & 0,0 & 0,0 & 0,0 & 0,0 & 0,0 & 0,0 & 0,0 & 0,0 & 0,0 & 0,0 & 0,0 & 1,0 & 0,0 & 0,0 & 0,0 & 0,0 & 0,0 & 0,0 & 0,0 & 1,7 & 0,0 & 1,7 & 2,0 & 0,9 & 0,6 &, 0 & 0,0 & 0,0 & 0,0 \\
\hline mmonia park & 0,0 & 0,0 & 1,0 & 0,0 & 1,0 & 0,0 & 3,7 & 1,0 & 0,0 & 9,6 & 7,3 & 3,8 & 0 & 1,8 & 2,5 & 3,3 & 0,0 & 3,9 & 4,3 & 3,9 & ,0 & 1,1 & 4,0 & 0,0 & 4,3 & 3,9 & 4,7 & 1,0 & 2,5 & 6,6 \\
\hline Ammonia tepida & 25,2 & 19,8 & 7,8 & 15,2 & 26,8 & 4,7 & 22,2 & 21,0 & 10,6 & 28,7 & 8,3 & 7,6 & 5,7 & 6,5 & 14,0 & 13,3 & 6,9 & 1,9 & 27,2 & 16,7 & 8,6 & 1,7 & 20,3 & 12,1 & 8,7 & 14,5 & 8,9 & 8,0 & 4,2 & 14,2 \\
\hline Ammonia sp & 1,9 & 0,9 & 1,0 & 2,0 & 0,0 & 0,0 & 1,9 & 1,0 & 1,0 & 1,2 & ,0 & 0,0 & 9 & 1,2 & 0,0 & 2,2 & 1,0 & 1,9 & 2,2 & 2,0 &, 7 & 1,1 & 2,3 & 0 & 9 &, 5 & 1,4 & 1,0 & 8 & 1,9 \\
\hline Ammotium salsum & 0,0 & 0,0 & 0,0 & 0,0 & 0,0 & 0,0 & 0,0 & 0,0 & 0, & 1,8 & 0,0 & 0,0 & 0,0 & 1,8 & 0,0 & 0,0 & 0,0 & 0,0 & 0,0 & 0,0 & 3,3 & 0,0 & 0,0 & 0,0 & 3,5 & 0,0 & 2,3 & 1,0 & 2,5 & 3,8 \\
\hline Amphicorina scalaris & 0,0 & 0,0 & 0,0 & 0,0 & 0,0 & 0,0 & 0,9 & 1,0 & 1,0 & 0,6 & 0,0 & 0,0 & 0,0 & 0,0 & 0,0 & 0,0 & 0,0 & 0,0 & 0,0 & 0,0 & 0,7 & 0,0 & 0,0 & 0,0 & 0,0 & 0,0 & 0,0 & 0,0 & 0,0 & 0,0 \\
\hline Angulogerina an & 0,0 & 0,0 & 0,0 & 0,0 & 0,0 & 0,9 & 1,9 & 1,9 & 0 , & 1 & 2,1 & 0,8 & 0,0 & 0,0 & 1,7 & 0,0 & 2,0 & 1,9 & 0,0 & 2, & 2,0 & 1,7 & 0,6 & 0,0 & 0,9 & 1,1 & 1,4 & 1,0 & 8 & 2,8 \\
\hline Arenoparrella $\mathrm{m}$ & 0,0 & 0,0 & 0,0 & 0,0 & 0,0 & 0,9 & 0,0 & 0,0 & 0,0 & 0 , & 0,0 & 0,0 & 0,0 & 0,0 & 0,0 & 0,0 & 0,0 & 0,0 & 0,0 & 0 & 0 & 0,0 & 0,0 & 0,0 & 0 & 0,0 & 0,0 & 0,0 &, 0 & 0,0 \\
\hline Astrononion sp & 3,9 & 1,7 & 4,9 & 4,0 & 1,0 & 3,7 & 4,6 & 2,9 & 7,7 & 0, & 0,0 & 2,3 & 0,0 & 0,6 & 0,0 & 0,0 & 0,0 & 0,0 & 0,0 & 0,0 & 0 & 0,0 & 0,0 & 1,0 & 0,0 & 0,0 & 0,5 & 0,0 & ,8 & 0,9 \\
\hline Bolivina compacta & 0,0 & 0,0 & 0,0 & 0,0 & 0,0 & 0,0 & 1,9 & 1,0 & 0 & 0 , & 0,0 & 2,3 & 0,0 & 0,6 & 0,0 & 0,0 & 1,0 & 0,0 & 2,2 & 2, & 1 & 0,0 & 1,7 & 0,0 &, 9 & 1,1 & 1,4 & 0,0 &, 8 & 0,9 \\
\hline Bolivina doniezi & 0,0 & 0,0 & 0,0 & 0,0 & 0,0 & 0,0 & 0,0 & 0,0 & 0 & 0 & 2,1 & 0,0 & 1,0 & 0,0 & 0,8 & 0,0 & 0,0 & 0,6 & 1,1 & 2,0 & 3 & 1,1 & 0,6 & 2,0 & 1,7 & 0,6 & 0,0 & 0,0 &, 0 & 0,9 \\
\hline Bolivina ordinaria & 1,0 & 0,9 & 0,0 & 0,0 & 0,0 & 0,0 & 0,9 & 2,9 & 0,0 & 0 , & 5,2 & 1,5 & 5,7 & 2,4 & 4,1 & 0,0 & 2,0 & 0,0 & 33 & 6,9 & 3,3 & 1,7 & 4,5 & 1,0 & 5,2 & 2,2 & 1,4 & 2,0 &, 0 & 0,0 \\
\hline Bolivina pseudoplic & 0,0 & 0,0 & 0,0 & 0,0 & 0,0 & 0,9 & 0,0 & 1,9 & 0,0 & 2 & 4, & 7,6 & 1,9 & 1,2 & 2,5 & 6,7 & 5,9 & 0,6 & 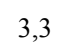 & 2 & 3 & 2,2 & 1,1 & , 0 & 1 & 8 & 4,7 & 3,0 & 0 & 2,8 \\
\hline Bolivina pulchella & 0,0 & 0,0 & 0,0 & 0,0 & 0,0 & 0,0 & 0,0 & 0,0 & 0,0 & 0 , & 0,0 & 0,0 & 0,0 & 0,0 & 0,0 & 1,1 & 0,0 & 0,0 & 0,0 & 0,0 & 0 & 0,0 & 0,0 & 0,0 & 0,0 & 0,0 & 0,5 & 0,0 & 0,0 & 0,0 \\
\hline Bolivi & 0,0 & 0,0 & 0,0 & 0,0 & 0,0 & 0,0 & 0,0 & 0,0 & 0 & 0 , & 0,0 & 0,0 & 0,0 & 0,0 & 0,0 & 0,0 & 0,0 & 0,0 & 0,0 & 0. & 0 & 0,0 & 0,0 & 0,0 &, 0 & 6,1 & 1,4 & 0,0 &, 0 & 0,0 \\
\hline Bolivina tortuosa & 0,0 & 0,0 & 0,0 & 0,0 & 0,0 & 0,0 & 0,0 & 0,0 & 1 , & م & 0,0 & 0,0 & 0,0 & 0,0 & 0,0 & 0,0 & 0,0 & 0,0 & & & 0 & 0,0 & 0,0 & 0 & 0 & 6 & 0,0 & 1,0 & ,0 & 0,0 \\
\hline Bolivina transluce & 0,0 & 0,0 & 0,0 & 0,0 & 0,0 & 0,0 & 0,0 & 0,0 & 0,0 & 0, & 1,0 & 0,0 & 0,0 & 0,0 & 0,8 & 0,0 & 0,0 & 0,0 & 0,0 & 0, & 0,0 & 0,0 & 0,0 & 0,0 & 0,0 & 0,0 & 0,0 & 0,0 &, 0 & 0,0 \\
\hline Bolivina sp & 1,0 & 0,0 & 0,0 & 0,0 & 0,0 & 0,0 & 3,7 & 2,9 & 0,0 & 0,0 & 0,0 & 0,0 & 1,0 & 0,6 & 0,0 & 4,4 & 0,0 & 1,9 & 1,1 & 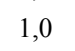 & 1,3 & 2,8 & 3,4 & 1,0 & 0 & 2,2 & 1,9 & 2,0 & 8 & 0,9 \\
\hline Brizalina sphatulat & 3,9 & 6,0 & 4,9 & 1,0 & 14,4 & 4,7 & 4,6 & 8,6 & 7 , & 0 & 2,1 & 3,8 & 1,9 & 0,0 & 1,7 & 6,7 & 4,9 & 0,6 & 5,3 & 2,0 & 0,7 & 3,4 & 2,3 & 2,0 & ,6 & 0,6 & 1,4 & ,0 & 4 & 0,9 \\
\hline Brizalina striatula & 14,6 & 12,9 & 5,8 & 3,0 & 2,1 & 3,7 & 20,4 & 9,5 & 9,6 & 7,2 & 7,3 & 2,3 & 2,9 & 3,5 & 8,3 & 6,7 & 2,0 & 0,6 & 12,0 & 9,8 & 10,5 & 4,5 & 9,6 & 2,0 & 11,3 & 7,8 & 4,7 & 3,0 & 5,9 & 0,9 \\
\hline Buccella peruviana & 0,0 & 0,9 & 0,0 & 0,0 & 1,0 & 0,0 & 0,0 & 0,0 & 0,0 & 0 & 0,0 & 0,0 & 0,0 & 0,0 & 0,0 & 0,0 & 0,0 & 0,0 & 0,0 & 0 & 0,0 & 0,0 & 0,0 & 0,0 & 0,0 & 0,0 & 0,0 & 0,0 &, 0 & 0,0 \\
\hline Bulimina & 0,0 & 0,0 & 0,0 & 0,0 & 0,0 & 0,0 & 0,0 & 0,0 & 0,0 & 0,0 & 0,0 & 0,0 & 0,0 & 0,0 & 0,0 & 0,0 & 0,0 & 0,0 & 0,0 & 0,0 & 0,0 & 0,0 & 0,0 & 2,0 & 0,0 & 2,2 & 6,6 & 0,0 &, 0 & 0,0 \\
\hline Bulimina elongata & 0,0 & 0,0 & 0,0 & 0,0 & 0,0 & 0,0 & 0,0 & 0,0 & 0,0 & 0,0 & 0,0 & 0,0 & 0,0 & 0,0 & 0,8 & 0,0 & 0,0 & 0,0 & 0,0 & 0,0 & 0,0 & 0,0 & 0,0 & 0,0 & 0,0 & 0,0 & 0,0 & 0,0 &, 0 & 0,0 \\
\hline Bulimina marginata & 0,0 & 0,0 & 0,0 & 0,0 & 0,0 & 0,0 & 0,0 & 1,9 & 0,0 & 0 , & 0,0 & 0,0 & 0,0 & 0,6 & 1,7 & 0,0 & 0,0 & 0,0 & 0,0 & 0,0 & 2,0 & 1,7 & 1,1 & 0,0 & 0,9 & 1,1 & 1,4 & 0,0 & 0 & 0,9 \\
\hline Bulimina pupoides & 0,0 & 0,9 & 1,0 & 0,0 & 0,0 & 0,9 & 0,0 & 0,0 & 1,9 & 0,0 & 0,0 & 0,8 & 1,0 & 0,0 & 0,0 & 0,0 & 0,0 & 0,0 & 0,0 & 0,0 & 0,0 & 0,0 & 0,0 & 0,0 & 0,0 & 0,0 & 0,0 & 0,0 & 0 & 0,0 \\
\hline Bulimina $\mathrm{sp}$ & 0,0 & 0,0 & 0,0 & 0,0 & 0,0 & 0,0 & 0,0 & 0,0 & 0,0 & 1,2 & 0,0 & 0,0 & 0,0 & 0,0 & 0,0 & 0,0 & 0,0 & 0,0 & 0,0 & 0,0 & 0,0 & 0,0 & 0,0 & 0,0 & 0,0 & 0,0 & 0,0 & 0,0 & 0,0 & 0,0 \\
\hline Buliminella ele & 0,0 & 0,0 & 0,0 & 0,0 & 0,0 & 0,0 & 0,9 & 5,7 & 1,0 & 2,4 & 1,0 & 0,0 & 0,0 & 0,0 & 0,8 & 2,2 & 0,0 & 0,6 & 3,3 & 1,0 & 3,9 & 0,6 & 2,3 & 0,0 & 0,9 & 0,6 & 0,0 & 0,0 &, 8 & 0,0 \\
\hline Cancris sagra & 1,9 & 2,6 & 0,0 & 4,0 & 2,1 & 0,9 & 0,0 & 0,0 & 0,0 & 0,6 & 0,0 & 0,8 & 0,0 & 0,6 & 0,8 & 0,0 & 0,0 & 5,2 & 0,0 & 1,0 & 0,7 & 0,6 & 0,6 & 0,0 & 0,9 & 0,0 & 0,0 & 0,0 & 0,0 & 0,9 \\
\hline Cassidela $\mathrm{sp}$ & 0,0 & 0,0 & 0,0 & 0,0 & 0,0 & 0,0 & 0,0 & 0,0 & 0,0 & 0,0 & 0,0 & 0,0 & 0,0 & 0,0 & 0,0 & 0,0 & 0,0 & 0,0 & 0,0 & 0,0 & 0,0 & 0,6 & 0,0 & 0,0 & 0,0 & 0,0 & 0,0 & 0,0 & 0,0 &, 0 \\
\hline
\end{tabular}


Anexo 43 - Continuação

Cassidulina crassa f. media

Cassidulina laevigata

Cassidulina subglobosa

Cibicides refulgens

Cibicides variabilis

Cibicides sp

Cornuspira involvens

Cribroelphidium advenum

Cribroelphidium articulatum

Cribroelphidium discoidale

Cribroelphidium excavatum

Cribroelphidium magellanicum

Cribroelphidium poyeanum

Cribroelphidium sp

Cribrostomoides sp

Dentalina sp

Discorbinella bertheloti

Discorbis isabelleanus

Discorbis williamsoni

Egerella scabra

Eponides repandus

Fissurina laevigata

Fissurina lucida

Fursenkoina pontoni

Gaudryina exilis

Gavelinopsis praegeri

Glabratella chasteri

Globulina sp

Gutulina lactea

\begin{tabular}{|c|c|c|c|c|c|c|c|c|c|c|c|c|c|c|c|c|c|c|c|c|c|c|c|c|c|c|c|c|c|}
\hline $\mathrm{Sc} 2$ & Sc3 & Sc5 & Sc6 & $\mathrm{Sc} 7$ & Sc8 & Sc9 & Sc10 & Sc11 & Sc12 & $\mathrm{Sc} 1$ & $\mathrm{Sc} 2$ & $\mathrm{Sc} 3$ & Sc4 & Sc5 & Sc6 & Sc7 & Sc8 & Sc9 & $\mathrm{Sc} 11$ & Sc1 & $\mathrm{Sc} 2$ & Sc3 & $\mathrm{Sc} 4$ & Sc5 & Sc6 & Sc7 & Sc8 & Sc9 & $\mathrm{Sc} 10$ \\
\hline 1,0 & 0,9 & 0,0 & 0,0 & 1,0 & 0,0 & 0,9 & 0,0 & 0,0 & 1,8 & 1,0 & 0,0 & 0,0 & 0,6 & 1,7 & 0,0 & 0,0 & 1,3 & 1,1 & 0,0 & 3,3 & 1,1 & 1,7 & 1,0 & 0,0 & 0,6 & 0,9 & 0,0 & 0,8 & 0,9 \\
\hline 0,0 & 0,0 & 0,0 & 0,0 & 0,0 & 0,0 & 0,0 & 0,0 & . & 0,0 & & 0,0 & 0,0 & 0,0 & 0,0 & 0,0 & 0,0 & 0,0 & 0 & & & 0 & 0 & 0,0 & 0 & 6 &, 9 & 0 & 7 & 9 \\
\hline 0,0 & 0,0 & 0,0 & 0,0 & 0,0 & 0,0 & 0,0 & 0,0 & o & 0, & , & 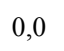 & 0,0 & 0,0 & 0,8 & 0,0 & 0,0 & 0,6 & 0,0 & 0,0 & 6 & 0,0 & 0,0 & 0,0 & 0,0 & 1,1 & 0,9 & 1,0 & ,8 & 0,0 \\
\hline 0,0 & 0,0 & 0,0 & 0,0 & 0,0 & 0,0 & 0,0 & 0,0 & 0,0 & 0,0 & 1,0 & 0,0 & 1,0 & 2,4 & 0,0 & 0,0 & 0,0 & 1,3 & 0,0 & 0,0 & 2,0 & 2,2 & 0,0 & 0,0 & 0,0 & 0,0 & 0,0 & 0,0 &, 0 & 0,0 \\
\hline 0,0 & 0,9 & 1,0 & 2,0 & 1,0 & 0,0 & 0,0 & 1,0 & 1,9 & 0,6 & 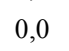 & , & 0,0 & 0,0 & 1,7 & 0,0 & 0,0 & 0,0 & 0,0 & 0,0 & & 0,6 & 0,0 & 0,0 & 0,0 & 0,0 & 0,0 & 0 & 0 & 0,0 \\
\hline 1,0 & 0,9 & 1,0 & 2,0 & 1,0 & 0,9 & 0,0 & 0,0 & 3,8 & 0, & 5,2 & 0,8 & 1,0 & 0,0 & 0,8 & 2,2 & 3,9 & 0,0 & 1,1 & 0,0 & 0,0 & 0,0 & 0,0 & 0,0 & 2,6 & 0,0 & 0,0 & 0,0 &, 0 & 0,9 \\
\hline 2,9 & 2,6 & 1,9 & 3,0 & 5,2 & 2,8 & 1,9 & 1,0 & 1,0 & 1,2 & 0,0 & 0,0 & 0,0 & 0,6 & 0,0 & 0,0 & 0,0 & 1,3 & 0,0 & 0,0 & 0,0 & 0,6 & 0,0 & 1,0 & 0,0 & 0,0 & 0,0 & 0,0 &, 8 & 0,0 \\
\hline 0,0 & 0,0 & 0,0 & 0,0 & 0,0 & 0,0 & 0,0 & 0,0 & 0,0 & 0 , & 0,0 & 0,0 & 0,0 & 0,0 & 0,0 & 0,0 & 0,0 & 0,0 & 0,0 & 0 , & - & 0,6 & 0,0 & 0,0 & 0,0 & 0 & 0,0 & 0 &, 7 & 0,9 \\
\hline 0,0 & 0,0 & 1,9 & 3,0 & 0,0 & 2,8 & 0,9 & 0,0 & 0,0 & 0 , & 1,0 & 1,5 & 0,0 & 0,6 & 0,0 & 0,0 & 2,0 & 0,6 & 0,0 & 0,0 & 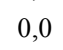 & 0,0 & 0,0 & 0,0 & 0,0 & ,0 & 0,0 & 0,0 &, 0 & 0,0 \\
\hline 1,0 & 0,9 & 1,0 & 0,0 & 0,0 & 0,0 & 0,0 & 0,0 & 0,0 & 0, & 0,0 & 0,0 & 0,0 & 0,0 & 0,0 & 0,0 & 0,0 & 0,0 & 0,0 & 0,0 & 0,0 & 0,6 & 0,0 & 0,0 & 2,6 & 0,0 & 0,0 & 0,0 &, 0 & 0,0 \\
\hline 0,0 & 0,0 & 0,0 & 0,0 & 0,0 & 0,0 & 0,0 & 0,0 & 0,0 & 0 , & . & 1, & 0, & 0,0 & 0 , & 1,1 & 0 , & 0 , & 0,0 & 1 , & & 0,0 & 0 & 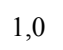 & 0,0 & 1,1 & 0,5 & 0 & 8 & 1,9 \\
\hline 0,0 & 0,0 & 0,0 & 0,0 & 0,0 & 0,0 & 0,0 & 0,0 & 0 , & 0, & 0,0 & 0,0 & 1,0 & 1,2 & 0,0 & 0,0 & 0,0 & 0,0 & 0,0 & 0,0 & 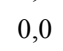 & 0,0 & 0,0 & 0,0 & 0,0 & 0,0 & 0,0 & 0,0 &, 0 & 0,0 \\
\hline 0,0 & 0,9 & 0,0 & 1,0 & 1,0 & 0,0 & 0,0 & 0,0 & 0 , & 0 , & 0,0 & 0,0 & 0,0 & 0,0 & 0,0 & 1,1 & 0,0 & 0,0 & 0,0 & 0, & & 1,1 & 0,6 & 0,0 & 0,0 & 0,0 & 0,0 & 0,0 &, 0 & 0,0 \\
\hline 1,0 & 0,0 & 0,0 & 1,0 & 0,0 & 0,0 & 0,9 & 1, & 0,0 & 0 , & 0 & 0 , & 0 & 0 & 0 & 0 , & 0 & 0 , & 0,0 & 0 & & 0,0 & 0 & & , , & & 0,9 & 0 & 8 & 0,0 \\
\hline 0,0 & 0,0 & 0,0 & 0,0 & 0,0 & 0,0 & 0,0 & 0,0 & 0 , & 0 , & 0,0 & 0,0 & 0,0 & 0,0 & 0,0 & 0,0 & 0, & 0,0 & 0,0 & 0,0 & . & 1,7 & 0,6 & 0,0 & 0,0 & 0,0 & 0,0 & 0,0 &, 0 & 0,0 \\
\hline 0,0 & 0,0 & 0,0 & 0,0 & 0,0 & 0,0 & 0,0 & 0,0 & 0 , & 0 , & 0,0 & 0,0 & 0,0 & 0,0 & 0,0 & 0,0 & 0,0 & 0,0 & 0,0 & 0 & & 0,0 & 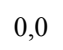 & 0,0 & 0,9 & 0,0 & 0,0 &, 0 & 8 & 0,0 \\
\hline 0,0 & 0,0 & 0,0 & 0,0 & 0,0 & 0,0 & 0,0 & 0,0 & 0,0 & 2 & 3 & 3,0 & 2, & 0 , & & 2 & 1, & 1, & 0,0 & 2,0 & & 1,7 & , & &, 0 & 0 & 0,0 & 0 & 8 & 0,9 \\
\hline 0,0 & 0,0 & 0,0 & 0,0 & 0,0 & 0,0 & 0,0 & 0,0 & 0,0 & 0,0 & 0,0 & 0,0 & 0,0 & 0,0 & 0,8 & 0,0 & 0,0 & 0,0 & 0,0 & 0,0 & 0,0 & 0,0 & 0,0 & 0,0 & 0,0 & 0,0 & 0,0 & 0,0 &, 0 & 0,0 \\
\hline 2,9 & 4,3 & 3,9 & 4,0 & 2,1 & 1,9 & 0,9 & 1,0 & 0,0 & 0,0 & 0,0 & 2,3 & 0,0 & 2,9 & 1,7 & 2,2 & 0,0 & 0,0 & 3,3 & 1,0 & & 0,6 & 2 , & 3, & 0,9 & 1,7 & 0,0 & 1,0 & 0 & 0,9 \\
\hline 0,0 & 0,0 & 0,0 & 0,0 & 0,0 & 0,0 & 0,0 & 0,0 & 0 , & 0, & 0,0 & 0,0 & 0,0 & 0,0 & 0,0 & 1,1 & 1,0 & 1,3 & 0,0 & 1,0 & J, & 0,6 & 0,6 & 0,0 & 0,0 & 0,0 & 1,9 & 0,0 &, 0 & 0,0 \\
\hline 1,9 & 0,0 & 0,0 & 0,0 & 0,0 & 0,0 & 0,0 & 0,0 & 0,0 & 0,0 & 0,0 & 0,0 & 1,0 & 0,0 & 0,0 & 1,1 & 1,0 & 0,0 & 0,0 & 0,0 & 0,0 & 0,6 & 0,0 & 0,0 & 0,9 & 0,0 & 0,0 & 0,0 & 0,0 & 0,0 \\
\hline 0,0 & 0,0 & 0,0 & 0,0 & 0,0 & 0,0 & 0,0 & 0,0 & 0,0 & 0,0 & 0,0 & 0,0 & 1,0 & 0,0 & 0,0 & 0,0 & 0,0 & 0,0 & 0,0 & 1,0 & 0,0 & 0,0 & 0,0 & 0,0 & 0,0 & 0,0 & 0,0 & 0,0 &, 0 & 0,0 \\
\hline 0,0 & 0,9 & 0,0 & 0,0 & 1,0 & 0,0 & 0,0 & 0,0 & 0,0 & 0,6 & 0,0 & 0,0 & 0,0 & 0,0 & 0,0 & 1,1 & 0,0 & 0,0 & 0,0 & 0,0 & 0,0 & 0,0 & 0,6 & 0,0 & 0,0 & 0,6 & 0,9 & 1,0 & 0,0 & 0,0 \\
\hline 0,0 & 0,9 & 0,0 & 0,0 & 1,0 & 0,0 & 0,9 & 0,0 & 7,7 & 0,6 & 0,0 & 0,0 & 0,0 & 0,0 & 0,0 & 1,1 & 0,0 & 0,0 & 0,0 & 0,0 & 0,0 & 0,0 & 0,0 & 0,0 & 0,0 & 0,0 & 0,0 & 0,0 & 0,0 & 0,0 \\
\hline 0,0 & 0,0 & 0,0 & 0,0 & 0,0 & 0,0 & 0,0 & 0,0 & 0,0 & 0,0 & 0,0 & 0,0 & 0,0 & 0,0 & 0,0 & 2,2 & 1,0 & 0,0 & 0,0 & 0,0 & 0,0 & 0,0 & 0,0 & 0,0 & 0,0 & 0,0 & 0,0 & 0,0 & 0,0 & 0,0 \\
\hline 9,7 & 8,6 & 23,3 & 26,3 & 7,2 & 32,7 & 7,4 & 9,5 & 17,3 & 2,4 & 12,5 & 4,5 & 6,7 & 17,6 & 18,2 & 0,0 & 5,9 & 20,0 & 7,6 & 12,7 & 2,0 & 5,6 & 6,2 & 8,1 & 6,1 & 5,6 & 4,2 & 12,0 & 16,0 & 12,3 \\
\hline 0,0 & 0,0 & 0,0 & 0,0 & 0,0 & 0,0 & 0,0 & 0,0 & 0,0 & 1,2 & 0,0 & 0,0 & 0,0 & 0,0 & 0,0 & 0,0 & 0,0 & 0,0 & 0,0 & 0,0 & 0,0 & 0,0 & 0,0 & 0,0 & 0,0 & 0,0 & 0,0 & 0,0 & 0,0 & 0,0 \\
\hline 0,0 & 0,0 & 0,0 & 0,0 & 0,0 & 0,0 & 0,0 & 0,0 & 0,0 & 0,0 & 0,0 & 0,0 & 0,0 & 0,0 & 0,0 & 0,0 & 0,0 & 0,0 & 0,0 & 0,0 & 0,0 & 0,6 & 0,0 & 0,0 & 0,0 & 0,0 & 0,0 & 0,0 & 0,0 & 0,0 \\
\hline 0,0 & 0,0 & 0,0 & 0,0 & 0,0 & 0,0 & 0,0 & 0,0 & 0,0 & 0,0 & 0,0 & 0,0 & 0,0 & 0,0 & 0,0 & 0,0 & 0,0 & 0,0 & 0,0 & 0,0 & 0,0 & 0,0 & 0,0 & 0,0 & 0,0 & 0,0 & 0,5 & 0,0 & 0,0 & 0,0 \\
\hline
\end{tabular}


Anexo 43 - Continuação

\begin{tabular}{|c|c|c|c|c|c|c|c|c|c|c|c|c|c|c|c|c|c|c|c|c|c|c|c|c|c|c|c|c|c|c|}
\hline & \multicolumn{10}{|c|}{ Setembro de 2005} & \multicolumn{10}{|c|}{ Junho de 2006} & \multicolumn{10}{|c|}{ Outubro de 2006} \\
\hline & Sc2 & Sc3 & Sc5 & Sc6 & Sc7 & Sc8 & Sc9 & Sc10 & Sc11 & Sc12 & Sc1 & $\mathrm{Sc} 2$ & $\mathrm{Sc} 3$ & Sc4 & Sc5 & Sc6 & Sc7 & $\mathrm{Sc} 8$ & Sc9 & Sc11 & $\mathrm{Sc} 1$ & $\mathrm{Sc} 2$ & $\mathrm{Sc} 3$ & $\mathrm{Sc} 4$ & Sc5 & Sc6 & Sc7 & Sc8 & Sc9 & Sc10 \\
\hline Hanzawaia boueana & 11,7 & 12,1 & 11,7 & 7,1 & 3,1 & 12,1 & 6,5 & 4,8 & 0,0 & 7,8 & 8,3 & 6,1 & 10,5 & 8,2 & 6,6 & 5,6 & 14,7 & 18,7 & 4,3 & 9,8 & 3,9 & 8,4 & 3,4 & 0,0 & 7,0 & 1,1 & 0,5 & 8,0 & 6,7 & 11,3 \\
\hline Haplophragmoides $\mathrm{sp}$ & 0,0 & 0,0 & 0,0 & 0,0 & 0,0 & 0,0 & 0,0 & 0,0 & 0,0 & 0,0 & 00 & 0,0 & 0,0 & 0,0 & 0,0 & 0,0 & 0,0 & 0,0 & 0,0 &, 0 & 3,9 & 0,0 & 0,0 & 0,0 & 0,0 & 0,0 & 0,0 & 0,0 & 0,0 & 0,0 \\
\hline Haynesina germanica & 0,0 & 0,9 & 0,0 & 0,0 & 0,0 & 0,0 & 0,0 & 0,0 & & 1 & 0,0 & 0,8 & 0,0 & 0,0 & 0,0 & 0,0 & 1,0 & 0,0 & 0,0 & 1,0 & 0,7 & 0,0 & 1,1 & 1,0 & 1,7 & 1,1 & 0,9 & 0,0 & 0,8 & 0,0 \\
\hline Hopkinsina pacifica & 1,0 & 0,0 & 0,0 & 0,0 & 0,0 & 0,0 & 2,8 & 0,0 & 0,0 & 0,6 & 1,0 & 0,0 & 0,0 & 0,0 & 1,7 & 0,0 & 1,0 & 0,0 & 0,0 & 0,0 & 1,3 & 0,0 & 1,1 & 0,0 & 0,9 & 0,0 & 0,0 & 0,0 & 0,8 & 0,0 \\
\hline Lagena striata & 0,0 & 0,0 & 0,0 & 0,0 & 0,0 & 0,0 & 0,0 & 0,0 & 0,0 & 0,0 & 0,0 & 0,0 & 0,0 & 0,0 & 0,0 & 0,0 & 0,0 & 0,0 & 0,0 & 0,0 & 1,3 & 0,6 & 0,6 & 0,0 & 0,0 & 0,0 & 0,0 & 0,0 & 0,0 & 0,0 \\
\hline Lagena $\mathrm{sp}$ & 0,0 & 0,0 & 0,0 & 0,0 & 0,0 & 0,0 & 0,0 & 0,0 & 0,0 & 0,0 & 0,0 & 0,8 & 0,0 & 0,0 & 0,0 & 0,0 & 0,0 & 0,0 & 0,0 & 0,0 & 0,7 & 0,0 & 0,0 & 0,0 & 0,0 & 0,0 & 0,0 & 0,0 & 0,0 & 0,0 \\
\hline Lenticulina $\mathrm{sp}$ & 1,0 & 0,0 & 0,0 & 0,0 & 2,1 & 0,0 & 0,0 & 1,0 & 4,8 & 0,0 & 0,0 & 0,8 & 0,0 & 0,0 & 0,0 & 0,0 & 0,0 & 0,0 & 0,0 & 0,0 & 0,0 & 0,0 & 0,0 & 0,0 & 0,0 & 0,0 & 0,5 & 0,0 & 0,0 & 0,0 \\
\hline Lepideuteramina ochracea & 0,0 & 0,0 & 1,0 & 0,0 & 0,0 & 3,7 & 0,0 & 1,0 & 1,0 & 3,0 & 1,0 & 0,0 & 1,0 & 7,6 & 2,5 & 1,1 & 0,0 & 9,0 & 3,3 & 0,0 & 0,0 & 3,9 & 2,3 & 6,1 & 0,0 & 0,0 & 1,9 & 3,0 & 5,9 & 8,5 \\
\hline Leptohalysis catela & 0,0 & 0,0 & 0,0 & 0,0 & 0,0 & 0,0 & 0,0 & 0,0 & 0,0 & 0,0 & 0,0 & 0,0 & 0,0 & 0,0 & 0,8 & 0,0 & 0,0 & 0,0 & 0,0 & 0,0 & 0,0 & 0,0 & 0,0 & 0,0 & 0,0 & 0,0 & 0,0 & 0,0 & 0,0 & 0,0 \\
\hline Lobatula lobatula & 0,0 & 4,3 & 4,9 & 2,0 & 1,0 & 0,9 & 0,9 & 1,9 & 0,0 & 0,6 & 7,3 & 3,0 & 1,9 & 2,4 & 3,3 & 3,3 & 0,0 & 0,6 & 4,3 & 2 , & 0,0 & 1,7 & 2,8 & 0,0 & 5,2 & 1,1 & 0,9 & 1,0 & 0,0 & 2,8 \\
\hline Massilina secans & 0,0 & 0,0 & 0,0 & 0,0 & 0,0 & 0,0 & 0,0 & 0,0 & 0,0 & 0, & 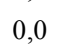 & 0,0 & 0,0 & 0,0 & 0,0 & 0,0 & 0,0 & 0,0 & 0,0 & 0,0 & 0,0 & 0,0 & 0,0 & 0,0 & 0,0 & 0,0 & 8 & 0,0 & 0,8 & 0,0 \\
\hline Melonis sp & 0,0 & 0,0 & 0,0 & 0,0 & 0,0 & 0,0 & 0,0 & 0,0 & 0,0 & 1,2 & 0,0 & 0,0 & 1,0 & 0,0 & 0,0 & 1,1 & 1,0 & 0,0 & 0,0 & 0,0 & 0,0 & 0,0 & 0,0 & 0,0 & 0,0 & 0,0 & 0,0 & 0,0 & 0,0 & 0,0 \\
\hline Miliolinella subrotunda & 0,0 & 0,0 & 0,0 & 0,0 & 0,0 & 0,0 & 0,0 & 1,0 & 3 , & 0 , & 0,0 & 2,3 & 5,7 & 0,0 & 0,8 & 0,0 & 2,0 & 0,0 & 0,0 & 1,0 & 0,0 & 3,4 & 1,7 & 3,0 & 2,6 & 0,6 & 0,0 & 2,0 & 2,5 & 0,9 \\
\hline Neocornobina terquemi & 2,9 & 5,2 & 12,6 & 7,1 & 7,2 & 10,3 & 1,9 & 1,0 & 2 & 4, & 1,0 & 11,4 & 11,4 & 8,8 & 4,1 & 4,4 & 6,9 & 6,5 & 4,3 & 1,0 & 0,0 & 6,2 & 2,3 & 8,1 & 2,6 & 5,6 & 5,2 & 18,0 & 6,7 & 1,9 \\
\hline Neocornobina sp & 0,0 & 0,0 & 0,0 & 0,0 & 0,0 & 0,0 & 0,0 & 0,0 & 0,0 & 0,0 & 0,0 & 0,0 & 0,0 & 0,0 & 0,0 & 2,2 & 2,9 & 1,3 & 0,0 & 0,0 & 0,0 & 0,0 & 0,0 & 3,0 & 0,0 & 0,6 & 0,5 & 0,0 & 0,0 & 0,0 \\
\hline Oolina sp & 0,0 & 0,0 & 0,0 & 0,0 & 0,0 & 0,0 & 0,0 & 0,0 & 0 & 0, & & 0,0 & 0,0 & 0,0 & 0,0 & 0,0 & 0,0 & 0,0 & 1,1 & 0 & 0,0 & 0,0 & 0,0 & 0,0 & 0,0 & 0,0 & 0 & 0,0 & 0,0 & 0,0 \\
\hline Pararotalia cananeiaensis & 1,0 & 3,4 & 0,0 & 1,0 & 2,1 & 0,0 & 0,9 & 1,0 & 0 , & 0 , & & 0,0 & 0,0 & 0,0 & 0,0 & 0,0 & 0,0 & 0,0 & 0,0 & 0,0 & 0,0 & 0,6 & 0,0 & 0,0 & 0,0 & 0,0 & 0,0 & 0,0 & 0,0 & 0,0 \\
\hline Paratrochammina sp & 0,0 & 0,0 & 0,0 & 0,0 & 0,0 & 0,0 & 0,0 & 0,0 & 0,0 & 0 , & 0,0 & 0,0 & 0,0 & 0,0 & 0,0 & 0,0 & 0,0 & 0,0 & 0,0 & 0,0 & 0,0 & 0,6 & 0,0 & 0,0 & 0,0 & 0,0 & 0,0 & 0,0 & 0,0 & 0,0 \\
\hline Patelina corrugata & 0,0 & 0,0 & 0,0 & 3,0 & 3,1 & 3,7 & 0,9 & 1,9 & 0,0 & 0,0 & & 3,0 & 1,0 & 3,5 & 0,0 & 1,1 & 4,9 & 1,3 & 0,0 & 0 & 1,3 & 1,7 & 0,6 & 0 & 1,7 & 2,8 & 0,9 & 1,0 & 4,2 & 0,0 \\
\hline Polymorphina complanata & 0,0 & 0,0 & 0,0 & 0,0 & 0,0 & 0,0 & 0,0 & 0,0 & 0,0 & 0 , & 0,0 & 0,0 & 0,0 & 0,0 & 0,0 & 0,0 & 0,0 & 0,0 & 0,0 & 0,0 & 0,0 & 0,0 & 0,0 & 0,0 & 0,0 & 2,8 & 0,5 & 0,0 & 0,8 & 0,0 \\
\hline Pseudononion atlanticum & 1,9 & 0,9 & 0,0 & 1,0 & 2,1 & 0,9 & 0,0 & 1,9 & 0,0 & 1,8 & 0,0 & 0,0 & 1,9 & 0,0 & 0,8 & 0,0 & 2,0 & 0,0 & 0,0 & 0,0 & 1,3 & 0,6 & 1,1 & 1,0 & 0,9 & 1,1 & 1,4 & 1,0 & 0,0 & 0,9 \\
\hline Pseudononion grateloupi & 0,0 & 0,0 & 0,0 & 0,0 & 0,0 & 0,0 & 0,0 & 0 & 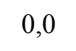 & 0 , & 1 & 0,0 & 0,0 & 0,6 & 0,0 & 0,0 & 0,0 & 0,0 & 0,0 & 0,0 & 1,3 & 0,0 & 0,6 & 0,0 & 0,0 & 0,0 & 0,0 & 0,0 & 0,0 & 0,0 \\
\hline Pseudononion pauperatus & 0,0 & 0,0 & 0,0 & 0,0 & 0,0 & 0,0 & 0,0 & 0,0 & 0,0 & 0,0 & 1,0 & 0,8 & 0,0 & 0,0 & 0,0 & 0,0 & 0,0 & 0,0 & 0,0 & 0,0 & 0,0 & 0,0 & 0,0 & 0,0 & 0,0 & 0,0 & 0,0 & 0,0 & 0,0 & 0,0 \\
\hline Pseudononion opima & 0,0 & 0,0 & 0,0 & 0,0 & 0,0 & 0,0 & 0,0 & 0,0 & 0,0 & 0,0 & 0,0 & 0,0 & 0,0 & 0,0 & 0,0 & 0,0 & 0,0 & 0,0 & 1,1 & 1,0 & 0,0 & 0,0 & 0,6 & 0,0 & 0,0 & 0,0 & 0,0 & 0,0 & 0,0 & 0,0 \\
\hline Pseudononion sp & 0,0 & 0,0 & 0,0 & 0,0 & 0,0 & 0,0 & 0,0 & 1,0 & 0 , & 0,0 & 0,0 & 0,0 & 0,0 & 0,0 & 0,0 & 0,0 & 0,0 & 0,0 & 0,0 & 0,0 & 0,0 & 0,0 & 0,0 & 0,0 & 0,0 & 0,0 & 0,5 & 0,0 & 0,0 & 0,0 \\
\hline Quinqueloculina atlantica & 0,0 & 0,0 & 0,0 & 0,0 & 0,0 & 0,0 & 0,0 & 0,0 & 0,0 & 0,0 & 0,0 & 0,0 & 1,0 & 0,0 & 0,0 & 0,0 & 0,0 & 0,0 & 0,0 & 0,0 & 0,0 & 0,0 & 0,0 & 0,0 & 0,0 & 0,0 & 0,0 & 0,0 & 0,0 & 0,0 \\
\hline Quinqueloculina bosciana & 0,0 & 0,0 & 0,0 & 0,0 & 0,0 & 0,0 & 0,0 & 0,0 & 0,0 & 0,0 & 0,0 & 0,0 & 0,0 & 0,6 & 0,0 & 0,0 & 0,0 & 0,0 & 0,0 & 0,0 & 0,0 & 0,0 & 0,0 & 0,0 & 0,0 & 0,0 & 0,0 & 0,0 & 0,0 & 0,0 \\
\hline Quinqueloculina ho & 0,0 & 0,0 & 0,0 & 0,0 & 0,0 & 0,0 & 0,0 & 0,0 & 0 & 0,0 & 0 & 0,0 & 0,0 & 0,0 & 0,0 & 0,0 & 0,0 & 0,0 & 0,0 & 0,0 & 0,0 & 0,0 & 0,0 & 0,0 & 0,0 & 0,0 & 0,0 & 0,0 & 0,8 & 0,0 \\
\hline Quinqueloculina laevigata & 0,0 & 0,0 & 0,0 & 0,0 & 2,1 & 0,0 & 0,0 & 0,0 & 0,0 & 0,0 & 0,0 & 0,0 & 0,0 & 0,0 & 0,0 & 0,0 & 0,0 & 0,0 & 0,0 & 0,0 & 0,0 & 0,0 & 0,0 & 0,0 & 0,0 & 0,0 & 0,0 & 0,0 & 0,0 & 0,0 \\
\hline
\end{tabular}




\section{Quinqueloculina} lamarckiana

Quinqueloculina milletti

Quinqueloculina patagonica

Quinqueloculina polygona

Quinqueloculina seminula

Quinqueloculina sp

Remaneica helgolandica

Reophax sp

Rolshausheni rolshauseni

Rosalina bradyi

Rosalina floridensis

Rosalina sp

Rubratella intermedia

Sigmolopsis schumbergeri

Siphogenerina rephanus

Spirillina vivipara

Spiroloculina depressa

Spiroplectamina biformis

Spiroloculina sp

Stanforthia concava

Textulria foliacea

Textularia gramen

Tiphotrocha comprimata

Triloculina cultrata

Triloculina earlandi

Triloculina laevigata

Triloculina oblonga

Triloculina trigonula

\begin{tabular}{|c|c|c|c|c|c|c|c|c|c|c|c|c|c|c|c|c|c|c|c|c|c|c|c|c|c|c|c|c|c|}
\hline \multicolumn{10}{|c|}{ Setembro de 2005} & \multicolumn{10}{|c|}{ Junho de 2006} & \multicolumn{10}{|c|}{ Outubro de 2006} \\
\hline $\mathrm{Sc} 2$ & Sc3 & Sc5 & Sc6 & Sc7 & Sc8 & Sc9 & Sc10 & Sc11 & Sc12 & Sc1 & $\mathrm{Sc} 2$ & $\mathrm{Sc} 3$ & Sc4 & Sc5 & Sc6 & Sc7 & Sc8 & Sc9 & Sc11 & $\mathrm{Sc} 1$ & Sc2 & Sc3 & Sc4 & Sc5 & Sc6 & Sc7 & Sc8 & Sc9 & Sc10 \\
\hline 0,0 & 0,9 & 0,0 & 0,0 & 1,0 & 0,9 & 0,0 & 0,0 & 1,0 & 0,0 & 1,0 & 0,0 & 1,0 & 0,0 &, 0 & 0,0 & 0,0 & 0,0 & 0,0 & 1,0 & 0,0 & 0,6 & 1,7 & 4,0 & 0,0 & 1,1 & 0,0 & 3,0 & 0,0 & 0,0 \\
\hline 0,0 & 0,9 & 0,0 & 0,0 & 0,0 & 0,0 & 0,0 & 0,0 & 0,0 & 0,0 & 0,0 & 0,0 & 1,9 & 0,0 & 0,0 & 1,1 & 1,0 & 0,6 & 0,0 & 1,0 & 0,0 & 2,2 & 0,0 & 2,0 & 2,6 & 0,0 & 2,3 & 1,0 & 3,4 & 0,0 \\
\hline 0,0 & 0,0 & 0,0 & 0,0 & 0,0 & 0,0 & 0,0 & 0,0 & 0,0 & 0,0 & 0,0 & 0,0 & 0,0 & 0,0 & 0,0 & 0,0 & 0,0 & 0,0 & 0,0 & 0,0 & 0,0 & 0,6 & 0,0 & 0,0 & 0,0 & 1,7 & 0,0 & 1,0 & 0,8 & 0,0 \\
\hline 0,0 & 0,0 & 0,0 & 0,0 & 0,0 & 0,0 & 0,0 & 0,0 & 0,0 & 0,0 & 0,0 & 0,0 & 1,0 & 0,0 & 0,0 & 0,0 & 0,0 & 0,0 & 0,0 & 0,0 & 0,0 & 0,0 & 0,0 & 0,0 & 0,0 & 0,0 & 0,0 & 0,0 & 0,0 & 0,0 \\
\hline 0,0 & 0,0 & 0,0 & 0,0 & 0,0 & 0,0 & 0,0 & 0,0 & 0,0 & 0,0 & 0,0 & 0,0 & 0,0 & 0,0 & 0,0 & 0,0 & 0,0 & 0,0 & 0,0 & 0,0 & 0,0 & 0,0 & 0,0 & 1,0 & 0,9 & 0,6 & 0,0 & 0,0 & 5,0 & 0,0 \\
\hline 0,0 & 0,0 & 1,0 & 1,0 & 0,0 & 0,9 & 0,0 & 0,0 & 1,0 & 0,0 & 0,0 & 0,0 & 0,0 & 0,0 & 0,0 & 1,1 & 1,0 & 0,0 & 0,0 & 0,0 & 0,7 & 0,6 & 0,0 & 0,0 & 0,0 & 0,0 & 0,5 & 0,0 & 0,0 & 2,8 \\
\hline 0,0 & 0,0 & 0,0 & 0,0 & 0,0 & 0,0 & 0,0 & 0,0 & 0,0 & 0,0 & 0,0 & 0,0 & 0,0 & 1,8 & 0,0 & 0,0 & 0,0 & 0,0 & 0,0 & 0,0 & 0,0 & 0,0 & 0,0 & 0,0 & 0,0 & 0,0 & 0,0 & 0,0 & 0,0 & 0,0 \\
\hline 0,0 & 0,0 & 0,0 & 0,0 & 0,0 & 0,0 & 0,0 & 0,0 & 0,0 & 0,0 & 0,0 & 0,0 & 0,0 & 0,6 & 0,0 & 0,0 & 0,0 & 0,6 & 0,0 & 0,0 & 0,0 & 0,0 & 0,0 & 1,0 & 0,0 & 0,0 & 0,0 & 0,0 & 0,0 & 0,0 \\
\hline 0,0 & 0,0 & 0,0 & 0,0 & 0,0 & 0,0 & 0,9 & 0,0 & 3,8 & 0,0 & 1,0 & 0,0 & 0,0 & 0,0 & 0,0 & 0,0 & 0,0 & 0,0 & 0,0 & 0,0 & 0,0 & 0,0 & 0,0 & 0,0 & 0,0 & 0,0 & 0,5 & 0,0 & 0,8 & 0,0 \\
\hline 0,0 & 0,0 & 0,0 & 0,0 & 0,0 & 0,0 & 0,0 & 0,0 & 0,0 & 0,0 & 0,0 & 0,0 & 0,0 & 0,0 & 0,0 & 0,0 & 0,0 & 1,3 & 0,0 & 0,0 & 0,0 & 0,0 & 0,0 & 0,0 & 0,0 & 0,0 & 0,0 & 0,0 & 0,0 & 0,0 \\
\hline 2,9 & 0,0 & 1,0 & 1,0 & 3,1 & 0,9 & 1,9 & 1,9 & 1,0 & 2,4 & 5,2 & 13,6 & 9,5 & 8,8 & 3,3 & 5,6 & 3,9 & 1,3 & 1,1 & 2,9 & 3,3 & 5,6 & 3,4 & 5,1 & 3,5 & 3,4 & 5,6 & 3,0 & 3,4 & 3,8 \\
\hline 0,0 & 0,0 & 0,0 & 0,0 & 0,0 & 0,0 & 0,0 & 0,0 & 0,0 & 0,0 & 0,0 & 0,0 & 0,0 & 0,6 & 0,0 & 0,0 & 0,0 & 1,3 & 0,0 & 0,0 & 0,0 & 0,0 & 0,0 & 0,0 & 0,0 & 0,0 & 0,0 & 0,0 & 0,0 & 0,0 \\
\hline 0,0 & 0,0 & 0,0 & 0,0 & 2,1 & 0,0 & 0,0 & 0,0 & 0,0 & 0,0 & 0,0 & 0,0 & 0,0 & 0,0 & 0,0 & 0,0 & 0,0 & 0,0 & 0,0 & 0,0 & 0,0 & 0,0 & 0,0 & 0,0 & 0,0 & 0,0 & 0,0 & 0,0 & 0,0 & 0,0 \\
\hline 0,0 & 0,0 & 0,0 & 0,0 & 0,0 & 0,0 & 0,0 & 0,0 & 0,0 & 0,0 & 0,0 & 0,0 & 0,0 & 0,0 & 0,0 & 0,0 & 0,0 & 0,0 & 0,0 & 0,0 & 0,7 & 0,0 & 0,6 & 0,0 & 0,0 & 0,0 & 0,0 & 1,0 & 0,0 & 0,0 \\
\hline 0,0 & 1,7 & 0,0 & 0,0 & 1,0 & 0,9 & 0,0 & 0,0 & 0,0 & 0,0 & 0,0 & 0,0 & 0,0 & 0,0 & 0,0 & 1,1 & 0,0 & 0,0 & 0,0 & 1,0 & 0,7 & 0,6 & 0,0 & 0,0 & 1,7 & 0,0 & 5,6 & 0,0 & 0,0 & 0,0 \\
\hline 0,0 & 0,0 & 0,0 & 0,0 & 0,0 & 0,0 & 0,0 & 0,0 & 0,0 & 0,0 & 2,1 & 6,1 & 7,6 & 4,1 & 3,3 & 6,7 & 13,7 & 0,0 & 2,2 & 2,9 &, 7 & 8,4 & 2,8 & 4,0 & 0,0 & 2,8 & 2,8 & 5,0 & 2,5 & 1,9 \\
\hline 0,0 & 0,0 & 0,0 & 0,0 & 0,0 & 0,0 & 0,0 & 0,0 & 0,0 & 1,2 & 0,0 & 0,0 & 0,0 & 0,0 & 0,0 & 0,0 & 0,0 & 0,0 & 0,0 & 0,0 & 0,0 & 0,0 & 0,0 & 0,0 & 0,0 & 0,0 & 0,0 & 0,0 & 0,0 & 0,0 \\
\hline 0,0 & 0,0 & 0,0 & 0,0 & 0,0 & 0,0 & 0,0 & 0,0 & 0,0 & 0,0 & 0,0 & 0,0 & 0,0 & 0,0 & 0,0 & 0,0 & 0,0 & 0,0 & 0,0 & 0,0 & 0,0 & 0,0 & 0,0 & 0,0 & 0,9 & 0,0 & 0,0 & 0,0 & 0,0 & 0,0 \\
\hline 0,0 & 0,0 & 0,0 & 0,0 & 0,0 & 0,0 & 0,0 & 0,0 & 0,0 & 0,0 & 0,0 & 0,0 & 0,0 & 0,0 & 0,0 & 0,0 & 0,0 & 0,6 & 0,0 & 0,0 & 0,0 & 0,0 & 0,0 & 0,0 & 0,0 & 0,0 & 0,0 & 0,0 & 0,0 & 0,0 \\
\hline 0,0 & 0,0 & 0,0 & 0,0 & 0,0 & 0,0 & 0,0 & 0,0 & 0,0 & 0,6 & 0,0 & 0,0 & 0,0 & 0,0 & 0,0 & 0,0 & 0,0 & 0,0 & 0,0 & 0,0 & 0,0 & 0,0 & 0,0 & 0,0 & 0,0 & 0,0 & 0,0 & 0,0 & 0,8 & 0,0 \\
\hline 0,0 & 0,0 & 0,0 & 0,0 & 0,0 & 0,0 & 0,0 & 0,0 & 0,0 & 0,0 & 0,0 & 0,0 & 0,0 & 0,6 & 0,0 & 0,0 & 0,0 & 0,0 & 0,0 & 0,0 & 0,0 & 0,0 & 0,0 & 0,0 & 0,0 & 0,0 & 0,0 & 0,0 & 0,0 & 0,0 \\
\hline 0,0 & 0,0 & 0,0 & 0,0 & 0,0 & 0,0 & 0,0 & 0,0 & 0,0 & 0,0 & 0,0 & 0,0 & 0,0 & 0,6 & 0,0 & 0,0 & 0,0 & 1,3 & 0,0 & 0,0 & 0,0 & 0,0 & 0,0 & 0,0 & 0,0 & 0,0 & 0,0 & 0,0 & 0,0 & 0,0 \\
\hline 0,0 & 0,0 & 0,0 & 0,0 & 0,0 & 0,0 & 0,0 & 1,9 & 0,0 & 0,0 & 0,0 & 0,0 & 0,0 & 0,0 & 0,0 & 0,0 & 0,0 & 0,0 & 0,0 & 0,0 & 0,0 & 0,0 & 0,0 & 0,0 & 0,0 & 0,0 & 0,0 & 0,0 & 0,0 & 0,0 \\
\hline 0,0 & 0,0 & 0,0 & 0,0 & 0,0 & 0,0 & 0,0 & 0,0 & 0,0 & 1,2 & 1,0 & 0,0 & 0,0 & 0,0 & 0,0 & 0,0 & 0,0 & 0,0 & 0,0 & 0,0 & 0,0 & 0,0 & 0,0 & 0,0 & 0,0 & 0,0 & 0,0 & 0,0 & 0,0 & 0,0 \\
\hline 0,0 & 0,0 & 0,0 & 0,0 & 0,0 & 0,0 & 0,0 & 0,0 & 0,0 & 0,0 & 0,0 & 0,0 & 0,0 & 0,0 & 0,0 & 0,0 & 0,0 & 0,0 & 0,0 & 0,0 & 0,7 & 0,0 & 0,0 & 0,0 & 0,0 & 0,0 & 0,0 & 0,0 & 0,0 & 0,9 \\
\hline 0,0 & 0,0 & 0,0 & 0,0 & 0,0 & 0,0 & 0,0 & 0,0 & 0,0 & 0,0 & 0,0 & 3,0 & 1,9 & 0,0 & 0,0 & 0,0 & 0,0 & 0,6 & 0,0 & 1,0 & 0,0 & 4,5 & 0,0 & 1,0 & 0,0 & 1,7 & 1,4 & 1,0 & 0,0 & 0,0 \\
\hline 0,0 & 0,0 & 0,0 & 0,0 & 0,0 & 0,0 & 0,0 & 0,0 & 1,0 & 1,8 & 0,0 & 0,0 & 1,0 & 0,0 & 0,8 & 2,2 & 2,9 & 1,3 & 0,0 & 1,0 & 0,0 & 1,1 & 0,6 & 0,0 & 0,0 & 0,0 & 0,0 & 1,0 & 1,7 & 2,8 \\
\hline 0,0 & 0,0 & 0,0 & 0,0 & 0,0 & 0,0 & 0,0 & 0,0 & 0,0 & 0,0 & 0,0 & 0,0 & 0,0 & 0,0 & 0,0 & 0,0 & 0,0 & 0,0 & 0,0 & 0,0 & 0,0 & 1,7 & 0,0 & 0,0 & 0,9 & 0,0 & 0,0 & 0,0 & 0,0 & 0,0 \\
\hline
\end{tabular}


Anexo 43 - Continuação

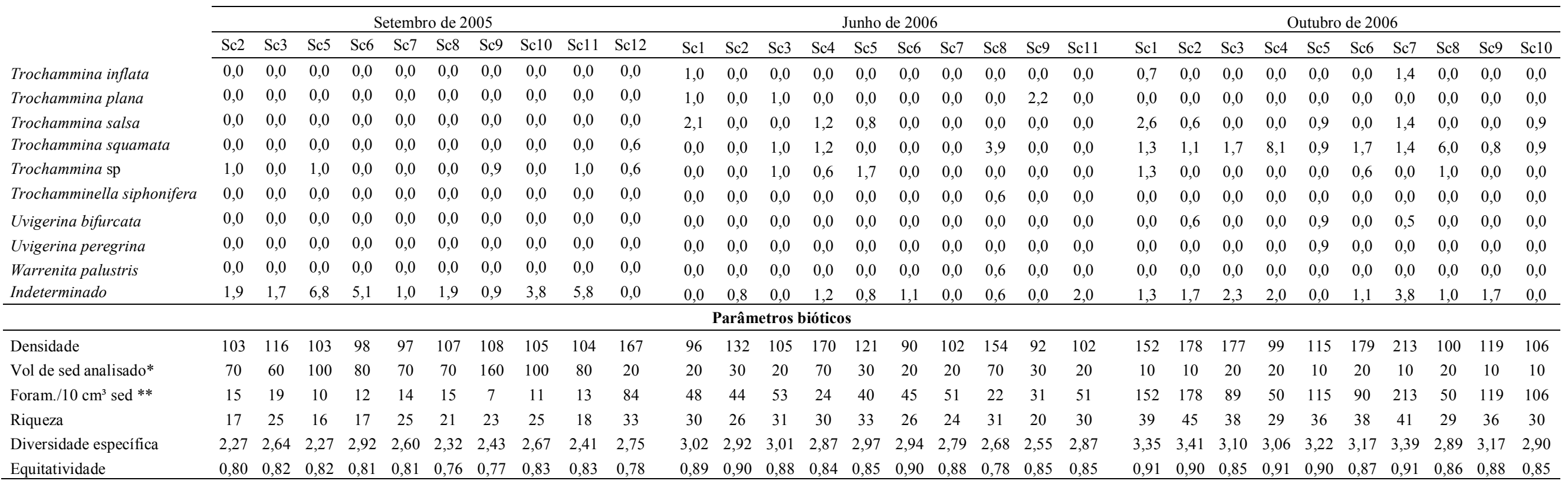

Legenda: *Volume de sedimento analisado, ** Foraminíferos $/ 10 \mathrm{~cm}^{3}$ de sedimento 
Anexo 44 - (Biocenoses) Distribuição de espécies bioindicadoras de ambiente óxico e enriquecido por matéria orgânica identificadas próximo ao emissário Saco da Capela.

Valores em porcentagem.

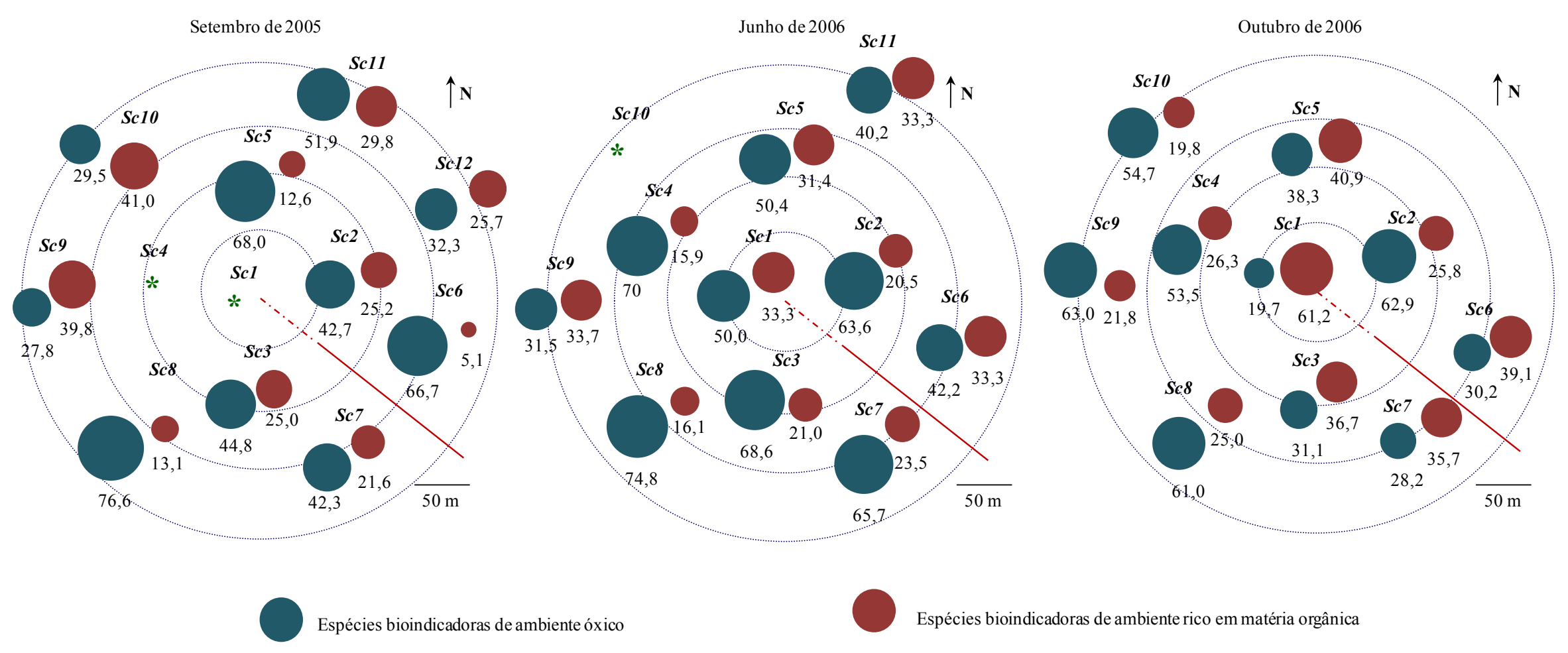

\footnotetext{
* Estação não amostrada
} 
Anexo 45 - (Biocenoses) Resultado das análises morfométricas realizadas nas carapaças dos foraminíferos obtidas próximo ao emissário Saco da Capela.

Valores em porcentagem.
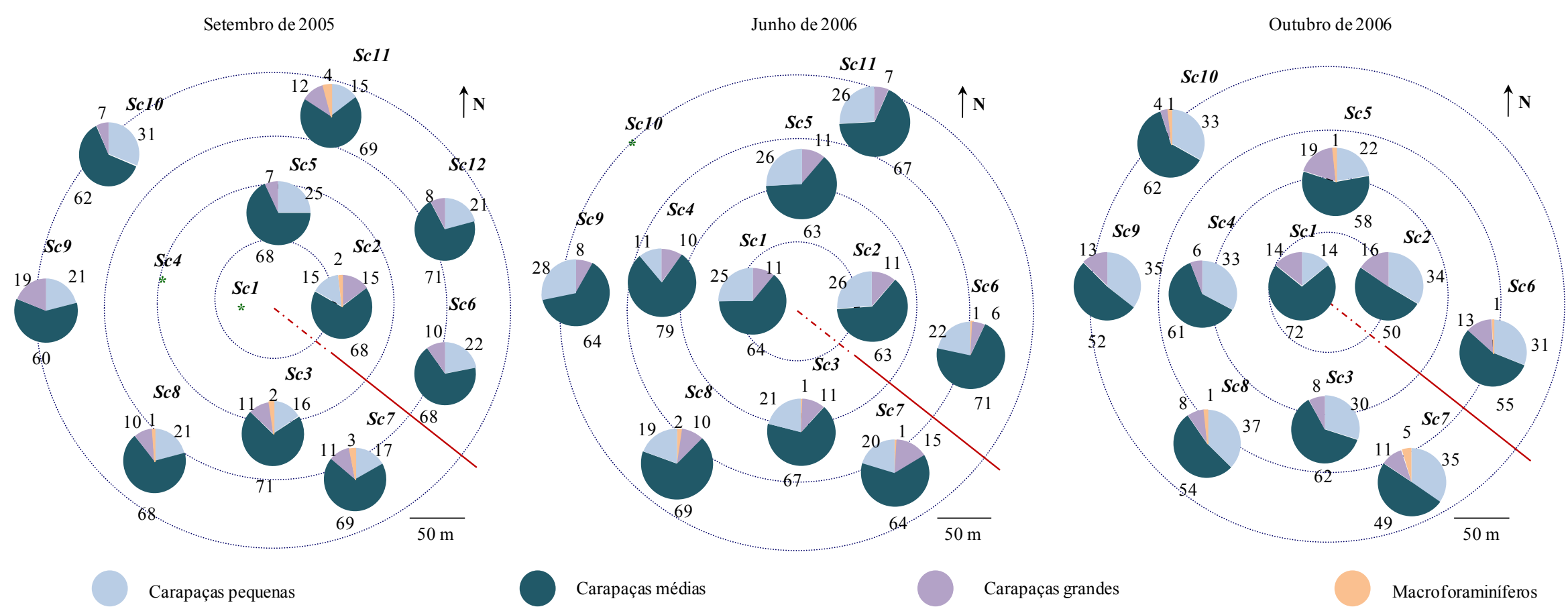

* Estação não amostrada 
Anexo 46 - Abundâncias relativas das espécies de foraminíferos identificadas próximo ao emissário Saco da Capela.

Dados pertencentes às tanatocenoses.

\begin{tabular}{|c|c|c|c|c|c|c|c|c|c|c|c|c|c|c|c|c|c|c|c|c|c|c|c|c|c|c|c|c|c|c|}
\hline \multirow[b]{2}{*}{ Estações } & \multicolumn{10}{|c|}{ Setemb1o de 2005} & \multicolumn{10}{|c|}{ Junho de 2006} & \multicolumn{10}{|c|}{ Outub1o de 2006} \\
\hline & Sc2 & Sc3 & Sc5 & Sc6 & Sc7 & $\mathrm{Sc} 8$ & Sc9 & Sc10 & Sc11 & Sc12 & Sc1 & Sc2 & $\mathrm{Sc} 3$ & Sc4 & Sc5 & Sc6 & Sc7 & Sc8 & Sc9 & $\mathrm{Sc} 11$ & Sc1 & Sc2 & Sc3 & Sc4 & Sc5 & Sc6 & Sc7 & Sc8 & Sc9 & Sc10 \\
\hline Adelosina mediterranensis & 0,0 & 0,0 & 0,0 & 0,0 & 0,0 & 0,0 & 0,0 & 0,0 & 0,0 & 0,0 & 0,0 & 0,0 & 0,0 & 0,0 & 0,9 & 0,0 & 0,6 & 0,0 & 0,0 & 0,0 & 0,0 & 0,0 & 0,0 & 0,0 & 0,0 & 0,0 & 0,0 & 0,0 & 0,0 & 0,0 \\
\hline Adelosina sp. & 0,0 & 0,0 & 0,0 & 0,0 & 0,0 & 0,0 & 0,0 & 0,0 & 0,0 & 0,0 & 0,0 & 0,0 & 0,4 & 0,3 & 0,3 & 0,0 & 0,3 & 0,0 & 0,0 & 0,0 & 0,0 & 0,0 & 0,7 & 0,0 & 0,3 & 1,1 & 0,0 & 0,0 & 0,0 & 0,0 \\
\hline Ammonia parkinsoniana & 1,6 & 0,0 & 0,6 & 0,0 & 0,0 & 0,0 & 1,4 & 1,1 & 0,0 & 2,5 & 1,5 & 0,4 & 2,8 & 0,8 & 2,9 & 3,2 & 2,2 & 0,6 & 1,8 & 1,2 & 0,0 & 0,0 & 0,0 & 0,0 & 0,3 & 0,0 & 0,4 & 0,0 & 0,0 & 0,0 \\
\hline Ammonia tepida & 10,7 & 3,2 & 6,5 & 0,0 & 7,7 & 6,5 & 7,7 & 2,7 & 8,9 & 13,7 & 2,0 & 2,4 & 6,1 & 2,8 & 5,2 & 10,4 & 6,0 & 2,5 & 4,2 & 8,1 & 8,1 & 7,1 & 9,9 & 6,8 & 7,5 & 11,9 & 14,8 & 5,6 & 6,9 & 11,0 \\
\hline Ammonia sp & 10,3 & 12,0 & 14,3 & 0,0 & 10,6 & 0,0 & 17,5 & 13,0 & 2,1 & 8,3 & 8,3 & 1,2 & 0,4 & 2,3 & 4,9 & 5,2 & 1,9 & 1,9 & 5,2 & 2,6 & 10,4 & 8,9 & 3,8 & 3,1 & 7,1 & 2,6 & 3,6 & 2,9 & 2,9 & 1,6 \\
\hline Ammobaculites $s p$ & 0,0 & 0,0 & 0,0 & 0,0 & 0,0 & 0,0 & 0,0 & 0,0 & 0,0 & 0,0 & 0,0 & 0,0 & 0,0 & 0,0 & 0,0 & 0,0 & 0,3 & 0,0 & 0,3 & 0,0 & 0,0 & 0,0 & 0,0 & 0,0 & 0,0 & 0,0 & 0,0 & 0,0 & 0,0 & 0,0 \\
\hline Ammotium salsum & 0,0 & 0,0 & 0,0 & 0,0 & 0,0 & 0,0 & 0,0 & 0,0 & 0,0 & 0,4 & 0,0 & 1,2 & 0,0 & 0,8 & 1,1 & 2,3 & 3,2 & 1,9 & 0,9 & 2,2 & 1,0 & 0,0 & 1,4 & 1,5 & 1,0 & 0,7 & 1,1 & 0,5 & 0,0 & 0,0 \\
\hline Amphicorina scalaris & 0,4 & 0,0 & 0,0 & 0,0 & 0,0 & 0,0 & 0,0 & 0,0 & 0,0 & 0,0 & 0,0 & 0,0 & 0,0 & 0,0 & 0,0 & 0,0 & 0,0 & 0,0 & 0,0 & 0,0 & 0,0 & 0,7 & 0,5 & 0,6 & 1,3 & 0,7 & 0,7 & 0,2 & 0,0 & 0,0 \\
\hline Angulogerina angulosa & 0,8 & 0,0 & 0,0 & 10,0 & 1,0 & 0,0 & 0,5 & 0,4 & 0,0 & 0,0 & 0,5 & 1,2 & 0,0 & 0,0 & 0,3 & 0,0 & 0,3 & 0,0 & 0,0 & 0,0 & 1,5 & 0,2 & 0,0 & 0,9 & 0,0 & 0,0 & 0,0 & 0,7 & 0,0 & 0,0 \\
\hline Astalacus $s p$ & 0,0 & 0,0 & 0,0 & 0,0 & 0,0 & 0,0 & 0,0 & 0,0 & 0,0 & 0,0 & 0,5 & 0,0 & 0,0 & 0,0 & 0,3 & 0,0 & 0,0 & 0,0 & 0,0 & 0,0 & 0 & 0,0 & 0,0 & 0,0 & 0,0 & 0,0 & 0,0 & 0,0 & 0,0 & 0,0 \\
\hline Astrononion sp & 0,0 & 0,0 & 0,0 & 0,0 & 0,0 & 0,0 & 0,0 & 0,0 & 0,0 & 0,0 & 0,0 & 0,4 & 0,4 & 0,0 & 0,0 & 0,0 & 0,0 & 0,0 & 0,0 & 0,0 & 0,0 & 0,0 & 0,0 & 0,0 & 0,0 & 0,0 & 0,0 & 0,0 & 0,0 & 0,0 \\
\hline Bolivina alata & 0,0 & 0,0 & 0,0 & 0,0 & 0,0 & 0,0 & 0,0 & 0,0 & 0,0 & 0,0 & 0,0 & 0,0 & 0,0 & 0,0 & 0,0 & 0,0 & 0,0 & 0,0 & 0,0 & 0,0 & 0,0 & 0,0 & 0,0 & 0,0 & 0,0 & 0,0 & 0,0 & 0,2 & 1,6 & 1,2 \\
\hline Bolivina compacta & 0,8 & 0,9 & 2,6 & 0,0 & 0,3 & 0,0 & 0,5 & 0,0 & 0,7 & 0,0 & 0,0 & 0,0 & 1,2 & 0,6 & 0,9 & 0,0 & 0,3 & 0,0 & 0,3 & 0 & 0,3 & 1,4 & 2,6 & 2,8 & 1,6 & 1,9 & 2,2 & 2,4 & 0,8 & 0,0 \\
\hline Bolivina danvilensis & 0,0 & 0,0 & 0,0 & 0,0 & 0,0 & 0,0 & 0,0 & 0,0 & 0,0 & 0,0 & 0,5 & 0,0 & 0,0 & 0,0 & 0,0 & 0,0 & 0,3 & 0,0 & 0,3 & 0,7 & 0,0 & 0,0 & 0,0 & 0,0 & 0,0 & 0,0 & 0,0 & 0,0 & 0,0 & 0,0 \\
\hline Bolivina doniezi & 0,8 & 1,3 & 0,0 & 0,0 & 0,0 & 0,0 & 0,0 & 0,0 & 0,7 & 0,0 & 0,5 & 0,0 & 0,4 & 0,0 & 1,1 & 0,0 & 0,0 & 1,3 & 0,9 & 1,0 & 2,8 & 2,1 & 1,0 & 0,6 & 0,6 & 1,5 & 0,4 & 0,7 & 0,4 & 1,2 \\
\hline Bolivina ordinaria & 3,2 & 0,9 & 0,0 & 0,0 & 2,6 & 0,0 & 0,7 & 1,9 & 1,4 & 1,4 & 1,0 & 0,8 & 2,0 & 0,0 & 0,6 & 0,6 & 1,0 & 1,3 & 0,0 & 1,0 & 2,5 & 0,0 & 1,4 & 0,6 & 1,9 & 0,4 & 1,8 & 1,9 & 0,8 & 1,6 \\
\hline Bolivina pseudoplicata & 2,0 & 0,0 & 0,0 & 0,0 & 1,6 & 0,0 & 2,3 & 0,8 & 1,4 & 0,0 & 1,0 & 2,8 & 1,2 & 0,0 & 0,9 & 1,0 & 1,3 & 0,6 & 0,0 & 0,5 & 0,0 & 0,0 & 0,0 & 0,0 & 0,0 & 0,0 & 0,0 & 0,0 & 0,0 & 0,0 \\
\hline Bolivina pulchella & 0,4 & 3,5 & 0,6 & 0,0 & 1,0 & 0,0 & 2,7 & 1,9 & 0,7 & 1,1 & 0,5 & 1,2 & 0,8 & 0,0 & 0,9 & 0,6 & 0,6 & 1,9 & 2,1 & 0,2 & 5,8 & 1,8 & 2,2 & 3,4 & 3,9 & 0,4 & 1,4 & 3,4 & 3,7 & 0,0 \\
\hline Bolivina seminuda & 0,0 & 0,0 & 0,0 & 0,0 & 0,0 & 0,0 & 0,0 & 0,0 & 0,0 & 0,0 & 0,0 & 0,0 & 0,0 & 0,0 & 0,0 & 0,0 & 0,0 & 0,0 & 0,0 & 0,0 & 0,0 & 0,0 & 0,0 & 0,0 & 0,0 & 0,0 & 0,0 & 0,0 & 0,0 & 2,0 \\
\hline Bolivina tortuosa & 0,0 & 0,0 & 0,0 & 0,0 & 0,0 & 0,0 & 0,0 & 0,0 & 0,0 & 0,0 & 0,0 & 0,0 & 0,0 & 0,0 & 0,0 & 0,0 & 0,0 & 0,0 & 0,0 & 0,0 & 0,0 & 0,0 & 0,0 & 0,0 & 0,0 & 0,4 & 0,0 & 0,0 & 0,0 & 0,0 \\
\hline Bolivina translucens & 0,0 & 0,0 & 0,0 & 0,0 & 0,0 & 0,0 & 0,0 & 0,0 & 0,0 & 0,4 & 0,5 & 0,0 & 0,0 & 0,0 & 0,0 & 0,0 & 0,0 & 0,0 & 0,0 & 0,0 & 0,0 & 0,0 & 0,0 & 0,0 & 0,0 & 0,0 & 0,0 & 0,0 & 0,0 & 0,0 \\
\hline Bolivina variabilis & 0,0 & 0,0 & 0,0 & 0,0 & 0,0 & 0,0 & 0,0 & 0,0 & 0,0 & 0,0 & 0,0 & 0,0 & 0,0 & 0,0 & 0,0 & 0,3 & 0,0 & 0,0 & 0,3 & 0,2 & 0,0 & 0,0 & 0,0 & 0,0 & 0,0 & 0,0 & 0,0 & 0,0 & 0,0 & 0,0 \\
\hline Bolivina $\mathrm{sp}$ & 3,2 & 2,2 & 0,6 & 0,0 & 4,2 & 3,2 & 3,9 & 3,1 & 3,4 & 2,9 & 0,5 & 2,8 & 0,8 & 1,4 & 2,6 & 2,3 & 0,6 & 4,4 & 1,5 & 2,4 & 0,8 & 0,9 & 1,4 & 1,9 & 1,6 & 0,7 & 0,7 & 5,8 & 6,1 & 1,2 \\
\hline Bolivinella pescicula & 0,0 & 0,0 & 0,0 & 0,0 & 0,0 & 0,0 & 0,0 & 0,0 & 0,0 & 0,0 & 0,0 & 0,0 & 0,0 & 0,3 & 0,0 & 0,0 & 0,0 & 0,0 & 0,0 & 0,2 & 0,0 & 0,0 & 0,0 & 0,0 & 0,0 & 0,0 & 0,0 & 0,0 & 0,0 & 0,0 \\
\hline Brizalina sphatulata & 0,0 & 0,0 & 0,0 & 0,0 & 1,0 & 0,0 & 0,7 & 0,4 & 0,7 & 0,7 & 0,0 & 0,0 & 1,2 & 1,7 & 0,9 & 0,3 & 0,6 & 0,0 & 0,3 & 0,2 & 0,0 & 0,0 & 0,0 & 0,0 & 0,0 & 0,0 & 0,0 & 0,0 & 0,0 & 0,0 \\
\hline Brizalina striatula & 2,8 & 3,2 & 2,6 & 0,0 & 3,2 & 0,0 & 2,5 & 1,5 & 2,1 & 2,9 & 0,5 & 2,0 & 1,2 & 1,7 & 1,4 & 2,6 & 0,6 & 0,6 & 1,2 & 1,2 & 0,3 & 0,5 & 1,0 & 1,2 & 0,6 & 0,7 & 1,1 & 1,2 & 2,0 & 2,9 \\
\hline Brizalina subaenarensis & 0,0 & 0,0 & 0,0 & 0,0 & 0,0 & 0,0 & 0,0 & 0,0 & 0,0 & 0,0 & 0,0 & 0,0 & 0,0 & 0,6 & 0,0 & 0,0 & 0,3 & 0,0 & 0,0 & 0,0 & 0,0 & 0,0 & 0,0 & 0,0 & 0,0 & 0,0 & 0,0 & 0,0 & 0,0 & 0,0 \\
\hline Buccella peruviana & 0,8 & 0,3 & 0,0 & 0,0 & 0,0 & 0,0 & 0,0 & 0,0 & 0,0 & 0,0 & 0,0 & 0,0 & 0,0 & 0,0 & 0,3 & 0,0 & 0,0 & 0,0 & 0,0 & 0,0 & 0,0 & 0,0 & 0,0 & 0,0 & 0,0 & 0,0 & 0,0 & 0,0 & 0,0 & 0,0 \\
\hline Buccella sp & 0,0 & 0,0 & 0,0 & 0,0 & 0,0 & 0,0 & 0,0 & 0,0 & 0,0 & 0,0 & 0,0 & 0,0 & 0,0 & 0,0 & 0,0 & 0,0 & 0,0 & 0,0 & 0,0 & 0,0 & 0,0 & 0,0 & 0,0 & 0,3 & 0,0 & 0,0 & 0,0 & 0,0 & 0,4 & 0,0 \\
\hline Bulimina elongata & 0,0 & 0,0 & 0,0 & 0,0 & 0,0 & 0,0 & 0,0 & 0,0 & 0,0 & 0,0 & 0,0 & 0,0 & 0,0 & 0,3 & 0,0 & 0,0 & 0,0 & 0,0 & 0,0 & 0,0 & 0,0 & 0,0 & 0,0 & 0,0 & 0,0 & 0,0 & 0,0 & 0,0 & 0,0 & 0,0 \\
\hline Bulimina marginata & 0,4 & 1,6 & 5,8 & 0,0 & 2,6 & 6,5 & 2,7 & 1,9 & 0,0 & 2,9 & 2,4 & 1,2 & 0,4 & 2,0 & 1,7 & 0,6 & 1,6 & 1,3 & 1,8 & 1,2 & 2,5 & 1,1 & 2,2 & 1,2 & 3,2 & 2,6 & 2,2 & 2,7 & 0,8 & 0,0 \\
\hline Bulimina pupoides & 0,4 & 0,0 & 0,0 & 0,0 & 0,6 & 0,0 & 0,5 & 0,0 & 0,7 & 0,0 & 0,0 & 0,0 & 0,0 & 0,0 & 0,0 & 0,3 & 0,0 & 0,0 & 0,0 & 0,0 & 0,0 & 0,0 & 0,0 & 0,0 & 0,0 & 0,0 & 0,0 & 0,0 & 0,0 & 0,0 \\
\hline
\end{tabular}


Anexo 46 - Continuação

\begin{tabular}{|c|c|c|c|c|c|c|c|c|c|c|c|c|c|c|c|c|c|c|c|c|c|c|c|c|c|c|c|c|c|c|}
\hline \multirow[b]{2}{*}{ Estações } & \multicolumn{10}{|c|}{ Setembro de 2005} & \multicolumn{10}{|c|}{ Junho de 2006} & \multicolumn{10}{|c|}{ Outubro de 2006} \\
\hline & Sc2 & Sc3 & Sc5 & Sc6 & Sc7 & $\mathrm{Sc} 8$ & Sc9 & Sc10 & Sc11 & Sc12 & $\mathrm{Sc} 1$ & Sc2 & Sc3 & $\mathrm{Sc} 4$ & Sc5 & Sc6 & Sc7 & $\mathrm{Sc} 8$ & $\mathrm{Sc} 9$ & Sc11 & Sc1 & Sc2 & $\mathrm{Sc} 3$ & Sc4 & Sc5 & Sc6 & Sc7 & $\mathrm{Sc} 8$ & $\mathrm{Sc} 9$ & Sc10 \\
\hline Bulimina sp & 0,0 & 0,0 & 0,0 & 0,0 & 0,0 & 0,0 & 0,5 & 0,0 & 0,0 & 0,4 & 0,0 & 0,0 & 0,4 & 0,3 & 0,3 & 0,0 & 0,0 & 0,0 & 0,3 & 0,0 & 0,0 & 0,0 & 0,0 & 0,0 & 0,0 & 0,0 & 0,0 & 0,0 & 0,0 & 0,0 \\
\hline Buliminella elegantissima & 1,2 & 2,2 & 1,9 & 0,0 & 1,0 & 0,0 & 1,1 & 2,3 & 2,1 & 2,5 & 2,4 & 0,8 & 4,5 & 1,7 & 2,0 & 2,3 & 1,3 & 2,5 & 2,4 & 1,4 & 0,5 & 4,3 & 2,4 & 3,4 & 3,2 & 2,2 & 2,5 & 2,2 & 1,6 & 2,0 \\
\hline Cancris sagra & 0,0 & 0,0 & 0,0 & 0,0 & 0,0 & 0,0 & 0,0 & 0,0 & 0,0 & 0,4 & 0,0 & 0,0 & 0,0 & 0,0 & 0,0 & 0,0 & 0,0 & 0,0 & 0,3 & 0,0 & 0,5 & 0,7 & 0,2 & 0,3 & 0,0 & 0,0 & 0,0 & 0,0 & 0,0 & 0,4 \\
\hline Cassidela sp. & 0,0 & 0,0 & 0,0 & 0,0 & 0,0 & 0,0 & 0,0 & 0,0 & 0,0 & 0,0 & 0,0 & 0,0 & 0,0 & 0,0 & 0,0 & 0,0 & 0,0 & 0,0 & 0,0 & 0,0 & 0,0 & 0,0 & 0,0 & 0,0 & 0,0 & 0,0 & 0,0 & 0,0 & 0,0 & 0,0 \\
\hline Cassidulina crassa f. media & 5,9 & 13,6 & 7,1 & 0,0 & 3,5 & 3,2 & 16,1 & 23,4 & 15,1 & 2,2 & 7,8 & 1,6 & 4,9 & 4,5 & 4,0 & 4,2 & 3,2 & 1,3 & 5,5 & 5,7 & 12,7 & 8,9 & 9,6 & 9,0 & 7,1 & 6,7 & 5,4 & 7,5 & 8,2 & 11,8 \\
\hline Cassidulina laevigata & 0,0 & 0,0 & 1,3 & 0,0 & 0,3 & 0,0 & 2,0 & 1,5 & 0,7 & 1,4 & 0,5 & 0,4 & 0,8 & 0,0 & 0,3 & 0,3 & 0,0 & 0,0 & 0,0 & 0,2 & 0,0 & 0,0 & 0,0 & 0,0 & 0,0 & 0,0 & 0,0 & 0,0 & 0,0 & 0,0 \\
\hline Cassidulina minuta & 0,0 & 0,0 & 0,0 & 0,0 & 0,0 & 0,0 & 0,0 & 0,0 & 0,0 & 0,0 & 0,5 & 0,4 & 2,4 & 1,1 & 0,0 & 1,0 & 0,3 & 0,0 & 1,2 & 1,4 & 0,0 & 0,0 & 0,0 & 0,0 & 0,0 & 0,0 & 0,0 & 0,0 & 0,0 & 0,0 \\
\hline Cassidulina subglobosa & 0,0 & 0,9 & 0,0 & 0,0 & 0,0 & 0,0 & 1,4 & 2,3 & 0,0 & 2,9 & 3,4 & 1,6 & 4,5 & 1,7 & 2,0 & 1,9 & 2,5 & 1,3 & 3,0 & 4,1 & 0,0 & 0,0 & 0,0 & 0,0 & 0,0 & 0,0 & 0,0 & 0,0 & 0,0 & 0,0 \\
\hline Cassidulina $s p$ & 0,0 & 0,0 & 0,0 & 0,0 & 0,0 & 0,0 & 0,0 & 0,0 & 0,0 & 0,0 & 0,5 & 0,8 & 0,0 & 0,3 & 0,3 & 0,0 & 0,0 & 0,0 & 0,0 & 0,0 & 0,3 & 0,0 & 0,0 & 0,0 & 0,0 & 0,0 & 0,0 & 0,0 & 0,0 & 0,0 \\
\hline Cassidulinoides brasiliensis & 0,0 & 0,0 & 0,0 & 0,0 & 0,0 & 0,0 & 0,0 & 0,0 & 0,0 & 0,0 & 0,0 & 0,0 & 0,0 & 0,0 & 0,3 & 0,0 & 0,0 & 0,0 & 0,0 & 0,0 & 0,0 & 0,0 & 0,0 & 0,0 & 0,0 & 0,0 & 0,0 & 0,0 & 0,0 & 0,0 \\
\hline Cibicides dispars & 0,0 & 0,0 & 0,0 & 0,0 & 0,0 & 0,0 & 0,0 & 0,0 & 0,0 & 0,0 & 0,0 & 0,0 & 0,0 & 0,0 & 0,0 & 0,0 & 0,0 & 0,0 & 0,0 & 0,0 & 0,0 & 0,0 & 0,2 & 0,0 & 0,0 & 0,0 & 0,0 & 0,0 & 0,0 & 0,0 \\
\hline Cibicides refulgens & 0,0 & 0,0 & 0,0 & 0,0 & 0,0 & 6,5 & 0,0 & 0,0 & 0,0 & 0,4 & 0,0 & 0,4 & 2,0 & 0,0 & 0,0 & 0,0 & 0,0 & 0,0 & 0,0 & 0 & 0,0 & 0,7 & 0,0 & 0,9 & 0,3 & 0,0 & 0,7 & 2,2 & 0,8 & 0,8 \\
\hline Cibicides variabilis & 0,8 & 0,0 & 1,3 & 0,0 & 1,3 & 0,0 & 0,7 & 0,0 & 0,0 & 0,0 & 0,0 & 0,4 & 0,0 & 0,3 & 0,0 & 0,0 & 0,3 & 0,6 & 0,3 & 0,0 & 0,0 & 0,0 & 0,0 & 0,0 & 0,0 & 0,0 & 0,0 & 0,0 & 0,0 & 0,0 \\
\hline Cibicides sp & 0,8 & 0,9 & 1,9 & 20,0 & 3,2 & 3,2 & 2,0 & 1,5 & 4,1 & 0,4 & 0,5 & 0,8 & 1,2 & 1,4 & 0,3 & 0,3 & 0,3 & 0,0 & 0,6 & 0,5 & 2,0 & 0,2 & 0,0 & 1,9 & 1,0 & 1,5 & 0,4 & 0,7 & 0,4 & 0,0 \\
\hline Cornobella pateliformis & 0,0 & 0,0 & 0,0 & 0,0 & 0,0 & 0,0 & 0,0 & 0,0 & 0,0 & 0,0 & 0,0 & 0,0 & 0,4 & 0,0 & 0,0 & 0,0 & 0,0 & 0,0 & 0,0 & 0,0 & 0,0 & 0,0 & 0,0 & 0,0 & 0,0 & 0,0 & 0,0 & 0,0 & 0,0 & 0,0 \\
\hline Cornuspira involvens & 0,8 & 0,3 & 0,0 & 0,0 & 1,3 & 0,0 & 0,2 & 0,0 & 0,0 & 0,0 & 0,0 & 0,4 & 0,4 & 0,3 & 0,3 & 0,6 & 0,6 & 0,6 & 0,0 & 0,0 & 0,0 & 0,2 & 0,0 & 1,9 & 0,3 & 3,4 & 0,0 & 1,2 & 0,4 & 0,0 \\
\hline Cribroelphidium advenum & 0,0 & 0,0 & 0,0 & 0,0 & 0,0 & 0,0 & 0,0 & 0,0 & 0,0 & 0,0 & 0,5 & 0,0 & 0,4 & 0,0 & 0,3 & 1,0 & 0,3 & 0,0 & 0,0 & 0,0 & 0,0 & 0,0 & 0,0 & 0,0 & 0,0 & 0,0 & 0,0 & 0,0 & 0,0 & 0,0 \\
\hline Cribroelphidium articulatum & 0,0 & 0,0 & 0,0 & 0,0 & 0,0 & 0,0 & 0,0 & 0,0 & 0,0 & 0,0 & 0,0 & 0,4 & 0,0 & 0,0 & 0,0 & 0,0 & 0,0 & 0,0 & 0,0 & 0,0 & 0,0 & 0,0 & 0,0 & 0,0 & 0,0 & 0,0 & 0,0 & 0,0 & 0,0 & 0,0 \\
\hline Cribroelphidium crispum & 0,0 & 0,0 & 0,0 & 0,0 & 0,0 & 0,0 & 0,2 & 0,0 & 0,0 & 0,0 & 0,0 & 0,0 & 0,0 & 0,0 & 0,0 & 0,0 & 0,0 & 0,0 & 0,0 & 0,0 & 0,0 & 0,0 & 0,0 & 0,0 & 0,0 & 0,0 & 0,0 & 0,0 & 0,0 & 0,0 \\
\hline Cribroelphidium discoidale & 0,0 & 0,0 & 0,0 & 0,0 & 0,0 & 0,0 & 0,0 & 0,0 & 0,0 & 0,7 & 0,5 & 0,0 & 0,0 & 0,8 & 0,6 & 0,0 & 1,9 & 0,0 & 0,0 & 0,7 & 0,0 & 0,5 & 1,2 & 0,0 & 0,0 & 0,0 & 0,4 & 0,5 & 0,4 & 0,8 \\
\hline Cribroelphidium excavatum & 2,0 & 0,6 & 1,3 & 0,0 & 1,3 & 0,0 & 1,1 & 0,8 & 0,7 & 0,4 & 9,3 & 3,2 & 4,9 & 2,8 & 1,1 & 3,2 & 1,9 & 0,6 & 1,8 & 3,1 & 0,3 & 0,0 & 0,0 & 1,2 & 0,3 & 1,1 & 0,7 & 0,2 & 0,0 & 0,0 \\
\hline Cribroelphidium gunteri & 0,0 & 0,0 & 0,0 & 0,0 & 0,0 & 0,0 & 0,0 & 0,0 & 0,0 & 0,0 & 1,0 & 0,0 & 0,0 & 0,3 & 0,3 & 0,0 & 0,0 & 0,0 & 0,0 & 0.0 & 0,0 & 0,0 & 0,0 & 0,0 & 0,0 & 0,0 & 0,0 & 0,0 & 0,0 & 0,0 \\
\hline Cribroelphidium magellanicum & 0,0 & 0,0 & 0,0 & 0,0 & 0,0 & 0,0 & 0,0 & 0,0 & 0,0 & 0,0 & 0,0 & 0,0 & 0,0 & 0,0 & 0,0 & 0,0 & 0,0 & 0,0 & 0,0 & 0,0 & 0,0 & 0,0 & 0,0 & 0,0 & 0,0 & 0,0 & 0,0 & 0,0 & 0,0 & 0,0 \\
\hline Cribroelphidium poyeanum & 0,8 & 0,6 & 0,6 & 0,0 & 1,0 & 0,0 & 0,9 & 0,0 & 0,0 & 0,7 & 0,5 & 0,0 & 0,0 & 0,3 & 0,3 & 0,0 & 0,3 & 0,6 & 0,6 & 1,4 & 3,0 & 1,6 & 0,5 & 0,3 & 1,3 & 0,7 & 5,4 & 3,6 & 1,6 & 1,6 \\
\hline Cribroelphidium sp & 0,8 & 1,6 & 3,2 & 0,0 & 2,2 & 0,0 & 2,0 & 2,7 & 2,7 & 2,2 & 1,5 & 1,6 & 0,4 & 0,3 & 1,1 & 0,6 & 0,3 & 3,1 & 0,3 & 0,7 & 2,3 & 0,7 & 1,2 & 0,6 & 0,6 & 0,7 & 0,4 & 1,2 & 0,0 & 0,4 \\
\hline Cribrostomoides jeffreysii & 0,0 & 0,0 & 0,0 & 0,0 & 0,0 & 0,0 & 0,0 & 0,0 & 0,0 & 0,0 & 0,0 & 0,0 & 0,0 & 0,3 & 0,0 & 0,0 & 0,3 & 0,0 & 0,6 & 0,7 & 0,0 & 0,0 & 0,0 & 0,0 & 0,0 & 0,0 & 0,0 & 0,0 & 0,0 & 0,0 \\
\hline Cribrostomoides sp. & 0,0 & 0,0 & 0,0 & 0,0 & 0,0 & 0,0 & 0,0 & 0,0 & 0,0 & 0,0 & 0,0 & 1,2 & 0,0 & 0,6 & 0,0 & 0,0 & 1,0 & 0,0 & 0,0 & 0,0 & 0,0 & 0,0 & 1,4 & 0,0 & 1,0 & 0,7 & 0,0 & 1,0 & 0,4 & 2,4 \\
\hline Cycloforina carinata & 0,0 & 0,3 & 0,6 & 0,0 & 0,0 & 0,0 & 0,0 & 0,0 & 0,0 & 0,0 & 0,0 & 0,0 & 0,0 & 0,0 & 0,0 & 0,0 & 0,3 & 0,0 & 0,0 & 0,0 & 0,0 & 0,0 & 0,0 & 0,0 & 0,0 & 0,0 & 0,0 & 0,0 & 0,0 & 0,0 \\
\hline Cycloforina quinquecarinata & 0,0 & 0,0 & 0,0 & 0,0 & 0,0 & 0,0 & 0,0 & 0,0 & 0,0 & 0,0 & 0,0 & 0,4 & 0,0 & 0,0 & 0,0 & 0,0 & 0,0 & 0,0 & 0,0 & 0,0 & 0,0 & 0,0 & 0,0 & 0,0 & 0,0 & 0,0 & 0,0 & 0,0 & 0,0 & 0,0 \\
\hline Cyclogira planorbis & 0,0 & 0,0 & 0,0 & 0,0 & 0,3 & 0,0 & 0,0 & 0,0 & 0,0 & 0,0 & 0,0 & 0,0 & 0,0 & 0,0 & 0,0 & 0,0 & 0,0 & 0,0 & 0,0 & 0,0 & 0,0 & 0,0 & 0,0 & 0,0 & 0,0 & 0,0 & 0,0 & 0,0 & 0,0 & 0,0 \\
\hline
\end{tabular}


Anexo 46 - Continuação

\begin{tabular}{|c|c|c|c|c|c|c|c|c|c|c|c|c|c|c|c|c|c|c|c|c|c|c|c|c|c|c|c|c|c|c|}
\hline \multirow[b]{2}{*}{ Estações } & \multicolumn{10}{|c|}{ Setembro de 2005} & \multicolumn{10}{|c|}{ Junho de 2006} & \multicolumn{10}{|c|}{ Outubro de 2006} \\
\hline & $\mathrm{Sc} 2$ & $\mathrm{Sc} 3$ & Sc5 & Sc6 & $\mathrm{Sc} 7$ & Sc8 & Sc9 & 10 & Sc11 & 12 & Sc1 & $\mathrm{Sc} 2$ & $\mathrm{Sc} 3$ & $\mathrm{Sc} 4$ & Sc5 & Sc6 & Sc7 & $\mathrm{Sc} 8$ & Sc9 & Sc11 & Sc1 & $\mathrm{Sc} 2$ & $\mathrm{Sc} 3$ & Sc4 & Sc5 & Sc6 & Sc7 & Sc8 & Sc9 & Sc10 \\
\hline Cycloforina $s p$ & 0,0 & 0,0 & 0,0 & 0,0 & 0,0 & 0,0 & 0 & 0,0 & 0,0 & 0,0 & 0,0 & 0,8 & 0,0 & 0,0 & 3 & 0,6 & 1,0 & 0,0 & 0,0 & 0 & 0,0 & 0,0 & 0,0 & 0,0 & ,0 & ,0 & , & ,0 &, 0 & ,0 \\
\hline & & 0,0 & 0,0 & 0 & 0,0 & 0,0 & 0 & 0 & & & & 0 & 0,0 & 0,0 & 0 &, 0 & 0,0 & 0 & 0 & & o & 0 & ,0 & 0 & 0 & 0 & 0 & 0 &, 0 & ,0 \\
\hline Dentalina sp. & 0 & 0,0 & 0 & 0 & 0,0 & 0,0 & 0,0 & 0 & & & 0 & 8 & 0,0 & 0,0 & 0 & 0,0 & 0,0 & 0 &, 0 & & 0 & 0 & 0,0 & 0 & 0 &, 0 & 0 & 0 & ,0 &, 0 \\
\hline & & 0,6 & 0,0 & 1,0 & 0,0 & 0,0 & 0,0 & 0, & 0,0 & & 0,5 & 0,4 & 0,4 & 0,0 & 0,0 & 0,0 & 0,3 & 1,3 & 0,0 & & 0,0 & 0,0 & 0,0 & 0,0 & 0,0 & 0,0 & 0,0 &, 0 & 0,0 & 0,0 \\
\hline leanus & 0,0 & 0,0 & 0,0 & 0,0 & 0,0 & 0,0 & 0 & 0 & & & & 0 & 0,0 & 0,0 & 0,0 & 0,0 & , & 0,0 & 0,0 & & 0 & 0 & 0,0 & 0,0 & 0 & 0,0 & 0,0 & 0 &, 0 &, 0 \\
\hline & 0 & 0,0 & P & 0 , & 0,0 & 0 , & 0 & 0 & & & & 0 & 0 & 0 & 0 & 0,0 & 0,0 & 0 & 0,0 & & 0 & 0 & 0,0 & 0 & 0 & 0,0 & 0 & 0 &, 0 & ,0 \\
\hline & 2 , & 0,9 & 2,6 & 0 & 0,3 & 9,7 & 0,0 & 0,4 & 2,1 & & 0,5 & 0,0 & 2,0 & 0,8 & 0,3 & 0,3 & 0,3 & 0,0 & 0,6 & & 2,3 & 3,9 & 4,3 & 3,1 & ,2 & 3,4 & 1,8 & ,9 & 6,9 & 6,1 \\
\hline Disco & 0 , & 0,6 & 1,9 & 0,0 & 0,3 & 0,0 & 0,0 & 0,8 & 2,1 & & & 0,0 & 0,0 & 0,0 & 0,0 & 0,0 & $0, \mathrm{C}$ & 0,0 & 0,0 & & 0 & 0 & 0,0 & 0,0 & 0 & 0,0 & 0,0 & 0 &, 0 &, 0 \\
\hline cabra & 0 , & 0,0 & 0,0 & 0,0 & 0,0 & 0,0 & 0,0 & 0, & 0,0 & 0 & 0 & 0,4 & 0,4 & 0,3 & 0,3 & 0,3 & 0,6 & 0,0 & 0,0 & 1 & 2,3 & 0,0 & 0,7 & 0,3 & 0,0 & 0,7 & 0,7 & ,2 & 0,0 & 0,0 \\
\hline Ep & 0 & 0,0 & 0 & & 0,0 & ,0 & 0 & 0 & & & & 0 & 0 , & & 9 & & & 6 & & & & 0 & 0 & & 0 & 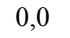 & 0 & 0 & 0 & 0 \\
\hline & 0 & 0,0 & 0 & 0 & 0,0 & 0,0 & 0 & 0 , & & & & 0 & 0,0 & 0,3 & 0 & 0,0 & 0 & 0,0 & 0,0 & & 0 & 0,0 & 0,0 & 0,0 & 0,0 & 0,0 & 0,0 & ,0 &, 0 & ,0 \\
\hline Epo & 0 , & 0,0 &, 0 & 0 & 0,0 & 0,0 & 0,0 & 0 & 0,0 & & 0,0 & 0,4 & 0,0 & 0,0 & 0,9 & 0,0 & 0,0 & 0,6 & 2,4 & & 0,0 & 0,0 & 0,0 & 0,0 & 0,0 & 0,0 & 0,0 &, 5 & 1,2 & 0,4 \\
\hline Eug & 0 & 0,0 & 0 & 0 & 2,2 & 0,0 & 0 & 0 & & & & 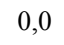 & 0 , & & 0 & 00 & & 0 & 0 & & & 0 & 00 & 0 & 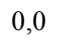 & 0 & 0 & 0 & 0 &, 0 \\
\hline Fiss & 0 , & 0,0 & v & 0 & 0,0 & 0,0 & 0 & 0 , & 0 & & & 0 & 0,0 & 0,0 & 0,0 & 0,0 & 0 & 0,0 & 0,0 & & 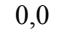 & 0 & 0,0 & 0,0 & ,0 & 0,0 & 0,0 & 0 & 0,0 &, 0 \\
\hline & 0 , & 0,0 & 0,0 & 0 & 0,6 & 0,0 & 0 & 0 , & 0 , & & 0 & 0,0 & 0,0 & 0,8 & 0,6 & 0,3 & 1,0 & 0,0 & 0,0 & & 0,3 & 0,0 & 0,2 & 0,0 & 0,0 & 0,4 & 0,0 & 0 & 0,0 & 0,0 \\
\hline & 0 , & 0,0 & 0,0 & 0,0 & 0,0 & 0,0 & 0,0 & 0 , & 0 & 0 & 1 & 0,0 & 0,0 & 0,3 & 0,0 & 0,0 & 0,0 & 0,6 & 0,6 & & 0,5 & ,2 & 0,2 & 0,0 & ,3 & 1,5 & 0 & ,0 & 0,4 &, 0 \\
\hline Fiss & 0 , & 0,0 & 0,0 & 0,0 & 0,0 & 0,0 & 0, & 0 , & 0 & & & 0,0 & 0,0 & 0,0 & 0,0 & 0,0 & 0, & 0,0 & 0,0 & & 0,0 & , & 0,5 & 0,0 & 0,0 & 0,0 & 0,4 & 0 & 0,0 & ,0 \\
\hline & 0,0 & 0,0 & 0,0 & 0,0 & 0,0 & 0,0 & 0,2 & 0 & 0,0 & 0 & 0,0 & 0,0 & 0,0 & 0,0 & 0,3 & 0,0 & 0,0 & 0,0 & 0,3 & 0 & 1,3 & 0,2 & 0,5 & 0,9 & 1,0 & 0,0 & 0,4 &, 5 & 1,2 & 0,0 \\
\hline a riggi & 0 , & 0,0 & 0,0 & 0,0 & 0,0 & 0,0 & 0,0 & 0 , & 0 & 0 & ) & 0,0 & 0,0 & 0,0 & 0,0 & 0,0 & 0,0 & 0,0 & 0,3 & 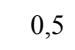 & 0,0 & 0,0 & 0,0 & 0,0 & 0,0 & 0,0 & 0,0 & ,0 & 0,0 &, 0 \\
\hline na sp & 0 , & 0,0 & 0,0 & 0,0 & 0,0 & 0,0 & 0,0 & 0 , & 0 & & & 0,0 & 0,0 & 0,0 & 0,3 & 0,0 & 0,0 & 0,0 & 0,0 & & 0,0 & 0,0 & 0,0 & 0,0 & 0,0 & 0,0 & 0,0 & 0 & 0,0 &, 0 \\
\hline a & 0 , & 0,0 & 0,0 & 0,0 & 0,0 & 0,0 & 0,0 & 0,0 & 0,0 & 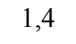 & 0,0 & 1,2 & 0,8 & 0,0 & 0,6 & 0,6 & 0,6 & 0,0 & 1,5 & & 0,5 & 1,8 & 1,4 & 1,5 & 1,0 & 2,2 & 1,4 & 4 & 0,0 & 0,8 \\
\hline Gav & 0,0 & 4,4 & 0,0 & 0,0 & 1,6 & 0,0 & 1,6 & 4,6 & 2,1 & 1, & 3,9 & 2,8 & 6,9 & 4,5 & 3,4 & 2,9 & 2,9 & 3,1 & 3,0 & & 0,0 & 0,0 & 0,0 & 0,0 & 0,0 & 0,0 & 0,0 &, 0 & 0,0 & 0,0 \\
\hline Glabratella chasteri & 0,0 & 0,0 & 0,0 & 0,0 & 0,0 & 0,0 & 0,0 & 0 , & & & & 0,0 & 0,0 & 0,0 & 0,0 & 0,0 & 0,0 & 0,0 & 0,0 & & 0,0 & 0,0 & 0,0 & 0,0 & 0,0 & 0,0 & 0,0 & ,0 & 0,0 & 0,0 \\
\hline Glabratellasp. & 0 , & 0,0 & 0,0 & 0,0 & 0,0 & 0,0 & 0,0 & 0,0 & , & 0 & 0,0 & 0,0 & 0,0 & 0,0 & 0,0 & 0,0 & 0,0 & 0,0 & 0,0 & & 0,0 & 0,0 & 0,0 & 0,3 & 0,0 & 0,0 & 0,0 & 0 & 0,0 & 0,0 \\
\hline Globigerina sp. & 0,0 & 0,0 & 0,0 & 0,0 & 0,0 & 0,0 & 0,2 & 0,0 & 0 & 0 , & 1,5 & 0,0 & 0,0 & 0,8 & 0,3 & 0,3 & 0,0 & 0,0 & 0,0 & 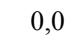 & 0,0 & 0,0 & 0,0 & 0,0 & 0,0 & 0,0 & 0,0 & ,0 & 0,0 & 0,0 \\
\hline Glol & 0 , & 0,0 & 0,0 & 0,0 & 0,0 & 0,0 & 0,0 & 0 , & & & 1 & 0,0 & 0,4 & 0,6 & 0,0 & 0,0 & 0,0 & 0,0 & 0,0 & & 0,3 & 0,2 & 0,0 & 0,0 & 0,0 & 0,0 & 0,0 & ,2 & 0,0 & 0,0 \\
\hline Globorotalia compressa & 0,0 & 0,0 & 0,0 & 0,0 & 0,0 & 0,0 & 0,0 & 0,0 & 0 & 0 , & 1,5 & 0,0 & 0,4 & 0,0 & 0,3 & 0,0 & 0,0 & 0,0 & ,3 & & 0,0 & 0 & 0,0 & 0,0 & 0 & 0,0 & 0 & 0 &, 0 &, 0 \\
\hline & 0,0 & 0,0 & 0,0 & 0,0 & 0,3 & 0,0 & 0,0 & 0,0 & 0,0 & 0 , & 0,0 & 0,0 & 0,0 & 0,0 & 0,0 & 0,0 & 0,0 & 0,0 & 0,0 & 0,0 & 0,0 & 0,0 & 0,0 & 0,0 & 0,0 & 0,0 & 0,0 &, 0 & 0,0 & 0,0 \\
\hline Gutulina lactea & 0 , & 0,0 & 0,0 & 0,0 & 0,0 & 0,0 & 0,0 & 0,0 & 0,0 & 0 & 0,0 & 0,4 & 0,0 & 0,0 & 0,0 & 0,0 & 0,3 & 0,0 & 0,0 & 0,0 & 0,0 & 0,0 & 0,2 & 0,0 & 0,0 & 0,0 & 0,7 & 0,0 & 0,0 & 0,4 \\
\hline
\end{tabular}


Anexo 46 - Continuação

\begin{tabular}{|c|c|c|c|c|c|c|c|c|c|c|c|c|c|c|c|c|c|c|c|c|c|c|c|c|c|c|c|c|c|c|}
\hline \multirow[b]{2}{*}{ Estações } & \multicolumn{10}{|c|}{ Setembro de 2005} & \multicolumn{10}{|c|}{ Junho de 2006} & \multicolumn{10}{|c|}{ Outubro de 2006} \\
\hline & Sc2 & $\mathrm{Sc} 3$ & Sc5 & Sc6 & $\mathrm{Sc} 7$ & $\mathrm{Sc} 8$ & Sc9 & $\mathrm{Sc} 10$ & $\mathrm{c} 11$ & Sc12 & Sc1 & $\mathrm{Sc} 2$ & Sc3 & Sc4 & Sc5 & Sc6 & $\mathrm{Sc} 7$ & Sc8 & Sc9 & Sc11 & Sc1 & $\mathrm{Sc} 2$ & Sc3 & $\mathrm{Sc} 4$ & Sc5 & Sc6 & Sc7 & Sc8 & Sc9 & $\mathrm{Sc} 10$ \\
\hline Mychostomina $r$ & 0 , & 0,0 & 0,0 & 0,0 & 0,0 & 0,0 & 0,0 & 0,0 & 0,0 & 0,0 & 0,0 & 0,0 & 0,0 & 0,0 & 0,0 & 0,0 & 0,3 & 0,0 & 0,0 & 0,0 & 0,0 & 0,0 & 0,0 & 0,0 & 0,0 &, 0 & 0,0 & 0,0 & 0,0 & 0,0 \\
\hline & 0 & 0,0 & 0,0 & 0,0 & 0,0 & 0,0 & 0,0 & 0 & 0,0 & 0 , & 0 & 0 & 0 & 0,0 & 0,0 & 0,3 & 3 & 0,0 & 0,0 & & 0 & 0 & 0 & 0,0 & 0,0 & 0 & 0,0 & 0,0 & 0,0 & 0,0 \\
\hline Neocornoomat & 0,0 & 0,9 & 0,0 & 0,0 & 3,5 & 0,0 & 0,0 & 0,0 & 0,0 & 0,4 & 0,0 & 2,4 & 1,2 & 3,7 & 0,0 & 1,6 & 0,3 & 3,1 & 0,0 & 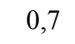 & 0 & 0,0 & 0,0 & 0,6 & 0,0 & 0,0 & 0,4 & 0,5 & 0,4 & 0,8 \\
\hline Neocornobina sp & 0 , & 0,0 & 0,0 & 0,0 & 0,0 & 0,0 & 0,0 & 0,0 & 0 & 0 , & 0,0 & 0,8 & 0,0 & 0,0 & 0,0 & 0,0 & 0,0 & 0,0 & 0,0 & 0,0 & 0 & 0 & 0,0 & 0,0 & 0,0 & 0,0 & 0,0 & 0,0 & 0,0 & 0,0 \\
\hline Neoeponides bradyi & 0,0 & 0,0 & 0,0 & 0,0 & 0,0 & 0,0 & 0,0 & 0,0 & 0,0 & 0 , & 0,0 &, 4 & 0,0 & 0,0 & 0,0 & 0,0 & 0,3 & 0,0 & 0,0 & 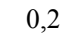 & 0 & 0,0 & 0,0 & 0,0 & 0,0 &, 0 & 0,0 & 0,0 & 0,0 & 0,0 \\
\hline Neouvigerin & 0 , & 0,0 & 0,0 & 0,0 & 0,0 & 0,0 & 0,0 & 0,0 & 0 & 0 & 0,0 & 0,0 & 0 & 0 & 0,3 & 0,3 & 0,0 & 0,0 & 0,0 & & 0 & 0 & 0,0 & 0,0 & 0,0 & ,0 & 0,0 & 0,0 & 0,0 & 0,0 \\
\hline Nodosaria sp. & 0 , & 0,0 & 0,0 & 0,0 & 0,0 & 0,0 & 0,0 & 0,0 & 0,7 & 0 , & 0,0 & 0,0 & 0,0 & 0,0 & 0,0 & 0,0 & 0,0 & 0,0 & 0,0 & 0 & 0 & 0,0 & 0,0 & 0,0 & 0,0 & 0,0 & 0,0 & 0,0 & 0,0 & 0,0 \\
\hline Oolina caudigera & 0,0 & 0,0 & 0,0 & 0,0 & 0,0 & 0,0 & 0,0 & 0,0 & 0,0 & 0 , & 0,0 & 0,0 & 0,0 & 0,0 & 0,0 & 0,3 & 0,0 & 0,0 & 0,0 & 0 & 0 & 0,0 & 0,0 & 0,0 & 0,0 & 0,0 & 0,0 & 0,0 & 0,0 & 0,0 \\
\hline Oolina hexag & 0,0 & 0,6 & 0,0 & 0,0 & 0,0 & 0,0 & 0,0 & 0,0 & 0,0 & 0 , & 0,0 & 0,0 & 0,0 & 0,0 & 0,0 & 0,0 & 0,3 & 0,0 & 0,0 & 0 & 0 & 0,0 & 0,0 & 0,0 & 0,0 & 0,0 & 0,0 & 0,0 & 0,0 & 0,0 \\
\hline Oolina st & 0 , & 0,0 & 0,0 & 0,0 & 0,0 & 0,0 & 0,0 & 0,0 & 0,0 & 0 , & 0,0 & 0,0 & 0,0 & 0,0 & 0,0 & 0,0 & 0,0 & 0,0 & 0,0 & 0,0 & 0 & 0,0 & 0,0 & 0,0 & 0,0 &, 0 & 0,0 & 0,0 & 0,0 & 0,0 \\
\hline Pararotalia $\mathrm{c}$ & 4,3 & 23,0 & 16,2 & 0,0 & 5,1 & 3,2 & 11,8 & 18,0 & 14,4 & 5, & 15,6 & 4,8 & 17,9 & 14,4 & 16,1 & 12,0 & 5,7 & 8,8 & 16,7 & 10,5 & 18,8 & 20,7 & 17,1 & 15,8 & 17,2 & 7,5 & 10,8 & 13,1 & 16,3 & 10,6 \\
\hline Paratrochammina clossi & 0,0 & 0,0 & 0,0 & 0,0 & 0,0 & 0,0 & 0,0 & 0,0 & 0,0 & 0 , & 0,0 & 2,0 & 0,4 & 0,0 & 0,0 & 0,0 & 0,3 & 0,0 & 0,0 & S & 0,0 & 0,0 & 0,0 & 0,0 & 0,0 & 0,0 & 0,0 & 0,0 & 0,0 & 0,0 \\
\hline Paratroc & 0 , & 0,0 & 0,0 & 0,0 & 0,0 & 0,0 & 0,0 & 0,0 & 0,0 & 0 & 0 , & 0,0 & 0,0 & 0,0 & 0,0 & 0,0 & 0,0 & 0,0 & 0,0 & 0 & 0,0 & 0,0 & 0,0 & 0,0 & 0,0 & 0,7 & 0,4 & 0,0 & 0,0 & 0,4 \\
\hline Pate & 1,6 & 0,0 & 0,6 & 0,0 & 0,6 & 0,0 & 0,0 & 0,0 & 0,7 & 0 , & 0,0 & 0,8 & 0,4 & 0,6 & 0,3 & 0,0 & 0,3 & 0,6 & 0,0 & . & 0 & 0,0 & 0,0 & 0,0 & 0,0 & 0,0 & 0,7 & 0,5 & 0,0 & 0,4 \\
\hline Polymorphina sp & 0,0 & 0,0 & 0,0 & 0,0 & 0,0 & 0,0 & 0,0 & 0,0 & 0,0 & 0 , & 0,0 & 0,0 & 0,4 & 0,0 & 0,6 & 0,0 & 0,0 & 0,0 & 0,0 & 0 & 0 & 0 & 0,0 & 0,0 & 0,0 & 0,0 & 0,0 & 0,0 & 0,0 & 0,0 \\
\hline Poroeponides lateralis & 0,0 & 0,3 & 0,0 & 0,0 & 0,0 & 0,0 & 0,0 & 0,0 & 2,1 & 0 , & 0,0 & 1,2 & 0,0 & 0,0 & 0,3 & 0,0 & 0,0 & 0,6 & 0,3 & 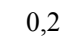 & 3 & 7 & 0,7 & 0,3 & 0,6 & 0,0 & 0,7 & 1,5 & 0,0 & 0,0 \\
\hline Prot & 0,0 & 0,3 & 0,0 & 0,0 & 0,3 & 0,0 & 0,0 & 0,0 & 0,0 & 0 , & 0,0 & 0,4 & 0,0 & 0,0 & 0,3 & 0,0 & 0,3 & 0,0 & 0,0 & & 0 & 0,0 & 0,0 & 0,0 & 0,0 & 0,0 & 0,0 & 0,0 & 0,0 & 0,0 \\
\hline Pseudononion atlanticum & 2,0 & 0,6 & 3,2 & 0,0 & 0,6 & 0,0 & 0,7 & 1,5 & 2,7 & 2, & 4,9 & 0,0 & 3,3 & 1,1 & 0,6 & 1,3 & 1,0 & 0,6 & 1,2 & 22 & 2,5 & 5,7 & 2,2 & 3,7 & 5,8 & 1,5 & 3,6 & 2,2 & 2,0 & 4,9 \\
\hline Pseudononion grateloupi & 0,0 & 0,0 & 0,0 & 0,0 & 0,0 & 0,0 & 0,0 & 0,0 & 0,0 & 0 , & 0,5 & 0,0 & 0,8 & 0,3 & 0,9 & 0,3 & 0,3 & 0,0 & 0,9 & 0,2 & 0 & 0,0 & 0,0 & 0,0 & 0,0 & 0,0 & 0,0 & 0,0 & 0,0 & 0,0 \\
\hline Pseudononion pauperatus & 0,0 & 0,0 & 0,0 & 0,0 & 0,0 & 0,0 & 0,0 & 0,0 & 0,0 & 0 & 0,0 & 0,0 & 0,0 & 0,6 & 0,0 & 0,0 & 0,0 & 0,0 & 0,3 & 0 & 0,0 & 0,0 & 0,0 & 0,0 & 0,0 & 0,0 & 0,0 & 0,0 & 0,0 & 0,0 \\
\hline opima & 0,0 & 0,9 & 0,6 & 0,0 & 0,0 & 0,0 & 0,0 & 0,0 & 0,0 & 0 , & 1,0 & 0,0 & 0,4 & 0,0 & 0,0 & 0,0 & 1,0 & 0,0 & 0,0 & 0,7 & 0,3 & 0,0 & 0,2 & 0,0 & 0,6 & 0,0 & 0,0 & 0,0 & 0,4 & 1,6 \\
\hline Pseudononion sp & 0,8 & 0,9 & 3,2 & 0,0 & 0,6 & 0,0 & 1,1 & 1,5 & 0,0 & 0,4 & 2,0 & 0,4 & 1,6 & 2,3 & 1,1 & 1,0 & 0,3 & 0,0 & 2,7 & 0,7 & 0,3 & 0,0 & 0,0 & 0,0 & 0,3 & 0,0 & 0,0 & 0,2 & 0,0 & 0,0 \\
\hline Pyrgo ringens & 0,4 & 0,0 & 0,0 & 0,0 & 0,0 & 0,0 & 0,0 & 0,0 & 0,0 & 0 & 0,0 & 0,0 & 0,0 & 0,0 & 0,0 & 0,0 & 0,0 & 0,0 & 0,0 & 0 & 0,0 & 0,0 & 0,0 & 0,0 & 0,0 & 0,0 & 0,0 & 0,0 & 0,0 & 0,0 \\
\hline Pyrg & 0,4 & 0,3 & 0,0 & 0,0 & 0,3 & 0,0 & 0,0 & 0,0 & 0,0 & 0 , & 0,5 & 0,4 & 0,0 & 0,0 & 0,3 & 0,3 & 0,0 & 0,0 & 0,0 & 0,0 & 0,0 & 0,2 & 0,0 & 0,0 & 0,3 & 0,0 & 0,4 & 0,0 & 0,0 & 0,0 \\
\hline Quinqueloculina atlantica & 0,4 & 0,0 & 0,0 & 0,0 & 0,0 & 0,0 & 0,0 & 0,0 & 0,0 & 0,0 & 0,0 & 0,0 & 0,4 & 0,0 & 0,0 & 0,0 & 0,0 & 0,0 & 0,0 & 0,0 & 0,0 & 0,0 & 0,0 & 0,0 & 0,0 & 0,4 & 0,0 & 0,2 & 0,0 & 0,0 \\
\hline Quinqueloculina bicostata & 0,0 & 0,0 & 0,0 & 0,0 & 0,0 & 0,0 & 0,0 & 0,0 & 0,0 & 0,0 & 0,0 & 0,0 & 0,0 & 0,0 & 0,0 & 1,9 & 0,3 & 0,0 & 0,0 & 0,0 & 0,0 & 0,0 & 0,0 & 0,0 & 0,0 & 0,0 & 0,0 & 0,0 & 0,0 & 0,0 \\
\hline Quinqueloculina bosciana & 0,0 & 0,0 & 0,0 & 0,0 & 0,0 & 0,0 & 0,0 & 0,0 & 0,0 & 0,0 & 0,0 & 0,0 & 0,0 & 0,0 & 0,6 & 0,0 & 0,0 & 0,0 & 0,0 & 0,0 & 0,0 & 0,0 & 0,0 & 0,0 & 0,0 & 0,0 & 0,0 & 0,0 & 0,0 & 0,0 \\
\hline Quinqueloculina brodermani & 0,0 & 0,0 & 0,0 & 0,0 & 0,0 & 0,0 & 0,0 & 0,0 & 0,0 & 0,0 & 0,0 & 0,0 & 0,0 & 0,0 & 0,0 & 0,0 & 0,0 & 0,0 & 0,0 & 0,0 & 0,0 & 0,5 & 0,0 & 0,0 & 0,0 & 0,0 & 0,0 & 0,0 & 0,0 & 0,0 \\
\hline Quinqueloculina gregaria & 0,4 & 0,0 & 0,6 & 0,0 & 0,0 & 0,0 & 0,0 & 0,0 & 0,0 & 0,0 & 0,0 & 0,0 & 0,0 & 0,0 & 0,3 & 0,0 & 0,0 & 0,0 & 0,0 & 0,0 & 0,0 & 0,0 & 0,0 & 0,0 & 0,0 & 0,0 & 0,0 & 0,0 & 0,0 & 0,0 \\
\hline
\end{tabular}




\begin{tabular}{|c|c|c|c|c|c|c|c|c|c|c|c|c|c|c|c|c|c|c|c|c|c|c|c|c|c|c|c|c|c|c|}
\hline \multirow[b]{2}{*}{ Estações } & \multicolumn{10}{|c|}{ Setembro de 2005} & \multicolumn{10}{|c|}{ Junho de 2006} & \multicolumn{10}{|c|}{ Outubro de 2006} \\
\hline & Sc2 & Sc3 & Sc5 & Sc6 & Sc7 & $\mathrm{Sc} 8$ & Sc9 & Sc10 & Sc11 & Sc12 & Sc1 & Sc2 & Sc3 & Sc4 & Sc5 & Sc6 & Sc7 & Sc8 & Sc9 & Sc11 & Sc1 & $\mathrm{Sc} 2$ & Sc3 & Sc4 & Sc5 & Sc6 & Sc7 & Sc8 & Sc9 & Sc10 \\
\hline Quinqueloculina horrida & 2,0 & 0,0 & 0,0 & 0,0 & 0,0 & 0,0 & 0,2 & 0,0 & 0,7 & 1,4 & 0,5 & 1,6 & 0,4 & 0,0 & 0,6 & 1,0 & 0,6 & 0,0 & 1,2 & 0,5 & 0,0 & 0,0 & 0,0 & 0,0 & 0,0 & 0,0 & 0,0 & 0,0 & 0,0 & 0,0 \\
\hline Quinqueloculina laevigata & 0,4 & 0,0 & 0,0 & 0,0 & 3,2 & 0,0 & 0,0 & 0,0 & 1,4 & 0,4 & 1,0 & 0,0 & 0,0 & 0,6 & 0,3 & 0,3 & 1,6 & 0,6 & 0,3 & 1,2 & 0,0 & 0,0 & 0,0 & 0,0 & 0,0 & 0,0 & 0,0 & 0,0 & 0,0 & 0,0 \\
\hline Quinqueloculina lamarckiana & 0,8 & 0,6 & 0,0 & 0,0 & 0,0 & 0,0 & 0,2 & 0,4 & 0,7 & 0,4 & 0,0 & 1,6 & 0,4 & 0,3 & 0,3 & 0,0 & 0,3 & 0,0 & 0,6 & 0,0 & 0,5 & 0,5 & 1,4 & 0,6 & 0,3 & 0,4 & 0,4 & 0,5 & 1,2 & 3,3 \\
\hline Quinqueloculina milletti & 0,0 & 0,0 & 0,0 & 0,0 & 0,0 & 0,0 & 0,0 & 0,0 & 0,0 & 1,4 & 1,0 & 0,8 & 0,0 & 0,6 & 0,3 & 0,3 & 2,2 & 0,0 & 0,9 & 1,0 & 0,0 & 0,0 & 0,0 & 0,0 & 0,0 & 0,0 & 0,0 & 0,0 & 0,0 & 0,0 \\
\hline Quinqueloculina multimarginata & 0,0 & 0,0 & 0,0 & 0,0 & 0,0 & 0,0 & 0,0 & 0,0 & 0,0 & 0,0 & 0,0 & 0,4 & 0,0 & 0,0 & 0,0 & 0,0 & 0,0 & 0,0 & 0,0 & 0,0 & 0,0 & 0,0 & 0,0 & 0,0 & 0,0 & 0,0 & 0,0 & 0,0 & 0,0 & 0,0 \\
\hline Quinqueloculina patagonica & 0,4 & 0,3 & 0,0 & 0,0 & 1,0 & 0,0 & 0,0 & 0,0 & 0,0 & 0,4 & 0,0 & 0,4 & 0,0 & 0,0 & 0,9 & 1,0 & 1,0 & 0,0 & 0,3 & 0,2 & 0,0 & 0,0 & 0,0 & 0,0 & 0,0 & 0,0 & 0,0 & 0,0 & 0,0 & 0,0 \\
\hline Quinqueloculina polygona & 3,6 & 0,3 & 0,0 & 10,0 & 0,0 & 0,0 & 0,0 & 0,0 & 0,0 & 0,0 & 0,0 & 0,0 & 0,0 & 0,0 & 0,0 & 0,0 & 0,0 & 0,0 & 0,0 & 0,2 & 0,0 & 0,0 & 0,0 & 0,0 & 0,0 & 0,0 & 0,0 & 0,0 & 0,0 & 0,0 \\
\hline Quinqueloculina reticulata & 0,0 & 0,0 & 0,0 & 0,0 & 0,0 & 0,0 & 0,0 & 0,0 & 0,0 & 0,0 & 0,0 & 0,8 & 0,0 & 0,0 & 0,0 & 0,0 & 0,0 & 0,0 & 0,0 & 0,0 & 0,0 & 0,0 & 0,0 & 0,0 & 0,0 & 0,0 & 0,0 & 0,0 & 0,0 & 0,0 \\
\hline Quinqueloculina seminula & 0,4 & 0,3 & 0,0 & 0,0 & 1,0 & 0,0 & 0,0 & 0,0 & 0,0 & 0,7 & 0,5 & 0,8 & 0,0 & 0,3 & 0,6 & 0,6 & 1,0 & 0,0 & 0,0 & 0,7 & 0,0 & 0,0 & 0,0 & 0,0 & 0,0 & 0,0 & 0,0 & 0,0 & 0,0 & 0,0 \\
\hline Quinqueloculina sp & 1,2 & 0,6 & 1,3 & 0,0 & 1,3 & 0,0 & 0,0 & 0,0 & 0,0 & 0,0 & 2,4 & 2,4 & 0,0 & 1,4 & 0,9 & 1,3 & 4,4 & 0,6 & 0,9 & 1,4 & 0,5 & 2,3 & 3,4 & 3,4 & 1,3 & 9,3 & 7,6 & 4,1 & 6,9 & 5,3 \\
\hline Remaneica helgolandica & 0,0 & 0,0 & 0,0 & 0,0 & 0,0 & 0,0 & 0,0 & 0,0 & 0,0 & 0,0 & 0,0 & 0,4 & 0,0 & 0,3 & 0,0 & 0,0 & 0,3 & 0,0 & 0,0 & 0,0 & 0,0 & 0,0 & 0,0 & 0,0 & 0,0 & 0,0 & 0,0 & 0,0 & 0,0 & 0,0 \\
\hline Reophax curtus & 0,0 & 0,0 & 0,0 & 0,0 & 0,0 & 0,0 & 0,0 & 0,0 & 0,0 & 0,0 & 0,0 & 0,0 & 0,0 & 0,0 & 0,0 & 0,0 & 0,0 & 0,0 & 0,0 & 1,7 & 0,0 & 0,0 & 0,0 & 0,0 & 0,0 & 0,0 & 0,0 & 0,0 & 0,0 & 0,0 \\
\hline Reophax scorpiurus & 0,0 & 0,0 & 0,0 & 0,0 & 0,0 & 0,0 & 0,0 & 0,0 & 0,7 & 0,0 & 0,0 & 4,0 & 0,0 & 0,0 & 0,6 & 0,0 & 1,3 & 1,3 & 0,0 & 0,0 & 0,0 & 0,0 & 0,0 & 0,0 & 0,0 & 0,0 & 0,0 & 0,0 &, 0 & 0,0 \\
\hline Reophax sp. & 0,0 & 0,0 & 0,0 & 0,0 & 0,0 & 0,0 & 0,2 & 0,0 & 0,0 & 0,0 & 0,0 & 0,4 & 0,0 & 0,3 & 0,6 & 0,6 & 0,6 & 0,0 & 0,6 & 0,2 & 0,5 & 0,0 & 0,0 & 0,0 & 0,0 & 0,0 & 0,0 & 0,0 & 0,0 & 0,0 \\
\hline Rolshausheni rolshaus & 0,0 & 0,3 & 0,6 & 0,0 & 0,0 & 0,0 & 0,0 & 0,0 & 0,0 & 1,1 & 0,0 & 0,0 & 0,0 & 0,0 & 0,0 & 0,0 & 0,0 & 0,0 & 0,0 & 0,0 & 0,0 & 0,0 & 0,0 & 0,3 & 0,0 & 0,4 & 0,0 & 0,2 & 0,0 & 0,0 \\
\hline Rosalina floridensis & 5,5 & 2,5 & 1,9 & 10,0 & 2,2 & 6,5 & 1,8 & 2,7 & 6,2 & 1,4 & 0,5 & 2,8 & 1,6 & 3,4 & 2,3 & 1,6 & 2,2 & 5,0 & 1,8 & 2,4 & 3,0 & 3,4 & 3,4 & 4,3 & 1,9 & 3,7 & 6,1 & 1,2 & 2,0 & 0,0 \\
\hline Rosalina orientalis & 0,0 & 0,0 & 0,0 & 0,0 & 0,0 & 0,0 & 0,0 & 0,0 & 0,0 & 0,0 & 0,0 & 0,4 & 0,0 & 0,6 & 0,0 & 0,0 & 0,0 & 0,0 & 0,0 & 0,0 & 0,0 & 0,0 & 0,0 & 0,0 & 0,0 & 0,0 & 0,0 & 0,0 & 0,0 & 0,0 \\
\hline Rosalina pellucida & 0,0 & 0,0 & 0,0 & 0,0 & 0,0 & 0,0 & 0,0 & 0,0 & 0,0 & 0,0 & 0,0 & 0,0 & 0,0 & 0,8 & 0,0 & 0,0 & 0,3 & 0,0 & 0,3 & 0,0 & 0,0 & 0,0 & 0,0 & 0,0 & 0,0 & 0,0 & 0,0 & 0,0 & 0,0 & 0,0 \\
\hline Rosalina $s p$ & 0,0 & 0,0 & 0,0 & 0,0 & 0,0 & 9,7 & 0,9 & 0,0 & 0,0 & 0,0 & 0,0 & 0,4 & 0,0 & 0,3 & 0,3 & 1,0 & 0,3 & 0,0 & 0,3 & 0,0 & 0,0 & 0,0 & 0,0 & 0,0 & 0,0 & 0,0 & 0,0 & 0,0 & 0,0 & 0,0 \\
\hline Rubratella intermedia & 0,0 & 0,3 & 0,0 & 0,0 & 1,0 & 0,0 & 0,0 & 0,4 & 0,7 & 1,1 & 0,0 & 0,0 & 0,0 & 0,0 & 0,0 & 0,0 & 0,0 & 0,0 & 0,0 & 0,0 & 0,0 & 0,0 & 0,0 & 0,0 & 0,0 & 0,0 & 0,0 & 0,0 & 0,0 & 0,0 \\
\hline Sigmolopsis schumbergeri & 0,0 & 0,0 & 0,0 & 0,0 & 0,0 & 0,0 & 0,0 & 0,0 & 0,0 & 0,0 & 0,5 & 0,0 & 0,0 & 0,0 & 0,0 & 0,0 & 0,0 & 0,6 & 0,3 & 0,0 & 0,0 & 0,0 & 0,0 & 0,0 & 0,0 & 0,0 & 0,0 & 0,0 & 0,0 & 0,0 \\
\hline Sigmoilopsis sp & 0,0 & 0,0 & 0,0 & 0,0 & 0,0 & 0,0 & 0,0 & 0,0 & 0,0 & 0,0 & 0,0 & 0,0 & 0,0 & 0,0 & 0,0 & 0,0 & 0,0 & 0,0 & 0,3 & 0,0 & 0,0 & 0,0 & 0,0 & 0,0 & 0,0 & 0,0 & 0,0 & 0,0 & 0,0 & 0,0 \\
\hline Sigmomorphina pauperata & 0,0 & 0,0 & 0,0 & 0,0 & 0,0 & 0,0 & 0,0 & 0,0 & 0,0 & 0,4 & 0,0 & 0,0 & 0,0 & 0,0 & 0,0 & 0,0 & 0,0 & 0,0 & 0,0 & 0,0 & 0,0 & 0,0 & 0,0 & 0,0 & 0,0 & 0,0 & 0,0 & 0,0 & 0,0 & 0,0 \\
\hline Siphogenerina rephanus & 2,4 & 0,0 & 0,0 & 10,0 & 0,0 & 0,0 & 0,0 & 0,0 & 0,0 & 1,1 & 0,5 & 0,8 & 0,0 & 0,3 & 0,0 & 0,3 & 0,3 & 0,0 & 0,3 & 0,0 & 0,0 & 0,0 & 0,0 & 0,3 & 0,0 & 0,0 & 0,0 & 0,0 & 0,4 & 0,0 \\
\hline Siphonoperta $s p$ & 0,0 & 0,0 & 0,0 & 0,0 & 0,0 & 0,0 & 0,0 & 0,0 & 0,0 & 0,0 & 0,0 & 0,0 & 0,0 & 0,3 & 0,0 & 0,0 & 0,0 & 0,0 & 0,0 & 0,0 & 0,0 & 0,0 & 0,0 & 0,0 & 0,0 & 0,0 & 0,0 & 0,0 & 0,0 & 0,0 \\
\hline Siphotrochammina $s p$ & 0,0 & 0,0 & 0,0 & 0,0 & 0,0 & 0,0 & 0,0 & 0,0 & 0,0 & 0,0 & 0,0 & 0,0 & 0,0 & 0,0 & 0,0 & 0,0 & 0,0 & 0,0 & 0,0 & 0,0 & 0,0 & 0,0 & 0,0 & 0,0 & 0,0 & 0,0 & 0,0 & 0,5 & 0,0 & 0,0 \\
\hline Spirillina vivipara & 0,0 & 0,0 & 0,0 & 0,0 & 0,0 & 0,0 & 0,0 & 0,0 & 0,0 & 0,4 & 0,0 & 2,8 & 0,4 & 3,7 & 0,9 & 0,6 & 1,3 & 3,1 & 0,0 & 0,2 & 0,0 & 0,0 & 0,0 & 0,0 & 0,0 & 0,0 & 0,0 & 0,0 & 0,0 & 0,0 \\
\hline Spirobolivina $s p$ & 0,0 & 0,0 & 0,0 & 0,0 & 0,0 & 0,0 & 0,0 & 0,0 & 0,0 & 0,0 & 0,0 & 0,0 & 0,0 & 0,0 & 0,0 & 0,0 & 0,0 & 0,6 & 0,0 & 0,0 & 0,0 & 0,0 & 0,0 & 0,0 & 0,0 & 0,0 & 0,0 & 0,0 & 0,0 & 0,0 \\
\hline Spiroloculina attenuata & 0,0 & 0,0 & 0,0 & 0,0 & 0,0 & 0,0 & 0,0 & 0,0 & 0,0 & 0,0 & 0,0 & 0,4 & 0,0 & 0,0 & 0,0 & 0,0 & 0,0 & 0,0 & 0,0 & 0,0 & 0,0 & 0,0 & 0,0 & 0,0 & 0,0 & 0,0 & 0,0 & 0,0 & 0,0 & 0,0 \\
\hline Spiroloculina ornata & 0,0 & 0,3 & 0,0 & 0,0 & 0,3 & 0,0 & 0,0 & 0,0 & 0,0 & 0,4 & 0,0 & 0,0 & 0,0 & 0,0 & 0,0 & 0,0 & 0,0 & 0,0 & 0,0 & 0,0 & 0,0 & 0,0 & 0,0 & 0,0 & 0,0 & 0,0 & 0,0 & 0,0 & 0,0 & 0,0 \\
\hline
\end{tabular}


Anexo 46 - Continuação

\begin{tabular}{|c|c|c|c|c|c|c|c|c|c|c|c|c|c|c|c|c|c|c|c|c|c|c|c|c|c|c|c|c|c|c|}
\hline \multirow[b]{2}{*}{ Estações } & \multicolumn{10}{|c|}{ Setembro de 2005} & \multicolumn{10}{|c|}{ Junho de 2006} & \multicolumn{10}{|c|}{ Outubro de 2006} \\
\hline & Sc2 & $\mathrm{Sc} 3$ & Sc5 & Sc6 & Sc7 & Sc8 & Sc9 & Sc10 & Sc11 & Sc12 & Sc1 & $\mathrm{Sc} 2$ & $\mathrm{Sc} 3$ & Sc4 & Sc5 & Sc6 & Sc7 & Sc8 & $\mathrm{Sc} 9$ & Sc11 & Sc1 & $\mathrm{Sc} 2$ & $\mathrm{Sc} 3$ & $\mathrm{Sc} 4$ & Sc5 & Sc6 & Sc7 & $\mathrm{Sc} 8$ & Sc9 & Sc10 \\
\hline Spiroloculina sp & 0,0 & 0,0 & 0,0 & 0,0 & 0,0 & 0,0 & 0,0 & 0,0 & 0,0 & 0,0 & 0,0 & 0,4 & 0,0 & 0,0 & 0,0 & 0,0 & 0,0 & 0,0 & 0,3 & 0,0 & 0,0 & 0,0 & 0,0 & 0,0 & 0,0 & 0,0 & 0,0 & 0,2 & 0,4 & 0,0 \\
\hline Spiroplectamina biformis & 0,4 & 0,0 & 0,0 & 0,0 & 0,0 & 0,0 & 0,0 & 0,0 & 0,0 & 0,0 & 0,0 & 0,0 & 0,0 & 0,0 & 0,0 & 0,0 & 0,0 & 0,0 & 0,0 & 0,0 & 0,0 & 0,0 & 0,0 & 0,0 & 0,0 & 0,0 & 0,0 & 0,0 & 0,0 & 0,0 \\
\hline Textularia aglutinans & 0,4 & 0,0 & 0,0 & 0,0 & 1,9 & 0,0 & 0,2 & 0,0 & 0,0 & 0,0 & 0,0 & 0,4 & 0,0 & 0,0 & 0,0 & 0,0 & 1,0 & 1,3 & 0,0 & 0,2 & 0,0 & 0,0 & 0,0 & 0,0 & 0,0 & 0,0 & 0,0 & 0,0 & 0,0 & 0,0 \\
\hline Textularia candeiana & 0,0 & 0,0 & 0,0 & 0,0 & 0,0 & 0,0 & 0,0 & 0,0 & 0,0 & 0,0 & 0,0 & 0,0 & 0,4 & 0,0 & 0,0 & 0,0 & 0,0 & 0,0 & 0,3 & 0,0 & 0,0 & 0,0 & 0,0 & 0,0 & 0,0 & 0,0 & 0,0 & 0,0 & 0,0 & 0,0 \\
\hline Textularia earlandi & 0,0 & 0,0 & 0,0 & 0,0 & 0,0 & 0,0 & 0,0 & 0,0 & 0,0 & 0,0 & 0,0 & 0,0 & 0,0 & 0,0 & 0,3 & 0,0 & 0,0 & 0,0 & 0,0 & 0,0 & 0,0 & 0,0 & 0,0 & 0,0 & 0,0 & 0,0 & 0,0 & 0,0 & 0,0 & 0,0 \\
\hline Textularia gramen & 2,8 & 0,6 & 0,0 & 30,0 & 1,6 & 3,2 & 0,2 & 0,0 & 0,0 & 1,1 & 0,0 & 2,0 & 0,0 & 1,4 & 1,1 & 0,6 & 1,0 & 3,8 & 0,3 & 0,7 & 0,0 & 0,0 & 0,0 & 0,0 & 0,0 & 0,0 & 0,0 & 0,0 & 0,0 & 0,0 \\
\hline Textuaria porrecta & 0,0 & 0,0 & 0,0 & 0,0 & 0,0 & 0,0 & 0,0 & 0,0 & 0,0 & 0,0 & 0,0 & 0,0 & 0,4 & 0,0 & 0,0 & 0,0 & 0,0 & 0,0 & 0,0 & 0,0 & 0,0 & 0,0 & 0,0 & 0,0 & 0,0 & 0,0 & 0,0 & 0,0 & 0,0 & 0,0 \\
\hline Textularia sp. & 0,4 & 0,3 & 1,3 & 0,0 & 1,0 & 0,0 & 0,5 & 0,0 & 0,0 & 2,9 & 0,0 & 0,0 & 0,0 & 0,6 & 0,3 & 0,0 & 0,0 & 0,0 & 0,6 & 0,0 & 0,0 & 0,0 & 0,0 & 0,0 & 0,0 & 0,0 & 0,0 & 0,0 & 0,0 & 0,0 \\
\hline Tiphotrocha comprimata & 0,0 & 0,0 & 0,0 & 0,0 & 1,0 & 0,0 & 0,0 & 0,0 & 0,0 & 0,4 & 0,0 & 0,0 & 0,0 & 0,0 & 0,0 & 0,0 & 0,0 & 0,0 & 0,0 & 0,0 & 0,0 & 0,0 & 0,0 & 0,0 & 0,0 & 0,0 & 0,0 & 0,0 & 0,0 & 0,0 \\
\hline Triloculina baldai & 0,0 & 0,0 & 0,0 & 0,0 & 0,0 & 3,2 & 0,0 & 0,0 & 0,7 & 0,0 & 0,0 & 0,0 & 0,0 & 0,0 & 0,0 & 0,0 & 0,3 & 0,0 & 0,3 & 0,2 & 0,0 & 0,0 & 0,0 & 0,0 & 0,0 & 0,0 & 0,0 & 0,0 & 0,0 & 0,0 \\
\hline Triloculina cultrata & 0,0 & 0,0 & 0,0 & 0,0 & 0,0 & 0,0 & 0,0 & 0,0 & 0,0 & 0,0 & 0,0 & 0,0 & 0,0 & 0,0 & 0,3 & 0,6 & 0,6 & 0,0 & 0,0 & 0,0 & 0,0 & 0,0 & 0,0 & 0,0 & 0,0 & 0,0 & 0,0 & 0,0 & 0,0 & 0,0 \\
\hline Triloculina laevigata & 0,0 & 0,0 & 0,0 & 0,0 & 0,0 & 0,0 & 0,0 & 0,0 & 0,0 & 0,4 & 0,0 & 0,0 & 0,0 & 0,0 & 0,0 & 0,0 & 0,0 & 0,0 & 0,0 & 0,0 & 0,0 & 0,0 & 0,0 & 0,0 & 0,0 & 0,0 & 0,0 & 0,0 & 0,0 & 0,0 \\
\hline Triloculina oblonga & 0,4 & 0,0 & 0,0 & 0,0 & 2,2 & 0,0 & 1,4 & 0,0 & 0,0 & 2,9 & 0,5 & 0,0 & 0,4 & 0,0 & 0,3 & 0,6 & 0,0 & 0,0 & 0,0 & 1,0 & 0,0 & 0,0 & 0,0 & 0,0 & 0,0 & 0,0 & 0,0 & 0,0 & 0,0 & 0,0 \\
\hline Triloculina trigonula & 0,0 & 0,0 & 0,6 & 0,0 & 0,0 & 0,0 & 0,0 & 0,0 & 0,0 & 0,4 & 0,0 & 0,0 & 0,0 & 0,0 & 0,0 & 0,0 & 0,0 & 0,0 & 0,0 & 0,0 & 0,0 & 0,0 & 0,0 & 0,0 & 0,0 & 0,0 & 0,0 & 0,0 & 0,0 & 0,0 \\
\hline Triloculina sp & 0,0 & 0,0 & 0,0 & 0,0 & 0,0 & 0,0 & 0,0 & 0,0 & 0,0 & 0,0 & 0,0 & 0,0 & 0,0 & 0,0 & 0,0 & 0,0 & 0,0 & 0,0 & 0,0 & 0,0 & 0,0 & 1,4 & 1,0 & 0,3 & 0,0 & 0,4 & 0,4 & 0,0 & 0,4 & 0,0 \\
\hline Trochammina squamata & 0,0 & 0,0 & 0,0 & 0,0 & 0,0 & 0,0 & 0,0 & 0,0 & 0,0 & 0,0 & 0,0 & 0,0 & 0,8 & 2,0 & 0,3 & 0,0 & 0,6 & 5,6 & 0,0 & 0,5 & 0,0 & 0,0 & 0,0 & 0,0 & 0,0 & 0,0 & 0,0 & 0,0 & 0,0 & 0,0 \\
\hline Trochammina sp & 0,4 & 0,3 & 0,0 & 0,0 & 1,0 & 3,2 & 0,2 & 1,1 & 0,0 & 0,7 & 0,0 & 1,6 & 0,4 & 0,3 & 0,3 & 0,6 & 0,6 & 0,6 & 0,6 & 0,0 & 0,0 & 0,2 & 0,5 & 0,0 & 0,0 & 0,0 & 1,4 & 0,5 & 0,0 & 0,8 \\
\hline Uvigerina peregrina & 0,0 & 0,0 & 0,0 & 0,0 & 0,0 & 0,0 & 0,0 & 0,0 & 0,0 & 0,0 & 0,0 & 0,0 & 0,0 & 0,0 & 0,0 & 0,0 & 0,0 & 0,0 & 0,0 & 0,0 & 0,0 & 0,0 & 0,0 & 0,0 & 0,0 & 0,0 & 0,0 & 0,2 & 0,8 & 0,0 \\
\hline Uvigerina striata & 0,0 & 0,0 & 0,0 & 0,0 & 0,0 & 0,0 & 0,0 & 0,0 & 0,0 & 0,0 & 0,5 & 0,0 & 0,0 & 0,0 & 0,0 & 0,0 & 0,0 & 0,6 & 0,6 & 0,0 & 0,0 & 0,0 & 0,0 & 0,0 & 0,0 & 0,0 & 0,0 & 0,0 & 0,0 & 0,0 \\
\hline Wiesnerella auriculata & 0,0 & 0,0 & 0,0 & 0,0 & 0,0 & 0,0 & 0,0 & 0,0 & 0,0 & 0,0 & 0,0 & 0,0 & 0,0 & 0,0 & 0,6 & 0,6 & 1,0 & 0,0 & 0,0 & 0,2 & 0,0 & 0,0 & 0,0 & 0,0 & 0,0 & 1,9 & 0,4 & 0,0 & 0,4 & 0,0 \\
\hline Indeterminado & 0,0 & 0,0 & 0,0 & 0,0 & 0,0 & 0,0 & 0,0 & 0,0 & 0,0 & 0,0 & 1,5 & 2,8 & 1,2 & 0,8 & 2,6 & 2,3 & 3,2 & 1,3 & 2,1 & 2,6 & 2,3 & 3,0 & 3,6 & 4,3 & 4,9 & 3,0 & 5,4 & 5,6 & 4,9 & 4,9 \\
\hline Fragmento & 2,0 & 5,0 & 7,8 & 0,0 & 4,5 & 3,2 & 1,6 & 0,0 & 3,4 & 4,7 & 3,4 & 5,6 & 2,4 & 8,2 & 5,5 & 6,2 & 6,7 & 12,5 & 6,4 & 6,0 & 1,8 & 3,9 & 4,1 & 7,7 & 6,8 & 11,9 & 6,1 & 5,3 & 6,1 & 5,3 \\
\hline \multicolumn{31}{|c|}{ Parâmetros abióticos } \\
\hline Densidade & 253 & 634 & 154 & 10 & 312 & 31 & 441 & 522 & 146 & 278 & 6560 & 496 & 1968 & 354 & 1392 & 1232 & 630 & 160 & 1320 & 1672 & 3152 & 3512 & 416 & 323 & 1232 & 536 & 2216 & 412 & 1960 & 1960 \\
\hline Fração analisada & 1 & $1 / 2$ & 1 & 1 & 1 & 1 & 1 & $1 / 2$ & 1 & 1 & $1 / 32$ & $1 / 2$ & $1 / 8$ & 1 & $1 / 4$ & $1 / 4$ & $1 / 2$ & 1 & $1 / 4$ & $1 / 4$ & $1 / 8$ & $1 / 8$ & 1 & 1 & $1 / 4$ & $1 / 2$ & $1 / 8$ & 1 & $1 / 8$ & $1 / 8$ \\
\hline Riqueza & 45 & 36 & 26 & 6 & 45 & 11 & 37 & 26 & 35 & 54 & 45 & 58 & 53 & 54 & 67 & 53 & 77 & 40 & 56 & 68 & 31 & 31 & 37 & 32 & 30 & 32 & 33 & 41 & 33 & 29 \\
\hline Diversidade específica & 3,36 & 2,64 & 2,69 & $*$ & 3,50 & * & 2,79 & 2,40 & 2,89 & 3,47 & 3,09 & 3,74 & 3,27 & 3,38 & 3,49 & 3,36 & 3,92 & 3,32 & 3,36 & 3,60 & 2,65 & 2,60 & 2,90 & 2,90 & 2,79 & 2,98 & 2,82 & 3,11 & 2,82 & 2,81 \\
\hline Equitatividade & 0,88 & 0,74 & 0,83 & $*$ & 0,92 & $*$ & 0,77 & 0,74 & 0,81 & 0,87 & 0,81 & 0,92 & 0,82 & 0,85 & 0,83 & 0,85 & 0,90 & 0,90 & 0,83 & 0,85 & 0,77 & 0,76 & 0,80 & 0,84 & 0,82 & 0,86 & 0,81 & 0,84 & 0,81 & 0,83 \\
\hline
\end{tabular}

Legenda: * não calculado, valor baixo de densidade 
Anexo 47 - (Tanatocenoses) Distribuição de espécies bioindicadoras de ambiente óxico e enriquecido por matéria orgânica identificadas próximo ao emissário Saco da Capela.

Valores em porcentagem.

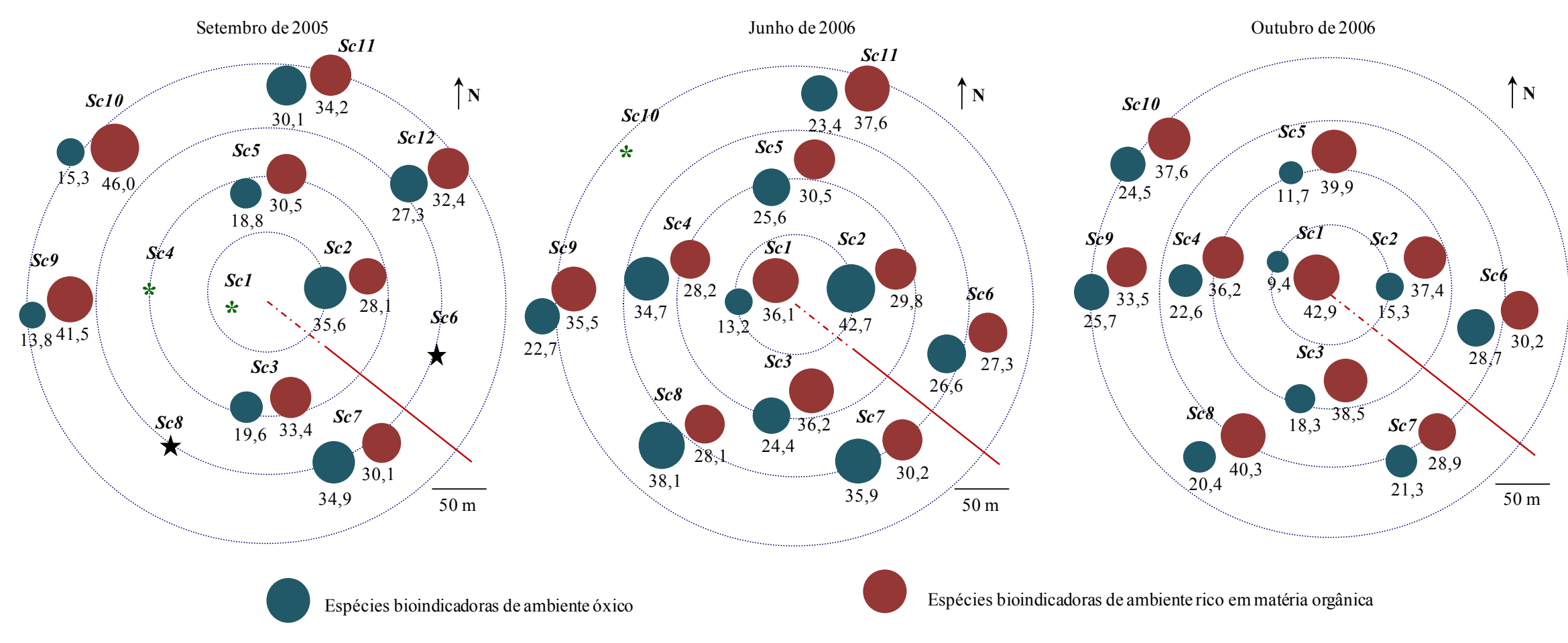

$\star \quad$ Não demonstrado devido à baixa densidade obtida nas estações

\footnotetext{
* Estação não amostrada
} 
Anexo 48 - (Tanatocenoses) Resultado das análises morfométricas realizadas nas carapaças dos foraminíferos obtidas próximo ao emissário Saco da Capela.

Valores em porcentagem.

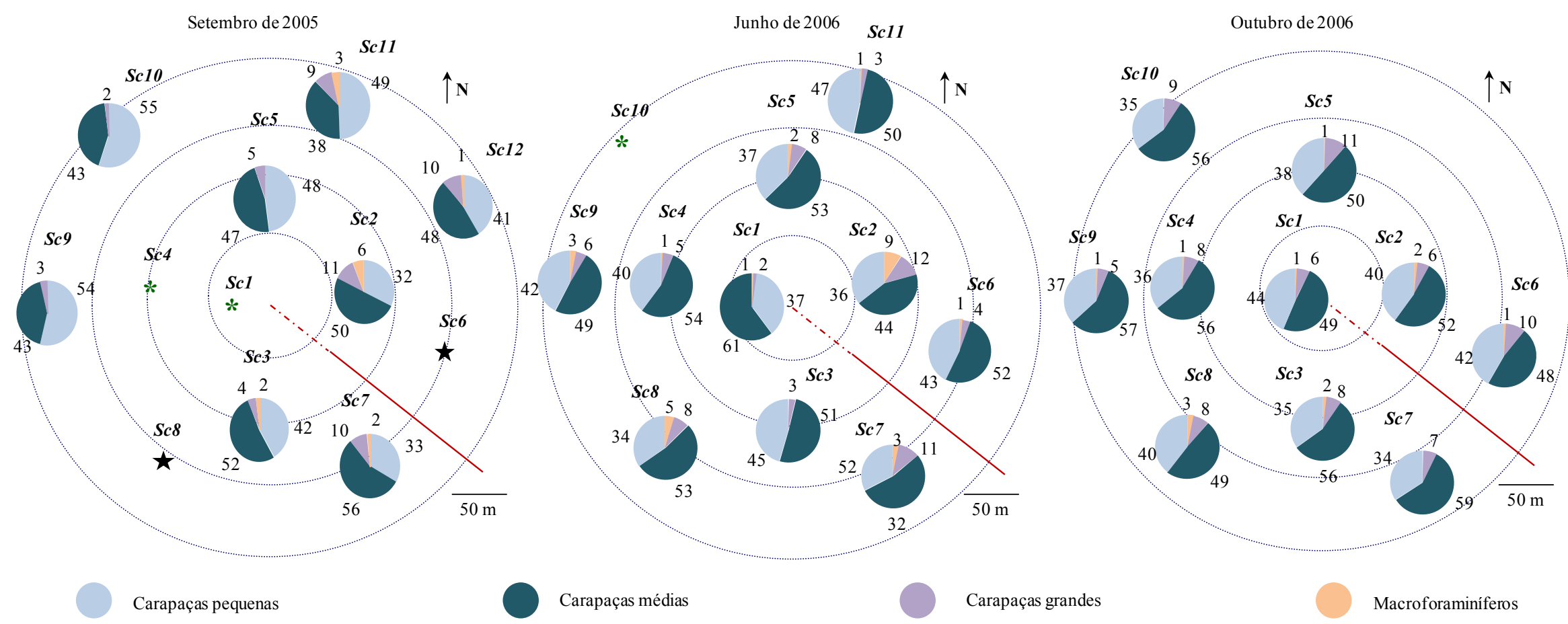

\footnotetext{
* Estação não amostrada
} 
Anexo 49 - Grau de preservação das carapaças que compuseram as tanatocenoses. Dados obtidos próximo ao emissário Saco da Capela. Valores em porcentagem.

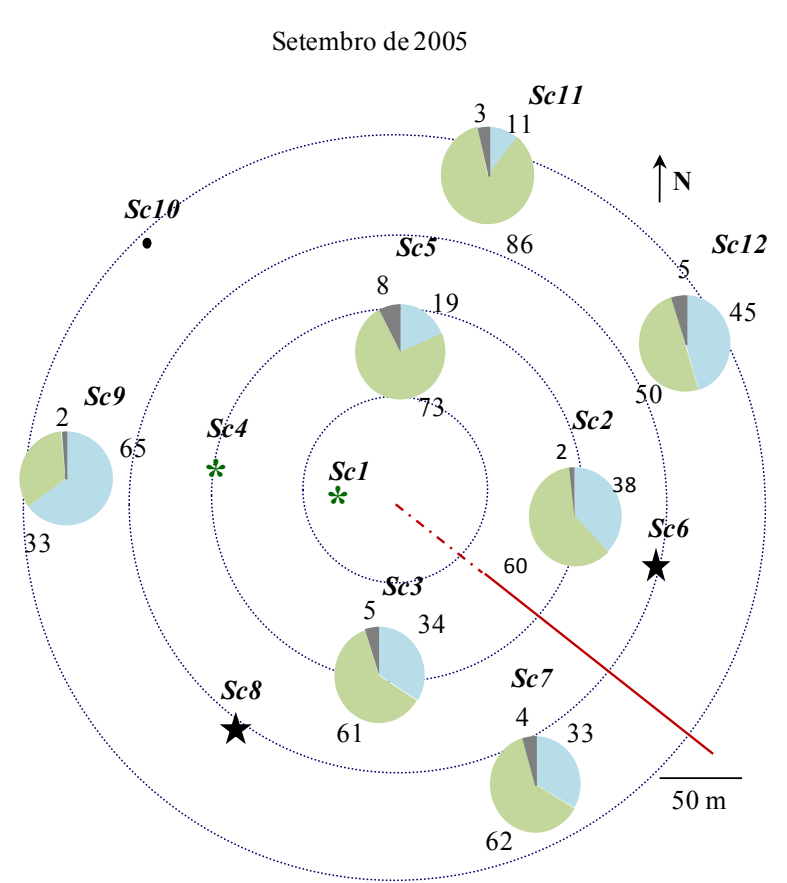

Carapaças inteiras

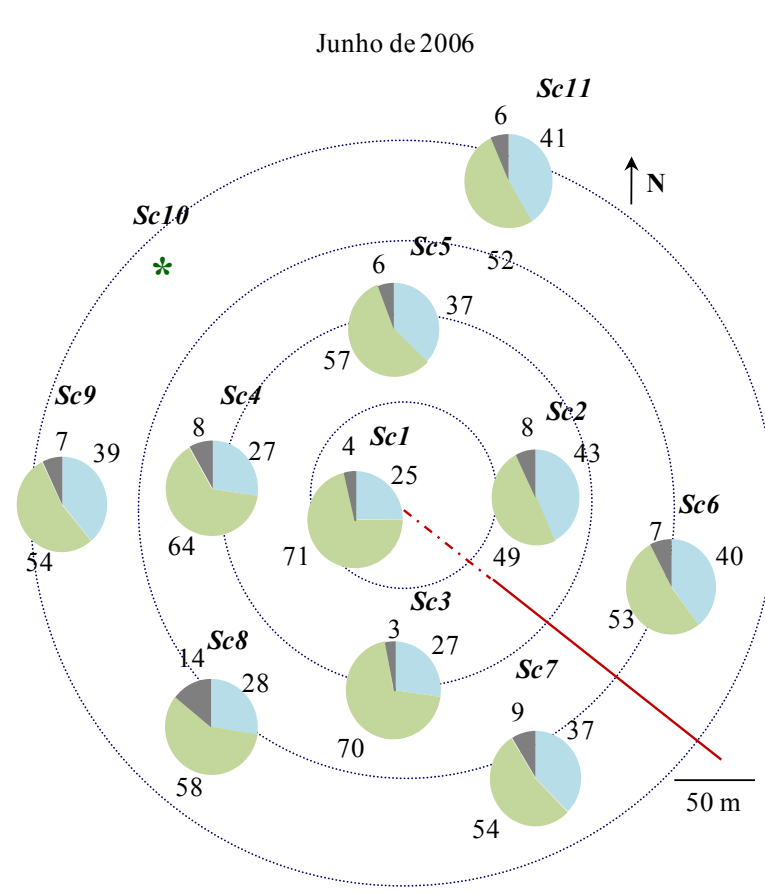

Carapaças parcialmente fragmentadas

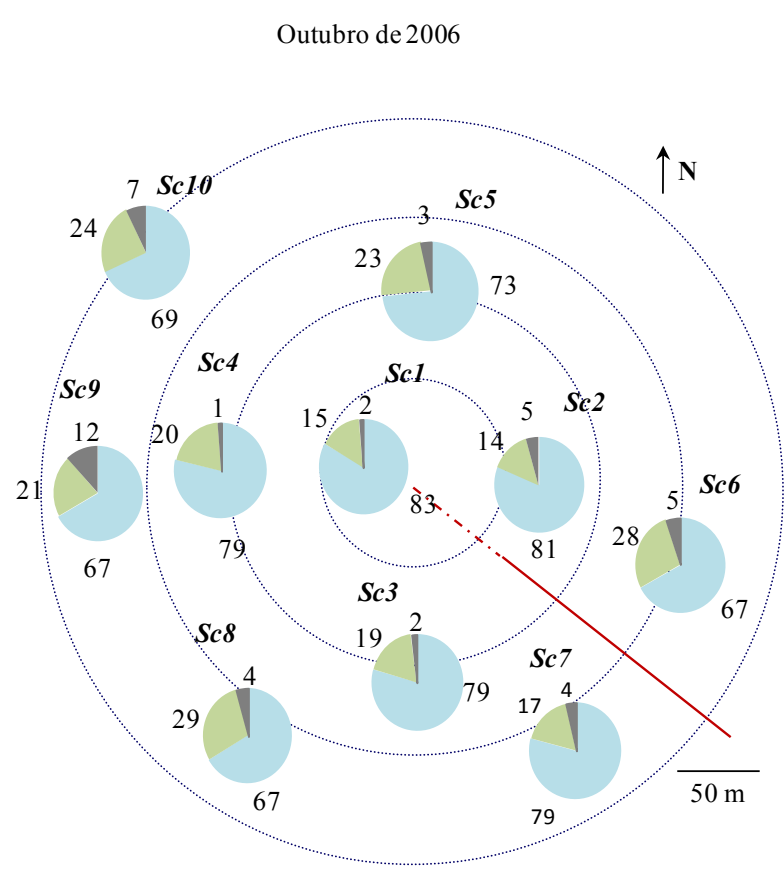

Fragmentos de carapaças

^ Não demonstrado devido à baixa densidade obtida nas estações

\section{* Estação não amostrada}


Anexo 50 - Estado de preservação e coloração das carapaças dos foraminíferos que compuseram as tanatocenoses. Dados obtidos próximo ao emissário Saco da Capela.

Valores em porcentagem.

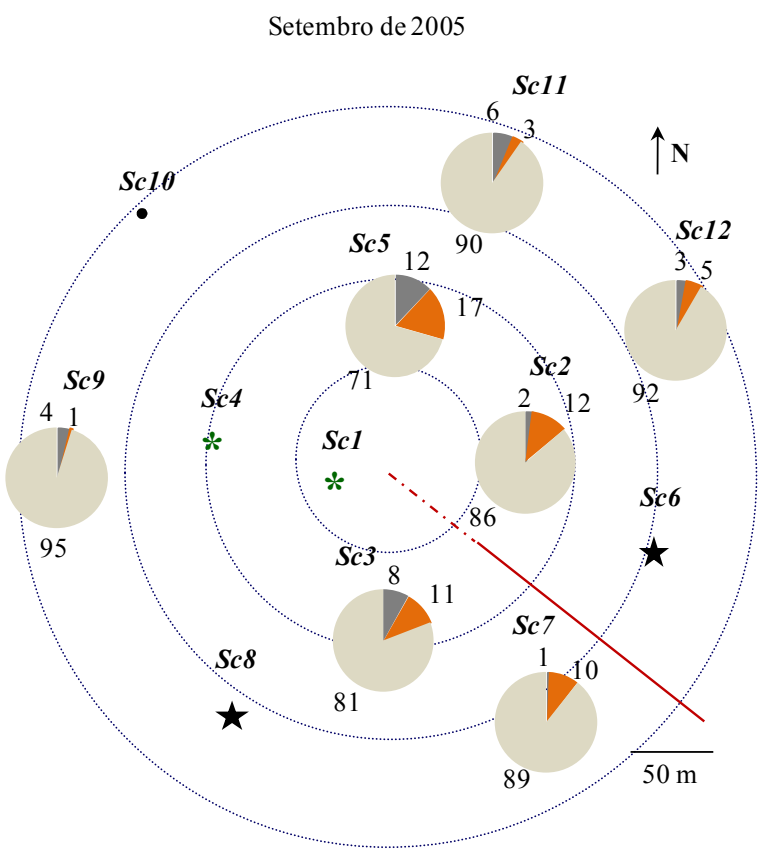

Carapaças sem sinais de preenchimento e/ou impregnação

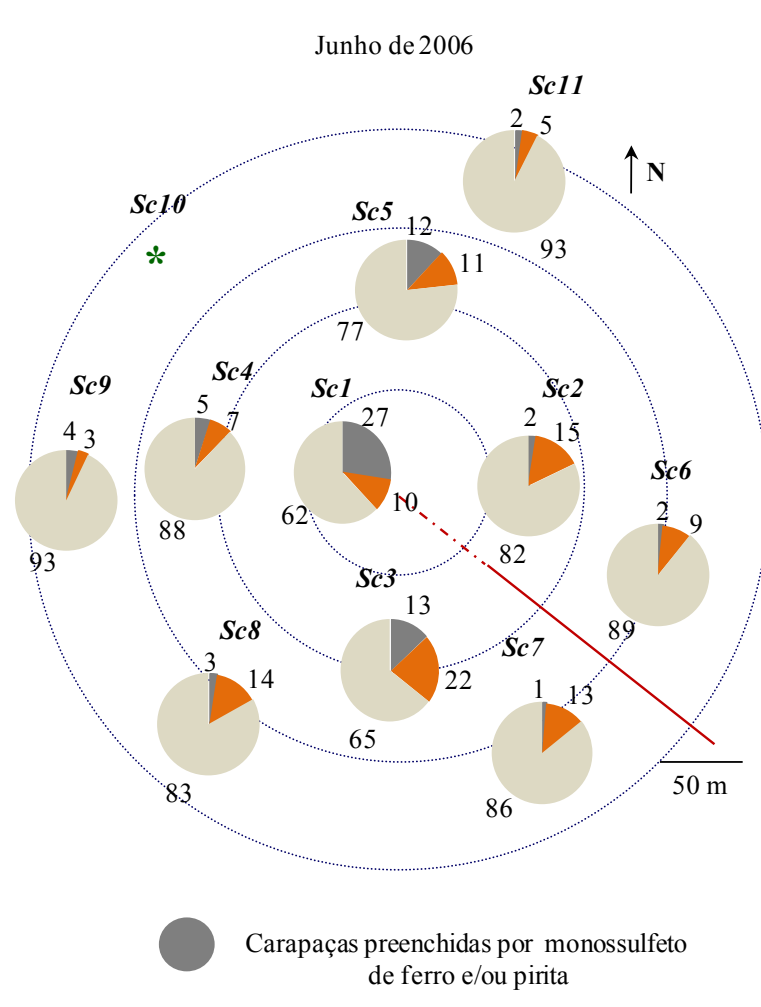

de ferro e/ou pirita
Outubro de 2006

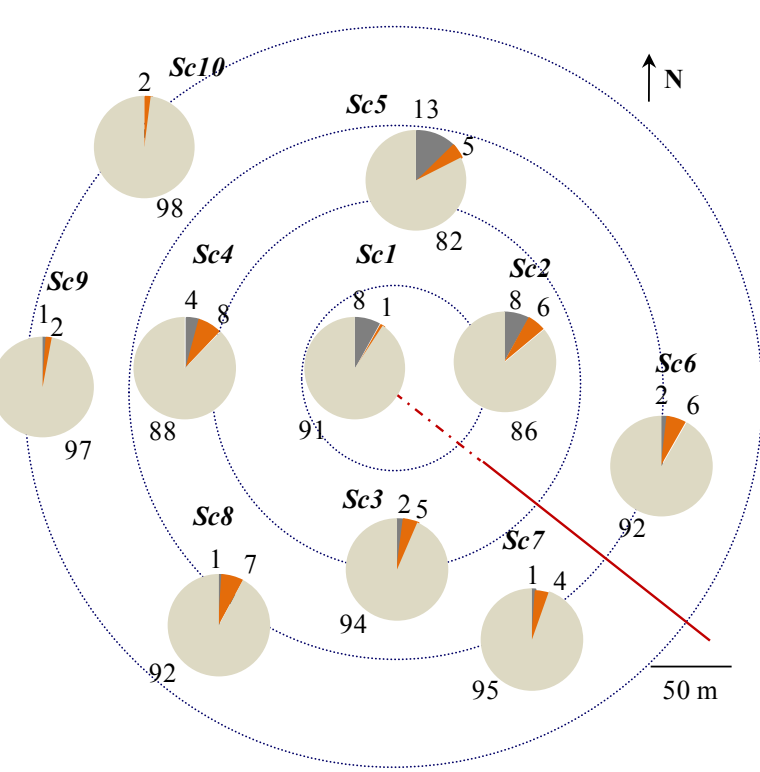

Carapaças limonitizadas

^ Não demonstrado devido à baixa densidade obtida nas estações

\section{* Estação não amostrada}


Anexo 51 - Matriz de correlação de Pearson obtida para os dados bióticos e abióticos obtidos no Saco da Capela, em Setembro de 2005.

Níveis de significância: $p<0,01$ (em vermelho) e $p<0,05$ (em negrito)

\begin{tabular}{|c|c|c|c|c|c|c|c|c|c|c|c|c|c|c|c|c|c|c|c|c|c|c|c|c|c|c|c|c|c|c|}
\hline & 岁 & 悹 & $\overline{\tilde{n}}$ & ชิ & $\overbrace{\tilde{ల}}^{0}$ & $\overrightarrow{0}$ & z & $\begin{array}{l}\text { जٓ } \\
\stackrel{0}{0} \\
\frac{0}{2}\end{array}$ & $\begin{array}{l}\text { bD } \\
\stackrel{0}{0}\end{array}$ & 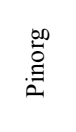 & $n$ & 苞 & 总 & $\stackrel{I}{2}$ & 포 & $\begin{array}{l}\dot{\Xi} \\
\stackrel{\tilde{\Xi}}{0}\end{array}$ & $\dot{\check{\Xi}}$ & I & $r$ & $\dot{\leftrightarrow}$ & نें & $\dot{0}$ & $\dot{\Xi}$ & $\ddot{z}$ & "ే & $\begin{array}{l}\dot{0} \\
\dot{\leftrightarrow} \\
\text { m }\end{array}$ & 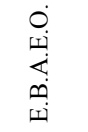 & 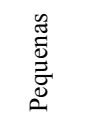 & $\begin{array}{l}\stackrel{\tilde{f}}{\tilde{g}} \\
\sum_{\Sigma}^{0}\end{array}$ & 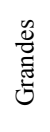 \\
\hline Prof & 1 & & & & & & & & & & & & & & & & & & & & & & & & & & & & & \\
\hline Temp & $-0,66$ & 1 & & & & & & & & & & & & & & & & & & & & & & & & & & & & \\
\hline Sal & 0,45 & $-0,49$ & 1 & & & & & & & & & & & & & & & & & & & & & & & & & & & \\
\hline OD & $-0,52$ & 0,70 & $-0,30$ & 1 & & & & & & & & & & & & & & & & & & & & & & & & & & \\
\hline $\mathrm{CaCO} 3$ & 0,75 & $-0,47$ & 0,30 & $-0,35$ & 1 & & & & & & & & & & & & & & & & & & & & & & & & & \\
\hline Cot & 0,55 & $-0,30$ & 0,66 & $-0,14$ & 0,42 & 1 & & & & & & & & & & & & & & & & & & & & & & & & \\
\hline $\mathrm{N}$ & $-0,12$ & $-0,31$ & $-0,26$ & $-0,06$ & $-0,23$ & $-0,36$ & 1 & & & & & & & & & & & & & & & & & & & & & & & \\
\hline Ptotal & 0,55 & $-0,09$ & 0,04 & $-0,38$ & 0,78 & 0,16 & $-0,36$ & 1 & & & & & & & & & & & & & & & & & & & & & & \\
\hline Porg & $-0,37$ & 0,58 & $-0,35$ & 0,45 & 0,18 & $-0,38$ & $-0,32$ & 0,44 & 1 & & & & & & & & & & & & & & & & & & & & & \\
\hline Pinorg & 0,70 & $-0,25$ & 0,14 & $-0,53$ & 0,80 & 0,28 & $-0,31$ & 0,97 & 0,20 & 1 & & & & & & & & & & & & & & & & & & & & \\
\hline S & 0,51 & $-0,61$ & $\mathbf{0 , 7 3}$ & $-0,24$ & 0,55 & 0,48 & $-0,38$ & 0,18 & $-0,13$ & 0,23 & 1 & & & & & & & & & & & & & & & & & & & \\
\hline Areia & $-0,35$ & 0,41 & $-0,73$ & 0,34 & $-0,28$ & $-0,25$ & 0,51 & $-0,23$ & 0,01 & $-0,25$ & $-0,83$ & 1 & & & & & & & & & & & & & & & & & & \\
\hline Finos & 0,41 & $-0,58$ & 0,78 & $-0,41$ & 0,36 & 0,46 & $-0,41$ & 0,19 & $-0,16$ & 0,25 & 0,90 & $-0,93$ & 1 & & & & & & & & & & & & & & & & & \\
\hline $\mathrm{pH}$ & 0,18 & $-0,36$ & $-0,27$ & $-0,60$ & $-0,05$ & $-0,13$ & 0,05 & $-0,07$ & $-0,44$ & 0,05 & $-0,14$ & 0,11 & $-0,06$ & 1 & & & & & & & & & & & & & & & & \\
\hline Eh & 0,11 & 0,34 & $-0,46$ & 0,27 & $-0,30$ & $-0,17$ & $-0,11$ & $-0,14$ & $-0,17$ & $-0,10$ & $-0,38$ & 0,31 & $-0,46$ & 0,29 & 1 & & & & & & & & & & & & & & & \\
\hline Dens. & $-0,46$ & 0,25 & 0,04 & $-0,27$ & $-0,27$ & 0,05 & $-0,22$ & $-0,06$ & $-0,01$ & $-0,06$ & $-0,23$ & 0,07 & 0,00 & 0,16 & $-0,42$ & 1 & & & & & & & & & & & & & & \\
\hline Riq. & $-0,20$ & $-0,10$ & 0,13 & $-0,39$ & 0,15 & 0,17 & $-0,38$ & 0,24 & 0,18 & 0,21 & 0,25 & $-0,31$ & 0,45 & 0,18 & $-0,63$ & 0,74 & 1 & & & & & & & & & & & & & \\
\hline $\mathrm{H}$ & $-0,45$ & $-0,05$ & $-0,28$ & 0,01 & $-0,18$ & $-0,33$ & 0,07 & $-0,33$ & $-0,02$ & $-0,36$ & 0,13 & 0,04 & 0,05 & 0,19 & $-0,22$ & 0,36 & 0,46 & 1 & & & & & & & & & & & & \\
\hline $\mathrm{J}$ & $-0,01$ & $-0,19$ & $-0,03$ & 0,37 & 0,25 & 0,09 & 0,44 & $-0,29$ & $-0,02$ & $-0,31$ & 0,11 & 0,38 & $-0,24$ & $-0,20$ & $-0,24$ & $-0,30$ & $-0,27$ & 0,19 & 1 & & & & & & & & & & & \\
\hline A.t. & $-0,52$ & 0,13 & 0,28 & $-0,08$ & $-0,22$ & 0,03 & $-0,39$ & $-0,19$ & 0,19 & $-0,26$ & 0,20 & $-0,36$ & 0,39 & $-0,02$ & $-0,61$ & $\mathbf{0 , 7 7}$ & $\mathbf{0 , 7 9}$ & 0,44 & $-0,18$ & 1 & & & & & & & & & & \\
\hline G.p. & 0,29 & 0,14 & $-0,51$ & $-0,01$ & $-0,03$ & $-0,21$ & 0,26 & 0,18 & $-0,20$ & 0,25 & $-0,50$ & 0,51 & $-0,60$ & 0,21 & 0,77 & $-0,37$ & $-0,62$ & $-0,24$ & $-0,14$ & $-0,83$ & 1 & & & & & & & & & \\
\hline B.str. & 0,27 & $-0,32$ & 0,91 & $-0,24$ & 0,26 & 0,39 & $-0,34$ & 0,17 & $-0,05$ & 0,20 & 0,71 & $-0,85$ & $\mathbf{0 , 8 0}$ & $-0,43$ & $-0,53$ & 0,08 & 0,22 & $-0,20$ & $-0,20$ & 0,39 & $-0,56$ & 1 & & & & & & & & \\
\hline H.b. & $-0,07$ & 0,65 & 0,04 & 0,23 & 0,04 & 0,24 & $-0,70$ & 0,39 & 0,35 & 0,32 & $-0,11$ & $-0,06$ & $-0,06$ & $-0,38$ & 0,18 & 0,37 & 0,16 & $-0,15$ & $-0,44$ & 0,17 & 0,13 & 0,18 & 1 & & & & & & & \\
\hline N.t. & $-0,14$ & 0,56 & $-0,48$ & 0,27 & $-0,29$ & 0,17 & $-0,10$ & 0,01 & $-0,06$ & 0,03 & $-0,64$ & 0,63 & $-0,58$ & 0,05 & 0,54 & 0,20 & $-0,10$ & $-0,14$ & $-0,23$ & $-0,28$ & 0,57 & $-0,59$ & 0,51 & 1 & & & & & & \\
\hline B.sph & 0,15 & $-0,28$ & $-0,15$ & 0,12 & 0,37 & 0,04 & 0,24 & 0,17 & 0,31 & 0,10 & 0,15 & 0,06 & 0,07 & $-0,01$ & $-0,23$ & $-0,49$ & 0,02 & $-0,17$ & 0,42 & $-0,21$ & $-0,22$ & $-0,21$ & $-0,56$ & $-0,22$ & 1 & & & & & \\
\hline E.B.A.O. & 0,03 & 0,39 & $-0,63$ & 0,25 & $-0,21$ & $-0,23$ & 0,30 & 0,04 & $-0,08$ & 0,06 & $-0,69$ & 0,71 & $-0,77$ & 0,03 & $\mathbf{0 , 7 3}$ & $-0,28$ & $-0,62$ & $-0,23$ & $-0,05$ & $-0,76$ & 0,94 & $-0,67$ & 0,21 & $\mathbf{0 , 7 3}$ & $-0,18$ & 1 & & & & \\
\hline E.B.A.E.O. & 0,42 & $-0,68$ & 0,73 & $-0,51$ & 0,55 & 0,35 & $-0,17$ & 0,27 & $-0,05$ & 0,30 & 0,76 & $-0,73$ & 0,81 & 0,04 & $-0,68$ & 0,01 & 0,41 & $-0,09$ & 0,08 & 0,38 & $-0,69$ & 0,71 & $-0,32$ & $-0,79$ & 0,32 & $-0,86$ & 1 & & & \\
\hline Pequenas & 0,51 & $-0,35$ & 0,06 & $-0,33$ & 0,40 & 0,39 & $-0,40$ & 0,12 & $-0,38$ & 0,23 & 0,37 & $-0,11$ & 0,19 & 0,62 & 0,31 & $-0,04$ & 0,12 & 0,22 & 0,08 & $-0,09$ & 0,15 & $-0,16$ & 0,01 & 0,07 & $-0,10$ & $-0,05$ & 0,13 & 1 & & \\
\hline Medias & $-0,66$ & 0,66 & $-0,50$ & 0,41 & $-0,35$ & $-0,26$ & 0,29 & $-0,09$ & 0,36 & $-0,20$ & $-0,74$ & 0,72 & $-0,69$ & $-0,36$ & $-0,14$ & 0,46 & 0,09 & 0,12 & 0,15 & 0,13 & 0,11 & $-0,41$ & 0,31 & 0,52 & $-0,12$ & 0,39 & $-0,58$ & $-0,55$ & 1 & \\
\hline Grandes & 0,04 & $-0,17$ & 0,47 & $-0,03$ & $-0,19$ & $-0,13$ & 0,00 & $-0,07$ & 0,03 & $-0,08$ & 0,34 & $-0,68$ & 0,53 & $-0,36$ & $-0,13$ & $-0,31$ & $-0,18$ & $-0,31$ & $-0,38$ & 0,06 & $-0,26$ & 0,66 & $-0,14$ & $-0,51$ & 0,02 & $-0,32$ & 0,36 & $-0,52$ & $-0,40$ & 1 \\
\hline
\end{tabular}

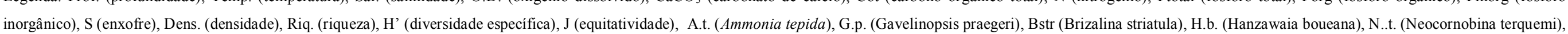

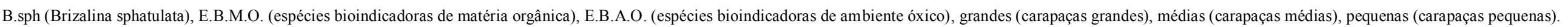


Anexo 52 - Matriz de correlação de Pearson obtida para os dados bióticos e abióticos obtidos no Saco da Capela, em Junho de 2006.

Níveis de significância: $p<0,01$ (em vermelho) e $p<0,05$ (em negrito)

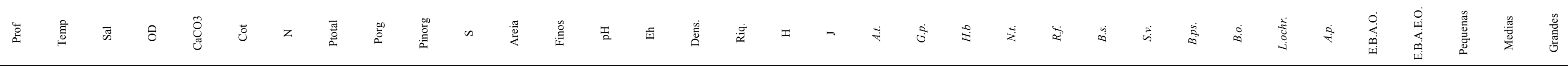

\begin{tabular}{|c|c|c|c|c|c|c|c|c|c|c|c|c|c|c|c|c|c|c|c|c|c|c|c|c|c|c|c|c|c|c|c|c|c|c|}
\hline Prof & 1 & & & & & & & & & & & & & & & & & & & & & & & & & & & & & & & & & \\
\hline Temp & $-0,79$ & 1 & & & & & & & & & & & & & & & & & & & & & & & & & & & & & & & & \\
\hline Sal & 0,81 & $-0,66$ & 1 & & & & & & & & & & & & & & & & & & & & & & & & & & & & & & & \\
\hline OD & $-0,65$ & 0,51 & $-0,80$ & 1 & & & & & & & & & & & & & & & & & & & & & & & & & & & & & & \\
\hline $\mathrm{CaCO}_{3}$ & 0,33 & $-0,34$ & 0,41 & $-0,83$ & 1 & & & & & & & & & & & & & & & & & & & & & & & & & & & & & \\
\hline Cot & 0,40 & $-0,21$ & 0,28 & $-0,65$ & 0,69 & 1 & & & & & & & & & & & & & & & & & & & & & & & & & & & & \\
\hline $\mathrm{N}$ & 0,02 & 0,13 & $-0,02$ & 0,04 & 0,09 & 0,06 & 1 & & & & & & & & & & & & & & & & & & & & & & & & & & & \\
\hline Ptotal & 0,47 & $-0,35$ & 0,47 & $-0,85$ & 0,90 & 0,92 & $-0,02$ & 1 & & & & & & & & & & & & & & & & & & & & & & & & & & \\
\hline Porg & 0,30 & $-0,22$ & 0,15 & $-0,26$ & 0,28 & $\mathbf{0 , 7 5}$ & 0,31 & 0,56 & 1 & & & & & & & & & & & & & & & & & & & & & & & & & \\
\hline Pinorg & 0,45 & $-0,34$ & 0,49 & $-0,89$ & 0,93 & $\mathbf{0 , 8 3}$ & $-0,10$ & 0,97 & 0,35 & 1 & & & & & & & & & & & & & & & & & & & & & & & & \\
\hline S & $-0,13$ & 0,22 & $-0,01$ & $-0,10$ & $-0,11$ & 0,22 & $-0,77$ & 0,15 & $-0,07$ & 0,18 & 1 & & & & & & & & & & & & & & & & & & & & & & & \\
\hline Areia & $-0,12$ & 0,24 & $-0,17$ & 0,63 & $-0,75$ & $-0,74$ & 0,33 & $-0,81$ & $-0,35$ & $-0,81$ & $-0,43$ & 1 & & & & & & & & & & & & & & & & & & & & & & \\
\hline Finos & 0,15 & 0,01 & 0,34 & $-0,57$ & 0,37 & 0,60 & $-0,52$ & 0,60 & 0,16 & 0,63 & 0,84 & $-0,68$ & 1 & & & & & & & & & & & & & & & & & & & & & \\
\hline pH & $-0,41$ & 0,37 & $-0,18$ & 0,45 & $-0,47$ & $-0,83$ & 0,21 & $-0,73$ & $-0,57$ & $-0,66$ & $-0,39$ & $\mathbf{0 , 7 7}$ & $-0,60$ & 1 & & & & & & & & & & & & & & & & & & & & \\
\hline Eh & $-0,47$ & 0,38 & $-0,41$ & 0,61 & $-0,36$ & $-0,55$ & 0,29 & $-0,53$ & $-0,18$ & $-0,55$ & $-0,51$ & 0,65 & $-0,67$ & 0,66 & 1 & & & & & & & & & & & & & & & & & & & \\
\hline Dens. & $-0,57$ & 0,21 & $-0,52$ & 0,28 & 0,06 & $-0,11$ & $-0,49$ & $-0,05$ & $-0,34$ & 0,04 & 0,33 & $-0,33$ & 0,18 & $-0,16$ & 0,17 & 1 & & & & & & & & & & & & & & & & & & \\
\hline Riq. & 0,27 & $-0,26$ & 0,31 & 0,10 & $-0,39$ & $-0,16$ & $-0,05$ & $-0,23$ & $-0,04$ & $-0,24$ & 0,18 & 0,22 & 0,14 & $-0,19$ & $-0,11$ & 0,01 & 1 & & & & & & & & & & & & & & & & & \\
\hline $\mathrm{H}$ & $-0,39$ & 0,28 & $-0,25$ & 0,25 & $-0,20$ & $-0,14$ & $-0,16$ & $-0,19$ & $-0,31$ & $-0,13$ & 0,41 & $-0,14$ & 0,30 & $-0,22$ & $-0,10$ & 0,60 & 0,61 & 1 & & & & & & & & & & & & & & & & \\
\hline J & $-0,73$ & 0,61 & $-0,62$ & 0,17 & 0,21 & 0,05 & $-0,13$ & 0,06 & $-0,28$ & 0,14 & 0,30 & $-0,43$ & 0,24 & $-0,11$ & $-0,01$ & $\mathbf{0 , 7 2}$ & $-0,32$ & 0,55 & 1 & & & & & & & & & & & & & & & \\
\hline A.t. & 0,39 & $-0,25$ & $-0,09$ & $-0,28$ & 0,48 & 0,64 & 0,05 & 0,56 & 0,40 & 0,52 & $-0,11$ & $-0,46$ & 0,04 & $-0,62$ & $-0,38$ & $-0,08$ & $-0,43$ & $-0,35$ & 0,06 & 1 & & & & & & & & & & & & & & \\
\hline G.p. & 0,67 & $-0,56$ & 0,65 & $-0,21$ & $-0,25$ & $-0,02$ & 0,21 & $-0,08$ & 0,27 & $-0,16$ & $-0,14$ & 0,28 & $-0,06$ & $-0,05$ & $-0,30$ & $-0,72$ & 0,60 & $-0,16$ & $-0,83$ & $-0,19$ & 1 & & & & & & & & & & & & & \\
\hline$H . b$ & 0,21 & $-0,28$ & 0,42 & 0,12 & $-0,46$ & $-0,49$ & 0,09 & $-0,44$ & $-0,03$ & $-0,49$ & $-0,24$ & 0,63 & $-0,32$ & 0,55 & 0,33 & $-0,47$ & 0,37 & $-0,29$ & $-0,77$ & $-0,66$ & 0,67 & 1 & & & & & & & & & & & & \\
\hline N.t. & $-0,02$ & $-0,01$ & 0,27 & $-0,06$ & 0,03 & $-0,43$ & 0,60 & $-0,26$ & $-0,27$ & $-0,21$ & $-0,59$ & 0,32 & $-0,46$ & 0,53 & 0,26 & $-0,35$ & 0,10 & 0,03 & $-0,10$ & $-0,43$ & 0,29 & 0,36 & 1 & & & & & & & & & & & \\
\hline R.f. & $-0,24$ & 0,18 & 0,01 & 0,02 & 0,04 & $-0,33$ & 0,30 & $-0,21$ & $-0,36$ & $-0,14$ & $-0,19$ & $-0,02$ & $-0,18$ & 0,22 & 0,01 & 0,00 & 0,12 & 0,43 & 0,35 & $-0,28$ & 0,02 & $-0,10$ & 0,80 & 1 & & & & & & & & & & \\
\hline B.str. & 0,46 & $-0,29$ & $-0,01$ & $-0,28$ & 0,33 & 0,67 & $-0,19$ & 0,54 & 0,37 & 0,51 & 0,23 & $-0,52$ & 0,32 & $-0,81$ & $-0,60$ & 0,01 & $-0,09$ & $-0,07$ & 0,05 & 0,90 & $-0,05$ & $-0,65$ & $-0,62$ & $-0,35$ & 1 & & & & & & & & & \\
\hline S.v. & $-0,63$ & 0,16 & $-0,45$ & 0,29 & 0,05 & $-0,42$ & 0,21 & $-0,31$ & $-0,37$ & $-0,24$ & $-0,34$ & $-0,01$ & $-0,39$ & 0,38 & 0,26 & 0,46 & $-0,26$ & 0,23 & 0,53 & $-0,28$ & $-0,41$ & $-0,11$ & 0,39 & 0,43 & $-0,44$ & 1 & & & & & & & & \\
\hline B.ps. & $-0,77$ & 0,57 & $-0,63$ & 0,34 & 0,05 & $-0,05$ & 0,08 & $-0,08$ & 0,05 & $-0,11$ & 0,02 & $-0,26$ & $-0,13$ & 0,09 & 0,31 & 0,42 & $-0,44$ & 0,22 & 0,72 & $-0,03$ & $-0,63$ & $-0,41$ & 0,14 & 0,45 & $-0,21$ & 0,50 & 1 & & & & & & & \\
\hline B.o. & 0,43 & $-0,60$ & 0,30 & $-0,36$ & 0,32 & 0,20 & $-0,49$ & 0,32 & $-0,20$ & 0,42 & 0,28 & $-0,50$ & 0,37 & $-0,60$ & $-0,52$ & 0,42 & 0,41 & 0,42 & 0,08 & 0,27 & 0,05 & $-0,33$ & $-0,23$ & 0,04 & 0,50 & $-0,07$ & $-0,33$ & 1 & & & & & & \\
\hline L.ochr. & 0,53 & $-0,27$ & 0,56 & $-0,14$ & $-0,31$ & $-0,19$ & 0,38 & $-0,23$ & 0,09 & $-0,28$ & $-0,27$ & 0,53 & $-0,22$ & 0,32 & $-0,11$ & $-0,90$ & 0,31 & $-0,37$ & $-0,79$ & $-0,26$ & $\mathbf{0 , 8 7}$ & 0,71 & 0,44 & 0,06 & $-0,24$ & $-0,35$ & $-0,58$ & $-0,31$ & 1 & & & & & \\
\hline A.p. & 0,24 & 0,10 & 0,28 & $-0,17$ & $-0,14$ & 0,31 & $-0,30$ & 0,19 & 0,39 & 0,11 & 0,55 & $-0,16$ & 0,46 & $-0,28$ & $-0,28$ & $-0,38$ & 0,12 & $-0,11$ & $-0,25$ & 0,05 & 0,31 & 0,10 & $-0,23$ & $-0,08$ & 0,18 & $-0,77$ & 0,02 & $-0,14$ & 0,26 & 1 & & & & \\
\hline E.B.A.O. & $-0,09$ & $-0,10$ & 0,33 & 0,06 & $-0,24$ & $-0,57$ & 0,29 & $-0,42$ & $-0,28$ & $-0,40$ & $-0,30$ & 0,42 & $-0,28$ & 0,58 & 0,28 & $-0,20$ & 0,41 & 0,17 & $-0,27$ & $-0,84$ & 0,45 & 0,72 & 0,78 & 0,50 & $-0,85$ & 0,38 & $-0,06$ & $-0,20$ & 0,49 & $-0,20$ & 1 & & & \\
\hline E.B.A.E.O. & $-0,06$ & 0,15 & $-0,39$ & 0,00 & 0,18 & 0,58 & $-0,42$ & 0,41 & 0,28 & 0,38 & 0,50 & $-0,49$ & 0,45 & $-0,66$ & $-0,29$ & 0,43 & $-0,24$ & 0,08 & 0,39 & 0,65 & $-0,50$ & $-0,71$ & $-0,90$ & $-0,57$ & 0,77 & $-0,30$ & 0,09 & 0,27 & $-0,63$ & 0,16 & $-0,93$ & 1 & & \\
\hline Pequenas & $-0,02$ & 0,04 & $-0,15$ & $-0,18$ & 0,45 & 0,61 & $-0,30$ & 0,59 & 0,45 & 0,54 & 0,25 & $-0,56$ & 0,34 & $-0,59$ & 0,04 & 0,43 & $-0,27$ & $-0,03$ & 0,30 & 0,52 & $-0,53$ & $-0,54$ & $-0,58$ & $-0,37$ & 0,49 & $-0,31$ & 0,32 & 0,20 & $-0,70$ & 0,27 & $-0,69$ & 0,73 & 1 & \\
\hline Medias & 0,13 & 0,07 & 0,03 & 0,26 & $-0,53$ & $-0,53$ & 0,24 & $-0,59$ & $-0,47$ & $-0,54$ & $-0,17$ & 0,60 & $-0,34$ & 0,44 & $-0,12$ & $-0,50$ & 0,22 & 0,01 & $-0,28$ & $-0,18$ & 0,46 & 0,28 & 0,39 & 0,31 & $-0,12$ & 0,00 & $-0,38$ & $-0,12$ & 0,67 & $-0,08$ & 0,30 & -44 & 35 & 1 \\
\hline Grandes & $-0,17$ & $-0,27$ & 0.25 & $-0,25$ & 0,29 & $-0,02$ & 0,06 & 0,13 & 0,09 & 0,12 & $-0,09$ & $-0,28$ & 0,09 & 0,09 & $-0,04$ & 0,18 & 0,07 & 0,11 & 0,06 & $-0,49$ & 0,10 & 0,32 & 0,34 & 0,20 & $-0,52$ & 0,59 & 0,16 & 0,02 & $-0,04$ & $-0,33$ & 0,63 & $-0,45$ & $-0,21$ & $-0,32$ \\
\hline
\end{tabular}

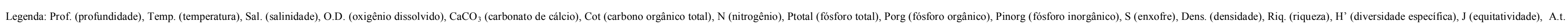

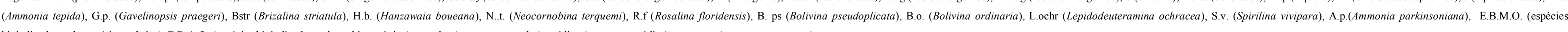
bioindicadoras de matéria orgânica), E.B.A.O. (espécies bioindicadoras de ambiente óxico), grandes (carapaças grandes), médias (carapaças médias), pequenas (carapaças pequenas). 
Anexo 53 - Matriz de correlação de Pearson obtida para os dados bióticos e abióticos obtidos no Saco da Capela, em Outubro de 2006. Níveis de significância: $p<0,01$ (em vermelho) e $p<0,05$ (em negrito)

\begin{tabular}{|c|c|c|c|c|c|c|c|c|c|c|c|c|c|c|c|c|c|c|c|c|c|c|c|c|c|c|c|c|c|c|c|c|c|}
\hline & 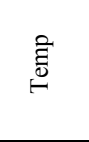 & $\overline{\mathrm{n}}$ & ठิ & $\mathscr{O}_{\tilde{U}}^{8}$ & $\bar{\delta}$ & z & 惡 & 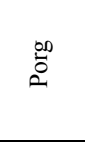 & 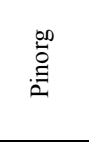 & n & 尊焉 & 兽 & $\stackrel{\pi}{2}$ & 畄 & $\stackrel{\dot{\omega}}{\bar{\Xi}}$ & $\dot{\vec{\varkappa}}$ & $I$ & - & $\dot{\vec{\Psi}}$ & نें & $\dot{\varphi}$ & $\dot{z}$ & i & $\rightleftarrows$ & $\stackrel{\leftrightarrow}{\Delta}$ & 害 & $\dot{\vec{\omega}}$ & $\frac{5}{4}$ & $\underset{\substack{\dot{\phi} \\
\dot{m}}}{\dot{m}}$ & 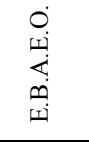 & 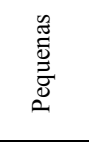 & 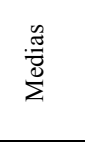 & 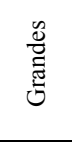 \\
\hline Temp & 1 & & & & & & & & & & & & & & & & & & & & & & & & & & & & & & & & \\
\hline $\begin{array}{l}\text { Sal } \\
\text { OD }\end{array}$ & $\mathbf{0 , 7 3}$ & 1 & & & & & & & & & & & & & & & & & & & & & & & & & & & & & & & \\
\hline OD & $\mathbf{0 , 9 0}$ & 0,79 & 1 & & & & & & & & & & & & & & & & & & & & & & & & & & & & & & \\
\hline $\mathrm{CaCO}_{3}$ & $-0,53$ & $-0,28$ & $-0,29$ & 1 & & & & & & & & & & & & & & & & & & & & & & & & & & & & & \\
\hline Cot & $-0,34$ & $-0,21$ & $-0,09$ & 0,90 & 1 & & & & & & & & & & & & & & & & & & & & & & & & & & & & \\
\hline $\mathrm{N}$ & $-0,31$ & 0,07 & $-0,39$ & 0,14 & 0,02 & 1 & & & & & & & & & & & & & & & & & & & & & & & & & & & \\
\hline Ptotal & 0,06 & 0,16 & 0,11 & 0,54 & 0,56 & 0,30 & 1 & & & & & & & & & & & & & & & & & & & & & & & & & & \\
\hline Porg & 0,17 & 0,30 & 0,04 & $-0,03$ & $-0,01$ & 0,55 & 0,64 & 1 & & & & & & & & & & & & & & & & & & & & & & & & & \\
\hline Pinorg & $-0,11$ & $-0,13$ & 0,10 & 0,70 & 0,71 & $-0,24$ & 0,53 & $-0,31$ & 1 & & & & & & & & & & & & & & & & & & & & & & & & \\
\hline S & $-0,25$ & $-0,41$ & $-0,03$ & 0,75 & 0,88 & $-0,27$ & 0,34 & $-0,24$ & 0,67 & 1 & & & & & & & & & & & & & & & & & & & & & & & \\
\hline Areia & 0,16 & 0,02 & $-0,21$ & $-0,67$ & $-0,83$ & 0,36 & $-0,27$ & 0,23 & $-0,59$ & $-0,82$ & 1 & & & & & & & & & & & & & & & & & & & & & & \\
\hline Finos & $-0,18$ & $-0,08$ & 0,14 & 0,78 & 0,85 & $-0,41$ & 0,40 & $-0,19$ & 0,71 & 0,83 & $-0,95$ & 1 & & & & & & & & & & & & & & & & & & & & & \\
\hline pH & 0,15 & 0,11 & 0,07 & $-0,76$ & $-0,83$ & $-0,34$ & $-0,71$ & $-0,25$ & $-0,60$ & $-0,70$ & 0,47 & $-0,52$ & 1 & & & & & & & & & & & & & & & & & & & & \\
\hline Eh & $-0,08$ & $-0,10$ & $-0,27$ & $-0,38$ & $-0,53$ & $-0,16$ & $-0,21$ & 0,31 & $-0,60$ & $-0,51$ & 0,39 & $-0,29$ & 0,60 & 1 & & & & & & & & & & & & & & & & & & & \\
\hline Dens. & 0,56 & 0,45 & 0,55 & 0,12 & 0,16 & 0,00 & 0,36 & 0,33 & 0,08 & 0,24 & $-0,20$ & 0,23 & $-0,43$ & $-0,16$ & 1 & & & & & & & & & & & & & & & & & & \\
\hline Riq. & 0,75 & 0,73 & 0,82 & 0,07 & 0,14 & $-0,13$ & 0,35 & 0,31 & 0,09 & 0,13 & $-0,26$ & 0,27 & $-0,26$ & $-0,20$ & 0,80 & 1 & & & & & & & & & & & & & & & & & \\
\hline $\mathrm{H}$ & 0,63 & 0,50 & 0,76 & 0,09 & 0,19 & $-0,20$ & 0,27 & 0,22 & 0,09 & 0,33 & $-0,37$ & 0,34 & $-0,26$ & $-0,24$ & 0,83 & 0,90 & 1 & & & & & & & & & & & & & & & & \\
\hline $\mathrm{J}$ & 0,20 & $-0,02$ & 0,38 & 0,06 & 0,12 & $-0,23$ & 0,00 & $-0,04$ & 0,05 & 0,43 & $-0,38$ & 0,28 & $-0,09$ & $-0,21$ & 0,51 & 0,37 & 0,74 & 1 & & & & & & & & & & & & & & & \\
\hline A.t. & 0,31 & 0,30 & 0,23 & $-0,20$ & 0,10 & 0,09 & 0,45 & 0,50 & 0,01 & $-0,13$ & 0,01 & $-0,05$ & $-0,14$ & $-0,02$ & $-0,14$ & 0,08 & $-0,12$ & $-0,40$ & 1 & & & & & & & & & & & & & & \\
\hline G.p. & $-0,19$ & 0,02 & $-0,45$ & $-0,27$ & $-0,51$ & 0,54 & $-0,29$ & 0,29 & $-0,68$ & $-0,68$ & 0,72 & $-0,68$ & 0,30 & 0,49 & $-0,19$ & $-0,21$ & $-0,41$ & $-0,55$ & $-0,14$ & 1 & & & & & & & & & & & & & \\
\hline B. str. & 0,39 & 0,31 & 0,51 & 0,31 & 0,54 & $-0,21$ & 0,58 & 0,37 & 0,31 & 0,46 & $-0,50$ & 0,53 & $-0,44$ & $-0,22$ & 0,31 & 0,65 & 0,56 & 0,15 & 0,54 & $-0,43$ & 1 & & & & & & & & & & & & \\
\hline N.t. & 0,30 & 0,06 & 0,09 & $-0,62$ & $-0,83$ & $-0,34$ & $-0,38$ & $-0,11$ & $-0,35$ & $-0,65$ & 0,65 & $-0,53$ & 0,76 & 0,63 & $-0,14$ & $-0,08$ & $-0,13$ & $-0,11$ & $-0,24$ & 0,33 & $-0,39$ & 1 & & & & & & & & & & & \\
\hline H.b. & $-0,17$ & 0,20 & $-0,09$ & 0,49 & 0,23 & 0,17 & 0,01 & $-0,29$ & 0,33 & 0,04 & $-0,12$ & 0,23 & $-0,26$ & $-0,23$ & 0,17 & 0,17 & $-0,04$ & $-0,33$ & $-0,46$ & 0,28 & $-0,19$ & $-0,08$ & 1 & & & & & & & & & & \\
\hline R.f. & 0,85 & 0,71 & 0,79 & $-0,37$ & $-0,28$ & $-0,05$ & 0,26 & 0,38 & $-0,09$ & $-0,22$ & 0,12 & $-0,14$ & $-0,01$ & $-0,05$ & 0,79 & $\mathbf{0 , 7 4}$ & 0,72 & 0,42 & 0,12 & $-0,19$ & 0,21 & 0,21 & $-0,11$ & 1 & & & & & & & & & \\
\hline B.ps. & 0,65 & 0,05 & 0,58 & $-0,32$ & 0,01 & $-0,60$ & $-0,05$ & $-0,18$ & 0,13 & 0,31 & $-0,15$ & 0,10 & $-0,05$ & $-0,26$ & 0,29 & 0,34 & 0,42 & 0,34 & 0,32 & $-0,56$ & 0,45 & 0,01 & $-0,49$ & 0,37 & 1 & & & & & & & & \\
\hline L.ochr. & $-0,18$ & 0,27 & $-0,25$ & $-0,21$ & $-0,41$ & 0,63 & $-0,24$ & 0,13 & $-0,44$ & $-0,61$ & 0,43 & $-0,50$ & 0,20 & 0,14 & 0,03 & $-0,19$ & $-0,28$ & $-0,25$ & $-0,27$ & 0,62 & $-0,70$ & 0,08 & 0,41 & 0,11 & $-0,68$ & 1 & & & & & & & \\
\hline S.v. & 0,65 & 0,80 & 0,66 & $-0,40$ & $-0,52$ & $-0,14$ & $-0,15$ & $-0,04$ & $-0,14$ & $-0,55$ & 0,24 & $-0,23$ & 0,44 & 0,09 & 0,34 & 0,54 & 0,38 & 0,04 & $-0,16$ & 0,11 & $-0,10$ & 0,53 & 0,35 & 0,66 & $-0,05$ & 0,35 & 1 & & & & & & \\
\hline A.p. & 0,48 & 0,23 & 0,23 & $-0,13$ & 0,10 & 0,24 & 0,50 & 0,55 & 0,01 & 0,01 & 0,19 & $-0,16$ & $-0,49$ & $-0,15$ & 0,46 & 0,33 & 0,17 & $-0,19$ & 0,64 & 0,02 & 0,40 & $-0,24$ & $-0,20$ & 0,44 & 0,46 & $-0,12$ & $-0,13$ & 1 & & & & & \\
\hline E.B.A.O. & $-0,34$ & $-0,06$ & $-0,40$ & $-0,15$ & $-0,51$ & 0,30 & $-0,53$ & $-0,30$ & $-0,32$ & $-0,55$ & 0,51 & $-0,48$ & 0,46 & 0,23 & $-0,30$ & $-0,36$ & $-0,41$ & $-0,26$ & $-0,65$ & 0,66 & $-0,80$ & 0,46 & 0,53 & $-0,24$ & $-0,69$ & 0,71 & 0,36 & $-0,57$ & 1 & & & & \\
\hline E.B.A.E.O. & 0,17 & $-0,04$ & 0,38 & 0,41 & 0,69 & $-0,51$ & 0,41 & 0,02 & 0,48 & 0,79 & $-0,80$ & 0,79 & $-0,44$ & $-0,25$ & 0,28 & 0,40 & 0,52 & 0,44 & 0,30 & $-0,78$ & 0,80 & $-0,47$ & $-0,31$ & 0,07 & 0,57 & $-0,81$ & $-0,33$ & 0,17 & $-0,87$ & 1 & & & \\
\hline Pequenas & 0,17 & 0,20 & $-0,13$ & $-0,69$ & $-0,90$ & 0,29 & $-0,35$ & 0,18 & $-0,62$ & $-0,94$ & 0,92 & $-0,88$ & 0,62 & 0,52 & $-0,15$ & $-0,21$ & $-0,36$ & $-0,39$ & $-0,08$ & 0,73 & $-0,62$ & 0,73 & 0,04 & 0,20 & $-0,31$ & 0,63 & 0,47 & 0,02 & 0,65 & $-0,88$ & 1 & & \\
\hline Medias & $-0,41$ & $-0,21$ & $-0,12$ & 0,49 & 0,73 & $-0,13$ & 0,19 & $-0,14$ & 0,40 & 0,62 & $-0,81$ & 0,69 & $-0,37$ & $-0,32$ & $-0,21$ & $-0,21$ & $-0,10$ & 0,08 & 0,29 & $-0,57$ & 0,30 & $-0,76$ & $-0,14$ & $-0,40$ & 0,04 & $-0,27$ & $-0,55$ & $-0,10$ & $-0,51$ & 0,61 & $-0,77$ & 1 & \\
\hline Grandes & 0,30 & 0,08 & 0,42 & 0,39 & 0,36 & $-0,27$ & 0,18 & $-0,10$ & 0,33 & 0,53 & $-0,35$ & 0,42 & $-0,34$ & $-0,34$ & 0,46 & $\mathbf{0 , 6 6}$ & 0,72 & 0,50 & $-0,30$ & $-0,30$ & 0,58 & $-0,08$ & 0,17 & 0,19 & 0,35 & $-0,57$ & 0,11 & $-0,04$ & $-0,24$ & 0,50 & $-0,48$ & $-0,16$ & \\
\hline
\end{tabular}

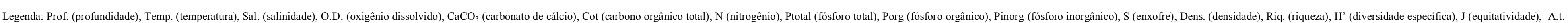

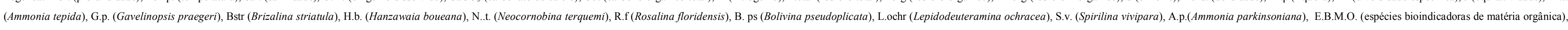
E.B.A.O. (espécies bioindicadoras de ambiente óxico), grandes (carapaças grandes), médias (carapaças médias), pequenas (carapaças pequenas) 


\section{CAPÍTULO 6 - EMISSÁRIO SUBMARINO PARA EFLUENTES PETROQUÍMICOS TERMINAL MARÍTIMO ALMIRANTE BARROSO (TEBAR)}

\subsection{RESULTADOS}

\subsubsection{Posicionamento geográfico e dados físico-químicos da coluna d’água}

O posicionamento geográfico e dados físico-químicos da coluna d'água das estações amostradas encontram-se na Tabela 12. Os dados apresentados referem-se às coletas realizadas em Agosto de 2005, Junho e Agosto de 2006.

Coletas realizadas em Agosto de 2005

Os valores de temperatura e salinidade oscilaram de 21,3 a $24,3{ }^{\circ} \mathrm{C}$ e de 34,8 a $37,7{ }^{\circ} \mathrm{C}$, respectivamente. Observou-se estratificação vertical e horizontal dos valores de temperatura. Verticalmente, ocorreu declínio entre 0,6 a $3{ }^{\circ} \mathrm{C}$ das águas de superfície em direção às águas de fundo, sendo as maiores diferenças obtidas nas estações posicionadas na parte mais externa da malha de amostragem. Horizontalmente, por sua vez, as diferenças encontradas nas águas de superfície foram de $2,3{ }^{\circ} \mathrm{C}$. Os valores de salinidade apresentaram suave estratificação vertical, com aumento de valores em direção às águas de fundo. Os valores de $\mathrm{pH}$ foram de 8,15 a 8,18 .

As concentrações de oxigênio dissolvido variaram de 6 a $7,35 \mathrm{mg} \mathrm{L}^{-1}$. Os valores obtidos encontram-se dentro do padrão estabelecido pela Resolução CONAMA 357/2005, para águas salinas, Classe 1.

Os valores de turbidez oscilaram entre 1,3 e 5,3 UNT. Pelo padrão de distribuição dos valores de turbidez, observou-se que sentido preferencial de dispersão da pluma gerada pelo efluente era de oeste para leste da malha de amostragem.

Os valores obtidos para nitrogênio amoniacal, nitrogênio Kjeldahl, ortofosfato e fósforo total estiveram abaixo do limite de detecção do método analítico. 
Os valores de temperatura variaram de 22,4 a $29,3{ }^{\circ} \mathrm{C}$ e os de salinidade de 34,1 a 35,5 ${ }^{\circ} \mathrm{C}$. Observou-se estratificação termohalina em todas as estações amostradas. As diferenças de temperatura encontradas ao longo da coluna d'água foram de 0,6 a $6,3{ }^{\circ} \mathrm{C}$. De modo geral, verificou-se que as maiores diferenças ocorreram em estações posicionadas em locais mais profundos, i.e. entre 21 e 34 metros. Em relação à salinidade, os valores aumentaram de 0,3 a 1,3 unidades em direção às águas de fundo.

Os valores de $\mathrm{pH}$ foram de 8,03 a 8,33, com suave declínio de valores em direção às águas de fundo.

As concentrações de oxigênio dissolvido oscilaram entre 5,29 e 6,56 $\mathrm{mg} \mathrm{L}^{-1}$, sendo observado em $80 \%$ das estações níveis abaixo do estabelecido pela Resolução CONAMA $357 / 2005$, para águas salinas, Classe 1, i.e. inferiores a $6 \mathrm{mg} \mathrm{L}^{-1}$.

Os valores de turbidez variaram de 0,07 a 3,90 UNT. Excetuando-se as estações Tb6 e Tb9, as maiores concentrações ocorreram nas águas de fundo, com sentido preferencial de dispersão de oeste para leste da malha de amostragem. O mesmo padrão de dispersão foi observado nas águas amostradas no meio da coluna d'água.

Os valores obtidos para nitrogênio amoniacal, nitrogênio Kjeldahl, ortofosfato e fósforo total estiveram abaixo do limite de detecção do método analítico.

Coletas realizadas em Março de 2006

Os valores de temperatura oscilaram de 22,23 a $23,44{ }^{\circ} \mathrm{C}$ e os de salinidade de 34,76 a $35,56{ }^{\circ} \mathrm{C}$. Ocorreu estratificação termohalina suave em todas as estações analisadas.

Os valores de pH foram de 8,12 a 8,15, com distribuição quase homogênea ao longo da coluna d'água.

Os níveis de oxigênio dissolvido variaram de 5,55 a 8,02 $\mathrm{mg} \mathrm{L}^{-1}$, com declínio de valores em direção às águas do fundo. As estações Tb2, Tb4, Tb8 e Tb9 apresentaram concentrações abaixo do limite de proteção à vida aquática estabelecido pela Resolução CONAMA 357/2005 para águas salinas de Classe 1. 
Os valores de turbidez oscilaram entre 0,64 e 4,0 UNT. Excetuando-se as estações Tb5 e Tb6, as maiores concentrações ocorreram nas águas de fundo. Para o período, não foi observado sentido preferencial de dispersão da pluma gerada pelo efluente.

Assim como para os demais períodos, os valores obtidos para nitrogênio amoniacal, nitrogênio Kjeldahl, ortofosfato e fósforo total estiveram abaixo do limite de detecção do método analítico. 
Tabela 12 - Posicionamentos geográficos e dados físico-químicos da coluna d'água obtidos próximo ao emissário do TEBAR.

Obs.: Em vermelho, valores abaixo dos limites estabelecidos pela Resolução CONAMA 357/2005.

\begin{tabular}{|c|c|c|c|c|c|c|c|c|c|c|c|c|c|}
\hline & 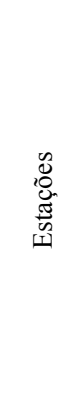 & 莺 & 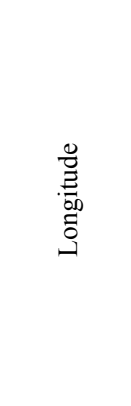 & 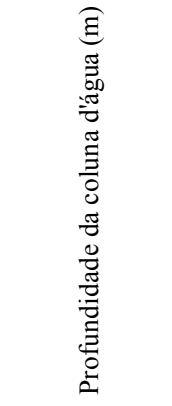 & 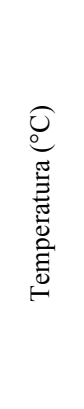 & 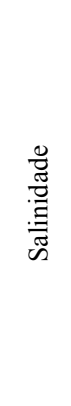 & 売 & 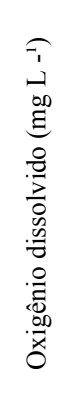 & 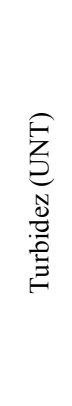 & 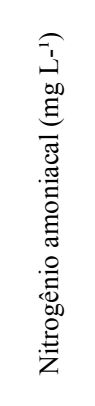 & 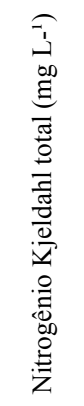 & 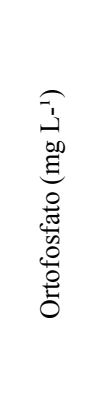 & 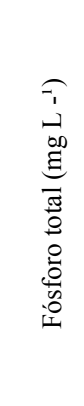 \\
\hline \multirow{31}{*}{ 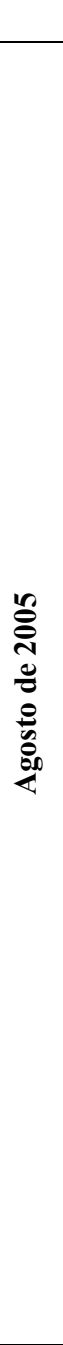 } & \multicolumn{3}{|c|}{ CONAMA 357/05 } & & & $\geq 30$ & 6,5 a 8,5 & 6 & & 0,4 & & & 0,06 \\
\hline & \multirow{3}{*}{$\mathrm{Tb} 1$} & \multirow{3}{*}{$-23,8060$} & \multirow{3}{*}{$-45,3870$} & Superfície (0) & 22,6 & 34,9 & 8,17 & 7,02 & 2,5 & $<0,01$ & $<0,1$ & $<0,01$ & $<0,01$ \\
\hline & & & & Meio (10) & 22,2 & 35,2 & 8,16 & 6,61 & 2,4 & $<0,01$ & $<0,1$ & $<0,01$ & $<0,01$ \\
\hline & & & & Fundo (19) & 21,6 & 35,5 & 8,17 & 6,55 & 2,7 & $<0,01$ & $<0,1$ & $<0,01$ & $<0,01$ \\
\hline & \multirow{3}{*}{$\mathrm{Tb} 2$} & \multirow{3}{*}{$-23,8050$} & \multirow{3}{*}{$-45,3870$} & Superfície (0) & 22,9 & 34,9 & 8,15 & 7,09 & 1,8 & $<0,01$ & $<0,1$ & $<0,01$ & $<0,01$ \\
\hline & & & & Meio (7) & 22,4 & 35,1 & 8,15 & 6,67 & 2,7 & $<0,01$ & $<0,1$ & $<0,01$ & $<0,01$ \\
\hline & & & & Fundo (14) & 21,9 & 35,3 & 8,16 & 6,65 & 2,4 & $<0,01$ & $<0,1$ & $<0,01$ & $<0,01$ \\
\hline & \multirow{3}{*}{ Tb3 } & \multirow{3}{*}{$-23,8060$} & \multirow{3}{*}{$-45,3860$} & Superfície (0) & 24,0 & 34,9 & 8,17 & 7,19 & 2,3 & $<0,01$ & $<0,1$ & $<0,01$ & $<0,01$ \\
\hline & & & & Meio (13) & 21,9 & 35,3 & 8,17 & 6,62 & 1,7 & $<0,01$ & $<0,1$ & $<0,01$ & $<0,01$ \\
\hline & & & & Fundo (25) & 21,4 & 35,7 & 8,18 & 6,34 & 4,5 & $<0,01$ & $<0,1$ & $<0,01$ & $<0,01$ \\
\hline & \multirow{3}{*}{$\mathrm{Tb} 4$} & \multirow{3}{*}{$-23,8060$} & \multirow{3}{*}{$-45,3870$} & Superfície (0) & 23,8 & 34,8 & 8,15 & 7,17 & 1,8 & $<0,01$ & $<0,1$ & $<0,01$ & $<0,01$ \\
\hline & & & & Meio (13) & 21,9 & 35,4 & 8,17 & 6,57 & 1,9 & $<0,01$ & $<0,1$ & $<0,01$ & $<0,01$ \\
\hline & & & & Fundo (26) & 21,3 & 35,6 & 8,16 & 6,52 & 2,5 & $<0,01$ & $<0,1$ & $<0,01$ & $<0,01$ \\
\hline & \multirow{3}{*}{ Tb5 } & \multirow{3}{*}{$-23,8060$} & \multirow{3}{*}{$-45,3860$} & Superfície (0) & 23,3 & 34,9 & 8,18 & 7,20 & 1,7 & $<0,01$ & $<0,1$ & $<0,01$ & $<0,01$ \\
\hline & & & & Meio (9) & 22,1 & 35,2 & 8,15 & 6,56 & 2,2 & $<0,01$ & $<0,1$ & $<0,01$ & $<0,01$ \\
\hline & & & & Fundo (17) & 21,5 & 35,5 & 8,16 & 6,56 & 2,9 & $<0,01$ & $<0,1$ & $<0,01$ & $<0,01$ \\
\hline & \multirow{3}{*}{ Tb6 } & \multirow{3}{*}{$-23,8050$} & \multirow{3}{*}{$-45,3860$} & Superficie (0) & 23 & 34,9 & 8,17 & 7,21 & 1,70 & $<0,01$ & $<0,1$ & $<0,01$ & $<0,01$ \\
\hline & & & & Meio (5) & 22,6 & 35,0 & 8,16 & 6,87 & 2,00 & $<0,01$ & $<0,1$ & $<0,01$ & $<0,01$ \\
\hline & & & & Fundo (10) & 22,4 & 35,1 & 8,15 & 6,6 & 3,10 & $<0,01$ & $<0,1$ & $<0,01$ & $<0,01$ \\
\hline & \multirow{3}{*}{$\mathrm{Tb} 7$} & \multirow{3}{*}{$-23,8040$} & \multirow{3}{*}{$-45,3870$} & Superfície (0) & 22,8 & 34,9 & 8,16 & 7,08 & 1,6 & $<0,01$ & $<0,1$ & $<0,01$ & $<0,01$ \\
\hline & & & & Meio (7) & 22,5 & 35,1 & 8,15 & 6,80 & 2,10 & $<0,01$ & $<0,1$ & $<0,01$ & $<0,01$ \\
\hline & & & & Fundo (13) & 22,19 & 35,3 & 8,15 & 6,53 & 3,5 & $<0,01$ & $<0,1$ & $<0,01$ & $<0,01$ \\
\hline & \multirow{3}{*}{ Tb8 } & \multirow{3}{*}{$-23,8060$} & \multirow{3}{*}{$-45,3850$} & Superfície (0) & 24,3 & 34,9 & 8,17 & 7,24 & 3,3 & $<0,01$ & $<0,1$ & $<0,01$ & $<0,01$ \\
\hline & & & & Meio (16) & 21,5 & 35,6 & 8,17 & 6,42 & 2,80 & $<0,01$ & $<0,1$ & $<0,01$ & $<0,01$ \\
\hline & & & & Fundo (31) & 21,4 & 35,7 & 8,17 & 6,42 & 5,3 & $<0,01$ & $<0,1$ & $<0,01$ & $<0,01$ \\
\hline & & & & Superfície (0) & 23,6 & 34,9 & 8,16 & 7,35 & 1,4 & $<0,01$ & $<0,1$ & $<0,01$ & $<0,01$ \\
\hline & Tb9 & $-23,8070$ & $-45,3860$ & Meio (15) & 21,6 & 35,5 & 8,17 & 6,58 & 1,3 & $<0,01$ & $<0,1$ & $<0,01$ & $<0,01$ \\
\hline & & & & Fundo (30) & 21,3 & 35,7 & 8,18 & 6,45 & 2,4 & $<0,01$ & $<0,1$ & $<0,01$ & $<0,01$ \\
\hline & & & & Superfície (0) & 23,7 & 34,9 & 8,15 & 7,17 & 1,7 & $<0,01$ & $<0,1$ & $<0,01$ & $<0,01$ \\
\hline & $\mathrm{Tb} 10$ & $-23,8070$ & $-45,3860$ & Meio (10) & 22,1 & 35,2 & 8,16 & 6,69 & 1,7 & $<0,01$ & $<0,1$ & $<0,01$ & $<0,01$ \\
\hline & & & & Fundo (19) & 21,4 & 35,5 & 8,16 & 6,56 & 2,8 & $<0,01$ & $<0,1$ & $<0,01$ & $<0,01$ \\
\hline
\end{tabular}


Tabela 12 - Continuação

\begin{tabular}{|c|c|c|c|c|c|c|c|c|c|c|c|c|c|}
\hline & 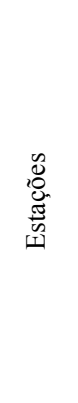 & 莺 & 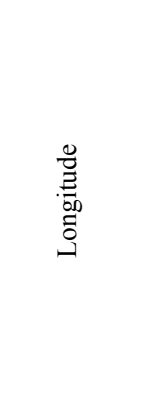 & 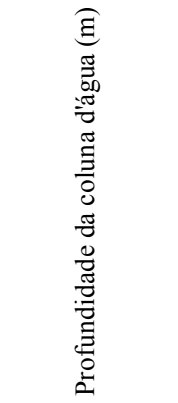 & 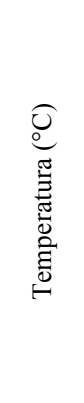 & 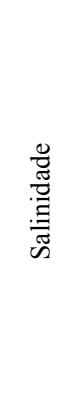 & 茎 & 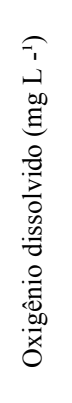 & 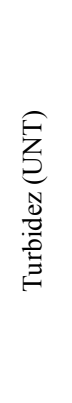 & 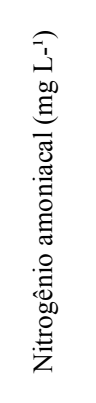 & 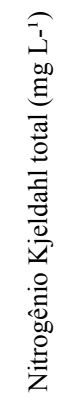 & 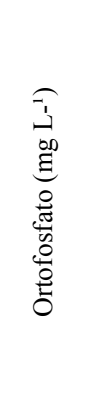 & 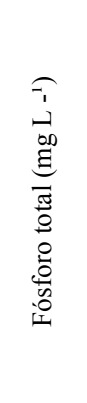 \\
\hline \multirow{31}{*}{ 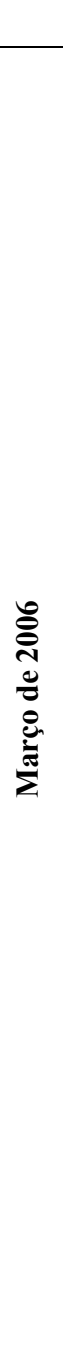 } & \multicolumn{3}{|c|}{ CONAMA 357/05 } & & & $\geq 30$ & 6,5 a 8,5 & 6 & & 0,4 & & & 0,06 \\
\hline & \multirow{3}{*}{ Tb1 } & \multirow{3}{*}{$-23,80557$} & \multirow{3}{*}{$-45,38719$} & Superfície (0) & 29,00 & 34,10 & 8,09 & 6,52 & 0,07 & $<0,01$ & $<0,1$ & $<0,01$ & $<0,01$ \\
\hline & & & & Meio (10) & 25,40 & 35,00 & 8,05 & 5,82 & 0,88 & $<0,01$ & $<0,1$ & $<0,01$ & $<0,01$ \\
\hline & & & & Fundo (21) & 22,70 & 35,50 & 8,03 & 5,47 & 1,60 & $<0,01$ & $<0,1$ & $<0,01$ & $<0,01$ \\
\hline & \multirow{3}{*}{$\mathrm{Tb} 2$} & \multirow{3}{*}{$-23,8044$} & \multirow{3}{*}{$-45,38645$} & Superfície (0) & 29,30 & 34,10 & 8,10 & 6,56 & 0,90 & $<0,01$ & $<0,1$ & $<0,01$ & $<0,01$ \\
\hline & & & & Meio (7) & 28,20 & 34,20 & 8,09 & 6,36 & 0,59 & $<0,01$ & $<0,1$ & $<0,01$ & $<0,01$ \\
\hline & & & & Fundo (17) & 24,00 & 35,20 & 8,03 & 5,51 & 1,60 & $<0,01$ & $<0,1$ & $<0,01$ & $<0,01$ \\
\hline & \multirow{3}{*}{$\mathrm{Tb} 3$} & \multirow{3}{*}{$-23,80556$} & \multirow{3}{*}{$-45,38558$} & Superficie (0) & 28,30 & 34,20 & 8,15 & 6,19 & 0,83 & $<0,01$ & $<0,1$ & $<0,01$ & $<0,01$ \\
\hline & & & & Meio (13) & 23,80 & 35,20 & 8,09 & 5,40 & 1,60 & $<0,01$ & $<0,1$ & $<0,01$ & $<0,01$ \\
\hline & & & & Fundo (24) & 22,80 & 35,50 & 8,08 & 5,29 & 2,00 & $<0,01$ & $<0,1$ & $<0,01$ & $<0,01$ \\
\hline & \multirow{3}{*}{$\mathrm{Tb} 4$} & \multirow{3}{*}{$-23,80639$} & \multirow{3}{*}{$-45,38683$} & Superficie (0) & 28,40 & 34,20 & 8,14 & 6,34 & 1,10 & $<0,01$ & $<0,1$ & $<0,01$ & $<0,01$ \\
\hline & & & & Meio (13) & 24,00 & 35,20 & 8,09 & 5,42 & 1,60 & $<0,01$ & $<0,1$ & $<0,01$ & $<0,01$ \\
\hline & & & & Fundo (26) & 22,90 & 35,50 & 8,08 & 5,39 & 3,90 & $<0,01$ & $<0,1$ & $<0,01$ & $<0,01$ \\
\hline & \multirow{3}{*}{$\mathrm{Tb} 5$} & \multirow{3}{*}{$-23,80589$} & \multirow{3}{*}{$-45,38862$} & Superficie (0) & 29,00 & 34,10 & 8,10 & 6,46 & 0,62 & $<0,01$ & $<0,1$ & $<0,01$ & $<0,01$ \\
\hline & & & & Meio (10) & 27,80 & 34,40 & 8,09 & 6,25 & 0,86 & $<0,01$ & $<0,1$ & $<0,01$ & $<0,01$ \\
\hline & & & & Fundo (16) & 27,30 & 34,50 & 8,09 & 6,19 & 1,20 & $<0,01$ & $<0,1$ & $<0,01$ & $<0,01$ \\
\hline & \multirow{3}{*}{ Tb6 } & \multirow{3}{*}{$-23,80467$} & \multirow{3}{*}{$-45,38855$} & Superficie (0) & 29,00 & 34,10 & 8,08 & 6,47 & 0,88 & $<0,01$ & $<0,1$ & $<0,01$ & $<0,01$ \\
\hline & & & & Meio (5) & 28,90 & 34,10 & 8,10 & 6,40 & 0,49 & $<0,01$ & $<0,1$ & $<0,01$ & $<0,01$ \\
\hline & & & & Fundo (10) & 28,40 & 34,20 & 8,09 & 6,31 & 0,47 & $<0,01$ & $<0,1$ & $<0,01$ & $<0,01$ \\
\hline & \multirow{3}{*}{$\mathrm{Tb} 7$} & \multirow{3}{*}{$-23,80314$} & \multirow{3}{*}{$-45,3866$} & Superficie (0) & 28,80 & 34,10 & 8,16 & 6,36 & 0,46 & $<0,01$ & $<0,1$ & $<0,01$ & $<0,01$ \\
\hline & & & & Meio (7) & 27,50 & 34,50 & 8,15 & 6,21 & 0,98 & $<0,01$ & $<0,1$ & $<0,01$ & $<0,01$ \\
\hline & & & & Fundo (13) & 24,90 & 34,90 & 8,11 & 5,75 & 1,50 & $<0,01$ & $<0,1$ & $<0,01$ & $<0,01$ \\
\hline & \multirow{3}{*}{$\mathrm{Tb} 8$} & \multirow{3}{*}{$-23,80548$} & \multirow{3}{*}{$-45,3848$} & Superfície (0) & 28,40 & 34,20 & 8,15 & 6,27 & 0,67 & $<0,01$ & $<0,1$ & $<0,01$ & $<0,01$ \\
\hline & & & & Meio (17) & 23,50 & 35,30 & 8,08 & 5,36 & 1,20 & $<0,01$ & $<0,1$ & $<0,01$ & $<0,01$ \\
\hline & & & & Fundo (34) & 22,40 & 35,50 & 8,08 & 5,41 & 2,30 & $<0,01$ & $<0,1$ & $<0,01$ & $<0,01$ \\
\hline & & & & Superfície (0) & 28,60 & 34,20 & 8,08 & 6,24 & 0,58 & $<0,01$ & $<0,1$ & $<0,01$ & $<0,01$ \\
\hline & $\mathrm{Tb} 9$ & $-23,8068$ & $-45,38637$ & Meio (12) & 24,30 & 35,10 & 8,03 & 5,42 & 1,50 & $<0,01$ & $<0,1$ & $<0,01$ & $<0,01$ \\
\hline & & & & Fundo (24) & 22,60 & 35,50 & 8,03 & 5,50 & 1,40 & $<0,01$ & $<0,1$ & $<0,01$ & $<0,01$ \\
\hline & & & & Superfície (0) & 29,20 & 34,10 & 8,30 & 6,41 & 0,58 & $<0,01$ & $<0,1$ & $<0,01$ & $<0,01$ \\
\hline & Tb10 & $-23,80647$ & $-45,38886$ & Meio (8) & 28,20 & 34,20 & 8,33 & 6,31 & 0,98 & $<0,01$ & $<0,1$ & $<0,01$ & $<0,01$ \\
\hline & & & & Fundo (17) & 24,00 & 35,20 & 8,28 & 5,52 & 1,30 & $<0,01$ & $<0,1$ & $<0,01$ & $<0,01$ \\
\hline
\end{tabular}


Tabela 12 - Continuação

\begin{tabular}{|c|c|c|c|c|c|c|c|c|c|c|c|c|c|}
\hline & 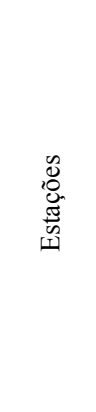 & 莺 & 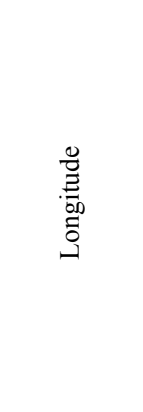 & 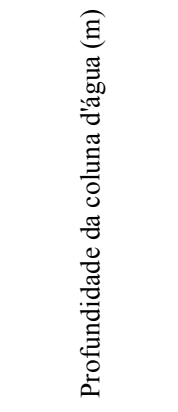 & 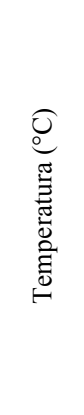 & 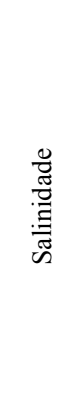 & 兑 & 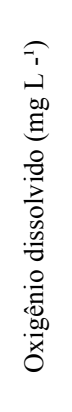 & 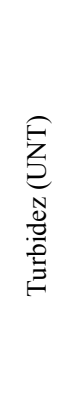 & 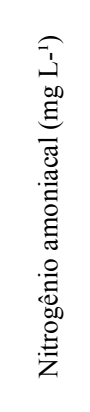 & 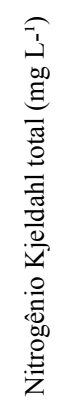 & 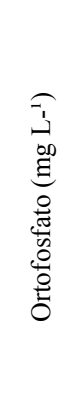 & 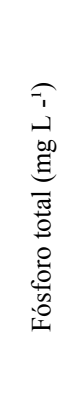 \\
\hline \multirow{31}{*}{ 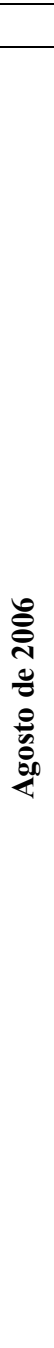 } & \multicolumn{3}{|c|}{ Resolução CONAMA 357/05 } & & & $\geq 30$ & 6,5 a 8,5 & 6,00 & & 0,40 & & & 0,06 \\
\hline & \multirow{3}{*}{ Tb1 } & \multirow{3}{*}{$-23,80557$} & \multirow{3}{*}{$-45,38719$} & Superfície (0) & 22,98 & 34,85 & 8,13 & 7,25 & 0,98 & $<0,01$ & $<0,1$ & $<0,01$ & $<0,01$ \\
\hline & & & & Meio (11) & 22,72 & 35,09 & 8,14 & 6,98 & 1,10 & $<0,01$ & $<0,1$ & $<0,01$ & $<0,01$ \\
\hline & & & & Fundo (22) & 22,38 & 35,37 & 8,13 & 6,21 & 3,70 & $<0,01$ & $<0,1$ & $<0,01$ & $<0,01$ \\
\hline & \multirow{3}{*}{$\mathrm{Tb} 2$} & \multirow{3}{*}{$-23,8044$} & \multirow{3}{*}{$-45,38645$} & Superfície (0) & 22,88 & 35,01 & 8,14 & 6,64 & 1,10 & $<0,01$ & $<0,1$ & $<0,01$ & $<0,01$ \\
\hline & & & & Meio (7) & 22,75 & 35,11 & 8,14 & 6,14 & 1,00 & $<0,01$ & $<0,1$ & $<0,01$ & $<0,01$ \\
\hline & & & & Fundo (14) & 22,73 & 35,13 & 8,14 & 5,99 & 2,50 & $<0,01$ & $<0,1$ & $<0,01$ & $<0,01$ \\
\hline & \multirow{3}{*}{ Tb3 } & \multirow{3}{*}{$-23,80556$} & \multirow{6}{*}{$-45,38683$} & Superfície (0) & 23,11 & 34,83 & 8,15 & 7,44 & 0,68 & $<0,01$ & $<0,1$ & $<0,01$ & $<0,01$ \\
\hline & & & & Meio (11) & 22,73 & 35,04 & 8,14 & 6,99 & 1,00 & $<0,01$ & $<0,1$ & $<0,01$ & $<0,01$ \\
\hline & & & & Fundo (22) & 22,61 & 35,20 & 8,14 & 6,38 & 2,00 & $<0,01$ & $<0,1$ & $<0,01$ & $<0,01$ \\
\hline & \multirow{3}{*}{$\mathrm{Tb} 4$} & \multirow{3}{*}{$-23,80639$} & & Superfície (0) & 22,99 & 34,97 & 8,15 & 7,25 & 1,30 & $<0,01$ & $<0,1$ & $<0,01$ & $<0,01$ \\
\hline & & & & Meio (13) & 22,58 & 35,22 & 8,14 & 6,44 & 1,40 & $<0,01$ & $<0,1$ & $<0,01$ & $<0,01$ \\
\hline & & & & Fundo (24) & 22,57 & 35,28 & 8,13 & 5,90 & 2,90 & $<0,01$ & $<0,1$ & $<0,01$ & $<0,01$ \\
\hline & \multirow{3}{*}{ Tb5 } & \multirow{3}{*}{$-23,80589$} & \multirow{3}{*}{$-45,38862$} & Superfície (0) & 23,09 & 34,87 & 8,14 & 8,02 & 1,00 & $<0,01$ & $<0,1$ & $<0,01$ & $<0,01$ \\
\hline & & & & Meio (8) & 23,05 & 34,88 & 8,14 & 7,46 & 1,50 & $<0,01$ & $<0,1$ & $<0,01$ & $<0,01$ \\
\hline & & & & Fundo (16) & 22,93 & 34,98 & 8,14 & 6,88 & 1,00 & $<0,01$ & $<0,1$ & $<0,01$ & $<0,01$ \\
\hline & \multirow{3}{*}{ Tb6 } & \multirow{3}{*}{$-23,80467$} & \multirow{3}{*}{$-45,38855$} & Superfície (0) & 23,34 & 34,78 & 8,14 & 7,71 & 0,69 & $<0,01$ & $<0,1$ & $<0,01$ & $<0,01$ \\
\hline & & & & Meio (5) & 23,05 & 34,90 & 8,14 & 7,34 & 1,70 & $<0,01$ & $<0,1$ & $<0,01$ & $<0,01$ \\
\hline & & & & Fundo (10) & 22,79 & 35,08 & 8,13 & 6,99 & 1,20 & $<0,01$ & $<0,1$ & $<0,01$ & $<0,01$ \\
\hline & \multirow{3}{*}{$\mathrm{Tb} 7$} & \multirow{3}{*}{$-23,80314$} & \multirow{3}{*}{$-45,3866$} & Superfície (0) & 23,31 & 34,85 & 8,15 & 7,63 & 0,66 & $<0,01$ & $<0,1$ & $<0,01$ & $<0,01$ \\
\hline & & & & Meio (6) & 22,84 & 35,04 & 8,13 & 7,24 & 1,60 & $<0,01$ & $<0,1$ & $<0,01$ & $<0,01$ \\
\hline & & & & Fundo (12) & 22,64 & 35,21 & 8,13 & 6,92 & 2,40 & $<0,01$ & $<0,1$ & $<0,01$ & $<0,01$ \\
\hline & \multirow{3}{*}{$\mathrm{Tb} 8$} & \multirow{3}{*}{$-23,80548$} & \multirow{3}{*}{$-45,3848$} & Superfície (0) & 23,04 & 34,87 & 8,15 & 7,34 & 1,00 & $<0,01$ & $<0,1$ & $<0,01$ & $<0,01$ \\
\hline & & & & Meio (17) & 22,74 & 35,06 & 8,14 & 6,65 & 1,60 & $<0,01$ & $<0,1$ & $<0,01$ & $<0,01$ \\
\hline & & & & Fundo (33) & 22,24 & 35,53 & 8,13 & 5,78 & 3,20 & $<0,01$ & $<0,1$ & $<0,01$ & $<0,01$ \\
\hline & \multirow{3}{*}{$\mathrm{Tb} 9$} & & & Superfície (0) & 23,22 & 34,80 & 8,15 & 7,58 & 0,64 & $<0,01$ & $<0,1$ & $<0,01$ & $<0,01$ \\
\hline & & $-23,8068$ & $-45,38637$ & Meio (12) & 22,80 & 35,07 & 8,14 & 6,96 & 1,60 & $<0,01$ & $<0,1$ & $<0,01$ & $<0,01$ \\
\hline & & & & Fundo (30) & 22,23 & 35,56 & 8,12 & 5,55 & 4,00 & $<0,01$ & $<0,1$ & $<0,01$ & $<0,01$ \\
\hline & & & & Superfície (0) & 23,44 & 34,76 & 8,15 & 7,69 & 0,71 & $<0,01$ & $<0,1$ & $<0,01$ & $<0,01$ \\
\hline & $\mathrm{Tb} 10$ & $-23,80647$ & $-45,38886$ & Meio (9) & 22,85 & 34,97 & 8,14 & 6,76 & 1,10 & $<0,01$ & $<0,1$ & $<0,01$ & $<0,01$ \\
\hline & & & & Fundo (18) & 22,75 & 35,10 & 8,13 & 6,03 & 2,00 & $<0,01$ & $<0,1$ & $<0,01$ & $<0,01$ \\
\hline
\end{tabular}




\subsubsection{Análises granulométricas}

Os resultados das análises granulométricas estão mencionados na Tabela 13 e ilustrados no Anexo 54.

\section{Coletas realizadas em Agosto de 2005}

Os sedimentos amostrados próximo aos difusores do TEBAR são predominantemente pelíticos, com concentrações de finos, variando entre 67,75 e $87,63 \%(\bar{x}=81,46 \pm 6,77 \%)$.

As porcentagens de sedimentos arenosos oscilaram de 0,74 a $27,54 \%(\bar{x}=16,72 \pm$ 7,90\%). As maiores porcentagens foram observadas nas estações Tb4 e Tb8, localizadas nas regiões sul e leste da malha de amostragem. A estação Tb5, localizada na região oeste, apresentou a menor concentração (Anexo 54)

Grânulos ocorreram somente nas estações Tb1 (0,14\%), Tb4 (5,01\%) e Tb5 (13,10\%). Segundo a classificação proposta por Shepard (1954), foram obtidos i) silte argiloso estações Tb1, Tb2, Tb7 e Tb10; ii) silte - estações Tb3 e Tb5; iii) silte argilo-arenoso estação Tb8 e iv) silte arenoso - estações Tb4, Tb6 e Tb9.

No tocante ao grau de seleção, foram observados sedimentos muito pobremente selecionados nas estações Tb4, Tb5 e Tb8 (2,21 a 3,93 $\delta)$ e pobremente selecionados nas demais estações $(1,45$ a $1,97 \delta)$.

\section{Coletas realizadas em Março de 2006}

Verificou-se predominância de sedimentos finos, cujas concentrações foram de 47,97 a 99,70\% ( $\bar{x}=75,85 \pm 16,09 \%)$. A estação Tb1 apresentou a menor concentração, ocorrendo o contrário nas estações Tb5 e Tb10, localizadas na região sudoeste da malha de amostragem (Anexo 54)

Os teores de sedimentos arenosos oscilaram entre 0,30 e $51,91 \%(\bar{x}=24,0 \pm 16,05 \%)$, sendo observado nas estações $\mathrm{Tb} 1 \mathrm{e} \mathrm{Tb} 4$ as maiores porcentagens.

Grânulos ocorreram somente nas estações Tb1, Tb6, Tb7 e Tb8, em teores que foram de 0,12 a $0,78 \%$. 
De acordo com a classificação proposta por Shepard (1954), os sedimentos são denominados i) areia síltica - estações Tb1 e Tb4; ii) silte arenoso - estações Tb3, Tb6 a Tb9 e iii) silte - estações Tb2, Tb5 e Tb10.

Em relação ao grau de seleção, os sedimentos foram classificados como muito pobremente selecionados nas estações $\mathrm{Tb} 1, \mathrm{~Tb} 4, \mathrm{~Tb} 7$ e $\mathrm{Tb} 8(2,22$ a 3,55 $\delta)$ e pobremente selecionados nas estações Tb2, Tb3, Tb5, Tb6, Tb9 e Tb10 (1,21 a 1,63 $\delta)$.

Coletas realizadas em Março de 2006

Assim como o verificado nos demais períodos, sedimentos pelíticos são predominantes, em porcentagens que oscilaram entre 65,04 e $94,18 \%(\bar{x}=75,52 \pm 9,54 \%)$ (Anexo 54).

As porcentagens de sedimentos arenosos variaram de 5,82 a $34,85 \%(\bar{x}=24,22 \pm$ 9,46\%). As estações Tb5 e Tb7 apresentaram as maiores concentrações, sendo observado o contrário na estação Tb6 (Anexo 54).

Grânulos ocorreram em quase todas as estações, porém em porcentagens pouco expressivas, os valores obtidos foram de 0 a $1,91 \%$.

Segundo classificação proposta por Shepard (1954), os sedimentos amostrados são denominados i) silte argiloso - estações Tb2, Tb3, Tb4 e Tb10; ii) silte - estação Tb6; iii) silte argilo-arenoso - estação Tb1 e iv) silte arenoso - estações Tb5, Tb7, Tb8 e Tb9.

No tocante ao grau de seleção, excetuando-se a estação Tb6, os sedimentos são classificados como muito pobremente selecionados (2,05 a 2,58 $\delta)$. Os sedimentos da estação Tb6 são classificados como pobremente selecionados $(1,62 \delta)$. 
Tabela 13 - Resultados granulométricos obtidos em região circunjacente aos difusores do emissário submarino do TEBAR.

Legenda: D. médio = diâmetro médio; D. padrão = desvio padrão; Mto. = muito.

\begin{tabular}{|c|c|c|c|c|c|c|c|c|c|c|c|}
\hline & & & & & & & & & & \\
\hline & & & & & \multicolumn{5}{|c|}{ Areia (\%) } & \multicolumn{2}{|c|}{ Pelíticos (\%) } \\
\hline \multirow{11}{*}{ 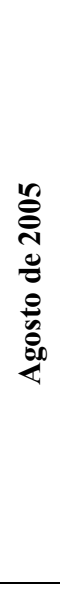 } & Estações & D. Médio $(\Phi)$ & D. Padrão $(\delta)$ & Grânulos (\%) & Mto. Grossa & Grossa & Média & Fina & Mto. Fina & Silte & Argila \\
\hline & $\mathrm{Tb} 1$ & 6,36 & 1,97 & 0,14 & 0,33 & 0,39 & 0,41 & 0,61 & 15,56 & 64,75 & 17,81 \\
\hline & $\mathrm{Tb} 2$ & 6,53 & 1,89 & 0,00 & 0,00 & 0,00 & 0,22 & 0,85 & 11,39 & 62,48 & 25,06 \\
\hline & $\mathrm{Tb} 3$ & 4,89 & 1,45 & 0,00 & 0,07 & 0,07 & 0,30 & 0,77 & 15,41 & 76,10 & 7,28 \\
\hline & $\mathrm{Tb} 4$ & 4,19 & 2,21 & 5,01 & 6,07 & 2,61 & 2,84 & 2,11 & 13,61 & 66,57 & 1,18 \\
\hline & Tb5 & 5,66 & 3,93 & 13,10 & 0,00 & 0,00 & 0,00 & 0,08 & 0,66 & 66,62 & 19,58 \\
\hline & Tb6 & 6,30 & 1,94 & 0,00 & 0,03 & 0,15 & 0,48 & 1,07 & 19,79 & 58,06 & 20,42 \\
\hline & $\mathrm{Tb} 7$ & 6,11 & 1,73 & 0,00 & 0,00 & 0,02 & 0,07 & 0,43 & 11,85 & 72,04 & 15,59 \\
\hline & $\mathrm{Tb} 8$ & 6,03 & 2,22 & 0,00 & 0,02 & 0,07 & 0,40 & 1,58 & 25,47 & 44,01 & 28,45 \\
\hline & $\mathrm{Tb} 9$ & 5,16 & 1,78 & 0,00 & 1,76 & 0,50 & 3,46 & 2,60 & 10,23 & 73,06 & 8,39 \\
\hline & Tb10 & 6,05 & 1,72 & 0,00 & 0,00 & 0,00 & 0,03 & 0,51 & 12,32 & 72,02 & 15,12 \\
\hline \multirow{10}{*}{ 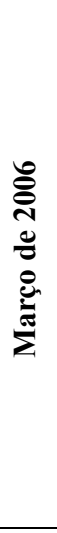 } & $\mathrm{Tb} 1$ & 4,10 & 2,86 & 0,12 & 6,41 & 13,36 & 7,10 & 5,05 & 19,98 & 35,74 & 12,23 \\
\hline & $\mathrm{Tb} 2$ & 5,44 & 1,37 & 0,00 & 0,04 & 0,10 & 0,17 & 0,66 & 15,06 & 78,92 & 5,04 \\
\hline & $\mathrm{Tb} 3$ & 5,54 & 1,62 & 0,00 & 0,09 & 0,12 & 0,24 & 1,09 & 18,51 & 72,81 & 7,14 \\
\hline & $\mathrm{Tb} 4$ & 4,53 & 3,55 & 0,00 & 11,84 & 14,61 & 8,73 & 3,67 & 7,46 & 27,63 & 26,07 \\
\hline & Tb5 & 6,21 & 1,21 & 0,00 & 0,00 & 0,03 & 0,14 & 0,07 & 0,06 & 89,84 & 9,86 \\
\hline & Tb6 & 5,17 & 1,58 & 0,19 & 0,16 & 0,51 & 0,47 & 1,24 & 26,05 & 67,63 & 3,75 \\
\hline & $\mathrm{Tb} 7$ & 5,56 & 2,22 & 0,45 & 0,24 & 1,04 & 1,35 & 2,43 & 25,95 & 50,64 & 17,90 \\
\hline & Tb8 & 6,02 & 2,26 & 0,78 & 0,94 & 1,22 & 2,13 & 2,66 & 12,94 & 59,35 & 19,98 \\
\hline & Tb9 & 5,62 & 1,63 & 0,00 & 0,05 & 0,08 & 0,15 & 0,86 & 18,02 & 72,02 & 8,83 \\
\hline & Tb10 & 6,13 & 1,63 & 0,00 & 0,00 & 0,02 & 0,03 & 0,15 & 6,68 & 76,84 & 16,28 \\
\hline \multirow{10}{*}{ 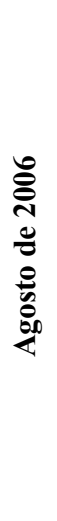 } & $\mathrm{Tb} 1$ & 5,75 & 2,58 & 1,91 & 1,40 & 1,43 & 2,11 & 2,53 & 19,39 & 45,68 & 25,55 \\
\hline & $\mathrm{Tb} 2$ & 6,31 & 2,05 & 0,05 & 0,00 & 0,07 & 0,24 & 4,57 & 7,93 & 60,59 & 26,55 \\
\hline & $\mathrm{Tb} 3$ & 5,93 & 2,12 & 0,04 & 0,44 & 0,59 & 0,26 & 1,48 & 17,77 & 56,14 & 23,27 \\
\hline & Tb4 & 5,85 & 2,57 & 0,37 & 2,48 & 5,03 & 1,48 & 1,33 & 11,88 & 53,38 & 24,06 \\
\hline & Tb5 & 5,72 & 2,24 & 0,07 & 0,08 & 0,28 & 0,31 & 3,33 & 30,82 & 42,42 & 22,70 \\
\hline & Tb6 & 6,21 & 1,62 & 0,00 & 0,01 & 0,08 & 1,06 & 3,49 & 1,17 & 82,82 & 11,36 \\
\hline & $\mathrm{Tb} 7$ & 5,57 & 2,22 & 0,10 & 0,08 & 0,23 & 1,30 & 4,69 & 28,56 & 44,59 & 20,46 \\
\hline & $\mathrm{Tb} 8$ & 5,84 & 2,30 & 0,02 & 0,14 & 0,25 & 2,02 & 4,71 & 23,19 & 44,41 & 25,26 \\
\hline & $\mathrm{Tb} 9$ & 5,76 & 2,21 & 0,00 & 0,07 & 0,23 & 0,77 & 5,86 & 24,22 & 45,81 & 23,04 \\
\hline & Tb10 & 6,12 & 2,06 & 0,00 & 0,06 & 0,08 & 0,29 & 1,31 & 21,14 & 52,36 & 24,76 \\
\hline
\end{tabular}


6.1.3 Análises geoquímicas e razões elementares

Os resultados das análises geoquímicas e razões elementares estão descritos na Tabela 14 e ilustrados nos Anexos 55 a 62.

Coletas realizadas em Agosto de 2005

Os valores de $\mathrm{pH}$ e Eh variaram de 6,48 a 7,37 e de -171 a $-81 \mathrm{mV}$, respectivamente. Sedimentos com sinais de acidez (i.e. valores inferiores a 7) foram observados nas estações Tb1, Tb3, Tb5, Tb6, Tb7 e Tb10.

As porcentagens de carbonato de cálcio oscilaram entre 17,82 a $27,77 \%(\bar{x}=22,77 \pm$ $3,24 \%$ ) (Anexo 55)

Os teores de carbono orgânico total variaram de 1,72 a $2,37 \%(\bar{x}=2,06 \pm 0,19 \%)$. As estações Tb5 e T10 apresentaram os maiores teores, sendo o contrário observado na estação Tb9 (Anexo 56).

As concentrações de nitrogênio foram de 0,19 a $0,29 \%(\bar{x}=0,24 \pm 0,04 \%$ ) (Anexo $57)$.

Em relação ao fracionamento do fósforo, foram obtidos os seguintes valores: fósforo total 0,122 a $0,178 \%$; fósforo orgânico 0,043 a $0,73 \%$ e fósforo inorgânico 0,065 a 0,110 (Anexos 58, 59 e 60).

Os teores de enxofre oscilaram de 0,36 a $0,60 \%(\bar{x}=0,49 \pm 0,08 \%)$. As maiores porcentagens ocorreram nas estações $\mathrm{Tb} 7(0,60 \%), \mathrm{Tb} 9(0,06 \%)$ e $\mathrm{Tb} 10$ (0,55\%) (Anexo 61).

Os resultados das razões $\mathrm{C} / \mathrm{N}$ e $\mathrm{C} / \mathrm{S}$ variaram de 9,15 a 55,99 e de 2,89 a 6,66 (Anexos 62 e 63$)$.

Coletas realizadas em Março de 2006

Os valores de $\mathrm{pH}$ oscilaram de 6,93 a 7,51. Sedimentos com sinais de acidez foram observados somente na estação Tb6. Os valores de Eh, por sua vez, foram de -233 a $-137 \mathrm{mV}$.

As concentrações de carbonato de cálcio variaram de 16,53 a $25,86 \%(\bar{x}=20,94 \pm$ $3,04 \%$ ) (Anexo 55). 
Os teores de carbono orgânico total oscilaram entre 1,29 e $2,35 \%(\bar{x}=1,92 \pm 0,31 \%)$. A menor e maior porcentagem foi observada na estação Tb4 e estação $\mathrm{Tb} 5$, respectivamente (Anexo 56).

Foram obtidos valores de nitrogênio entre 0,10 e $0,33 \%(\bar{x}=0,23 \pm 0,07 \%)$. As maiores porcentagens foram observadas nas estações Tb1 e Tb2, localizadas na saída do emissário submarino (Anexo 57).

Para o fósforo foram obtidos os seguintes valores: fósforo total 0,060 a $0,281 \%$; fósforo orgânico de 0,026 a 0,239\% e fósforo inorgânico de 0,033 a 0,056\% (Anexos 58, 59 e $60)$.

Os teores de enxofre variaram de 0,38 a $0,53 \%\left(\bar{x}=0,44{ }^{ \pm} 0,05 \%\right)$ (Anexo 61$)$.

Valores das razões $\mathrm{C} / \mathrm{N}$ oscilaram de 6,15 a 14,33. Já os valores das razões $\mathrm{C} / \mathrm{S}$ foram de 2,89 a 5,03 (Anexo 62 e 63).

\section{Coletas realizadas em Agosto de 2006}

Os valores de $\mathrm{pH}$ e Eh variaram de 7,13 a 8,40 e de -158 a $-96 \mathrm{mV}$, respectivamente. O maior valor de $\mathrm{pH}$ foi verificado na estação Tb5.

As porcentagens de carbonato de cálcio variaram de 15,51 a $23,375(\bar{x}=19,94 \pm$ 2,33\%). As maiores concentrações ocorreram nas estações Tb1, Tb5 e Tb10 (Anexo 55).

Os teores de carbono orgânico total oscilaram de 1,33 a $2,75 \%(\bar{x}=2,09 \pm 0,36 \%)$, ocorrendo nas estações Tb5 e Tb9 as maiores porcentagens, e o inverso na estação Tb4 (Anexo 56).

As concentrações de nitrogênio variaram entre 0,01 e $0,25 \%(\bar{x}=0,10 \pm 0,07 \%)$. Comparativamente, os valores obtidos em Agosto de 2006 são, em média, 2 vezes inferiores aos teores observados para os períodos anteriores. As maiores concentrações ocorreram circunjacentes aos difusores do emissário submarino, bem como na estação Tb10 (Anexo 57).

Para o fracionamento do fósforo, foram obtidos os seguintes valores: fósforo total 0,040 a $0,068 \%$; fósforo orgânico de 0,014 a $0,024 \%$ e fósforo inorgânico de 0,026 a $0,043 \%$ (Anexos 58, 59 e 60). 
Os valores de enxofre oscilaram de 0,26 a $0,46 \%(\bar{x}=0,38 \pm 0,05 \%)$. A estação Tb4 e Tb6 apresentaram as maiores e menores concentrações, respectivamente (Anexo 61).

Os resultados das razões C/N variaram entre 8,9 e 199 e os das razões $\mathrm{C} / \mathrm{S}$ entre 4,6 e 6,7 (Anexos 62 e 63). 
Tabela 14 - Resultados geoquímicos e razões elementares obtidos em região circunjacente ao emissário submarino do TEBAR.

\begin{tabular}{|c|c|c|c|c|c|c|c|c|c|c|c|c|c|}
\hline \multirow{11}{*}{ 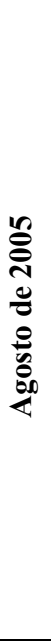 } & Estações & $\begin{array}{l}\text { Prof. } \\
\text { (m) }\end{array}$ & $\mathrm{pH}$ & $\begin{array}{l}\text { Eh } \\
\mathrm{mV}\end{array}$ & $\begin{array}{c}\mathrm{CaCO}_{3} \\
(\%)\end{array}$ & $\begin{array}{l}\text { Cot } \\
(\%)\end{array}$ & $\begin{array}{c}\mathrm{N} \\
(\%)\end{array}$ & $\begin{array}{c}\text { Ptotal } \\
(\%)\end{array}$ & $\begin{array}{c}\text { Porg } \\
(\%)\end{array}$ & $\begin{array}{c}\text { Pinorg } \\
(\%)\end{array}$ & $\begin{array}{c}\mathrm{S} \\
(\%)\end{array}$ & $\begin{array}{c}\text { Razão } \\
\mathrm{C} / \mathrm{N}\end{array}$ & $\begin{array}{l}\text { Razão } \\
\text { C/S }\end{array}$ \\
\hline & $\mathrm{Tb} 1$ & 19,5 & 6,85 & -121 & 22,06 & 2,07 & 0,21 & 0,145 & 0,044 & 0,101 & 0,43 & 10,2 & 4,8 \\
\hline & $\mathrm{Tb} 2$ & 14,5 & 7,15 & -105 & 25,06 & 2,19 & 0,23 & 0,152 & 0,054 & 0,098 & 0,42 & 12,0 & 5,2 \\
\hline & $\mathrm{Tb} 3$ & 25,5 & 6,48 & -149 & 17,82 & 2,05 & 0,28 & 0,134 & 0,047 & 0,087 & 0,55 & 11,8 & 3,7 \\
\hline & $\mathrm{Tb} 4$ & 26,5 & 7,11 & -110 & 23,73 & 1,85 & 0,25 & 0,138 & 0,073 & 0,065 & 0,46 & 56,0 & 4,0 \\
\hline & Tb5 & 17,5 & 6,6 & -129 & 23,99 & 2,37 & 0,21 & 0,144 & 0,057 & 0,087 & 0,36 & 11,8 & 6,7 \\
\hline & Tb6 & 10,5 & 6,72 & -81 & 19,69 & 2,04 & 0,28 & 0,129 & 0,043 & 0,086 & 0,46 & 9,1 & 4,5 \\
\hline & $\mathrm{Tb} 7$ & 13,5 & 6,97 & -171 & 27,77 & 2,03 & 0,29 & 0,158 & 0,048 & 0,109 & 0,60 & 11,9 & 3,4 \\
\hline & $\mathrm{Tb} 8$ & 31,5 & 7,15 & -110 & 21,15 & 2,05 & 0,29 & 0,153 & 0,059 & 0,095 & 0,48 & 10,3 & 4,2 \\
\hline & Tb9 & 30,5 & 7,37 & -87 & 19,72 & 1,72 & 0,19 & 0,122 & 0,045 & 0,077 & 0,60 & 9,9 & 2,9 \\
\hline & Tb10 & 19,5 & 6,98 & -126 & 26,68 & 2,25 & 0,21 & 0,178 & 0,068 & 0,110 & 0,55 & 9,9 & 4,1 \\
\hline \multirow{10}{*}{ 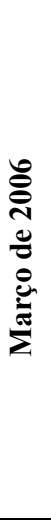 } & $\mathrm{Tb} 1$ & 21,5 & 7,02 & -173 & 22,75 & 2,24 & 0,29 & 0,281 & 0,239 & 0,042 & 0,45 & 7,7 & 5,0 \\
\hline & $\mathrm{Tb} 2$ & 17,5 & 7,20 & -160 & 18,9 & 2,03 & 0,33 & 0,096 & 0,047 & 0,050 & 0,41 & 6,2 & 5,0 \\
\hline & $\mathrm{Tb} 3$ & 24,5 & 7,23 & -217 & 17,98 & 1,72 & 0,12 & 0,060 & 0,026 & 0,034 & 0,38 & 14,3 & 4,5 \\
\hline & $\mathrm{Tb} 4$ & 26,5 & 7,39 & -137 & 24,3 & 1,29 & 0,1 & 0,064 & 0,026 & 0,038 & 0,45 & 12,9 & 2,9 \\
\hline & $\mathrm{Tb} 5$ & 16,5 & 7,20 & -221 & 21,47 & 2,35 & 0,22 & 0,094 & 0,048 & 0,046 & 0,49 & 10,7 & 4,8 \\
\hline & Tb6 & 10,5 & 6,93 & -170 & 16,53 & 1,94 & 0,25 & 0,072 & 0,039 & 0,033 & 0,43 & 7,8 & 4,5 \\
\hline & $\mathrm{Tb} 7$ & 13,5 & 7,51 & -141 & 17,81 & 1,67 & 0,23 & 0,234 & 0,183 & 0,051 & 0,39 & 7,3 & 4,3 \\
\hline & Tb8 & 34,5 & 7,45 & -214 & 22,27 & 1,84 & 0,22 & 0,099 & 0,050 & 0,049 & 0,53 & 8,4 & 3,5 \\
\hline & Tb9 & 24,5 & 7,40 & -225 & 21,54 & 2,05 & 0,25 & 0,112 & 0,058 & 0,054 & 0,49 & 8,2 & 4,2 \\
\hline & Tb10 & 17,5 & 7,19 & -233 & 25,86 & 2,12 & 0,25 & 0,085 & 0,029 & 0,056 & 0,44 & 8,5 & 4,8 \\
\hline \multirow{10}{*}{ 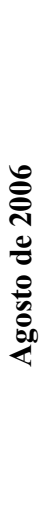 } & $\mathrm{Tb} 1$ & 21 & 7,73 & -103 & 23,37 & 2,02 & 0,14 & 0,055 & 0,022 & 0,034 & 0,37 & 14,4 & 5,5 \\
\hline & $\mathrm{Tb} 2$ & 17 & 7,92 & -126 & 19,93 & 2,06 & 0,14 & 0,056 & 0,022 & 0,034 & 0,38 & 14,7 & 5,4 \\
\hline & Tb3 & 25 & 7,72 & -135 & 19,98 & 1,96 & 0,11 & 0,057 & 0,023 & 0,034 & 0,39 & 17,8 & 5,0 \\
\hline & $\mathrm{Tb} 4$ & 27 & 7,36 & -96 & 19,34 & 2,11 & 0,06 & 0,048 & 0,017 & 0,031 & 0,46 & 35,2 & 4,6 \\
\hline & Tb5 & 17 & 8,4 & -158 & 22,98 & 2,75 & 0,03 & 0,068 & 0,024 & 0,043 & 0,41 & 91,7 & 6,7 \\
\hline & Tb6 & 11 & 7,23 & -98 & 15,51 & 1,33 & 0,03 & 0,040 & 0,014 & 0,026 & 0,26 & 44,3 & 5,2 \\
\hline & $\mathrm{Tb} 7$ & 16 & 7,13 & -117 & 19,99 & 2,02 & 0,11 & 0,048 & 0,016 & 0,032 & 0,37 & 18,4 & 5,5 \\
\hline & $\mathrm{Tb} 8$ & 35 & 7,44 & -121 & 17,35 & 1,99 & 0,01 & 0,045 & 0,017 & 0,028 & 0,41 & 199,0 & 4,9 \\
\hline & Tb9 & 33 & 7,57 & -124 & 19,85 & 2,42 & 0,09 & 0,049 & 0,018 & 0,030 & 0,37 & 26,9 & 6,5 \\
\hline & Tb10 & 20 & 7,57 & -124 & 21,08 & 2,23 & 0,25 & 0,053 & 0,021 & 0,032 & 0,40 & 8,9 & 5,6 \\
\hline
\end{tabular}


6.1.4 Análise das associações de foraminíferos

6.1.4.1 Biocenoses - composição, distribuição e análise morfométrica

As espécies e gêneros identificados nas coletas realizadas em Agosto de 2005, Março e Agosto de 2006 encontram-se relacionadas no Anexo 64 Algumas das espécies encontramse ilustradas na Prancha 1.

Coletas realizadas em Agosto de 2005

Foram identificados 7 gêneros e 38 espécies de foraminíferos, as quais estão distribuídas entre as Subordens Miliolina (2 espécies), Textulariina (3 espécies) e Rotaliina (33 espécies).

Foram obtidos entre 5 e 25 foraminíferos por $10 \mathrm{~cm}^{3}$ de sedimento $\left(\bar{x}=12^{ \pm} 7 \%\right.$ ). Os volumes de sedimento analisados oscilaram entre 40 e $190 \mathrm{~cm}^{3}(\bar{x}=120 \pm 40 \%)$.

Os valores de riqueza variaram de 10 a 23 espécies $\left(\bar{x}=16^{ \pm} 4\right)$, sendo observado na estação Tb6 o menor valor. Os maiores valores valores de riqueza foram identificadas nas estações Tb8 (23 espécies) e Tb9 (20 espécies), localizadas nas regiões leste e sul da malha de amostragem.

Os valores de diversidade específica e equitatividade foram de 1,22 a 2,24 e de 0,50 a 0,75 .

Ammonia tepida é a espécie predominante em todas as estações, em abundâncias relativas que variaram de 38,5 a $65,7 \%(\bar{x}=53,1 \pm 9,2 \%)$. Posteriormente, as espécies que apresentaram expressivas abundâncias relativas foram Buliminella elegantissima $(0,9$ a $11,8 \% ; \bar{x}=5,3^{ \pm} 3,8 \%$ ), Pararotalia cananeiaensis (0,9 a 20,2\%; $\bar{x}=6,6^{ \pm} 7,6 \%$ ), Brizalina striatula (0 a $\left.6,4 \% ; \bar{x}=3,8^{ \pm} 1,8 \%\right)$, Bolivina ordinaria $\left(0\right.$ a $\left.6 \% ; \bar{x}=3,5^{ \pm} 1,5 \%\right)$, Bulimina marginata (1 a $\left.6,3 \% ; \bar{x}=2,7^{ \pm} 1,5 \%\right)$ e Ammonia parkinsoniana $(0$ a 7,$35 ; \bar{x}=3,2 \pm 3 \%$ ).

Espécies infaunais e bioindicadoras de ambiente enriquecido por matéria orgânica são predominantes em todas as estações, em abundâncias relativas que variaram de 16,3 a 46,2\% ( $\bar{x}=27,7 \pm 8,6 \%$ ) (Anexo 65). Espécies epifaunais e bioindicadoras de ambiente óxico 
estiveram presentes em todas as estações, em abundâncias relativas que oscilaram entre 2,0 e $9,5 \%(\bar{x}=5,6 \pm 2,8 \%)($ Anexo 65$)$.

Os resultados das análises morfométricas indicaram ligeiro predomínio de carapaças médias em relação às carapaças pequenas (Anexo 66). Carapaças médias ocorreram em porcentagens que variaram de 38 a $65 \%(\bar{x}=51,9 \pm 9,29 \%)$. Carapaças pequenas, por sua vez, ocorreram em concentrações que oscilaram entre 32 e $62 \%(\bar{x}=46,9 \pm 10 \%)$. A maior porcentagem de carapaças pequenas foi observada na estação Tb10, localizada na região sudoeste da malha de amostragem. Carapaças grandes foram identificadas em quase todas as estações, porém em porcentagens pouco expressivas, entre 0 e $3 \%$.

\section{Coletas realizadas em Março de 2006}

Foram identificados 9 gêneros e 55 espécies, as quais distribuem-se entre as Subordens Miliolina (5 espécies), Textulariina (8 espécies) e Rotaliina (55 espécies). Algumas das espécies identificadas estão ilustradas na Prancha 1.

As densidades variaram entre 34 e 217 foraminíferos por $10 \mathrm{~cm}^{3}$ de sedimento. Para o período verificou-se aumento significativo nas densidades, as quais foram, em média, 7 vezes maiores em relação à Agosto de 2005. Foram utilizados entre 10 a $30 \mathrm{~cm}^{3}$ de sedimento $(\bar{x}=$ $20 \pm 7 \%)$.

Os valores de riqueza oscilaram de 21 a 36 espécies $(\bar{x}=26 \pm 4 \%)$. Já os valores de diversidade específica e equitatividade variaram de 2,2 a 2,8 e de 0,70 a 0,86, respectivamente.

Ammonia tepida é a espécie dominante, cujas abundâncias relativas oscilaram entre 13,8 e $43,9 \%(\bar{x}=30,0 \pm 9,6 \%)$. Subsequentemente, as espécies que foram identificadas em abundâncias expressivas foram Buliminella elegantissima $(5,1$ a $11 \% ; \bar{x}=7,4 \pm 1,5 \%)$, Ammonia parkinsoniana $(2,0$ a $11,8 \% ; \bar{x}=6,0 \pm 3,1 \%)$, Hopkinsina pacifica $(3,1$ a $9,6 \% ; \bar{x}=$ $6,0 \pm 2,5 \%)$, Cassidulina crassa $(0,8$ a $27,2 \% ; \bar{x}=6,6 \pm 7,9 \%)$, Brizalina striatula $(2,0$ a $\left.9,7 \% ; \bar{x}=4,8^{ \pm} 2,4 \%\right)$ e Cassidulina subglobosa $\left(0,6\right.$ a $\left.9,2 \% ; \bar{x}=3,6^{ \pm} 2,7 \%\right)$.

Espécies infaunais e bioindicadoras de ambiente enriquecido por matéria orgânica são dominantes, em abundâncias que variaram de 43 a $76 \%(\bar{x}=55 \pm 10 \%$ ) (Anexo 65). Em 
relação às espécies bioindicadoras de ambiente óxico, verificou-se ligeiro declínio de abundâncias, as quais foram de 0,6 a $14 \%(\bar{x}=4,3 \pm 3,8 \%)$. A maior concentração foi observada na estação $\mathrm{Tb} 4$, localizada na região sul, em relação à saída do emissário submarino (Anexo 65).

No tocante à análise morfométrica, verificou-se decréscimo na porcentagem de foraminíferos com carapaças pequenas, as quais variaram de 24 a $52 \%$ ( $\bar{x}=34,4 \pm 8 \%$ ) (Anexo 66). Carapaças médias são predominantes, em porcentagens que oscilaram entre $46 \mathrm{e}$ $69 \%\left(\bar{x}=61,8^{ \pm} 7,03\right)$. Carapaças grandes ocorreram em porcentagens que foram de 2 a $8 \%($ $\bar{x}=3,8 \pm 2,1 \%)$.

\section{Coletas realizadas em Agosto de 2006}

Foram identificados 17 gêneros e 41 espécies de foraminíferos, as quais se distribuem entre as Subordens Textulariina ( 8 espécies) e Rotaliina (33 espécies). Não foram identificados representantes da Subordem Miliolina em Agosto de 2006.

Verificou-se ligeiro declínio nas densidades, os valores obtidos foram de 24 a 144 foraminíferos por $10 \mathrm{~cm}^{3}$ de sedimento $(\bar{x}=60 \pm 43)$.

As riquezas oscilaram entre 14 e 18 espécies $\left(\bar{x}=16^{ \pm} 2\right)$. As estações Tb1, Tb8 e Tb9 apresentaram as menores riquezas, foram identificadas 14 espécies em cada estação.

Os valores de diversidade específica equitatividade variaram de 1,49 a 2,27 e de 0,57 a 0,79, respectivamente.

Ammonia tepida é a espécie dominante, com abundâncias relativas que foram de 29,5 a $60,4 \%(\bar{x}=39,7 \pm 9,6 \%)$. Secundariamente, as espécies que foram identificadas em abundâncias significativas foram Ammonia parkinsoniana $(9,4$ a $37,5 \% ; \bar{x}=18 \pm 7,8 \%)$, Buliminella elegantissima $(3,4$ a $17,3 \% ; \bar{x}=7,7 \pm 4,5 \%)$, Pseudononion atlanticum (0 a $13,4 \% ; \bar{x}=2,9 \pm 4,0 \%)$, Fursenkoina fragilis (0 a 8,8\%; $\bar{x}=2,4 \pm 3,0 \%)$, Bulimina marginata $(0,8$ a $8,4 \% ; \bar{x}=3 \pm 6 \%)$, Brizalina striatula $(0$ a $6,3 \% ; \bar{x}=3,2 \pm 1,9 \%)$ e Bolivina compacta $(0$ a $6,1 \% ; \bar{x}=2,2 \pm 1,9 \%)$. 
As abundâncias relativas de espécies epifaunais oscilaram entre 0 e $4,1 \%(\bar{x}=1,2 \pm$ 1,3\%). Comparativamente, verificou-se declínio expressivo na abundância de espécies epifaunais, em média, 3 vezes, em relação à Agosto de 2005, e 4 vezes em relação à Março. Não foram identificadas nas estações Tb1, Tb7 e T8 (Anexo 65).

Espécies infaunais ocorreram em abundâncias relativas que variaram de 24 a 48,4\% ( $\bar{x}=37,1 \pm 8,5 \%)($ Anexo 65$)$.

Os resultados das análises morfométricas indicaram predominância de foraminíferos com carapaças pequenas, cujas porcentagens oscilaram de 43,5 a $62,9 \%$ ( $\bar{x}=51,5 \pm 7,0 \%$ ) (Anexo 66). Foraminíferos com carapaças médias ocorreram em porcentagens que foram de 36,4 a $54,9 \%(\bar{x}=46,9 \pm 6,7 \%)$. Carapaças grandes, por sua vez, estiveram ausentes na estação Tb1, sendo observado para as demais estações porcentagens que variaram entre 0,7 e $4,7 \%\left(\bar{x}=1,7^{ \pm} 1,3 \%\right)$.

6.1.4.2 Tanatocenoses - composição, distribuição, aspectos morfométricos e tafonômicos (coloração e grau de preservação)

A relação das espécies e gêneros identificados nas coletas realizadas em Agosto de 2005, Março e Agosto de 2006 encontra-se mencionada no Anexo 67. Alguns exemplares dos foraminíferos identificados encontram-se ilustrados na Prancha 1.

\section{Coletas realizadas em Agosto de 2005}

Foram identificados 15 gêneros e 59 espécies de foraminíferos, as quais se distribuem entre as Subordens Textulariina (3 espécies), Miliolina (8 espécies) e Rotaliina (48 espécies).

As densidades variaram de 520 a 1436 foraminíferos por $10 \mathrm{~cm}^{3}$ de sedimento. As estações Tb8 e Tb9 apresentaram os maioers valores de densidade, sendo o contrário observado nas estações Tb1 e Tb2.

Os valores de riqueza oscilaram entre 26 e 36 espécies $(\bar{x}=32 \pm 4 \%)$, sendo os menores valores verificados nas estações Tb1 (26 espécies) e Tb2 (29 espécies).

As diversidades específicas e equitatividades foram de 2,38 a 2,72 e de 0,71 a 0,76, respectivamente. 
Pararotalia cananeiaensis é a espécie dominante, cujas abundâncias relativas variaram de 11,1 a $28,4 \%(\bar{x}=23,0 \pm 5,5 \%)$. Posteriormente, as espécies que apresentaram abundâncias relativas significativas foram Ammonia tepida $(6,3$ a 21,$3 ; \bar{x}=13,2 \pm 5,3 \%)$, Buliminella elegantissima $(2,3$ a $6,1 \% ; \bar{x}=3,5 \pm 1,1 \%)$, Bulimina marginata $(\bar{x}=32 \pm 4 \%)$, Pseudononion atlanticum (1,9 a 6,$2 ; \bar{x}=3,8 \pm 1,5 \%)$, Cassidulina crassa $(1,0$ a $6,2 \% ; \bar{x}=$ $\left.3,0^{ \pm} 1,5 \%\right)$ e Hanzawaia boueana (0 a 5,3\%; $\left.\bar{x}=2,0^{ \pm} 1,6 \%\right)$.

Espécies infaunais são predominantes em todas as estações analisadas, em porcentagens que oscilaram entre 22,0 e $36,4 \%(\bar{x}=29,6 \pm 5,6 \%)$ (Anexo 68). Espécies epifaunais e bioindicadoras de ambiente óxico foram observadas em abundâncias relativas que variaram de 3,1 a $10,1 \%\left(\bar{x}=7,6^{ \pm} 2,3 \%\right)$ (Anexo 68).

Os resultados das análises morfométricas indicaram ligeiro predomínio de carapaças pequenas em relação às carapaças médias (Anexo 69). As porcentagens de carapaças pequenas foram de 39,0 a $67,0 \%(\bar{x}=49,3 \pm 8,0 \%)$. Carapaças médias foram observadas em porcentagens que oscilaram de 32,0 a $55,0 \%(\bar{x}=46,9 \pm 7,0 \%)$. Foraminíferos com carapaças grandes foram identificados somente na estação $\mathrm{Tb} 4$, em porcentagem pouco expressiva, $1 \%$.

A análise tafonômica evidenciou a dominância de carapaças com sinais de fragmentação, devido à abrasão mecânica (Anexo 70). As porcentagens obtidas variaram de 58,5 a $72,7 \%\left(\bar{x}=64,2^{ \pm} 5,1 \%\right)$. Carapaças inteiras ocorreram em porcentagens que foram de 24,5 a $39,0 \%(\bar{x}=32,3 \pm 5,2 \%)$. As estações $\mathrm{Tb} 8$ e Tb9 apresentaram as maiores porcentagens. Fragmentos de carapaças foram observados em todas as estações, em porcentagens que oscilaram entre 2,2 e $7,7 \%(\bar{x}=3,9 \pm 2,0 \%)$.

No tocante ao grau de coloração, as carapaças são normais, em sua grande maioria (Anexo 71). As porcentagens obtidas variaram de 64,6 a 89,2\% $(\bar{x}=76,9 \pm 8,0 \%)$. Carapaças preenchidas por monossulfeto de ferro/pirita foram observadas em porcentagens significativas, as quais oscilaram de 9,4 a $34,8 \%(\bar{x}=21,1 \pm 8,8 \% \%)$. As maiores concentrações foram obtidas nas estações Tb4 (33,6\%) e Tb9 (34,8\%), localizadas na região sul da malha de amostragem. Carapaças acastanhadas, devido à impregnação por óxido/hidróxido de ferro estiveram presentes em todas as estações, porém em baixas porcentagens $\left(0,6\right.$ a $\left.4,6 \% ; \bar{x}=2,0^{ \pm} 1,2 \%\right)$. 
Carapaças com sinais de bioerosão foram observadas nas estações Tb4 (Pseudononion atlanticum), Tb5 (Pseudononion atlanticum), Tb6 (Ammonia tepida) e Tb9 (Hanzawaia boueana, Pseudononion atlanticum e Cribroelphidium sp.

Coletas realizadas em Março de 2006

Foram identificados 23 gêneros e 107 espécies de foraminíferos, as quais se encontram distribuídas entre as Subordens Miliolina (11 espécies), Textulariina (13 espécies) e Rotaliina (83 espécies).

As densidades variaram entre 2264 e 10528 foraminíferos por $10 \mathrm{~cm}^{3}$ de sedimento. Verificou-se diferença significativa de valores entre Agosto de 2005 e Março de 2006, 5 vezes em média.

Os valores de riqueza oscilaram de 34 e 50 espécies $(\bar{x}=43 \pm 5)$, sendo os maiores e menores valores observados nas estações $\mathrm{Tb} 7$ e Tb1, respectivamente.

Os valores das diversidades específicas e equitatividades foram de 2,68 a 2,92 e de 0,71 a 0,80 .

Pararotalia cananeiaensis é a espécie dominante, cujas abundâncias relativas variaram de 16,6 a $31,4 \%(\bar{x}=25,2 \pm 5 \%)$. Subsequentemente, as espécies que foram identificadas em abundâncias relativas expressivas foram Ammonia tepida $(5,0$ a $15,8 \% ; \bar{x}=$ 9,5 $\left.{ }^{ \pm} 3,6\right)$, Ammonia parkinsoniana (3,0 a 5,8\%; $\bar{x}=4,2 \pm 1,1 \%$ ), Pseudononion atlanticum $(2,1$ a $6,5 \% ; \bar{x}=3,9 \pm 1,5 \%)$, Buliminella elegantissima $(1,8$ a $4,8 \% ; \bar{x}=3,4 \pm 1,0 \%)$, Cassidulina crassa $(1,0$ a $7,6 \% ; \bar{x}=3,2 \pm 2,0 \%)$ e Bulimina marginata $\left(0,8\right.$ a $5,8 \% ; \bar{x}=3,0^{ \pm}$ $1,5 \%)$.

Espécies epifaunais e infaunais estiveram presentes em todas as estações, em proporções quase similares às verificadas para o período anterior de estudo (Anexo 68). As abundâncias relativas variaram de 6,5 a $14,6 \%(\bar{x}=9,5 \pm 2,2 \%)$ para espécies epifaunais e de 28,7 a $36,0 \%\left(\bar{x}=32,2^{ \pm} 2,7 \%\right)$ para espécies infaunais.

As análises morfométricas indicaram a ocorrência de carapaças pequenas, médias, grandes e alguns exemplares de macroforaminíferos (Anexo 69). Carapaças médias e pequenas estiveram presentes quase na mesma proporção, na área de estudo. As porcentagens 
de carapaças médias variaram de 36,4 a $55,7 \%\left({ }^{\bar{x}}=48,7^{ \pm} 5,9 \%\right)$ e as de carapaças pequenas de 30,9 a $62,5 \%(\bar{x}=47,8 \pm 9,7 \%)$. As porcentagens de carapaças grandes oscilaram de 0,3 a $12,7 \%\left(\bar{x}=3,6^{ \pm} 4,2 \%\right)$. Macroforaminíferos foram observados nas estações $\operatorname{Tb} 3(0,6 \%)$, $\operatorname{Tb} 4(1,7 \%)$ e $\operatorname{Tb} 6(0,6 \%)$.

As carapaças em sua grande maioria apresentaram sinais de fragmentação, os quais devem ter ocorrido durante processos de transporte (i.e. saltação e/ou rolação) (Anexo 70). As porcentagens obtidas foram de 42,8 a $62,1 \%(\bar{x}=51,9 \pm 6,4 \%)$. Carapaças inteiras estiveram presentes em porcentagens que oscilaram entre 36,5 e $56,2 \%\left(\bar{x}=46,4^{ \pm} 6,8 \%\right)$. As maiores concentrações foram observadas nas estações Tb1, Tb5, Tb7 e Tb8, nas quais são dominantes. Fragmentos de carapaças, por sua vez, ocorreram em todas as estações, porém em baixas concentrações, entre 0,3 e $3 \%(\bar{x}=1,7 \pm 0,9 \%)$.

As carapaças em geral apresentam-se sem sinais de impregnação ou preenchimento (Anexo 71). As porcentagens das carapaças normais variaram de 64,3 a $95 \%(\bar{x}=73,7 \pm$ 9,3\%). Carapaças preenchidas por monossulfeto de ferro/pirita foram observadas em porcentagens que oscilaram entre 3,3 e $35,5 \%(\bar{x}=24,9 \pm 9,9 \%)$. Carapaças acastanhadas ocorreram em concentrações que foram de 0,6 a $4,6 \%(\bar{x}=2,0 \pm 1,2 \%)$.

arapaças com sinais de bioerosão foram observadas nas estações Tb5 (Pseudononion sp e Bulimina marginata), Tb6 (Fursenkoina riggi), Tb7 (Bulimina marginata), Tb8 (Ammonia parkinsoniana), Tb9 (Fursenkoina pontoni e Bolivina doniezi) e Tb10 (Ammonia tepida).

Coletas realizadas em Agosto de 2006

Foram identificados 21 gêneros e 81 espécies de foraminíferos, as quais estão distribuídas entre as Subordens Miliolina (2 espécies), Textulariina (12 espécies) e Rotaliina (67 espécies).

Os valoers de densidade variaram entre 1192 e 14560 foraminíferos por $10 \mathrm{~cm}^{3} \mathrm{de}$ sedimento. Comparativamente, em Agosto de 2006 o valores das densidades foram 2 vezes superiores aos verificadas em Março. 
Os valores de riqueza oscilaram entre 31 e 47 espécies $\left(\bar{x}=40^{ \pm} 6\right)$. As diversidades específicas e equitatividades foram de 2,35 a 3,01 e de 0,65 a 0,78, respectivamente.

Pararotalia cananeiaensis permanece como sendo a espécie dominante. As abundâncias relativas oscilaram entre 13,8 e $37,7 \%(\bar{x}=25,1 \pm 7,3 \%)$. Posteriormente, as espécies que apresentaram abundâncias relativas significativas foram Ammonia tepida (6,8 a $21,6 ; \bar{x}=13,0 \pm 4,5 \%)$, Pseudononion atlanticum $(2,4$ a $11,9 \% ; \bar{x}=5,3 \pm 2,8 \%)$, Bulimina marginata $(1,4$ a $8,5 \% ; \bar{x}=4,4 \pm 2,8 \%)$, Ammonia parkinsoniana $(1,2$ a $7,6 \% ; \bar{x}=4,4 \pm$ $1,8 \%)$, Buliminella elegantissima $(1,5$ a $4,7 \% ; \bar{x}=3,1 \pm 1,1 \%)$ e Cassidulina crassa $(1,4$ a $\left.5,6 \% ; \bar{x}=2,9^{ \pm} 1,5 \%\right)$.

Espécies infaunais e bioindicadoras de ambiente enriquecido organicamente são dominantes (Anexo 68). As abundâncias relativas variaram de 22,1 a 40,7\% $(\bar{x}=31,2 \pm$ 5,6\%). Espécies epifaunais e bioindicadoras de ambiente óxico, por sua vez, ocorreram em abundâncias relativas que foram de 2,7 a 10,5\% $\left(\bar{x}=6,1^{ \pm} 2,6 \%\right)$ (Anexo 68).

Os resultados das análises morfométricas indicaram a presença de foraminíferos com carapaças pequenas, médias, grandes e macroforaminíferos. Observou-se alternância de dominância entre carapaças médias e carapaças pequenas (Anexo 69). As porcentagens de carapaças pequenas variaram de 26,8 a $70,4 \%(\bar{x}=44,7 \pm 13,6 \%)$. A maior concentração foi identificada na estação Tb5. Carapaças médias ocorreram em porcentagens que oscilaram entre 29,3 e $60,4 \%(\bar{x}=48,9 \pm 9,1 \%)$. Carapaças grandes foram observadas em abundâncias que foram de 0,3 a $15,3 \%(\bar{x}=6,1 \pm 5,5 \%)$. Macroforaminíferos foram identificados nas estações Tb1 (1,3\%), Tb6 (0,3\%), Tb7 (0,5\%), Tb8 (0,6\%) e Tb9 (0,2\%).

Diferentemente do observado para os períodos anteriores, em Agosto de 2006 as carapaça inteiras são dominantes, em porcentagens que oscilaram ente 43,7 e $55,4 \%(\bar{x}=$ $51,5 \pm 3,8 \%$ ) (Anexo 70). Carapaças parcialmente fragmentadas, devido à abrasão mecânica, ocorreram em porcentagens que variaram de 39,9 a $55,2 \%(\bar{x}=45,5 \pm 4,2 \%)$. Foram observados fragmentos de carapaças em todas as estações, em porcentagens que foram de 1,1 a $4,7 \%(\bar{x}=2,9 \pm 1,4 \%)$.

Verificou-se predomínio de carapaças sem alteração da coloração, i.e. normais. As porcentagens obtidas oscilaram de 68,0 a $88,3 \%(\bar{x}=80,7 \pm 7,0 \%)$. As porcentagens de 
carapaças preenchidas por monossulfeto de ferro/pirita variaram entre 8,7 e $31,1 \%\left(\bar{x}=17,6^{ \pm}\right.$ 7,5\%). As estações $\operatorname{Tb} 7(31,1 \%)$, Tb8 (27,7\%) e Tb9 (23,3\%) apresentaram as maiores porcentagens. Ausentes na estação Tb4, carapaças acastanhadas, foram observadas em porcentagens que oscilaram de 0,8 a $3,0(\bar{x}=1,7 \pm 0,9 \%$ ) (Anexo 71 ).

Carapaças com sinais de bioerosão foram identificadas nas estações Tb3 (Cassidulina crassa), Tb4 (Bulimina marginata [2 espécimes], Buccella peruviana e Criboelphidium disdoidale), Tb5 (Pseudononion grateloupi e Pseudononion atlanticum), Tb6 (Bulimina marginata [3 espécimes], Hanzawaia boueana e Pseudononion opima), Tb7 (Bulimina marginata e Cribroelphidium poyeanum), Tb8 (Pseudononion atlanticum e Buccella peruviana [2 espécimes]) e Tb9 (Bulimina marginata [4 espécimes], Pseudononion atlanticum [2 espécimes] e Ammonia tepida [2 espécimes]).

\subsubsection{Análises estatísticas dos dados}

\subsection{Coeficientes de correlação de Pearson (r)}

Os resultados das correlações de Pearson encontram-se nos Anexos 72, 73 e 74.

Em Agosto de 2005 (Anexo 72), verificou-se que os valores de densidade possuem relação inversa aos parâmetros profundidade $(\mathrm{r}=-0,80 ; p<0,01)$ e salinidade $(\mathrm{r}=-0,83 ; p<$ $0,01)$ e positivamente pela temperatura $(\mathrm{r}=0,83 ; p<0,01)$. Os valores de riqueza, por sua vez, são positivamente influenciados pelas profundidades $(\mathrm{r}=0,64 ; p<0,05)$ e de $\mathrm{pH}(\mathrm{r}=$ 0,$83 ; p<0,01$. Já em relação à composição observou-se que Ammonia tepida e Brizalina striatula possuem relação inversa aos valores de $\mathrm{pH}$. Pararotalia cananeiaensis é negativamente associada à profundidade $(\mathrm{r}=-0,67 ; p<0,05)$ e salinidade $(\mathrm{r}=-0,70 ; p<$ $0,05)$ e positivamente em relação à temperatura $(\mathrm{r}=0,72 ; p<0,05)$ e oxigênio dissolvido $(\mathrm{r}=$ $0,69 ; p<0,05)$. Bolivina ordinaria correlaciona-se negativamente com as profundidades $(\mathrm{r}=$ $0,72 ; p<0,05)$ e com sedimentos arenosos $(\mathrm{r}=-0,70 ; p<0,05)$. Verificou-se para a espécie correlação positiva em relação aos valores de fósforo inorgânico $(\mathrm{r}=0,69 ; p<0,05)$, de sedimentos finos $(\mathrm{r}=0,85 ; p<0,01)$ e de Eh $(\mathrm{r}=0,69 ; p<0,05)$.

Em Março de 2006 (Anexo 73), observou-se que as diversidades específicas estão positivamente associadas aos valores de salinidade $(\mathrm{r}=0,72 ; p<0,05)$ e carbonato de cálcio $(\mathrm{r}=0,67 ; p<0,05)$, e negativamente em relação aos valores de temperatura $(\mathrm{r}=-0,69 ; p<$ 
0,05). Ammonia tepida teve sua distribuição correlacionada negativamente com os teores de carbonato de cálcio $(\mathrm{r}=-0,75 ; p<0,05)$ e fósforo inorgânico $(\mathrm{r}=-0,64 ; p<0,05)$. As abundâncias da espécie estão influenciando negativamente as diversidades específicas $(r=-$ $0,64 ; p<0,05)$ e as equitatividades $(\mathrm{r}=-0,78 ; p<0,01)$. Ammonia parkinsoniana correlacionou-se negativamente com os sedimentos arenosos $(\mathrm{r}=-0,80 ; p<0,01)$, e positivamente com os teores de finos $(\mathrm{r}=0,80 ; p<0,01)$ e com os valores de $\mathrm{Eh}(\mathrm{r}=0,94 ; p<$ 0,01). As abundâncias relativas de Cassidulina crassa possuem relação positiva com as profundidades $(\mathrm{r}=0,74 ; p<0,05)$ e com os teores de enxofre $(\mathrm{r}=0,73 ; p<0,01)$. Brizalina striatula correlacionou-se positivamente com os valores de temperatura $(\mathrm{r}=0,77 ; p<0,01) \mathrm{e}$ oxigênio dissolvido $(\mathrm{r}=0,74 ; p<0,01)$, e negativamente com os valores de salinidade $(\mathrm{r}=$ $0,77 ; p<0,05)$.

Em Agosto de 2006 (Anexo 74), observou-se que os valores de densidade correlacionam-se positivamente com os valores de oxigênio dissolvido $(\mathrm{r}=0,76 ; p<0,05)$, sendo observado relação inversa para enxofre $(\mathrm{r}=-0,70 ; p<0,05)$ e profundidade $(\mathrm{r}=-0,66$; $p<0,05)$. Os valores de riqueza estão positivamente associados às temperaturas $(\mathrm{r}=-0,64 ; p$ $<0,05)$. A distribuição de Fursenkoina fragilis foi influenciada positivamente pelos teores de finos $(\mathrm{r}=0,70 ; p<0,05)$.

\subsection{Estudo comparativo da estrutura das associações de foraminíferos}

\subsection{Biocenoses - estudo comparativo entre os periodos de coleta}

Os períodos analisados apresentaram expressivas diferenças em suas estruturas composicionais, conforme pode ser observado nos gráficos de ordenação (Figura 28).

Em todas as análises, as dissimilaridades foram estatisticamente significativas somente no Eixo1, os valores obtidos para o Eixo 2 são considerados baixos.

Entre Agosto de 2005 e Março de 2006 (Figura 28 A), os resultados obtidos foram Eixo $1 \mathrm{t}=-7,738 ; p<0,001$ e Eixo $2 \mathrm{t}=0,004 ; p=0,997$.

Entre Agosto de 2005 e Agosto de 2006 (Figura 28 B), os valores observados foram Eixo $1 \mathrm{t}=-8,545 ; p<0,001$ e Eixo $2 \mathrm{t}=0,400 ; p=0,694$. 
Em relação ao estudo comparativo realizado entre Março e Agosto de 2006 (Figura 28 C), foram obtidos os seguintes valores: Eixo $1 \mathrm{t}=7,879 ; p<0,001$ e Eixo $2 \mathrm{t}=0,047 ; p=$ 0,963 .

Para todas as análises foi obtido valor baixo de estresse, entre 0,22 e 0,28, indicando ausência de distorção nos dados durante as análises realizadas.

Descritivamente, verificou-se que somente $29 \%$ das espécies são comuns aos três períodos analisados, com significativa diferença em suas abundâncias. As espécies identificadas nos três períodos foram Ammonia tepida, Ammonia parkinsoniana, Ammotium salsum, Bolivina compacta, Bolivina doniezi, Bolivina ordinaria, Brizalina striatula, Bulimina marginata, Buliminella elegantissima, Cassidulina crassa, Cribroelphidium excavatum, Cribroelphidium poyeanum, Fursenkoina pontoni, Haynesina germanica, Hopkinsina pacifica, Lobatula lobatula, Neocornobina terquemi, Pararotalia cananeiaensis, Pseudononion atlanticum, Pseudononion opima e Rosalina floridensis. 

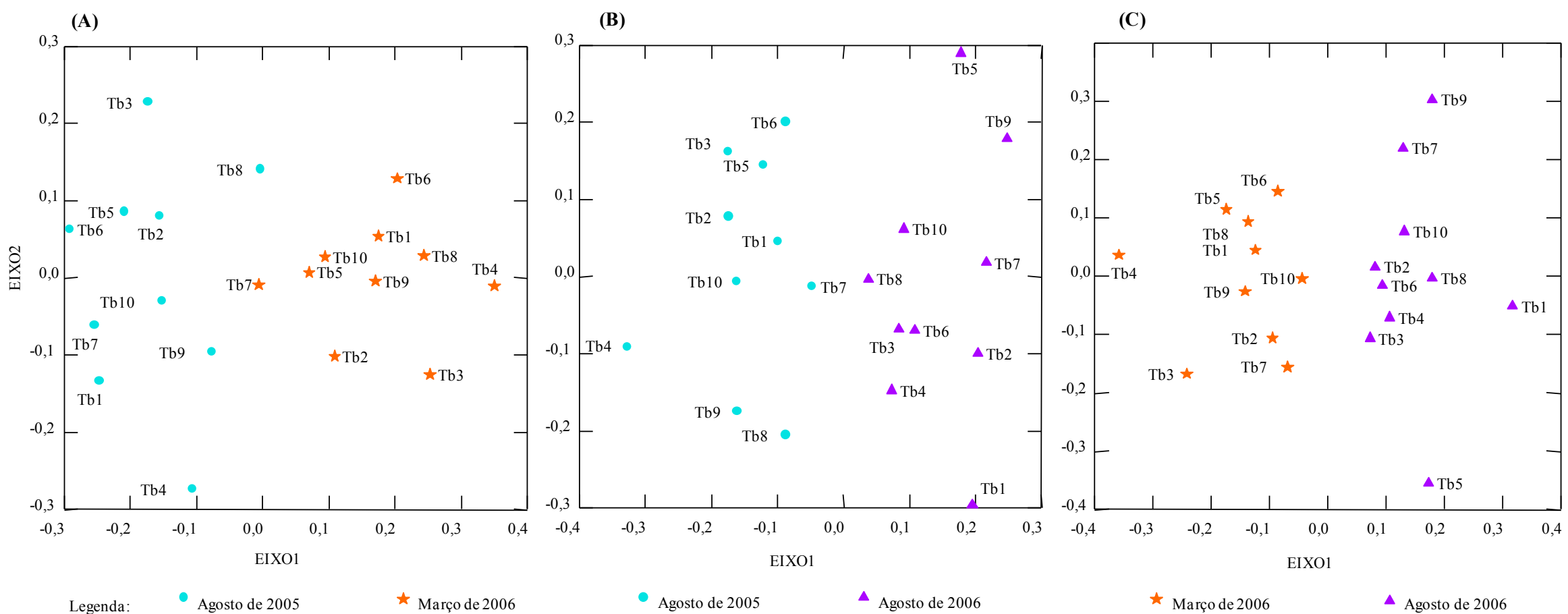

Figura 28 - Gráficos de ordenação (NMDS e teste t) obtidos no estudo comparativo entre as biocenoses. 
6.1.4.3.2.2 Tanatocenoses - estudo comparativo entre os periodos de coleta

Foram obtidas dissimilaridades significativas nas estruturas das associações de foraminíferos, conforme pode ser observado na Figura 29.

Entre Agosto de 2005 e Março de 2006 (Figura 29 A), as diferenciações ocorreram nos Eixos 1 e 2. Os valores obtidos para o Eixo 1 foram $\mathrm{t}=-3,386 ; p<0,001$ e para o Eixo $2 \mathrm{t}=$ $-3,194 ; p<0,001$.

Entre Agosto de 2005 e Agosto de 2006 (Figura 29 B), as diferenciações ocorreram nos dois eixos, porém com baixo nível de significância no Eixo $2(\mathrm{t}=0,390 ; p=0,701)$. Os valores obtidos para o Eixo 1 foram $\mathrm{t}=-7,204 ; p<0,001$.

Em relação a Março de 2006 e Agosto de 2006 (Figura 29 C), verificou-se diferenciação significativa somente no Eixo $1(\mathrm{t}=-3,386 ; p<0,001)$. Os valores obtidos para o Eixo 2 foram $\mathrm{t}=-0,512 ; p=0,615$.

Em todos os estudos comparativos o valor do estresse é considerado baixo, entre 0,25 e 0,26 , motivo pelo qual infere-se que não houve distorção dos dados nas técnicas utilizadas. Descritivamente verificou-se que somente $35 \%$ das espécies identificadas estão presentes nos três períodos amostrados, porém com diferenciações expressivas nas abundâncias relativas. 

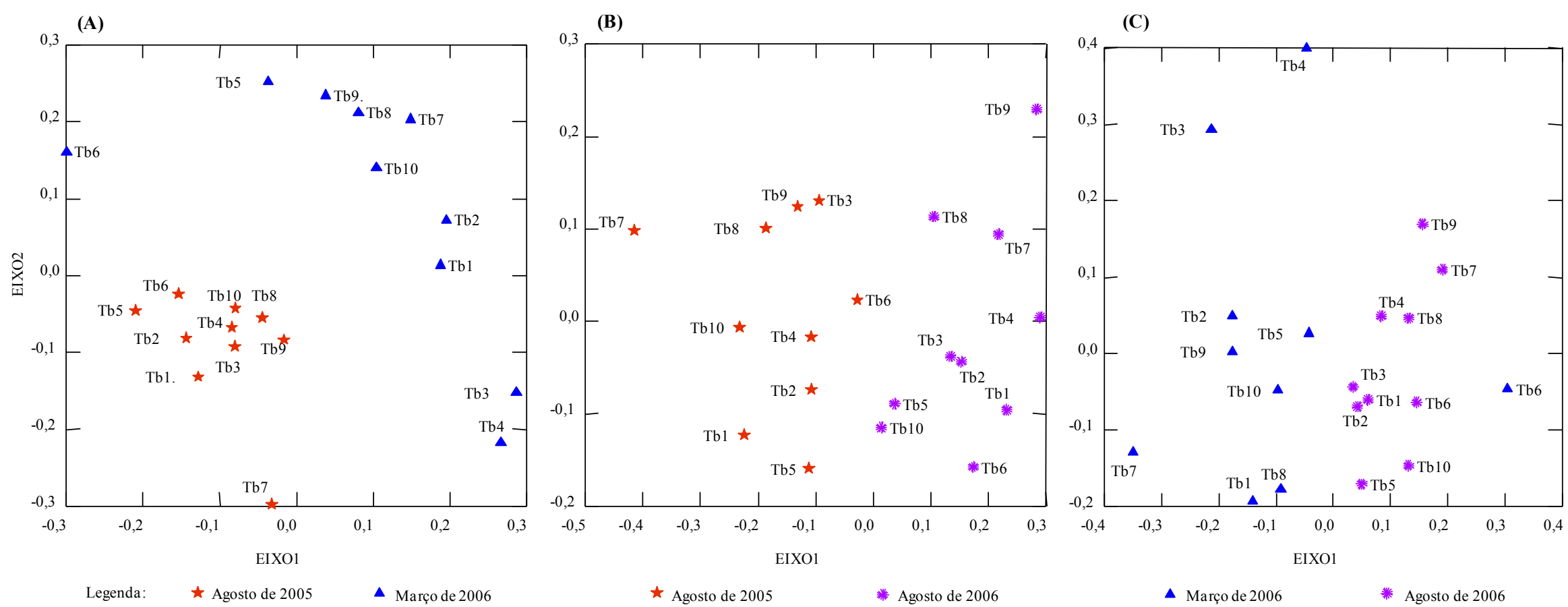

Figura 29 - Gráficos de ordenação (NMDS e teste t) obtidos no estudo comparativo entre as tanatocenoses. 
6.1.4.3.2.3 Biocenoses versus Tanatocenoses - estudo comparativo entre os períodos de coleta

Os estudos comparativos realizados entre as biocenoses e tanatocenoses indicaram dissimilaridades composicionais significativas. Conforme observado nos gráficos de ordenação (Figura 30) há maior heterogeneidade de espécies nas tanatocenoses, o que corrobora os resultados obtidos pelas diversidades específicas e equitatividades (Anexo 64 e 67)

Em Agosto de 2005 (Figura 30 A), as diferenciações ocorreram somente no Eixo 1, cujos resultados foram $\mathrm{t}=9,707 ; p<0,001$. Os valores do Eixo 2 foram $\mathrm{t}=0,048 ; p$ $=0,962$.

Em Março de 2006 (Figura 30 B), verificou-se diferenciação significativa no Eixo $1(\mathrm{t}=15,208 ; p<0,001)$. Os valores obtidos para o Eixo 2 foram $\mathrm{t}=-0,224 ; p=$ 0,825 .

Em Agosto de 2006 (Figura 30 C), verificou-se dissimilaridade significativa somente para o Eixo 1, cujos valores obtidos foram $\mathrm{t}=23,199 ; p<0,001$. Para o Eixo 2 obteve-se os seguintes valores $\mathrm{t}=0,334 ; p=0,742$.

O estresse obtido para todos os estudo comparativos é considerado baixo, entre 0,15 e 0,22 , motivo pelo qual infere-se ausência de distorção nos dados durante as técnicas utilizadas.

Descritivamente, verificou-se que algumas espécies, as mais abundantes, são comuns às biocenoses e tanatocenoses. Os percentuais de espécies comuns às duas associações foram de 38\% para Agosto de 2005, 43\% para Março de 2006 e 41\% para Agosto de 2006.

Ammonia parkinsoniana, Ammonia tepida, Bolivina compacta, Bolivina doniezi, Bolivina ordinaria, Vrizalina striatula, Buliminella elegantissima, Cassidulina crassa, Criboelphidium excavatum, Cribroelphidium poyeanum, Fursenkoina pontoni, Hopkinsina pacifica, Lobatula lobatula, Neocornobina terquemi, Pararotalia cananeiaensis, Pseudononion atlanticum, Pseudononion opima e Rosalina floridensis, foram as espécies identificadas em todos os períodos estudados, nas duas associações. 

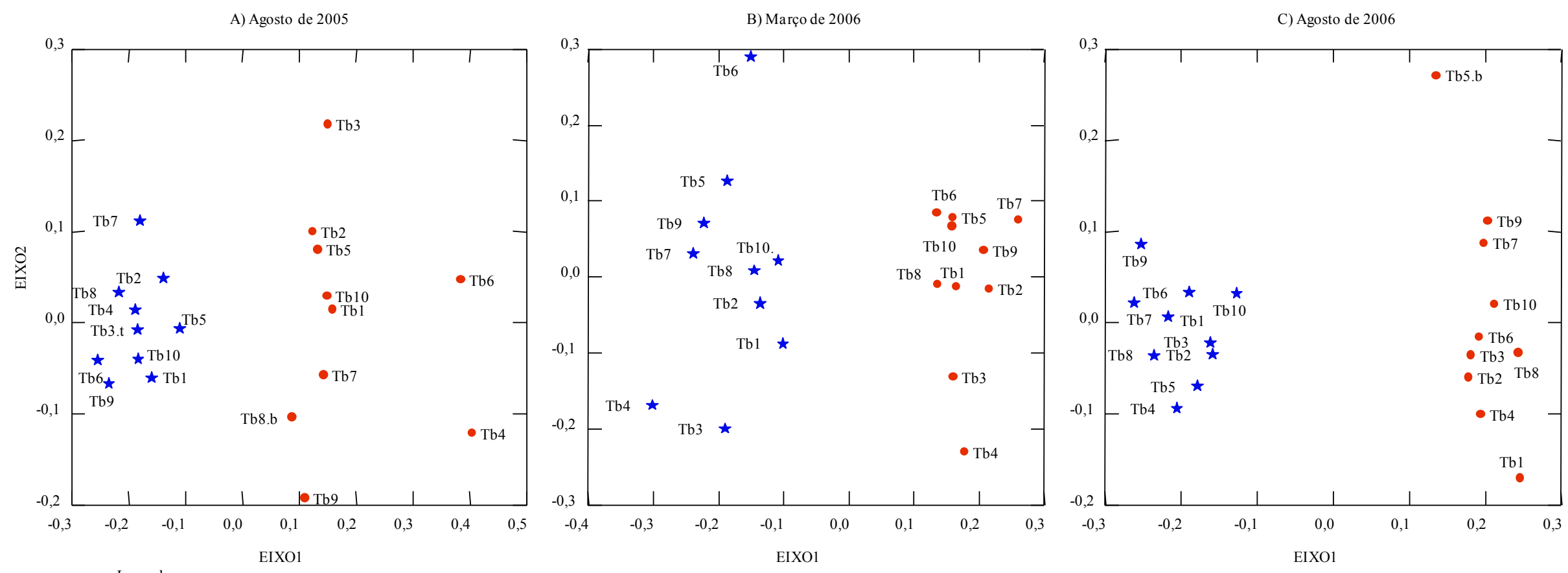

$\star$ Tanatocenose

- Biocenose

Figura 30 - Gráficos de ordenação (NMDS e teste t) dos estudos comparativos entre as tanatocenoses e as biocenoses. 
Em Agosto de 2005, com nível de similaridade igual a 0,76, verificou-se a formação de dois grupos nas tanatocenoses (Figura 31). O grupo T1 é formado pelas estações Tb1, Tb2, Tb6 e Tb5, o grupo T2, por sua vez, engloba as estações Tb7, Tb4, Tb3, Tb9, Tb10 e Tb8. Para as biocenoses verificou-se a formação de dois grupos principais, o B1 que abrange as estações Tb6 e Tb2, e o B2 que subdividiu-se nos subgrupos B2.1 e B2.2. O subgrupo B2.1 engloba as estações Tb8, Tb10 e Tb7, ao passo que o subgrupo B2.2 abrange as estações Tb5, Tb3, Tb4 e Tb1. A estação Tb9 não se associou a nenhum dos grupos formados (Figura 31).

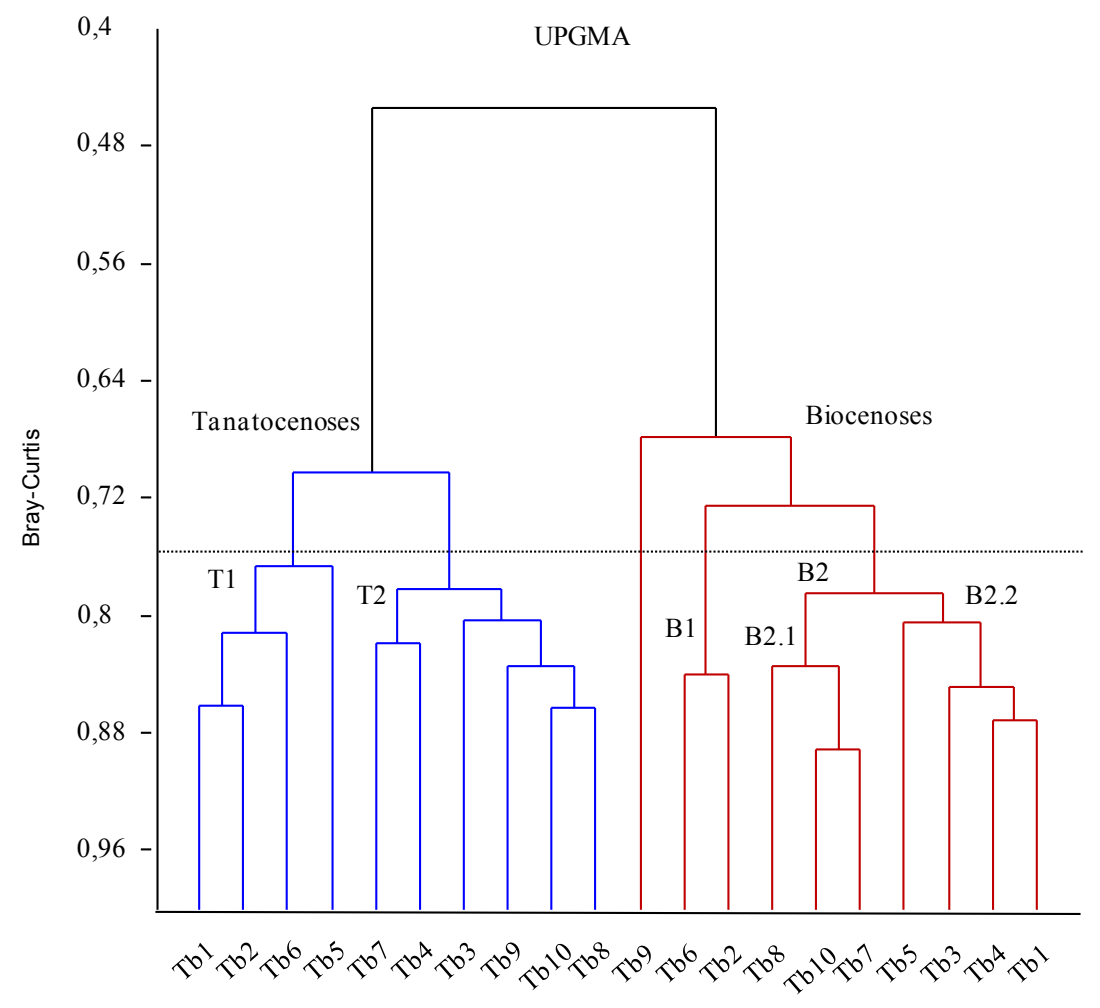

Figura 31 - Dendrograma, modo Q, obtido para o período de Agosto de 2005.

Em Março de 2006, com nível de similaridade igual a 0,66, verificou-se a formação de dois grupos nas biocenoses, sendo o grupo B1 formado pelas estações Tb6, Tb5, Tb3, Tb7 e Tb2, e o grupo B2, o qual abrangeu as estações Tb9, Tb4, Tb10 e Tb1 (Figura 32). A estação Tb8 não se associou aos grupos formados. Em relação às tanatocenoses, as estações dividiram-se nos grupos T1, o qual é composto pela maioria das estações e o grupo T2, no qual se associaram as estações Tb5 e Tb6 (Fgura 32). 


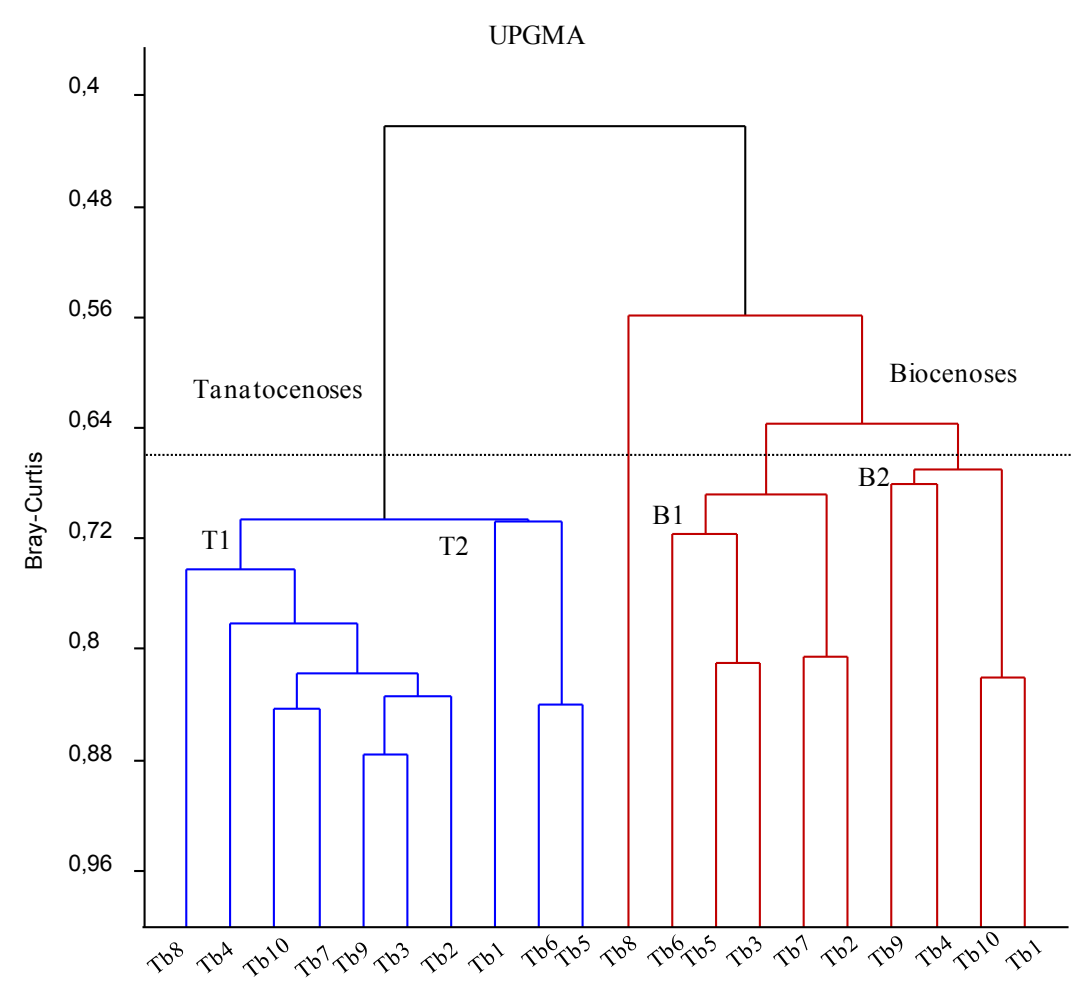

Figura 32 - Dendrograma, modo Q, obtido para o período de Março de 2006.

Em Agosto de 2006, com nível de similaridade de 0,70, biocenoses formaram os grupos B1, que abrangeu as estações Tb5 a Tb10, e o grupo B2, que compreendeu as estações Tb1 a Tb4 (Figura 33). As estações pertencentes às tanatocenoses, por sua vez, dividiram-se em dois grupos distintos, o T1, que foi formado pelas estações $\mathrm{Tb} 1, \mathrm{~Tb} 2$, Tb3, Tb4, Tb5, Tb6 e Tb10 e o grupo T2, no qual se associaram as estações Tb7, Tb8 e Tb9 (Figura 32). 


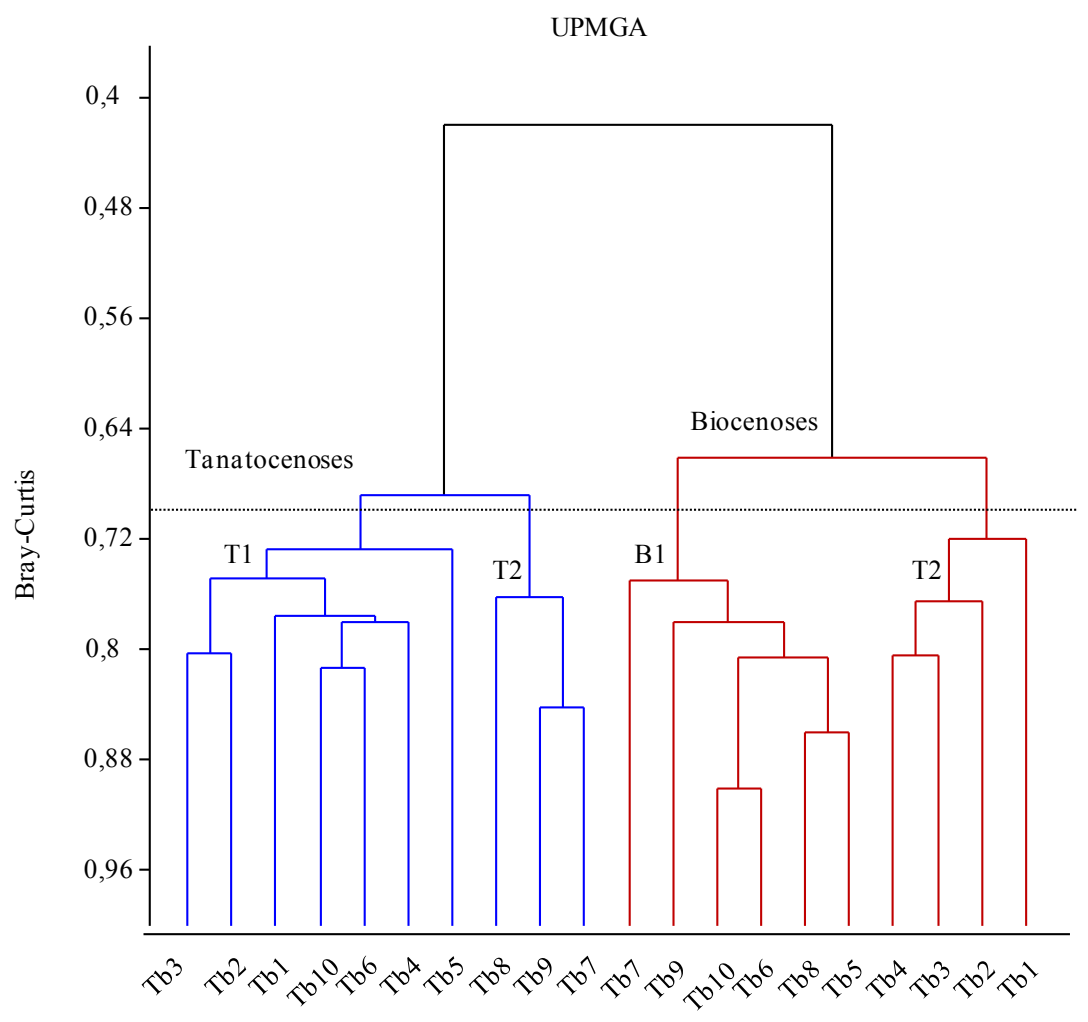

Figura 33 - Dendrograma, modo Q, obtido para o período de Agosto de 2006

\subsection{Análise de Correspondência Canônica}

Os resultados obtidos na Análise de Correspondência Canônica inferem significante relacionamento entre as espécies de foraminíferos que compuseram as biocenoses e as variáveis ambientais estudadas.

Segundo a extensão dos vetores, em ordem decrescente de importância, as variáveis ambientais selecionadas pelo programa CANOCO foram oxigênio dissolvido (O.D.), enxofre (S) e o potencial hidrogeniônico (pH) (Figura 34)

Juntos os Eixos 1 e 2 explicam 93,3\% da variância do relacionamento existente entre as espécies de foraminíferos e as variáveis ambientais. O Eixo 1, explica 57,1\% e o Eixo 2, por sua vez, explica 36,2\% das variâncias existentes (Tabela 15). 
Tabela 15 - Síntese dos resultados obtidos pela Análise de Correspondência Canônica.

\begin{tabular}{lrrrrr}
\hline \multicolumn{1}{c}{ Eixos } & \multicolumn{1}{c}{2} & 3 & 4 & Inércia total \\
\hline Autovalores & & & & & \\
\hline Correlações: espécies - ambiente & 0,077 & 0,048 & 0,009 & 0,103 & 0,517 \\
Variância em porcentagem acumulada: & 0,731 & 0,757 & 0,567 & 0 & \\
dos dados das espécies & 14,8 & 24,2 & 25,9 & 45,9 & \\
dos dados das espécies e ambiente & 57,1 & 93,3 & 100 & 0 & \\
\hline
\end{tabular}

No Eixo 1, lado positivo estão associadas as espécies Bolivina ordinaria, Ammonia tepida, Pseudononion atlanticum, Bulimina marginata, Brizalina striatula e Pararotalia cananeiaensis. Ao lado negativo do Eixo 1 associaram-se as espécies Hopkinsina pacifica, Gaudryina exilis e Fursenkoina fragilis.

No Eixo 2, lado positivo, Ammonia parkinsoniana, Ammotium salsum e Bolivina compacta. Ao lado negativo do Eixo 2 relacionaram-se as espécies Rosalina floridensis, Brizalina sphatulata, Fursenkoina pontoni e Cassidulina crassa.

Cribroelphidium excavatum associou-se tanto ao lado negativo do Eixo 1, como ao lado positivo do Eixo 2.

O posicionamento de Buliminella elegantissima no centro do diagrama de ordenação indica que sua distribuição ocorre, na área de estudo de forma aleatória, bem como pode ocorrer de acordo com alguma variável não selecionada pelo programa CANOCO. Mesma situação é verifica para Cassidulina subglobosa, a qual foi posicionada na extremidade do diagrama de ordenação. 


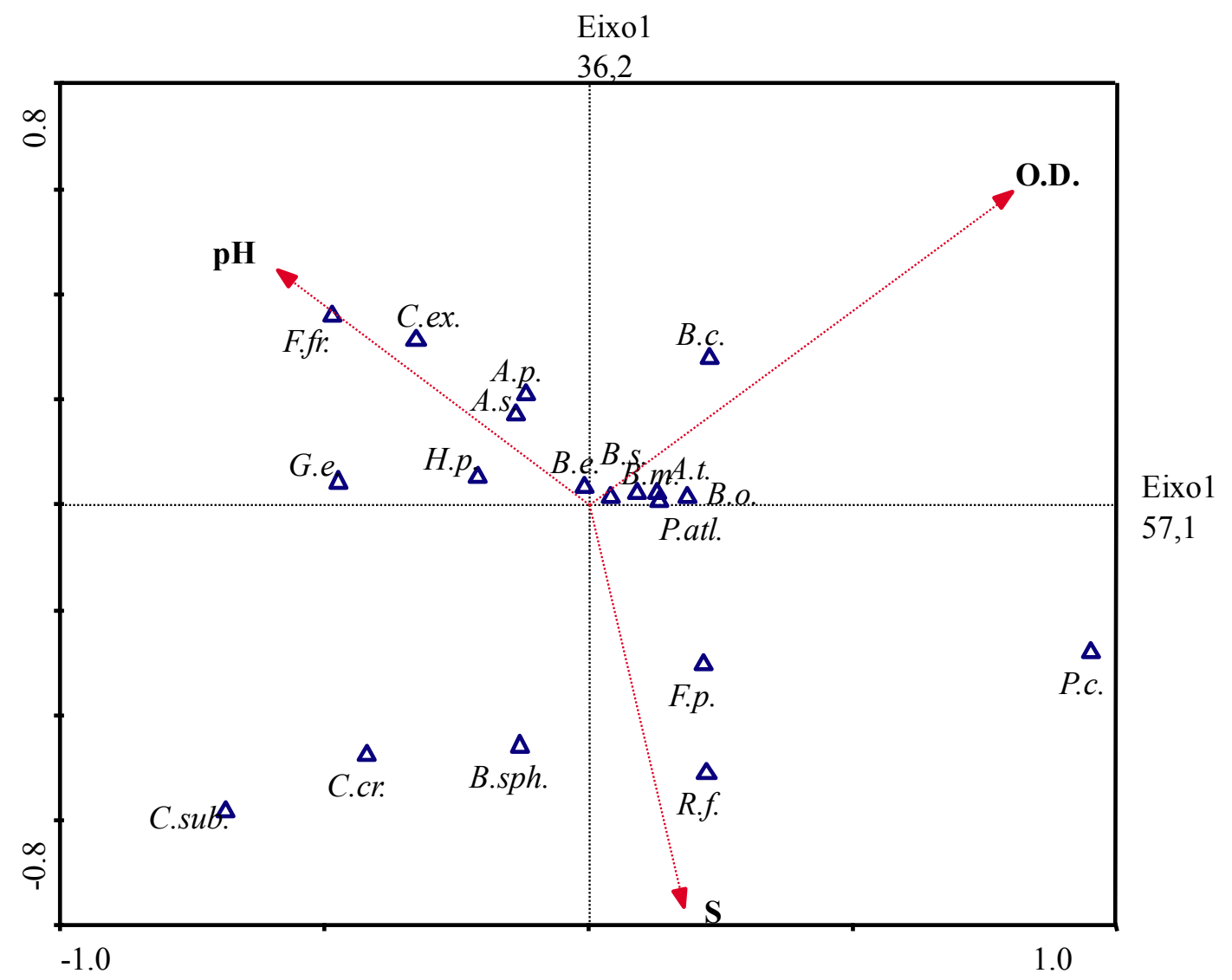

Figura 34 - Diagrama de ordenação da relação existente entre as espécies de foraminíferos que compõem as biocenoses e os parâmetros abióticos.

Legenda: A.p. (Ammonia parkinsoniana), A.t. (Ammonia tepida), A.s.(Ammotium salsum), B.c. (Bolivina compacta), B.o. (Bolivina ordinaria), B. sph. (Brizalina sphatulata), B.s. (Brizalina striatula), B.m. (Bulimina marginata), B.e. (Buliminella elegantissima), C.cr. (Cassidulina crassa), C.sub. (Cassidulina subglobosa), C.ex. (Cribroelphidium excavatum), F.p. (Fursenkoina pontoni), G.e. (Gaudryina exilis), H.p. (Hopkinsina pacifica), P.c. (Pararotalia cananeiaensis), P. atl. (Pseudononion atlanticum), R.f. (Rosalina floridensis) e F. fr. (Fursenkoina fragilis).

O diagrama de ordenação, da relação existente entre as estações de amostragem e as variáveis ambientais, indica que as amostragens foram realizadas em diferentes condições ambientais (Figura 35).

Segundo o posicionamento das estações no diagrama de ordenação, em Agosto de 2005, as coletas foram realizadas em ambiente com melhores níveis de oxigenação, porém com sinais de acidez nos sedimentos de fundo. Neste período $60 \%$ das amostras apresentaram valores de $\mathrm{pH}$ abaixo de 7 . As espécies que estiveram associadas ao mesmo lado do Eixo são consideradas tolerantes, sendo comumente encontradas em ambientes sob estresse. 
Para Março de 2006, verificou-se que as amostragens foram realizadas em ambiente com $\mathrm{pH}$ alcalino, porém com expressivos teores de enxofre e baixos níveis de oxigenação no compartimento bentônico. As espécies que relacionaram-se aos mesmos lados dos Eixos foram Brizalina sphatulata, Fursenkoina pontoni, Hopkinsina pacifica, Gaudryina exilis, Fursenkoina fragilis e Rosalina floridensis. Ressalta-se que o relacionamento de Rosalina floridensis às características ambientais é o oposto de suas preferências ecológicas (q.v. Murray, 1991).

Em relação à Agosto de 2006, verificou-se que as amostragens foram realizadas em ambiente com baixos níveis de oxigenação na interface-água sedimento, porém com diferenciação nos teores de enxofre, o qual foi inferior, em relação aos demais períodos amostrados. As espécies que estiveram associadas foram Hopkinsina pacifica, Gaudryina exilis, Ammotium salsum, Cribroelphidium excavatum e Fursenkoina fragilis.

O ponto controle, estação $\mathrm{C} 3$, posicionou-se no lado positivo do Eixo 2, indicando que o mesmo foi amostrado em ambiente com baixos teores de enxofre. 


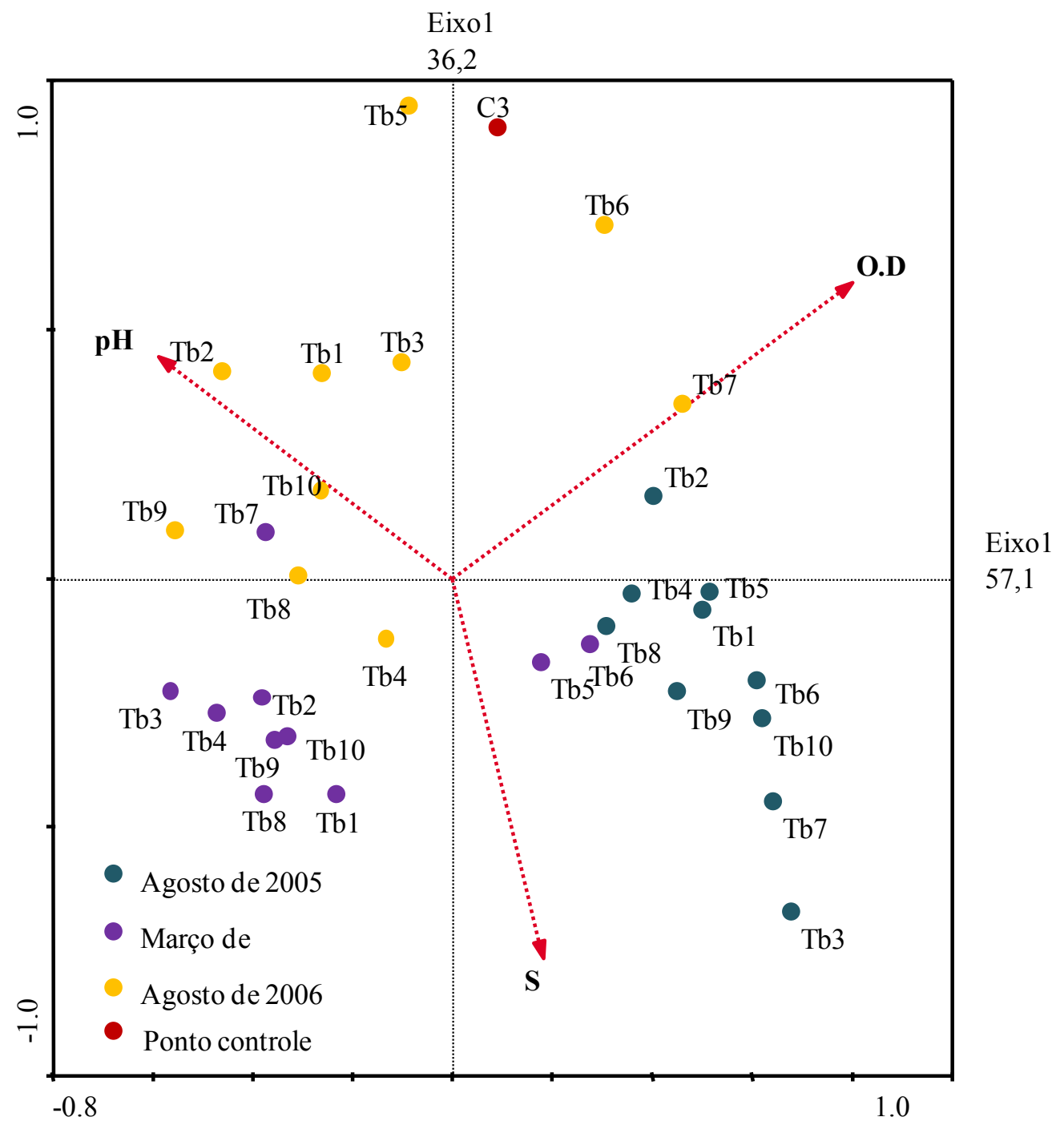

Figura 35 - Diagrama de ordenação das relações existentes entre as estações e os parâmetros abióticos.

\subsection{DISCUSSÃO}

\subsubsection{Parâmetros físico-químicos da coluna d’água}

Verificou-se estratificação térmica significativa ao longo da coluna d'água na área de estudo, em Agosto de 2005 e Março de 2006. As diferenças obtidas, entre 3 e 6 ${ }^{\circ} \mathrm{C}$, passaram a ocorrer a partir das águas do meio. De acordo com as características físico-químicas da coluna d'água, verificou-se durante os três períodos de coleta a mistura das massas Água Costeira e Água Tropical. 
Em Março e Agosto de 2006 foram observados valores de oxigênio dissolvido abaixo do limite de proteção à vida aquática, para águas salinas de Classe 1 (Resolução CONAMA 357/2005). Em Agosto baixos níveis de oxigênio dissolvido foram observados somente nas águas de fundo de quatro estações (Tb2, Tb4, Tb8 e Tb9), das quais duas estações apresentaram valor aproximado do limite padrão estabelecido pela Resolução acima citada (i.e. $6 \mathrm{mg} \mathrm{L}^{-1}$ ). Em Março, por sua vez, 80\% das estações apresentaram declínio de oxigênio dissolvido a partir das águas do meio. Infere-se, entretanto, que as alterações encontradas são de origem natural. Tal inferência deve-se ao fato de que os valores de turbidez são pouco expressivos, não indicando consumo de oxigênio dissolvido para degradação de matéria orgânica. As menores concentrações de oxigênio dissolvido foram encontradas em estações com as maiores profundidades e estratificações térmicas expressiva, entre 4 e $6{ }^{\circ} \mathrm{C}$. Situação semelhante foi observada no Saco da Capela.

Os valores de turbidez, conforme mencionado acima são baixos quando comparados com os valores obtidos próximo ao emissário submarino de esgotos domésticos do Araçá e do Saco da Capela.

A pluma gerada pelo efluente disposto pelo emissário do TEBAR possui características físico-químicas diferentes das geradas pelos emissários do Araçá e do Saco da Capela.

Nesses dois emissários a pluma tende a aflorar na superfície, ao passo que no TEBAR, devido à alta densidade do efluente, a mesma permanece submersa (Marcellino, 2000). Por permanecer submersa, e nesta posição percorrer longas distâncias (Fortis, 2005), há maior dificuldade de se visualizar um sentido preferencial de dispersão. Entretanto, com base nos valores de turbidez obtidos nos dois primeiros períodos de análise, nas águas de meio e fundo, verificou-se sentido preferencial de dispersão de oeste para leste da malha de amostragem.

Os valores de $\mathrm{pH}$ obtidos ao longo da coluna d'água são levemente alcalinos, sendo entretanto, típicos de ambientes marinhos. Os efluentes antes de serem liberados passam pela etapa de neutralização, na qual o $\mathrm{pH}$ é corrigido para valor aproximado ao do compartimento aquoso no qual será lançado, i.e. próximo a 7 (Fortis, 2005).

Assim como para os demais emissários, os valores de nutrientes analisados ao longo da coluna d'água estiveram abaixo do método analítico. 


\subsubsection{Parâmetros granulométricos e geoquímicos}

Em todos os períodos de estudo, verificou-se sedimentação litoclástica, com predomínio de sedimentos pelíticos na área de estudo. $\mathrm{O}$ aporte de finos para a região ocorre através do material carreado do continente, bem como pelo material particulado que retorna, em suspensão, da região norte para a região central do canal, devido a giros anti-horários (Furtado et al., 2008). Já a fração areia, é oriunda tanto do aporte de material continental, bem como pelo retrabalhamento de sedimentos relictos.

Pelo padrão de distribuição granulométrica, verifica-se como sentido preferencial das correntes de sudoeste para leste-nordeste da malha de amostragem. Em Março observou-se menor porcentagem de sedimentos finos nas estações Tb1 e Tb4, localizadas na saída do emissário e na região sul da malha de amostragem, respectivamente. Para este período, foi possível inferir maior ação do efluente na dispersão de finos nas estações mencionadas.

Comparando-se os resultados geoquímicos obtidos no TEBAR, com os dos demais emissários, infere-se elevada degradação ambiental, ocasionada pelas atividades antropogênicas que ocorrem na região.

Em todos os períodos, os sedimentos apresentaram características redutoras, cujos valores de Eh indicavam redução do nitrogênio para amônia e enxofre para sulfeto (Mitsch e Gosselink, 1986 in Esteves, 1998). Com base nos valores de Eh, alguns autores propuseram classificações para o compartimento sedimentar. Hergrave et al. (2009), ao compilar dados de pesquisas realizadas, inferiu que sedimentos com valores de Eh entre - 50 e - $150 \mathrm{mV}$ são considerados hipóxicos, e abaixo de $-150 \mathrm{mV}$ são considerados anóxicos. Pearson e Rosenberg (1978), Wildish et al. (2001) e Sutherland et al. (2007), consideram que sedimentos com valores de Eh entre 0 e -100 são hipóxicos, ao passo que sedimentos com valores abaixo de $-100 \mathrm{mV}$ são considerados anóxicos. Os valores obtidos no TEBAR indicam para o compartimento sedimentar oscilação entre hipoxia e anoxia. Contudo, infere-se que períodos prolongados de anoxia não ocorrem, uma vez que não foram identificadas regiões azóicas, conforme será demonstrado posteriormente, quando os resultados das análises das associações de foraminíferos forem discutidos. Com base no disposto em Hergrave et al. (2009), os valores obtidos indicam que a reação metabólica predominante no compartimento bentônico é a realizada por bactérias sulfato redutoras. 
Em Agosto de 2006, 60\% das estações apresentaram sinais de acidez nos sedimentos, o que pode ser associado à degradação de elevada quantidade de matéria orgânica existente nos sedimentos, uma vez que o $\mathrm{pH}$ da coluna d'água, em todas as estações e períodos apresentou-se alcalino.

Os teores obtidos para carbono orgânico total, nitrogênio, fósforo e enxofre são expressivamente superiores aos obtidos para os emissários do Araçá e Saco da Capela, bem como possuem distribuição mais homogênena por entre as estações.

As diferenças de teores encontradas entre os emissários submarinos relacionamse tanto ao hidrodinamismo, a topografia, à composição textural dos sedimentos, como também ao tipo de efluente. No TEBAR, o efluente disposto é principalmente derivado das águas de nas lavagens dos tanques e das águas de produção, a qual é a maior parte do subproduto derivado do processo de exploração e produção de petróleo. A água de produção possui complexa composição, sendo observado entre os principais compostos e elementos, os nutrientes, o sulfeto, a amônia e os hidrocarbonetos (Utvik, 1999). Como a pluma gerada pelo efluente tende a permanecer por mais tempo próximo aos difusores, grande parte dos elementos e compostos mais persistentes são depositados nos sedimentos.

Os valores de carbono orgânico total são considerados entre moderados, quando comparados com outras regiões sob estresse ambiental, tais como o Araçá, cujos resultados foram anteriormente discutidos e Baía de Santos (0,09 a 2,91; Abessa et al., 2005), a qual além da disposição oceânica de esgotos é considerada uma zona portuária de grande importância. Entre os períodos, verificou-se pouca diferenciação de teores, o que indica aporte contínuo de carbono orgânico total para a área de estudo.

Os teores de nitrogênio, considerados elevados em Agosto de 2005 e Março de 2006, sofreram declínio expressivo de concentrações em Agosto de 2006. Uma das hipóteses prováveis para esta diminuição de concentração pode estar relacionada a algum tipo de alteração, seja no volume ou composição, no efluente disposto. Tal inferência deve-se ao fato de que em coleta realizada em Abril de 2007, os valores obtidos foram duas vezes superiores aos observados para Agosto de 2005 e Março de 2006 (Gubitoso, 2010).

Assim como para nitrogênio, verificou-se diminuição significativa nos teores de fósforo em Agosto de 2006. Além das formas de fósforo existentes nos detergentes, na região do TEBAR há outra fonte de origem, i.e. as águas de produção. Segundo Rocha et al, (1998), durante a exploração de petróleo nas plataformas, são utilizados inibidores 
enriquecidos em fósforo (fosfinopolicarboxilatos) nos sistemas de perfuração, com o intuito de inibir incrustações geradas por sulfato de bário $\left(\mathrm{BaSO}_{4}\right)$ e sulfato de estrôncio $\left(\mathrm{SrSO}_{4}\right)$, cujo acúmulo tende a difícultar o fluxo de captação do petróleo. Subseqüentemente, os inibidores que ficam agregados ao óleo cru são dispostos no ambiente marinho durante a lavagem dos tanques. Em Agosto de 2005 verificou-se quase homogeneidade de valores, em Março os valores sofreram declínio, sendo observado na estação Tb1, localizada na parte final do emissário submarino, teor entre 2 e 4 vezes superior ao observado para estações posicionadas adjacentes, indicando enriquecimento pontual de fósforo. Teor levemente inferior aos obtido para a estação Tb1 ocorreu na estação Tb7. A diminuição de teores, no decorrer dos períodos amostrados, deve-se a regulamentação da Resolução CONAMA 359, a qual passou a vigorar em 2005. Nesta Resolução consta a necessidade de diminuição dos teores de fósforo nos detergentes em um período máximo de 3 anos a contar de 2005. Apesar dos teores encontrados em Agosto de 2006, serem considerados elevados quando comparados com os obtidos no Araçá, fósforo decorrente de atividades antropogênicas somente foram identificados em Agosto de 2005 e Março de 2006. ${ }^{19}$ Menciona-se que alternâncias de maior ou menor porcentagem das frações inorgânicas e orgânicas são decorrentes do próprio ciclo do fósforo, onde sob $\mathrm{pH}$ alcalino da água do mar o fosfato orgânico é hidrolisado e retorna à sua forma inorgânica, tornando-se novamente biodisponível para o fitoplâncton (Soares-Gomes e Figueiredo, 2002).

Os teores de enxofre são considerados elevados e de origem antrópica ${ }^{20}$. Além da presença de compostos de enxofre na formulação de detergentes utilizados nas lavagens dos tanques, existe na região a liberação de águas de lastro, as quais contêm resíduos de petróleo, que é uma fonte de enxofre para o ambiente marinho (Baird, 2002). O enxofre observado na área de estudo também pode ser devido à ineficiência do sistema de tratamento, uma vez que no efluente há quantidade significativa de sulfeto, bem como em uma das etapas para o tratamento é adicionado ácido sulfúrico.

Os resultados das razões $\mathrm{C} / \mathrm{N}$ indicaram forte componente continental na origem da matéria orgânica, sendo mais acentuado em Agosto de 2006. Os valores obtidos em Agosto de 2005 e Março de 2006 são em geral indicativos de origem mista, porém com tendência a origem continental, i.e. valores muito próximos de 12.

\footnotetext{
${ }^{19}$ Teor de fósforo indicativo de atividades antropogênicas: superior a $0,7 \%$ (Baturin, 2003).

${ }^{20}$ Teor de fósforo indicativo de atividades antrópicas: superior a 0,13\% (Turekian e Wedepohl, 1961)
} 
No tocante ao potencial de oxi-redução dos sedimentos, analisado por meio de razões $\mathrm{C} / \mathrm{S}$, caracterizou-se a região circunjacente do emissário petroquímico do TEBAR como sendo ambiente marinho sub-óxico ${ }^{21}$. Sedimentos com características redutoras foram observados nos locais onde foram posicionadas as estações Tb3 e Tb9 (Agosto de 2005) e Tb4 e Tb8 (Março de 2006). Os sedimentos dos locais onde foram posicionadas as estações Tb5 e Tb9 (Agosto de 2006) são considerados óxicos.

A degradação ambiental que há na região pôde ser verificada tanto pelos resultados geoquímicos, bem como pelas associações de foraminíferos, cujos resultados serão abordados.

\subsubsection{Associações de foraminíferos - biocenoses e tanatocenoses}

Assim como o verificado para os emissários submarinos de esgotos domésticos do Araçá e Saco da Capela, foram obtidas dissimilaridades significativas nos estudos composicionais realizados entre as biocenoses e tanatocenoses no TEBAR. Pelos gráficos de ordenação verificou-se que há maior homogeneidade na estrutura composicional das biocenoses, o que se deve à predominância de poucas espécies. A porcentagem de espécies comuns às duas associações é baixa e com diferenciação expressiva em suas abundâncias relativas. Os resultados estatísticos obtidos pelo NMDS, MANOVA, Análise de Agrupamento e teste $t$ ressaltam a importância de estudos em separado das tanatocenoses e biocenoses.

Na região circunjacente ao emissário do TEBAR, a composição e distribuição das associações de foraminíferos foram influenciadas pelos níveis de oxigenação da interface água-sedimento, pelos teores de enxofre, pelos valores de $\mathrm{pH}$, pelas profundidades e temperaturas. Tal inferência tem como base os resultados das correlações de Pearson e da Análise de Correspondência Canônica.

Comparativamente, entre os três emissários submarinos existentes no lado continental do Canal de São Sebastião (Araçá, Cigarras e TEBAR), a região circundante ao emissário para efluentes petroquímicos do TEBAR é a que apresenta maior grau de estresse ambiental. No TEBAR ocorreram os menores valores de densidade, riqueza, diversidade específica e equitatividade. Os valores baixos de diversidade específica e

\footnotetext{
${ }^{21}$ Classificação conforme o disposto em Aller et al. (2004). Segundo os autores razões C/S entre 4 e 6 são encontradas em ambientes marinhos sub-óxicos e inferiores a 3 são observadas em ambientes redutores.
} 
equitatividade são forte e negativamente influenciados pela dominância da espécie Ammonia tepida (qv. Anexos 72, 73 e 74).

Entre os três períodos amostrados, verificou-se oscilação nos valores de densidade e riqueza, sendo observado maior estresse ambiental em Agosto de 2005 onde foi necessário analisar volumes de sedimento 5 a 6 vezes superiores, para a obtenção de um $\mathrm{n}_{\text {amostral }}$ mínimo, i.e. 100 foraminíferos.

Pelas correlações de Pearson, não foi encontrada relação direta entre os descritores ecológicos e a geoquímica dos sedimentos, o que talvez esteja relacionado à distribuição quase homogênea dos macronutrientes analisados.

O aporte crônico de matéria orgânica, tende a alterar as características físicoquímicas do compartimento bentônico, dentre as quais os níveis de oxigenação, um importante parâmetro que influencia diretamente a composição e distribuição das associações de foraminíferos (Jorissen et al., 1995; van der Zwaan et al., 1999).

Os níveis de oxigenação influenciaram significantemente a composição das associações de foraminíferos. A relação entre a qualidade e quantidade de matéria orgânica e os níveis de oxigenação observados no TEBAR é inversa à observada na região do Saco da Capela. No TEBAR há dominância de espécies infaunais, comumente identificadas em ambientes enriquecidos por matéria orgânica e com baixos níveis de oxigenação na interface água-sedimento, tais como Ammonia tepida, Buliminella elegantissima, Hopkinsina pacifica, Fursenkoina pontoni, Pseudononion atlanticum (q.v. Apêndice 1.1).

Espécies epifaunais e estebonobióticas, por sua vez, ocorreram em abundâncias pouco expressivas, sendo observada sua ausência em Agosto de 2006 nas estações Tb1, Tb7 e Tb8. Em Março de 2006, verificou-se que as espécies bioindicadoras de ambiente óxico estiveram presentes em relação inversa ao verificado para os teores de carbono orgânico total $(\mathrm{r}=-0,70 ; p<0,05)$ e nitrogênio $(\mathrm{r}=-0,70 ; p<0,01)$. Representantes da Subordem Miliolina, presentes em abundâncias pouco expressivas em Agosto de 2005 e Março de 2006, não foram observados Agosto de 2006.

Mendes (2010), ao analisar a macrofauna bentônica no Canal de São Sebastião, verificou próximo ao TEBAR a presença dominante de espécies oportunistas (Cossura candida e Mediomastus capensis), sendo Cossura candida capaz de se adaptar em ambientes hipóxicos (Lamont e Gage, 2000 in Mendes, 2010). Ainda segundo o autor, com o distanciamento das áreas sob maior influência antrópica, bem como com alteração dos sedimentos para uma granulação mais grossa, verificou-se aumento de 
diversidade específica, das equitatividades, bem como alteração na composição estrutural da macrofauna.

O tamanho das carapaças dos foraminíferos evidencia os baixos níveis de oxigenação, que há na região do TEBAR. Em todos os períodos verificou-se abundância expressiva de foraminíferos com carapaças pequenas, as quais chegaram a ser dominantes em Agosto de 2006. Com base nos resultados obtidos, e segundo o disposto na literatura a cerca da influência do oxigênio dissolvido sobre o tamanho das carapaças dos foraminíferos (Bradshaw, 1961; Phleger e Soutar, 1973; Sen Gupta e MachainCastillo, 1993), infere-se que a região do TEBAR é ambiente hipóxico, cujos níveis de oxigenação são suficientes somente para suprir as necessidades metabólicas de organismos pequenos e/ou de tamanho médio. Conforme observado pelas correlações de Pearson carapaças pequenas possuem distribuição significantemente inversa em relação à carapaças médias (q.v. Anexos 72, 73 e 74).

Apesar de valores de $\mathrm{pH}$ inferiores a 7,5 serem propícios a iniciar processos de dissolução nas carapaças dos foraminíferos, não foram observadas nas biocenoses e tanatocenoses carapaças com sinais de dissolução. Menciona-se, entretanto, que diferentemente do observado para os emissários do Araçá e Saco da Capela, os foraminíferos do TEBAR apresentaram, em grande maioria, carapaças pequenas com paredes mais finas.

Em relação às tanatocenoses, verificou-se que os valores de densidade, de riqueza, de diversidade específica e equitatividade são superiores quando comparados com as biocenoses; resultado já esperado e evidenciado nas demais áreas de estudo. Entretanto, no geral, a degradação ambiental que ocorre no TEBAR e que foi evidenciada pelas biocenoses, também é demonstrada pelas tanatocenoses, cujos resultados passam a ser discutidos.

Pararotalia cananeiaensis é a espécie predominante em todas as estações e em todos os períodos estudados. As características desta espécie como bioindicadora de aporte de água marinha, bem como suas preferências ecológicas já foram discutidas em capítulos anteriores, motivo pelo qual não serão aqui apresentadas. Apesar da presença abundante e conspícua de Pararotalia cananeiaensis nas tanatocenoses, nas biocenoses esteve presente em abundância expressiva somente em Agosto de 2005, período em que foi a segunda espécie mais abundante. Em Março e Agosto de 2006 foram identificados somente 3 e 1 espécimes, respectivamente, o que indica que as carapaças identificadas nas tanatocenoses podem representar processos de transporte e deposição, longos 
períodos de acúmulo de carapaças, ou mesmo a união de ambas as hipóteses. A presença constante e expressiva de Pararotalia cananeiaensis indica o aporte de águas marinhas para a região central do Canal de São Sebastião, bem como corrobora baixo hidrodinamismo que há na região, a qual já foi evidenciada pelos resultados das análises granulométricas e geoquímicas.

A entrada de águas da plataforma externa também é inferida pela presença de foraminíferos planctônicos, identificados em todos os períodos analisados.

Ammonia tepida é a segunda espécie mais abundante, porém com diferença significativa em relação às abundâncias obtidas nas biocenoses (q.v. Anexos 64 e 57). As diferenças encontradas em relação à Pararotalia cananeiaensis também são expressivas, em média entre 30 e $60 \%$.

Assim como o verificado para as biocenoses, espécies infaunais, bioindicadoras de ambiente enriquecido por matéria orgânica são predominantes em todas as estações nas tanatocenoses. As espécies que apresentaram as maiores abundâncias foram Pseudononion atlanticum, Buliminella elegantissima, Cassidulina crassa e Bulimina marginata.

Espécies epifaunais, apesar presentes em todas as estações e ter sido verificado ligeiro aumento em suas abundâncias, não alteram as informações obtidas pelas biocenoses. Relação entre espécies infaunais e epifaunais identificadas nas tanatocenoses ainda indicam o enriquecimento orgânico e os baixos níveis de oxigenação que ocorrem na região. Rosalina floidensis, Neocornobina terquemi e Lobatula lobatula foram as principais espécies epifaunais identificadas.

Assim como o verificado nas biocenoses, miliolídeos diminuíram de abundância entre os períodos, sendo a abundância relativa obtida em Agosto de 2006 pouco expressiva. Foram identificados 6 espécimes, distribuídos entre 2 espécies (Pyrgo ringens e Quinqueloculina milleti) e 3 gêneros (Adelosina sp, Miliolinella sp e Quinqueloculina sp).

Miliammina fusca foi identificada em Março e Agosto de 2006. O bom estado de preservação das carapaças indica que há aporte de águas fluviais em região próxima ao TEBAR. Como possíveis fontes menciona-se o porto de São Sebastião e o canal de drenagem que há entre o porto e o TEBAR.

Em relação à morfometria, carapaças pequenas e médias estiveram presentes quase na mesma proporção, sendo observado para Agosto de 2005 predomínio de carapaças pequenas. Diferentemente do observado nas biocenoses, nas tanatocenoses 
foram identificados foraminíferos com carapaças grandes, em porcentagem significativa, e macroforaminíferos, os quais devem ter sido transportados de áreas adjacentes.

No tocante ao grau de preservação das carapaças verificou-se alternância entre carapaças inteiras e parcialmente fragmentadas, devido à abrasão mecânica durante processos de transporte. Apesar de ser considerado ambiente de baixa energia, pelos teores de areia verifica-se que há circulação atuando no retrabalhamento dos sedimentos de fundo. Outros fatores que contribuem para a fragmentação das carapaças, seja parcial ou total, é a espessura das paredes. Carapaças com paredes mais finas, como as obtidas na região do TEBAR, tendem a se fragmentar com mais facilidade. Outro fator que pode estar influenciando na porcentagem de carapaças parcialmente fragmentadas é o transporte de carapaças alóctones para a região, as quais podem tanto ser transportadas em suspensão, bem como por saltação e/ou rolação.

Assim como o verificado para os demais emissários, as carapaças no TEBAR são predominantemente normais, i.e. sem alteração em sua coloração devido à impregnação e/ou preenchimento. Entretanto, foram observadas porcentagens expressivas de carapaças preenchidas por monossulfeto de ferro/pirita. Para que o monossulfeto de ferro/pirita se precipite são necessárias certas condições, entre elas a presença de minerais de ferro, sulfato dissolvido, matéria orgânica e bactérias sulfato redutoras (Berner, 1970, 1974 in Duleba, 1994), condições estas existentes no TEBAR. Ressalta-se, entretanto, que a ocorrência de carapaças preenchidas por monossulfeto de ferro/pirita indicam que as mesmas são relíctas no ambiente, e que durante seu tempo de deposição as condições redutoras foram constantes, uma vez que com a alteração da oxigenação do meio, ou seja, de redutor para oxidante, o monossulfeto de ferro pode ser transformado em óxido e/ou hidróxido de ferro, alterando desta forma a coloração das carapaças (Maiklem, 1967 in Duleba, 1994). Carapaças acastanhadas, devido à presença de óxido e/ou hidróxido de ferro também foram encontradas, porém em concentrações pouco significativas.

As porcentagens de carapaças com sinais de bioerosão são bem superiores às obtidas para os demais emissários, o que se relaciona ao menor hidrodinamismo que há na região, bem como a maior abundância de espécies predadoras de foraminíferos. 


\section{Anexos}

Anexo 54 - Distribuição granulométrica obtida próximo ao emissário submarino de esgotos domésticos do TEBAR.

Valores em porcentagem.
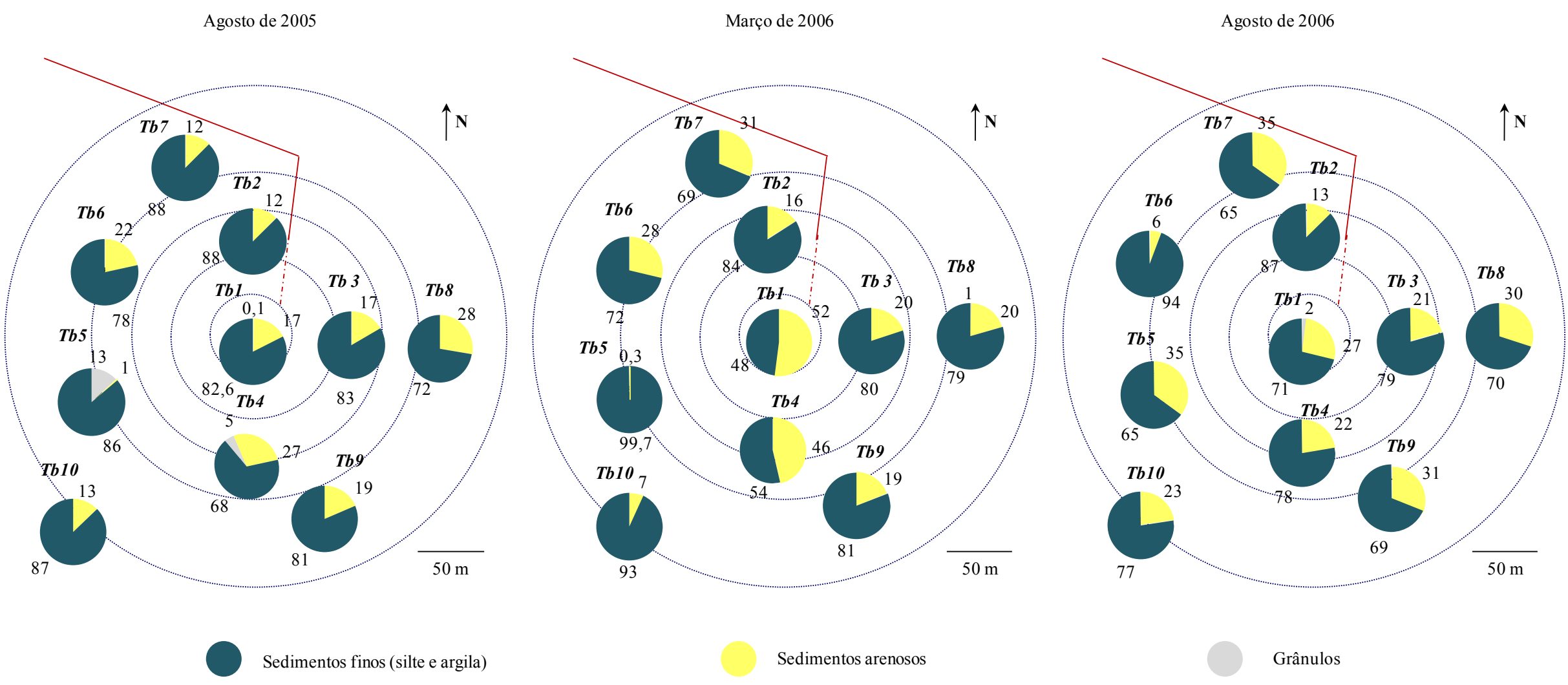
Anexo 55 - Concentrações de carbonato de cálcio obtidas próximo ao emissário do TEBAR.

Valores em porcentagem.
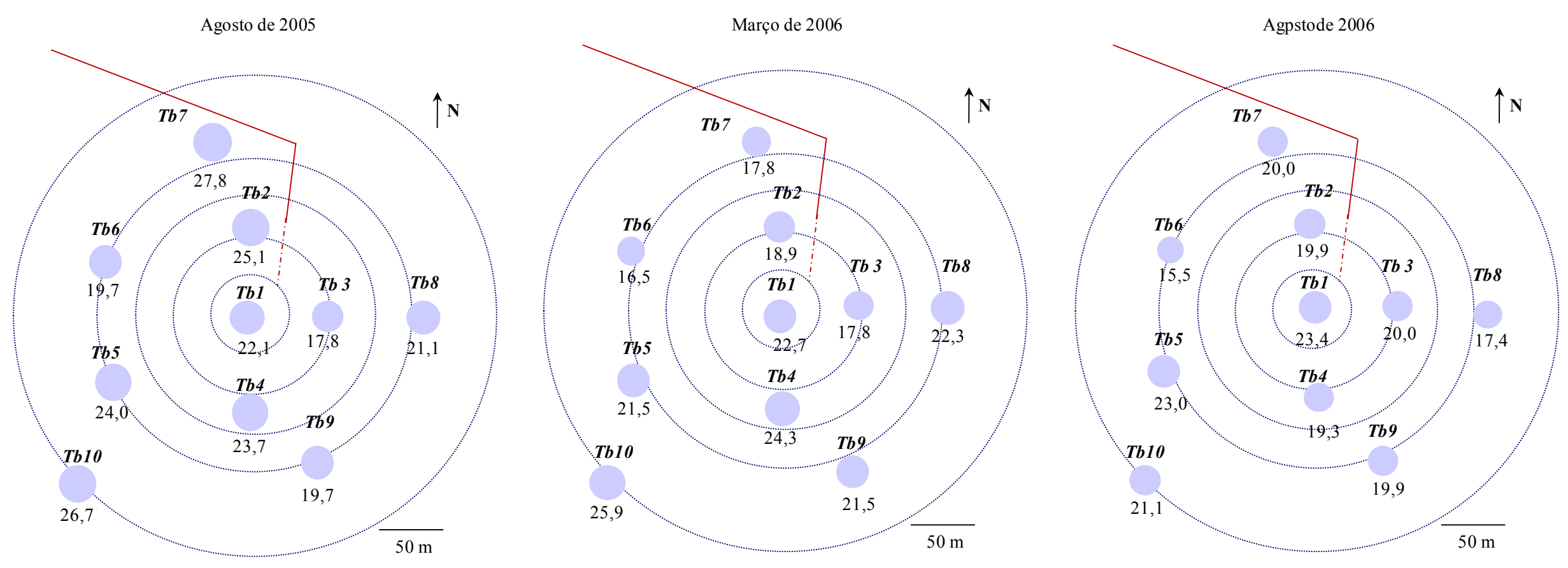
Anexo 56 - Concentrações carbono orgânico total obtidas próximo ao emissário do TEBAR.

Valores em porcentagem.
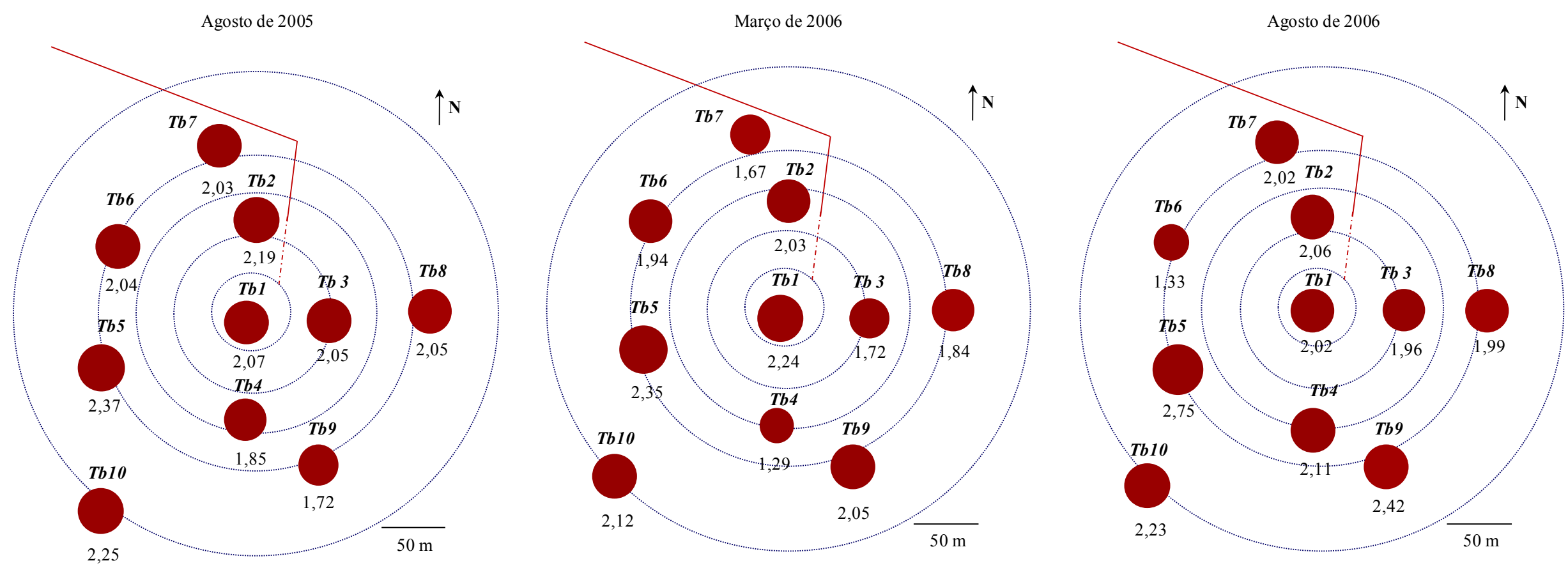
Anexo 57 - Concentrações nitrogênio obtidas próximo ao emissário do TEBAR.

Valores em porcentagem.
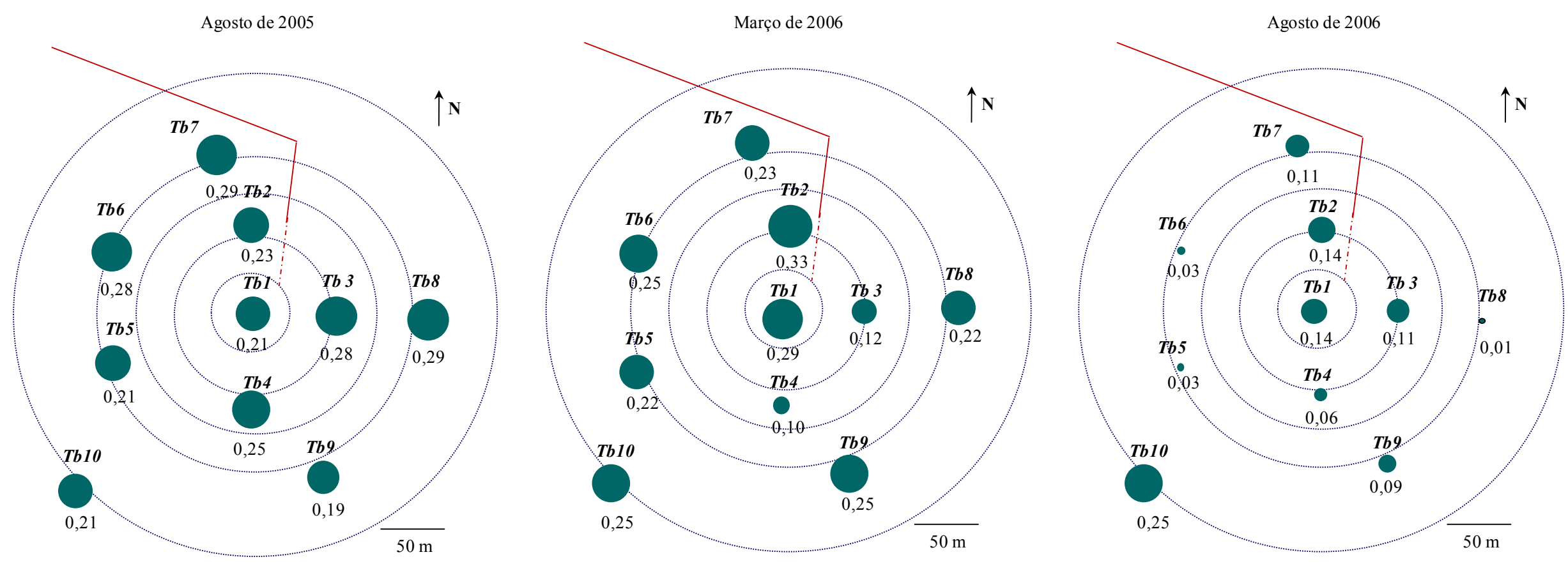
Anexo 58 - Concentrações fósforo total obtidas próximo ao emissário do TEBAR.

Valores em porcentagem.
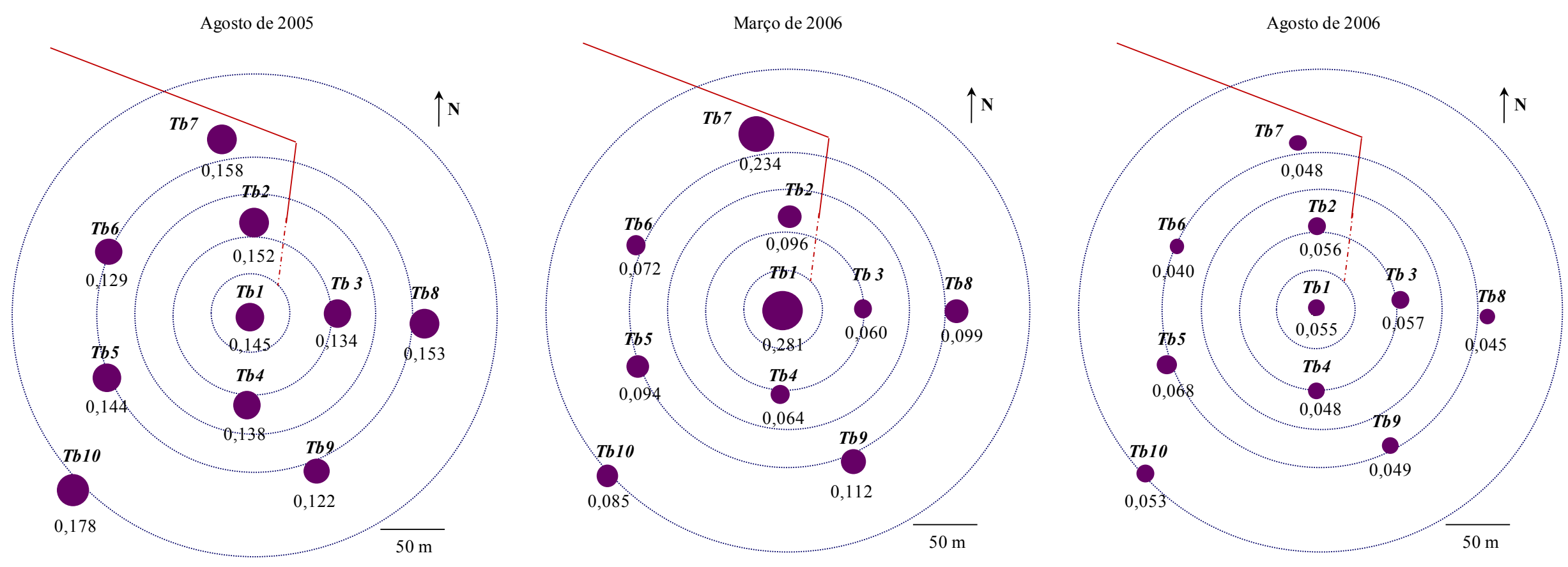
Anexo 59 - Concentrações fósforo orgânico obtidas próximo ao emissário do TEBAR.

Valores em porcentagem.
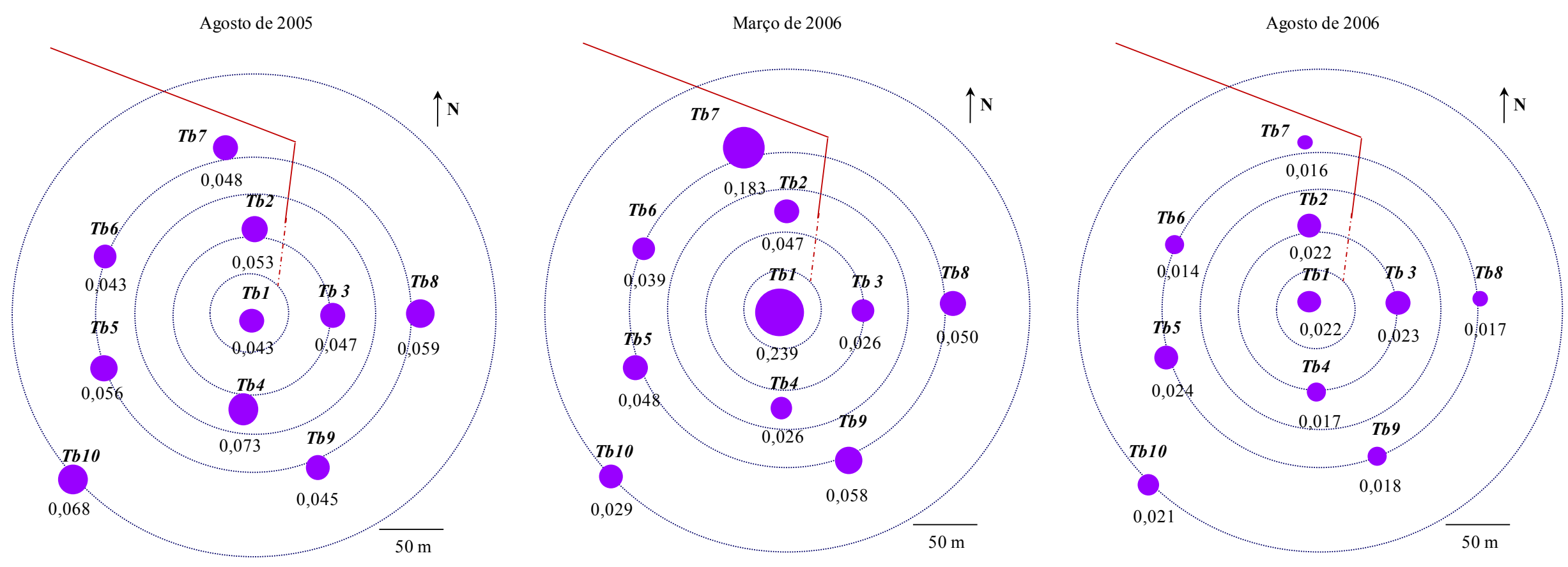
Anexo 60 - Concentrações fósforo inorgânico obtidas próximo ao emissário do TEBAR.

Valores em porcentagem.
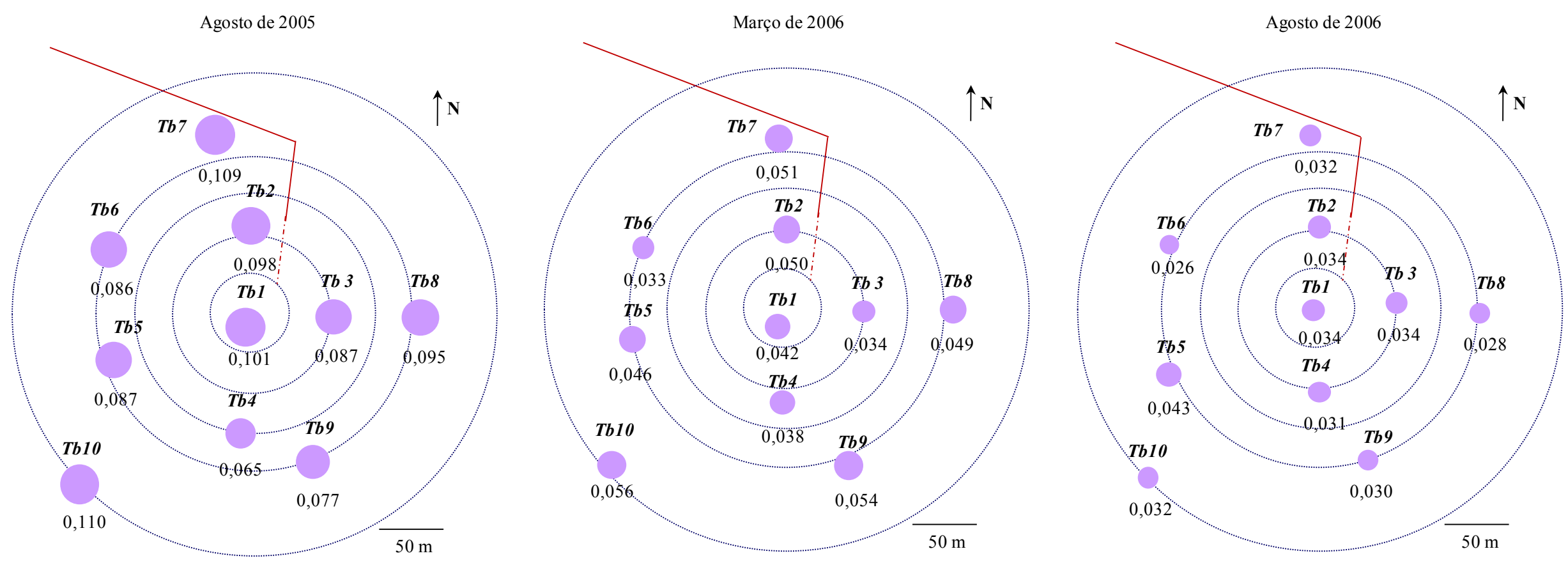
Anexo 61 - Concentrações enxofre obtidas próximo ao emissário do TEBAR.

Valores em porcentagem
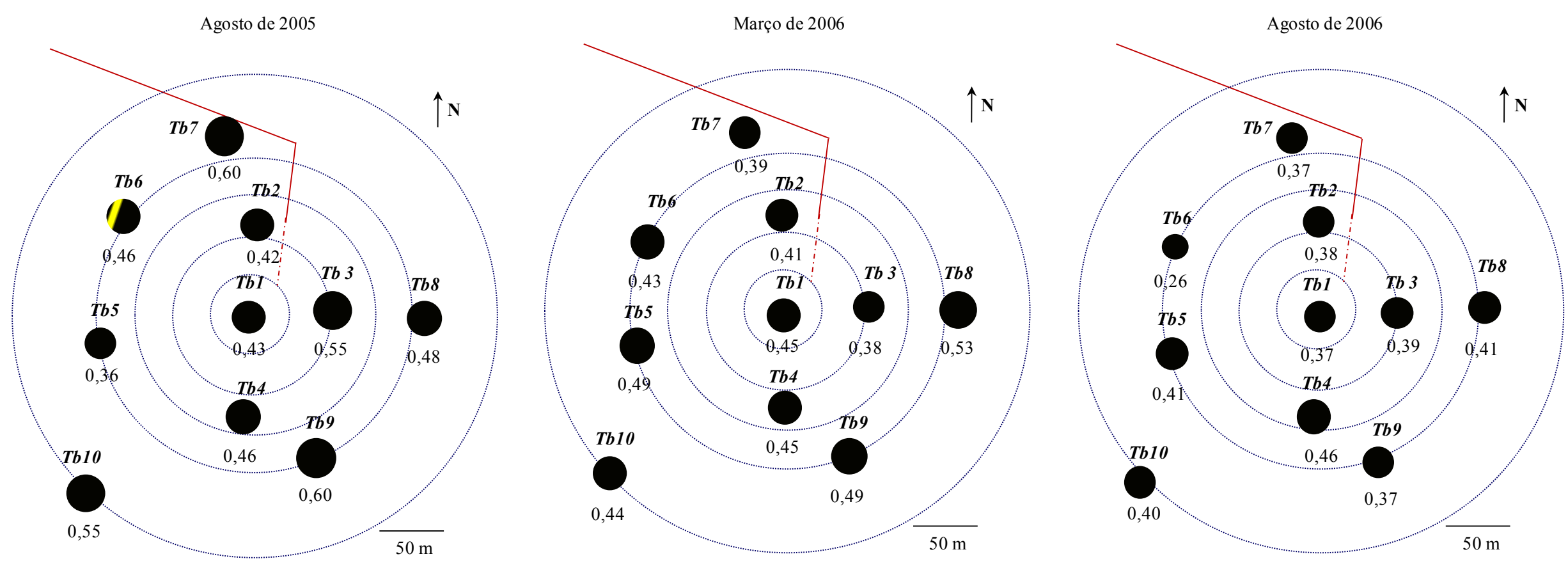
Anexo 62 - Origem da matéria orgânica analisada pelas razões elementares $\mathrm{C} / \mathrm{N}$.

Dados obtidos próximo ao emissário do TEBAR.

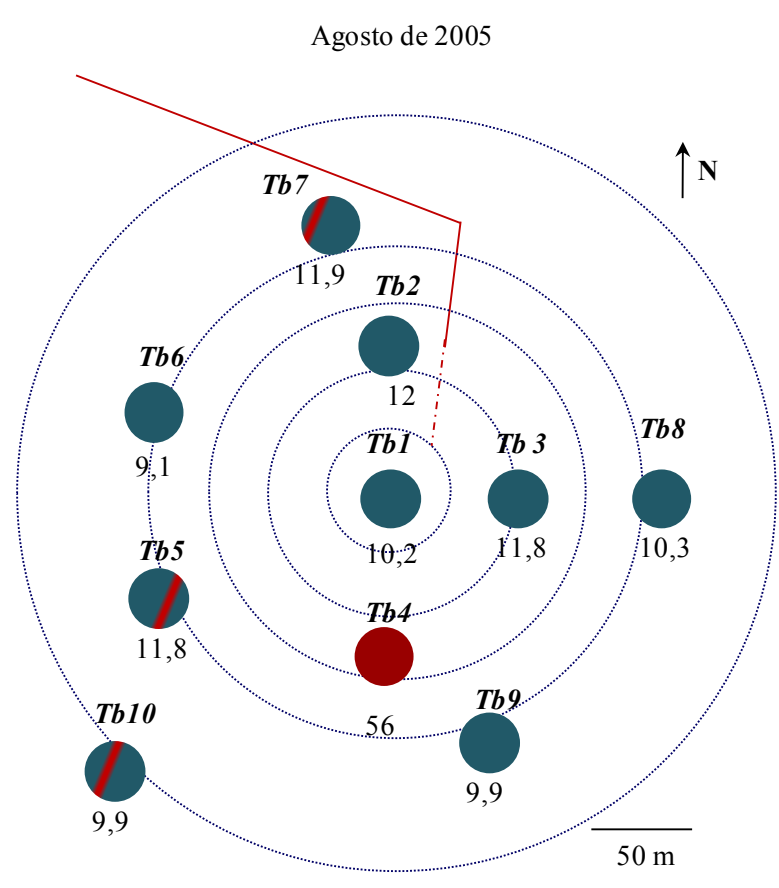

Matéria orgânica de origem marinha

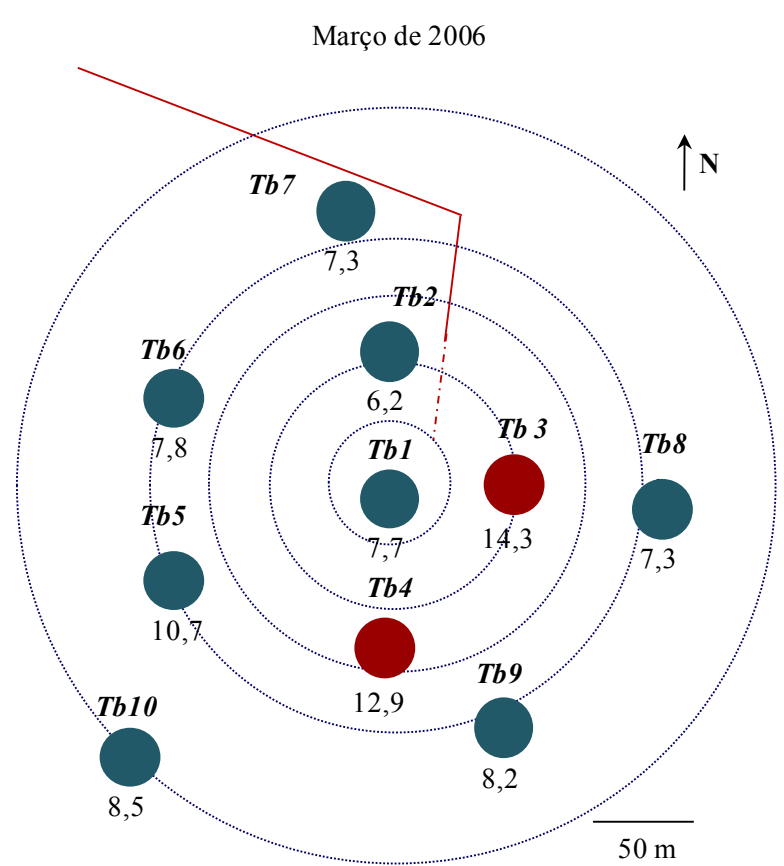

Matéria orgânica de origem continental

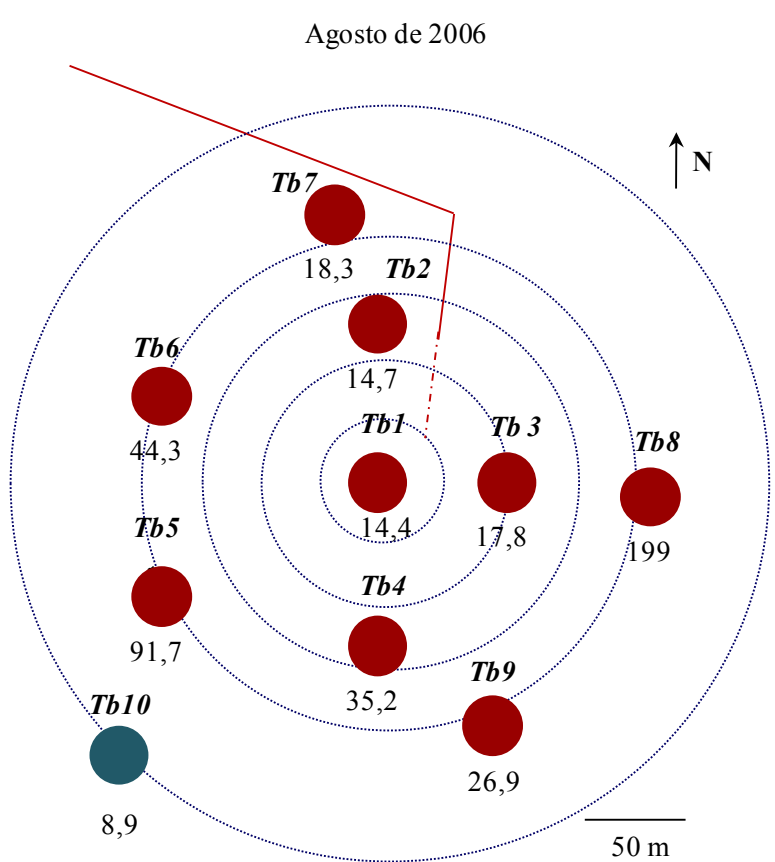

Matéria orgânica de origem mista 
Anexo 63 - Potencial de oxi-redução dos sedimentos de fundo analisado por meio de razões elementares C/S. Dados obtidos próximo ao emissário TEBAR.

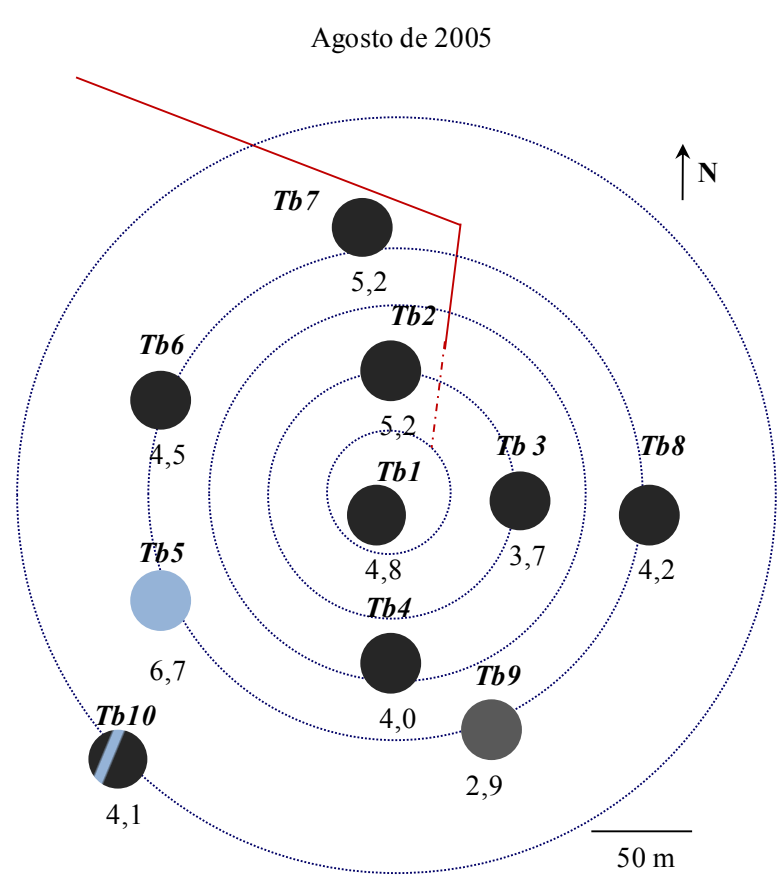

Ambiente óxico

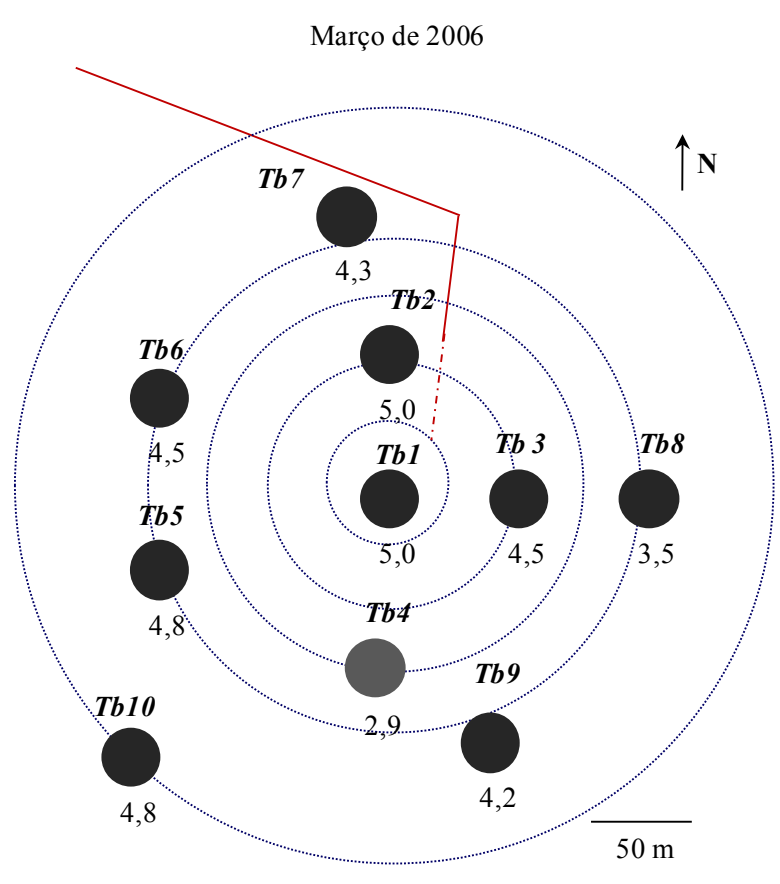

Ambiente redutor

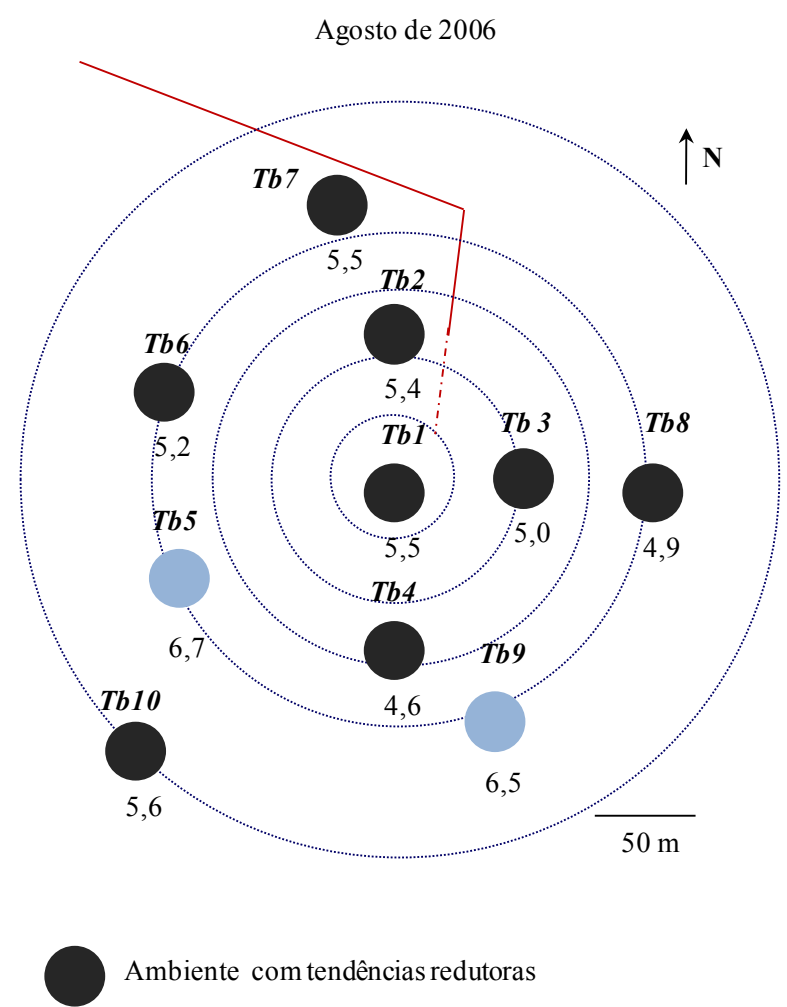


Anexo 64 - Abundâncias relativas das espécies de foraminíferos identificadas próximo ao emissário TEBAR.

Dados pertencentes às biocenoses.

\begin{tabular}{|c|c|c|c|c|c|c|c|c|c|c|c|c|c|c|c|c|c|c|c|c|c|c|c|c|c|c|c|c|c|c|}
\hline \multirow[b]{2}{*}{ Estações } & \multicolumn{10}{|c|}{ Agosto de 2005} & \multicolumn{10}{|c|}{ Março de 2006} & \multicolumn{10}{|c|}{ Agosto de 2006} \\
\hline & $\mathrm{Tb} 1$ & $\mathrm{~Tb} 2$ & $\mathrm{~Tb} 3$ & $\mathrm{~Tb} 4$ & Tb5 & Tb6 & $\mathrm{Tb} 7$ & $\mathrm{~Tb} 8$ & Tb9 & Tb10 & $\mathrm{Tb} 1$ & $\mathrm{~Tb} 2$ & $\mathrm{~Tb} 3$ & $\mathrm{~Tb} 4$ & Tb5 & Tb6 & $\mathrm{Tb} 7$ & Tb8 & $\mathrm{Tb} 9$ & Tb10 & $\mathrm{Tb} 1$ & $\mathrm{~Tb} 2$ & $\mathrm{~Tb} 3$ & $\mathrm{~Tb} 4$ & Tb5 & Tb6 & $\mathrm{Tb} 7$ & $\mathrm{~Tb} 8$ & Tb9 & Tb10 \\
\hline Adelosina $\mathrm{sp}$ & 0,0 & 0,0 & 0,0 & 0,0 & 0,0 & 0,0 & 0,0 & 0,0 & 0,0 & 0,0 & 0,0 & 0,0 & 0,0 & 0,0 & 0,0 & 0,0 & 0,0 & 0,0 & 0,0 & 0,0 & 0,0 & 0,0 & 0,0 & 0,0 & 0,0 & 0,0 & 0,0 & 0,0 & 0,0 & 0,0 \\
\hline Ammobaculites exiguus & 0,0 & 0,0 & 0,0 & 0,0 & 0,0 & 0,0 & 1,0 & 0,0 & 0,0 & 0,0 & 0,0 & 0,0 & 0,0 & 0,0 & 0,0 & 0,0 & 0,0 & 0,0 & 0,0 & 0,0 & 0,0 & 0,0 & 0,0 & 0,0 & 0,0 & 0,0 & 0,0 & 0,0 & 0,0 & 0,0 \\
\hline Ammonia tepida & 64,2 & 41,3 & 62,3 & 65,7 & 53,6 & 54,8 & 52,0 & 46,8 & 38,5 & 51,4 & 24,0 & 36,2 & 39,0 & 28,6 & 34,4 & 37,1 & 43,9 & 13,8 & 20,6 & 22,8 & 31,3 & 30,1 & 29,5 & 31,6 & 41,5 & 44,4 & 39,4 & 44,1 & 60,4 & 45,0 \\
\hline Ammonia sp & 3,2 & 2,8 & 2,8 & 1,0 & 1,8 & 1,9 & 6,0 & 0,9 & 2,2 & 1,0 & 3,2 & 4,7 & 1,7 & 2,0 & 1,2 & 1,1 & 2,0 & 1,4 & 1,0 & 1,6 & 1,0 & 1,8 & 2,1 & 3,1 & 3,4 & 2,1 & 0,0 & 1,0 & 1,0 & 0,8 \\
\hline Ammoscalaria pseudospiralis & 0,0 & 0,0 & 0,0 & 0,0 & 0,0 & 0,0 & 0,0 & 0,0 & 0,0 & 0,0 & 0,0 & 0,0 & 0,0 & 0,0 & 0,0 & 0,0 & 0,0 & 0,0 & 0,0 & 0,0 & 0,0 & 0,0 & 0,0 & 0,0 & 0,0 & 0,0 & 0,0 & 0,0 & 0,0 & 0,0 \\
\hline Ammoscalaria $\mathrm{sp}$ & 0,0 & 0,0 & 0,0 & 0,0 & 0,0 & 0,0 & 0,0 & 0,0 & 0,0 & 0,0 & 0,0 & 0,0 & 0,0 & 0,0 & 0,0 & 0,0 & 0,0 & 0,0 & 0,0 & 0,0 & 0,0 & 0,0 & 0,0 & 0,0 & 0,0 & 0,0 & 0,0 & 0,0 & 0,0 & 0,0 \\
\hline Ammotium diversus & 0,0 & 0,0 & 0,0 & 0,0 & 0,0 & 0,0 & 0,0 & 0,0 & 0,0 & 0,0 & 0,0 & 0,0 & 0,0 & 0,0 & 0,0 & 0,0 & 0,0 & 0,0 & 0,0 & 0,0 & 0,0 & 0,0 & 0,0 & 0,0 & 0,0 & 0,0 & 0,0 & 0,0 & 0,0 & 0,0 \\
\hline Ammotium salsum & 0,0 & 0,0 & 0,0 & 0,0 & 0,0 & 0,0 & 0,0 & 2,8 & 1,1 & 0,0 & 0,8 & 0,0 & 0,0 & 0,0 & 0,0 & 2,3 & 0,0 & 2,3 & 2,0 & 0,8 & 1,0 & 2,7 & 1,1 & 4,1 & 0,0 & 2,1 & 2,4 & 0,0 & 1,0 & 2,3 \\
\hline Ammotium sp & 0,0 & 0,0 & 0,0 & 0,0 & 0,0 & 0,0 & 0,0 & 0,0 & 0,0 & 0,0 & 0,0 & 0,0 & 0,0 & 0,0 & 0,0 & 0,0 & 1,0 & 0,0 & 0,0 & 0,0 & 0,0 & 0,0 & 0,0 & 0,0 & 0,0 & 0,0 & 0,0 & 0,0 & 0,0 & 0,0 \\
\hline Angulogerina angulosa & 0,0 & 0,9 & 0,0 & 0,0 & 0,0 & 0,0 & 0,0 & 0,0 & 0,0 & 0,0 & 0,0 & 0,0 & 1,7 & 0,0 & 0,0 & 0,0 & 1,0 & 0,0 & 0,0 & 0,0 & 0,0 & 0,0 & 0,0 & 0,0 & 0,0 & 0,0 & 0,0 & 0,0 & 0,0 & 0,0 \\
\hline Angulogerina $\mathrm{sp}$ & 0,0 & 0,0 & 0,0 & 0,0 & 0,0 & 0,0 & 0,0 & 0,0 & 0,0 & 0,0 & 0,0 & 0,0 & 0,0 & 0,0 & 0,0 & 0,0 & 0,0 & 0,0 & 0,0 & 0,0 & 0,0 & 0,0 & 0,0 & 0,0 & 0,0 & 0,0 & 0,0 & 0,0 & 0,0 & 0,0 \\
\hline Astalacus crepidulus & 0,0 & 0,0 & 0,0 & 0,0 & 0,0 & 0,0 & 0,0 & 0,0 & 0,0 & 0,0 & 0,0 & 0,0 & 0,0 & 0,0 & 0,0 & 0,0 & 0,0 & 0,0 & 0,0 & 0,0 & 0,0 & 0,0 & 0,0 & 0,0 & 0,0 & 0,0 & 0,0 & 0,0 & 0,0 & 0,0 \\
\hline Astrononion sp & 0,0 & 0,0 & 0,0 & 0,0 & 0,0 & 0,0 & 0,0 & 0,0 & 0,0 & 0,0 & 0,0 & 0,0 & 0,0 & 0,0 & 0,0 & 0,0 & 0,0 & 0,0 & 0,0 & 0,0 & 0,0 & 0,0 & 0,0 & 0,0 & 0,0 & 0,0 & 0,0 & 0,0 & 0,0 & 0,0 \\
\hline Bolivina alata & 0,0 & 0,0 & 0,0 & 0,0 & 0,0 & 0,0 & 0,0 & 0,0 & 0,0 & 0,0 & 0,0 & 0,0 & 0,0 & 0,0 & 0,0 & 0,0 & 0,0 & 0,0 & 0,0 & 0,0 & 0,0 & 0,0 & 0,0 & 0,0 & 0,0 & 0,0 & 0,0 & 0,0 & 0,0 & 0,0 \\
\hline Bolivina danvilensis & 0,0 & 0,0 & 0,0 & 0,0 & 0,0 & 0,0 & 0,0 & 0,0 & 0,0 & 0,0 & 1,6 & 0,0 & 0,6 & 1,0 & 0,0 & 0,0 & 0,0 & 0,9 & 1,0 & 0,0 & 0,0 & 0,0 & 0,0 & 0,0 & 0,0 & 0,0 & 0,0 & 0,0 & 0,0 & 0,0 \\
\hline Bolivina dilatata & 0,0 & 0,0 & 0,0 & 0,0 & 0,0 & 0,0 & 0,0 & 0,0 & 0,0 & 0,0 & 0,0 & 0,0 & 0,0 & 0,0 & 0,0 & 0,0 & 0,0 & 0,0 & 0,0 & 0,0 & 0,0 & 0,0 & 0,0 & 0,0 & 0,0 & 0,0 & 0,0 & 0,0 & 0,0 & 0,0 \\
\hline Bolivina doniezi & 0,0 & 2,8 & 1,9 & 0,0 & 0,0 & 0,0 & 0,0 & 0,9 & 0,0 & 1,0 & 1,6 & 0,0 & 0,6 & 0,0 & 0,0 & 0,0 & 1,0 & 0,0 & 0,0 & 1,6 & 0,0 & 0,0 & 1,1 & 0,0 & 0,0 & 0,7 & 0,0 & 2,0 & 0,0 & 0,8 \\
\hline Bolivina pescicula & 0,0 & 0,0 & 0,0 & 0,0 & 0,0 & 0,0 & 0,0 & 0,0 & 0,0 & 0,0 & 0,0 & 0,0 & 0,0 & 0,0 & 0,0 & 0,0 & 0,0 & 0,0 & 0,0 & 0,0 & 0,0 & 0,0 & 0,0 & 0,0 & 0,0 & 0,0 & 0,0 & 0,0 & 0,0 & 0,0 \\
\hline Bolivina ordinaria & 4,2 & 4,6 & 3,8 & 2,0 & 3,6 & 2,9 & 6,0 & 0,9 & 2,2 & 4,8 & 0,8 & 3,9 & 4,0 & 3,1 & 2,5 & 1,1 & 3,1 & 0,9 & 0,0 & 0,8 & 1,0 & 0,9 & 2,1 & 1,0 & 3,4 & 2,1 & 1,6 & 2,9 & 4,2 & 2,3 \\
\hline Bolivina pseudoplicata & 0,0 & 0,0 & 0,0 & 0,0 & 0,0 & 0,0 & 0,0 & 0,9 & 0,0 & 0,0 & 0,0 & 0,0 & 0,0 & 0,0 & 0,0 & 0,0 & 0,0 & 0,0 & 0,0 & 0,0 & 0,0 & 0,0 & 0,0 & 0,0 & 0,0 & 0,0 & 0,0 & 0,0 & 0,0 & 0,0 \\
\hline Bolivina pulchella & 0,0 & 0,0 & 0,0 & 1,0 & 0,0 & 0,0 & 0,0 & 0,0 & 0,0 & 1,0 & 0,0 & 0,0 & 0,0 & 0,0 & 0,0 & 0,0 & 0,0 & 0,0 & 0,0 & 0,0 & 0,0 & 0,0 & 0,0 & 0,0 & 0,0 & 0,0 & 0,0 & 0,0 & 0,0 & 0,0 \\
\hline Bolivina translucens & 0,0 & 0,0 & 0,0 & 0,0 & 0,0 & 0,0 & 0,0 & 0,0 & 0,0 & 0,0 & 2,4 & 0,8 & 0,6 & 0,0 & 0,6 & 1,7 & 0,0 & 0,9 & 1,0 & 1,6 & 0,0 & 0,9 & 0,0 & 0,0 & 0,0 & 0,0 & 0,0 & 0,0 & 0,0 & 0,0 \\
\hline Bolivina $\mathrm{sp}$ & 1,1 & 1,8 & 0,0 & 0,0 & 1,8 & 1,9 & 0,0 & 6,4 & 4,4 & 1,9 & 2,4 & 1,6 & 2,8 & 3,1 & 1,8 & 1,1 & 3,1 & 3,7 & 0,0 & 1,6 & 1,0 & 1,8 & 3,2 & 1,0 & 0,8 & 0,7 & 0,0 & 7,8 & 1,0 & 0,0 \\
\hline Brizalina sphatulata & 0,0 & 0,9 & 0,0 & 1,0 & 0,0 & 0,0 & 0,0 & 0,9 & 4,4 & 1,0 & 0,0 & 0,8 & 2,8 & 3,1 & 1,2 & 0,0 & 1,0 & 0,5 & 1,0 & 0,0 & 0,0 & 0,0 & 0,0 & 0,0 & 0,0 & 0,0 & 0,0 & 0,0 & 0,0 & 0,0 \\
\hline Brizalina striatula & 4,2 & 2,8 & 4,7 & 4,0 & 6,4 & 5,8 & 3,0 & 0,0 & 3,3 & 3,8 & 5,6 & 4,7 & 2,3 & 3,1 & 4,9 & 9,7 & 5,1 & 3,2 & 2,0 & 7,1 & 0,0 & 3,5 & 4,2 & 1,0 & 5,1 & 3,5 & 1,6 & 2,9 & 6,3 & 3,8 \\
\hline Brizalina subaenarensis & 0,0 & 0,0 & 0,0 & 0,0 & 0,0 & 0,0 & 0,0 & 0,0 & 0,0 & 0,0 & 0,0 & 0,0 & 0,0 & 0,0 & 0,0 & 0,0 & 0,0 & 0,0 & 0,0 & 0,0 & 0,0 & 0,0 & 0,0 & 0,0 & 0,0 & 0,0 & 0,0 & 0,0 & 0,0 & 0,0 \\
\hline
\end{tabular}


Anexo 64 - Continuação

Estações

Bulimina elongata

Bulimina marginata

Bulimina pupoides

Bulimina sp

Buliminella elegantissima

Cancris sagra

Cassidulina crassa

Cassidulina laevigata

Cassidulina minuta

Cassidulina subglobosa

Cassidulina sp

Cibicides refulgens

cibicides variabilis

Cibicides sp

Cornobella pateliformis

Cornuspira involven

Discorbis bertheloti

Discorbis williamsoni

Cribroelphidium advenum

Cribroelphidium discoidale

Cribroelphidium galvestonense

Cribroelphidium excavatum

Cribroelphidium poyeanum

Cribroelphidium sp

Cribrostomoides jeffreysii

Cribrostomoides sp

Dentalina sp

Deuteramina discorbis
Agosto de 2005

\begin{tabular}{llllllllll}
\multicolumn{10}{c}{ Agosto de 2005 } \\
\hline Tb1 & Tb2 & Tb3 & Tb4 & Tb5 & Tb6 & Tb7 & Tb8 & Tb9 & Tb10
\end{tabular}

$\begin{array}{llllllllll}0,0 & 0,0 & 0,0 & 0,0 & 0,0 & 0,0 & 0,0 & 0,0 & 0,0 & 0,0\end{array}$

$\begin{array}{llllllllll}6,3 & 3,7 & 2,8 & 2,0 & 2,7 & 1,0 & 1,0 & 2,8 & 2,2 & 2,9\end{array}$

$\begin{array}{llllllllll}0,0 & 0,0 & 0,0 & 0,0 & 0,0 & 0,0 & 0,0 & 0,9 & 0,0 & 0,0\end{array}$

$\begin{array}{llllllllll}0,0 & 0,0 & 0,0 & 0,0 & 0,0 & 0,0 & 0,0 & 0,0 & 0,0 & 0,0\end{array}$

$\begin{array}{lllllllllll}4,2 & 1,8 & 0,9 & 6,1 & 11,8 & 1,0 & 7,0 & 3,7 & 11,0 & 5,7\end{array}$

$\begin{array}{llllllllll}0,0 & 0,0 & 0,0 & 0,0 & 0,0 & 0,0 & 0,0 & 0,0 & 0,0 & 0,0\end{array}$

$\begin{array}{llllllllll}0,0 & 0,0 & 0,0 & 0,0 & 0,0 & 0,0 & 1,0 & 2,8 & 1,1 & 0,0\end{array}$

$\begin{array}{llllllllll}0,0 & 0,0 & 0,0 & 0,0 & 0,0 & 0,0 & 0,0 & 0,0 & 0,0 & 0,0\end{array}$

$\begin{array}{llllllllll}0,0 & 0,0 & 0,0 & 0,0 & 0,0 & 0,0 & 0,0 & 0,0 & 0,0 & 0,0\end{array}$

$\begin{array}{llllllllll}0,0 & 0,0 & 0,0 & 0,0 & 0,0 & 0,0 & 0,0 & 0,0 & 0,0 & 0,0\end{array}$

$\begin{array}{llllllllll}0,0 & 0,0 & 0,0 & 0,0 & 0,0 & 0,0 & 0,0 & 0,0 & 0,0 & 0,0\end{array}$

$\begin{array}{llllllllll}0,0 & 0,0 & 0,0 & 0,0 & 0,0 & 0,0 & 0,0 & 0,0 & 0,0 & 0,0\end{array}$

$\begin{array}{lllllllllll}0,0 & 0,0 & 0,0 & 0,0 & 0,0 & 0,0 & 0,0 & 0,0 & 0,0 & 0,0\end{array}$

$\begin{array}{llllllllll}0,0 & 0,0 & 0,0 & 0,0 & 0,0 & 0,0 & 0,0 & 0,0 & 0,0 & 0,0\end{array}$

$\begin{array}{llllllllll}0,0 & 0,0 & 0,0 & 0,0 & 0,0 & 0,0 & 0,0 & 0,0 & 0,0 & 0,0\end{array}$

$\begin{array}{llllllllll}0,0 & 2,8 & 0,0 & 0,0 & 0,9 & 0,0 & 0,0 & 0,0 & 0,0 & 1,0\end{array}$

$\begin{array}{llllllllll}0,0 & 0,0 & 0,0 & 0,0 & 0,0 & 0,0 & 0,0 & 0,0 & 0,0 & 0,0\end{array}$

$\begin{array}{llllllllll}0,0 & 0,0 & 0,0 & 0,0 & 0,0 & 0,0 & 0,0 & 0,0 & 0,0 & 0,0\end{array}$

$\begin{array}{llllllllll}0,0 & 0,0 & 0,0 & 0,0 & 0,0 & 0,0 & 0,0 & 0,0 & 0,0 & 0,0\end{array}$

$\begin{array}{llllllllll}0,0 & 0,0 & 0,0 & 0,0 & 0,0 & 0,0 & 0,0 & 0,0 & 0,0 & 0,0\end{array}$

$\begin{array}{llllllllll}0,0 & 0,0 & 0,0 & 0,0 & 0,0 & 0,0 & 0,0 & 0,0 & 0,0 & 0,0\end{array}$

$\begin{array}{llllllllll}0,0 & 0,9 & 0,0 & 0,0 & 0,0 & 0,0 & 0,0 & 0,9 & 0,0 & 0,0\end{array}$

$\begin{array}{lllllllllll}0,0 & 0,0 & 0,0 & 0,0 & 0,0 & 0,0 & 1,0 & 0,0 & 0,0 & 0,0\end{array}$

$\begin{array}{lllllllllll}0,0 & 0,0 & 0,0 & 0,0 & 0,0 & 1,0 & 0,0 & 0,0 & 0,0 & 0,0\end{array}$

$\begin{array}{llllllllll}0,0 & 0,0 & 0,0 & 0,0 & 0,0 & 0,0 & 0,0 & 0,0 & 0,0 & 0,0\end{array}$

$\begin{array}{llllllllll}0,0 & 0,0 & 0,0 & 0,0 & 0,0 & 0,0 & 0,0 & 0,0 & 0,0 & 0,0\end{array}$

$\begin{array}{llllllllll}0,0 & 0,0 & 0,0 & 0,0 & 0,0 & 0,0 & 0,0 & 0,0 & 0,0 & 0,0\end{array}$ $\begin{array}{llllllllll}0,0 & 0,0 & 0,0 & 0,0 & 0,0 & 0,0 & 0,0 & 0,0 & 0,0 & 0,0\end{array}$
Marco de 2006

Agosto de 2006

$\begin{array}{llllllllllllllllllll}\mathrm{Tb} 1 & \mathrm{~Tb} 2 & \mathrm{~Tb} 3 & \mathrm{~Tb} 4 & \mathrm{~Tb} 5 & \mathrm{~Tb} 6 & \mathrm{~Tb} 7 & \mathrm{~Tb} 8 & \mathrm{~Tb} 9 & \mathrm{~Tb} 10 & \mathrm{~Tb} 1 & \mathrm{~Tb} 2 & \mathrm{~Tb} 3 & \mathrm{~Tb} 4 & \mathrm{~Tb} 5 & \mathrm{~Tb} 6 & \mathrm{~Tb} 7 & \mathrm{~Tb} 8 & \mathrm{~Tb} 9 & \mathrm{~Tb} 10\end{array}$
$\begin{array}{llllllllll}2,4 & 1,6 & 1,7 & 0,0 & 1,2 & 1,7 & 0,0 & 0,9 & 2,0 & 0,8\end{array}$ $\begin{array}{llllllllll}5,6 & 3,9 & 1,7 & 3,1 & 1,8 & 1,7 & 1,0 & 1,8 & 2,0 & 4,7\end{array}$ $\begin{array}{llllllllll}0,0 & 0,0 & 0,0 & 0,0 & 0,0 & 0,0 & 0,0 & 0,0 & 0,0 & 0,0\end{array}$ $\begin{array}{lllllllllll}0,0 & 0,0 & 0,0 & 0,0 & 0,0 & 0,0 & 0,0 & 0,0 & 0,0 & 0,0\end{array}$ $\begin{array}{llllllllll}6,4 & 7,9 & 5,1 & 7,1 & 7,4 & 7,4 & 7,1 & 7,4 & 6,9 & 11,0\end{array}$ $\begin{array}{llllllllll}0,0 & 0,0 & 0,0 & 0,0 & 0,0 & 0,0 & 0,0 & 0,0 & 0,0 & 0,0\end{array}$ $\begin{array}{llllllllll}5,6 & 0,8 & 5,6 & 4,1 & 8,6 & 1,1 & 1,0 & 27,2 & 9,8 & 2,4\end{array}$ $\begin{array}{llllllllll}0,0 & 0,0 & 0,6 & 0,0 & 0,0 & 0,6 & 0,0 & 0,0 & 0,0 & 0,8\end{array}$ $\begin{array}{lllllllllll}0,0 & 0,8 & 0,6 & 3,1 & 1,2 & 0,0 & 0,0 & 3,7 & 2,0 & 0,0\end{array}$ $\begin{array}{llllllllll}4,8 & 5,5 & 1,1 & 1,0 & 3,1 & 0,6 & 5,1 & 9,2 & 3,9 & 1,6\end{array}$ $\begin{array}{llllllllll}0,0 & 0,0 & 0,0 & 0,0 & 0,0 & 0,0 & 0,0 & 0,0 & 0,0 & 0,0\end{array}$ $\begin{array}{lllllllllll}0,0 & 0,0 & 0,0 & 0,0 & 0,0 & 0,0 & 0,0 & 0,0 & 0,0 & 0,0\end{array}$ $\begin{array}{llllllllll}0,0 & 0,0 & 0,0 & 2,0 & 0,0 & 0,0 & 0,0 & 0,0 & 0,0 & 0,0\end{array}$ $\begin{array}{lllllllllll}1,6 & 0,0 & 0,0 & 0,0 & 2,5 & 0,0 & 0,0 & 0,0 & 0,0 & 0,0\end{array}$ $\begin{array}{llllllllll}0,0 & 0,0 & 0,0 & 0,0 & 0,0 & 0,0 & 0,0 & 0,0 & 0,0 & 0,0\end{array}$ $\begin{array}{lllllllllll}0,0 & 0,0 & 0,0 & 0,0 & 0,0 & 0,0 & 0,0 & 0,0 & 0,0 & 0,0\end{array}$ $\begin{array}{llllllllll}0,0 & 0,0 & 0,0 & 0,0 & 0,0 & 0,0 & 0,0 & 0,0 & 0,0 & 0,0\end{array}$ $\begin{array}{llllllllll}0,0 & 0,0 & 0,0 & 0,0 & 0,0 & 0,0 & 0,0 & 0,0 & 0,0 & 0,0\end{array}$ $\begin{array}{lllllllllll}0,0 & 0,0 & 0,0 & 0,0 & 0,0 & 0,0 & 0,0 & 0,0 & 0,0 & 0,0\end{array}$ $\begin{array}{llllllllll}0,0 & 0,0 & 0,0 & 0,0 & 0,0 & 0,0 & 0,0 & 0,0 & 0,0 & 0,0\end{array}$ $\begin{array}{lllllllllll}0,0 & 0,0 & 0,0 & 0,0 & 0,0 & 0,0 & 0,0 & 0,0 & 0,0 & 0,0\end{array}$ $\begin{array}{llllllllll}1,6 & 1,6 & 0,6 & 1,0 & 0,6 & 0,0 & 3,1 & 0,5 & 1,0 & 0,8\end{array}$ $\begin{array}{llllllllll}0,0 & 1,6 & 0,0 & 0,0 & 0,0 & 0,0 & 0,0 & 0,0 & 0,0 & 0,0\end{array}$ $\begin{array}{lllllllllll}0,0 & 0,0 & 0,0 & 0,0 & 0,0 & 0,0 & 0,0 & 0,0 & 0,0 & 0,0\end{array}$ $\begin{array}{llllllllll}0,0 & 0,0 & 0,0 & 0,0 & 0,0 & 0,0 & 0,0 & 0,0 & 0,0 & 0,0\end{array}$ $\begin{array}{llllllllll}0,0 & 0,0 & 0,0 & 0,0 & 0,0 & 0,0 & 0,0 & 0,0 & 0,0 & 0,0\end{array}$ $\begin{array}{llllllllll}0,0 & 0,0 & 0,0 & 0,0 & 0,0 & 0,0 & 0,0 & 0,0 & 0,0 & 0,0\end{array}$ $\begin{array}{llllllllll}0,0 & 0,0 & 0,0 & 0,0 & 0,0 & 0,0 & 0,0 & 0,0 & 0,0 & 0,0\end{array}$ $\begin{array}{llllllllll}0,0 & 0,9 & 0,0 & 1,0 & 0,0 & 0,0 & 0,0 & 0,0 & 0,0 & 0,0\end{array}$ $\begin{array}{llllllllll}1,0 & 1,8 & 3,2 & 2,0 & 5,9 & 7,6 & 0,8 & 6,9 & 1,0 & 8,4\end{array}$ $\begin{array}{llllllllll}0,0 & 0,0 & 0,0 & 0,0 & 0,0 & 0,0 & 0,0 & 0,0 & 0,0 & 0,0\end{array}$ $\begin{array}{lllllllllll}0,0 & 0,0 & 0,0 & 0,0 & 0,0 & 0,0 & 0,0 & 0,0 & 0,0 & 0,0\end{array}$ $\begin{array}{lllllllllll}7,3 & 9,7 & 12,6 & 17,3 & 3,4 & 4,2 & 7,9 & 5,9 & 4,2 & 4,6\end{array}$ $\begin{array}{llllllllll}0,0 & 0,0 & 0,0 & 0,0 & 0,0 & 0,0 & 0,0 & 0,0 & 0,0 & 0,0\end{array}$ $\begin{array}{lllllllllll}1,0 & 0,0 & 2,1 & 2,0 & 0,0 & 0,7 & 0,0 & 1,0 & 0,0 & 0,0\end{array}$ $\begin{array}{lllllllllll}0,0 & 0,0 & 0,0 & 0,0 & 0,0 & 0,0 & 0,0 & 0,0 & 0,0 & 0,0\end{array}$ $\begin{array}{lllllllllll}0,0 & 0,0 & 0,0 & 0,0 & 0,0 & 0,0 & 0,0 & 0,0 & 0,0 & 0,0\end{array}$ $\begin{array}{llllllllll}1,0 & 0,0 & 0,0 & 0,0 & 0,0 & 0,0 & 0,0 & 0,0 & 0,0 & 0,0\end{array}$ $\begin{array}{lllllllllll}0,0 & 0,0 & 0,0 & 0,0 & 0,0 & 0,0 & 0,0 & 0,0 & 0,0 & 0,0\end{array}$ $\begin{array}{llllllllll}0,0 & 0,0 & 0,0 & 0,0 & 0,0 & 0,0 & 0,0 & 0,0 & 0,0 & 0,0\end{array}$ $\begin{array}{llllllllll}0,0 & 0,0 & 0,0 & 0,0 & 0,0 & 0,0 & 0,0 & 0,0 & 0,0 & 0,0\end{array}$ $\begin{array}{lllllllllll}0,0 & 0,0 & 0,0 & 0,0 & 0,0 & 0,0 & 0,0 & 0,0 & 0,0 & 0,0\end{array}$ $\begin{array}{llllllllll}0,0 & 0,0 & 0,0 & 0,0 & 0,8 & 0,0 & 0,0 & 0,0 & 0,0 & 0,0\end{array}$ $\begin{array}{lllllllllll}0,0 & 0,0 & 0,0 & 0,0 & 0,0 & 0,0 & 0,0 & 0,0 & 0,0 & 0,0\end{array}$ $\begin{array}{llllllllll}0,0 & 0,0 & 0,0 & 0,0 & 0,0 & 0,0 & 0,0 & 0,0 & 0,0 & 0,0\end{array}$ $\begin{array}{llllllllll}0,0 & 0,0 & 0,0 & 0,0 & 0,0 & 0,0 & 0,0 & 0,0 & 0,0 & 0,0\end{array}$ $\begin{array}{llllllllll}0,0 & 0,0 & 0,0 & 0,0 & 0,0 & 0,0 & 0,0 & 0,0 & 1,0 & 0,0\end{array}$ $\begin{array}{llllllllll}0,0 & 0,0 & 0,0 & 0,0 & 0,0 & 0,0 & 0,0 & 0,0 & 0,0 & 0,0\end{array}$ $\begin{array}{lllllllllll}0,0 & 0,0 & 0,0 & 0,0 & 0,0 & 0,0 & 0,0 & 0,0 & 0,0 & 0,0\end{array}$ $\begin{array}{llllllllll}0,0 & 0,9 & 2,1 & 1,0 & 2,5 & 0,7 & 0,8 & 0,0 & 0,0 & 0,0\end{array}$ $\begin{array}{llllllllll}0,0 & 0,9 & 1,1 & 0,0 & 0,0 & 0,0 & 0,0 & 0,0 & 1,0 & 0,8\end{array}$ $\begin{array}{lllllllllll}0,0 & 0,0 & 0,0 & 0,0 & 0,0 & 0,0 & 0,0 & 0,0 & 0,0 & 0,0\end{array}$ $\begin{array}{llllllllll}0,0 & 0,0 & 0,0 & 0,0 & 1,7 & 0,0 & 0,0 & 0,0 & 0,0 & 0,0\end{array}$ $\begin{array}{lllllllllll}0,0 & 0,0 & 1,1 & 1,0 & 0,0 & 0,0 & 0,0 & 0,0 & 0,0 & 0,0\end{array}$ $\begin{array}{llllllllll}0,0 & 0,0 & 0,0 & 0,0 & 0,0 & 0,0 & 0,0 & 0,0 & 0,0 & 0,0\end{array}$ \begin{tabular}{llllllllll}
0,0 & 0,0 & 0,0 & 0,0 & 0,0 & 0,0 & 0,0 & 0,0 & 0,0 & 0,0 \\
\hline
\end{tabular} 
Anexo 64 - Continuação

\begin{tabular}{|c|c|c|c|c|c|c|c|c|c|c|c|c|c|c|c|c|c|c|c|c|c|c|c|c|c|c|c|c|c|c|}
\hline \multirow[b]{2}{*}{ Estações } & \multicolumn{10}{|c|}{ Agosto de 2005} & \multicolumn{10}{|c|}{ Março de 2006} & \multicolumn{10}{|c|}{ Agosto de 2006} \\
\hline & $\mathrm{Tb} 1$ & $\mathrm{~Tb} 2$ & $\mathrm{~Tb} 3$ & $\mathrm{~Tb} 4$ & Tb5 & Tb6 & $\mathrm{Tb} 7$ & $\mathrm{~Tb} 8$ & $\mathrm{~Tb} 9$ & Tb10 & $\mathrm{Tb} 1$ & $\mathrm{~Tb} 2$ & $\mathrm{~Tb} 3$ & $\mathrm{~Tb} 4$ & Tb5 & Tb6 & $\mathrm{Tb} 7$ & $\mathrm{~Tb} 8$ & Tb9 & Tb10 & $\mathrm{Tb} 1$ & $\mathrm{~Tb} 2$ & $\mathrm{~Tb} 3$ & $\mathrm{~Tb} 4$ & Tb5 & Tb6 & $\mathrm{Tb} 7$ & $\mathrm{~Tb} 8$ & $\mathrm{~Tb} 9$ & Tb10 \\
\hline Discorbinella bertheloti & 0,0 & 0,0 & 0,0 & 0,0 & 0,0 & 0,0 & 0,0 & 0,0 & 0,0 & 0,0 & 0,8 & 0,0 & 0,0 & 1,0 & 0,0 & 0,0 & 0,0 & 0,5 & 0,0 & 0,0 & 0,0 & 0,0 & 0,0 & 0,0 & 0,0 & 0,0 & 0,0 & 0,0 & 0,0 & 0,0 \\
\hline Discorbis peruvians & 0,0 & 0,0 & 0,0 & 0,0 & 0,0 & 0,0 & 0,0 & 0,0 & 0,0 & 0,0 & 0,0 & 0,0 & 0,0 & 0,0 & 0,0 & 0,0 & 0,0 & 0,0 & 0,0 & 0,0 & 0,0 & 0,0 & 0,0 & 0,0 & 0,0 & 0,0 & 0,0 & 0,0 & 0,0 & 0,0 \\
\hline Discorbis williamsoni & 1,1 & 0,0 & 0,0 & 0,0 & 0,0 & 0,0 & 0,0 & 0,0 & 1,1 & 0,0 & 0,0 & 0,0 & 0,0 & 0,0 & 0,0 & 0,0 & 0,0 & 0,0 & 0,0 & 0,0 & 0,0 & 0,0 & 0,0 & 0,0 & 0,0 & 0,0 & 0,0 & 0,0 & 0,0 & 0,0 \\
\hline Eggerela scabra & 0,0 & 0,0 & 0,0 & 0,0 & 0,0 & 0,0 & 0,0 & 0,0 & 0,0 & 0,0 & 0,0 & 0,0 & 0,6 & 1,0 & 0,0 & 0,6 & 0,0 & 0,0 & 1,0 & 0,0 & 0,0 & 0,0 & 1,1 & 0,0 & 0,0 & 0,7 & 0,0 & 0,0 & 0,0 & 0,0 \\
\hline Epistominela vitrea & 0,0 & 0,0 & 0,0 & 0,0 & 0,0 & 0,0 & 0,0 & 0,0 & 0,0 & 0,0 & 0,0 & 0,8 & 0,0 & 0,0 & 0,0 & 0,0 & 0,0 & 0,0 & 0,0 & 0,0 & 0,0 & 0,0 & 1,1 & 0,0 & 0,0 & 0,0 & 0,0 & 0,0 & 0,0 & 0,0 \\
\hline Eponides repandus & 0,0 & 0,0 & 0,0 & 0,0 & 0,0 & 0,0 & 0,0 & 0,0 & 2,2 & 0,0 & 0,0 & 0,0 & 0,0 & 0,0 & 0,6 & 0,0 & 0,0 & 0,0 & 0,0 & 0,0 & 0,0 & 0,0 & 0,0 & 0,0 & 0,0 & 0,0 & 0,0 & 0,0 & 0,0 & 0,0 \\
\hline Fissurina laevigata & 0,0 & 0,0 & 0,0 & 0,0 & 1,8 & 0,0 & 0,0 & 0,0 & 0,0 & 0,0 & 0,0 & 0,0 & 0,0 & 0,0 & 0,6 & 0,0 & 0,0 & 0,0 & 0,0 & 0.0 & 0,0 & 0,0 & 0,0 & 0,0 & 0,0 & 0,0 & 0,0 & 0,0 & 0,0 & 0,0 \\
\hline Fissurina lucida & 1,1 & 0,0 & 0,0 & 2,0 & 0,0 & 0,0 & 0,0 & 0,0 & 0,0 & 0,0 & 0,0 & 0,0 & 0,0 & 0,0 & 0,0 & 0,0 & 0,0 & 0,0 & 0,0 & 0,0 & 0,0 & 0,0 & 0,0 & 0,0 & 0,0 & 0,0 & 0,8 & 0,0 & 1,0 & 0,0 \\
\hline Fissuripolimorphina & 0,0 & 0,0 & 0,0 & 0,0 & 0,0 & 0,0 & 0,0 & 0,0 & 0,0 & 0,0 & 0,0 & 0,0 & 0,0 & 0,0 & 0,0 & 0,0 & 0,0 & 0,0 & 0,0 & 0,0 & 0,0 & 0,0 & 0,0 & 0,0 & 0,0 & 0,0 & 0,0 & 0,0 & 0,0 & 0,0 \\
\hline Fissurina sp & 0,0 & 0,0 & 0,0 & 4,0 & 0,0 & 0,0 & 0,0 & 0,0 & 0,0 & 0,0 & 0,0 & 0,0 & 0,0 & 0,0 & 0,0 & 0,0 & 0,0 & 0,0 & 0,0 & 0,0 & 0,0 & 0,0 & 0,0 & 0,0 & 0,0 & 0,0 & 0,0 & 0,0 & 0,0 & 0,0 \\
\hline Fursenkoina fragilis & 0,0 & 0,0 & 0,0 & 0,0 & 0,0 & 0,0 & 0,0 & 0,0 & 0,0 & 0,0 & 0,8 & 0,8 & 0,6 & 0,0 & 0,0 & 0,0 & 0,0 & 0,5 & 7,8 & 1,6 & 0,0 & 8,8 & 6,3 & 2,0 & 1,7 & 3,5 & 0,8 & 1,0 & 0,0 & 0,0 \\
\hline Fursenkoina pontoni & 0,0 & 0,0 & 0,0 & 1,0 & 0,0 & 0,0 & 1,0 & 0,9 & 1,1 & 0,0 & 0,8 & 0,0 & 0,0 & 0,0 & 0,6 & 4,0 & 0,0 & 0,9 & 1,0 & 3,1 & 0,0 & 0,0 & 0,0 & 0,0 & 0,8 & 0,0 & 1,6 & 0,0 & 0,0 & 0,0 \\
\hline Fursenkoina riggi & 0,0 & 0,0 & 0,0 & 0,0 & 0,0 & 0,0 & 0,0 & 0,0 & 0,0 & 0,0 & 0,0 & 0,0 & 0,0 & 0,0 & 0,0 & 0,0 & 0,0 & 0,0 & 0,0 & 0,0 & 0,0 & 0,0 & 0,0 & 0,0 & 0,0 & 0,0 & 0,0 & 0,0 & 0,0 & 0,0 \\
\hline ina tegulata & 0,0 & 0,0 & 0,0 & 0,0 & 0,0 & 0,0 & 0,0 & 0,0 & 0,0 & 0,0 & 0,0 & 0,0 & 0,0 & 0,0 & 0,0 & 0,0 & 0,0 & 0,0 & 0,0 & 0,0 & 0,0 & 0,0 & 0,0 & 0,0 & 0,0 & 0,0 & 4,7 & 2,0 & 0,0 & 0,8 \\
\hline Fursenkoina sp & 0,0 & 0,0 & 0,0 & 0,0 & 0,0 & 0,0 & 0,0 & 0,0 & 0,0 & 0,0 & 0,0 & 0,0 & 0,0 & 0,0 & 0,0 & 0,0 & 0,0 & 0,0 & 0,0 & 0,0 & 0,0 & 0,0 & 0,0 & 0,0 & 0,0 & 0,0 & 0,8 & 0,0 & 0,0 & 0,0 \\
\hline Gaudryina exilis & 0,0 & 0,0 & 0,0 & 0,0 & 0,0 & 0,0 & 0,0 & 0,0 & 0,0 & 0,0 & 0,8 & 0,8 & 1,7 & 0,0 & 0,6 & 3,4 & 3,1 & 0,5 & 2,9 & 1,6 & 1,0 & 3,5 & 0,0 & 0,0 & 0,0 & 1,4 & 0,0 & 0,0 & 0,0 & 0,0 \\
\hline Gavelinopsis praegeri & 0,0 & 0,0 & 0,0 & 0,0 & 0,0 & 0,0 & 0,0 & 0,0 & 0,0 & 0,0 & 0,0 & 0,0 & 0,6 & 0,0 & 0,0 & 0,0 & 0,0 & 0,9 & 0,0 & 0,0 & 0,0 & 0,0 & 0,0 & 0,0 & 0,0 & 0,0 & 0,0 & 0,0 & 1,0 & 0,0 \\
\hline Globobulima pacifica & 0,0 & 0,0 & 0,0 & 0,0 & 0,0 & 0,0 & 0,0 & 0,0 & 0,0 & 0,0 & 0,0 & 0,0 & 0,6 & 0,0 & 0,0 & 0,0 & 0,0 & 0,0 & 0,0 & 0,0 & 0,0 & 0,0 & 0,0 & 0,0 & 0,0 & 0,0 & 0,0 & 0,0 & 0,0 & 0,0 \\
\hline Gutulina lactea & 0,0 & 0,0 & 0,0 & 0,0 & 0,0 & 0,0 & 0,0 & 0,0 & 0,0 & 0,0 & 0,0 & 0,0 & 0,0 & 0,0 & 0,0 & 0,0 & 0,0 & 0,0 & 0,0 & 0,0 & 0,0 & 0,0 & 0,0 & 0,0 & 0,0 & 0,0 & 0,0 & 0,0 & 0,0 & 0,0 \\
\hline Hanzawaia boueana & 0,0 & 0,0 & 0,0 & 0,0 & 0,0 & 0,0 & 0,0 & 0,0 & 0,0 & 0,0 & 0,0 & 0,0 & 0,0 & 2,0 & 0,0 & 0,0 & 0,0 & 0,5 & 0,0 & 0,0 & 0,0 & 0,0 & 0,0 & 0,0 & 0,0 & 0,0 & 0,0 & 0,0 & 1,0 & 0,8 \\
\hline Haynesina depressula & 0,0 & 0,0 & 0,0 & 0,0 & 0,0 & 0,0 & 0,0 & 0,0 & 0,0 & 0,0 & 0,0 & 0,0 & 0,0 & 0,0 & 0,0 & 0,0 & 0,0 & 0,0 & 0,0 & 0,0 & 0,0 & 0,0 & 0,0 & 0,0 & 0,0 & 0,0 & 0,0 & 0,0 & 0,0 & 0,0 \\
\hline Haynesina germanica & 0,0 & 0,0 & 0,0 & 1,0 & 0,0 & 1,0 & 0,0 & 0,0 & 0,0 & 0,0 & 0,0 & 0,0 & 0,0 & 0,0 & 1,2 & 0,6 & 1,0 & 0,0 & 0,0 & 0,8 & 0,0 & 0,0 & 0,0 & 0,0 & 0,8 & 0,0 & 1,6 & 0,0 & 1,0 & 1,5 \\
\hline Hopkinsina pacifica & 1,1 & 1,8 & 0,0 & 0,0 & 0,9 & 1,0 & 1,0 & 3,7 & 4,4 & 0,0 & 9,6 & 3,9 & 3,4 & 8,2 & 4,9 & 8,0 & 3,1 & 4,6 & 4,9 & 9,4 & 3,1 & 3,5 & 6,3 & 2,0 & 3,4 & 4,2 & 3,1 & 2,9 & 4,2 & 5,3 \\
\hline Lagena striata & 0,0 & 0,0 & 0,0 & 0,0 & 0,0 & 0,0 & 0,0 & 0,0 & 0,0 & 0,0 & 0,0 & 0,0 & 0,6 & 0,0 & 0,0 & 0,0 & 0,0 & 0,0 & 0,0 & 0,0 & 0,0 & 0,0 & 0,0 & 0,0 & 0,8 & 0,0 & 0,0 & 0,0 & 0,0 & 0,0 \\
\hline Lenticulina gibba & 0,0 & 0,0 & 0,0 & 0,0 & 0,0 & 0,0 & 0,0 & 0,0 & 0,0 & 0,0 & 0,0 & 0,0 & 0,0 & 0,0 & 0,0 & 0,0 & 0,0 & 0,0 & 0,0 & 0,0 & 0,0 & 0,0 & 0,0 & 0,0 & 0,0 & 0,0 & 0,0 & 0,0 & 0,0 & 0,0 \\
\hline Lenticulina sp & 0,0 & 0,0 & 0,0 & 0,0 & 0,0 & 0,0 & 0,0 & 0,0 & 0,0 & 0,0 & 0,0 & 0,0 & 0,0 & 0,0 & 0,0 & 0,0 & 0,0 & 0,5 & 0,0 & 0,8 & 0,0 & 0,0 & 0,0 & 0,0 & 0,0 & 0,0 & 0,0 & 0,0 & 0,0 & 0,0 \\
\hline Lepdodeuteuramina ochracea & 0,0 & 0,0 & 0,0 & 0,0 & 0,0 & 0,0 & 0,0 & 0,0 & 0,0 & 0,0 & 0,0 & 0,0 & 0,0 & 0,0 & 0,0 & 0,0 & 0,0 & 0,0 & 0,0 & 0,0 & 0,0 & 0,0 & 0,0 & 1,0 & 0,0 & 0,7 & 0,0 & 0,0 & 0,0 & 0,0 \\
\hline Leptohalysis catela & 0,0 & 0,0 & 0,0 & 0,0 & 0,0 & 0,0 & 0,0 & 0,0 & 0,0 & 0,0 & 2,4 & 0,0 & 0,0 & 1,0 & 0,0 & 0,0 & 0,0 & 0,5 & 0,0 & 0,0 & 0,0 & 0,0 & 0,0 & 0,0 & 0,0 & 0,0 & 0,0 & 0,0 & 0,0 & 0,0 \\
\hline Lobatula lobatula & 1,1 & 0,9 & 6,6 & 0,0 & 1,8 & 0,0 & 1,0 & 1,8 & 0,0 & 0,0 & 0,0 & 0,0 & 0,0 & 0,0 & 0,0 & 0,0 & 0,0 & 0,0 & 2,0 & 0,0 & 0,0 & 0,0 & 1,1 & 0,0 & 0,0 & 0,0 & 0,0 & 0,0 & 0,0 & 0,0 \\
\hline
\end{tabular}


Anexo 64 - Continuação

\begin{tabular}{|c|c|c|c|c|c|c|c|c|c|c|c|c|c|c|c|c|c|c|c|c|c|c|c|c|c|c|c|c|c|c|}
\hline \multirow[b]{2}{*}{ Estações } & \multicolumn{10}{|c|}{ Agosto de 2005} & \multicolumn{10}{|c|}{ Março de 2006} & \multicolumn{10}{|c|}{ Agosto de 2006} \\
\hline & $\mathrm{Tb} 1$ & $\mathrm{~Tb} 2$ & $\mathrm{~Tb} 3$ & $\mathrm{~Tb} 4$ & $\mathrm{~Tb} 5$ & Tb6 & $\mathrm{Tb} 7$ & $\mathrm{~Tb} 8$ & $\mathrm{~Tb} 9$ & Tb10 & $\mathrm{Tb} 1$ & $\mathrm{~Tb} 2$ & $\mathrm{~Tb} 3$ & $\mathrm{~Tb} 4$ & Tb5 & Tb6 & $\mathrm{Tb} 7$ & $\mathrm{~Tb} 8$ & Tb9 & Tb10 & $\mathrm{Tb} 1$ & $\mathrm{~Tb} 2$ & $\mathrm{~Tb} 3$ & $\mathrm{~Tb} 4$ & Tb5 & Tb6 & $\mathrm{Tb} 7$ & $\mathrm{~Tb} 8$ & Tb9 & Tb10 \\
\hline Miliamina fusca & 0,0 & 0,0 & 0,0 & 1,0 & 0,0 & 0,0 & 0,0 & 0,0 & 0,0 & 0,0 & 0,0 & 0,0 & 0,0 & 0,0 & 0,0 & 0,0 & 0,0 & 0,0 & 0,0 & 0,0 & 0,0 & 0,0 & 0,0 & 0,0 & 0,0 & 0,0 & 0,0 & 0,0 & 0,0 & 0,0 \\
\hline Miliamina sp &, 0 & 0,0 & 0,0 & 0,0 & 0,0 & 1,0 & 0,0 & 0,0 & 0,0 & 0, & 0,0 & 0,0 & 0,0 & 0,0 & 0,0 & 0,0 & 0,0 & 0,0 & 0,0 & 0,0 & 0,0 & 0,0 & 0,0 & 0,0 & 0,0 & 0,0 & 0,0 & 0,0 & 0,0 & 0,0 \\
\hline Melonis sp & 0,0 & 0,0 & 0,0 & 0,0 & 0,0 & 0,0 & 0,0 & 0,0 & 0,0 & 0, & 0,0 & 0,0 & 0,0 & 0,0 & 0,0 & 0,0 & 0,0 & 0,0 & 0,0 & 0,0 & 0,0 & 0,0 & 0,0 & 0,0 & 0,0 & 0,0 & 0,0 & 0,0 & 0,0 & 0,0 \\
\hline Miliolinela su & 0,0 & 0,0 & 0,0 & 0,0 & 0,0 & 0,0 & 0,0 & 0,0 & 0,0 & 0,0 & 0,0 & 0,0 & 0,0 & 2,0 & 0,0 & 0,0 & 0,0 & 0,0 & 0,0 & 0,0 & 0,0 & 0,0 & 0,0 & 0,0 & 0,0 & 0,0 & 0,0 & 0,0 & 0,0 & 0,0 \\
\hline Miliolinella sp & 0,0 & 0,0 & 0,0 & 0,0 & 0,0 & 0,0 & 0,0 & 0,0 & 0,0 & $0, \mathrm{c}$ & 0,0 & 0,0 & 0,0 & 0,0 & 0,0 & 0,0 & 0,0 & 0,0 & 0,0 & 0,0 & 0,0 & 0,0 & 0,0 & 0,0 & 0,0 & 0,0 & 0,0 & 0,0 & 0,0 & 0,0 \\
\hline Neocornobina marginata & 0,0 & 0,0 & 0,0 & 0,0 & 0,0 & 0,0 & 0,0 & 0,0 & 0,0 & 0,0 & 0,0 & 0,0 & 0,0 & 0,0 & 0,0 & 0,0 & 0,0 & 0,0 & 0,0 & 0,0 & 0,0 & 0,0 & 0,0 & 0,0 & 0,0 & 0,0 & 0,0 & 0,0 & 0,0 & 0,0 \\
\hline Neocornobina terquemi & 3,2 & 0,9 & 0,0 & 0,0 & 0,0 & 0,0 & 1,0 & 0,9 & 1,1 & 2 , & 0,0 & 0,8 & 0,6 & 0,0 & 0,0 & 0,0 & 1,0 & 0,0 & 0,0 & 0,0 & 0,0 & 0,0 & 1,1 & 1,0 & 0,0 & 0,0 & 0,0 & 0,0 & 0,0 & 0,0 \\
\hline Neocornobina sp & 0,0 & 0,0 & 0,0 & 0,0 & 0,0 & 0,0 & 0,0 & 0,0 & 0,0 & 0 , & 0,0 & 0,0 & 0,0 & 0,0 & 0,0 & 0,0 & 0,0 & 0,5 & 0,0 & 0,0 & 0,0 & 0,0 & 0,0 & 0,0 & 0,0 & 0,0 & 0,0 & 0,0 & 0,0 & 0,0 \\
\hline Oolina $\mathrm{sp}$ & 0,0 & 0,0 & 0,0 & 0,0 & 0,0 & 0,0 & 0,0 & 0,0 & 0,0 & 0,0 & 0,8 & 0,0 & 0,0 & 0,0 & 0,0 & 0,0 & 0,0 & 0,0 & 1,0 & 0,0 & 0,0 & 0,0 & 0,0 & 0,0 & 0,0 & 0,0 & 0,0 & 0,0 & 0,0 & 0,0 \\
\hline Pararotalia cananeiaensis & 0,0 & 20,2 & 0,0 & 0,0 & 6,4 & 20,2 & 6,0 & 2,8 & 5,5 & 4,8 & 0,0 & 0,0 & 0,6 & 0,0 & 0,0 & 0,0 & 2,0 & 0,0 & 0,0 & 0,0 & 0,0 & 0,0 & 0,0 & 0,0 & 0,0 & 0,0 & 0,0 & 0,0 & 0,0 & 0,8 \\
\hline Paratrochamina sp & 0,0 & 0,0 & 0,0 & 0,0 & 0,0 & 0,0 & 0,0 & 0,0 & 0,0 & 0 , & 0,0 & 0,0 & 0,0 & 0,0 & 0,0 & 0,0 & 0,0 & 0,0 & 0,0 & 0,0 & 0 & 0,0 & 0,0 & 0,0 & 0,0 &, 0 & 0,0 & 0,0 &, 0 & 0,0 \\
\hline rrugata & 0,0 & 0,0 & 0,0 & 0,0 & 0,0 & 0,0 & 0,0 & 0,0 & 0,0 & 0 , & 0,0 & 0,0 & 0,0 & 0,0 & 0,0 & 0,0 & 0,0 & 0,0 & 0,0 & 0,0 & 0,0 & 0,0 & 0,0 & 0,0 & 0,0 & 0,0 & 0,0 & 0,0 & 0,0 & 0,0 \\
\hline Poroeponides lateralis & 0,0 & 0,0 & 0,0 & 0,0 & 0,0 & 0,0 & 0,0 & 0,0 & 0,0 & 0,0 & 0,0 & 0,0 & 0,0 & 0,0 & 0,0 & 0,0 & 0,0 & 0,0 & 0,0 & 0,0 & 0,0 & 0,0 & 0,0 & 0,0 & 0,0 & 0,0 & 0,0 & 0,0 & 0 & 0,0 \\
\hline Protochista findens & 0,0 & 0,0 & 0,0 & 0,0 & 0,0 & 0,0 & 0,0 & 0,0 & 0,0 & 0,0 & 0,8 & 0,8 & 0,6 & 0,0 & 0,0 & 0,6 & 0,0 & 0,9 & 1,0 & 0,8 & 1,0 & 0,0 & 0,0 & 1,0 & 0,0 & 0,0 & 0,0 & 1,0 & 0,0 & 0,0 \\
\hline Pseudononion atlanticum & 0,0 & 2,8 & 2,8 & 2,0 & 2,7 & 1,0 & 0,0 & 2,8 & 4,4 & 1, & 0,8 & 3,1 & 0,0 & 5,1 & 2,5 & 6,9 & 4,1 & 3,2 & 3,9 & 0,8 & 3,1 & 3,5 & 0,0 & 3,1 & 0,0 & 3,5 & 13,4 & 2,0 & 0,0 & 0,8 \\
\hline Pseudononion grateloupi & 0,0 & 0,0 & 0,0 & 0,0 & 0,0 & 0,0 & 0,0 & 0,9 & 0,0 & 0 , & 1,6 & 0,0 & 0,0 & 1,0 & 1,2 & 1,7 & 0,0 & 0,5 & 0,0 & 0,8 &, 0 & 0,0 & 0,0 & 0,0 & 0,0 & 0,0 & 0,0 & 0,0 &, 0 & 0,0 \\
\hline Pseudononion opima & 0,0 & 0,0 & 0,0 & 0,0 & 0,0 & 0,0 & 0,0 & 0,9 & 0,0 & 0,0 & 1,6 & 0,8 & 0,6 & 0,0 & 0,6 & 2,3 & 0,0 & 0,5 & 2,9 & 1,6 & 0,0 & 0,0 & 0,0 & 0,0 & 0,0 & 0,0 & 2,4 & 0,0 & 0,0 & 0,0 \\
\hline Pseudononion pauperatus & 0,0 & 0,0 & 0,0 & 0,0 & 0,0 & 0,0 & 0,0 & 0,0 & 0,0 & 0,0 & 0,0 & 0,0 & 0,0 & 0,0 & 0,0 & 0,0 & 0,0 & 0,0 & 0,0 & 0,0 & 1,0 & 0,0 & 0,0 & 0,0 & 0,0 & 0,0 & 0,0 & 0,0 & 0,0 & 0,0 \\
\hline Pseudononion sp & 0,0 & 0,0 & 0,0 & 0,0 & 0,0 & 0,0 & 0,0 & 0,0 & 0,0 & 0 , & 1,6 & 1,6 & 0,6 & 1,0 & 2,5 & 0,0 & 1,0 & 0,0 & 1,0 & 2,4 & 0,0 & 0,0 & 0,0 & 0,0 & 0,0 & 0,0 & 0,0 & 0,0 & 0,0 & 0,0 \\
\hline Quinqueloculina atlantica & 0,0 & 0,0 & 0,0 & 0,0 & 0,0 & 0,0 & 0,0 & 0,0 & 0,0 & 0,0 & 0,0 & 0,0 & 0,6 & 1,0 & 0,0 & 0,0 & 0,0 & 0,0 & 0,0 & 0,0 & 0,0 & 0,0 & 0,0 & 0,0 & 0,0 & 0,0 & 0,0 & 0,0 & 0,0 & 0,0 \\
\hline Quinqueloculina brodermani & 0,0 & 0,0 & 0,0 & 0,0 & 0,0 & 0,0 & 0,0 & 0,0 & 0,0 & 0,0 & 0,0 & 0,0 & 0,0 & 0,0 & 0,0 & 0,0 & 0,0 & 0,0 & 0,0 & 0,0 & 0,0 & 0,0 & 0,0 & 0,0 & 0,0 & 0,0 & 0,0 & 0,0 & 0,0 & 0,0 \\
\hline Quinqueloculina milletti & 0,0 & 0,0 & 0,0 & 1,0 & 0,0 & 0,0 & 0,0 & 1,8 & 1,1 & 1,0 & 0,0 & 0,8 & 0,0 & 0,0 & 0,0 & 0,0 & 1,0 & 0,0 & 0,0 & 0,8 & 0,0 & 0,0 & 0,0 & 0,0 & 0,0 & 0,0 & 0,0 & 0,0 &, 0 & 0,0 \\
\hline Quinqueloculina lamarckiana & 0,0 & 0,0 & 0,0 & 0,0 & 0,0 & 0,0 & 0,0 & 0,0 & 0,0 & 0,0 & 0,0 & 0,0 & 0,0 & 0,0 & 0,0 & 0,0 & 0,0 & 0,0 & 0,0 & 0,0 & 0,0 & 0,0 & 0,0 & 0,0 & 0,0 & 0,0 & 0,0 & 0,0 & 0,0 & 0,0 \\
\hline Quinqueloculina laevigata & 0,0 & 0,0 & 0,0 & 0,0 & 0,0 & 0,0 & 0,0 & 0,0 & 0,0 & 0,0 & 0,0 & 0,0 & 0,0 & 0,0 & 0,0 & 0,0 & 0,0 & 0,0 & 0,0 & 0,0 & 0,0 & 0,0 & 0,0 & 0,0 & 0,0 & 0,0 & 0,0 & 0,0 & 0,0 & 0,0 \\
\hline Quinqueloculina patagonica & 0,0 & 0,0 & 0,0 & 0,0 & 0,0 & 0,0 & 0,0 & 0,0 & 0,0 & 0,0 & 0,0 & 0,0 & 0,0 & 0,0 & 0,0 & 0,0 & 0,0 & 0,0 & 0,0 & 0,0 & 0,0 & 0,0 & 0,0 & 0,0 & 0,0 & 0,0 & 0,0 & 0,0 & 0,0 & 0,0 \\
\hline Quinqjueloculina seminula & 0,0 & 0,0 & 0,0 & 0,0 & 0,0 & 0,0 & 0,0 & 0,0 & 0,0 & 0,0 & 0,0 & 0,0 & 0,0 & 0,0 & 0,0 & 0,6 & 0,0 & 0,0 & 0,0 & 0,0 & 0,0 & 0,0 & 0,0 & 0,0 & 0,0 & 0,0 & 0,0 & 0,0 & 0,0 & 0,0 \\
\hline Quinqueloculina stalkeri & 0,0 & 0,0 & 0,0 & 0,0 & 0,0 & 0,0 & 0,0 & 0,0 & 0,0 & 0,0 & 0,0 & 0,0 & 0,0 & 0,0 & 0,0 & 0,0 & 0,0 & 0,0 & 0,0 & 0,0 & 0,0 & 0,0 & 0,0 & 0,0 & 0,0 & 0,0 & 0,0 & 0,0 & 0,0 & 0,0 \\
\hline
\end{tabular}


Anexo 64 - Continuação

\begin{tabular}{|c|c|c|c|c|c|c|c|c|c|c|c|c|c|c|c|c|c|c|c|c|c|c|c|c|c|c|c|c|c|c|}
\hline \multirow[b]{2}{*}{ Estações } & \multicolumn{10}{|c|}{ Agosto de 2005} & \multicolumn{10}{|c|}{ Março de 2006} & \multicolumn{10}{|c|}{ Agosto de 2006} \\
\hline & $\mathrm{Tb} 1$ & $\mathrm{~Tb} 2$ & $\mathrm{~Tb} 3$ & $\mathrm{~Tb} 4$ & $\mathrm{~Tb} 5$ & Tb6 & $\mathrm{Tb} 7$ & Tb8 & $\mathrm{Tb} 9$ & $\mathrm{~Tb} 10$ & Tb1 & $\mathrm{Tb} 2$ & $\mathrm{~Tb} 3$ & $\mathrm{~Tb} 4$ & Tb5 & $\mathrm{Tb} 6$ & $\mathrm{~Tb}$ & $\mathrm{~Tb} 8$ & $\mathrm{Tbs}$ & Tb10 & $\mathrm{Tb} 1$ & $\mathrm{~Tb} 2$ & $\mathrm{~Tb} 3$ & $\mathrm{~Tb} 4$ & $\mathrm{~Tb} 5$ & Tb6 & $\mathrm{Tb} 7$ & Tb8 & $\mathrm{Tb} 9$ & $\mathrm{~Tb} 10$ \\
\hline Quinqueloculina sp & 0,0 & 0,0 & 0,0 & 0,0 & 0,0 & 0,0 & 0,0 & 0,0 & 0,0 & 0,0 & 0,0 & 0,0 & 0,0 & 1,0 & 0,0 & 0,0 & 0,0 & 0,0 & 0,0 & 0,0 & 0,0 & 0,0 & 0,0 & 0,0 & 0,0 & 0,0 & 0,0 & 0,0 & 0,0 & 0,0 \\
\hline Reophax scorpiurus & 0,0 & 0,0 & 0,0 & 0,0 & 0,0 & 0,0 & 0,0 & 0,0 & 0,0 & 0,0 & 0,0 & 0,0 & 0,0 & 0,0 & 0,0 & 0,0 & 0,0 & 0,0 & 0,0 & 0,0 & 0,0 & 0,0 & 0,0 & 0,0 & 0,0 & 0,0 & 0,0 & 0,0 & 0,0 & 0,0 \\
\hline Reophax sp & 0,0 & 0,0 & 0,0 & 0,0 & 0,0 & 0,0 & 0,0 & 0,0 & 0,0 & 0,0 & 0,0 & 0,0 & 0,0 & 0,0 & 0,0 & 0,0 & 0,0 & 0,0 & 0,0 & 0,0 & 0,0 & 0,0 & 0,0 & 0,0 & 0,0 & 0,7 & 0,0 & 0,0 & 0,0 & 0,0 \\
\hline Rolshausheni rolshauseni & 0,0 & 0,0 & 0,0 & 0,0 & 0,0 & 0,0 & 0,0 & 0,0 & 0,0 & 0,0 & 0,0 & 0,0 & 0,0 & 0,0 & 0,0 & 0,0 & 0,0 & 0,0 & 0,0 & 0,0 & 0,0 & 0,0 & 0,0 & 0,0 & 0,0 & 0,0 & 0,0 & 0,0 & 0,0 & 0,0 \\
\hline Rosalina bradyi & 0,0 & 0,0 & 0,0 & 0,0 & 0,0 & 0,0 & 0,0 & 0,0 & 0,0 & 0,0 & 0,0 & 0,0 & 0,0 & 0,0 & 0,0 & 0,0 & 0,0 & 0,0 & 0,0 & 0,0 & 0,0 & 0,0 & 0,0 & 0,0 & 0,0 & 0,0 & 0,0 & 0,0 & 0,0 & 0,0 \\
\hline Rosalina floridana & 1,1 & 2,8 & 2,8 & 1,0 & 0,0 & 1,0 & 1,0 & 1,8 & 1,1 & 4,8 & 0,8 & 0,8 & 3,4 & 5,1 & 0,6 & 0,0 & 0,0 & 0,0 & 2,0 & 0,0 & 0,0 & 0,9 & 0,0 & 2,0 & 0,0 & 0,0 & 0,0 & 0,0 & 0,0 & 0,0 \\
\hline Rosalina vilardeboana & 0,0 & 0,0 & 0,0 & 0,0 & 0,0 & 0,0 & 0,0 & 0,0 & 0,0 & 0,0 & 0,0 & 0,0 & 0,0 & 0,0 & 0,0 & 0,0 & 0,0 & 0,0 & 0,0 & 0,0 & 0,0 & 0,0 & 0,0 & 0,0 & 0,0 & 0,0 & 0,0 & 0,0 & 0,0 & 0,0 \\
\hline Rosalina $\mathrm{sp}$ & 0,0 & 0,0 & 0,0 & 0,0 & 0,0 & 0,0 & 0,0 & 0,0 & 0,0 & 0,0 & 0,0 & 0,0 & 0,0 & 0,0 & 0,0 & 0,0 & 0,0 & 0,0 & 0,0 & 0,0 & 0,0 & 0,0 & 0,0 & 0,0 & 0,0 & 0,0 & 0,0 & 0,0 & 0,0 & 0,0 \\
\hline Sigmoilopsis schlumbergeri & 0,0 & 0,0 & 0,0 & 0,0 & 0,0 & 0,0 & 0,0 & 0,0 & 0,0 & 0,0 & 0,0 & 0,0 & 0,0 & 0,0 & 0,0 & 0,0 & 0,0 & 0,0 & 0,0 & 0,0 & 0,0 & 0,0 & 0,0 & 0,0 & 0,0 & 0,0 & 0,0 & 0,0 & 0,0 & 0,0 \\
\hline Sigmoilopsis minuta & 0,0 & 0,0 & 0,0 & 0,0 & 0,0 & 0,0 & 0,0 & 0,0 & 0,0 & 0,0 & 0,0 & 0,0 & 0,0 & 0,0 & 0,0 & 0,0 & 0,0 & 0,0 & 0,0 & 0,0 & 0,0 & 0,0 & 0,0 & 0,0 & 0,0 & 0,0 & 0,0 & 0,0 & 0,0 & 0,0 \\
\hline Siphotrochammina lobata & 0,0 & 0,0 & 0,0 & 0,0 & 0,0 & 0,0 & 0,0 & 0,0 & 0,0 & 0,0 & 0,0 & 0,0 & 0,0 & 0,0 & 0,0 & 0,0 & 0,0 & 0,0 & 0,0 & 0,0 & 0,0 & 0,0 & 0,0 & 0,0 & 0,0 & 0,0 & 0,0 & 0,0 & 0,0 & 0,0 \\
\hline Spirilina vivipara & 0,0 & 0,0 & 0,0 & 0,0 & 0,0 & 0,0 & 0,0 & 0,0 & 0,0 & 0,0 & 0,0 & 0,0 & 0,0 & 0,0 & 0,0 & 0,0 & 0,0 & 0,0 & 0,0 & 0,0 & 0,0 & 0,0 & 0,0 & 0,0 & 0,0 & 0,0 & 0,0 & 0,0 & 0,0 & 0,0 \\
\hline Spirobolivina $\mathrm{sp}$ & 0,0 & 0,0 & 0,0 & 0,0 & 0,0 & 0,0 & 0,0 & 0,0 & 0,0 & 0,0 & 0,0 & 0,0 & 0,0 & 0,0 & 0,6 & 0,6 & 0,0 & 0,5 & 0,0 & 0,0 & 1,0 & 0,0 & 0,0 & 0,0 & 0,0 & 0,0 & 0,0 & 0,0 & 0,0 & 0,0 \\
\hline Stainforthia concava & 0,0 & 0,0 & 0,0 & 0,0 & 0,0 & 0,0 & 0,0 & 0,0 & 1,1 & 0 & 0 & 0,8 & 0,6 & 1,0 & 1,2 & 0, & 1 & 0,5 & 0 , & 1 & 0,0 & 0,0 & 0,0 & 0,0 & 0,0 & 0,0 & 0,0 & 0,0 & 0,0 & 0,0 \\
\hline Stanphortia fusiformis & 0,0 & 0,0 & 0,0 & 0,0 & 0,0 & 0,0 & 0,0 & 0,0 & 0,0 & 0,0 & 0,0 & 0,0 & 0,0 & 0,0 & 0,0 & 0,0 & 0,0 & 0,0 & 0,0 & 0,0 & 0,0 & 0,0 & 0,0 & 0,0 & 0,0 & 0,0 & 0,0 & 0,0 & 0,0 & 0,0 \\
\hline Textularia aglutinans & 0,0 & 0,0 & 0,0 & 0,0 & 0,0 & 0,0 & 0,0 & 0,0 & 0,0 & 0,0 & 0,0 & 0,0 & 0,0 & 0,0 & 0,0 & 0,0 & 1,0 & 0,0 & 1,0 & 0,8 & 0,0 & 0,0 & 0,0 & 0,0 & 0,0 & 0,0 & 0,0 & 0,0 & 0,0 & 0,0 \\
\hline Textularia candeiana & 0,0 & 0,0 & 0,0 & 0,0 & 0,0 & 0,0 & 0,0 & 0,0 & 0 , & 0 , & & 0,0 & 0,0 & 0,0 & 0,0 & 0,0 & 0,0 & 0,0 & 0,0 & 0,0 & 0,0 & 0,0 & 0,0 & 0,0 & 0,8 & 0,0 & 0,0 & 0,0 & 0,0 & 0,0 \\
\hline Textularia earlandi & 0,0 & 0,0 & 0,0 & 0,0 & 0,0 & 0,0 & 0,0 & 0,0 & 0,0 & 0,0 & 0,0 & 0,0 & 0,0 & 0,0 & 0,0 & 0,0 & 0,0 & 0,0 & 0,0 & 0,0 & 0,0 & 0,0 & 0,0 & 0,0 & 0,0 & 0,0 & 0,0 & 0,0 & 0,0 & 0,0 \\
\hline Textularia gramen & 0,0 & 0,0 & 0,0 & 0,0 & 0,0 & 0,0 & 0,0 & 0,0 & 0,0 & 0,0 & 0,0 & 0,0 & 0,0 & 0,0 & 0,0 & 0,0 & 0,0 & 0,0 & 0,0 & 0,0 & 0,0 & 0,0 & 0,0 & 0,0 & 0,0 & 0,0 & 0,0 & 0,0 & 0,0 & 0,0 \\
\hline Textularia sp & 0,0 & 0,0 & 0,0 & 0,0 & 0,0 & 1,9 & 0,0 & 0,0 & 0,0 & 0,0 & 0,0 & 0,0 & 0,6 & 0,0 & 0,0 & 0,0 & 0,0 & 0,0 & 0,0 & 0,0 & 0,0 & 0,0 & 0,0 & 0,0 & 0,0 & 0,0 & 0,0 & 0,0 & 0,0 & 0,0 \\
\hline Tiphotrocha $\mathrm{sp}$ & 0,0 & 0,0 & 0,0 & 0,0 & 0,0 & 0,0 & 0,0 & 0,0 & 0,0 & 0,0 & 0,0 & 0,0 & 0,0 & 0,0 & 0,0 & 0,0 & 0,0 & 0,0 & 0,0 & 0,0 & 0,0 & 0,0 & 0,0 & 0,0 & 0,0 & 0,0 & 0,0 & 0,0 & 0,0 & 0,0 \\
\hline Triloculina cultrata & 0,0 & 0,0 & 0,0 & 0,0 & 0,0 & 0,0 & 0,0 & 0,0 & 0,0 & 0, & 0, & 0,0 & 0,0 & 0,0 & 0,0 & 0,0 & 0,0 & 0,0 & 0,0 & 0,0 & 0,0 & 0,0 & 0,0 & 0,0 & 0,0 & 0,0 & 0,0 & 0,0 & 0,0 & 0,0 \\
\hline Triloculina laevigata & 0,0 & 0,0 & 0,0 & 0,0 & 0,0 & 0,0 & 0,0 & 0,0 & 0,0 & 0,0 & 0,0 & 0,0 & 0,6 & 0,0 & 0,0 & 0,0 & 0,0 & 0,0 & 0,0 & 0,0 & 0,0 & 0,0 & 0,0 & 0,0 & 0,0 & 0,0 & 0,0 & 0,0 & 0,0 & 0,0 \\
\hline Triloculina oblonga & 0,0 & 0,0 & 0,0 & 0,0 & 0,0 & 0,0 & 0,0 & 0,0 & 0,0 & 0,0 & 0,0 & 0,0 & 0,0 & 0,0 & 0,0 & 0,0 & 0,0 & 0,0 & 0,0 & 0,0 & 0,0 & 0,0 & 0,0 & 0,0 & 0,0 & 0,0 & 0,0 & 0,0 & 0,0 & 0,0 \\
\hline Trochammina inflata & 0,0 & 0,0 & 0,0 & 0,0 & 0,0 & 0,0 & 0,0 & 0,0 & 0,0 & 0,0 & 0, & 0,0 & 0,0 & 0,0 & 0,0 & 0,0 & 0,0 & 0,0 & 0,0 & 0,0 & 0,0 & 0,0 & 0,0 & 0,0 & 0,0 & 0,0 & 0,0 & 0,0 & 0,0 & 0,0 \\
\hline Trochammina macrescens & 0,0 & 0,0 & 0,0 & 0,0 & 0,0 & 0,0 & 0,0 & 0,0 & 0,0 & 0,0 & 0,0 & 0,8 & 0,6 & 0,0 & 0,0 & 0,0 & 0,0 & 0,0 & 0,0 & 0,0 & 0,0 & 0,0 & 0,0 & 0,0 & 0,0 & 0,0 & 0,0 & 0,0 & 0,0 & 0,0 \\
\hline Trochammina ochracea & 0,0 & 0,0 & 0,0 & 0,0 & 0,0 & 0,0 & 0,0 & 0,0 & 0,0 & 0,0 & 0,0 & 0,8 & 0,6 & 0,0 & 0,0 & 0,0 & 0,0 & 0,0 & 0,0 & 0,0 & 0,0 & 0,0 & 0,0 & 0,0 & 0,0 & 0,0 & 0,0 & 0,0 & 0,0 & 0,0 \\
\hline
\end{tabular}




\section{Anexo 64 - Continuação}

\begin{tabular}{|c|c|c|c|c|c|c|c|c|c|c|c|c|c|c|c|c|c|c|c|c|c|c|c|c|c|c|c|c|c|c|}
\hline \multirow[b]{2}{*}{ Estações } & \multicolumn{10}{|c|}{ Agosto de 2005} & \multicolumn{10}{|c|}{ Março de 2006} & \multicolumn{10}{|c|}{ Agosto de 2006} \\
\hline & $\mathrm{Tb} 1$ & $\mathrm{~Tb} 2$ & $\mathrm{~Tb} 3$ & $\mathrm{~Tb} 4$ & $\mathrm{~Tb} 5$ & Tb6 & $\mathrm{Tb} 7$ & Tb8 & $\mathrm{Tb} 9$ & $\mathrm{~Tb} 10$ & $\mathrm{~Tb} 1$ & $\mathrm{~Tb} 2$ & $\mathrm{~Tb} 3$ & $\mathrm{~Tb} 4$ & $\mathrm{~Tb} 5$ & Tb6 & $\mathrm{Tb} 7$ & $\mathrm{~Tb} 8$ & Tb9 & Tb10 & $\mathrm{Tb} 1$ & $\mathrm{~Tb} 2$ & $\mathrm{~Tb} 3$ & Tb4 & Tb5 & Tb6 & $\mathrm{Tb} 7$ & $\mathrm{~Tb} 8$ & Tb9 & Tb10 \\
\hline Trochammina salsa & 0,0 & 0,0 & 0,0 & 0,0 & 0,0 & 0,0 & 0,0 & 0,0 & 0,0 & 0,0 & 0,0 & 0,0 & 0,0 & 0,0 & 0,0 & 0,0 & 0,0 & 0,0 & 0,0 & 0,0 & 0,0 & 0,0 & 0,0 & 0,0 & 0,0 & 0,0 & 0,0 & 0,0 & 0,0 & 0,0 \\
\hline Trochammina squamata & 0,0 & 0,0 & 0,0 & 0,0 & 0,0 & 0,0 & 0,0 & 0,0 & 0,0 & 0,0 & 0,0 & 0,0 & 0,0 & 0,0 & 0,0 & 0,0 & 0,0 & 0,0 & 0,0 & 0,0 & 0,0 & 0,0 & 0,0 & 0,0 & 0,0 & 0,0 & 0,8 & 0,0 & 0,0 & 0,0 \\
\hline Trochammina sp & 0,0 & 0,0 & 0,0 & 0,0 & 0,0 & 0,0 & 0,0 & 0,9 & 0,0 & 0,0 & 0,0 & 0,0 & 0,0 & 0,0 & 0,0 & 0,0 & 0,0 & 0,0 & 0,0 & 0,0 & 1,0 & 0,0 & 0,0 & 0,0 & 0,0 & 0,0 & 0,0 & 0,0 & 0,0 & 0,0 \\
\hline Uvigerina bifurcata & 0,0 & 0,0 & 0,9 & 0,0 & 0,0 & 0,0 & 0,0 & 0,0 & 0,0 & 0,0 & 0,0 & 0,0 & 0,0 & 0,0 & 0,0 & 0,0 & 0,0 & 0,0 & 0,0 & 0,0 & 0,0 & 0,0 & 0,0 & 0,0 & 0,0 & 0,0 & 0,0 & 0,0 & 0,0 & 0,0 \\
\hline Uvigerina peregrina & 0,0 & 0,0 & 0,0 & 1,0 & 0,0 & 0,0 & 0,0 & 0,0 & 0,0 & 0,0 & 0,0 & 0,0 & 0,0 & 0,0 & 0,0 & 0,0 & 0,0 & 0,0 & 1,0 & 0,0 & 0,0 & 0,0 & 0,0 & 0,0 & 0,0 & 0,0 & 0,0 & 0,0 & 0,0 & 0,0 \\
\hline Uvigerina striata & 0,0 & 0,0 & 0,0 & 0,0 & 0,0 & 0,0 & 0,0 & 0,0 & 0,0 & 0,0 & 0,0 & 0,0 & 0,6 & 0,0 & 0,0 & 0,0 & 0,0 & 0,0 & 0,0 & 0,0 & 0,0 & 0,0 & 0,0 & 0,0 & 0,0 & 0,0 & 0,0 & 0,0 & 0,0 & 0,0 \\
\hline Não identificado & 1,1 & 2,8 & 0,9 & 0,0 & 0,9 & 2,9 & 0,0 & 0,0 & 0,0 & 2,9 & 0,8 & 0,0 & 0,6 & 2,0 & 1,8 & 0,0 & 0,0 & 0,9 & 1,0 & 0,0 & 1,0 & 0,9 & 1,1 & 1,0 & 0,8 & 0,7 & 0,8 & 0,0 & 1,0 & 0,8 \\
\hline \multicolumn{31}{|c|}{ Parâmetros bióticos } \\
\hline Densidade & 33 & 55 & 29 & 30 & 44 & 43 & 34 & 45 & 58 & 42 & 68 & 53 & 53 & 67 & 57 & 58 & 51 & 80 & 69 & 64 & 30 & 46 & 55 & 51 & 36 & 38 & 47 & 40 & 29 & 34 \\
\hline Vol de sed analisado* & 90 & 80 & 190 & 170 & 170 & 50 & 40 & 180 & 180 & 60 & 10 & 20 & 20 & 20 & 20 & 20 & 20 & 10 & 30 & 30 & 20 & 40 & 40 & 40 & 20 & 10 & 10 & 20 & 40 & 20 \\
\hline Foram. $/ 10 \mathrm{~cm}^{3} \mathrm{sed} * *$ & 11 & 14 & 6 & 6 & 6 & 21 & 25 & 6 & 5 & 18 & 125 & 64 & 89 & 49 & 82 & 88 & 49 & 217 & 34 & 42 & 48 & 28 & 24 & 25 & 59 & 144 & 127 & 51 & 24 & 66 \\
\hline Riqueza & 12 & 17 & 12 & 16 & 13 & 10 & 16 & 23 & 20 & 16 & 26 & 27 & 36 & 24 & 24 & 22 & 21 & 29 & 26 & 27 & 13 & 16 & 18 & 18 & 16 & 17 & 18 & 14 & 14 & 16 \\
\hline Diversidade específica & 1,3 & 1,9 & 1,4 & 1,4 & 1,6 & 1,2 & 1,7 & 2,1 & 2,2 & 1,8 & 2,69 & 2,42 & 2,51 & 2,61 & 2,34 & 2,30 & 2,15 & 2,52 & 2,79 & 2,63 & 1,65 & 2,09 & 2,27 & 2,15 & 1,92 & 1,93 & 2,07 & 1,83 & 1,49 & 1,82 \\
\hline Equitatividade & 0,54 & 0,68 & 0,58 & 0,50 & 0,64 & 0,53 & 0,63 & 0,67 & 0,75 & 0,66 & 0,82 & 0,73 & 0,70 & 0,82 & 0,74 & 0,74 & 0,71 & 0,75 & 0,86 & 0,80 & 0,64 & 0,75 & 0,79 & 0,74 & 0,69 & 0,68 & 0,72 & 0,69 & 0,57 & 0,66 \\
\hline
\end{tabular}

Legenda: * Volume de sedimento analisado, ${ }^{* *}$ Foraminíferos $/ 10 \mathrm{~cm}^{3}$ de sedimento 
Anexo 65 - (Biocenoses) Distribuição de espécies bioindicadoras de ambiente óxico e enriquecido por matéria orgânica identificadas próximo ao emissário do TEBAR.

Valores em porcentagem.

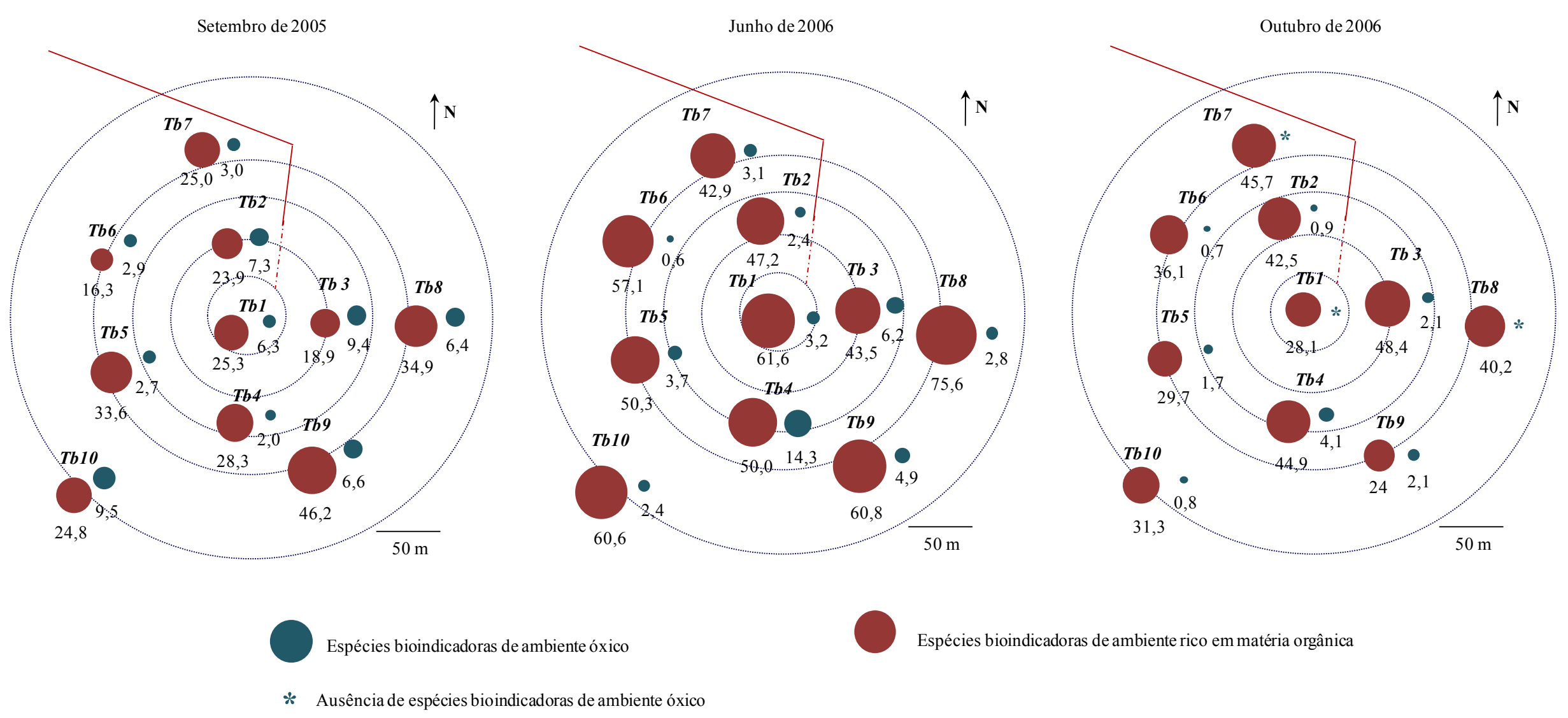


Anexo 66 - (Biocenoses) Resultado das análises morfométricas realizadas nas carapaças dos foraminíferos obtidas próximo ao emissário Saco da Capela.

Valores em porcentagem.

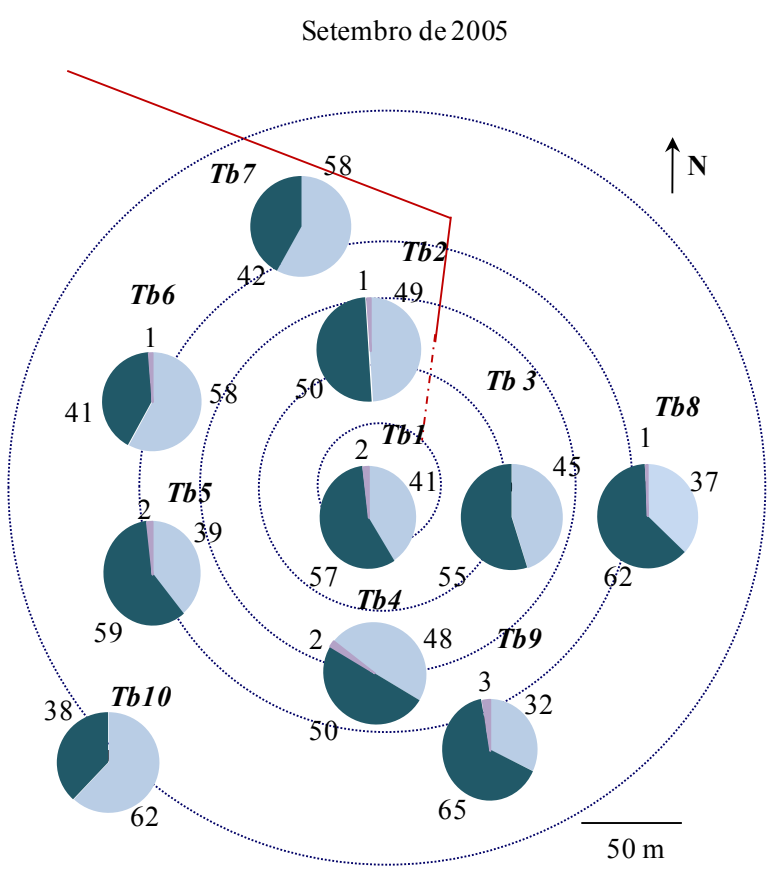

Carapaças pequenas

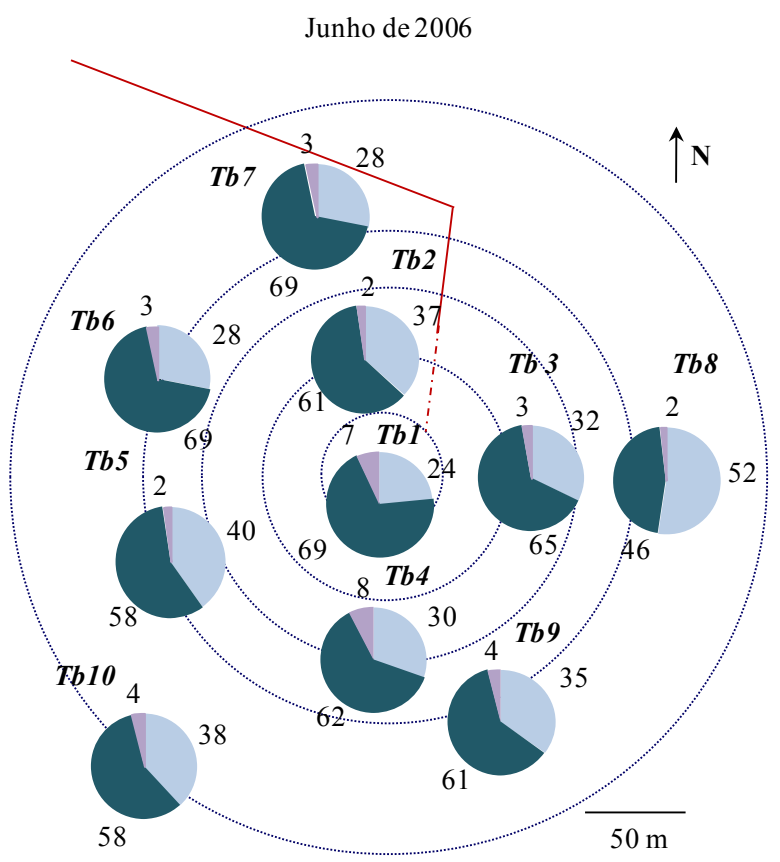

Carapaças médias

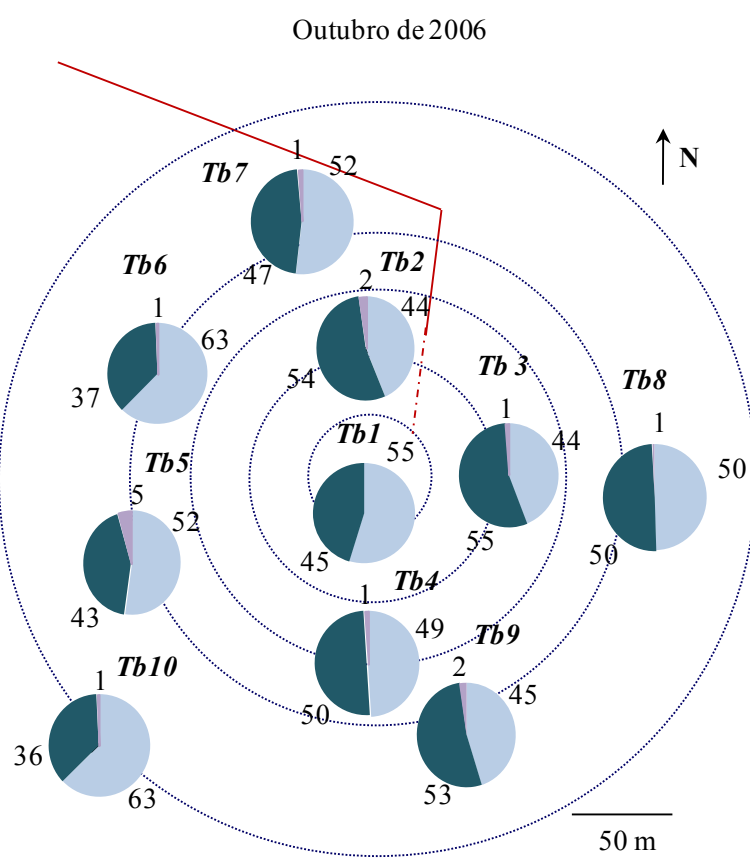

Carapaças grandes 
Anexo 67- Abundâncias relativas das espécies de foraminíferos identificadas próximo ao emissário do TEBAR.

Dados pertencentes às tanatocenoses.

\begin{tabular}{|c|c|c|c|c|c|c|c|c|c|c|c|c|c|c|c|c|c|c|c|c|c|c|c|c|c|c|c|c|c|c|}
\hline \multirow[b]{2}{*}{ Estações } & \multicolumn{10}{|c|}{ Agosto de 2005} & \multicolumn{10}{|c|}{ Março de 2006} & \multicolumn{10}{|c|}{ Agosto de 2006} \\
\hline & Tb1 & $\mathrm{Tb} 2$ & $\mathrm{~Tb} 3$ & $\mathrm{~Tb} 4$ & Tb5 & Tb6 & $\mathrm{Tb} 7$ & Tb8 & $\mathrm{Tb} 9$ & Tb10 & $\mathrm{Tb} 1$ & $\mathrm{~Tb} 2$ & $\mathrm{~Tb} 3$ & $\mathrm{~Tb} 4$ & Tb5 & Tb6 & $\mathrm{Tb} 7$ & $\mathrm{~Tb} 8$ & $\mathrm{~Tb} 9$ & Tb10 & $\mathrm{Tb} 1$ & $\mathrm{~Tb} 2$ & $\mathrm{~Tb} 3$ & $\mathrm{~Tb} 4$ & $\mathrm{~Tb} 5$ & Tb6 & $\mathrm{Tb} 7$ & $\mathrm{~Tb} 8$ & Tb9 & Tb10 \\
\hline Adelosina $\mathrm{sp}$ & 0,0 & 0,0 & 0,0 & 0,0 & 0,0 & 0,0 & 0,0 & 0,0 & 0,0 & 0,0 & 0,0 & 0,0 & 0,0 & 0,0 & 0,0 & 0,0 & 0,0 & 0,0 & 0,3 & 0,0 & 0,0 & 0,0 & 0,0 & 0,0 & 0,0 & 0,0 & 0,0 & 0,0 & 0,2 & 0,0 \\
\hline Ammobaculitres exiguus & 0,0 & 0,0 & 0,0 & 0,0 & 0,0 & 0,0 & 0,0 & 0,0 & 0,0 & 0,0 & 0 & 0,3 & 0,0 & 0,0 & 0,0 & 0,0 & 0,0 & 0,0 & 0,0 & 0,0 & 0 & 0,3 & 0,0 & 0,0 & 0,0 & 0,3 & 0,3 & 0,0 & 0,0 & 0,0 \\
\hline Ammonia parkinsoniana & 2,2 & 1,5 & 1,0 & 0,3 & 4,9 & 3,7 & 2,5 & 0,6 & 1,1 & 0,8 & 3,2 & 4,8 & 3,6 & 3,0 & 4,9 & 5,5 & 3,3 & 5,8 & 5,0 & 3,0 & 3,6 & 7,6 & 4,9 & 5,1 & 6,4 & 3,6 & 2,7 & 1,2 & 3,7 & 5,2 \\
\hline Ammonia tepida & 18,0 & 18,5 & 12,1 & 6,3 & 21,3 & 18,0 & 11,1 & 11,5 & 6,4 & 9,4 & 9,5 & 9,6 & 6,4 & 5,0 & 15,8 & 15,5 & 7,9 & 6,6 & 9,5 & 9,6 & 12,4 & 10,6 & 12,2 & 13,5 & 18,1 & 15,2 & 11,2 & 6,8 & 8,1 & 21,6 \\
\hline Ammonia sp & 14,2 & 17,3 & 12,1 & 13,6 & 23,0 & 14,9 & 16,8 & 12,4 & 12,5 & 10,5 & 11,0 & 11,3 & 7,3 & 5,0 & 10,0 & 6,8 & 11,2 & 8,4 & 1,5 & 8,1 & 5,5 & 5,3 & 11,5 & 6,8 & 16,1 & 7,8 & 3,6 & 7,4 & 6,4 & 11,0 \\
\hline Ammotium salsum & 0,0 & 0,0 & 0,0 & 0,0 & 0,0 & 0,0 & 0,0 & 0,0 & 0,0 & 0,0 & 0,0 & 0,0 & 0,0 & 0,7 & 0,0 & 0,0 & 0,0 & 0,0 & 0,0 & 0,0 & 0,0 & 0,3 & 0,5 & 0,3 & 0,3 & 0,3 & 0,0 & 0,3 & 0,2 & 0,0 \\
\hline Angulogerina angulosa & 0,4 & 0,8 & 0,0 & 0,7 & 0,3 & 0,0 & 0,0 & 0,6 & 0,0 & 0,3 & 0 & 0,0 & 0,0 & 0,3 & 0,6 & 0,3 & 0,0 & 0,3 & 0,6 & 0,0 & 0,0 & 0,0 & 0,2 & 0,0 & 0,0 & 0,0 & 0,0 & 0,0 & 0,0 & 0,7 \\
\hline Angulogerina jamaicensis & 0,0 & 0,0 & 0,0 & 0,0 & 0,0 & 0,0 & 0,0 & 0,0 & 0,0 & 0,0 & 0,0 & 0,0 & 0,0 & 0,3 & 0,3 & 0,0 & 0,0 & 0,0 & 0,0 & 0,0 & 0,0 & 0,0 & 0,0 & 0,0 & 0,0 & 0,0 & 0,3 & 0,0 & 0,0 & 0,0 \\
\hline Astrononion sp & 0,0 & 0,0 & 0,0 & 0,0 & 0,0 & 0,0 & 0,0 & 0,0 & 0,0 & 0,0 & 0,0 & 0,3 & 0,0 & 0,0 & 0,0 & 0,3 & 0,4 & 0,5 & 0,3 & 0,0 & 0,0 & 0,0 & 0,0 & 0,0 & 0,0 & 0,0 & 0,0 & 0,0 & 0,0 & 0,3 \\
\hline Bolivina compacta & 0,0 & 0,4 & 0,7 & 0,3 & 0,0 & 0,0 & 0,0 & 0,0 & 0,6 & 0,0 & 0,0 & 0,5 & 0,3 & 0,0 & 0,6 & 0,0 & 0,8 & 0,5 & 0,0 & 0,5 & 0,3 & 0,6 & 0,0 & 0,3 & 0,0 & 0,0 & 0,3 & 0,0 & 0,0 & 0,0 \\
\hline Bolivina danvilensis & 0,0 & 0,0 & 0,0 & 0,0 & 0,0 & 0,0 & 0,0 & 0,0 & 0,0 & 0,0 & 0,0 & 0,5 & 0,0 & 0,0 & 0,3 & 0,0 & 0,4 & 0,0 & 0,3 & 0,7 & 0,3 & 0,6 & 0,5 & 0,3 & 0,0 & 0,3 & 0,3 & 0,3 & 0,4 & 0,0 \\
\hline Bolivina dilatata & 0,0 & 0,0 & 0,0 & 0,0 & 0,0 & 0,0 & 0,0 & 0,0 & 0,0 & 0,0 & 0,0 & 0,0 & 0,0 & 0,0 & 0,0 & 0,0 & 0,0 & 0,0 & 0,0 & 0,0 & 0,0 & 0,0 & 0,0 & 0,0 & 0,0 & 0,3 & 0,0 & 0,0 & 0,0 & 0,0 \\
\hline Bolivina doniezi & 0,0 & 0,8 & 0,0 & 0,0 & 0,0 & 0,0 & 0,0 & 0,0 & 0,0 & 0,0 & 1,1 & 1,8 & 0,9 & 0,3 & 0,3 & 0,3 & 1,5 & 0,3 & 0,9 & 1,2 & 0,3 & 0,9 & 0,7 & 0,0 & 0,0 & 0,0 & 0,0 & 0,0 & 0,2 & 0,3 \\
\hline Bolivina gracilis & 0,0 & 0,0 & 0,0 & 0,0 & 0,0 & 0,0 & 0,0 & 0,0 & 0,0 & 0,0 & 0,0 & 0,0 & 0,3 & 0,0 & 0,0 & 0,0 & 0,0 & 0,0 & 0,0 & 0,0 & 0,0 & 0,0 & 0,5 & 0,7 & 0,0 & 0,0 & 0,5 & 0,3 & 0,0 & 0,0 \\
\hline Bolivina ordinaria & 0,0 & 0,8 & 0,3 & 0,3 & 1,4 & 0,6 & 0,7 & 1,2 & 2,5 & 1,3 & 1,1 & 2,5 & 0,9 & 0,0 & 0,0 & 0,0 & 1,2 & 0,3 & 0,3 & 0,2 & 0,3 & 0,6 & 0,2 & 0,0 & 0,0 & 0,0 & 0,0 & 0,3 & 0,4 & 0,3 \\
\hline Bolivina pseudoplicata & 0,0 & 0,4 & 0,3 & 0,0 & 0,0 & 0,0 & 0,7 & 0,9 & 0,6 & 0,5 & 1,1 & 0,8 & 0,3 & 0,3 & 0,3 & 0,0 & 0,2 & 0,3 & 0,6 & 0,5 & 3 & 0,3 & 0,7 & 0,3 & 0,3 & 0,3 & 0,0 & 0,0 & 0,4 & 0,0 \\
\hline Bolivina pulchella & 3,0 & 1,2 & 1,4 & 3,8 & 0,3 & 0,8 & 2,1 & 0,6 & 3,6 & 1,1 & 0,4 & 1,8 & 2,1 & 1,3 & 0,3 & 1,3 & 0,4 & 0,0 & 1,5 & 1,0 & 0,7 & 1,5 & 0,7 & 0,0 & 0,0 & 0,9 & 1,9 & 3,7 & 1,3 & 1,0 \\
\hline Bolivina sphatulata & 0,0 & 0,0 & 0,0 & 0,0 & 0,0 & 0,0 & 0,0 & 0,0 & 0,0 & 0,0 & 0,0 & 0,3 & 0,9 & 0,7 & 0,0 & 0,0 & 0,0 & 0,0 & 0,0 & 0,0 & 0,0 & 0,3 & 0,0 & 1,0 & 0,0 & 0,0 & 0,0 & 0,0 & 0,0 & 0,0 \\
\hline Bolivina translucens & 0,0 & 0,0 & 0,0 & 1,0 & 0,7 & 0,8 & 0,4 & 0,9 & 0,0 & 0,0 & 0,7 & 0,0 & 0,3 & 0,0 & 0,3 & 0,0 & 1,0 & 0,3 & 0,0 & 0,5 & 0,3 & 0,0 & 0,2 & 0,0 & 1,0 & 0,3 & 0,0 & 0,3 & 0,0 & 0,3 \\
\hline Bolivina variabilis & 0,0 & 0,0 & 0,0 & 0,0 & 0,0 & 0,0 & 0,0 & 0,0 & 0,0 & 0,0 & 0,0 & 0,0 & 0,0 & 0,0 & 0,0 & 0,0 & 0,0 & 0,0 & 0,0 & 0,7 & 0,0 & 0,0 & 0,0 & 0,0 & 0,0 & 0,0 & 0,0 & 0,0 & 0,0 & 0,0 \\
\hline Bolivina $\mathrm{sp}$ & 2,2 & 2,3 & 2,8 & 3,1 & 1,7 & 2,2 & 1,4 & 0,9 & 1,4 & 2,2 & 2,1 & 1,5 & 0,9 & 1,7 & 1,1 & 1,0 & 0,4 & 1,6 & 0,9 & 1,7 & 0,7 & 1,8 & 1,4 & 0,3 & 0,3 & 0,6 & 0,3 & 1,2 & 0,4 & 0,7 \\
\hline Bolivinella pescicula & 0,0 & 0,0 & 0,0 & 0,0 & 0,0 & 0,0 & 0,0 & 0,0 & 0,0 & 0,0 & 0,0 & 0,0 & 0,0 & 0,0 & 0,0 & 0,0 & 0,2 & 0,0 & 0,3 & 0,0 & 0,0 & 0,0 & 0,0 & 0,0 & 0,0 & 0,0 & 0,0 & 0,0 & 0,0 & 0,0 \\
\hline Brizalina sphatulata & 0,0 & 0,0 & 0,0 & 0,0 & 0,0 & 0,0 & 0,0 & 0,0 & 0,0 & 0,0 & 0,0 & 0,0 & 0,0 & 0,0 & 0,3 & 0,0 & 0,0 & 0,0 & 0,0 & 0,5 & 0,0 & 0,0 & 0,0 & 0,3 & 0,0 & 0,0 & 0,0 & 0,3 & 0,2 & 0,3 \\
\hline Brizalina striatula & 2,2 & 1,5 & 2,8 & 1,0 & 1,0 & 1,4 & 1,1 & 1,9 & 2,2 & 1,9 & 1,8 & 1,0 & 1,8 & 2,3 & 1,7 & 0,6 & 2,1 & 1,8 & 2,4 & 2,7 & 0,7 & 2,4 & 0,9 & 2,0 & 0,0 & 1,2 & 0,5 & 0,6 & 1,3 & 1,4 \\
\hline Buccella peruviana & 0,0 & 0,0 & 0,0 & 0,0 & 0,0 & 0,3 & 0,0 & 0,0 & 0,3 & 0,0 & 0,0 & 0,0 & 0,0 & 0,0 & 0,0 & 0,3 & 0,0 & 0,0 & 0,0 & 0,0 & 0,3 & 0,3 & 0,0 & 0,3 & 0,0 & 0,0 & 0,3 & 0,6 & 0,2 & 0,0 \\
\hline Bulimina elongata & 0,0 & 0,0 & 0,0 & 0,0 & 0,3 & 0,8 & 0,0 & 0,3 & 0,8 & 0,5 & 0,0 & 0,0 & 0,0 & 0,7 & 0,0 & 0,3 & 0,2 & 0,0 & 0,3 & 0,2 & 0,0 & 0,0 & 0,0 & 0,3 & 0,0 & 0,0 & 0,0 & 0,3 & 0,0 & 0,0 \\
\hline Bulimina gibba & 0,0 & 0,0 & 0,0 & 0,0 & 0,0 & 0,0 & 0,0 & 0,0 & 0,0 & 0,0 & 0,0 & 0,0 & 0,0 & 0,0 & 0,0 & 0,0 & 0,4 & 0,0 & 0,0 & 0,0 & 0,0 & 0,0 & 0,0 & 0,0 & 0,0 & 0,0 & 0,0 & 0,0 & 0,0 & 0,0 \\
\hline Bulimina marginata & 2,6 & 1,5 & 4,8 & 6,3 & 2,1 & 3,4 & 1,8 & 4,0 & 3,3 & 1,9 & 1,8 & 0,8 & 4,6 & 3,7 & 2,9 & 5,8 & 2,3 & 2,1 & 3,8 & 2,2 & 8,5 & 2,1 & 1,4 & 5,7 & 1,7 & 7,5 & 7,7 & 2,2 & 5,3 & 2,1 \\
\hline Bulimina pupoides & 0,0 & 0,0 & 2,1 & 0,3 & 0,0 & 0,0 & 0,0 & 0,0 & 0,0 & 0,0 & 0,7 & 0,3 & 0,3 & 0,0 & 0,0 & 0,0 & 0,2 & 0,3 & 0,0 & 0,0 & 0,0 & 0,0 & 0,0 & 0,0 & 0,0 & 0,0 & 0,0 & 0,0 & 0,0 & 0,0 \\
\hline Bulimina $\mathrm{sp}$ & 0,4 & 0,0 & 0,0 & 0,0 & 0,0 & 0,0 & 0,0 & 0,0 & 0,0 & 0,0 & 0,0 & 0,0 & 0,0 & 0,0 & 0,0 & 0,0 & 0,0 & 0,0 & 0,0 & 0,0 & 0,0 & 0,0 & 0,0 & 0,0 & 0,0 & 0,0 & 0,0 & 0,0 & 0,2 & 0,3 \\
\hline Buliminella elegantissima & 4,5 & 2,3 & 2,4 & 3,5 & 3,1 & 3,1 & 6,1 & 2,8 & 3,9 & 3,0 & 2,8 & 4,8 & 1,8 & 3,3 & 4,3 & 2,6 & 3,5 & 4,7 & 3,3 & 2,5 & 2,6 & 4,1 & 3,7 & 4,7 & 4,0 & 2,1 & 2,7 & 1,5 & 2,0 & 3,1 \\
\hline
\end{tabular}


Anexo 67 - Continuação

\begin{tabular}{|c|c|c|c|c|c|c|c|c|c|c|c|c|c|c|c|c|c|c|c|c|c|c|c|c|c|c|c|c|c|c|}
\hline \multirow[b]{2}{*}{ Estações } & \multicolumn{10}{|c|}{ Agosto de 2005} & \multicolumn{10}{|c|}{ Março de 2006} & \multicolumn{10}{|c|}{ Agosto de 2006} \\
\hline & Tb1 & $\mathrm{Tb} 2$ & $\mathrm{~Tb} 3$ & $\mathrm{~Tb} 4$ & Tb5 & Tb6 & $\mathrm{Tb} 7$ & Tb8 & $\mathrm{Tb} 9$ & $\mathrm{~Tb} 10$ & $\mathrm{~Tb} 1$ & $\mathrm{~Tb} 2$ & $\mathrm{~Tb} 3$ & $\mathrm{~Tb} 4$ & $\mathrm{Tb5}$ & Tb6 & $\mathrm{Tb} 7$ & $\mathrm{~Tb} \varepsilon$ & $\mathrm{Tb} 9$ & $\mathrm{~Tb} 10$ & $\mathrm{~Tb} 1$ & $\mathrm{~Tb} 2$ & $\mathrm{~Tb} 3$ & $\mathrm{~Tb} 4$ & Tb5 & Tb6 & $\mathrm{Tb} 7$ & $\mathrm{~Tb} 8$ & $\mathrm{~Tb} 9$ & Tb10 \\
\hline Cancris sagra & 0,0 & 0,0 & 0,0 & 0,0 & 0,0 & 0,0 & 0,0 & 0,0 & 0,0 & 0,0 & 0,0 & 0,0 & 0,0 & 0,0 & 0,0 & 0,0 & 0,2 & 0,0 & 0,0 & 0,0 & 0,0 & 0,0 & 0,0 & 0,0 & 0,0 & 0,0 & 0,0 & 0,0 & 0,0 & 0,0 \\
\hline Cassidulina crassa & 3,4 & 2,3 & 3,8 & 2,1 & 1,0 & 2,0 & 2,1 & 6,2 & 2,5 & 4,3 & 5,3 & 1,0 & 2,4 & 3,3 & 2,3 & 1,3 & 2,5 & 7,6 & 2,4 & 3,4 & 2,0 & 2,4 & 5,6 & 1,4 & 3,4 & 1,8 & 1,4 & 4,9 & 4,0 & 2,4 \\
\hline Cassidulina laevigata & 0,0 & 0,0 & 0,7 & 0,0 & 0,0 & 0,0 & 0,0 & 1,2 & 0,8 & 1,1 & 0,0 & 0,3 & 0,0 & 0,0 & 0,3 & 0,0 & 0,6 & 0,3 & 0,0 & 0,0 & 0,0 & 0,0 & 0,5 & 0,3 & 0,3 & 0,0 & 0,0 & 0,3 & 0,2 & 0,0 \\
\hline Cassidulina minuta & 0,0 & 0,8 & 0,7 & 0,3 & 0,0 & 0,0 & 1,4 & 0,3 & 0,0 & 0,0 & 0,0 & 0,5 & 0,9 & 0,0 & 1,4 & 0,0 & 1,2 & 3,4 & 1,5 & 0,5 & 1,0 & 0,3 & 0,2 & 0,3 & 0,7 & 0,0 & 0,5 & 0,6 & 0,2 & 0,0 \\
\hline Cassidulian rossensis & 0,0 & 0,0 & 0,0 & 0,0 & 0,0 & 0,0 & 0,0 & 0,0 & 0,0 & 0,0 & 0,0 & 0,0 & 0,0 & 0,0 & 0,0 & 0,0 & 0,0 & 0,0 & 0,0 & 0,0 & 0,0 & 0,3 & 0,2 & 0,0 & 0,0 & 0,0 & 0,0 & 0,0 & 0,0 & 0,0 \\
\hline Cassidulina subglobosa & 4,5 & 1,2 & 1,7 & 2,4 & 2,4 & 2,2 & 0,0 & 1,5 & 3,9 & 3,0 & 2,1 & 1,3 & 1,8 & 1,3 & 1,1 & 1,3 & 0,8 & 3,7 & 1,5 & 1,2 & 0,3 & 1,5 & 0,9 & 0,0 & 0,3 & 0,0 & 0,5 & 0,6 & 2,0 & 0,7 \\
\hline Cassidulina sp & 0,0 & 0,0 & 0,0 & 0,0 & 0,0 & 0,0 & 0,0 & 0,0 & 0,0 & 0,0 & 0,0 & 0,0 & 0,0 & 0,0 & 0,0 & 0,0 & 0,0 & 0,0 & 0,0 & 0,0 & 0,0 & 0,0 & 0,2 & 0,0 & 0,0 & 0,0 & 0,0 & 0,0 & 0,0 & 0,3 \\
\hline Cibicides dispars & 0,0 & 0,0 & 0,0 & 0,0 & 0,0 & 0,0 & 0,0 & 0,3 & 0,0 & 0,0 & 0,0 & 0,0 & 0,3 & 0,3 & 0,0 & 0,0 & 0,0 & 0,0 & 0,0 & 0,0 & 0,0 & 0,0 & 0,0 & 0,0 & 0,0 & 0,0 & 0,0 & 0,0 & 0,0 & 0,0 \\
\hline Cibicides refulgens & 0,0 & 0,0 & 0,0 & 0,0 & 0,0 & 0,0 & 0,0 & 0,0 & 0,0 & 0,0 & 0,0 & 0,0 & 0,0 & 0,0 & 0,6 & 0,0 & 0,2 & 0,3 & 0,0 & 0,2 & 0,0 & 0,0 & 0,0 & 0,0 & 0,3 & 0,0 & 0,0 & 0,3 & 0,0 & 0,0 \\
\hline Cibicides variabilis & 0,0 & 0,0 & 0,0 & 0,0 & 0,0 & 0,0 & 0,0 & 0,0 & 0,0 & 0,0 & 0,0 & 0,0 & 0,6 & 0,0 & 0,0 & 0,0 & 0,0 & 0,0 & 0,0 & 0,0 & 0,0 & 0,0 & 0,0 & 0,0 & 0,0 & 0,0 & 0,0 & 0,0 & 0,0 & 0,0 \\
\hline Cibicides sp & 0,0 & 0,4 & 1,7 & 1,7 & 0,0 & 0,6 & 0,7 & 0,6 & 0,6 & 0,3 & 1,1 & 0,0 & 0,0 & 0,0 & 0,6 & 0,3 & 0,0 & 1,0 & 0,3 & 0 & 0,0 & 0,3 & 0,0 & 0,3 & 0,0 & 0,0 & 0,0 & 0,0 & 0,2 & 0,0 \\
\hline Cornobella pateliformis & 0,0 & 0,0 & 0,0 & 0,0 & 0,0 & 0,0 & 0,0 & 0,0 & 0,0 & 0,0 & 0,7 & 0,3 & 0,0 & 0,0 & 0,0 & 0,0 & 0,0 & 0,5 & 0,3 & 0,5 & 0,0 & 0,0 & 0,0 & 0,0 & 0,0 & 0,0 & 0,0 & 0,0 & 0,2 & 0,0 \\
\hline Cornuspira involvens & 0,0 & 0,0 & 0,0 & 0,0 & 0,0 & 0,0 & 0,4 & 0,0 & 0,0 & 0 & 0,0 & 0,0 & 0,0 & 0,0 & 0,0 & 0,0 & 0,0 & 0,0 & 0,0 & 0,0 & 0,0 & 0,0 & 0,0 & 0,0 & 0,0 & 0,0 & 0,0 & 0,0 & 0,0 & 0,0 \\
\hline Cribroelphidium advenum & 0,0 & 0,0 & 0,0 & 0,0 & 0,0 & 0,0 & 0,0 & 0,0 & 0,3 & 0 , & 0,0 & 1,0 & 0,6 & 0,0 & 0,0 & 0,0 & 0,4 & 0,0 & 0,0 & 0 & 0,0 & 0,0 & 0,0 & 0,0 & 0,0 & 0,0 & 0,0 & 0,3 & 0,0 & 0,3 \\
\hline Cribroelphidium discoidale & 0,0 & 1,2 & 0,0 & 1,0 & 0,0 & 0,3 & 0,0 & 1,2 & 0,8 & 0,5 & 0,7 & 0,5 & 0,9 & 1,0 & 0,0 & 2,6 & 0,4 & 0,5 & 1,8 & 0,0 & 2,6 & 0,6 & 0,0 & 2,0 & 0,0 & 0,3 & 1,6 & 0,9 & 1,8 & 0,0 \\
\hline Cribroelphidium excavatum & 1,9 & 1,5 & 0,7 & 2,4 & 3,1 & 1,1 & 2,1 & 1,5 & 0,8 & 1,9 & 2,8 & 3,8 & 3,6 & 2,3 & 2,9 & 3,5 & 3,9 & 1,3 & 2,7 & 1,7 & 4,6 & 1,8 & 3,0 & 2,4 & 2,7 & 1,8 & 0,5 & 1,2 & 2,2 & 1,4 \\
\hline Cribroelphidium gunteri & 0,0 & 0,0 & 0,0 & 0,0 & 0,0 & 0,0 & 0,0 & 0,0 & 0,0 & 0 & 0,0 & 0,0 & 0,3 & 0,0 & 0,0 & 0,0 & 0,0 & 0,0 & 0,0 & 0, & 0,0 & 0,0 & 0,0 & 0,0 & 0,0 & 0,0 & 0,0 & 0,0 & 0,0 & 0,0 \\
\hline Cribroelphidium lessonii & 0,0 & 0,0 & 0,0 & 0,0 & 0,0 & 0,0 & 0,0 & 0,0 & 0,0 & 0,0 & 0,0 & 0,0 & 0,0 & 0,0 & 0,0 & 0,0 & 0,0 & 0,0 & 0,0 & 0,0 & 0,3 & 0,0 & 0,2 & 0,0 & 0,0 & 0,6 & 0,3 & 0,0 & 0,2 & 0,0 \\
\hline Cribroelphidium magellanicum & 0,0 & 0,0 & 0,0 & 0,0 & 0,0 & 0,0 & 0,0 & 0,0 & 0,0 & 0,0 & 0,0 & 0,0 & 0,0 & 0,3 & 0,0 & 0,0 & 0,0 & 0,0 & 0,0 & 0,0 & 0,0 & 0,0 & 0,0 & 0,0 & 0,0 & 0,0 & 0,0 & 0,0 & 0,0 & 0,0 \\
\hline Cribroelphidium poyeanum & 0,4 & 0,4 & 1,0 & 0,3 & 0,7 & 1,4 & 0,4 & 1,2 & 0,8 & 0,8 & 0,0 & 0,3 & 1,2 & 2,7 & 0,0 & 2,3 & 0,8 & 0,3 & 0,6 & 0,5 & 0,7 & 0,6 & 1,6 & 2,0 & 2,7 & 2,1 & 3,6 & 3,7 & 0,9 & 2,1 \\
\hline Cribroelphidium sp & 2,6 & 0,8 & 2,1 & 1,7 & 2,4 & 2,8 & 4,3 & 1,5 & 1,9 & 1,9 & 2,8 & 0,5 & 1,5 & 2,0 & 1,1 & 1,0 & 1,2 & 1,3 & 1,8 & 1,0 & 0,7 & 2,6 & 0,7 & 0,7 & 2,0 & 0,9 & 0,8 & 0,9 & 0,4 & 0,3 \\
\hline Cribrostomoides jefreysii & 0,0 & 0,0 & 0,0 & 0,0 & 0,0 & 0,0 & 0,0 & 0,0 & 0,0 & 0 & 0,0 & 0,0 & 0,0 & 0,0 & 0,0 & 0,0 & 0,2 & 0,0 & 0 & 0,0 & 0,0 & 0,0 & 0,0 & 0,0 & 0,0 & 0,0 & 0,0 & 0,0 & 0,0 & 0,0 \\
\hline Cribrostomoides sp & 0,0 & 0,0 & 0,0 & 0,0 & 0,0 & 0,0 & 0,0 & 0,0 & 0,0 & 0,0 & 0,0 & 0,0 & 0,0 & 0,0 & 0,0 & 0,0 & 0,0 & 0,0 & 0,0 & 0,0 & 0,7 & 0,3 & 0,0 & 0,0 & 0,0 & 0,0 & 0,0 & 0,0 & 0,0 & 0,7 \\
\hline Cycloforina sp & 0,0 & 0,0 & 0,0 & 0,0 & 0,0 & 0,0 & 0,0 & 0,3 & 0,3 & 0,0 & 0,0 & 0,0 & 0,0 & 0,0 & 0,3 & 0,0 & 0,0 & 0,0 & 0,0 & 0,0 & 0,0 & 0,0 & 0,0 & 0,0 & 0,0 & 0,0 & 0,0 & 0,0 & 0,0 & 0,0 \\
\hline Dentalina $\mathrm{sp}$ & 0,0 & 0,0 & 0,0 & 0,0 & 0,0 & 0,0 & 0,0 & 0,0 & 0,0 & 0,0 & 0,0 & 0,0 & 0,0 & 0,0 & 0,0 & 0,0 & 0,0 & 0,0 & 0,0 & 0,0 & 0,0 & 0,0 & 0,0 & 0,0 & 0,0 & 0,0 & 0,0 & 0,0 & 0,0 & 0,3 \\
\hline Discorbis berthelotti & 0,0 & 0,0 & 0,0 & 0,0 & 0,0 & 0,0 & 0,0 & 0,0 & 0,3 & 0,0 & 0,0 & 0,0 & 0,3 & 0,0 & 0,0 & 0,0 & 0,0 & 0,0 & 0,0 & 0,0 & 0,0 & 0,0 & 0,0 & 0,0 & 0,0 & 0,0 & 0,0 & 0,3 & 0,2 & 0,0 \\
\hline Discorbis peruvians & 0,0 & 0,0 & 0,0 & 0,0 & 0,0 & 0,0 & 0,0 & 0,0 & 0,0 & 0,0 & 0,0 & 0,0 & 0,0 & 0,0 & 0,0 & 0,0 & 0,0 & 0,0 & 0,0 & 0,0 & 0,0 & 0,0 & 0,0 & 0,0 & 0,0 & 0,0 & 0,0 & 0,3 & 0,0 & 0,0 \\
\hline Discorbis williamsoni & 0,0 & 0,8 & 1,0 & 0,0 & 0,0 & 0,6 & 0,4 & 0,3 & 0,6 & 0,5 & 1,4 & 0,3 & 0,0 & 0,3 & 0,0 & 0,0 & 1,0 & 1,0 & 0,9 & 0,0 & 0,0 & 0,0 & 0,2 & 0,0 & 0,0 & 0,3 & 0,0 & 1,5 & 0,2 & 0,0 \\
\hline Discorbis $\mathrm{sp}$ & 0,0 & 0,0 & 0,3 & 0,0 & 0,0 & 0,3 & 0,0 & 0,3 & 0,0 & 0,0 & 0,0 & 0,0 & 0,0 & 0,0 & 0,0 & 0,0 & 0,0 & 0,0 & 0,0 & 0,0 & 0,0 & 0,0 & 0,0 & 0,0 & 0,0 & 0,0 & 0,0 & 0,0 & 0,0 & 0,0 \\
\hline Egerella scabra & 0,0 & 0,0 & 0,0 & 0,0 & 0,0 & 0,0 & 0,0 & 0,0 & 0,0 & 0,0 & 0,0 & 0,0 & 0,3 & 0,3 & 0,0 & 0,0 & 0,0 & 0,3 & 0,3 & 0,0 & 0,0 & 0,0 & 0,2 & 0,0 & 0,0 & 0,6 & 0,0 & 0,0 & 0,4 & 0,0 \\
\hline Epistominella vitrea & 0,0 & 0,0 & 0,0 & 0,0 & 0,0 & 0,0 & 0,0 & 0,0 & 0,0 & 0,0 & 1,8 & 0,3 & 0,0 & 0,3 & 0,0 & 0,6 & 0,8 & 1,8 & 0,6 & 0,0 & 0,7 & 0,9 & 0,9 & 0,3 & 0,7 & 0,0 & 0,0 & 0,0 & 0,2 & 0,3 \\
\hline
\end{tabular}




\section{Anexo 67 - Continuação}

\begin{tabular}{|c|c|c|c|c|c|c|c|c|c|c|c|c|c|c|c|c|c|c|c|c|c|c|c|c|c|c|c|c|c|c|}
\hline \multirow[b]{2}{*}{ Estações } & \multicolumn{10}{|c|}{ Agosto de 2005} & \multicolumn{10}{|c|}{ Março de 2006} & \multicolumn{10}{|c|}{ Agosto de 2006} \\
\hline & Tb1 & $\mathrm{Tb} 2$ & Tb3 & Tb4 & Tb5 & Tb6 & $\mathrm{Tb} 7$ & Tb8 & $\mathrm{Tb} 9$ & Tb10 & $\mathrm{Tb} 1$ & $\mathrm{~Tb} 2$ & $\mathrm{~Tb} 3$ & $\mathrm{~Tb} 4$ & Tb5 & Tb6 & $\mathrm{Tb} 7$ & Tb8 & Tb9 & Tb10 & $\mathrm{Tb} 1$ & $\mathrm{~Tb} 2$ & Tb3 & Tb4 & Tb5 & Tb6 & $\mathrm{Tb} 7$ & Tb8 & $\mathrm{Tb} 9$ & Tb10 \\
\hline Eponides repandus & 0,0 & 0,0 & 0,0 & 0,0 & 0,0 & 0,0 & 0,0 & 0,0 & 0,0 & 0,0 & 0,0 & 0,0 & 0,0 & 0,0 & 0,0 & 0,3 & 0,0 & 0,0 & 0,0 & 0,0 & 0,0 & 0,0 & 0,0 & 0,0 & 0,0 & 0,0 & 0,0 & 0,0 & 0,0 & 0,0 \\
\hline Fissurina laevigata & 1,5 & 1,9 & 1,7 & 0,7 & 1,0 & 0,8 & 0,4 & 0,9 & 1,1 & 0,8 & 8 & 0,5 & 1,5 & 1,7 & 0,9 & 1,0 & 0,6 & 0,0 & 0,3 & 2 & , 0 & 0,3 & 0,5 & 2,7 & 0,3 & 1,5 & 1,6 & 0,6 & 0,9 & 0,7 \\
\hline Fissurina lucida & 0,0 & 0,0 & 0,0 & 0,0 & 0,0 & 0,3 & 0,0 & 0,0 & 0,0 & 0,0 & 0,4 & 0,0 & 0,0 & 0,0 & 0,6 & 0,0 & 0,2 & 0,5 & 0,0 & 0 & 0,3 & 0,0 & 0,2 &, 0 & 0,0 &, 9 & ,0 & 0,0 &, 0 & 0,0 \\
\hline Fissurina $\mathrm{sp}$ & 0,0 & 0,0 & 0,0 & 0,0 & 0,0 & 0,0 & 0,0 & 0,0 & 0,0 & 0,0 & 0,0 & 0,0 & 0,0 & 0,0 & 0,0 & 0,0 & 0,0 & 0,0 & 0,0 & 0 , & 0,3 & 0,0 & 0,0 & 0,0 & 0,0 & 0,0 & 0,0 & 0,0 & 0,0 & 0,0 \\
\hline Fursenkoina acuta & 0,0 & 0,0 & 0,0 & 0,0 & 0,0 & 0,0 & 0,0 & 0,0 & 0,0 & 0,0 & 0,0 & 0,0 & 0,0 & 0,0 & 0,0 & 0,0 & 0,0 & 0,0 & 0,0 & 0 & 0,0 & 0,0 & 0,0 & 0,0 & 0,0 & 0,0 & 0,0 & 0,0 &, 2 & 0,0 \\
\hline Fursenkot & 0,0 & 0,0 & 0,0 & 0,0 & 0,0 & 0,0 & 0,0 & 0,0 & 0,0 & 0 , & 0,4 & 0,0 & 0,0 & 0,3 & 0,0 & 0,0 & 0,0 & 0,0 & 0,0 & 0 & 0,0 & 0,0 & 0,0 &, 0 & 0,0 & 0,0 & 0 & 0,0 & 0 &, 0 \\
\hline Fursenkoina fragilis & 0,0 & 0,0 & 0,0 & 0,0 & 0,0 & 0,0 & 0,0 & 0,0 & 0,0 & 0,0 & 0,0 & 0,0 & 0,0 & 0,0 & 0,0 & 0,0 & 0,0 & 0,0 & 0,3 & 0 , & 0,0 & 0,3 & 0,0 & 0,3 & 0,0 & 0,0 & 0,0 & 0,0 & 0,0 & 0,0 \\
\hline Fursenkoina pontoni & 0,0 & 0,0 & 0,0 & 0,3 & 0,3 & 0,3 & 0,0 & 0,3 & 0,0 & 0,8 & 0,4 & 0,0 & 0,0 & 0,0 & 0,6 & 1,9 & 0,4 & 0,5 & 0,6 & 0 & 0,3 & 0,0 & 0,5 & 0,0 & 0,0 & 0,3 & 0,5 & 0,0 &, 0 & 1,4 \\
\hline Fursenkoina riggi & 0,0 & 0,0 & 0,3 & 0,3 & 0,7 & 0,8 & 0,0 & 0,0 & 0,0 & 0,3 & 0,0 & 0,0 & 0,3 & 0,0 & 0,3 & 0,0 & 0,0 & 0,3 & 0,0 & 0 , & 0,0 & 0,0 & 0,5 & 1,7 & 0,3 & 0,6 & 0,0 & 0,0 & 0,0 & 0,3 \\
\hline Gaudryina exilis & 0,0 & 0,0 & 0,0 & 0,0 & 0,0 & 0,6 & 0,0 & 0,0 & 0,0 & 0 , & 0 & 0,8 & 0,0 & 0,0 & 1,1 & 1,3 & 0,8 & 0,3 & 0,3 & 0 & 1,0 & 0,6 & 0,7 & 1,7 & 0,0 & 0,3 &, 5 & 0,6 & 4 &, 0 \\
\hline Gavelinopsis praegeri & 3,0 & 1,2 & 1,4 & 1,0 & 0,7 & 1,7 & 2,1 & 0,9 & 0,8 & 1,6 & 2,5 & 2,5 & 2,1 & 4,0 & 0,9 & 0,6 & 2,9 & 2,9 & 2,4 & 3 , & 0,7 & 2,1 & 1,2 & 0,3 & 4,0 & 0,0 & 0,5 & 1,2 & 2,0 & 0,7 \\
\hline Globigerina calida & 0,0 & 0,0 & 0,0 & 0,0 & 0,0 & 0,0 & 0,0 & 0,0 & 0,0 & 0,0 & 0,0 & 0,5 & 0,6 & 0,0 & 0,0 & 0,0 & 0,0 & 0,0 & 0,0 & 0 , & 0,0 & 0,0 & 0,0 & 0,0 & 0,0 & 0,0 & 0,0 & 0,0 &, 0 & 0,0 \\
\hline Globigerina $\mathrm{sp}$ & 0,0 & 0,4 & 0,0 & 0,3 & 0,3 & 0,0 & 0,0 & 1,2 & 0,8 & 1, & 0 & 0,8 & 0,0 & 0,0 & 0,3 & 0,0 & 0,0 & 2,6 & 0,3 & & 0 & 0 & 0,0 & 0 & 3 & 0,0 & 3 & 0,0 & 0 & 0 \\
\hline Globigerinoides ruber & 0,0 & 0,0 & 0,0 & 0,3 & 0,0 & 0,3 & 0,0 & 0,3 & 0,3 & 0,0 & 0 & 0,5 & 0,3 & 0,3 & 0,9 & 0,0 & 0,2 & 0,0 & 0,3 & 0 & 0,7 & 0,0 & 0,2 & 0,0 & 0,3 & 0,0 & 0,3 & 0,0 & 0,0 & 0,0 \\
\hline Globigerinoides sp & 0,0 & 0,0 & 0,0 & 0,0 & 0,0 & 0,0 & 0,0 & 0,0 & 0,0 & 0,0 & 0,0 & 0,0 & 0,0 & 0,0 & 0,0 & 0,0 & 0,0 & 0,5 & 0,0 & 0 , & 0,7 & 1,2 & 0,5 & 0,0 & 0,3 & 0,0 & 0,8 & 0,6 & 1,3 & 1,4 \\
\hline Globorotalia compressa & 0,0 & 0,0 & 0,0 & 0,0 & 0,0 & 0,0 & 0,0 & 0,0 & 0,0 & 0,0 & 0,0 & 0,0 & 0,0 & 0,0 & 0,6 & 0,0 & 0,4 & 0,0 & 0,3 & 0 , & 0,3 & 0,3 & 0,5 & 0,3 & 0,0 & 0,0 & 0,3 & 0,0 &, 2 &, 0 \\
\hline Gutulina lactea & 0,0 & 0,0 & 0,0 & 0,0 & 0,0 & 0,0 & 0,0 & 0,0 & 0,0 & 0, & 0,0 & 0,0 & 0,3 & 0,3 & 0,0 & 0,0 & 0,0 & 0,0 & 0,0 & 0 , & 0,0 & 0,0 & 0,0 & 0,0 & 0,0 & 0,0 & 0,0 & 0,0 & 0,0 & 0,0 \\
\hline Hanzawaia boueana & 1,5 & 0,0 & 1,4 & 3,5 & 0,3 & 5,3 & 2,5 & 1,2 & 1,7 & 2,7 & 0,4 & 1,8 & 2,1 & 4,0 & 2,9 & 4,2 & 0,6 & 1,0 & 2,7 & 1,2 & 2,6 & 0,6 & 0,9 & 0,3 & 1,3 & 2,1 & 1,9 & 2,5 & 4,6 & 2,1 \\
\hline Haynesina depressula & 0,0 & 0,0 & 0,0 & 0,0 & 0,0 & 0,0 & 0,0 & 0,0 & 0,0 & 0,0 & 0,0 & 0,0 & 0,0 & 0,0 & 0,0 & 0,0 & 0,0 & 0,3 & 0,0 & 0,0 & 0,0 & 0,6 & 0,0 & 0,0 & 0,3 & 0,0 & 0,0 & 0,0 & 0,0 & 0,3 \\
\hline Haynesina germanica & 0,0 & 0,0 & 0,0 & 0,0 & 0,0 & 0,0 & 0,0 & 0,0 & 0,0 & 0,0 & 0,0 & 0,0 & 0,9 & 0,3 & 1,7 & 0,3 & 0,2 & 1,3 & 0,6 & 0,5 & 1,3 & 0,0 & 0,2 & 0,0 & 0,0 & 0,9 & 0,3 & 0,3 & 0,2 & 0,3 \\
\hline Haynesina sp & 0,0 & 0,4 & 0,0 & 0,0 & 0,0 & 0,3 & 0,0 & 1,2 & 1,4 & 1,1 & 0,0 & 0,0 & 0,0 & 0,0 & 0,0 & 0,0 & 0,0 & 0,0 & 0,0 & 0,0 & 0,0 & 0,0 & 0,0 & 0,0 & 0,0 & 0,0 & 0,0 & 0,0 & 0,0 & 0,0 \\
\hline Hopkinsina pacifica & 0,4 & 0,0 & 0,0 & 0,0 & 0,7 & 0,6 & 0,0 & 0,3 & 0,6 & 0,0 & 1,8 & 0,5 & 0,6 & 0,3 & 1,1 & 0,6 & 0,4 & 0,0 & 0,3 & 1,0 & 1,3 & 1,8 & 0,9 & 0,7 & 1,7 & 1,2 & 0,0 & 0,0 & 0,4 & 1,4 \\
\hline Hopkinsinella sp & 0,0 & 0,0 & 0,3 & 0,0 & 0,0 & 0,3 & 0,0 & 0,3 & 0,0 & 0,0 & 0,0 & 0,0 & 0,0 & 0,0 & 0,0 & 0,3 & 0,0 & 0,0 & 0,3 & 0,2 & 0,0 & 0,0 & 0,0 & 0,0 & 0,0 & 0,0 & 0,0 & 0,0 & 0,0 & 0,0 \\
\hline Lagena clavata & 0,0 & 0,0 & 0,0 & 0,0 & 0,0 & 0,0 & 0,0 & 0,0 & 0,0 & 0,0 & 0,0 & 0,0 & 0,0 & 0,3 & 0,0 & 0,0 & 0,0 & 0,0 & 0,0 & 0,0 & 0,0 & 0,0 & 0,0 & 0,0 & 0,0 & 0,0 & 0,0 & 0,0 & 0,0 & 0,0 \\
\hline Lagena hispidula & 0,0 & 0,0 & 0,0 & 0,0 & 0,0 & 0,0 & 0,0 & 0,0 & 0,0 & 0,0 & 0,0 & 0,0 & 0,0 & 0,0 & 0,0 & 0,0 & 0,0 & 0,0 & 0,0 & 0,0 & 0,0 & 0,0 & 0,0 & 0,0 & 0,0 & 0,0 & 0,3 & 0,0 & 0,0 & 0,0 \\
\hline Lagena laevis & 0,0 & 0,4 & 0,0 & 0,0 & 0,3 & 0,6 & 0,0 & 0,0 & 0,0 & 0,0 & 0,0 & 0,0 & 0,0 & 0,0 & 0,0 & 0,3 & 0,0 & 0,0 & 0,0 & 0,0 & 0,0 & 0,0 & 0,5 & 0,0 & 0,0 & 0,3 & 0,0 & 0,3 & 0,0 & 0,0 \\
\hline Lagena striata & 0,4 & 0,0 & 0,3 & 0,0 & 0,0 & 0,3 & 0,0 & 0,0 & 0,0 & 0,0 & 0,0 & 0,0 & 0,0 & 0,0 & 0,0 & 0,0 & 0,0 & 0,5 & 0,0 & 0,2 & 0,3 & 0,3 & 0,2 & 0,0 & 0,3 & 0,6 & 0,0 & 0,0 &, 0 & 0,0 \\
\hline Lagena sulcata & 0,4 & 0,0 & 0,0 & 0,0 & 0,0 & 0,0 & 0,0 & 0,0 & 0,0 & 0,3 & 0,0 & 0,0 & 0,0 & 0,0 & 0,0 & 0,0 & 0,0 & 0,0 & 0,0 & 0,0 & 0,0 & 0,0 & 0,0 & 0,0 & 0,0 & 0,0 & 0,0 & 0,0 & 0,0 & 0,0 \\
\hline Lenticulina cultrata & 0,0 & 0,0 & 0,0 & 0,0 & 0,0 & 0,0 & 0,0 & 0,0 & 0,0 & 0,0 & 0,0 & 0,0 & 0,0 & 0,0 & 0,0 & 0,3 & 0,0 & 0,0 & 0,0 & 0,0 & 0,0 & 0,0 & 0,0 & 0,0 & 0,0 & 0,0 & 0,0 & 0,0 & 0,0 & 0,0 \\
\hline
\end{tabular}




\begin{tabular}{|c|c|c|c|c|c|c|c|c|c|c|c|c|c|c|c|c|c|c|c|c|c|c|c|c|c|c|c|c|c|c|}
\hline \multirow[b]{2}{*}{ Estações } & \multicolumn{10}{|c|}{ Agosto de 2005} & \multicolumn{10}{|c|}{ Março de 2006} & \multicolumn{10}{|c|}{ Agosto de 2006} \\
\hline & Tb1 & $\mathrm{Tb} 2$ & $\mathrm{~Tb} 3$ & $\mathrm{~Tb} 4$ & $\mathrm{Tb5}$ & $\mathrm{Tb6}$ & $\mathrm{Tb} 7$ & $\mathrm{~Tb} 8$ & $\mathrm{~Tb} 9$ & $\mathrm{~Tb} 10$ & $\mathrm{~Tb} 1$ & $\mathrm{~Tb} 2$ & $\mathrm{~Tb} 3$ & $\mathrm{~Tb} 4$ & $\mathrm{~Tb} 5$ & Tb6 & $\mathrm{Tb} 7$ & $\mathrm{~Tb} 8$ & $\mathrm{~Tb} 9$ & Tb10 & $\mathrm{Tb} 1$ & $\mathrm{~Tb} 2$ & $\mathrm{~Tb} 3$ & $\mathrm{~Tb} 4$ & $\mathrm{~Tb} 5$ & Tb6 & $\mathrm{Tb} 7$ & $\mathrm{~Tb} 8$ & $\mathrm{~Tb} 9$ & $\mathrm{~Tb} 10$ \\
\hline Lenticulina gibba & 0,0 & 0,0 & 0,0 & 0,0 & 0,0 & 0,0 & 0,0 & 0,0 & 0,0 & 0,0 & 0,0 & 0,0 & 0,0 & 0,0 & 0,0 & 0,0 & 0,2 & 0,0 & 0,0 & 0,0 & 0,0 & 0,0 & 0,0 & 0,0 & 0,0 & 0,0 & 0,0 & 0,0 & 0,0 & 0,0 \\
\hline Lenticulina sp & 0,0 & 0,4 & 0,3 & 0,0 & 0,0 & 0,0 & 0,0 & 0,3 & 0,0 & 0,3 &, 0 & 0,0 & 0,0 & 0,0 & 0,0 & 0,0 & 0,0 & 0,0 & 0,3 & 0,0 & 0,0 & 0,0 & 0,5 & 0,0 & 0,3 & 0,0 & 0,0 & 0,0 & 0,0 & 0,0 \\
\hline Lepidodeuteramina ochracea & 0,0 & 0,8 & 0,0 & 0,0 & 0,0 & 0,0 & 0,4 & 0,0 & 0,0 & 0,5 & 0,0 & 0,3 & 0,0 & 0,3 & 0,9 & 0,0 & 0,0 & 0,0 & 0,3 & 0,2 & 0,7 & 0,3 & 0,0 & 0,0 & 0,0 & 0,9 & 0,0 & 0,3 & 0,0 & 1,0 \\
\hline Leptohalysis catela & 0,0 & 0,0 & 0,0 & 0,0 & 0,0 & 0,0 & 0,0 & 0,0 & 0,0 & 0,0 & 0,4 & 0,3 & 0,0 & 0,0 & 0,0 & 0,0 & 0,0 & 0,5 & 0,0 & 0,0 & 0,7 & 0,0 & 0,2 & 0,3 & 0,3 & 0,0 & 0,0 & 0,0 & 0,0 & 0,0 \\
\hline Lobatula lobatula & 0,0 & 0,0 & 0,7 & 0,3 & 0,0 & 0,0 & 0,0 & 0,3 & 0,8 & 0,3 & 0,4 & 0,0 & 0,0 & 1,0 & 0,0 & 0,0 & 0,0 & 0,3 & 0,0 & 0,5 & 0,0 & 0,0 & 0,2 & 0,3 & 0,3 & 0,0 & 0,3 & 0,9 & 0,9 & 0,3 \\
\hline Lochostoma limbatum & 0,0 & 0,0 & 0,0 & 0,0 & 0,0 & 0,0 & 0,0 & 0,0 & 0,0 & 0,0 & 0,0 & 0,3 & 0,0 & 0,0 & 0,3 & 0,0 & 0,0 & 0,0 & 0,0 & 0,0 & 0,0 & 0,0 & 0,0 & 0,0 & 0,0 & 0,0 & 0,0 & 0,0 & 0,0 & 0,0 \\
\hline Miliolinella subrotunda & 0,0 & 0,0 & 0,3 & 0,0 & 0,0 & 0,0 & 0,0 & 0,0 & 0,3 & 0,0 & 0,0 & 0,0 & 0,0 & 0,0 & 0,0 & 0,0 & 0,2 & 0,0 & 0,0 & 0,0 & 0,0 & 0,0 & 0,0 & 0,0 & 0,0 & 0,0 & 0,0 & 0,0 & 0,0 & 0,0 \\
\hline Miliolinella sp & 0,0 & 0,0 & 0,0 & 0,0 & 0,0 & 0,0 & 0,0 & 0,0 & 0,0 & 0,0 & 0,0 & 0,0 & 0,0 & 0,0 & 0,0 & 0,0 & 0,0 & 0,0 & 0,0 & 0,0 & 0,0 & 0,0 & 0,0 & 0,0 & 0,0 & 0,0 & 0,0 & 0,0 & 0,2 & 0,0 \\
\hline Miliammina fusca & 0,0 & 0,0 & 0,0 & 0,0 & 0,0 & 0,0 & 0,0 & 0,0 & 0,0 & 0,0 & 0,0 & 0,0 & 0,0 & 0,0 & 0,0 & 0,0 & 0,0 & 0,0 & 0,3 & 0,0 & 0,3 & 0,0 & 0,0 & 0,0 & 0,0 & 0,0 & 0,0 & 0,0 & 0,0 & 0,0 \\
\hline Neocornobina marginata & 0,0 & 0,0 & 0,0 & 0,0 & 0,0 & 0,0 & 0,0 & 0,0 & 0,0 & 0,0 & 0,0 & 0,0 & 0,0 & 0,0 & 0,0 & 0,0 & 0,0 & 0,0 & 0,3 & 0,0 & 0,0 & 0,0 & 0,0 & 0,0 & 0,0 & 0,0 & 0,0 & 0,0 & 0,0 & 0,0 \\
\hline Neocornobina terquemi & 0,4 & 0,0 & 0,3 & 0,3 & 0,3 & 0,0 & 0,0 & 0,0 & 0,0 & 0,8 & 0,0 & 0,3 & 0,3 & 0,0 & 0,0 & 0,0 & 0,0 & 0,0 & 0,0 & 0,2 & 0,3 & 0,0 & 0,5 & 0,0 & 0,0 & 0,3 & 0,0 & 0,3 & 0,0 & 0,0 \\
\hline Neocornobina sp. & 0,0 & 0,0 & 0,0 & 0,0 & 0,0 & 0,0 & 0,0 & 0,0 & 0,0 & 0,0 & 0,0 & 0,0 & 0,0 & 0,3 & 0,0 & 0,0 & 0,0 & 0,0 & 0,0 & 0,0 & 0,0 & 0,0 & 0,0 & 0,0 & 0,0 & 0,0 & 0,0 & 0,0 & 0,0 & 0,0 \\
\hline Neoeponides bradyi & 0,0 & 0,0 & 0,0 & 0,0 & 0,0 & 0,0 & 0,0 & 0,0 & 0,0 & 0, & 0,0 & 0,0 & 0,0 & 0,0 & 0,3 & 0,3 & 0,0 & 0,0 & 0,0 & 0,0 & 0,0 & 0,0 & 0,0 & 0,0 & 0,0 & 0,0 & 0,3 & 0,3 & 0,4 & 0,3 \\
\hline Nonionella chiliensis & 0,0 & 0,0 & 0,0 & 0,0 & 0,0 & 0,0 & 0,0 & 0,0 & 0,0 & 0,0 & 0,0 & 0,0 & 0,0 & 0,0 & 0,0 & 0,0 & 0,0 & 0,0 & 0,0 & 0,0 & 0,0 & 0,0 & 0,0 & 0,0 & 0,0 & 0,0 & 0,0 & 0,0 & 0,2 & 0,0 \\
\hline Oolina globosa & 0,0 & 0,0 & 0,0 & 0,0 & 0,0 & 0,0 & 0,0 & 0,0 & 0,0 & 0,0 & 0,0 & 0,0 & 0,0 & 0,0 & 0,0 & 0,0 & 0,0 & 0,0 & 0,0 & 0,0 & 0,0 & 0,0 & 0,0 & 0,0 & 0,0 & 0,0 & 0,0 & 0,0 & 0,2 & 0,0 \\
\hline Oolina $\mathrm{sp}$ & 0,0 & 0,0 & 0,0 & 0,0 & 0,0 & 0,0 & 0,0 & 0,0 & 0,0 & 0 & 0,0 & 0,3 & 0,0 & 0,0 & 0,0 & 0,0 & 0,0 & 0,0 & 0,0 & 0,0 & 0,0 & 0,0 & 0,0 & 0,0 & 0,0 & 0,0 & 0,0 & 0,0 & 0,0 & 0,0 \\
\hline Pararotalia cananeiaensis & 21,7 & 21,5 & 23,8 & 24,8 & 11,1 & 16,6 & 27,5 & 26,0 & 28,4 & 28,2 & 20,1 & 26,4 & 30,7 & 29,6 & 16,6 & 21,0 & 23,9 & 23,4 & 31,4 & 29,3 & 17,3 & 23,5 & 24,8 & 26,0 & 13,8 & 21,5 & 37,7 & 32,9 & 31,4 & 22,3 \\
\hline Patelina corrugata & 0,0 & 0,0 & 0,0 & 0,0 & 0,0 & 0,0 & 0,0 & 0,0 & 0,0 & 0,0 & 0,0 & 0,0 & 0,0 & 0,0 & 0,0 & 0,0 & 0,2 & 0,0 & 0,0 & 0,0 & 0,0 & 0,0 & 0,0 & 0,0 & 0,0 & 0,0 & 0,0 & 0,0 & 0,0 & 0,0 \\
\hline Polymorphina complana & 0,0 & 0,0 & 0,0 & 0,0 & 0,0 & 0,0 & 0,0 & 0,0 & 0,0 & 0 & 0 & 0 , & 0 & 0,0 & 0,0 & 0,0 & 0 & 0 , & 0,0 & 0 & 0,0 & 0,0 & 0,0 & 0,0 & 0,0 & 0,0 &, 0 & 0,0 & 0,0 & 0,0 \\
\hline Poroeponides lateralis & 0,0 & 0,0 & 0,0 & 0,0 & 0,0 & 0,0 & 0,0 & 0,0 & 0,0 & 0,0 & 0,0 & 0,0 & 0,0 & 0,3 & 0,0 & 0,0 & 0,0 & 0,0 & 0,0 & 0,0 & 0,0 & 0,0 & 0,0 & 0,0 & 0,0 & 0,0 & 0,0 & 0,0 & 0,0 & 0,0 \\
\hline Protochista findens & 0,0 & 0,0 & 0,0 & 0,0 & 0,0 & 0,0 & 0,0 & 0,0 & 0,0 & 0,0 & 0,4 & 0,5 & 0,0 & 0,0 & 0,0 & 0,0 & 0,0 & 0,3 & 0,0 & 1,0 & 0,0 & 0,0 & 0,2 & 0,0 & 0,0 & 0,0 & 0,0 & 0,0 & 0,0 & 0,0 \\
\hline Pseudoclavulina sp & 0,0 & 0,0 & 0,0 & 0,0 & 0,0 & 0,0 & 0,0 & 0,0 & 0,0 & 0 & 0 , & 0,0 & 0,0 & 0,0 & 0,0 & 0,0 & 0,0 & 0,0 & 0,0 & 0 , & 0,0 & 0,0 & 0,0 & 0,0 & 0,0 & 0,0 &, 0 & 0,0 & 0,0 & 0,0 \\
\hline Pseudononion atlanticum & 2,6 & 1,9 & 2,8 & 4,2 & 2,4 & 2,8 & 4,3 & 5,9 & 5,0 & 6,2 & 3,2 & 3,0 & 3,3 & 3,0 & 6,0 & 6,5 & 5,4 & 2,1 & 3,3 & 3,4 & 6,8 & 5,3 & 2,8 & 2,4 & 3,0 & 11,9 & 6,8 & 5,8 & 4,4 & 4,1 \\
\hline Pseudononion grateloupi & 0,4 & 1,2 & 1,4 & 1,4 & 0,3 & 1,1 & 0,0 & 0,0 & 0,0 & 0,0 & 0,0 & 0,0 & 0,6 & 0,7 & 0,6 & 0,6 & 1,0 & 0,3 & 0,9 & 0,5 & 2,0 & 1,2 & 0,7 & 1,0 & 1,3 & 1,5 & 0,8 & 0,9 & 2,0 & 1,0 \\
\hline Pseudononion opima & 0,0 & 0,8 & 0,3 & 0,3 & 0,3 & 0,0 & 0,0 & 0,3 & 0,3 & 0,0 & 1,1 & 0,8 & 1,5 & 1,3 & 0,6 & 0,6 & 0,2 & 0,5 & 0,3 & 1,5 & 2,6 & 0,3 & 0,2 & 2,4 & 0,3 & 0,9 & 0,5 & 0,6 & 0,9 & 1,0 \\
\hline Pseudononion $\mathrm{sp}$ & 0,0 & 1,2 & 2,8 & 3,1 & 0,0 & 0,6 & 0,7 & 1,2 & 1,4 & 1,1 & 2,5 & 1,3 & 1,5 & 2,3 & 1,1 & 1,0 & 2,5 & 0,5 & 1,2 & 1,7 & 1,3 & 2,6 & 0,9 & 0,3 & 1,3 & 0,9 & 0,5 & 1,2 & 0,4 & 0,3 \\
\hline Pyrgo ringens & 0,0 & 0,0 & 0,0 & 0,0 & 0,0 & 0,0 & 0,0 & 0,0 & 0,0 & 0 , & 0,0 & 0,0 & 0,0 & 0,0 & 0,0 & 0,0 & 0,0 & 0,0 & 0,0 & 0,0 & 0,0 & 0,0 & 0,0 & 0,0 & 0,0 & 0,0 & 0,0 & 0,0 & 0,2 & 0,0 \\
\hline Pyrgo sp & 0,0 & 0,0 & 0,0 & 0,0 & 0,0 & 0,0 & 0,0 & 0,0 & 0,0 & 0,0 & 0,0 & 0,0 & 0,0 & 0,0 & 0,0 & 0,3 & 0,2 & 0,0 & 0,0 & 0,0 & 0,0 & 0,0 & 0,0 & 0,0 & 0,0 & 0,0 & 0,0 & 0,0 & 0,0 & 0,0 \\
\hline Quinqueloculina atlantica & 0,0 & 0,0 & 0,0 & 0,0 & 0,0 & 0,0 & 0,0 & 0,0 & 0,0 & 0,0 & 0,0 & 0,0 & 0,3 & 0,0 & 0,0 & 0,0 & 0,0 & 0,0 & 0,0 & 0,0 & 0,0 & 0,0 & 0,0 & 0,0 & 0,0 & 0,0 & 0,0 & 0,0 & 0,0 & 0,0 \\
\hline Quinqueloculina horrida & 0,4 & 0,0 & 0,0 & 0,0 & 0,0 & 0,0 & 0,0 & 0,0 & 0,3 & 0,0 & 0,0 & 0,0 & 0,0 & 0,7 & 0,0 & 0,0 & 0,0 & 0,0 & 0,0 & 0,0 & 0,0 & 0,0 & 0,0 & 0,0 & 0,0 & 0,0 & 0,0 & 0,0 & 0,0 & 0,0 \\
\hline Quinqueloculina laevigata & 0,0 & 0,0 & 0,0 & 0,0 & 0,0 & 0,0 & 0,0 & 0,0 & 0,0 & 0,3 & 0,0 & 0,0 & 0,0 & 0,0 & 0,3 & 0,0 & 0,0 & 0,0 & 0,0 & 0,0 & 0,0 & 0,0 & 0,0 & 0,0 & 0,0 & 0,0 & 0,0 & 0,0 & 0,0 & 0,0 \\
\hline
\end{tabular}




\begin{tabular}{|c|c|c|c|c|c|c|c|c|c|c|c|c|c|c|c|c|c|c|c|c|c|c|c|c|c|c|c|c|c|c|}
\hline \multirow[b]{2}{*}{ Estações } & \multicolumn{10}{|c|}{ Agosto de 2005} & \multicolumn{10}{|c|}{ Março de 2006} & \multicolumn{10}{|c|}{ Agosto de 2006} \\
\hline & $\mathrm{Tb} 1$ & $\mathrm{~Tb} 2$ & $\mathrm{~Tb} 3$ & $\mathrm{~Tb} 4$ & $\mathrm{~Tb} 5$ & $\mathrm{Tb6}$ & $\mathrm{Tb} 7$ & $\mathrm{~Tb} 8$ & $\mathrm{~Tb} 9$ & Tb10 & $\mathrm{Tb} 1$ & $\mathrm{~Tb} 2$ & $\mathrm{~Tb} 3$ & $\mathrm{~Tb} 4$ & $\mathrm{~Tb} 5$ & Tb6 & $\mathrm{Tb} 7$ & $\mathrm{~Tb} 8$ & $\mathrm{~Tb} 9$ & $\mathrm{~Tb} 10$ & Tb1 & $\mathrm{Tb} 2$ & $\mathrm{~Tb} 3$ & $\mathrm{~Tb} 4$ & $\mathrm{Tb5}$ & Tb6 & $\mathrm{Tb} 7$ & $\mathrm{~Tb} 8$ & $\mathrm{~Tb} 9$ & Tb10 \\
\hline Quinqueloculina lamarckiana & 0,0 & 0,0 & 0,0 & 0,0 & 0,0 & 0,0 & 0,0 & 0,0 & 0,0 & 0,0 & 0,4 & 0,0 & 0,0 & 0,3 & 0,0 & 0,0 & 0,0 & 0,0 & 0,0 & 0,0 & 0,0 & 0,0 & 0,0 & 0,0 & 0,0 & 0,0 & 0,0 & 0,0 & 0,0 & 0,0 \\
\hline Quinqueloculina milletti & 0,0 & 0,0 & 0,0 & 0,0 & 0,0 & 0,0 & 0,0 & 0,0 & 0,0 & 0,0 & 0,0 & 0,0 & 0,9 & 0,0 & 0,6 & 0,0 & 0,2 & 0,0 & 0,6 & 0,5 & 0,0 & 0,0 & 0,0 & 0,0 & 0,0 & 0,0 & 0,0 & 0,0 & 0,2 & 0,0 \\
\hline Quinqueloculina patagonica & 0,0 & 0,0 & 0,0 & 0,0 & 0,0 & 0,0 & 0,4 & 0,0 & 0,0 & 0,0 &, 0 & 0,0 & 0,3 & 0,0 & 0,0 & 0,0 & 0,0 & 0,0 & 0,0 & 0,0 & 0,0 & 0,0 & 0,0 & 0,0 & 0,0 & 0,0 & 0,0 & 0,0 & 0,0 & 0,0 \\
\hline Quinqueloculina seminula & 0,0 & 0,0 & 0,0 & 0,7 & 0,0 & 0,0 & 0,4 & 0,0 & 0,3 & 0,0 & 0,0 & 0,3 & 0,0 & 0,0 & 0,0 & 0,0 & 0,0 & 0,0 & 0,3 & 0,0 & 0,0 & 0,0 & 0,0 & 0,0 & 0,0 & 0,0 & 0,0 & 0,0 & 0,0 & 0,0 \\
\hline Quinqueloculina sp & 0,4 & 1,2 & 0,0 & 0,3 & 0,3 & 0,0 & 0,0 & 0,0 & 0,0 & 0 , & 0,4 & 0,0 & 0,3 & 0,0 & 0,3 & 0,0 & 0,2 & 0,0 & 0,3 & 0 , &, 0 & 0,0 & 0,0 & 0,0 & 0,3 & 0,3 & 0,0 & 0,0 & 0,0 & 0,0 \\
\hline Remaneica helgolandica & 0,0 & 0,0 & 0,0 & 0,0 & 0,0 & 0,0 & 0,0 & 0,0 & 0,0 & 0 & 0,0 & 0,0 & 0,0 & 0,0 & 0,0 & 0,0 & 0,0 & 0,3 & 0,0 & 0,0 & 0,0 & 0,0 & 0,0 & 0,0 & 0,0 & 0,0 & 0,0 & 0,0 & 0,0 & 0,0 \\
\hline Reophax dentaliformis & 0,0 & 0,0 & 0,0 & 0,0 & 0,0 & 0,0 & 0,0 & 0,0 & 0,0 & 0 & 0,0 & 0,0 & 0,0 & 0,0 & 0,0 & 0,0 & 0,0 & 0,0 & 0,0 & 0,0 & 0,7 & 0,3 & 0,0 & 1,0 & 0,0 & 0,3 & 0,3 & 0,3 & 0,0 & 0,0 \\
\hline Reophax scorpiurus & 0,0 & 0,0 & 0,0 & 0,0 & 0,0 & 0,0 & 0,0 & 0,0 & 0,0 & 0,0 & 0,0 & 0,0 & 0,0 & 0,0 & 0,0 & 0,3 & 0,0 & 0,0 & 0,0 & 0,0 & 0,7 & 0,0 & 0,0 & 0,0 & 0,0 & 0,0 & 0,0 & 0,0 & 0,0 & 0,0 \\
\hline Reophax sp & 0,0 & 0,0 & 0,0 & 0,0 & 0,0 & 0,0 & 0,0 & 0,0 & 0,0 & 0 & 0,4 & 0,8 & 0,0 & 0,0 & 0,3 & 0,0 & 0,0 & 0,8 & 0,0 & 0,2 & 0,3 & 0,0 & 0,2 & 0,0 & 0,0 & 0,3 & 0,0 & 0,0 & 0,4 & 0,3 \\
\hline Rolshauseni rolshaus & 0,4 & 0,4 & 0,3 & 0,7 & 0,0 & 0,8 & 0,0 & 0,0 & 0,0 & 0,0 & 0,0 & 0,0 & 0,9 & 2,0 & 0,0 & 0,3 & 0,0 & 0,0 & 0,0 & 0,0 & 0,7 & 0,0 & 0,0 & 0,0 & 0,0 & 0,0 & 1,1 & 0,3 & 0,0 & 0,0 \\
\hline Rosalina floridensis & 0,7 & 0,4 & 1,4 & 0,7 & 0,3 & 0,3 & 0,7 & 0,3 & 0,6 & 1,6 & 1,4 & 0,5 & 0,6 & 0,7 & 0,6 & 1,0 & 1,7 & 0,0 & 0,6 & 0,0 & 0,7 & 0,6 & 0,0 & 0,3 & 1,3 & 0,3 & 0,3 & 1,2 & 0,0 & 0,0 \\
\hline Sigmoilopsis schumbergeri & 0,0 & 0,0 & 0,0 & 0,0 & 0,0 & 0,0 & 0,0 & 0,0 & 0,0 & 0 & 0,0 & 0,0 & 0,0 & 0,0 & 0,0 & 0,0 & 0,0 & 0,3 & 0,3 & 0 &, 0 & 0,0 & 0,0 & 0,0 & 0,0 & 0,0 & 0,0 &, 0 & 0,0 & 0,0 \\
\hline Spirob & 0,0 & 0,0 & 0,0 & 0,0 & 0,0 & 0,0 & 0,0 & 0,0 & 0,0 & 0 , & 0,4 & 0,0 & 0,3 & 0,3 & 0,0 & 0,6 & 0,0 & 0,0 & 0,0 & 0 & 0,0 & 0,0 & 0,2 & 0,0 & 0,0 & 0,0 & 0,0 & 0,0 & 0,0 & 0,0 \\
\hline Spiroplectamina biformis & 0,0 & 0,0 & 0,0 & 0,0 & 0,0 & 0,0 & 0,0 & 0,0 & 0,0 & 0,0 & 0,4 & 0,0 & 0,0 & 0,0 & 0,0 & 0,0 & 0,0 & 0,0 & 0,0 & 0,0 & 0,3 & 0,0 & 0,0 & 0,0 & 0,0 & 0,0 & 0,0 & 0,0 & 0,0 & 0,0 \\
\hline Stanforthia concava & 0,4 & 0,0 & 0,0 & 0,0 & 0,0 & 0,0 & 0,0 & 0,0 & 0,3 & 0,3 & 0,7 & 0,0 & 0,0 & 0,0 & 0,3 & 0,0 & 0,4 & 0,3 & 0,0 & 0,2 & 0,3 & 0,3 & 0,0 & 0,0 & 0,0 & 0,3 & 0,0 & 0,0 & 0,0 & 0,0 \\
\hline Stanforthis fusiformis & 0,0 & 0,0 & 0,0 & 0,0 & 0,0 & 0,0 & 0,0 & 0,0 & 0,0 & 0 , & 0,0 & 0,0 & 0,0 & 0,0 & 0,3 & 0,0 & 0,0 & 0,0 & 0,0 & 0,0 & 0,0 & 0,0 & 0,0 & 0,0 & 0,0 & 0,3 & 0,0 & 0,3 & 0,0 & 0,0 \\
\hline Stanforthia sp & 0,0 & 0,0 & 0,0 & 0,0 & 0,0 & 0,0 & 0,0 & 0,0 & 0,0 & 0 & 0 & 0,5 & 0,0 & 0,0 & 0,0 & 0,0 & 0,2 & 0,0 & 0,0 & 0 &, 0 & 0,0 & 0,0 & 0,0 & 0,0 & 0,0 & 0,0 & 0 & 0,0 & 0,0 \\
\hline Textularia candeiana & 0,0 & 0,0 & 0,0 & 0,0 & 0,0 & 0,0 & 0,0 & 0,0 & 0,0 & 0,0 & 0,4 & 0,0 & 0,9 & 0,0 & 0,0 & 0,0 & 0,0 & 0,0 & 0,0 & 0,0 & 0,0 & 0,0 & 0,0 & 0,0 & 0,0 & 0,0 & 0,0 & 0,0 & 0,0 & 0,0 \\
\hline Textularia earlandi & 0,0 & 0,0 & 0,3 & 0,0 & 0,0 & 0,3 & 0,0 & 0,0 & 0,0 & 0,0 & 0,0 & 0,0 & 0,0 & 0,0 & 0,0 & 0,0 & 0,0 & 0,0 & 0,0 & 0,0 & 0,0 & 0,0 & 0,0 & 0,0 & 0,0 & 0,0 & 0,3 & 0,0 & 0,2 & 0,0 \\
\hline Textularia gran & 0,0 & 0,0 & 0,0 & 0,0 & 0,0 & 0,0 & 0,0 & 0,0 & 0,0 & 0,0 & 0,0 & 0,0 & 0,0 & 0,0 & 0,3 & 0,0 & 0,0 & 0,0 & 0,0 & 0,0 & 0,0 & 0,0 & 0,0 & 0,0 & 0,0 & 0,0 & 0,0 & 0,0 & 0,0 & 0,0 \\
\hline Textularia $\mathrm{sp}$ & 0,0 & 0,4 & 0,0 & 0,0 & 1,0 & 0,3 & 0,7 & 0,3 & 0,0 & 0,3 & 0,0 & 0,3 & 0,0 & 0,0 & 0,0 & 0,0 & 0,4 & 0,3 & 0,0 & 0,2 & 0,3 & 0,3 & 0,2 & 0,7 & 0,0 & 0,0 & 0,0 & 0,0 & 0,4 & 0,0 \\
\hline Triloculina oblonga & 0,0 & 0,0 & 0,0 & 0,0 & 0,0 & 0,0 & 0,4 & 0,3 & 0,3 & 0,5 & 0,0 & 0,0 & 0,0 & 0,0 & 0,3 & 0,0 & 0,0 & 0,0 & 0,0 & 0,5 & 0,0 & 0,0 & 0,0 & 0,0 & 0,0 & 0,0 & 0,0 & 0,0 & 0,0 & 0,0 \\
\hline Triloculina trigc & 0,0 & 0,0 & 0,0 & 0,0 & 0,0 & 0,0 & 0,0 & 0,0 & 0,0 & 0,0 & 0,0 & 0,0 & 0,0 & 0,0 & 0,0 & 0,0 & 0,0 & 0,0 & 0,3 & 0,0 & 0,0 & 0,0 & 0,0 & 0,0 & 0,0 & 0,0 & 0,0 & 0,0 & 0,0 & 0,0 \\
\hline Triloculina $\mathrm{sp}$ & 0,0 & 0,0 & 0,0 & 0,0 & 0,0 & 0,0 & 0,0 & 0,0 & 0,0 & 0,0 & 0,0 & 0,0 & 0,0 & 0,0 & 0,0 & 0,0 & 0,0 & 0,0 & 0,3 & 0,0 & 0,0 & 0,0 & 0,0 & 0,0 & 0,0 & 0,0 & 0,0 & 0,0 & 0,0 & 0,0 \\
\hline Trochammina squ & 0,0 & 0,0 & 0,0 & 0,0 & 0,3 & 0,3 & 0,0 & 0,0 & 0,0 & 0,0 & 0,0 & 0,0 & 0,0 & 0,0 & 0,0 & 0,0 & 0,0 & 0,0 & 0,0 & 0,0 & 0,0 & 0,0 & 0,0 & 0,0 & 0,0 & 0,0 & 0,0 & 0,0 & 0,0 & 0,0 \\
\hline Trochammina sp & 0,4 & 0,0 & 0,0 & 0,0 & 0,3 & 0,3 & 0,0 & 0,0 & 0,0 & 0,0 & 1,1 & 0,0 & 0,0 & 0,0 & 0,0 & 0,0 & 0,2 & 0,0 & 0,0 & 0,0 & 0,0 & 0,0 & 0,0 & 0,3 & 0,0 & 0,0 & 0,0 & 0,0 & 0,0 & 0,0 \\
\hline Uvigerina bifurcata & 0,0 & 0,0 & 0,0 & 0,0 & 0,0 & 0,0 & 0,0 & 0,0 & 0,0 & 0,0 & 0,0 & 0,0 & 0,0 & 0,0 & 0,0 & 0,0 & 0,0 & 0,0 & 0,0 & 0,2 & 0,0 & 0,0 & 0,0 & 0,3 & 0,0 & 0,0 & 0,0 & 0,0 & 0,0 & 0,0 \\
\hline Uvigerina peregrina & 0,0 & 0,0 & 0,0 & 0,0 & 0,0 & 0,0 & 0,0 & 0,0 & 0,0 & 0,0 & 0,0 & 0,3 & 0,0 & 0,0 & 0,0 & 0,0 & 0,0 & 0,0 & 0,0 & 0,0 & 0,0 & 0,0 & 0,0 & 0,0 & 0,0 & 0,0 & 0,0 & 0,0 & 0,0 & 0,0 \\
\hline
\end{tabular}




\section{Anexo 67 - Continuação}

\begin{tabular}{|c|c|c|c|c|c|c|c|c|c|c|c|c|c|c|c|c|c|c|c|c|c|c|c|c|c|c|c|c|c|c|}
\hline \multirow[b]{2}{*}{ Estações } & \multicolumn{10}{|c|}{ Agosto de 2005} & \multicolumn{10}{|c|}{ Março de 2006} & \multicolumn{10}{|c|}{ Agosto de 2006} \\
\hline & $\mathrm{Tb} 1$ & $\mathrm{~Tb} 2$ & $\mathrm{~Tb} 3$ & $\mathrm{~Tb} 4$ & $\mathrm{~Tb} 5$ & Tb6 & $\mathrm{Tb} 7$ & $\mathrm{~Tb} 8$ & $\mathrm{~Tb} 9$ & Tb10 & $\mathrm{Tb} 1$ & $\mathrm{~Tb} 2$ & $\mathrm{~Tb} 3$ & $\mathrm{~Tb} 4$ & $\mathrm{Tb5}$ & $\mathrm{Tb6}$ & $\mathrm{Tb} 7$ & $\mathrm{~Tb} 8$ & $\mathrm{~Tb} 9$ & $\mathrm{~Tb} 10$ & $\mathrm{~Tb} 1$ & $\mathrm{~Tb} 2$ & $\mathrm{~Tb} 3$ & $\mathrm{~Tb} 4$ & $\mathrm{~Tb} 5$ & Tb6 & $\mathrm{Tb} 7$ & $\mathrm{Tb8}$ & $\mathrm{Tb} 9$ & Tb10 \\
\hline Uvigerina striata & 0,0 & 0,0 & 0,0 & 0,3 & 0,7 & 0,0 & 0,0 & 0,3 & 0,0 & 0,0 & 0,0 & 0,0 & 0,0 & 0,0 & 0,3 & 0,0 & 0,0 & 0,0 & 0,3 & 0,2 & 0,7 & 0,3 & 0,5 & 0,0 & 0,7 & 0,0 & 0,0 & 0,6 & 0,4 & 0,0 \\
\hline Wiesnerella auriculata & 0,0 & 0,0 & 0,0 & 0,0 & 0,0 & 0,0 & 0,0 & 0,3 & 0,0 & 0,0 & 0,0 & 0,0 & 0,0 & 0,0 & 0,0 & 0,0 & 0,2 & 0,0 & 0,0 & 0,0 & 0,0 & 0,0 & 0,0 & 0,0 & 0,0 & 0,0 & 0,0 & 0,0 & 0,0 & 0,0 \\
\hline Não identificado & 0,0 & 0,0 & 0,0 & 0,0 & 0,0 & 0,0 & 0,0 & 0,0 & 0,0 & 0,0 & 0,7 & 1,5 & 0,6 & 1,3 & 2,6 & 0,3 & 1,5 & 1,8 & 1,5 & 1,5 & 0,7 & 1,5 & 1,2 & 0,3 & 1,3 & 0,0 & 0,8 & 0,9 & 0,4 & 1,4 \\
\hline Fragmento & 2,6 & 7,3 & 3,1 & 2,8 & 7,7 & 3,4 & 3,2 & 2,2 & 2,5 & 2,7 & 1,1 & 2,5 & 0,3 & 1,3 & 1,4 & 2,3 & 2,1 & 0,8 & 2,7 & 3,0 & 2,0 & 4,7 & 4,0 & 4,1 & 4,7 & 2,7 & 1,1 & 3,4 & 1,5 & 1,4 \\
\hline
\end{tabular}

Parâmetros biológicos

\begin{tabular}{|c|c|c|c|c|c|c|c|c|c|c|c|c|c|c|c|c|c|c|c|c|c|c|c|c|c|c|c|c|c|c|}
\hline Dens & 534 & 520 & 1160 & 1144 & 574 & 712 & 1120 & 1292 & 1436 & 744 & 264 & 6352 & 10528 & 2408 & 5584 & 4960 & 7712 & 3048 & 2704 & 3248 & 2456 & 5440 & 13664 & 2368 & 1192 & 5360 & 11712 & 10400 & 14560 & 9312 \\
\hline & $1 / 2$ & $1 / 2$ & $1 / 4$ & $1 / 4$ & $1 / 2$ & $1 / 2$ & $1 / 4$ & $1 / 4$ & $1 / 4$ & $1 / 2$ & $1 / 8$ & $1 / 16$ & $1 / 32$ & $1 / 8$ & $1 / 16$ & $1 / 16$ & $1 / 16$ & $1 / 8$ & $1 / 8$ & $1 / 8$ & $1 / 8$ & $1 / 16$ & $1 / 32$ & $1 / 8$ & $1 / 4$ & $1 / 16$ & $1 / 32$ & $1 / 32$ & $1 / 32$ & $1 / 32$ \\
\hline & 2 & 29 & 33 & 36 & $3 x$ & 35 & 26 & 3 & 3 & 33 & & 4 & 4 & 43 & 4 & 3 & 50 & 43 & 46 & 46 & 47 & 41 & 7 & 38 & 31 & 39 & 50 & 45 & 40 & 32 \\
\hline Div & 47 & 2,40 & 2,66 & 2,65 & 2,51 & 2,72 & 2,38 & 2,57 & 2,64 &, 58 & 89 & 2,71 & 2,85 & 2,82 & 2,92 & 2,68 & 2,92 & 2,78 & 2,73 & 2,74 & 3,01 & 2,72 & 2,71 & 2,67 & 2,62 & 2,64 & 2,35 & 2,63 & 2,67 & 2,46 \\
\hline Equitatividade & 0,76 & 0,71 & 0,76 & 0,75 & 0,74 & 0,76 & 0,73 & 0,72 & 0,74 & 0,74 & 0,80 & 0,72 & 0,74 & 0,75 & 0,76 & 0,76 & 0,75 & 0,74 & 0,71 & 0,72 & 0,78 & 0,73 & 0,70 & 0,73 & 0,76 & 0,72 & 0,65 & 0,69 & 0,70 & 0,71 \\
\hline
\end{tabular}


Anexo 68 - (Tanatocenoses) Distribuição de espécies bioindicadoras de ambiente óxico e enriquecido por matéria orgânica identificadas próximo ao emissário do TEBAR. Valores em porcentagem.
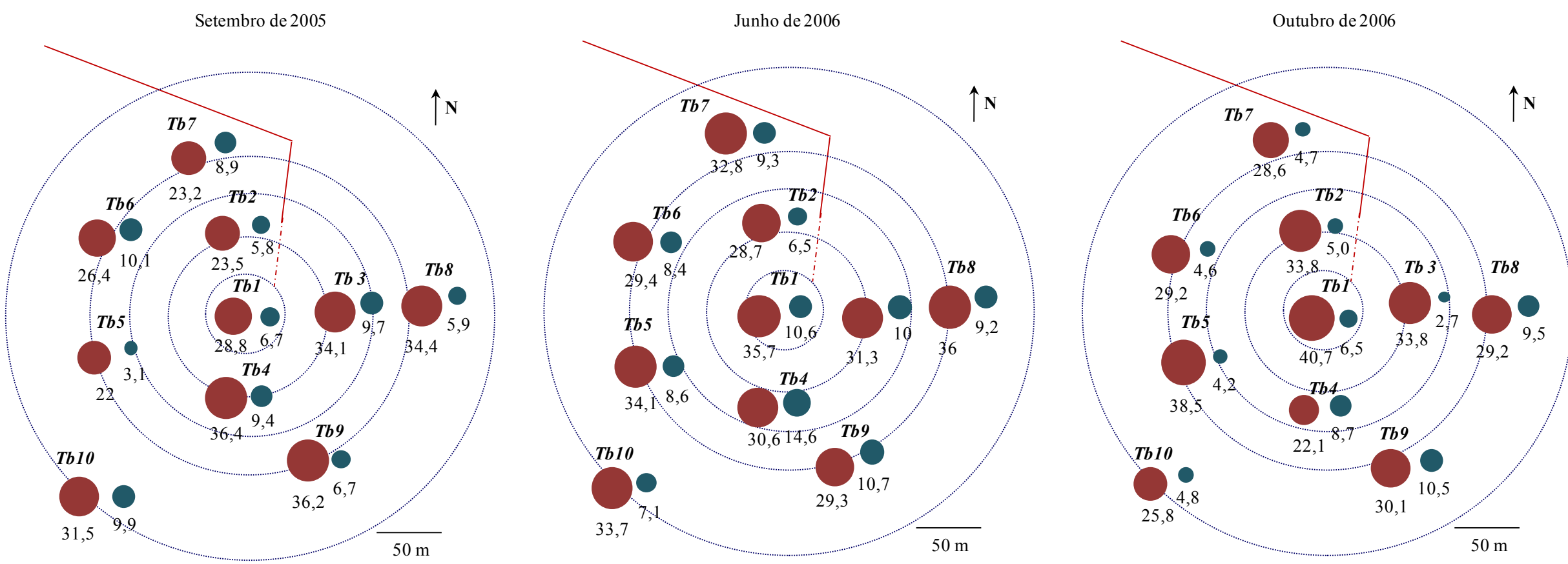

Espécies bioindicadoras de ambiente óxico

Espécies bioindicadoras de ambiente rico em matéria orgânica 
Anexo 69 - (Tanatocenoses) Resultado das análises morfométricas realizadas nas carapaças dos foraminíferos obtidas próximo ao emissário Saco do TEBAR. Valores em porcentagem.
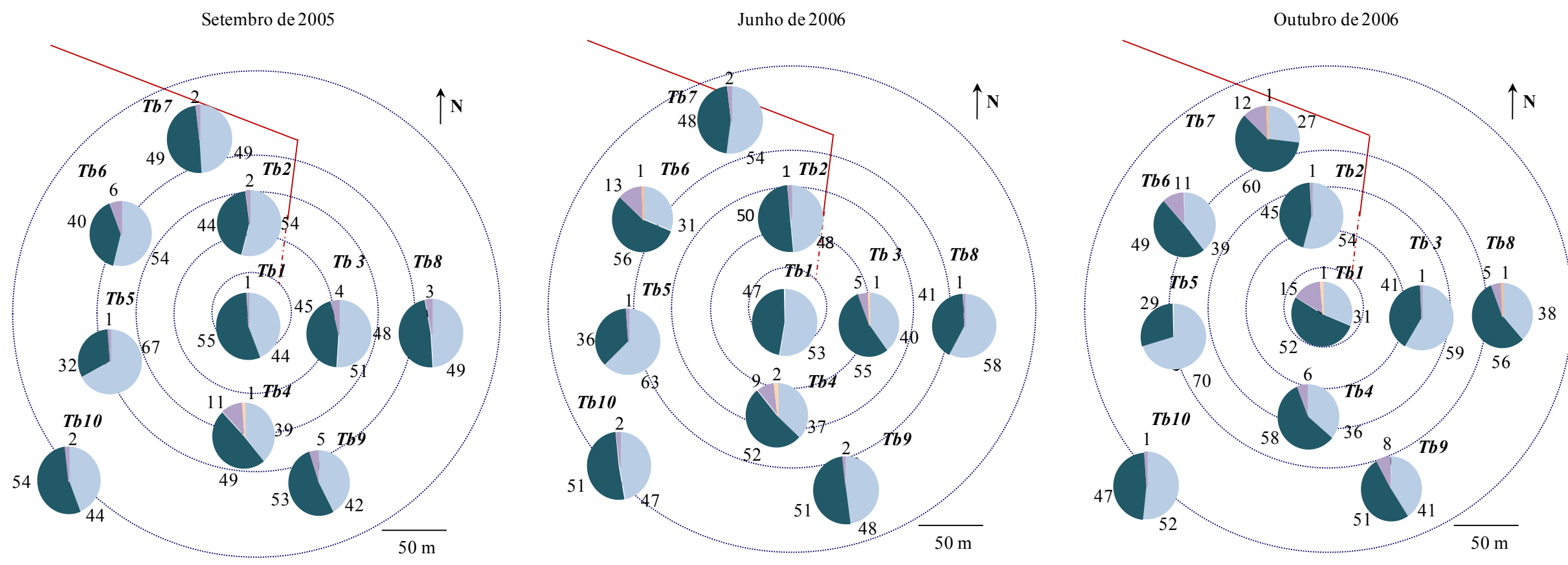
Anexo 70 - Grau de preservação das carapaças que compuseram as tanatocenoses.

Dados obtidos próximo ao emissário do TEBAR. Valores em porcentagem.

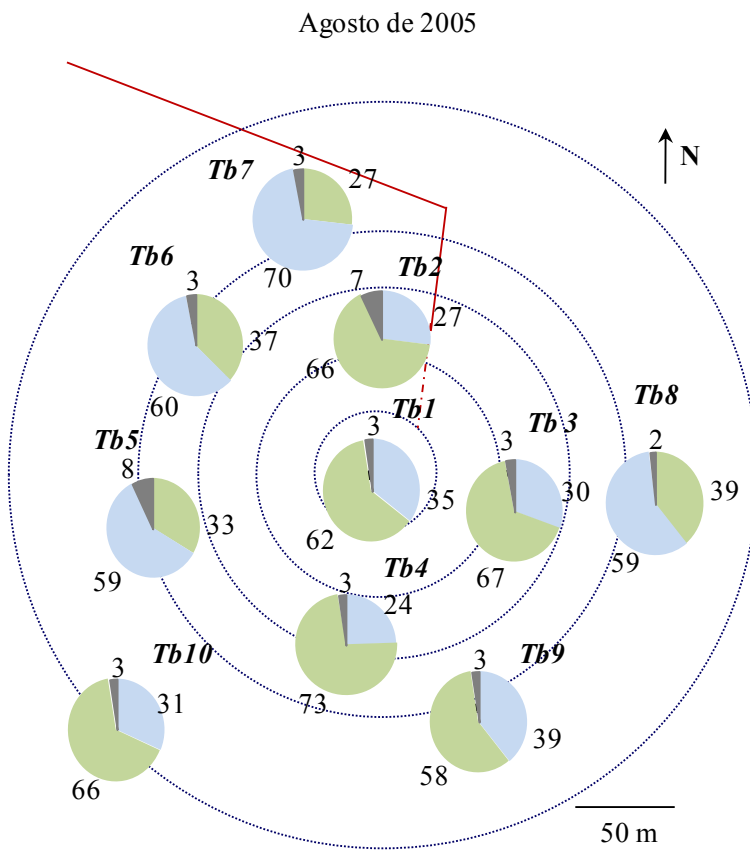

Carapaças inteiras

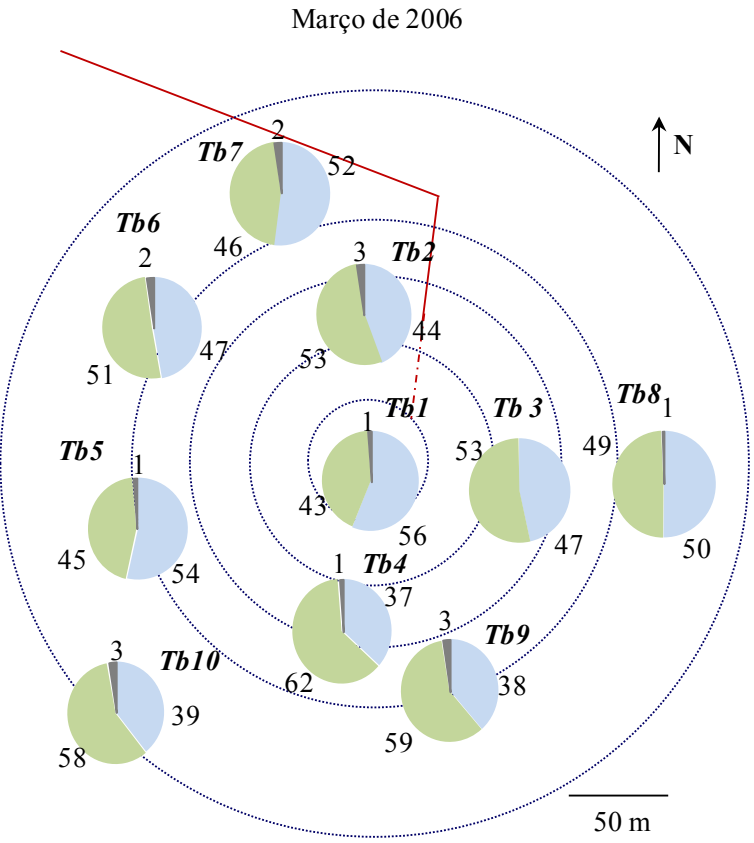

Carapaças parcialmente fragmentadas

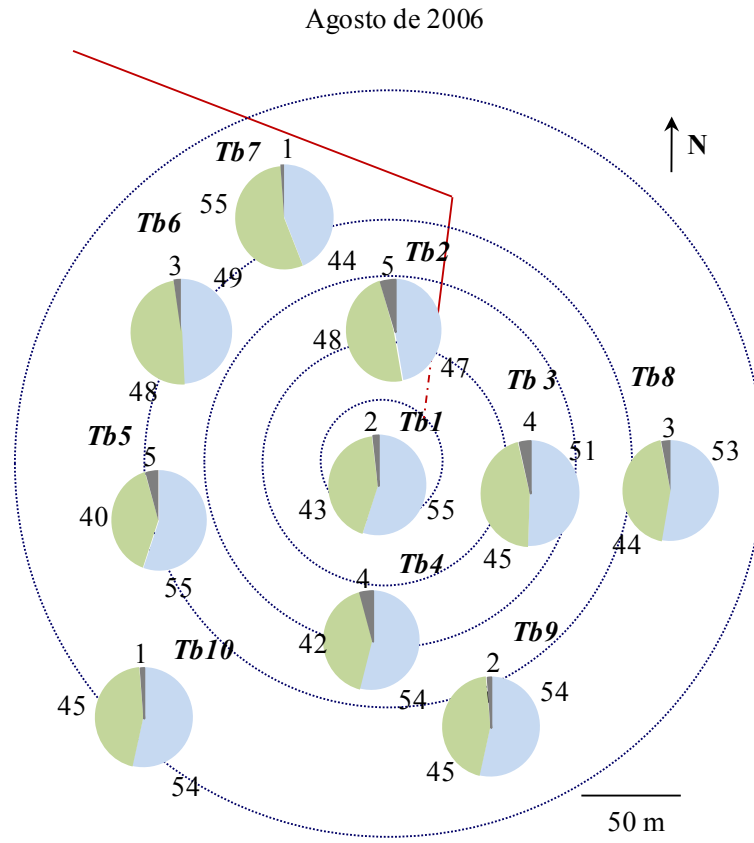

Fragmentos de carapaças 
Anexo 71 - Coloração das carapaças dos foraminíferos que compuseram as tanatocenoses.

Dados obtidos próximo ao emissário do TEBAR. Valores em porcentagem.

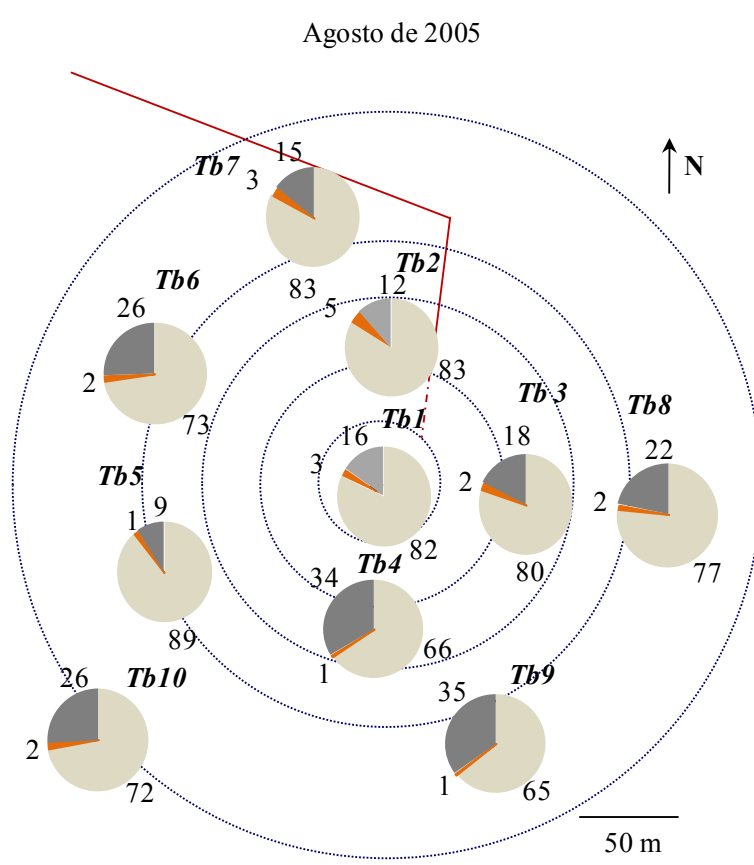

Carapaças sem sinais de preenchimento e/ou impregnação

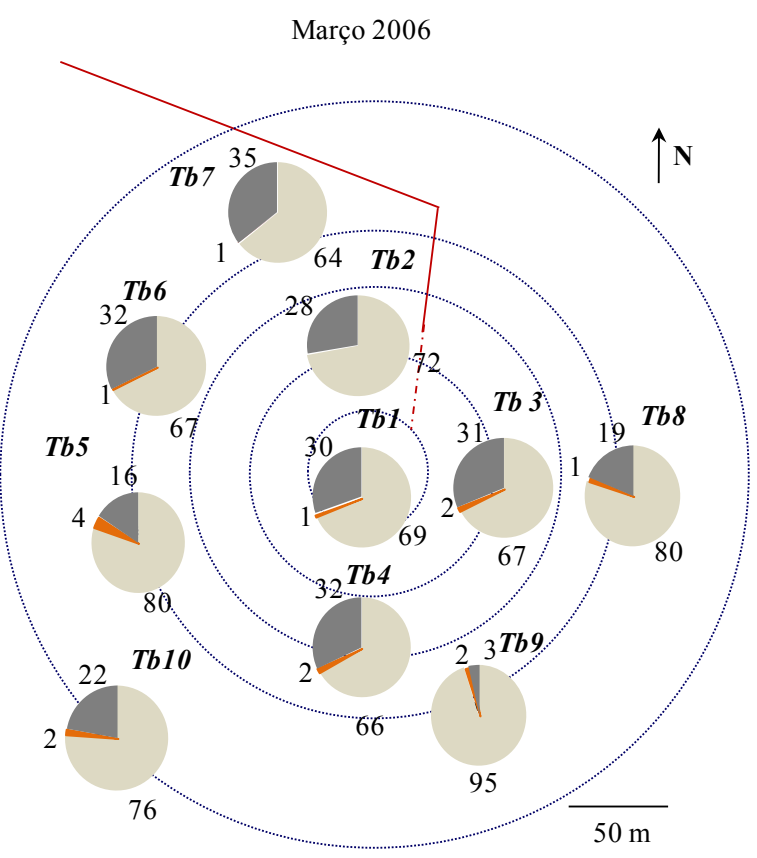

Carapaças preenchidas por monossulfeto de ferro e/ou pirita

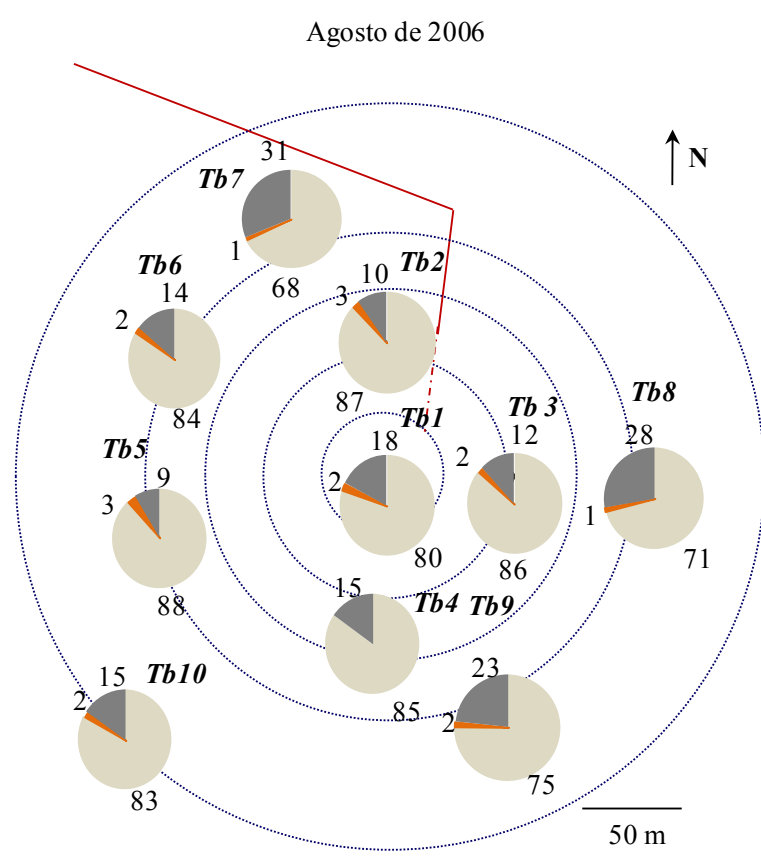

Carapaças limonitizadas 
Anexo 72 - Matriz de correlação de Pearson obtida para os dados bióticos e abióticos obtidos próximo ao emissário do TEBAR, em Agosto de 2005.

Níveis de significância: $p<0,01$ (em vermelho) e $p<0,05$ (em negrito)

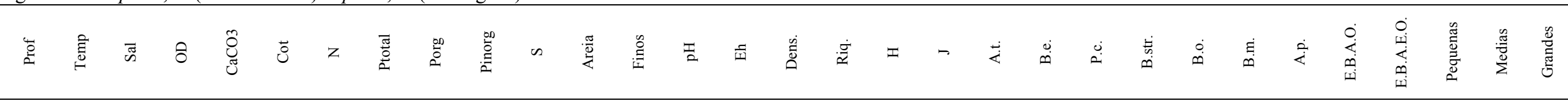

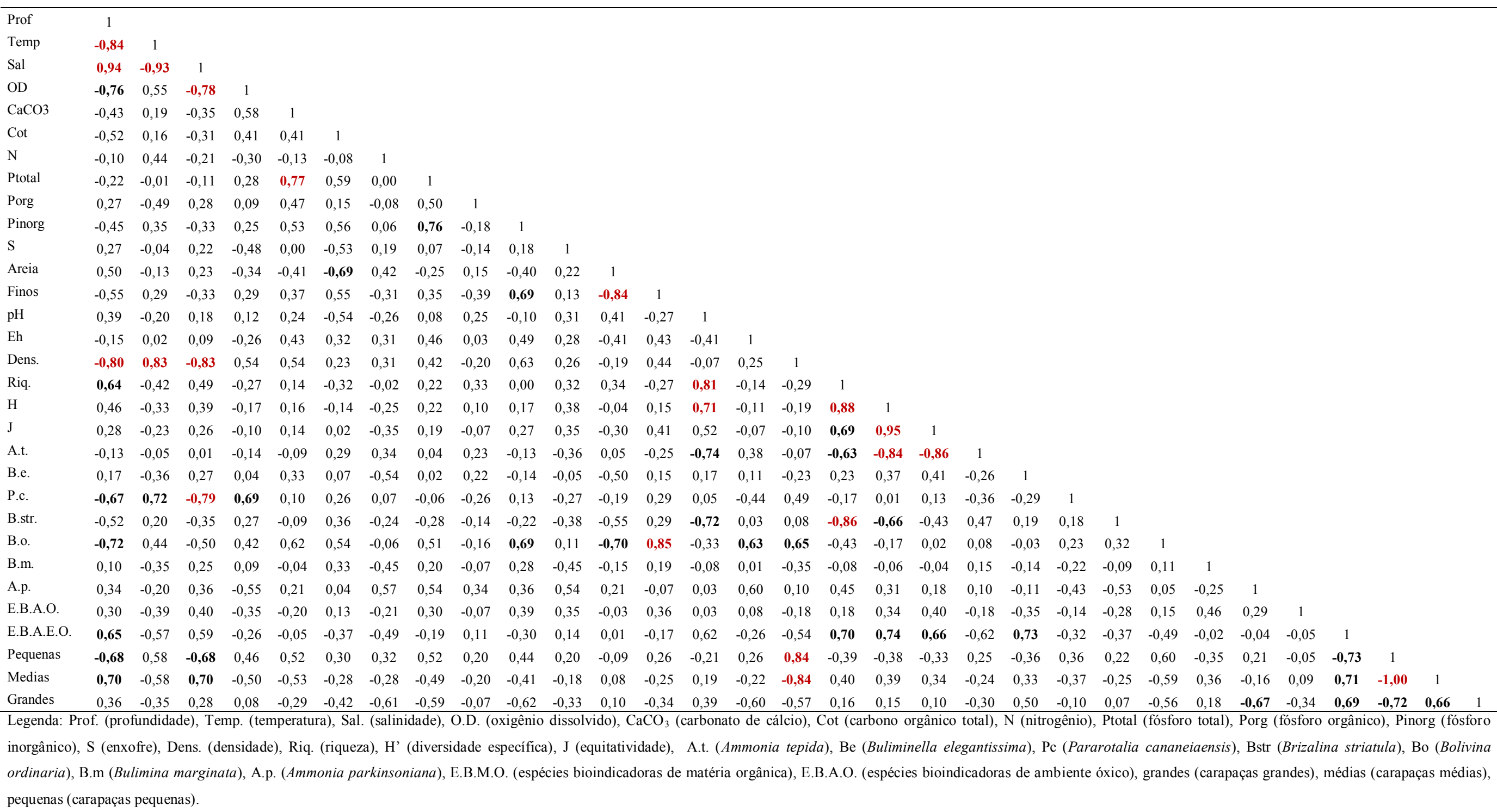

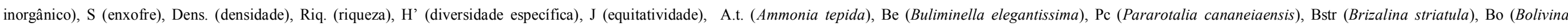

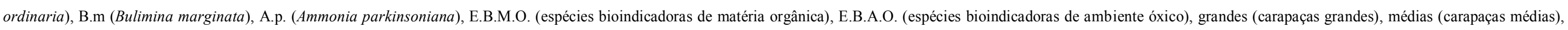
pequenas (carapaças pequenas). 
Anexo 73 - Matriz de correlação de Pearson obtida para os dados bióticos e abióticos obtidos próximo ao emissário do TEBAR, em Março de 2006.

Níveis de significância: $p<0,01$ (em vermelho) e $p<0,05$ (em negrito)

\begin{tabular}{|c|c|c|c|c|c|c|c|c|c|c|c|c|c|c|c|c|c|c|c|c|c|c|c|c|c|c|c|c|c|c|c|c|c|c|c|c|c|c|c|}
\hline 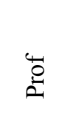 & छे & \multicolumn{2}{|c|}{$\overline{\tilde{D}}$} & ิิ & ర్ల & \multicolumn{2}{|c|}{$\overrightarrow{0}$} & z & 焉 & \multicolumn{2}{|c|}{$\stackrel{\infty}{0}$} & 号 & \multicolumn{2}{|c|}{ n } & $\frac{\frac{\pi}{2}}{2}$ & \multicolumn{2}{|c|}{ 兽 } & & 牙 & \multicolumn{2}{|c|}{$\dot{\ddot{D}}$} & $\dot{\check{\Xi}}$ & \multicolumn{2}{|c|}{ \pm} & $r$ & $\ddot{\dot{u}}$ & $\dot{\infty}$ & $\stackrel{\dot{4}}{\dot{4}}$ & $\stackrel{\dot{\Psi}}{\dot{I}}$ & $\begin{array}{l}\dot{\Delta} \\
\dot{u}\end{array}$ & $\begin{array}{l}\dot{n} \\
\stackrel{n}{n}\end{array}$ & \multicolumn{2}{|c|}{$\stackrel{\dot{\vec{n}}}{\dot{0}}$} & $\begin{array}{l}\dot{0} \\
\dot{\leftrightarrow} \\
\infty \\
\dot{\varphi}\end{array}$ & \multicolumn{2}{|c|}{ 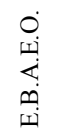 } & \multicolumn{2}{|c|}{ 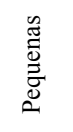 } & 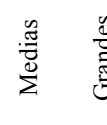 \\
\hline
\end{tabular}

\begin{tabular}{|c|c|c|c|c|c|c|c|c|c|c|c|c|c|c|c|c|c|c|c|c|c|c|c|c|c|c|c|c|c|c|}
\hline Prof & 1 & & & & & & & & & & & & & & & & & & & & & & & & & & & & & \\
\hline Temp & $-0,79$ & 1 & & & & & & & & & & & & & & & & & & & & & & & & & & & & \\
\hline Sal & 0,79 & $-1,00$ & 1 & & & & & & & & & & & & & & & & & & & & & & & & & & & \\
\hline OD & $-0,72$ & 0,97 & $-0,97$ & 1 & & & & & & & & & & & & & & & & & & & & & & & & & & \\
\hline $\mathrm{CaCO} 3$ & 0,45 & $-0,45$ & 0,48 & $-0,40$ & 1 & & & & & & & & & & & & & & & & & & & & & & & & & \\
\hline Cot & $-0,30$ & 0,30 & $-0,29$ & 0,37 & 0,08 & 1 & & & & & & & & & & & & & & & & & & & & & & & & \\
\hline $\mathrm{N}$ & $-0,39$ & 0,19 & $-0,22$ & 0,24 & $-0,11$ & 0,71 & 1 & & & & & & & & & & & & & & & & & & & & & & & \\
\hline Ptotal & $-0,16$ & $-0,16$ & 0,11 & $-0,06$ & $-0,02$ & 0,24 & 0,42 & 1 & & & & & & & & & & & & & & & & & & & & & & \\
\hline Porg & $-0,17$ & $-0,13$ & 0,09 & $-0,04$ & $-0,06$ & 0,20 & 0,37 & 0,99 & 1 & & & & & & & & & & & & & & & & & & & & & \\
\hline Pinorg & 0,05 & $-0,25$ & 0,20 & $-0,18$ & 0,42 & 0,36 & 0,51 & 0,21 & 0,11 & 1 & & & & & & & & & & & & & & & & & & & & \\
\hline $\mathrm{S}$ & 0,56 & $-0,13$ & 0,13 & 0,04 & 0,54 & 0,29 & 0,07 & $-0,13$ & $-0,17$ & 0,34 & 1 & & & & & & & & & & & & & & & & & & & \\
\hline Areia & 0,14 & $-0,31$ & 0,31 & $-0,27$ & 0,02 & $-0,47$ & $-0,17$ & 0,52 & 0,57 & $-0,43$ & $-0,20$ & 1 & & & & & & & & & & & & & & & & & & \\
\hline Finos & $-0,15$ & 0,32 & $-0,31$ & 0,27 & $-0,01$ & 0,47 & 0,16 & $-0,52$ & $-0,58$ & 0,43 & 0,20 & $-1,00$ & 1 & & & & & & & & & & & & & & & & & \\
\hline $\mathrm{pH}$ & 0,49 & $-0,48$ & 0,44 & $-0,44$ & 0,17 & $-0,51$ & $-0,35$ & 0,00 & $-0,05$ & 0,46 & 0,20 & $-0,07$ & 0,06 & 1 & & & & & & & & & & & & & & & & \\
\hline Eh & 0,27 & $-0,10$ & 0,11 & $-0,06$ & 0,29 & 0,55 & 0,02 & $-0,34$ & $-0,38$ & 0,31 & 0,46 & $-\mathbf{0 , 7 0}$ & $\mathbf{0 , 7 0}$ & $-0,05$ & 1 & & & & & & & & & & & & & & & \\
\hline Dens. & 0,56 & $-0,18$ & 0,16 & $-0,11$ & 0,01 & 0,10 & 0,04 & 0,10 & 0,12 & $-0,16$ & 0,50 & 0,10 & $-0,11$ & $-0,02$ & 0,17 & 1 & & & & & & & & & & & & & & \\
\hline Riq. & 0,55 & $-0,55$ & 0,58 & $-0,63$ & 0,02 & $-0,03$ & $-0,30$ & $-0,33$ & $-0,31$ & $-0,19$ & $-0,08$ & $-0,21$ & 0,21 & 0,01 & 0,52 & 0,30 & 1 & & & & & & & & & & & & & \\
\hline $\mathrm{H}$ & 0,58 & $-0,69$ & 0,72 & $-0,61$ & 0,67 & 0,11 & $-0,05$ & $-0,06$ & $-0,08$ & 0,18 & 0,40 & 0,18 & $-0,17$ & $-0,01$ & 0,40 & $-0,01$ & 0,39 & & & & & & & & & & & & & \\
\hline $\mathrm{J}$ & 0,29 & $-0,39$ & 0,41 & $-0,27$ & 0,68 & 0,09 & 0,07 & 0,11 & 0,08 & 0,26 & 0,46 & 0,33 & $-0,32$ & $-0,01$ & 0,12 & $-0,21$ & $-0,19$ & 0,83 & 1 & & & & & & & & & & & \\
\hline A.t & $-0,47$ & 0,62 & $-0,60$ & 0,49 & $-0,75$ & 0,04 & $-0,16$ & $-0,29$ & $-0,23$ & $-0,64$ & $-0,52$ & $-0,26$ & 0,26 & $-0,44$ & $-0,02$ & 0,01 & 0,20 & $-0,64$ & $-0,78$ & 1 & & & & & & & & & & \\
\hline B.e. & 0,09 & 0,30 & $-0,31$ & 0,28 & 0,14 & 0,33 & 0,19 & $-0,39$ & $-0,41$ & 0,11 & $-0,54$ & $-0,54$ & 0,53 & $-0,23$ & 0,49 & 0,57 & 0,13 & $-0,14$ & $-0,26$ & 0,15 & 1 & & & & & & & & & \\
\hline A.p. & 0,12 & $-0,03$ & 0,05 & $-0,06$ & 0,26 & 0,58 & 0,12 & $-0,39$ & $-0,44$ & 0,33 & 0,26 & $-0,80$ & 0,80 & $-0,15$ & 0,94 & 0,09 & 0,57 & 0,28 & $-0,05$ & 0,10 & 0,55 & 1 & & & & & & & & \\
\hline H.p. & $-0,07$ & 0,29 & $-0,26$ & 0,30 & 0,29 & 0,29 & 0,13 & $-0,07$ & $-0,04$ & $-0,30$ & 0,30 & 0,14 & $-0,14$ & $-0,70$ & 0,18 & 0,37 & $-0,09$ & 0,19 & 0,26 & 0,01 & 0,59 & 0,16 & 1 & & & & & & & \\
\hline C.cr. & 0,74 & $-0,31$ & 0,28 & $-0,21$ & 0,19 & 0,01 & $-0,10$ & $-0,12$ & $-0,14$ & 0,13 & 0,73 & $-0,17$ & 0,16 & 0,36 & 0,39 & $\mathbf{0 , 8 7}$ & 0,32 & 0,12 & $-0,09$ & $-0,21$ & 0,58 & 0,25 & 0,14 & 1 & & & & & & \\
\hline B.str. & $-0,56$ & 0,77 & $-0,77$ & 0,74 & $-0,29$ & 0,33 & 0,33 & $-0,12$ & $-0,09$ & $-0,31$ & $-0,01$ & $-0,12$ & 0,12 & $-0,72$ & 0,00 & 0,20 & $-0,33$ & $-0,41$ & $-0,24$ & 0,46 & 0,62 & 0,07 & 0,75 & $-0,06$ & 1 & & & & & \\
\hline C.sub. & 0,60 & $-0,32$ & 0,28 & $-0,23$ & 0,10 & 0,11 & 0,23 & 0,13 & 0,10 & 0,33 & 0,60 & $-0,11$ & 0,10 & 0,37 & 0,18 & 0,84 & 0,18 & $-0,01$ & $-0,16$ & $-0,28$ & 0,49 & 0,11 & 0,00 & 0,90 & $-0,08$ & 1 & & & & \\
\hline E.B.A.O. & 0,44 & $-0,42$ & 0,46 & $-0,44$ & 0,37 & $-0,70$ & $-0,77$ & $-0,26$ & $-0,23$ & $-0,30$ & $-0,01$ & 0,41 & $-0,41$ & 0,39 & $-0,31$ & $-0,25$ & 0,09 & 0,33 & 0,33 & $-0,25$ & $-0,51$ & $-0,38$ & $-0,25$ & $-0,11$ & $-0,60$ & $-0,28$ & 1 & & & \\
\hline E.B.A.E.O. & 0,51 & $-0,25$ & 0,23 & $-0,11$ & 0,47 & 0,28 & 0,26 & 0,03 & 0,00 & 0,28 & 0,81 & 0,00 & $-0,01$ & $-0,03$ & 0,42 & 0,65 & 0,04 & 0,48 & 0,46 & $-0,53$ & 0,59 & 0,27 & 0,58 & 0,71 & 0,22 & 0,64 & $-0,27$ & 1 & & \\
\hline Pequenas & 0,53 & $-0,15$ & 0,14 & $-0,12$ & 0,28 & 0,16 & 0,04 & $-0,45$ & $-0,50$ & 0,44 & 0,67 & $-0,64$ & 0,63 & 0,39 & 0,56 & 0,52 & 0,30 & 0,07 & $-0,14$ & $-0,18$ & 0,70 & 0,55 & $-0,01$ & 0,80 & $-0,06$ & 0,74 & $-0,17$ & 0,53 & 1 & \\
\hline Medias & $-0,66$ & 0,29 & $-0,28$ & 0,25 & $-0,47$ & $-0,07$ & 0,05 & 0,43 & 0,48 & $-0,43$ & $-0,75$ & 0,50 & $-0,49$ & $-0,42$ & $-0,52$ & $-0,52$ & $-0,29$ & $-0,23$ & $-0,04$ & 0,35 & $-0,65$ & $-0,49$ & $-0,05$ & $-0,82$ & 0,15 & $-0,73$ & 0,00 & $-0,61$ & $-0,97$ & 1 \\
\hline Grandes & 0,20 & $-0,39$ & 0,43 & $-0,36$ & 0,52 & $-0,35$ & $-0,32$ & 0,28 & 0,31 & $-0,25$ & $-0,03$ & 0,78 & $-0,78$ & $-0,07$ & $-0,39$ & $-0,21$ & $-0,16$ & 0,54 & 0,68 & $-0,49$ & $-0,53$ & $-0,49$ & 0,23 & $-0,31$ & $-0,27$ & $-0,37$ & 0,67 & 0,03 & $-0,56$ & 0,34 \\
\hline
\end{tabular}

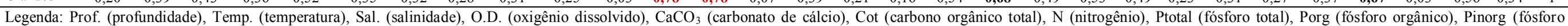

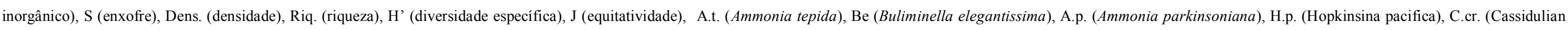

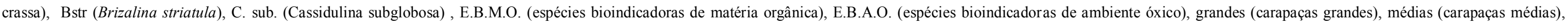
pequenas (carapaças pequenas). 
Anexo 74 - Matriz de correlação de Pearson obtida para os dados bióticos e abióticos obtidos próximo ao emissário do TEBAR, em Agosto de 2006.

Níveis de significância: $p<0,01$ (em vermelho) e $p<0,05$ (em negrito)

\begin{tabular}{|c|c|c|c|c|c|c|c|c|c|c|c|c|c|c|c|c|c|c|c|c|c|c|c|c|c|c|c|c|c|c|c|c|c|c|}
\hline $\begin{array}{l}\text { 岁 } \\
\text { D }\end{array}$ & 害 & $\overline{\tilde{n}}$ & $\approx$ & & & ن & z & $\begin{array}{l}\text { जू } \\
\frac{\pi}{2}\end{array}$ & $\theta$ & & & n & 苞 & 袁 & $\stackrel{\pi}{2}$ & 포 & & $\overline{\widetilde{\Omega}}$ & \pm & - & + & 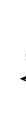 & & $\dot{\varphi}$ & تُ & 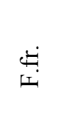 & $\underset{\dot{\Xi}}{\dot{\emptyset}}$ & 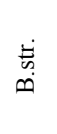 & $\dot{\varphi}$ & $\begin{array}{l}\dot{0} \\
\dot{\varphi} \\
\dot{\varphi} \\
\dot{\omega}\end{array}$ & 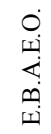 & $\begin{array}{l}\tilde{z} \\
\tilde{\Xi} \\
\vec{\Xi} \\
\tilde{g}\end{array}$ & 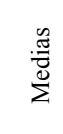 & 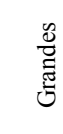 \\
\hline
\end{tabular}

\begin{tabular}{|c|c|c|c|c|c|c|c|c|c|c|c|c|c|c|c|c|c|c|c|c|c|c|c|c|c|c|c|c|c|c|c|}
\hline Prof & 1 & & & & & & & & & & & & & & & & & & & & & & & & & & & & & & \\
\hline Temp & $-0,83$ & 1 & & & & & & & & & & & & & & & & & & & & & & & & & & & & & \\
\hline Sal & 0,85 & $-0,99$ & 1 & & & & & & & & & & & & & & & & & & & & & & & & & & & & \\
\hline OD & $-0,81$ & 0,70 & $-0,71$ & 1 & & & & & & & & & & & & & & & & & & & & & & & & & & & \\
\hline $\mathrm{CaCO} 3$ & $-0,06$ & 0,11 & $-0,15$ & $-0,02$ & 1 & & & & & & & & & & & & & & & & & & & & & & & & & & \\
\hline Cot & 0,30 & 0,02 & 0,02 & $-0,25$ & 0,72 & 1 & & & & & & & & & & & & & & & & & & & & & & & & & \\
\hline $\mathrm{N}$ & $-0,19$ & 0,13 & $-0,18$ & $-0,21$ & 0,45 & 0,12 & 1 & & & & & & & & & & & & & & & & & & & & & & & & \\
\hline Ptotal & $-0,15$ & 0,40 & $-0,42$ & 0,13 & 0,83 & 0,74 & 0,21 & 1 & & & & & & & & & & & & & & & & & & & & & & & \\
\hline Porg & $-0,03$ & 0,26 & $-0,30$ & $-0,06$ & 0,80 & 0,65 & 0,38 & 0,94 & 1 & & & & & & & & & & & & & & & & & & & & & & \\
\hline Pinorg & $-0,23$ & 0,48 & $-0,48$ & 0,27 & $\mathbf{0 , 8 0}$ & 0,76 & 0,07 & 0,97 & 0,84 & 1 & & & & & & & & & & & & & & & & & & & & & \\
\hline $\mathrm{S}$ & 0,55 & $-0,17$ & 0,19 & $-0,50$ & 0,46 & 0,66 & 0,11 & 0,44 & 0,42 & 0,42 & 1 & & & & & & & & & & & & & & & & & & & & \\
\hline Areia & 0,42 & $-0,33$ & 0,35 & $-0,10$ & 0,54 & 0,72 & $-0,08$ & 0,37 & 0,25 & 0,43 & 0,53 & 1 & & & & & & & & & & & & & & & & & & & \\
\hline Finos & $-0,42$ & 0,34 & $-0,36$ & 0,10 & $-0,56$ & $-0,72$ & 0,07 & $-0,38$ & $-0,26$ & $-0,43$ & $-0,52$ & $-1,00$ & 1 & & & & & & & & & & & & & & & & & & \\
\hline $\mathrm{pH}$ & $-0,08$ & 0,34 & $-0,35$ & 0,02 & 0,65 & 0,67 & 0,02 & 0,91 & 0,88 & $\mathbf{0 , 8 7}$ & 0,30 & 0,19 & $-0,19$ & 1 & & & & & & & & & & & & & & & & & \\
\hline Eh & 0,02 & 0,32 & $-0,30$ & 0,13 & 0,44 & 0,70 & 0,00 & 0,78 & 0,73 & 0,76 & 0,28 & 0,43 & $-0,41$ & 0,76 & 1 & & & & & & & & & & & & & & & & \\
\hline Dens. & $-0,66$ & 0,38 & $-0,38$ & 0,76 & $-0,40$ & $-0,53$ & $-0,14$ & $-0,43$ & $-0,56$ & $-0,30$ & $-\mathbf{- 0 , 7 0}$ & $-0,17$ & 0,18 & $-0,48$ & $-0,26$ & 1 & & & & & & & & & & & & & & & \\
\hline Riq. & $-0,50$ & 0,64 & $-0,62$ & 0,49 & $-0,20$ & $-0,27$ & 0,05 & 0,00 & $-0,11$ & 0,08 & 0,01 & $-0,36$ & 0,38 & $-0,20$ & $-0,06$ & 0,24 & 1 & & & & & & & & & & & & & & \\
\hline $\mathrm{H}$ & $-0,32$ & 0,53 & $-0,53$ & 0,36 & $-0,18$ & $-0,24$ & $-0,06$ & 0,12 & 0,06 & 0,16 & 0,19 & $-0,33$ & 0,34 & $-0,03$ & 0,07 & 0,03 & 0,90 & 1 & & & & & & & & & & & & & \\
\hline $\mathrm{J}$ & $-0,23$ & 0,44 & $-0,45$ & 0,28 & $-0,12$ & $-0,22$ & $-0,09$ & 0,19 & 0,16 & 0,20 & 0,26 & $-0,29$ & 0,30 & 0,06 & 0,10 & $-0,08$ & 0,77 & 0,97 & 1 & & & & & & & & & & & & \\
\hline A.t. & $-0,21$ & 0,16 & $-0,12$ & 0,23 & $-0,36$ & $-0,06$ & $-0,03$ & $-0,36$ & $-0,42$ & $-0,29$ & $-0,52$ & $-0,01$ & 0,04 & $-0,25$ & 0,04 & 0,62 & $-0,20$ & $-0,47$ & $-0,60$ & 1 & & & & & & & & & & & \\
\hline A.p. & $-0,56$ & 0,31 & $-0,38$ & 0,26 & 0,47 & $-0,08$ & 0,41 & 0,32 & 0,35 & 0,27 & $-0,20$ & $-0,19$ & 0,15 & 0,32 & $-0,11$ & 0,18 & $-0,21$ & $-0,18$ & $-0,09$ & $-0,12$ & 1 & & & & & & & & & & \\
\hline B.e. & 0,02 & 0,08 & $-0,08$ & $-0,10$ & $-0,10$ & $-0,22$ & 0,05 & $-0,11$ & $-0,12$ & $-0,09$ & 0,41 & $-0,26$ & 0,26 & $-0,28$ & $-0,38$ & $-0,27$ & 0,71 & 0,75 & 0,74 & $-0,68$ & $-0,21$ & 1 & & & & & & & & & \\
\hline P.atl. & $-0,42$ & 0,12 & $-0,11$ & 0,48 & $-0,16$ & $-0,32$ & 0,02 & $-0,34$ & $-0,49$ & $-0,20$ & $-0,25$ & 0,13 & $-0,13$ & $-0,57$ & $-0,31$ & 0,66 & 0,42 & 0,26 & 0,19 & 0,12 & 0,01 & 0,23 & 1 & & & & & & & & \\
\hline F.fr. & $-0,37$ & 0,42 & $-0,43$ & 0,15 & $-0,28$ & $-0,34$ & $-0,05$ & 0,10 & 0,14 & 0,06 & $-0,23$ & $-0,69$ & 0,70 & 0,22 & 0,11 & $-0,09$ & 0,51 & 0,64 & 0,65 & $-0,32$ & 0,02 & 0,37 & $-0,03$ & 1 & & & & & & & \\
\hline B.m. & $-0,30$ & 0,44 & $-0,44$ & 0,29 & $-0,36$ & $-0,23$ & $-0,01$ & $-0,15$ & $-0,12$ & $-0,16$ & $-0,33$ & $-0,34$ & 0,36 & $-0,01$ & 0,09 & 0,45 & $-0,04$ & $-0,06$ & $-0,09$ & 0,62 & 0,18 & $-0,44$ & $-0,25$ & $-0,04$ & 1 & & & & & & \\
\hline B.str. & $-0,09$ & 0,33 & $-0,29$ & 0,08 & $-0,16$ & 0,27 & $-0,05$ & 0,18 & 0,18 & 0,17 & $-0,27$ & $-0,09$ & 0,14 & 0,36 & 0,61 & 0,05 & $-0,07$ & $-0,16$ & $-0,26$ & 0,64 & $-0,29$ & $-0,57$ & $-0,39$ & 0,18 & 0,50 & 1 & & & & & \\
\hline B.c. & 0,09 & 0,02 & $-0,04$ & 0,05 & 0,30 & 0,08 & $-0,20$ & 0,21 & 0,11 & 0,26 & 0,55 & 0,14 & $-0,17$ & 0,06 & $-0,25$ & $-0,27$ & 0,28 & 0,38 & 0,44 & $-0,69$ & 0,10 & 0,64 & $-0,03$ & $-0,14$ & $-0,31$ & $-0,69$ & 1 & & & & \\
\hline E.B.A.O. & 0,28 & 0,08 & $-0,03$ & $-0,27$ & 0,02 & 0,28 & $-0,17$ & 0,11 & 0,05 & 0,15 & 0,47 & $-0,07$ & 0,08 & 0,11 & $-0,01$ & $-0,51$ & 0,37 & 0,30 & 0,22 & $-0,27$ & $-0,51$ & 0,54 & $-0,39$ & 0,09 & $-0,22$ & 0,07 & 0,48 & 1 & & & \\
\hline E.B.A.E.O. & $-0,07$ & 0,17 & $-0,18$ & 0,18 & $-0,37$ & $-0,40$ & $-0,13$ & $-0,18$ & $-0,20$ & $-0,16$ & 0,18 & $-0,25$ & 0,26 & $-0,34$ & $-0,14$ & 0,05 & 0,76 & 0,90 & 0,90 & $-0,48$ & $-0,33$ & 0,79 & 0,42 & 0,52 & $-0,19$ & $-0,36$ & 0,33 & 0,16 & 1 & & \\
\hline Pequenas & $-0,51$ & 0,37 & $-0,39$ & 0,43 & $-0,11$ & $-0,32$ & 0,22 & $-0,25$ & $-0,27$ & $-0,22$ & $-0,44$ & $-0,22$ & 0,21 & $-0,26$ & $-0,30$ & 0,68 & $-0,06$ & $-0,25$ & $-0,31$ & 0,59 & 0,51 & $-0,38$ & 0,12 & $-0,37$ & 0,75 & 0,06 & $-0,11$ & $-0,36$ & $-0,34$ & 1 & \\
\hline Medias & 0,56 & $-0,47$ & 0,48 & $-0,49$ & 0,05 & 0,20 & $-0,17$ & 0,13 & 0,19 & 0,08 & 0,42 & 0,16 & $-0,16$ & 0,13 & 0,16 & $-0,69$ & 0,05 & 0,25 & 0,32 & $-0,65$ & $-0,50$ & 0,45 & $-0,09$ & 0,35 & $-0,78$ & $-0,17$ & 0,14 & 0,34 & 0,39 & $-0,98$ & 1 \\
\hline Grandes & $-0,13$ & 0,42 & $-0,36$ & 0,21 & 0,32 & 0,71 & $-0,29$ & 0,65 & 0,45 & 0,75 & 0,21 & 0,36 & $-0,33$ & 0,71 & 0,80 & $-0,15$ & 0,05 & 0,05 & 0,02 & 0,14 & $-0,16$ & $-0,27$ & $-0,16$ & 0,16 & $-0,02$ & 0,59 & $-0,14$ & 0,22 & $-0,20$ & $-0,31$ & 0,13 \\
\hline
\end{tabular}




\section{CAPÍTULO 7 - ESTUDO COMPARATIVO ENTRE AS ÁREAS DE ESTUDO E INTEGRAÇÃO DE DADOS}

\subsection{Biocenoses}

\subsubsection{NMDS e MANOVA}

O estudo comparativo, realizado entre as composições das associações de foraminíferos, permitiu identificar as similaridades e dissimilaridades existentes entre as áreas de estudo (Figuras 36, 37 e 38).

Em relação às amostragens realizadas no ano de 2005, verificou-se diferenciação significativa nos Eixos 1 e 2, os resultados obtidos foram: Eixo $1 \mathrm{~F}_{3,35}=34,243 ; p<0,0001 \mathrm{e}$ Eixo $2 \mathrm{~F}_{3,35}=18,584 ; p<0,0001$.

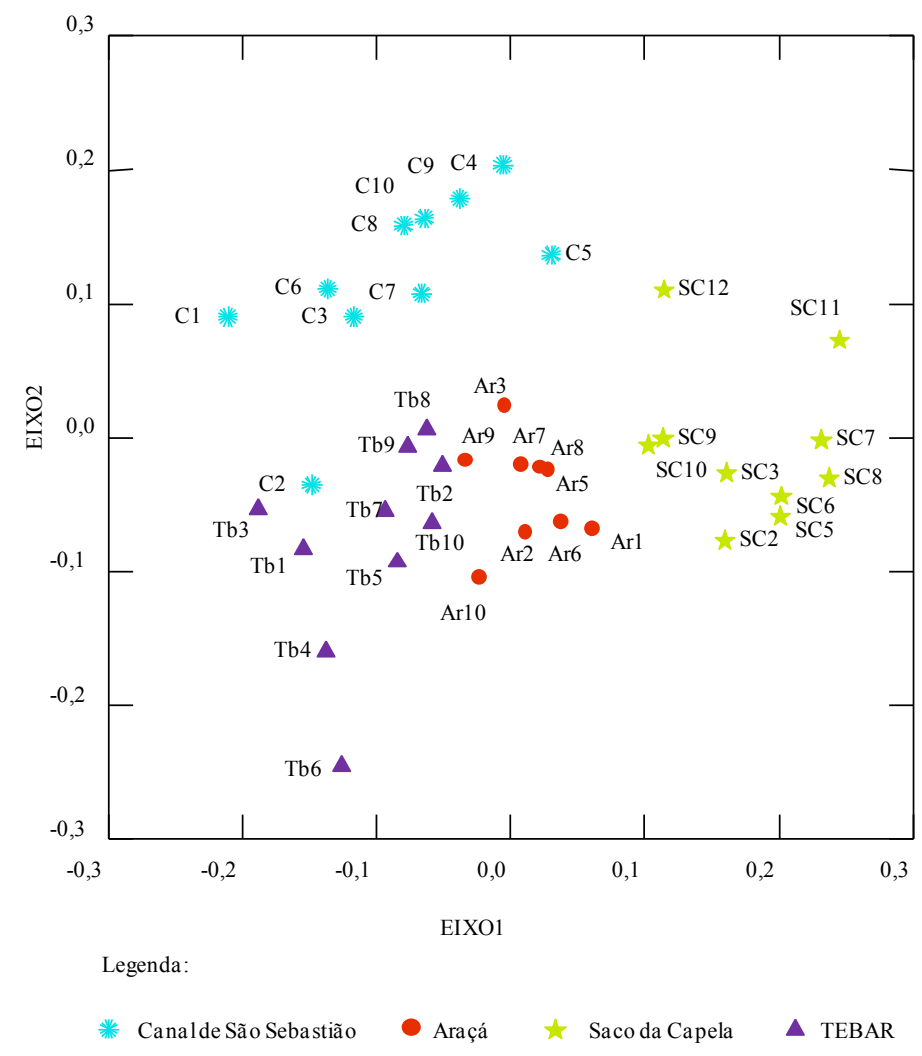

Figura 36 - Diagrama de ordenação obtido para o estudo composição das espécies identificadas ao longo do Canal de São Sebastião, no Araçá, no Saco da Capela e no TEBAR. Dados referentes às biocenoses identificadas em 2005. 
As amostragens realizadas no primeiro semestre de 2006 apresentaram diferenciações significativas, em suas estruturas composicionais, em ambos os Eixos. Os resultados obtidos foram Eixo $1 \mathrm{~F}_{3,36}=47,424 ; p<0,0001$ e Eixo $2 \mathrm{~F}_{3,36}=6,777 ; p=0,001$.

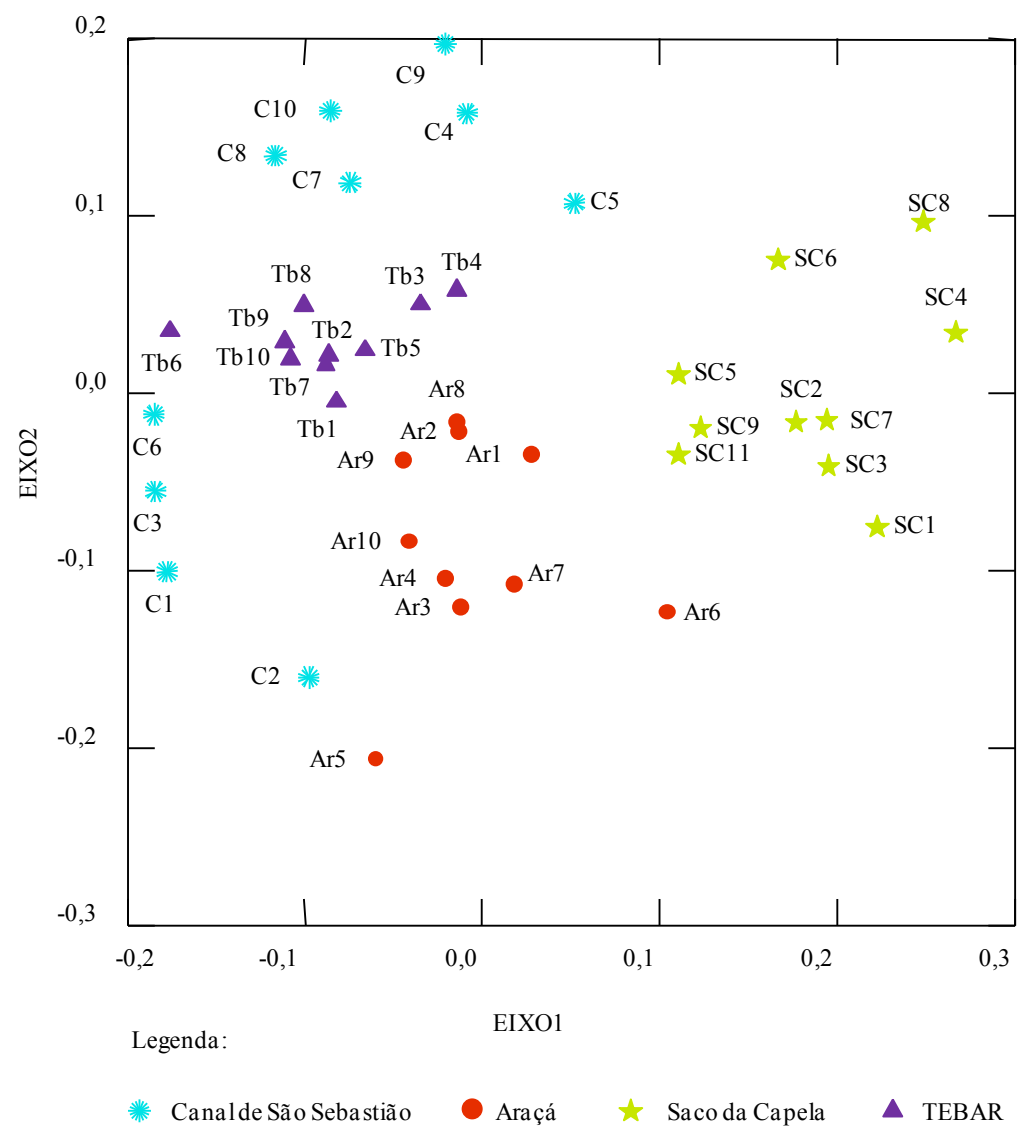

Figura 37 - Diagrama de ordenação obtido para o estudo composição das espécies identificadas ao longo do Canal de São Sebastião, no Araçá, no Saco da Capela e no TEBAR.

Dados referentes às biocenoses identificadas no primeiro semestre de 2006.

Para as amostragens realizadas no segundo semestre de 2006, as diferenciações ocorreram com nível de significância elevado somente no Eixo $1\left(\mathrm{~F}_{3,36}=20,244 ; p<0,0001\right)$. Os resultados obtidos para o Eixo 2 foram $\mathrm{F}_{3,36}=2,246 ; p=0,1$.

Em todos os estudos comparativos verificou-se baixo valor de estresse, entre 0,22 e 0,26, o que indica ausência de distorção dos dados nas análises realizadas. 


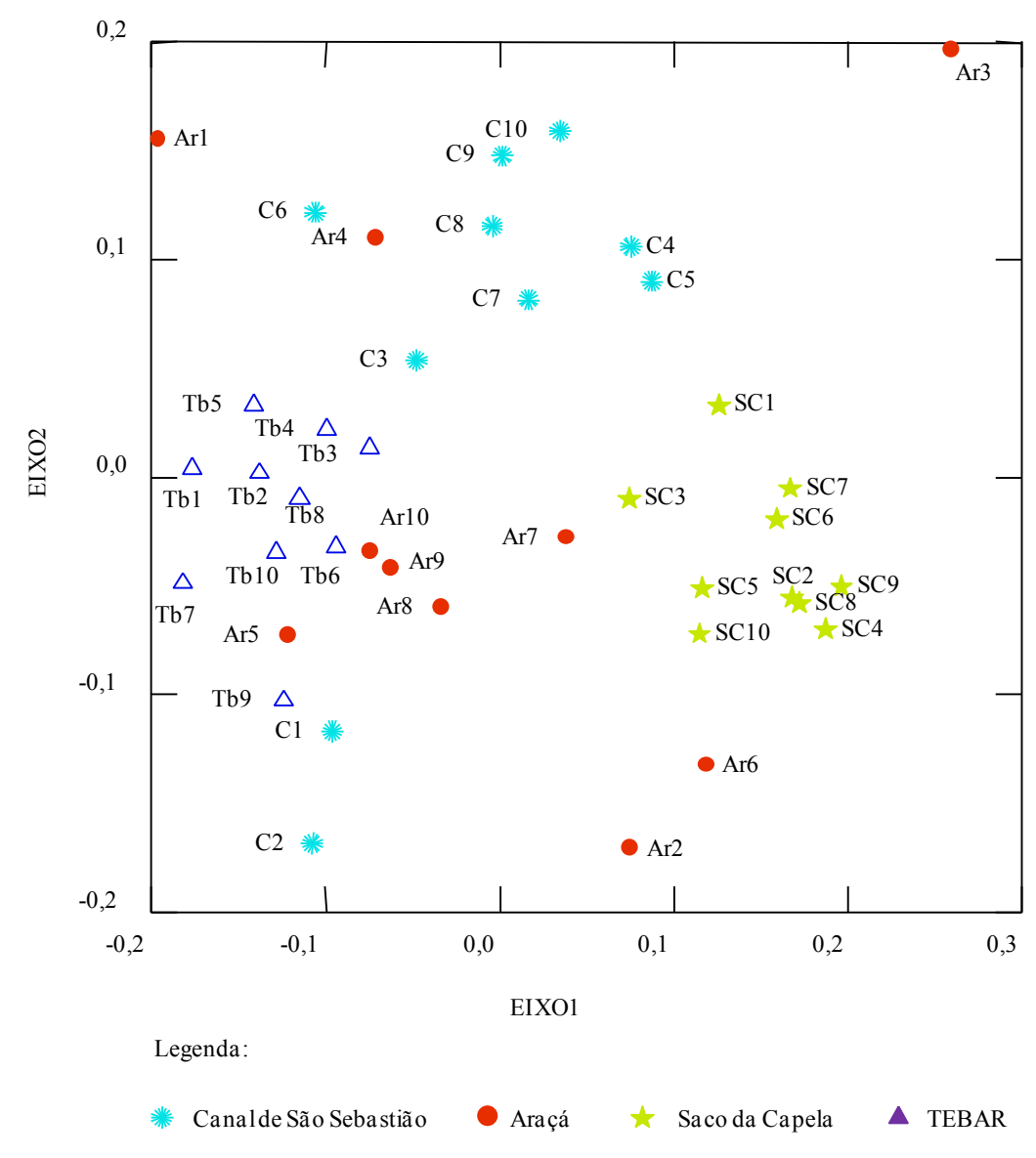

Figura 38 - Diagrama de ordenação obtido para o estudo composição das espécies identificadas ao longo do Canal de São Sebastião, no Araçá, no Saco da Capela e no TEBAR.

Dados referentes às biocenoses identificadas no segundo semestre de 2006.

Descritivamente, verificou-se que em 2005 , somente $24 \%$ das espécies identificadas estiveram presentes no Araçá, no Saco da Capela e no TEBAR.

Em relação às amostragens realizadas no primeiro semestre de 2006, 30\% das espécies foram identificadas nas áreas de estudo.

Para o segundo semestre de 2006, somente 19\% das espécies identificadas são comuns às três áreas de estudo. 
Das espécies identificadas, em todos os períodos, somente $8 \%$ estiveram presentes nas amostras coletadas ao longo do Canal de São Sebastião, Araçá, Saco da Capela e TEBAR. As espécies identificadas foram Ammonia parkinsoniana, Ammonia tepida, Ammotium salsum, Bolivina compacta, Bolivina ordinaria, Brizalina striatula, Bulimina marginata, Buliminella elegantissima, Cassidulina crassa, Haynesina germanica, Pseudononion atlanticum e Rosalina floridensis. 


\subsubsection{Análise de Agrupamento}

Em agosto de 2005, com nível de similaridade de 0,50, verificou-se a formação de 8 grupos distintos (Figura 39). O grupo G1 é composto pelas estações C5 e C4, as quais localizam-se lado insular do canal. O grupo G2 é formado pelas estações C8, C7 e C6, posicionadas na região central do canal. O grupo G3 compreende as estações Ar7 e Ar3. O grupo G4 engloba a maioria das estações amostradas no Araçá - Ar1, Ar2, Ar5, At6, Ar8 e Ar9. Ao grupo G5 associaram-se as estações Tb8 e Tb9. O grupo G6 é formado pela maioria das estações amostradas no TEBAR - Tb1 a Tb7 e Tb10. As estações $\mathrm{C} 1$ e $\mathrm{C} 2$, localizadas na região norte do canal, formaram o grupo G7. O grupo G8, por sua vez, englobou quase todas as estações amostradas no Saco da Capela - Sc2, Sc3, Sc5 a Sc11.

As estações C3, C9, C10, Ar10, Sc12 não se associaram aos grupos formados.

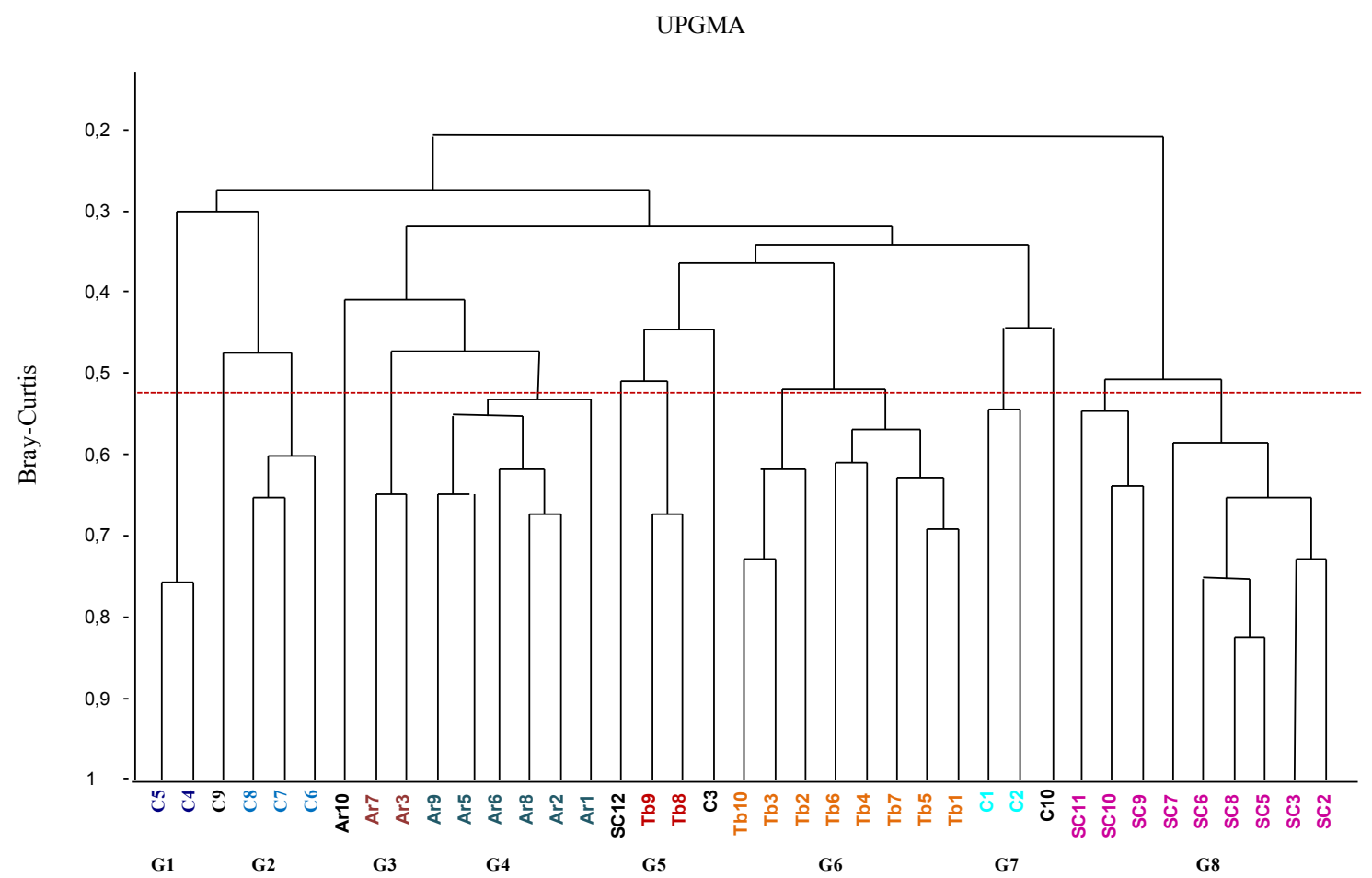

Figura 39 - Dendrograma obtido para as estações amostradas no ano de 2005.

Dados referentes às biocenoses. 
As estações amostradas no primeiro semestre de 2006, com nível de similaridade de 0,45, distribuíram-se em 7 grupos (Figura 40). O grupo G1 é composto pelas estações C2, Ar3, Ar4, Ar5 e Ar10. As estações Ar1, Ar2, Ar7, Ar8 e Ar9 formaram o grupo G2. O grupo G3 compreende as estações C1 e C10, posicionadas nas regiões norte e sul do canal, respectivamente. O grupo G4 abrange as estações C3, C6 a C8. Assim como o verificado em 2005, C4 e C5 posicionam-se separadas das demais estações, e estão associadas ao grupo G5. Excetuando-se a estação Tb7, o grupo G6 compreende todas as demais estações amostradas no TEBAR. O grupo G7, por sua vez, desconsiderando-se a estação Sc6, abrange todas as estações a amostradas no Saco da Capela.

As estações Ar6, Tb7, e Sc6 não se associaram aos grupos formados.

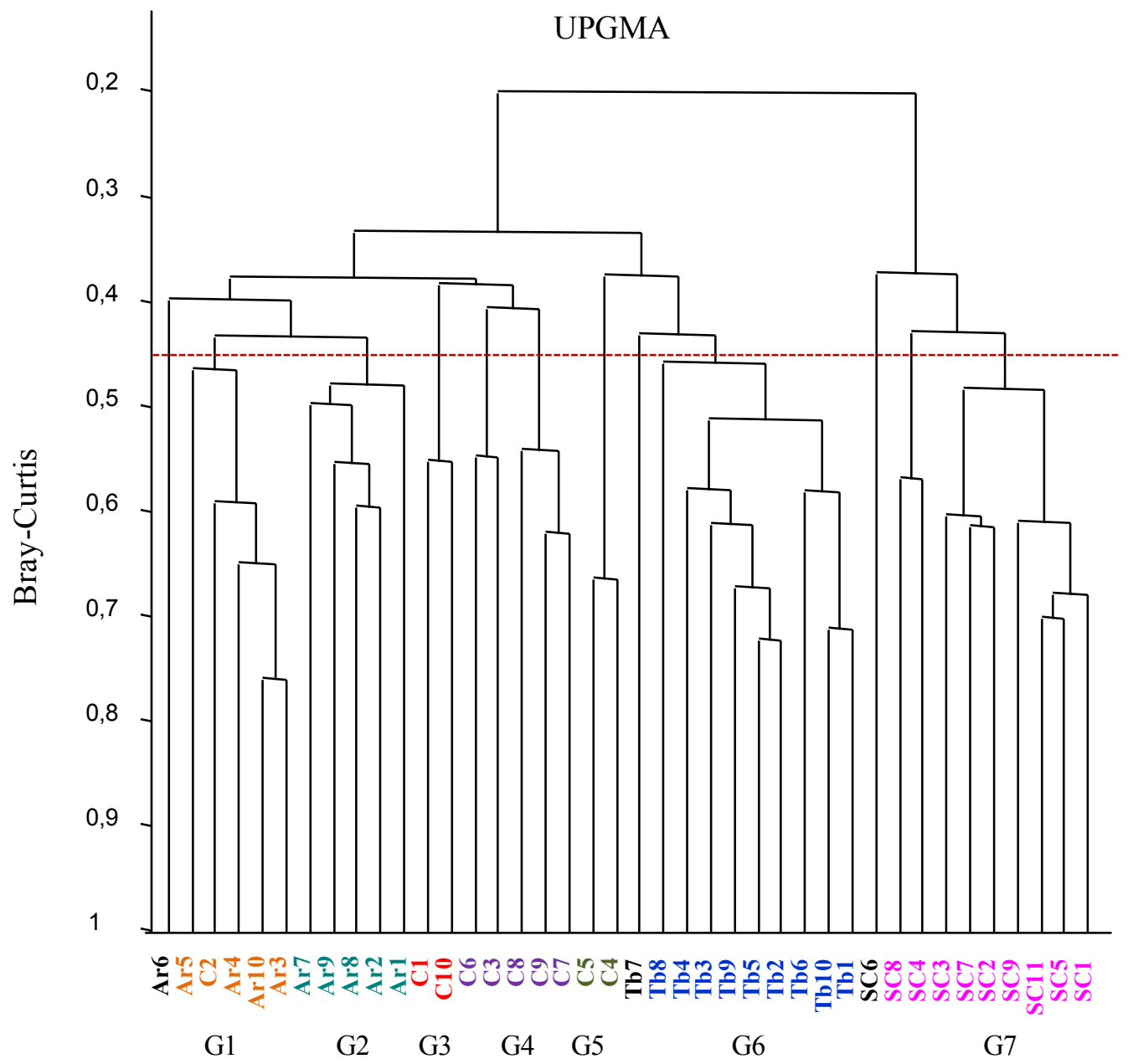

Figura 40 - Dendrograma obtido para as estações amostradas no primeiro semestre de 2006.

Dados referentes às biocenoses. 
No segundo semestre de 2006, com nível de similaridade de 0,45, verificou-se a formação de 8 grupos (Figura 41). As estações C1 e C2 formaram o grupo G1. O grupo G2 compreendeu as estações C3, Ar5, Ar9 e Ar10. O grupo G3 englobou todas as estações amostradas no TEBAR. Ao grupo G4 estão associadas às estações Ar3 e C10. O grupo G5 é composto pelas estações C6 a C9. As estações C4 e C5, assim como o verificado para os dois períodos amostrados, estão localizadas no mesmo grupo, o G6. O grupo G7 compreende todas as estações amostradas no Saco da Capela. O grupo G8, por sua vez, é composto pelasestações Ar2, Ar7 e Ar8. As estações Ar1, Ar4 e Ar4 não se associaram aos grupos formados.

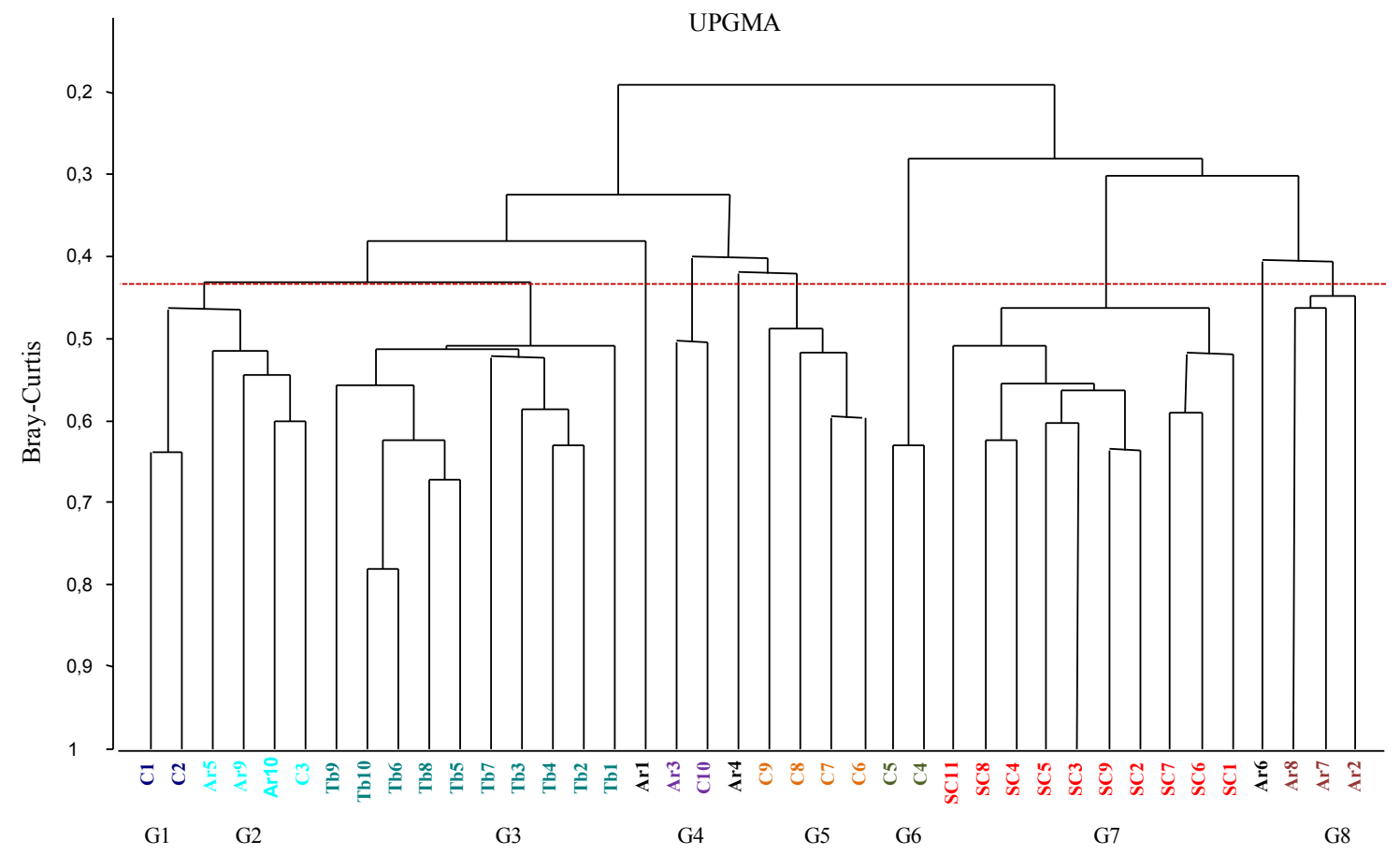

Figura 41 - Dendrograma obtido para as estações amostradas no segundo semestre de 2006.

Dados referentes às biocenoses. 


\subsection{Tanatocenoses}

\subsubsection{NMDS e MANOVA}

Apesar de as estações estarem posicionadas muito próximas umas às outras no diagrama de ordenação, foram observadas diferenciações composicionais significativas nas associações de foraminíferos, em todos os períodos analisados (Figura 42, 43 e 44).

Para o ano de 2005, as dissimilaridades ocorreram nos Eixos 1 e 2, sendo, contudo, observado maior nível de significância no Eixo 2. Os valores obtidos foram Eixo1 $\mathrm{F}_{3,35}=$ 7,487; $p<0,01$ e Eixo $2 \mathrm{~F}_{3,35}=9,787 ; p<0,0001$.

Diferentemente das demais estações, Sc6 e Sc8 posicionaram-se em separado, o que é decorrente da baixa densidade obtida em ambas as estações.

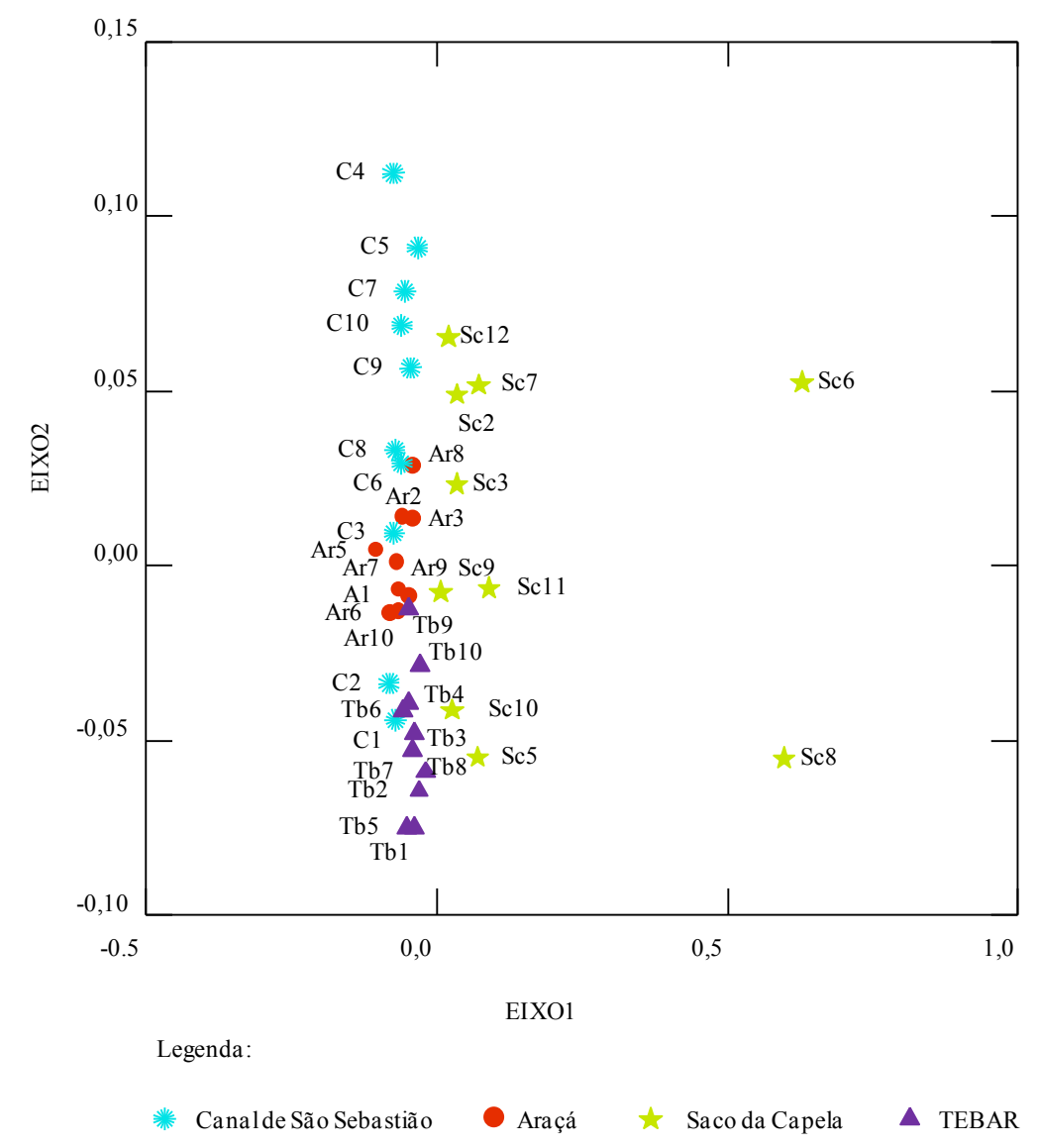

Figura 42 - Diagrama de ordenação obtido para o estudo composição das espécies identificadas ao longo do Canal de São Sebastião, no Araçá, no Saco da Capela e no TEBAR. Dados referentes às tanatocenoses identificadas em 2005. 
Em relação às amostragens realizadas no primeiro semestre de 2006, foram observadas diferenciações significativas nos dois Eixos do diagrama de ordenação. Para o Eixo 1 foram verificados os valores $\mathrm{F}_{3,36}=22,123 ; p<0,001$. Já para o Eixo 2 foram observados os valores $\mathrm{F}_{3,36}=4,568 ; p<0,005$.

Pelo posicionamento das estações, verifica-se maior similaridade composicional entre o Araçá e TEBAR, bem como com algumas das estações amostradas ao longo do Canal de São Sebastião.

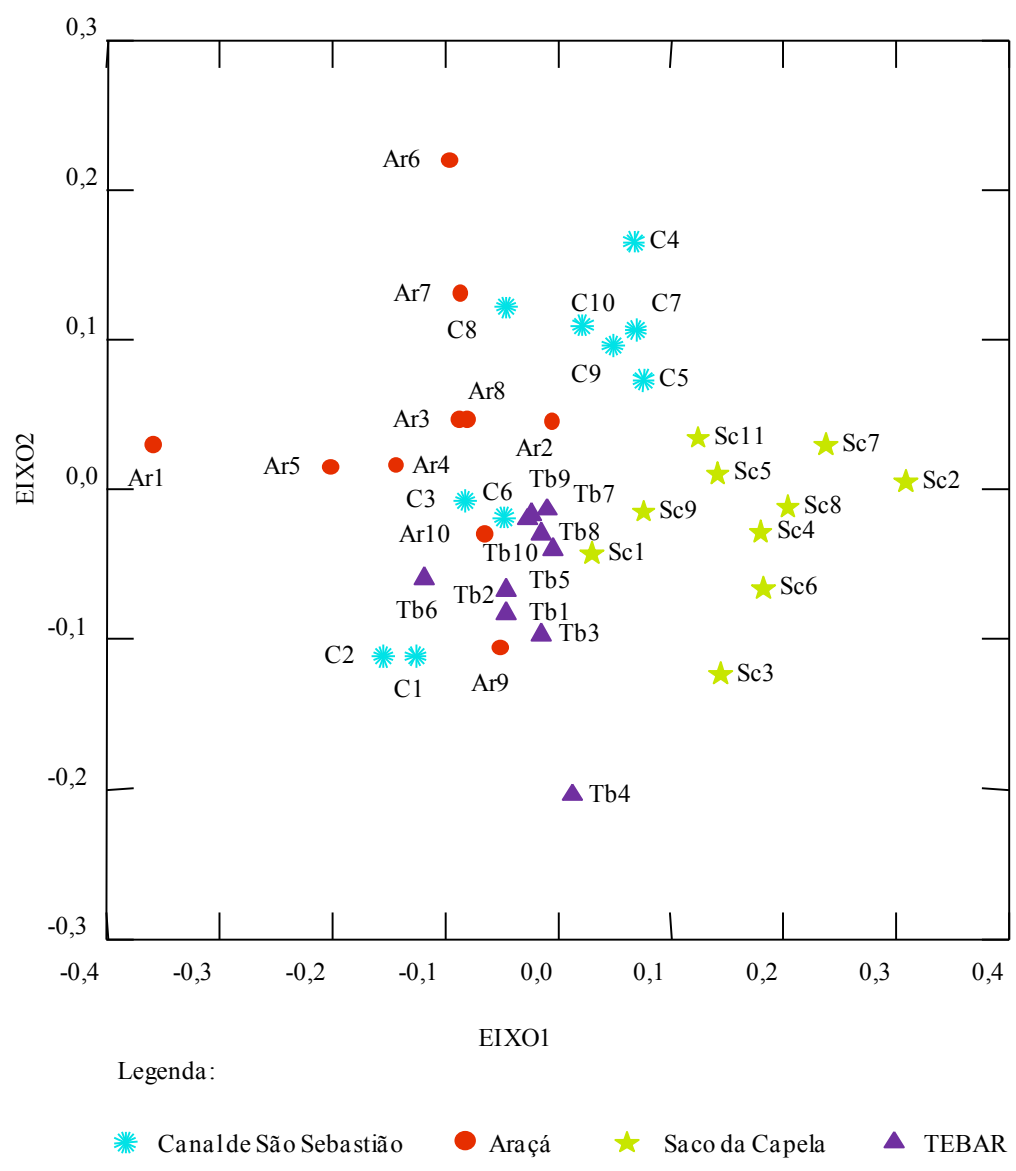

Figura 43 - Diagrama de ordenação obtido para o estudo composição das espécies identificadas ao longo do Canal de São Sebastião, no Araçá, no Saco da Capela e no TEBAR.

Dados referentes às tanatocenoses identificadas no primeiro semestre de 2006. 
O estudo comparativo realizado no segundo semestre de 2006 indicou diferenças expressivas entre as áreas de estudo. Contudo, o maior nível de significância ocorreu somente no Eixo 1. Os valores obtidos foram Eixo $1 \mathrm{~F}_{3,36}=42,867 ; p<0,0001$ e Eixo $2 \mathrm{~F}_{3,36}=2,950$; $p<0,05$.

Assim como o verificado no período anterior de estudo, no segundo semestre de 2006 verificou-se maior semelhança composicional entre o Araçá e o TEBAR, bem como com algumas estações amostradas ao longo do Canal de São Sebastião.

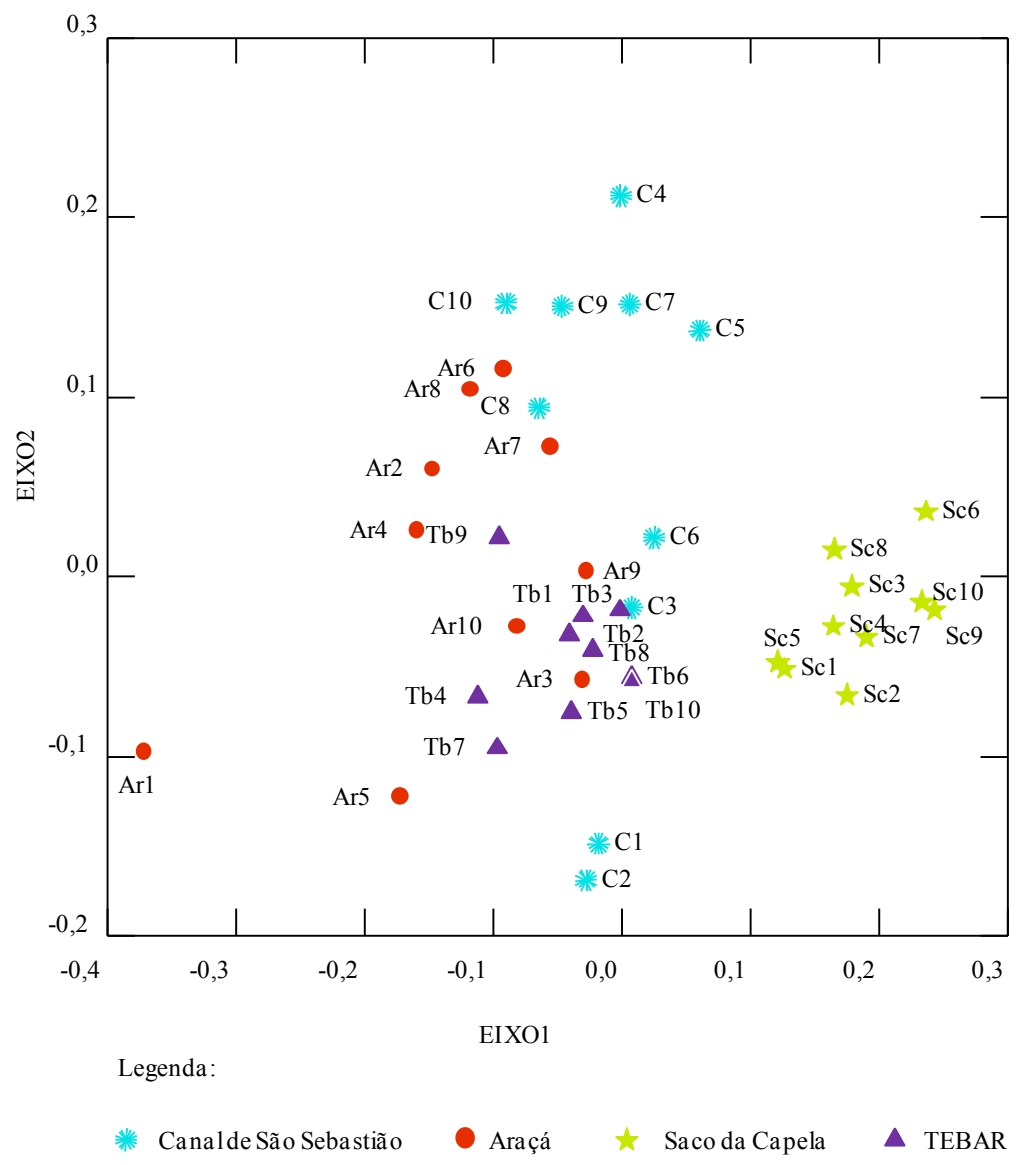

Figura 44 - Diagrama de ordenação obtido para o estudo composição das espécies identificadas ao longo do Canal de São Sebastião, no Araçá, no Saco da Capela e no TEBAR.

Dados referentes às tanatocenoses identificadas no segundo semestre de 2006.

Descritivamente, para 2005 , somente $33 \%$ das espécies são comuns às três áreas de estudo. No primeiro semestre de 2006, a porcentagem de espécies identificadas nas três áreas é de $30 \%$. Para o segundo semestre de 2006, verificou-se que somente $21 \%$ das espécies estão presentes no Araçá, Saco da Capela e TEBAR. 
Das espécies identificadas em todos os períodos de estudo, somente $11 \%$ estiveram presentes em todas as áreas, incluindo as estações posicionadas ao longo do Canal de São Sebastião. As espécies identificadas são Ammonia parkinsoniana, Ammonia tepida, Ammotium salsum, Angulogerina angulosa, Bolivina compacta, Bolivina doniezi, Bolivina ordinaria, Bolivina pulchella, Brizalina striatula, Bulimina marginata, Buliminella elegantissima, Cassidulina crassa, Cribroelphidium discoidale, Cribroelphidium excavatum, Cribroelphidium poyeanum, Discorbis williamsoni, Fissurina laevigata, Fursenkoina pontoni, Gaudryina exilis, Gavelinopsis praegeri, Hanzawaia boueana, Hopkinsina pacifica, Lobatula lobatula, Neocornobina terquemi, Pararotalia cananeiaensis, Pseudononion atlanticum, Pseudononion opima e Rosalina floridensis.

\subsubsection{Análise de Agrupamento}

Verificou-se a formação de 8 grupos, nível de similaridade de 0,49, para as amostras coletadas em 2005 (Figura 45).

O grupo $\mathrm{G} 1$ foi formado pelas estações $\mathrm{C} 1$ e $\mathrm{C} 2$, posicionadas na região norte do Canal de São Sebastião. O grupo G2 abrangeu todas as estações amostradas no Araçá e a estação C3. O grupo G3 foi formado pelas estações Tb2, Tb3, Tb4, Tb7 a Tb10. O grupo G4 englobou as demais estações amostradas no TEBAR, estações Tb1, Tb5 e Tb6. O grupo G6 foi composto pelas estações C9 e C10, localizada na região sul do canal. As estações Sc10 e Sc11 estão associadas ao grupo G7. O grupo G8, por sua vez, englobou as estações Sc2, Sc7, Sc8 e Sc9.

As estações Sc3, Sc5, Sc6 e Sc12 não foram associadas aos grupos formados. 


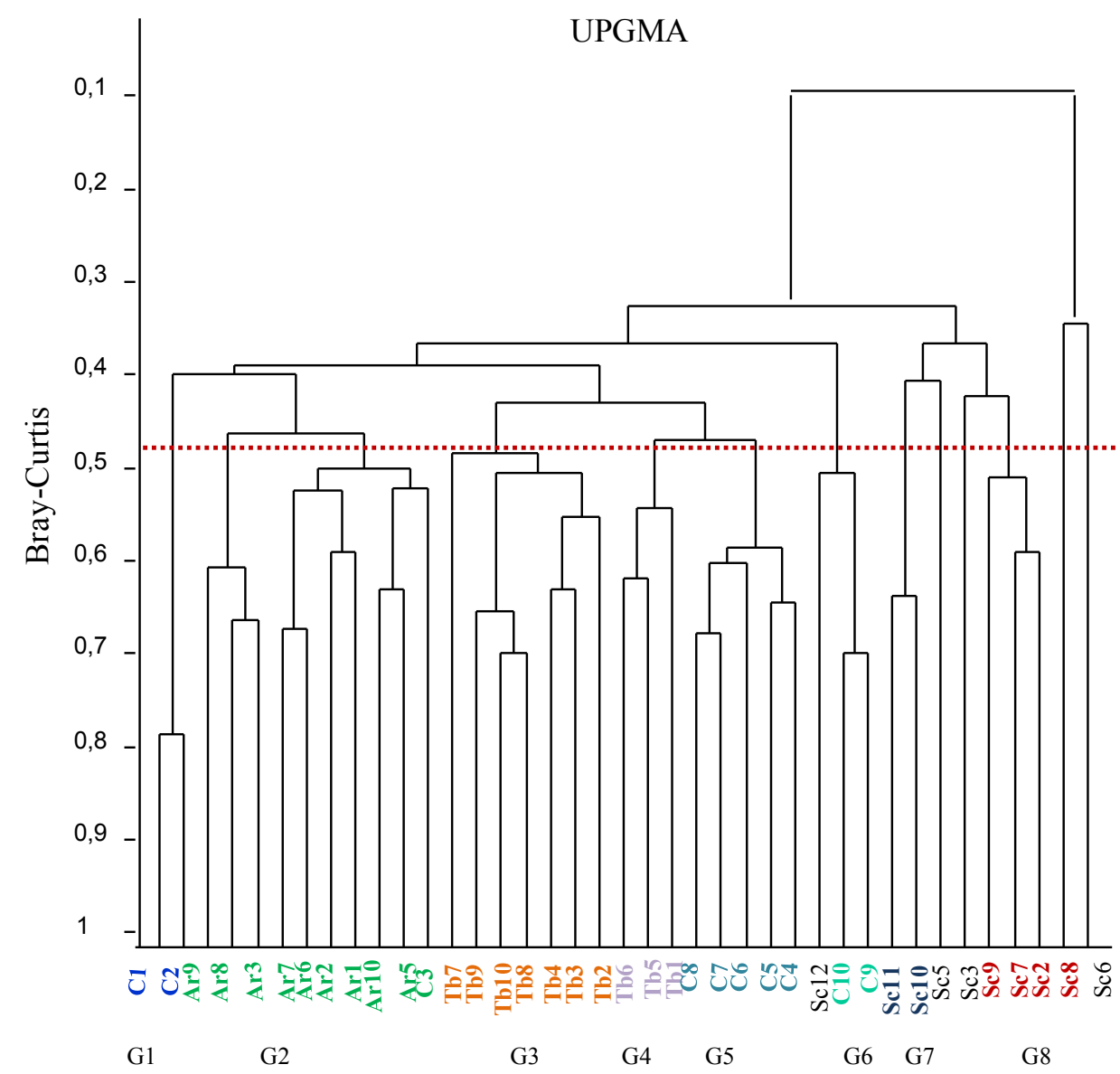

Figura 45 - Dendrograma obtido para as estações amostradas em 2005.

Dados referentes às tanatocenoses.

Com nível de similaridade de 0,45, verificou-se para as estações amostradas no primeiro semestre de 2006 a existência de 9 grupos (Figura 46).

Grupo G1 foi formado pelas estações $\mathrm{C} 1, \mathrm{C} 2$ e C3, localizadas na região norte do Canal de São Sebastião. O grupo G2 compreendeu as estações Tb1 e Tb8. O grupo G3 englobou a maioria das estações amostradas no Araçá - estações Ar2, Ar3, Ar4, Ar7, Ar8 e Ar10. O grupo G4 foi formado pelas estações Tb2, Tb3, Tb4, Tb7 e Tb10. O grupo G5 englobou as estações Tb5, Tb6, Tb9, Ar9, C6 e C8. O grupo G6 abrangeu as estações Sc9, C4, C5 e C7. As estações C9 e C10 foram associadas ao grupo G7 e as estações Sc4 e Sc8 ao grupo G8. O grupo G9, por sua vez, foi formado pelas estações Sc2, Sc3, Sc5, Sc6, Sc7 e Sc11. 


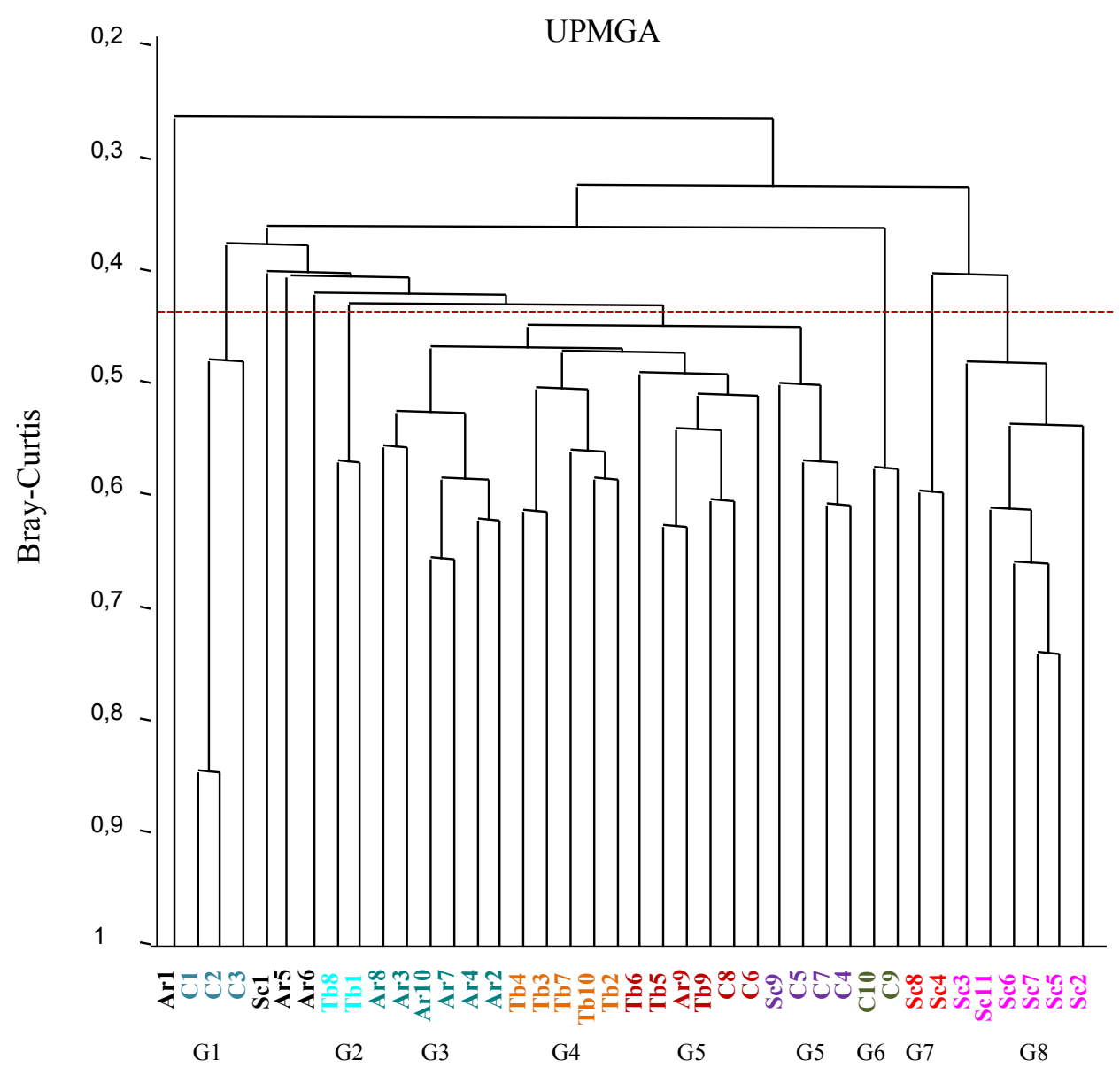

Figura 46 - Dendrograma obtido para as estações amostradas no primeiro semestre de 2006.

Dados referentes às tanatocenoses.

Em relação às estações amostradas no segundo semestre de 2006, com nível de similaridade de 0,50 , verificou-se a ocorrência de 8 grupos (Figura 47). $O$ grupo 1 foi formado pelas estações $\mathrm{C} 1, \mathrm{C} 2, \mathrm{C} 4, \mathrm{C} 5, \mathrm{C} 7, \mathrm{C} 9$ e C10. O grupo G2 foi composto pelas estações C6 e Tb10. O grupo G3 englobou as estações Ar3, Tb1 a Tb8. O grupo G4 abrangeu as estações C8, Ar2, Ar4, Ar6, Ar7, Ar8, Ar9 e Tb9. O grupo G5 foi composto pelas estações C3, Ar5 e Ar10. As estações Sc9 e Sc10 formaram o grupo G6 e as estações Sc4 e Sc8 formaram o grupo G7. Por sua vez, o grupo G8 abrangeu as estações Sc1, Sc2, Sc3, Sc5 e sc7. 


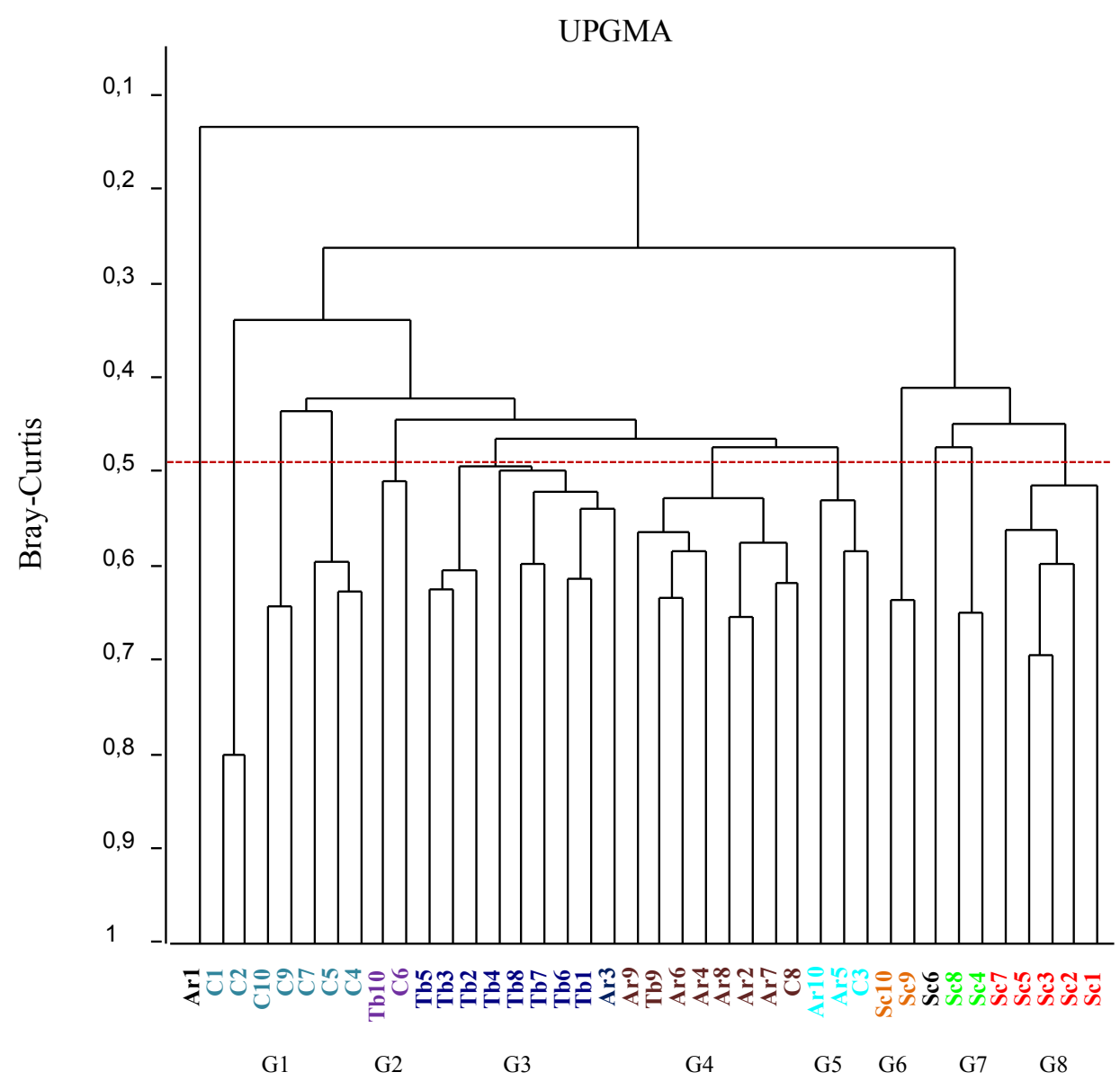

Figura 47 - Dendrograma obtidos para as estações amostradas no segundo semestre de 2006.

Dados referentes às tanatocenoses.

\subsubsection{Análise de Correspondência Canônica}

Os resultados obtidos na Análise de Correspondência Canônica, cuja matriz abrangeu dados de todas as áreas de estudo, indicaram que os principais fatores ambientais que influenciaram a composição e distribuição das associações de foraminíferos foram os teores de areia, os níveis de oxigênio dissolvido, os teores de carbono orgânico total (Cot), de enxofre (S), de nitrogênio (N) e de fósforo total (P) (Figura 48).

Juntos, os Eixos 1 e 2 explicam 80,7\% da variância do relacionamento existente entre as espécies de foraminíferos identificadas nas biocenoses e os parâmetros abióticos. O Eixo 1 explica $60,8 \%$ e o Eixo 2 explica $27,9 \%$ das variâncias existentes (Tabela 16). 
Tabela 16 - Síntese dos resultados obtidos pela Análise de Correspondência Canônica.

\begin{tabular}{lccccr}
\hline \multicolumn{1}{c}{ Eixos } & 1 & 2 & 3 & 4 & Inércia total \\
\hline Autovalores & 0,224 & 0,073 & 0,030 & 0,022 & 1,330 \\
\hline Correlações: espécies - ambiente & 0,834 & 0,791 & 0,700 & 0,608 & \\
Variância em porcentagem acumulada: & & & & & \\
dos dados das espécies & 16,9 & 22,4 & 24,6 & 26,3 & \\
dos dados das espécies e ambiente & 60,8 & 80,7 & 88,9 & 94,8 & \\
\hline
\end{tabular}

Ao lado positivo do Eixo 1 estão associadas as espécies Bulimina marginata, Haynesina germanica, Fursenkoina fragilis, Bulimina elongata, Buliminella elegantissima, Leptohalysis catela, Bolivina compacta, Pseudononion atlanticum, Bolivina ordinaria, Ammonia tepida, Ammonia parkinsoniana, Cassidulina crassa, Cribroelphidium excavatum, Ammotium salsum, Pseudononion opima e Cassidulina subglobosa. Ao lado negativo do Eixo 1 estão associadas as espécies Quinqueloculina milletti, Rosalina floridensis, Brizalina sphatulata, Lobatula lobatula, Discorbis williamsoni, Neocornobina terquemi, Gavelinopsis praegeri, Hanzawaia boueana, Cancris sagra, Angulogerina angulosa, Patelina corrugata, Discobinela berthelotti, Miliolinella subrotunda, Bolivina pseudoplicata e Lepidodeuteramina ochracea.

Ao lado positivo do Eixo 2 relacionaram-se as espécies Brizalina striatula, Fursenkoina pontoni, Cribroelphidium poyeanum, Pararotalia cananeiaensis e Cornuspira involvens. Ao lado negativo, por sua vez, relacionaram-se as espécies Epistominela vitrea, Pseudononion grateloupi, Bolivina doniezi e Hopkinsina pacifica. Gaudryina exilis esteve associada ao lado positivo do Eixo 2 e ao lado negativo do Eixo 1.

O posicionamento das espécies Trochammina squamata, Triloculina levigata $e$ Spirilina vivipara na extremidade do diagrama de ordenação, indica que a distribuição de ambas as espécies ocorre de forma aleatória, ou de acordo com alguma variável ambiental não selecionada pelo programa $C A N O C O$. 


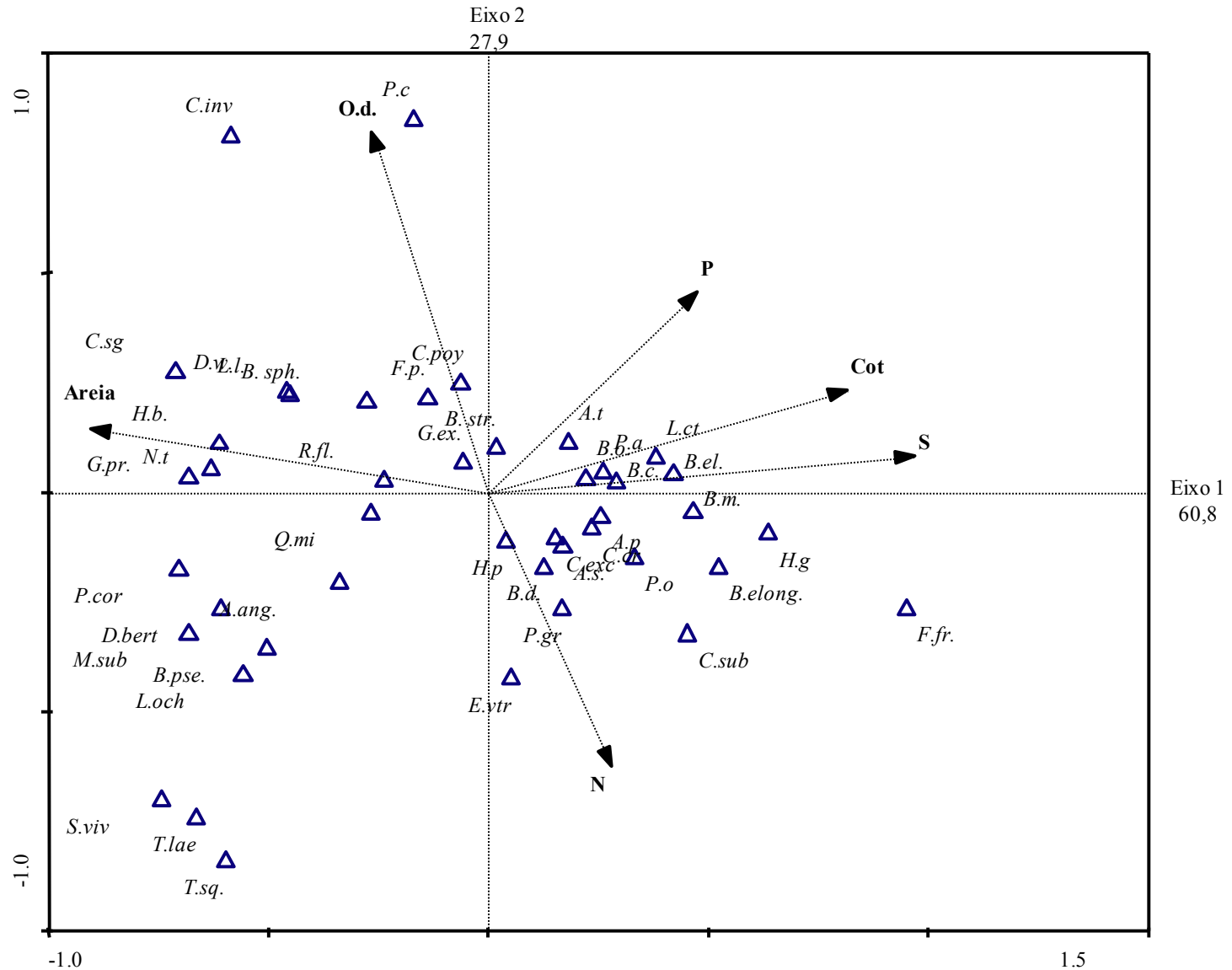

Figura 48 - Diagrama de ordenação da relação existente entre as espécies de foraminíferos que compõem as biocenoses e os parâmetros abióticos.

Legenda: COT (carbono orgânico total), N (nitrogênio), O.d. (oxigênio dissolvido), P (fósforo total), S (enxofre), A.p. (Ammonia parkinsoniana), A.t. (Ammonia tepida), A.s (Ammotium salsum), A.ang. (Angulogerina angulosa), B.c. (Bolivina compacta), B.d. (Bolivina doniezi), B.o. (Bolivina ordinaria), P.pse. (Bolivina pseudoplicata), B. sph (Brizalina sphatulata), B. str. (Brizalina striatula), B. elong. (Bulimina elongata), B.el. (Buliminella elegantissima), B.m. (Bulimina marginata), C. sg (Cancris sagra), C.cr (Cassidulian crasssa), C. sub (Cassidulina subglobosa), C. inv. (Cornuspira involvens), C.exc. (Cribroelphidium excavatum), C.poy (Cribroelphidium poyeanum), D. Bert. (Discorbinella berthelotti), D.w. (Discorbis williamsoni), E.v. (Epistominela vitrea), F. fr (Fursenkoina fragilis), F.p. (Fursenkoina pontoni), G. ex. (Gaudryina exilis), G. PR. (Gavelinopsis praegeri), H.b. (Hanzawaia boueana), H.g. (Haynesina germanica), L. och (Lepidodeuteramina ochracea), L. ct (Leptohalysis catela), L.1. (Lobatula lobatula), M.sub. (Miliolinella subrotunda), N.t. (Neocornobina terquemi), P.c. (Pararotalia cananeiaensis), P.cor. (Patelina corrugata), P.a. (Pseudononion atlanticum), P.gr. (Pseudononion grateloupi), P.o. (Pseudononion opima), Q.mi. (Quinqueloculina milletti), R. fl. (Rosalina floridensis), S.viv. (Spririlina vivipara), T.lae. (Triloculina laevigata) e T.sq. (Trochammina squamata).

O diagrama de ordenação, da relação existente entre as estações e os parâmetros abióticos, permitiu visualizar as características ambientais existentes em cada área de estudo, durante os períodos de amostragem (Figura 49). 


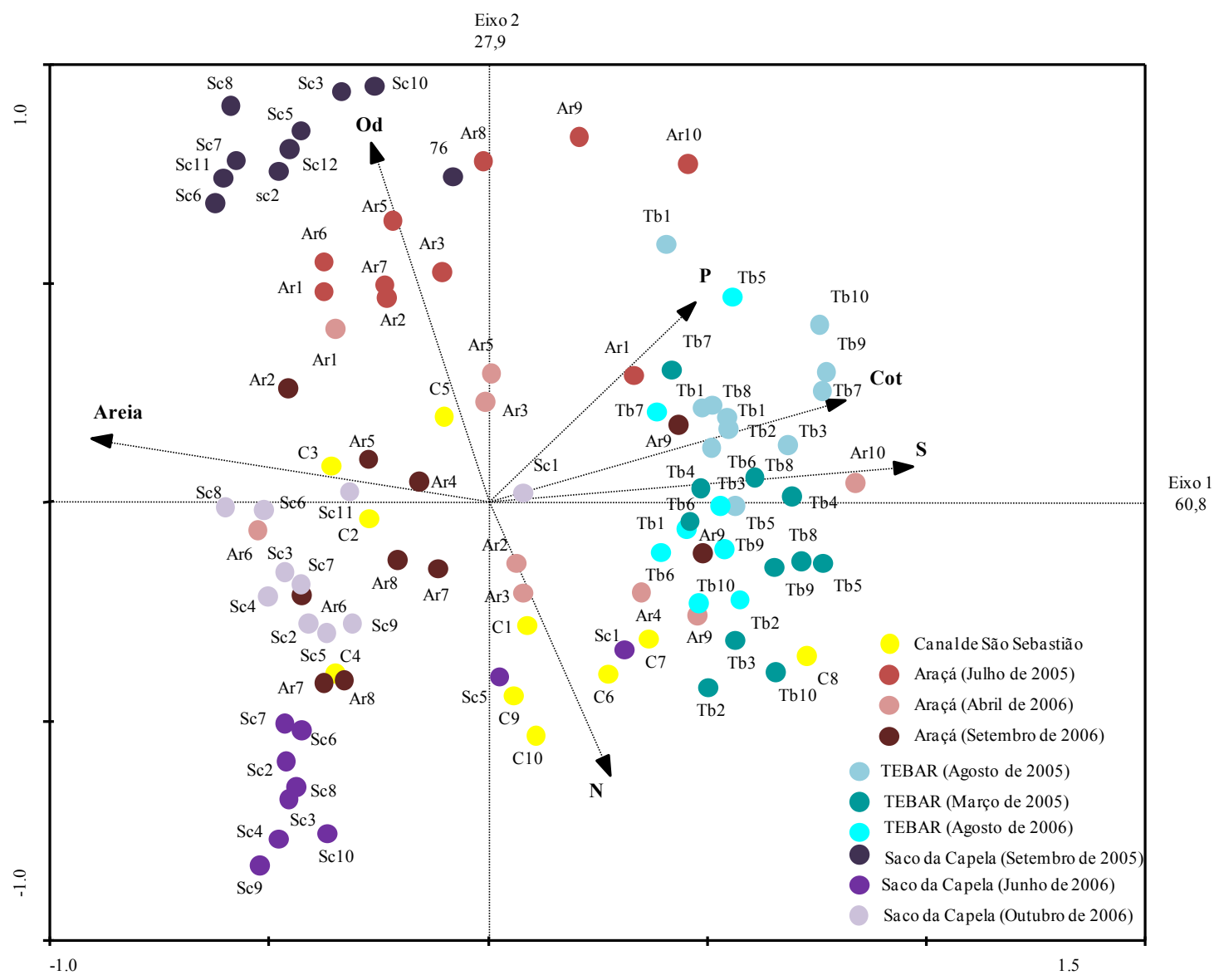

Figura 49 - Diagrama de ordenação obtido para o relacionamento existente entre as estações e parâmetros ambientais.

Pelo posicionamento das estações no diagrama de ordenação, verificou-se que as estações amostradas ao longo do canal estão sob influência de diferentes parâmetros ambientais. As estações C8 e C7 estão relacionaram-se ao lado positivo do Eixo 1, cujas variáveis ambientais indicam ambiente com baixo hidrodinamismo, rico em matéria orgânica e com baixo níveis de oxigenação. As estações C1, C6, C9 e C10 estão localizadas no lado negativo do Eixo 2, indicam ambiente com baixos npiveis de oxigenação na interface águasedimento e teores elevados de nitrogênio. As estações C2 e C3 estão posicionadas em ambiente com maiores teores de sedimentos arenosos, cuja hidrodinamismo inibe a preservação de sedimentos finos. A estação C4 está associada ao lado negativo do Eixo 1 e Eixo 2, indicando ambiente com sedimentos arenosos, concentrações baixas de oxigênio 
dissolvido e teores elevados de nitrogênio. A estação C5, por sua vez, indica maiores níveis de oxigenação, bem como de sedimentos arenosos.

No Araçá, foi possível visualizar as diferentes características ambientais a que a região esteve sujeita. Na primeira amostragem, verificou-se ambiente de maior oxigenação, com teores baixos de nitrogênio, porém teores expressivos de fósforo. No segundo e no terceiro período de amostragem verificou-se que as estações foram posicionadas em ambientes com características hidrodinâmicas diferentes, parte das amostras foi coletada em ambiente com baixa energia de fundo, cujo enriquecimento orgânico é demonstrado pelos teores de carbono orgânico total e enxofre. Em contrapartida, algumas das amostras indicam que ambiente mais energético o que inibe a deposição de matéria orgânica.

Em relação ao TEBAR, todas as amostras de todos os períodos estiveram posicionadas no lado positivo do Eixo 1, cujos parâmetros ambientais indicam baixos níveis de oxigenação da interface água-sedimento e enriquecimento orgânico.

Em relação ao emissário do Saco da Capela, verificou-se para o primeiro período de coleta, que as estações foram amostradas em ambiente predominantemente óxico. Para o segundo período verificou-se como características ambientais os teores baixos de oxigênio dissolvido e os teores expressivos de nitrogênio. Menciona-se, conforme já discutido no Capítulo 5, que a os teores baixos de oxigênio dissolvido na coluna d'água foram de origem natural. Para o terceiro período, verificou-se ambiente com forte hidrodinamismo, o que propiciou teores baixos de matéria orgânica. O enriquecimento orgânico ocorreu de forma pontual, i.e. estação Sc1, localizada na saída do emissário submarino.

\subsection{DISCUSSÃO}

Os resultados obtidos pelas análises estatísticas demonstraram a importância de estudos integrados, os quais realçaram e/ou reforçaram as diferenças composicionais existentes entre as associações de foraminíferos que compuseram as biocenoses. No estudo comparativo entre as estruturas composicionais das biocenoses, os métodos NMDS e MANOVA demonstraram as dissimilaridades existentes entre as áreas de estudo, ao passo que a análise de Agrupamento permitiu a melhor visualização das similaridades existentes. Com a união das duas análises foi possível verificar que apesar de haver espécies similares, as áreas 
de estudo são diferentes em suas composições, as quais refletem as características ambientais e o nível de estresse ambiental de cada local amostrado.

Já a Análise de Correspondência Canônica demonstrou quais são os principais parâmetros ambientais que estão influenciando a distribuição das espécies identificadas.

Conforme observado nos gráficos de ordenação há maior homogeneidade de composição nas biocenoses, o que de fato reflete a dominância de poucas espécies. A heterogeneidade observada nas tanatocenoses, por sua vez, reflete os processos diagenéticos a que as tanatocenoses estão sujeitas. Descritivamente, nas áreas de estudo verificou-se diferença significativa tanto nas abundâncias relativas das principais espécies, bem como alternância de dominância. Por exemplo, no Araçá, Ammonia tepida é a espécie dominante nas biocenoses, ao passo que nas tanatocenoses a espécie dominante é Pararotalia cananeiaensis. Caso a análise para avaliar a influência da disposição oceânica de esgotos domésticos sobre as associações de foraminíferos fosse feita com base na fauna total, as informações obtidas pela composição, pela distribuição, pelas principais espécies, pela morfometria das carapaças não indicariam o estresse ambiental a que a região está sujeita. Mesma situação ocorreria para a região do TEBAR.

Menciona-se, entretanto, que é importante a integração dos resultados obtidos pelas biocenoses e tanatocenoses, pois as informações se complementam e dão um melhor panorama de quais são os fatores ambientais, sejam eles de origem natural e/ou antrópica, a que as regiões estão submetidas.

Comparativamente, verificou-se que as regiões do Araçá e do TEBAR, apesar de disporem efluentes com diferentes composições (domésticos versus petroquímico), são as que mais se assemelham em relação em relação à geoquímica e associações de foraminíferos. Entretanto, como verificado no diagrama de ordenação (Figura 40), parte das estações amostradas no Araçá estão posicionadas em ambiente com maior hidrlodinamismo, motivo pelo qual o estresse ambiental que ocorre na região é observado somente em algumas estações. No TEBAR, entretanto, todas as estações foram amostradas com as mesmas características hidrodinâmicas, a qual se demonstrou pouco enérgica em todos os períodos amostrados. Diante disto, a degradação ambiental a que a região do TEBAR está submetida é bem superior à verificada para o Araçá, conforme foi demonstrado no diagrama de ordenação no relacionamento existente dentre as estações e parâmetros abióticos. 
O emissário do Saco da Capela está posicionado em ambiente com características ambientais opostas às verificadas para as regiões do Araçá e do TEBAR. Conforme observado nos diagramas de ordenação, as biocenoses e tanatocenoses obtidas no Saco da Capela apresentam maior heterogeneidade, devido à ausência de dominância de espécies. $\mathrm{O}$ emissário do Saco da Capela está posicionado em ambiente com forte hidrodinamismo, cujo retrabalhamento dos sedimentos pelas correntes de fundo, propiciam uma constante oxigenação da interface água-sedimento, bem como inibe a deposição de finos e matéria orgânica. Diferentemente do observado para as demais áreas de estudo, o estresse ambiental que há no Saco da Capela ocorre pontualmente e predominantemente na estação posicionada na saída do emissário submarino. Com base no estudo das biocenoses e tanatocenoses os resultados obtidos seriam divergentes, porém em menor nível, o que deve ocorrer devido à ação das correntes de fundo auxiliarem no transporte das carapaças. Com baixo acúmulo de carapaças os resultados possuem menor tendência de serem mascarados.

A disposição oceânica de esgotos está ocasionando o enriquecimento orgânico nas regiões circunjacentes aos emissários submarinos para efluentes domésticos e petroquímicos, entretanto, é importante ressaltar que os níveis de degradação também são favorecidos pelas características oceanográficas de cada região. 


\section{CAPÍTULO 8 - CONCLUSÕES}

As análises geoquímicas e os teores de oxigênio dissolvido evidenciaram que a região central do Canal de São Sebastião é a que apresenta maior enriquecimento orgânico de origem antrópica. Nesta área do canal foram observados os maiores valores de carbono orgânico total, fósforo e enxofre. Além do fato de ser verificado para esta região menor hidrodinamismo, o que auxilia no maior acondicionamento de matéria orgânica, há também a presença significativa de atividades antrópicas, e.g. os emissários submarinos do Araçá, do TEBAR e o porto de São Sebastião. A origem da matéria orgânica, inferida por razões $\mathrm{C} / \mathrm{N}$, é predominantemente marinha na região norte e mista nas regiões central e sul. Já os valores das razões $\mathrm{C} / \mathrm{S}$ e valores de Eh indicaram tendências redutoras para os sedimentos da interface água-sedimento. No tocante às associações de foraminíferos, verificou-se, pelas biocenoses, dominância de espécies euribiontes ao longo do Canal de São Sebastião. Ammonia tepida é a espécie predominante em estações posicionadas no lado continental do canal, sendo, contudo, verificado alternância de espécies para as estações posicionadas na faixa central e no lado insular. Nestas regiões verificou-se maior abundância de Cassidulina spp, Rosalina floridensis e Hanzawaia boueana. De acordo com as abundâncias absolutas de Pararotalia cananeiaensis, espécie predominante nas tanatocenoses, verificou-se a intrusão de águas marinhas, assim como mapeou-se a hidrodinâmica no interior do canal, sendo o resultado semelhante ao observado na literatura. Os resultados das análises morfométricas e tafonômicas realizadas nas carapaças dos foraminíferos corroboram as inferências obtidas pelas análises geoquímicas e granulométricas. Observou-se heterogeneidade no tamanho das carapaças, com aumento de concentração de carapaças médias e pequenas, devido à diminuição de fluxo de sul para norte, com locais de maior hidrodinamismo em estações posicionadas próximas a região insular. De acordo com a abundância de carapaças preenchidas por monossulfeto de ferro/pirita infere-se que há elevada concentração de sedimentos/carapaças relictas, bem como há aporte crônico de matéria orgânica.

Pela integração dos dados granulométricos, geoquímicos e das associações de foraminíferos foi possível caracterizar e diferenciar os ambientes em que os emissários submarinos estão localizados.

O emissário do Saco da Capela está posicionado em ambiente com forte hidrodinamismo, cujas correntes de fundo inibem a preservação de valores significativos de matéria orgânica, bem como propiciam maior oxigenação no compartimento bentônico. Nesta região foram obtidos os menores valores de nutrientes, carbono orgânico total e enxofre. A matéria orgânica existente na região é considerada como sendo predominantemente de origem marinha. Os resultados das razões $\mathrm{C} / \mathrm{S}$, por sua vez, conferiram características oxidantes para os sedimentos de fundo. Em relação às associações de foraminíferos, no Saco da Capela 
foram verificados os maiores valores de diversidade específica e equitatividade, o que se deve a ausência de espécies dominantes. Os níveis de oxigenação, os teores de areia e o nitrogênio são os principais parâmetros abióticos que estão influenciando a composição e distribuição das biocenoses. Excetuando a estação Sc1 (Outubro de 2006), localizada na saída do emissário, espécies epifaunais e biondicadoras de ambiente bem oxigenado foram predominantes em todas as estações. Nas biocenoses e tanatocenoses os resultados das análises morfométricas são parecidos e refletem as características ambientais da região. A predominância de carapaças impregnadas por óxido/hidróxido de ferro corroboram os resultados das análises geoquímicas, bem como as inferências realizadas pelas associações de foraminíferos. O efeito negativo do esgoto disposto na região ocorre de forma pontual, i.e. na saída do emissário submarino. Na estação Sc1 foram obtidos os maiores valores de carbono orgânico total e enxofre. A matéria orgânica oscila entre mista e continental, sendo os sedimentos caracterizados como redutores. A influência adversa do efluente também é observada nos foraminíferos. $\mathrm{Na}$ estação $\mathrm{Scl}$ observou-se predomínio de espécies euribiontes (Outubro de 2006), sendo Ammonia tepida e Brizalina striatula as espécies mais abundantes.

O emissário do Araçá está posicionado em ambiente com circulação de fundo oscilando entre fraca e moderada. Pelo padrão de distribuição da granulometria e da geoquímica, em Abril e Setembro de 2006, verificou-se diminuição da circulação de fundo de sudoeste para nordeste, o que indica que possivelmente há retorno do efluente disposto pelo emissário para o interior do Araçá. A influência do esgoto disposto foi evidenciada pelos teores elevados de enxofre e fósforo, os quais foram inferidos como sendo oriundos da disposição oceânica de esgotos. A degradação ambiental que há na região foi observada pelo potencial redox e pelas razões $\mathrm{C} / \mathrm{S}$. Segundo os valores obtidos infere-se ambiente com características redutoras, com decomposição por anaerobiose da matéria orgânica, a qual predominantemente continental e mista. A baixa qualidade dos sedimentos reflete-se nas associações de foraminíferos. Nas biocenoses, verificou-se, domínio de espécies euribiontes em toda a área analisada. Entre os períodos analisados verificou-se declínio gradual de espécies estenobióticas, as quais estiveram em abundâncias inexpressivas e/ou ausentes na região sob maior influência do esgoto disposto. O maior nível de degradação ambiental foi observado em Setembro, período em que foram observadas as menores densidades. Para a obtenção de um $\mathrm{n}_{\text {amostral }}$ mínimo, foram analisados $210 \mathrm{~cm}^{3}$ de sedimento, sendo Ammonia tepida e Buliminella elegantissima as espécies mais abundantes. Nesta estação, nas tanatocenoses, observou-se dominância de espécies aglutinantes (Gaudryina exilis), bem como verificou-se sinais de dissolução nas carapaças de espécimes hialinos.

Comparativamente, o emissário do TEBAR é o que apresenta maior nível de degradação ambiental. Em todos os períodos analisados, foram obtidos valores elevados de carbono orgânico total, fósforo e enxofre. As condições redutoras da interface água-sedimento 
são evidenciadas pelos valores de Eh, pelos valores levemente ácidos do $\mathrm{pH}$ e pelas razões C/S. A matéria orgânica foi identificada como mista e continental. O estresse ambiental que há na região reflete-se na composição, na morfologia e na morfometria das carapaças dos foraminíferos. No TEBAR observou-se dominância de espécies oportunistas, típicas de ambientes hipóxicos. Ammonia tepida é a espécie dominante seguida por Buliminella elegantissima. Nas biocenoses e tanatocenoses foram observadas elevadas porcentagens de organismos pequenos com carapaças de paredes finas. Nas tanatocenoses, foraram observadas porcentagens elevadas de carapaças preenchidas por monossulfeto de ferro/pirira, o que confere para o TEBAR características de ambiente redutor, com aporte crônico de matéria orgânica, o que corrobora as inferências feitas pelas análises geoquímicas.

Os estudos uni e multivariado indicaram que as regiões do Araçá e do TEBAR são as que mais se assemelham em relação à geoquímica e composição das associações de foraminíferos, apesar de disporem efluentes com diferentes composições.

Descritivamente e pelas análises estatísticas, foram verificadas diferenciações significativas na estrutura composicional das associações de foraminíferos, quando as biocenoses e tanatocenoses são comparadas entre si e, principalmente, quando as biocenoses são comparadas com as tanatocenoses. Caso a análise para avaliar a influência da disposição oceânica de esgotos sobre as associações de foraminíferos fosse feita com base na fauna total (biocenoses + tanatocenoses) as informações seriam divergentes, e não seriam condizentes com o nível de estresse ambiental a que cada região está submetida. Ressalta-se, entretanto, a necessidade de integração dos resultados obtidos pelas tanatocenoses e biocenoses, uma vez que as informações tendem a se complementar e fornecem um panorama mais amplo sobre as características ambientais de cada região.

Diante do exposto, infere-se que a disposição oceânica de esgotos domésticos e petroquímicos está ocasionando degradação ambiental no compartimento bentônico das regiões circundantes aos emissários submarinos, o que se deve a ineficiência dos sistemas de tratamento. Ressalta-se, entretanto, que os níveis de degradação tendem a ser agravados pelas características oceanográficas de cada região. 


\section{REFERÊNCIAS BIBLIOGRÁFICAS}

ABESSA, D. M. S.; CARR, R. S.; RACHID, B. R. F.; SOUSA, E. C. P. M.; HORTELANI, M. A.; SARKIS, J. E. Influence of a Brazilian sewage outfall on the toxicity and contamination of adjacent sediments. Marine Pollution Bulletin 50:875-885. 2005.

AIDAR, E.; GAETA, S.A.; GIANESELLA-GALVÃO, S.; KUTNER, M.B.B.; TEIXEIRA, C. Ecossistema costeiro subtropical: nutrientes dissolvidos, fitoplâncton e clorofila $a$ e suas relações com as condições ocenaográficas na região de Ubatuba, SP.Publicação Especial do instituto Oceanográfico, 19:9-43. 1993.

ALAVI, S. N. Late Holocene deep-sea benthic foraminifera from Sea of Marmara. Marine Micropaleontology, v. 13, p. 213-237, 1988.

ALLER, R.C.; HANNIDES, A.; HEILBRUN, C.; PANZECA, C. Coupling of early diagenetic processes and sedimentary dynamics in tropical shelf environments: the Gulf of Papua deltaic complex. Continental Shelf Research, v. 24, p. 2455-2486, 2004.

ALMEIDA, F.F.M.; HASUI, Y.; PONÇANO, W.L.; DANTAS, A.S.L.; CARNEIRO, C.R.; MELO, M.S.; BISTRICHI, C.A. Mapa geológico do Estado de São Paulo, escala: 1:5000.000 V.I. - Nota explicativa. IPT-DMGA, 126p. (Monografia 6), 1981.

ALOUlOU, F.; ELLEUCH, B.E.; KALLEL, M. Benthic foraminiferal assemblages as pollution proxies in the northern coast of Gabes Gulf, Tunisia. Environmental Monitoring and Assessment

ALTENBACH, A. V.; LUTZE, G. F.; SCHIEBEL, R.; SCHÖNFELD, J. Impact of interrelated and independent ecological controls on benthic foraminifera: an example from the Gulf of Guinea. Palaeogeography, Palaeoclimatology, Palaeoecology, v. 197, p. 213238, 2003.

ALVE, E. Benthic foraminifera in sediment cores reclecting heavy metal pollution in SØrfjord, Western Norway. Journal of Foraminiferal Research, 21: 1-19.1991.

ALVE, E. Benthic foraminiferal responses to estuarine pollution: A review. Journal Foraminiferal Research, 25, p. 190-203.1995.

ALVE, E., BERNHARD, J. M. Vertical migratory response of benthic foraminifera to controlled oxygen concentrations in an experimental mesocosm. Marine Ecology-Progress Series, v. 116, p. 137-151, 1995. 
ALVE, E.; MURRAY, J. Ecology and taphonomy of benthic foraminifera in a temperate mesotidal inlet. Journal of Foraminiferal Research, v. 24, p. 18-27, 1994

AMARAL, G.; CORDANI, U.G.; KAWASHITA, K. "Potassium-Argon data os Basaltic rocks from Southern Brazil”. Geochemical, Cosmochemical Acta, 31:117-142. 1966.

AMARAL, A.C.Z., DENADAI, M.R., TURRA, A. \& RIZZO, A.E. Intertidal macrofauna in Brazilian subtropical sandy beaches landscape. Journal Coastal Research. 35:446-455. 2003.

AMERICAN PUBLIC HEALTH ASSOCIATION (APHA). Standard methods for the examination of water and wastewater. Washington, $19^{\text {th }}$ ed. 1995.

ARMYNOT du CHÂTELET, E.; DEBENAY, J.P. The anthropogenic impact on the western French coasts as revealed by foraminifera: A review. Revue Micropaléontologie, 53: 129137. 2010.

ARMYNOT DU CHÂTELET, E.; DEBENAY, J. P. ; SOULARD, R. Foraminiferal proxies for pollution monitoring in moderately polluted harbors. Environmental Pollution, v. 127, p. $27-40,2004$.

ARMYNOT DU CHÂTELET, E.; BOUT-ROUMAZEILlES, V.; RBOULLEAU, A.; Trentesaux, A. Sediment (grain size and clay mineralogy) and organic matter quality control on living foraminifera. Revue de Micropaléontologie, 52, p. 75-84, 2008.

ASTON, S.R., HEWITT, C. N. Phosphorus and carbon distributions in a polluted coastal environment. Estuarine and Coastal Marine Science, v. 5, p. 243-254, 1977.

Bader, R.G. 1955. Carbon and nitrogen relations in surface and subsurface marine sediments. Geochimica Cosmochimica Acta, 7 (5/6), 205-211.

BAIRD, C. Química ambiental. Porto Alegre: Bookam, 2002, 622 p.

BARCELLOS, R. L.; FURTADO, V.V. Caracterização dos componentes da fração arenosa (0,500 mm/0,250 mm) no Canal de São Sebatião. Pesquisas em Geociências, 28:35-51, 2001.

BARCELLOS, R. L. Processo sedimentar atual e a distribuição de matéria orgânica sedimentar no Canal de São Sebastião e plataforma continental interna adjacente, 2000, 187 p. Dissertação de Mestrado, Instituto Oceanográfico, Universidade de São Paulo.

BARMAWIDJAJA, D. M., van der ZWAAN, G. J., JÖRISSEN, F. J., PUSKARIC, S. 750 years of eutrophication in the northern Adriatic Sea: evidence from a benthic foraminiferal record. Marine Geology, v. 122, p. 367-384, 1995. 
BATURIN, G.N. Phosphorus cycle in the ocean. Lithology and Mineral Resources, v . 38, p. 101-119, 2003.

BERNER,R.A. 1970. Sedimentary pyrite formation. American Journal Science, 268:1-23.

BERNHARD, J. M.; SEN GUPTA, B. K. Foraminifera of oxygen-depled environments. In: Sen Gupta, B. K. (Ed.), Modern Foraminifera, Kluwer Academic Publishers, 1999, p. 201216.

BERNHARD, J. M.; REIMERS, C. E. Benthic foraminiferal population fluctuations related to anoxia: Santa Barbara Basin. Biogeochemistry, v. 15, p. 127-149, 1991.

BERNHARD, J. M.; SEN GUPTA, B. K. Foraminifera of oxygen-depled environments. In: Sen Gupta, B. K. (Ed.), Modern Foraminifera, Kluwer Academic Publishers, 1999, p. 201 216.

BERNHARD, J.M. Benthic foraminiferal distribution and biomass related to pore-water oxygen content: Central California Continental Slope and Rise. Deep-Sea Research, 39: 585-605. 1992.

BOLTOVSKOY, E.; GIUSSANI, G.; WATANABE, S.; WRIGHT, R. Atlas of benthic shelf foraminifera of southwest Atlantic. Netherlands, Dr. W. Junk, 1980, 147p.

BOLTOVSKOY, E. 1958. Foraminifera as biological indicators in the study of ocean currents. Micropaleontology, 5: 473-481.

BOLTOVSKOY, E. Foraminifera as biological indicator in the study of ocean currents. Departamento de Oceanografia Servício de Hidrografia Naval Buenos Aires, Argentina. Micropaleontology, v. 5, p. 473 - 481, fig. 1, pls. 1 - 3, 1959.

BONETTI, C. 2000. Foraminíferos como bioindicadoras do gradiente de estresse ecológico em ambientes costeiros poluídos. Estudo aplicado ao sistema estuarino de Santos-São Vicente (SP, Brasil). Tese de Doutorado. Instituto Oceanográfico, Universidade de São Paulo, SP, 229p.

BONFANTE, R. L.; DULEBA, W.; MAHIQUES, M. M. 2005. Dinâmica de fundo da Enseada do Flamengo, Ubatuba, Brasil, inferida a partir da distribuição espacial, morfometria e tafonomia de foraminíferos. Revista Brasileira de Paleontologia, 8 (3): 181192.

BORDOVSKIY, O. K. Accumulation of organic matter in bottom sediments. Marine Geology, v. 3, p. 33-82, 1965. 
BORREGO, J.; LOPES, M.; PENDON, J. G.; MORALES, J. A. C/S ratios is estuarine sediments of the Odiel River-mouth, S. W. Spain. Journal of Coastal Research, v. 14, p. 1276-1283, 1998.

BOUCHET, V.; DEBENAY, J. P.; SAURIAU, P. G.; RADFORD-KNOERY, J.; SOLETCHNIK, P. Effects of short-term environmental disturbances on living benthic foraminifera during the Pacific oyster summer mortality in the Marennes Oléron Bay (France). Marine Environmental Research, v. 64, p. 358-383, 2007.

HERMELIN, J. O. R.; SHIMMIELD, G. B. The importance of the oxygen minimum zone and sediment geochemistry in the distribution of recent benthic foraminifera in the northwest Indian Ocean. Marine Geology, v. 91, p. 1-29, 1990.

BRADSHAW, J. S. Laboratory experiments in the ecology of foraminifera. Contributions from the Cushman Foundation for Foraminiferal Research, v. 12, p. 87-106, 1961.

BRASIL-LIMA, G. M. S. de S. Efeitos do efluente doméstico do emissário submarino de São Sebastião (SP), sobre o fitoplâncton marinho: estudos de campo e de laboratório. Tese (Doutorado) - Instituto Oceanográfico, Universidade de São Paulo, São Paulo, 160 p. 1998. BUBENSHCHIKOVA, N.V.; NURNBERG, D.; GORBARENKO, S.A.; LEMBKE-JENE, L. Variations of the oxygen minimum zone of the Okhotsk Sea during the last $50 \mathrm{ka}$ as indicated by benthic foraminiferal and biogeochemical data. Marine Geology, 50:93-106. 2010.

BURONE, L.; PIRES-VANIN, A. M. S. Foraminiferal assemblages in Ubatuba Bay, southeastern Brazilian coast. Scientia Matina, v. 70, p. 203-217, 2006.

BURONE, L.; VENTURINI, N.; SPRECHMANN, P.; VALENTE, P.; MUNIZ, P. Foraminiferal responses to polluted sediments in the Montevideo coastal zone, Uruguay. Marine Pollution Bulletin, v. 52, p. 61-73, 2006.

BURONE, L.; VALENTE, P.; PIRES-VANIN, A. M.; SOUSA, S. H. M.; MAHIQUES, M. M.; BRAGA, E. Scientia Marina, v. 71, p. 775-792, 2007.

BUZAS, M. A.; HAYEK, L.-A. C.; REED, S. A.; JETT, J. A. Foraminiferal densities over five years in the Indian River Lagoon, Florida: a model of pulsating patches: Journal of Foraminiferal Research, v. 32, p. 68-92, 2002.

BUZAS-STEPHENS,P.; BUZAS, M. A.; ELLIOT, B.A. Foraminiferal populations response to fluctuating inflow into Nueces Bay, TEXAS. Journal of Foraminiferal Research, 41: 1421. 2011. 
CABRERA, L. C. Formas de enxofre na coluna d'água e sedimentar numa enseada rasa do estuário da Lagoa dos Patos. Dissertação (Mestrado) - Fundação Universidade do Rio Grande, Oceanografia Física, Química e Geológica. 2005, 104 p.

CARREIRA, R. S.; WAGENER, A. L. R. 1998. Speciation of sewage derived phosphorus in coastal sediments from Rio de Janeiro, Brazil. Marine Pollution Bulletin, 36 (10), 818-827.

CASTRO FILHO, B.M. Subtidal response to wind forcing in the South Brazil Bight during the winter. PH.D. Dissertation. RSMAS University of Miami, 211 p.1985.

CASTRO FILHO, B.M. Wind driven currents in the Channel of São Sebastião: winter 1979. Boletim do Instituto Oceanográfico, São Paulo, 38:111-132, 1990.

CATTENA, C. O. Avaliação do potencial trófico das águas adjacentesao terminal aquaviário de São Sebastião (SP) e da toxicidade de seus efluentes sobre o fitoplâncton. Tese (Doutorado) - Instituto Oceanográfico, Universidade de São Paulo, São Paulo, 120p. 2003.

CEARRETA, A.; IRABIEN, M. J.; LEORRI, E.; YUSTA, I.; QQUINTANILHA, A.; ZABALETA, A. Environmental transformation of the Bilbao estuary, N. Spain: microfaunal and geochemical proxies in the recent sedimentary record. Marine Pollution Bulletin, v. 44, p. 487-503, 2002.

CESAR, A.; CHOUERI, R. B.; RIBA, I.; MORALLES-CASELLES, C.; PEREIRA, C. D. S.; SANTOS, A. R.; ABESSA, D. M. S.; DEVALlS, T. A. 2007. Comparative sediment quality assessment in different littoral ecosystems from Spain (Gulf of Cadiz) and Brazil (Santos and São Vicente estuarine systems). Environmental International, 33: 429-435.

COMPANHA AMBIENTAL DO ESTADO DE SÃO PAULO (CETESB). Qualidade das águas litorâneas no Estado de São Paulo: Balneabilidade das praias 2004/CETESB. São Paulo: CETESB, 2005, 331p.COMPANHA AMBIENTAL DO ESTADO DE SÃO PAULO (CETESB). Relatório de monitoramento de emissário submarino. Série Relatório, Secretaria de Estado do Meio Ambiente, 116 p. 2007. Site: http://www.cetesb.sp.gov.br/Agua/praias/publicacoes.asp

COMPANHA AMBIENTAL DO ESTADO DE SÃO PAULO (CETESB). Relatório de Qualidade das praias litorâneas no Estado de São Paulo, 2008/CETESB. São Paulo, 2008, $330 \mathrm{p}$.

COMPANHA AMBIENTAL DO ESTADO DE SÃO PAULO (CETESB). Relatório de Qualidade das praias litorâneas no Estado de São Paulo, 2008/CETESB. São Paulo, 2009, $167 \mathrm{p}$. 
CHERCHI, A.; da PELO, S.; IBBA, A.; MANA, D.; BUOSI, C. FLORI, N. 2009. Benthic foraminífera response and geochemical characterization of the coastal environment surrounding the polluted industrial area of Portovesme (South-Western Sardinia, Italy). Marine Pollution Bulletin, 59: 281-296.

COCCIONI, R.; FRONTALINI, F.; MARSILI, A.; MANA, D. 2009. Benthic foraminífera and trace element distribution: A case-study from the heavily polluted lagoon of Venice (Italy). Marine Pollution Bulletin, 59: 257-267.

CONNEL, D. W.; MILLER, G. J. Chemistry and eCotoxicology of pollution. New York: John Wiley and Son, 1984, 444 p.

CONSELHO DE AUTORIDADE PORTUÁRIA (CAP). Plano de Desenvolvimento e Zoneamento do Porto de São Sebastião, São Paulo. Disponível em: $<$ http://www.portodesaosebastiao.com.br/documenta/PDZ-PORTO-DE-AOSEBASTIAO08-09.pdf $>$ Acessado em: 17 de novembro de 2009.

CONSELHO NACIONAL DO MEIO AMBIENTE (CONAMA). Resolução 357 de 2005.

CONSELHO NACIONAL DO MEIO AMBIENTE (CONAMA). Resolução 359 de 29 de abril de 2005.

CONTI, L. A. Aplicação de técnicas de geoprocessamento na caracterização de aspectos morfossedimentares do Canal de São Sebastião, litoral norte do estado de São Paulo. 1998. 84 p. Dissertação (Mestrado) - Instituto Oceanográfico, Universidade de São Paulo, São Paulo.

CORLISS, B.H.; EMERSON, S. Distribution of Rose Bengal stained deep-sea benthic foraminifera from the Nova Scotian continental margin and Gulf of Maine. Deep-Sea Research, 37:381-400.

DEBENAY, J.P.; EICHLER, B. B.; FERNANDEZ-GONZALEZ, M.; MATHIEU, R.; BONETTI, C. ; DEULEBA, W., 1996, Les foraminfères paraliques des côtes d'afrique et d'amerique du sud, de part et d'autre de l'atlantique: comparaison-discussion, in Jardiné, S., de Klasz, I. and Debenay, J.P. (eds.), Géologie de l'Afrique et de l'Atlantique sud: Mémoire Elf Aquitaine, Edition, Pau, v. 16, p. 463-471.

DEBENAY, J. P.; ANDRE, O. ; BEZIE, S. ; RAMBAUD, S. Foraminifers used as bioindicators in La Turballe harbor (Loire Atlantique, France). COASTAL ZONE MONITORING AND MEDIUM TO LONG TERM FORECASTING, FRENCHJAPANESE INTERNATIONAL SYMPOSIUM, 1997, Paris, October 6-8, Abstracts. 
DEBENAY, J. P.; EICHELER, B.B.; DULEBA, W.; BONETTI, C.; EICHLER, P. P. 1998. Sensivity of foraminifera to stratification of water masses in shallow coastal lagoon. Marine Micropaleontology, 35, p. 67-89.

DEBENAY, J. P.; DUleBA, W.; BONETTI, C., SOUZA, S. H. M.; EICHLER, B. Pararotalia cananeiaensis N. SP.: indicartor of marine influence and water circulation in Brazilian coast and paralic environments. Journal of Foraminiferal Research, v. 31, p. 152$163,2001$.

DEBENAY, J. P.; FERNANDEZ, J-M. Benthic foraminífera records of complex anthropogenic environmental changes combined with geochemical data in a tropical bay of New Caledonia (SW Pacific). Marine pollution Bulletin, 59:311-322.2009

DIZ, P.; FRANCÉS, G.; ROSÓN, G. Effects of contrasting upwelling-downwlling on benthic foraminiferal distribution in the Ría de Vigo (NW Spain). Journal of Marine Systems, v. 60, p. 1-18, 2006.

DIZ, P.; FRANCÉS, G.; Distribution of live benthic foraminifera in the Ría de Vigo (NW Spain). Marine Micropaleontology, 66:165-191, 2008.

DULEBA, W.; DEBENAY, J. P. Hydrodynamic circulation in the estuaries of estação ecológica Juréia-Itatins, Brazil, inferred from foraminifera and thecamoebian assemblages. Journal Foraminiferal Research, v. 33, p. 62 - 93, 2003.

DUlEBA, W.; COIMBRA, J. C.; PETRI, S.; BARBOSA, C. F. 2005. Foraminíferos tecamebas e ostracodes recentes utilizados como bioindicadores em estudos ambientais brasileiros. In: SOUSA, C. R. G.; SUGUIO, K.; SANTOS, M.; OLIVEIRA, P. E. Quaternário do Brasil. Ribeirão Preto: Editora Holos, 2005, capítulo 9.

DULEBA, W. Interpretações paleoambientais obtidas a partir das variações na coloração das carapaças de foaminíferos, da Enseada do Flamengo, SP. Boletim do Instituto Oceanográfico, São Paulo, 42:63-72, 1994.

ENVIRONMENTAL PROTECTION AGENCY (EPA) "Strategy for Water Quality Standards and Criteria: Setting Priorities to Strengthen the Foundation for Protecting and Restoring the Nation's Waters" US Environmental Protection Agency, Washington, D.C.

ESTEVES, F. Fundamentos de limnologia. Rio de Janeiro: Interciência, 2a . edição, 1998. 
FAGANELLI, J.; MALEJ, A.; PEZDIC. J..; MALACIC, V. C:N:P ratios and stable C isotopic ratios as indicator of sources of organic matter in the Gulf of Trieste (northern Adriatic). Oceanologia Acta, v. 11, p. 377-382, 1988.

FENCHEL, T., FINLAY, B. J. Ecology and evolution in anoxic worlds. Oxford University Press. Oxford. 1995

FERRARO, L.; SPROVIERIL, M.; ALBERICO, I.; LIRER, F.; PREVEDELLO, L.; MARSELLA, E. Benthic foraminifera and heavy metals distribution: A case study from de Naples Harbour (Tyrrhenian Sea, Southern Italy). Environmental Pollution, v. 142, p. 274 287, 2006.

FILIPPOS, L. S. Estudo geoquímico e microfaunístico da região circunjacente ao emissário submarino de esgoto das Cigarras, São Paulo, SP. Dissertação (Mestrado) - Instituto de Geociências, Universidade de São Paulo, São Paulo, 151p, 2010.

FOLK, R. R.; WARD, W. C. Brazos river bar: study of significance of grain size parameters. Journal of Sedimentary Petrology, v. 17, p. 3-27, 1957.

FONTES, R. F. C. As correntes do Canal de São Sebastião. Dissertação (Mestrado) Instituto Oceanográfico, Universidade de São Paulo, São Paulo. 159p. 1995

FORTIS, M. R. Modelagem computacional da dispersão da pluma do efluente dos emissários submarinos do TEBAR - Petrobras. Dissertação (Mestrado) Escola Politécnica Universidade de São Paulo, São Paulo, 2005.

FRONTALINI, F.; COCCIONI, R.. Benthic foraminífera for heavy metal pollution monitoring: A case study from the central Adriactic Sea cost of Italy. Estuarine, Coastal and Shelf Science, 76 (2): 404-417.2008

FRONTALINI, F.; COCCIONI, R. Benthic foraminifera as bioindicators of pollution: A review of Italian research over the last three decades. Revue de Micropaléontologie, in press, 2011

FUNDAÇÃO DE ESTUDO E PESQUISAS AQUÁTICAS (FUNDESPA). Levantamento oceanográfico da área diretamente afetada por efluentes dos emissários submarinos de esgotos da SABESP, entre os municípios de São Sebastião e Mongaguá, Estado de São Paulo. 1999, 364 p.

FUNDAÇÃO DE ESTUDO E PESQUISAS AQUÁTICAS (FUNDESPA). Avaliação da biota aquática, consolidação de dados secundários e modelagem hidrodinâmica para 
subsidiar o licenciamento da expansão do porto em São Sebastião. Relatório Técnico, 458p. 2009.

FURTADO, V.V. Contribuição ao estudo da sedimentação atual no Canal de São Sebastião, Estado de São Paulo. 2 vol. Tese (Doutorado) - Instituto Oceanográfico, Universidade de São Paulo. 1978

FURTADO, V. V. Sedimentação quaternária no Canal de São Sebastião. Publicação Especial, Instituto Oceanográfico da Universidade de São Paulo, 11, p. 27-35, 1995.

FURTADO, V. V.; BARCELLOS, R. L.; CONTI, L. A.; RODRIGUES, M.; MAHIQUES, M. M. Sedimentação. In: PIRES-VANIN, A. M. Oceanografia de um ecossistema subtropical: Plataforma de São Sebastião, SP. Editora da Universidade de São Paulo (EDUSP), 2008, p. 141-180.

GARDA, G.M. Os diques básicos e ultrabásicos da região costeira entre as cidades de São Sebastião e Ubatuba, Estado de São Paulo. Tese (Doutorado) - Instituto de Geociências, Universidade de São Paulo, 156p. 1995.

gauch, H. G.. Multivariate analysis in community ecology. Cambridge: Cambridge University Press. 1982

GIANESELLA, S.M.F.; KUTNER, M.B.B. SALDANHA-CORRÊA, F.M.; POMPEU, M. Assessment of plankton community and environmental conditions in São Sebastião Channel prior to the construvtion of a produced water outfall. Revista Brasileira de Oceanografia, 47: 29-46.1999

GONÇALVES, F.B.; SOUZA, A.M. Disposição oceânica de esgotos sanitários: história, teoria e prática. Associação Brasileira de Engenharia Sanitária, Rio de Janeiro, 348p, 1997.

GROSS, M. G. Carbon determination. In: CARVER, R. E. Procedures in sedimentary petrology. New York: Wiley, 1971, p. 573-596.

GUbitoso, S; DUleBA, W; TEODORO, A. C.; PRADA, S. M.; ROCHA, M. M.; LAMPARELLI, C. C.; BEVILACQUA, J. E.; MOURA, D. O. Estudo geoambiental da região circunjacente ao emissário submarino de esgoto do Araçá, São Sebastião (SP). Revista Brasileira de Geociências, v. 38, p. 467-475, 2008.

GUBITOSO, S. Influência de efluentes domésticos e petroquímicos em sedimentos e carapaças de foraminíferos do Canal de São Sebastião, SP. Dissertação (Mestrado) Instituto de Geociências, Universidade de São Paulo, 128p, 2010. 
HAMMER, Ø., HARPER; D.A.T.; RYAN, P. D.PAST: Paleontological Statistics Software Packagefor Education and Data Analysis. Palaeontologia Electronica 4(1): 9pp.2001

HEITOR, S.R. Composição e distribuição da macrofauna bentônica em áreas sob influência da disposição oceânica de esgotos municipais na Baixada Santista e no Canal de São Sebastião, São Paulo, Brasil. Tese (Doutorado) - Instituto Oceanográfico, Universidade de São Paulo, 245p, 2002.

INSTITUTO BRASILEIRO DO MEIO AMBIENTE E DOS RECURSOS NATURAIS RENOVÁVEIS (IBAMA) GEO Brasil - Perspectivas do Meio Ambiente no Brasil. Brasília, 409p. 2002.

INTERNATIONAL ASSOCIATION OF OIL AND GAS PRODUCERS (OGP). 2002. Aromatics in produced water: occurrence, fate, effects and treatment. Report nr. 1.20/324.

JORISSEN, F. J. 1999. Benthic foraminiferal microhabitats below the sediment-water interface. In Sen Gupta, B. K. (Ed.), Modern Foraminifera. Kluwer Academic Publishers, Dordrecht, pp. 161-179.

JORISSEN, F. J.; STIGETER, H. C.; WIDMARK, J. G. V. 1995. A conceptual model explaining benthic foraminiferal microhabitats. Marine Micropaleontology, 26: 3-15.

KAIHO, K. Benthic foraminiferal dissolved-oxygen index and dissolved-oxygen levels in the modern ocean. Geology, v. 22, p. 719-722, 1994.

KITAZATO, H. Foraminiferal microhabitats in four marine environments around Japan. Marine Micropaleontology, v. 24, p. 29-41, 1994.

KVINGE, T. On the special current and water level variations in the Channel of São Sebastião. Boletim do Instituto Oceanográfico, São Paulo, v. 16, p. 23-38, 1967.

LAMONT,P.A.; GAGE, J.D. Morphological responses of macrobenthic polychaetes to low oxygen on the Oman continental slope, NW Arabian Sea. Deep-Sea Research II, 47:9-24, 2000.

LAMPARELLI, C.C. Desafios para o licenciamento e monitoramento ambiental de emissários: a experiência de São Paulo. In: LAMPARELLI, C.C.; ORTIZ, J.P. (org). Emissários submarinos: projeto, avaliação de impacto ambiental e monitoramento. São Paulo: SMA,p.11-23.

LARSSONEUR, C.; BOUYSSE, P.; AUFRET, J.P. The Superficial Sediments of The English Channel and its Western Approach. Sedimentology, 19, p. 851-864, 1982. 
LASSEN, R.; TJELL, J. C. ; HANSE, J. A. 1984. Phosphorus recovery from sewage for agriculture. Waste Management and Research, v. 2, p. 369-378, 1984.

LÊ CADRE, V. ; DEBENAY, J. P. Morphological and cytological responses of Ammonia (foraminifera) to cooper contamination: Implications for the use of foraminifera as bioindicators of pollution. Environmental Pollution, v. 143, p. $304-317,2006$.

LEGG, J. O.; BLACK, C. A. Determination of organic phosphorus in soils: II. Ignition method. Soil Science Society of America Proceedings, v. 19, p. 139-143, 1955.

LEVENTHAL, J.S. An interpretation of carbon and sulfur relationship in Black Sea sediments as indicators of environment of deposition. Geochemical, Cosmochemical Acta, 47:133-137, 1983.

LOEBLICH, A.R.; TAPPAN, H. 1964. Parte C, Protista2, Sarcodina chiefly "Thecamoebians" and Foraminifera. In: MOORE, R. C., ed. Teatrise on invertebrate paleontology. New York: The University Kansas Press, vol. 1, 510p., vol. 2, 390p. 1964.

LOPES, C. F.; MILANELLI, J.C.C.; PROSPERI, V.A.; ZANARDI, E.; TRUZZI. Coastal monitoring program of São Sebastião Channel: Assessing the effects of "TEBAR v" oil spill on rocky shore population. Marine Pollution Bulletin, 34: 923-927, 1997.

LUTZE, G. F.; COULBOURN, W. T. Recent benthic foraminifera from the continental margin of Northwest Africa: community structure and distribution. Marine Micropaleontology, v. 8, p. 361-401, 1984.

LYONS, T. W.; BERNER, R. A. Carbon-sulfur-iron systematics of the uppermost deep-water sediments of the Black Sea. Chemical Geology, v. 99, p. 1-27, 1992.

MAIKLEM, W.R. Black and brown speckled foraminiferal sand from the southern part of the Great Barrier reef. J.Sedim. Petrology, 37:1023-1030, 1967.

MARCELLINO, E. B. 2000. Sistematização dos projetos de emissários submarinos da SABESP e avaliação de desempenho através do modelo computacional CORMIX. 2000, 272p. Dissertação de Mestrado, Universidade de São Paulo, Escola Politécnica.

MARINS, R. V., PAULA FILHO, F. J.; ROCHA, C. A. S. 2007. Geoquímica do fósforo como indicadora da qualidade ambiental e dos processos estuarinos do Rio Jaguaribe Costa nordeste oriental brasileira. Química Nova, 30 (5), 1208-1214.

MARTINS, V. ; JOUANNEAU, J-M., WEBER, O., ROCHA, F. Tracing the late Holocene evolution of the NW Iberian upwelling system. Marine Micropaleontology, v. 59, p. 35-55, 2006. 
MARTINS, V.; DUBERT, J.; JOUANNEAU, J-M.; WEBER, O.; SILVA, E. F.; PATINHA, C.; DIZ, J. M. A.; ROCHA, F. A multiproxy approach of the Holocene evolution of shelfslope circulation on the NW Iberian Continental Shelf. Marine Geology, v. 239, p. 1-18, 2007.

MELO, S.L.R.; NIPPER, M. Sediment toxicity tests using the burrowing amphipod Tiburonella viscana (Amphipoda: Pltischonopidae). Ecotoxicology and Environmental Safety, 56: 412-420.

MELO, M.S.; PIRES NETO, A.G. Esboço geológico da Província Costeira entre as serras do Juquerequirê e do Parati, Estado de São Paulo. In: Simpósio de Geologia Regional, 1, São Paulo, 1977. Atas. São Paulo, SBG-NSP, p. 303-323, 1977.

MENDES, F. M. Estrutura da comunidade macrozoobentônica na região de influência do Terminal Almirante Barroso (TEBAR) no Canal de São Sebastião (SP, Brasil). 2007. 75 p. Dissertação de Mestrado - Instituto Oceanográfico, Universidade de São Paulo

MIRANDA, L. B. Análise de massas de água da plataforma continental e da região oceânica adjacente: Cabo de São Tomé (RJ) e Ilha de São Sebastião (SP). 1982. Tese de livre Docência. Universidade de São Paulo, Instituto Oceanográfico de São Paulo, 125 p.

MIRANDA, L. B.; CASTRO-FILHO, B. M. Variabilidade da circulação e do transporte de volume no Canal de São Sebastião (SP). Publicação especial do Instituto Oceanográfico, v. 11, p. 1-9, 1995.

MITSCH, W. J.; GOSSELINK, J. G. Wetlands. New York, Van Nostrand Reinhol, 1986, $539 \mathrm{p}$.

MOJTAHID, M.; JORISSEN, F.; PEARSON, T. H. Comparison of benthic foraminiferal and macrofaunal responses to organic pollution in the Firth of Clyde (SCotland). Marine Pollution Bulletin, v. 56, p. 42-76, 2008.

MOJTAHID, M.; JORISSEN, F.; LANSARD, B.; FONTAINER, C.; BOMBLED, B.; RABOUILLE. Spatial distribution of live benthic foraminifera in the Rhône prodelta: Faunal response to a continental - marine organic matter gradient. Marine Macropaleontology, 70: 177-200, 2009.

MOODLEY, L., HESS, C. Tolerance of infaunal benthic foraminifera for low and high oxygen concentrations. Biological Bulletin, v. 183, p. 94-98, 1992.

MUNIZ, P.; PIRES, A. M. S. Trophic structure of polychaetes in the São Sebastião Channel (Southeastern Brazil). Marine Biology, 134, p. 517-528, 1999. 
MURRAY, J. Benthic foraminifera: The validity of living, dead or total assemblages for the interpretation of palaeoecology. Journal of Micropaleontology, 1, p. 137-140, 1982.

MURRAY, J. Living and dead Holocene foraminifera of Lime Bay, southern England. Journal of foraminiferal Research, 16, p. 347-352, 1986.

MURRAY, J. W. Ecology and paleoecology of benthic foraminifera. London, Longman Scientific and Technical, 1991, 397 p.

MURRAY, J. W. Foraminiferal assemblage formation in depositional sinks on the continental shelf west of SCotland. Journal of Foraminiferal Research, v. 33, p. 101-121, 2003.

NAGAI, R. H., SOUSA, S. H. M., BURONE, L., MAHIQUES, M. M. Paleoproductivity changes during the Holocene in the inner shelf of Cabo Frio, southeaster Brazilian continental margin: Benthic foraminifera and sedimentological proxies. Quaternary International, v. 206, p. 62-71, 2009.

OZÓRIO, V. K. L., OLIVEIRA, W. Polifosfatos em detergentes em pó comerciais. Química Nova, v. 24, p. 700-708, 2001.

PAIXÃO, S.V. Transporte de volume e condições hidrográficas no Canal de São Sebastião. Dissertação (Mestrado) - Instituto Oceanográfico, Universidade de São Paulo, São Paulo, 210p. 2008.

PEARSON, T.H.; ROSENBERG, R. Macrobenthic sucession in relation to organic enrichment and pollution of the marine environment. Oceanography and Marine Biology: An Annual Review, 16:229-331. 1978.

PEARSON, T. H. 1986. Disposal of sewage in dispersive and non-dispersive areas, contrasting histories in British coastal waters. In.: G. Kullenberg (Ed.), The role of oceans as a waste disposal option, 577-595.

PHLEGER, F. B.; SOUTAR, A. Production of benthic foraminifera in three east Pacific oxygen minima. Micropaleontology, v. 19, p. 110-115, 1973.

PIELOU, E. C. The measurement of diversity in different types of biological collections. Journal of Theorical Biology, v. 13, p. 131-144, 1969.

PIRES-VANIN, A. M. S. Megafauna e Macrofauna. In: PIRES-VANIN, A. M. Oceanografia de um ecossistema subtropical: Plataforma de São Sebastião, SP. Editora da Universidade de São Paulo (EDUSP), 2008, p. 311-349. 
RACHID, B. R. F. Ecotoxicidade de efluentes sanitários urbanos lançados ao mar através de Emissários Submarinos. Dissertação (Mestado) - Instituto Oceanográfico, Universidade de São Paulo, São Paulo, 106p. 1996.

RACHID, B. R. F. Avaliação ecotoxicológica dos efluentes domésticos lançados pelos sistemas de disposição oceânica da Baixada Santista, SP. Tese (Doutorado) - Instituto Oceanográfico, Universidade de São Paulo, São Paulo. 2002.

RESIG, J. M. Foraminiferal ecology around ocean outfalls of southern Califórnia. Waste disposal in the marine environment. Pergamon Press. London, 1960, p. 104-121.

ROCHA, A. A.; MIEKELEY, N.; SILVEIRA, C. L. P. Determinação de fósforo orgânico em águas de produção petrolífera por ICP-AES e ICP-MS após pré-concentração em coluna de sílica - $\mathrm{C}_{18}$. Química Nova, 21, p. 584-589, 1998.

ROMANO, E.; BERGAMIN, L.; AUSILI, A.; PIERFRANCESCHI, G.; MAGGI, C.; SESTA, G.; GABELLINI, M. 2008. The impacto $\mathrm{f}$ the Bagnoli industrial site (Naples, Italy) on sea-bottom environment. Chemical and textural features of sediments and the related response of benthic foraminifera. Marine Pollution Bulletin, 59: 245-256.

ROMANO, H.; BERGAMIN, L.; AUSILI, A.; PIERFRANCESCHI,G.; MAGGI, C.;SESTA, G.;GABELLINI, M.. The impact of the Bagnoli industrial site (Naples, Italy) on sea-bottom environment. Chemical and textural features of sediments and the related response of benthic foraminifera. Marine Pollution Bulletin, 59: 245-256. 2009.

SABEAN, J. A. R.; SCOTT, D. B.; LEE, K.; VENOSA, A. D. 2009. Monitoring oil spill bioremediation using marsh foraminifera as indicators. Marine Pollution Bulletin, 59: 352361.

SAMIR, A.M.; EL-DIN, A.B. Benthic foraminiferal assemblages and morphological abnormalities as pollution proxies in two Egyptian bays. Marine Micropaleontology, 41: 193-227. 2001.

SCHÖNFELD, J. Recent benthic foraminiferal in deep high-energy environments from the Gulf of Cadiz (Spain). Marine Micropaleontology, v. 44, p. 141-162, 2002.

SCOTT, D. B.; MEDIOLI F. S. Living vs. total foraminiferal populations: their relative usefulness in paleocology. Journal of Paleontology, 54, p. 814-831.

SEN GUPTA,B.K.; MACHAIN-CASTILLO, M.L. Benthic foraminifera in oxygen-poor habitats. Marine Micropaleontology, 20:183-201. 
SHANNON, C. E. The mathematical theory of communication. University of Illinois Press, Urbana, 1948.

SHEPARD, F.P. Nomenclature based on sand-silt-clay ratios. Journal Sedimentary Petrology, v. 24, p. 151-158, 1954.

SIGOLO, J. B. ; PINHEIRO, C. H. R. . Lodo de esgoto da ETE Barueri-SP: Proveniência do enxofre elementar e correlações com Metais Pesados associados. Geologia USP. Série Científica, v. 10, p. 39-51, 2010.

SILVA, L. S.; MIRANDA, L. B.; CASTRO, B. M. Oceanografia da plataforma interna de São Sebastião (OPISS). Subprograma Oceanografia Física. Relatório Técnico do Instituto Oceanográfico, v. 47, p. 1-31, 2001.

SOARES-GOMES, A.; FIGUEIREDO, A. G. 2002. O ambiente marinho. In: PEREIRA, R. C.; SORES-GOMES, A. Biologia Marinha. Rio de Janeiro: Interciência. 2002, 382 p.

SOMMERVILLE, H.J.; BENNETH, D.; DAVENPORT, J.N.; HOLT, M.S., LYNES, A.; MATHIEU, A.; MCOURT, B.; PARKER, J. C..; STEPHENSON, R.R..; WATKINSON, T.G. Environmental effects of produced water from North sea oil operations. Marine Pollution Bulletin, 18: 549-558. 1987.

STEIN, R. Accumulation of organic carbon in marine sediments. Results from the Deep Sea Drilling Project/Ocean Drilling Program, In: BHATTACHARJI, S.; FRIEDMAN, G. M.; NEUGEBAUER, H. J.; SEILACHER, A. Lecture Notes in Earth Sciences. Berlin: Springer, 1991, $217 \mathrm{p}$.

SUTHERlAND, T. F.; LEVINGS, C. D.; PETERSEN, S. A.; PIERCEY, B. The use of meiofauna as an indicator of benthic organic enrichment associated with salmonid aquaculture. Marine pollution Bulletin, v. 54, p. 1249-1261, 2007.

Ter BRAAK, C. J. F.; SMILAUER, P. 2002. CANOCO Reference Manual and User's Guide to Canoco for Windows: Software for Canonical Community Ordination. Versão 4.5. Microcomputer Power, Ithaca, NY, $500 \mathrm{p}$.

THOMAS, E.; GAPOTCHENKO, T.; VAREKAMP, J. C.; MECRAY, E. L.; BUCHHOLZ TEN BRINK, M. R. Benthic foraminifera and environmental changes in Long Island Sound. Journal of Coastal Research, v. 16, p. 641-655, 2000.

TUREKIAN, K. K.; WEDEPOHL, K. H. Distribution of the Elements in some major units of the Earth's crust. Geological Society of America Bulletin, v. 72, 175 p, 1961. 
TYSON, R. V.; PEARSON, T. H. 1991. Modern and ancient continental shelf anoxia. Geological Society of London Special Publication, 1991, 474 p.

UTVIK, T. I. R. Chemical characterization of produced water from four offshore oil production platafforms in the North Sea. Chemosphere, 39, p. 2593-2606, 1999.

van der ZWAAN, G. J., JORISSEN, F. J. 1991. Biofacial patterns in river-induced shelf anoxia. Geological Society of London Special Publication, v. 58, p. 65-82, 1991.

WILLIAMSON, M. A. Recent foraminiferal diversity on the continental margin of Nova SCotia, Canada. Journal of Foraminiferal Research, v. 15, p. 43-51, 1985.

van der ZWAAN, G. J.; DUIJNSTEE, I. A. P.; den DULK M.; ERNEST, S. R.; JANNINK, N. T.; KOUWENHOVEN, T. J. 1999. Benthic foraminifers: proxies or problems? A review of paleoecological concepts. Earth Science Reviews, 46: 213-236.

WALTON, W. R. 1952. Techniques for recognition of living foraminifera. Contribution of Cushman Foundation for Foraminiferal Research, v. 3, p. 56-60, 1952.

WARD, J. N.; POND, D. W.; MURRAY, J. W. 2003. Feeding of benthic foraminifera on diatoms and sewage-derived organic mater: an experimental application of lipid biomarker techniques. Marine Environmental Research, v. 56, p. 515-530, 2003.

WEBER, R.R.; ZANARDI, E. BÍCEGO, M. C. "Distribuição e ocorrência dos hidrocarbonetos biogênicos de petróleo, na água superficial e nos sedimentos de superfície da região da plataforma interna do Canal de São Sebastião, SP, Brasil”. Relatório Técnico, Instituto Oceanográfico, 43:1-14. 1998.

WENTWORTH, C. K. 1922. A scale of grade and class terms for clastics sediments. Journal of Geology, v. 30, p. 377-392, 1922.

Werme, C., Hunt, C.D. 2004. Outfall monitoring overview. Boston: Massachusetts Water Resources Authority. Report 2004-13. 97 p.

WETZEL, R. G., LIKEN, G. L. Limnological analyses. New York:Springer-Verlag, 1991, $391 \mathrm{p}$.

WILDISH, D. J.; HARGRAVE, B. T.; POHLE, G. W. Cost-effective monitoring of organic enrichment resulting from salmon mariculture. ICES Journal of Marine Science, 58:469476. 2001.

YANKO, V.; KRONFELD, J.; FLEXER, A. Response of benthic foraminifera to various pollution sources: implications for pollution monitoring. Journal of Foraminiferal Research, v. 24, p 1-17, 1994. 
ZAGATTO, E. A. G.; JACINTHO, A. O.; REIS, B. F.; KRUG, F. J.; BERHGAMIN FILHO, H.; PESSENDA, L. C. R.; MORTATTI, J.; GINÉ, M. F. Manual de análises de plantas e águas empregando sistemas de injeção em fluxo. Piracicaba: Universidade de São Paulo, CENA/Seção de Química Analítica, 1981, 45p.

ZALESNY, E. R. 1959. Foraminiferal ecology of Santa Monica Bay, California. Micropaleontology, v. 5, p. 101-126, 1959.

ZANARDI, E. Hidrocarbonetos no Canal de São Sebastião e na Platforma Interna Adjacente

- Influência do derrame de Maio de 1994. Dissertação (Mestrado) - Instituo Oceanográfico, Universidade de São P 


\begin{abstract}
APÊNDICE
Apêndice 1.1. Espécies bioindicadoras de ambiente enriquecido por matéria orgânica
\end{abstract}

As espécies pertencentes a este grupo são espécies dominantes em ambiente com baixos níveis de oxigenação e enriquecidos organicamente. Apesar bolivinídeos e bumininídeos serem reportados em ambientes óxicos (Debenay et al., 1997; 2001; Bouchet et al., 2007), tais gêneros sobrevivem no interior de camadas de sedimento com depleção de oxigênio, e podem sobreviver em condições anóxicas por longos períodos de tempo (Moodley e Hess, 1992). Bolivina ordinaria (Hermelin e Shimmield, 1990; Martins et al., 2007); Brizalina striatula (Lutze e Coulbourn, 1984; Bernhard e Gupta, 1999; Martins et al., 2006); Bolivina. cf. sphatulata (Alavi, 1988; de Stigter et al., 1998; Martins et al., 2006); Bulimina marginata (Alavi, 1988; Alve e Bernhard, 1995; Bernhard e Sen Gupta, 1999; van der Zwaan e Jorissen, 1991; Burone e Pires-Vanin, 2006; Martins et al., 2006; Nagai et al., 2009, Nagai et al., 2010, Bubenshchikova et al., 2010), Buliminella elegantissima (Bernhard e Sen Gupta, 1999; Burone e Pires-Vanin, 2006); Pseudononion atlanticum (Burone e Pires-Vanin, 2006; Nagai et al., 2009); Cassidulina crassa f. media (Alavi, 1988; Bernhard e Sen Gupta, 1999), Fursenkoina pontoni (Bernhard e Sen Gupta, 1999, Bubenshchikova et al., 2010 ); Trochammina spp. (Schönfeld, 2002), Brizalina pseudoplicata (Bubenshchikova et al., 2010), Angulogerina angulosa (Bubenshchikova et al., 2010), Cassidulina laevigata (Bubenshchikova et al., 2010), Uvigerina spp (Kaiho, 1994; Martins et al., 2007)

Apêndice 1.2. Espécies bioindicadoras de ambiente bem oxigenado

Este grupo é composto por espécies frequentemente observadas em ambientes bentônicos bem oxigenados, com forte hidrodinamismo e baixos teores de nutrientes, tais como Gavelinopsis praegeri (Altenbach et al., 2003; Duleba et al., 2005; Martins et al., 2006), Discorbis williamsoni (Nagai et al., 2009; Murray, 1991; Linke e Lutze, 1993); Hanzawaia boueana (Barmawidjaja et al., 1995 [as Hanzawaia concentrica]; Duleba et al., 2005); Lobatula lobatula (Williamson, 1985; Bubenshchikova et al., 2010); Lepidodeuteuramina ochracea (Martins et al., 2006; Murray, 1991); Quinqueloculina spp (Kaiho, 1994; Martins et al., 2006; Nagai et al., 2009); Rosalina floridana (Martins et al., 2006; Duleba et al., 2005; 
Murray, 1991); Neocornobina terquemi (Duleba et al., 2005; Murray, 1991), Patelina corrugata (Martins et al., 2006; Murray, 1991), Cibicides spp. (Kaiho, 1994; Altenbach, 2003 [as Cibicides gerthi]; Duleba et al., 2005), Triloculina spp (Bubenshchikova et al., 2010) 


\section{PRANCHAS}

\section{Prancha 1}

1) Ammonia tepida, lado ventral, $30 \mu \mathrm{m}$

2) Ammonia tepida, lado umbilical, $20 \mu \mathrm{m}$

2A) Detalhe do lado umbilical da Ammonia tepida, onde são observadas frústulas de diatomáceas, $10 \mu \mathrm{m}$

3) Brizalina striatula, $20 \mu \mathrm{m}$

4) Buliminela elegantissima, $30 \mu \mathrm{m}$

5) Bulimina marginata, $10 \mu \mathrm{m}$

6) Neocornobina terquemi, lado umbilical, $30 \mu \mathrm{m}$

7) Cassidulina crassa, $20 \mu \mathrm{m}$

8) Gaudryina exilis, $30 \mu \mathrm{m}$

9) Fursenkoina pontoni, $20 \mu \mathrm{m}$

10) Hopkinsina pacifica, $10 \mu \mathrm{m}$

11) Lobatula lobatula, $30 \mu \mathrm{m}$

12) Bolivina ordinaria, $10 \mu \mathrm{m}$

13) Pararotalia cananeiaensis, lado ventral, $20 \mu \mathrm{m}$

14) Hanzawaia boueana, lado ventral, $20 \mu \mathrm{m}$

15) Pseudononion atlanticum, lado umbilical, $20 \mu \mathrm{m}$

16) Rosalina floridensis, lado umbilical, $20 \mu \mathrm{m}$ 

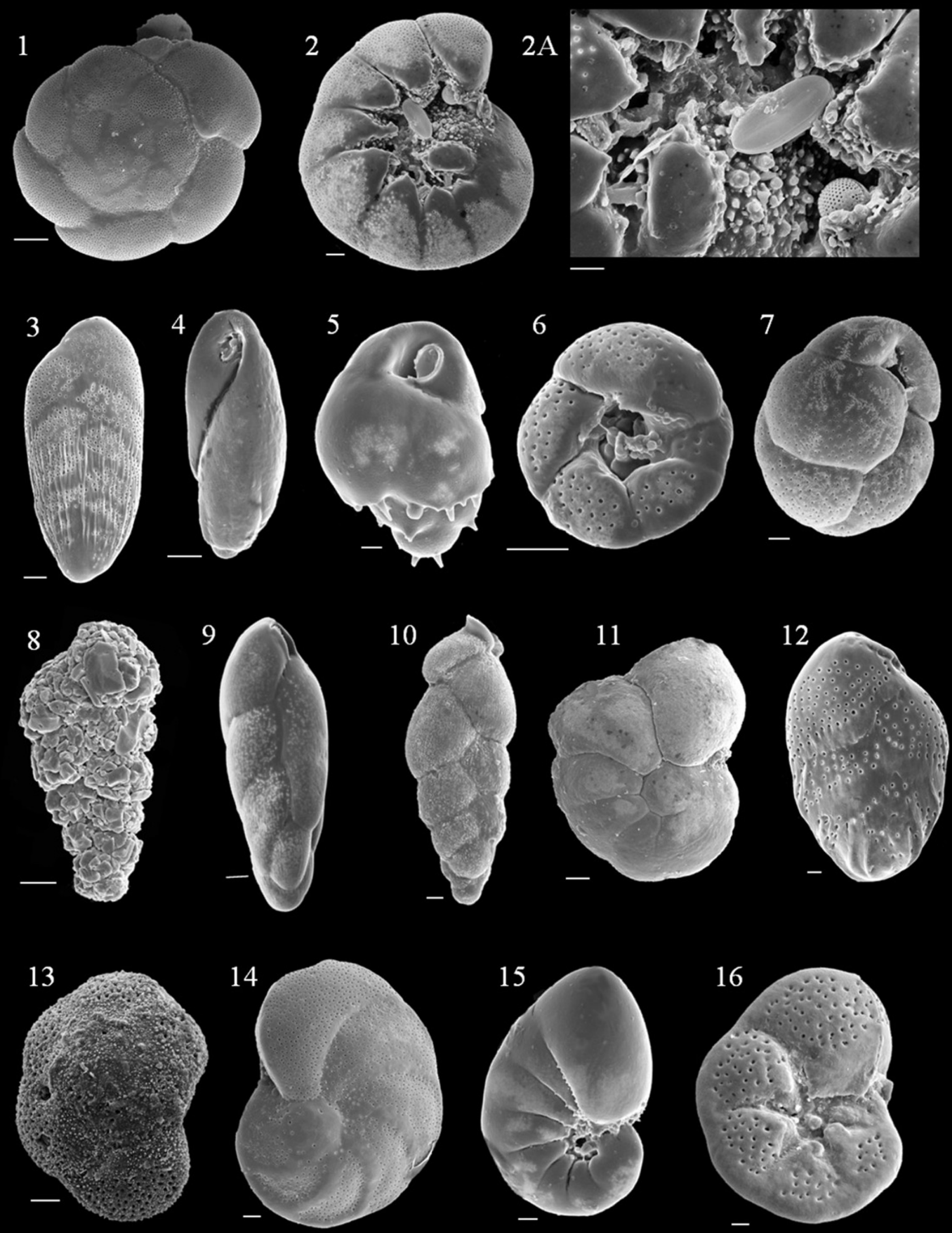
Prancha 2

Carapaças com sinais de bioerosão

1) Bulimina marginata, $30 \mu \mathrm{m}$

2) Fursenkoina pontoni, $30 \mu \mathrm{m}$

3) Buccela peruviana, $30 \mu \mathrm{m}$

Carapaças com sinais de dissolução

4) Bulimina marginata

5) Fissurina laevigata, $20 \mu \mathrm{m}$

6) Fissurina laevigata, $20 \mu \mathrm{m}$

7) Buliminella elegantissima, $10 \mu \mathrm{m}$

8) Buliminella elegantissima, $30 \mu \mathrm{m}$

9) Bolivina sp, $20 \mu \mathrm{m}$

10) Buliminella elegantissima, $30 \mu \mathrm{m}$

11) Bolivina pulchella, $20 \mu \mathrm{m}$

12) Ammonia sp, $20 \mu \mathrm{m}$ 

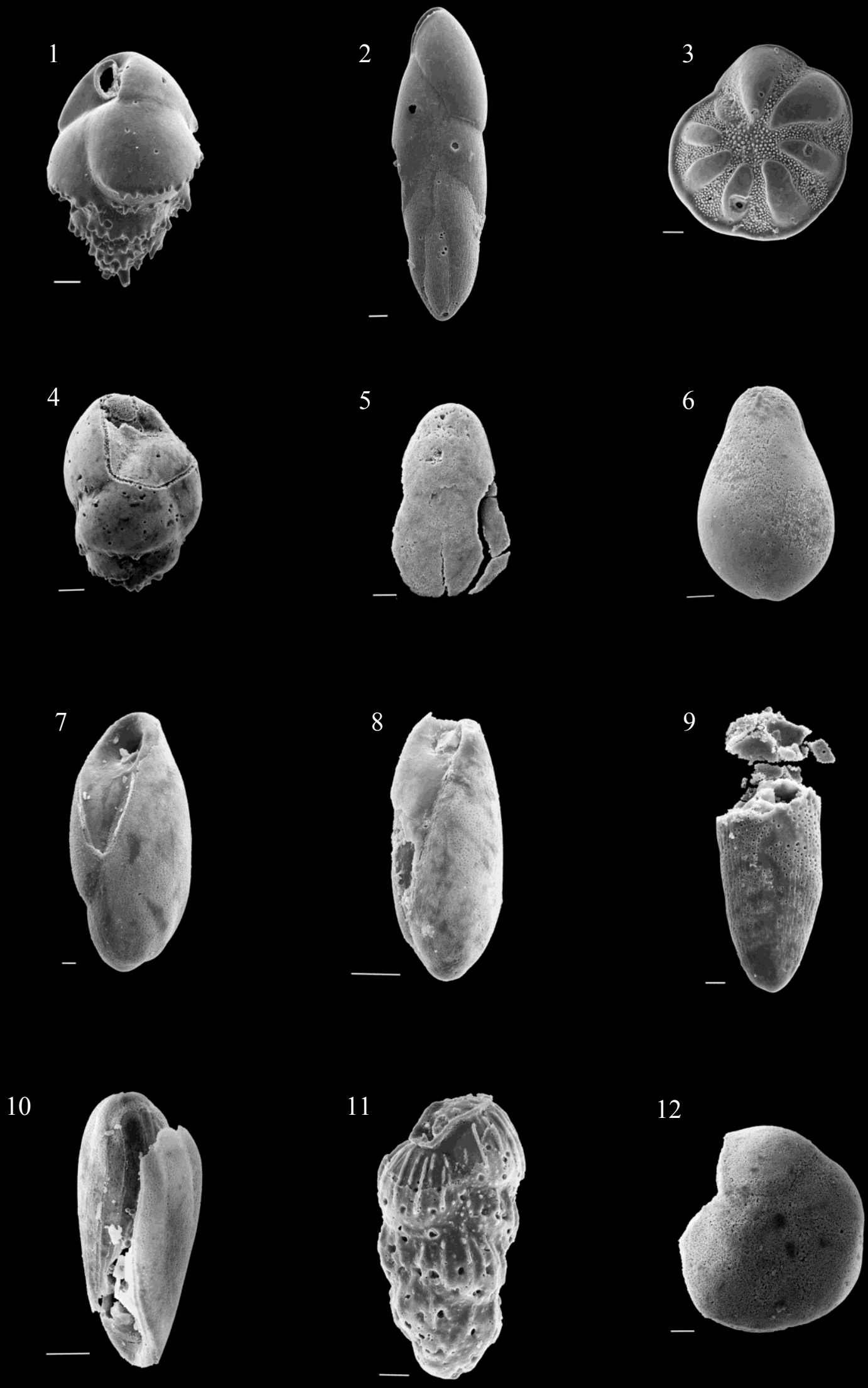
Prancha 3

1) Buliminella elegantissima, $20 \mu \mathrm{m}$

2) Em detalhe, preenchimento da carapaças por pirita, $10 \mu \mathrm{m}$

3) Imagem EDS

4) Haynesina sp, $30 \mu \mathrm{m}$

5) Em detalhe, preenchimento da carapaça por pirita, $10 \mu \mathrm{m}$

6) Imagem EDS 

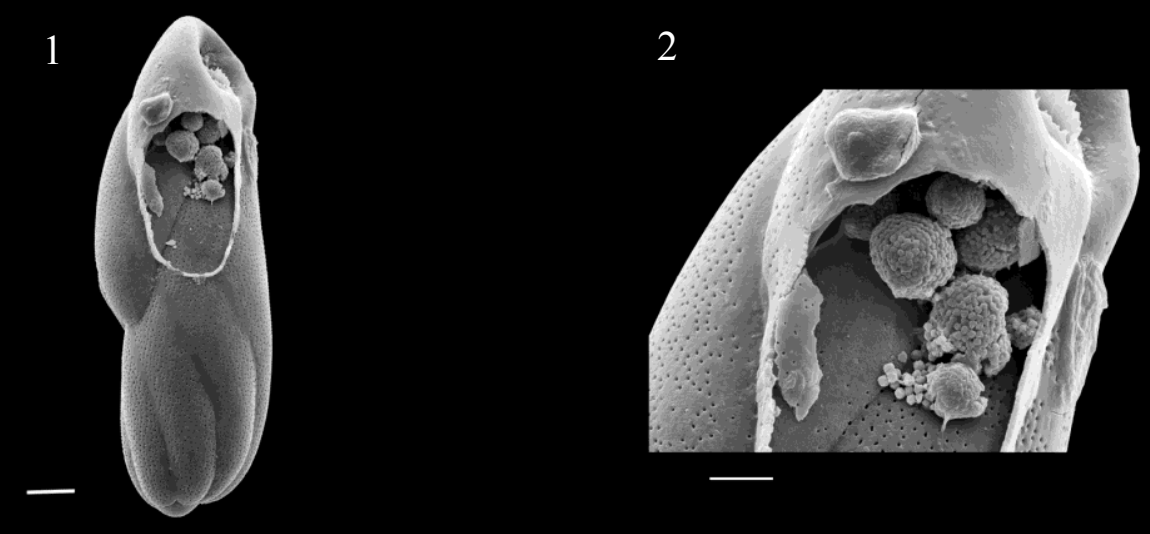

3

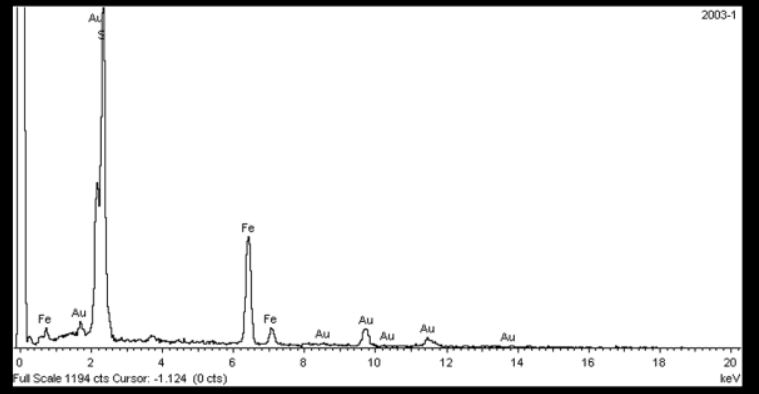

4

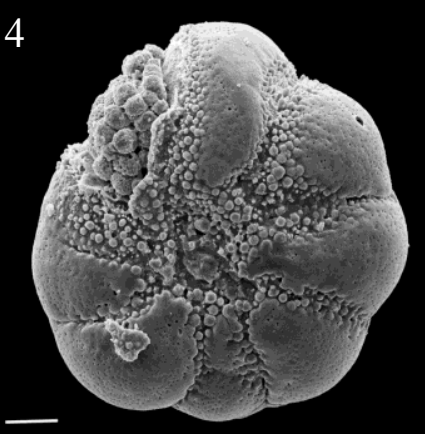

6

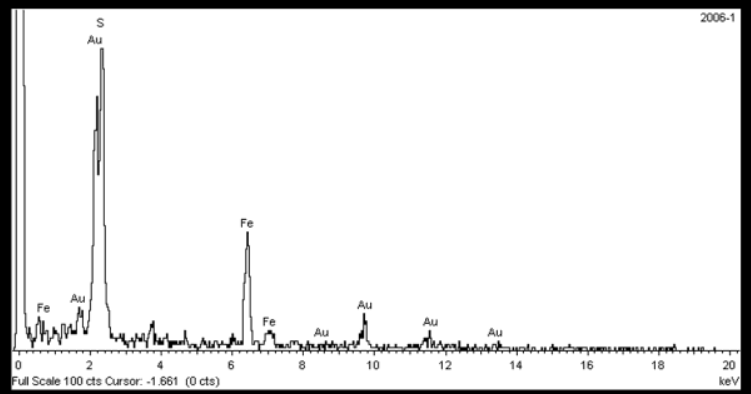

5

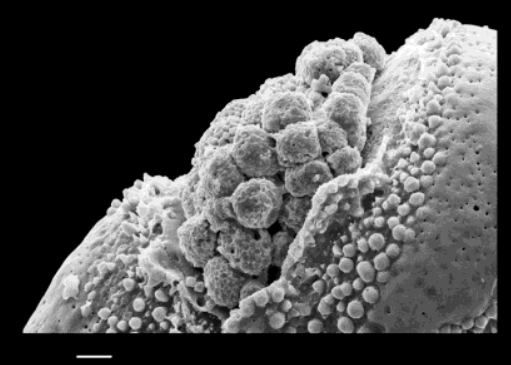

